\title{
Die Nazifizierung und Entnazifizierung der Physik an der Universität Göttingen
}

\author{
Dissertation \\ zur Erlangung des philosophischen Doktorgrades \\ an der Philosophischen Fakultät \\ der Georg-August-Universität Göttingen
}

vorgelegt von

Gerhard Rammer

aus

Wien

Göttingen 2004 
1. Gutachter: Dr. habil. Klaus Hentschel

2. Gutachter: Professor Dr. Nicolaas A. Rupke

Tag der mündlichen Prüfung: 24. Mai 2004 


\section{Inhaltsverzeichnis}

Einleitung ................................................................................................................. 6

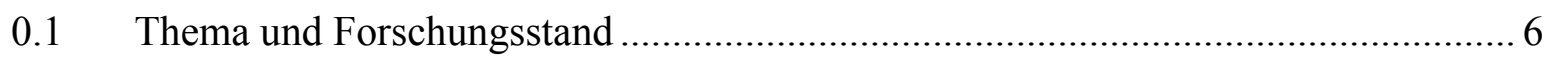

0.2 Zur allgemeinen Fragestellung ..................................................................... 10

0.3 Die Leitthese vom kollegialen Netz ……………........................................... 12

0.4 Zum Gegenstand Göttinger Physik - Fragestellungen............................................ 14

0.5 Über Modellannahmen zur Wissenschaftsentwicklung ........................................ 20

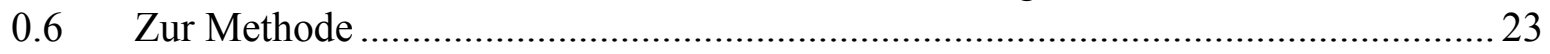

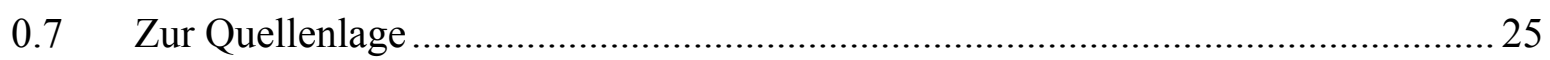

1 Der Lehrkörper - eine kollegiale Gemeinschaft..................................................... 27

$1.1 \quad$ Institutionelle und personelle Ausgangssituation..................................................28

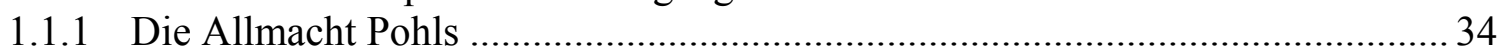

1.2 Personalpolitik an den Physikinstituten im Nationalsozialismus............................... 36

1.2.1 Die Besetzung des zweiten Lehrstuhls für Experimentalphysik ............................ 39

1.2.2 Die Besetzung des Lehrstuhls für theoretische Physik ......................................... 49

1.2.3 Bewertung der Ordinarien-Neubesetzungen 1935/36 .........................................5 55

1.2.4 Eine taktische Übergangslösung am Lehrstuhl für angewandte Elektrizität.........58

1.2.5 Joos' Verzicht auf seinen Lehrstuhl und die folgende Nachbesetzung ................. 62

1.2.6 Personalentwicklung auf den unteren Ebenen..................................................... 71

1.2.7 Zwischenbilanz Kriegsende ........................................................................ 89

1.3 Nachkriegszeit - die Rhetorik der Richtungsänderung ........................................... 91

1.3.1 Der neue Senat und das Aufleben alter Ideale .................................................... 93

1.3.2 Die personelle Entnazifizierung der Physik ........................................................ 99

1.3.3 Keine Rückkehr der Vertriebenen - unterbliebene und gescheiterte Versuche. 110

1.3.4 Das Phänomen Wanderschaft und wie das kollegiale Netz Karrieren rettete.... 114

1.3.5 Die Nachkriegskarrieren des Göttinger physikalischen Nachwuchses ............... 140

1.3.6 Wiederaufnahme internationaler Verbindungen ................................................. 161

$2 \quad$ Die Studenten - der Familiennachwuchs ........................................................... 175

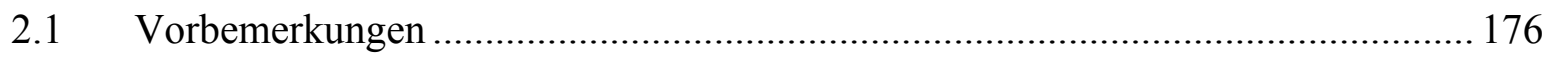

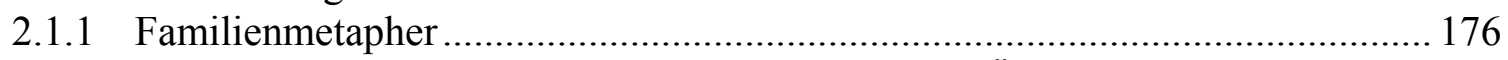

2.1.2 Die zeitliche Entwicklung der Studentenzahlen im Überblick ……………........ 178

2.2 Die Entwicklung von 1930 bis zum Kriegsende .................................................. 181

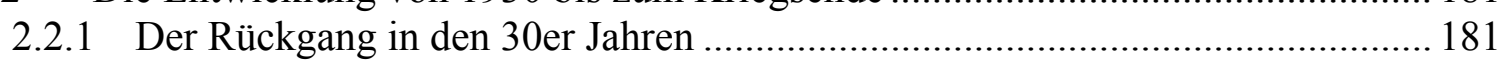

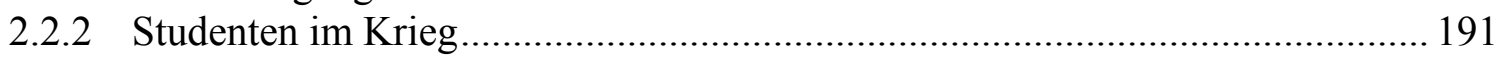

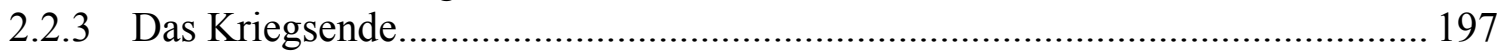

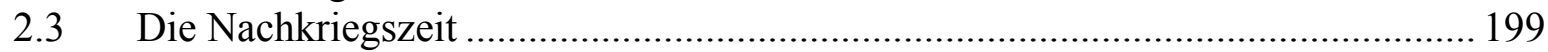

2.3.1 Zur politischen Haltung der Studenten nach dem verlorenen Krieg ................... 199

2.3.2 Aufnahmebedingungen in den ersten Nachkriegssemestern .............................. 206

2.3.3 Entnazifizierung des Nachwuchses .................................................................... 212

2.3.4 Abschreckung und formale Ablehnungskriterien.............................................. 223

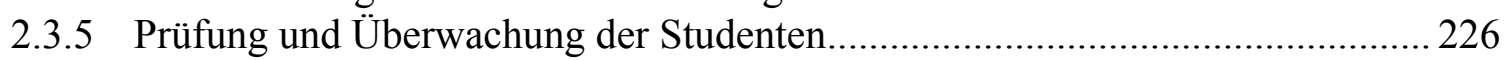

2.3.6 Die Charakterprüfung................................................................................. 242

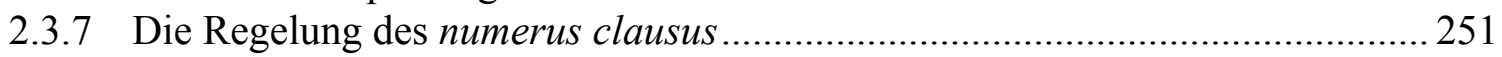


2.3.8 Die Normalisierung und das starke Wachstum nach 1953 _.............................. 259

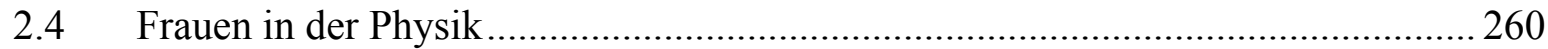

2.4.1 Das Frauenstudium von 1930 bis 1945 .......................................................... 260

2.4.2 Die Verdrängung der Physikstudentinnen nach 1945 ...................................... 276

3 Physik für Krieg und Frieden - Forschungsthemen im Wandel der Zeit ...... 296

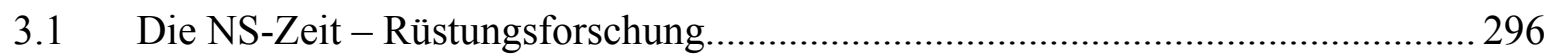

3.1.1 Forschung im Auftrag des Militärs an den Göttinger Physikinstituten............... 300

3.2 Kontinuität in der Forschung - der Übergang in die Nachkriegszeit..................... 309

3.2.1 Überwachung der Forschungstätigkeit in den ersten Monaten der Besatzung .. 309

3.2.2 Gesetzliche Bestimmungen der Forschungskontrolle ................................... 314

3.2.3 Die Fortsetzung der Forschung in den Göttinger Instituten .............................. 317

3.3 Die Pohl-Schule der experimentellen Festkörperphysik .................................... 319

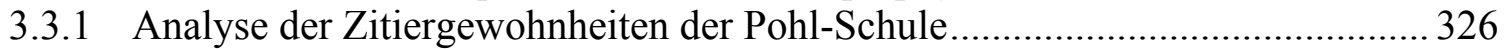

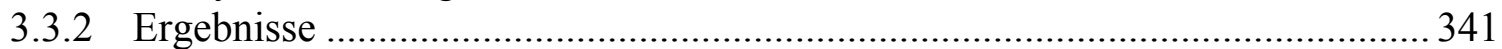

3.3.3 Vergleich des Zitationsverhaltens der Pohl-Schule mit Außenstehenden ......... 352

3.3.4 Auswertung des Vergleichs............................................................................ 354

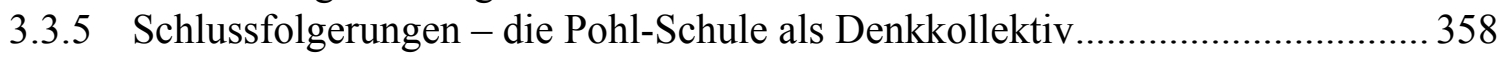

3.4 Forschungen ohne militärische Aufträge............................................................ 372

3.4.1 Beschäftigung mit grundsätzlichen physikalischen Fragen während des Kriegs 373

3.5 Experimentierende Theoretiker - Beckers Forschungsstil .................................... 374

3.6 Die Entnazifizierung und die besondere Produktivität von Physikern................... 376

3.7 Forschungsbeschränkungen bewirken Innovationen - Physiker und Mediziner ... 379

3.7.1 Hans König und die Untersuchung von Bakterien.......................................... 379

3.7.2 Neuer Teilchenbeschleuniger trotz Verbot der angewandten Kernphysik.......... 380

$4 \quad$ Das Lehrangebot: mehr als ein Spiegel der Forschungsthemen ........................ 389

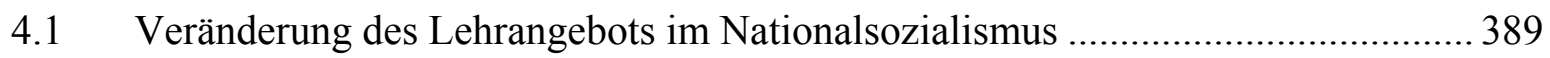

4.1.1 Veränderungen in der Organisation des physikalischen Praktikums .................. 396

4.1.2 Versuch einer Bewertung der Lehre während der NS-Zeit ................................ 398

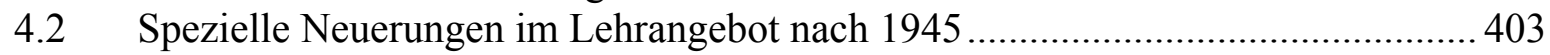

4.2.1 Das studium generale als Reaktion auf den Kriegsschock................................ 405

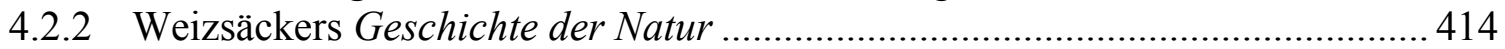

4.2.3 Vorlesungen über die Geschichte der Physik ................................................... 422

4.2.4 Ernst Lamla und die Didaktik der Physik ....................................................... 431

5 Das Institut für angewandte Mechanik - Kollegialität auf dem Prüfstand .... 445

5.1 Die Geschichte des Instituts bis Anfang der dreißiger Jahre................................. 445

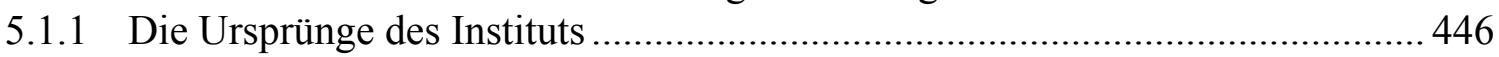

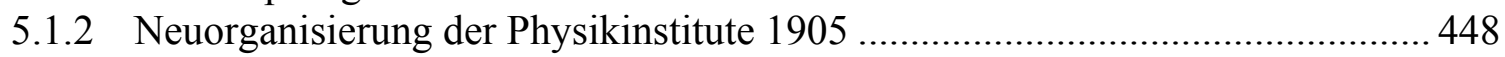

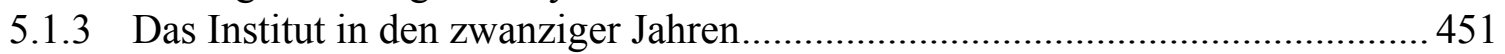

5.1.4 Max Schuler und das Institut in der Weimarer Republik ................................. 453

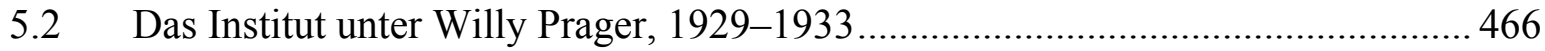

5.2.1 Spannungen zwischen 'reiner' und angewandter Physik ................................... 469

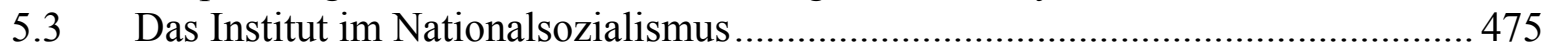

5.3.1 Politische Unruhen im Institut - der Leitungswechsel Prandtl-Schuler .............476

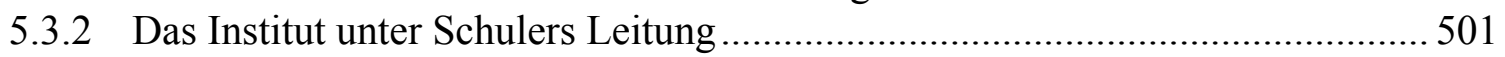


5.4 Entnazifizierung des Instituts - missglückte Versuche konstruierter Kontinuität. 518

5.4.1 Der Konflikt zwischen Schuler und Hohenemser ............................................. 519

5.4.2 Der Kampf der Universität gegen Hohenemsers Rehabilitierung.......................5 524

5.4.3 Der Fall Hohenemser gelangt 1946 ans Ministerium......................................... 537

5.4.4 Schulers frühzeitige Emeritierung. Diskussion um die Zukunft des Fachs ....... 548

5.5 Das III. Physikalische Institut - das Ende der angewandten Mechanik................. 561

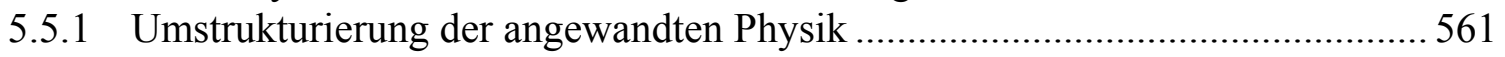

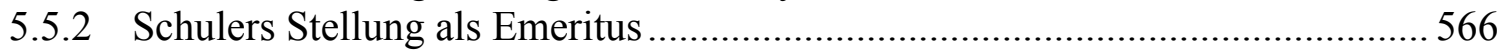

5.6 Zusammenfassende Interpretation des Falles Hohenemser.................................. 567

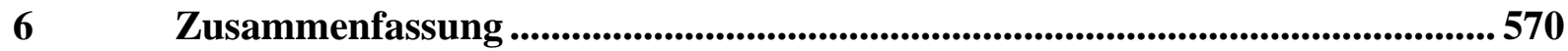

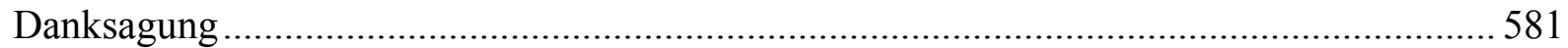

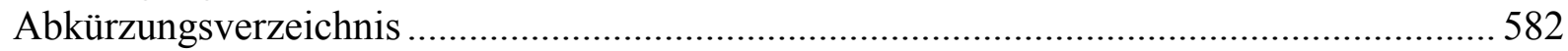

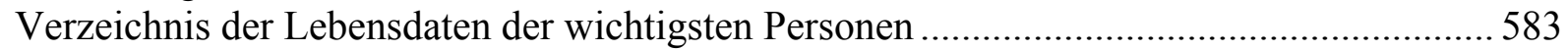

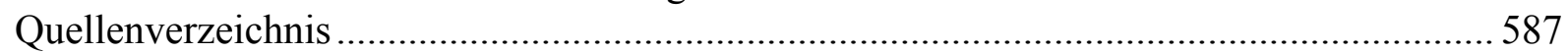

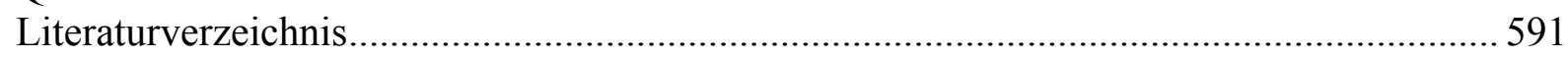




\section{Einleitung}

\subsection{Thema und Forschungsstand}

Diese Arbeit möchte in erster Linie zwei Prozesse untersuchen: die Nazifizierung und die Entnazifizierung der Physik an der Universität Göttingen. Damit steht die politische Beeinflussung der Wissenschaft im Zentrum der Untersuchung, die am Beispiel eines lokal und disziplinär begrenzten Teilbereichs der Hochschulwissenschaft durchgeführt wird. Unter Nazifizierung ist jene Veränderung des Wissenschaftsbetriebs zu verstehen, die ihn in ideologischer und personeller Hinsicht sowie bezogen auf die Forschungsinhalte und Anwendungen auf die Ziele des NS-Staates ausgerichtet hat. ${ }^{1}$ Wie tiefgreifend die Universitäten nazifiziert wurden, ob man überhaupt von einer Nazifizierung sprechen solle und ob sich der Einfluss des NS-Staates von anderen staatlichen Eingriffen grundlegend unterscheide, ist Gegenstand neuester vergleichender Studien. ${ }^{2}$ Die Entnazifizierung ist demgegenüber ein Prozess, der von den Alliierten und den Deutschen in zwei fast entgegengesetzte Richtungen gelenkt wurde. Dementsprechend besitzt auch der Begriff Entnazifizierung zwei unterschiedliche Bedeutungen: Ursprünglich bezeichnet er die Rückgängigmachung der Nazifizierung. Unter alliierter Führung wurde an den Universitäten das Personal politisch überprüft, Wiedergutmachung der NS-Vertreibungspolitik gefordert und die Forschung entmilitarisiert und kontrolliert. ${ }^{3}$ Von deutscher Seite wurde die Entnazifizierung bald zu einem Prozess umgewandelt, der in den meisten Fällen zu einer Bescheinigung der jeweiligen politischen Unverdächtigkeit führte, und in diesem Sinn wurde

\footnotetext{
${ }^{1}$ Von einer Nazifizierung der deutschen Hochschulen wurde bereits unmittelbar nach Ende der NS-Herrschaft gesprochen. In dem erstmals 1946 publizierten Buch Hitler's Professors schreibt Max Weinreich [1946/99] S. 240: „As time progressed, the bulk of university scholars, of scholarly periodicals, of publishing houses was entirely Nazified." Der amerikanische Universitätskontrolloffizier Daniel Penham äußerte im Februar 1946 ganz ähnlich: „Heidelberg University, as well as all of the German Universities, had been, over a period of twelve years, Nazified to the core." Zitiert nach Remy [2002] S. 146. Zu einer Einschätzung dieses wie des gegenteiligen Standpunkts der deutschen Professoren siehe Schildt [1997]; Führ [1993].

${ }^{2}$ In diesem Zusammenhang äußerte sich kürzlich Walker [2003]a S. 1 skeptisch. Obwohl in den vergangenen drei Jahrzehnten viele ausgezeichnete Studien zu der Verbindung von Wissenschaft und Nationalsozialismus verfasst wurden, stehe man heute immer noch vor der Frage, ob, und wenn ja, welchen spezifischen Einfluss der Nationalsozialismus auf die Wissenschaften nahm. Siehe auch das Kapitel „Nazifizierung und Entnazifizierung“ in Walker [1990/92] und [1994]a zur Anwendung des Begriffspaars auf die Physik. Zur Physik im Nationalsozialismus siehe Hentschel \& Hentschel (Hrsg.) [1996].

${ }^{3}$ Zur Forschungskontrolle siehe die zeitgenössischen Berichte Frowein [1950]a, [1950]b; sowie die historischen Arbeiten Stamm [1981]; Osietzky [1984]; Cassidy [1994], [1996] und Heinemann [2001]. Zur

Forschungsplanung siehe die wissenschaftshistorischen Arbeiten Eckert [1990]; Carson [1999]; Mertens [1996] sowie die Darstellung des damals beteiligten Zierold [1984].
} 
dann auch der Begriff Entnazifizierung von den Deutschen gebraucht. ${ }^{4}$ Dieser Wandel im Verständnis ist ein Charakteristikum des Entnazifizierungsprozesses und erklärt auch das Scheitern der ursprünglichen Zielsetzung. ${ }^{5}$

Die bisherige Forschung zum skizzierten Themenkomplex hat sich vorwiegend mit der Wissenschaft im Nationalsozialismus auseinandergesetzt. ${ }^{6}$ Dabei hat sie die Nützlichkeit der einzelnen wissenschaftlichen Disziplinen für die Legitimation und Umsetzung der NS-Politik in zahlreichen Untersuchungen nachgewiesen. Die Wissenschaftler waren an der Nutzbarmachung ihrer Fächer selbst aktiv beteiligt, verfolgten eigene politische Interessen und brachten diese in den Wandlungsprozess mit ein. In der Forschung haben sich die Begriffe „Selbstgleichschaltung“ und „Selbstmobilisierung“ etabliert, um den deutlich vorhandenen internen Antrieb in der Dynamik der nationalsozialistischen Umgestaltung des Wissenschaftssystems zu betonen. ${ }^{7}$

Einen wichtigen Platz in der wissenschaftshistorischen Forschung nehmen die Untersuchungen einzelner Universitäten im Nationalsozialismus ein. ${ }^{8}$ In ihnen zeigt sich, wie die jeweiligen lokalen Voraussetzungen zu unterschiedlichen Ausmaßen und Ausprägungen der Nazifizierung geführt haben. Ein Grund dafür war, dass die Wissenschaftspolitik im Nationalsozialismus keine klaren Leitlinien vorgab. ${ }^{9}$ Deshalb finden die ausgehandelten Kooperationsformen zwischen Staat/Militär und den einzelnen Forschungsbetrieben verstärktes Interesse in der historischen Forschung, die sich in dieser Frage auch den außeruniversitären Forschungseinrichtungen zuwendet. ${ }^{10}$ Für diese wie für die Hochschulen

\footnotetext{
${ }^{4}$ Niethammer [1972] hat hierfür die treffende Bezeichnung „Mitläuferfabrik“ geprägt. Zu den Unterschieden der Entnazifizierung in den vier Besatzungszonen siehe Vollnhals (Hrsg.) [1991]; Dotterweich [1979].

${ }^{5}$ Einen Überblick über die Entnazifizierung der Wissenschaften gibt vom Bruch [2002]. Zum methodischen Vorgehen in dieser Fragestellung siehe Ash [1995]b, [1996]. Die Physik behandelt exemplarisch Walker [1994]a.

${ }^{6}$ Einen Überblick über den aktuellen Forschungsstand bieten Szöllösi-Janze [2001]; Chroust [1993]; siehe auch Knigge-Tesche (Hrsg.) [1999]; Renneberg \& Walker (Hrsg.) [1994].

${ }^{7}$ Den Begriff Selbstmobilisierung prägte Ludwig [1974]. Siehe dazu auch Mehrtens [1994]a und in Bezug auf die Luftfahrtforschung Trischler [1994]. Zur Selbstgleichschaltung am Beispiel der Universität Gießen siehe Bernhardt [1994].

${ }^{8} \mathrm{Zu}$ den Hochschulen allgemein siehe Grüttner [2003]a; Heiber [1991-94]; als wichtigste Studien zu einzelnen Hochschulen sind zu nennen: zu Göttingen Becker, Dahms \& Wegeler (Hrsg.) [1987/98]; zu Hamburg Krause, Huber \& Fischer (Hrsg.) [1991]; zu Köln Golczewski [1988]; kürzlich zu Jena Hoßfeld, John, Lemuth \& Stutz (Hrsg.) [2003]; zu Freiburg John, Martin, Mück \& Ott (Hrsg.) [1991]; zu Halle Eberle [2002]; zu Heidelberg Buselmeier, Harth \& Jansen (Hrsg.) [1985/86]; zu Marburg Nagel (Hrsg.) [2000]; zu Wien Heiß, Mattl, Meissl, Saurer \& Stuhlpfarrer (Hrsg.) [1989].

${ }^{9}$ Zur Wissenschaftspolitik im Nationalsozialismus siehe im Überblick Grüttner [2000]; Sieg [2001]; Mertens [1996].

${ }^{10}$ Siehe die Einleitung in Maier (Hrsg.) [2002]; dieser Band gibt eine Reihe von Beispielen der Rüstungsforschung an außeruniversitären Einrichtungen; siehe auch Maier [2002]c. Zur Rüstungsforschung an der Preußischen Akademie siehe Ciesla [2000]. Zur Kaiser-Wilhelm-Gesellschaft und der in ihren Instituten
} 
gilt gemeinsam, dass die „Arisierung“ des Personals relativ schnell und gründlich umgesetzt wurde. Etwa $15 \%$ der habilitierten Hochschullehrer verloren ihre Stelle, die meisten von ihnen emigrierten. ${ }^{11}$ Besonders in disziplingeschichtlichen Studien wird danach gefragt, ob eine Nazifizierung, die nicht nur in der Personalstruktur, sondern auch in der Veränderung, Anpassung und Mobilisierung des eigenen Faches erreicht wurde, zu einer effektiven oder ineffektiven Wissenschaft geführt hat und wie die Bedingungen für einen Erfolg aussahen. ${ }^{12}$

Ende der siebziger Jahre entstanden die ersten wegweisenden Arbeiten zur Naturwissenschaftsgeschichte im Nationalsozialismus. ${ }^{13}$ Besondere Aufmerksamkeit fanden ideologische Ausformungen wie zum Beispiel die „Deutsche Physik“, die kurz nach der Regierungsübernahme in verschiedenen Naturwissenschaften auftauchten, aber gegen Ende der Diktatur kaum noch irgend eine Bedeutung besaßen. ${ }^{14}$ Diese gescheiterten Versuche der Selbstmobilisierung wurden von stärker pragmatisch orientierten Vorstößen überholt. ${ }^{15}$

Erst in jüngerer Zeit sind auch die Nachkriegszeit und die Entnazifizierung der Wissenschaft Gegenstand wissenschaftshistorischer Arbeiten. Im Vordergrund stehen dabei Untersuchungen über Disziplinen, die eine inhaltliche Affinität zur NS-Ideologie besaßen. ${ }^{16}$ Die Transformation der teilweise in Verruf geratenen wissenschaftlichen Ressourcen in den neuen politischen Kontext der Nachkriegszeit war ein vielschichtiger Prozess mit oft unvorhersehbarem Ausgang. ${ }^{17}$ Die Fortführung alter Programme unter eventuell neuer Bezeichnung konnte besonders dann gelingen, wenn die entsprechenden Forschergruppen ihre berufliche Kontinuität über das Jahr 1945 sicherstellen konnten. Die zahlreichen ungebrochenen oder rasch wieder hergestellten Karrieren politisch Belasteter sind ein bereits gut untersuchtes Kennzeichen der deutschen Nachkriegsgesellschaft, das auch die

durchgeführten Forschung siehe auch Kaufmann (Hrsg.) [2000]; Vierhaus \& vom Brocke (Hrsg.) [1990]; Macrakis [1986], [1993]. Zur Deutschen Forschungsgemeinschaft siehe Hammerstein [1999].

11 Zur Exilforschung siehe Fischer [1991]b, [1995]; Ash \& Söllner (Hrsg.) [1996]; Strauss, Fischer, Hoffmann \& Söllner (Hrsg.) [1991]; Ash [2000]a; Krohn [2002]; in Bezug auf die Universität Göttingen siehe Dahms [1986]. Zur Vertreibung in der Mathematik siehe Siegmund-Schultze [1998]; Brüning, Ferus \& SiegmundSchultze [1999]; in der Physik Fischer [1988]a, [1991]a; Wolff [1993]; in der Chemie und Biologie Deichmann [2001].

12 Diesen Fragen geht am Beispiel der Rüstungsforschung Maier [2002] nach. Überzeugend in dieser Hinsicht ist auch Biagioli [1992], der die Veränderung der Wissenschaftspraxis an der medizinischen Forschung an Konzentrationslager-Häftlingen untersucht.

13 Beyerchen [1980/82]; Mehrtens \& Richter (Hrsg.) [1980]. Siehe auch die späteren Arbeiten Meinel \& Voswinckel (Hrsg.) [1994]; Mehrtens [1994]a. Das Uranprojekt wurde historisch untersucht von Walker [1989], [1995] sowie Powers [1993]; Rose [1998]. Zur Biologie und Chemie siehe Deichmann [1992], [1995], [2002]; zur Mathematik Mehrtens [1994]b.

${ }^{14}$ Zur „Deutschen Physik“ siehe Beyerchen [1980/82]; Richter [1980]; Walker [1990/92] S. 79-101; Eckert [1993] S. 196-206; Hentschel \& Hentschel (Hrsg.) [1996] S. lxxv; Litten [2000] S. 377-384.

15 Siehe Hoffmann [2002].

${ }^{16}$ Siehe Weisbrod (Hrsg.) [2002]; Etzemüller [2001]; Pehle \& Sillem (Hrsg.) [1992]. 
Professorenschaft aufweist. ${ }^{18}$ Die Professoren arbeiteten mit dem NS-Staat wie mit der Besatzungsmacht teils aus Überzeugung teils aus Opportunismus zusammen, je nach ihrer politischen Haltung. $\mathrm{Zu}$ fragen bleibt, welche Form das Arrangement mit dem jeweiligen Machthaber annahm und wie es sich veränderte. Ein Ergebnis der Remigrationsforschung ist, dass die Hochschulen in der Nachkriegszeit teilweise die Rückgängigmachung alter Arrangements verweigerten, indem sie beispielsweise politisch begünstigte Karrieren kollegial-diskret beschwiegen, und gleichzeitig manche Wiedereingliederung von NSVerfolgten, die mit unter als Ruhestörer empfunden wurden, strikt abwehrten. ${ }^{19}$ Von den Alliierten wurde eine Strukturreform der deutschen Ordinarienuniversität angestrengt, die zu einer Demokratisierung und sozialen Öffnung führen sollte, letztlich aber scheiterte. ${ }^{20}$ Ähnlich erging es den Bemühungen um Re-education, welche die Deutschen zur Demokratie erziehen sollten. An den Universitäten führten sie zwar zu Neuerungen im Lehrangebot, diese blieben aber in ihrer Wirkung beschränkt. ${ }^{21}$

Die neuere Forschung sieht einen möglichen Zusammenhang zwischen der personellen Entnazifizierung und der inhaltlichen Ausrichtung der Nachkriegswissenschaft und untersucht die Frage, ob eine durchgreifende Entfernung politisch Belasteter sich auf die Wissenschaft innovationsfördernd auswirkte, und ob eine milde Überprüfung einen Konservatismus der Forschungsprogamme begünstigte. ${ }^{22}$ Neuere Untersuchungen über die Entnazifizierung von Universitäten haben deutlich herausgearbeitet, dass die Auswirkungen der personellen Entnazifizierung stark von den lokalen Bedingungen abhängig waren. ${ }^{23}$ Am besten untersucht ist in dieser Beziehung die Universität Heidelberg. In seinem wegweisenden Kapitel über die Grenzen der Entnazifizierung zeigt Steven Remy, wie der schwierige Aushandlungsprozess zwischen der neuen Universitätsführung und der alliierten Kontrollbehörde das Ausmaß der

\footnotetext{
17 Siehe Ash [1995]b.

18 Allgemein zur deutschen Nachkriegselite siehe Frei (Hrsg.) [2001]; Loth \& Rusinek (Hrsg.) [1998].

${ }^{19} \mathrm{Zu}$ den zaghaften Bemühungen zur Wiedergewinnung vertriebener Wissenschaftler niedersächsischer Hochschulen (v. a. zur Universität Göttingen) siehe Szabo [2000].

${ }^{20}$ Zur Universitätsreform und der Entwicklung der Hochschulen in der Nachkriegszeit siehe im Überblick Oehler \& Bradatsch [1998]; Pollmann [1995]; Schneider [1984]. Siehe auch Phillips [1983]b, [1995]; Pingel [1985]; Heinemann (Hrsg.) [1981], (Hrsg.) [1990]a, (Hrsg.) [1990]b, (Hrsg.) [1996]; Hearnden (Hrsg.) [1978]; am Beispiel Aachens Haude [1993]. Siehe auch die Zusammenstellung der Dokumente zur Universitätsreform von Neuhaus [1961].

${ }^{21}$ Zur 'Umerziehung' siehe Heinemann (Hrsg.) [1981] und [1990] und [1992]; Philips (Bearb.) [1991]; Pakschies [1979], [1981]; Welch [1989].

${ }^{22}$ Dass sich eine solche Annahme bestätigt, zeigt Ash [1995]b. Zum Verhältnis eines politischen Systembruchs zur Innovation in der Wissenschaft siehe Mertens (Hrsg.) [2001]. Zur Entwicklung der Physik in der Nachkriegszeit siehe Hoffmann (Hrsg.) [2003].

${ }^{23}$ Siehe den Überblicksartikel von Defrance [2000]. Sie weist besonders auf die verschieden stark ausgeprägte Nazifizierung der Universitäten hin sowie auf die daher unterschiedliche Ausgangslage für die Entnazifizierung.
} 
politischen Überprüfung stark beschränkte. ${ }^{24}$ Leider gibt es für keine andere deutsche Hochschule eine ähnlich detaillierte Studie über die weichenstellenden Entscheidungen der ersten Nachkriegsjahre. ${ }^{25}$ Remy bestätigt frühere Ergebnisse, denen zufolge der vielschichtige Prozess der Entnazifizierung der Universitäten auf deutscher Seite mehr durch korporative Solidarität geprägt war als durch das Bestreben, überzeugte Nationalsozialisten zu entfernen. ${ }^{26}$ Mit dem baldigen Ende der Entnazifizierung und der folgenden amnestierenden Gesetzgebung setzte sich die deutsche Seite durch und brachte die einzelnen Universitäten durch den Rückkehranspruch vormals Entlassener zu einer erneuten Auseinandersetzung mit der ,,akademischen Vergangenheitspolitik““.27

An diese Befunde knüpft meine Arbeit an. Auf Grund der vorwiegend lokal wirkenden Solidarität und korporativen Verbundenheit wird die Wissenschaft nicht in ihrer disziplinären Ausbreitung, sondern an einem bestimmten Ort untersucht. Im Unterschied zur bisherigen Forschung wird in dieser Arbeit vor allem danach gefragt, wie die Wissenschaftlergemeinschaft ihre Zusammensetzung kontrollierte und nach welchen Gesichtspunkten sie sich selbst reproduzierte.

\subsection{Zur allgemeinen Fragestellung}

Spätestens seit Thomas Kuhn und seiner Studie zu wissenschaftlichen Revolutionen wissen wir, dass über die personelle wie inhaltliche Entwicklung eines Faches vor allem die scientific community entscheidet. Es war Kuhn selbst, der nach der Ausarbeitung seines zyklischen Modells der Wissenschaftsentwicklung folgende Fragen als die wesentlichen für die zukünftige Wissenschaftsgeschichte ansah: ,Wie wählt man, und wie wird man zum Mitglied einer bestimmten wissenschaftlichen [...] Gemeinschaft gewählt? Worin bestehen der Prozeß und die Stadien der Sozialisation in der Gruppe? Was sieht die Gruppe kollektiv als ihre Ziele an? Welche individuellen oder kollektiven Abweichungen wird sie tolerieren? Und wie wird sie

\footnotetext{
24 Remy [2002]. Zu Heidelberg siehe auch Heß, Lehmann \& Sellin (Hrsg.) [1996].

25 Einen Überblick über die Entnazifizierung der Hochschulen geben Chroust [1999]; Haude [1998]; zu Niedersachsen Schneider [1989]. Zur Universität Göttingen siehe Brynjølfsson [1996]; zu Münster siehe Respondek [1992]; zu Jena John, Wahl \& Arnold (Hrsg.) [1998]; zu Tübingen Paletschek [2002]; zu Aachen Düwell [1998], zu den Hochschulen in der französischen Besatzungszone siehe Faßnacht [2000] zu Mainz Zauner [1998].

${ }^{26}$ Für die Universität Münster zeigten dies Kurz \& Witte [1980].

27 Zur 'vergangenheitspolitischen' Gesetzgebung der frühen Bundesrepublik siehe Frei [1996/99]. Die deutschen Professoren hatten durchaus ein Interesse an der Entfernung bestimmter Kollegen, die in der NS-Zeit wissenschaftliche Standards grob verletzt oder vor allem sich unkollegial verhalten hatten. In diesem Zusammenhang kann man in Analogie zur Selbstgleichschaltung von einer Selbst-Entnazifizierung der
} 
mit unzulässigen Abweichungen fertig?"28 Gerade in der politischen Umbruchszeit 1945 sind solche Fragen in der Wissenschaft wieder gestellt und neu entschieden worden. Daher ist es angebracht, Kuhns Fragen in Zusammenhang mit einer Nazifizierung und Entnazifizierung zu behandeln. Die Wissenschaftler versuchten, mit veränderter Rhetorik und unterschiedlichen Strategien ihre Interessen durchzusetzen, sie artikulierten also vor wie nach 1945 ihre gleichbleibenden Bemühungen um wissenschaftliche „Ressourcen“ (Ash) unterschiedlich. Dadurch lässt sich das Veränderliche vom Gleichbleibenden im Handeln und Argumentieren gut trennen. Die wechselnden politischen Verhältnisse erleichtern auch die Untersuchung der Personalpolitik einer Disziplin. Von den politisch belasteten Wissenschaftlern konnten einige ihre Karriere in der Nachkriegszeit fortsetzen, andere schafften dies aufgrund interner Widerstände innerhalb der scientific community trotz intensiver Bemühung nicht. Die genaue Untersuchung der Trennlinie, welche die Wissenschaftlergemeinschaft zwischen dem Innen und Außen ihrer Gruppe zog, liefert interessante Einblicke in die Mechanismen jener Gemeinschaft, die schließlich die Entwicklung ihrer Disziplin prägte. Während es in Fragen der personellen Zusammensetzung 1945 also zu einer Verhandlung über die Grenzziehung innerhalb der Gemeinschaft kam, blieb die Vorstellung von den die Physik leitenden erkenntnistheoretischen Prinzipien von den äußeren Umbrüchen relativ unberührt. Trotzdem orientierte sich die inhaltliche Ausrichtung der Forschung teilweise nach politischen Vorgaben.

Wenn man nach Veränderungen in der Wissenschaftsentwicklung mit dem Ziel fragt, besondere politische Einflüsse, wie eine Nazifizierung, auszumachen, ist es hilfreich, zuerst Annahmen über einen normalen, unbeeinflussten Verlauf der Wissenschaften zu machen. In dieser Arbeit wird die „Normalwissenschaft“, wie sie Kuhn definierte, als Modell zu Grunde gelegt. Dies ist für die Göttinger Physik der dreißiger und vierziger Jahre insofern gerechtfertigt, als sich in dieser Zeit offenbar keine Paradigmenwechsel vollzogen. Die innere Dynamik der Physikentwicklung war durch jene Charakteristika geprägt, die Kuhn für die Normalwissenschaft ausführlich herausgearbeitet hat. Kurz gesagt zeichnet sich Normalwissenschaft dadurch aus, dass ein Konsens über Methoden, Theorien und Ziele der Disziplin herrscht. ${ }^{29}$ Um Kuhns unscharfe Begriffe wie Paradigma oder disziplinäre Matrix zu vermeiden, wird hier auf Ludwik Flecks Wissenssoziologie und seine Begriffe

\footnotetext{
Wissenschaften sprechen; siehe Weisbrod [2002], [2003]. Zur Auseinandersetzung der Universitäten mit den „amtsverdrängten“ Hochschullehrern siehe Schael [2002].

28 Kuhn [1969/97] S. 221.

${ }^{29}$ Zur Normalwissenschaft siehe Kuhn [1962/97] bes. Kap. 2-5.
} 
„Denkkollektiv“, „Denkstil““ und „Denkzwang“ zurückgegriffen. ${ }^{30}$ Zur Erklärung des Nazifizierungs- und Entnazifizierungsprozesses, genauer gesagt der dadurch hervorgerufenen Veränderungen in einem lokalen Wissenschaftsbetrieb, wird eine Annahme über die soziale Verbundenheit der Physiker getroffen.

\subsection{Die Leitthese vom kollegialen Netz}

Die Hauptthese dieser Arbeit stellt den Begriff der Kollegialität in den Mittelpunkt. Sie lautet, kurz gesagt: Der Übergang von einer nazifizierten zu einer entnazifizierten Wissenschaft war entscheidend geprägt durch die kollegiale Verbundenheit der Forscher; die Struktur des kollegialen Netzes war für den Ausgang des Transformationsprozesses von grundlegender Bedeutung. Diese These wird im Folgenden erläutert.

Die Prozesse der Nazifizierung und Entnazifizierung der Wissenschaften wurden von innen wie von außen geformt. Der äußere Anteil in Form politischer Einflussnahme auf die Personalstruktur gefährdete die Stellung einzelner Wissenschaftler. Zum einen wurden nach den Umbrüchen 1933 und 1945 einige entlassen, zum anderen blieb aber auch für diejenigen, die 'ungeschoren' davon gekommen waren, eine gewisse Unsicherheit durch unvorhersehbare Gesetzesänderungen oder mögliche Denunziationen bestehen. Diese Verhältnisse führten dazu, dass ein loyales Verhalten unter Kollegen besonders wichtig wurde, da sein Fehlen, also ein unkollegiales Verhalten, ernsthafte Folgen nach sich ziehen konnte. Zur Kollegialität gehörte, dass man in der NS-Zeit politisch oder rassistisch verfolgte Kollegen deckte und dass man in der Nachkriegszeit (ehemaligen) Nationalsozialisten durch Persilscheine und andere Unterstützungen in ihrem beruflichen Fortkommen half. Eine Mindestanforderung an kollegiales Verhalten war gegeben durch das Tabu der Denunziation - nur von Kollegen, wohlgemerkt.

Die Verbindungen in der scientific community waren von Normen und Werten bestimmt, die mit dem Begriff der Kollegialität beschrieben werden können. Ein Beispiel aus der Zeit des Krieges zeigt, dass in der Berufung auf kollegiales Verhalten eine Hoffnung auf politische Amnestie zwischen Wissenschaftlern verfeindeter Staaten lag. Als Karl Wirtz 1942 in Norwegen mit Physikern zusammentraf, bat er sie darum, dass es auch in Zukunft eine gewisse Kollegialität unter Wissenschaftlern gebe. ${ }^{31}$ Heinz Maier-Leibnitz berichtete über das

\footnotetext{
${ }^{30}$ Fleck [1935/99].

${ }^{31}$ Siehe Powers [1993] S. 225. 
Verhältnis der deutschen und amerikanischen Physiker nach 1945, „wie die anfängliche Feindseligkeit bald in Achtung und in die alte Kollegialität umschlug. "32

Offenbar gab es einen kollegialen Verhaltenskodex, welcher der Wissenschaftlergemeinschaft Stabilität verlieh. Doch was waren seine Bestimmungsstücke? $\mathrm{Zu}$ diesen gehörte: Anerkennung der wissenschaftlichen Leistung anderer; gemeinsames Eintreten für berufsständische Interessen (wie zum Beispiel die Sicherstellung von wissenschaftlichen Standards im Fach, die Bemühung um Finanzierung und ein positives Ansehen des Fachs in der Öffentlichkeit); das Beschützen gefährdeter Kollegen sowie das Gewähren von Hilfe (vor allem in Zeiten politischer Eingriffe); das Tabu der Denunziation von Kollegen; Wahrung eines bestimmten Maßes an Diskretion, um die Stabilität der Gruppe und ihr öffentliches Prestige zu sichern; das sich-Einordnen in die kollegiale Hierarchie und die Akzeptanz der patriarchalen Ordnungsstruktur. Die patriarchale Ordnung zeichnete sich ihrerseits aus durch die Entscheidungsgewalt des Institutsdirektors über die anderen Institutsmitglieder; eine einerseits auf Autorität und Fürsorge und andererseits auf pietätvollen Gehorsam basierende Professor-Schüler-Beziehung sowie durch Schutz- und Fürsorgepflicht des Professors gegenüber seinen Schülern bezüglich deren Karrieren. Hiermit ist nur ein Prototyp einer patriarchalen Ordnung skizziert. Die Kopplung von Autorität und Fürsorge (Lehrer) mit Gehorsam (Schüler) in der Lehrer-Schüler-Beziehung ist jedoch ein durchgängig anzutreffendes Muster. Auf die Karriereverläufe hatte diese Ordnung insofern entscheidenden Einfluss, als der Patriarch für seine Schützlinge nicht nur als Förderer auftrat, sondern die community ihm auch die Verantwortung für sie übertrug, das heißt, dass er für sie zu bürgen hatte. Diese Verantwortung bezog sich auf die wissenschaftlichen Qualitäten wie auch auf die „charakterlichen“ Eigenschaften der Schüler.

Um die Vorgänge an den Göttinger Instituten zu erklären, reicht die bloße Feststellung einer kollegialen Verbundenheit unter den Physikern nicht aus. Es ist notwendig, die jeweiligen Verbindungen nach ihrer Schwäche und Stärke zu gewichten. Dadurch erhält man ein kollegiales Netz der eng verbundenen Physiker, dessen Struktur eine Erklärungskraft besitzt. Soziologische Analysen von Netzwerken haben die Bedeutung der Netzstruktur für ganz unterschiedliche soziale Prozesse gezeigt. ${ }^{33}$ In dieser Arbeit wird versucht, aus der Art, wie die einzelnen Akteure miteinander verbunden sind, eine zusätzliche Erklärung der Personalentwicklungen zu gewinnen, die dem Blick auf fachliche Qualitäten und politische

\footnotetext{
32 Maier-Leibnitz [1991]a S. 64.

${ }^{33}$ Einen guten Überblick über die verschiedenen Methoden und Ergebnisse der Netzwerkanalyse gibt Jansen [1999].
} 
Orientierungen an die Seite gestellt werden muss. Entscheidend ist die Position, die jemand im Netz einnimmt, oder anders gesagt, die soziale Rolle, die jemand in der Gruppe verkörpert. Zerfällt ein Netz in mehrere Untergruppen, die nur lose miteinander verbunden sind, so fällt den Mittlerrollen, die eine Verbindung der Subgruppen herstellen, besondere Bedeutung zu. Es sind vor allem diese Vermittler und Makler, die das Geschehen entscheidend lenken können.

Meine Auffassung vom kollegialen Netz unterscheidet sich von der in der neueren Forschung anzutreffenden Ansicht, alte Seilschaften oder rechte Netzwerke hätten sich in der Nachkriegszeit durchsetzen können. ${ }^{34}$ Die entscheidende Differenz besteht darin, dass ich ein einziges Netz in seiner Struktur analysiere, während im anderen Fall separierte Bestandteile betrachtet werden, die durch ihren inneren Zusammenhalt erfolgreich sein konnten. Die integrierende Sicht auf ein einziges, großes Netz und seine Struktur eröffnet ein besseres Verständnis, denn es waren nicht etwaige 'rechte Klüngel' allein entscheidend, sondern deren notwendige Verbindung $\mathrm{zu}$ dem restlichen Netz der etablierten Wissenschaftler, um erfolgreich sein zu können. ${ }^{35}$ Damit erhalten die Makler, wie sie oben bezeichnet wurden, entscheidende Bedeutung in der Interpretation der personellen Veränderungen. Die Analyse des kollegialen Netzes erlaubt also, die vorhandene oder fehlende Macht einzelner Gruppen von Wissenschaftlern durch die Art ihres Eingebundenseins ins Gesamtnetz zu erklären.

\subsection{Zum Gegenstand Göttinger Physik - Fragestellungen}

Die Prüfung der These erfolgt am Beispiel der Göttinger Physik. Die lokale und fachliche Einengung des Untersuchungsgegenstandes ergibt sich daraus, dass die engsten kollegialen Verbindungen innerhalb einer Disziplin herrschten. Genauer gesagt existierten sie dort, wo am intensivsten zusammengearbeitet wurde, und dies geschah normalerweise innerhalb eines Instituts. Aus der These des kollegialen Netzes ergeben sich einige Bereiche der Göttinger Physik, die zu untersuchen sind und in denen sich die Erklärungskraft der These zeigen wird:

\footnotetext{
34 Von alten Seilschaften spricht beispielsweise Frei (Hrsg.) [2001] S. 332. Die Kritik trifft aber auch mich selbst, denn in Hentschel \& Rammer [2001] S. 205 schreiben wir: „The old boys' network of some of these farrightwing physicists who were in power at the time [1946] worked against those who were perceived as outsiders and intruders."

35 Die engsten Verbindungen des Netzes sind zwar innerhalb eines Instituts vorhanden, doch erlaubt die Methode auch die Erfassung der überregionalen Netz-Verzweigungen. In anderen Disziplinen ist die Beschäftigung mit der räumlichen Ausbreitung kollegialer Netze fester Bestandteil der Analysemethoden. Beispielsweise wurde in der Sozial- und Wirtschaftsgeografie die räumliche Verteilung des Kommunikationsverhaltens von Wissenschaftlern unterschiedlicher Fächer untersucht von Fischer \& Rammer [1992].
} 
die Personalentwicklung, insbesondere die Reaktion auf Entnazifizierungsbestrebungen. Die These lässt vermuten, dass von Seite der Professoren nicht nach politischen Kriterien 'entnazifiziert' wurde, sondern nach Einhaltung oder Verletzung des kollegialen Verhaltenskodex. Ebenfalls zu untersuchen sind die Karriereverläufe der Göttinger Physiker und die Auswirkung des Göttinger Netzes auf diese. Generell zeichnete sich eine Hochschulkarriere durch viele kleine Karriereschritte aus, die häufig an Ortswechsel gekoppelt waren. Das Ziel, eine ordentliche Professur zu bekommen oder Leiter eines Forschungsinstituts $\mathrm{zu}$ werden, erreichten nur ganz wenige; jeder Schritt war mit einer deutlichen Selektion verbunden. Die Netzthese legt nahe, dass die besser eingebundenen Wissenschaftler größere Chancen für einen beruflichen Aufstieg besaßen. ${ }^{36}$

Ein Testfall kollegialer Verbundenheit ergibt sich aus der Untersuchung der 'Außenverbindungen' des lokalen Netzes. Nach der Isolation der deutschen Wissenschaften im Nationalsozialismus war das Bedürfnis nach Anschluss an die internationale scientific community nach 1945 groß. Im Gegensatz zu den Schwierigkeiten, die es nach dem Ersten Weltkrieg diesbezüglich gab, gelang die Wiederherstellung der internationalen Verbindungen nach 1945 relativ rasch. ${ }^{37}$ Der wichtigste Schauplatz der Nachkriegsphysik war die USA. Die vielen emigrierten Physiker wirkten als Katalysator für die Aufnahme der Deutschen im Ausland. Allerdings nahmen die Emigranten feine Differenzierungen vor, und nicht jedem deutschen Physiker gelang der Auftritt auf der internationalen Bühne gleichermaßen. Auch die Göttinger Physiker waren in unterschiedlichem Maß als Gäste willkommen, wie in Abschnitt 1.3.6 gezeigt wird.

Nicht alle Aspekte der Nazifizierung und Entnazifizierung lassen sich unter Zuhilfenahme der Netzthese erklären. Um die vielfältigen Auswirkungen zu erfassen, wird die Göttinger Physik - bildlich gesprochen - mit einem Weitwinkelobjektiv fokussiert, um eine möglichst große Breite der Prozesse in den Blick zu bekommen. Der Untersuchungsgegenstand wird in dieser Arbeit über jene fünf Universitätsinstitute definiert, die den Kernbereich der universitären Physik abdeckten: das I. und II. Physikalische Institut, das Institut für theoretische Physik, das Institut für angewandte Elektrizität und das Institut für angewandte Mechanik. Der Schwerpunkt der Betrachtung liegt bewusst auf den Instituten, die als jene Orte verstanden werden, in denen Wissen produziert wurde, Physiker für Industrie und höhere Schulen

\footnotetext{
${ }^{36} \mathrm{Zu}$ den geringen Erfolgsaussichten einer wissenschaftlichen Karriere siehe Weber [1919]; Titze [1984] und [1995]; Schmeiser [1994].
} 
ausgebildet wurden und der akademische Nachwuchs auf eine Hochschullaufbahn vorbereitet wurde. Die politischen Einflüsse und Veränderungen, nach denen in dieser Arbeit gefragt wird, sind möglicherweise in allen oder nur in einzelnen dieser Bereiche aufzufinden. Um eine Gesamteinschätzung geben zu können, werden daher das Personal wie auch die Studenten untersucht, die in den Instituten durchgeführten Forschungen und die angebotene Lehre. Der Untersuchungszeitraum ist durch die Prozesse Nazifizierung wie Entnazifizierung gegeben. Das Ende ist durch den Abschluss der gesetzlichen Entnazifizierung markiert sowie durch den grundsätzlichen personellen Umbau der Göttinger Physik zu Beginn der fünfziger Jahre. Drei Ordinarien mussten in kurzer Folge ersetzt werden: Robert Pohl wurde 1952 emeritiert, Hans Kopfermann wurde 1953 wegberufen, und Richard Becker starb 1955.

Zur Göttinger Physik liegen bereits wissenschaftshistorische Arbeiten vor, die einen guten Überblick über ihre Geschichte vermitteln. Sie haben gezeigt, dass die Göttinger Physik mehrfach internationale Bedeutung erlangte, zum Beispiel in der Weimarer Zeit wie auch nach 1945. ${ }^{38}$ Der Nationalsozialismus markierte durch die Vertreibung von über der Hälfte der Physikprofessoren und -assistenten einen gravierenden Einschnitt. ${ }^{39}$ Trotzdem konnte ein relativ hohes Niveau in Forschung und Lehre gehalten werden. ${ }^{40}$ Die Nachkriegszeit brachte einen neuen Aufschwung in der Physik, der durch den Zuzug berühmter Physiker wie Werner Heisenberg, Otto Hahn, Max von Laue und Carl Friedrich von Weizsäcker erkennbar ist. ${ }^{41}$ Diese 'großen Köpfe' beeinflussten die Entwicklung der universitären Physik jedoch nur am Rande, da sie vor allem am Kaiser-Wilhelm- beziehungsweise Max-Planck-Institut für Physik

\footnotetext{
${ }^{37}$ Zum Einbruch der internationalen Beziehungen für die deutsche Physikerschaft nach dem Ersten Weltkrieg siehe Metzler [2000]. Der dortige Abschnitt über die Zeit nach 1945 weist eher essayistischen Charakter auf; diesbezüglich bedarf es noch weiterer Forschungsarbeit, wie Metzler selbst feststellt (S. 211).

38 Siehe Hund [1969], [1982], [1987], [1994]; speziell zur Weimarer Zeit Lemmerich [1982]; zur NS-Zeit Rosenow [1987/98]. Auch in der Aerodynamik rangierte Göttingen an international führender Stelle, siehe Trischler [1992]; Rotta [1990].

${ }^{39}$ Die beste Arbeit zur Vertreibung der Göttinger Physiker und Mathematiker ist immer noch Beyerchen [1980/82]. Unter Zugrundelegung seiner Personalauflistung der beiden Experimentalphysikinstitute und des Instituts für theoretische Physik (Tabelle 1 am Ende seines 2. Kapitels) wurden 1933 vier Siebtel der Göttinger Physiker entlassen. Wenn man die beiden Institute der angewandten Physik hinzurechnet ergibt sich, dass ziemlich genau die Hälfte der Göttinger Physiker entlassen wurde. Zur den Entlassungen an der Universität Göttingen 1933 siehe Dahms [1986].

40 Diese These vertreten Hund [1987] und Rosenow [1987/98]; siehe auch Beyerchen [1980/82].

${ }^{41} \mathrm{Zu}$ den bedeutenden Göttinger Physikern liegen eine Reihe (auto)biografische Arbeiten vor. Siehe beispielsweise die Autobiografien von Max Born [1975]; Max Laue [1952]; Werner Heisenberg [1969]; siehe auch Cassidy [1995]; Geyer, Herwig \& Rechenberg (Hrsg.) [1993]. Zu Max Born und James Franck siehe auch Lemmerich [1982]; außerdem befinden sich zwei biografische Studien zu James Franck von Jost Lemmerich und Alan D. Beyerchen in Vorbereitung. Hans Kopfermann steht im Zentrum einer wissenschaftshistorischen Arbeit von Klaus Schlüpmann, deren vorläufige Version im Internet unter http://www.aleph99.org/etusci/ks/ einzusehen ist. Zu Houtermans siehe Landrock [2003]; Amaldi [1998]. Zur Karriere des Göttinger Astronomen Otto Heckmann siehe Hentschel \& Renneberg [1994], [1995]. Über den ersten Nachkriegsdekan und
} 
wirkten. ${ }^{42}$ Das Geschehen an den Physikinstituten der Universität wurde hingegen von den jeweiligen Institutsdirektoren maßgebend bestimmt. Sie stehen daher in Absehung von ihrer fachlichen Bedeutung und Berühmtheit im Zentrum der Untersuchung.

Die Universität Göttingen weist in ihrer Nachkriegsentwicklung im Unterschied zu anderen Hochschulen einige Besonderheiten auf, auf Grund derer sie in der Besatzungszeit eine herausragende Bedeutung erlangte. ${ }^{43}$ Die Universität war fast unzerstört aus dem Krieg hervorgegangen und fungierte als wichtiger Kristallisationspunkt für die Reorganisation der westdeutschen Hochschulen. ${ }^{44}$ Die erste Nachkriegs-Hochschulkonferenz fand Ende September 1945 in Göttingen statt. Dort bekam auch das Sekretariat der Nordwestdeutschen Hochschulkonferenz seinen ständigen Sitz. ${ }^{45}$ Die vorher in Berlin ansässige Kaiser-WilhelmGesellschaft wurde, nachdem sie in Max-Planck-Gesellschaft umbenannt worden war, mit ihrem neuen Sitz in Göttingen wieder zugelassen, zuerst nur für die britische und dann auch für die anderen West-Zonen. ${ }^{46}$ Mit ihr kam auch das MPI für Physik 1946 dorthin und begünstigte die Reorganisierung der Physik. Im Oktober 1946 fand in Göttingen die erste Nachkriegs-Physikertagung statt, auf der die Deutsche Physikalische Gesellschaft wieder gegründet wurde. ${ }^{47}$ Auch die erste Teilgründung der Gesellschaft Deutscher Chemiker vollzog sich im September 1946 in Göttingen.48 Zum 1. Januar 1946 errichtete der Kontrolloffizier Bertie Blount einen Deutschen Wissenschaftlichen Rat für die britische Zone (German Advisory Council), der anfangs aus den Göttinger Wissenschaftlern Carl Correns, Arnold Eucken, Hermann Rein, Otto Hahn, Werner Heisenberg und dem Vorsitzenden Adolf Windaus, sowie aus Ernst Telschow und Erika Bollmann von der MPG bestand. ${ }^{49}$ Der wissenschaftliche Rat forcierte nicht nur die Reorganisation der MPG, sondern setzte sich

\footnotetext{
Physikochemiker Arnold Eucken existiert eine Biografie von Becke-Goehring \& Eucken [1995]. Ludwig Prandtl wurde von seiner Tochter biografisch gewürdigt: Vogel-Prandtl [1993].

42 Zum MPI für Physik siehe Carson [2000]; Kant [1992]; Heisenberg [1971]. Zum Göttinger KWI für Strömungsforschung und der damit verbundenen Aerodynamischen Versuchsanstalt siehe Tollmien [1987]; Trischler [1992]; Rotta [1990]; Wuest [1991].

43 Zur Universität Göttingen in der Nachkriegszeit siehe Heimpel, Kamp \& Kertz [1986]; Dahms [1999]; Brinkmann [1985]b; Conze [1950] sowie die Berichte des Kontrolloffiziers Bird [1978], [1981], [1983]. Eine Studie über die Nachkriegsstudenten mit starkem Bezug auf Göttingen liegt mit Krönig \& Müller [1990] vor; zur Studiensituation in Göttingen siehe auch Bahrdt [1988]. Eine Studie zur Stadt Göttingen im Nationalsozialismus hat Cordula Tollmien [1998] mit ihrer Dissertation vorgelegt.

44 Dahms [1999].

$45 \mathrm{Zu}$ den Nordwestdeutschen Hochschulkonferenzen siehe Heinemann (Hrsg.) [1990]c.

46 Zur Entstehung der MPG in Göttingen siehe Oexle [1994], [2003].

47 Siehe hierzu meine demnächst erscheinende Studie: ,„»Sauberkeit im Kreise der Kollegen«: die Vergangenheitspolitik der DPG“،.

48 Hoer (Hrsg.) [1999] S. 6. Zu den Physiker- und Chemikertagungen in Göttingen im Herbst 1946 siehe Physikalische Blätter 2 (1946), S. 178, 182, 192, 246.

49 Osietzky [1984] S. 96.
} 
auch für das Weiterbestehen der Physikalisch-Technischen Reichsanstalt ein, dessen zwischenzeitlicher Präsidialausschuss 1947 aus den Göttinger Physikern Heisenberg, Kopfermann, Pohl und Laue bestand. ${ }^{50}$ Für den Fortbestand der PTR engagierte sich vor allem Max Laue, der auch der erste Nachkriegsvorsitzende der Deutschen Physikalischen Gesellschaft in der Britischen Zone wurde. ${ }^{51}$

Dass Göttingen eine führende Rolle in der Forschungspolitik der Nachkriegszeit zugewiesen bekam, lag an Entscheidungen, die in England schon gegen Ende des Krieges getroffen worden waren. ${ }^{52}$ Trotzdem brachte das Jahr 1945 einen Moment der Unsicherheit für die Göttinger Wissenschaftler mit sich. Der erste Göttinger Nachkriegsrektor, Rudolf Smend, meinte sogar, die Universitäten stünden in einer Krise und vor ,allerlei Bewährungsproben“, da sie ,aus der Zeit des nationalsozialistischen Regimes“ kompromittiert herausgegangen seien. ${ }^{53}$ Für die Göttinger Physik gilt ebenso wie für die Physik in Deutschland allgemein, dass sie im Krieg in erheblichem Ausmaß in militärische Projekte eingebunden war. Wegen des dadurch erworbenen Know-how erschienen die Physiker den Alliierten einerseits als gefährlich, andererseits als ein für eigene Ziele verwertbarer Wissensträger, sodass aus beiden Gründen einige von ihnen inhaftiert und teilweise aus Deutschland gebracht wurden. ${ }^{54}$ Das technische und wissenschaftliche Wissen, das in Deutschland während des Kriegs angesammelt wurde, wurde von dafür eigens gegründeten, alliierten Einheiten ausgewertet und in die Siegerstaaten transferiert. Ein Beispiel für dieses Unternehmen sind die zahlreichen publizierten FIAT-Berichte (Field Intelligence Agency, Technical), an denen auch Göttinger Physiker beteiligt waren. Auch wissenschaftliche Geräte wurden demontiert und aus Deutschland gebracht. Davon waren die Göttinger Physikinstitute kaum betroffen, in großem Ausmaß jedoch die Göttinger aerodynamische Versuchsanstalt. ${ }^{55}$

\footnotetext{
501948 wurde Wilhelm Köster neuer Präsident der PTR. Peltzer [1995] S. 117. Zur PTR siehe auch Kern [1994]; Moser [1962]. Zur Gründung des Präsidialausschusses siehe auch Physikalische Blätter 3 (1947), S. 273. Aus dem zonalen Forschungsrat ging später der Deutsche Forschungsrat hervor. Siehe Carson \& Gubser [2002].

51 Zur Rolle Max Laues in der Nachkriegszeit siehe die Arbeit von Katharina Zeitz „Max von Laue und seine Bedeutung für den Wiederaufbau der Deutschen Wissenschaft nach dem Zweiten Weltkrieg“ [im Erscheinen].

52 Hierzu überzeugend Oexle [2003].

53 Dies äußerte Smend auf der ersten Hochschulkonferenz in Göttingen im September 1945. Siehe Heinemann (Hrsg.) [1990]c, S. 47.

${ }^{54}$ Zur Internierung der deutschen Atomphysiker in England siehe Hoffmann (Hrsg.) [1993]. Besonders die kriegsrelevanten Anteile der Forschung behandeln Deichmann [2000] für Biologie und Chemie; Epple \& Remmert [2000] für angewandte Mathematik; Eckert [2000] und Walker [2000] für (theoretische) Physik; Trischler [2000] für die Luftfahrtforschung.

55 Zur Inhaftierung deutscher Wissenschaftler durch die Briten siehe den zeitgenössischen Bericht von John Gimbel [1946/90] und dessen Standardwerk zur Ausbeutung der deutschen Wissenschaften als Reparationsleistung durch die USA, Gimbel [1990]; Judt \& Ciesla (Hrsg.) [1996]. Zur Ausbeutung der
} 
Auf Grund dieser Ausgangslage ergeben sich einige Fragen zu den Nazifizierungs- und Entnazifizierungsprozessen in der Göttinger Physik. Gerade in Hinblick auf den Aufschwung nach 1945 ist es von besonderem Interesse, nach dem Ausmaß der vorhergehenden Nazifizierung zu fragen. Da auf das Jahr 1933 ein beträchtlicher personeller Umbau folgte, sind besonders die Bedingungen und das Resultat der Nachbesetzungen der vakanten Lehrstühle zu untersuchen. Erklärt sich eventuell der relativ geringe alliierte Zugriff auf die Göttinger Physik mit einer nicht stattgefundenen Nazifizierung?

Die wissenschaftspolitisch günstigen Verhältnisse in Göttingen ließen die Stadt zu einem Auffangbecken für viele derjenigen Physiker werden, die auf Grund der Ereignisse des Jahres 1945 stellungslos geworden waren. In der Deutung der Zusammensetzung der neu hinzugekommenen Physiker greift wieder die Netzthese. Die neue lokale Personalkonstellation wird verständlich, wenn man die alten kollegialen Verbindungen zu den in Göttingen Ansässigen aufspürt.

Göttingen war nach Kriegsende nicht nur für Physikdozenten ein Anziehungspunkt, sondern in hohem Maß auch für Studenten. ${ }^{56}$ Auf Grund des enormen Andrangs war ein numerus clausus unvermeidlich. In der Auswahl und Abwehr der Studenten wurden mehrere Maßnahmen angewendet, zu denen anfangs auch die Entnazifizierung zählte. Das vielschichtige Auswahlverfahren veränderte die Zusammensetzung der Studentenschaft grundlegend, vor allem in der Geschlechterverteilung. Eine nähere Untersuchung des Umgangs der Professoren mit den Studenten gibt Auskunft über die eingangs gestellten Fragen nach dem Aufnahmemodalitäten einer wissenschaftlichen Gemeinschaft. Sie ist vor allem deshalb aufschlussreich, weil bei den Studenten in größerem Ausmaß auch nicht fachwissenschaftliche Merkmale für oder gegen eine Aufnahme entscheidend waren. Es wurden also bestimmte Kriterien, die notwendig waren, um Mitglied in der Physikergemeinschaft zu werden, viel deutlicher ausgesprochen und angewendet, als dies bei den Stellenbesetzungen im Lehrkörper der Fall war. Daher gibt der Umgang mit den Studenten einen guten Einblick in die zusätzlich zur fachlichen Qualifikation geforderten Eigenschaften eines guten Akademikers.

Ein noch nicht angesprochener Bereich der Göttinger Physik, der ebenfalls einer politischen Einflussnahme unterlag, ist das Lehrangebot. Wenn auch diesbezüglich nach einer Nazifizie-

deutschen Wissenschaften durch die Sowjetunion siehe Mick [2000]; Uhl [2001]; Albrecht, Heinemann-Grüder \& Wellmann [1992].

56 Siehe Krönig \& Müller [1990]. Eine gute Studie existiert zu den Nachkriegsstudenten an der TH Braunschweig, Maaß [1998]. 
rung gefragt wird, so ist damit nicht nur eine ideologische Umorientierung in der Lehre gemeint, sondern allgemein eine politisch zu deutende Veränderung im Angebotsspektrum auch in Hinblick auf kriegsrelevante Unterrichtsthemen. Eine deutliche Beeinflussung zeigte sich nach 1945, hervorgerufen durch die Re-education-Politik in Verbindung mit der geistigen Verunsicherung durch Kriegsgreuel, Konzentrationslager und Atombomben, um nur die wichtigsten Schlagworte zu nennen. Erkennbar ist sie unter anderem am Aufleben des studium generale in den ersten Nachkriegsjahren. Die klassische humanistische Bildung gewann an Bedeutung; man suchte ein Weltbild, das vor allem den jungen Menschen Halt bieten konnte. ${ }^{57}$ Auch die Göttinger Naturwissenschaftler beteiligten sich am studium generale. Welche Inhalte sie vermittelten, zeigt Kapitel 4.

\section{5 Über Modellannahmen zur Wissenschaftsentwicklung}

Um die Wechselwirkung zwischen Wissenschaft und Politik analytisch erfassen zu können, schlug Mitchell Ash ein Challenge-Response-Modell vor, das allerdings bis jetzt nur in skizzenhafter Form vorliegt. ${ }^{58}$ Politische Veränderungen, die nichts mit Wissenschaft im engeren Sinn zu tun haben müssen, konnten Wissenschaftswandlungen ermöglichen oder stimulieren, indem sie neue Zielsetzungen, Probleme oder Herausforderungen aufwarfen, die von den Wissenschaftlern aufgegriffen oder abgewehrt wurden. Weder Kontinuität noch Wandel waren in solchen Zeiten selbstverständlich; beides musste von der daran interessierten Seite erst durchgesetzt werden. Die Betonung liegt auf dem Aushandlungsprozess und nicht auf dem (vermeintlich zu erwartenden) Ergebnis. Ash spricht daher von „Ermöglichungsverhältnissen“, welche die Verzahnung von Wissenschaft und Politik beschreiben. ${ }^{59}$

Meiner These zu Folge waren die einzelnen Physikinstitute durch die dort vorhandenen, engen kollegialen Bindungen der maßgebende Ort für den Verlauf der Nazifizierung wie Entnazifizierung. Daher fungieren sie in der Analyse der Göttinger Physik als Grundeinheit der Betrachtung. An ihrer Spitze stand der Institutsdirektor. Er war der einzige Ordinarius im Institut; die anderen Institutsmitglieder, zu denen ein deutliches Machtgefälle herrschte, waren außerplanmäßige Professoren, Privatdozenten, Assistenten, Hilfsassistenten und

\footnotetext{
${ }^{57}$ Die deutschen Professoren bekannten sich auf der ersten Nachkriegs-Hochschulkonferenz im September 1945 in Göttingen einstimmig zu der von dem späteren Kultusminister Adolf Grimme geforderten „Rückkehr zum humanistischen Gymnasium, als dem dringendsten Erfordernis im Erziehungswesen“. Siehe Heinemann (Hrsg.) [1990]c S. 66ff.

${ }^{58}$ Siehe Ash [1995]a und [1999] S. 353f.
} 
Doktoranden. Er entschied über alle wichtigen Vorgänge im Institut: über die Forschungsrichtung, die Vergabe bezahlter Stellen, die Durchführung spezialisierter Ausbildung und in gewissen Maßen auch über den Erfolg der Karrieren seiner Schüler. Die engsten kollegialen Verbindungen in der Göttinger Physik gab es innerhalb der hierarchisch strukturierten Institute. Um die Verhältnisse an einem einzelnen Institut zu modellieren, bietet sich folgendes Schema an:

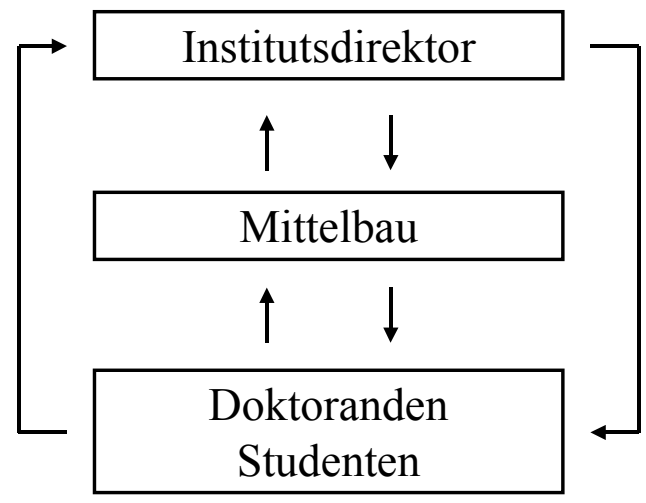

Betrachtet man die Wechselbeziehungen zwischen zwei Instituten, so lässt sich dieses Modell einfach erweitern:

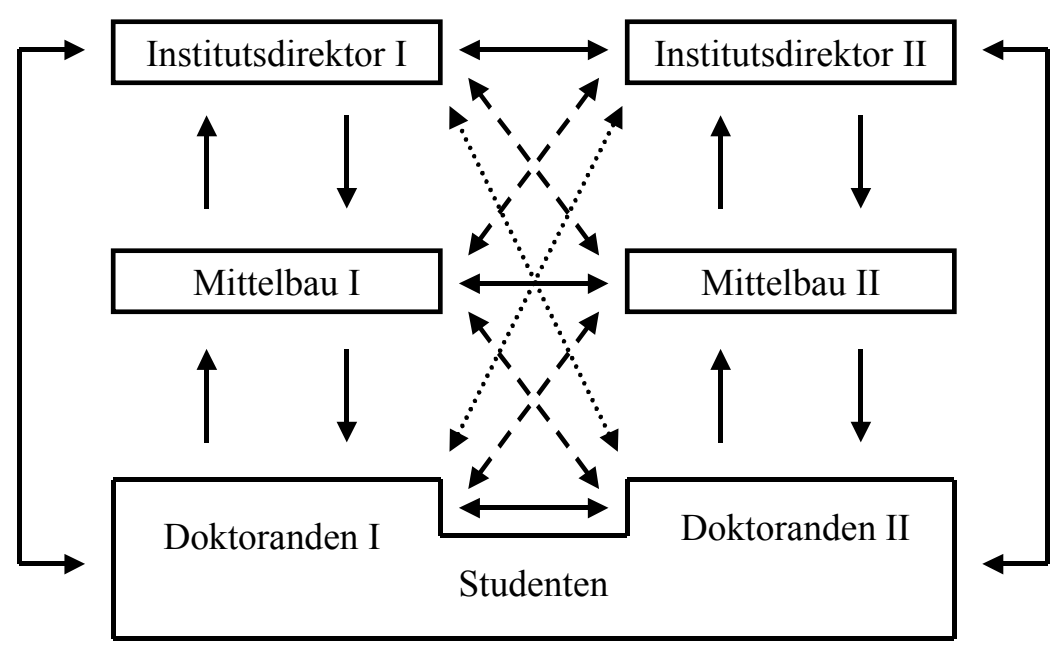

Hatten die Studenten noch mit allen Instituten Berührung, so konzentrierte sich die Aufmerksamkeit während der Promotionsphase und der Assistentenzeit auf ein bestimmtes. Während also auf der untersten Stufe ein Institutswechsel relativ einfach möglich war, wurde dies auf

59 Siehe dazu besonders die Einleitung in Ash [1995]a und auch [1995]b. 
den höheren Stufen schwieriger. Enge kollegiale Bindungen entwickelten sich gewöhnlich innerhalb eines einzelnen Institutes, zwischen verschiedenen waren sie weniger selbstverständlich.

In diesem Bild gesprochen wirkten die Institutsdirektoren nicht nur nach unten, sondern in Fakultät und Senat bezüglich hochschulpolitischer Fragen auch nach oben. In den Fakultätssitzungen wurden unter Vorsitz des Dekans die Institutsbelange koordiniert, und es wurde die Personalpolitik der Fakultät entschieden. Es konnte beispielsweise einem Institut eine Stelle weggenommen und einem anderen zugewiesen werden, während neue zusätzliche Stellen vom Ministerium bewilligt werden mussten. Die Verbindung zum Ministerium wurde über den Rektor, der Vorsitzender des Senats war, hergestellt. Diese nächste Hierarchisierung der Universität veranschaulicht folgendes Diagramm:

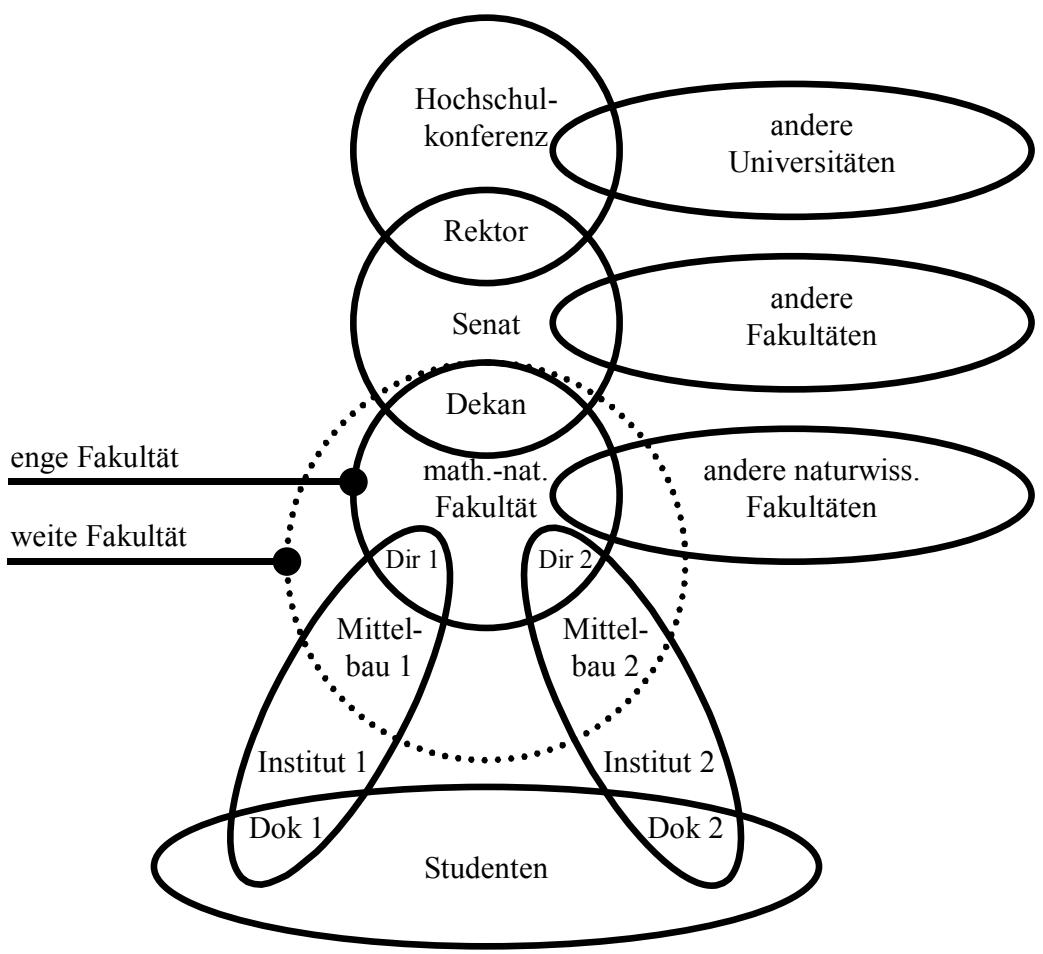

In der NS-Zeit wurde der Rektor, der seinerseits die Dekane bestimmte, vom Ministerium ernannt. 1945 erhielt die Universität ihr traditionelles Selbstbestimmungsrecht zurück. Die Dekane und der Rektor wurden wieder von ihren Kollegen gewählt. ${ }^{60}$ Im kollegialen Netz nehmen diese Führungspersonen aufgrund ihrer Machtposition eine ausgezeichnete Stellung ein. Um die Entscheidungsfindung auf Universitätsebene $\mathrm{zu}$ analysieren, müssen das 
Ministerium und andere Verbindungen nach außen mit in Betracht gezogen werden. Als Mittler zwischen Universität und Ministerium fungierte der Kurator. Über ihn liefen die universitären Anträge ans Ministerium. Er sorgte für Kontinuität in der Verwaltung und war auch wichtiger Ansprechpartner für die regelmäßig wechselnden Rektoren, da er einen besseren Überblick über die Personalstruktur der Universität besaß. Gleich nach Kriegsende versuchte die Universität Göttingen erfolglos, den Kuratorposten abzuschaffen, um ihre Autonomie zu stärken. ${ }^{61}$ Der Kurator blieb erhalten und übte neben dem Ministerium, dem Senat und der Fakultät auf die Personalentscheidungen der Universität weiterhin Einfluss aus. Dies wird vor allem in Abschnitt 5.4 herausgearbeitet.

\subsection{Zur Methode}

Diese Arbeit untersucht den Lehrkörper, die Studenten, die Forschungsthemen und das Lehrangebot in getrennten Kapiteln. Dieses Vorgehen empfiehlt sich, da die Prozesse der Nazifizierung und Entnazifizierung sich auf die genannten Bereiche der Göttinger Physik in unterschiedlicher Weise auswirkten. Es bietet weiter den Vorteil, dass in den einzelnen Kapiteln die jeweils geeigneten Methoden der historischen Untersuchung angewendet werden können. Diese Methodenvielfalt erleichtert die Erfassung der Vielschichtigkeit des Transformationsprozesses. Der Lehrkörper wird prosopografisch untersucht, die Veränderungen in der Studentenschaft zum Teil statistisch und die inhaltliche Entwicklung der Forschungsthemen unter Zuhilfenahme von Zitationsanalysen ${ }^{62}$ und Flecks Wissenschaftstheorie. Fleck folgend wird exemplarisch ein „Denkkollektiv“ der Göttinger Physiker analysiert, um aus ihrem „Denkstil“ und „Denkzwang“ die inhaltliche Entwicklung der von dieser Gruppe durchgeführten Forschungen zu erklären. Dieses Vorgehen erlaubt auch, politische Einflüsse auf die Theoriebildung in der Physik zu identifizieren, die im konkreten Fall jedoch nicht vorhanden waren. Ihr Nachweis gelänge dadurch, dass sie zu einer Veränderung des Denkstils führen würden. Die in dieser Arbeit durchgeführte methodische Erfassung eines Denkkollektivs mittels Zitationsanalysen ergab, dass die Göttinger Physik aus mehreren Denkkollektiven bestand. Im untersuchten Fall beschränkte sich das Kollektiv auf ein bestimmtes Institut. Dieses Ergebnis rechtfertigt das besondere Augenmerk auf die jeweiligen Institute in der Untersuchung der Nazifizierungs- und

\footnotetext{
${ }^{60}$ Zur Universitätssatzung der Nachkriegszeit, die auf jener des Jahres 1930 fußte, siehe Gundelach [1955].

${ }^{61}$ Zur Rolle des Kurators siehe Zierold [1984] S. 11-14.

62 Zur Methode der Zitationsanalyse und ihren Möglichkeiten siehe Felt, Nowotny \& Taschwer [1995] Kap. 8.5 und die dort angegebene Literatur.
} 
Entnazifizierungsprozesse. Die Göttinger Physiker bildeten gesamt gesehen keine homogene Gruppe, sondern man findet unter ihnen Anhänger unterschiedlicher wissenschaftlicher Traditionen; auch besaßen die einzelnen Forscher jeweils verschiedene politische Überzeugungen. ${ }^{63}$

Im letzten Kapitel wird die Geschichte des Instituts für angewandte Mechanik in den Mittelpunkt gestellt. Die Konzentration auf dieses Institut hat Vor- wie Nachteile: Mit der 1934 erfolgten Absetzung Ludwig Prandtls verliert man einen der wichtigsten Organisatoren der Luftfahrtforschung aus den Augen, was als nachteilig gelten kann. Jedoch gewinnt man durch diese Konzentration Einblick in einen universitären Forschungsbereich, der zu dem vielleicht folgenreichsten deutschen militärischen Projekt beigetragen hat: der deutschen Raketenentwicklung, an die das Institut eng angebunden war; auch an anderen Rüstungsforschungen war es beteiligt. Trotz der militärischen Relevanz der Forschungen gibt es bisher keine historischen Arbeiten über dieses Institut, obgleich seine Geschichte noch aus einem weiteren Grund einer Bearbeitung würdig ist: Seine konfliktreiche Entnazifizierung bietet einen sehr guten Einblick in die Grenzen der Wiedergutmachung an Universitäten. In der Interpretation finden die Thesen zum kollegialen Netz wie auch die Modellannahmen über den hierarchischen Aufbau von Instituten mit seinen Abhängigkeiten Anwendung.

In der Ermittlung des kollegialen Netzes wurde methodisch wie folgt vorgegangen. Es wurden aus den Quellen alle Hinweise, die auch nur auf eine oberflächliche kollegiale Verbindung schließen ließen, gesammelt und in ihrer Summe ausgewertet, nämlich:

- private Briefwechsel (darin auch Aussagen über Dritte)

- formale Beziehungen wie Assistent - Professor, oder Doktorand - Betreuer, oder ein Mitarbeiterverhältnis

- gemeinsame Publikationen

- gemeinsame Lehrveranstaltungen

- gemeinsame Vorträge auf Tagungen

- gemeinsamer Einsatz für verfolgte Kollegen

- gemeinsame Urlaube

- Einladungen zu privaten Festen

- fachliche Zusammenarbeit

- Überlassung von Institutseinrichtungen, Instrumenten, Präparaten, usw.

- Vertretungen (z. B. in der Institutsleitung)

- Danksagungen in Publikationen

- Vorlegen von Arbeiten anderer bei der Akademie der Wissenschaften

- Vorschlag zur Aufnahme in wissenschaftliche Gesellschaften

- Gutachten

- „Persilscheine“

${ }^{63}$ Auf die Heterogenität der Wissenschaftlergemeinschaft weist Galison [1998] hin. 
- fachliche Betreuung bei Habilitation

- Nachrufe

- Widmung eines Aufsatzes zum Geburtstag

- Würdigung eines Forschers anlässlich dessen Geburtstags

- Anekdoten über Freundschaften zwischen Physikern

- Interviews mit 'Netzmitgliedern' ${ }^{64}$ oder Zeitzeugen

Ein einzelner Hinweis allein, wie eine Erwähnung in einer Danksagung, kann relativ nichtssagend sein, doch selbst in den Formulierungen der Danksagungen findet man auch Qualitätsunterschiede, sodass man auf die Nähe der kollegialen Verbindung vorsichtig rückschließen kann. Es ist auch klar, dass in der obigen Liste Kriterien genannt sind, die auch auf eine negative Verbindung schließen lassen, wie zum Beispiel ein vernichtendes Urteil in einem Gutachten. Eine Fülle von positiven Hinweisen, bei gleichzeitigem Fehlen von negativen, ist allerdings ein verlässliches Anzeichen für eine enge und tragfähige kollegiale Verbindung. Aus den auf diese Art ermittelten engen Verbindungen lässt sich ein Netz konstruieren, wie es in Abschnitt 1.3.4 abgebildet ist. Es handelt sich allerdings nur um die Darstellung der Verhältnisse zu einem bestimmten Zeitpunkt. Eine dynamische Entwicklung ist damit nicht darstellbar. Auch bleibt die Auswertung rein qualitativ; eine quantitative Behandlung, wie sie in der modernen Netzwerkanalyse üblich ist, verbietet sich schon auf Grund der nur bruchstückhaften Überlieferung privater Kommunikation und anderer wichtiger Kriterien aus obiger Liste. ${ }^{65}$

\subsection{Zur Quellenlage}

Die Quellenlage zur Physik an der Universität Göttingen ist in vielen Bereichen sehr gut. Die Hauptquellen machen die Bestände des Universitätsarchivs Göttingen und des gemeinsamen Prüfungsamts der mathematisch-naturwissenschaftlichen Fakultäten aus. Die Vorgänge in der Göttinger Physik fanden hier ihren Niederschlag in Personalakten, Instituts- und Assistentenakten und sogenannten Etatakten (die leider keine Auskunft über die Etatzuweisungen an die jeweiligen Institute geben, stattdessen die Bezahlung von Hilfsassistenten beinhalten, sowie diverse Sonderzahlungen). Eine wichtige Quelle zur Ermittlung der Studentenfrequenz in der Physik waren, mangels publizierter Daten, die Matrikelbücher. Für die Personalentwicklung aufschlussreich waren auch der Nachlass des Kultusministers Adolf Grimme im Geheimen

\footnotetext{
${ }^{64}$ Diese Interviews erlaubten die Konstruktion von ego-zentrierten Netzen. Zur Erhebung und Analyse solcher Netzwerke siehe Jansen [1999] S. 99f.

65 Eine quantitative Analyse der Professorenschaft in der Nachkriegszeit unternahm Bernhardt [1990] für die Universität Gießen. Seine statistisch vorgehende Arbeit behandelt Parteizugehörigkeiten und Karriereverläufe, nicht aber kollegiale Netze.
} 
Staatsarchiv, Berlin, sowie die Akten des Kultusministeriums im Hauptstaatsarchiv Hannover. Dort befinden sich auch die seit 2001 freigegebenen Entnazifizierungsakten, die wichtige Hinweise über vorhandene oder fehlende Netzverbindungen der Physiker enthalten. Weniger gut sieht die Überlieferung in Form von Nachlässen aus. Von den Institutsdirektoren der vierziger Jahre gibt es keine der Forschung zugänglichen Nachlässe. Als ergiebig erwies sich aber der in Berlin und Göttingen befindliche Nachlass von Ludwig Prandtl, außerdem jener von Max Laue in Berlin. Korrespondenzen mit Göttinger Physikern fanden sich in zahlreichen Nachlässen im In- und Ausland. Um Wiederanknüpfungsversuche an die internationale Wissenschaftlergemeinschaft aufzuspüren, wurden die Bestände des Archive for the History of Quantum Physics in Berkeley, Kalifornien, und der Niels Bohr Library in College Park, Maryland, gesichtet.

Eine reichhaltige Quelle zur Nachkriegsgeschichte stellt der Nachlass von Kurt Hohenemser dar, der aus einer umfangreichen Korrespondenz, vielen Fotografien, Tagebüchern, Reisenotizen und autobiografischen Manuskripten besteht. Er gestattet einen tiefen Einblick in die Vorgänge um Hohenemsers gescheiterte Rehabilitierung und gibt Aufschluss über den zeitlichen Wandel seiner Absichten. Der Nachlass befindet sich noch in Familienbesitz.

Eine andere ausgewertete Quellengattung sind Interviews mit Zeitzeugen, in denen wichtige, anders nicht zu erhaltende Informationen ermittelt werden konnten. Eine Auflistung der Interviewpartner findet sich im Quellenverzeichnis. Auch Kurt Hohenemser konnte ich ein knappes Jahr vor seinem Tod noch befragen. Dieses Interview wurde auszugsweise publiziert. 66

\footnotetext{
66 Rammer [2002].
} 


\section{Der Lehrkörper - eine kollegiale Gemeinschaft}

In diesem Kapitel wird die quantitative wie qualitative ${ }^{67}$ Entwicklung des Lehrkörpers in den vierziger Jahren untersucht. Markante Veränderungen in der Größe des Lehrkörpers vollzogen sich erwartungsgemäß um die Jahre der politischen Einschnitte 1933 und 1945, wie in Abbildung 1 veranschaulicht. Der quantitative Einbruch 1933 gründete aber nicht in der Vertreibung der Ordinarien James Franck und Max Born, deren Lehrstühle nachbesetzt wurden, sondern jener „nichtarischen“ und politisch unerwünschten Dozenten des Mittelbaus, die zum Teil keine Planstellen besaßen. Die rassistischen NS-Gesetze zerstörten auch ein positives wissenschaftliches Klima in Göttingen. Bis 1933 waren die Göttinger Physikinstitute ein internationaler Anziehungspunkt für die besten Nachwuchswissenschaftler.

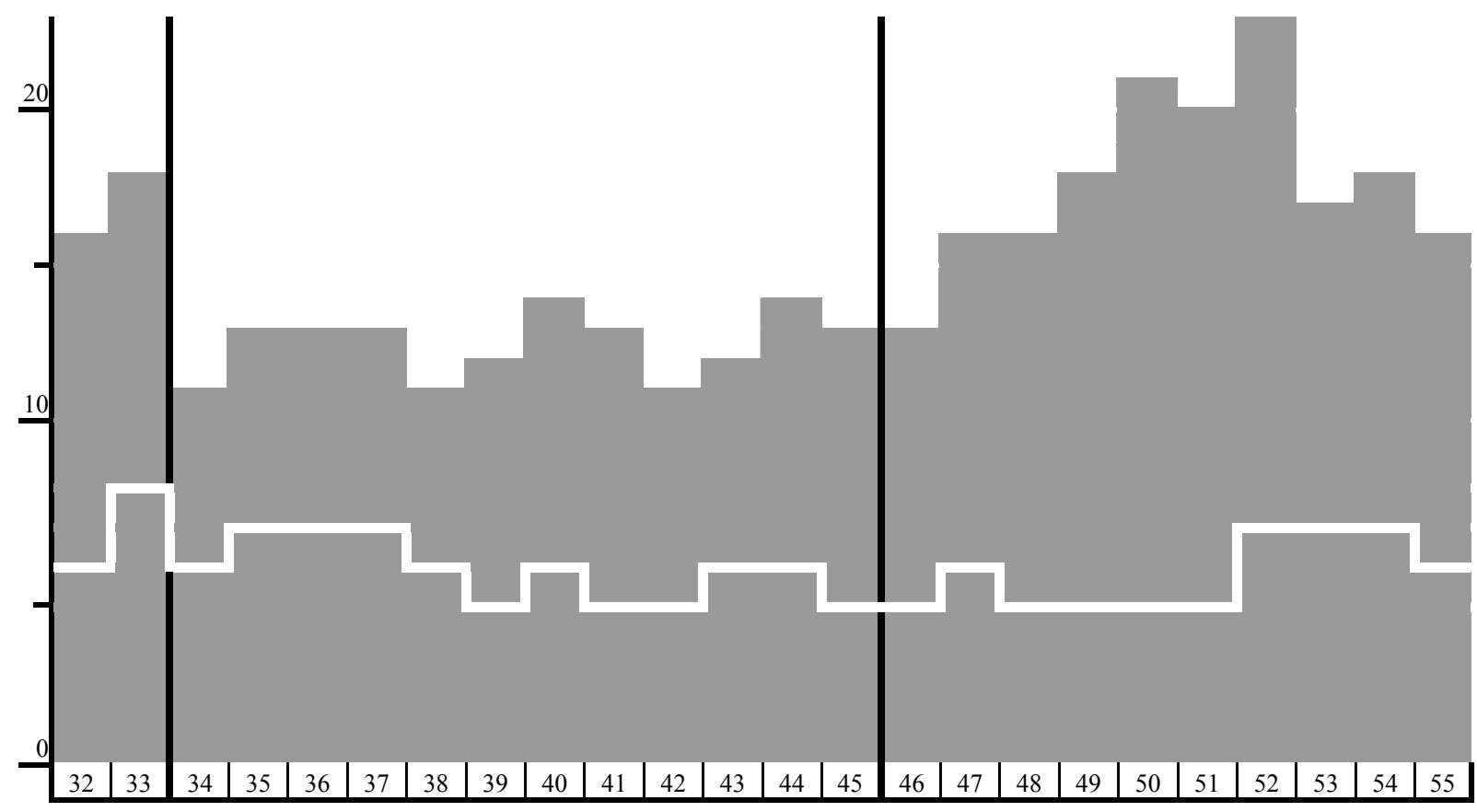

Abbildung 1 Größe des am Physikcurriculum beteiligten Lehrkörpers der Universität Göttingen. Oberhalb der weißen Linie: Experimentelle und theoretische Physik; unterhalb: Angewandte Physik.

In Abbildung 1 ist nicht die Anzahl der vorhandenen Planstellen angezeigt, sondern jene der am Physikcurriculum beteiligten Dozenten. Aus dem Größenverlauf erkennt man, dass es nach 1933 an jungen habilitierten Nachwuchswissenschaftlern mangelte. ${ }^{68}$ Überraschender

\footnotetext{
${ }^{67}$ Näheres zu den Inhalten folgt auch in den Kapiteln zum Lehrangebot und den Forschungsthemen.

68 Auf die Konstanz der Anzahl der Ordinarien zur Zeit der Weimarer Republik und des Nationalsozialismus wies Chroust [1994] hin, der für die Personalentwicklung der gesamten Universität Gießen ein anschauliches Diagramm entwarf, in dem die Größenanteile der verschiedenen Statusgruppen in ihrer zeitlichen Entwicklung
} 
als die Entwicklung zu Beginn der NS-Herrschaft ist jene nach deren Ende. Gerade in der Hochphase der Entnazifizierung zwischen 1945 und 1948, wo vielerorts der Lehrkörper drastisch reduziert wurde, wuchs er in der Göttinger Physik deutlich an. Dieses erklärungsbedürftige Phänomen wird in der zweiten Hälfte dieses Kapitels eingehend diskutiert. Es kann hier schon vorausgeschickt werden, dass es sich nicht um eine Vermehrung der Planstellen handelte, sondern dass eine Reihe von stellenlosen Physikern in fürsorglicher Weise aufgenommen wurde.

Bei der Frage nach der Qualitätsänderung in der Göttinger Physik interessiert, wie der neue Anforderungskatalog an Hochschullehrer, der 'Qualitäten ' wie rückhaltloses Eintreten für den „nationalen Staat“ und „arische Rasse“ enthielt, sich in der Besetzung der Göttinger Lehrstühle und der Assistentenstellen auswirkte. Mit dieser Fragestellung rückt die Berufungspraxis ins Zentrum der Untersuchung. Auch wenn das Hauptinteresse den Karriereverläufen und ihren Bedingungen in den vierziger Jahren gilt, so ist für ein tieferes Verständnis die Kenntnis der Vorgeschichte nötig, zum Beispiel die Umstände der Lehrstuhlnachbesetzungen nach den Vertreibungen des Jahres 1933. Zu Beginn der Darstellung wird die personelle Ausgangsbasis zu Ende der Weimarer Republik kurz skizziert.

\subsection{Institutionelle und personelle Ausgangssituation}

Die Neuordnung der Physikinstitute und -lehrstühle geschah in den Jahren 1920/21 mit der Neubesetzung des Extraordinariats für angewandte Elektrizität und der beiden Ordinariate für Experimentalphysik und mathematische Physik. Mit Wirkung vom 1. April 1921 wurden auf den Lehrstuhl für Experimentalphysik James Franck und auf jenen für mathematische Physik Max Born berufen. Die außerordentliche Professur für angewandte Elektrizität erhielt im Oktober 1920 Max Reich, der bei dieser Gelegenheit zum persönlichen Ordinarius ernannt wurde. Gleichzeitig wurde die außerordentliche Professur für Experimentalphysik, die seit 1916 mit Robert Wichard Pohl besetzt war, zu einem planmäßigen Ordinariat aufgewertet. ${ }^{69}$ Diese vier Abteilungen der Göttinger Physik bekamen 1922 neue Institutsnamen: ${ }^{70}$

\footnotetext{
abzulesen sind (S. 95). Nicht nur für Gießen, sondern auch für Göttingen dürfte zutreffen, dass über einem stabilen Sockel der Ordinarien sich ein in den zwanziger Jahren stetig wachsender Überbau von Nichtordinarien ausbreitete, der als Folge der NS-Wissenschaftspolitik wieder zusammenschrumpfte.

69 Diese hier verkürzt und vereinfacht dargestellten Verhältnisse in der Abfolge der Lehrstuhlinhaber waren in Wirklichkeit etwas verwickelter. Dies fürhte dazu, dass sie in der Literatur teilweise so dargestellt sind, als wurde um 1920 mit Tricks ein neuer Lehrstuhl geschaffen. Am ausgeschmücktesten findet sich diese Darstellung bei Jungk [1956/90] S. 37. Den Ursprung dieses Mythos lieferte Born in dem kommentierten
} 
- Erstes Physikalisches Institut (Pohl)

- Zweites Physikalisches Institut (Franck)

- Institut für theoretische Physik (Born)

- Institut für angewandte Elektrizität (Reich)

Dieser Zustand blieb auch personell bis 1933 erhalten. Mit den Neubesetzungen von 1920/21 wurde der Grundstein für eine ungemein fruchtbare Atmosphäre der physikalischen Forschung in Göttingen gelegt. Viele spätere Nobelpreisträger erhielten hier ihre Ausbildung. Die Weiterentwicklung der modernen Physik bekam entscheidende Impulse aus Göttingen, besonders in der Quantenmechanik. Der Höhepunkt dieser fruchtbaren Zeit war mit Beginn der dreißiger Jahre bereits überschritten. ${ }^{71}$

Neben den bereits genannten Instituten existierte räumlich getrennt noch das von Ludwig Prandtl geleitete Institut für angewandte Mechanik. ${ }^{72}$ Auch Prandtls Stellung wurde 1920 angehoben, als er in Abwehr eines Rufs nach München vom persönlichen zum planmäßigen Ordinarius ernannt wurde. Allein die Betrachtung der Professuren zeigt, dass der Status der Göttinger Physik ab 1920 ein höherer war. Das etatmäßige Verhältnis von Ordinarien zu Extraordinarien war vor 1920 eins zu vier und danach vier zu eins. - Von den der Physik fachlich nahestehenden Instituten und Professoren sei noch das Institut für physikalische Chemie mit Arnold Eucken erwähnt. 1930 kam Eucken als Nachfolger Tammanns nach Göttingen und gewann großen Einfluss innerhalb der Fakultät, besonders nach 1945. Er arbeitet mit manchen Göttinger Physikern auch auf der inhaltlichen Ebene eng zusammen.

\footnotetext{
Briefwechsel mit Einstein, Born [1969] S. 47-50, und in seiner Autobiografie, Born [1975] S. 274ff. Born zufolge ging das Ministerium davon aus, ein Ordinariat nicht nachbesetzen zu müssen. Born wies den Ministerialbeamten Wende nach Einsicht in die Etatplanungen des Ministeriums auf diesen Irrtum hin und konnte so die Nachbesetzung dieses Lehrstuhls erreichen und außerdem durchsetzen, dass diesen sein Freund James Franck erhielt Lemmerich [1982] S. 51 folgt dieser Darstellung. Bei Rosenow [1987/98] S. 552 ist allerdings von einem „Buchungsfehler“ und der Einrichtung eines neuen Lehrstuhls die Rede. Hund [1987] S. 56-64 geht auf die Datails der Lehrstuhlfolge nicht näher ein. Dies holte kürzlich Dahms [2002] nach, der Borns aus der Erinnerung geschriebene Darstellung mit der Quellenlage abglich. Im Jahr 1914 wurde für einen jungen Theoretiker ein neues Extraordinariat geschaffen, das mit Debye besetzt wurde. Nach dem Tod des einzigen planmäßigen Physikordinarius Riecke bekam Debye dieses Ordinariat, und als Nachfolger von Riecke wurde Pohl berufen, der Debyes Extraordinariat bekam. Nach dem Weggang Debyes nach Zürich 1920 und dem Tod Voigts 1919, mussten diese beiden Lehrstühle neu besetzt werden. Dahms erwähnt nicht, dass Voigt ein persönliches Ordinariat besaß, das im Etat wie ein Extraordinariat behandelt wurde. Born erreichte nun in den Verhandlungen mit dem Ministerium, dass Voigts Lehrstuhl in ein planmäßiges Ordinariat umgewandelt und mit Franck besetzt wurde und außerdem, dass Pohl zunächst am 17. Juli 1920 zum persönlichen ordentlichen Professor ernannt und schließlich am 23. Dezember 1920 sein Extraordinariat ebenfalls auf ein planmäßiges Ordinariat höhergestuft wurde. UAG, Kur. PA Pohl. - Max Reich wurde am 18. Mai 1920 zum außerordentlichen Professor ernannt. Am 1. Oktober 1920 wurde er Simons Nachfolger als Direktor des Instituts für angewandte Elektrizität, bekam dessen Extraordinariat und wurde zum persönlichen ordentlichen Professor ernannt. UAG, Kur. PA Reich.

${ }^{70}$ Der Minister genehmigte im Mai 1922 die Neubenennung. UAG, Sek. 335.58.

71 Aus der Vielzahl an Literatur zur Göttinger Physik der Weimarer Zeit sei genannt: Hund [1969], [1982] und [1987]; Born [1975] bes. S. 288-325; Jordan [1975]; Meyenn \& Hermann [1976]; Lemmerich [1982].

72 Auf die Geschichte dieses Instituts wird im letzten Kapitel ausführlich eingegangen.
} 
Seine Schüler berichten, dass er sich selbst in erster Linie als Physiker fühlte. ${ }^{73}$ Diese Nähe zur Physik ist auch dadurch gekennzeichnet, dass er seinen Grundriß der physikalischen Chemie ab der dritten Auflage Lehrbuch der chemischen Physik nannte. ${ }^{74}$

Das folgende Diagramm 1 liefert eine bequeme Übersicht über die Besetzungsverhältnisse der Institutsstellen und soll die Zuordnung der zahlreichen Namen von Göttinger Physikern, erleichtern die in dieser Arbeit besprochen werden. Zusätzlich zeigt es nicht nur die unterschiedlich große Ausstattung der einzelnen Institute mit Assistentenstellen, sondern auch die verschieden lange Verweildauer der Assistenten auf ihren Stellen. Dies hing auch mit eventuellen Wechseln in der Institutsleitung zusammen. Auch wenn die meisten der im Diagramm aufgeführten Assistenten später zu Professoren aufstiegen, so waren sie in Göttingen nicht unbedingt Mitglieder des Lehrkörpers. Einen Überblick über die an der Lehre beteiligten Physiker und die Dauer ihrer Lehrtätigkeit in Göttingen geben Diagramm 2 und Diagramm 3.

\footnotetext{
73 Wicke [1984] S. 26.

${ }^{74}$ Eucken [1922] und [1932]. 


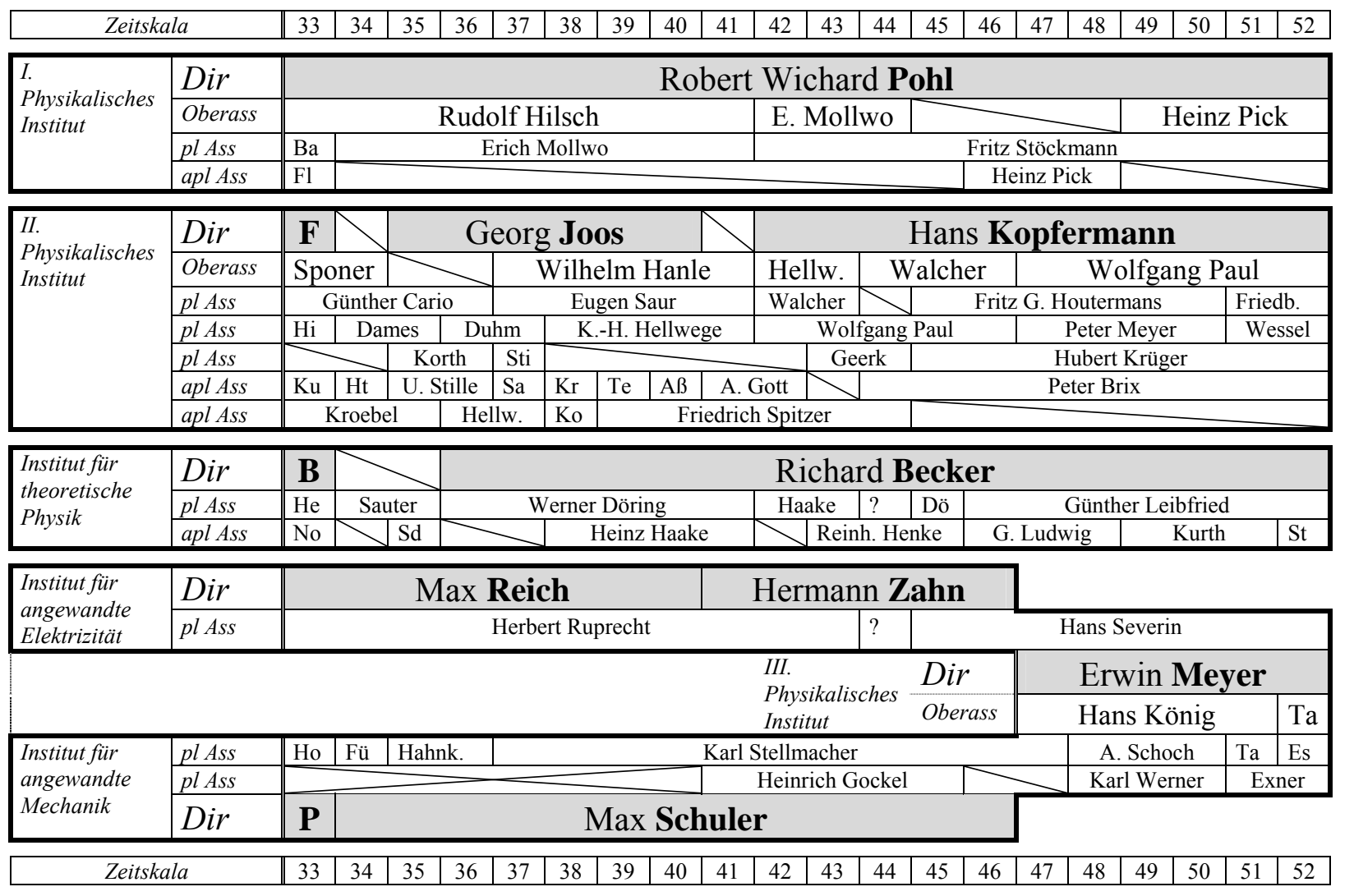

Diagramm 1 Besetzung der Stellen an den Göttinger Physikinstituten 1933-1952.

Stellenbezeichnungen: Dir: Direktor, Oberass: Oberassistent, $p l$ Ass: planmäßiger Assistent, apl Ass: außerplanmäßiger Assistent. Die nähere Spezifizierung der Assistentenstellen gilt nur für die dreißiger Jahre. Unbesetzte Stellen sind durch einen diagonalen Balken gekennzeichnet, im Etat nicht eingerichtete Stellen durch gekreuzte Balken. Namensabkürzungen: B: Max Born, F: James Franck, P: Ludwig Prandtl, Aß: Fritz Aßmus, Ba: Gerhard Bauer, Dö: Werner Döring, Es: Rolf Esche, Fl: Rudolf Fleischmann, Friedb.: Helmut Friedburg, Fü: Wilhelm Flügge, Hahnk.: Erich Hahnkamm, He: Walter Heitler, Hellw.: Karl-Heinz Hellwege, Hi: Arthur von Hippel, Ho: Kurt Hohenemser, Ht: Karl Hecht, Ko: R. Koops, Kr: Hans Kraft, Ku: Heinrich Kuhn, No: Lothar Nordheim, Sa: Eugen Saur, Sd: Heinz Schild, St: Helmut Steinwedel, Sti: Ulrich Stille, Ta: Konrad Tamm, Te: Joachim Teltow. Quelle: Vorlesungsverzeichnis der Universität Göttingen und Institutsakten im UAG. 


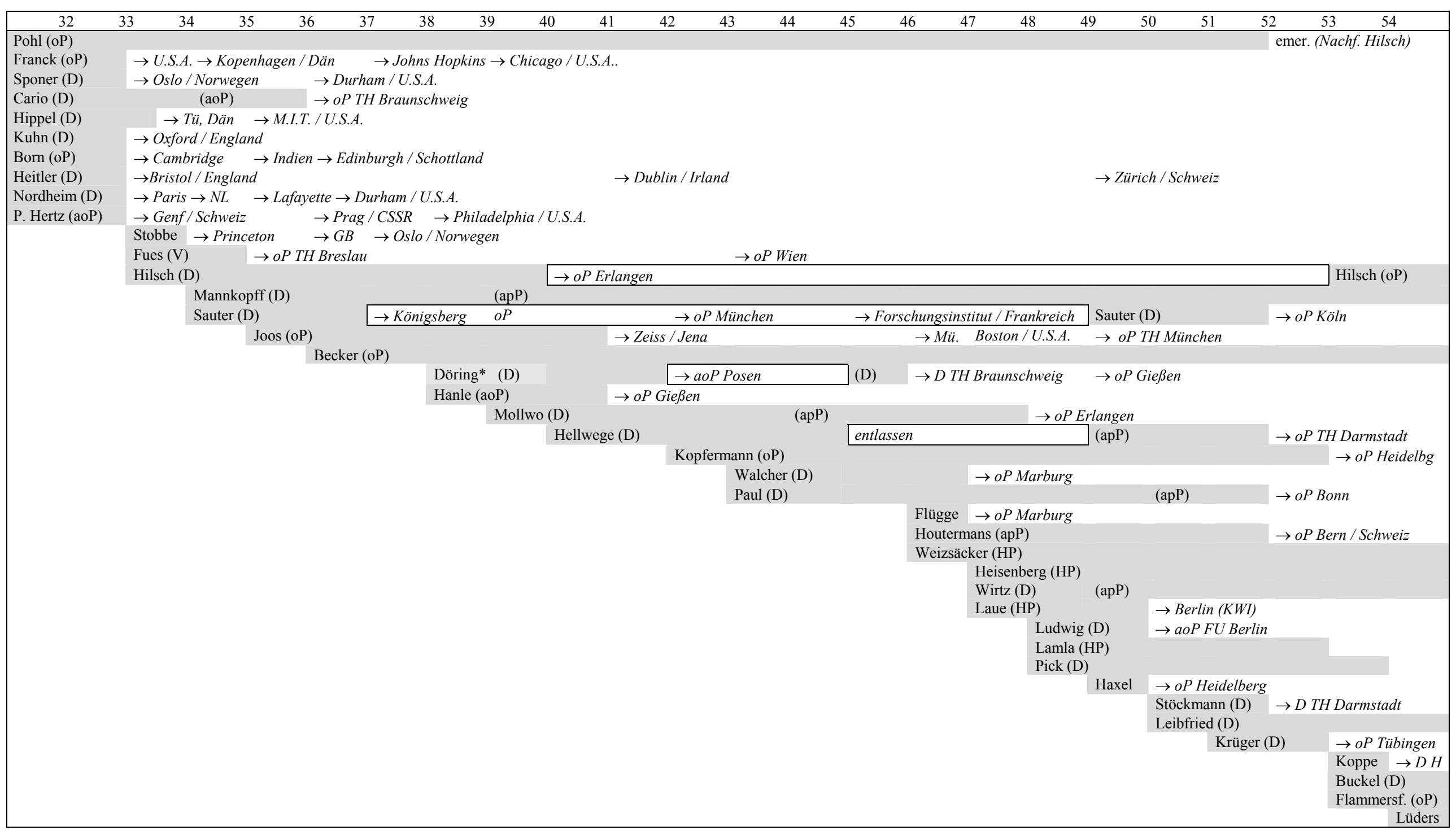

Diagramm 2 Übersicht über die an der Lehre der experimentellen und theoretischen Physik beteiligten Dozenten 1932-1954. Abkürzungen: Dän.: Dänemark, emer.: emeritiert, H.: Heidelberg, Nachf:: Nachfolger, NL: Niederlande, M.: München, Tü.: Türkei, (aoP): außerordentlicher Professor, (apP): außerplanmäßiger Professor, (D): Dozent, (HP): Honorarprofessor, (HvV): mit dem Halten von Vorlesungen beauftragt, (oP): ordentlicher Professor, (V): mit der Vertretung eines Lehrstuhls beauftragt. *: Döring beteiligte sich ab WS 1938/39 an der Vorlesungstätigkeit seines Lehrers Becker, durfte aber im Vorlesungsverzeichnis nicht namentlich genannt werden. 


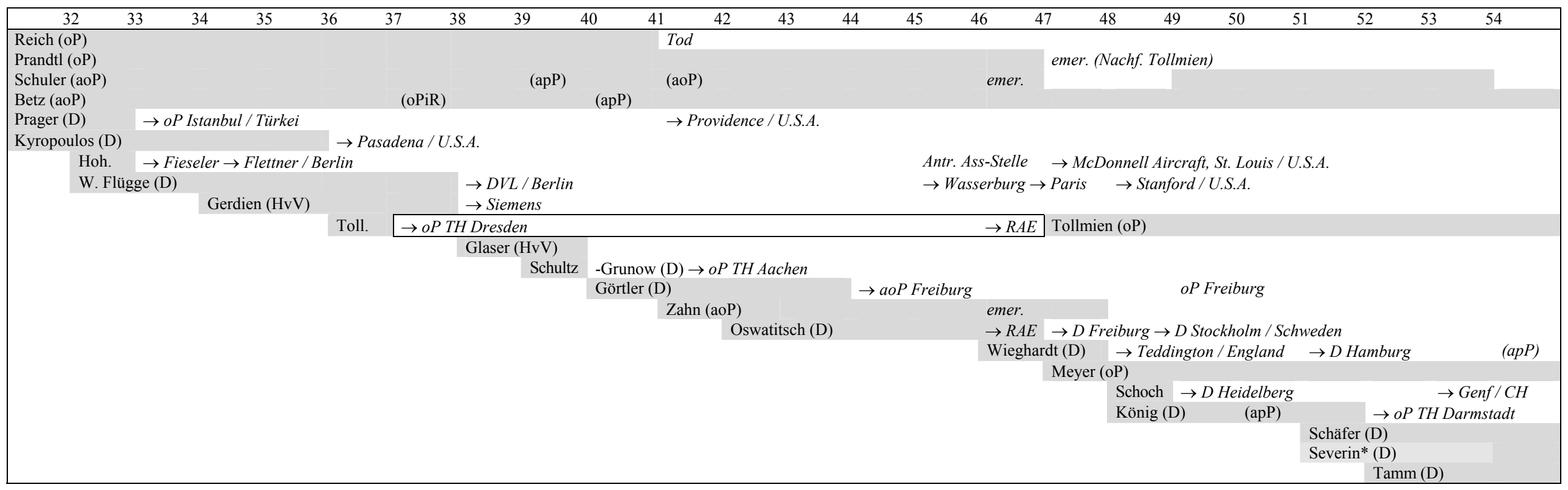

Diagramm 3 Übersicht über die an der Lehre der angewandten Physik beteiligten Dozenten 1932-1954. Abkürzungen: Hoh.: Hohenemser, CH: Schweiz, DVL.: Deutsche Versuchsanstalt für Luftfahrt, emer.: emeritiert, Nachf:: Nachfolger, RAE: Royal Aircraft Establishment, Farnborough, (aoP): außerordentlicher Professor, (apP): außerplanmäßiger Professor, (D): Dozent, (HP): Honorarprofessor, (HvV): mit dem Halten von Vorlesungen beauftragt, (oP): ordentlicher Professor, (oPiR): ordentlicher Professor im Reichsdienst, *: Severin hielt unter Meyers Namen Spezialvorlesungen zur Höchstfrequenztechnik. 
Wie Diagramm 2 zeigt, gab es 1933 in der experimentellen und theoretischen Physik einen radikalen Austausch des Lehrpersonals. ${ }^{75}$ Auf der Ordinarienebene blieb nur Pohl der Göttinger Physik erhalten. Er übernahm anfangs auch vertretungsweise die Leitung der beiden verwaisten Institute und sicherte somit ein Mindestmaß an Kontinuität. Dabei gewann er auch an lokaler Entscheidungsbefugnis, welche er unter anderem dazu ausnutzte, sich gegen den weiteren Verbleib der ,arischen“ Oberassistentin am II. Physikalischen Institut, Hertha Sponer, auszusprechen. Der Kurator notierte im Dezember 1933: „Pohl ist dagegen, daß Frauen in die akademische Laufbahn eintreten, und glaubt daher, den jetzigen Zeitpunkt benutzen zu müssen. “76 Sponer verließ noch 1933 Deutschland.

\subsubsection{Die Allmacht Pohls}

Pohl besaß nicht nur in Göttingen großen Einfluss auf die Personalentscheidungen, sondern in der gesamten deutschen akademischen Welt der Physiker. Gegen Ende seines Lebens waren von den über 60 bei ihm promovierten Physikern 11 in Deutschland Ordinarien, weitere 6 erhielten Professuren im Ausland. ${ }^{77}$ Der Pohl-Schüler Heinz Pick formulierte es im Rückblick überspitzt: Es gab den Pohl'schen Verein, der einen gewissen Bereich in Deutschland mit Nachwuchs versorgte, und es gab den Münchner Verein, der den anderen Teil übernahm. Das war den Physikern damals „ganz klar“.78 In Pohls Institut war die aktuelle Politik kein Diskussionsthema; auch in den Umbruchszeiten 1933 und 1945 nicht. Die in seinem Institut forschende Gastwissenschaftlerin aus Wien, Marietta Blau, schrieb im Februar 1933: „Von den politischen Verhältnissen merkt man hier gar nichts, da im Institut prinzipiell nicht über Politik gesprochen werden darf." 79 Pohl war auch bekannt für seinen betont autoritären Stil in der Institutsleitung, der aber gegen Ende seiner Professorenzeit milder wurde. Sein Auftreten war nicht frei von Eitelkeit. Beispielsweise konnte in der Nachkriegszeit das physikalische Kolloquium, das durch die daran teilnehmenden Größen des Faches eine große Anziehungskraft hatte, nicht in Pohls großem Hörsaal stattfinden, da dieser für seine nächste Vorlesung vorbereitet werden musste. So fand das Kolloquium in Kopfermanns kleinem Hörsaal statt, wo es manchmal schwer war, noch einen Platz als Zuhörer zu finden. Wenn jedoch Pohls eigene Schüler vortrugen, stellte er seinen Hörsaal zur Verfügung. Von seinen

\footnotetext{
75 Dieser wird eingehend behandelt von Rosenow [1987/98]. Dort werden auch die Emigrationswege der einzelnen Vertriebenen beschrieben.

76 Notiz des Kurators vom 18. Dezember 1933, zitiert nach Rosenow [1987/98] S. 561f.

77 Minnigerode [1976] S. 142.

78 Interview mit Pick, 2. Oktober 1981. NBL.
} 
Schülern wurde er hoch verehrt: Sie nannten ihn „den lieben Gott“. ${ }^{80}$ Von Maier-Leibnitz wurde er „ein Patriarch der Physik“ genannt. ${ }^{81}$ Seine Macht äußerte sich nicht nur in den erfolgreichen Karrieren seiner Schüler, sondern zum Beispiel auch darin, dass er über ein Radfahrverbot am Institutsgelände und ein Rauchverbot in den Fakultätssitzungen bestimmen konnte. ${ }^{82}$ Seine Kollegen wussten um seinen Einfluss und nutzten ihn auch aus, sofern sie ein gutes Verhältnis zu Pohl hatten. „Hatte einer Ambitionen auf eine Hochschullaufbahn, war es notwendig, sich Pohls wohlwollender Unterstützung $\mathrm{zu}$ versichern."83 Neben der wissenschaftlichen Befähigung benötigte man auch einen Förderer in einflussreicher Position, der unter der Hand bei Berufungsvorgängen die Fäden spann. Es ist jedoch eher ein Zufall, wenn derartige verdeckte Handlungen in der Personalpolitik aktenkundig geworden sind. Ein solches Beispiel aus dem Jahre 1933 soll illustrieren, auf welche Weise Pohl agierte.

Im Februar 1933 versuchte Pohl die Interessen zweier seiner engeren Kollegen gleichzeitig zu bedienen, da sie sich gut zu ergänzen schienen. Er schrieb an seinen ehemaligen Assistenten und Freund, Bernhard Gudden, der bereits selbst zum Ordinarius an der Universität Erlangen aufgestiegen war, um ihm eine Personalrocharde vorzuschlagen. Gudden erbat sich nämlich von Pohl Unterstützung, seine Assistenten irgendwo unterzubringen, und nun bot sich eine Chance. Pohls Göttinger Kollege Max Reich hatte für seine Assistentenstelle zwei jüngere Wissenschaftler, die er abwechselnd benutzte. ${ }^{84}$ Einer von ihnen, Stierstadt, suchte nun eine andere Stelle und hatte sogar zwei Angebote; das eine war eine Oberassistentenstelle an einer technischen Hochschule und das andere eine wissenschaftliche Hilfsarbeiterstelle beim Reichspostzentralamt. Die erste wollte er nicht annehmen, da er lieber an eine Universität statt an eine TH ginge, und die zweite nicht, weil dies zu sehr nach Protektion aussähe, da sein Schwiegervater der Präsident des Reichspostzentralamtes war. In dieser Situation bot

\footnotetext{
79 Blau an Stefan Meyer, 8. Februar 1933, zitiert nach Rosner \& Strohmaier (Hrsg.) [2003] S. 37.

80 Siehe die Interviews mit Heinz Pick, 2. Oktober 1981 und mit Fritz Lüty, 4. April 1982. NBL. Bestätigung erbrachte auch mein Interview mit Hans König. Eine Physikstudentin der Nachkriegszeit, die hier anonym bleiben möchte, nannte in einem Gespräch Pohl einen „Despot“. Joos meinte, Pohl besaß eine „fast angeborene menschliche Autorität.“ Joos [1954] S. 339.

81 Siehe Maier-Leibnitz [1974].

82 Über das Radfahrverbot berichtete Hans König in einem Interview vom 10. Februar 2001. Tollmien brach das Rauchverbot in den Fakultätssitzungen nach Pohls Emeritierung und wurde von seinen Kollegen zurecht gewiesen. Er verteidigte sich: „Der Vorgang war vielmehr der, daß vor einiger Zeit das damalige Mitglied unserer Fakultät, Professor Pohl, in brüsker Manier das Verlangen auf Einstellung des Rauchens vorbrachte. Dabei verbat er sich ausdrücklich jede Diskussion über sein Anliegen. Die Raucher unter den Fakultätsmitgliedern unterließen daraufhin die beanstandete Betätigung." Tollmien an Dekan Bartels, 3. August 1953. GPAMNFG, Lehrkörper (ausgeschieden), Tollmien.

83 Achilles [1977] S. 159.

84 Vom 1. April 1929 an war Otto Stierstadt planmäßiger Assistent am Institut für angewandte Elektrizität. Von Oktober 1931 bis September 1932 war er Research Fellow der Rockefeller-Foundation in Pasadena, Californien.
} 
sich also ein Tausch an. Pohl schlug vor, dass Gudden seinen eigenen Assistenten ins Reichspostzentralamt gebe und dafür Stierstadt als Assistenten übernehme. Für die Qualitäten Stierstadts könne Pohl allerdings keine Verantwortung übernehmen, da dieser ,nicht aus meinem Laden hervorgegangen ist“ und er ihn persönlich nicht genau kenne. „Ich bin ja in der ganzen Angelegenheit vollständig desinteressiert. Betrachten Sie mich nur als Makler, dem Sie evtl. ganz kurz auf einer Postkarte ein Nein schreiben können." 85

Dieser letzte Satz zeigt ganz eindrucksvoll, wie die Verbindungen innerhalb des kollegialen Netzes wirkten. Selbst wenn Reich und Gudden keine direkte engere Berührung hatten, so wurden sie über den Makler Pohl in die Lage versetzt, ihren Nachwuchs zu protegieren. ${ }^{86}$ Dass Pohl bei jenen Nachwuchswissenschaftlern, die aus seinem eigenen „Laden“ hervorgingen, effektiver vorgehen konnte, legt der geschilderte Vorgang nahe; ein paar Beispiele sind bei Eckert und Schubert nachzulesen. ${ }^{87}$ Dass diese geplante Rochade gerade in der politisch heißen Zeit Anfang 1933 zur Debatte stand, ist bloß ein Zufall und hat in diesem Fall nichts mit dem politischen Machtwechsel und den neuen Gesetzen zu tun. Wie der nächste Abschnitt zeigt, wirkten sich die neue Gesetzeslage in Göttingen gerade in der Physik besonders stark aus. In einzelnen Fällen hätte aber der Weggang eines Dozenten auch ohne die gesetzlich legitimierte Vertreibung erfolgen können.

\subsection{Personalpolitik an den Physikinstituten im Nationalsozialismus}

Der Verlust von Franck und Born für Göttingen 1933 wird meist als Folge der NSGesetzgebung dargestellt. Nun ist es unstrittig, dass die Emigration beider ins Ausland eine Folge der neuen Gesetze war, doch wenn man den Blickwinkel nicht nur auf Göttingen richtet, so sieht die Lage etwas anders aus. Es ist nämlich möglich, dass Franck Göttingen auch dann verlassen hätte, wenn es zu keiner rassistischen Gesetzgebung gekommen wäre. Er stand seit 1931 in Berufungsverhandlungen mit dem Ministerium wegen der anstehenden Besetzung des Nernst'schen Lehrstuhls in Berlin. Ende 1932 stand er an erster Stelle der Berufungsliste und fuhr im Januar $1933 \mathrm{zu}$ Verhandlungen ins Ministerium. Neben der

In dieser Zeit bekleidete Herbert Ruprecht die Assistentenstelle. Anschließend bekam sie wieder Stierstadt, der dann mit 31. März 1933 endgültig ausschied. Sein Nachfolger wurde wieder Ruprecht. UAG, Sek. 335.60.

85 Brief Pohl an Gudden, 6. Februar 1933. UAG, Rek. 5250 / 7A.

86 Letztendlich fand kein Tausch mit Guddens Assistent statt, sondern Stierstadt übernahm die Oberassistentenstelle an der TH Hannover bei Professor Precht. 1934 wurde er Dozent und wehrwissenschaftlicher Mitarbeiter für das Reichskriegsministerium und das Reichsluftfahrtministerium am I. Physikalischen Institut der Universität Berlin.

87 Zu Pohls Einfluss in der akademischen Personalpolitik siehe Eckert \& Schubert [1986] S. 119-121, 125f. 
Professur an der Berliner Universität wurden ihm auch die Übernahme der Direktorstelle am dortigen KWI für Physik oder nach Habers 1936 geplantem Ausscheiden jene des KWI für physikalische Chemie als mögliche Optionen eröffnet. ${ }^{88}$ Das Berliner Angebot war sehr verlockend. In einem Brief an Bonhoeffer schrieb Franck im Februar 1932, dass er sich nicht sicher sei, auf immer in Göttingen zu bleiben. Der Anlass des Schreibens waren Francks Schwierigkeiten, seine Schüler zur Habilitation zu bringen, im konkreten Fall Eugene Rabinowitch. Pohl würde Franck Schwierigkeiten machen, da Pohl selbst jemanden habilitieren wollte und Franck schon vier Habilitierte hatte. Franck wollte außerdem seinem eventuellen Nachfolger „,kein Haus voll von Habilitierten hinterlassen“. Eine Alternative wäre gewesen, dass Rabinowitch in die physikalische Chemie wechselte, doch Eucken als Professor der physikalischen Chemie in Göttingen hatte seine eigenen Leute und „nebenbei paßt ihm auch die Konfession von Rabinowitsch [sic] nicht". 89 Hier deutet Franck antisemitische Vorurteile in seiner Kollegenschaft nur vorsichtig an. ${ }^{90}$ Doch die Stimmung in Göttingen mag auch ein Beweggrund gewesen sein, das Berliner Angebot, das ein Leben in einer liberaleren Stadt bedeutete, näher in Betracht zu ziehen. Der heftige Protest von 42 Göttinger Hochschullehrern nach Francks freiwilligem Verzicht auf seine Professur im April 1933 mit dem Vorwurf der „Sabotage“ der ,nationalen Regierung“ machte nur öffentlich und offensichtlich, was vorher an unterschwelligen antisemitischen und nationalistischen Überzeugungen schon vorhanden war. ${ }^{91}$

Ein weiteres Indiz für den Antisemitismus an der Göttinger naturwissenschaftlichen Fakultät finden wir in einem Brief Ladenburgs an Haber vom Februar 1932. Pohl hatte einen Ruf nach Heidelberg bekommen, und als seinen Nachfolger wünschten sich Born und Franck Rudolf Ladenburg. Dieser machte sich aber wenig Hoffnung, denn die Schwierigkeiten, ihn „nach Göttingen zu berufen, seien sehr groß, da dann alle 3 Physiker jüdischer Abstammung

\footnotetext{
${ }^{88}$ Beyerchen [1980/82] S. 40f.

${ }^{89}$ Brief Franck an Bonhoeffer, 29. Februar 1932. MPG-Archiv, III, 23, 20,9. In einem Brief an Gerlach vom 23. Juni 1922 macht Eucken Zugeständnisse an den vorherrschenden Antisemitismus. Eucken fragt wegen einer geplanten Berufung von Professor Fraenkel nach Breslau an. „Es ist uns bekannt, dass er semitischer Abstammung ist, was bei den stark antisemitischen Tendenzen gerade der Technischen Hochschüler immerhin etwas bedenklich ist. Falls aber seine Abstammung in seinem ganzen Wesen nicht sehr hervortritt, würden wir vielleicht doch in Erwägung ziehen, ihn mit auf die Liste zu setzen." SHQP 19,2, W. Gerlach, Corr. 1916-37. ${ }^{90}$ Das Verhältnis zwischen Franck und Eucken ist aber als ein enges kollegiales zu beschreiben, das von fachlicher und menschlicher Wertschätzung geprägt war. Die wissenschaftliche Zusammenarbeit der beiden zeigt sich zum Beispiel in zwei Vorträgen, die sie im Februar 1932 hielten. Franck referierte „Allgemeine Bemerkungen über den Übergang von Translationsenergie in Schwingungsenergie beim Zusammenstoß von Molekülen“, woran sich Euckens Referat „Der Übergang von Translationsenergie in Schwingungsenergie beim Zusammenstoß verschiedenartiger Moleküle auf Grund von Schalldispersionsmessungen“ anschloss. DPGArchiv, 40019. Zur menschlichen Wertschätzung siehe den Briefwechsel in Papers of James Franck, Special Collections Research Center, University of Chicago Library.
} 
wären.“ Dieses 'Problem‘ blieb der Fakultät erspart, denn Pohl lehnte den Ruf ab und Bothe ging statt ihm nach Heidelberg. ${ }^{92}$

Etwas verwirrend ist ein ministerieller Erlass vom August 1934: „Das Extraordinariat für Experimentalphysik (zuletzt besetzt mit Professor Franck) in der MathematischNaturwissenschaftlichen Fakultät ist in ein Ordinariat umgewandelt worden. Die Mittel für die Umwandlung des Extraordinariats in ein Ordinariat sind durch den Staatshaushalt 1934 bereitgestellt worden."93 Würde es stimmen, dass Franck 'nur' ein Extraordinariat inne hatte, wäre das Berliner Angebot noch eine Stufe attraktiver gewesen. Tatsächlich war aber Franck von Anfang an seit 1. April 1921 in Göttingen planmäßiger Ordinarius und Nachfolger von Woldemar Voigt. ${ }^{94}$

Die Entlassung von James Franck und Max Born wurden nicht sofort nach dem Inkrafttreten des Berufsbeamtengesetzes ausgesprochen. Beide wurden zuerst 'nur' beurlaubt, Franck bis Anfang 1934, Born bis Mitte 1935; Erst die Entlassungen ermöglichten der Fakultät die Wiederbesetzung der Lehrstühle. Die Neubesetzungen fielen in die Formierungsphase der NS-Herrschaft, in der ideologische Kämpfe und damit politische Kriterien bei der Vergabe von Universitätsstellen eine große Rolle spielten. Angegriffen war auch das Selbstrekrutierungsrecht der Universität, was zu einer Konfliktsituation zwischen dem neuen nationalsozialistischen Ministerium, das eine politische Veränderung in die Universität bringen wollte, und einer sich auf akademische Traditionen berufenden Fakultät führte. Die genaue Betrachtung der Auseinandersetzung um die Nachfolge Franck und Born erlaubt es, die wichtigen Kriterien der akademischen Tradition dieser Zeit zu erfassen. Die auf Göttinger Seite entscheidenden Akteure waren der Ordinarius der Experimentalphysik Robert Pohl, der damalige Dekan und Professor der angewandten Elektrizität, Max Reich, ${ }^{95}$ der Rektor Friedrich Neumann ${ }^{96}$, der Führer des NS-Dozentenbundes Werner Blume und der Kurator Justus Valentiner. Die These vom kollegialen Netz ${ }^{97}$ soll einen neuen Blick auf Besetzungsfragen eröffnen. Da anzunehmen ist, dass vor allem Robert Pohl die hier

\footnotetext{
91 Zu Francks Rücktritt und der folgenden „Kundgebung Göttinger Dozenten“ siehe Dahms [1987/98] S. 41f.

92 Brief von Ladenburg an Haber, 17. Februar 1932, zitiert nach Schlüpmann [http]. Auf der Heidelberger Berufungsliste standen hinter Pohl noch Bothe und Ladenburg. Als Quelle gibt Schlüpmann den Nachlass Haber im MPG-Archiv an.

93 Preußischer Minister für Wissenschaft, Kunst und Volksbildung (gez. Vahlen) an den Universitätskurator in Göttingen, 30. August 1934. UAG, Kur. PA Franck.

${ }^{94}$ Siehe dazu das Ernennungsschreiben des Ministers an Franck, 15. November 1920. UAG, Kur. PA Franck.

95 Max Reich war vom WS 1932/33 bis zum WS 1936/37 Dekan der mathematisch-naturwissenschaftlichen Fakultät. UAG, Rek. 2101a.

${ }^{96}$ Friedrich Neumann war vom SS 1933 bis zum S 1937/38 Rektor der Universität Göttingen. UAG, Rek. 2101a.
} 
diskutierten universitären Anträge in ihrem Inhalt geprägt hat, geben die Vorschläge der Fakultät auch Auskunft über das kollegiale Ordinariennetz des Göttinger Physikers Pohl. Auf der anderen Seite geben die Vorschläge des Ministeriums einen Hinweis auf das politische Kapital der von dort genannten Physiker. Die Verhandlungen wurden im Ministerium von dem Professor für organische Chemie, Franz Bachér,98 geführt. Für die Durchsetzung einer Erneuerung der Universität im nationalsozialistischen Sinn war vor allem die im Oktober 1933 ins Leben gerufene „Dozentenschaft“ beziehungsweise der im Juli 1935 gegründete NSDDB und der vom Ministerium eingesetzte und nicht mehr vom Senat gewählte Rektor zuständig. Es soll aber nicht übersehen werden, dass auch ein 'gleichgeschalteter' Rektor Teil eines kollegialen Netzes und daher nicht nur dem Ministerium verpflichtet war. Diese Vorannahmen sind vor allem ein heuristisches Hilfsmittel zum besseren Verständnis der Vorgänge. ${ }^{99}$

\subsubsection{Die Besetzung des zweiten Lehrstuhls für Experimentalphysik}

In der Bemühung, einen geeigneten Nachfolger für Franck zu finden, dachte die Fakultät zuerst an folgende drei Wissenschaftler: Walter Bothe, Helmuth Kulenkampff und Paul Scherrer. Der eindeutige Wunschkandidat war Walter Bothe aus Heidelberg. ${ }^{100}$ Großen Eindruck in Göttingen - und speziell bei Pohl - machten Bothes Versuche aus dem Jahr 1926, in denen er den elementaren Emissionsakt von einzelnen Lichtkorpuskeln nachweisen und somit die Grenzen des Wellenbildes aufzeigen konnte. ${ }^{101}$ Die Fakultät war so sehr auf ihn fixiert, dass sie im Fall seiner Ablehnung das Ordinariat gar nicht nachbesetzen und stattdessen zwei Extraordinariate schaffen wollte, die mit jüngeren Spezialisten für Kernphysik und Spektroskopie zu besetzen gewesen wären. Die Oberassistentenstelle wäre dann weggefallen. ${ }^{102}$ Die in diesem ersten Fakultätsvorschlag vom November 1934 angekündigten Konsequenzen für den Fall, dass Bothe nicht gewonnen werden konnte, waren wohl nicht ganz ernst gemeint. Bothe war im April 1934 Direktor des Instituts für Physik im

\footnotetext{
97 Siehe Abschnitt 0.3.

98 Franz Bachér war Schüler von Richard Stoermer, ab 1920 Assistent, 1925 Oberassistent, 1928 Privatdozent und 1933 außerordentlicher Professor in Rostock, von 1934-1945 ordentlicher Professor an der TH Berlin. 99 Eine kurze Diskussion der Nachfolge Born und Franck findet sich bei Rosenow [1987/98] S. 564ff., jedoch unter etwas anderem Blickwinkel. Dort sind leider einzelne Angaben fehlerhaft; auch die Quellenbelege sind nicht immer nachvollziehbar, z.B. gibt es keine Akte R, III, A, 1, 299e, auf der die Angaben zur Nachfolge Borns angeblich beruhen, und in der vorhandenen Akte Sek. III, A, 1, 299e befindet sich nicht das bei Rosenow Zitierte. Die Darstellung leidet auch darunter, dass Rosenow 1986/87 viele wichtige Personalakten auf Grund von Sperrfristen noch nicht zugänglich waren.

$100 \mathrm{Zu}$ Bothe siehe Maier-Leibnitz [1991]a.

101 Siehe die anerkennende Darstellung des Versuchs in Pohl [1940]a 2. u. 3. Aufl. 1941, S. 289.
} 
Kaiser-Wilhelm-Institut für medizinische Forschung in Heidelberg geworden. Obwohl Heidelberg mit Philipp Lenard am Physikinstitut ein politisch aufgeladener Ort war und Bothe die 1932 angetretene Nachfolge Lenards 1934 an den Lenard Schüler August Becker abgab, sagte Bothe Göttingen im November 1934 ab. ${ }^{103}$ Daraufhin schlug die Göttinger Fakultät entgegen ihrer ersten Ankündigung den vorher zweitgereihten Kulenkampff aus München vor. Hervorgehoben wurden seine Arbeiten zur Röntgen-Optik und zur Höhenstrahlung, außerdem sei „Kulenkampff auf atomphysikalischen Gebiet mit an erster Stelle marschiert." ${ }^{104}$

Zwei weitere wesentliche Kriterien wurden vom Dekan hervorgehoben, die Kulenkampff erfüllen würde: Der zu berufende Physiker müsse unbedingt eine andere Arbeitsrichtung als Pohl haben und außerdem mit Pohl „die Gewähr guter persönlicher Zusammenarbeit“ bieten. Es kam der Fakultät also nicht nur auf wissenschaftliche, sondern auch auf persönliche Qualifikationen der Bewerber an. Der von der Fakultät zuerst drittgenannte Scherrer hätte beide Forderungen vermutlich ebenfalls erfüllt, jedoch bekam er für sein Züricher Institut einen Erweiterungsbau bewilligt und stand damit Göttingen nicht mehr zur Verfügung. Es blieb also nur Kulenkampff übrig.

Eine weitere Qualifikation, die zwar nicht von der Fakultät, dafür aber vom Ministerium vom Bewerber eingefordert wurde, betraf dessen politische Haltung. Die Fakultät machte in ihren Berufungsvorschlägen kein Hehl daraus, dass sie von einer rein politischen Berufung wenig hielt. Falls das Ministerium nämlich einen in der Partei aktiven „Herrn“ berufen wolle, so solle trotzdem Kulenkampff das Ordinariat bekommen und nur die Oberassistentenstelle dem Parteitreuen übertragen werden. ${ }^{105}$ Dass hier von einem „Herrn“ statt von einem Fachvertreter gesprochen wurde, ist auch ein Hinweis auf die distanzierte Haltung der Fakultät gegenüber einer solchen Besetzung.

Der favorisierte Kulenkampff erfuhr von der NS-Dozentenschaft eine klare Abfuhr aus politischen Gründen. Kulenkampff sei untragbar. Er galt selbst Ende 1934 noch als eine „demokratisch eingestellte Natur“. Hinzu kam noch, dass er in München als engster Mitarbeiter Zennecks in ein 'ungünstiges“ Netz eingebunden war, denn „das ganze Institut Zenneck scheint sich auch heute noch einer geschlossenen Ablehnung dem

\footnotetext{
102 Dekan Reich an Rektor Neumann, 1. November 1934. UAG, Rek. 3206b.

103 Breger [1985/86] S. 43; Beyerchen [1980] S. 141. Laut Brix \& Putlitz [1986] S. 67 machte man Bothe nach 1933 das Leben an der Universität unerträglich.

104 Schreiben Dekan Reich an Ministerium, 10. November 1934. Zwei Tage davor hatte Bothe abgesagt. UAG, Rek. 3206b.
} 
Nationalsozialismus gegenüber zu befleißigen." 106 Von der Dozentenschaft ins Spiel gebracht wurden Walther Kossel (Danzig) und Georg Joos (Jena), über die das Ministerium ein Fakultätsurteil wünschte. ${ }^{107}$ Die Nennung dieser beiden Kandidaten erscheint in politischer Hinsicht ein wenig widersprüchlich, denn beide arbeiteten früher wie Kulenkampff in Zennecks Institut. Man begibt sich auf die falsche Fährte, wenn man der politischen Klassifizierung der Dozentenschaft zu viel Glauben schenkt. Das pauschale Urteil über das Zenneck'sche Institut erscheint unangebracht. Der dort bis 1924 tätige Assistent Georg Joos war schon 1922/23 NSDAP Mitglied geworden. Joos änderte seine politische Haltung in der Zeit der Weimarer Republik und trat 1929 der Deutschen Volkspartei bei, deren Mitglied er bis 1932 blieb. ${ }^{108}$ Nach dem Machtwechsel 1933 trat er bis 1935 folgenden angeschlossenen Verbänden und Gliederungen der NSDAP bei: NSFB (Frontkämpferbund), Luftsportverband Fliegerortsgruppe Jena, NSV (Volkswohlfahrt), Reichsbund der Kinderreichen, Reichsverband deutscher Offiziere, NSLB (Lehrerbund). ${ }^{109}$ Am 1. April 1933 trat er dem Stahlhelm bei, der ein republikfeindlicher Veteranenverband der Frontkämpfer war und in Konkurrenz zur SA stand. Dieser Beitritt wurde ihm in politischen Gutachten negativ angelastet. ${ }^{110}$ In dieser Hinsicht ist die Unterstützung, die er durch die Dozentenschaft genoss, seltsam. Die politischen Koordinaten, die sich aus Joos' Mitgliedschaften ergeben, weisen ihn als Nationalkonservativen aus, der nicht alle Aspekte des Nationalsozialismus unterstützte. In einer neueren Arbeit von Rüdiger Stutz und Oliver Lemuth wird Joos sehr überzeugend als staatstreuer und besonders pflichtbewusster Physiker mit militärischer Sozialisation beschrieben, der sich vor allem für berufsständische Interessen einsetzte. ${ }^{111}$

Bei Kossel erweist sich das politisches Kapital ähnlich. Positiv im Sinne der Dozentenschaft wog, dass er Doktorand von Lenard war und somit aus einer Schule kam, die später das Etikett „Deutsche Physik“ bekam. Kossel war zwar kein Vertreter der „Deutschen Physik“,

\footnotetext{
105 Schreiben des Dekans Reich ans Ministerium, 30. November 1934. UAG, Rek. 3206b.

106 Schreiben Blume vom NS-Dozentenbund an Rektor, 5. Dezember 1934. UAG, Rek. 3206b.

107 Laut Aktennotiz war dies der Inhalt eines Telefongesprächs von 10. Dezember 1934 zwischen dem Rektor Neumann und Prof. Bachér aus dem Ministerium. UAG, Rek. 3206b.

108 Siehe zur NSDAP Mitgliedschaft den von Joos handschriftlich ausgefüllten Fragebogen aus dem Jahr 1935 in UAG, Kur. PA Joos. Zur Mitgliedschaft in der Deutschen Volkspartei siehe BAB, R 21/10009.

109 Aus Personalblatt, etwa 1935. UAJ, D, 1319, PA Joos. In einem Schreiben an den Kurator, 14. November 1938, gab Joos an, seit 1933 im NSFK (Fliegerkorps) Mitglied gewesen zu sein. UAG, Kur. PA Joos. Jedoch wurde das NSFK erst am 17. April 1937 gegründet. Krammer \& Bartsch [1992/99] S. 171f.; Overesch \& Saal [1982/91] S. 352.

${ }^{110}$ In einer politischen Beurteilung durch die NSDAP Ortsgruppe Göttingen vom 31. Juli 1940 heißt es: Die politische Zuverlässigkeit werde zwar bejaht, aber „daß der Vg. ausgerechnet am 1.4.1933 noch dem Stahlhelm beitrat, ist bei einem Mann von dem Bildungsgrad doch recht beachtlich!“ BAB, Akte Ingenieure, Joos.
} 
leugnete aber nicht seine wissenschaftliche Herkunft. In einer Würdigung von Lenards Verdiensten anlässlich des 80. Geburtstags, publiziert im Mai 1942, bezeichnete es Kossel als Glück, in Lenards Institut gearbeitet zu haben. Er würdigte Lenards Arbeiten aus der Zeit um die Jahrhundertwende, ging aber mit keinem Wort auf Lenards Nähe zum Nationalsozialismus oder die Entwicklung der „Deutschen Physik“ ein. ${ }^{112}$ Kossel hielt auf diese Weise politische Distanz und sicherte sich durch die alleinige Würdigung der in der Fachwelt anerkannten Leistungen Lenards seine eigene wissenschaftliche Anerkennung innerhalb des Kollegenkreises. Er schaffte es, zu so gegensätzlichen Physikern wie Lenard und Laue gute Beziehungen zu behalten. Es lässt sich also schließen, dass sowohl Kossel wie auch Joos 1933/34 nicht als eindeutige Nationalsozialisten gelten konnten, ungeachtet der Unmöglichkeit, den Begriff ,eindeutiger Nationalsozialist““ klar zu definieren.

Da die Fakultät das geforderte Urteil über Joos und Kossel verweigerte und sich über die politische Haltung der Kandidaten verschlossen hielt, wurde nun der Göttinger Rektor aktiv und erkundigte sich persönlich bei seinem Danziger Amtsgenossen über Kossel. Das Urteil des Rektors der TH Danzig, Pohlhausen, fiel ambivalent aus. Er äußerte sich kritisch zu Kossels Qualitäten als Wissenschaftler. Kossel trüge zwar einen guten Namen, ob er allerdings auch an einem großen Experimentalphysik Institut ganz am Platze wäre, stand für Pohlhausen nicht fest. Die Seminarteilnehmer klagten über Kossel, dass er über die neuesten Fortschritte in der Physik nicht auf dem Laufenden sei. Pohlhausen bekam von Kollegen auch die Auskunft, dass eine „nochmalige Berufung etwas unverdient sei“. Positiv bewertete er, dass Kossel sich als Rektor in Kiel „sehr brav gegen links geschlagen“ habe. „Deutschnational im guten Sinne, nie Soldat gewesen, kein Pg., aber durchaus Verständnis für die nat.soz. Auffassungen.“ In politischer und kollegialer Hinsicht erschien Kossel dem Danziger Rektor nicht hundertprozentig verlässlich. Die Frage, ob es eine gedeihliche Zusammenarbeit mit anderen Kollegen geben könne, quittierte er mit: ,ja?“113 Also auch Kossels politisches Kapital war mit Makel versehen. Als Deutschnationaler genoss er nur eingeschränktes Vertrauen bei den Nationalsozialisten.

Eine Woche nach der ministeriellen Anfrage zu Kossel und Joos berichtete der Göttinger Dekan dem Rektor über eine Unterredung mit Pohl. Die Namen Kossel und Joos werden

\footnotetext{
111 Siehe Lemuth \& Stutz [2003]. Zu Joos Haltung siehe auch die geglättete Nachkriegsdarstellung seines Kollegen Meißner [1954]. Allgemeine Überlegungen zu Klassifizierungen von Naturwissenschaftlern in der Zeit von 1900 bis 1933 liefert Harwood [1993].

112 Kossel [1942].

113 Rektor der TH Danzig, Pohlhausen, an den Göttinger Rektor Neumann, 14. Dezember 1934. UAG, Rek. 3206b.
} 
darin gar nicht erwähnt, stattdessen betont, dass sich die Unterrichtspflichten bis dahin beide Direktoren der I. und II. Physik geteilt haben. „Eine erfolgreiche Zusammenarbeit erfordert, daß sich die beiden Direktoren harmonisch ergänzen." Tatsächlich empfanden manche Physiker damals die Göttinger Zweiteilung der Experimentalphysiklehrstühle als eine problematische Struktur. Im Rückblick schrieb Joos hierüber aus eigener Erfahrung: „Ich muss gestehen, dass die Göttinger Einrichtung sehr viel Takt und diplomatisches Geschick erfordert, da es auf Schritt und Tritt Reibungsflächen gibt."114 Pohl nannte es das „Zweischläfrige Bett der beiden [...] in einem Haus vereinigten Göttinger Institute“. 115 Daher ist es nur verständlich, dass sich Pohl seinen neuen Kollegen im Hinblick auf ein harmonisches Arbeitsklima aussuchen wollte. Bei anders vorgenommener Besetzung müsste laut Pohl auf einen Zustand von vor 1920 zurückgegriffen werden, der beiden Direktoren die Möglichkeit geschaffen hätte, „ihren Schülerkreis getrennt nach ihren Methoden heranzubilden“. Pohl wollte sich also bei einer drohenden 'politischen“ Berufung seine Unabhängigkeit und Freiräume sichern. ${ }^{116}$

Mit dieser Stellungnahme der Fakultät ausgestattet wendete sich der Rektor ans Ministerium und äußerte darin eine eigenständige, vom Dekan abweichende Auffassung. Bei einer hypothetischen Berufung von Bothe hätte man den bisherigen Zustand beibehalten können. Man hätte von einem einzigen Institut sprechen können, deren zwei Direktoren ihre Tätigkeit derart aufeinander abgestimmt hätten, dass ihre Arbeitsweisen die Einheit des Instituts gewahrt hätten. Selbstverständlich hätten die beiden Institute wieder verselbstständigt werden können. „Ich darf selbst in Übereinstimmung mit dem Herrn Dekan dabei hervorheben, daß bei einer stärkeren Trennung der Institute Hochschullehrer für diese Professur erwünscht sein können, die eine Brücke zur theoretischen Physik hinschlagen, wie dies bei den Professoren Kossel und Joos der Fall ist.“ Während sich Pohl zu den beiden gar nicht äußern wollte - sie erschienen ihm ,aus verschiedenen Gründen für Göttingen nicht tragbar“117 -, gab der Rektor mit Rückendeckung des Dekans eine positive Stellungnahme zu ihnen ab. Trotzdem erbat der Rektor vom Ministerium, es solle noch weitere Namen zur Begutachtung in Vorschlag bringen. Die Fronten verliefen nicht nur zwischen Ministerium und Universität, sondern auch

\footnotetext{
114 Joos an den Dekan der naturwissenschaftlichen Fakultät der Universität Straßburg, Niemeier, 3. Juli 1941. BACZ, 22768.

115 Zitiert nach Joos [1954] S. 339.

116 Dekan Reich an Rektor, 18. Dezember 1934. UAG, Rek. 3206b.

117 So berichtete Rektor Neumann an den Minister, 8. Februar 1935. UAG, Rek. 3206b.
} 
innerhalb der Universität und, wie es scheint, sogar zwischen den 'dagebliebenen“ Physikordinarien Reich und Pohl. ${ }^{118}$

Die Fakultät wurde erneut zur Einreichung einer Vorschlagsliste aufgefordert und erfüllte dies im Februar 1935 mit folgender Dreierliste: 1) Kulenkampff (München), 2) Geiger (Tübingen), 3) Gerthsen (Gießen). Pohl zeigte sich keine Spur anpassungsbereit, und auch die Rückendeckung Reichs, die der Rektor reklamierte, erscheint durch diese Berufungsliste zweifelhaft. Die Argumente pro Kulenkampff sind in dieser Situation auf eine Abgrenzung gegen Joos und Kossel hin zu interpretieren. Zuerst wurden fast selbstverständlich seine wissenschaftlichen Leistungen und die Fähigkeit, andere Mitarbeiter anzuleiten, gewürdigt. Dank seiner Tätigkeit an der TH München - er war dort seit 1932 außerordentlicher Professor - habe er Verständnis für die Notwendigkeit, in der Ausbildung der Studenten die technischen Belange zu berücksichtigen. Dies könnte als Abgrenzung gegen Joos gelesen werden, der seit 1924 Professor für theoretische Physik an der Universität Jena war, weniger gegen Kossel, der selbst seit 1932 an einer TH als Ordinarius lehrte. Eine etwas überraschende Argumentation betraf das Alter Kulenkampffs. Da er 11 Jahre jünger als Pohl war, würde mit seiner Berufung das gleichzeitige „Altwerden der Dozenten eines Faches“ verhindert werden. Dies war möglicherweise gegen Kossel gerichtet, der nur vier Jahre von Pohl getrennt war. Joos allerdings war mit Kulenkampff fast gleichaltrig. Die Nennung Geigers an zweiter Stelle war schon ihrer Formulierung nach nicht als ernstzunehmende Berufungsvariante gedacht und hatte eher Pro-forma-Charakter. Geiger habe einen großen wissenschaftlichen Namen und sei ein führender Forscher auf dem Gebiet der Radioaktivität und der Höhenstrahlung, allerdings sei er zwei Jahre älter als Pohl und hänge „sehr an seinem Tübinger Wirkungskreis“. Das hier vermittelte Bild vom schwer zu gewinnenden Geiger täuscht etwas, denn kurze Zeit später wurde er als Nachfolger von Gustav Hertz an die TH Berlin berufen. ${ }^{119}$ Geigers 'halbherzige“ Nennung sollte vermutlich den drittgenannten Gerthsen in seiner Bedeutung stärken. Dieser war Geigers Assistent in Tübingen gewesen und habe mit seiner Erforschung der Kanalstrahlen vielseitige Anerkennung gefunden. Er war wie Joos Jahrgang 1894 und hatte sich wie dieser ebenfalls in der theoretischen Physik betätigt, als er über mehrere Semester in Tübingen die Vorlesung für theoretische Physik vertretungsweise übernommen hatte. Mit Gerthsen sollte offensichtlich eine Alternative zu Joos genannt werden. Zur allgemeinen

\footnotetext{
118 Rektor an Ministerium, 19. Dezember 1934. UAG, Rek. 3206b.

119 Zu Geigers Berufung nach Berlin siehe Cassidy [1979] bes. S. 379; zu seinen wissenschaftlichen Leistungen Haxel [1982].
} 
Bekräftigung wird am Ende der Berufungsliste erwähnt, dass die Göttinger Privatdozenten Cario, Hilsch und Mannkopff ebenfalls Gerthsen, Geiger und Kulenkampff vorschlagen. ${ }^{120}$

Die Geschlossenheit der Fakultät in Ablehnung von Joos und Kossel wurde nun auch vom Rektor unterstützt. Am 7. Februar 1935 referierte er in einem Schreiben ans Ministerium die Bedenken der Fakultät, die Kossel für nicht produktiv genug hielt und von Joos glaubte, dass er nach seinen bisherigen Forschungen keine genügende Ergänzung nach Göttingen bringen würde. Tags darauf äußerte der Rektor zusätzliche, eigene Bedenken. Er fühle sich gegenüber der Nennung beider nicht wohl, zumal zumindest „Joos keine politische Persönlichkeit zu sein scheint“. In dieser Logik wog Joos' politisches Kapital nicht genug, um die 'fachlichen“ Einwände der Fakultät auszugleichen. Jedenfalls sprach sich der Rektor für eine Berufung Gerthsens aus. ${ }^{121}$

Die Dozentenschaft blieb bei ihrer Forderung, Joos oder Kossel zu berufen. Daraufhin kündigte die Fakultät an, ein neues Gutachten einzureichen, in dem ausführlich dargelegt werden würde, warum Joos und Kossel aus sachlichen Gründen nicht in Frage kommen könnten, „da ja die Arbeitsgebiete der am gleichen Ort wirkenden Physiker sich ergänzen müssen“. 122 Es soll an dieser Stelle aber schon angezweifelt werden, ob es tatsächlich sachliche Gründe waren, die für die Ablehnung der beiden und der Bevorzugung von Kulenkampff und Gerthsen ausschlaggebend waren. In späterer Zeit gab es allerdings zwischen Pohl und Kossel tatsächlich fachliche Differenzen zum Beispiel in der Darstellung der Elektrizitätslehre, die Pohl nach 1945 zu einer als Erwiderung betitelten kleinen Publikation veranlassten. ${ }^{123} \mathrm{Ob}$ diese Differenzen schon Anfang der dreißiger Jahre bestanden oder ob es andere sachliche Auseinandersetzungen gab, entzieht sich meiner Kenntnis.

Einer zwar sachlichen, aber von jener der Fakultät abweichenden Argumentationslinie bediente sich der Kurator in einer ausführlichen Stellungnahme ans Ministerium. Nach dem Weggang Francks sei der Lehrstuhl nicht etwa mit einem Physiker zu besetzen, der mit seiner Fachrichtung die entstandene Lücke zu schließen vermöge, sondern vielmehr solle er eine gänzlich andere Ausrichtung aufweisen. Denn mit Francks 'dagebliebenem“ Oberassistenten Günther Cario sei die Spektraloptik bereits vertreten, sodass die Berufung Joos' keine Ergänzung der vorhandenen Forschungsrichtungen bringe. Zwar räumte der Kurator ein, dass eine baldige Wegberufung Carios zu erwarten sei - tatsächlich blieb er nur noch ein Jahr in

\footnotetext{
120 Vorschlagsliste der Fakultät vom 4. Februar 1935. UAG, Rek. 3206b.

121 Rektor an Ministerium, 7. und 8. Februar 1935. UAG, Rek. 3206b.

122 Dozentenbund an Dekan, 7. Februar 1935; Dekan an Rektor, 8. Februar 1935. UAG, Rek. 3206 b.

123 Pohl [1950].
} 
Göttingen und wurde am 1. November 1936 Ordinarius an der TH Braunschweig -, doch wäre es dann kein Problem, einen neuen jungen Forscher des Sondergebietes Optik zu finden. Joos' wissenschaftliche Leistungen wurden vom Kurator hoch gelobt. Sie stammten außerdem aus einem Gebiet, das jenem Carios und der Göttinger Doktoranden sehr ähnlich sei, was als ein negatives Faktum gelten sollte. Genauso abwertend könnte der Hinweis gemeint sein, dass Joos die „einwandfreieste experimentelle Verteidigung [...] für die Relativitätstheorie“" gelungen sei. ${ }^{124}$ Dies hätte wohl in den Ohren von Lenard und Stark schlecht geklungen. Ob es im Ministerium aber ebenfalls als Kritik gelesen wurde, ist nicht so sicher. Genauso könnte auch die von nationalsozialistischer Seite erwünschte Verbindung von theoretischer und experimenteller Physik in Joos Arbeiten erkannt worden sein. Sicherlich war Joos kein Vertreter einer 'abstrakten', 'unanschaulichen' theoretischen Physik. Möglicherweise lieferte der Kurator mit seiner vermeintlichen Kritik hier ungewollt Argumente für eine Berufung von Georg Joos. In der Ablehnung von Kossel ging der Kurator geschickter vor. Kossel sei zwar „ein sehr vielseitig gebildeter, kultivierter und im Umgang ungewöhnlich gewandter Mann“, ${ }^{125}$ doch hätte er in der experimentellen Physik nicht Fuß fassen können, kein eigenes Arbeitsgebiet entwickelt und keinen großen Schülerkreis um sich gesammelt. Seine großen Leistungen lägen lange zurück, und er besäße nicht das mathematische Rüstzeug, um in der theoretischen Physik erfolgreich zu sein. Gerüchteweise würde ihn die TH Danzig gerne freigeben. Das sollte als vernichtende Kritik wohl ausgereicht haben. Um nun andere Forscher durchzusetzen, argumentierte er mit der Bedeutung des Standortes Göttingen. Dieser Lehrstuhl dürfe nur einer „wirklich überragenden Persönlichkeit“" anvertraut werden, die ihrerseits aber auch „hierher passen“ müsse. In dieser Hinsicht seien nur Bothe und Geiger zu nennen, und da Bothe schon abgesagt hatte, bliebe nur Geiger übrig. Mit seinen Forschungen zur Strahlenphysik würde er die gewünschte Ergänzung zu den vorhandenen Arbeitsgebieten bringen. Da das angelsächsische und skandinavische Ausland die Wiederbesetzung des Franck'schen Lehrstuhls „sehr ernst beachten“ werde, die Besetzung also „außenpolitische Bedeutung“ gewinne, sei es wichtig, dass der zu Berufende im Ausland hoch angesehen sei, was bei Geiger der Fall wäre. ${ }^{126}$

\footnotetext{
124 Gemeint ist hier Joos' mit größter Präzision durchgeführte Wiederholung des Michelson 'schen Versuchs. In den Naturwissenschaften gibt Joos einen geschichtlichen Überblick über die zahlreichen Wiederholungen dieses anfänglich umstrittenen Versuchs pro oder contra die Relativitätstheorie; siehe Joos [1931]. Eine ausführliche Darstellung seines eigenen Versuchs gab er 1930 in den Annalen der Physik.

125 Kossel stammte aus einer alten Gelehrtenfamilie, sein Vater war Professor der Physiologie und erhielt 1910 den Nobelpreis. In der Erwähnung des kultivierten und gebildeten Auftretens ehrte der Kurator die besondere Herkunft Kossels.

${ }^{126}$ Stellungnahme des Kurators, die dem Minister in Berlin überreicht wurde, 8. Februar 1935. UAG, Rek. $3206 \mathrm{~b}$.
} 
Aus der Sicht des Ministeriums gab es nun eine Fülle von Vorschlägen: Die Fakultät bevorzugte Kulenkampff und Gerthsen, der Rektor Gerthsen, der Kurator Geiger und die Dozentenschaft Joos und Kossel. Die zuletzt erreichte Einigkeit zwischen Fakultät, Rektor und Kurator in der Ablehnung von Joos uns Kossel nutzte nichts, denn mit 1. April 1935 wurde Georg Joos als ordentlicher Professor für Experimentalphysik und Direktor des II. Physikalischen Instituts berufen. Um diese Entscheidung beurteilen zu können, muss man den Blickwinkel erweitern und die Situation an der Universität Jena mit in Betracht ziehen.

Joos akademische Karriere vollzog sich in den wichtigsten Schritten in Jena. 1924 wurde er dort zum nbao. Professor ernannt, 1927 zum beamteten ao. Professor, 1928 zum persönlichen ordentlichen Professor und 1931 schließlich zum planmäßigen ordentlichen Professor. ${ }^{127}$ Zwischen 1928 und 1932 lehnte er insgesamt vier Rufe an andere Hochschulen ab. ${ }^{128}$ Dass er in Jena gehalten werden konnte, verdankte die Fakultät vor allem der finanziellen Unterstützung der Firma Carl Zeiss, mit der Joos in enger Zusammenarbeit stand. Als Joos 1935 den Ruf nach Göttingen erhielt, waren die Jenaer wieder sehr bemüht, ihn zu halten. Zur gleichen Zeit emeritierte in Jena Max Wien, und es bestand der Plan, Joos von seinem Lehrstuhl für theoretische Physik auf diesen prestigeträchtigeren für Experimentalphysik zu befördern. Damit wäre er „der erste Physiker“ in Jena gewesen. ${ }^{129}$ Alle Hebel wurden in Gang gesetzt, Major Ansat vom HWA, Ministerialdirektor Vahlen im REM und Kapitän Grassmann vom Marine-Waffenamt der Marineleitung wurden zur Unterstützung der Jenaer Pläne bemüht. ${ }^{130}$ Als Hauptargument wurden militärtechnische Versuche bei Zeiss angeführt, die unter Joos' Leitung durchgeführt wurden und nach seinem Weggang nicht mehr hätten fachgerecht betreut werden können. Der im REM mit dieser Berufungsangelegenheit befasste Professor Franz Bachér entschied allerdings sowohl gegen die Jenaer als auch gegen die Göttinger Wünsche, indem er Joos nach Göttingen berief und den dort lieber gesehenen Kulenkampff zum Nachfolger von Max Wien in Jena machte.

Man fragt sich sofort, warum nicht andersherum besetzt wurde, was sicher viel Missmut in Jena und Göttingen erspart hätte. Joos selbst zog es wenig nach Göttingen; er empfand seine

\footnotetext{
127 UAG, Kur. PA Joos; BAB, R 21/10009; UAJ, N, 46/1.

1281928 Würzburg (theor. Physik), 1930 TH Karlsruhe (theor. Physik), 1931 Danzig (Experimentalphysik), 1932 TH München (technische Physik). UAJ, N, 46/1.

129 Zitat nach Schreiben des Thüringischen Ministeriums für Volksbildung, Ministerialrat Stier, an REM, Ministerialdirektor Vahlen, 5. April 1935. BACZ, PA 2105.

130 Schreiben von Zeiss an HWA, 2. April 1935; Schreiben des Thüringischen Ministeriums für Volksbildung, Ministerialrat Stier, an REM, Ministerialdirektor Vahlen, 5. April 1935; Zeiss an das Marine-Waffenamt, 17. April 1935. BACZ, PA 2105.
} 
Berufung als „Versetzung“. 131 Einzig die Göttinger Dozentenschaft konnte sich mit der erfolgten Berufung zufrieden zeigen. Ein weiterer politischer Grund könnte die Rücksicht auf die Reaktion des Auslands gewesen sein. Da Joos' Arbeiten eine Bestätigung der Relativitätstheorie erbrachten, war von dort keine Kritik zu befürchten. Damit erfüllte die Berufung die seit 1935 erkennbare Abschirmungsstrategie der Reichsregierung, die ihren forcierten Revisionsdruck nach außen kaschieren sollte. In fachlicher Hinsicht sprach für Joos, dass die Arbeitsrichtung von Franck fortgesetzt wurde, zumindest was den optischen Teil betraf. Die Doktoranden erhielten dadurch einen fachlich passenden Betreuer. Joos war außerdem als Autor eines viel beachteten Lehrbuchs der theoretischen Physik hervorgetreten, ${ }^{132}$ sodass mit seiner Berufung auch die Hoffnung auf eine besonders gute Ausbildung der Studenten verbunden gewesen sein könnte.

Obwohl Joos (auch) theoretischer Physiker war, hing er der Forderung nach Anschaulichkeit in der Physik nach. Er regte in seiner Berufungsverhandlung an, dass das Ministerium bei der „Besetzung des Lehrstuhls für Mathematik [...] einen nicht abstrakten Mathematiker nach Göttingen“ berufen solle. Der Ministerialbeamte Bachér willigte ein. Es handelt sich wahrscheinlich um die im Oktober 1935 erfolgte Berufung Theodor Kaluzas, der anstelle des bis dahin von der Fakultät favorisierten Hellmuth Kneser den Vorzug bekam. ${ }^{133}$ Außerdem sagte Bachér Joos für die Institutseinrichtungen, insbesondere für die Werkstatt, RM 10000,zu. ${ }^{134}$ Mit Kaluza entwickelte Joos in der Folge eine fruchtbare Zusammenarbeit, die zu dem gemeinsam verfassten Lehrbuch der höheren Mathematik für den Praktiker führte. ${ }^{135}$ Das vielleicht interessanteste Faktum an der Berufung Joos' ist, dass sich die Fakultät ein Jahr lang heftig dagegen gewehrt hat, aber ein Jahrzehnt später, nachdem sie Joos wieder los geworden war, in einem Berufungsvorschlag 1946 schrieb: „Mit Abstand an erster Stelle nennt sie Professor Dr. Georg Joos.“136 Von Kulenkampff war dann keine Rede mehr, obwohl beide, Kulenkampff und Joos, durch das Kriegsende eine Karriereunterbrechung erlitten

\footnotetext{
131 Joos an die Geschäftsleitung der Firma Carl Zeiss, 7. Juli 1935. BACZ, PA 2105.

132 Joos [1932]. Siehe auch die positiven Rezensionen von Jordan [1940]a und Seeliger [1942].

133 Ähnlich wie bei der Franck-Nachfolge wurde auch bei der Besetzung des ehemaligen Courantschen Lehrstuhls nicht dem Wunsche der Fakultät entsprochen. Schappacher [1987/98] S. 535 nahm an, dass vor allem Prandtls Einsatz gegen den von der Fakultät erwünschten Hellmuth Kneser hier Wirkung zeigte. Am 27. März 1935 setzte sich Prandtl für eine Berufung Trefftzs ein. Die Vereinbarung zwischen Joos und Bachér war Schappacher offenbar nicht bekannt.

134 Vereinbarung zwischen Joos und Bachér vom 30. März 1935. UAG, Kur. PA Joos.

135 Joos \& Kaluza [1938]. Mit Hellmuth Kneser unterhiel Joos aber ebenfalls eine fachliche Zusammenarbeit, wie der Briefwechsel vom November 1941 in BACZ, 22768 zeigt.

136 Berufungsliste für Nachfolge Zahn; Dekan Eucken an Oberpräsident in Hannover, 20. Februar 1946. UAG, Rek. PA Zahn.
} 
hatten. Darauf wird noch näher einzugehen sein, wenn die Berufungspraxis der Nachkriegszeit zur Diskussion steht.

\subsubsection{Die Besetzung des Lehrstuhls für theoretische Physik}

Da die Entlassung Borns sich etwas länger hinzog als jene Francks, konnte die Fakultät ihre Schritte zur Wiederbesetzung ebenfalls erst später einleiten. Dies hatte aber den Vorteil, dass sie die in der Auseinandersetzung um die Franck-Nachfolge gemachten Erfahrungen hier verwerten konnte. Schon bevor der Born'sche Lehrstuhl frei wurde, gab die Universität ihren Wunschkandidaten bekannt: Es war der kurz zuvor mit dem Nobelpreis ausgezeichnete Werner Heisenberg. Er sei im Januar 1934 bereit gewesen, für einige Jahre vertretungsweise nach Göttingen zu kommen. ${ }^{137}$ Doch im Ministerium gab es Widerstände gegen Heisenbergs Berufung. Nachdem Heisenberg ein Ruf in die USA erreichte, bat ihn Pohl, er solle ihm doch einen Brief schreiben, indem er nach seinen Göttinger Chancen nachfragen und den Ruf in die USA erwähnen solle. „Fassen Sie bitte den Brief so ostensibel ab, daß ich ihn mit einem angsterfüllten Begleitschreiben via Dekan und Rektor nach Berlin bugsieren kann. Ich suche nach jedem Anlaß, um den Berlinern [gemeint ist das Ministerium] immer von neuem die Notlage der Göttinger Physik zu schildern." ${ }^{138}$

Im Oktober 1934 konnte sich Heisenberg auch eine Dauervertretung in Göttingen vorstellen. ${ }^{139} \mathrm{Da}$ seine Berufung aber nicht sofort möglich war, mussten einstweilen andere die Vertretung der theoretischen Physik übernehmen. Es waren dies nacheinander Otto Heckmann ${ }^{140}$, Martin Stobbe ${ }^{141}$, Erwin Fues ${ }^{142}$ aus Hannover und schließlich ab SS 1934 der frühere Hilfsassistent von Richard Becker an der TH Berlin, Fritz Sauter. In den Jahren 1933 und 1934 arbeitete Sauter eine Vortragsreihe aus, die Born im WS 1932/33 an der TH Berlin gehalten hatte und die 1934 unter dem Titel Moderne Physik unter Borns und Sauters Namen im Springerverlag erschien. ${ }^{143}$ Nachdem er sich im Mai 1933 für das Fach theoretische Physik habilitiert hatte, wurde dem 28-jährigen Sauter im April 1934 die planmäßige Assistentenstelle am Institut für theoretische Physik übertragen und ein unbesoldeter

\footnotetext{
137 Schreiben Rektor an Ministerium, 27. Januar 1934. UAG, Rek. III, A, 1, 299e.

138 Pohl an Heisenberg, 13. Juni 1934. MPI für Physik und Astrophysik, NL Heisenberg.

139 Dies geht aus einem Schreiben des Rektors vom Oktober 1934 hervor. UAG, Rek. III, A, 1, 299 e.

140 Zu Heckmann siehe Hentschel \& Renneberg [1995].

141 Stobbe gehörte zu den wenigen couragierten Dozenten, die sich weigerten für Hitler-Deutschland zu arbeiten. Siehe Born an Mr. Gent vom AAC, 1. Dezember 1933. BLO, MS SPSL 556/2, Corr. Stobbe.

142 Zu Fues siehe Schaefer [1952].

143 Siehe Sauters Beilage zum Fragebogen für die politische Überprüfung, 17. November 1948. HStAH, Nds. 171 Hildesheim 12794.
} 
Lehrauftrag erteilt. Fues hielt die elementaren Kursvorlesungen und Sauter Spezialvorlesungen über aktuelle Fragen der theoretischen Physik. Bezahlt wurde Fues über sein Ordinariat an der TH Hannover. Als Fues 1934 an die TH Breslau berufen wurde, bekam Sauter im Dezember 1934 die Lehrstuhlvertretung aufgetragen, was ihm die aufkommenden Vorlesungshonorare einbrachte. Dies waren für das WS 1934/35 immerhin RM 500; zusätzlich wurde ihm eine Vergütung für die Lehrstuhlvertretung von RM 300 gewährt. Im April 1935 wurde der österreichische Staatsbürger Sauter ins Deutsche Reich eingebürgert. ${ }^{144}$ Im September 1935 stand er an achter und vorletzter Stelle einer Berufungsliste für den Lehrstuhl der theoretischen Physik der Universität München. ${ }^{145}$

Die Fakultät wurde offenbar aufgefordert, Alternativen zu Heisenberg zu nennen, jedenfalls nahm sie im November 1934 zu den Namen Friedrich Hund und Pascual Jordan Stellung. Das Urteil fiel klar aus: „Herr Hund steht der Praxis nahe im Gegensatz zu Herrn Jordan, der sich mehr mit den abstrakten Theorien beschäftigt. Die Fakultät würde daher Herrn Hund bei weitem vorziehen." 146 Es ist nicht als eine Konzession ans Regime zu verstehen, wenn die Fakultät „abstrakte“ Theoretiker ablehnte, sondern es entsprach dem wissenschaftlichen Selbstbild der Göttinger Physiker Pohl, Reich und Prandtl, das von einem Hang zur praktischen und anschaulichen Physik gekennzeichnet war. Auch die untere Ebene von Dozenten, die in der Fakultät weniger Mitspracherechte genossen, wie Schuler, Mannkopff und Cario sind in diese Physikauffassung einzureihen.

Im Sommer 1935 forderte das Ministerium die Fakultät zu einer Berufungsliste auf. Zu dieser Zeit hatte Pohl mit Joos schon einen zweiten Experimentalphysiker zur Seite bekommen, der nun in den Besetzungsangelegenheiten mitmischte. Mit den Worten Richard Beckers kann man auch sagen, dass in Göttingen „Pohl und Joos regieren“. ${ }^{147}$ Die Fakultät blieb bei ihrer alten Auffassung. In der neuen Berufungsliste schrieb der Dekan Reich zu Anfang programmatisch: In „Anbetracht der großen Tradition [kommt] nur eine allererste Kraft in Frage“. Daher käme Sauter, der sich in der Vertretung Borns ausgezeichnet bewährt habe und

\footnotetext{
144 Die erste Anfrage an Sauter, ob er in Göttingen die Vertretung übernehmen könne, datiert vom 12. Januar 1934. Fünf Tage später sagte Sauter zu. Die planm. Assistentenstelle wurde ihm am 28. April 1934 übertragen. Am 10. Dezember 1934 trug ihm das Ministerium die Lehrstuhlvertretung auf. Alle Angaben aus GPAMNFG, Lehrkörper (ausgeschieden), Sauter. Siehe auch Rektor Neumann an Ministerium, 27. November 1934. Die Einbürgerung ins Deutsche Reich datiert vom 18.April 1935 (aus Schreiben Rektor Neumann an Kurator, 6. Mai 1935). UAG, Rek. 5250 / 8A. Siehe auch Lebenslauf von Sauter, ohne Datum, vermutlich 1935. UAG, Kur. 4 V $\mathrm{h} / 35$.

145 Berufungsausschuss an Dekan der Universität München, 18. Januar 1940. LMU-Archiv, OC-N-10.

146 Dekan Reich an Rektor Neumann, 1. November 1934. UAG, Rek. 3206b.

147 Brief von Richard Becker an Max Born, 12. Juli 1936, wo er von einem Besuch in Göttingen zu Pfingsten 1936 berichtet. StB-B, NL Born 34.
} 
für fast alle Lehrstühle in Deutschland geeignet sei, nicht in Frage, sondern eigentlich nur Heisenberg, der der Fakultät neuen Glanz verleihen würde. Heisenberg wurde auch zu einem Vortrag ins Kolloquium eingeladen, wo er am 23. Januar 1936 über die Kräfte im Innern des Atomkerns sprach. ${ }^{148}$ Falls er aber nicht zu gewinnen sei, so schlug die Fakultät gleichwertig Friedrich Hund und Richard Becker vor. Bei Hund erwartete die Fakultät eine fruchtbare Zusammenarbeit mit den Experimentalphysikern Pohl und Joos, denn Hund beachte in seinen Fragestellungen experimentelle Tatsachen und könne den Experimentalphysikern wertvolle Anregung geben. Becker stehe noch mehr als Hund „in der Wirklichkeit“ und bearbeite Probleme von technischer Bedeutung in höchst origineller Weise. Mit kritischen Kommentaren wurde zuletzt noch Jordan genannt, der sich ,ganz allgemein philosophischen Fragen zugewandt" habe und daher bei praktisch wichtigen Fragen kaum Anregung und Rat geben könne. Dies sei besonders deshalb von Nachteil, wo doch ,gerade in Göttingen [...] die angewandte Physik besonders stark vertreten ist“". Jordans Sprachfehler, sein Stottern, wurde auch noch gegen ihn ins Spiel gebracht. ${ }^{149}$ Eine verhaltene Anerkennung dürften Jordans philosophischen Betrachtungen, zum Beispiel zur Verbindung von Physik und Biologie und die naturwissenschaftliche Erfassung des Lebendigen, bei Eucken gefunden haben, doch war dieser an den Kommissionssitzungen nicht beteiligt. ${ }^{150}$

Die Fakultätsmeinung, wie sie sich aus der eben zitierten offiziellen Berufungsliste ergibt, tritt noch viel klarer und zugespitzter in den Fakultätsprotokollen hervor. An der die Born Nachfolge besprechenden Sitzung nahmen von den Physikern nur Prandtl, Reich und Joos teil. In Bezug auf Heisenberg befürchteten der Rektor Neumann und Joos, dass die Universitäten Berlin und München eine ernste Konkurrenz zu Göttingen sein könnten. Deshalb müsse Heisenberg in erster Linie genannt werden. Prandtl fand, Becker sei ein „sympathischer Mann“, auch von Sauter hatte er einen „sympathischen Eindruck“. Joos wies darauf hin, dass Hund und besonders Becker die vorhandenen Arbeitsgebiete ergänzen würden. Zu Jordan meinte Joos abfällig, er ,ist immer Philosoph und Formalmathematiker“‘. Auch der Astronom Kienle würde Sauter wegen der theoretischen Einstellung Jordan vorziehen, und der Geophysiker Angenheister erhoffte sich von Becker mehr Gewinn für die angewandte Physik. Der Rektor gab zu bedenken, dass Jordan „nie wieder weggerufen“

\footnotetext{
148 UAG, Rek. 5250 / 6A.

149 Dekan Reich an Ministerium, 23. August 1935. UAG, Rek. 3206b.

150 Jordan wurde vom Euckenbund zu einem Vortrag über das Einheitsproblem der physikalischen und biologischen Wissenschaften eingeladen. In der anschließenden Diskussion würdigte Eucken den „Vorstoß des Kollegen Jordan“, Lebensvorgänge mit dem Wissen über die unbelebte Natur in Verbindung zu bringen. Siehe Jordan [1938]a und die dort folgenden Diskussionsbeiträge. Eine ausführliche und sehr positive Rezension von Jordan [1936] gab Eucken [1939].
} 
werden würde. Schließlich meinte Prandtl, der ebenfalls gegen Jordan war, die „Berufungsliste soll sich nicht nur nach der wissenschaftlichen Leistung richten, sondern danach, was wir haben wollen“. Dazu Reich: „Will schreiben Jordan wollen wir nicht.“ Dies ist also die Übersetzung in die Alltagssprache der oben erwähnten Gründe gegen eine Berufung Jordans. Sauters Nennung wurde damit begründet, dass es einen großen Mangel an jüngeren theoretischen Physikern gebe, sodass der Maßstab heruntergesetzt werden müsse. Sauter sei noch einer der Besseren, der außerdem bei den Studenten beliebt sei. Ihn nicht zu nennen wäre „menschlich hart“".151

Wenn also ein Theoretiker berufen werden sollte, der zusammen mit Born „den mathematisch formalen Apparat der Quantenmechanik entwickelt hat", wie die Fakultät über Jordan schrieb, ${ }^{152}$ dann muss es schon Heisenberg sein, der neuen Glanz verleihen konnte. Die inhaltliche Präferenz der Fakultät tendierte zwar mehr zu einer technischen Ausrichtung der theoretischen Physik und weniger $\mathrm{zu}$ einer quantenmechanischen, bei entsprechender Reputation des Kandidaten wurden solche Überlegungen jedoch beiseite geschoben. Den Standort Göttingen auf diese Weise zu stärken schien das wichtigere Kriterium zu sein. Politische Überlegungen kamen in den Beurteilungen der Fakultät nicht zur Sprache.

Das Ministerium lehnte die Berufung aller vier Genannten (Heisenberg, Hund, Becker, Jordan) ab und schlug seinerseits vor, den Dozenten Sauter zum tatsächlichen Nachfolger Borns zu berufen. Diesen Vorschlag hielt die Fakultät im Mai 1936 für eine „tragbare Lösung““. ${ }^{153}$ Eucken berichtete schon im Sommer 1934, dass die Göttinger über Sauters „Hiersein [...] sehr erfreut sind““. ${ }^{154}$ Zwischen Eucken und Sauter entwickelte sich eine fruchtbare Zusammenarbeit, die 1934 zu einer gemeinsamen Publikation in der Zeitschrift für physikalische Chemie führte. Während Sauter innerhalb der Fakultät einen guten Ruf genoss, wurde er vom Dozentenbund kritischer betrachtet. Zwar beurteilte dieser Sauter im März 1936 in wissenschaftlicher und charakterlicher Hinsicht positiv, politisch fiel das Urteil aber schlechter aus. „Ob Dr. Sauter Nationalsozialist ist, muss bezweifelt werden. Es ist ja leider so, dass nur wenige Naturwissenschaftler auch als Nationalsozialisten einbewertet werden können. “155 Ein halbes Jahr später formulierte derselbe Vertreter des Dozentenbunds, Blume,

\footnotetext{
151 Protokoll der Sitzung des Fakultätsausschusses vom 21. August 1935. GPAMNFG, Protokollbuch III der mathematisch-naturwissenschaftlichen Fakultät WS 1927/28 - SS 1946.

152 Dekan Reich an Ministerium, 23. August 1935. UAG, Rek. 3206b.

153 Dekan Reich an Ministerium, 4. Mai 1936. UAG, Rek. 3206b.

154 Brief Eucken an Born, 9. Juni 1934. StB-B, NL Born 210.

155 Dozentenbund (Blume) an Rektor, 19. März 1936. UAG, Rek. 3306 b.
} 
sein Urteil vorsichtiger und hielt es offen, ob Sauter Nationalsozialist sei oder nicht. ${ }^{156}$ Nach eigener Beschreibung war der Österreicher Sauter großdeutsch-gesinnt. ${ }^{157}$ Seit 6. März 1934 war er Mitglied des „Kampfrings der Deutschösterreicher im Reich“. ${ }^{158}$ Im September 1934 trat er dem NSLB bei. ${ }^{159}$ Als Sauter im Sommer 1936 um eine Reiseerlaubnis nach Zürich ansuchte, um an der dortigen ETH einen physikalischen Vortrag zu halten, stellte der Kultusminister eine Anfrage bei der Gestapo, da „dem Vernehmen nach Dr. Sauter durch das Geheime Staatspolizeiamt überwacht wird.“ Erst als der zuständige Kriminalkommissar bestätigte, dass gegen Sauter keine Bedenken bestünden, wurde die Reise genehmigt. Die Genehmigung kam allerdings so spät, dass Sauter schon die halbe Tagung versäumt hatte und schließlich auf die Reise ganz verzichtete. Die Akten geben leider keinen Hinweis, weshalb Sauter von der Gestapo überwacht wurde. ${ }^{160}$

$\mathrm{Ob}$ es Zweifel an der politischen Zuverlässigkeit Sauters waren, die das Ministerium dazu brachte, seine Meinung zu ändern, ist ungewiss. Jedenfalls beschloss es, die Professur für theoretische Physik an der TH Berlin aufzugeben und den dortigen Lehrstuhlinhaber, Richard Becker, nach Göttingen zu berufen. Die Bemühungen der Berliner Physiker, Becker samt Lehrstuhl zu erhalten, fruchteten nicht. Becker wurde vor die Wahl gestellt, den Ruf nach Göttingen anzunehmen, oder andernfalls zwangsversetzt zu werden. Er nahm an und wurde zu Beginn des WS 1936/37 Borns Nachfolger. ${ }^{161}$

Becker hatte ein schlechtes Gewissen, die Stelle des vertriebenen und hoch geschätzten Kollegen einzunehmen, und er glaubte, Born um Entschuldigung bitten zu müssen. Er bedauerte außerdem, dass er die ,große Göttinger Tradition“ nicht fortführen könne, da er, wie er selbst schrieb, ,zur Zeit [...] die Einzelheiten der Quanten-Elektrodynamik nicht verfolgen“ konnte und stattdessen nur seine „ehrlichen, aber doch immer ziemlich dürftigen

\footnotetext{
156 Dozentenbund (Blume) an Kreisleitung der NSDAP, Göttingen, Kreispersonalamtsleiter Büsselmann, 12. Oktober 1936. BAB, BDC-NSLB-Listen, 3330010232.

157 Sauter wuchs in Tirol in einer vorwiegend deutschnational gesinnten Gesellschaft auf. In einer Volksabstimmung nach dem Ende des Ersten Weltkriegs stimmten über $90 \%$ für für den Anschluss an Deutschland. In Innsbruck gewannen die Nationalsozialisten bei einer Wahl 193340 \% der Stimmen. Die politische Einstellung des Tirolers Sauter, der aus adeliger Familie stammt, die 1919 ihr „von“ verlor, war also nichts Ungewöhnliches. Vocelka [2002] 276, 290.

158 BAB, R $21 / 10017$.

159 BAB, NSLB-Kartei.

160 Antrag Sauter um Reiseerlaubnis für die Tagung vom 30. Juni bis 4. Juli 1936 an Rektor, 25. Mai 1936. Anfrage des Ministeriums an die Gestapo, 23. Juni 1936. Handschriftlicher Vermerk, dass keine Bedenken bestünden, 29. Juni 1936. Genehmigung der Reise, 29. Juni 1936. Absage Sauters an Kurator, 30. Juni 1936. BAB, R 4901, 2943.

161 Die angedrohte Zwangsversetzung wird berichtet bei Kersten [1978]. Am 20. August 1936 vereinbarte Becker mit Mentzel im REM die Bedingungen, unter denen er bereit sei, nach Göttingen zu wechseln, und am 26. September 1936 teilte das Ministerium Becker die Berufung nach Göttingen mit. UAG, Kur. PA Becker. GPAMNFG, Lehrkörper (ausgeschieden), Becker. Zu den Vorgängen an der TH Berlin siehe Cassidy [1979].
} 
Bemühungen um Ferromagnetismus, Plastizität und solche Dinge fortsetzen werde“. Becker empfand seine Berufung unter den gegebenen politischen Bedingungen ,als ein kleineres Übel“ für Göttingen. ${ }^{162}$ Schlimmer hätte er vermutlich eine Berufung eines „Deutschen Physikers" empfunden.

Becker war auf Grund seiner bisherigen akademischen Laufbahn prädestiniert für eine Stelle an einer Technischen Hochschule. ${ }^{163}$ Seine Berufung veränderte das Profil der Göttinger theoretischen Physik. Als Sohn eines Kaufmanns promovierte Becker 1910 in Zoologie mit einer Arbeit über Dipterenlarven. Der Physik widmete er sich anschließend in München und Göttingen, wo er 1911 das Staatsexamen fürs höhere Lehramt absolvierte. Nach kurzer Assistentenzeit unter anderem bei Fritz Haber im KWI in Dahlem war er von 1913 bis 1926 in der Industrie beschäftigt; die ersten sechs Jahre in der Sprengstoffindustrie. Von Oktober 1916 bis März 1919 war er außerdem im Waffen- und Munitionsbeschaffungsamt in Berlin tätig. ${ }^{164}$ Mit seiner Arbeit „Stosswelle und Detonation“, in der er eine theoretische Erklärung für die bis dahin unverstandene hohe Erwärmung in einer Explosion lieferte, habilitierte er sich 1923 an der Universität Berlin bei Max Laue, Walther Nernst und Max Planck. Die Habilitation ging keineswegs glatt über die Bühne, denn Nernst konnte anfänglich in Beckers eingereichter Arbeit keinen wesentlichen Fortschritt, der die physikalische Chemie oder experimentelle Physik betreffe, erkennen, weil die Formeln, zu denen Becker gelangte, bereits kurz zuvor von einem anderen publiziert worden waren. Die übrigen Veröffentlichungen von Becker hielt Nernst für so wenig erfolgreich, dass sie keinen Ersatz für die Habilitationsschrift darstellen könnten. Erst als sich nicht nur Laue, sondern auch Planck für seine Habilitation ausgesprochen hatten, und Becker eine neue Arbeit über den Starkeffekt bei Alkalien nachgereicht hatte, in der er eine quantentheoretische Erklärung der durch ein elektrisches Feld hervorgerufenen Aufspaltung der Spektrallinien lieferte, zu der sich auch Einstein anerkennend geäußert haben soll, nahm das Verfahren einen positiven Ausgang. ${ }^{165}$ Neben seiner Dozententätigkeit war er von 1922 bis 1926 bei der Glühlampenfirma Osram in Berlin beschäftigt. 1926 wurde Becker als ordentlicher Professor für theoretische Physik an die TH Berlin berufen. Seine Forschungen konzentrierten sich dort auf (Ferro-)Magnetismus,

\footnotetext{
162 Brief Becker an Born, 12. Juli 1936. StB-B, NL Born 34.

163 Sein Kollege Gustav Hertz urteilte über Becker in einem Schreiben an den Rektor der TH Berlin vom 23. Februar 1931: „Unter den theoretischen Physikern in Deutschland weiß ich keinen zu nennen, der so wie Herr Becker gerade für die Vertretung seines Faches an der Technischen Hochschule geeignet wäre. "UAG, Kur. PA Becker.

164 UAG, Kur. PA Becker.

165 Becker reichte seine Habilitation im Dezember 1921 ein. Die erfolgreiche Habilitation datierte vom 15. Januar 1923. UAHU, Rep. 1238.
} 
Plastizität und Kondensation. Bekannt wurde er im Kollegenkreis und unter den Studenten auch durch sein Lehrbuch über die Theorie der Elektrizität. ${ }^{166} 1931$ erhielt er einen Ruf an die TH Karlsruhe, den er ablehnte, nachdem sein Gehalt in Berlin um etwa die Hälfte erhöht worden war. ${ }^{167} \mathrm{Zu}$ seinen Fachkollegen Gustav Hertz und Max Vollmer unterhielt er ein harmonisches Arbeitsverhältnis. Politisch hielt Becker Distanz zum Nationalsozialismus; zum einen bei Mitgliedschaften und zum anderen bei symbolischen Gesten wie dem Hitlergruß. Schüler von ihm berichten, dass er deutlich zu erkennen gab, dass man in seinen Vorlesungen nicht mit „Heil Hitler“ grüßen sollte. ${ }^{168}$ In einer politischen Beurteilung bezeichnet ihn Rektor Hans Drexler als Skeptiker und Ironiker, von dem „man niemals ein positives Eintreten erwarten“ könne. Er hielt ihn für „durchaus ungefährlich“ und schätzte ihn als Mann „großer Vornehmheit und bester Rasse“.169 Nach eigener Angabe war Becker ab 1935 Mitglied der NSV und des Reichsluftschutzbundes. ${ }^{170}$ Während er auf der symbolischen Ebene wenig Anpassungsbereitschaft signalisierte, war er auf der praktischen Ebene durchaus bereit, für die Ziele des NS-Staates zu arbeiten (dazu mehr in Kapitel 3).

\subsubsection{Bewertung der Ordinarien-Neubesetzungen 1935/36}

Wenn man diese beiden Besetzungen vergleicht, so lassen sich bestimmte Gemeinsamkeiten feststellen. Das Ziel der Fakultät war, besonders angesehene Forscher nach Göttingen zu ziehen, um einerseits ein hohes Niveau in der Forschung sicherzustellen und andererseits die Reputation der Universität zu erhöhen. Sowohl Bothe wie Heisenberg zählten damals zu den 'größten Köpfen' in Deutschland, und sie genossen auch international hohes Ansehen. Um ihre Wunschkandidaten durchzusetzen beschränkte sich die Fakultät auf eine sachliche, vor allem auf wissenschaftliche Kriterien bezogene Argumentation. Daneben forderte sie, dass nur eine angesehene „Persönlichkeit“ den Göttinger Lehrstühlen gerecht werden könne, vermied es aber, politisch Stellung zu beziehen. Mit dieser Strategie war die Fakultät jedoch nicht erfolgreich. Zumindest im Fall Heisenberg sind politische Widerstände als ausschlaggebende Gründe fürs Scheitern anzunehmen. Politische Zugeständnisse oder wenigstens politische Argumente lieferten Rektor und Kurator. Diese zeigten gegenüber den Vorschlägen des Dozentenbundes eine weniger strikte Ablehnung als die Fakultät.

\footnotetext{
166 Siehe Abraham [1930].

167 UAG, Kur. PA Becker.

168 Interview mit Friedrich Schlögl, 22. Juni 2001.

169 Abschrift einer politischen Beurteilung Beckers durch Rektor Drexler vom 1. September 1944. BAB, WI, Becker, Richard.

170 UAG, Kur. PA Becker.
} 
Das Ministerium sah sich einer großen Zahl an Vorschlägen und Argumenten gegenüber. Wenn das Ministerium auch aus der Sicht der Fakultät nicht die beste Entscheidung traf, da die Erstplatzierten bei jeder Berufungsliste abgelehnt wurden, so war die jeweilige Entscheidung aus der Sicht des Ministeriums durchaus ein kluger Kompromiss. Die berühmten Physiker gingen durch die Nicht-Berufung zwar Göttingen verloren, nicht aber Deutschland. Das heißt, das Deutsche Reich konnte sich weiterhin mit ihren Namen schmücken. Mit Joos und Becker bekam Göttingen zwei theoretische Physiker, die beide einen Hang zum Experiment hatten. Außerdem waren sie Autoren von angesehenen Lehrbüchern, womit sie für eine solide physikalische Grundausbildung der Studenten beste Voraussetzungen mitbrachten. ${ }^{171}$ Der Kompromiss ist auch aus einem weiteren Grund als geglückt zu bezeichnen: Mit Joos kam jemand zum Zug, den der Dozentenbund in Vorschlag gebracht hatte, und mit Becker der zweitgereihte auf der Berufungsliste der Fakultät. Mit der Wegberufung Beckers aus Berlin wurde dort außerdem seine Stelle für eine geplante Umstrukturierung der TH frei. Die TH wurde verstärkt auf wehrwissenschaftliche Bereiche ausgerichtet, und die theoretische Physik erschien nicht so dringlich, sodass sie nicht mehr mit einem Ordinariat vertreten sein musste.

Was der Göttinger Fakultät möglicherweise fehlte, um ihre Interessen effektiver durchzusetzen, waren persönliche Verbindungen ins Ministerium. Mit dem Machtwechsel 1933 wurden solche bestehenden Beziehungen gekappt. In dieser Hinsicht klagte Richard von Mises in einem Brief an Prandtl im März 1933, weil er Nachwuchswissenschaftler nicht mehr protegieren konnte: „Alle Voraussicht, die man hinsichtlich der Zukunftsmöglichkeiten sonst hatte, beruhte ja auf Beziehungen, die man zu den betreffenden Stellen im Ministerium besass."172 Im Laufe der Zeit verbesserte sich für die Göttinger die Situation. Doch bis zu den neuen Ministerialbeamten ein gutes Verhältnis hergestellt wurde, bis man dort geeignete Stellen für sich gewinnen konnte, dauerte es eine Weile.

Aus den gesamten Berufungsverfahren lassen sich drei Gruppen von Kriterien bilden, die bei der Beurteilung der Kandidaten Anwendung fanden:

- Wissenschaftliche Leistung

- Charakterliche Eigenschaften

- Politische Einstellung

\footnotetext{
171 Studenten, auch solche, die später selbst hervorragende Physiker wurden, fühlten sich nicht unbedingt von glänzenden Forschern angezogen. Wolfgang Paul berichtete, dass er als Student 1934 nur kurz in Leipzig bei Heisenberg, Hund und Debye war und unversehens weiter an die TH Berlin zog, wo er sich bei Kopfermann und Becker bedeutend wohler fühlte. Steiner [1995] S. 197. Siehe auch Abschnitt 4.1.2.

172 Mises an Prandtl, 8. März 1933. MPG-Archiv, NL Prandtl, III, 61, 1082. Mises hegte in diesem Brief wie viele seiner Kollegen noch die Hoffnung, ,dass in ein bis zwei Jahren die Dinge sich wieder eingerenkt haben.“
} 
Die Gewichtung dieser Faktoren fiel je nach beteiligter Instanz unterschiedlich aus. Es wurden aber von allen Instanzen alle Kriterien berücksichtigt, wobei zwischen ihnen keine scharfe Trennung gezogen wurde, sich vielmehr die verschiedenen Bereiche überlappten. So zählte zum Beispiel die „formalistische“ Ausrichtung Jordans und vor allem seine philosophischen Neigungen mehr zum Bereich der Persönlichkeit, als zu dem der wissenschaftlichen Leistung. Denn wie Prandtl bemerkte, sollte Jordan abgelehnt werden, indem sich die Fakultät nicht nur nach der wissenschaftlichen Leistung richten solle.

Es ist allerdings festzuhalten, dass die Fakultät bei der Beurteilung der Physiker mit politischen und persönlichen Argumenten sehr zurückhaltend vorging. 1935 wurde in Göttingen auch die Besetzung der Professur für Tektonik verhandelt, und dabei ging dieselbe Fakultät in deutlich anderer Weise vor. Gegen einen vom Ministerium vorgeschlagenen Kandidaten wurden die schwersten Bedenken aus politischen Gründen geäußert. Außerdem solle der Kandidat eine tschechische Mutter haben und folglich eine gewisse Zugehörigkeit zum „Slaventum“; „charaktermäßig“ sei er eine „,weiche, unkämpferische Natur“. Dem hielt der Physiker Reich entgegen, dass ihm Kollegen in menschlicher Hinsicht ein gutes Zeugnis ausstellten. Erst nach ausführlicher Diskussion um den Charakter kamen auch seine wissenschaftlichen Fähigkeiten zur Sprache. Darüber herrschte allerdings Uneinigkeit, wobei ihn diejenigen für wissenschaftlich oberflächlich und minder befähigt hielten, die ihn vorher schon 'menschlich' kritisierten - und umgekehrt. Nun wurden alle Kriterien miteinander verschmolzen. Der Professor für Agrarwesen und Agrarpolitik und gleichzeitig Gaudozentenbundsführer, Artur Schürmann, ${ }^{173}$ befürchtete ein Übergewicht des rein wissenschaftlichen Moments; daher forderte er: „Entscheidend für uns hätte zu sein, wie sich Rüger in seiner Gesamthaltung uns darstelle, Bluterbe, Charakter und wissenschaftliche Befähigung seien nur verschiedene Seiten eines unteilbaren Ganzen, der Persönlichkeit.“ Bekräftigend stimmte Othenio Abel, Professor der Paläontologie, zu: „persönliche, charakterliche und wissenschaftliche Befähigung sind untrennbar.“ Daraufhin ließ sich erst recht keine Einigung über ihn erzielen, sodass der Dekan Jonas Schmidt beschloss, dem Ministerium mitzuteilen, dass der größte Teil der Kommission „schwerste Bedenken [...] in menschlicher (politischer) Hinsicht" hege. Auch das positive Urteil über die rein wissenschaftliche Befähigung erführe keine ungeteilte Zustimmung mehr. „Eine Nachprüfung der Nationalität sei daher unerlässlich."174

\footnotetext{
173 Zu Schürmann siehe Becker [1987/98] S. 642-646.

174 Kommissionssitzung über die Besetzung einer Professur für Tektonik, 26. November 1935. GPAMNFG, Protokollbuch III der mathematisch-naturwissenschaftlichen Fakultät WS 1927/28 - SS 1946.
} 
Dieser Fall soll zeigen, welch krasse Formen Berufungsverhandlungen in der mathematischnaturwissenschaftlichen Fakultät annehmen konnten. Die rassistische Auslese wurde hier nicht ausschließlich 'extern“ vom Dozentenbund eingefordert, sondern kam auch von den anderen Fachvertretern selbst. Verglichen mit dieser üblen Art der Argumentation verliefen die Berufungsverhandlungen $\mathrm{zu}$ den Physiklehrstühlen wesentlich sachlicher. Die Fachvertreter der Physik respektierten 'rein' wissenschaftliche Leistungen, und wenn sie den an sich Befähigten trotzdem nicht wollten, dann stellten sie andere Argumente, zum Beispiel die Persönlichkeit betreffend, dagegen, ohne damit die Leistungen des Bewerbers zu schmälern. Es gab nicht diese vollkommene Vermischung der Argumentationsebenen. Es blieb die wissenschaftliche Ebene dominierend, wenn auch nicht allein entscheidend.

\subsubsection{Eine taktische Übergangslösung am Lehrstuhl für angewandte Elektrizität}

Der im Jahr 1920 auf den Lehrstuhl für angewandte Elektrizität berufene Max Reich gehörte dem Göttinger Lehrkörper schon seit 1912 an. Mit seiner Berufung zum persönlichen ordentlichen Professor wurde er Nachfolger des verstorbenen Extraordinarius Hermann Theodor Simon. Reichs Forschungen standen schon vor dem Ersten Weltkrieg im Dienste des Militärs. Ab 1909 leitete er die in Göttingen ansässige „radioelektrische Versuchsanstalt für Heer und Marine“". Vor Beginn des Ersten Weltkriegs hatte er regelmäßig an Truppenübungen teilgenommen. Ab 1914 fanden die kriegstechnischen Forschungen dann ihre Anwendung. Als 1933 die Regierung wechselte und Hitler seine Diktatur errichtete, hatte Reich gerade das Amt des Dekans inne. Die Einrichtung des Führerprinzips an den Universitäten führte nicht zu seiner Absetzung, sondern im Gegenteil zur Verlängerung seiner Amtszeit, die dann bis einschließlich SS 1935 dauerte. Reich trat am 1. Mai 1933 in die NSDAP ein und symbolisierte damit die Zustimmung zur neuen Regierung. Die schon lange vorhandene Ausrichtung seiner Forschung und anderer Tätigkeit auf militärische Belange war im Nationalsozialismus 'zeitgemäß‘ und brachte ihm Unterstützung ein. Im Januar 1938 schloss er einen Vertrag mit dem Heereswaffenamt, worauf eine besondere Abteilung mit einem Physiker und zwei Mechanikern in seinem Institut errichtet wurde. Welche Arbeiten diese Abteilung durchführte, ist leider nicht bekannt. Auch für die Kriegsmarine wurden Arbeiten durchgeführt; nicht näher erläuterte Apparate wurden dazu geliefert. Die Informationen stammen aus einem Bericht des Dekans Correns ans Ministerium aus dem Jahr 1941. Der Bericht schließt mit: „Aus alledem geht eindeutig hervor, daß das Institut bereits vor dem Krieg für die Aufgaben der Landesverteidigung eingesetzt war, daß es im Kriege völlig in 
diesen Aufgaben aufgeht und daß es auch nach dem Kriege weiter im Interesse der Landesverteidigung arbeiten wird." 175 Eine kurze Mitteilung Reichs vom April 1940, in der er begründet, warum niemand aus seinem Institut an einer anstehenden Physikertagung teilnehmen könne, bestätigt die obige Darstellung. „Die Doktoranden sind fort, und das Institut ist ganz auf Arbeiten für die Marine eingestellt mit Assistenten und einigen von der Marine reklamierten Kräften." 176 Die Situation schien sich bis 1944 nicht geändert zu haben. Als der RFR im November 1943 eine Auflistung des gesamten männlichen Personals der Universitätsinstitute einforderte, gab Zahn für sein Institut nur drei Beschäftigte an: einen Mechanikermeister, einen -gehilfen und einen -lehrling. Offenbar war kein Doktorand oder Assistent im Institut angestellt. Zum Vergleich gaben Pohl und Becker für ihr Institut jeweils drei Physiker an, Kopfermann sogar acht, zusätzlich zum Werkstättenpersonal, das bei Pohl aus sechs Personen bestand, bei Kopfermann aus acht. ${ }^{177}$

Im Jahr 1938 hatte Reich die Führung der Göttinger Luftschutzwarnzentrale übernommen, deren „Feuerprobe er zu seinem Schmerze“ nicht selbst leiten konnte, da er im September 1939 als Leiter des Nachrichtenmittelversuchskommandos der Kriegsmarine abkommandiert worden war. ${ }^{178}$ Zum WS 1939/40 erreichte Reich die Altersgrenze, wurde entpflichtet und vertrat sich selbst in den folgenden Semestern. Die Fakultät wusste keinen geeigneten Nachfolger, doch als Reich im Januar 1941 verstarb, musste eine Lösung gefunden werden. Schon Ende Januar schlug sie Hermann Zahn als Nachfolger vor, denn weder Pohl noch Joos hätten Reichs Lehrstuhl vertreten können. Pohl wurde vom Luftfahrtministerium angefordert und beurlaubt, und Joos hatte gerade selbst ein Jahr Beurlaubung erbeten. Zahn sollte deshalb sofort mit der Lehrstuhlvertretung beauftragt werden, bis nach Klärung der politischen Fragen seine Berufung erfolgen könne. ${ }^{179}$

Da man im Ministerium dem Parteigenossen Zahn wohl gesonnen war, ergaben sich keine Schwierigkeiten politischer Natur. Dafür waren bürokratische Hindernisse zu überwinden, denn Reichs Professur war als „k-w-Stelle“ (künftig wegfallend) gekennzeicht, und somit

\footnotetext{
175 Dekan Correns an Ministerium, 28. August 1941. UAG, Rek. PA Reich, Max.

176 Reich an Kopfermann, 29. April 1940. Der Anlass des Schreibens war eine von Kopfermann vorgeschlagene Tagung des Gauvereins Niedersachsen für 1940, die anscheinend nicht stattgefunden hat. Georg Joos sprach sich auch im Namen Pohls gegen die Gauvereinstagung aus, da ,alle Institute [in Göttingen] lediglich Geheimarbeiten“ durchführten, worüber nicht vorgetragen werden konnte. Joos an Kopfermann, 6. Mai 1940. DPG-Archiv, 40023.

177 Siehe die entsprechenden Listen ,,der sämtlichen reichsdeutschen männlichen Gefolgschaftsmitglieder der Institute" vom November 1943 in UAG, Kur. 2018.

178 Alle Angaben zu Max Reich nach UAG, Kur. PA Reich, Max; UAG, Rek. PA Reich, Max. Das Zitat stammt aus einem undatierten Zeitungsartikel von Georg Joos, ebenda.

179 Dekan Correns an Ministerium, 27. Januar 1941. UAG, Rek. PA Reich, Max.
} 
nicht zur Wiederbesetzung verfügbar. Die Fakultät bat aufs Dringendste, diesen Zustand zu ändern, da es sich „dabei um eine Maßnahme der Systemzeit“ handele. Das Institut habe seine Wichtigkeit für den Krieg unter Beweis gestellt, und es „,würde deshalb in der heutigen Zeit nicht verstanden werden, wenn ein derartiges Institut und ein solcher Lehrstuhl eingehen müßten. Die pazifistische Einstellung einer Systemregierung kann unmöglich jetzt noch als maßgebend angesehen werden." 180 Diese dick aufgetragene Rhetorik war vermutlich gar nicht nötig, auf alle Fälle war sie erfolgreich. Das Ministerium unterstützte das Institut, aber noch musste man eine Übergangslösung finden, denn erst für das folgende Haushaltsjahr, das heißt ab April 1942, konnte wieder eine außerordentliche Professur für angewandte Elektrizität eingerichtet werden. Da bot es sich an, dass durch die Berufung von Drescher-Kaden nach Straßburg eine ordentliche Professur in Göttingen frei geworden war, aus der Zahn vorübergehend bezahlt wurde. Die Berufung Zahns verlief schnell und unkompliziert. Ein Grund dafür war auch, dass Zahn im Ministerium einen guten Ruf genoss. Der mit dieser Berufung befasste Ministerialbeamte Führer schrieb im Juni 1941: „Ich schätze Prof. Zahn sowohl als Lehrer als auch als Physiker und würde mich sehr freuen, wenn es [...] gelänge, Herrn Professor Zahn für den noch verbleibenden Rest seines akademischen Wirkens die wohlverdiente Stellung zu geben.“181

Innerhalb der Fakultät ging die Initiative zur Berufung Zahns wahrscheinlich von Pohl aus. Vier Tage nach Reichs Tod begründete Pohl gegenüber dem Rektor, warum Zahn als einzig „allseitig befriedigende Lösung“ in Frage kam. Er nannte das „erhebliche Interesse“ an Zahn im Ministerium; Zahn habe große Erfahrungen auf Reichs Arbeitsgebiet und seine Persönlichkeit hätte in vielem Ähnlichkeit mit der von Reich. Zur Persönlichkeit Zahns zählte wohl auch die Tatsache, dass er Professorensohn war, dass er mit Milly Freiin Gedult von Jungenfeld eine Ehe schloss, und dass er durch zwei Schmisse seine frühere Zugehörigkeit zu Männerbünden offen zur Schau trug. Dies erwähnte Pohl nicht, dafür aber, dass er Zahn aus der gemeinsamen Assistentenzeit in Berlin kannte. Zahn war also Teil von Pohls kollegialem Netz und in persönlicher Hinsicht in Göttingen willkommen. Joos und Becker schlossen sich Pohls Ausführungen ,in jeder Hinsicht““ an. ${ }^{182}$ Aber auch im Fachlichen entsprach Zahn den Göttinger Ansprüchen. Zahn war bis 1907 Assistent von Drude in Gießen und Berlin, anschließend bei Röntgen in München. 1908 habilitierte er sich in Kiel und wurde Assistent von Diderici. Dort hielt er Vorlesungen über die Entwicklungen der neueren theoretischen

\footnotetext{
${ }^{180}$ Dekan an Ministerium, 10. Juni 1941. Nur der Entwurf dieses Schreibens befindet sich in den Akten. GPAMNFG, Lehrkörper (ausgeschieden), Reich.

${ }^{181}$ Ministerium (Führer) an Rektor, 5. Juni 1941. UAG, Rek. PA Zahn.
} 
Physik, so zum Beispiel über elektromagnetische Lichttheorie. Daneben hielt er experimentelle Vorlesungen, zum Beispiel Wirbelstromlehre mit Experimenten. Zahn war kein Spezialist im negativen Sinn, sondern ein Physiker mit einer breiten fachlichen Ausrichtung. ${ }^{183}$ Im ersten Weltkrieg war er mit wissenschaftlich-technischen Prüfungsaufgaben an der Kieler Werft beschäftigt, später bei der Feldartillerie und der Nachrichtentruppe im Heeresdienst. Seine wissenschaftlichen Arbeiten in der Weimarer Zeit behandelten vor allem Fragen der Dielektrizitätskonstante, des Halleffektes und der Hochfrequenzleitfähigkeit. 1922 wurde er immer noch in Kiel zum nicht beamteten außerordentlichen Professor ernannt; ab 1929 übernahm er nach Geigers Weggang nach Tübingen die Lehrstuhlvertretung für zwei Jahre bis er 1933 selbst zum Ordinarius nach Ankara berufen wurde, wo er ein eigenes physikalisches Institut leitete. Der Beginn des Zweiten Weltkrieges beendete seine Zeit in der Türkei. Zuerst fand er als Gast in der PTR in Berlin eine Tätigkeit, doch ab Dezember 1940 war er in München nur noch privat wissenschaftlich tätig. Es bestand daher ein Bedürfnis, ihm eine Stelle zu verschaffen. ${ }^{184}$

Eine weitere wichtige Eigenschaft von Zahn, die zu seiner Berufung nach Göttingen führte, war sein damaliges Alter. Zum Zeitpunkt der Berufungsverhandlungen war er bereits 64 Jahre alt, sodass die Fakultät nach dem erwarteten Kriegsende, egal ob es bis dahin noch ein oder vier Jahre dauern möge, die Möglichkeit der Neubesetzung hatte. Pohl nannte dies explizit als einen von Zahns Vorzügen. 1941 hatte die Fakultät nur beschränkte Auswahl an geeigneten Fachmännern der technischen Physik, da die meisten in Industrie oder Universität mit kriegswichtigen Forschungen belegt und für Göttingen nicht verfügbar waren. Dieser Zustand würde nach Kriegsende erwartungsgemäß wegfallen. In diesem Sinne war die Berufung Zahns ein vor allem taktisches Manöver, das der Fakultät alle Möglichkeiten für die Zukunft offen halten sollte.

Am 19. Juli 1941 konnte Zahn endlich ,die laufenden Institutsgeschäfte - einschliesslich derjenigen, die aus einem Vertrag zwischen dem Institut und der Marineverwaltung herrühren -, die Akten, sowie die unter Verschluss gehaltenen Schriftstücke und Gegenstände“" vom mit der Verwaltung beauftragten Assistenten Ruprecht übernehmen. ${ }^{185}$ Formell war Zahn noch außerplanmäßiger Professor an der Universität Kiel und dort beurlaubt. Erst mit Wirkung

\footnotetext{
182 Pohl an Rektor, 24. Januar 1941. GPAMNFG, Lehrkörper (ausgeschieden), Reich.

183 Geiger urteilte über Zahn in einem Schreiben an den Kieler Kurator, 24. Mai 1928: „Seiner grossen Tatkraft und seinem regen Verständnis für die modernen Fragen der Physik ist es zu danken, daß nach meiner Berufung nach Kiel die Übungen in kurzer Zeit in modernem Geiste umgestellt werden konnten." UAG, Kur. PA Zahn. 184 Angaben nach UAG, Kur. PA Zahn; UAG, Rek. PA Zahn..

185 Aktenvermerk des Kurators, 19. Juli 1941. UAG, Kur. PA Zahn.
} 
vom 1. Januar 1942 wurde er zum außerordentlichen Professor in Göttingen ernannt und zum Direktor des Instituts bestellt. Von Rektor Hans Plischke wurde er wenig später als geeigneter Redner im Landkreis Göttingen genannt, der vor allem „technopolitische Vorträge über Fragen aus dem Gebiet der Elektrotechnik“ halten könne. ${ }^{186}$

Wie gezeigt spielten auch bei der Berufung Zahns die drei Beurteilungskriterien Wissenschaftlichkeit, Persönlichkeit und politische Haltung eine Rolle. Die wissenschaftliche Ausrichtung und Qualität entsprach den Göttinger Anforderungen. Eine persönliche Verbindung existierte zu Pohl; Zahn war eingegliedert in Pohls kollegialem Netz. In politischer Hinsicht gab es weder von Staatsseite noch von der Fakultät oder dem Dozentenbund Einwände. Die Schwierigkeiten, in Kriegszeiten überhaupt einen verfügbaren und geeigneten Kandidaten für den Göttinger Lehrstuhl $\mathrm{zu}$ finden, wirkten sich letztlich beschleunigend auf das Berufungsverfahren aus. Alle waren mit Zahn einverstanden. Etwa zur gleichen Zeit als Zahn nach Göttingen kam verließ ein anderer Physikordinarius die kleine Universitätsstadt.

\subsubsection{Joos' Verzicht auf seinen Lehrstuhl und die folgende Nachbesetzung}

Obwohl die Fakultät wie auch Joos selbst seine Berufung nach Göttingen nur widerwillig akzeptiert hatten, konnte er sich dort gut einleben und eine erfolgreiche Forschungs- und Lehrtätigkeit entfalten. $\mathrm{Zu}$ wissenschaftlicher Zusammenarbeit kam es vor allem mit dem Mathematiker Kaluza und dem Physikochemiker Eucken. ${ }^{187}$ Es ist daher etwas überraschend, dass Joos 1941 ein Jahr Urlaub nahm und zu Zeiss nach Jena wechselte. Der Grund dafür liegt in Joos' Teilnahme an der Auseinandersetzung innerhalb der Physikerschaft um die Geltung der modernen theoretischen Physik.

Im November 1940 fand in München ein Streitgespräch zwischen einer Gruppe allgemein anerkannter Hochschulphysiker und Vertretern der „Deutschen Physik“ statt. Joos verteidigte neben Weizsäcker, Scherzer, Heckmann und Kopfermann die moderne theoretische Physik. ${ }^{188}$

\footnotetext{
186 Dies geht aus einem Schreiben des Kreisamtsleiters Dr. Ambronn hervor. Neben Zahn wurden von Plischke auch Carl Correns, Max Schuler und Günther Rienäcker genannt. Ambronn selbst wies noch besonders auf Georg Joos hin, der ,auf der Plassenburg einen ausgezeichneten Vortrag über moderne physikalische Forschung gehalten" hatte, aber wieder nach Jena zurückgekehrt war. Undatiertes Schreiben von Ambronn (aus der Rektoratszeit Plischkes: 14. November 1941 bis 30. September 1943), BAB, BDC, WI, Zahn, Hermann. 187 Zeugnis dafür sind die gemeinsam erarbeiteten Lehrbücher Joos \& Kaluza [1938] und Eucken [1932], dessen 1. und 2. Auflage (1938) in Zusammenarbeit mit Georg Joos entstand.

188 Initiiert wurde die Zusammenkunft in München 1940 von dem Dozentenbundführer Wolfgang Finkelnburg. Die Leitung hatte der Arzt Gustav Borger. Herbert Stuart und Johannes Malsch waren Beisitzer. Die „Deutschen Physiker" waren vertreten durch Alfons Bühl, Wilhelm Müller, Rudolf Tomaschek, Bruno Thüring, Harald Volkmann und Ludwig Wesch. Ihre Kontrahenten waren außer Finkelnburg, Hans Kopfermann (Exp.-Physiker,
} 
Das Ergebnis war, dass sich die Vertreter der modernen theoretischen Physik durchsetzen und eine Aufladung der Physik mit rassistischen Wertungen verhindern konnten. Nun schätzte Joos die aus dieser Teilnahme erwachsene politische Gefahr für ihn höher ein, als es die anderen aus seiner Gruppe taten. ${ }^{189}$ Er war der einzige von ihnen, der deshalb auf die Universitätslaufbahn verzichtete und in die Industrie wechselte. Was ihm Sorgen bereitete, war sein konsequenter Einsatz für die vorrangige Berücksichtigung von fachlichen Belangen in Stellenbesetzungen. In einem Schreiben an den Dekan in Straßburg kommt eines seiner Prinzipien zum Ausdruck: „In der Physik schätze ich aber nur restlos klare Köpfe.“190 Er vertraute nicht sehr darauf, dass sich sein Engagement mit Staatsinteressen zur Deckung bringen ließe, indem er die Physik in den Dienst des Krieges stellen wollte und dabei auf den höchsten Wirkungsgrad bedacht war. ${ }^{191}$ Er fürchtete einen Konflikt, weil er seine Prinzipien auch auf Physiker anwandte, die Unterstützung von Parteiinstanzen erhielten. Deshalb bat er im Dezember 1940 um einen einjährigen unbezahlten Urlaub beginnend mit 1. April 1941. Im Februar 1941 wurde der Urlaub bewilligt. Auf seinen Antrag wurde Joos mit Ablauf des Monats März 1942 aus dem Staatsdienst entlassen. ${ }^{192}$

Bevor sein Urlaubsgesuch genehmigt worden war, erreichte ihn ein Angebot auf eine Professur an der Universität Straßburg. Joos hätte vermutlich selbst dann Göttingen verlassen, wenn sein Wechsel in die Industrie vom Ministerium nicht genehmigt worden wäre. Im Februar 1941 schrieb er an die Geschäftsführung von Zeiss: „Für den Fall dass mich das Erziehungsministerium doch nicht hätte gehen lassen, hätte mich die Aufgabe, in Strassburg aus dem Nichts ein neues Institut aufzubauen, trotz der guten Arbeitsverhältnisse in Göttingen gelockt." ${ }^{193}$ Er war dann aber ganz froh, dass er das Angebot von Zeiss annehmen konnte. Dort wurde er als Chefphysiker angestellt, konnte nach zwei Jahren in die Geschäftsleitung eintreten und bekam ein eigenes Forschungslabor, das ganz nach seinen Wünschen

Kiel), Otto Scherzer (Theoretiker, TH Darmstadt), Carl Friedrich Weizsäcker (Theoretiker, KWI Berlin), Georg Joos (Exp.-Physiker, Göttingen) sowie Otto Heckmann (Astronom, Göttingen). Zur Vorgeschichte und zum Kontext der Auseinandersetzung siehe Richter [1980] S. 127f.; Beyerchen [1980/82] S. 238-241; Hentschel \& Hentschel [1996] Kap. 5.3; Litten [2000] Kap. 3.1 und Schlüpmann [http] Kap. „Instrumentalisierung der Physiker".

${ }^{189}$ Siehe knapp Beyercher [1980/82] S. 235. Dieser Punkt ist deutlicher herausgearbeitet bei Stutz \& Lemuth [im Erscheinen]. Joos ging von einer längerfristigen Auseinandersetzung aus, die keineswegs ungefährlich sei. Das Studium der Joos betreffenden Akten lässt den Eindruck entstehen, dass er ein leicht verletzlicher Mensch war, der auf politischen Druck sensibler als andere reagierte. Sein Kollege Walther Meißner schrieb ihm ein sanguinisches Temperament zu. Meißner [1954] S. 193.

190 Joos an den Dekan der naturwissenschaftlichen Fakultät der Universität Straßburg, Niemeier, 3. Juli 1941. BACZ, 22768.

${ }^{191}$ Dazu überzeugend Stutz \& Lemuth [im Erscheinen].

192 Joos an Dekan, 31. Dezember 1940. Die Bewilligung erfolgte am 3. Februar 1941. Die Entlassung zum 31. März 1942 wurde am 22. April 1942 ausgesprochen. UAG, Kur. PA Joos. 
eingerichtet wurde. ${ }^{194}$ Die Bezeichnung „Chefphysiker“ war ihm sehr wichtig, denn „es muss aber hier etwas darauf bedacht genommen werden, dass ich meine Professur nicht wegen einer $\mathrm{x}$-beliebigen Industrie-Stelle aufgebe. Die Göttinger Verhältnisse machen dies notwendig." 195 Im Juni 1942 wurde er außerdem an der Universität Jena zum Honorarprofessor ernannt, sodass er in Spezialvorlesungen zur Atomphysik den Kontakt zu Studenten wieder erhielt. 196

Der Urlaubsstatus hielt ihm eine Rückkehr nach Göttingen offen. Doch schon recht bald entschied er sich endgültig für Zeiss, wo er sich mit einem großen Mitarbeiterstab ganz der Forschung widmen konnte. ${ }^{197}$ Im Mai 1941 teilte er mit: „Meine neue Tätigkeit gefällt mir ausgezeichnet. Ich habe das Gefühl 25 Jahre nur gelernt zu haben und jetzt das erlernte sehr nützlich anwenden zu können. Ich komme tatsächlich auf allen Gebieten der Physik herum. " 198 Diese Gebiete besaßen selbstverständlich militärische Bedeutung, aber das war es eben, was Joos suchte. „Wir geben uns hier die grösste Mühe die besten Flak-Geräte zu konstruieren“, schrieb er zur selben Zeit an den Kieler Astronom Unsöld. ${ }^{199}$ Er bat die Firmenleitung darum, ihm eine uk-Stellung zu besorgen, weil er in der Forschung den Kriegsanstrengungen am effektivsten dienen konnte. „An sich würde ich gerne einmal wieder Soldat sein. Da aber die alten Offiziere doch allmählich aus der Front gezogen werden, würde ich wahrscheinlich wieder Rekruten ausbilden oder irgendwo eine Etappenkommandantur erhalten und da würde ich wohl bei Zeiss mich doch nützlicher machen können."200

Joos beteiligte sich selbst an der Suche nach einem geeigneten Nachfolger für ihn in Göttingen. Sein Favorit war Josef Mattauch. Dieser wurde jedoch von Pohl abgelehnt, nachdem Mattauch in Göttingen einen Vortrag gehalten hatte, der laut Joos inhaltlich ausgezeichnet, jedoch „redetechnisch wenig gelungen“ gewesen sei. Pohl sah darin eine laxe

193 Joos an Professor Bauersfeld, Geschäftsleiter der Firma Carl Zeiss, 9. Februar 1941. BACZ, PA 2105.

194 Bauersfeld, Geschäftsleiter der Firma Carl Zeiss, 21. Dezember 1940. BACZ, PA 2105.

195 Joos an Dr. Ing. Kotthaus, Geschäftsleiter der Firma Carl Zeiss, 5.12.1940. BACZ, PA 2105.

196 Die Ernennung zum Honorarprofessor nahm ein ganzes Jahr in Anspruch. Im Mai 1941 drängte der Ministerialrat Stier vom Thüringischen Ministerium für Volksbildung den Jenaer Rektor Astel, eine Honorarprofessur für Joos zu beantragen. Erst im Dezember 1941 wurde ein solcher ans REM geleitet, und dort dauerte die Ernennung bis zum 4. Juni 1942. UAJ, BA, 2163. Joos' Vorlesungen in Jena umfassten laut Vorlesungsverzeichnis folgende Themen: Elektronenoptik (WS 1942/43), Theorie der Spektren (SS 1943), Der Bau der Atomkerne (WS 1943/44), Die elektromagnetischen und optischen Eigenschaften der Stoffe im Zusammenhang mit dem Atombau (SS 1944).

197 Das geht aus der chronologisch sortierten Korrespondenz von Joos von 1941 bis 1944 deutlich hervor. BACZ, 22768.

198 Joos an Hasse, 12. Mai 1941. BACZ, 22768.

199 Joos an Unsöld, 18. Mai 1942. Am 23. Februar 1942 schrieb Joos an seinen Freund Hanle: „Tatsächlich kann man mich im jetzigen Augenblick nicht entbehren, aber ich hätte nichts dagegen, wenn ich zur Abwechslung Batterieführer wäre, vielleicht in der Nachbarbatterie meines Sohns!“ BACZ, 22768. 
Pflichtauffassung, obwohl Mattauch Joos versicherte, dass er sich lange auf den Vortrag vorbereitet hatte. Für Pohl kam Mattauch deswegen nicht mehr in Frage. ${ }^{201}$

Der Dreiervorschlag, den die Fakultät dann zur Wiederbesetzung einreichte, weist große Ähnlichkeit mit jenem des Jahres 1934 auf. An erster Stelle stand wieder Walter Bothe (Heidelberg), gefolgt von Paul Scherrer (Zürich) und Hans Kopfermann (Kiel). Die Fakultät rechtfertigte sich für die Aufstellung dieser Liste, indem sie so etwas wie eine 'Entstehungsgeschichte' der Berufungsliste darlegte. Sehr sorgfältig wurden von der Kommission die überhaupt in Frage kommenden Herren geprüft. Einige mussten aus Altersgründen ausscheiden, da die Fakultät immer noch der Meinung war, der zu Berufende müsste sich im Alter von Pohl unterscheiden, um eine gleichzeitige Vakanz zu vermeiden. Dieses Argument ist nicht sehr überzeugend, denn die tatsächliche Entwicklung führte 1952/53 zu einer doppelten Vakanz, obwohl ein jüngerer Kollege berufen worden war. Als Pohl emeritierte, wechselte der jüngere nämlich nach Heidelberg. Es wurden aber noch weitere Kandidaten ausgeschieden: „Bei anderen Herren hätte ein sachliches oder persönliches [sic] Kompromiß geschlossen werden müssen, weil zwar gute wissenschaftliche Leistungen vorhanden, aber eine gewissenhafte Auffassung der Unterrichtspflichten nicht unbedingt gesichert erschien oder weil persönliche Eigenschaften ein gedeihliches Zusammenarbeiten mit den übrigen Fachvertretern nicht erwarten ließen. “202 Im Protokoll der Kommissionssitzung werden die Namen dieser Physiker mitgeteilt, die aus den eben genannten Gründen ausscheiden mussten: Mattauch, Schüler, Kossel und Kirchner. Teilgenommen an der Sitzung hatten der Rektor Plischke, Dekan Correns und die Professoren Drexler, Zahn, Kaluza, Eucken, Pohl, Becker, Prandtl und Joos. ${ }^{203}$ Diese Professoren teilten also unumwunden dem Ministerium mit, dass wissenschaftliche Leistungen alleine nicht ausreichen, dass neben der Froschung die Lehre ernst genommen werden müsse und auch die persönlichen Eigenschaften stimmen müssten. Bei den drei in der Liste Genannten waren sie sich einig, dass alle Forderungen erfüllt und keine Kompromisse nötig gewesen wären.

\footnotetext{
200 Joos an Bauersfeld, 9. Februar 1941. BACZ, PA 2105.

201 Joos an den Dekan der naturwissenschaftlichen Fakultät der Universität Straßburg, Niemeier, 24. Februar 1942. BACZ, 22768.

202 Dekan Correns an Ministerium, (betrifft: Planmäßige Professur für Experimentalphysik), 27. Januar 1942. UAG, Rek. PA Joos.

203 Protokoll der Kommissionssitzung zur Nachfolge Joos vom 17. Januar 1942. GPAMNFG, Protokollbuch III der mathematisch-naturwissenschaftlichen Fakultät WS 1927/28 - SS 1946. Der Mathematiker Hasse, der am 2. Dezember 1941 gegenüber dem Rektor Plischke sein lebhaftestes Interesse an der Nachfolge Joos bekundete und an der Beratung mitwirken wollte, weil davon abhinge, ob ,zwischen den Mathematikern und Physikern eine wirkliche Harmonie hergestellt“ werden könne, konnte offensichtlich nicht teilnehmen. Möglicherweise teilte er Plischke seine Wünsche mit, der sie in die Kommission für ihn einbrachte. UAG, Rek. PA Joos.
} 
Dieser Vorspann vor den eigentlichen Würdigungen der Kandidaten könnte als Abwehr gegen potentielle Eingriffe anderer Instanzen gedacht gewesen sein. Neben der überraschend offenen Argumentation, die präventiv eine Reihe von Kriterien zur Ablehnung anderer möglicher Kandidaten bereit legte, zeigt die Liste keine Zugeständnisse an die damalige politische Lage, insbesondere nicht an den Kriegszustand. Von keinem der Genannten wurde behauptet, er könne die deutschen Kriegsanstrengungen auf physikalischem Gebiet wirkungsvoll unterstützen. Im Gegenteil wurde zum Beispiel hervorgehoben, dass Kopfermanns besonderes Geschick in der Förderung der Studenten gerade in der Nachkriegszeit wichtig sein werde.

Die Fakultät blieb ihren alten Prinzipien treu und versuchte unbeirrt, den besten Physiker für Göttingen zu gewinnen. Dies war ihrer Meinung nach immer noch Bothe, nur dass im Vergleich zum ersten Berufungsversuch von 1934 ein weiterer Vorteil für ihn sprach. Bothe war von Herrn Voegler von der Helmholtz-Gesellschaft ein Zyklotron für sein Heidelberger KWI Institut zugesagt worden, und die Göttinger hofften, mit Bothe auch das noch nicht existierende Zyklotron nach Göttingen holen zu können. Damit würde Göttingen sowohl an Reputation wie an erstklassiger Forschungsausstattung einen großen Gewinn erzielen. Zusätzlich, so versicherte die Fakultät, würde Bothe seine Unterrichtspflichten sehr ernst nehmen;204 in Heidelberg zeigte er ein besonderes Interesse am Praktikum. Bothe sei also in jeder Hinsicht die beste Wahl. ${ }^{205}$ Zuletzt ermahnte die Fakultät das Ministerium, „bewährte Universitäten im Wettbewerb um die ersten Köpfe der Wissenschaft gegenüber den Forschungsinstituten nicht zu benachteiligen.“"206

An zweiter Stelle wurde wie 1934 jemand genannt, der der Fakultät schwer erreichbar schien. Paul Scherrer war Schweizer Staatsbürger, und die Fakultät war sich völlig im Klaren, „daß die derzeitige politische Lage die Verwirklichung dieses Vorschlages nicht zulassen wird.“ Dank Scherrers ungewöhnlicher Experimentierkunst konnte er in den schwierigsten Gebieten, um die sich zuvor andere vergeblich bemüht hatten, ,saubere Verhältnisse“ schaffen. In der Würdigung Scherrers Qualitäten finden sich Hinweise darauf, was die Fakultät unter „persönlichen Eigenschaften“ möglicherweise verstand. „Scherrer ist ein besonders kräftiger Mann mit einer Begeisterung für wissenschaftliche Arbeit, die nicht nur auf den Nachwuchs,

\footnotetext{
204 Siehe dazu bestätigend Maier-Leibnitz [1991]a S. 64.

205 Die guten Beziehungen zwischen Pohl und Bothe wirkten sich nicht nur in den Göttinger Berufungslisten aus. Auch Pohl profitierte davon, als ihn Bothe für den Nobelpreis für das Jahr 1953 vorschlug. Diesen erhielt aber der holländische Physiker Frits Zernike für die Entwicklung des Phasenkontrastmikroskops. MPG-Archiv, III, $6,125,60$.
} 
sondern auch auf die Kollegen packend wirkt. Er versteht es wie wenige, die Studierenden durch seinen wissenschaftlichen Schwung mitzureißen." Es lag offenbar an diesen Eigenschaften, warum Scherrer auf die Liste gesetzt wurde, denn die Fakultät fuhr fort: „Eine so ausgeprägte Persönlichkeit darf nach unserer Ansicht nicht auf einer physikalischen Liste für Göttingen fehlen."207 Wieso war sich die Kommission einig, einen Schweizer in Kriegszeiten auf die Liste zu setzen? War es eine Trotzreaktion, mit der die Fakultät an ein altes Wissenschaftsideal erinnern wollte, demzufolge nur die wissenschaftliche Größe und nicht die Herkunft zähle?208 Es war eine mutige, wenn auch folgenlose Entscheidung, Scherrer zu nennen. Der Rektor hielt die Sache für so aussichtslos, dass er nicht einmal ein Gutachten des Dozentenbundes einforderte. Stattdessen setzte er sich besonders dafür ein, dass Bothe nach Göttingen berufen würde. ${ }^{209}$

Die Beschreibung des drittgenannten Kopfermann ist sehr sachlich gehalten. Als Schüler von Franck in Göttingen wurde er mit dem Gebiet der Spektroskopie vertraut, in dem er später beachtenswerte Erfolge erzielte. Seine Forschungsergebnisse hatte Kopfermann erst kurz zuvor in seinem Buch Kernmomente zusammengefasst. Für sein Arbeitsgebiet waren die Hilfsmittel des Zweiten Physikalischen Instituts besonders geeignet. Auch wenn es die Fakultät nicht aussprach, so wurde doch mit einer gewissen Tradition argumentiert. Kopfermann würde an seine eigene Ausbildungsstätte nach Göttingen zurückkommen und ein bei Franck begonnenes Forschungsprogramm fortführen können. Seine besonderen Unterrichtsqualitäten waren ein weiterer Pluspunkt für ihn.

In Vertretung des Dozentenbundführers sprach sich Drexler, der schon in der Kommissionssitzung der Liste zugestimmt hatte, an erster Stelle für die Berufung Bothes und an zweiter für die Kopfermanns aus. ${ }^{210}$ In gleicher Weise äußerte sich Rektor Plischke, der der Kommission ebenfalls angehört hatte. Er kam zu der Überzeugung, „dass diese Liste in der Tat Experimentalphysiker nennt, die den besonders verantwortungsvollen Aufgaben der Mathematisch-Naturwissenschaftlichen Fakultät unserer Hochschule gerecht werden.“ Er gewann aus den Fakultätsbesprechungen auch den Eindruck, „dass sich sowohl Professor

\footnotetext{
206 Dekan Correns an Ministerium, (Anlage 1 zum Vorschlag der Fakultät betr. Nachfolge Joos), 27. Januar 1942. UAG, Rek. PA Joos.

207 Dekan Correns an Ministerium, (Anlage 2 zum Vorschlag der Fakultät betr. Nachfolge Joos), 27. Januar 1942. UAG, Rek. PA Joos.

$208 \mathrm{Zu}$ Scherrer und seiner Funktion als Informant des amerikanischen Geheimdienstes während des Kriegs siehe Powers [1993] bes. Kapitel 25.

209 Rektor Plischke an Ministerium, 31. Januar 1942. Der Kurator schloss sich in einem Schreiben an das REM, 31. Januar 1942, Plischkes Auffassung über die Nennung Scherrers an. UAG, Rek. PA Joos.

210 Dozentenbund (Drexler) an Rektor, 2. März 1942. UAG, Rek. PA Joos.
} 
Dr. Bothe wie Professor Dr. Kopfermann gut in den weitverzweigten Lehr- und Forschungsbetrieb der Mathematisch-Naturwissenschaftlichen Fakultät, ebenso aber auch in die Verwaltungsarbeit der Physikalischen Institute gut und reibungslos eingliedern werden." 211

Durch die Einbindung der Universitätsinstanzen Rektor und Dozentenbund in die Beratungen zur Nachfolge konnte eine gewichtige Einigkeit erzielt werden. Das Ministerium konnte schwerlich gegen den Willen des von ihm eingesetzten Rektors und gegen Dekan und Dozentenbund entscheiden. Der favorisierte Bothe konnte allerdings nicht für Göttingen gewonnen werden, wobei die Gründe dafür aus den herangezogenen Akten leider nicht zu entnehmen sind. Die Wahl fiel auf Kopfermann, der am 1. Mai 1942 den Göttinger Lehrstuhl übernahm.

Worin liegen die Gründe, dass sich die verschiedenen Instanzen auf Kopfermann einigen konnten? Manches erklärt sich aus der Biografie Kopfermanns. Klaus Schlüpmann hat sein Buchprojekt über Kopfermann im internet zugänglich gemacht, wovon ich im Folgenden Gebrauch machen werde. ${ }^{212}$ Kopfermann wurde 1895 geboren und von seinem Vater, der Pfarrer war, autoritär erzogen. 1913 bestand er das Abitur an einem Realgymnasium. Als der Erste Weltkrieg begann, meldete sich der 19-Jährige freiwillig zur Front, wo er Schreckliches durchlebte. Viele kameradschaftliche Freundschaften wuchsen in Extremsituationen und endeten traumatisch. Oft war er dem eigenen Sterben nahe. Er verweigerte sich aber nicht einer militärischen Karriere, wurde Offizier und Stabsoffizier. Nach dem Krieg beteiligte er sich wieder an gewalttätigen Kämpfen, diesmal als Korpskämpfer in München an der Seite Franz Epps gegen die Räterepublik. Es war Mitte 1919, als er nach all den Kämpfen nach Göttingen kam und in der Musik seine Zuflucht fand. Die Aufführungen der Göttinger Händelfestspiele waren Höhepunkte für ihn. Er selbst meinte später, dass die Musik ihn von den traumatischen Kriegserlebnissen geheilt hätte. Von militärischen Traditionsverbänden und verkrampften nationalen Gefühlen hatte er genug. Er schloss sich auch keiner Burschenschaft an, was nach seinem bisherigen Lebensweg erstaunt. Richard Courant, Max Born und James Franck wurden seine akademischen Lehrer. Nach dem Staatsexamen fürs Lehramt wurde er Francks erster Doktorand. Das Studium wurde vom Vater finanziert. Nach dem Tod des Vaters sorgte ein Notgemeinschaftsstipendium für den Unterhalt. 1923 schloss er die Promotion mit einer Arbeit über sensibilisierte Fluoreszenz von Blei- und Wismutdampf ab.

\footnotetext{
${ }^{211}$ Rektor Plischke an Ministerium, 31. Januar 1942. UAG, Rek. PA Joos.

212 Siehe http://www.aleph99.org/etusci/ks/. 
Nach der Promotion wechselte er ins Kaiser-Wilhelm-Institut für physikalische Chemie in Berlin-Dahlem, wo er Assistent von Rudolf Ladenburg wurde. 1925 heiratete er Hertha Schwertfeger, die drei Jahre später bei Max Wertheimer mit einer wahrnehmungspsychologischen Arbeit promovierte. In einer Festschrift für Fritz Haber publizierte Kopfermann zusammen mit Ladenburg 1928 einen Nachweis der negativen Dispersion an Linien elektrisch angeregten Neons. Die Anzahl der Atome in dem für jede Linie verschiedenen oberen Zustand konnte angegeben werden und damit die quantentheoretische Dispersionsformel von Ladenburg und Kramers bestätigt werden. Kopfermann machte sich auch mit seinen folgenden Arbeiten zur anormalen Dispersion angeregter Gase einen Namen in der Fachwelt. 1930 wandte er sich dem aktuellen Gebiet der Hyperfeinstruktur-Spektroskopie zu. Ein Jahr später gelang ihm parallel zu Schüler und Keystone die Entdeckung der Isotopieverschiebung in der Hyperfeinstruktur. Mit dieser Arbeit habilitierte er sich 1932 an der Berliner Universität. Anschließend ging er für acht Monate als Rockefeller-Stipendiat nach Kopenhagen, wo er mit seiner neuen Experimentiertechnik ein willkommener Gast war, gerade weil sich das Bohr'sche Institut auf die theoretischen Fragen der Kernphysik konzentrierte.

Kopfermann schlug den Weg einer Universitätslaufbahn ein, doch war er im Jahr 1933 mit seinen 38 Jahren dafür schon relativ alt. Seit 1932 war er Privatdozent an der Universität in Berlin. 1934 bekam er die Oberassistentenstelle an der TH Charlottenburg, die durch die Vertreibung von Fritz Houtermans frei geworden war. Im Jahr 1934 trat er dem Nationalsozialistischen Lehrerbund (NSLB) bei. Anfang 1937 wurde er nicht beamteter außerordentlicher Professor an der TH Berlin-Charlottenburg. Im Zusammenhang damit steht vielleicht auch sein im selben Jahr erfolgter Beitritt zur NSV. In diesem Jahr kam er auch für zwei Lehrstühle in Leipzig und in Frankfurt zum Vorschlag.

Im April 1937 wurde er vom REM ersucht, die Vertretung der frei gewordenen Professur für Experimentalphysik und die damit verbundene Institutsleitung an der Universität Kiel wahrzunehmen. Bis 1937 hatte dort Heinrich Rausch von Traubenberg die Professur inne, und sein Ausscheiden war keineswegs freiwillig. Durch die Ehe mit einer 'Jüdin` (nach NSDefinition) geriet er unter Druck, was dazu führte, dass er 1937 entpflichtet wurde. Er starb 1944, unmittelbar nachdem er seine von der Gestapo angeforderte Frau zur Eisenbahn gebracht hatte, an einem Herzschlag. Zum zweiten Mal war Kopfermanns Karriereschritt die Vertreibung eines Kollegen vorausgegangen. In Kiel wurde Kopfermann 1938 zum 
Vorsitzenden des Gauvereins Niedersachsen der DPG gewählt. Dieses Amt behielt er bis zum Kriegsende. ${ }^{213}$

1941 wurde er vom Kieler Rektor zum Dekan ernannt und zum Eintritt in die Partei aufgefordert. Widerwillig gab er dem Drängen nach. Sein Ansuchen um Parteimitgliedschaft wurde vom Kieler Dozentenbund, der „Kopfermann in seiner ganzen Haltung jahrelang [...] beobachten“"konnte, wärmstens befürwortet.

„Es muss festgestellt werden, dass K. alle Bedingungen bestens erfüllt, die an einen einsatzbereiten Parteigenossen gestellt werden müssen. In dieser Erkenntnis ist auch Prof. Kopfermann zum Dekan der Philosophischen Fakultät ernannt worden, obwohl er nicht Parteigenosse war. Es kommt das nur in einigen wenigen Ausnahmefällen vor, in denen alle beteiligten Stellen der Ueberzeugung sind, dass der Betreffende als ebenso zuverlässig wie ein Parteigenosse zu beurteilen ist.“214

An dieser Stelle wurde auch erwähnt, dass Kopfermann im Ersten Weltkrieg das EK I und II erworben hatte und nach dem Krieg Freikorps-Kämpfer gewesen war. Dies wurde als rückhaltloser politischer und menschlicher Einsatz gewertet. Am 1. September 1941 wurde er mit Mitgliedsnummer 8869553 Parteigenosse. Politisch ist Kopfermann stets positiv beurteilt worden. Die Göttinger Kreisleitung der NSDAP bekam im Sommer 1943 eine Anfrage der Gestapo wegen politischer Überprüfung Kopfermanns. Die Beurteilung fiel auch hier uneingeschränkt positiv aus. ${ }^{215}$

Kopfermann nahm auch an den Schlichtungsgesprächen zur Geltung der „Deutschen Physik“, die im Herbst 1940 in München stattfanden, als Vertreter der modernen Physik teil. ${ }^{216}$ Aus der Biografie Kopfermanns wird ersichtlich, wie er es geschafft hat, den verschiedenen Ansprüchen, die in der NS-Zeit an einen Hochschulphysiker gestellt wurden, gerecht zu werden. Sein Lebenslauf weicht an einzelnen Stellen von Musterverläufen ab. So besuchte er ein Realgymnasium und nicht ein humanistisches. ${ }^{217}$ In seiner Studienzeit schloss er sich keiner Studentenverbindung an. Er begann seine Karriere in einem außeruniversitären Institut und kam relativ spät als Dozent an die Hochschule. Er konnte in der NS-Zeit bis zum Ordinarius aufsteigen, ohne in die Partei einzutreten. Die politische Beurteilung seitens der Parteistellen fiel uneingeschränkt positiv aus, trotzdem er gegen die „Deutsche Physik“

\footnotetext{
213 DPG-Archiv, Nr. 40014.

214 Gaudozentenführer an Kreisleitung der NSDAP, Kiel, 17. Juni 1941. BAB, BDC, PK Kopfermann, Hans.

215 Ausgefüllter Fragebogen der Kreisleitung Göttingen, 3. Juli 1943. BAB, BDC, PK Kopfermann, Hans.

216 Siehe Fußnote 188.

217 Der Besuch eines humanistischen Gymnasiums wurde zum Beispiel von Walther Gerlach als Regelfall für Naturwissenschaftler beschrieben. Gerlach [1953] S. 3. Auch Eucken war der Auffassung, dass die meisten
} 
auftrat. Kopfermann war in der Verfolgung seiner Berufsziele ungemein geschickt. Als Physiker war er unter seinen Fachgenossen sehr geschätzt und als Kollege beliebt. Diese Beliebtheit wirkte sich auch nach Kriegsende positiv aus, als die Verbindung zum Ausland wieder hergestellt werden musste. Darauf wird später noch eingegangen werden.

\subsubsection{Personalentwicklung auf den unteren Ebenen}

Nachdem die Personalentwicklung auf der Ebene der Institutsdirektoren analysiert wurde, folgen nun die unteren Ebenen. Das Ziel dieser Untersuchung ist es, die Bedingungen der auf eine angestrebte Professur hinführenden Karriereschritte anzugeben, soweit dies aus den Quellen möglich ist. Anders gesagt lautet die Frage, welcher Art die Hindernisse waren, die im Erreichen einer Assistentenstelle, in der Zulassung zur Habilitation oder in der Erlangung des Privatdozentenstatus zu überwinden waren. Es wird hier keine vollständige Erfassung aller Assistenten und Privatdozenten angestrebt, sondern beispielhaft die Situation dieser Gruppe aufgezeigt.

Die Gliederung folgt dem in der Einleitung entworfenen Modell, demnach das Institut als kleinstes abgeschlossenes System gelten kann. Deshalb werden folgend die einzelnen Institute getrennt behandelt. Die in der Regel innerhalb eines Instituts erfolgten ersten Karriereschritte waren besonders durch den Institutsdirektor beeinflusst. Wenn er auch für Assistentenstellen Kandidaten frei vorschlagen konnte, so mischten in der tatsächlichen Besetzung doch auch andere Instanzen mit. Im April 1938 wurde im Fakultätsprotokoll festgehalten: „Assistentenstellen werden über den Dozentenbund vermittelt." 218 Der Kandidat musste also sowohl den Maßstäben des Professors genügen wie die politischen Hürden überwinden, um schließlich vom Ministerium die Stelle zugesprochen zu bekommen. Ähnlich sah es auf der nächsten Karrierestufe aus. Die Ernennung zum Dozenten war schon mit Erlass vom Oktober 1933 und später durch die Reichshabilitationsordnung vom Dezember 1934 an den Besuch von NS-Dozentenlagern gebunden. ${ }^{219}$ Zur Erlangung der Lehrerlaubnis musste zu dieser politischen Pflichtübung noch ein positives Urteil vom Dozentenbund hinzukommen.

Naturwissenschaftler durch den Besuch eines humanistischen Gymnasiums eine ,ausreichende Fühlung mit den Geisteswissenschaften“ gewonnen haben. Eucken [1939]b S. 140.

218 Protokoll vom 12. April 1938. GPAMNFG, Protokollbuch III der mathematisch-naturwissenschaftlichen Fakultät WS 1927/28 - SS 1946.

219 Zur Praxis des Göttinger Dozentenlagers siehe Dahms [1987/98] S. 50f. 


\subsubsection{Das I. Physikalische Institut}

Anhand der Karriere des Assistenten am I. Physikalischen Institut, Erich Mollwo, lassen sich die zeittypischen Einflüsse gut ablesen. Mollwo ist Jahrgang 1909; sein Großvater war der Göttinger Physikprofessor Woldemar Voigt. Mollwo war nach seiner Promotion im Jahr 1933 zuerst Hilfsassistent und seit 1934 planmäßiger Assistent von Pohl. Im März 1935 trat er dem NSLB bei. ${ }^{220} 1936$ und 1937 beteiligte er sich freiwillig an zwei achtwöchigen militärischen Übungen in Braunschweig und Hildesheim. 1937 reichte er die Arbeit „Über Elektronenersatzleitung und Halogenüberschuss in Alkalihalogenidkristallen“ zur Habilitation ein. ${ }^{221}$ In dem Gutachten Pohls wird die Bedeutung der Arbeit für die moderne Halbleitertechnik herausgestellt. Aber auch die Würdigung der Persönlichkeit Mollwos nimmt dort einen großen Raum ein. Er besitze eine bemerkenswerte Allgemeinbildung und beschäftige sich viel mit Musik. „Er hat von seinem Großvater Woldemar Voigt offenbar auch diese Begabung geerbt. Dr. Mollwo ist gesund und kräftig, immer guter Dinge und bei allen Institutsinsassen sehr beliebt.“ Wissenschaftlich und persönlich war Mollwo also bestens geeignet, außerdem herrschte damals ein Mangel an „wirklich tüchtigen physikalischen Privatdozenten“, sodass seine Habilitation sehr erwünscht war. ${ }^{222}$ Der Rektor urteilte, Mollwo habe ein „sicheres Auftreten von soldatischer Gradheit“ in der wissenschaftlichen Aussprache bewiesen. ${ }^{223}$

Im Sommer 1938 bekam er die Dozentur verliehen, hielt die öffentliche Lehrprobe „Über optische und elektrische Anisotropie von Kristallen“, nahm an einem vierwöchigen Gemeinschaftslager und Dozentenakademielehrgang in Tännich in Thüringen teil ${ }^{224}$ und leistete seine erste sechswöchige Reserveübung beim I.R. 82 in Göttingen ab. Zusätzlich wurde er auch „S.A. Mann beim Marine-Sturm 13/35“.225 Die Mitgliedschaft in der SA, die 1938 ihre einstige Bedeutung eingebüst hatte, könnte Mollwo als das geringere Übel zur Erlangung der Dozentur betrachtet haben. Als er im folgenden Sommer 1939 wieder eine Reserveübung beim I.R. 82 ableistete, fiel diese mit dem Kriegsbeginn zusammen. Bis Ende 1939 kam der Unteroffizier an die Front nach Polen, dann nach Westen und anschließend als Ausbilder auf einen Truppenübungsplatz. Ende März 1940 wurde er vom RLM nach Göttingen für einen

\footnotetext{
220 BAB, BDC, REM Mollwo.

221 Zur Vita Mollwo siehe die beiden Lebensläufe vom 7. Mai 1937 und undatiert (vermutl. Juni 1939).

GPAMNFG, Lehrkörper (ausgeschieden), Mollwo.

222 Gutachten Pohl, 7. Juni 1937. GPAMNFG, Lehrkörper (ausgeschieden), Mollwo.

223 Rektor Neumann an REM, 9. November 1937. BAB, BDC, REM Mollwo.

224 In der am Ende des Dozentenlagers über ihn abgegebenen Beurteilung wird er als ,ppolitisch mässig interessiert“ beschrieben. „Zu aktiver politischer Teilnahme besitzt er keine Neigung, obwohl ihm wohlwollende Gesinnung eigen ist.“ Allgemeine Beurteilung durch Prof. Gerullis und Obstbf. Grundig, 28. August 1937.

BAB, BDC, REM Mollwo.
} 
Sonderauftrag reklamiert und forschte fortan an kriegswichtigen Aufgaben. ${ }^{226} 1942$ stieg er zum Oberassistenten auf. ${ }^{227}$ Er unterstützte Pohl erfolgreich bei den Einführungsvorlesungen, sodass ihn Pohl 1944 für die Ernennung zum außerordentlichen Professor vorschlug. Als besondere Qualitäten Mollwos führte Pohl neben seiner Selbständigkeit an, dass er Physik aus „,innerer Passion“ treibe und stets erfolgreich bemüht sei, „einseitiges Spezialistentum zu vermeiden“. Mollwo sei sicher geeignet, ein eigenes Physikinstitut zu leiten. ${ }^{228}$ Kopfermann fügte dem Antrag noch hinzu, dass Mollwo „ein ausgezeichneter Physiker, ein erfahrener Pädagoge und ein liebenswürdiger Kollege“" sei.229 Damit er sich besser seinen für die Heeresverwaltung ausgeführten Forschungsaufgaben widmen könne, beantragte Pohl einen Monat später, ihn von den Assistentenpflichten zu entlasten und ihm eine Diätendozentur zu verleihen. ${ }^{230} \mathrm{Da}$ den Physikern damals nur eine einzige freie Diätendozentur zur Verfügung stand, gleichzeitig aber auch der Oberassistent am II. Physikalischen Institut, Hellwege, befördert werden sollte, war es notwendig, Stellen zwischen den Fächern zu tauschen, um die Anträge zu erfüllen. Das Ministerium bewilligte mit Wirkung vom 1. April 1944 Diäten für Mollwo und holte Gutachten wegen seiner Ernennung zum außerplanmäßigen Professor ein. Dort wird zwar kritisiert, dass seine Arbeiten „fast ausnahmslos unter dem Einfluss seines Lehrers Pohl“" stünden, doch seine Eignung zum Professor anerkannt. ${ }^{231}$ Die Ernennung folgte im September desselben Jahres. ${ }^{232}$

Das Typische an Mollwos Karriere ist, dass er, ohne in irgendeinem Aspekt außergewöhnlich zu sein, den unterschiedlichen Anforderungen an einen jungen aufstrebenden Physiker gerecht wurde. Die Qualität seiner Forschungsarbeiten entsprach den fachinternen Ansprüchen. Sein Wissen war breit genug, um dem Vorwurf des Spezialisten zu entgehen. Menschlich hatte er Glück, dass ihm sein Großvater positiv vermerkt wurde. ${ }^{233}$ Wichtiger war

225 Lebenslauf von Mollwo, undatiert (vermutl. Juni 1939). GPAMNFG, Lehrkörper (ausgeschieden), Mollwo.

226 Siehe undatierten Lebenslauf, vermutlich Anfang 1944. GPAMNFG, Lehrkörper (ausgeschieden), Mollwo.

227 Siehe Schreiben des Kurators vom 13. März 1942. UAG, Rek. 5250 / 5A.

228 Pohl an Dekan, 4. Februar 1944. GPAMNFG, Lehrkörper (ausgeschieden), Mollwo.

${ }^{229}$ Kopfermann in Anschluss an Pohls Antrag vom 4. Februar 1944. GPAMNFG, Lehrkörper (ausgeschieden), Mollwo.

230 Pohl an Ministerium, 3. März 1944. GPAMNFG, Lehrkörper (ausgeschieden), Mollwo.

${ }^{231}$ Gutachten von Clemens Schaefer, 4.Mai 1944, und Georg Joos, 19.April 1944. Das Zitat stammt von Schaefer. BAB, BDC, REM Mollwo.

232 Die Diätendozentur wurde am 12. Juni 1944 bewilligt, die Ernennung zum apl. Professor erfolgte am 22. Septmeber 1944. GPAMNFG, Lehrkörper (ausgeschieden), Mollwo.

${ }^{233}$ Solche Auffassungen über das Vererben von Genialität waren damals üblich. Pohls Freund Max Born schreibt zum Beispiel in seiner Autobiografie an seine eigenen Kinder gerichtet: ,[...] doch glaube ich, daß das Wesen meiner Natur - und auch der Euren, meine Kinder [...] - auf den Genius des Born'schen Geschlechts zurückzuführen ist.“ Born [1975] S. 25. Pohl selbst zählte Johannes Kepler zu seinen Ahnen. Gudden [1944] S. 168. Der Physiker Klumb glaubte von physikalischen Begabungen, sie seien „wahrscheinlich nicht lehrbar, sondern Ergebnisse der Vererbung bzw. einer längeren Zuchtwahl“. Klumb [1944] S. 41. 
jedoch, dass er als liebenswürdiger Kollege seinen Platz im kollegialen Netz gefunden hatte. Dies alles sicherte ihm die Unterstützung der Göttinger Physikordinarien, die für das berufliche Weiterkommen unumgänglich war. Politisch leistete er die notwendige Anpassung durch Mitgliedschaften und zeigte freiwilliges militärisches Engagement, das den Machthabern eine gewisse Kooperationsbereitschaft signalisierte. Dieser gewöhnliche, und wenn man so will unspektakuläre Karriereverlauf war eine gute Voraussetzung, um die Laufbahn nach dem politischen Umbruch 1945 ohne Schwierigkeiten fortsetzen zu können.

Der 9 Jahre jüngere Fritz Stöckmann (Jahrgang 1918) begann seine akademische Karriere ebenfalls mit einer Doktorarbeit im Pohl'schen Institut. Da er kurz nach der Geburt ein Auge verloren hatte, war er untauglich und konnte in der Kriegszeit 'ungestört' studieren. ${ }^{234}$ Eigentlich wollte er Doktorand bei Hilsch werden. Doch als er nach zwei Auswärtssemestern nach Göttingen zurückkam, erfuhr er von Pohl, dass Hilsch einen Ruf nach Erlangen angenommen hatte. Er solle doch besser in Göttingen bei Pohl promovieren. „Damals war es für einen Studenten undenkbar, sich gegen eine so klare Entscheidung eines Professors - und gar von Pohl - zu wehren.“235 Im Jahr 1942 reichte er seine Doktorarbeit über den selektiven GrenzschichtPhotoeffekt der Alkalimetalle ein. ${ }^{236}$ Nach bestandener Promotion wurde er Mollwos Nachfolger als Institutsassistent. Der wissenschaftlichen Qualifikation war ein politisches Engagement vorausgegangen, das deutlicher als bei Mollwo ausfiel: NSDAP 1938-45, HJ 1934-38, NSDStB 1937-42, NS Altherrenbund 1942-45.237 Auch bei Stöckmann waren gute Voraussetzungen gegeben, die zur Professur führenden Karriereschritte nach dem Krieg zu vollziehen, wie im Abschnitt 1.3.5.1 gezeigt wird. Die relativ glatte Karriere in Kriegszeiten wurde durch seine militärische Untauglichkeit begünstigt.

Einen Abbruch der akademischen Laufbahn in der NS-Zeit hat Heinz Pick gewählt. Pick liegt als Jahrgang 1912 im Alter zwischen Mollwo und Stöckmann. Er studierte in Köln, München und Göttingen, war Mitglied der Burschenschaften Ring katholischer deutscher Burschenschaften (RKDB), Novesia Köln und Rheno Isaria München. ${ }^{238} 1935$ kam er ins Pohl'sche Institut. In einem Interview von 1981 berichtet er über die näheren Umstände hierzu. ${ }^{239}$ Der damalige Praktikumsassistent Hellwege, der gerade bei Pohl promovierte, machte Pohl auf Pick aufmerksam. Um als Doktorand aufgenommen zu werden, musste er die Temperaturab-

\footnotetext{
234 Aus Stöckamnns Lebenslauf, 16. Februar 1950. GPAMNFG, Lehrkörper (ausgeschieden), Stöckmann.

235 Stöckmann [1978] S. 29.

236 Siehe Stöckmann [1946].

237 Fragebogen der Militärregierung, 24. September 1947. UAG, Kur. XVI. V. C. h. 2. III.

238 Nach Fragebogen der Militärregierung, 14. März 1946. HStAH, Nds. 171 Hildesheim 14431.

239 Interview mit Pick, 2. Oktober 1981. NBL.
} 
hängigkeit der lichtelektrischen Leitung am Selen untersuchen; dies war eine Aufgabe, die einzig dazu diente, sein experimentelles und physikalisches Geschick zu testen. Nach Bestehen dieses Aufnahmerituals begann er in Pohls Auftrag, über den Einfluss der Temperatur auf die Erregung von Farbzentren zu forschen. Damit war er in den Pohl'schen Kreis aufgenommen. Die Einsichten ins Institutsleben waren ihm völlig neu, er war sehr angetan vom „hochakademischen Bereich“, der ihm neue Weltbilder eröffnete. Im Dezember 1937 promovierte er mit seiner Arbeit über die Farbzentren. Den Text der publizierten Fassung hat Pohl formuliert. Erschienen ist sie nur unter Picks Namen. Pohl konnte seinen nicht dazusetzen, da es sich schließlich um eine Doktorarbeit handelte. ${ }^{240}$ Diese Praxis war bei Pohl anscheinend üblich, denn auch sein früherer Schüler Gudden berichtet 1944, dass viele Dissertationen bei Pohl „nichts anderes sind, als »unter erschwerten Verhältnissen entstandene Arbeiten des Chefs«." 241 Walther Gerlach charakterisierte die Zusammenarbeit zwischen Pohl und seinen Mitarbeitern im Allgemeinen: „Problem, Planung und Niederschrift waren wesentlich Pohls Anteil, die Durchführung der Versuche und vor allem die oft umfangreichen Messungen lagen in der Hand des Mitarbeiters.“242 Pick blieb als Mitarbeiter in Pohls Institut und wurde zur Habilitation ermuntert. Doch ergaben sich für die akademische Karriere politisch-religiöse Schwierigkeiten.

1933 war Pick in München in die SA eingetreten. In seinem Entnazifizierungsverfahren rechtfertigte er diesen Schritt damit, dass in München vom SA-Hochschulamt zur Fortsetzung des Studiums der Eintritt in die SA verlangt und das Testieren der Vorlesungen davon abhängig gemacht wurde. In Göttingen kam er auf Vermittlung des Mechanikermeisters am I. Physikalischen Institut, der ein mittlerer SA-Führer gewesen sein soll (Standartenführer?), zur Marine-SA. 1937 wurde er Parteimitglied, was Pick damit erklärte, dass in Göttingen alle SA Mitglieder als Anwärter in die Partei überführt wurden. ${ }^{243}$ Trotz Parteizugehörigkeit sah Pick in dem obligatorischen NS-Dozentenlager, das ihm bevorstand, ein unüberwindbares Hindernis. Der Grund sei seine intensiv religiöse Orientierung gewesen, die ihm seine katholische Familie mitgegeben hatte. Er hatte das Problem ausführlich mit Pohl besprochen, der ihm schließlich zu einer Industriestelle verhalf. Im Mai 1940 schied er aus der Universität nach eigenen Angaben (1948) „schweren Herzens aus, weil ich derzeit bei meiner

\footnotetext{
240 Interview mit Pick, 2. Oktober 1981. NBL. Siehe auch Pick [1938].

241 Gudden [1944] S. 167.

242 Gerlach [1978] S. 219.

243 Nach Fragebogen der Militärregierung, 14. März 1946. HStAH, Nds. 171 Hildesheim 14431. Zu den Angaben über den Mechanikermeister siehe Interview mit Pick, 2. Oktober 1981. NBL.
} 
konfessionellen Bindung in der Hochschullaufbahn keine Aussicht sah. "244 Bis Juli 1945 war er dann als Laborleiter bei der Firma Electroacustic in Kiel angestellt, wo er im Zellenlaboratorium unter anderem an Spektraluntersuchungen der Empfindlichkeitsverteilung von Photozellen forschte. Ziel seiner Untersuchungen war, die Struktur der lichtempfindlichen Schichten kennenzulernen und den Mechanismus der lichtelektrischen Leitung der Zellenschichten aufzuklären. Mit diesen Forschungen blieb Pick recht nahe an dem bei Pohl zuvor erlernten Gebiet. Er hatte in Kiel sogar Gelegenheit, bei seinen Hilfskräften durch Vorträge und Unterricht seine pädagogischen Fähigkeiten auszubilden. ${ }^{245}$

Nach dem Wechsel in die Industrie gelang es Pick im Mai 1940, seine SA- und Parteimitgliedschaft $\mathrm{zu}$ kündigen. Zur gleichen Zeit trat er - möglicherweise zur Kompensation - der DAF und der KdF bei. Seit 1935 war er außerdem noch Mitglied in der NSV. ${ }^{246} \mathrm{Da}$ nach Kriegsende die politisch-religiösen Hindernisse für eine Universitätslaufbahn weggefallen waren, konnte Pick nach Göttingen zurückkehren und wieder Assistent bei Pohl werden (dazu mehr im Abschnitt 1.3.5.1).

\subsection{Der Fall Hans König}

Pohl gelang 1941 eine Erweiterung seines Instituts und die Akquirierung eines weiteren Geldgebers für physikalische Forschung. Dank seiner angeblich guten Beziehungen zu Adolf Baeumker im Luffahrtministerium konnte er erreichen, dass in Göttingen eine Zweigstelle der damals im großen Maßstab geplanten neuen Luftfahrtforschungsanstalt München angesiedelt wurde. Zwar gab es in Göttingen mit der AVA, deren Mitarbeiterzahl während des Krieges auf über 700 anwuchs, bereits ein großes Zentrum der Luftfahrtforschung. ${ }^{247}$ Pohl hatte aber nicht im Sinn, der AVA Konkurrenz zu machen. Er sah vielmehr eine günstige Gelegenheit, mit Baeumkers Unterstützung einen weiteren Experimentalphysiker in sein Institut zu bekommen. ${ }^{248}$ Im RLM war damals Hans König beschäftigt, der vorher Dozent an der TH Danzig gewesen war. Die folgende Darstellung beruht zu großen Teilen auf einem Interview, das ich im Februar 2001 mit Hans König führte.

König begann sein Studium der technischen Physik 1929 an der TH Danzig. Der Entscheidung für diese Hochschule waren Werbemaßnahmen der damaligen Regierung für

\footnotetext{
244 Aus Lebenslauf, 12. Juni 1948. GPAMNFG, Lehrkörper (ausgeschieden), Pick.

245 Zeugnis der Electroacustic, 31. Juli 1945. GPAMNFG, Lehrkörper (ausgeschieden), Pick.

246 Nach Fragebogen der Militärregierung, 14. März 1946. HStAH, Nds. 171 Hildesheim 14431.

247 Zur AVA siehe Tollmien [1987/98]; Rotta [1990]; Trischler [1992].

$248 \mathrm{Zu}$ Baeumker und die Organisation der Luftfahrtforschung siehe Trischler [1992]; Hein [1995]; Budrass

[2002]. Eine Verbindung zu Pohl wird leider in keiner dieser Arbeiten erwähnt.
} 
die TH Danzig vorausgegangen, von denen König in seinem letzten Schuljahr 1928/29 in Ansbach Kenntnis bekam. Die Besetzung von Lehrstühlen durch deutsche oder polnische Professoren hing von dem Verhältnis der Zahl deutscher zu polnischer Studenten ab. „Von dem Wunsche beseelt, das Grenzdeutschtum kennenzulernen,“ ging er zum Studium nach Danzig. Dort ist er 19-jährig im Jahr 1929 ,in vaterländischer Begeisterung“ dem NSStudentenbund und der NSDAP beigetreten. Andere NS-Organisationen, ,wie SA oder SS, habe ich bewusst gemieden, da ich den Zeitaufwand mit meinen wissenschaftlichen Interessen nicht vereinbaren konnte.“ Sein Engagement für die Partei sollte dem „Deutschtum in Danzig [...] dienen." 249

In Danzig wollte er zuerst Flugzeugbau studieren, wurde aber von Eberhard Buchwald gleich für die Physik begeistert. Im Dezember 1933 absolvierte er sein Diplom Examen und wurde Assistent von Buchwald ${ }^{250}$ am Lehrstuhl für theoretische Physik. Im Oktober 1937 promovierte er mit der Arbeit „Magnetische Doppelbrechung organischer Flüssigkeiten und ihrer Dämpfe“ zum Dr.-Ing. und im folgenden April erhielt er einen Lehrauftrag für Experimentalphysik. Nachdem Alfred Kalähne in Ruhestand gegangen war, übernahm König zu Beginn des Jahres 1938 die Verwaltung des Photophysikalischen Laboratoriums und führte die Neuordnung des photophysikalischen Praktikums durch. Seine Vorlesungen behandelten Themen der wissenschaftlichen Fotografie und der physikalischen Grundlagen des Ferromagnetismus. Er gab auch Einführungen der Anfänger ins Messen und Rechnen und ins physikalische Praktikum. Die wissenschaftliche Tätigkeit wurde durch den Kriegsbeginn verzögert. Im Juni 1939 musste er sich bei der Kaserne melden, bekam eine Uniform und galt als eingezogen, wenn er auch nicht kaserniert war. Am 1. September 1939 sah er die Flieger kommen und hörte die Bomben auf der Westerplatte einschlagen. Ein paar Tage später kämpfte er als Soldat um das E-Werk in Gotenhafen. Obwohl er an den ersten Kriegshandlungen als Soldat beteiligt war, konnte er seine wissenschaftliche Karriere bald einen Schritt weiterbringen. Im April 1940 wurde er habilitiert. Die Einberufung zum Militärdienst ließ sich aber allein dadurch noch nicht verhindern. ${ }^{251}$

König war froh, als er durch die Vermittlung des Danziger Ordinarius Hans Schwenkhagen die Möglichkeit bekam, nach Berlin ins RLM zu wechseln, um dort in der Forschungsorganisation mitzuwirken. Dieser Wechsel nach Berlin ist nur durch das Interview

\footnotetext{
249 Zitate aus einer Beilage zum Entnazifizierungsfragebogen. HStAH, Nds. 171 Hildesheim 13131.

$250 \mathrm{Zu}$ Buchwald siehe Kersten [1976].

251 Angaben nach Interview mit König, 10. Februar 2001 und Fragebogen der Militärregierung, 21. Oktober 1946. HStAH, Nds. 171 Hildesheim 13131.
} 
belegt. In den Akten finden sich vom Mai 1941 zwei Gutachten über König, ausgestellt von seinen Lehrern Buchwald und Kossel. Der Anlass der Begutachtung bleibt unerwähnt; es dürfte sich aber um Königs Übernahme der physikalischen Abteilung der Luftfahrtforschungsanstalt München handeln. König wurden von Kossel besondere organisatorische Fähigkeiten bescheinigt, womit er sich ,auch in weit größerem Felde bewähren wird."252 Nach eigenen Angaben bereiste König im Auftrag des RLM die deutschen physikalischen und physikalisch-chemischen Institute, um sie mit kriegswichtiger Forschung zu beauftragen. So reiste er zum Beispiel nach München, Erlangen und Prag, im Herbst 1941 auch nach Riga, Dorpat (Estland), ${ }^{253}$ Charkow und Kiew. Er trug Uniform und bekleidete den Rang eines Fliegerstabsingenieurs. Ab 1. Mai 1941 war er offiziell Professor Heinrich Peters unterstellt und bei der Luftfahrtforschungsanstalt München angestellt, deren physikalische Abteilung in Pohls Institut untergebracht worden war. ${ }^{254}$ Es war angeblich Pohls Verdienst, dass König durch die Unterbringung in Göttingen wieder physikalische Forschungen durchführen konnte. Mit der zufälligen Entdeckung einer neuen Eiskristallform bei Versuchen mit Elektronenstrahlen machte sich König einen guten Namen bei seinen Göttinger Kollegen, vor allem bei Pohl, Eucken und Correns. 1946 wurde seine Arbeit auch in der renomierten Zeitschrift Nature besprochen. ${ }^{255}$

König war kein Mitglied des Göttinger Lehrkörpers, jedenfalls nicht während des Krieges. Er konnte sich ganz der Forschung widmen, hatte einige Mitarbeiter, die Physikstudenten, Diplomanden oder Doktoranden waren und ebenfalls vom RLM bezahlt wurden. Diese Mitarbeiter konnte er sich selbst aussuchen. An der Lehre brauchte sich König nicht zu beteiligen. Im Dezember 1942 erklärte er sich einverstanden, dass der bei ihm arbeitende Obergefreite Hans Severin als Hilfskraft im II. Physikalischen Institut eingestellt werde. Severin wurde dort vermutlich für die Praktikumsbetreuung benötigt. ${ }^{256}$ Königs Forschung galt zuerst

\footnotetext{
${ }^{252}$ Gutachten von Kossel, 22. Mai 1941; das Gutachten von Buchwald datiert vom 20. Mai 1941. GPAMNFG, Lehrkörper (ausgeschieden), König.

${ }^{253}$ Riga wurde im Juni 1941 von den Deutschen angegriffen. Im REM gab es einen Plan, in Riga eine deutsche TH zu errichten. Dazu kam es aber nicht. Ebenso plante das REM in Dorpat, Estland, eine deutsche Hochschule zu gründen. Die Planungen dazu waren schon fortgeschritten, als Dorpat noch gar nicht in deutschen Händen war. Mitte Februar 1942 wurde die Universität Dorpat mit Medizinischer, Tierärztlicher und Landwirtschaftlicher Fakultät eröffnet. Siehe Heiber [1992] Bd. 1, Teil 2, S. 202.

${ }^{254}$ Lebenslauf König, 21. Oktober 1949. UAG, Rek. PA König.

255 Die Entdeckung publizierte er in den Nachrichten der Akademie der Wissenschaften; siehe König [1942]. Internationale Verbreitung erfuhr seine Entdeckung durch die Mitteilung „A Cristobalite Modification of Ice“ in Nature 157 (1946), S. 449. Eine Besprechung von Königs Arbeit folgt in Abschnitt 3.7.1.

256 König an Kurator, 18. Dezember 1942. Dieses Schreiben trägt den Briefkopf der Physikalischen Abteilung der Luftfahrtforschungsanstalt München e. V., z. Zt. Göttingen, Bunsenstr. 9. Unterzeichnet hat König als Flieger-Stabsing. UAG, Kur. XVI. V. C. h. 2. II. Königs Mitarbeiter standen zum Teil auch dem Institutsdirektor Pohl zur Verfügung, wie aus einem Schreiben von Pohl an den Kurator Büchsel vom 1. Juni 1945 zu entnehmen
} 
Eisenkristallen, die er mit Hilfe von Elektronenstrahlen untersuchte. 1943 wurde im Erdgeschoß des I. Instituts ein in Rom erbeutetes Elektronenmikroskop aufgestellt, das seine weitere Forschungsausrichtung bestimmte. 257 Unter den Göttinger Physikern fiel König dadurch auf, dass er selbst im Institut in Uniform erschien. ${ }^{258}$ Pohl erreichte mit der Gewinnung von König eine Bereicherung der Göttinger Forschungslandschaft mit eigener Finanzierung 259 und eine zusätzliche Arbeitskraft in der Ausbildung fortgeschrittener Stundenten. Forschungspolitisch bedeutete die Versetzung Königs nach Göttingen den Abzug eines hochbefähigten Experimentalwissenschaftlers von der Forschungsverwaltung und -organisation und seine direkte Verwendung in der Kriegsforschung. Dass Baeumker dieser Verlagerung zustimmte, hängt vielleicht damit zusammen, dass er zu dieser Zeit im RLM bereits auf dem absteigenden Ast saß. ${ }^{260}$

\subsubsection{Das II. Physikalische Institut}

Durch den zweimaligen Wechsel der Institutsleitung in der NS-Zeit waren die Nachwuchswissenschaftler im II. Physikalischen Institut zu größerer Flexibilität gezwungen. Auf der Ebene der Assistenten konnte ein Wechsel zwischen den Instituten noch relativ leicht erfolgen, wie am Beispiel Karl-Heinz Hellwege zu sehen ist. ${ }^{261}$ Er studierte bei Franck und wurde 1933 bei ihm als Stipendiat der Studienstiftung vorgesehen. ${ }^{262}$ Nach der Vertreibung Francks wechselte Hellwege ins I. Physikalische Institut und promovierte 1935 bei Pohl mit einer Arbeit über den „Einfluß kleiner mechanischer Spannungen auf den elektrischen Widerstand von Chromnickeldrähten“. Auch für damalige Verhältnisse fiel diese Arbeit vom Umfang recht bescheiden aus. Im A 5-Format weist sie insgesamt 11 Seiten auf. ${ }^{263}$ Gleich anschließend an die Promotion wechselte er zurück ins II. Institut und wurde dort Assistent, nur zwei Monate bevor Georg Joos als neuer Institutsleiter kam, der ihn dann als Assistent

ist: „Während des Krieges haben der Invalide Tischler Karl Fiege und die Photographin Ursula Braun für die Luftfahrtforschungsanstalt München als Notdienstverpflichtete im Institutsgebäude gearbeitet und dabei im Bedarfsfalle auch Arbeiten für das Institut ausgeführt.“ UAG, Kur. XVI. V. C. g. 2. III.

${ }^{257} \mathrm{Zu}$ Königs Forschungsaktivitäten siehe Abschnitt 3.7.1.

258 Siehe Rosenow [1987/98] S. 569.

${ }^{259} \mathrm{Am}$ 3. Februar schrieb Pohl an die Universitätskasse: „Die sich bei uns als Gast befindliche Physikalische Abteilung der Luftfahrtforschungsanstalt München e. V., wird Ihnen in den nächsten Tagen einen Betrag von RM 1800 überweisen als Betrag für die laufenden Unkosten.“UAG, Kur. XVI. V. C. g. 2. III.

260 Siehe dazu kurz Budrass [2002].

261 Die folgenden Daten stammen aus: GPAMNFG, Lehrkörper (ausgeschieden), Hellwege.

262 Siehe Hellweges Eingabe an den Entnazifizierungs-Hauptausschuss, 4. November 1946. HStAH, Nds. 171 Hildesheim 11847.

263 Nach vier Seiten Einleitung, Messverfahren und Versuchsanordnung folgen vier Seiten Messergebnisse, zwei Seiten über die Temperaturabhängigkeit der Spannungskoeffizienten und schließlich eine einseitige Zusammenfassung. 
übernahm. Hellwege gehörte seit Juli 1933 der SA an und wurde im November 1938 Oberscharführer und Sportreferent der SA-Reiterstandarte 57. Laut einer politischen Beurteilung habe er sich schon vor 1933 sehr für die Bewegung eingesetzt. ${ }^{264}$ In den Jahren 1936 bis 1938 leistete er insgesamt fünf Monate freiwilligen Wehrdienst bei der 19. Erg. Battr. in Fulda, der 10. (E) / A.R. 31 in Halberstadt und bei der 8. / A.R. 31 in GöttingenWeende ab. Im November 1938 war sein Dienstgrad Unteroffizier der Reserve und ReserveOffizier Anwärter im A.R. 31. Im Mai 1937 wurde er Parteimitglied. ${ }^{265}$

Im November 1938 überreichte er der Fakultät seine Habilitationsschrift „Untersuchungen im langwelligen Ultrarot über Kombinationsschwingungen und über die Existenz von Metallhydratkomplexen in Kristallen“. Im Gutachten lobte Joos Hellweges Experimentierkunst aufs Höchste. Hellwege habe die Empfindlichkeit seiner Thermoelemente derart steigern können, dass diese auf den Winddruck an den Fensterscheiben reagierten, sodass die Experimente nur noch nachts bei Windstille durchgeführt werden konnten. Eine gewisse Zurückhaltung im Urteil ist bei dem Doktorvater Pohl festzustellen. Nachdem er die Qualitäten der Hellwegeschen Arbeit sachlich referiert hatte, folgerte er leicht distanziert: „Ich stimme also dem Urteil von Kollegen Joos durchaus zu.“ Besonders betonen wollte Pohl noch Hellweges ,anständige Gesinnung, seine Zuverlässigkeit und sein frisches Wesen“. Eucken erblickte in der Tatsache, dass neben der Dissertation und der Habilitationsschrift nur drei Veröffentlichungen vorlagen, „das Minimum dessen [...], was gerade die Göttinger mathematisch-naturwissenschaftliche Fakultät verlangen sollte.“ Da aber ein spürbarer Mangel an wissenschaftlichem Nachwuchs herrschte, stimmten alle Fakultätsmitglieder der Zulassung $\mathrm{zu}$ den weiteren Habilitationsleistungen zu. ${ }^{266}$ Im Juli 1939 konnte Hellwege seine Lehrprobe über das Thema „das Neutron“ abhalten, im September wurde er vom Ministerium zum Dozenten ernannt. Der Dozentenbund befürwortete die Ernennung. ${ }^{267}$

An Hand der Habilitation Hellweges kann man wieder das Bemühen der Fakultät um Wahrung eines Mindestmaßes an wissenschaftlicher Qualität erkennen. Auch ein gewisses Ressentiment von Pohl gegenüber Hellwege ist in dem Habilitationsverfahren noch zu merken. Möglicherweise lag es daran, dass Hellwege zum Kollegen Joos übergetreten war. Seine kollegialen Verbindungen zum I. Institut waren jedenfalls nicht besonders eng. Die

\footnotetext{
264 Politische Beurteilung Hellweges durch die Ortsgruppe Sternwarte, 30. September 1939. BAB, BDC, PK, Hellwege, Karl-Heinz.

265 Aus Lebenslauf vom 30. November 1938. GPAMNFG, Lehrkörper (ausgeschieden), Hellwege.

266 Siehe Gutachten von Joos, 14. Dezember 1938, von Pohl, 18. Januar 1939, von Eucken, 21. Januar 1939.

GPAMNFG, Lehrkörper (ausgeschieden), Hellwege.
} 
politische Betätigung Hellweges wurde in den Gutachten weder positiv noch negativ erwähnt. Die mehrfache Betonung seiner menschlichen Zuverlässigkeit (so Joos) lässt vermuten, dass Hellweges Verbindung von naturwissenschaftlichem und militärisch-politischem Engagement durchaus erwünscht war.

Als Dozent musste Hellwege bei 4 / Art. Ers. Abt. 216 in Göttingen seinen Truppendienst vom 10. September bis zum 8. Dezember 1939 leisten, ${ }^{268}$ wurde dann aber mit kriegswichtigen Versuchen beauftragt, die teilweise auch am Institut für angewandte Elektrizität unter Leitung von Max Reich und später Hermann Zahn durchgeführt wurden. Diese Forschungen sicherten ihm die uk-Stellung. Als Joos im Jahr 1941 nach Jena ging, übertrug er die vertretungsweise Institutsleitung seinem Oberassistenten Hanle, doch als auch dieser kurz darauf Göttingen verließ und ein Ordinariat in Gießen antrat, wurde Hellwege damit beauftragt. Die meisten militärischen Geheimaufträge wanderten zusammen mit Hanle nach Gießen; nur ein Auftrag des Nachrichtenmittelversuchskommandos blieb zur Bearbeitung in Göttingen. ${ }^{269}$ Trotzdem stieg unter Hellweges Leitung das II. Physikalische Institut in seiner Kriegswichtigkeit auf und wurde vom Kommando des Rüstungsbereichs Hannover im Mai 1941 schließlich als Spezialbetrieb der Rüstungsindustrie anerkannt. 270

Zum Zeitpunkt der Ernennung zum Oberassistenten im Februar 1942 betreute Hellwege drei Doktoranden. ${ }^{271}$ Ein Jahr darauf wurde er Mitglied im NSDDB. 1944 schied er aus der Oberassistentenstelle aus und wurde zum Diätendozenten befördert. Der neue Institutsdirektor Kopfermann befürwortete die Beförderung, vermutlich auch deshalb, um die Oberassistentenstelle seinem eigenen Schüler Walcher übertragen zu können. Jedenfalls lobte er Hellweges gediegenes Wissen, große pädagogische Erfahrung und erfreuliche menschliche Reife. Ihn von der Assistentenstelle zu entlasten bringe den Vorteil, dass sich Hellwege besser seinen „wissenschaftlichen und kriegswissenschaftlichen Forschungen widmen“ könne. ${ }^{272}$ Bis Kriegsende sah es auf Grund der aktenkundigen Vorgänge so aus, als ob die verschiedenen

\footnotetext{
267 Am 14. September 1939 wurde er ins Beamtenverhältnis berufen und zum Dozenten ernannt. Vom Dozentenbund beurteilte ihn am 16. August 1939 Ebel positiv. UAG, Rek. PA Hellwege.

268 Siehe seine Angaben im Fragebogen der Militärregierung. HStAH, Nds. 171 Hildesheim 11847.

269 Siehe die Protokolle zur Übergabe der Institutsleitung vom 31. März 1941 und 2. Mai 1941 in: UAG, Kur. XVI. V. C. h. 1. III.

270 Am 28. August 1941 teilte Hellwege dem Dekan mit, dass am 30. Mai 1941 das Institut vom Kommando des Rüstungsbereichs Hannover als Spezialbetrieb der Rüstungsindustrie anerkannt wurde. UAG, Rek. PA Hellwege.

271 Anne-Marie Rosa: „Über die Absorptionsspektren einiger wasserhaltiger Salze des Dysprosiums“, siehe Rosa [1943], Hans Severin: ,Absorptionsspektren einiger wasserhaltiger Salze des Erbiums“, siehe Severin [1947], Yu-Kang Chow: „Über das Absorptionsspektrum des Neodymfluorids $\mathrm{NdF}_{3}$ “, siehe Chow [1948]. GPAMNFG, Lehrkörper (ausgeschieden), Hellwege.

272 Kopfermann an Ministerium, 28. Februar 1944. UAG, Rek. PA Hellwege.
} 
Forschungen im Institut reibungslos nebeneinander durchgeführt wurden und die Personalentwicklung einen normalen Verlauf nahm. Erst im Entnazifizierungsverfahren wurden verborgene Spannungen offengelegt (siehe Abschnitt 1.3.2.1).

Wie am Beispiel Hellwege zu sehen ist, konnte ein Wechsel zwischen den Experimentalphysikinstituten relativ einfach vollzogen werden. Hellwege studierte bei Franck, promovierte bei Pohl und wurde Assistent von Joos. - Auch Günther Leibfried war von den Wechseln in der Institutsleitung betroffen, doch seine Laufbahn führte ihn schließlich weg von der Experimentalphysik. Leibfried wurde 1915 als Sohn eines Offiziers ${ }^{273}$ in Fraulautern bei Saarlouis geboren. Nach dem Tod seiner Eltern 1929 absolvierte er 1933 das Abitur in Hameln, wo er bei seiner Großmutter lebte. Nach vier Semestern Physik- und Mathematikstudium in Göttingen leistete er einen halbjährigen Arbeitsdienst und zwei Jahre Wehrdienst ab. Durch die 1935 eingeführte Wehrpflicht waren solche langen Studienunterbrechungen bei Männern üblich. Im WS 1937/38 kam er nach Göttingen zum Studium zurück und begann ein Jahr darauf mit seiner Doktorarbeit über den Ramaneffekt an Alaun- und Zuckerkristallen im II. Physikalischen Institut bei Joos. Zu Kriegsbeginn wurde er eingezogen, konnte aber die mündliche Doktorprüfung während eines Urlaubs im Oktober 1939 ablegen. Die ersten drei Kriegsjahre war er beim Feldheer, bis er Mitte 1942 von der E-Stelle Rechlin für die Sonnenforschung reklamiert wurde. Dort beschäftigte er sich in Zusammenarbeit mit KarlOtto Kiepenheuer mit Lyotschen Farb-Interferenzfiltern und dem Bau einer Apparatur für Nachthimmelslichtregistrierung. Von Mitte 1943 bis Kriegsende arbeitete er für die Forschungsführung der Luftwaffe in der Geschossentwicklung. ${ }^{274}$ Diese zuletzt genannten Forschungen wurden von Leibfried als Sachbearbeiter am Göttinger Institut für theoretische Physik ausgeführt. ${ }^{275}$ Unterstellt war der mittlerweile zum Oberleutnant aufgestiegene Leibfried dem Luftnachrichtenregiment Köthen. ${ }^{276}$ Seine politischen Mitgliedschaften stammen aus der Anfangszeit seines Studiums. 1933 trat er in die SA ein, in der er 1934 Rottenführer wurde. 1938 wurde er nach eigenen Angaben von der SA automatisch in die

273 In zwei undatierten Lebensläufen benennt Leibfried seinen Vater einmal als Oberleutnant, dann als Hauptmann. Siehe Lebenslauf (vermutlich Dezember 1949) in: GPAMNFG, Lehrkörper (ausgeschieden), Leibfried, und Lebenslauf (nach Mai 1950) in: UAG, Rek. PA Leibfried.

274 Angaben nach Lebenslauf (vermutlich Dezember 1949) in: GPAMNFG, Lehrkörper (ausgeschieden), Leibfried.

275 Dies ergibt sich aus dem Schreiben Leibfried an Kurator, 11. April 1951; UAG, Kur. XVI. V. C. i. 2. Siehe dazu Abschnitt 3.1.

276 Dies geht aus einer Beilage zu seinem Fragebogen der Militärregierung vom 10. September 1945 hervor. HStAH, Nds. 171 Hildesheim 34286. 
Partei überführt. Dem NSDStB gehörte er von 1938 bis 1939 an, dem NS Altherrenbund seit 1938.277

Leibfrieds akademische Karriere wurde durch den Wehr- und Kriegsdienst um etwa sieben Jahre verzögert. Trotzdem konnte er in dieser Zeit wissenschaftlich arbeiten. Die Verbindung von experimenteller Forschung und Theorie in Beckers Institut erleichterten ihm den Wechsel zur theoretischen Physik, den er schon durch seine Kriegsforschungen eingeleitet hatte und nach 1945 endgültig vollzog. Der Weggang von Joos aus Göttingen mag mit eine Rolle für den institutionellen und fachlichen Richtungswechsel gespielt haben.

Der Weggang des Institutsleiters führte bei zumindest zwei Assistenten zum Wechsel zu einer anderen Universität. Eugen Saur und Adelheid Gott gingen auf diese Weise nach Erlangen. Saur habiltierte sich im März 1942 in Göttingen. Joos war damals schon ein Jahr in Jena und kam extra zur wissenschaftlichen Aussprache Saurs angereist, die dann zur vollen Befriedigung ausfiel. ${ }^{278}$ Rudolf Hilsch holte Saur danach als Dozenten an die Universität Erlangen und sicherte ihm dadurch auch eine uk-Stellung; Gott bot er dort eine Assistentenstelle an. ${ }^{279}$ Dieser Transfer wurde begünstigt durch die kollegialen Verbindungen, die zwischen den beteiligten Physikern bestanden. Erlangen entwickelte sich zu einer Art Dependance der Göttinger Physik, vor allem der Pohl'schen Schule. Pohl platzierte schon 1926 seinen Schüler Bernhard Gudden auf ein Ordinariat in Erlangen. Nach Guddens Wechsel an die Universität und TH Prag 1939 wurde Pohls Oberassistent Hilsch sein Nachfolger. Pohls nächster Oberassistent Mollwo wurde 1948 als Ordinarius ebenfalls nach Erlangen berufen. Joos und Saur hatten in ihrer gemeinsamen Göttinger Zeit ein gutes Verhältnis zu Hilsch aufgebaut, das schließlich nach Joos Weggang den Assistenten nützlich war. ${ }^{280}$ Eine Universitätskarriere konnte Joos seinen Schülern nicht mehr anbieten, höchstens den Wechsel in die Industrie. Die Bedingungen, in Göttingen eine akademische Karriere fortzuführen, waren nicht besonders gut. Im II. Institut würde der neue Institutsleiter eigene Assistenten mitbringen, sodass diese Stellung unsicher war. Pohl und Becker hatten ihre

\footnotetext{
277 Fragebogen der Militärregierung vom 10. September 1945. HStAH, Nds. 171 Hildesheim 34286. Leibfried war seit 1. Mai 1937 Parteianwärter und bekam die Mitgliedsnummer 5076495. BAB, BDC, PK, Leibfried, Günther.

278 Protokoll des Fakultätsausschusses, 16. März 1942. Befragt wurde Saur von Joos, Pohl, Eucken, Becker; anwesend waren weiters Correns, Drexler und Rienäcker. GPAMNFG, Protokollbuch III der mathematischnaturwissenschaftlichen Fakultät WS 1927/28 - SS 1946.

279 Hilsch an Joos, 22. September 1941. BACZ, 22768. Zur Verbindung Saurs zur Pohl-Schule siehe auch den Abschnitt 3.3.

280 Siehe den Briefwechsel Hilsch - Joos vom September 1941 in BACZ, 22768.
} 
eigenen Assistenten. Wie am Beipiel Leibfried gesehen, drohte auch die Einberufung zum Militär. Die Dozentur in Erlangen löste somit ein ganzes Bündel von Problemen. ${ }^{281}$

\subsubsection{Das Institut für theoretische Physik}

Nachdem Becker 1936 das Institut übernommen hatte, beantragte er im September 1937, Dr. B. Kockel als außerplanmäßigen Assistenten anzustellen. Der Dozentenbundführer Blume lehnte dies jedoch entschieden ab, da Kockel 1929 bis 1931 an den Universitäten Leipzig und Hamburg der sozialistischen Studentengruppe angehört habe, auch 1937 noch „,vollständig abseits“ stünde und sich in keiner Gliederung der Partei betätigt habe. Rektor Neumann schloss sich den politischen Bedenken an, sodass Becker einen Monat später beantragte, die Stelle dem SA-Mitglied Dipl. Ing. Heinz Haake zu übertragen. Haake war außerdem seit 1935 NSDStB-Mitglied und diente 1936/37 ein Jahr lang in der Kriegsmarine, aus der er als Reserveoffiziersanwärter entlassen wurde. ${ }^{282}$ Auch wenn es Becker nicht wollte, kam es so schon auf der Ebene der außerplanmäßigen Assistenten zu einer politischen Selektierung des Physikernachwuchses.

Beckers planmäßiger Assistent, Werner Döring, den er aus Berlin mitgebracht hatte, kam ebenfalls unter politischen Druck, als 1938 seine Stelle verlängert werden sollte. Der Dekan Lenkeit meldete Bedenken an: „Der Institutsdirektor ist darauf hingewiesen worden, Herrn Döring zum Eintritt in eine Gliederung der Partei zu veranlassen.“ Dieser Schritt erschien dem Dekan als „sehr notwendig“. Besonders der Dozentenbundführer Blume forderte einen Nachweis, dass Döring ,,in einer Gliederung der Partei Dienst tut ““. ${ }^{283}$ Zum 1. November 1938 wurde Döring SA-Anwärter; seine Stelle wurde verlängert. ${ }^{284}$ Nach Auskunft seines für die Militärregierung ausgefüllten Fragebogens kündigte er seine SA-Mitgliedschaft zum November 1939 und wechselte in die Reichsdozentenschaft, der er bis Kriegsende angehörte. 285

Im Dezember 1939 wurde Werner Döring und Hans Polley zur Geheimhaltung verpflichtet, da sie kriegswichtige Aufgaben für das Herreswaffenamt und das Luftfahrtministerium durch-

\footnotetext{
281 Eine andere Möglichkeit wäre gewesen, mit dem gerade nach Gießen berufenen Wilhelm Hanle mitzugehen. Dies tat der Mitarbeiter des II. Instituts Schmillen, doch hatte Hanle größte Mühe, eine Stelle für ihn zu bekommen, denn als er nach Gießen kam, waren alle drei Assistentenstellen schon besetzt; außerdem wurde Schmillen kurzzeitig einberufen. Siehe Hanle an Joos, 6. Februar 1942 und 19. Oktober 1942. BACZ, 22768. 282 Anträge Becker vom 7. September und 12. Oktober 1937; Stellungnahme des Rektors, 4. Oktober 1937; Stellungnahme des Dozentenbundes; Lebenslauf von Heinz Haake (undatiert). UAG, Rek. 5250 / 8A. 283 Zustimmung des Dekans zur Verlängerung der Assistentenstelle von Döring, 25. Oktober 1938; Stellungnahme des Dozentenbundes, 29. Oktober 1938. UAG, Rek. 5250 / 8A.

284 GPAMNFG, Lehrkörper (ausgeschieden), Döring.
} 
führten. Im Protokoll heißt es: „Herr Prof. Becker hat daher gewünscht, dass wir besonders auf die Bestimmungen des Landesverrats hingewiesen würden."286 Ab 1941 waren vor allem Kranke als wissenschaftliche Hilfskräfte im Institut für theoretische Physik eingestellt; die Gesunden standen in der Regel an der Front. ${ }^{287}$

Döring wurde von Becker wegen seiner wissenschaftlichen Fähigkeiten besonders hoch geschätzt. 1939 schrieb er an Born über seine Göttinger Kollegen: „Der Beste am Ort ist mein Assistent Döring“. 288 Als Ergebnis der gemeinsamen Arbeit erschien im selben Jahr das Buch Ferromagnetismus. ${ }^{289}$ Es war auch das Jahr, in dem sich Döring mit der Arbeit „,Reversible Vorgänge in magnetischen Materialien mit kleinen inneren Spannungen“ habilitierte und zum Dozenten ernannt wurde. ${ }^{290}$ Trotz des gering gehaltenen politischen Engagements Dörings wurde er 1942 auf ein Extraordinariat der Reichsuniversität Posen berufen. Ohne dass mir Belege bekannt sind, ist doch anzunehmen, dass die einflussreiche Vermittlung durch Becker bei dieser Berufung förderlich wirkte. Seinen Schützling Döring fing er nach Kriegsende wieder in Göttingen auf und unterstütze ihn in der Wiedererlangung einer akademischen Stellung. Hierin lässt sich Beckers Einflussnahme aus den Quellen gut rekonstruieren (siehe Abschnitt 1.3.4.5). Becker hatte im Krieg gute Kontakte zur Luftwaffe und war seit 1. März 1942 korrespondierendes Mitglied der von Göring 1935/36 gegründeten Deutschen Akademie für Luftfahrtforschung. ${ }^{291}$ Während Becker durch seine Forschungen den Interessen des Staates diente und dafür auch mit dem Kriegsverdienstkreuz zweiter Klasse beehrt wurde, ${ }^{292}$ behielt er mental Distanz zur NS-Ideologie. Er bemühte sich, den politischen Druck von seinen Schülern fernzuhalten und ihnen kleine Freiräume in der akademischen Welt zu sichern. Ein Beispiel dafür liefert Beckers Einsatz für die Hilfskräfte in der von ihm im SS 1942 eingeführten „Arbeitsgemeinschaft zur Wiederholung und Befestigung des Schulpensums in Mathematik für Studierende der Naturwissenschaften“. Die Arbeitsgemeinschaft war so organisiert, dass die Teilnehmer in kleinen Gruppen zusammengefasst und von älteren Studenten geleitet wurden. Becker entschädigte die Gruppenleiter mit RM 50 monatlich,

\footnotetext{
285 Siehe Dörings Fragebogen vom 19. August 1945. GPAMNFG, Lehrkörper (ausgeschieden), Zahn [sic].

286 Aus der Verpflichtung zu Geheimhaltung durch den Kurator und Abwehrbeauftragten, i. V. Hillmann,

12. Dezember 1939. UAG, Kur. 4 V h / 35.

287 Siehe die Lebensläufe von Diether Grohne, Friedrich Kaempffer und Reinhard Henke in UAG, Kur. 4 V h / 35.

288 Brief Becker an Born, 23. Juli 1939. StB-B, NL Born 34.

289 Becker \& Döring [1939].

290 Die Ernennung zum Dozenten verbunden mit der Lehrbefugnis für theoretische Physik erfolgte am

25. August 1939. GPAMNFG, Lehrkörper (ausgeschieden), Döring.

291 UAG, Kur. PA Becker.

292 Am 30. Januar 1942 wurde ihm das Kriegsverdienstkreuz zweiter Klasse verliehen. UAG, Kur. PA Becker.
} 
bekam allerdings Schwierigkeiten in der weiteren Durchführung des Arbeitskreises, da der Kurator Lebenslauf, Ariernachweis und Arbeitsbuch von den Leitern einforderte, um sie auf ihre „charakterlichen und menschlichen Qualifikationen“ zu beurteilen. Daraufhin pochte Becker auf seine Autorität und versicherte dem Kurator, alle von ihm mit der Gruppenleitung beauftragten Studenten seien „charakterlich absolut einwandfrei und zuverlässig“. Er hoffte, dass das „nützliche und im besten Sinne vaterländische Unternehmen“ nicht vom Kurator in Frage gestellt werde. In mündlicher Rücksprache wurde die Frage erledigt und die RM 50 den Studenten ausbezahlt. ${ }^{293}$ Den Studenten blieb eine unangenehme politische und charakterliche Überprüfung erspart. Beckers Haltung wird auch durch seine Einschätzung eines Englandaufenthaltes kurz vor Kriegsbeginn plastisch.

Im Sommer 1939 war Becker für zwei Wochen in England anlässlich der Konferenz über „internal strains in solids“ in Bristol. $\mathrm{Zu}$ seiner Überraschung interessierten sich die englischen Kollegen (Mott, Bragg, Stoner, Sykes und Preston) viel mehr für seine Arbeiten als die deutschen. Trotz der politisch angespannten Lage war nicht nur der sachliche, sondern auch der menschliche Kontakt sehr erfreulich. Becker kam damals zu einer erstaunlich realistischen Einschätzung der Zukunft: „Ich fühle mich schon beinahe heimisch in diesem herrlichen Land, unbeschadet gewisser sprachlicher Schwierigkeiten. Aber was nützt das alles, morgen muss ich ins dritte Reich zurück, mit dem bangen Gefühl, dass hinter mir die Brücke zusammenbrechen und für lange Zeit unpassierbar bleiben kann."294 Becker bedauerte die internationale Isolierung, die in der NS-Zeit und besonders im Krieg die deutsche Wissenschaft einschnürte. ${ }^{295}$

\subsubsection{Institut für angewandte Elektrizität}

Wie Diagramm 1 zeigt, gab es am Institut für angewandte Elektrizität nur eine Assistentenstelle, die von 1931 bis etwa 1944 mit einer halbjährigen Unterbrechung 1932/33 mit Herbert Ruprecht besetzt war. Er war 1904 geboren, besuchte ein Realgymnasium in Bremen und eine Oberrealschule in Göttingen, studierte in Göttingen und München Physik, Elektrophysik, Mathematik, physikalische Chemie und Chemie und promovierte 1930 in Göttingen bei Max Reich. Neben seiner Assistententätigkeit unterrichtete er an der Reichenbachschule technische

\footnotetext{
293 Becker an Kurator, 11. Juni 1942. Die mündliche Klärung ergibt sich aus einer darauf befindlichen handschriftlichen Notiz des Vertreters des Kurators. UAG, Rek. 5250 / 8A. Institut für theoretische Physik, Feb. 1934-Dez. 1959.

294 Brief Becker an Born, 23. Juli 1939. StB-B, NL Born 34.

295 Siehe auch seinen „Bericht über eine Reise nach Straßburg zur Teilnahme an der Réunion d'étude sur le magnetisme in der Zeit vom 21. bis 25. Mai 1939“vom 19. Juni 1939. BAB, R 4901, 2943.
} 
Assistentinnen in Elektrophysik, außerdem gab er Abendkurse für Elektrohändler in Südhannover. Im Jahr 1933 nahm er an Ausbildungskursen der Reichswehr teil; kurz vor Kriegsbeginn bestand er die Offiziersübung. Bis Dezember 1939 diente er als Feldwebel in einem Ersatzregiment. Kriegswichtige Forschungsaufträge des NachrichtenmittelVersuchskommandos der Kriegsmarine in Kiel brachten im die uk-Stellung. 1940 übernahm er Vorlesungen und Praktika für den erkrankten Institutsdirektor Reich. Nach dessen Tod wurde er mit der vertretungsweisen Leitung des Instituts beauftragt. Im Jahr 1934 trat er der SS bei, in der er vor Kriegsbeginn Sturmschulungsleiter war. 1937 wurde er Parteigenosse. ${ }^{296}$

Ende 1940 war Ruprecht bereits neun Jahre Assistent gewesen, sein Chef Max Reich war schwer erkrankt. Georg Joos hatte Mühe, die Verlängerung der Stelle zu rechtfertigen, denn Ruprecht hatte bis dahin insgesamt nur drei Veröffentlichungen vorzuweisen. Joos hob hervor, dass Ruprecht jedenfalls einen Sender entwickelt habe, der sich in der Praxis gut bewährt habe. Außerdem war er der einzige Assistent am Institut und musste den erkrankten Direktor vertreten. Ruprechts Stelle wurde daher verlängert. ${ }^{297}$ Die Fertigstellung seiner 1939 begonnen Habilitationsschrift verzögerte sich durch seine militärischen Verpflichtungen, doch konnte er im Sommer 1941 die als Geheimarbeit geltende Schrift für das NachrichtenmittelVersuchskommando, nachdem sie vom Oberkommando der Kriegsmarine freigegeben worden war, einreichen. Die Arbeit behandelte die Erzeugung gerichteter Dezimeterwellenausstrahlung und diente vermutlich der Entwicklung eines Radargeräts. ${ }^{298}$

Bei dem folgenden Habilitationsverfahren machte sich das Fehlen seines früheren Fürsprechers, Vorgesetzten und Onkels, Max Reich, bemerkbar. Diese Rolle nahm 'vertretungsweise' Georg Joos ein,299 der in der schriftlichen Beurteilung Ruprecht die erschwerten Umstände bei der Durchführung der Forschungen zu Gute hielt. Die wissenschaftliche Aussprache brachte jedoch nur ein befriedigendes Ergebnis. Joos stellte eine Frage nach der Methode der Richtung der elektromagnetischen Strahlung, Becker nach dem Fundamentalvorgang der Elektronenemission und Pohl nach der Zukunftsentwicklung der Telefonie. Am Ende sprach sich der Dekan Correns für die Ernennung zum Dr. habil. aus, doch die Entscheidung der Vergabe einer Dozentur behielt sich die Fakultät noch vor. ${ }^{300}$ Zwei typische Vorbehalte der Göttinger Physiker machten sich hier bemerkbar: die strikte

\footnotetext{
296 Angaben nach GPAMNFG, Lehrkörper (ausgeschieden), Ruprecht.

297 Joos an Dekan, 31. Dezember 1940. UAG, Rek. 5250 / 6A.

298 GPAMNFG, Lehrkörper (ausgeschieden), Ruprecht.

299 Siehe den Schriftwechsel Ruprecht - Joos in BACZ, 22768.

300 Protokoll zur wissenschaftlichen Aussprache vom 29. November 1941. GPAMNFG, Protokollbuch III der mathematisch-naturwissenschaftlichen Fakultät WS 1927/28 - SS 1946.
} 
Ablehnung eines 'Spezialistentums', also einer zu starken fachlichen Einengung, und prinzipielle Vorbehalte gegen bloß angewandte Forschung, die nicht an eine Universität, sondern eine Technische Hochschule gehöre. Im Fakultätsausschuss wurde daher beschlossen, ,in dem Bericht an den Rektor den Satz aufzunehmen, daß die Erteilung einer Dozentur an der Universität Göttingen nicht erwünscht sei, da sein Arbeitsgebiet zu eng ist und seine Arbeitsrichtung zu weitgehend auf technische Anwendungen spezialisiert ist." Eine gleichlautende Ablehnung teilte der Dekan auch Ruprecht selbst mit und gab ihm den Rat, „sich an einer Technischen Hochschule um die Zulassung zur Dozentur zu bewerben“.302

Ein ähnliches Schicksal erlitt der Geophysiker Alfred Ramspeck anlässlich seiner Habilitation. Bei der wissenschaftlichen Aussprache, an der die Physikprofessoren Reich, Prandtl, Joos und Pohl teilnahmen, zeigte sich Ramspecks gutes Spezialwissen und sein praktischer Blick für die Anwendungen. Da aber umfassende Kenntnisse der grundsätzlichen physikalischen Zusammenhänge nicht vorhanden gewesen seien, sei er als Dozent an einer Universität nicht in Frage gekommen. Als ausgeprägter Spezialist sei er eher für eine Technische Hochschule geeignet gewesen. ${ }^{303}$

Ruprecht war also nicht der einzige, dem der Schritt zum Privatdozenten in Göttingen misslang. Dies geschah aber nicht aus politischen Gründen (für den Dozentenbund war er ein „guter Kamerad und SS-Mann“), ${ }^{304}$ sondern aus fachlichen. Genauer gesagt, passte Ruprecht nicht in das Profil der Göttinger Fakultät. Trotzdem behielt er seine Assistentenstelle, wenngleich 1941 seine Dienstanschrift „Berlin W 35, Bissingzeile 13, Oberk. d. Kriegsmarine, M Wa Stb F“ [= Marine Waffenamt, Stab Forschung] lautete. ${ }^{305}$ Beim OKM zog er in ein neues Forschungsinstitut ein und führte seine Göttinger Forschungen fort. ${ }^{306}$ Aus dem Stab Forschung im Marine Waffenamt entsprang die Abteilung FEP (Forschung, Erfindung, Patentwesen), in dessen 70 Mitarbeiter starken Gruppe FEP III unter Leitung des Göttinger Mathematikers Helmuth Hasse Ruprecht die Unterabteilung C, Elektromagnetische Wellen, leitete. 307 Im Sommer 1945 wurde ,unter Vorbehalt jederzeitigen Widerrufs längstens bis zur Rückkehr von Dr. Rupprecht [sic]“ Hans Severin eine Vergütung von 260

\footnotetext{
301 Protokoll der Sitzung des Fakultätsausschusses vom 6. Dezember 1941. GPAMNFG, Protokollbuch III der mathematisch-naturwissenschaftlichen Fakultät WS 1927/28 - SS 1946.

302 Dekan Correns an Ruprecht, 23. Januar 1942. GPAMNFG, Lehrkörper (ausgeschieden), Ruprecht.

303 Protokoll der wissenschaftlichen Aussprache mit Alfred Ramspeck, Ende 1937. GPAMNFG, Protokollbuch

III der mathematisch-naturwissenschaftlichen Fakultät WS 1927/28 - SS 1946.

304 Beurteilung des NSD-Dozentenbundes (Blume), 20. Februar 1937. UAG, Rek. 5250 / 7A.

305 GPAMNFG, Lehrkörper (ausgeschieden), Ruprecht.

306 Ruprecht an Joos, 24. September 1941. BACZ, 22768.
} 
RM für wissenschaftliche Hilfstätigkeiten bewilligt. ${ }^{308}$ Diese nach dem bisherigen Verlauf von Ruprechts Karriere seltsam anmutende Unterstützung, einem für die Universitätslaufbahn als ungeeignet erachteten Assistenten, dessen Assistentenzeit bereits 14 Jahre betrug, eine finanzierte Stelle in Göttingen $\mathrm{zu}$ reservieren, versteht sich nur aus den besonderen Umständen der unmittelbaren Nachkriegszeit, die in den Abschnitten 1.3.4 und 1.3.5 eingehend besprochen werden. Ruprecht kam jedenfalls nicht wieder zurück und Severin wurde sein Nachfolger als Assistent.

\subsubsection{Zwischenbilanz Kriegsende}

Bei den Nachbesetzungen der Ordinarien konnte sich die Fakultät mit den erstgereihten Wunschkandidaten in den Berufungsverfahren nicht durchsetzen. Trotzdem entwickelte sich zwischen den alten Göttingern und den Neuberufenen ein konstruktives kollegiales Verhältnis. Wenn auch die Argumentationen zur Durchsetzung von Kandidaten politisch aufgeladen waren, standen doch fachliche Kriterien im Vordergrund. Die NS-Rektoren und Dekane trugen besonders um die Reputation der Göttinger Fakultät Sorge; in heutiger Sprache würde man sagen, dass sie um die Standortsicherung bemüht waren. Zum Beispiel wurde der vom Dozentenbund aus politischen Überlegungen ins Spiel gebrachte Walther Kossel vom Danziger und Göttinger Rektor in rein fachlicher Argumentation völlig degradiert.

Die Interpretation der Berufungsverfahren gestaltet sich mitunter schwierig, denn, wie Richard Becker 1939 bemerkte, es entbrannte „um jede freie Stelle [...] zunächst ein zäher unterirdischer Kampf der vielen Instanzen, welche dabei mitzureden haben."309 Die Schwierigkeit besteht darin, dass all die verborgenen Kämpfe heute nicht mehr nachverfolgt werden können. Deshalb bleibt zum Beispiel die Ablehnung Kulenkampffs für Göttingen und seine Berufung nach Jena rätselhaft. Wenn die unterschiedlichen Instanzen offenbar Einigkeit erzielen konnten, vollzog sich eine Berufung wie im Fall Hermann Zahn rasch und unkompliziert.

Mit der Berufung von Becker und Joos kamen Physiker nach Göttingen, die in ihren eigenen Forschungen eine Verknüpfung von theoretischer und experimenteller Physik herstellten und dabei den Blick für technische Anwendungen behielten. Dies legte den akademischen Nach-

307 BIOS Final Report No. 79, Applied Mathematical Research in Germany, with Particular Reference to Naval Applications, S. 46.

308 Schreiben des Kurators, 8. Juni 1945. UAG, Rek. 5250 / 7A. 
wuchs nicht so schnell auf eine bestimmte Richtung fest und erleichterte ihm den Wechsel zwischen der theoretischen und experimentellen Physik. Die zweifache Neubesetzung der II. Experimentalphysik innerhalb eines Jahrzehnts schuf Verhältnisse, in denen Assistenten leichter zum Übertritt in ein anderes Institut aufgefordert waren. Die Karrieren des Nachwuchs waren schon auf der untersten Ebene der Hilfsassistenten durch eine politische Selektion gekennzeichnet, gegen die sich die Institutsdirektoren nur bedingt zur Wehr setzen konnten. Außer aus politischen Gründen mussten die jungen Physiker die Universität vor allem wegen des Kriegsdiensts verlassen; ein einziger nach eigenen Angaben auch aus konfessionellen Gründen. Die meisten der nicht aus politischen Gründen Ausgeschiedenen konnten sich schon vor ihrem Weggang ins Göttinger kollegiale Netz integrieren, sodass ihnen eine Rückkehr teils noch während des Krieges, teils unmittelbar danach erleichtert wurde. Praktisch alle Nachwuchsphysiker passten sich während ihrer Karriere an die politischen Verhältnisse durch Mitgliedschaften in der Partei oder ihren Gliederungen und angeschlossenen Verbänden an. Bei der Auswertung vieler Lebensläufe in den Assistenzakten ist mir nur eine einzige Ausnahme begegnet, die aber umso bemerkenswerter ist. Helmut Schaefer setzte 1942 ans Ende seines Lebenslaufes folgende „Erklärung. Ich gehöre weder der N.S.D.A.P. noch einer ihrer Gliederungen an. "310 Diese Erklärung bestätigte er mit einer zweiten Unterschrift, wodurch sie den Charakter einer Protestbekundung bekam. Schaefer konnte ohne politische Anpassung an der TH Berlin 1939 zum Dipl. Ing. und 1942 zum Dr. Ing. aufsteigen. In Göttingen war er Mitarbeiter von Walcher am II. Physikalischen Institut. Dies ist vermutlich kein Zufall, denn Walcher war einer der wenigen Physiker, der bloß mit einer kurzzeitigen NSKK Mitgliedschaft seine Habilitation erreichte. ${ }^{311}$ Über Schaefers weitere Karriere ist aus den Akten nichts zu entnehmen. Eine Assistentenstelle bekam er nicht; dafür wurde zur selben Zeit Jens Geerk Assistent am II. Institut, der 1932 sowohl in die SA als auch in die Partei eingetreten war. ${ }^{312}$ Geerk war damals Kopfermanns bester Schüler, „war drei Jahre lang leitender Ingenieur eines Front-Ubootes und hat sich auf zehn Feindfahrten hervorragend bewährt." 313

In der Auswahl des akademischen Nachwuchses führten die durch den NS hinzugekommenen politischen und rassistischen Anforderungen nicht zur Aufweichung der traditionellen wissen-

\footnotetext{
309 Brief Becker an Born, 23. Juli 1939. StB-B, NL Born 34.

310 Lebenslauf von Schaefer, 4. Dezember 1942. Daraus auch die folgenden Angaben. UAG, Kur. XVI. V. C. h. 2. II.

311 Die NSKK Mitgliedschaft währte angeblich nur ein halbes Jahr. Siehe Rosenow [1987/98] S. 574.

312 Lebenslauf von Jens Geerk, 18. Mai 1943. UAG, Kur. XVI. V. C. h. 2. II.

313 Kopfermann an Kurator, 20. Mai 1943. UAG, Rek. 5250 / 6A. 
schaftlichen und charakterlichen Ansprüche. Das zusätzliche Auswahlkriterium führte zu einem Rückgang von in jeder Hinsicht 'qualifizierten' Wissenschaftlern. Einen kleinen Anteil daran mag auch der Rückgang der Studentenzahlen ab zirka 1931 gehabt haben. Es ist dabei aber zu berücksichtigen, dass nur etwa $2 \%$ der Studenten die Professorenlaufbahn anstrebten, und auch nur so ein geringer Teil laut Einschätzung der Professoren die charakterlichen und intellektuellen Fähigkeiten dazu mitbrachte. Es ist $\mathrm{zu}$ vermuten, dass der allgemeine Studentenrückgang sich nicht in gleicher Weise auch auf diese Elitestudenten auswirkte. Ein Hinweis darauf liefern die Zahlen der Promotionen, die in viel geringerem Maße zurückgingen als die Studentenzahlen. ${ }^{314}$

Eine erste Erholung der personell angespannten Lage brachte im letzten Kriegsjahr die sogenannte Osenbergaktion. Die auf Initiative des Professors Werner Osenberg von der TH Hannover im RFR unter dem Begriff Forschung laufende Rückholaktion von an der Front kämpfenden Wissenschaftlern brachte den Göttinger Physikinstituten bis Mitte August 1944 einen personellen Zuwachs von 13 Personen, der sich aufteilt in vier zurückgerufene Kräfte und neun neu zugewiesene Kräfte. Besonderer Nutznießer war Zahns Institut für angewandte Elektrizität mit fünf neu zugewiesenen Kräften, einem Feinmechaniker und vier Diplomingenieuren. Alle Göttinger Universitätsinstitute zusammen wuchsen durch die Aktion um 32 Personen an. Der an der Universität dafür zuständige Obmann des RFR war der vormalige Rektor Hans Plischke. ${ }^{315}$

\subsection{Nachkriegszeit - die Rhetorik der Richtungsänderung}

Die militärische Niederlage Deutschlands führte zu einem radikalen Wandel der die Universität umgebenden und beeinflussenden Institutionen. Die vielfältige Umwelt der Physikinstitute wurde nicht nur durch hinzukommende Bereiche neu strukturiert, auch in den schon vorher existierenden Verwaltungsebenen kam es durch personelle Umbesetzungen zu einer veränderten Umgebung. ${ }^{316}$ Die Organsiation der Forschung musste neu geregelt werden, eine tragfähige Verbindung zu den nun entscheidenden Instanzen hergestellt werden. Mitchell

\footnotetext{
314 Auch Rosenow [1987/98] S. 568 argumentiert in dieser Richtung. Siehe dazu auch den Abschnitt 2.2.1. Dort wird auch eine Eingabe von 75 Physikprofessoren ans REM besprochen, in der sie eine Verbindung des Studentenrückgangs mit einem befürchteten Ausbleiben des Professorennachwuchses konstruierten.

315 Siehe die entsprechende Liste des RFR, Sachbearbeiter Dipl.-Ing. Voos, Stichtag 11. August 1944 sowie Plischkes Schreiben an den Kurator vom 18. September 1944. UAG, Kur. 2018. Zur Aktion Osenberg siehe Federspiel [2002] und Abschnitt 2.2.2.

316 Zur Neuordnung der Verwaltung siehe Schnoor [1986].
} 
Ash spricht in diesem Zusammenhang von einer Neuordnung der Ressourcenkonstellation. ${ }^{317}$ Eine solche Ressource bildete die Reputation der Universität. Um das Ansehen vor dem neuen Machthaber wiederherzustellen, mussten neue Strategien angewendet werden. Die Rhetorik, mit der das Produkt der Universität, nämlich Forschung und Ausbildung, gepriesen wurde, erfuhr eine deutliche Wandlung. In der Nachkriegsgeschichtsschreibung wurden die diesbezüglichen Äußerungen der Universitätsführungen oft $\mathrm{zu}$ wörtlich genommen, und daraus wurde ein Neubeginn für 1945 gefolgert. In welchem Maß die proklamierte Richtungsänderung tatsächlich umgesetzt wurde, wird hier am Beispiel der Physik gezeigt.

Die Literatur zu den deutschen Hochschulen unmittelbar nach 1945 hat gezeigt, dass in dieser politischen Umbruchsphase die lokalen Verhältnisse eine viel entscheidendere Rolle spielten, als es zuvor oder in der späteren Bundesrepublik der Fall war. ${ }^{318}$ Verschiedene Verläufe in der Hochschulentwicklung gab es aber nicht nur zwischen den vier Besatzungszonen und auf Grund der unterschiedlich starken Zerstörungen durch den Krieg. Es waren auch die einzelnen Kontrolloffiziere, die jeder Universität zugeordnet wurden, die durch ihren großen Entscheidungsspielraum der Entwicklung an jeder Hochschule ein eigenes charakteristisches Gepräge verliehen. ${ }^{319}$

In dieser Hinsicht waren in Göttingen die Voraussetzung für einen Weiterbetrieb der Universität günstig. ${ }^{320}$ Sowohl der erste Kontrolloffizier L. H. Sutton wie auch sein Nachfolger Geoffey Bird standen der Universität wohlwollend gegenüber. 321 Zusätzlich begünstigend wirkte die geografische und geistige Lage Göttingens, die viele aus dem Osten flüchtende Menschen, darunter auch einige Hochschullehrer, auffing. Schon im Oktober 1945 verkündete der Anglistikprofessor Herbert Schöffler vor den Studenten den zukünftigen Aufstieg seiner Forschungsstätte: „Die Georgia-Augusta steht vor neuer Blüte inmitten eines Erdrutsches. Dadurch, dass alle ihre Fakultäten aus dem Elend aller Zeiten retten, was zu

\footnotetext{
317 Ash [1995]b.

318 Zur Wissenschaft nach 1945 siehe die Literaturbesprechung in der Einleitung.

319 Die Bedeutung der Kontrolloffiziere, die individuell unterschiedliche Ziele verfolgt und Methoden der Kontrolle angewendet haben, belegt die eindrucksvolle Studie über das Beispiel Heidelberg von Remy [2002]. Siehe auch die Zeitzeugenberichte in Heinemann (Hrsg.) [1990]a, (Hrsg.) [1990]b.

320 Schneider \& Dumke [1985]; Thadden [1985]; Brinkmann [1985]b.

${ }^{321} \mathrm{Zu}$ Suttons Zeit als Universitätskontrolloffizier der Universität Göttingen von Oktober bis Dezember 1945 siehe seinen zeitgenössischen Bericht Sutton [1946/83]. Sein Nachfolger Bird (bis 1951) hat mehrfach über seine Tätigkeit in Göttingen und die britische Haltung zum Wiederaufbau der deutschen Hochschulen berichtet: Bird [1978], [1981] und [1983]. Auch von Seiten der deutschen Professoren wurde ein wohlwollendes Verständnis der britischen Militärregierung festgestellt. Siehe Rein [1948] S. 230.
} 
retten ist, findet sich eine Fülle der Geistigkeit im Städtchen zusammen, wie sie nur die hohen Zeiten ihrer Vergangenheit aufgewiesen haben.“"322

Schöffler täuschte sich nicht mir seiner Prognose. Keine fünf Jahre später wurde rückblickend ein hoher personeller Zuwachs nach 1945 besonders in der Medizinischen und Math.-Nat. Fakultät festgestellt, der mit Hilfe der zahlreichen Assistentenstellen, über die diese beiden Fakultäten verfügten, einigermaßen versorgt werden konnte. ${ }^{323}$ Die Zeit der Entnazifizierung bescherte der Universität zwar einen zahlenmäßigen Zuwachs an Lehrpersonal, jedoch mussten auch manche ihre Stelle räumen. Insgesamt wurden etwa die Hälfte aller Lehrstühle zwischen 1945 und 1949 neu besetzt; in der Mathematisch-Naturwissenschaftlichen Fakultät waren es nur etwa ein Fünftel. ${ }^{324}$ Die Weichenstellung, die diesen personellen Aufschwung hervorbrachte, erfolgte auf der höchsten Ebene der Universität schon im April 1945. Die Naturwissenschaftler hatten in der Person ihres neu gewählten Dekans Arnold Eucken erheblichen Anteil an dieser Richtungsentscheidung. Im Senat wurde der Rahmen geschaffen, der die Personalentscheidungen in der bewegten Zeit der Entnazifizierung in ihrer Zielsetzung bestimmte. Am Anfang war jede Universität auf sich selbst gestellt; erst allmählich kam es auf den (zuerst nordwestdeutschen) Hochschulkonferenzen zum Abgleich der unterschiedlichen Vorgehensweisen. ${ }^{325}$

\subsubsection{Der neue Senat und das Aufleben alter Ideale}

Am Tag nachdem Göttingen von den amerikanischen Truppen eingenommen worden war, traf sich der Senat im Kuratorium zu einer Besprechung, in der die neue Situation in ihrer Bedeutung für die Hochschule diskutiert wurde. Dabei ergaben sich „beträchtliche grundsätzliche Meinungsverschiedenheiten“. Der zuletzt und immer noch amtierende Rektor Drexler wurde von seinem Amtsvorgänger Plischke angegriffen und fühlte sich offenbar in die Enge gedrängt. Eine Besprechung des amerikanischen Sergant Brown mit Rektor Drexler am selben Tag war zu keinem Ergebnis gekommen. Am folgenden Tag, den 10. April tagte der Senat erneut. Drexler stellte am Vormittag die Vertrauensfrage, die zu einer grundsätzlichen Erörterung führte. Erst am Nachmittag war er bereit, das „,nun Opportune“ zu tun, und zwar seine Stelle für einen Nachfolger frei zu machen. Wenn man bedenkt, dass

\footnotetext{
322 Aus der Rede Herbert Schöfflers an die Göttinger Studenten vom 28. Oktober 1945, abgedruckt in Krönig \& Müller [1990] S. 342-348, hier S. 346.

323 Bollnow [1950] S. 157.

324 Bollnow [1950] S. 157.

325 Heinemann (Hrsg.) [1991]c und [1991]d.
} 
dieser Senat aus dem vom Ministerium eingesetzten Rektor und den von diesem bestimmten Dekanen bestand, so ist man doch überrascht, wie schnell die Zeichen der Zeit erkannt wurden. ${ }^{326}$

Am 11. April wurde Drexler von der amerikanischen Militärpolizei als Kriegsgefangener festgenommen. Der Stadtkommandant, Leutnant Sailor, wünschte eine Liste für in Frage kommende neue Rektoren, damit nach Streichung ungeeigneter Kandidaten eine Wahl stattfinden konnte. Doch wechselte am 14. April die Leitung der Militärregierung von den Amerikanern zu den Briten, die ihrerseits den Rektor selbst bestimmen wollten. Statt einer vorher angefertigten Liste mit acht Namen ${ }^{327}$ wurde nun eine mit nur zweien eingereicht: Rudolf Smend und Hermann Rein. Smend hatte schon bis dahin die wichtigsten Gespräche mit den Besatzern und dem Oberbürgermeister geführt und wurde nun von der britischen Militärregierung zum Rektor ernannt. Seine Tätigkeit als letzter Kriegsdekan der Rechts- und Staatswissenschaftlichen Fakultät gereichte ihm nicht zum Schaden. Am 19. April wurden die alten Dekane durch neu gewählte ersetzt. Eine bestätigende Wahl des provisorisch ernannten Rektors Smend durch alle ordentlichen und nach Anordnung der Militärregierung auch aller außerordentlichen Professoren fand erst am 27. Juli 1945 statt. Bei dieser Gelegenheit wurde Hermann Rein zum Prorektor gewählt. 328

Im Senat wurde Ende April „die durch den Fortfall aller bisher die Universität tragenden Zusammenhänge" geschaffene neue Lage eingehend besprochen. In der Wahrnehmung der neuen Universitätsführung schien die Universität ,in einem bisher unerhörten Sinn auf sich gestellt" zu sein. Die Hauptsorge der Senatsmitglieder galt der Frage, wie sie eine möglichst rasche Wiedereröffnung der Universität erreichen könnten. Ein fruchtbarer Weg wurde darin gesehen, mit einer grundsätzlichen Erklärung an die Öffentlichkeit zu treten. Dabei sollte eine geschlossene Haltung präsentiert werden, das heißt, zuerst musste eine interne Klärung über Ziele und Aufgaben der Hochschule stattgefunden haben. Einigkeit bestand darüber, dass es nicht mehr genüge, nur auf ,ihre sachliche Facharbeit“" hinzuweisen, da sie damit Gefahr liefe, zur Fachschule degradiert zu werden ,unter Preisgabe ihrer Geschichte seit mindestens vier Jahrhunderten“.329 Vier Professoren verfassten dazu Entwürfe; der neue Dekan der

\footnotetext{
326 Aus Aufzeichnungen von Otto Weber über die Verhandlungen im Senat vom 9. bis 21. April 1945. UAG, Senatsprotokolle 1945-1949.

327 Diese acht waren: Rein, Smend, Martius, Bauer, Brandi, Eucken, Prandtl und Windaus. Siehe Fesefeldt [1962]. Fesefeldt bezieht sich auf dieselben Senatsprotokolle, die auch mir vorlagen, jedoch scheinen diese vor vierzig Jahren noch vollständiger gewesen zu sein, denn die Namensliste fehlt heute.

328 Fesefeldt [1962] S. 140. Siehe auch das Schreiben des Kurators an den Oberpräsidenten in Hannover vom 28. Juli 1945, wo er um die Bestätigung der Wahl bittet. HStAH, Nds. 401 Acc. 92 / 85, Nr. 399.

329 Protokoll der Senatssitzung vom 28. April 1945. UAG, Senatsprotokolle 1945-1949.
} 
mathematisch-naturwissenschaftlichen Fakultät, Arnold Eucken, Herbert Schöffler als Dekan der philosophischen Fakultät, der Forstwissenschaftler Theodor Schmucker und der Theologe Otto Weber. ${ }^{330}$ Als erster formulierte Otto Weber „Programmatische Erwägungen zur Neugestaltung der Universität", die leider nur bruchstückhaft in einer späteren Notiz überliefert sind. 331 Eucken beginnt seinen Gegenentwurf mit einer klaren Rhetorik der Richtungsänderung: „Durch die umwälzenden Ereignisse der kürzlich vergangenen Zeit wird auch die Universität Göttingen gezwungen, eine wesentliche Änderung der ihr in den letzten zwölf Jahren gegebenen Ausrichtung vorzunehmen.“332 Dieser Wortlaut klingt seltsam defensiv, als würde Eucken einer Änderung nur äußerst ungern zustimmen. Dies war vermutlich nur unglücklich formuliert und gar nicht so gemeint. Ihm schwebte kein völlig neuer Weg vor, sondern ein Anknüpfen an eine jahrhunderte alte Tradition der deutschen Universität im Sinne des Idealismus und Universalismus. Ohne es auszusprechen, ist hier das Humboldtsche Ideal gemeint, das es zwar nie verwirklicht gab, an dem die deutschen Professoren aber um so stärker hingen, je weiter sich die Realität der Hochschulen davon entfernt hatte. ${ }^{333}$ Treffenderweise sprechen wir heute in diesem Zusammenhang vom Mythos Humboldt. Euckens Variante der Humboldt'schen Universität beinhaltete Objektivität als Grundlage jeder akademischen Lehr- und Forschungstätigkeit. Darauf aufbauend müsste aber dem Forscher und Lehrer völlige Freiheit seiner Betätigung und seines Urteils gewährleistet sein. Vom Wissenschaftler forderte er vollste Hingabe und Einsatz der ganzen Persönlichkeit in der wissenschaftlichen Tätigkeit. Die Auswahl der Dozenten sollte allein nach wissenschaftlicher Leistung geschehen, wobei ein „völlig einwandfreier Charakter“ vorausgesetzt wurde (eine Besprechung dieser Charakterforderung folgt im nächsten Kapitel, speziell im Abschnitt 2.3.6). Dies waren nach Eucken altbewährte Grundsätze, doch gingen sie über den Kern der Humboldt'schen Forderungen hinaus. ${ }^{334}$ Eucken rechtfertigte die 'Neuausrichtung' durch ein rhetorisches Anknüpfen an eine nicht kompromittierte Tradition. Für ihn war eine der alten Aufgaben der Universität die Verteidigung der Kultur gegen bloße

\footnotetext{
330 Sowohl Schmucker wie Weber waren bis Kriegsende Dekane ihrer Fakultät.

331 Programmatische Erwägungen zur Neugestaltung der Universität von Otto Weber, 19. Juni 1945. Weber wollte die Universität an der Zeit vor 1933 wiederanknüpfen lassen. Sie sollte ihre wissenschaftlichen Kräfte in den Dienst des Geists der Zusammenarbeit und des Friedens stellen. UAG, Senatsprotokolle 1945-1949.

332 Dieses und auch die folgenden Eucken-Zitate stammen aus seinem Entwurf einer grundsätzlichen Stellungnahme vom 27. April 1945. UAG, Senatsprotokolle 1945-1949.

333 Der langsame Abschied von 'Humboldt' von 1810 bis 1945 ist beschrieben bei vom Bruch [1999].

334 Als Kern des Humboldt'schen Ideals sind zu nennen: Abgrenzung vom staatlichen Einfluss, Idee der Einheit der Wissenschaften, individuelle Persönlichkeitsentfaltung durch Wissenschaft und die Ausrichtung der Wissenschaft auf Forschung statt auf enzyklopädischer Wissenschaftstradition. Siehe dazu vom Bruch [1999] S. $35 f$.
} 
Zivilisation und Technik. ${ }^{335}$ Hier herrschte eine deutliche Widersprüchlichkeit zwischen der proklamierten Anknüpfung an Altbewährtes und den tatsächlichen Möglichkeiten der Umsetzung. Wie Konrad Jarausch treffend zeigte, kehrte die Universität mit solchen Forderungen und Sichtweisen zu den Problemen des Elitedenkens, der intellektuellen Arroganz und der apolitischen Grundhaltung zurück. 336

Die apolitische Haltung steigerte sich bei Eucken zu der Forderung: „Die Universität muss entpolitisiert werden." Sie solle kein Tummelplatz verschiedener politischer Meinungen sein, sondern es solle als breite und solide Grundlage nur noch eine gemeinsame geben, und zwar die „volle Bejahung des Staatsgedankens an sich“. Diese Loyalitätsbekundung sollte staatliche Einflussnahme unnötig erscheinen lassen und sie damit abwehren. Als letzter Aspekt sei noch erwähnt, dass Eucken auch kulturelle Aufgaben der Universität behauptete, zum Beispiel die Verbreitung deutscher Kultur im Ausland.

Die Entwürfe von Schöffler und Schmucker bedienen sich in ähnlicher Weise der Humboldt'schen Rhetorik. Der Anglist Schöffler hob stärker die Bedeutung der Wissenschaft für das Zusammenleben der Völker hervor und betonte, dass die Universität ihre alten Selbstverwaltungsformen wiedergewinnen müsse. ${ }^{337}$ Schmucker fügte der Reinwaschung der Universität noch den Topos des Missbrauchs hinzu, der die Wissenschaft in der NS-Zeit getroffen hätte. 338 Indem Schmucker behauptete, die Freiheit von Forschung und Lehre bedinge die Autonomie der Universität, bediente er sich klar dem Humboldt'schen Ideal. ${ }^{339}$ Zur Abwehr staatlichen Einflusses versuchten die Göttinger Professoren, den Kurator abzuschaffen, womit sie allerdings erfolglos blieben. ${ }^{340}$

\footnotetext{
335 Protokoll der Senatssitzung vom 25. April 1945. UAG, Senatsprotokolle 1945-1949.

$336 \mathrm{Zu}$ diesem Schluss kam Jarausch in der Analyse der Rückkehr zur Humboldt'schen Rhetorik in der Nachkriegszeit. Jarausch [1999] S. 61.

${ }^{337}$ Entwurf Schöffler, April 1945. UAG, Senatsprotokolle 1945-1949. Zu Schöffler und sein kurzes Wirken in Göttinger nach Kriegsende siehe Scholl [1998] S. 416-418.

338 Diese Argumentation findet sich in der Nachkriegszeit vor allem in den Technik- und Naturwissenschaften. Siehe Mehrtens [1995].

339 Entwurf Schmucker. UAG, Senatsprotokolle 1945-1949.

340 Von den in der NS-Zeit tätigen Kuratoren Büchsel, Stich und Bojunga, die alle 1945 entlassen wurden, kehrte nur Bojunga noch im Sommer 1945 auf seinen Posten zurück. Während die Hochschulleitung seiner Person in den politisch bedingten Schwierigkeiten Unterstützung zusicherte und ihm das Vertrauen aussprach, wurde das Vorhandensein eines Kurators an sich für die Universität in Frage gestellt. Siehe als frühesten Beleg: Protokoll der Senatssitzung vom 12. Mai 1945. UAG, Senatsprotokolle 1945-1949. Die Universitätsführung hielt aber an dem Ziel der Abschaffung hartnäckig, wenn auch erfolglos, fest, was in den Protokollen der Hochschulkonferenzen deutlich ersichtlich wird. Siehe dazu Heinemann (Hrsg.) [1990]c. Erfolgreich war allerdings die Universität Bonn, die sich unter dem Rektorat des Physikers Heinrich Konen, der gleichzeitig Kultusminister des Landes Nordrhein-Westfalen war, 1947 der Institution des Kurators entledigte. Haude [1998] S. 57.
} 
Die Selbstdefinitionen der Göttinger Universität in ihren verschiedenen Entwurfsformen fanden kaum praktische Verwendung. Zu groß und drängend waren die Alltagssorgen der Hochschule in den ersten Nachkriegsmonaten. Einen geeigneten Zeitpunkt, mit einer Grundsatzerklärung an die Öffentlichkeit zu treten, scheint es nicht gegeben zu haben. Neben der Rhetorik, die eine rasche Wiedereröffnung herbeiführen sollte, finden sich in ihnen auch die wesentlichen Eckpunkte einer von der Universität verfochtenen Hochschulpolitik. Der Rettungsversuch von geschätzten Kollegen, die auch zukünftig zur Elite zählen sollten, bei Ausklammerung der politischen Komponente, war das versteckte Programm. Zu diesem Zweck sammelte der Senat entsprechendes Material über den Göttinger Lehrkörper, um in den Verhandlungen mit den Besatzungsbehörden angemessen argumentieren zu können. Aus den Kuratorialakten wurden zwei Lebensläufe der Dozenten erstellt: ein amtlicher und ein politischer „(Zugehörigkeit zur Partei, Eintritt, Betätigung, Ämter)“. Außerdem gesammelt wurden Erklärungen der Universitätslehrer zu ihrer politischen Karriere und eigene Informationen und Stellungnahmen der Göttinger amtlichen Stellen. ${ }^{341}$ So war man im Stillen gerüstet. Bald kamen auch die ersten Fragebogen des Lehrkörpers, zu denen beschlossen wurde, „strikteste Verschwiegenheit bezüglich der Stellungnahme des Senats zu ihnen zu wahren.“342

Den Schritt in die Öffentlichkeit unternahm Karl Jaspers mit seinem 1946 erschienen Buch Die Idee der Universität. Er erwies seinen deutschen Kollegen einen großen Dienst, wenn er „dieser abendländischen, übernationalen, hellenisch-deutschen Idee“, die zugleich Element einer Lebensanschauung sei, eine Rechtfertigung gab. Jaspers schuf kein neues Hochschulkonzept, sondern versuchte, die alte akademische Tradition an die neuen Verhältnisse anzupassen. Es ist aufschlussreich zu sehen, in welchen Punkten Eucken von Jaspers abweicht. Ihm schien ein Punkt zu kurz gekommen zu sein, und zwar die „Krise, in der sich die Wissenschaft durch ihre unermeßliche Verzweigung und Aufsplitterung in zahllose, beziehungslose Einzelfächer gegenwärtig befindet“". Für Eucken war dieser Zustand deswegen bedrohlich, weil er der „Grundforderung der Wissenschaft nach Universalität“ widersprach. Die gesehene Gefahr wurde als Spezialistentum bezeichnet, das nicht dazu geeignet sei, ganze Persönlichkeiten zu formen, und daher unbedingt abzulehnen sei (zum Spezialistentum siehe Abschnitt 4.2). Ein ähnliches Problem lag in dem Massenzudrang an die Universitäten, ,welcher der geistesaristokratischen Grundhaltung der Universität [...]

\footnotetext{
341 Protokoll der Senatssitzung vom 9. Mai 1945. UAG, Senatsprotokolle 1945-1949.

342 Protokoll der Senatssitzung vom 26. Mai 1945. UAG, Senatsprotokolle 1945-1949.
} 
direkt zuwiderläuft und der unbedingt irgendwie gesteuert und abgelenkt werden muß“ (zur 'Vermassung' siehe Abschnitt 2.3). ${ }^{343}$

Es ist äußerst bezeichnend, welche Probleme hier als zeitgemäße angesehen wurden und welche nicht. Als im Senat von Rektor Smend eine Auseinandersetzung mit den Konzentrationslagergreuel, dem „ethisch-politischen Problem der Zeitlage“, angeregt wurde, warnte Eucken „vor Abgleiten in Kriegsschuldfragenerörterung“. Demgegenüber unterstrich Otto Weber die Notwendigkeit grundsätzlicher Besinnung. Die Besprechung wurde abgebrochen. 344 Es scheint, dass die Mentalität der exakten Naturwissenschaftler einen Rückzug zu 'objektiver Forschung' als Reaktion auf die politische und gesellschaftliche Entgleisung stärker nahe legte, als dies bei den geisteswissenschaftlichen Kollegen der Fall war. Von dort kamen unpassende Versuche, die Politik zu verniedlichen, wie zum Beispiel von Schöffler vom Oktober 1945: „In Zeiten wie diesen steht der Kleinkram der Politik zurück an Bedeutsamkeit; viele sind nach den Erfahrungen der Jahre, durch die wir gehen mussten, aller Politik müde.“"345

Langsam besserten sich die Verbindungen $\mathrm{zu}$ den entscheidenden Personen in der Militärregierung. Im Juni 1945 war Smend zur Besprechung bei dem für die Hochschulen zuständigen Major Beattie in Hannover. Smend drückte dort sein Bedauern über bereits vollzogene Entlassungen aus, da es doch im Interesse der politischen Erziehung und Beruhigung sehr darauf ankomme, dass die personellen Entscheidungen der Militärregierung einleuchtend seien. Smend erreichte aber nicht ganz das Gewünschte: „Major Beattie läßt sich nur langsam vorwärts drängen“, teilte er seinen Göttinger Kollegen mit. ${ }^{346}$ Die Situation verbesserte sich im Laufe der Zeit, denn auf Seiten der Besatzer gab es unterschiedliche Auffassungen über Ziel und Umfang der politischen Überprüfung des Lehrkörpers. Zum Beispiel äußerte sich der britische Kontrolloffizier L. H. Sutton, der bis Ende 1945 für die Universität Göttingen zuständig war, schon damals kritisch zur Entnazifizierungspraxis. Ihm erschien die Anzahl der entlassenen Professoren zu hoch. Sie könnten Keimzellen von umstürzlerischen Gruppen werden, befürchtete er. Da sie ihre Stellen bereits verloren hatten, fehle ihnen jene Hemmung vor solch unerwünschten Handlungen, die sie in Amt und Würden

\footnotetext{
343 Alle Zitate stammen aus Euckens Besprechung von Jaspers Buch in Eucken [1946]c.

344 Protokoll der Senatssitzung vom 6. Juni 1945. UAG, Senatsprotokolle 1945-1949.

345 Herbert Schöffler in einer Rede an die Göttinger Studenten am 28. Oktober 1945. Zitiert nach Krönig \& Müller [1990] S. 342.

346 Aus Smends Protokoll seines Besuchs bei Major Beattie in Hannover, 19. Juni 1945. Bei dieser Gelegenheit traf er auch mit dem Oberpräsidenten Dr. Hagemann, der die Rolle des früheren Kultusministers übernahm, zusammen. UAG, Senatsprotokolle 1945-1949.
} 
noch besäßen. ${ }^{347}$ Tatsächlich wurde zwischen Mai 1945 und Juli 1947 an der Universität Göttingen etwa ein Drittel des gesamten wissenschaftlichen Personals zumindest zeitweise entlassen. ${ }^{348}$ Angesichts dieses Ausmaßes erscheint die Sorge des Kontrolloffiziers durchaus berechtigt. In den Naturwissenschaften und speziell in der Physik sahen die Verhältnisse jedoch anders aus. Aus seiner Stelle entlassen wurde in der Physik nur ein einziger Dozent. Bevor dieser Fall untersucht wird, ist aber der gesetzliche Rahmen und die Verfahrensweise der Entnazifizierung kurz zu beschreiben.

\subsubsection{Die personelle Entnazifizierung der Physik}

Die Schwierigkeiten, mit denen die personelle Entnazifizierung der deutschen Gesellschaft verbunden war, sind viel diskutiert und oft historisch untersucht worden. Daher wird hier auf eine breitere, gesellschaftsbezogene Analyse verzichtet und nur das Verfahren der Entnazifizierung und seine Auswirkungen in der Göttinger Physik dargestellt. Zuerst werden kurz die wichtigsten gesetzlichen Rahmenbedingungen, die für Göttingen gültig waren, skizziert, anschließend die Umsetzung der gesetzlichen Vorgaben an der Universität beschrieben.

Von Mai bis Dezember 1945 gab es erste Entlassungen, die ohne gesetzliche Grundlage auf Grund von vorhandenen Listen durch die Besatzungsmacht unter beratender Mitwirkung deutscher Ausschüsse durchgeführt wurden. Mit der Verordnung Nr. 24 vom Januar 1946 kam die erste gesetzliche Grundlage, die zur Bildung von deutschen Entnazifizierungsausschüssen führte. Auf Grund der Direktive Nr. 38 vom Oktober 1946 wurden die zu Überprüfenden durch die deutschen Ausschüsse in 5 Gruppen eingeteilt (Kategorie I: Hauptschuldige ... Kategorie V: Entlastete); eine Bestätigung durch die Militärbehörde war jedoch erforderlich. Ein Schritt zur Vereinheitlichung der Entnazifizierungsverfahren bezüglich Strafen, Sanktionen und Beschränkungen bedeutete Verordnung Nr. 79 vom Februar 1947. Im Oktober 1947 wurde die Verantwortung der Entnazifizierung offiziell in deutsche Hände übergeben mit ansonsten gleichbleibender Verfahrensweise (Verordnung Nr.110). Zur selben Zeit kam es zur Einrichtung eines Ministeriums für Entnazifizierung (CDU-Minister). Das Ende der Entnazifizierung kündigte sich im März 1948 mit der Verordnung über Fortführung und Abschluss der Entnazifizierung an. Ein gutes Stück der Klassifizierungsarbeit wurde mit der Verordnung über Aufhebung der

\footnotetext{
347 Siehe Sutton [1946/83] S. 131f.
}

348 Schneider [1989] S. 338. 
erneuten Überprüfung der Entnazifizierungsentscheidungen vom Juni 1949 zunichte gemacht. Durch sie kam es zur automatischen Herabstufung in die unterste Kategorie V der zuvor in III und IV Eingestuften. Das endgültige Ende wurde im Dezember 1951 mit dem Gesetz zum Abschluss der Entnazifizierung erreicht. ${ }^{349}$ Für die hartnäckigen Fälle, die bis dahin noch nicht wieder rehabilitiert worden waren, schaffte der Artikel 131 des Grundgesetzes den rechtlichen Anspruch zur Rückkehr in die akademische Welt. ${ }^{350}$ In der Göttinger Physik spielte dies jedoch keine Rolle.

Für die Entnazifizierung der Universität Göttingen ${ }^{351}$ waren drei Unterausschüsse gebildet worden: einer für die Verwaltung, einer für das nicht-wissenschaftliche Klinikpersonal und einer für den Lehrkörper. Diese Unterausschüsse hatten formell nur beratende Funktion. Die von ihnen durchgeführte Einteilung der Überprüften in Gruppen (1: keine Einwände, 2: nomineller Nazianhänger, 3: eifriger Nazianhänger a) sofort zu entlassen, b) innerhalb eines Monats zu entlassen, 4: besonderer Fall und 5: keine Beurteilung) musste vom zuständigen Hauptausschuss und schließlich von der Militärregierung genehmigt werden. Insofern ist die Arbeit des Unterausschusses für die politische Überprüfung des Lehrkörpers vor allem in Hinblick auf den Selbstreinigungscharakter der akademischen Korporation von Bedeutung.

Bei den ersten Entnazifierungsfällen suchte die Besatzungsbehörde in einzelnen Fällen um Stellungnahmen von Professoren an, die bekannte 'Nicht-Nazis' waren. Anfang 1946 wurde ein Viererausschuss gebildet, dem die Professoren Hermann Rein, Robert Wichard Pohl, Eberhard Schmidt und Heinrich Düker angehörten. ${ }^{352}$ Dem Dekan Eucken war es ein Anliegen, seine Verbundenheit mit den bis dahin entlassenen Kollegen Ausdruck zu geben. Die Fakultät dankte Hermann Rein für seinen Einsatz für die Betroffenen und die ,geschickte und energische Behandlung der Angelegenheit“".353 Im März 1946 erklärte der Kontrolloffizier Geoffrey Bird den Viererausschuss für ein vollgültiges Äquivalent zum

\footnotetext{
${ }^{349} \mathrm{Zu}$ den Mitteln und Zielen der Entnazifizierung in der britischen Zone und den gesetzlichen Bestimmungen siehe Krämer [2001]. Einen kurzen Überblick über die Entnazifizierung in den vier Zonen gibt Vollnhals (Hrsg.) [1991].

$350 \mathrm{Zu}$ dem Nachspiel der Entnazifizierung und der gesellschaftlichen Eingliederung ehemaliger NS-Täter siehe Frei [1996/99].

351 Zum Folgenden siehe, wenn nicht anders belegt, Brynjølfsson [1996] S. 19-27.

352 Protokoll der Senatssitzung vom 21. Januar 1946. UAG, Senatsprotokolle 1945-1949. Der Physiologe Hermann Rein war eine der zentralen Figuren, welche die Geschicke der Universität in der Nachkriegszeit lenkten. Er wurde als zweiter Nachkriegsrektor Smends Nachfolger. Der Strafrechtler Eberhard Schmidt spielte ebenfalls eine bedeutende Rolle und wurde 1948/49 Dekan der Rechts- und Staatswissenschaftlichen Fakultät. Der Psychologe Heinrich Düker war der einzige unter den im NS entlassenen Göttinger Privatdozenten, der voll rehabilitiert wurden. Zu seinem Fall siehe Abschnitt 5.4.2.1.

353 Protokoll der Fakultätssitzung vom 25. Januar 1946. GPAMNFG, Protokollbuch III der mathematischnaturwissenschaftlichen Fakultät WS 1927/28 - SS 1946.
} 
Kreisausschuss. ${ }^{354}$ Hier wurde der gesamte Lehrkörper politisch klassifiziert und bei Einsprüchen in Entlassungsfällen eine Stellungnahme abgegeben. Die letzte Entscheidung lag in den Händen von Bird. Dem Oberpräsidenten in Hannover wurde auf seinen Wunsch hin bei jeder Berufung eine politische Charakterisierung des Kandidaten von der Universität beigegeben, da er ja wissen müsse, ,welche etwa bestehenden politischen Bedenken er den Engländern gegenüber decken soll.“355 Mit der Weiterentwicklung des Spruchkammersystems wurde am 30. Juni 1946 ein Unterausschuss für die Überprüfung des Lehrkörpers gebildet, dem sechs Universitätsangehörige und sechs Personen des öffentlichen Lebens angehörten: 356

Universität

- Ludwig Raiser ${ }^{357}$ als Vorsitzender

- Robert Pohl

- Heinrich Düker

- Wolfgang Trillhaas ${ }^{358}$

- Rudolf Schoen 359

- Otto Mertens 360 ex populo

- Helmut Kuß (Stadtsyndikus)

- Dr. med. Walter Gerson

- Dr. med. Anna Hempelmann

- Heinrich Schoemaker (Postinspektor)

- Heinrich Hagelstein (Buchdruckmeister)

- Hella Fuchs

Die von der Militärregierung den ex populo-Mitgliedern zugedachte Rolle, die Objektivität in den Verfahren sicherzustellen, wurde von der Praxis, in der die Professoren in autoritärer Weise die Einstufungen bestimmten, zunichte gemacht. ${ }^{361}$ Dass Robert Pohl in den Ausschuss kam, lag vermutlich daran, dass er als Mitwisser des 20. Juli galt, und damit glaubhaft eine antinationalsozialistische Haltung verkörperte. ${ }^{362}$ Mit Pohl hatten die Physiker einen mächtigen Fürsprecher im Ausschuss sitzen. Dies mag mit ein Grund dafür sein, dass die personelle Entnazifizierung in der Physik so geringe Auswirkungen hatte.

Der Unterausschuss hatte seine Stellungnahme an den Hauptausschuss der Stadt Göttingen abzugeben, der sie an die Militärregierung zur endgültigen Entscheidung weiterleitete. Anfang 1947 verlor der Kontrolloffizier seine Entscheidungsgewalt und hatte fortan nur noch beratende Funktion. Eine wichtige Rolle spielte nach Zeitzeugenberichten der Vorsitzende Ludwig Raiser, unter dessen Vorsitz seine eigene Einstufung in Gruppe 1 (keine Einwände)

\footnotetext{
354 Protokoll der Senatssitzung vom 23. März 1946. UAG, Senatsprotokolle 1945-1949.

355 Protokoll der Senatssitzung vom 30. November 1945. UAG, Senatsprotokolle 1945-1949.

356 UAG, Kur. IX. 97 I.

357 Der Professor für bürgerliches Recht, Handels- und Wirtschaftsrecht war der dritte Nachkriegsrektor in Göttingen.

358 Der Professor für praktische Theologie war 1947/48 Dekan der theologischen Fakultät und 1950-52 Rektor.

359 Rudolf Schoen war Professor für innere Medizin und erster Nachkriegsdekan der medizinischen Fakultät.

360 Dr. med. Otto Mertens war Physiologe und wurde in den ersten Nachkriegssemestern Privatdozent an der Universität Göttingen.

${ }^{361}$ Brynjølfsson [1996] S. 100.
} 
im November 1947 erfolgte. Das entsprechende Sitzungsprotokoll unterschrieb er selbst. ${ }^{363}$ Raiser verglich die Entnazifizierung mit ,einer blutigen Operation am todwunden Volkskörper“. Er kritisierte die Klassifizierungspraxis, die auf formelle Kriterien ausgelegt war und Partei- und Formationszugehörigkeiten unterschiedslos gleichstellte. Zustimmen konnte er der „Bereinigung“ des öffentlichen Lebens von „all den Persönlichkeiten“, die bis 1945 Stützen des Regimes gewesen waren. In diesem Sinn bildete die Entnazifizierung für ihn ein „gewiß hartes aber notwendiges Zucht- und Erziehungsmittel [...]. Ihre reinliche Beendigung ist Sache des ganzen Volkes“..364 Die Beurteilung der Physiker durch den Universitätsausschuss sah in der Regel so aus, dass einer formalen Belastung Aussagen von Kollegen entgegengestellt wurden, die den Betreffenden als grundanständig und völlig unpolitisch beschrieben. $\mathrm{Zu}$ Entlassungen in der mathematisch-naturwissenschaftlichen Fakultät kam es nur in drei Fällen, in denen die formale Belastung durch die Ausübung eines Amtes in einer Partei-Gliederung gegeben war. ${ }^{365}$ Insofern entsteht der Eindruck, dass die formalen Kriterien allein entscheidend waren. Dies liegt aber vor allem daran, dass den Physikern von ihren Kollegen in der Regel eine antinationalsozialistische Haltung bescheinigt wurde. Dekan Eucken ging sogar so weit, eine Mitgliedschaft als mögliche „Bekämpfung des Nationalsozialismus“ zu interpretieren. Die Militärregierung, die von deutscher Seite vor allem Entlastungszeugnisse vorgelegt bekam, aber in jedem Fall letztlich die Entscheidung zu treffen hatte, konnte zur Feststellung 'wirklicher' Nationalsozialisten daher nur auf formale Belastungen, insbesondere ausgeübte Ämter in Partei-Gliederungen, zurückgreifen. Dieses Vorgehen wurde durch die Entnazifizierungs-Verordnungen unterstützt. ${ }^{366}$

\footnotetext{
362 Rosenow [1987/98] S. $572 \mathrm{f}$.

363 Brynjølfsson [1996] S. 27.

364 Raiser [1946/47] S. 6-8.

365 Entlassen wurden insgesamt drei Dozenten: Küstner (med. Physik), Münzner (Mathematik) und Hellwege (Physik). Johannes Küstner war von 1941 bis 1945 NSV Amtleiter der Ortsgruppe Hainberg. HStAH, Nds. 171 Hildesheim 7501. Münzner war ab 1935 Blockleiter und hatte in der Hochschulgruppe Göttingen des NSDDB das Amt für Kasse und Verwaltung inne. GPAMNFG, Lehrkörper (ausgeschieden), Münzner.

366 Im Fall Münzner sprach sich Eucken gegen seine Amtsenthebung aus und nahm wie folgt Stellung: „Der Fall Münzner ist in vieler Hinsicht typisch. Denn M. gehört ganz offenkundig zu dem großen Kreis derjenigen Mathematiker und Naturwissenschaftler, die politisch recht wenig interessiert und alles andere als politische Kämpfernaturen sind. Diese Tatsache dürfte letzten Endes auch die Ursache dafür sein, daß M. sich dem auf ihn ausgeübten Druck nicht zu entziehen vermochte und nicht nur der Partei als Mitglied beitrat, sondern sogar zeitweise, wenn auch mit großem inneren Widerstreben, das Amt eines Blockleiters innehatte. [...] Unter den geschilderten Umständen war naturgemäß die Auswirkung seiner Parteiangehörigkeit - sei es im Sinne einer Förderung, sei es im Sinne einer Bekämpfung des Nationalsozialismus - recht geringfügig. “ GPAMNFG, Lehrkörper (ausgeschieden), Münzner.
} 


\subsubsection{Die Entlassung Hellweges}

Hellwege war seit 1935 Assistent im II. Physikalischen Institut. Anlässlich seiner beginnenden Lehrtätigkeit 1939 bescheinigte ihm der damalige Institutsdirektor Joos: „Auch als Mensch ist Herr Dr. Hellwege eine gewinnende starke Persönlichkeit und ausgesprochene Führernatur." 367 Am 19. Juli 1945 wurde Hellwege von der Militärregierung entlassen. ${ }^{368}$ Leider sind keine Gründe dafür angegeben, doch aus späteren Beschreibungen lässt sich schließen, dass er unter den Göttinger Physikern als überzeugter 'Nazi' bekannt war und dass mündliche Anschuldigungen gegen ihn geäußert wurden. Hanle berichtet in einem Brief, er hielt Hellwege während seiner Göttinger Zeit (1937-1941) „für den gefährlichsten Nazi im Institut".369 Nur einen Monat nach der Entlassung wurde Hellwege nach eingelegtem Einspruch und einer Unterredung mit der Militärregierung wieder eingestellt, ${ }^{370}$ aber schon im Januar 1946 auf Grund der ersten geltenden Entnazifizierungs-Vorschriften erneut entlassen. ${ }^{371}$ Diesmal war der Entlassungsgrund seine Stellung als Oberscharführer im SAReitersturm, die ihn formal zu sehr belastete, während seine Partei- und NSDDBMitgliedschaften weniger stark wogen. ${ }^{372}$ Hellwege erhob Einspruch, und der Dekan Eucken formulierte in diesem Zusammenhang eine bemerkenswerte Stellungnahme:

„Besonders bedeutungsvoll für die Beurteilung dieses Falles scheint mir die Bemerkung Professor Beckers zu sein, daß der Charakter Dr. Hellweges sich durch eine große Aufrichtigkeit und Ehrlichkeit auszeichnet. So vermeidet er denn in seinem Einspruchschreiben die sonst oft gebrauchte Wendung wie 'ich habe nie ein inneres Verhältnis zum Nationalsozialismus besessen` odgl. Indirekt gibt er auf diese Weise $\mathrm{zu}$, daß er den Nationalsozialismus an sich billigte, das ist sympathisch und sollte ihm nicht zum Vorwurf gemacht, sondern anerkannt werden. Diese seine Haltung schließt aber keineswegs aus, daß er doch in erster Linie Naturwissenschaftler war und, sobald nationalsozialistische Gepflogenheiten in einen Gegensatz zu seiner Wissenschaft traten, eindeutig den Standpunkt der letzteren vertrat. Da er sich überdies als Nationalsozialist politisch nicht aktiv betätigte und in keiner Weise dadurch der Universität geschadet hat, glaubt die Fakultät insgesamt seinen Einspruch gegen seine Entlassung aus dem

\footnotetext{
367 Joos an Dekan, 20. Juli 1939. GPAMNFG, Lehrkörper (ausgeschieden), Hellwege.

368 Kurator an Hellege, 19. Juli 1945. UAG, Rek. PA Hellwege.

369 Aus einer als „Vertraulich“ überschriebenen Beilage des Briefes von Wilhelm Hanle an James Franck, 18. Dezember 1961. NL Franck, Box 3, Folder 11. Hellwege wird in diesem Brief nicht namentlich genannt. Die Identifizierung ist aber auf Grund der angegebenen biografischen Daten gesichert.

370 Die Entlassung wurde am 16. August 1945 wieder aufgehoben. Kurator an Hellwege, 23.August 1945. UAG, Rek. PA Hellwege.

371 Der Kurator teilte Hellwege seine erneute Entlasung am 24. Januar 1946 mit. Siehe Einspruch Hellweges vom 2. Februar 1946. HStAH, Nds. 171 Hildesheim 11847.

372 Auf Grund der am 12. Januar 1946 erlassenen Direktive Nr. 24 waren alle Mitglieder der SA, die zu irgendeiner Zeit einen Offiziers- oder Unteroffiziersrang bekleidet hatten zu entfernen. Auch nach der eine Woche darauf folgenden Zonen-Instruktion Nr. 3 waren SA- und SS-Mitglieder vom Rang des Scharführers aufwärts automatisch entlassungspflichtig. Vollnhals (Hrsg.) [1991] S. 24-26; Krämer [2001] S. 155-157.
} 
Amt durchaus befürworten zu sollen, zumal er zweifellos zu den Besten unseres physikalischen Nachwuchses gehört." 373

Für Eucken genoss ein 'richtiger' Naturwissenschaftler den Status des Unpolitischen, selbst wenn er überzeugter Parteigänger war. Eucken bediente sich hier dem verbreiteten Vorurteil der technokratischen Unschuld naturwissenschaftlicher Forschung. Damit verbunden war die zeittypische Einschätzung von Wissenschaftlern, die Diktatur allzu oberflächlich mit 'Wissenschaftsfeindlichkeit' gleichzusetzen und daraus fälschlich die selbstverständliche Forderung nach 'Wissenschaftsfreiheit' abzuleiten. ${ }^{374}$ Solange nur die physikalische Forschung und die akademischen Traditionen frei von parteipolitischen Einflüssen gehalten wurden, sah Eucken keinen entscheidenden Grund zur Kritik. Damit betrieb Eucken eine Rehabilitierung des Nationalsozialismus, nämlich in dem Ausmaß, in dem dieser mit 'der Wissenschaft‘ nicht in Gegensatz geriet.

Die Eingabe Euckens brachte aber nicht den für Hellwege erwünschten Erfolg. Zu seiner weiteren Entlastung sammelte er fleißig Persilscheine. Zumindest 57 Personen haben sich auf diese Weise für Hellwege verwendet, manche mehrfach. In den Bescheinigungen kam nicht nur Entlastendes zur Sprache. Sein Vermieter berichtete von Unterhaltungen über Saalschlachten, aus denen er den Eindruck gewonnen habe, als sei Hellwege dabei gewesen. Dies sei aber nicht gewiss, denn Hellwege neigte „,bei derartigen Gesprächen zu lebhaften Beschreibungen“. Um diesen Verdacht aus dem Weg zu räumen, wurde Hellwege von anderen bescheinigt, dass es keine Anzeichen für ,aktive nazistische Handlungen wie z. B. Tätlichkeiten“" gegeben habe. ${ }^{375}$

Von größerem Interesse sind jedoch die Bescheinigungen seiner Physikerkollegen. Diese geben Aufschlüsse über seine kollegialen Verbindungen und deren Tragfähigkeit. In diesem Sinn besonders aufschlussreich ist der Persilschein, den ihm der Institutsdirektor Kopfermann und dessen Assistenten Walcher, Paul und Brix ausstellten. Diese vier Institutskollegen, die ihn durch die tägliche Arbeit in denselben Räumlichkeiten gut kannten, stellten gleich zu Beginn klar, dass die Bescheinigung auf seinen Wunsch hin zustande kam. Sie fuhren fort:

"Sein Arbeitsgebiet lag dem unseren relativ fern, ebenso die von ihm bearbeiteten Kriegsuntersuchungen, die er auch uns gegenüber geheim zu halten hatte. Auf diese Weise entstand eine Sonderstellung Hellweges im Institut, deren Ausgleich

\footnotetext{
373 Dekan Eucken in einer Stellungnahme zum Einspruch des Dozenten Hellwege gegen seine Entlassung, 4. Februar 1946. HStAH, Nds. 171 Hildesheim 11847.

374 Schlüpmann [http] Kapitel „Wissenschaft als Beruf“.

375 Siehe die beiden Persilscheine von Herbert Luckmann, 10. November 1946 und von Ernst und Elfriede Trostmann, 9. November 1946. HStAH, Nds. 171 Hildesheim 11847.
} 
in Folge persönlicher Verschiedenheit zum Leidwesen beider Seiten nicht gelungen ist. Wenn wir auch in politischen Fragen und in Fragen des Kriegseinsatzes der Wissenschaft oft verschiedener Meinung waren, so haben wir an Hellwege stets geschätzt, dass er sich für eine von Politik freie Wissenschaft eingesetzt hat. Auf Grund der immer von ihm an den Tag gelegten Sauberkeit der Gesinnung sind wir der Überzeugung, dass er es abgelehnt haben würde, einen von uns auf Grund der genannten Meinungsverschiedenheiten in irgendeiner Form zu schädigen." 376

Viel Entlastendes wollten ihm seine Institutskollegen offenbar nicht bescheinigen. Es bestand aber noch eine minimale Verbundenheit, die auf der Übereinstimmung zu einem berufsständischen Wissenschaftsideal fußte. Zwei Charakteristika des Ideals wurden angesprochen: die objektive Wissenschaft (politikfreie Wissenschaft) und die kollegiale Haltung, die in zeittypischer Terminologie als „Sauberkeit der Gesinnung“ umschrieben wurde. Wesentlich für die kollegiale Haltung war, dass sie Denunziationen ausschloss. Als Anerkennung dafür unterstützen die vier Institutskollegen seine Bemühungen um Wiederanstellung. Es gab aber Kollegen Hellweges, die von dieser kollegialen Haltung, die zumindest ein Denunzieren ausschloss, nicht überzeugt waren. Einer davon war Wilhelm Hanle, der allerdings 1941 von Göttingen nach Gießen berufen wurde und in der Entnazifizierung Hellweges keinen nachweisbaren Einfluss ausübte. Er schätzte Hellwege viel gefährlicher ein: „Wir hätten nie gewagt, bei ihm ein Wort der Kritik zu äußern. Ich war überzeugt, daß ich dann im KZ landen würde. Ich war feige genug, das Experiment nicht zu machen. Vielleicht war es ein Fehler. Das hätte manchen Kollegen die Augen geöffnet.“377

Hellweges früherer Chef, Georg Joos, bescheinigte ihm zweierlei. Er habe Einmischungen der Partei in wissenschaftliche Angelegenheiten verurteilt, und er verdanke seine Karriere nur wissenschaftlichen Leistungen. ${ }^{378}$ Es lässt manche Vermutungen aufkommen, dass Joos, der 1941 auf sein Ordinariat verzichtete, seinem Assistenten keine Kollegialität zu Gute hielt. In ähnlicher Form ist der Persilschein gehalten, den Kopfermann alleine schon im Juli 1945 ausgestellt hat. ${ }^{379}$ Noch ein weiterer Persilschein soll hier vollständig zitiert werden, vor

\footnotetext{
376 Bescheinigung von Hans Kopfermann, Wilhelm Walcher, Wolfgang Paul und Peter Brix, 18. November 1946. HStAH, Nds. 171 Hildesheim 11847.

377 Wilhelm Hanle an James Franck, 18. Dezember 1961. NL Franck, Box 3, Folder 11. Auch hier wird Hellwege nicht namentlich genannt. Es ist aber sehr wahrscheinlich, dass auch an dieser Stelle Hellwege gemeint ist.

378 Bescheinigung von Georg Joos, 13. April 1947. HStAH, Nds. 171 Hildesheim 11847.

379 Bescheinigung von Hans Kopfermann, 27. Juli 1945. Er stellt vor allem Hellweges wissenschaftliche Leistungen heraus und meinte, seine Entfernung von der Universität würde für die deutsche Physik ein fühlbarer Verlust sein. HStAH, Nds. 171 Hildesheim 11847.
} 
allem deswegen, weil er so wenig beinhaltet. Er stammt vom Oberassistenten am I. Institut, Erich Mollwo:

„Herrn Dr. K.H. Hellwege kenne ich seit etwa 12 Jahren. Ich habe während dieser Zeit oft, meist über wissenschaftliche, vereinzelt aber auch über politische Fragen, mit ihm gesprochen. Ich habe dabei nie Bedenken gehabt, ihm gegenüber meine Meinung offen zum Ausdruck zu bringen, auch wenn sie nicht mit der seinen übereinstimmte. “380

Hellweges um ein Jahr älterer Kollege, der Oberassistent am Pohl'schen Institut war und gleichzeitig mit ihm 1944 zum Diätendozenten ernannt wurde, bescheinigte bloß, dass er ihm offen seine Meinung sagen konnte. Überraschend und untypisch ist vor allem, dass in diesem Persilscheinen, wie auch in den davor zitierten, nichts Positives über Hellweges politische Haltung ausgesagt wird. Dies legt den Schluss nahe, dass Hellwege auch zum benachbarten Institut keine besonders guten Beziehungen unterhielt. Pohl, der im Entnazifizierungs-Unterausschuss saß, wollte bei der mündlichen Vernehmung wissen, weshalb Hellwege 1943 dem Dozentenbund beigetreten war. Hellwege klärte die Frage im Nachhinein schriftlich, indem er die NSDDB-Zugehörigkeit als Pflichtmitgliedschaft für Parteigenossen darstellte, die er geschickterweise sechs Jahre hinauszögern konnte. ${ }^{381}$

Typische Persilscheine für Physiker, wie sie sich auch reichlich in Hellweges Entnaziffizierungsakte befinden, betonen die Opposition des Betreffenden zum Nationalsozialismus und weisen wenn möglich auf dessen religiöse Bindungen hin. Sie führen Hilfeleistungen für „nichtarische“ Bekannte an und stilisieren den Verdächtigen zum Kämpfer für eine saubere Wissenschaft. ${ }^{382}$ Nur dies letztgenannte Kriterium fand sich bei Eucken und den vier Institutskollegen deutlich ausgesprochen.

Nach Offenlegung der schwachen kollegialen Verbindungen, die auf einem Minimalkonsens beruhten, bleibt die Frage zu klären, zu wem es belastbarere, engere Verbindungen gab. Die bedeutendste Verbindungsperson war Richard Becker, der den ersten Persilschein in diesem Verfahren beisteuerte. Der Unterschied zu den vorherigen Bescheinigungen fällt gleich im ersten Satz auf. „Mit Bestürzung erfuhr ich, daß der Dozent Dr. Hellwege auf Anordnung der Militärregierung fristlos entlassen sei.“ Becker kenne Hellwege seit 1936 aus beinahe täglichem Umgang. Seine Hochachtung vor ihm als Mensch und wissenschaftlicher Persönlichkeit sei dauernd gestiegen. Er hielt ihm drei Eigenschaften zugute: Hellwege

\footnotetext{
380 Bescheinigung von Erich Mollwo, 19. November 1946. HStAH, Nds. 171 Hildesheim 11847.

381 Hellwege an Pohl, 25. August 1946. HStAH, Nds. 171 Hildesheim 11847.

$382 \mathrm{Zu}$ den Mustern von Persilscheinen siehe Sachse [2002] S. 230f. 
respektiere die Forschungsergebnisse ,jüdischer Forscher", er habe aus seiner Parteimitgliedschaft keine beruflichen Vorteile gezogen und er sei besonders ehrlich und aufrichtig. ${ }^{383} \mathrm{Zu}$ Becker bestand nicht nur ein kollegiales, sondern auch ein freundschaftliches Verhältnis. Dies bestätigte mir Beckers Tochter, Dr. Eva Opitz, in einem Gespräch. Hellwege sei häufig in Beckers Haus zu Gast gewesen, teilweise in Begleitung seiner Ehefrau. Die politische Haltung Hellweges war kein Geheimnis, und daher wurden kritische Bemerkungen zur Politik vermieden. ${ }^{384}$ Ein ebenso freundschaftliches Verhältnis existierte zu Beckers Assistenten Günther Leibfried, der seinerseits zwei Persilscheine beisteuerte. ${ }^{385}$ Es gab also eine tragfähige Verbindung zu den Göttinger Theoretikern, die durch die Person Becker auch eine wichtige Stimme in der Fakultät für Hellwege sicherstellte. Wie oben gezeigt bezog sich der Dekan Eucken in der offiziellen Stellungnahme der Fakultät vor allem auf Beckers Bescheinigung.

Eine große Gruppe von Unterstützern fand er in seinen Studenten und Doktoranden. Ein gewisses Eigeninteresse dürfte hierbei eine Rolle gespielt haben, denn ein entlassener Dozent ist für die Studenten, die bei ihm eine Diplom- oder Doktorarbeit anstrebten oder ihr schon nachgingen, von geringem Wert. Dies dürfte aber nur für einen Teil der Unterzeichner zutreffen. Der Stil der Bescheinigungen zeigt eine Hochachtung vor Hellwege als Lehrer und vor seiner Sachlichkeit in der Physik. ${ }^{386}$

In der Zeit, in der Hellwege entlassen war, bemühte sich die Fakultät nicht nur, seine Wiederanstellung zu erwirken, sondern auch eine Diätendozentur für ihn frei zu halten, obwohl es ihr durchaus unklar war, ob er jemals wieder in Göttingen angestellt werden dürfe. Ein wenig Stellenschieberei war dazu nötig, aber letztlich blieb die Fakultät erfolgreich. ${ }^{387}$ Die Wiedereinstellung verzögerte sich allerdings bis Ende 1948. ${ }^{388}$ Hellwege durfte dann wieder

\footnotetext{
383 Bescheinigung von Richard Becker, 27. Juli 1945. HStAH, Nds. 171 Hildesheim 11847.

384 Gespräch mit Eva Opitz, 21. November 2001.

385 Bescheinigungen von Günther Leibfried, 1. Februar 1946 und 19. November 1946. Hierin wurde bescheinigt, dass Hellwege sich niemals aktiv nationalsozialistisch betätigt habe und dass er niemals fähig gewesen wäre, andere aus politischen Gründen zu schädigen. HStAH, Nds. 171 Hildesheim 11847. 386 Siehe die von 25 Hörern seiner Vorlesungen unterzeichnete Bescheinigung vom 1. Februar 1946; Bescheinigung von Dipl. Phys. Detlef Kamke (,jüdischer Mischling 1. Grades“), 30. Oktober 1946; Bescheinigung von Dr. Dietrich Meyer, Dipl. Phys. Bettina Rinck, Dr. Hans Severin und Dr. Anne-Marie Rosa, 14. April 1947. HStAH, Nds. 171 Hildesheim 11847.

387 Zu den wechselnden Besetzungen und Reservierungen der Diätendozenturen in der mathematischnaturwissenschaftlichen Fakultät siehe GPAMNFG, Lehrkörper (ausgeschieden), Hellwege; und die entsprechenden Schriftwechsel in HStAH, Nds. 401 Acc. 92 / 85 Nr. 136.

388 Im September 1946 wurde Hellwege vom Unterausschuss der Universität in Gruppe 2 der nominellen Nazianhänger eingestuft. Hellwege sei bloß aus sportlichem Ehrgeiz zum Oberscharführer im Reitersturm der SA aufgestiegen. Der Entnazifizierungs-Hauptausschuss der Stadt Göttingen folgte dieser Empfehlung allerdings nicht und reihte ihn wenige Tage später auch auf Grund von mündlichen Anschuldigungen in Gruppe 3a ein. Nach einer Vernehmung im Hauptausschuss im November 1946 wurde die Einstufung bestätigt.
} 
Vorlesungen halten und wurde im Januar 1950 zum außerplanmäßigen Professor ernannt, da er aus Göttinger Perspektive zu den Besten des physikalischen Nachwuchses gehörte. ${ }^{389}$ Die Begründung im Senatsprotokoll ist ganz kurz gehalten: „Dieser ist 10 Jahre habilitiert. Er war in der Reiter-SA. Der Senat stimmt dem Antrag zu. “390 Max Laue stellte mit „grosser Freude“ Hellweges Ernennung zum Professor fest und gratulierte herzlich. ${ }^{391}$ Hellwege war wieder in die schützende Gemeinde der amtierenden Hochschulphysiker integriert, und es dauerte nicht mehr lange bis zu seinem nächsten großen Karriereschritt. Zum 1. November 1952 wurde er zum Ordinarius ernannt und übernahm gleichzeitig die Leitung des Instituts für technische Physik an der TH Darmstadt. ${ }^{392}$

Dass die Entnazifizierung der Göttinger Physiker so vergleichsweise geringe Auswirkungen hatte, liegt zunächst daran, dass in der ersten Phase vor den gesetzlichen Regelungen in der britischen Zone weniger radikal eingegriffen wurde als zum Beispiel in der amerikanischen und sowjetischen Zone. Als 1946 verstärkt auf formale Belastungen durch Mitgliedschaften und Ämter Wert gelegt wurde, wirkte sich dann der geringe parteipolitische Organisationsgrad der Physiker positiv für sie aus. Etwa ein Drittel der in den Nachkriegsvierzigerjahren zu den Göttinger Instituten gehörenden Physiker war ehemaliges Parteimitglied. Zum Vergleich waren die in der PTR beschäftigten Atomwissenschaftler zu mehr als die Hälfte Mitglieder der NSDAP gewesen. ${ }^{393}$ Außer Hellwege und Kurt Magnus bekleideten die Göttinger keine Ämter in irgendwelchen Parteigliederungen, oder sie verschwiegen diese in ihrem Entnazifizierungsverfahren, was mit geringer Wahrscheinlichkeit möglich wäre (zu Magnus siehe Kapitel 5).

(HStAH, Nds. 171 Hildesheim 11847.) Am 1. März 1947 bestätigte Bird die Entlassung Hellweges. (UAG, Rek. PA Hellwege.) Im März 1948 wurden in einer Überprüfung seines Falles durch den Unterausschuss der Universität die schriftlichen Entlastungszeugnisse stärker gewichtet und wieder eine Einstufung in Gruppe 2 empfohlen. (HStAH, Nds. 171 Hildesheim 11847.) Am 28. April 1948 und wiederholt am 23. September und 24. November 1948 beantragte die Fakultät die Wiederzulassung Hellweges zur Dozentur begründet mit der Notlage im Unterricht hervorgerufen durch den Zuwachs an Studenten. (GPAMNFG, Lehrkörper (ausgeschieden), Hellwege. UAG, Rek. PA Hellwege.) Im September 1948 wurde er schließlich vom Entnazifizierungs-Hauptausschuss der Stadt Göttingen als entlastet festgestellt und in Kategorie V eingeordnet. (HStAH, Nds. 171 Hildesheim 11847.) Am 22. November 1948 gab das Kultusministerium bekannt, dass es keine Bedenken gegen eine Vorlesungstätigkeit Hellweges und der Übertragung einer Diätendozentur an ihn trage. Im Dezember 1948 trat Hellwege wieder seinen Dienst an. GPAMNFG, Lehrkörper (ausgeschieden), Hellwege. UAG, Rek. PA Hellwege.

389 Das Kultusministerium ernannte ihn am 27. Januar 1950 zum außerplanmäßigen Professor. UAG, Rek. PA Hellwege.

390 Protokoll der Senatssitzung vom 2. November 1949. UAG, Senatsprotokolle 1945-1949.

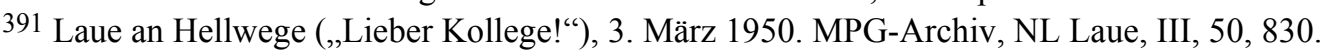

392 GPAMNFG, Lehrkörper (ausgeschieden), Hellwege.

393 Peltzer [1995] S. 124. 
Neben dem allgemeinen Bemühen nach Rettung der entlassenen Kollegen sah die Universität aber auch eine Notwendigkeit in der Ausgrenzung untragbarer Professoren. Wie Brynjølfsson für die philosophische Fakultät gezeigt hat, wurde die Grenze nicht nur auf Grund politischer Belastung gezogen. Er betonte auch, dass es nicht richtig ist, dass eine politisch unterstützte Hochschulkarriere in der NS-Zeit ohne Vorweisung der üblichen wissenschaftlichen Qualifikationen einen Verbleib in der Korporation unmöglich machte, wie das Gegenbeispiel des Theologen Otto Weber zeigt. ${ }^{394}$ Mir erscheint in diesem Zusammenhang die These vertretbar, dass diejenigen ausgegrenzt wurden, die in der NS-Zeit den kollegialen Schutz, oder anders gesagt, die berufsständische Solidarität verspielt hatten. Einerseits konnte dies durch völligen wissenschaftlichen Dilettantismus hervorgerufen worden sein, selbst wenn die formalen Ansprüche bei Berufungen, wie Promotion und Habilitation, gegeben waren. Andererseits konnte unwissenschaftliches und unkollegiales Verhalten wie Nichtanerkennung wissenschaftlicher Leistungen aus politischen Gründen und politische Denunziationen von Kollegen für die Ausgliederung aus dem kollegialen Netz gesorgt haben. Für die in diesem Sinn Betroffenen war es in der Nachkriegszeit schwer, eine Mehrheit der Fachgenossen für sich zu gewinnen und diese von der eigenen Verlässlichkeit zu überzeugen.

Auch in der Nachkriegszeit wurden die Physiker von ihren Kollegen auf ihre fachliche Qualifikation, ihren Charakter und ihr politisches Verhalten hin beurteilt. Ein eindrucksvolles Beispiel ist einem Brief Heisenbergs an den Hannoveraner Kollegen Jensen zu entnehmen:

„Herr Hopmann besitzt zweifellos große Kenntnisse auf dem Gebiet der Astronomie und der Verfahrenstechnik. [...] Hopmann hat sich damals mit vollen Segeln im Winde des Dritten Reiches treiben lassen, und hat auch den reinen Unsinn der damaligen Zeit in einer Weise ernst genommen, die eigentlich nicht mehr vertretbar war. Dabei glaube ich nicht, das möchte ich besonders betonen, daß Hopmann dies um des persönlichen Vorteils willen getan hat, sondern er ist menschlich eben so gebaut, daß er sich einer Massensuggestion nicht gut entziehen kann und dass er ehrlich an die Dinge glaubt, die gerade mit großem Getöse von der herrschenden Partei verkündet werden. Er ist also menschlich nicht sehr kräftig, dabei aber in mancher Weise ein netter und angenehmer Kollege. Er hat im Dritten Reich wohl niemanden aus Fanatismus denunziert, aber auch sicher niemals gegen den verbrecherischen Unsinn gekämpft, der von der Partei an Universitäten getrieben wurde. Die Unterrichtstätigkeit von Hopmann war erfolgreich. “"395

Zusammengefasst kann man sagen, Hopmann war politisch ein überzeugter Nationalsozialist, seine fachlichen Leistungen entsprechen den allgemeinen Anforderungen, er hat

\footnotetext{
394 Brynjølfsson [1996] S. 102f.

395 Heisenberg an Jensen, 13. Dezember 1947. MPI für Physik und Astrophysik, NL Heisenberg.
} 
charakterliche Schwächen, verhielt sich aber kollegial. Es geht bei diesem Beispiel nicht um den Leipziger Astronomen Hopmann, sondern um die Art, wie die einzelnen Kriterien sorgfältig beurteilt wurden. Heisenberg enthielt sich einer abschließenden Wertung, aber seine detaillierte Beschreibung ermöglichte es dem Empfänger, die Frage, ob man Hopmann zum eigenen Kollegen haben will, recht gut zu beantworten.

Die Grenzziehungen innerhalb der Physikergemeinschaft werden die nächsten zwei Abschnitte dominieren. Zuerst wird die Frage behandelt, wie mit denjenigen, die 1933 entlassen wurden, bis dahin aber ins kollegiale Netz eingebettet waren und zum Teil zentrale Stellen darin besetzten, verfahren wurde. Danach wird die großzügige Solidarität untersucht, die denjenigen zuteil wurde, die bis 1945 fester Bestandteil des Netzes waren.

\subsubsection{Keine Rückkehr der Vertriebenen - unterbliebene und gescheiterte Versuche}

Schon im Mai 1945 wurde im Senat die Frage der Rehabilitierung der im Nationalsozialismus entlassenen Kollegen diskutiert. Vier von ihnen waren damals in Göttingen anwesend, darunter kein Physiker. Diese sollten wieder in die Korporation aufgenommen werden, in einer Art Ehrenerklärung. Eine Einweisung in Amt und Institut sei aber nicht möglich. Eucken, Rein und Schöffler drängten auf eine rasche, bloß formale Wiedereingliederung, da sie dann „,noch in Ruhe und in den angegebenen Grenzen möglich“ sei. ${ }^{396}$ Ein grenzziehendes Kriterium wurde einen Monat später festgelegt: „Man ist einig darüber, daß diese Ausgeschiedenen nicht unbedingt und lediglich der Rehabilitation wegen wieder in Göttinger Stellen zu berufen sind, sondern nur im Zuge eines Berufungsverfahrens mit dem Ziel der Ergänzung durch die Besten.“"397

An Wiedergutmachung war die Universität und speziell die mathematischnaturwissenschaftliche Fakultät nicht interessiert. In Euckens Entwurf einer Grundsatzerklärung tauchte an keiner Stelle eine Bemühung um Entschädigungen für die vertriebenen Kollegen auf. In den Köpfen der Universitätsführung stand das Retten des Vorhandenen im Vordergrund. An dieser Auffassung, die ein Recht auf Wiedergutmachung nur mit Einschränkungen anerkannte, hielt die Universität im Folgenden fest. Der vorhandene Personalbestand sollte erhalten bleiben und durch Remigranten höchstens ergänzt werden, aber nur dort, wo es die Universität für wünschenswert hielt. „In Rehabilitationsfällen kann

\footnotetext{
396 Protokoll der Senatssitzung vom 5. Mai 1945. UAG, Senatsprotokolle 1945-1949.

397 Protokoll der Senatssitzung vom 9. Juni 1945. UAG, Senatsprotokolle 1945-1949. 
eine Stelle nur dann verliehen werden, wenn sie frei ist - auf eine besetzte besteht kein Anspruch."398 Es gab kein Bewusstsein für das Anrecht der Vertriebenen auf eine Entschädigung für das ihnen zugefügte Unrecht. Diese Mentalität spiegelt sich auch in den ersten brieflichen Kontaktaufnahmen mit den Emigrierten nach Kriegsende wider. Die in Deutschland gebliebenen Wissenschaftler stellten sich teilweise als Opfer dar. ${ }^{399}$ Außerdem meinten sie, dass die Emigranten durch das frühe Verlassen Deutschlands „vor dem Schlimmsten bewahrt geblieben“" seien und sie das Schicksal sozusagen bevorzugt habe. ${ }^{400}$ In eine andere Klasse von Briefen fällt zum Beispiel jener dreiseitige von Pohl an Max Born. Pohl berichtet über die Geschehnisse am Institut und das Schicksal der Kollegen so, als ob in der Zwischenzeit nichts Besonderes passiert wäre. Er selbst hatte keinen Anlass, sich als Opfer zu gebärden, denn seine „eigene Familie ist gesund und vollständig in Göttingen.“ Die Hauptaussage des Briefes ist, dass es den deutschen Physikern im Moment nicht besonders gut ginge, sie mit einigen Schwierigkeiten zu kämpfen haben, aber zuversichtlich in die Zukunft schauen könnten. Die Sorge um die 'Dagebliebenen' kontrastiert mit der fehlenden Sorge um die Vertriebenen. Am Schluss des Briefes heißt es bloß: „Es würde mich sehr freuen, von Dir einmal ein Lebenszeichen zu bekommen. Wir haben doch jetzt 6 Jahre nicht mehr voneinander hören können.“"401

Folge dieser Mentalität und der daraus entspringenden Politik war, dass von den 1933 in die Emigration gezwungenen Physikern kein einziger an die Universität zurückkehrte. Die Umstände der einzelnen Fälle sind von Anikó Szabó detailliert untersucht worden. ${ }^{402}$ In einer ersten Liste für die Militärregierung vom Februar 1946 bekundete die Fakultät ein Interesse an der Rückkehr „sämtlicher ordentlicher Professoren“. ${ }^{403}$ Dies betraf bei den Physikern Born und Franck. Insgesamt 16 ehemalige Göttinger Hochschullehrer wurden in der Liste genannt. Der Dekan Eucken wollte Rückberufungen generell nur auf die ehemaligen Ordinarien beschränkt wissen; die Fakultät schloss sich dieser Auffassung an. ${ }^{404}$ Trotzdem wurde auch die Rückkehr der ehemaligen Privatdozenten Arthur Hippel, Walter Heitler, Lothar Nordheim

\footnotetext{
398 Protokoll der Senatssitzung vom 5. Juli 1945. UAG, Senatsprotokolle 1945-1949.

399 Ein eindrucksvolles Beispiel hierfür ist der Brief von Günther Schulz an Richard Mises. Der ehemalige Assistent berichtet seinem verehrten Lehrer vier Seiten lang über das eigene Schicksal, rechtfertigt sich für seine politischen Anpassungsleistungen und erbittet einen Persilschein. HUA, Mises papers, HUG 4574.5, Box 4, Corr. 1903-1953

400 Ein Beispiel hierfür ist der erste Nachkriegsbrief von Siegfried Flügge aus Göttingen an Max Born in Edinburgh, 13. Januar 1947, aus dem das Zitat stammt. StB-B, NL Born, 222.

401 Pohl an Born, 13. August 1945. StB-B, NL Born, 591.

402 Szabó [2000].

403 Schreiben des Dekans Eucken vom 5. Februar 1946. UAG, Kur. IX. 83.

404 Protokoll der Kommissionssitzung vom 23. Januar 1946. GPAMNFG, Protokollbuch III der mathematischnaturwissenschaftlichen Fakultät WS 1927/28 - SS 1946.
} 
und Heinrich Kuhn als „erwünscht“ bezeichnet - allerdings wurden ihnen nur ihre ehemaligen Assistentenstellen angeboten. Einige positive Beispiele wurden in dem Schreiben an die Militärregierung hervorgehoben: Fritz Houtermans war als Privatdozent von der Fakultät bereits aufgenommen, Hans Wartenberg und Heinrich Düker waren bereits rehabilitiert, und für Kurt Hohenemser habe die Fakultät die Wiedererteilung der venia legendi beantragt. ${ }^{405}$ Auf der Liste fehlten allerdings einige vertriebene Dozenten. Nach Beanstandung durch die Militärregierung wurde einen Monat später eine zweite Liste aufgestellt, in der 22 ehemalige Hochschullehrer des „eigentlichen Lehrkörpers“ (einschließlich zweier Verstorbener) und als Nachtrag weitere 16 Assistenten und Mitarbeiter aufgeführt waren. Trotz vorhandener Vorbehalte erklärte sich die Fakultät bereit, den früheren nbao. Professor Paul Hertz „aus kollegialen Gründen“ wieder in ihren Kreis aufzunehmen; die Abstimmung in der Fakultät fiel mit $10 \mathrm{zu} 9$ denkbar knapp aus. ${ }^{406}$ Einen Anspruch auf eine Stelle bedeutete diese 'kollegiale' Geste aber nicht. Sie war ohnehin überflüssig, denn Paul Hertz war 1940 verstorben, was der Fakultät nicht bekannt war. Zu Hertha Sponer wurde angegeben, sie sei 1934 „einem Ruf an die Universität Oslo [gefolgt], ohne dass hierfür politische Gründe vorlagen.“ Der hinzugefügte handschriftliche Vermerk „Kommt nicht in Frage“ macht deutlich, wie gering das Interesse an ihrer Rückkehr war. ${ }^{407}$ Schließlich war Pohl, der ihren Fortgang 1933 beschleunigte, immer noch mächtiger Ordinarius in Göttingen. ${ }^{408}$ In der selben Liste wurde aber die Rückkehr ihres Ehemanns James Franck ,als sehr erwünscht bezeichnet“. Eine Rückkehr des ehemaligen Privatdozenten Willy Prager sei „durchaus erwünscht“, da er „sowohl wissenschaftlich wie auch menschlich d. bes. Schätzung der Göttinger Kollegen“ genieße, jedoch hatte die Fakultät keine Kenntnis von seinem

\footnotetext{
405 Schreiben des Dekan Eucken vom 5. Februar 1946. UAG, Kur. IX. 83.

406 Protokoll der Fakultätssitzung vom 1. März 1946. GPAMNFG, Protokollbuch III der mathematischnaturwissenschaftlichen Fakultät WS 1927/28 - SS 1946.

407 „Aufstellung über die seit 1933 aus politischen Gründen verdrängten Hochschullehrer der Universität Göttingen“, 19. März 1946. UAG, Kur. IX. 83.

408 Die negative Einstellung von Pohl gegenüber Sponer blieb lange aufrecht. Als die Zeitschrift für Physik ein Festheft anlässlich des 70. Geburtstags von Franck und Born vorbereitete, tauschten sich die beiden Herausgeber Laue und Pohl darüber aus, wer zu einem Beitrag aufgefordert werden sollte. Auf einer ersten Liste stand auch „Sponer“ (obwohl sie damals Sponer-Franck hieß), was Laue kritisierte, denn in „Familienangelegenheiten sollte man sich nicht einmischen." Darauf Pohl: „Ich freue mich, dass wir in dieser Sache gleicher Meinung sind. Dies gilt natürlich auch hinsichtlich einer Beteiligung von Frau Sponer-Franck, nur konnte dieses Bedenken nicht gut von meiner Seite formuliert werden, da Sie ja meine Differenzen mit dieser Dame kennen.“ Dagegen, dass mit Arthur Hippel Francks Schwiegersohn auf der Liste stand, hatten beide nichts einzuwenden. Siehe Laue an Pohl, 29. September 1951 und Pohl an Laue, 28. September 1951. MPG-Archiv, NL Laue, III, $50,1551$.
} 
damaligen Aufenthaltsort, weshalb sie ihm dies nicht mitteilen konnte (zu Prager siehe Kapitel 5). 409

Diese weniger als halbherzigen Bemühungen um Wiedergutmachung im ersten Jahr nach der deutschen Niederlage lassen ihre Erfolglosigkeit nur konsequent erscheinen. Von den vertriebenen Naturwissenschaftlern kehrte nur ein einziger, nämlich der Mathematiker Carl Siegel 1950, an die Göttinger Universität zurück. Die Militärregierung war zwar um Rehabilitierungen bemüht, setzte aber die Universität diesbezüglich wenig unter Druck. ${ }^{410}$ Auch die Politik des neuen SPD-Kultusministers Adolf Grimme bot den ehemals Vertriebenen wenig Unterstützung. Grimmes Standpunkt war, „daß die Universitäten nun nicht nur auf dem Papier, sondern auch wirklich ihrem Gefühl nach wieder völlig frei ihn ihren [Besetzungs-] Vorschlägen sind.“411 Von den emigrierten Physikern sind keine Initiativen zur Rückkehr an ihre frühere Arbeitsstätte bekannt. So berichtete Eucken im Mai 1946: „Unmittelbare Wünsche auf Rückkehr nach Göttingen hat bisher noch keiner der Emigranten geäußert“. Nur eine indirekte Mitteilung von Siegel über die Erwägung der Rückkehr sei bis dahin bekannt geworden. ${ }^{412}$ Einzelne beantragten nicht einmal eine geldliche Wiedergutmachung, als sie in den fünfziger Jahren einen Anspruch darauf erhielten. ${ }^{413}$ Das Interesse an einer Rückkehr war nicht nur aus materiellen, sondern auch aus politischen Gründen gering. Max Born schrieb 1948 an Pohl:

„Offen gestanden, es zieht mich nicht recht stark in die alte Heimat. Du wirst das vielleicht verstehen. Alte Freunde wieder zu sehen wäre natürlich schön. Aber mehr wäre da des Schmerzlichen und Aufwühlenden. Die lange Liste meiner Verwandten, die während der Hitler-Zeit umgekommen sind, ist immer in meinem Sinn. Ich habe keinerlei Vergeltungsgefühle und weiß genau, wie völlig ahnungslos und unschuldig die meisten Menschen sind. Aber irgendwo laufen doch auch die herum, die es getan haben, und dieser Gedanke hält mich zurück." ${ }^{14}$

Und an Max Laue schrieb er kurze Zeit später: „Im übrigen habe ich etwas gemischte Gefühle bei dem Gedanken an Rückkehr in die Heimat - man hört jetzt soviel davon, daß frühere Nazis wieder obenauf sind. - Mit herzlichen Grüßen“. ${ }^{415}$ Die positive Seite der Rückkehr bestand in dem Kontakt zu den früheren Freunden, zu denen er in Göttingen unter anderem

\footnotetext{
409 „Aufstellung über die seit 1933 aus politischen Gründen verdrängten Hochschullehrer der Universität Göttingen“, 19. März 1946. UAG, Kur. IX. 83. Siehe auch Szabó [2000] S. 260-262.

410 Szabó [2000] S. 263-264.

411 Grimme an Lamla, 28. Januar 1946. GStA PK, I HA Rep. 92, Grimme 1992.

412 Eucken an Rektor, 25. Mai 1946. UAG, Kur. IX. 83. I.

413 Szabó [2000] S. 486.

414 Born an Pohl, 25. April 1948. Dienstzimmernachlass Pohl.
} 
Becker, Pohl, Heisenberg, Houtermans und Hahn zählte. ${ }^{416}$ Auch wenn Born im Jahr 1954 nach seiner Emeritierung seinen Alterswohnsitz in Bad Pyrmont wählte, ist er nicht mehr als Rückkehrer zu zählen, da er keine Anstellung an einer deutschen Universität mehr besaß. Noch deutlicher als bei Born war die anfängliche Distanz zu Deutschland bei James Franck, der als Konsequenz der Shoah entschlossen war, niemals wieder nach Deutschland zu kommen. ${ }^{417}$ Einer Rückkehr an die Universität stand auch teilweise die Erinnerung an die Umstände der Vertreibung entgegen. Der in München 1933 entlassene Hans Bethe antwortete seinem Lehrer Sommerfeld im Mai 1947 auf das Angebot, den Münchener Lehrstuhl zu übernehmen: „Für uns, die wir in Deutschland von unseren Stellungen vertrieben wurden, ist es nicht möglich, zu vergessen. Die Studenten von 1933 wollten nicht theoretische Physik von mir hören (und es war eine starke Gruppe der Studenten, vielleicht sogar die Majorität), und selbst wenn die Studenten von 1947 anders denken, ich kann ihnen nicht trauen.“418

Während die Emigranten nach 1945 nicht wieder in den Dienst der Universität Göttingen traten und es auch gar nicht versuchten, beantragte der in Deutschland gebliebene ehemalige Privatdozent Kurt Hohenemser 1945 seine Wiederanstellung. Das führte zu einem heftigen Konflikt zwischen der Universität und ihm, welcher ausführlich in Abschnitt 5.4 analysiert wird. Es sei hier schon vorweggenommen, dass seine Rehabilitierung scheiterte. In starkem Kontrast zum Umgang mit den ab 1933 Vertriebenen steht die Fürsorge für diejenigen Kollegen, die in der Zeit der Diktatur akademische Stellen bekleideten und 1945 aus unterschiedlichen Gründen in Schwierigkeiten gerieten. ${ }^{419}$

\subsubsection{Das Phänomen Wanderschaft und wie das kollegiale Netz Karrieren rettete}

Ein Motto der Professoren in der Nachkriegszeit lautete: „Wir müssen einander wieder näher rücken... Wir wollen aufhören, zu denunzieren!“420 Dieses Näherrücken war durchaus doppelt

\footnotetext{
415 Born an Laue, 19. Juni 1948. MPG-Archiv, NL Laue, III, 50, 317.

416 Die Genannten bezeichnete Born in einem Brief an Laue vom 14. Januar 1949 als seine Freunde. MPGArchiv, NL Laue, III, 50, 317.

${ }^{417}$ Franck konnte von seinen deutschen Kollegen zur Aufweichung seiner Haltung bewogen werden. Bei seinem fünften Deutschlandbesuch starb Franck in Göttingen an einem Herzschlag. Kroebel [1982] S. 270.

418 Bethe an Sommerfeld, 20. Mai 1947, zitiert nach Eckert [1993] S. 258.

419 Die Göttinger Universität lag damit im Trend der Zeit. In der Frankfurter Rundschau vom 20. März 1947 war eine Regierungserklärung von CDU Kultusminister Erwin Stein abgedruckt: „Es bestehen Zweifel, ob Senate und Fakultäten heute in ihrer Zusammensetzung wirklich einen Willen zur Änderung der Geisteshaltung zeigen, denn bisher will es scheinen, dass sie an der Rettung Gefährdeter stärker interessiert sind als an der Zurückgewinnung Verfolgter.“ Zitiert nach UAG, Rek. 1408.

420 Dies sind Notizen, die sich ein Student zu einer kurz nach der Niederlage gehaltenen Rede eines (vermutlich Göttinger) Professors machte. Krönig \& Müller [1990] S. 74. Leider ist das Zitat dort nicht genauer belegt.
} 
zu verstehen: mental und räumlich. Das „Großdeutsche Reich“ war 1945 erheblich geschrumpft. Einige 'deutsche" Universitäten lagen nun in anderen Staaten; viele Hochschullehrer befanden sich deshalb auf der Suche nach neuen Arbeitsstätten. Auf der ersten nordwestdeutschen Hochschulkonferenz im September 1945 wurde sogar von ,einer Art akademischer Völkerwanderung von Hochschule zu Hochschule“ gesprochen. ${ }^{421}$ Das fast unzerstörte Göttingen bot sich als Sammelbecken an, zumal es in einer Westzone gelegen war. ${ }^{422}$ Viele Physiker fanden in den ersten Nachkriegsjahren hier eine vorübergehende Bleibe. Walther Gerlach schrieb an Richard Gans: „Wenn Ihr Weg Sie jemals über Göttingen führen sollte, so geben Sie nur acht, dass Sie keinen Physiker tottreten; die haben dort so ungefähr Kritische Dichte; manchmal soll einer schon verdampft gewesen sein." ${ }^{2} 3$ Nach der hier vertretenen These wird behauptet, dass vor allem diejenigen Physiker in Göttingen aufgenommen und mit Stellen versorgt wurden, die eine kollegiale Verbindung zu einem oder besser mehreren Göttingern besaßen. Zwischen den alteingesessenen Ordinarien und dem jüngeren Nachwuchs war es nicht nur Kollegialität, die zur Stellenvergabe führte, sondern auch „väterliches Wohlwollen“.424 Eine Veranschaulichung des Göttinger kollegialen Netzes in der Form, die es um 1946 angenommen hat, liefert folgende Abbildung:

\footnotetext{
421 Heinemann (Hrsg.) [1990]c S. 52.

422 Von einem Sammelbecken spricht in diesem Zusammenhang auch der Zeitzeuge Walcher [1995] S. F-108.

423 Gerlach an Gans, 12. Februar 1946. Zitiert nach Swinne [1992] S. 137.

424 Dieses väterliche Wohlwollen erwähnt zum Beispiel Hans Otto Kneser in einem Brief an Sommerfeld vom 20. Februar 1946. Er bezog sich aber auf die NS-Zeit, in der ihm Grüneisen, trotz Knesers NS-Engagement, das väterliche Wohlwollen nicht entzog, sprich, seine Karriere weiter unterstützte. DMM, NL Sommerfeld.
} 


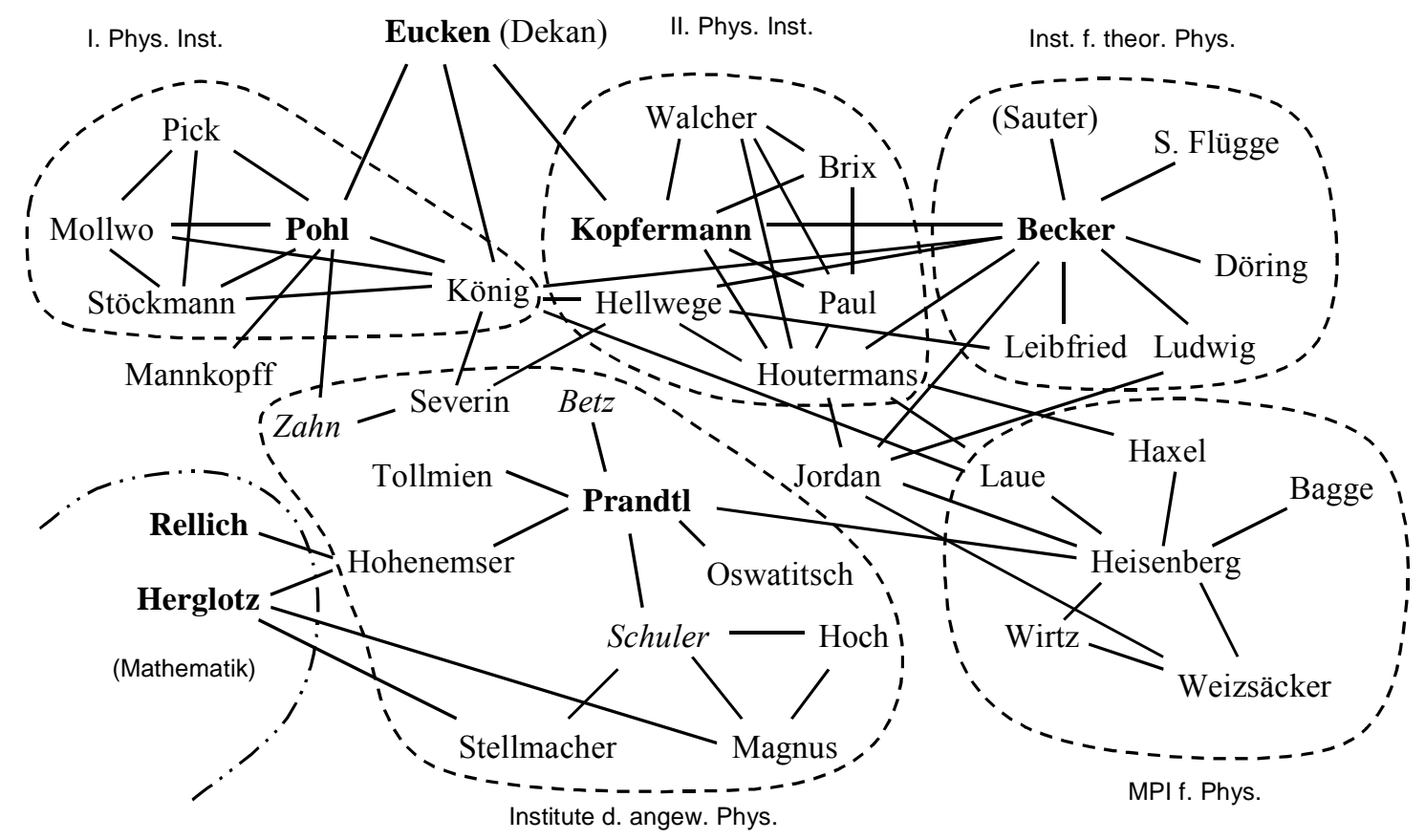

Abbildung 2 Kollegiales Netz der Göttinger Physiker um 1946. Ordinarien sind fett gedruckt, außerordentliche Professoren kursiv. Sauter kam erst 1948 nach Göttingen, ist hier aber in Klammern mit seinen Verbindungen eingetragen.

Pohl versuchte, auch in der wirren Lage den Überblick über die Personalverhältnisse in der deutschen Physik zu behalten. Im August 1945 schrieb er an Born:

„In wenigen Wochen sollen wir hier wieder mit dem Unterricht beginnen. Bis dahin müssen wir noch die Frage klären, wen von den zurzeit stellungslosen Kollegen wir hierher bekommen können. Für die deutschen Ordinarien sehe ich nicht schwarz. Soviel ich im Augenblick sehe, haben nur 5 oder 6 kein Institut, aber es müssten mindestens 10 Institute neu besetzt werden, etwa zur Hälfte wegen der Altersgrenze. “425

\subsubsection{Hans Otto Kneser und Ulrich Stille}

Einer von diesen stellungslosen Kollegen war Hans Otto Kneser, der von 1940 bis zum Kriegsende außerordentlicher Professor an der Universität Berlin gewesen war. 1933 war er in die SA eingetreten und hat dort das Amt eines Scharführers bekleidet. 1937 wurde er

425 Pohl an Born, 13. August 1945. StB-B, NL Born, 591. 
,automatisch“ Parteigenosse und ein Jahr später Mitglied im NSDDB. ${ }^{426}$ Wegen dieses politischen Engagements verlor er seine Berliner Professur und kam in amerikanische Gefangenschaft. Nach seiner Entlassung zog er im September 1945 mit seiner Familie nach Göttingen. ${ }^{427}$ Aber auch dort ging seine Rehabilitierung nur schleppend voran. Im April 1947 wurde er von der Militärregierung in Göttingen als „Ardent Nazi supporter“ eingestuft. Trotz der politischen Probleme wurde Kneser von den Göttinger Kollegen Ende 1946 auf die Berufungsliste für den neu errichteten Lehrstuhl des III. Physikalischen Instituts gesetzt (zu dieser Lehrstuhlbesetzung siehe Abschnitt 5.4.4). Für eine Universitätsstelle war Kneser bis 1948 aber nicht verwendbar; dann wurde er vom Entnazifizierungs-Hauptausschuss der Stadt Göttingen in Kategorie V eingestuft und als entlastet festgestellt. ${ }^{428}$ Die Bemühungen seiner Kollegen zielten aber gar nicht mehr in die Richtung, ihn an der Universität unterzubringen, sondern vor allem Max Laue setzte sich vehement dafür ein, ihn an der in Braunschweig neu aufgebauten PTR anzustellen, was schließlich Erfolg hatte. Nebenher konnte er auch in der Lehre tätig sein, indem er in Göttingen Pohl in der Vorlesung vertrat und an der TH Hannover einen Lehrauftrag erfüllte. Die Rückkehr an die Universität gelang ihm 1951 als ao. Professor in Tübingen und schließlich 1952 als Ordinarius in Stuttgart. 429

Ein ähnliches Nachkriegsschicksal erfuhr Ulrich Stille, ${ }^{430}$ dessen Verbindung nach Göttingen auf seine Studienzeit zurückging. 1933 promovierte er bei James Franck, danach wurde er Assistent von Georg Joos, wechselte 1937 mit Cario an die TH Braunschweig, wo er bis 1945 Dozent war. Vermutlich kostete ihm seine SS-Mitgliedschaft die Dozentenstelle. ${ }^{431}$ Zwischen 1945 und 1948 hielt er sich in Göttingen ${ }^{432}$ als selbständiger Physiker auf, bis er wie Kneser an die PTR als wissenschaftlicher Mitarbeiter kam. Ab 1949 konnte er an der TH Braunschweig wieder lehren, gleichzeitig wurde er an der PTR erst Regierungsrat und schließlich 1958 Direktor.

\footnotetext{
426 In die SA trat er ein, weil er, wie er in einer Erklärung anlässlich seiner Entnazifizierung angab, als Dozent nicht nur lehren, sondern den Studenten auch vorleben wollte. In der Studenten-SA hoffte er den Geist des sozialen Verständnisses und des fairen Sports zu finden. Siehe Anlage zu seinem Fragebogen der Militärregierung vom 24. Februar 1947. In einer späteren, undatierten Erklärung gab Kneser an, dass er als SARottenführer 1939 „,in ganz überraschender und ungewöhnlicher Weise“ das Scharführer-Abzeichen von einem SA-Kameraden in seine Wohnung gebracht bekam. HStAH, Nds. 171 Hildesheim 7645.

427 Siehe Brief von Kneser an Sommerfeld, 20. Februar 1946. DMM, NL Sommerfeld.

428 Entnazifizierungs-Entscheidung vom 15. Oktober 1948. HStAH, Nds. 171 Hildesheim 7645.

429 Oberst [1961]. Zur Vorlesungstätigkeit siehe auch das Vorlesungsverzeichnis vom WS 1948/49, wo Kneser unter der Rubrik „Mit der Abhaltung von Vorlesungen beauftragt“ aufgeführt ist.

$430 \mathrm{Zu}$ Stille siehe Schrader [1976].

431 Über eine SS-Mitgliedschaft berichtet Rosenow [1987/98] S. 569.

432 Siehe Schlüpmann [http].
} 


\subsubsection{Pascual Jordan}

Ein weiterer Berliner, den das Kriegsende nach Göttingen brachte, ist Pascual Jordan. ${ }^{433} \mathrm{Im}$ Krieg arbeitete Jordan an meteorologischen Berechnungen im Auftrag der Luftwaffe am Astrophysikalischen Observatorium in Potsdam von 1939 bis 1943. Anschließend kam er zur Abteilung FEP III des OKM, wo er an der Unterwasserausbreitung von Schall forschte. ${ }^{434}$ 1944 trat er an der Universität Berlin die Nachfolge von Max Laue an. Im Sommer 1945 überlegten die Göttinger Physiker, wie sie ihn „fest in Göttingen [...] verankern“ könnten. ${ }^{435}$ Wenn Physiker in Schwierigkeiten gerieten, verschob sich die Bewertung durch ihre Kollegen zu ihren Gunsten. 1935 wollten die Göttinger Jordan als Nachfolger Borns einfach nicht haben, 1945 bemühten sie sich, ihn irgendwie unterzubringen. Aber auch im Fall Jordan dachten Pohl und seine Kollegen dabei weniger an eine Universitätsstelle, vermutlich wegen Jordans politischer Belastung. Es gab Pläne, ihm an der Göttinger Akademie der Wissenschaften eine „sehr angenehme (und ehrenvolle)“ Stellung zu verschaffen, die im Frühjahr 1946 an finanziellen Fragen scheiterten. Im Mai 1946 hatte er für einen nicht näher genannten Zweck einen ersten Fragebogen der Militärregierung ausgefüllt. ${ }^{436}$ Jordan dachte nicht an eine Rückkehr nach Berlin und verhielt sich in Göttingen abwartend. Er entwickelte im ersten Nachkriegsjahr eine rege Vortragstätigkeit und bereiste Weil, Freiburg, Bielefeld und Essen. ${ }^{437}$ Einen für Sommer 1946 geplanten Vortrag in Hamburg über Biophysik sagte Jordan zur Vermeidung politischer Schwierigkeiten ab. 438

Jordan war in das Netz der Göttinger Physiker in vielfältiger Weise eingebunden (siehe Abbildung 2). Vor allem die 1946 ins Max-Planck-Institut für Physik gekommenen Theoretiker hatten eine enge Verbindung zu ihm. Ein wesentlicher Grund dafür waren Jordans anerkannt hochrangigen Leistungen in der theoretischen Physik. ${ }^{439}$ Seine Behandlung von grundsätzlichen Fragen in der Physik, die auch von philosophischem Interesse war, fand zum Beispiel bei Arnold Eucken großen Anklang. 440 Trotz der guten Einbindung ins

\footnotetext{
433 Zu Jordan siehe Beyler [1994] und Wise [1994].

434 BIOS Final Report No. 79, Applied Mathematical Research in Germany, with Particular Reference to Naval Applications, S. 57.

435 Pohl an Born, 13. August 1945. StB-B, NL Born, 591.

436 Jordan an Schimank, 1. Juni 1946. UH-HSGS, NL Schimank, Korr. Jordan. In den Nachrichten der Akademie der Wissenschaften konnte Jordan 1945 zwei Arbeiten publizieren. Siehe Jordan [1945]a und [1945]b.

437 Jordan an Schimank, 19. Juni 1946. UH-HSGS, NL Schimank, Korr. Jordan.

438 Jordan an Schimank, 1. Juni 1946. UH-HSGS, NL Schimank, Korr. Jordan.

439 Eine historische Würdigung seiner Leistungen erfuhr Jordan erst kürzlich von Ehlers \& Schücking [2002].

440 Siehe Eucken [1939]b. Beide sprachen sich entschieden für eine Geschlossenheit und Einheit der Naturwissenschaften aus. Vergleiche zum Beispiel Euckens Rezension von Jaspers Buch „Die Idee der Universität“", Eucken [1946]c, mit der Einleitung in Jordan [1941].
} 
kollegiale Netz fand Jordan seine erste Nachkriegsanstellung nicht an der Göttinger Universität sondern an der Hamburger, und zwar 1947 zuerst als Gastprofessor. Dort half ihm unter anderem die entscheidende Befürwortung durch Wilhelm Lenz. ${ }^{441}$ Unter den damaligen Physikern herrschte die Meinung vor, dass eine besondere wissenschaftliche Befähigung ein politisches Fehlverhalten in gewissem Sinn aufwiegt. ${ }^{442}$ Nachdem Jordan 1950 wieder eine zweijährige Gastprofessur in Hamburg bewilligt bekam, dankte er dem dortigen Professor Schimank in einem Brief für die „freundliche, tätige Anteilnahme an meiner Affäre“ mit der Grußformel: „Ihr kollegial ergebener“.443 Trotz erfolgreichen Überstehens der Entnazifizierung dauerte seine Berufung auf ein Ordinariat in Hamburg bis zum Jahr 1953. In Göttingen konnte Jordan 1946 seinen Berliner Schüler Günther Ludwig in Beckers Institut als Assistent unterbringen. Ludwigs Karriereverlauf wird weiter unten dargestellt (siehe Abschnitt 1.3.5.2).

\subsubsection{Siegfried Flügge}

Ein weiterer Berliner, der die unmittelbare Nachkriegszeit in Göttingen verbrachte, ist der theoretische Physiker Siegfried Flügge. Seine Verbindung zu Göttingen ist schon durch seine Studienzeit dort und die 1933 erfolgte Promotion bei Max Born gegeben. Danach war er Assistent Madelungs am Institut für theoretische Physik in Frankfurt sowie in Leipzig bei Werner Heisenberg. Von 1937 bis 1942 war er am KWI für Chemie in Berlin Dahlem bei der durch Otto Hahn, Lise Meitner und Josef Mattauch bekannten kernphysikalischen Abteilung beschäftigt und von 1940 bis 1944 Dozent an der dortigen Universität. Im Frühjahr 1944 wurde er als außerordentlicher Professor nach Königsberg berufen. Seine dortige Vorlesungstätigkeit dauerte nur wenige Monate, bis er im Juli 1944 Königsberg verließ. Zu Ostern 1944 war er zu Gastvorträgen nach Göttingen eingeladen worden, wofür er eine beträchtliche Vergütung von RM 800 bekam. ${ }^{444}$ Am 20. April 1944 heiratete er Lieselotte Dittus. ${ }^{445}$ Im Juni 1945 kam er auf Initiative Beckers nach Göttingen, der ihn sich mit Pohls Worten „zur Hilfe geholt“ habe. ${ }^{446}$ Im August 1945 beantragte Becker für ihn eine Dozentur.

\footnotetext{
441 Ehlers \& Schücking [2002] S. 72.

442 Dieser Punkt wird in der Diskussion der Aufnahmeprüfungen für neue Studenten in Abschnitt 2.3 noch deutlicher zu Tage treten.

443 Diese Grußformel ist ungewöhnlich für Jordan, der normalerweise „stets Ihr ergebener“ benutzte. Jordan an Schimank, 8. Oktober 1950. UH-HSGS, NL Schimank, Korr. Jordan.

444 Zur Vita siehe UAG, Kur. PA Flügge; UAG, Mat. Nat. Fak., Nr. 19a; Lebenslauf Februar 1942 und Schreiben Flügge an Dekan in Königsberg, 17. Juli 1944, BAB, R 4901, 10041. Schreiben Becker an Dekan, 24. August 1945. UAG, Kur. XVI. V. C. i. 2.

445 BAB, R 4901, 10041.

446 Pohl an Born, 13. August 1945. StB-B, NL Born, 591.
} 
Flügge sollte das Gebiet der Kernpyhsik und außerdem die Geschichte der Naturwissenschaften im Unterricht vertreten. Auf Wunsch Euckens bekam Flügge eine Diätendozentur aber nur für das Fach Geschichte der exakten Naturwissenschaften (zur Einführung dieses Lehrfachs siehe Abschnitt 4.2.3). ${ }^{447}$ Zwei Zwecke konnte die Fakultät mit dieser Ernennung erfüllen: Erstens suchte sie einen Fachvertreter, der die Geschichte der Naturwissenschaften in der Lehre übernehmen konnte, und zweitens sollte der stellenlose Flügge, den seine Kollegen zu den besten deutschen Kernphysikern zählten, irgendwie versorgt werden. ${ }^{448}$ Dass es sich nur um eine Übergangslösung handelte, war allen klar. 1947 erhielt Flügge schließlich ein Ordinariat für theoretische Physik in Marburg. Anlässlich seines Weggangs aus Göttingen dankte er dem Dekan ergebenst „,ür die hilfsbereite und freundliche Aufnahme, die ich aus Königsberg kommend hier nach dem Zusammenbruch fand. Meine Verbundenheit mit der Göttinger Universität [...] ist dadurch erneut vertieft und befestigt worden." 449

\subsubsection{Fritz Houtermans}

Noch ein 'Berliner' Physiker fand 1945 den Weg nach Göttingen, allerdings auf recht verschlungenen und abenteuerlichen Wegen. Es war der in Danzig geborene und in Wien bei seiner österreichischen Mutter aufgewachsene Fritz Houtermans. ${ }^{450}$ Schon als Schüler engagierte er sich in Wien in sozialistischen Gruppen. Er wurde vom Akademischen Gymnasium verwiesen, weil er Mitschülern am 1. Mai das Kommunistische Manifest vorgetragen hatte. Er absolvierte die letzten beiden Schuljahre in der freien Schulgemeinde Wickersdorf bei Saalfeld (Thüringen). ${ }^{451}$ Anschließend studierte er in Göttingen Physik und promovierte 1927 bei James Franck mit einer Arbeit über die Bandenfluoreszenz des Quecksilberdampfes und über die lichtelektrische Ionisierung des Quecksilberdampfes. In der

\footnotetext{
447 Protokoll der Fakultätssitzung vom 27. August 1945. GPAMNFG, Protokollbuch III der mathematischnaturwissenschaftlichen Fakultät WS 1927/28 - SS 1946. Dekan Eucken an Rektor Smend, 28. August 1945; Kurator an Oberpräsidenten, 13. September 1945. Am 27. Oktober 1945 wurde ihm die Diätendozentur bewilligt. HStAH, Nds. 401 Acc. 92 / 85, Nr. 135.

448 Siehe das Gutachten von Heisenberg und Laue über Flügge, 21. April 1947. MPG-Archiv, NL Laue, III, 50, 608.

449 Siegfried Flügge an Dekan Harder, 19. Mai 1947. GPAMNFG, Lehrkörper (ausgeschieden), Flügge, Wilhelm [sic].

$450 \mathrm{Zu}$ Houtermans siehe den neuen Überblicksartikel von Landrock [2003] und die leider in Details unzuverlässigen Arbeiten von Khriplovich [1992] und Amaldi [1998]. In historischer Sicht eine Größenordnung ungenauer ist die Anekdotensammlung von Buttlar (Hrsg.) [1982]. Ich habe mich sehr bemüht, die Legenden von den Fakten zu scheiden und auch bisher unbeachtetes Archivmaterial zu Hilfe gezogen.

451 Zu Houtermans Jugendzeit siehe Amaldi [1998] S. 596-601.
} 
Studienzeit war er nach eigenen Angaben vorübergehend Mitglied der KPD. ${ }^{452}$ Neue Forschungen haben ergeben, dass Houtermans in Berlin in einem konspirativ agierenden Betriebsberichterstattungs-Ressort der KPD aktiv war. Dem auch „Klub der Geistesarbeiter“ genannten Zirkel gehörten Felix Bobek, Günther Kromrey, Walter Caro und Fritz Eichenwald an. ${ }^{453}$ Von 1927-28 war Houtermans Notgemeinschaftsstipendiat im II. Physikalischen Institut, wurde 1928 Assistent von Wilhelm Westphal an der TH Berlin, habilitierte sich 1932 mit einer Arbeit über die Isotopie-Hyperfeinstruktur am Neon und war anschließend Oberassistent bei Gustav Hertz. 1933 entzog er sich durch Flucht nach England der drohenden Verhaftung. Bis dahin hatte sich Houtermans in der Fachwelt schon einen Namen gemacht. Dazu trugen vor allem seine Gemeinschaftsarbeit mit George Gamow „Zur Quantenmechanik des radioaktiven Kerns“ (1928) und die Anwendung dieser Theorie auf die thermonukleare Reaktion zwischen leichten Elementen in der mit Robert d'E. Atkinson publizierten Arbeit „Zur Frage der Aufbaumöglichkeit der Elemente in Sternen“ (1929) bei. Houtermans und Atkinson gaben hierin eine Erklärung der Energieumwandlung im Inneren von Sternen; ursprünglich sollte diese Arbeit „Wie kann man einen Heliumkern im Potentialtopf kochen“ lauten, doch die Herausgeber der Zeitschrift für Physik lehnten diesen Titel ab. ${ }^{454}$ Unter „Transmutations of the Lighter Elements in Stars“ erschien eine Kurzfassung davon in Nature. ${ }^{455}$

Während seiner Assistentenzeit in Berlin knüpfte er wichtige Kontakte, die ihm später von großem Nutzen waren. ${ }^{456}$ Als erstes ist hier Max Laue zu nennen, der ihm in fachlichen Fragen weiter half und zu dem auch eine menschlich herzliche Beziehung entstand. ${ }^{457}$ Von Bedeutung waren auch die Verbindungen zu seinen Kollegen an der TH Berlin, die bis 1933 seine fachlichen Ansprechpartner waren. Hans Kopfermann, der 1933 Houtermans Nachfolger als Oberassistent wurde, der ordentliche Professor Richard Becker und der

\footnotetext{
452 Dies gab Houtermans im Fragebogen der Militärregierung am 1. September 1945 an. UAG, Kur. PA Houtermans.

453 Siehe Landrock [2003] S. 191, der sich auf noch unpublizierte Forschungen von S. Grundmann bezieht.

454 Geiss \& Goldberg [1963] S. VIII.

455 George Gamow \& Fritz Houtermans: 'Zur Quantenmechanik des radioaktiven Kerns', Zeitschrift für Physik 52 (1928), S. 496-509; Robert d'E. Atkinson \& Fritz Houtermans: 'Zur Frage der Aufbaumöglichkeit der Elemente in Sternen', Zeitschrift für Physik 54 (1929), S. 656-665; Robert d'E. Atkinson \& Fritz Houtermans: 'Transmutations of the Lighter Elements in Stars', Nature 123 (1929), S. 567-568.

${ }^{456} \mathrm{Zu}$ Houtermans Zeit in Berlin siehe Amaldi [1998] S. 604-612. Charlotte Houtermans schrieb ihren Kindern einiges über den Vater auf, zum Beispiel dass er ein sehr geselliger Zeitgenosse war. Einmal pro Woche veranstaltete er in seiner Wohnung ein Treffen, das er „eine kleine Nachtphysik“ nannte, zu dem viele seiner Kollegen und Freunde eingeladen waren. Auch sonst gab es viele Besuche bei Houtermans', und es war nicht ungewöhnlich, wenn sich 35 Leute zufällig bei ihnen zum Tee einfanden (S. 610).

457 Siehe Brief Houtermans an Laue, 7. Oktober 1949, in dem Houtermans seine abenteuerliche Lebensgeschichte und Laues Einflüsse Revue passieren lässt. MPG-Archiv, NL Laue, III, 50, 929.
} 
jüngere Wilhelm Walcher kamen auf unterschiedlichen Wegen in der Folgezeit nach Göttingen, und es ist daher kein Zufall, dass Houtermans in den letzten Kriegsmonaten gerade in Göttingen eine Zufluchtsstätte fand.

Wie kam es aber, dass Houtermans, der das Land 1933 verlassen musste, vor dem Ende der Diktatur in Deutschland wieder auftauchen konnte? Über Kopenhagen erreichte er im Sommer 1933 seine erste längere Emigrationsstation England, wo er im Forschungslaboratorium der EMI eine Beschäftigung fand. Ende 1934 erreichte ihn durch Sasha Leipunski ein Angebot auf eine Professur verbunden mit der Leitung des kernphysikalischen Laboratoriums an dem physikalisch-technischen Institut in Charkow, das er 1935 annahm. Trotz der durch die Emigration bedingten Schwierigkeiten gelang es Houtermans, im Alter von 32 Jahren zum Abteilungsleiter aufzusteigen. Seine dortige Schaffenszeit wurde allerdings schon nach zwei Jahren beendet. Die Bemühungen um eine Emigration nach England kamen zu spät. ${ }^{458}$ Als 1937 die Verhaftungswelle das Charkower Institut erreichte, fiel auch Houtermans der Stalinschen Terrorwelle zum Opfer. Er wurde am 1. Dezember 1937 vom russischen Geheimdienst NKWD verhaftet, während er auf seine Ausreisebewilligung aus der UdSSR wartete. Seine Frau mit den beiden kleinen Kindern konnte noch das Land verlassen und gelangte auf einer Odyssee über Riga und Kopenhagen nach London. ${ }^{459}$ Eine internationale Hilfsaktion für Fritz Houtermans startete, an der sich Albert Einstein, Patrick Blackett, Jean Perrin, Irene und Frederic Joliot-Curie, Harald und Niels Bohr mit Petitionen an russische Stellen beteiligten. ${ }^{460}$ Trotzdem musste Houtermans über zwei Jahre in russischen Gefängnissen sitzen, bis er als Folge des deutsch-sowjetischen Nichtangriffspaktes vom August 1939 Teil einer Gefangenen-Rückgabeaktion wurde. ${ }^{461} \mathrm{Er}$ war einer von 484 Reichsdeutschen, die im Frühjahr 1940 aus russischen Gefängnissen nach Deutschland kamen. Vorher musste er einwilligen, für den russischen Geheimdienst zu arbeiten. ${ }^{462}$ Das RSHA, IV A 1, machte die Gestapo in Berlin auf ihn besonders aufmerksam.

\footnotetext{
458 Im Sommer 1937 fuhr Charlotte Houtermans nach London, um für ihren Mann eine Einladung nach England zu erwirken. Amaldi [1998] S. 620. Erst am 15. Oktober 1937 bewilligte das Executive Committee der SPSL ein Stipendium von monatlich 250 für die Dauer von sechs Monaten für Fritz Houtermans, welches ihm nur durch Patrick Blackett mitgeteilt werden durfte. Schreiben von Walter Adam an P. M. S. Blackett, 16. Oktober 1937. BLO, MS SPSL 330/8, Corr. Houtermans.

${ }^{459}$ Amaldi [1998] S. 612-624.

460 Siehe BLO, MS SPSL 330/8, Corr. Houtermans.

${ }^{461}$ Ein chronologischer Bericht von Houtermans über seine Erlebnisse während der Gefangenschaft, verfasst im Mai 1945, ist abgedruckt bei Amaldi [1998] S. 625-631. Siehe auch das von Houtermans und Konstantin Feodossovitch Shteppa unter den Pseudonymen Beck \& Godin [1951] verfasste Buch über die russischen 'Säuberungen'. Siehe auch die ausführliche Beschreibung aus der Sicht eines Freundes Houtermans', Weissberg-Cybulski [1951].

462 Landrock [2003] S. 193; Amaldi [1998] S. 630. In einem Rundschreiben des RSHA IV A $1-5827 / 38$ g vom 12. Oktober 1940, wird Houtermans unter den Russlandrückkehrern aufgelistet, die zwischen 1.12.1939 und
} 
„H. ist Mischling 2. Grades, ehem. KPD.-Funktionär und war Dozent an der Techn. Hochschule in Charlottenburg sowie leitender Funktionär des BB.[Betriebsberichterstattung]Apparates in Berlin. [...Er] ist sofort in Schutzhaft zu nehmen, als RR. [Russlandrückkehrer] zu vernehmen und anschliessend dem Reichssicherheitshauptamt - Sachgebiet IV A 2 - zu überstellen." 463

Ende April 1940 wurde Houtermans nach Brest-Litowsk gebracht und der Gestapo übergeben. Am 25. Mai 1940 kam er in Berlin an und wurde dort zuerst ins Gefängnis am Alexanderplatz gesperrt und eine Woche später in die Zentrale der Gestapo in die PrinzAlbrecht-Straße gebracht. Max Laue erfuhr von Houtermans Anwesenheit, ging zur Gestapo, brachte ihm Geld und erreichte, dass Houtermans am 16. Juli 1940 freigelassen wurde. ${ }^{464}$ Laue gelang es, Houtermans für kriegswichtige Forschung einzusetzen, was ihm das drohende KZ ersparte. Kaum freigekommen, publizierte Houtermans eine kurze Nachricht in den Naturwissenschaften über die Halbwertszeit des Radiotantal, die statt einer Institutsadresse seine Charlottenburger Privatanschrift Uhlandstraße 189 nannte. So ging am 6. September 1940 die Nachricht in die Fachwelt, dass Houtermans wieder frei war und in Berlin physikalischer Arbeit nachgehen konnte - dies war der eigentliche Zweck der Publikation. ${ }^{465}$

Im Januar 1941 trat Houtermans in Manfred Ardennes Laboratorium für Elektronenphysik ein, wo er an den Forschungen des Uranvereins beteiligt war. ${ }^{466}$ Er beschäftigte sich auch mit Isotopentrennung und knüpfte hierbei an Arbeiten seines früheren Berliner Kollegen Wilhelm Walcher an. ${ }^{467}$ In einem internen Bericht diskutierte Houtermans die Möglichkeiten der Energieproduktion mittels einer durch die Spaltung schwerer Elemente ausgelösten

\footnotetext{
1.9.1940 für den NKWD verpflichtet wurden. Diesen Personen wurde eine Belohnung versprochen, falls sie durch ihre Mithilfe dazu beitrügen, einen anlaufenden NKWD-Agenten festzunehmen. Außerdem seien sie unabhängig von der sonst üblichen Überwachung mindestens noch vier Jahre nach ihrer Rückkehr jährlich einbis zweimal zu unregelmäßigen Zeiten zu überprüfen. BAB, ZB 7268 A 8.

463 Zitat aus Schreiben des RSHA, IV A 1 (4218/39) an den Kommandeur der Sicherheitspolizei und des SD in Lublin, an den Kommandeur der Sicherheitspolizei und des SD in Krakau und an die Geheime Staatspolizei in Berlin, betr. Russlandrückkehrer, 6. Mai 1940. "Jüdische Rückkehrer" sollten entweder ins KZ-Dachau überführt werden oder im Generalgouvernement bis zur endgültigen Abwanderung einer jüdischen Arbeitsabteilung angegliedert werden. Laut Schreiben des RSHA, IV A 1 (4218/39) an den Kommandeur der Sicherheitspolizei und des SD in Lublin, 23. Januar 1940. BAB, ZB 7271 A 3. Das Amt IV im RSHA war das Geheime Staatspolizeiamt und zuständig für die Verfolgung von als Gegnern des NS angesehenen Personen.

464 Amaldi [1998] S. 630f.

465 Siehe Houtermans [1940].

466 Ardenne [1972/82] S. 135. Zu den kernphysikalischen Arbeiten in Ardennes Labor siehe Stange [1998]. Zu Houtermans Forschungsgebiet siehe seine Publikationen zwischen 1941 und 1944. Goudsmit legte Wert darauf, dass Houtermans nicht zum Uranverein zählte, anders, als es Heisenberg in der Nachkriegszeit darstellte. Siehe z. B. Goudsmit an Weisskopf, 7. Dezember 1948. NBL, Samuel Abraham Goudsmit, papers, box 24, series III, 257, Weisskopf.

467 Houtermans [1941]. Zwei Jahre zuvor publizierte Walcher in den Ergebnissen der exacten Naturwissenschaften 18 (1939), S. 155-228 über „Isotopentrennung“.
} 
Kettenreaktion. ${ }^{468}$ Durch diese Arbeiten kam er in näheren Kontakt mit den wichtigsten Forschern im Uranverein, wie Werner Heisenberg und Carl Friedrich Weizsäcker. Zu einem Vertrauensverhältnis und einer Freundschaft kam es mit Otto Haxel, obgleich dieser Parteimitglied war. ${ }^{469}$

Im Herbst 1941, kurz nach dem deutschen Überfall auf die Sowjetunion, wurde Houtermans auf Anregung von Robert Rompe einer drei Mann starken zivilen Kommission zugewiesen, um die eroberten Physikinstitute in Kiew und Charkow zu inspizieren. Seine Begleiter waren Hans König und Dr. Bewilogua. ${ }^{470}$ Ein Interview mit Hans König brachte bisher Unbekanntes zu Tage (zu König siehe auch Abschnitt 1.2.6.1.1). Houtermans kannte König aus einer Begegnung in Danzig, die vermutlich 1932/33 (oder mit etwas geringerer Wahrscheinlichkeit 1936/37) stattgefunden hatte. In Danzig hatte König seinen ersten Kolloquiumsvortrag über ein neues Wasserstoffisotop zu halten und suchte deshalb den gerade (bei seinem Vater?) in Zoppot weilenden Houtermans auf, der ihn als Spezialist auf diesem Gebiet beraten konnte. Houtermans kam dann auch zum Kolloquiumsvortrag, hörte interessiert zu und klatschte am Schluss Beifall. - 1941 war die Kommission mit König und Houtermans im Auftrag des RLM unterwegs und sollte in den Physikinstituten wichtige Materialien und Geräte ausfindig machen und mitnehmen. Aus Kiew nahmen sie zum Beispiel Platinschalen mit. Gefährlich wurde es für Houtermans, als er in Kiew von der dort gerade operierenden Einsatzgruppe als „Jude“ angesehen wurde und zu den Massenerschießungen abgeführt werden sollte. Die Intervention des in Fliegeruniform anwesenden König rettete ihm das Leben. ${ }^{471}$ Houtermans wurde vom RLM für dieses Unternehmen ausgewählt, weil er russisch sprach und die lokalen Verhältnisse kannte. Seine eigenen Motive für die Teilnahme waren neben der Vermeidung einer KZ-Einweisung bei Ablehnung, die physikalischen Institute und vor allem seine ehemaligen Kollegen zu retten. Dies sei ihm nach eigenen Aussagen auch teilweise gelungen. ${ }^{472}$ Manche Kollegen außerhalb Deutschlands verstanden seine Handlungen nicht

\footnotetext{
468 Amaldi [1998] S. 643f.; Khriplovich [1992] S. 35f.

469 Powers [1993] S. 136.

${ }^{470}$ Siehe die Abschrift des Briefes Houtermans an Touschek, etwa Juli 1947. Demzufolge sei die Teilnahme Houtermans an der Kommission mit Rompe, Jensen und Laue abgesprochen gewesen. Dort berichtet Houtermans auch, dass es sich um eine zivile Kommission handelte, die aus drei Mann bestand: Dr. König, Dr. Bewilogua und ihm. Ein paar Tage später sei ihm vom RLM der „S.S. Häuptling Beuthe“ nachgeschickt worden. StB-B, NL Born, 320. In der Forschung wurde bisher angenommen, dass Houtermans an der Seite von Kurt Diebner und Erich Schumann in die Sowjetunion gereist sei. Siehe zum Beispiel Powers [1993] und Rose [1998]. Bei Landrock [2003] S. 196 wird behauptet, dass Diebner, Ludwig Bewilogua und Heinrich Rausch von Traubenberg mit Houtermans reisten.

471 So erzählte mir König diese Gegebenheit in einem Interview. Am 2. Oktober 1941 wurden in Kiew durch das Einsatzkommando 4 a mit Unterstützung zweier Abteilungen des Ordnungspolizeiregiments Süd zirka 33000 Juden ermordet. Hilberg [1961/97] S. 311.

472 Houtermans an Touschek, etwa Juli 1947. StB-B, NL Born, 320. Siehe auch Amaldi [1998] S. 645f.
} 
und klassifizierten ihn folglich als Kollaborateur der Nationalsozialisten. ${ }^{473}$ Auf der Russlandreise machte er auch Bekanntschaft mit dem SS Obersturmbannführer Theodor Cammann, mit dessen Hilfe er später das Leben von Marie Rausch von Traubenberg und deren Mutter retten konnte. ${ }^{474}$

Houtermans verließ das Labor von Ardenne und arbeitete vom 15. Mai 1942 bis zum 31. Januar 1945 mit einem Stipendium von FEP 3 als Gast an der PTR bei C. F. Weiss. ${ }^{475}$ Dem Ende dieser Anstellung war eine typisch Houtermans'sche Aktion vorausgegangen, die hier nach Auskunft seiner damaligen Frau wiedergegeben wird. Ein Firmenangehöriger machte Houtermans darauf aufmerksam, dass in der PTR lagernde zollverplombte Säcke ein Gemisch aus Tabak und Sand bzw. Staub enthielten. Houtermans, der im Umgang mit Bürokratie nicht zuletzt aus Russland entsprechende Übung hatte, schrieb an die zuständige Zollbehörde mit der Bitte um Freigabe eines der Säcke zu strahlenanalytischen Untersuchungen am Tabakvirus - mit Erfolg. Mit einem Küchensieb wurden die kostbaren Tabakkrümel vom Schmutz getrennt, und der Kettenraucher Houtermans teilte sich die Beute mit dem Initiator der Aktion. Bei einem zweiten Versuch landete das Genehmigungsschreiben der Behörde jedoch auf dem Tisch von Abraham Esau, dem Präsidenten der PTR. Houtermans wurde sofort entlassen und sah sich wieder einmal in großer Gefahr, da Esau auch eine Strafanzeige gegen ihn gestellt hatte. ${ }^{476}$ Seine Frau Ilse riet ihm, die Kollegen vom KWI in Stadtilm aufzusuchen. So kam Houtermans (nicht ohne selbstausgestellten Reisebefehl) zu Heisenberg, der dann die Weiterreise zu Kopfermann 'legalisieren“ konnte. Weizsäcker formulierte den Schüttelreim: „Heisenberg mußte die Reise bescheinigen, Kopfermann die Sch... bereinigen“. 477 Auf diese Weise und mit Unterstützung von Walther Gerlach im RFR war er anschließend in Göttingen tätig. Um für ihn eine uk-Stellung zu erwirken, setzte Kopfermann ein entsprechendes Schreiben auf und schickte seinen Assistenten Wolfgang Paul mit dem Fahrrad $\mathrm{zu}$ einer Außenstelle der

\footnotetext{
473 Als zwei Beispiele seien Paul Scherrer und Max Born genannt. Siehe Amaldi [1998] S. 645f. Zu Scherrer Powers [1993] S. 380. Auch der Historiker Paul Lawrence Rose beurteilt Houtermans skeptisch. Rose hat Probleme, Houtermans Charakter einzuordnen, der ihm merkwürdig und rätselhaft erscheine. Houtermans sei bis Sommer 1941 klarer Anti-Nazi gewesen, habe sich dann aber moralisch kompromittiert (Uranprojekt, Russlandreise) und in der Nachkriegszeit bereitwillig in das Lügennetz seiner Kollegen verstrickt. Rose [1998] S. 135,145 .

474 Bescheinigung von Marie Rausch von Traubenberg für Houtermans, 22. November 1945. BLO, MS SPSL 330/8, Corr. Houtermans.

475 Aus Lebenslauf von Fritz Houtermans, September 1945. GPAMNFG, Lehrkörper (ausgeschieden), Houtermans.

476 Landrock [2003] S. 197.

477 Von dieser Geschichte gibt es mehrere Varianten. Die hier gebrachte ist von Schlüpmann [http] abgeschrieben, der seine Informationen aus einem Interview mit Ilse Haxel hat. Siehe für eine andere Variante Amaldi [1998] S. 656f.
} 
Wehrforschungsgemeinschaft (Aktion Osenberg), die im Harz gelegen war. ${ }^{478}$ So wurde Houtermans Mitarbeiter an dem Göttinger Forschungsprojekt zur Demagnetisierung von UBooten, das Richard Becker in der theoretischen Physik leitete. ${ }^{479}$

Obwohl Houtermans in Deutschland unter der Bewachung der Gestapo stand und in einer permanenten Unsicherheit lebte, setzte er sich für bedrohte Kollegen ein. Gemeinsam mit Becker, Gerlach, Jensen, Kopfermann, Rosbaud, Rompe und Haxel gelang es ihm zum Beispiel, den „Nichtarier“" Richard Gans zu retten. ${ }^{480}$ Dieses gemeinsame Eintreten stärkte die kollegiale Verbundenheit der Beteiligten. Solche Extremsituationen schufen Allianzen, in denen politische Differenzen keine Rolle mehr spielten. Ein Minimalkonsens herrschte in der Abwehr von Lebensbedrohungen von Kollegen; und dafür wurden auch eigene Risiken in Kauf genommen.

Als die Alliierten Göttingen einnahmen, wären sie verpflichtet gewesen, Houtermans an die Sowjetunion auszuliefern, weil er auf der russischen Liste der Kriegsverbrecher stand. ${ }^{481}$ Durch Max Borns Intervention konnte dies verhindert werden. ${ }^{482}$ Houtermans, dessen Familie durch die Shoah dezimiert worden war und von dessen Wiener Verwandten und großen Wiener Freundeskreis fast niemand übrig geblieben war, ${ }^{483}$ verhielt sich auch gegenüber den überzeugten Nationalsozialisten unter den Göttinger Physikern kollegial. Dies schloss fachliche Diskussionen und sogar gemeinsame Publikationen mit ein. ${ }^{484}$ Dieses Verhalten hat aber nichts mit der von Hermann Lübbe postulierten nicht-symmetrischen Diskretion zu tun, denn Lübbes These zufolge hätte Houtermans anstelle von Eucken zum Dekan ernannt werden müssen.485 Der kollegiale Verhaltenskodex, der hier als Erklärung besser herangezogen wird, beinhaltete eine symmetrische Diskretion in dem Sinne, dass fachlich anerkannte Forscher, die sich in der NS-Zeit keine Denunziationen von Kollegen zu Schulden

\footnotetext{
478 Vermutlich war das Ziel der Radfahrt Lindau, wo Werner Osenberg als Vorsitzender des Planungsamtes des RFR mit seinen Mitarbeitern angesiedelt war. Siehe Gimbel [1990] S. 17.

479 Amaldi [1998] S. 657. Leider sind dort keine Quellen genannt, aber da Amaldi Interviews mit Wolfgang Paul und Wilhelm Walcher geführt hatte, ist anzunehmen, dass die detaillierten Informationen von ihnen stammten.

480 Weisskopf [1964] S. 181. Zu Richard Gans siehe Swinne [1992]. Dort ist Houtermans Einsatz in dem Anschnitt „Die »Affäre Prof. Dr. Richard Gans«“"von Heinz Schmellenmeier belegt.

${ }^{481}$ Houtermans machte unter Folter in der russischen Haft ein fungiertes 'Geständnis', dass er ein deutscher Spion sei. Möglicherweise kam er deshalb auf die Kriegsverbrecherliste. Siehe Houtermans an die Mathematisch-Naturwissenschaftliche Fakultät, 3. September 1945. GPAMNFG, Lehrkörper (ausgeschieden), Houtermans.

482 Born informierte die SPSL über Houtermans Existenz auf der Liste der Kriegsverbrecher, woraufhin die SPSL die Control Commission Authorities der Britischen Zone benachrichtigte, ihn nicht auszuliefern. BLO, MS SPSL 330/8, Corr. Houtermans.

483 Brief Houtermans an Born, 26. Dezember 1947. StB-B, NL Born, 320.

${ }^{484}$ Houtermans \& Jordan [1945] und [1946].
} 
haben kommen lassen, nicht aus politischen Gründen angeschwärzt wurden. „Anständigkeit“ während der NS-Zeit ist eine zeitgenössische Vokabel für das, was als Voraussetzung für kollegiale Rücksichtnahme in der Nachkriegszeit Bedingung war. ${ }^{486}$ Die Symmetrie der kollegialen Solidarität ist offensichtlich: Während Houtermans in der Kriegszeit notwendige und lebensrettende Hilfe bekam, vor allem von Laue, aber nach Königs Angaben auch von diesem in Kiew und zuletzt von den Göttinger Physikern, zeigte er sich nach 1945 ihnen gegenüber erkenntlich. Diese Gegenseitigkeit beförderte seine Wiedergutmachung in Göttingen.

Der Antrag von Houtermans auf Rehabilitation als Privatdozent vom 3. September $1945^{487}$ löste in der Fakultät allerdings Bedenken bei Eucken und Harder aus, die vor der Schaffung eines Präzedenzfalles warnten. Richard Becker befürwortete seine Ernennung zum Dozenten. ${ }^{488}$ In einer eigens anberaumten Kommissionssitzung zum Fall Houtermans führte Eucken aus, dass vom Minister Grimme die Verleihung der venia legendi nur für ein Semester gestattet sei. Houtermans solle seine Habilitierung beantragen und bei Beschränkung auf einen Probevortrag die venia auf ein Semester verliehen bekommen. Kopfermanns Antrag, die Verleihung auf höchstens zwei Jahre zu verlängern, wurde zugestimmt. ${ }^{489}$ Zwei Hindernisse standen einer weitreichenden Rehabilitation im Wege: Einflussreiche Fakultätsmitglieder, die Houtermans nicht persönlich kannten, die zusätzlich Vorbehalte gegenüber der Verpflichtung zur Wiedergutmachung hegten und nur bereit waren, „die Besten“ aufzunehmen, wollten keinen Präzedenzfall schaffen. Auf der anderen Seite hatte Kopfermann als vertrauter Kollege kein gutes Gefühl dabei, Houtermans auf längere Zeit in seinem Institut zu haben. Da es nur einen einzigen Institutsleiter gab (und geben sollte), konnten sie nicht beide auf derselben Hierarchiestufe stehen, obwohl beiden nach ihren Qualifikationen und Karriereverläufen eine Direktorstelle zustand. Houtermans bekam in Kopfermanns Institut 1946 aber nur eine Assistentenstelle, sodass allein schon diese Konstellation ein ungünstiges Klima erzeugte. 490

\footnotetext{
485 Lübbe [1983].

486 Heisenberg soll noch 1947 ausgerechnet zu dem Emigranten Franz Simon gesagt haben: „Man hätte die Nazis nur fünfzig Jahre dran lassen wollen; dann wären sie auch anständig geworden." Zitiert nach Rose [1998] S. 314.

487 Houtermans an die Mathematisch-Naturwissenschaftliche Fakultät, 3. September 1945. GPAMNFG, Lehrkörper (ausgeschieden), Houtermans.

488 Protokoll der Fakultätssitzung, 13. September 1945. GPAMNFG, Protokollbuch III der mathematischnaturwissenschaftlichen Fakultät WS 1927/28 - SS 1946.

489 An dieser Kommissionssitzung vom 19. September 1945 nahmen Eucken, Becker, Kopfermann, Rellich, Pohl, ten Bruggencate und Mollwo teil. Harder war entschuldigt. GPAMNFG, Protokollbuch III der mathematisch-naturwissenschaftlichen Fakultät WS 1927/28 - SS 1946.

490 Die Assistentenstelle erhielt er am 1. September 1946. HStAH, Nds. 401 Acc. 92 / 85 Nr. 109.
} 
Beiden Bedenken wurde Abhilfe geschaffen. Kopfermann und Becker konnten die Fakultät davon überzeugen, dass seine ,allerseits anerkannten wissenschaftlichen Leistungen“ eine Aufnahme in den Lehrkörper rechtfertige. ${ }^{491}$ Außerdem wurde dafür gesorgt, dass Houtermans eine gewisse Selbständigkeit im Institut entfalten konnte und nicht an Kopfermann gebunden war. Nachdem er zum Dozenten ernannte worden war, wurde er im August 1946 zum außerplanmäßigen Professor ernannt, um „das ihm zugefügte Unrecht dadurch in geringem Umfang wieder gut [zu] machen“. 492 Im Oktober 1949 wurde er zum Diätendozenten für Kernphysik ins Beamtenverhältnis berufen. ${ }^{493}$ Eine Unabhängigkeit vom Institutsdirektor sicherte sich Houtermans, indem er sich eine eigene Nische in der Forschungslandschaft suchte. Er richtete seine weiterhin kernphysikalischen Forschungen auf Anwendungen in der Mineralogie und Geologie aus. Mehr als die Hälfte seiner Göttinger Arbeiten betrafen Voraussetzungen und Verfahren zur geologischen Altersbestimmung. ${ }^{494}$ So konnte er sich eine eigene Abteilung im Institut aufbauen, wenngleich mit nur geringen finanziellen Mitteln.

Bei jedem dieser Schritte zur Selbständigkeit und Unabhängigkeit war Houtermans doch von den Göttinger Ordinarien abhängig, die ihm wohlgesonnene Gutachten und Anträge beizusteuern hatten. Die Unterstützung durch die Fakultät war aber nicht bloß ein Akt der sozialen Fürsorge, sondern brachte auch Vorteile für Göttingen. Auf einer von der Militärregierung angeforderten Liste der Wiedergutmachungsfälle konnte er als erledigter Fall angeführt werden. 495 Somit konnte die Universität ihre 1945 proklamierte Richtungsänderung nach außen glaubwürdig machen. Auch half Houtermans durch seine Bereitschaft zur Zusammenarbeit mit Physikern wie Jordan und Hellwege, 496 zu einer 'Normalität' im Fach zurückzukehren. Es war allerdings ein bedenklicher Normalisierungsprozess, der beinhaltete,

491 Zitat aus Antrag des Dekans an den Oberpräsidenten auf Ernennung Houtermans zum außerplanmäßigen Assistenten, 3. Juni 1946. UAG, Kur. PA Houtermans.

492 Zitat aus Antrag des Dekans an den Oberpräsidenten auf Ernennung Houtermans zum außerplanmäßigen Assistenten, 3. Juni 1946. UAG, Kur. PA Houtermans.

493 Am 11. Oktober 1945 fand die öffentliche Lehrprobe zum Thema „Anwendung radioaktiver Indikatoren in der Naturforschung“ statt, die ,zur vollen Zufriedenheit der Fakultät“ ausfiel. Eucken an Kurator, 16. Oktober 1945. Die Ernennung zum apl. Professor erfolgte am 29. August 1946. Am 20. Oktober 1949 ernannte ihn das Kultusministerium zum Diätendozenten. UAG, Kur. PA Houtermans.

494 Landrock [2003] S. 197.

495 Siehe Fußnote 405.

496 Im Vorlesungsverzeichnis des WS 1948/49 ist ein zusammen von Houtermans und Hellwege geleitetes Physikalisches Proseminar angekündigt. Von der Zusammenarbeit mit Jordan zeugen Houtermans \& Jordan [1945], [1946]. Jordan faszinierte seine Kollegen als brillianter Physiker. Der für die Briten als Spion tätige Paul Rosbaud schrieb über Jordan: „I had many frank discussions with Jordan, and I enjoyed arguing with him very much." Auch Houtermans scheint die wissenschaftliche Auseinandersetzung mit Jordan gesucht zu haben. Zu Rosbaud siehe Kramish [1986]. Die zitierte Einschätzung Jordans stammt aus einem undatierten Bericht 
dass das Nachdenken über die Beteiligung der Physikerschaft in die Kriegs- und Vernichtungsziele des Nationalsozialismus in den Hintergrund gedrängt wurde. Statt über die Organisation der Wissenschaft in der Gesellschaft nachzudenken, suchte man den Halt in der wissenschaftlichen Objektivität, in dem verlässlichen Erkenntnisgewinn durch physikalische Forschung. Houtermans beteiligte sich an diesem Programm, was insofern naheliegend war, als ihm die Abhängigkeiten, die seine Wissenschaftlerexistenz in Deutschland mit sich brachte, wenig Alternativen ließen. Vielleicht in Erkenntnis dieser beschränkten Möglichkeiten schrieb er schon im September 1945 in seinem Antrag auf Rehabilitierung, dass er es für möglich - und damals wahrscheinlich auch für erwünscht - hielt, „daß sich mir in nicht $\mathrm{zu}$ ferner Zukunft die Möglichkeit bietet, eine wissenschaftliche Stellung im angelsächsischen Ausland anzunehmen."497 Falls Houtermans überhaupt Pläne in dieser Richtung verfolgte, so wurden sie jedenfalls nicht verwirklicht. 1951 erhielt er zwei Angebote auf Experimentalphysik-Professuren: ein Extraordinariat an der FU Berlin und ein Ordinariat an der Universität Bern. Es lag wohl mehr an Houtermans Werdegang als an seiner Qualifikation, dass der fast Fünfzigjährige in Deutschland nicht die volle Anerkennung erhielt. 1952 folgte er schließlich dem Ruf nach Bern.

Eine andere, außerwissenschaftliche Eigenschaft Houtermans' spielte in der erfolgreichen Eingliederung in die Göttinger Physikerschaft eine begünstigende Rolle. Es war dies sein ungebrochener Humor. Auch König bestätigte mir im Interview: „Mit Houtermans war es immer lustig." Wie die unterhaltsame Anekdotensammlung seiner Schüler zeigt, ließ er kaum eine Gelegenheit für Späße aus. ${ }^{498}$ Auch Unmutsäußerungen wurden witzig verpackt. Als er 1948 erneut einen Fragebogen der Militärregierung auszufüllen hatte, beantwortete er die Frage nach Ort und Zeitpunkt schon früher abgegebener Fragebogen: „Göttingen 1945-1947 ununterbrochen" ${ }^{499}$

Wenn auch die Wege und Motive, die Kneser, Jordan, Flügge und Houtermans nach Göttingen führten, unterschiedliche waren, so gab es doch Gemeinsamkeiten dieser Fälle. Der Hauptzweck aller Bemühungen um diese Personen bestand darin, sie irgendwie unterzubringen, wenn auch nur vorübergehend. Es gab aber auch einen wesentlichen Unterschied, der die Chancen auf Reintegration in Göttingen verschieden ausfallen ließ. Die

Rosbauds in NBL, Goudsmit papers, box 28, folder 41. Zur Einstufung Jordans als brillianter Physiker siehe auch Rosbaud an Goudsmit, 26. Mai 1949, NBL, Goudsmit papers, box 28, folder 43.

497 Houtermans an die Mathematisch-Naturwissenschaftliche Fakultät, 3. September 1945. GPAMNFG, Lehrkörper (ausgeschieden), Houtermans.

498 Buttlar (Hrsg.) [1982].

499 Fragebogen der Militärregierung, 31. März 1948. UAG, Kur. PA Houtermans. 
'Ostflüchtlinge' waren Bittsteller und hatten keine Rechte auf eine Stelle in Göttingen. Sie mussten mit dem zufrieden sein, was ihnen geboten wurde. Genauso erging es Houtermans bis zum April 1945. Nach der Befreiung vom NS fühlte er sich jedoch im Recht, eine Anstellung einzufordern. Mit ihm konnte die Fakultät daher nicht nach Belieben umgehen. 500 Sein Einfordern eines Wiedergutmachungsrechtes nahmen einzelne Fakultätsmitglieder als unwillkommene Anspruchshaltung wahr, die sie eine vorsichtige Distanz einnehmen ließ. Paradoxerweise waren die Chancen auf Eingliederung ins Göttinger Netz für Houtermans in der NS-Zeit besser als danach. Wie wir im Fall Hohenemser in Abschnitt 5.4 sehen werden, kann diese Distanz zu einer heftigen Abwehr anwachsen. Bei Houtermans konnten die engen Kollegen jedoch schützend eingreifen.

\subsubsection{Werner Döring}

Zwei weitere ehemalige Berliner Assistenten von Richard Becker sind unter dem Phänomen Wanderschaft noch zu erwähnen. Beide besaßen auch enge Bindungen an Göttingen, erlitten 1945 einen Karriereknick und benutzten Göttingen als Zwischenstation bis zur Rückkehr zur Universitätsprofessur an anderen Orten. Der Erste ist Werner Döring, der sein Extraordinariat in Posen verloren hatte. Seine Rückkehr nach Göttingen war naheliegend, da seine Familie dort geblieben und nicht nach Posen mitgezogen war. ${ }^{501}$ An der Universität wurde er von seinem früheren Lehrer Becker fürsorglich aufgenommen und bekam eine Assistentenstelle übertragen. ${ }^{502}$ Im September 1945 wurde ihm die venia legendi wiedererteilt. ${ }^{503}$ Daraufhin beteiligte er sich an Beckers Seminaren zur theoretischen Physik ${ }^{504}$ bis ihm 1946 nach „Überwindung zahlreicher bürokratischer Schwierigkeiten“ die Anstellung als Diätendozent an der TH Braunschweig gelang. ${ }^{505}$ Zuvor setzten ihn seine Kollegen auf die Berufungsliste eines Göttinger Lehrstuhls, gleichwohl nicht eines für theoretische Physik, sondern für

\footnotetext{
500 Es wäre aber denkbar gewesen, dass die Fakultät Göttingen sich in der Frage der Rehabilitation für nicht zuständig erklärt, da Houtermans in Berlin entlassen wurde. 1947 stellte sich zum Beispiel der Kurator genau aus diesem Grund in etatrechtlichen Belangen auf den Standpunkt, Houtermans „Wiedergutmachungsfall im eigentlichen Sinne [...] nicht anzuerkennen“. Kurator an Kultusministerium, 16. August 1947. HStAH, Nds. 401 Acc. 92 / 85 Nr. 109.

501 Simon \& Zehler [1981].

502 Protokoll der Fakultätsitzung vom 13. September 1945. GPAMNFG, Protokollbuch III der mathematischnaturwissenschaftlichen Fakultät WS 1927/28 - SS 1946.

503 Eucken an Oberpräsidenten in Hannover, 15. September 1945. GPAMNFG, Lehrkörper (ausgeschieden), Döring.

504 Eine Ankündigung im Vorlesungsverzeichnis für das S 1945/46 klappte offenbar aus Termingründen nicht, aber für das SS 1946 ist das Seminar zur theoretischen Physik durch Becker gemeinsam mit Döring und Flügge angekündigt.

505 Zitat aus Schreiben Döring an Dekan Eucken, 18. Dezember 1946. GPAMNFG, Lehrkörper (ausgeschieden), Döring.
} 
angewandte Mechanik (siehe Abschnitt 5.4.4). Diese Nennung war vor allem eine Solidaritätsbekundung seiner Kollegen, die möglicherweise auch dazu dienen sollte, seine Braunschweiger Schwierigkeiten überwinden zu helfen. 1949 wurde er schließlich als Ordinarius nach Gießen berufen.

\subsubsection{Fritz Sauter}

Der zweite ehemalige Assistent von Becker, den Göttingen in der Nachkriegszeit aufgefangen hat, ist Fritz Sauter, der 1945 als Ordinarius in München von den Amerikanern entlassen wurde und 1948 nach Aufweichung der Entnazifizierungsbestimmungen als Dozent an das Physikalisch-Chemische Institut zu Eucken kam. Sauters Karriere wurde nicht erst 1945 durch politische Schwierigkeiten verzögert. Schon 1936, als er in Königsberg die Nachfolge von Richard Gans antreten sollte, wurde seine politische Haltung einer genaueren Prüfung unterzogen, die die Berufung drei Jahre hinauszögerte. Obwohl Sauter zuerst vom Ministerium entgegen der Königsberger Berufungsliste in Vorschlag gebracht und vom NSDDB positiv beurteilt worden war, kamen kurz danach Bedenken beim Dozentenbund auf. Sauter sei katholisch, gehöre keiner Parteigliederung an und gelte als politisch völlig indifferent. In einer Ansprache vor Studenten seines Instituts habe er den Geburtstag „des Führers“ mit jenem des ,alten Kaisers“ gleichgesetzt. Er habe ein Bild von Gustav Hertz im Institut aufgehängt und die Leistungen von Philipp Lenard als nicht maßgeblich bezeichnet. ${ }^{506}$ Nachdem sich sogar Martin Bormann persönlich negativ über Sauter geäußert hatte, konnte der Königsberger Rektor Sauter überzeugen, in den NSKK einzutreten, wo er sich als Truppführer aktiv beteiligte. ${ }^{507} 1937$ war er aus der katholischen Kirche ausgetreten. ${ }^{508} 1939$ erfolgte Sauters Eintritt in die Partei und seine Ernennung zum persönlichen Ordinarius. Dann war er aber ein halbes Jahr lang nicht mit theoretischer Physik, sondern im Militärdienst mit der Fliegerabwehr beschäftigt. ${ }^{509}$

1942 wurde er als planmäßiger Ordinarius an die TH München berufen, wobei diese Berufung von seinen Kollegen als Gegenmaßnahme gegen die politisch motivierte Berufung von

\footnotetext{
506 NSDDB an REM, 15. Juli 1937. Swinne [1992] S. 102. Die Angabe, dass Sauter keiner Gliederung angehörte ist übrigens nicht richtig. Am 1. September 1934 trat er dem NSLB bei und seit 1935 war er Mitglied der NSV. BAB, NSLB Kartei Sauter; Fragebogen für die politische Überprüfung, 16. November 1948. HStAH, Nds. 171 Hildesheim 12794.

507 Schreiben des Stellvertreters des Führers, Bormann, an REM, 26. Oktober 1937. Swinne [1992] S. 103. Siehe auch Fragebogen für die politische Überprüfung, 16. November 1948. HStAH, Nds. 171 Hildesheim 12794 .

508 Aus Fragebogen für die politische Überprüfung, 16. November 1948. HStAH, Nds. 171 Hildesheim 12794.

509 Vom 10. August 1939 bis zum 12. März 1940 diente er bei der 119 Flak-Scheinwerfer-Ersatz-Abteilung. Fragebogen für die politische Überprüfung, 16. November 1948. HStAH, Nds. 171 Hildesheim 12794.
} 
Wilhelm Müller auf den Lehrstuhl für theoretische Physik an der Universität München wahrgenommen wurde. ${ }^{510}$ In der Nachkriegszeit wurde Sauter schon aus diesem Grund zum Parteigegner stilisiert. Um den Jahreswechsel 1944/45 arbeitete er an der Entwicklung eines geräuschfreien Antriebs von U-Booten.511 Im September 1945 wurde er in München dienstenthoben, weil er seit 1942 Luftschutzleiter der TH München gewesen war. Damit zählte er zur Hochschulführung, die von den Amerikanern vollständig entlassen wurde. ${ }^{512} \mathrm{Er}$ fand dann vom November 1945 bis Ende 1948 eine Anstellung als wissenschaftlicher Mitarbeiter an einem französischen, wissenschaftlichen Institut in Saint Louis, wo er sich weiterhin mit Rüstungsforschung beschäftigte. ${ }^{513}$ Dann erreichte ihn eine Einladung nach Göttingen, die ihm die Chance zur Rückkehr in den Hochschulbetrieb bot.

1948 hatten schon einige der wandernden Physiker Göttingen wieder verlassen, trotzdem sah es mit freien Stellen vor allem in der theoretischen Physik schlecht aus. Sauter musste sich mit einer Assistentenstelle bei Eucken zufrieden geben. Um diese antreten zu können, musste er aber vorher seine politische Überprüfung überstehen. Obwohl seine formale Belastung bei der Ende 1948 üblichen Entnazifizierungspraxis der deutschen Stellen kaum eine Gefahr für ihn bedeuten konnte und das ganze Verfahren eine bloße Formsache hätte sein können, rechtfertigte sich Sauter in sehr umfangreicher und fragwürdiger Weise wegen seiner politischen Haltung. Seine Liebe zum Deutschtum habe er im Elternhaus und in der Schule eingeimpft bekommen. „Ich habe daher von je als einziges grosses politisches Ziel die Erstarkung des Deutschtums in und ausserhalb des Deutschen Reiches und den Anschluss des deutschsprachigen Restes der ehemaligen österreichisch-ungarischen Monarchie an das Deutsche Reich erstrebt.“ Er sei daher auch des Öfteren in der „Deutschtumsarbeit für Südtirol“ wie auch der „Anschlusspropaganda“ tätig gewesen. „An dieser meiner unpolitischen Haltung [...] änderte sich auch nichts, als ich 1929 [...] meine Studien in Deutschland“ fortsetzte. Der Einsatz für „Großdeutschland“ war offenbar so selbstverständlich, dass er als unpolitisch beschrieben werden konnte. Als Sauter sich 1933 in Berlin habilitierte, sei er deshalb nicht in die Partei eingetreten, weil er keine besonderen

\footnotetext{
$510 \mathrm{Zu}$ Müller siehe Litten [2000].

511 Siehe den Briefwechsel Sauter - Prandtl in: MPG-Archiv, KWI für Strömungsforschung, I, 44, 1377.

512 Am 13. September 1945 wurde er vorläufig und am 3. Dezember 1945 endgültig dienstenthoben. Am

21. Oktober 1945 legte er einen offenbar abgelehnten Widerspruch ein. Ich danke Frau Margot Fuchs vom historischen Archiv der TU München für diese Auskunft aus Sauters Personalakte. Für seinen Einsatz im Luftschutz der TH München ist er 1944 mit dem Kriegsverdienstkreuz I. Klasse ausgezeichnet worden. Noch 1948 bedauerte er in einer zum Entnazifizierungsfragebogen beigefügten Erklärung, dass es ihm und seinen Leuten trotz eifrigsten Einsatzes nicht gelungen sei, die weitgehende Zerstörung der TH zu verhindern. Siehe Fragebogen für die politische Überprüfung, 16. November 1948. HStAH, Nds. 171 Hildesheim 12794.

513 Siehe Abschnitt 3.6.
} 
Sympathien für die Erziehungsmethoden der NSDAP besaß. Besonders wichtig war es Sauter, seine Karriere als unabhängig von politischen Anpassungen darzustellen.

„Es erschien mir eben damals und erscheint mir auch heute noch mit meinem Ehrgefühl unvereinbar, irgendein Amt durch den Eintritt in irgend eine Partei zu erkaufen. Es erfüllt mich noch heute mit Befriedigung, dass sich dann trotz aller Widerstände selbst in dem als radikal bekannten Königsberg die Vernunft durchsetzte und ich allein auf Grund meiner wissenschaftlichen Leistungen und nicht infolge irgendwelcher "politischer Verdienste« zum Professor ernannt wurde.

Erst einige Monate nach dieser Ernennung habe ich dann aus freien Stücken mein Aufnahmegesuch in die NSDAP eingereicht. “514

Als Gründe für den Eintritt nannte Sauter die „unbestreitbaren innen- und außenpolitischen Erfolge der Staatsführung“‘. Das Eigenartige an diesen Ausführungen ist, dass er sie aus freien Stücken ablieferte, ohne darum gebeten worden zu sein. In der Mitglieder-Kartei der NSDAP ist festgehalten, dass der Antrag auf Parteieintritt vom 26. Januar 1939 datierte. ${ }^{515}$ Seine Ernennung zum ordentlichen Professor wurde am 1. Juni 1939 ausgesprochen. Daher scheint dem Parteieintritt doch ein opportunistisches Motiv zu Grunde gelegen zu haben. Die offiziellen Daten liefern ein für Sauter besseres Bild, denn die Ernennung galt rückwirkend zum 1. April und die Aufnahme in die Partei erfolgte erst am 1. November 1939. Nun ist es zwar verständlich, dass Sauter 1948 die Chronologie der Ereignisse in seinem Sinn darstellte, doch rätselhaft und zumindest unklug erscheint heute die ausführliche Begründung, warum er aus freien Stücken Parteigenosse wurde. Die Erfüllung seines „lang ersehnten Wunschtraumes der Vereinigung meiner engeren Heimat mit dem Deutschen Mutterland“ hätte den Ausschlag gegeben. „Mein Dank für diese grosse Tat der deutschen Staatsführung war mein Eintritt in die NSDAP.“

Die Widerspüchlichkeit der Darstellung wird noch verstärkt durch die von Sauter gesammelten Persilscheine. Sein Lehrer Becker bescheinigte ihm, dass er sich durch eine besonders aufrechte und ehrliche Natur auszeichne. Sommerfeld meinte in seinem Gutachten: "Persönliche Vorteile hat er aus seiner Parteizugehörigkeit nicht gezogen; andererseits hat er seinen politischen Standpunkt nie verleugnet.” Demgegenüber bescheinigte Eucken, daß er sich an keine politischen Gespräche mit Sauter erinnern könne, obwohl sie häufig im Familienkreis zusammen gewesen seien; Sauter sei aber innerlich auf keinen Fall Anhänger

\footnotetext{
514 Beilage Sauters zum Fragebogen für die politische Überprüfung „Bemerkungen zum Lebenslauf von Prof. F. Sauter“, 17. November 1948. HStAH, Nds. 171 Hildesheim 12794.

515 BAB, NSDAP Mitglieder Kartei Sauter. Ernennungsschreiben des REM, 1. Juni 1939. UAG, Rek. PA Sauter.
} 
des Nationalsozialismus gewesen. Eine vermutlich weniger zutreffende aber dafür umso üblichere Formulierung verwendete Sauters Königsberger Kollege Koehler, der bescheinigte, „dass er im Inneren ausgesprochener Nazifeind“ gewesen sei. 516

So ausgestattet bat Sauter am 17. November 1948 in Göttingen um seine politische Überprüfung, aufgrund derer er Ende des Jahres als entlastet festgestellt wurde. Im Mai 1949 beantragten Becker und Eucken in der Fakultätssitzung, Sauter einen unbesoldeten Lehrauftrag zu erteilen. ${ }^{517}$ Im Juni 1949 hat man Sauter "unter Beschränkung der geforderten Leistung neu habilitiert", und im Juli 1950 wird für ihn eine Diätendozentur beantragt. ${ }^{518} \mathrm{Ab}$ dem SS 1950 hielt er in Göttingen Vorlesungen. Schon im SS 1949 übernahm er die Vertretung des vakanten Lehrstuhls für theoretische Physik an der TH Hannover, wo er ein Jahr lang wöchentlich zwei Tage unterrichtete. ${ }^{519}$ Eine für das WS 1950/51 geplante Berufung Sauters auf diesen Lehrstuhl an der TH Hannover scheiterte am Widerstand des Ministeriums. ${ }^{520}$ Entscheidend fürs Scheitern soll ein Gutachten von Gerlach gewesen sein, in dem dieser behauptet haben soll, dass Sauter noch immer Nationalsozialist sei. ${ }^{521}$

Neben der Vertretung in Hannover hatte Sauter auch einen Lehrauftrag an der Hochschule Bamberg. ${ }^{522}$ Seine finanzielle Lage blieb aber unsicher. Als Becker im WS 1950/51 ein Gastsemester in den USA wahrnahm, vertrat ihn Sauter in den Vorlesungen, woraufhin ihm die eigentlich auslaufende Assistentenstelle nochmals bis September 1951 verlängert wurde. Danach bekam er als Dozent ohne Dienstbezüge eine einmalige Beihilfe von DM 500.523 1952 stand Sauter an erster Stelle der Berufungsliste für die ordentliche Professor der Universität Köln. Doch das Ministerium wollte den zweitgereihten Heinz Schlechtweg berufen, was Richard Becker veranlasste, sich in einem Schreiben persönlich an die Kultusministerin Christine Teusch zu wenden, um entsprechend seinem „Gefühl der

\footnotetext{
516 Persilschein von Becker, 12. November 1948; Persilschein von Eucken, 12. November 1948; Persilschein von Sommerfeld, 8. September 1948; Persilschein von Koehler, 13. Oktober 1948. HStAH, Nds. 171 Hildesheim 12794.

517 Protokoll der Fakultätssitzung vom 13. Mai 1949. GPAMNFG, Protokollbuch IV der mathematischnaturwissenschaftlichen Fakultät WS 1946/47 - WS 1949/50.

518 Die venia legendi erhielt er am 18. Juni 1949 verliehen. GPAMNFG, Lehrkörper (ausgeschieden), Sauter. Dekan ten Bruggencate an Kultusministerium, 31. Juli 1950. UAG, Rek. PA Sauter.

519 Sauter an Dekan, 13. Juni 1949, demzufolge er am 17. Mai 1949 vom Kultusministerium aufgefordert worden war, für die Dauer des SS 1949 die Vertretung des vakanten Lehrstuhls für theoretische Physik an der TH Hannover zu übernehmen. GPAMNFG, Lehrkörper (ausgeschieden), Sauter. Siehe auch MPG-Archiv, III, $50,1711$.

520 Siehe Hans Bartels an Heisenberg, 1. November 1950. MPI für Physik und Astrophysik, NL Heisenberg.

521 Siehe Hans Bartels an Heisenberg, 8. November 1950. MPI für Physik und Astrophysik, NL Heisenberg.

522 Sauter an Rektor, 11. März 1952. UAG, Rek. PA Sauter.

523 Sauter an Dekan, 26. Oktober 1950. GPAMNFG, Lehrkörper (ausgeschieden), Sauter. Sauter an Rektor, 11. März 1952. UAG, Rek. PA Sauter.
} 
Mitverantwortung für die Entwicklung der theoretischen Physik in Deutschland" sich entschieden für Sauter auszusprechen. „Besonders zu rühmen sind seine charakterlichen Eigenschaften. Ich kenne Herrn Sauter seit 20 Jahren und hatte immer wieder Gelegenheit, seine absolute Zuverlässigkeit sowie seine unermüdliche, aktive Hilfsbereitschaft gegenüber Studenten und Kollegen zu bewundern.“ Um seiner Darstellung mehr Gewicht zu verleihen, fügte er hinzu, dass Heisenberg ,sich der vorstehend dargelegten Auffassung in vollem Umfang anschließt." ${ }^{\text {(524 }}$ Beckers und Heisenbergs ${ }^{525}$ Einsatz war erfolgreich, sodass Sauter in Köln „,endlich wieder in die wohlverdiente reguläre akademische Stellung“ kam, wie es Max Laue ausdrückte. ${ }^{526}$

\subsubsection{Elf weitere Fälle zur Wanderschaft}

Die bisher besprochenen Fälle haben klar gezeigt, wie sich die Göttinger Physiker solidarisch um ihre auf Wanderschaft befindlichen Kollegen kümmerten. Nur um das Ausmaß dieses Phänomens deutlich zu machen, seien noch elf weitere Physiker, die in diese Kategorie fallen beiläufig genannt. Walter Tollmien kam Anfang 1945 nach Göttingen, nachdem im Februar Dresden komplett zerstört worden war. Er war 1937 von Göttingen als Ordinarius an die TH Dresden berufen worden und fand nun bei seinem Lehrer Prandtl wohlwollende Aufnahme. 1947 wurde er Prandtls Nachfolger in Göttingen. - Nur kurzfristig zurück an die Universität kam Kurt Magnus, der vor seiner Kriegstätigkeit Assistent bei Schuler war (siehe zu diesen beiden Fällen Abschnitt 5.4). - Als Honorarprofessor kam Ernst Lamla an die Universität Göttingen, als er 1947 Direktor des Staatlichen Gymnasiums wurde. Er bereicherte den Unterricht durch seine Vorlesungen über Didaktik der Physik (siehe Abschnitt 4.2.4).

Durch die Verlagerung der Kaiser-Wilhelm-Gesellschaft nach Göttingen kurz vor Kriegsende und der anschließenden Wiedergründung des Max-Planck-Instituts für Physik kamen gleich eine ganze Gruppe ausgezeichneter Physiker nach Göttingen. Sieben der zehn in England bis Ende 1945 festgehaltenen Atomphysiker fanden eine Anstellung am MPI für Physik. Es waren dies Werner Heisenberg, Max Laue, Carl Friedrich Weizsäcker, Karl Wirtz, Horst

\footnotetext{
524 Becker an Ministerin Christine Teusch, 24. Juni 1952. MPI für Physik und Astrophysik, NL Heisenberg. 525 Heisenberg schrieb am 25. Juni an den Kölner Physiker Clemens Schaefer, um sich für Sauter einzusetzen. Über ihn urteilt er: „Seine politische Einstellung habe ich im wesentlichen als Zeichen des allgemeinen österreichischen Wunsches nach Anschluß empfunden. Jedenfalls habe ich Sauter immer als einen absolut anständigen Charakter gerade in politischen Fragen kennen gelernt. Als ich z. B. 1935 zusammen mit Max Wien und Geiger eine Aktion gegen die sogenannte »deutsche Physik « à la Stark und Lenard übernahm, hat sich Sauter mit voller Kraft auf die Seite der vernünftigen Physiker gestellt, während andere (auch einen Ihrer Kölner Kollegen nicht ausgenommen) gekniffen haben." MPI für Physik und Astrophysik, NL Heisenberg.

526 Laue an Sauter, 8. November 1952. MPG-Archiv, III, 50, 1711.
} 
Korsching, Otto Hahn und Erich Bagge. ${ }^{527}$ Die vier Erstgenannten übernahmen auch Professuren an der Universität und bereicherten damit das Physikcurriculum (siehe Abschnitt 4.2). Im Sommer 1946 kam ein weiterer früherer Mitarbeiter des Uranvereins ins MPI für Physik. Otto Haxel war von 1939 bis 1945 Dozent an der TH Berlin gewesen. Haxels Lehrer Geiger verstarb 1945 und konnte ihm in den Nachkriegswirren nicht mehr behilflich sein. So kam er nach Kriegsende als Gast ins physikalische Institut der Universität München, erhielt dann eine Assistentenstelle an der Universitätsfrauenklinik in Tübingen, bis er schließlich den Weg nach Göttingen fand. Sein kollegiales Netz bestand vor allem aus den Mitarbeitern des Uranvereins, insofern erklärt es sich, dass er in Göttingen zuerst nicht an der Universität, sondern am MPI aufgenommen wurde. 1948 bekam er eine Dozentur, ein Jahr später wurde er zum außerplanmäßigen Professor ernannt. Die Übergangszeit in Göttingen wurde 1950 durch den Ruf auf ein Ordinariat in Heidelberg beendet. 528

Was die Zeitgenossen aber auch heute noch vor allem erinnern, wenn die Sprache auf die MPI-Physiker kommt, ist das Physik-Kolloquium, das durch sie zum großen Ereignis wurde. Während es dort sehr anregende Diskussionen auf höchstem Niveau gab, bleibt doch festzustellen, dass es zwischen den MPI-Physikern und jenen an der Universität nur geringe Zusammenarbeit gab. Offenbar waren das MPI und die Universität getrennte Welten. Auch hierin kann man eine Wirkung des kollegialen Netzes erkennen. Keiner der sieben MPIPhysiker hatte während der NS-Zeit eine engere Bindung zu Göttingen, hingegen waren sie untereinander gut vernetzt, nicht zuletzt wegen der dreivierteljährigen gemeinsamen Zeit der Internierung 1945. Dass sie 1946 nach Göttingen kamen, lag weniger am Einsatz der dortigen Physiker, sondern wurde schon viel früher von englischer Seite angebahnt. ${ }^{529}$ Die Göttinger begrüßten aber den Zuzug von einer Reihe der besten der deutschen Kollegen. ${ }^{530}$ In der Ausbildung des fortgeschrittenen Nachwuchs standen die beiden Gruppen in Konkurrenz. Die begrenzte Zahl von zu vergebenden Diätendozenturen führte mitunter zu Schwierigkeiten, wenn MPI-Physiker einen ihrer Schützlinge zum Dozenten an der Universität ernennen wollten.

\footnotetext{
527 Hoffmann (Hrsg.) [1993] S. 49.

528 Angaben zu Haxel aus GPAMNFG, Lehrkörper (ausgeschieden), Haxel; HStAH, Nds. 401 Acc. 92 / 85, Nr. 111.

529 Oexle [2003], [1994].

530 Dekan Eucken schrieb am 9. Februar 1946 an den Rektor: „Die Fakultät würde es auf das allerlebhafteste begrüssen, wenn das wiederzuerrichtende Forschungsinstitut für Physik seinen Sitz in Göttingen erhielte." UAG, Kur. XVI. V. B. 30. I; auch HStAH, Nds. 401 Acc. 92 / 85, Nr. 317.
} 


\subsubsection{Die Suche nach Stellen für die wandernden Kollegen}

$\mathrm{Zu}$ Beginn der Besatzungszeit waren die Diätendozenturen ein Mittel, stellenlosen Professoren ein Einkommen $\mathrm{zu}$ sichern. Obwohl eine beträchtliche Zahl von Diätendozenturen vorhanden war, reichte diese nicht für alle aus. Anfang 1946 standen der theologischen Fakultät eine einzige, der rechts- und staatswissenschaftlichen 3, der philosophischen 8 , der mathematisch-naturwissenschaftlichen 87 und der medizinischen 73 solcher Stellen zur Verfügung. ${ }^{531}$ Für die solidarisch aufgenommenen früheren Ostprofessoren wurde außerdem im Januar 1946 bei der Kommerzbank ein Konto „Flüchtlingshilfe“ eingerichtet, in das die beamteten Kollegen ein Viertel ihres Einkommens überweisen sollten. ${ }^{532}$ Nach Abklingen der durch die Entnazifizierung hervorgerufenen Entlassungen gab es einen gewissen Rückstrom an die Universität. Die ab 1947/48 erkennbare Häufung der Ernennungen zum außerplanmäßigen Professor ging darauf zurück, „dass in der unruhigen Vergangenheit sich eine Zahl von Fällen aufgestaut hat, denen jetzt Rechnung getragen werden muss."533 In der Physik betraf dies Karl-Heinz Hellwege, Hans König und Otto Haxel, bei denen erst ein günstiger Entnazifizierungsbescheid abgewartet werden musste, außerdem Wolfgang Paul und Karl Wirtz und schon etwas früher Fritz Houtermans.

\subsubsection{Die gescheiterte Nachbesetzung der Professur für angewandte Elektrizität - die Solidarität mit Joos}

Ebenfalls als Hilfestellung für einen wandernden Physiker ist das Vorgehen der Fakultät zur Nachbesetzung des Lehrstuhls für angewandte Elektrizität zu verstehen. Der scheidende Institutsleiter Zahn gab seinen Kollegen in der Kommissionssitzung bekannt, dass sein Institut nicht für irgendeine Arbeitsrichtung prädestiniert sei. Dies eröffnete der Fakultät die Möglichkeit, die unterschiedlichsten Kollegen in Vorschlag zu bringen. Zahn selbst schlug im August 1945 an erster Stelle Justi, ${ }^{534}$ ferner Steenbeck ${ }^{535}$, Knoll536, Bergmann ${ }^{537}$, Busch ${ }^{538}$,

\footnotetext{
531 Protokoll der Senatssitzung vom 5. Januar 1946. UAG, Senatsprotokolle 1945-1949.

532 Protokoll der Senatssitzung vom 23. Januar 1946. UAG, Senatsprotokolle 1945-1949.

533 Protokoll der Senatssitzung vom 8. Dezember 1948. UAG, Senatsprotokolle 1945-1949.

534 Eduard Justi war von 1929 bis 1944 in der PTR tätig und anschließend Ordinarius für angewandte Physik an der Universität Posen. Er bekam 1946 eine ordentliche Professur an der TH Braunschweig.

535 Max Steenbeck war von 1927 bis 1945 als technischer Physiker bei den Siemens-Schuckert-Werken in Berlin tätig. Von 1946 bis 1955 war er in der UdSSR; 1956 wurde er Professor an der Universität Jena. 536 Max Knoll war von 1932 bis 1945 Privatdozent an der TH Berlin. 1946 wurde er ao. Professor an der Universität München, 1948 ging er nach Princeton, USA. 1956 kam er als Ordinarius an die TH München. Zwei Nachkriegsgöttinger hatten mit Knoll zusammen über Untersuchungen mit einem Elektronenmikroskop publiziert: Fritz G. Houtermans in Zeitschrift für Physik 78 (1932), S. 340-362; und Wilhelm Walcher in Zeitschrift für Physik 96 (1935), S. 612-619.
} 
Hiedemann ${ }^{539}$ und Erwin Meyer ${ }^{540}$ vor, doch als die Frage der Rückberufungen angesprochen wurde, war sich die Fakultät schnell einig und beschloss einstimmig, Georg Joos an erster Stelle zu nennen. Auf die Dreierliste wurden noch Steenbeck und Knoll gesetzt. Mit Joos hätte das Institut sein Arbeitsgebiet auf die angewandte Optik und Elektrizität ausgerichtet. ${ }^{541}$ Joos wurde als Mitglied der Geschäftsführung von Zeiss Ende Juni 1945 von den Amerikanern mitgenommen und in den Westen nach Heidenheim gebracht. ${ }^{542}$ Auch die Physiker der Universität Jena, wie zum Beispiel Kulenkampff kamen auf diese Weise nach Heidenheim. Den Göttingern war das bekannt, und es ist nur verständlich, dass sie sich für sie einsetzten. ${ }^{543}$ Die Hilfestellung erfuhr aber nur Joos und nicht Kulenkampff, obwohl zehn Jahre zuvor bei der Besetzung des Lehrstuhls der II. Physik die Prioritäten genau umgekehrt verteilt waren. Die Solidarität, die Joos genoss, lag an den festen kollegialen Verbindungen, die er während seiner Göttinger Zeit knüpfen konnte. Von besonderer Bedeutung erscheint in diesem Zusammenhang die Verbindung zwischen Eucken und Joos, die unter anderem an Joos' Beteiligung an Euckens Lehrbuch der chemischen Physik ersichtlich ist. ${ }^{544}$ Euckens Stimme hatte großes Gewicht in den Fakultätssitzungen, und es erscheint plausibel, dass er sich als Dekan besonders für die Rückgewinnung seines verehrten Kollegen einsetzen konnte.

Im September 1945 erklärte Joos, dass er sehr gerne kommen würde, woraufhin ihm die Fakultät mitteilte, „dass ihm auf jeden Fall die Göttinger-Berufung sicher ist" . ${ }^{545}$ Gleichzeitig erhielt Joos auch verlockende Rufe an andere Hochschulen, darunter die TH München. Die Göttinger zeigten sich abwartend und reservierten ihm ihren Lehrstuhl. ${ }^{546}$ Einen Monat später

537 Ludwig Bergmann war von 1932 bis 1945 Professor in Breslau und schaffte die Rückkehr an eine Hochschule erst 1950 als Honorarprofessor in Gießen.

538 Hans Busch war von 1930 bis 1952 Professor für Elektrotechnik an der TH Darmstadt. 1933 bekam er die Gauß-Weber-Denkmünze von der Universität Göttingen verliehen.

539 Egon Hiedemann war von 1941 bis 1945 Ordinarius für angewandte Physik an der Universität Straßburg. 1946 wurde er Professor und Direktor des Physikalischen Instituts an der TH Karlsruhe. 1947 wanderte er in die USA aus, wo er bis 1950 für die US Navy in Maryland arbeitete. Danach bekam er eine Professur am Michigan State College East Lansing.

540 Erwin Meyer war bevor er 1947 nach Göttingen kam seit 1934 Professor an der TH Berlin.

541 Protokoll der Kommissionssitzung vom 29. August 1945. GPAMNFG, Protokollbuch III der mathematischnaturwissenschaftlichen Fakultät WS 1927/28 - SS 1946.

542 BACZ, 30273.

543 „Kossel, Kulenkampff und Joos befinden sich zurzeit in Heidenheim in Württemberg“, schrieb Pohl an Born, 13. August 1945. StB-B, NL Born, 591.

544 Joos steuerte das Kapitel über die korpuskularen Bausteine der Materie bei. Siehe Eucken [1932] und auch die 2. Aufl. 1938.

545 Protokoll der Kommissionssitzung vom 28. September 1945. GPAMNFG, Protokollbuch III der mathematisch-naturwissenschaftlichen Fakultät WS 1927/28 - SS 1946.

546 Protokoll der Fakultätssitzung vom 28. September 1945. GPAMNFG, Protokollbuch III der mathematischnaturwissenschaftlichen Fakultät WS 1927/28 - SS 1946. 
erwarteten sie sein Eintreffen. ${ }^{547}$ Im Januar 1946 wurde eine neue Berufungsliste mit Joos an erster und Hippel ${ }^{548}$ an zweiter Stelle erstellt. Außerdem wurden Goubau ${ }^{549}$, Knoll, Hiedemann und Bergmann genannt. ${ }^{550}$ Die Nennung von Hippel ist vermutlich der Reklamation der Militärregierung geschuldet, die auf die Rückberufung von Emigranten drängte. ${ }^{551}$ Pohl äußerte wegen Hippels Nennung Bedenken, da Joos ein endgültiges Versprechen gegeben worden sei. In seiner Sicht stellten die Emigranten eine Bedrohung für Absprachen unter den Dagebliebenen dar, da sie die Rückendeckung der Militärregierung genossen. Eine unverzüglich eingeschobene Kommissionssitzung klärte die Frage. Hippel wurde auf Rang drei zurückgesetzt. ${ }^{552}$ Einer eigenen Sitzung bedurfte die Nennung eines Zweitgereihten. Zur Diskussion standen Goubau, Freiherr von Handel553, Bergmann, Hiedemann und Knoll. Die Wahl fiel auf Handel, der ein Spezialist für Hochfrequenzphysik war. ${ }^{554}$ An der Vielzahl der Genannten erkennt man, wie offen die Besetzung und Neuausrichtung des Instituts für angewandte Elektrizität war. Bis auf den einmal erwähnten Hans Busch waren alle in Vorschlag gebrachten Kandidaten entweder ehemalige Berliner Hochschullehrer oder Professoren von Universitäten, die nach Kriegsende nicht mehr innerhalb des deutschen Gebiets lagen. Göttingen diente als Auffangbecken für eine ganz bestimmte Gruppe von deutschen Physikern.

Noch im Juli 1946 suchte Joos bei USFET um die Erlaubnis an, die Göttinger Professur übernehmen zu dürfen. Da er aber unter besonderer Aufsicht der Amerikaner stand, waren die Erfolgsaussichten auf Genehmigung recht gering. Trotzdem hatte Joos gehofft, „nach Göttingen gehen zu dürfen, wo ich nicht nur ein heiles Institut, sondern auch grosse wissenschaftliche Anregung und einen mir gehörenden Garten finden würde.“ Im September

\footnotetext{
547 Protokoll der Fakultätssitzung vom 26. Oktober 1945. GPAMNFG, Protokollbuch III der mathematischnaturwissenschaftlichen Fakultät WS 1927/28 - SS 1946.

548 Als Assistent von Franck emigrierte Arthur Hippel 1933 zuerst nach Istanbul, wo er eine Professur übernahm. Ab 1934 war er Gastprofessor in Kopenhagen bis er 1936 ans MIT nach Cambridge / Massachussetts kam.

549 Georg Goubau war von 1940 bis 1945 Professor für technische Physik an der Universität Jena, kam im Sommer 1945 wie Joos und Kulenkampff nach Heidenheim und ging dann in die USA, wo er in Fort Monouth / New Jersey für die US-Armee arbeitete.

550 Protokoll der Kommissionssitzung vom 23. Januar 1946. GPAMNFG, Protokollbuch III der mathematischnaturwissenschaftlichen Fakultät WS 1927/28 - SS 1946.

551 Siehe dazu Abschnitt 1.3.3.

552 Protokoll der Fakultätssitzung vom 25. Januar 1946. GPAMNFG, Protokollbuch III der mathematischnaturwissenschaftlichen Fakultät WS 1927/28 - SS 1946.

553 Paul Freiherr von Handel war von 1928 bis 1942 an der DVL beschäftigt, von 1937 bis 1945 Professor an der TH Berlin, außerdem von 1942 bis 1945 Direktor des Ferdinand-Braun-Instituts Reichsstelle Hochfrequenzforschung. Ihm gelang die Rückkehr an die Hochschule nicht; 1953 wanderte er in die USA aus. 554 Protokoll der Kommissionssitzung vom 8. Februar 1946. GPAMNFG, Protokollbuch III der mathematischnaturwissenschaftlichen Fakultät WS 1927/28 - SS 1946.
} 
1946 entschied sich Joos schließlich dafür, einen Ruf an die TH München anzunehmen. 555 Nachdem Joos versorgt war, ließen die Göttinger ihre bis dahin erstellten Berufungslisten fallen und entschlossen sich $\mathrm{zu}$ einer Neuordnung der beiden Institute der angewandten Physik. Berufen wurde Erwin Meyer, der bis dahin in der Diskussion um die Zahn Nachfolge nur beiläufig Erwähnung gefunden hatte. Die Hintergründe dafür werden in den Abschnitten 5.4.4 und 5.5 besprochen.

\subsubsection{Die Nachkriegskarrieren des Göttinger physikalischen Nachwuchses}

Wie oben gezeigt, haben der Krieg und das Kriegsende die Karriereverläufe der deutschen Physiker in entscheidender Weise beeinflusst. Fehlendes, oder aus NS-Sicht falsch ausgerichtetes politisches Engagement konnte im Krieg, zu deutliches Pro-NS-Engagement in der Besatzungszeit zu einer zumindest vorübergehenden Unterbrechung der akademischen Laufbahn führen. Die Betroffenen konnten meist mit der solidarischen Hilfe ihrer im Amt gebliebenen Kollegen rechnen. In der Untersuchung der Entlassung Hellweges und auch des Phänomens Wanderschaft wurde dies ausführlich belegt. Bei der Behandlung der 'normalen` Karriereverläufe des in Göttingen ansässigen Nachwuchs sind diese zeittypischen Begebenheiten ebenfalls zu berücksichtigen, welche dazu führten, dass die Institutsschranken eine geringere Rolle spielten. Das Modell des Instituts als kleine Einheit innerhalb der Universität, das die Karrieren prägt, reicht hier zur Erklärung nicht mehr aus. Die deutlich die Institutsgrenzen überschreitende Solidarität unter den Physikern wertet die Netzverbindungen auf, die für die Stellenvergabe in dieser Zeit eine größere Rolle spielten. Natürlich gab es die engsten kollegialen Verbindungen meist unter den Institutsmitgliedern. Es war aber gerade in dieser Zeit von Vorteil, auch zu anderen Kollegen eine enge Verbindung zu besitzen, da sich damit die Chance auf eine Stelle vergrößerte. Die Möglichkeiten der Stellenvergabe waren allerdings durch die politischen Vorgaben beschränkt, jedoch änderten sich diese relativ rasch.

Bis etwa 1949 war die Berufung auf einen Lehrstuhl für viele junge Dozenten wegen ihrer politischen Belastung nur schwer möglich, vor allem wenn der Ruf aus der britischen Zone herausführen sollte. Sie verweilten solange in Göttingen in sicherer Position, bis sie in den Jahren 1950 bis 1952 in einem Schub von Berufungen an andere Universitäten zu meist ordentlichen Professoren aufstiegen. Diese Phase des Endes der Entnazifizierung signalisierte eine Rückkehr zur Normalität an den Hochschulen. Normalität ist allerdings ein kritisch zu

555 Joos an Kurator in Göttingen, 6. September 1946. UAG, Rek. PA Joos. 
beleuchtender Begriff, denn er beinhaltet auch die Wiederherstellung personeller Kontinuitäten zur NS-Zeit, die nicht unbedingt begleitet war von einer Reflexion und Änderung ihrer eigenen Haltung zum Staat, deren nationalistischer oder nationalkonservativer Kern oft eine Konstante war.

Die Rückkehr zur Normalität konnte sich in der Göttinger Physik rasch vollziehen, da alle Ordinarien in Amt und Würden blieben. Sie behielten nicht nur ihre Stellung, sondern auch ihren Einfluss auf personalpolitische Entscheidungen. Dies lag zum Teil an der entgegenkommenden Politik der Briten, die in der Entnazifizierung anfangs weniger streng durchgriffen als ihre russischen oder amerikanischen Kollegen. Der letzte Kriegs-Dekan der mathematisch-naturwissenschaftlichen Fakultät, Hans Kopfermann, wäre in der amerikanischen Zone wie alle Mitglieder der Universitätsführung entlassen worden. ${ }^{556}$ In Göttingen blieb er wie auch Pohl und Becker im Amt. Die beiden Letztgenannten waren symbolisch, das heißt durch Mitgliedschaften, wenig belastet. Die geringe symbolische Belastung wurde von Becker selbst gegenüber den Briten auf Null reduziert, indem er alle Mitgliedschaften im Fragebogen der Militärregierung verneinte, auch NSV und Reichsluftschutzbund, wo er nach eigenen, früheren Angaben und anderer Quellen zufolge Mitglied gewesen war. In der angewandten Physik sah die Situation gänzlich anders aus, da die drei maßgeblichen Professoren Prandtl, Schuler und Zahn 1946/47 die Altergrenze erreichten oder schon überschritten hatten, sodass es hier auf höchster Ebene zu einem kompletten Personalwechsel kam, und zwar unabhängig vom Entnazifizierungsverfahren.

Während die Verhältnisse in der angewandten Physik im letzten Kapitel ausführlich dargestellt sind, sollen hier anhand der übrigen drei Institute beispielhaft die Bedingungen, unter denen Nachwuchsphysiker ihren akademischen Aufstieg vollzogen, erläutert werden. $\mathrm{Zu}$ diesen Bedingungen ist auch die Hungersnot der ersten Nachkriegsjahre zu zählen. So schlossen sich die Physiker beispielsweise zur Beschaffung und Verarbeitung von Lebensmitteln zusammen. Im Garten des Mineralogen Carl Wilhelm Correns wurde Gemüse und Obst (z. B. Johannisbeeren) angebaut. Die eigene Ernte fuhren die Physiker dann mit einem Leiterwagen zu Richard Becker, um in dessen Keller daraus einen Sirup zu kochen dabei kochte einiges über, sodass sich in der Waschküche Apfelkraut und Zuckerrüben nicht nur in den Wäschekesseln sammelte. ${ }^{557}$

\footnotetext{
556 Dies hätte natürlich auch den Dekan der Rechts- und Staatswissenschaftlichen Fakultät, Rudolf Smend betroffen, der in Göttingen nicht nur im Amt bleiben, sondern auch erster Nachkriegsrektor werden konnte. 557 Interview mit Hans König, 10. Februar 2001 und mit Eva Opitz, 21. November 2001.
} 
Nicht nur das gemeinsame Bewältigen der Alltagsprobleme schuf ein festes Zusammengehörigkeitsgefühl. Auch der in der Nachkriegszeit ganz ausgeprägte Arbeitsfleiß, der zum Teil eine Flucht vor der Vergangenheit war, brachte die Physiker näher zusammen. Die betonte Ausrichtung der eigenen Arbeit auf die Zukunft lag auch daran, dass zum Anschluss an den internationalen Forschungsstand einiges aufzuholen war. Wie Peter Brix es ausdrückte, war es eine „hoffnungsfrohe, begeisterte Beschäftigung mit der Physik in einer materiell armen Zeit. Da gab es Muße zum Nachdenken."558 In der Besatzungszeit wurde damit für die Doktoranden und Assistenten, aber auch für die Professoren das Institut mehr als sonst zum Lebensmittelpunkt. Die Institutsmitglieder bildeten so etwas wie eine große Familie. Einige Eheschließungen kamen durch die intensiven sozialen Kontakte dort zustande. Für manche diente es vorübergehend als Wohnung. Als Kopfermanns Haus von den Briten in Beschlag genommen wurde, zog die ganze Familie ins Institut um. Gegen Kriegsende hatte dort schon der Assistent Peter Brix als Luftschutzwart gewohnt. ${ }^{559} \mathrm{Um}$ Diebstähle zu verhindern, zog im November 1946 der Assistent Heinz Pick zur Bewachung der Räume in den dritten Stock des I. Physikalischen Instituts ein. ${ }^{560}$ Erich Mollwo hatte auf dem Institutsgrund einen Gemüsegarten angelegt, dessen Ertrag in der Hungerszeit sehr willkommen war. ${ }^{561}$ Es wurde fast zur Selbstverständlichkeit für die Institutsmitarbeiter, dass man auch am Wochenende dort der Forschung nachging. Auch die Zeiten, in denen Vorlesungen angeboten wurden, zeigen, wie sehr das Forscherleben auf die Wissenschaft ausgerichtet war. Wochentags wurden von 8 bis 22 Uhr und samstags von 8 bis 13 Uhr Vorlesungen und Praktika angeboten. Nur der Sonntag wurde frei gehalten. ${ }^{562}$ Um ein familiäres Klima herzustellen, richtete Wolfgang Paul nach seiner Berufung nach Bonn 1952 dort einen Tischtennisraum ein, der die gewünschte Wirkung entfaltete. Die Doktoranden blieben bis spät abends im Institut und nach einer Tischtennispause gingen sie wieder ins Labor an die Arbeit. ${ }^{563}$ Diese Episode soll zeigen, wie bewusst den Physikern die soziale

\footnotetext{
558 Brix [1994]a S. 1153.

559 Brix [1994]b S. 10.

560 Pohl an Kurator, 5. November 1946. Im oberen Stockwerk des Instituts war der Hörsaal III gelegen, der von Studenten anderer Fakultäten mitbenutzt wurde. Pick zahlte für Strom, Gas und Wasser RM 5 an die Universität und blieb bis mindestens zum Frühjahr 1949 dort wohnen. UAG, Kur. XVI. V. C. g. 2. III und IV.

561 Frederick Seitz, Memorial Symposium in honor of Heinz Pick, Stuttgart, November 5, 1985, S. 7. NBL.

562 Am Samstag gab es von 8 bis 9 Uhr eine Ergänzungsvorlesung zur Pohl'schen Einführung in die Experimentalphysik. Von 9 bis 12 fand das Physikalische Praktikum bei Kopfermann statt, von 9 bis 13 Uhr das Mechanik- und Elektrophysikpraktikum ab SS 1947 bei Meyer, davor hieß es Elektrophysikalisches Praktikum und wurde zur selben Tageseit von Zahn abgehalten.

563 Brix [1994]a S. 1155. Die pointierteste Charakterisierung des Institutsklimas gibt Brix auf S. 1157: „Paul lebte mit seinen Schülern." Auch in einem Interview mit Paul kam seine Vorliebe für ein familiäres Klima in den Arbeitsgruppen zum Ausdruck; siehe Steiner [1995]. Wirklich familiär wurde die Forschung nach seiner
} 
Komponente in der Organisation der Forschung und Ausbildung war und wie die Göttinger Atmosphäre mit Berufungen exportiert wurde. ${ }^{564}$

Eine weitere nicht zu unterschätzende Stärkung des Zusammengehörigkeitsgefühl bewirkte das Begräbnis von Max Planck in Göttingen 1947. Mit der hohen Verehrung an Max Planck war auch ein Gedenken an die Leistungen der deutschen Physik in seiner Blütezeit verbunden. Das Zusammenkommen zur Trauerfeier erzeugte ein starkes Wir-Gefühl. Die Physiker fühlten sich als geistige Erben des Verstorbenen. „Um Max Planck weht ein Hauch aus heiligem Bezirk. Seine wissenschaftliche Leistung gehört der Geschichte an. Sein Name wird weitergereicht werden wie das olympische Feuer." Diese pathetischen Worte fand Ernst Brüche in der Besprechung der Gedenkfeier zu Plancks 90. Geburtstag, die ein halbes Jahr nach seinem Tod in Göttingen stattfand. ${ }^{565}$

\subsubsection{Der Pohl-Kreis}

Die Zeitgenossen empfanden ihre Verbundenheit innerhalb der einzelnen Institute als eine familiäre, ${ }^{566}$ sprachen aber selbst selten von einer Familie als von einem Kreis, in den sie aufgenommen wurden. Wer als fortgeschrittener Student in so einen Kreis integriert wurde und nach bestandenen wissenschaftlichen Qualifikationen für eine akademische Karriere als reif erklärt worden war, genoss weitreichende Unterstützung und bekam nicht selten eine Professur, teilweise durch äußere Umstände wie Entnazifizierungsvorschriften verzögert. Dadurch, dass die Göttinger Ordinarien durch die stabilen Verhältnisse vor Ort und durch ihre Schutzfunktion für stellungslose Kollegen anderer Hochschulen eine mächtige Position in der deutschen Nachkriegsphysik inne hatten, waren die Voraussetzungen für den Göttinger Nachwuchs außerordentlich günstig. Neidisch zur Kenntnis genommen wurde diese Begünstigung von den außenstehenden Kollegen, wie zum Beispiel von Wolfgang Finkelnburg, der seine Straßburger Professur 1945 eingebüßt hatte und im August 1947 resigniert und deutlich übertrieben konstatierte, man habe in Deutschland nur Aussicht auf eine Anstellung, „wenn man in Göttingen die Priesterweihen empfangen“567 habe. Finkelnburgs Metapher einer klerikalen Gemeinschaft korrespondiert gut mit der Rede von

Emeritierung, als er mit seinen beiden Söhnen Versuche zur Speicherung von Neutronen startete; siehe Paul [1992].

564 Auch vom Mollwo“schen Institut in Erlangen wird berichtet, dass es eine „Familien-Athmosphäre [besaß], wie sie heute kaum noch vorkommt.“" Lohmann [1994]b S. 234.

565 „Gedenkfeier zum 90. Geburtstag von Max Planck“, Physikalische Blätter 4 (1948), S. 125-126, 126.

566 Stöckmann [1964] sprach von einem „Familientreffen“ in Göttingen anlässlich Pohls 80. Geburtstags. Siehe auch Fußnote 564.

567 Finkelnburg an Sommerfeld, 8. August 1947. DMM, Archiv, NL 89, 008. 
Pohl als dem lieben Gott. ${ }^{568}$ Auch wenn diese Bilder nicht zu ernst zu nehmen sind - ihre Botschaft ist völlig klar.

Mit dem Ende der NS-Herrschaft kümmerte sich Pohl darum, seinen Kreis wieder vollständig um ihn zu versammeln. 1940 war ihm mit Heinz Pick ein Schüler verloren gegangen. Pick lebte im ersten Nachkriegsjahr mit seiner Frau in Limburg und überlegte, in den Schuldienst zu wechseln. Mit etwas Glück erreichte ihn eine Anfrage von Pohl, warum er nicht wieder schnellstens nach Göttingen zurückkommen wolle. Mit dieser Einladung änderte Pick seine Zukunftspläne und schlug die akademische Laufbahn (wieder) ein. Ab April 1946 war er Assistent bei Pohl. 1948 habilitierte er sich mit einer Arbeit über lichtelektrische Leitung am Bleisulfid. Darin enthalten sind elektronenmikroskopische Abbildungen von Bleisulfidschichten, die ihm Hans König herstellte. ${ }^{569}$ Eigentlich wollte Pick sich mit einer anderen Arbeit habilitieren, doch diese war noch nicht fertiggestellt und Pohl brauchte dringend einen neuen Dozenten für die Vorlesungen, da sein einziger Dozent Mollwo gerade wegberufen worden war. ${ }^{570}$ Die durch äußere Gründe beschleunigte Habilitation schmälert aber nicht Picks Qualifikation. Darauf wies auch Kopfermann in seinem Gutachten hin. „Herr Pick stammt aus der Pohl'schen Schule“, lautet der erste Satz des Gutachtens. Seine Arbeit behandelt daher ein Thema „des Problemkreises seines Lehrers“. Aber man erkenne darin eine ,ansteigende Linie einer eigenen Note“. Dies rührte daher, dass seine Habilitationsschrift aus seiner Forschungstätigkeit in der Industrie hervorgegangen war. Die dadurch errungene Selbständigkeit wurde ihm positiv vermerkt. Kopfermann würdigte auch die menschliche Seite von Pick: „Er ist eine klare und eindrucksvolle Persönlichkeit, scharf im Urteil, mit ausgesprochenem pädagogischen Talent und mit sichtlicher Freude am Unterricht. Er hat auch die Fähigkeit, sich mit Energie durchzusetzen. "571 Nachdem Pick im März 1949 vom Entnazifizierungshauptausschuss in Kategorie V eingereiht worden war und als entlastet galt, wurde er am 1. April 1949 Oberassistent am I. Physikalischen Institut. ${ }^{572}$ Nach Pohls Emeritierung nahm er im WS 1952/53 die Dienstgeschäfte des Institutsdirektors vertretungsweise wahr. Im SS 1953 folgte Pick einer Einladung von Frederick Seitz als Visiting Research Associate an die University of Illinois, Urbana. Als Kopfermann nach

\footnotetext{
568 Siehe Fußnote 80.

569 Pick [1948].

570 Siehe das Gutachten zur Habilitationsschrift von Pohl, 22. Juni 1948. GPAMNFG, Lehrkörper (ausgeschieden), Pick.

571 Gutachten von Kopfermann, 15. Juli 1948. GPAMNFG, Lehrkörper (ausgeschieden), Pick.

572 Siehe den Bescheid des Entnazifizierungs-Hauptausschuss der Stadt Göttingen, 11. März 1949. HStAH, Nds. 171 Hildesheim 14431. Zur Ernennung zum Oberassistenten siehe Schreiben des Kurators an das Kultusministerium, 4. Mai 1949. HStAH, Nds. 401 Acc. 92 / 85, Nr. 136.
} 
Heidelberg wechselte, vertrat Pick im WS 1953/54 auch diesen Lehrstuhl. ${ }^{573}$ Ein weiteres Jahr später wurde er schließlich selbst zum Ordinarius ernannt. Vielleicht hing es mit seinem Katholizismus zusammen, dass er nach Baden-Württemberg ging, jedenfalls bekam er seine Professur an der $\mathrm{TH}$ Stuttgart. In einem Interview sagte er über den Einfluss Pohls bei Berufungen: „[...] ein guter Mann, empfohlen von Herrn Pohl kam immer an.“"574 Es wird auf ihn selbst wohl auch zugetroffen haben.

An anderer Stelle formulierte es Pick so: Eine Empfehlung von Herrn Pohl war „auf jeden Fall ein offenes Tor." 575 Mit Picks Einsicht in das Innenleben der Gemeinschaft der deutschen Experimentalphysiker lässt sich die Formation der Pohl-Schule besser einordnen und begreifen. Die Tore öffneten sich für seine Schüler zum Beispiel regelmäßig in Erlangen. Davon profitierte Erich Mollwo, der 1948 als Ordinarius dorthin berufen wurde. Schon 1945 kam Mollwo ins Gespräch für eine Professur, als in Freiburg ein Physiker ohne Parteimitgliedschaft gesucht wurde. Eucken empfahl seinem Freiburger Kollegen Hermann Staudinger Mollwo als den einzigen der Jüngeren, den er mit dieser Eigenschaft kenne. „Es kann für mich kein Zweifel bestehen, daß dieser wegen seines Seltenheitswertes sehr bald ein Ordinariat erhalten wird und möchte glauben, daß es für Freiburg empfehlenswert ist, sich ihn möglichst rasch zu sichern." 576 Es ist eigenartig, dass Eucken nur Mollwo und nicht auch Wilhelm Walcher nannte. Diese jungen Nichtparteimitglieder genossen bis 1949 einen Wettbewerbsvorteil auf dem Weg zur Professur, den sie beide durch Berufungen 1947 und 1948 zu nutzen wussten. 577 Warum Mollwo nicht nach Freiburg berufen wurde, ist aus den Göttinger Akten nicht festzustellen. In Erlangen kam er an die Seite seines früheren Kollegen Rudolf Hilsch. Als Pohl 1952 emeritierte, wurde Hilsch sein Nachfolger. Auf der Berufungsliste standen ausschließlich ehemalige Göttinger: Walcher, Hilsch und Mollwo. 578 Mit Hilsch fand in Göttingen die Pohl'sche Schule ihren denkbar geeignetsten Nachfolger zur Wahrung der Kontinuität in Forschungs- und Unterrichtsstil. Die in Erlangen freigewordene

573 GPAMNFG, Lehrkörper (ausgeschieden), Pick.

574 Interview mit Pick, 2. Oktober 1981. NBL.

575 Interview mit Pick, 2. Oktober 1981. NBL.

576 Eucken an Staudinger, 7. Dezember 1945. Siehe auch das Schreiben Staudinges an Eucken, 14. November 1945, in dem die Situation in Freiburg geschildert wird. Professor Steinke ist als Dozentenführer entlassen worden, und das physikalische Institut war vollkommen zerstört. GPAMNFG, Lehrkörper (ausgeschieden), Mollwo. Zu Staudinger siehe Schnabel [1991] S. 222, 229f.

577 Walcher erhielt 1946 einen Ruf nach Leipzig, während er bereits in Marburg um ein Extraordinariat verhandelte. Das hessische Ministerium schlug ihm dann ganz unerwartet die Nachfolge des Marburger Ordinarius Wilhelm Grüneisen (1877-1949) vor. Walcher nahm 1947 an, doch Grüneisen war zu diesem Zeitpunkt noch nicht emeritiert, geschweige über seinen Nachfolger informiert gewesen. Aber man konnte sich verständigen und Walcher übernahm 1948 den Lehrstuhl. Siehe Schlüpmann [http].

578 Dekan an Kultusministerium, 26. Juli 1952. UAG, Rek. PA Hilsch. 
Professur wurde mit Rudolf Fleischmann besetzt, der in der Göttinger Dependance ebenfalls für 'schulische' Kontinuität sorgte. Fleischmann promovierte bei dem Pohl-Schüler Gudden in Erlangen, war von 1929 bis 1932 Assistent von Pohl in Göttingen und nach einer Kriegsgefangenschaft in den USA in der Zeit der allgemeinen Wanderschaft von 1946 bis 1947 kurz in seiner Geburtsstadt Erlangen. 579

Die Macht der Pohl-Schule in Besetzungsfragen an deutschen Universitäten wurde von Außenstehenden zum Teil heftig kritisiert. 1961 diagnostizierte der nicht aus der Pohl-Schule stammende Wilhelm Hanle, der Pohl und die Göttinger Verhältnisse aus seiner Studienzeit bei James Franck und seiner Oberassistentenzeit bei Georg Joos kannte, in einem privaten Brief an Franck: „Fast bei allen Berufungen auf Experimentalphysik-Lehrstühle in Deutschland hat Pohl seine Hand im Spiel“".580 Auch konnte Pohl die Berufungsbedingungen zum Vorteil für seine Leute beeinflussen: „Die Pohlleute sind meist viel besser dran. Pohl besorgt ihnen 2 Rufe, [...] damit können sie etwas aushandeln. " 581 Hanle war als Ordinarius in Gießen sichtlich frustriert, dass er seine eigenen Leute nicht in ähnlicher Weise protegieren konnte. In Bezug auf Pohls Macht zog er den radikalen Schluss: „Kurz und gut, ich bleibe dabei. Pohl und seine Leute sind ein Unglück für uns. Aber das darf ich nur im Vertrauen sagen. Pohl hat uns ja in der Hand.“ 582

Hanle scheint in Bezug auf Pohls Macht ein allgemeines Bewusstsein deutscher Experimentalphysiker ausgesprochen zu haben. Diese Wahrnehmung führte dazu, dass die Physiker sich bei Karrierebestrebungen oft mit Bittbriefen an Pohl wandten. Gerade in der unmittelbaren Nachkriegszeit, in der viele sich auf Wanderschaft befanden und Unterstützung suchten, wurde Pohls Vermittlung oft erbeten. Heinz Maier-Leibnitz schrieb im März 1947 an Pohl, nachdem er zum Jahreswechsel 1946/47 einen Halbjahresvertrag für Amerika unterschrieben hatte. „Der Hauptgrund, weshalb ich Ihnen heute schreibe, ist, Ihnen zu sagen, dass ich nicht die Absicht habe, die Wissenschaft in Deutschland zu verlassen und Amerikaner zu werden.“" 583 Er hoffte, nach seiner Rückkehr aus den USA in Deutschland wieder in der Wissenschaft Fuß fassen zu können. Dass er dies Pohl mitteilte, hatte offenbar den Zweck, sich Hilfe bei der Wiedereingliederung in die deutsche akademische Welt zu

\footnotetext{
579 Zu Fleischmann siehe Schopper [1978] und den autobiografischen Bericht Fleischmann [1994].

580 Wilhelm Hanle an James Franck, 25. September 1961. NL Franck, Box 3, Folder 11.

581 Wilhelm Hanle an James Franck, 25. September 1961. NL Franck, Box 3, Folder 11.

582 Aus einer als „Vertraulich“ überschriebenen Beilage des Briefes von Hanle an Franck, 18. Dezember 1961. NL Franck, Box 3, Folder 11.

583 Maier-Leibnitz an Pohl, 17. März 1947. Pohl Dienstzimmernachlass. Maier-Leibnitz kannte Pohl von seiner Studienzeit in Göttingen von 1931 bis 1935. Er promovierte bei Franck, wurde 1935 aber von Pohl in der Experimentalphysik geprüft. Siehe Edingshaus [1986] S. 28-53. Siehe auch Maier-Leibnitz [1974].
} 
sichern. Auf Pohl hätte er vermutlich zurückgegriffen, falls seine Hauptunterstützung durch seinen Lehrer Bothe in Heidelberg nicht erfolgreich gewesen wäre. Als Maier-Leibnitz Mitte 1948 zurückkam, wurde er auf Vorschlag Bothes Abteilungsleiter am MPI für medizinische Forschung in Heidelberg. ${ }^{584}$

In einer ähnlichen Situation schrieb Wolfgang Finkelnburg an Pohl. Finkelnburg entschloss sich zur Annahme einer Einladung in die USA, nachdem er in den ersten beiden Nachkriegsjahren „trotz Entnazifizierung“ (verstanden als das persönliche Überstehen des Entnazifizierungsverfahren) es nicht geschafft hatte, eine auch nur „bescheidenste Hochschulstellung in Deutschland“ zu erlangen.

„Ich kann nicht leugnen, dass mich das tief bekümmert hat, da wesentlich jüngere Kollegen Dozenturen und Professuren in grosser Zahl erhielten, man mich aber trotz meiner 4 immerhin anerkannten Bücher und über 60 Veröffentlichungen und trotz meiner Bewährung als Direktor des grossen Strassburger Instituts einfach zu vergessen schien. [...] Ich fühle mich aber nach wie vor als deutscher Hochschullehrer und habe immer noch die Hoffnung, dass in absehbarer Zeit man wieder an mich denken wird. [...] Ich wäre auch Ihnen, verehrter Herr Kollege, sehr dankbar, wenn Sie mich nicht vergessen und bei Gelegenheit immer wieder einmal auf mich hinweisen würden." 585

Finkelnburgs Hilferuf hatte zwar nicht den gewünschten Erfolg, doch erfuhr er dadurch zumindest die Hintergründe für die Schwierigkeiten bei seiner Stellensuche. Dies lag nämlich ausgerechnet an Pohl, der entsetzt darüber war, wie das Strassburger Institut unter Finkelnburgs Leitung ,in einen Zustand versetzt worden ist, wie ihn selbst Militär nicht schlimmer hätte bewirken können.“ Pohl teilte dies Finkelnburg offen mit und fügte noch hinzu, „dass jeder, der den Tatbestand aus eigener Anschauung kennt, die berechtigte Angst hat, dass sich so etwas wiederholen könnte." 586 Dass einem mit einer Empfehlung von Pohl Tür und Tor offen standen, galt also auch in der umgekehrten Richtung. ${ }^{587}$ Finkelnburg war sehr verbittert, dass er von den deutschen Hochschulen ausgeschlossen war und schrieb entsprechend an Heisenberg. Er müsse „aber nun seit Jahren sehen, wie mir unter einem fadenscheinigen Vorwand nach dem anderen diese Betätigung unmöglich gemacht wird und ein Göttinger Assistent nach dem anderen, der noch keinerlei selbständigen Befähigungsnachweis erbracht hat, massgebende Stellungen bekommt. Diese letzte Tatsache

\footnotetext{
584 Zu Maier-Leibnitz' Zeit in Heidelberg bei Bothe und dem Jahr in den USA siehe Edingshaus [1986]

3. Kapitel. Den Kontakt zu Bothe hatte 1935 Pohl hergestellt.

585 Finkelnburg an Pohl, 15. August 1947. Dienstzimmernachlass Pohl.

586 Pohl an Finkelnburg, 21. August 1947. Dienstzimmernachlass Pohl.
} 
wurde nicht von mir festgestellt nebenbei, sondern von einem so friedlichen und unaggressiven Manne wie Herrn [Marianus] Czerny, der mir auf der Überfahrt sagte, so gange [sic] es nun doch nicht, dass man nur als Göttinger noch als Physiker anerkannt würde. “588 Dieses Urteil der Außenstehenden ist überzogen, aber wahr ist, dass der Göttinger Nachwuchs gute Karrierebedingungen vorfand.

Kein eigentlicher Pohl-Schüler, aber doch ganz in den Kreis aufgenommen war Hans König. Für seine vom RLM in Göttingen finanzierte Stelle musste nach 1945 Ersatz gefunden werden. Pohl suchte eine Lösung, und da er ihm keine eigene Assistentenstelle anbieten konnte, wurde dem neuen Direktor der III. Physik in der Berufungsverhandlung zur Bedingung gestellt, Hans König als Oberassistenten $\mathrm{zu}$ übernehmen. ${ }^{589} \mathrm{Zu}$ welchen argumentativen Widersprüchen das bei der komplizierten Personalpolitik in der angewandten Physik führte, wird noch im letzten Kapitel im Einzelnen gezeigt werden. Hier ist nur von Bedeutung, dass Pohl mit Hilfe des Dekans Eucken einen seiner Schützlinge protegieren konnte. Im Oktober bat König, als Privatdozent in Göttingen zugelassen zu werden. Daraufhin wurde vom Dekan Eucken die politische Überprüfung Königs in die Wege geleitet. ${ }^{590}$ Eventuelle Probleme im Entnazifizierungsverfahren umging König, indem er als Eintrittsdatum zur NSDAP nicht 1929, sondern 1936 angab. Mit etwas mehr Wissen in die Aufnahmebedingungen hätte König vermutlich das Jahr 1937 angegeben, denn erst dann wurde der im Mai 1933 verfügte allgemeine Aufnahmestopp aufgehoben, was zu einem großen Schwung von Neueintritten führte.591 Eine kritische Nachfrage im Entnazifizierungsverfahren scheint es aber nicht gegeben zu haben. Vermutlich war es auch hilfreich, dass Pohl im Ausschuss saß und die Beurteilung Königs beeinflussen konnte.

Eine Studentin erinnerte sich in einem Interview, dass König wild über die Attentäter des 20. Juli geflucht habe. Solche Leute müsse man rädern, soll er zum Beispiel gesagt haben. Auch in den von König vorgelegten Persilscheinen kam nicht nur Entlastendes zur Sprache. Professor Walter Seiz bescheinigte, dass König „die sehr aggressive Tonart, die einzelne

587 Finkelnburg versuchte sich zwar vor Pohl zu rechtfertigen, doch ohne Erfolg. Sein langer Brief vom 15. Oktober 1947 an Pohl blieb unbeantwortet. Dies geht hervor aus Finkelnburg an Heisenberg, 6. Februar 1948. MPI für Physik und Astrophysik, NL Heisenberg.

588 Finkelnburg an Heisenberg, 6. Februar 1948. MPI für Physik und Astrophysik, NL Heisenberg

589 Erwin Meyer an „Fräulein Will“" vom Dekanat, 17. März 1967.

590 Dekan Eucken an Rektor, 25. Oktober 1946; Pohl an Raiser, Vorsitzender des Entnazifizierungsausschusses, 19. November 1946. HStAH, Nds. 171 Hildesheim 13131.

591 Benz, Graml \& Weiß [1997/98] S. 604. 
[Partei-] Vorträge in aussenpolitischer Hinsicht anschlugen, billigte. “592 Sein früherer Lehrer Eberhard Buchwald suggerierte unvorsichtigerweise, König sei alter Parteigenosse gewesen, doch treffe auf ihn das diesen pauschal vorgehaltene Urteil des fanatischen Nationalsozialisten nicht zu. ${ }^{593}$ Wegen dieser nur bedingt brauchbaren Bescheinigungen war sein Auftreten vor dem Unterausschuss der Universität von großer Bedeutung. „Bei seiner mündlichen Vernehmung machte er den Eindruck eines ruhigen, der Wissenschaft zugewandten Mannes.“ Seine ,jugendliche Begeisterung“ für den Nationalsozialismus habe er abgelegt, deshalb wurde er in Gruppe 2 eingestuft. Der Hauptausschuss stimmte dieser Klassifizierung zu, woraufhin König im Juni 1947 von der Militärregierung in seinem Amt bestätigt wurde. Schließlich wurde er im März 1949 endgültig als entlastet festgestellt. ${ }^{594}$ Seit Mai 1947 bekleidete König eine Assistentenstelle im neuen III. Physikalischen Institut. In einer Kommissionssitzung besprachen sich im Juli 1947 Pohl, Kopfermann, Becker, Masing, Eucken, Heisenberg und der Dekan Harder über Königs wissenschaftliche Leistungen und seine Lehrbefähigung. Er wurde „als sehr geeignet angesehen“, doch sollte ihm eine Dozentur nur unter Vorbehalt erteilt werden, da er ,noch nicht voll entnazifiziert“ sei. ${ }^{595}$ Im September 1947 wurde er zum Oberassistenten ernannt und einen Monat darauf hielt er seine Umhabilitationsvorlesung zum Thema „Erkundung des Feinbaues von Oberflächen mit Elektronen“, die bei den Fakultätsmitgliedern Lob fand. ${ }^{596} 1948$ wurde Kurt Heinrich Hans Christian Albrecht Walter Bartold von Bassewitz zur Bedienung des Elektronenmikroskops für medizinische Zwecke Laborant bei König. Bassewitz war im Alter von 17 Jahren HJ Hauptscharführer und stieg im Krieg als Soldat bis zum Oberleutnant auf. ${ }^{597}$ Anfang 1950 wurde König genauso wie Hellwege zum außerplanmäßigen Professor ernannt; der entsprechende Antrag wurde in der Fakultätssitzung einstimmig angenommen. ${ }^{598}$ Für Max

\footnotetext{
592 Persilschein von Professor Walter Seiz, Institut für Elektrische Maschinen und Geräte, TH München, 3. Januar 1947. HStAH, Nds. 171 Hildesheim 13131.

593 Persilschein von Eberhard Buchwald, 28. November 1946. HStAH, Nds. 171 Hildesheim 13131.

594 Siehe Königs Bestätigung durch die Militärregierung vom 19. Juni 1947; Entscheidung des Entnazifizierungs-Hauptausschusses vom 7. März 1949, darin auch die Zitate der Äußerungen des Unterausschusses vom 22. April 1947. HStAH, Nds. 171 Hildesheim 13131.

595 Protokoll der Kommissionssitzung vom 4. Juli 1947. GPAMNFG, Protokollbuch IV der mathematischnaturwissenschaftlichen Fakultät WS 1946/47 - WS 1949/50.

596 Am 6. Oktober 1947 fand der Vortrag statt. Anwesend waren Bederke, Correns, Bartels, Pohl, Becker, Eucken, Erwin Meyer, ten Bruggencate, Dekan Harder „und zahlreiche weitere Fakultätsmitglieder“. Protokoll der Fakultätssitzung zum Umhabilitationsvortrag von König, 6. Oktober 1947. GPAMNFG, Protokollbuch IV der mathematisch-naturwissenschaftlichen Fakultät WS 1946/47 - WS 1949/50. Siehe auch GPAMNFG, Lehrkörper (ausgeschieden), König. 597 UAG, Kur., Neu, XVI. V. C. hh. 6.

598 Am 6. Februar 1950 ernannte ihn das Kultusministerium (gez. Voigt) zum apl. Professor. GPAMNFG, Lehrkörper (ausgeschieden), König. Der Beschluss zur Ernennung Hellweges und Königs zum apl. Professor fand in der Fakultätssitzung vom 16. Juli 1949 statt, an der Eucken, Goubeau, Schermer, Gärtner, Scheffer,
} 
Laue war dies ein Anlass für große Freude: „Lieber Kollege! Aus den Mitteilungen des Rektors ersehe ich mit grosser Freude, dass Sie den Professor-Titel erhalten haben. Ich gratuliere herzlichst, wenngleich ich ja glaube, dass Sie nicht lange in diesem Stadium verharren, sondern bald ein Ordinariat bekommen werden." ${ }^{599}$

Laue sollte recht behalten. Wie mir König berichtete, kam durch Pohls und Buchwalds Vermittlung ein Ruf an die TH Darmstadt zustande. Doch das hessische Ministerium lehnte König ab, „ohne klare Gründe anzugeben“. Deshalb richtete der Darmstädter Professor der theoretischen Physik Otto Scherzer eine Anfrage an seinen Duzfreund, den Göttinger Rektor Wolfgang Trillhaas, „ob irgend etwas Nachteiliges über König bekannt geworden“ sei.600 Trillhaas erkundigte sich bei Kopfermann und Pohl, die der Meinung waren, die Schwierigkeiten könnten nur im Entnazifizierungsverfahren liegen,

„da erfahrungsgemäß die hessische Regierung den Entnazifizierungen aus der Britischen Zone mit Mißtrauen begegnet. Auch höre ich, daß ein Darmstädter Konkurrent Herrn König den Rang abzulaufen droht. Beide Kollegen, die ich befragte, waren der Auffassung, daß Herr König als Wissenschaftler und als schulebildender Lehrer eine vorzügliche Kraft sei, die unbedingt für die Verleihung eines Ordinariats in Betracht kommt, und daß die nationalsozialistische Vergangenheit von Herrn König lediglich eine jugendliche Epoche darstellt, von der er sich völlig gelöst hat.“

Nun saß ja nicht nur Pohl, sondern auch Trillhaas selbst im Entnazifizierungsausschuss der Universität, und er konnte sich erinnern, wie „König bei der Vernehmung sehr offen und rückhaltlos von seiner jugendlichen Begeisterung als Schüler und Student gesprochen hat und daß wir damals von der Ehrlichkeit seiner Darlegungen sehr angetan waren und in Verbindung mit dem Eindruck von einem ernsten Wissenschaftler gegen ihn keine Bedenken geltend machten.“601 Die Schwierigkeiten konnten aus dem Weg geräumt werden, und im November 1951 konnte König die Leitung des Physikalischen Instituts in Darmstadt übernehmen. Nach seinem Ausscheiden bedankte er sich bei der Fakultät für das, was er in Göttingen Wichtiges gelernt habe:

„Es sind jetzt etwa 10 Jahre her, daß ich auf Veranlassung von Herrn Professor Pohl Gelegenheit hatte in Göttingen zu arbeiten und die Naturwissenschaften von so hoher Warte zu betrachten. Ich habe in dieser Zeit sehr viel gelernt und bin

Wörmann, Tornau, Bederke, Bartels, Correns, Masing, Kopfermann, Pohl, Rein, Becker, A. Schmidt, Houtermans, Henke, Harder, v. Allesch, Schuler, Seedorf, Meinardus, Rippel, Mortensen, Tollmien, Erwin Meyer, Winkler, ten Bruggencate und der Dekan Rellich teilnahmen. Protokollbuch IV der mathematischnaturwissenschaftlichen Fakultät WS 1946/47 - WS 1949/50.

599 Laue an König, 3. März 1950. MPG-Archiv, NL Laue, III, 50, 1079.

600 Scherzer an Trillhaas, 26. Mai 1951. UAG, Rek. PA König.

601 Trillhaas an Scherzer, 30. Mai 1951. UAG, Rek. PA König. 
besonders dankbar, daß es mir vergönnt war in den letzten Jahren an den Sitzungen der Fakultät teilzunehmen. Gerade dieser Einblick gab mir viel für die jetzige Tätigkeit.“602

Der frisch erwählte Institutsdirektor König hatte in Göttingen nicht nur wissenschaftliches Rüstzeug, sondern auch die nötige soziale Kompetenz erworben, die für eine erfolgreiche Tätigkeit in seiner neuen Stellung unerlässlich war. Seine Wahl zum Fakultätsvertreter der Nichtordinarien, die ihm die lehrreiche Partizipation an der Fakultätspolitik ermöglichte, erfolgte im Juni 1949.603 In Darmstadt ließ er einen neuen Hörsaal für 450 Hörer errichten, dessen akustische Eigenschaften von seinem Göttinger Kollegen Erwin Meyer optimiert wurden. Sein neues Reich nahm nach seinen Wünschen Gestalt an. Eine automatische Tafel fuhr bei Druck eines himmelblauen Knopfes nach oben, bei Druck des schwarzen nach unten in den Keller, wo sie saubergewischt wurde. Aus Göttingen nahm er sich Stöckmann als Oberassistenten, Wilfried Hampe und Günter Behrens mit. Die DFG finanzierte ihm ein neues Elektronenmikroskop. Für seinen engen Göttinger Kollegen Karl-Heinz Hellwege leitete er eine Berufung in die Wege. Für Hellwege wurde mit Richard Viewegs ${ }^{604}$ Hilfe ein neues von der Industrie finanziertes Institut für Kunststoffe eingerichtet. Hellwege konnte einerseits seine Physik weiter betreiben, ein neues Institut aufbauen, musste sich aber andererseits in das neue Gebiet der Kunststoffe einarbeiten, was ihm schnell gelang. ${ }^{605}$

$\mathrm{Zu}$ Hellweges Werdegang wurde bereits das Wichtigste gesagt; er erhielt in Darmstadt seine Lebensstellung und wurde dort 1976 emeritiert. Der dritte, der zusammen mit König und Hellwege den beruflichen Aufstieg durch den Wechsel nach Darmstadt schaffte, war Fritz Stöckmann. Sein Weg zur Promotion bei Pohl 1942 wurde schon beschrieben. Er blieb bis zu seinem Weggang Assistent bei Pohl.606 1950 habilitierte er sich mit einer Arbeit über die elektrische Leitfähigkeit von Zinkoxyd. ${ }^{607}$ Pohl hatte Bedenken, kurz vor seiner Emeritierung einen neuen Dozenten im Institut aufzunehmen. Seine Kollegen ermunterten ihn aber dazu, da

\footnotetext{
602 König an Dekan Firbas, 30. November 1951. GPAMNFG, Lehrkörper (ausgeschieden), König.

603 An der entsprechenden Wahlversammlung nahmen Paul, Haxel, Wicke, v. Denffer, Houtermans, König, Pick, Arnold Schmidt, Münzner und Winkler teil. Gewählt wurden Haxel, König und Wicke; als deren Vertreter Houtermans, Arnold Schmidt und Schumann. Protokoll der Wahlversammlung der Fakultätsvertreter der Nichtordinarien, 24. Juni 1949. Protokollbuch IV der mathematisch-naturwissenschaftlichen Fakultät WS $1946 / 47$ - WS 1949/50.

604 Richard Vieweg war ab 1935 o. Prof. an der TH Darmstadt, ab 1952 Hon.Prof. an der TH Braunschweig, ab 1951 Präs. der PTB in Braunschweig u. Berlin.

605 Interview mit Hans König, 10. Februar 2001.

606 Die immer neuen Begründungen, um ihm 10 Jahre Assistentenzeit zu bewilligen, finden sich in HStAH, Nds. 401 Acc. 112 / 83, Nr. 895-899.

607 Stöckmann [1950]a. Die venia legendi wurde ihm am 10. Mai 1950 verliehen. UAG, Rek. PA Stöckmann.
} 
Stöckmann in den Kolloquien so positiv aufgefallen war. ${ }^{608}$ Becker urteilte über Stöckmann kurz: „Von seiner charakterlichen und wissenschaftlichen Zuverlässigkeit hatte ich stets den allerbesten Eindruck."609 In Darmstadt stieg der Oberassistent 1956 zum außerplanmäßigen Professor auf; 1959 erfolgte die Berufung auf ein Ordinariat an der TH Karlsruhe.

Die politischen Daten von König, Hellwege und Stöckmann suggerieren, dass hier eine rechte Seilschaft ihre Karriere durchsetzte. Alle drei waren ehemalige NSDAP-Mitglieder, einer wurde im Entnazifizierungsverfahren entlassen, einer rettete sich mit falschen Angaben. Diese Interpretation der drei Karrieren hat aber nicht nur den Nachteil der moralischen Konnotation, sie trifft auch nicht den Kern der Sache. Denn als Motor im akademischen Aufstieg wirkte das kollegiale Netz, in das die drei gut eingebunden waren, und nicht ihre politische Orientierung. Diese Einbindung funktionierte ganz wesentlich über fachliche Auszeichnung, wobei die Einzubindenden die Anerkennung eines kollegialen Verhaltenskodex signalisieren mussten. Dass nach Darmstadt gleich eine ganze Gruppe von Göttingern kam, lag an Hans König, der dies allerdings auch nur mit Hilfe einflussreicher Kollegen erreichen konnte. Dies waren in erster Linie Pohl und Buchwald. Aber auch der Darmstädter theoretische Physiker Scherzer, der vom Göttinger Rektor Trillhaas eine positive Auskunft über König bekam, half bei der Berufung mit. Es wäre irreführend, dieses größere Netz, das hier seine Wirkung entfaltete, als rechte Seilschaft zu bezeichnen, außerdem würde dadurch die politische Dimension fälschlich in den Vordergrund gerückt.

Sein Ordinariat konnte König keine 10 Jahre genießen, denn 1962 wurde er „wegen dauernder Dienstunfähigkeit in den Ruhestand versetzt“. Laut Erwin Meyer waren „geschäftliche Manipulationen“ der Grund. ${ }^{610}$ Fünf Jahre später wurde Königs ,,arglistige Täuschung“ im Entnazifizierungsverfahren aufgedeckt, woraufhin er aus dem Beamtenverhältnis entlassen wurde. König hatte die kollegiale Solidarität verspielt. Sein früherer Institutschef Erwin Meyer distanzierte sich nun deutlich vom ,ehemaligen Privatdozenten in unserer Fakultät, Herrn Dr. Hans König“. Ihm erschien es zweckmäßig, „unsere Fakultätsakten über Herrn König durch beiliegende Zeitungsnotizen [über seine

\footnotetext{
608 Pohls Gutachten zum Habilitationsgesuch von Stöckmann, 22. Februar 1950. GPAMNFG, Lehrkörper (ausgeschieden), Stöckmann.

609 Beckers Gutachten zu Stöckmanns Habilitation, ohne Datum. GPAMNFG, Lehrkörper (ausgeschieden), Stöckmann.

610 Wilhelm Hanle berichtet, König solle nach dem Krieg Apparate des Luftfahrtministeriums als Privatbesitz verkauft haben. Hanle an Franck, 16. August 1962. NL Franck, Box 3, Folder 11.
} 
Entlassung] zu ergänzen."611 Die Hintergründe, die zum Fall Königs beitrugen, wären eine eigene Untersuchung wert.

Vereinzelt gab es auch schon in den vierziger Jahren Kritik an der Wiedereingliederung belasteter Physiker in den Hochschulbetrieb. Das eindrucksvollste Beispiel ist ein Artikel einer damaligen Physikdoktorandin der TH Berlin aus dem Jahr 1947. Ihre Kritik wurde von einflussreichen Physikern abgewehrt, die, allen voran Max Laue, den meisten der namentlich kritisierten Physikern ihre Unterstützung zusicherten. ${ }^{612}$ Auch Hans König besaß ein gutes Verhältnis zu Laue, das aber seine Wurzeln nicht in politischer Übereinstimmung, sondern in fachlichen Diskussionen hatte.

Betrachtet man die Karrieren der Mitarbeiter im Pohl-Kreis von den Dreißigerjahren bis zu seiner Emeritierung 1952, fällt auf, dass alle seine Assistenten später eine Professur bekamen. Der hohe Wirkungsgrad wurde durch zwei Umstände begünstigt: 1. blieben die Assistenten bis zu ihrer Wegberufung relativ lange in Pohls Institut, und 2. hatte Pohl nur zwei Assistentenstellen zur Verfügung, sodass in einem Zeitraum von 18 Jahren nur vier aus seinem Kreis den normalen Karriereweg einschlagen konnten (Hilsch, Mollwo, Pick und Stöckmann; siehe auch Diagramm 1). ${ }^{613}$

\subsubsection{Unterschiedliche Assistenten in der theoretischen Physik}

Anhand zweier Assistenten in der theoretischen Physik zeigt sich, wie sich ein unterschiedliches Eingebundensein ins Göttinger Netz auf die Karriereverläufe auswirken kann. In den ersten Nachkriegsjahren hatte Richard Becker gleichzeitig zwei Assistenten, die eine unterschiedliche Ausbildung mitbrachten, da sie aus verschiedenen wissenschaftlichen Schulen kamen. Dies äußerte sich in merklich divergierenden Denkstilen der beiden Theoretiker. Becker 'fühlte' diese unterschiedlichen Denkstile deutlich. Laut Auskunft eines damaligen Doktoranden charakterisierte er seine Assistenten in überspitzter Form folgendermaßen: Den einen (Leibfried) versteht er schnell; doch der lag nicht immer richtig. Den anderen (Ludwig) versteht er nie; doch der behielt immer recht. ${ }^{614}$ Diese holzschnittartige Charakterisierung darf nicht als fachliche Abqualifizierung der Assistenten

\footnotetext{
611 Meyer an „Fräulein Will“ vom Dekanat, 17. März 1967. Die obigen Zitate stammen aus: „Beamtenschaft zu Recht aberkannt“, Die Welt, 7. März 1967 und „Professor zu Recht entlassen“, Göttinger Tageblatt, 8. März 1967.

612 Der kritische Artikel ist Martius [1947]. Zu den Auseinandersetzung innerhalb der Physikergemeinschaft siehe meine in Vorbereitung befindliche Studie: „Max von Laue und die Vergangenheitspolitik der Physiker“. 613 Siehe auch Eckert \& Schubert [1986] S. 119f.

614 Interview mit Friedrich Schlögl, 22. Juni 2001.
} 
missinterpretiert werden. In der zitierten Anekdote wird vielmehr offensichtlich, dass ein klarer Stilunterschied vorlag. Dass Becker Günther Leibfried besser verstand, lag daran, dass Leibfried sein Schüler war, sie also dem selben Denkkollektiv angehörten, sie im selben Stil dachten. Hinzu kam, dass Leibfried sich mit den in Beckers Arbeitsrichtung gestellten Aufgaben beschäftigte, während der besonders abstrakt denkende Günther Ludwig wesentlich andere Fragestellungen verfolgte.

Ludwig stand in fachlich enger Verbindung mit Pascual Jordan. Von März 1940 bis zum Kriegsende war Ludwig in Peenemünde mit der Entwicklung der V2 und der Flakrakete „Wasserfall“ beschäftigt. ${ }^{615}$ Da Jordan ebenfalls in Peenemünde tätig war, ist es anzunehmen, dass die beiden dort in Kontakt traten. Das Kriegsende brachte sie beide nach Göttingen, wo Ludwig im September 1946 vertretungsweise die Assistentenstelle des nicht aus der Kriegsgefangenschaft zurückgekehrten Heinz Haake übertragen bekam. ${ }^{616}$ Im Oktober 1947 bat er um Zulassung als Dozent und reichte seine Habilitationsschrift „Fortschritte der projektiven Relativitätstheorie“ ein, die auf Anregung von Jordan entstanden war. ${ }^{617}$ Becker urteilte über die Arbeit seines Assistenten, dass sie ein Spezialgebiet behandele, „dessen Einzelheiten ich selbst nicht völlig beherrsche." Deshalb hat er auch Jordan um ein Gutachten gebeten. Becker habe in Diskussionen feststellen können, dass Ludwig die Relativitätstheorie und Gruppentheorie wahrhaft souverän beherrsche. Bedenken hatte er wegen Ludwigs Spezialisierung in „einem nur wenigen Fachgenossen geläufigen Sondergebiet“", die alleine „keine Gewähr für eine erfolgreiche Dozententätigkeit“ biete. Aus dem Institutsalltag wusste Becker aber, dass Ludwig „das Gesamtgebiet der theoretischen Physik nicht nur vollständig beherrscht, sondern auch in geradezu meisterhafter Klarheit darüber vortragen kann."618

Auch die anderen Professoren befürworteten Ludwigs Habilitation. Kopfermann, der sich „auf die Gutachten der Theoretiker verlassen“" musste, sah in Ludwig einen ausgezeichneten akademischen Lehrer. Der Begründer der projektiven Relativitätstheorie, Theodor Kaluza, erkannte „eine selten reife Arbeit“; Heisenberg stellte fest, dass Ludwig die Methoden und Fragestellungen der allgemeinen Relativitätstheorie vollständig beherrsche und „das Gewicht mathematischer Deduktionen im Verhältnis zur physikalischen Realität richtig beurteilt.“619

\footnotetext{
615 Lebenslauf von Günther Ludwig, 8. Oktober 1947. GPAMNFG, Lehrkörper (ausgeschieden), Ludwig.

616 Kurator an Kultusministerium, 17. August 1948. HStAH, Nds. 401 Acc. 112 / 83, Nr. 899.

617 Siehe zum damaligen Stand der projektiven Relativitätstheorie Jordan [1947]e.

618 Gutachten von Richard Becker zum Habilitationsantrag von Günther Ludwig, 25. November 1947. GPAMNFG, Lehrkörper (ausgeschieden), Ludwig.

619 Gutachten von Kopfermann, 10. Dezember 1947; Kaluza, 29. Dezember 1947 und Heisenberg, 10. Januar 1948. GPAMNFG, Lehrkörper (ausgeschieden), Ludwig.
} 
Auf den eigentlichen Inhalt der Arbeit ging aber nur Jordan näher ein. Es scheint, als verließen sich die anderen Professoren in Anerkennung Jordans fachlicher Autorität auf sein Gutachten. Das Neue an Ludwigs Arbeit bestünde in der Annahme einer veränderlichen Gravitations-'Konstanten“. „Der von ihm [Ludwig] entwickelte Formalismus erlaubt es, alle in Betracht kommenden Typen physikalischer Felder - neben Gravitation und Elektromagnetismus auch Spinorfelder und Mesonfelder usw. - in fünfdimensional bezw. projektiv invarianter Form zu beschreiben und damit die grundsätzliche Berechtigung der projektiv-fünfdimensionalen Theorie lückenlos zu erweisen.“ Ludwig habe bei der Formulierung der verallgemeinerten Feldgleichungen mit veränderlicher Gravitationskonstanten durch geschickte Behandlung eines Variationsproblems sehr befriedigende Ergebnisse erzielt. „Der Referent, der teilweise schon selber eine ähnliche Abänderung des Variationsproblems versucht hatte, vermochte - da er nicht im Besitz der Ludwig'schen Methode war - trotz ein bis zweijähriger Bemühungen die Ausrechnung der zugehörigen Feldgleichungen nicht durchzuführen, wegen uferlos werdender rechnerischer Komplikationen. Die Ludwig'sche Methode erledigt dies Problem in einfachster Weise.“ Jordan glaubte, „objektiv aussprechen zu dürfen“, dass die eingereichte Arbeit „als eine ungewöhnliche wissenschaftliche Leistung angesehen werden muß.“620 Das Habilitationskolloquium wurde mit ,genügend“ angenommen, die Probevorlesung über die „Quantenmechanische Begründung des Weiss'schen Feldes“ fiel zur Befriedigung der Fakultät aus. ${ }^{621}$

Für Ludwig war Göttingen eine durch das Kriegsende bedingte Zwischenstation, wo er wissenschaftlich keine Wurzeln schlagen konnte. $\mathrm{Zu}$ verschieden war sein Stil der theoretischen Physik von dem Beckers. 1949 nahm er im Alter von 31 Jahren einen Ruf als außerordentlicher Professor an die FU Berlin an. ${ }^{622}$ Das war eine schnelle Karriere, wenn man bedenkt, dass er fünf Jahre lang für militärische Forschung abkommandiert gewesen war. Drei Jahre später wurde er in Berlin zum Ordinarius befördert.

Ganz anders verlief die Karriere des Assistenten Günther Leibfried. Mit seiner bei Georg Joos angefertigten Doktorarbeit war er ausgebildeter Experimentalphysiker. Im Krieg arbeitete er an der Geschossentwicklung in Beckers Institut, in dem er nach der Entlassung aus einer

\footnotetext{
620 Gutachten von Jordan, ohne Datum, GPAMNFG, Lehrkörper (ausgeschieden), Ludwig.

621 Siehe Notiz über das Kolloquium vom 13. Januar 1948. Die Probevorlesung fand am 13. Februar 1948 statt und brachte ihm die venia legendi ein. GPAMNFG, Lehrkörper (ausgeschieden), Ludwig. Zur Ludwig'schen Behandlung der Relativitätstheorie siehe Ludwig [1947]a, [1947]b, [1948]a und [1949].

622 Im Oktober 1949 schied er aus dem Göttinger Lehrkörper aus. HStAH, Nds. 401 Acc. 92 / 85, Nr. 136.
} 
kurzen Gefangenschaft im Herbst 1945 eine Assistentenstelle bekam. ${ }^{623}$ Bis zu diesem Zeitpunkt weisen die Karrieren von Ludwig und Leibfried einige Gemeinsamkeiten auf. Beider Ausbildung wurde durch den Krieg deutlich verzögert, bei dem um knapp drei Jahre älteren Leibfried etwas stärker. Beide arbeiteten in den letzten Kriegsjahren an der Entwicklung von Flakgeräten. Leibfried war sogar schon in Beckers Institut tätig, trotzdem ging seine Karriere langsamer voran. Leibfried war stärker an seinen Lehrer Becker gebunden, fachlich wie privat. ${ }^{624}$ Aus dem Abhängigkeitsverhältnis zwischen Lehrer und Schüler folgt, dass der Lehrer über die Zeit seiner Schüler verfügen kann und, um erfolgreich zu sein, davon auch Gebrauch macht. ${ }^{625}$ Deshalb ist es nicht verwunderlich, dass die eng an die Lehrer gebundenen Assistenten langsamer vorwärts kommen, anders gesagt kann eine Distanz zum Ordinarius das eigene Fortkommen beschleunigen. ${ }^{626}$

Im Dezember 1949 reichte er seine Habilitationsschrift „Theoretische und experimentelle Beiträge zur Dynamik der Versetzungen bei plastischer Deformation“ ein. Dass Leibfried für die Abfassung dieser Arbeit etwas länger als Ludwig gebraucht hat, lag zum guten Teil an seiner Eingebundenheit in die Institutsbelange. Becker hob dies im Gutachten hervor: „Seine verständnisvolle und aufopfernde Mitarbeit an allen Aufgaben des Instituts kann nicht genug gerühmt werden."627 Ebenfalls zeitraubend waren vermutlich die selbst durchgeführten Experimente und die Entwicklung einer neuen Apparatur zur Beobachtung kleinster plastischer Deformationen in der Größenordnung von Angström. Dass sich Leibfried in seinem Arbeitsstil von Ludwig unterscheidet, wurde von den Göttinger Ordinarien positiv vermerkt. Pohl schrieb: „Auch gefällt mir, daß er nicht nur rechnet, sondern auch experimentiert, und zwar auf einem physikalisch wie technisch gleich wichtigen Gebiet." ${ }^{2} 8$

\footnotetext{
${ }^{623}$ Lebenslauf von Leibfried, vermutl. 1956. UAG, Rek. PA Leibfried.

${ }^{624}$ Nach Auskunft von Beckers Tochter ging Leibfried bei ihnen zu Hause ein und aus, ohne groß angemeldet zu sein. Interview mit Eva Opitz, 21. November 2001.

625 Pierre Bourdieu hat dieses Phänomen anhand der französischen Hochschullandschaft untersucht. „Was die Fähigkeit, »Schüler zu haben, sie unterzubringen, sie in Abhängigkeit von einem selbst zu halten« und so die Grundlagen einer dauerhaften Macht sicherzustellen, was also die Tatsache, »Schüler mit guten Stellen zu haben « (Geograph 1971), vermutlich mehr als alles andere erfordert, das ist die Fertigkeit, die Zeit der anderen zu manipulieren, oder genauer, den Rhythmus ihrer Karriere, ihres Bildungsganges; ist das Vermögen, vielfältigste Leistungsnachweise [...], die Veröffentlichung von Artikeln oder Büchern, die Berufung auf einen Universitätsposten usw. gleichermaßen beschleunigen wie hinauszuzögern. Umgekehrt läßt sich diese Kunst [...] meist mit dem mehr oder weniger bewußten und stillschweigenden Einverständnis der Betroffenen ausüben, die so zuweilen bis ins fortgeschrittene Alter hinein in jener gehorsam-unterwürfigen, kurz, ein wenig infantilen Haltung gehalten werden - nicht umsonst heißt es im Deutschen »Doktorvater « -, die den guten Schüler noch jeden Alters auszeichnet.“ Bourdieu [1988/98] S. 155. Dieser Befund trifft nicht nur auf das Verhältnis Becker - Leibfried zu, sondern auch auf die anderen Göttinger Schulen, besonders auf Pohl. ${ }^{626}$ Siehe dazu Bourdieu [1988/1998] bes. die Abschnitte „Zeit und Macht“ (S. 158-180) und „Eine Zeitordnung" (S. 244-250).

${ }^{627}$ Gutachten von Becker, 6. Februar 1950. GPAMNFG, Lehrkörper (ausgeschieden), Leibfried.

628 Gutachten von Pohl, 11. Februar 1950. GPAMNFG, Lehrkörper (ausgeschieden), Leibfried.
} 
Der angewandte Physiker Erwin Meyer hob hervor, dass ihm Leibfried ,als besonders anschaulich denkender und sich auch für experimentelle Fragen stark interessierender Physiker bekannt“" sei. ${ }^{629}$ Im Mai 1950 wurde ihm die venia legendi verliehen. ${ }^{630}$ Er blieb Beckers Assistent und war als „Berater und Helfer der älteren Studenten [...] unermüdlich und mit vorzüglichem Erfolg tätig“.631 Im Mai 1953 wurde ihm eine Diätendozentur verliehen. ${ }^{632}$ Nach Beckers Tod im März 1955 übernahm er vertretungsweise die Institutsleitung. Als ihn die Fakultät im März 1956 zum außerplanmäßigen Professor ernennen wollte, kam die größte Unterstützung von seinem Doktorvater Georg Joos (Leibfried habe sich vorzüglich entwickelt) und dem Becker-Schüler Werner Döring (Leibfried gelte als der beste deutsche Theoretiker auf dem Gebiet der plastischen Verformung von Metallkristallen und besitze die Reife für ein Ordinariat). ${ }^{633}$ Beides waren auswärtige Gutachten; der Göttinger Theoretiker Friedrich Hund hielt sich mit Lob deutlich zurück. Leibfrieds Arbeiten über die Struktur des festen Körpers haben ihm in der ganzen Welt Anerkennung verschaffen und er erfülle die Voraussetzungen, „die bei einem Antrag auf Verleihung der Bezeichnung apl. Professor zu stellen sind.“634 Die Ernennung zum außerplanmäßigen Professor erfolgte schließlich am 27. Juli 1956.635 Ein Jahr später ging er als außerordentlicher Professor an die TH Aachen; der jüngere Kollege Ludwig war damals schon fünf Jahre lang Ordinarius.

\subsubsection{Erfolgreiche Karrieren in Kopfermanns Institut}

Im Unterschied zu den anderen Physikinstituten besaß das II. Physikalische Institut eine größere Zahl an Assistenten. Der Grund lag darin, dass eine der Institutsaufgaben die Betreuung des Praktikums war. Einige äußere Umstände führten dazu, dass die inhaltliche Ausrichtung der Forschung sehr breit angelegt war. Kopfermann war 1942 nach Göttingen gekommen und hatte den bei Franck, Pohl und Joos ausgebildeten Karl-Heinz Hellwege übernommen, der sich vor allem mit der spektroskopischen Analyse der Seltenen Erden in Kristallen befasste. Seine militärischen Forschungen im Krieg brachten ihn in engen Kontakt

\footnotetext{
629 Gutachten von Erwin Meyer, 11. Februar 1950. GPAMNFG, Lehrkörper (ausgeschieden), Leibfried. ${ }^{630}$ Am 3. Mai 1950 wurde die venia legendi gleichzeitig an Leibfried und Arnold Schoch verliehen. Dekan ten Bruggencate an Kultusministerium, 6. Mai 1950. HStAH, Nds. 401 Acc. 92 / 85, Nr. 136.

631 Becker an Kurator, 9. Mai 1952. Die Anträge zur weiteren Verlängerung Leibfrieds Assistentenstelle finden sich in HStAH, Nds. 401 Acc. 112 / 83, Nr. 895-898.

632 UAG, Rek. PA Leibfried.

633 Siehe Gutachten von Joos, 14. März 1956 und von Döring, 3. April 1956. GPAMNFG, Lehrkörper (ausgeschieden), Leibfried.

634 Gutachten von Hund, 29. März 1956. GPAMNFG, Lehrkörper (ausgeschieden), Leibfried.

635 GPAMNFG, Lehrkörper (ausgeschieden), Leibfried.
} 
mit dem Institut für angewandte Elektrizität. Bei Hellwege hatten bis Kriegsende drei Physiker promoviert. Einer davon war Hans Severin, der von 1943 bis 1945 Mitarbeiter von Hellwege im II. Institut und ab 1945 Assistent im Institut für angewandte Elektrizität bei Zahn war. Er wurde 1947 vom neuen Institutsleiter Erwin Meyer als Assistent übernommen. ${ }^{636}$ Hellwege besaß nicht nur eine Brückenfunktion zur angewandeten Physik, sondern durch seine enge Verbindung zu Richard Becker auch zur theoretischen Physik. Neben dem persönlich freundschaftlichen Kontakt gab es auch einen fachlichen, der zum Beispiel dazu führte, dass Hellwege bei der Betreuung der Doktoranden in der theoretischen Physik half. - Die unkonventionelle Stellenvergabe in der Besatzungszeit führte dazu, dass mit Fritz Houtermans jemand eine Assistentenstelle bekam, der zehn Jahre zuvor eine Abteilung des modernen und vorzüglich ausgestatteten Physikinstituts in Charkow geleitet hatte. Houtermans arbeitete mit dem Göttinger Mineralogen Carl Correns zusammen und verlagerte seinen Forschungsschwerpunkt auf geophysikalische Fragestellungen. Auch er sammelte einen eigenen Schülerkreis um sich. Wie Gemeinschafts-Publikationen zeigen, gab es eine Zusammenarbeit mit dem eigentlichen Kern des Kopfermann'schen Instituts. ${ }^{637}$ Auch zu Hellwege unterhielt Houtermans eine fachliche Verbindung, wie das im WS 1948/49 gemeinsam abgehaltene Physikalische Proseminar zeigt. - Kopfermann brachte aus Kiel seine beiden Assistenten Wilhelm Walcher und Wolfgang Paul nach Göttingen mit. Walcher war Spezialist für Massenspektroskopie. Sein Rüstzeug hatte er sich bei Gustav Hertz an der TH Berlin erworben, bevor er mit Kopfermann 1937 nach Kiel ging. Mit seinen Fähigkeiten war er im deutschen Uranprojekt willkommen, wo er an einer massenspektroskopischen Methode zur Trennung des U 235 Isotops vom natürlichen Uran arbeitete. ${ }^{638}$ Eine ähnliche Forschungsausrichtung wies Paul auf, der sich 1944 mit der Arbeit „Ein Massenspektrometer zur Bestimmung von Isotopenmischungsverhältnissen“ habilitierte. ${ }^{639}$ In der Nachkriegszeit wendete sich Paul vor allem dem neuen Teilchenbeschleuniger zu, mit dem sich neue kernphysikalische Fragen sowie Anwendungen in der Medizin untersuchen ließen. Kopfermann selbst teilte die Forschungsinteressen dieser beiden Assistenten und ergänzte das Forschungsspektrum des Instituts um ein weiteres Thema, das er seit seiner Berliner Zeit verfolgte. Die Hyperfeinstrukturanalyse und die damit gefundenen Isotopieverschiebungen

\footnotetext{
636 Severins Promotion war am 20. März 1944. HStAH, Nds. 401 Acc. 112 / 83, Nr. 896; die Doktorarbeit behandelte das Thema „Über die Spektren einiger wasserhaltiger Salze des Erbiums“, siehe Severin [1947]. GPAMNFG, Lehrkörper (ausgeschieden), Severin.

637 Siehe Brix, Buttlar, Houtermans \& Kopfermann [1951] und [1952].

638 Walcher [1944]a, [1944]b und [1948].

639 Paul [1948]b. Siehe zur Habilitation die durchweg positiven Gutachten in BAB, BDC, REM, Paul, Wolfgang.
} 
bildeten eine Konstante in Kopfermanns Forschungstätigkeit seit Anfang der Dreißigerjahre. In Göttingen war vor allem sein Schüler Peter Brix mit Untersuchungen zur Isotopieverschiebung befasst, der auch eigene Doktoranden an diesem Themenbereich forschen ließ. ${ }^{640}$

Die breit gefächerte Forschungsausrichtung war nur ein begünstigender Umstand dafür, dass die Kopfermann'sche Schule so besonders erfolgreich werden konnte. Hinzu kam die weitgehende personelle und auch inhaltliche Kontinuität über das Jahr 1945. Kopfermann galt auch in den Augen der Alliierten als politisch integre Person. Sein Assistent Walcher konnte mit politischer Minimalanpassung (kurzfristige NSKK-Mitgliedschaft) Karriere machen; der jüngere Paul wurde aber 1937 Parteimitglied und 1942 Mitglied im NSDDB. ${ }^{641}$ Nur der politisch stärker belastete Jens Geerk (NSDAP 1932), der bei Walcher eine „Methode zur Erzeugung von Schwärzungskurven mit mittelschnellen Protonen“ entwickelt hatte, verließ aus naheliegenden Gründen die Universität und setzte die 'Kriegsforschung' in französischen Diensten in St. Louis fort. Dort traf er auch Sauter, für den St. Louis ebenfalls eine Überbrückung der Entnazifizierungszeit darstellte. So weit das zu überblicken ist, konnten außer Geerk alle Institutsmitarbeiter in der Besatzungszeit weiterhin in Göttingen tätig sein. Die personelle Kontinuität war eine gute Voraussetzung für die inhaltliche, doch musste diese mit den Besatzern erst ausgehandelt werden. Auf welche Weise die Göttinger hierbei erfolgreich waren, wird in den Abschnitten 3.2 und 3.7 noch gezeigt. Eine weitere Voraussetzung für den Erfolg der Kopfermann'schen Schule lag in der gründlichen Ausbildung, in bestimmten Ritualen, die in der Forschungs-, Vortrags- und Publikationstätigkeit eingeübt wurden. Einige, die durch diese 'Göttinger' Schule gingen, wurden später selbst Professor: Karl-Heinz Althoff, Friedrich Begemann, Hans Gerhard Bennewitz, Peter Brix, Hans Günter Bucka, Hans-Georg Dehmelt, Hans Ehrenberg, Dieter Ehrenstein, Gerhard Fricke, Helmut Friedburg, Hans Georg Häfele, Walter Humbach, HeinzGerhard Kahle, Hubert Krüger, Gerold Lührs, Peter Meyer, Ulrich Meyer-Berkhout, Gerhard Nöldecke, Otto Osberghaus, Wolfgang Paul, Herbert Reich, Christoph Schlier, Andreas Steudel, Rolf Taubert, Wilhelm Walcher und andere. Zwei davon bekamen später den Nobelpreis verliehen: Dehmelt und Paul.

Für die Göttinger Forschungslandschaft war vor allem Wolfgang Paul von entscheidendem Einfluss, dessen Karriere hier näher betrachtet werden soll. Paul ist Jahrgang 1913, Sohn des

\footnotetext{
${ }^{640}$ Brix \& Frank [1950], Brix \& Humbach [1950], Brix \& Steudel [1950] und [1951], Brix \& Engler [1951] und [1952]. ${ }^{641}$ BAB, BDC, REM, Paul, Wolfgang.
} 
Universitätsprofessors für pharmazeutische Chemie Theodor Paul. Er begann sein Physikstudium an der TH München in jenem Semester, in dem die NSDAP an die Regierung kam. Im WS 1934/35 wechselte er an die TH Berlin, wo er im August 1937 seine Diplomprüfung bei Hans Geiger ablegte. Im Oktober des Jahres folgte er Kopfermann nach Kiel, zuerst als außerplanmäßiger und ab Oktober 1938 als planmäßiger Assistent. Im Sommer 1938 leistete er einen freiwilligen Dienst im Flak-Regiment 62 in Wismar ab. Im November 1939 promovierte er an der TH Berlin zum Dr.-Ing. Zu Kriegsbeginn wurde er eingezogen, doch Forschungsaufträge des RLM und des OKH sicherten ihm ab Frühjahr 1940 für die ganze Kriegsdauer eine uk-Stellung. Genauso wie sein drei Jahre älterer Kollege Walcher wurde er für Arbeiten zur Isotopentrennung für den Uranverein reklamiert. ${ }^{642}$ Eine erste symbolische politische Anpassung stellte die NSKK-Mitgliedschaft vom Oktober 1933 dar. Im Mai 1937 wurde er Parteigenosse und 1942 auch Mitglied des NSDDB. 1940 heiratete er, 1942 folgte er Kopfermann von Kiel nach Göttingen. Im Sommer 1944 habilitierte er sich mit der Arbeit „Ein Massenspektrometer zur Bestimmung von Isotopenmischungsverhältnissen“. ${ }^{643}$ Diese Arbeit zeige laut Kopfermann Pauls „vielseitiges Interesse für physikalische, chemische und biologische Fragen und die Wendigkeit, mit der er sich schnell in ein neues Gebiet einzuarbeiten versteht". ${ }^{644}$ Pohl kannte Paul als „kenntnisreichen und tüchtigen Physiker“, der auf ihn auch menschlich einen „sehr guten Eindruck gemacht“ habe. ${ }^{645}$ Becker äußerte sich in für ihn typischer Weise: „Stets hatte ich von seinen wissenschaftlichen Fähigkeiten sowie von seiner charakterlichen Zuverlässigkeit einen ganz vorzüglichen Eindruck." ${ }^{646}$ Selbst Eucken, der wieder einmal die zu geringe Zahl an Veröffentlichungen bemängelte, war der Meinung, dass Pauls wissenschaftliches Niveau in vollem Umfang den Göttinger Anforderungen an eine Habilitation entspräche. ${ }^{647} \mathrm{Im}$ Oktober 1944 wurde Paul zum Dozenten ernannt. ${ }^{648}$ Seine Karriere wurde durch drei Eigenschaften begünstigt: Er galt bei den Ordinarien als besonders fähiger Physiker, er war als Partei- und NSDDB-Mitglied bis 1945 ausreichend politisch angepasst und als Porfessorensohn der Zunft entsprechend sozialisiert. Da er keine politischen Ämter bekleidete, überstand er auch die Entnazifizierung unbeschadet, sodass er seine Laufbahn in der Nachkriegszeit bruchlos fortsetzen konnte. Ende 1947 wurde er zum Oberassistenten,

\footnotetext{
${ }^{642}$ Steiner [1995] S. 199.

643 Paul [1948]b.

644 Gutachten Kopfermann, ohne Datum. GPAMNFG, Lehrkörper (ausgeschieden), Paul.

645 Gutachten Pohl, 10. Mai 1944. GPAMNFG, Lehrkörper (ausgeschieden), Paul.

646 Gutachten Becker, 15. Mai 1944. GPAMNFG, Lehrkörper (ausgeschieden), Paul.

647 Gutachten Eucken, 23. Mai 1944. GPAMNFG, Lehrkörper (ausgeschieden), Paul.

648 Kurator an Kultusministerium, 14. November 1947. HStAH, Nds. 401 Acc. 112 / 83, Nr. 899.
} 
Anfang 1951 zum außerplanmäßigen Professor ernannt und im Oktober 1952 zum Ordinarius auf seine Lebensstelle nach Bonn berufen. ${ }^{649}$

In Göttingen reifte Paul zum Spezialisten in der Entwicklung und im Betrieb von Teilchenbeschleunigern heran. Das erworbene Know-how nahm er genauso wie das Göttinger Betatron nach Bonn mit, wo er eine moderne Beschleunigeranlage aufbaute und eine besonders erfolgreiche Schule der Elementarteilchenphysik etablierte. ${ }^{650}$ Neben Paul wurde zu dieser Zeit auch eine Reihe anderer Dozenten aus Göttingen wegberufen. ${ }^{651}$ Hinzu kam, dass Kopfermann 1953 nach Heidelberg wechselte und einige seiner Schüler mitnahm, und dass Pohl 1952 emeritiert wurde. Die Göttinger Institute leerten sich deutlich. Nach Beckers Tod 1955 fing mit den drei neuberufenen Institutsdirektoren Hilsch, Flammersfeld und Hund eine neue Ära an.

In der Zeit der akademischen Wanderschaft bestimmten die kollegialen Verbindungen unter den deutschen Physikern weitgehend die Stellenvergabe an der Universität Göttingen. Eine andere Art von kollegialer Verbundenheit bekam in dieser Zeit auch entscheidende Bedeutung auf dem Weg zur Normalität in der deutschen Physik. Es waren dies die Kontakte zu den ausländischen Physikern, die nach dem Krieg wiederhergestellt werden mussten, zu welchem Zweck sich eine frühere Kollegialität positiv auswirken konnte.

\subsubsection{Wiederaufnahme internationaler Verbindungen}

Die internationale Isolation, in die die deutsche Wissenschaft durch den Nationalsozialismus geriet, konnte nach 1945 erst allmählich überwunden werden. Die Deutschen waren von den ersten großen Physikerkonferenzen der Nachkriegszeit ausgeschlossen. Dazu zählen zum Beispiel die Konferenz über Elementarteilchen in Cambridge 1946, die Shelter-IslandKonferenz von 1947, die Richard Feynman als die weltweit bedeutendste Theoretikerzusammenkunft aller Zeiten bezeichnete, und die Solvay-Konferenz 1948. ${ }^{652}$ Die

\footnotetext{
649 Alle Informationen zu Paul stammen, soweit nicht anders angegeben aus GPAMNFG, Lehrkörper (ausgeschieden), Paul.

${ }^{650} \mathrm{Bis}$ zu seinem 60. Geburtstag hatten 95 Physiker bei ihm promoviert (Paul als Referent oder Korreferent) und 21 habilitiert. Siehe Bennewitz (Hrsg.) [1973] S. 125-138. Kurz vor seinem Tod sagte Paul im Interview, dass etwa 25 Doktoranden von ihm bei CERN und etwa dieselbe Zahl bei DESY arbeiteten. Steiner [1995] S. 205.

651 Auf ein Ordinariat wurden berufen 1951 König, 1952 Hellwege, Sauter und Houtermans. Die neuen Ordinarien nahmen auch eine Reihe von Institutsmitarbeitern mit. Stöckmann ging 1952 als Oberassistent nach Darmstadt.

652 Metzler [2000] S. 218f. Zur Sheter-Island-Konferenz und Feynmans Wertung siehe Eckert [1993] S. 254. Der Ausschluss von internationalen Koferenzen gilt auch in der angewandten Physik. Ende September 1947
} 
Beteiligung der deutschen Physiker an den NS-Kriegsanstrengungen sorgte im Ausland anfangs für Verstimmung: ,[...] they worked for the cause of Himmler and Auschwitz, for the burners of books and the taker of hostages. The communitiy of science will be long delayed in welcoming the armorers of the Nazis." ${ }^{653}$ Trotz dieser warnenden Worte gelang es aber verglichen mit der Zeit nach dem Ersten Weltkrieg relativ schnell, die Isolation zu überwinden. Als Katalysator wirkten die Emigranten, die zu den in Deutschland gebliebenen und als „Nicht-Nazis“ angesehenen Physikern weiterhin ein kollegiales entgegenkommendes Verhältnis behielten. Solche wichtigen Verbindungen der Emigranten gab es auch zu Göttinger Physikern, sodass von hier einige Impulse zur Wiedereingliederung in die internationale scientific community ausgingen.

Ersten Kontakt mit ausländischen Physikern gab es auf den ersten deutschen Physikertagungen. Auch hier hatte Göttingen die Vorreiterrolle inne, allerdings fanden sich auf der im Oktober 1946 stattgefundenen Tagung nur fünf ausländische Kollegen ein. ${ }^{654}$ Auch im folgenden Jahr kamen nur sieben Gäste aus Amsterdam, Cambridge, Kopenhagen, London und Manchester nach Göttingen. ${ }^{655}$ Neben diesem ersten Entgegenkommen interessiert vor allem der Transfer in der anderen Richtung.

Auf der politischen Bühne wurden schon früh Signale für eine Aufnahme der Deutschen gesetzt. Als einziger Deutscher konnte der für seine politische Integrität bekannte Max Laue im Juli 1946 zu einer internationalen Kristallographentagung nach London reisen; eingeladen waren noch zwei weitere Deutsche, die allerdings keine Ausreise-Erlaubnis erhielten. ${ }^{656}$ Der Nestor der deutschen Physik, Max Planck, bekam zur selben Zeit eine symbolträchtige Einladung der Royal Society. Im Juli 1946 reiste er nach London, um als einziger Deutscher an der Feier des 300. Geburtstags von Isaac Newton teilzunehmen. ${ }^{657}$ Dass die beiden Nobelpreisträger gerade aus Göttingen nach England reisten, ist eher ein Zufall. ${ }^{658}$ Wie sahen

fand der 5. Kongress für angewandte Mechanik in Paris ohne deutsche Beteiligung statt. Siehe Physikalische Blätter 3 (1947), S. 93.

653 Professor Morrison von der Cornell University in einer Besprechung von Goudsmits Buch Alsos, zitiert nach MPG-Archiv, Atomforschung, V, 13, Atomforschung und Folgen, 1.

654 Berg aus Harrow/London, Bloch, Bowden, Michel aus Holland und Mott aus Bristol. Dies ergibt sich aus den handschriftlichen Korrekturen in Laues Ansprache zur Eröffnung der Tagung. Der aus Cambridge erwartete Burcham konnte offenbar nicht kommen. MPG-Archiv, NL Laue, III, 50, 124.

655 Siehe dazu Walcher [1995] S. F108f. Laut einer Unterbringungsliste waren aus dem Ausland erschienen: Jordan (Kopenhagen), Michels (Amsterdam), Pippard (Cambridge), Shoenberg (Cambridge), Sondheimer (Cambridge), Tolansky (London), Wilson (Manchester), DPG-Archiv, Nr. 40044.

656 Laue [1952] S. 205. Siehe auch Laue [1945].

657 Siehe Heinemann [1990]b S. 414.

658 Dass Planck 1945 nach Göttingen kam, lag an der Vermittlung Robert Pohls. Siehe Hermann [1973] S. 116 und Casimir [1983] S. 218. 
demgegenüber die ersten Schritte ins Ausland jener Physikprofessoren aus, die nicht internationale Berühmtheit genossen?

Am Beispiel von Hans Kopfermann soll gezeigt werden, unter welchen Bedingungen diese Schritte erfolgten. Kopfermann war durch seine Aufenthalte in Niels Bohrs Institut in Kopenhagen in die internationale Gemeinschaft der Atom- und Kernphysiker gut eingebunden. Sein dortiger acht-monatiger Aufenthalt als Rockefeller-Stipendiat 1932/33 bekam unbeabsichtigt eine politische Bedeutung, denn 1933 war gerade Kopenhagen ein erster Anlaufpunkt für einige in die Emigration gezwungene Physiker. Kopfermann besuchte im Mai 1933 Göttingen, Berlin und Rostock und konnte sich so einen ersten unmittelbaren Überblick über die Vertreibungswelle verschaffen. In Kopenhagen schloss er mit den Vertriebenen Bekanntschaften und Freundschaften, wenngleich er die meisten schon von früher kannte. ${ }^{659}$ Auch in den folgenden Jahren besuchte Kopfermann jährlich das Bohr'sche Institut, pflegte die Kontakte und die wissenschaftliche Zusammenarbeit. Auf einem Foto aus dem Jahr 1936 ist er in Bohrs Institut mit Pauli, Jordan, Heisenberg, Born, Meitner, Stern, Franck, Eulers und Bohr zu sehen, 1937 mit Bohr, Heisenberg, Pauli, Stern, Meitner, Ladenburg, Jacobsen, Weisskopf, Møller, Euler, Peierls, Hund, Goldhaber, Heitler, Segrè, Placzek, Weizsäcker, Jensen, Rosenfeld und Wick. Zu Kopfermanns Freunden, die emigrieren mussten, zählten zum Beispiel Victor Weisskopf, Otto Robert Frisch, Rudolf Peierls und Georg Placzek. Diese Emigranten kamen auf unterschiedlichen Wegen nach Los Alamos und arbeiteten am amerikanischen Atomprojekt mit. Ab dieser Zeit gab es keine direkte Verbindung zu den in Deutschland gebliebenen Kollegen mehr. Eine innere Verbundenheit blieb aber bestehen. ${ }^{660}$ Ein Grund dafür lag auch in Kopfermanns Haltung seinen ausländischen Kollegen gegenüber.

Der in Holland unter deutscher Besatzung arbeitende Physiker Hendrik Casimir, anerkannter Spezialist und Theoretiker der Hyperfeinstruktur-Spektroskopie, gab in seinen Lebenserinnerungen eine vergleichende Beurteilung der Haltung deutscher Physiker während des Krieges. Einer davon war Kopfermann. Obwohl Casimir in der Besatzungszeit ständig mit Deutschen zu tun hatte, traf er nur mit drei seiner deutschen Physikerkollegen zusammen, die zufälligerweise alle (Nachkriegs-) Göttinger waren. Richard Becker kam im Winter 1942/43 nach Eindhoven. Beckers erste Frage galt dem Schicksal eines ehemaligen Studenten von

\footnotetext{
659 Aus Göttingen emigrierten die Assistenten Eugen Rabinowitch und Eduard Teller über Kopenhagen nach England und weiter in die USA. Der Assistent Arthur von Hippel emigrierte zuerst nach Istanbul, wo er nur kurz blieb. 1934 ging er nach Kopenhagen und schließlich weiter nach Boston. Rosenow [1987/98] S. 561.

660 Schlüpmann [http] S. 205ff.
} 
ihm, der unter dem Druck der NS Gesetze nach Holland geflohen war. Im Gespräch mit Casimir gestand Becker ein, dass er für die schlechten Lebensbedingungen in Holland mitverantwortlich sei. Für dieses Unrecht würde ohne Zweifel die Abrechnung kommen, und er wolle nicht leugnen, dass das nur gerecht sei. Doch Casimir müsse verstehen, dass Becker Deutscher sei und nicht „seine“ Truppen in Stalingrad vernichtet sehen wolle. Wenn er aufgefordert werde, die Kriegsanstrengung seines Landes $\mathrm{zu}$ unterstützen, fühle er sich verpflichtet, das zu tun. Vielleicht sei das unlogisch, aber das sei sein Standpunkt. ${ }^{661}$

1943 kam Werner Heisenberg. Bei einem Spaziergang fing er an, über Geschichte und Weltpolitik vorzutragen. Er erklärte, dass es immer Deutschlands Aufgabe gewesen sei, den Westen und seine Kultur gegen den Ansturm der Horden aus dem Osten zu verteidigen. Der damalige Konflikt sei ein weiteres Beispiel dafür gewesen. Angesichts dieser notwendigen Verteidigung sei vielleicht doch ein Europa unter deutscher Führung das kleinere Übel. ${ }^{662}$

Der dritte Besucher war Hans Kopfermann, den Casimir wegen gemeinsamer Forschungsinteressen an Hyperfeinstruktur-Untersuchungen gut kannte. Kopfermann traf Casimir im Philipswerk und fragte ihn diskret, ob er ihn privat treffen könne. Als ihn Casimir am Abend vom Hotel abholte und ihn zu sich nach Hause einlud, fragte Kopfermann als sie durch die verdunkelten Straßen von Eindhoven gingen: „Kommen Sie nicht in Schwierigkeiten mit ihren Kollegen, wenn die herausfinden, dass Sie einen Deutschen zu sich nach Hause einladen?“ Casimir antwortete prompt: ,Jetzt, wo Sie danach gefragt haben, kann es mir egal sein." 663

Drei kurze Sätze charakterisierten in Casimirs Augen die unterschiedliche Haltung dreier Physiker, die er alle als integre Menschen, „anti-Nazis“, einstufte, die aber doch deutsche Patrioten gewesen seien, bereit, bestimmte Kompromisse einzugehen: „Die Rechnung wird schon präsentiert werden“; ,Vielleicht wäre ein Europa unter deutscher Führung das kleinere Übel“ und „Kommen Sie nicht in Schwierigkeiten mit Ihren Kollegen?“ Casimir deutete sie so, dass Kopfermann die größte Sensibilität hatte, Becker vielleicht den größten Sinn für

\footnotetext{
661 Casimir [1983] S. 207. Ich habe Beckers dort auf englisch zitierte Aussage ins Deutsche übersetzt und in indirekte Rede übertragen.

662 Casimir [1983] S. 208. Auch hier handelt es sich um eine Rückübersetzung, mit Ausnahme der Stelle: „vielleicht [wäre] doch ein Europa unter deutscher Führung das kleinere Übel.“

663 Casimit [1983] S. 209.
} 
Gerechtigkeit und Heisenberg - der weitaus bedeutendste Physiker - die geringste Einsicht in die Lage. 664

Das Bild, das über die deutschen Physiker nach Kriegsende in der übrigen Fachwelt existierte, hing auch von solchen Begegnungen und Wahrnehmungen ab. Eine bescheidene Möglichkeit für die Deutschen, sich den ausländischen Physikern kollegial verbunden zu zeigen, bestand in der Anerkennung ihrer Arbeiten durch entsprechende Zitationen. Auch wenn das heute fast selbstverständlich anmutet, so wurde es damals wie ein kleiner Widerstandsakt aufgefasst und im Ausland auch entsprechend gewürdigt. In seinem 1940 erschienenen ersten und einzigen Buch Kernmomente bezog sich Kopfermann im Vorwort positiv auf die Arbeiten des holländischen Physikers Samuel Goudsmit, ${ }^{665}$ nicht ahnend, dass ihm dieser Kollege fünf Jahre später als amerikanischer Offizier gegenübertreten würde. Sicherlich trug die Würdigung der Forschungsergebnisse der Emigranten im Buch wie auch in Aufsätzen dazu bei, dass ihm 1945 die ersten alliierten Inspekteure nicht feindselig gegenübertraten. Kopfermann berichtet in einem privaten Brief an eine frühere Kieler Bekannte über die Institutsdurchsuchungen: „Bei den Kommissionen waren eine Reihe mir bekannter amerikanischer Kollegen, die sich reizend benommen haben."666 Als Bestätigung für die gegenseitige Achtung sei ein Satz aus einem Brief von Goudsmit an Weisskopf zitiert: „I have a very high opinion of Kopfermann even though he became a member of the Nazi party during the war and there are several arguments in his favor." 667

Die erste Gelegenheit zu einem wissenschaftlichen Auslandsbesuch ergab sich für Kopfermann im Jahr 1948. Bis dahin hatte er seine alten Kontakte und Freundschaften nur brieflich gepflegt. An Niels Bohr richtete er im April 1948 die Bitte, er möge bei den englischen Stellen in Kopenhagen Viktor Weisskopf eine Aufenthaltserlaubnis für Göttingen besorgen. „Dr. Fraser will von hier aus alles tun, falls er von Kopenhagen aus dazu aufgefordert wird. [...] Sie können sich vorstellen, welche Freude es für uns wäre, Familie Weisskopf ein paar Tage hier zu haben. Hoffentlich klappt es.“ Es war aber nicht nur das menschliche Bedürfnis, Freunde wieder zu sehen, sondern auch der Wunsch nach fachlichem

\footnotetext{
664 Casimit [1983] S. 209. Eine neue vergleichende Studie dreier Göttinger Wissenschaftler, Hahn, Heisenberg und Weizsäcker, verfasste Kraus [2001]. Sie fragt nach der Verantwortung des Wissenschaftlers und nennt ihre Studie eine verantwortungstypologische.

665 Aber nicht nur Goudsmit (V, E), sondern auch die Emigranten Bethe, Elsasser, Estermann, Farkas, Fermi (E), Frisch, Fröhlich, Heitler, Kemmer, Kuhn, Landé (E), Racah, Segrè (E), Stern (E) und Wigner fanden im Buch Erwähnung; einige sogar im kurzen Vorwort (V) und der sechseitigen Einleitung (E). Siehe Kopfermann [1940].

666 Schlüpmann [http] S. 384.

667 Goudsmit an Weisskopf, 11. Februar 1948. NBL, Samuel Abraham Goudsmit, papers, box 24, series III, 257, Weisskopf.
} 
Austausch, weshalb Kopfermann eine Zusammenkunft mit den internationalen Größen in der Physik herbeisehnte. ${ }^{668}$ Kurz darauf lud Viktor Weisskopf Familie Kopfermann zu einem Besuch in Tisvilde ein. Kopfermann bat wieder Bohr um Hilfe, da das dänische Konsulat in Hamburg die nötigen Visa nicht ausstellen konnte. Doch das dänische Justizministerium lehnte trotz Bohrs Fürsprache ab. ${ }^{669}$ Die Reise nach Dänemark kam dann aber doch über eine Einladung an Jensen und Kopfermann zustande, die von einem dänischen Komitee mit der Aufgabe, Lehrer an deutschen Universitäten und Schulen sowie deutsche Studenten zum Besuch nach Dänemark einzuladen, ausgesprochen wurde. „Diese Einladung soll dem Zweck dienen, Ihnen die Wiederaufnahme der persönlichen Verbindung und der wissenschaftlichen Zusammenarbeit mit dänischen Kollegen zu ermöglichen, und das Kommité [sic] wird die Reisekosten von und bis zur deutsch-dänischen Grenze, sowie Ihre Ausgaben für den Aufenthalt in Kopenhagen decken können." 670 Unterstützt wurden die Bemühungen vom britischen Scientific Advisor des Research Branch, Ronald Fraser, der kurz zuvor bei Bohr zu Besuch gewesen war. „I need hardly add that these invitations have the warmest support of the British authorities."671 Kopfermann war nach eigenen Angaben der erste deutsche Physiker, der nach dem Krieg in Bohrs Institut kommen konnte; Jensen folgte etwas später nach. Ein dritter im Bunde der Kopenhagenreisenden im Herbst 1948 war der junge Gerhart Lüders (Jahrgang 1920) aus Hamburg. 672

Eine Funktion der Besuche war, im Ausland ein positives Bild der deutschen Physik zu vermitteln. In einem Reisebericht an den Kultusminister betonte Jensen, er habe in seinen Vorträgen zeigen können, dass ,ein sehr großer Teil der deutschen Physiker auch während des Krieges an seriösen wissenschaftlichen Problemen von internationalem Interesse gearbeitet hatte und nicht etwa alle Arbeitskraft darauf verwendet hatte, Hitlers Kriegsmaschine auf immer höhere Tourenzahl zu bringen." 673 Wichtiger als das Vermitteln dieser Botschaft war aber, den Anschluss an den internationalen Stand in der Physik wieder zu erlangen. „Im Institut sind viele interessante Diskussionen über lauter neue Dinge, die zum grossen Teil noch gar nicht nach Deutschland gedrungen sind“ berichtete Kopfermann vom Aufenthalt bei Bohr. Während der wissenschaftliche Kontakt weniger problematisch

\footnotetext{
668 Kopfermann an Bohr, 12. April 1948. NBL, AHQP/BSC, 1946-1962, Kopfermann. Eine der physikalischen Fragen, die er damals gerne mit Bohr und Weisskopf besprochen hätte, betraf die Feinstrukturanomalien an der $\mathrm{H}_{\alpha}$-Linie.

${ }^{669}$ Kopfermann an Bohr, 29. Juli 1948. NBL, AHQP/BSC, 1946-1962, Kopfermann.

670 Kopenhagener Rektor J. Nörregard an Hans Jensen in Hannover, 23. Juli 1948. Zitiert nach Schlüpmann [http].

671 Fraser am 2. August 1948. Zitiert nach Schlüpmann [http].

${ }^{672}$ Siehe Lüders an Bohr, 28.Oktober 1948. NBL, AHQP/BSC, 1946-1962, Lüders.
} 
erschien, ${ }^{674}$ befürchtete man auf der menschlichen Seite einen verständlichen Groll der Dänen, doch Kopfermann wurde in dieser Beziehung ,auf das angenehmste enttäuscht““

„Die Leute sind alle rührend, haben erstaunlich viel Verständnis und Mitgefühl und sitzen so wenig auf dem hohen Ross, dass man fast beschämt ist. Es ist eigentlich so, als ob die 10 Jahre, die dazwischen liegen, gar nicht gezählt würden. Ich treffe hier auch eine Reihe von amerikanischen Kollegen, z. T. deutsche Emigranten, die eine wirklich erfreuliche Haltung zeigen. Weisskopf sagte zu mir: »Ihr habt es ja viel schlimmer gehabt. Wir sind ins Fettnäpfchen gefallen«."675

Weisskopfs Aussage ist problematisch. War es doch dieses Argument, mit dem Emigranten eine bevorzugte Rückkehr von deutscher Seite nicht zugestanden wurde. Auch in der späteren Diskussion um Wiedergutmachung schwang diese Ansicht noch mit. In dem persönlichen Gespräch zwischen Kopfermann und Weisskopf war es ein Freundschaftsbeweis und ein Ausdruck der Verbundenheit mit einem Teil der deutschen Kollegen sowie eine Anerkennung ihrer schweren Lebensverhältnisse in der Diktatur und im Krieg. Das schnelle und wie es scheint relativ unkomplizierte Wiederherstellen alter Freundschaften zwischen Emigranten und in Deutschland Gebliebenen ist angesichts der zahlreichen schrecklichen Familienschicksale bei den Emigranten doch erstaunlich. Diese Freundschaften wirkten dann als Katalysator für die Integration der Deutschen in den neuen Heimatländern der Emigranten.

$\mathrm{Zu}$ Weihnachten hatte Kopfermann genügend Abstand, um Bohr über die Wirkung des einen Monats in seinem Kreis berichten zu können.

„Es ist ein starkes Gefühl der Zusammengehörigkeit, das Bewusstsein nicht mehr so isoliert $\mathrm{zu}$ sein und $\mathrm{zu}$ wissen, dass es grosse gemeinsame Aufgaben gibt. Fraser und ich haben oft darüber diskutiert, ob man so etwas wie einen Europäischen Club gründen sollte und wenn wir nicht öffentlich versucht haben, ihn zu starten, so nur deshalb, weil ich das Gefühl hatte, es dürfe nicht ein Deutscher damit anfangen. Die Gespräche, die ich mit Ihnen hatte, haben mich in meiner Haltung sehr bestärkt und ich war sehr glücklich, [in] diesen Dingen weitgehend einer Meinung mit Ihnen zu sein. Auch die Art und Weise, wie die andern dänischen Kollegen mir entgegengekommen sind, war beglückend und anspornend.“

Am Ende des Briefs hatte Kopfermann noch eine Bitte: „Unsere Fakultät, angeregt durch Herrn Eucken, denkt daran, Herrn Bjerrum zu seinem 70. Geburtstag zum Ehrendoktor zu

\footnotetext{
673 Reisebericht von Hans Jensen an den Kultusminister, zitiert nach Schlüpmann [http].

674 Ein Beispiel hierfür ist ein vierseitiger Brief, den der Sohn Niels Bohrs, Aage, an Kopfermann im Anschluss an seinen Besuch schrieb. Darin werden ausschließlich verschiedenste fachliche Probleme besprochen, und der Brief zeigt, wie der Besuch gegenseitig befruchtend wirkte. Kopfermann hielt Aage Bohr über seine Göttinger Forschungen weiterhin am laufenden. Aage Bohr an Kopfermann, 4. Januar 1949; Kopfermann an Niels Bohr, 4. März 1949. NBL, AHQP/BSC, 1946-1962, Kopfermann.

675 Kopfermann an Charlotte Gmelin, 11. September 1948. Zitiert nach Schlüpmann [http].
} 
machen. Würden Sie so freundlich sein, mir mitzuteilen, ob Sie glauben, dass eine solche Verleihung jetzt schon wieder richtig verstanden wird."676

Was die Ehrung betrifft, so glaubte Bohr, dass sie mit Freude aufgenommen werden würde. ${ }^{677}$ Kopfermann hatte offenbar Bedenken, wenn politische oder symbolische Maßnahmen zur Anbindung ans Ausland von Deutschland ausgingen. $\mathrm{Zu}$ wenig waren im deutschen Nachkriegsbewusstsein die Nöte und Sorgen des Auslands vorhanden, sodass solche Schritte leicht falsch verstanden werden konnten. Für Bohr brachte Kopfermanns Besuch ,gute Erinnerungen und neue Hoffnungen hervor. [...] Vor allem aber war das Zusammensein mit Ihnen für uns eine Verstärkung des Gefühls der Zusammengehörigkeit und ich hoffe, dass wir wie in alten Zeiten einander in mancher Weise behilflich und aufmunternd sein können.“"678

Das Gefühl der Zusammengehörigkeit war für die im Krieg weitgehend isolierten Deutschen von großer Bedeutung. Und auch Hilfe war in vielerlei Hinsicht sehr willkommen und teilweise auch dringend benötigt. Richard Becker bekam 1947 ein Care Paket von Hendrik Kramers aus Holland, über das er sich mehr als über alle anderen freute.

„Seit meinem mir unvergesslichen Besuch in Holland im Jahre 1943 und seit unserem formlosen, für mich aber ungeheuer bewegten Abschied an einem neblig grauen Morgen am Hafen von Amsterdam war dies der Wiederbeginn eines persönlichen Verkehrs. Es machte mich richtig froh, daraus zu sehen, dass Sie immer noch freundschaftlich an mich denken, ebenso wie ich damals die Einladung nach Holland als einen Akt weitherziger Freundschaft so lebhaft und froh begrüsst und genossen habe.“

Becker hatte wie schon 1936, als er Borns Lehrstuhl übernommen hatte, ein beklemmendes Gefühl, weil er in der Physik mit den 'Großen' nicht ganz mithalten konnte. Deshalb habe er Kramers auch nicht eher geschrieben, weil er ,immer das törichte Gefühl habe, ich müsste mich wegen mangelnder physikalischer Leistungen bei Ihnen entschuldigen. Dabei weiss ich natürlich gut, dass es bei uns um mehr und um anderes geht als um einzelne bessere oder schlechtere Theorien."679 Und gerade in der Nachkriegszeit ging es in der scientific community der Physiker in der Wiederherstellung der internationalen Verbindungen um mehr als um die Physik. Der gerade entstehende West-Ost-Konflikt wirkte sich auch in der Physikerschaft aus. Aber Becker meinte natürlich die menschliche und nicht die politische

\footnotetext{
676 Kopfermann an Bohr, 24. Dezember 1948. NBL, AHQP/BSC, 1946-1962, Kopfermann.

677 Bohr an Kopfermann, 4. Januar 1949. Göttingen hat dann Bjerrum den Ehrendoktor verliehen. Siehe Kopfermann an Bohr, 4. März 1949. NBL, AHQP/BSC, 1946-1962, Kopfermann.

${ }^{678}$ Bohr an Kopfermann, 4. Januar 1949. NBL, AHQP/BSC, 1946-1962, Kopfermann.
} 
Seite der Beziehung. Szenen einer Freundschaft kamen ihm in den Sinn, als er an Kramers über „Gewitter und Idyllen“ der vergangenen Zeit schrieb: „Ihre Dispersionstheorie ist für mich innig verknüpft mit einem Gasofen, in welchem unten ein nicht erlaubtes Feuer brennt und auf welchem oben schwarzer Tabak trocknet. Auch ein Idyll im Gewitter."680

Die Herzlichkeit und die menschliche Wärme, die Kopfermann und Becker auszeichnete, war mit ein Grund, warum sie bei den ausländischen Kollegen so freundlich aufgenommen wurden. ${ }^{681}$ Gingen die ersten Reisen noch in nahe, europäische Länder, so folgten bald Einladungen in die USA. 1949 kam Laue, für dessen Besuch sich vor allem Goudsmit sehr eingesetzt hatte. ${ }^{682}$ Unter den Emigranten galt Laue als ,der einzige deutsche Physiker, der sich restlos anständig und vom Standpunkt der Leute hier [der Emigranten in den USA] einwandfrei benommen habe“. ${ }^{683}$ Die Integrität Laues nutzte auch seinen Kollegen und Mitarbeitern am MPI, um im Ausland Aufnahme zu finden. Heinz Koppe kam ebenfalls 1949 an die University of British Columbia in Vancouver, Kanada. ${ }^{64}$ - Im Jahr 1950 lud Victor Weisskopf Kopfermann in die Vereinigten Staaten ein. ${ }^{685}$ Ein halbes Jahr war Kopfermann Gast am MIT, und am Ende war er froh, dort gewesen zu sein. Probleme bereitete ihm die Sprache, die er nur schlecht beherrschte. Am besten verstand er die Emigranten. Sein früherer Vorgesetzter aus den zwanziger Jahren im KWI in Berlin, Rudolf Ladenburg, der im NS in die USA emigriert war, empfing Kopfermann und machte ihn mit einer Reihe amerikanischer Kollegen bekannt. Außerdem besuchte er im Brookhaven National Laboratory auf Long Island, New York Samuel Goudsmit, den er schon 1945 in Göttingen getroffen hatte. ${ }^{686}$ Der allgemein lockere menschliche Umgang war erst verwirrend, aber erfreulich fand er, dass auf den Menschen und nicht auf die Schale geachtet wurde. Die wissenschaftlichen Diskussionen waren eine große Herausforderung für ihn.

\footnotetext{
679 Becker an Kramers, 24. März 1947. NBL, AHQP, Kramers Correspondence, 1940-1952, Becker. In der damaligen Hungersnot 1946/47 in Göttingen waren Lebensmittelsendungen von immenser Bedeutung und zum Erhalt der Gesundheit unbedingt notwendig, wie mir Beckers Tochter, Dr. Eva Opitz, im Gespräch bestätigte. 680 Becker an Kramers, 29. Dezember 1947. NBL, AHQP, Kramers Correspondence, 1940-1952, Becker.

681 Weisskopf sagte über Kopfermann: „There was hardly any scientist for whom the human side of science played such a big part. It was the social side of scientific activity, the collaboration towards a great ideal, which played an essential part with him.“"Weisskopf [1964] S. 177.

682 Goudsmit an Kemble, 18. Januar 1950. NBL, Samuel Abraham Goudsmit, papers, box 12, series III, 119 , Kemble.

683 Finkelnburg an Heisenberg, 6. Februar 1948. MPI für Physik und Astrophysik, NL Heisenberg.

$684 \mathrm{Zu}$ der in Kanada durchgeführten Forschung siehe Koppe [1949]e.

685 Goudsmit unterstützte die Einladung und schrieb einen Brief an Laue, ,in which I mentioned Kopfermann and stressed the fact that Kopfermann would be extremely welcome here." Goudsmit an Weisskopf, 28. Februar 1950. NBL, Samuel Abraham Goudsmit, papers, box 24, series III, 257, Weisskopf.

686 Siehe Rudolf Ladenburg an Max Laue, 20. Februar 1950, zitiert bei Schlüpmann [http].
} 
„Was aber das Anstrengendste ist, ist das Bestehen der wissenschaftlichen Probe. Weder in Copenhagen, Cambridge, Oxford oder Zürich hatte ich das Gefühl sehr aus mir herausgehen zu müssen, um der Kritik und der Konkurrenz Stand zu halten. Hier fordern einem aber die vielen ausgezeichneten Leute mit ihrem Wissen und Können das Letzte ab. Und man möchte schliesslich doch bestehen." 687

Seine Arbeiten zur Systematik der Kernmomente waren in den USA bekannt und geschätzt. Einen Unterschied zwischen der Haltung der amerikanischen und der deutschen Professoren konnte er auch feststellen:

„Ich sehe natürlich nur eine Auslese aus dem Besten, was USA zu bieten hat, vergleiche aber auch nur etwa mit Göttingen. Vieles ist jünger, frischer, lebendiger. Vor allem bewundere ich den Mangel an professörlicher Überheblichkeit und an Brotneid. Wenn ich denke, dass auf Weisskopfs Schreibtisch alle Manuskripte theoretischer Art liegen und mit den Autoren diskutiert werden, ehe sie im Druck erscheinen, so empfinde ich das als grossartig und erstrebenswert. Bei uns hüllt man sich in Schweigen, damit der liebe Kollege nur ja nicht erfährt, was man selber tut.“”

Der Gesamteindruck fiel so positiv aus, dass er sich vielleicht überlegt hätte, dort zu bleiben, wenn er „30 wäre oder noch jünger [...]. Mit meinen nun beinah 55 Jahren denke ich natürlich nicht daran und wahrscheinlich würde ich es auch nicht tun, wenn ich jung wäre. Was mir fehlt ist die Ruhe Göttingens, die Landschaft, die Sprache.“

Die Verlockungen der USA mit ihrem offeneren Umgang in der Wissenschaft, den großen gut ausgestatteten Laboratorien wirkten sich in der Tat stärker auf die jüngere Generation der Physiker aus. Die etablierten Professoren genossen die Gastaufenthalte, waren aber doch zu sehr in Deutschland verwurzelt. Im WS 1950/51 kam Richard Becker als Gastprofessor ans Carnegie Institute of Technology in Pittsburgh. Vorträge hielt er in Washington, New York, New Haven, Cambridge, Chicago, Urbana, Columbus, Oak Ridge, Los Alamos, Berkeley und Durham. Sein Urteil über die amerikanische Physik fiel aus einem anderen Blickwinkel kritischer als bei Kopfermann aus. Becker interessierte sich sehr für Fragen des Unterrichts. Diesen fand er in den Vereinigten Staaten schulmäßiger und daher schlechter. Dass die USA in der Physik die führende Rolle übernommen hatten, lag nach seiner Ansicht an der höheren Studentenzahl, die trotz schlechterer Ausbildung mit höherer Wahrscheinlichkeit Spitzenbegabungen hervorbringe. 688 - Auch Pohls erster Besuch der USA kam im Jahr 1950 zu Stande. Ihn erreichte eine Einladung von Frederick Seitz von der University of Illinois.

687 Diese und die folgenden Zitate aus Kopfermann an Charlotte Gmelin, 29. März 1950, zitiert nach Schlüpmann [http] S. 443. 
Der Einladung voraus gegangen waren zwei Treffen der beiden: zuerst im Sommer 1945 in Berlin, als Seitz in Begleitung von Goudsmit die Universität Göttingen inspizierte, und dann 1949, als Pohl ihn zu einer Tagung der Festkörperphysik nach Göttingen eingeladen hatte. Dieser wissenschaftliche Kontakt führte 1950, als Auslandsreisen für Deutsche wieder leichter möglich waren, zu der erwarteten Gegeneinladung. Die weniger hierarchische und gemeinschaftlichere Art der Institutsführung in den USA beeindruckte Pohl, sodass er nach seiner Rückkehr ein entspannteres Verhältnis zu seinen Studenten und Kollegen in Göttingen anstrebte. Er war nun eher bereit, die anstehenden Angelegenheiten des Instituts mit seinen Mitarbeitern gemeinsam zu entscheiden. ${ }^{689}$

Nach den Reisen der Ordinarien bekamen auch deren Schüler Einladungen in die USA. 1951 reiste der Kopfermann-Schüler Wolfgang Paul zur Columbia University. Dort diskutierte er mit Charles Townes Anwendungsmöglichkeiten des elektrischen Quadrupols, was ein Schritt auf dem Weg zur Entwicklung des Maser war. ${ }^{690}$ Paul besuchte auch James Franck in Chicago, der mit ihm ein prüfendes Gespräch führte, in dem ihm nichts geschenkt wurde. Daraufhin lud ihn Franck zu einem Treffen der Emigranten ein und führte ihn dort mit den Worten ein: „Hier stelle ich Ihnen meinen wissenschaftlichen Enkel Wolfgang Paul vor.“691 Franck war der wissenschaftliche Großvater und als Vermittler fungierte der Doktorvater Kopfermann. Hier wurde die Familienmetapher benutzt, um ein Vertrauensverhältnis zu jungen deutschen Physikern in den USA herzustellen. Diese Möglichkeit war den Deutschen besonders durch die vielen einflussreichen Emigranten gegeben. - Auch ein Pohl-Schüler kam 1951 in die USA. Wie sein Lehrer wurde Heinz Pick von Frederick Seitz an die University of Illinois eingeladen. Anders als der kurz vor der Emeritierung stehende Pohl wurde Pick in die Gemeinschaft der amerikanischen Festkörperphysiker aktiv integriert. Zwei Jahre nach dem ersten Besuch folgte bereits ein zweiter, bei dem Pick seine Familie mitbrachte. ${ }^{692}$ Sowohl Pick wie Paul kamen im Schlepptau ihrer Lehrer in die USA. Es erwies sich für den Göttinger Nachwuchs als vorteilhaft, dass die Institutsdirektoren fachlich wie politisch angesehen waren.

\footnotetext{
688 Reisebricht von Richard Becker. UAG, Kur. PA Becker.

689 Frederick Seitz, Memorial Symposium in honor of Heinz Pick, Stuttgart, November 5, 1985, S. 11. NBL. Seitz [1994] S. 196-199.

690 Steiner [1995] S. 211.

691 Zitiert nach Brix [1994]a S. 1153.

692 Frederick Seitz, Memorial Symposium in honor of Heinz Pick, Stuttgart, November 5, 1985, S. 12. NBL. Seitz [1994] S. 214f.
} 


\subsubsection{Kritik gegen Einladungen Weizsäckers in die USA}

Gegen manche Einladung von deutschen Physikern in die USA gab es Proteste seitens der Emigranten. Mit solcherart Schwierigkeiten hatte Carl Friedrich Weizsäcker zu kämpfen. Schon Anfang 1948 planten Edward Teller und George Gamow, Weizsäcker einzuladen. Doch Samuel Goudsmit hatte unter den deutschen Emigranten einen Brief von Weizsäcker an Laue bekannt gemacht, in dem Weizsäcker Laue aufgefordert haben soll, bei Vorträgen in der Frage der Relativitätstheorie nicht zu aggressiv zu sein. Der frühe Versuch einer Einladung Weizsäckers sei nach Darstellung von Finkelnburg an der „unnachgiebigen Haltung Francks gescheitert“. ${ }^{693} 1949$ bemühte sich Weizsäcker wieder um verschiedene Einladungen. Die Hindernisse, die er dabei zu überwinden hatte, lagen an der Bemühung einzelner amerikanischer Physiker, keine politisch belasteten Deutschen einzuladen. Die bevorzugte Auskunftsstelle für eine politische Beurteilung der deutschen Kollegen war Samuel Goudsmit, der diese Rolle mit Eifer übernahm. Doch die Urteile, die Goudsmit unter seinen amerikanischen Kollegen verbreitete, stammten nur teilweise aus eigener Erfahrung. In vielen Fällen benutzte er die Berichte, die er von Paul Rosbaud bekommen hatte, der bis Kriegsende als Spion für die Briten in Deutschland tätig war. ${ }^{694}$

Edwin C. Kemble erkundigte sich 1949 bei Goudsmit, ob politische Gründe gegen eine Einladung Weizsäckers an das Physikalische Laboratorium der Harvard University sprächen. Die Antwort war eindeutig. Für Goudsmit war Weizsäcker in politischer Hinsicht „one of the worst among our German colleagues.“ Wenn man nur nach wissenschaftlicher Qualifikation ginge, so Goudsmit weiter, könne man Weizsäcker durchaus einladen. Doch die amerikanischen Standards seien glücklicherweise „more humanitarian. In our judgement a man's character and behaviour are more important than his technical knowledge."695 Goudsmit irrte sich in dem behaupteten Gegensatz zu Deutschland, denn auch dort wurde der Charakter und die Persönlichkeit bewertet, nur dass dabei demokratische Gesichtspunkte möglicherweise weniger Gewicht hatten. Auf drei Seiten begründete Goudsmit ausführlich, was ihn an Weizsäckers politischer Haltung störte. Dieser Brief verfehlte nicht seine

\footnotetext{
693 Finkelnburg an Heisenberg, 6. Februar 1948. MPI für Physik und Astrophysik, NL Heisenberg.

${ }^{694}$ Die teilweise höchst zweifelhaften Urteile Rosbauds und die Weiterverbreitung durch Goudsmit sind bisher noch nicht untersucht worden. Die Goudsmit papers im NBL geben detailierte Auskunft über diesen Prozess der Meinungsmache. Zu Rosbauds Tätigkeit als Spion siehe Kramish [1986]. Ein anderer Fall zweifelhafter Beurteilung deutscher Intellektueller, der vor allem Künstler betraf, stellt Carl Zuckmayers Geheimreport dar, der mittlerweile in Form einer wissenschaftlichen Edition vorliegt: Zuckmayer [2002].

695 Goudsmit an Kemble, 18. Januar 1950. NBL, Samuel Abraham Goudsmit, papers, box 12, series III, 119, Kemble.
} 
Wirkung. Kemble nahm Abstand von einer Einladung, doch Weizsäcker kam trotzdem nach Harvard, da ihn die dortigen Astronomen zu einem Vortrag eingeladen hatten. ${ }^{696}$

Goudsmit vermutete, dass Weisskopf hinter der Einladung der Astronomen stünde und schrieb einen sehr unfreundlichen Brief an ihn. ${ }^{697}$ Daraufhin erklärte Weisskopf, dass Weizsäcker sich im Herbst 1949 bei ihm nach Möglichkeiten einer Einladung ans MIT erkundigte, worauf er eine höflich ablehnende Auskunft gab und auch den AstronomenKollegen (Bart Bok) sagte, dass er Weizsäcker aus politischen Gründen niemals einladen würde. Dann traf er Weizsäcker in Washington, wo ihm dieser erklärte, er sei in der Diktatur zeitweilig „verblendet“ gewesen. Weisskopf gewann in dem Gespräch auch den Eindruck, dass Weizsäckers Verhalten im Krieg weniger gravierend sei als seine aktuelle Einstellung und seine Philosophie, die Weisskopf aus den persönlichen Gesprächen beurteilen konnte. Er berichtete den Astronomen in Harvard, und von einer Einladung ans Observatorium schien keine Rede mehr. Vermutlich wurde Weizsäcker durch Edward Tellers Fürsprache zum Vortrag eingeladen. Weisskopf war deutlich verärgert darüber, dass ihn Goudsmit mit Teller auf eine Stufe stellte und ihm die Unterstützung Weizsäckers unterstellte. Um Missverständnisse auszuräumen, betonte er seine Einstellung zu den Deutschen durch ein anderes Beispiel: „I have told you several times that some of the reasons why I invited Kopfermann was to counteract a trend of inviting only former Nazis to this country." 698 Bei seinem Aufenthalt in den USA kam Weizsäcker auch an die Universität in Chicago, wo er Vorlesungen und Übungen über Philosophie und Geschichte der Naturwissenschaften gab. ${ }^{699}$ Dass er nicht nur über Physik sprach, verstärkte vermutlich die Zurückhaltung auf Seiten der Emigranten, ihn einzuladen.

Weisskopf blieb bei seiner ablehnenden Haltung gegenüber Weizsäcker. Als dieser im Frühjahr 1952 zur Harvard Sommerschule eingeladen wurde, wandte sich Weisskopf an Otto Oldenberg im Harvard Physik Laboratorium. „I feel that this invitation will do very much harm in scientific circles abroad." Weizsäcker wurde in diesem Schreiben recht pauschal ins rechte Eck gestellt. Seine Philosophie läge nahe an irrationalen und antiwissenschaftlichen

\footnotetext{
696 Kemble an Goudsmit, 13. Januar 1950; Goudsmit an Kemble, 18. Januar 1950; Kemble an Goudsmit, 14. Februar 1950. NBL, Samuel Abraham Goudsmit, papers, box 12, series III, 119, Kemble.

697 „I really can't understand how Teller and you can be so utterly stupid to promote such a character as your friend Von Weizsäcker", ist nur einer der vielen unfreundlichen Sätze in: Goudsmit an Weisskopf, 20. Februar 1950. NBL, Samuel Abraham Goudsmit, papers, box 24, series III, 257, Weisskopf.

698 Weisskopf an Goudsmit, 24. Februar 1950. NBL, Samuel Abraham Goudsmit, papers, box 24, series III, 257, Weisskopf.

699 Das geht aus einem Brief von Weizsäcker an den Dekan Tollmien vom 13. Juli 1954 hervor. GPAMNFG, Lehrkörper (ausgeschieden), Weizsäcker. Zu Weizsäckers Behandlung der Geschichte der Naturwissenschaft siehe Abschnitt 4.2.2.
} 
Tendenzen der Nazi-Philosophie. Ihn einzuladen würde ein falsches Zeichen setzen, denn als Folge der McCarthy Politik sei es unmöglich gewesen, eine Einreise für so hervorragende Physiker wie Blackett, Powell, Bauer, Kastler und Chain zu bekommen, weil ihnen fadenscheinige Verbindungen zu linken Idealen nachgesagt wurden. Sichtlich verärgert über diesen Zustand kam Weisskopf zu der Schlussfolgerung: "The extension of the priviledge of a visa at this time to a man who is widely recognized as being strongly involved in philosophical and political ideas of the extreme right would have a terribly discouraging effect upon our friends abroad."700 Weisskopf wurde der Nachkriegshaltung von Weizsäcker mit dieser Beurteilung wohl nicht gerecht. Es scheint mir eher eine Auswirkung der politisch aufgeladenen Zeit (Koreakrieg) gewesen zu sein, die gerade die Emigranten gegenüber bestimmten Deutschen eine nachtragende Haltung einnehmen ließ.

700 Weisskopf an Oldenberg, 7. Februar 1952. Mit Datum vom 11. Februar 1952 schickte Weisskopf einen Durchschlag davon auch an Goudsmit. NBL, Samuel Abraham Goudsmit, papers, box 24, series III, 257 , Weisskopf. 


\section{Die Studenten - der Familiennachwuchs}

Die Studenten sind ein fester Bestandteil jeder Universität. Wenn man nach den Ausmaßen politischer Einflussnahme auf die Universität fragt, ist es in zweierlei Hinsicht aufschlussreich, einen Blick auf die Studenten zu werfen. Einerseits sind die Studenten Objekt der Einflussnahme, andererseits spielten sie in der Geschichte mehrmals eine bedeutende Rolle, indem sie aktiv politische Ziele verfochten, so zum Beispiel in der Revolution von 1848/49, zu Beginn des Nationalsozialismus ${ }^{701}$ und in der Achtundsechzigerbewegung. In dieser Arbeit interessiert besonders, wie von Staats- und Universitätsseite mit den Studenten umgegangen wurde, welche Steuerungsmaßnahmen zur Förderung bestimmter Gruppen und zur Abwehr anderer gesetzt wurden. Soweit es möglich ist, wird dabei auf die speziellen Bedingungen in der Göttinger Physik eingegangen. Da viele Maßnahmen alle Studenten gleichermaßen betrafen, kann hier auf die Ergebnisse der historischen Forschung zur deutschen Studentenschaft zurückgegriffen werden. ${ }^{702}$

Ein Vergleich der quantitativen Entwicklung der Göttinger Studentenschaft von 1930 bis 1960 mit der deutschlandweiten Entwicklung bietet einen ersten Überblick über eventuelle lokale Abweichungen vom allgemeinen Verlauf. Die schlechte Quellenlage bezüglich der unmittelbaren Nachkriegszeit erschwert diesen Vergleich. ${ }^{703}$ Wie noch im Detail gezeigt

\footnotetext{
${ }^{701}$ Zur Rolle der Studenten bei der personellen Umgestaltung der Universitäten, der Vertreibung 'linker' und „nichtarischer" Professoren siehe Grüttner [1995] S. 62-100, 474. Siehe auch in der vorliegenden Arbeit das Kapitel zur angewandten Mechanik, besonders Abschnitt 5.3.1, in dem die konkreten Auswirkungen studentischer Einflussnahme auf die Göttinger Physik am Beispiel des Instituts für angewandte Mechanik analysiert werden.

702 Einen guten Überblick über die Geschichte der deutschen Studentenschaft von 1800 bis 1970 bietet Jarausch [1984]. Speziell die NS-Zeit untersuchten Giles [1985] und Grüttner [1995]. Die Studentenschaft der Nachkriegszeit ist bisweilen erst wenig untersucht worden. Hauptsächlich auf Interviews vor allem ehemaliger Göttinger Studenten basiert die Arbeit von Krönig \& Müller [1990]. Unter den Untersuchungen mit lokaler Beschränkung gibt es eine vorbildliche Arbeit über die Nachkriegs-Studentenschaft der TH Braunschweig von Maaß [1998].

703 Detaillierte Statistiken zu den deutschlandweiten Studentenfrequenzen bis 1941/44 bieten Lorenz [1943]a und [1943]b und Titze [1987]. Einen Überblick über die Entwicklung in den 50er Jahren bieten Kath [1952], [1954], [1957] und [1960] und Quetsch [1960]. Die Göttinger Zahlen sind zusammengestellt in [Studentenzahlen] [1987]. Eine Aufschlüsselung in die einzelnen Fächer ist für die 40er und 50er Jahre leider nicht gegeben. Die Physik-Zahlen sind aus anderen, vereinzelten Quellen zusammengetragen, wobei sich die Schwierigkeit ergibt, dass man für jedes Semester fast so viele voneinander abweichende Angaben erhält, wie man unterschiedliche Quellen benutzt. Ein Grund für die zum Teil deutlich differierenden Studentenzahlen liegt vermutlich in den unterschiedlichen Zählmodi. Unterschieden wird zwischen deutschen und ausländischen Studenten, außerdem zwischen ordentlichen Hörern, beurlaubten Studenten und Gasthörern. Meist fehlt eine Angabe zum gewählten Zählmodus. Um nur ein Beispiel zu nennen: Für das SS 1951 gibt der Deutsche Hochschulführer von 1952 für Göttingen 3949 Studenten an. In [Studentenzahlen] [1987] sind hingegen 4259 angeführt aber selbst bei beliebig kombinierter Addition und/oder Subtraktion von Beurlaubten-, Ausländer- und Gasthörerzahlen lässt sich die im Hochschulführer angegebene Zahl nicht verifizieren. Die hier angegebenen Zahlen sind daher mit entsprechender Vorsicht zu genießen.
} 
wird, beeinflusste bis 1945 vor allem der NS-Staat und danach hauptsächlich die Universitäten Größe und Zusammensetzung der Studentenschaft, sodass für die Analyse der Nachkriegszeit vor allem die lokalen Verhältnisse an der Universität Göttingen in den Vordergrund rücken. Das Jahr 1945 markiert einen Wechsel des äußeren Zugriffs auf die Studentenschaft, der sich am deutlichsten in der geschlechtlichen Zusammensetzung auswirkte. Nach 1945 gab es eine regelrechte Verdrängung der Frauen aus der Universität Göttingen, die sich in den mathematisch-naturwissenschaftlichen Fächern deutlicher und in der Physik am stärksten zeigte (siehe Diagramm 10). Die speziellen Bedingungen des Frauenstudiums in der Physik werden daher in einem eigenen Abschnitt behandelt. Zuerst wird aber ein Überblick über die allgemeinen Studienbedingungen und die quantitative Entwicklung der Studentenschaft ab dem Ende der Weimarer Republik gegeben, wobei für die Nachkriegszeit der Schwerpunkt auf der Universität Göttingen liegt.

\subsection{Vorbemerkungen}

\subsubsection{Familienmetapher}

„Der Professor war - bei aller Distanz - stets der Vater.“704 Diese Familienmetapher findet man häufig in Beschreibungen von Mitgliedern der Wissenschaftlergemeinschaft, wenn sie über die menschlichen Beziehungen in der akademischen Welt schreiben, vor allem über jene zwischen Professor und Student während des hier untersuchten Zeitraums. Dies gilt für rückblickende Darstellungen, wie die eben zitierte, genauso wie für zeitgenössische Berichte. Das Bild einer familiären Beziehung wurde auf unterschiedlich große Teilgemeinschaften bezogen. Über die Physikertagung in Bad Nauheim 1950, die erste Tagung des neugegründeten Verbandes Deutscher Physikalischer Gesellschaften, hieß es in den Physikalischen Blättern, dass sie ,wirklich ein Familienfest!“ gewesen sei. ${ }^{705}$ In diesem Zusammenhang wirkt das Bild recht abstrakt, doch bezogen auf kleinere Ausschnitte der Physikerschaft erhält es eine gewisse Erklärungskraft. Anlässlich Pohls 80. Geburtstags kamen viele seiner Schüler nach Göttingen. Stöckmann nannte es ein „Familientreffen“.706 Pohl schuf eine wissenschaftliche Schule, die nicht nur in der Art wie sie die Physik auffasste

\footnotetext{
704 Erinnerungen des im WS 1945/46 immatrikulierten Chemiestudenten Hans-Hellmut Grun, Göttinger Tageblatt, 30. September 1995, S. 29. Ich danke Rudolf Wolgast für den Hinweis auf diesen Artikel. 705 Siehe Physikalische Blätter 6 (1950), S. 480. Über eine Physikertagung 1947 in Heidenheim schrieb der Herausgeber Ernst Brüche: „Was der Tagung in Heidenheim besondere Note gab, war das Gefühl einer »Familientagung«". Physikalische Blätter 3 (1947), S. 399.
} 
und betrieb, ${ }^{707}$ sondern auch in ihrer sozialen Verbundenheit eine klar erkennbare Gruppe bildete. In Bezug auf die Pohl-Schule ist die Familienmetapher eine in vieler Hinsicht zutreffende Beschreibung. Pohl war eindeutig das mächtige Familienoberhaupt. In einem Bericht von Stöckmann, wie er in den Pohl-Kreis aufgenommen wurde, kommt die soziale Macht zur Sprache:

„Eigentlich wollte ich Doktorand bei Hilsch werden, aber als ich nach zwei Auswärtssemestern nach Göttingen zurückkam und mich im Institut nach einer Möglichkeit erkundigen wollte, traf ich als ersten Pohl selbst. Er sagte mir, Hilsch habe inzwischen einen Ruf nach Erlangen angenommen, was ich denn da wolle. Ich könne auch bei ihm promovieren und ich möge mich bitte am nächsten Montag morgen nach der Vorlesung bei ihm melden. Damals war es für einen Studenten undenkbar, sich gegen eine so klare Entscheidung eines Professors und gar von Pohl - zu wehren. Also wurde ich Mitarbeiter von Pohl, ohne daß das meine Absicht gewesen war." ${ }^{\text {"708 }}$

Pohl suchte sich seinen akademischen Nachwuchs selbst aus und behielt so die Kontrolle über seine 'Familie'. Die fortgeschrittenen Studenten in seinem Institut nahmen ihn wie einen autoritären aber auch gütigen Vater wahr. 1947 wies er die Universitätskasse an, von seinem Gehalt RM 500 abzuzweigen und dem Institut gutzuschreiben, „damit die Bezüge von Frau Dr. Meyer-Schützmeister in den Monaten Januar bis März 1947 sichergestellt werden können." ${ }^{709}$ Ein weiteres Beispiel für seine Fürsorge berichtete eine Studentin im Interview. Pohl habe sich in den ersten Nachkriegsjahren, als viele nicht genug zu Essen hatten, fürsorglich um 'seine' Leute gekümmert und die verhungert aussehenden Diplomanden oder Doktoranden am Wochenende zu sich nach Hause zum Essen eingeladen. Hier verschwimmt die Metapher mit dem tatsächlichen sozialen Verhältnis in dem Sinn, als die erlebte Bindung im Institut den Status einer Ersatzfamilie bekam.

Die Gemeinschaft der Lehrer und Schüler, welche die Universität ihrem Ideal nach darstellen sollte, nahm für einen bestimmten Ausschnitt der Studenten, nicht für die Masse, eine konkrete Form an. In die Familie aufgenommen wurde diejenige Elite unter den Studenten, die für eine akademische Laufbahn als geeignet und erwünscht angesehen wurden. Diese Metapher trifft nicht nur auf Pohl und seine Mitarbeiter zu, sondern auch auf die anderen Physikinstitute. Die Kopfermann-Schule und ihre besonders enge soziale Verbundenheit beschreibt Schlüpmann in seiner Kopfermann Biografie. Die menschliche Bindung durch das

\footnotetext{
706 Stöckmann [1964].

707 Siehe Abschnitt 3.3.

708 Stöckmann [1978] S. 29.

${ }^{709}$ Pohl an Universitätskasse, 19. Dezember 1949. UAG, Kur. XVI. V. C. g. 2. III.
} 
tägliche Zusammenarbeiten blieb auch im Privatleben bestehen und zeigt sich an gemeinsam verbrachten Urlauben. ${ }^{710}$ Die in Kopfermanns Institut gefeierten Feste waren wie Familienfeiern. ${ }^{711}$

Die Familienmetapher bekommt in der Nachkriegszeit eine besondere Bedeutung. Erstmals konnten die Professoren sich die neu aufzunehmenden Studenten durch persönliche Gespräche selbst aussuchen. Sie waren gezwungen, aus vielen Bewerbern diejenigen auszuwählen, die sie für das Studium als geeignet erachteten. Im Familienbild gesprochen wurden möglichst nur die Bewerber abgelehnt, die als neue Familienmitglieder unerwünscht waren. Dass in dieser Situation nur wenige Frauen aufgenommen wurden, könnte auch daran liegen, dass Frauen keine bedeutenden Positionen in der Familie besetzt haben und womöglich auch nicht besetzen sollten. Sie stellten keinen erwünschten „Nachwuchs“ dar. Dieser Erklärungsversuch, der sich aus der zeitgenössischen Beschreibung der sozialen Verbundenheit der Institutsmitglieder seine Begriffe entlehnt hat, wird in der folgenden, vor allem statistischen Erfassung der Veränderungen von Größe und Zusammensetzung der Studentenschaft nicht streng durchgeführt. Er kann aber gerade im letzten Abschnitt über das Frauenstudium als Deutung der Vorgänge hilfreich sein.

\subsubsection{Die zeitliche Entwicklung der Studentenzahlen im Überblick}

\footnotetext{
710 Siehe Schlüpmann [http].

711 Weisskopf schrieb über Kopfermann: „... it was a joy to watch him participating in celebrations at his institute, when the students made fun of him and his colleagues. This kind of happy get-together was unmatched by any other institute and he enjoyed it more than anything else." Weisskopf [1964] S. 183.
} 


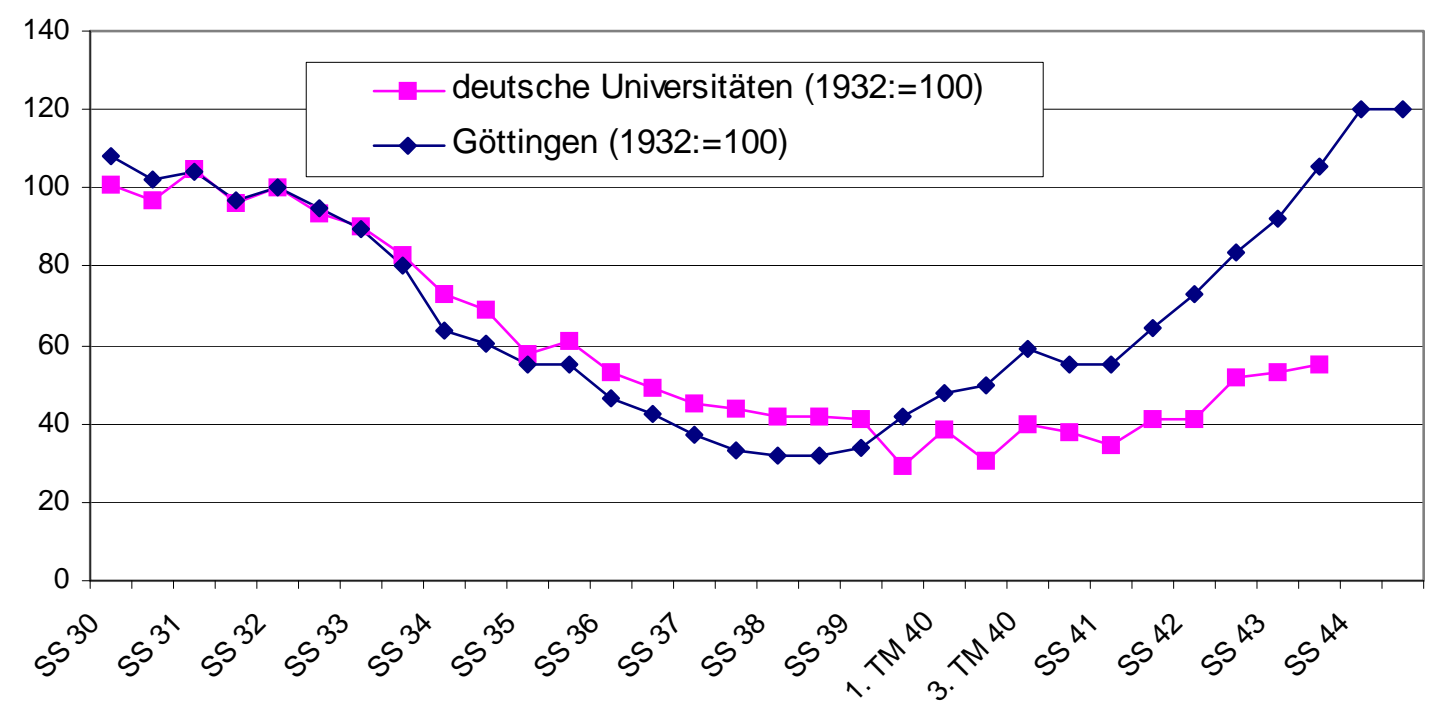

Diagramm 4 Vergleich der relativen Studentenfrequenz der Universität Göttingen mit der gesamtdeutschen Entwicklung von 1930 bis $1944 .{ }^{712}$

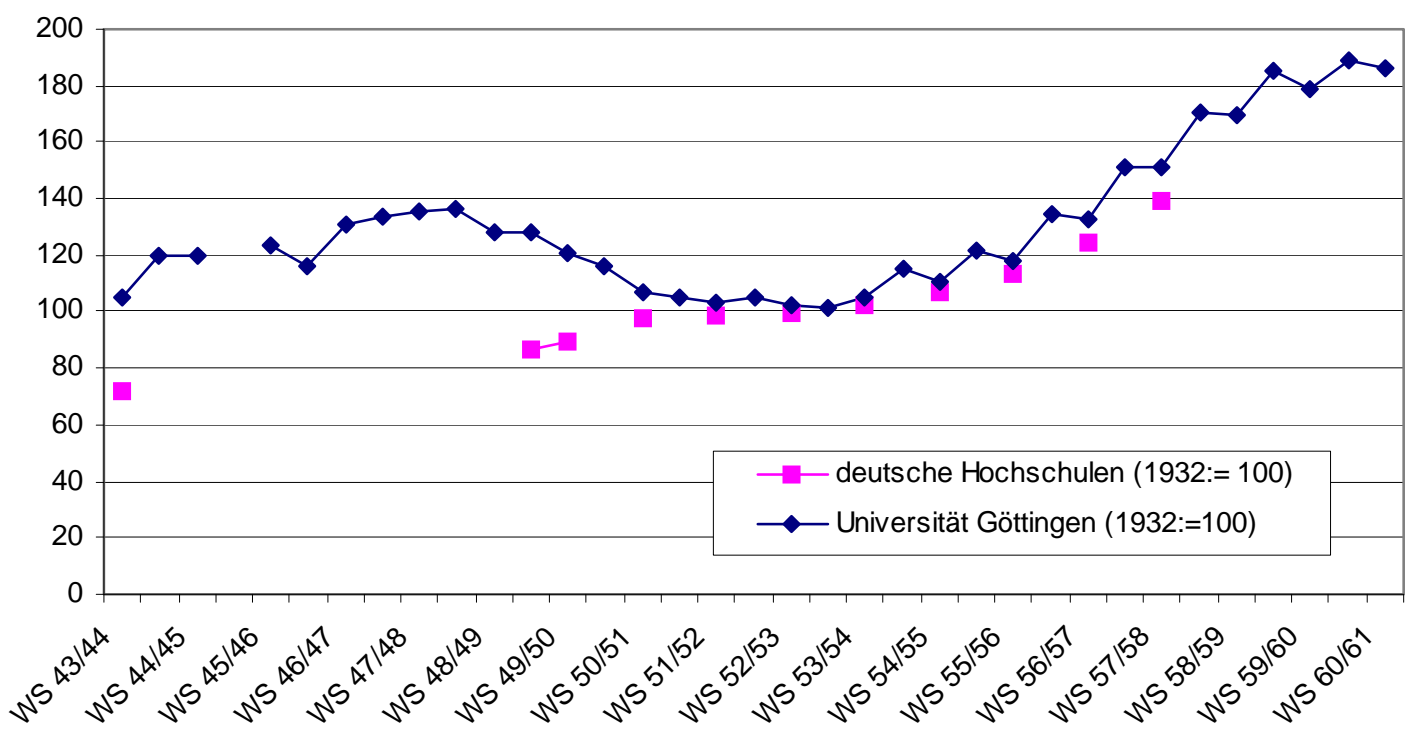

Diagramm 5 Vergleich der relativen Studentenfrequenz der Universität Göttingen mit der gesamtdeutschen Entwicklung (einschließlich technischer Hochschulen) von 1944 bis $1960 . .^{713}$

Wie Diagramm 4 für die Jahre 1930 bis 1944 zeigt, korrespondiert das Auf und Ab der Studentenzahlen in Göttingen gut mit der gesamtdeutschen Entwicklung. Die für den

\footnotetext{
712 Gesamtdeutsche Zahlen nach Titze [1987] S. 30, Tab. 1. Die Göttinger Zahlen stammen aus [Studentenzahlen] [1987].

713 Gesamtdeutsche Zahlen nach Quetsch [1960] S. 42, Tab. 1, wo nur die deutschen Studenten erfasst sind, ohne Gasthörer und Beurlaubte. Die Angabe vom WS 1943/44 bezieht sich auf das deutsche Reichsgebiet einschließlich Österreich, ab 1949 auf die Bundesrepublik, ab 1950 einschließlich West-Berlin. Die Göttinger Zahlen stammen aus [Studentenzahlen] [1987].
} 
reichsweiten Rückgang in den 30er Jahren gefundenen Erklärungen sind demnach auch für Göttingen zutreffend. In Göttingen zeigt sich ein stärkerer Anstieg während des Kriegs, der allerdings etwas irreführend ist, da die zum Kriegsdienst eingezogenen und beurlaubten Studenten in der Statistik mitgezählt werden.

Für die unmittelbare Nachkriegszeit fehlen leider brauchbare Vergleichszahlen. In Diagramm 5 ist der Göttinger Studienfrequenz jene der deutschen Hochschulen gegenübergestellt. Während man für die späten 40er Jahre keine verlässlichen Aussagen treffen kann, so lässt sich für die Zeit der frühen Bundesrepublik ein Unterschied zwischen der Göttinger und der bundesweiten Entwicklung feststellen. Einem kontinuierlichen Wachsen der Gesamtzahlen steht ein Abfallen von 1948 bis 1953 in Göttingen gegenüber. ${ }^{714}$

Einen Überblick über die Zahl der an der Universität Göttingen von 1930 bis 1960 tatsächlich anwesenden Studenten, also ohne Einbeziehung der beurlaubten Studenten, dafür unter Berücksichtigung der Gasthörer, gibt folgendes Diagramm 6.

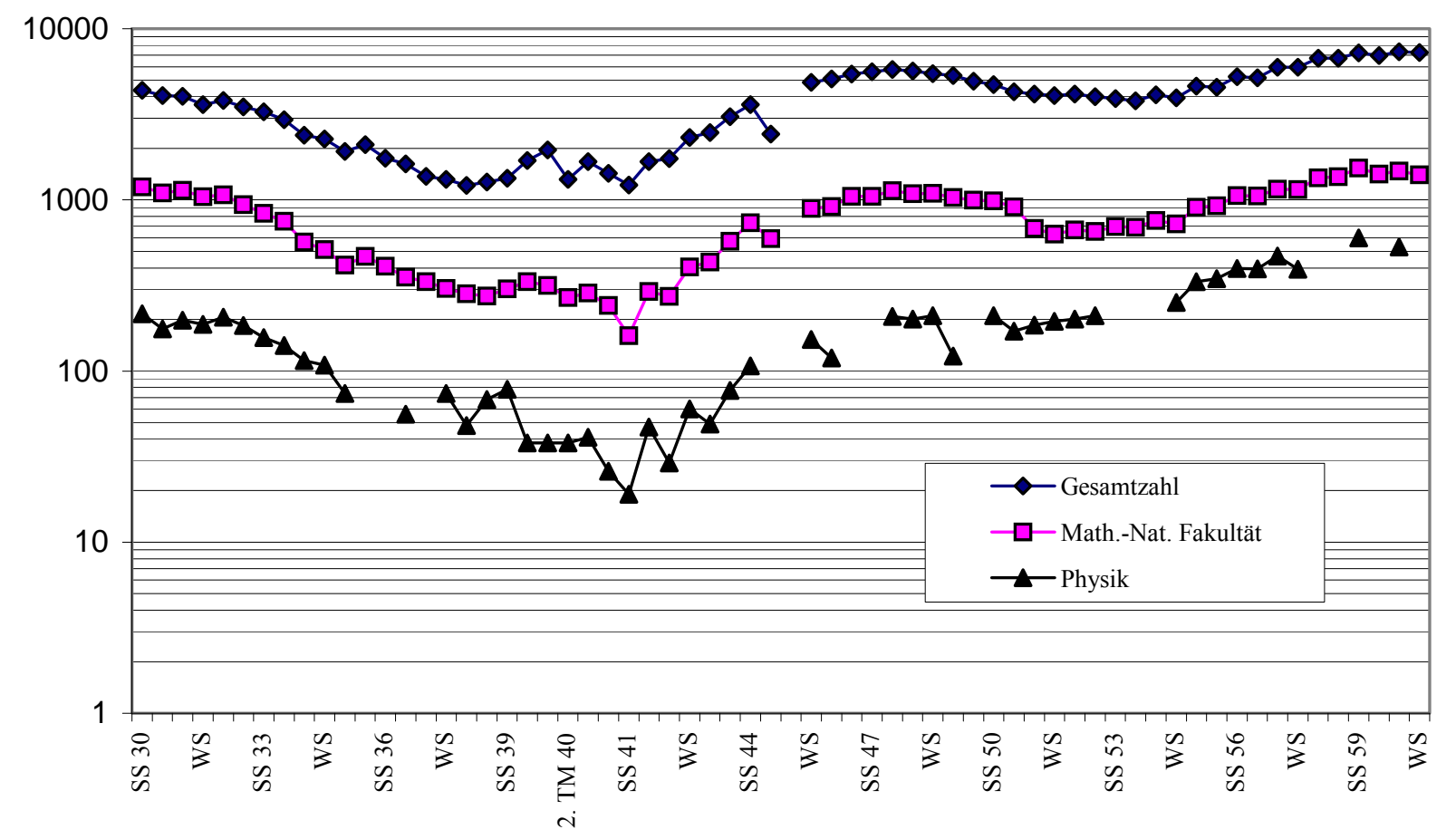

Diagramm 6 Studentenzahlen der Universität Göttingen 1930-1960. ${ }^{715}$

\footnotetext{
714 Dieser Rückgang in Göttingen kontrastiert mit einem starken Wachstum in Braunschweig. An der dortigen TH gab es fast eine Verdopplung der Studentenzahlen im selben Zeitraum, von 1473 (1948) auf 2609 (1953). Siehe Maßß [1998] S. 293.

715 Zahlen nach [Studentenzahlen] [1987], Titze [1995] und Lorenz [1943]a. Vor allem die Nachkriegszahlen der Physikstudenten mussten durch eigene Zählung aus den Studentenverzeichnissen im UAG ermittelt werden. Für die folgenden Semester enthalten die Studentenverzeichnisse nur Angaben über die Zugehörigkeit der
} 
Der Vergleich der Gesamtstudentenzahlen mit jener der mathematisch naturwissenschaftlichen Fakultät und jener der Physik zeigt, dass die Entwicklungen weitgehend parallel verlaufen. Gut erkennbar ist das Sinken in der Zeit des Nationalsozialismus bis in die ersten Kriegsjahre. Ab 1942 steigen die Zahlen wieder an und erzielen im vorletzten Kriegssemester einen Höchstwert, der aber sowohl unterhalb des Standes von 1930 als auch des Niveaus des ersten Nachkriegssemesters lag. Ähnlich wie nach dem Ersten Weltkrieg führte der Ansturm der entlassenen Soldaten auch nach 1945 zu einem Anstieg der Studentenzahlen. Zur Regulierung wurde ein numerus clausus eingeführt, der die Zahlen auf einem konstanten Niveau halten sollte, was aber nur teilweise gelang. Auf den Wegfall der Zulassungsbeschränkung folgte ein stetes Anwachsen der Studentenschaft.

\subsection{Die Entwicklung von 1930 bis zum Kriegsende}

\subsubsection{Der Rückgang in den 30er Jahren}

Die erste naheliegende Erklärung für den Rückgang der Studentenzahlen in den 30er Jahren bietet der allgemeine und wissenschaftspolitische Umschwung, den die nationalsozialistische Diktatur bewirkte. Die Studentenschaft wurde einer politischen „Auslese“ unterzogen, die vor allem linke und „nichtarische“ Studenten traf. Die Zahl der aus politischen Gründen relegierten Studenten war relativ klein. Etwa ein halbes Prozent der Studenten aller Hochschulen (ein Viertel davon Frauen) wurde deshalb auf eine Schwarze Liste gesetzt und nicht mehr zugelassen. In Göttingen waren es genau neun Studenten $(0,3 \%) .{ }^{716}$ Die geringe Auswirkung der politischen Relegierungen korreliert damit, dass linke oder liberale Ansichten unter den Studenten nur schwach vertreten waren. In den letzten Jahren der Weimarer Republik konnten bei AStA-Wahlen nur 10-15\% der Studenten für republikanische oder sozialistische Ideen gewonnen werden. Nur ein Zehntel der Studenten war dem demokratischen Lager zuzurechnen. ${ }^{717}$ Der NSDStB hatte an den deutschen

\footnotetext{
Studenten zu den Fakultäten, nicht aber über ihre gewählten Fächer: WS 1935/36, SS 1936, erstes Trimester 1941, WS 1944/45 (für dieses Semester existiert kein Verzeichnis), WS 1945/46, WS 1946/47, SS 1947, WS 1947/48, WS 1949/50, SS 1950, WS 1950/51, SS 1951 und WS 1952/53.

716 Grüttner [1995] S. 210, 504, Tab. 31.

717 Siehe Grüttner [1995] S. 41. Die weite Verbreitung deutschnationaler Ansichten unter den Studenten betont Weyrather [1981] S. 131f. Zu antisemitischen und frauenfeindlichen Strömungen unter den Studenten siehe Grüttner [1995] S. 481 und Clephas-Möcker \& Krallmann [1992] S. 171. Zur Genese dieser Einstellungen nach 1918 siehe Jarausch [1984] Kap. 4.
} 
Universitäten im SS 1933 einen Mitgliederanteil von etwa 30 \%. In Göttingen waren 47 \% in ihm organisiert. 718

Die antisemitische Politik wirkte sich demgegenüber stärker aus. Während im WS 1932/33 noch 3336 deutsche Studenten jüdischen Glaubens an einer Universität studierten, waren es in den folgenden beiden Jahren nur noch 812 und 538. Das „Gesetz gegen die Überfüllung deutscher Schulen und Hochschulen“ vom 25. April 1933, das den Hochschulzugang insgesamt drosselte, hieß bis kurz vor seiner Verabschiedung „Gesetz gegen die Überfremdung deutscher Schulen und Hochschulen“ und war in erster Linie als Instrument zur Vertreibung der Juden eingerichtet worden. ${ }^{719}$ Auf Grund des neuen Gesetzes durfte der Anteil „nichtarischer“ Studenten $5 \%$ nicht überschreiten. Erstimmatrikulationen jüdischer Studenten waren nur möglich, wenn ihr Anteil unter 1,5\% lag und blieb. Nur insgesamt 49 jüdische Studenten mussten wegen des Überfüllungsgesetzes ihr Studium aufgeben, in Göttingen kein einziger. Auch für die Zahl der Erstimmatrikulationen spielte das Gesetz kaum eine Rolle, denn in Göttingen gab es schon im Jahr 1930 insgesamt nur 48 jüdischen Studenten (1,1\%).720 Auch wenn das Überfüllungsgesetzt nicht das ausschlaggebende Instrument war, wurden die als jüdisch Eingestuften in den ersten fünf Jahren der NS-Diktatur so wirksam aus den Hochschulen vertrieben, dass ihre endgültige Vertreibung nach dem Novemberpogrom 1938 nur noch wenige verbliebene ,jüdische“ Studenten im „Altreich“ traf. Diese Effektivität wurde durch verschiedene Maßnahmen erreicht: Jüdischen Abiturienten wurde die Hochschulreife verweigert, die antisemitischen Politik verschlechterte die materielle Situation für Juden und erschwerte damit ein Studium. Besonders ausgrenzend wirkte die Regelung der Arbeitsdienstpflicht. Die bis dahin freiwillige Ableistung dieses Dienstes wurde ab 1934 für die Erstimmatrikulation verpflichtend. Da für den Dienst ab Juni 1935 der „Arier-Nachweis“ erforderlich war, wurde den „Nichtariern“ dadurch das offizielle Studium unmöglich. ${ }^{721}$ In den Kriegsjahren wurden die Maßnahmen gegen die sogenannten „Mischlinge“ verschärft, sodass diese 1944 nur noch 0,5 \% aller Studenten ausmachten. Die meisten „Mischlinge“ studierten in Wien und München. ${ }^{722}$ Das durch diese Vertreibungen und die sich anschließenden Verfolgungen zugefügte menschliche Leid war beklemmend groß, die Auswirkung auf die Größe der Studentenschaft unauffällig klein. In Summe

\footnotetext{
718 Grüttner [1995] S. 246.

719 Huerkamp [1996]a S. 80.

720 Grüttner [1995] S. 213f, 495, Tab. 24.

${ }^{721}$ Huerkamp [1996]a S. 88. Grüttner [1995] S. 215ff.

722 Grüttner [1995] S. 220ff.
} 
bewirkte die Vertreibung der Juden und „Nichtarier“ einen Rückgang der Studentenzahlen um etwa 3-4 \%. ${ }^{723}$

Unter dem Eindruck der Überfüllungskrise hatten die Kultusminister der Länder noch vor der nationalsozialistischen Gleichschaltung im Februar 1933 eine Beschränkung des Hochschulzugangs vereinbart. Für das Jahr 1934 wurde dieser Politik folgend vom Reichsinnenministerium die Zahl der Abiturenten mit Hochschulreife (Studienerlaubnis) auf maximal 15000 begrenzt. Diese Maßnahme war aber schon früh umstritten, und als die hochschulpolitische Entscheidungskompetenz 1934 an das neu gegründete Reichserziehungsministerium überging, nahm man von solchen Beschränkungen Abstand. Die Hochschulkommission der NSDAP wies Ende 1934 auf die Gefahr eines künftigen Nachwuchsmangels in den akademischen Berufen hin und warnte vor einer zahlenmäßigen Beschränkung der Studenten. Ab Februar 1935 gab es keinen Hochschulreifevermerk mehr und damit weitgehend freien Zugang zur Hochschule. ${ }^{724}$

Für den trotzdem anhaltenden Rückgang der Studentenzahlen war die in der bisherigen Forschung oft betonte wissenschaftsfeindliche Politik des Nationalsozialismus nur ein Moment unter vielen. Grüttner versucht das Bild zurechtzurücken und meint, dass die Hochschulpolitik des NS-Staates für die Entwicklung der Studentenzahlen weniger wichtig war, als lange Zeit angenommen. ${ }^{725}$ Bei genauerer Betrachtung fällt auf, dass die Zahlen in Göttingen schon seit 1930 (der gesamten Hochschulen seit 1931) abfallen und nicht erst nach der Regierungsübernahme der Nationalsozialisten. Pauwels machte deutlich, dass sich hier die geburtenschwachen Jahre des Ersten Weltkriegs auswirkten. Die Geburtenzahl sank zwischen 1913 und 1918 auf die Hälfte (von 1,8 Millionen auf 926000), sodass sich damit zum Teil erklärt, warum die Studentenzahlen an den deutschen Universitäten von 1932 (98852) bis 1937 (44467) um etwas mehr als die Hälfte zurück gingen. ${ }^{726}$ Dieser starke Rückgang wurde schon Anfang März 1933 und damit noch vor der eigentlichen Gleichschaltung von der „Volkswirtschaftlichen Zentralstelle für Hochschulstudium und akademisches Berufswesen“ prognostiziert. 727 Inwieweit war diese Entwicklung durch die demografische Ausgangslage vorherzusehen, und welche Rolle spielten andere Faktoren?

\footnotetext{
723 Grüttner [1995] S. 106.

724 Grüttner [1995] S. 102f. Der Hochschulreifevermerk wurde im Dezember 1933 eingeführt und im Februar 1935 wieder abgeschaff.

725 Grüttner [1995] S. 103.

726 Siehe Pauwels [1984] S. 37 und die tabellarische Auflistung der Geburtenzahlen auf S. 144, Tab. 1;

Studentenzahlen nach Titze [1987] S. 30, Tab. 1.

727 Grüttner [1995] S. 103.
} 
Die bisherige Forschung gibt in der Gewichtung des demografischen Faktors nur vorsichtige Einschätzungen an, die darauf basieren, die Größe der Studentenschaft mit dem Anteil der 18bis 25-jährigen Bevölkerung zu vergleichen. ${ }^{728}$ Hier soll ein anderer Weg beschritten werden. Zur vereinfachten Abschätzung des Rückgangs nur auf Grund der rückläufigen Geburtenzahlen müssen zuerst einige vereinfachende Annahmen getroffen werden. Die Abiturientenquote und die Studienanfängerquote des Jahres 1932 werden zur Grundlage der Berechnung herangezogen und für die folgenden Jahre als konstant angenommen; außerdem wird das Studienanfängeralter mit 19 Jahren angesetzt. Es werden deshalb die Daten von 1932 als Ausgangsbasis der Berechnung gewählt, da die geburtenschwachen Jahrgänge der Jahre 1914f. sich erst ab 1933 auswirkten. ${ }^{729}$ Mit diesen Annahmen lassen sich die zu erwartenden jährlichen Zugänge $\mathrm{zu}$ den Universitäten nur unter Hinzuziehung der Geburtenzahlen von jeweils 19 Jahre zuvor errechnen. ${ }^{730}$

Kurz gesagt berechne ich: Stud-Anf $f_{\mathrm{t}}=\mathrm{Geb}_{\mathrm{t}-19} * \mathrm{Abi}^{-\mathrm{Qu}_{1932}} *$ St-Qu $\mathrm{u}_{1932}$

Stud-Anf $\mathrm{t}_{\mathrm{t}}$... Anzahl der Studienanfänger im Jahr t

$\mathrm{Geb}_{\mathrm{t}-19} \ldots$ Geburtenzahl im Jahr t-19

Abi-Qu 1932 ... Abiturientenquote des Jahres 1932

St-Qu ${ }_{1932} \ldots$ Studienanfängerquote des Jahres 1932 $\mathrm{t}=1933,1934, \ldots, 1937$

Um die Entwicklung der Gesamtzahl prognostizieren zu können, müssen aber auch die voraussichtlichen jährlichen Abgangszahlen abgeschätzt werden. Erst die Differenz aus errechnetem Zugang und Abgang führt zu Aussagen über die Gesamtentwicklung. In den Jahren 1926 bis 1930 gab es ein großes Wachstum der Studentenschaft; die Gesamtzahl stieg in relativ gleichmäßigen Schritten um jährlich 8300. Der mittlere jährliche Zugang an neuen Studenten betrug $21100 .{ }^{731}$ Folglich gab es nur 12800 Studienabgänge (d. h. Absolventen plus Abbrecher) pro Jahr. Die Universitäten waren auf einem Höhepunkt einer zyklischen Wellenbewegung; sie wirkten wie künstlich aufgeblasen. ${ }^{732}$ Es ist sofort einsichtig, dass diese

\footnotetext{
728 Mertens [1991] S. 106 gibt vorsichtige Schätzungen an, nach denen der tatsächliche Rüchgang der Studentenzahlen bis 1938 zu einem Viertel bis zur Hälfte durch die Geburtenrückgänge zu erwarten gewesen sei. Jarausch [1984] S. 179 berechnete, dass der Studentenrückgang von 1932 bis 1939 zu zwei Fünftel auf den demografischen Faktor zurückzuführen sei. Er bezog den Rückgang auf den Anteil der 18- bis 25-jährigen Bevölkerung. Wie die Berechnung im Einzelnen durchgeführt wurde, bleibt offen. Eine grafische Darstellung des demografischen Einflusses auf die Studentenfrequenz, die ebenfalls auf den Anteil der 18- bis 25-jährigen Bevölkerung bezogen ist, gibt Titze [1987] S. 75. Zur Konstruktion der Grafik siehe dort auch S. 68f.

${ }^{729}$ Die schwächsten Jahrgänge 1915 bis 1918 legten zwischen 1934 und 1937 ihr Abitur ab. Huerkamp [1996]a S. 60 .

730 Die für die folgenden Berechnungen herangezogenen Daten stammen sämtlich aus Titze [1987].

731 Dabei zeigen die Anfängerzahlen eine leicht steigende Tendenz: 1926 waren es 19013 und 1929 22952, das Maximum war 1928 mit 23359. Die Zahlen sind entnommen aus Titze [1987] S. 189, Tab. 89.

732 Zu den zyklischen Schwankungen der Studentenzahlen siehe Nath [1988]; Titze [1990]. Titze zeigt, dass der Studentenboom 1930 zu einem großen Anteil demografisch bedingt war; siehe S. 468.
} 
Entwicklung nicht unverändert fortbestehen konnte. Die hohen Anfängerzahlen mussten später zu entsprechend hohen Abgängen führen. Die Abgängerzahlen der Jahre 1932 bis 1937 hingen ursächlich mit den Anfängerzahlen der vorhergehenden vier bis fünf Jahre zusammen. Zur Vereinfachung wird als jährliche Abgangszahl die Anfängerzahl von vier Jahren zuvor angenommen. ${ }^{733}$

Zur Berechnung der Gesamtzahlen benutze ich: G-Stud $_{t}=$ G-Stud $_{\mathrm{t}-1}+$ Stud-Anf $_{\mathrm{t}}-$ Stud-Anf $_{\mathrm{t}-4}$ G-Stud $_{\mathrm{t}} \ldots$.. Gesamtstudentenzahl im Jahr t.

G-Stud $\mathrm{t}-1$... Gesamtstudentenzahl im Jahr t-1.

Stud-Anf $\mathrm{t}_{\mathrm{t}} .$. Anzahl der Studienanfänger im Jahr t.

Stud-Anf ${ }_{\mathrm{t}-4} \ldots$ Anzahl der Studienanfänger im Jahr t-4. ${ }^{734}$

$\mathrm{t}=1933,1934, \ldots, 1937$

Damit ergibt sich für das Jahr 1937 eine zu erwartende Gesamtstudentenzahl von 56400. Die tatsächliche Zahl war 44467. ${ }^{735}$ Diese Ergebnis bedeutet zweierlei: Erstens gibt es einen unabhängig von politischen Steuerungsversuchen und wirtschaftlichen Entwicklungen zu erwartenden Rückgang der Studentenzahlen in der Größe von etwa 43 \% bezogen auf das SS 1932. Tatsächlich nahmen die Zahlen aber um 55 \% ab. Daher ist zweitens zu schließen, dass der demografische Faktor 78 \% des tatsächlichen Rückgangs erwarten ließ.

Zur Interpretation des Ergebnisses muss darauf hingewiesen werden, dass in die Berechnung die rückläufige Tendenz der ersten 30er Jahre insofern mit einfloss, als die Prognose des Absinkens der Erstimmatrikulationen ausgehend von der Abiturienten- und Studienanfängerquote des Jahres 1932 berechnet wurde. Die Anfängerzahl war aber 1932 durch die Wirtschaftkrise und die schlechten Berufsaussichten schon auf einem niedrigeren Wert als zum Beispiel ein und zwei Jahre zuvor.

Die Berechnung zeigt aber, wie erheblich der ab 1931/32 zu verzeichnende Abfall der Studenten- und vor allem Anfängerzahlen durch die Geburtenausfälle im Ersten Weltkrieg verstärkt wurde. Gelegentlich wurde das schon früh einsetzende Sinken als Argument gegen einen bedeutenden demografischen Einfluss und für einen stärkeren Einfluss der NS-Politik angeführt. ${ }^{736}$ Deshalb soll hier betont werden, dass der demografische Faktor zwar einerseits 'nur' als Verstärker wirkte, aber in dieser Weise eben für etwa drei Viertel des Rückgangs verantwortlich war.

\footnotetext{
733 Zur durchschnittlichen Studiendauer siehe Quetsch [1960] S. 32. Lorenz [1943]b S. 252ff. Ein Durchschnitt von 8 bis 9 Semestern Studiendauer scheint demnach angemessen zu sein.

734 Für die Jahre bis 1932 wurden die tatsächlichen Anfängerzahlen eingesetzt, für das Jahr 1933 hingegen die durch den Geburtenverlauf erwarteten 19019 statt der tatsächlichen 15972.

735 Titze [1987] S. 30, Tab. 1.

736 Huerkamp [1996]a S. 307f. Huerkamp [1996]b S. 326.
} 
Eine Stütze dieser These liefert die Studentenentwicklung der TH Wien. Dort sank die Gesamtzahl der Studenten von 1932 bis 1937 um $45 \%$. In Wien ist von einer ähnlichen wirtschaftlichen und demografischen Ausgangslage auszugehen, aber von der nationalsozialistischen Politik war Österreich damals noch nicht betroffen. ${ }^{737}$

Da für die Berechnung nur Daten aus den Jahren vor 1933 verwendet wurden, kann aus der Differenz zur tatsächlichen Zahl die Wirkung der politischen Maßnahmen des Nationalsozialismus abgeschätzt werden. Es wurde oben schon gezeigt, mit welchen Mitteln die Vertreibung der „Nichtarier“ durchgesetzt wurde. Auf Grund des jüdischen Studentenanteils kurz vor 1933 wäre zu erwarten gewesen, dass von 1932 bis 1937 insgesamt etwa 3000 jüdische Studienanfänger an die Universitäten gekommen wären. ${ }^{738} \mathrm{Ihr}$ Ausbleiben in die für 1937 prognostizierte Zahl mit eingerechnet ergibt 53400. Die zur wirklichen Studentenzahl verbleibende Differenz von 8900 lässt sich mit einer Vielzahl von Gründen, die in der einschlägigen Literatur angeführt werden, verständlich machen. Die Überfüllungskrise der ausgehenden Weimarer Republik wirkte sich negativ auf die Studierwilligkeit aus. Dies erkennt man anhand der Daten aus Tabelle 1. Während die Abiturientenzahl von 1931 auf 1932 zunahm, nahm die Studierwilligkeit von 66,5 \% der Abiturienten auf 51,9\%, und die Zahl der Studienanfänger von 54,3\% auf 44,4 \% ab. Dieser Trend sinkender Anfängerzahlen setzte sich bis 1937 fort und zwar in viel stärkerem Maß als die Geburtenausfälle des Ersten Weltkriegs erwarten ließen. Im Gegensatz $\mathrm{zu}$ den Studienanfängern blieben die Abiturientenzahlen über den Werten, die die demografische Lage erwarten ließen. Zu erkennen ist ein deutlicher Trend zur vermehrten höheren Schulbildung. Die Abiturientenrate stieg bis 1937 an und war dann doppelt so hoch wie 1928. 739 Zusammengefasst gesagt gab es zwar immer mehr Abiturienten (bezogen auf den gleichaltrigen Bevölkerungsanteil), aber immer weniger von ihnen wollten studieren.

\footnotetext{
737 Studentenzahlen der TH Wien aus Mikoletzky [1997]a S. 116, Tab. 4.1. Allerdings gab es auch in Österreich ab 1933 ein Gesetz gegen die „Überfüllung der österreichischen Hochschulen“, das sich vor allem gegen ausländische Studenten richtete. (S. 115ff.). Trotzdem kamen in Österreich im Jahr 1937 auf 10000 Einwohner 26 Studenten. Damit lag Österreich im europäischen Vergleich an der Spitze. Das deutschen Reich lag mit nur 9 Studenten je 10000 Einwohner am Schluss der Liste. Siehe Quetsch [1960] S. 13.

${ }^{738}$ Da ich keine Angaben über den jüdischen Anteil an den Erstsemestern bis 1933 gefunden habe, ist dieser Berechnung der Anteil jüdischer Studenten von 1932/33 (4,695 \%) zugrunde gelegt. Von den prognostizierten 64000 Neuzugängen der Jahre 1932 bis 1937 wären erwartungsgemäß 3000 Juden gewesen.

739 Siehe Titze [1987] S. 173, Tab. 78. In Spalte 4 kam es allerdings zu einem Druckfehler bei der Angabe der männlichen Bevölkerung von 1937. Als Folgefehler ist in Spalte 5 eine falsche Quote angeführt. Vermutlich sollte 299510 statt 599510 in Spalte 4 stehen, was zu einer Quote von 7,67 führt statt der angegebenen 3,82.
} 


\begin{tabular}{|l|l|l|l|l|l|l||l|l|}
\hline $\begin{array}{l}\text { Jahr } \\
740\end{array}$ & gesamt & $\begin{array}{l}\text { davon stu- } \\
\text { dierwillig }\end{array}$ & männlich & $\begin{array}{l}\text { davon stu- } \\
\text { dierwillig }\end{array}$ & weiblich & \multicolumn{2}{|l||}{$\begin{array}{l}\text { davon stu- } \\
\text { dierwillig }\end{array}$} & \multicolumn{2}{|l|}{$\begin{array}{l}\text { Geburtenzahlen } \\
741\end{array}$} \\
\hline 1931 & 40630 & 27022 & 31086 & 20939 & 9544 & 6083 & & \\
\hline 1932 & 43214 & 22413 & 32363 & 17788 & 10851 & 4625 & 1913 & 1838750 \\
\hline 1933 & 43559 & & & & & & 1914 & 1818596 \\
\hline 1934 & 40215 & & & & & & 1915 & 1382546 \\
\hline 1935 & 31814 & 15103 & 24750 & 12593 & 7064 & 2510 & 1916 & 1029484 \\
\hline 1936 & 25811 & 12445 & 20725 & 10676 & 5086 & 1769 & 1917 & 912109 \\
\hline 1937 & 43150 & & 39134 & & 4016 & & 1918 & 926813 \\
\hline 1938 & 37650 & 20100 & 29986 & 17153 & 7664 & 2947 & 1919 & 1260500 \\
\hline 1939 & 45361 & 25545 & 36281 & 21633 & 9080 & 3912 & 1920 & 1599287 \\
\hline 1940 & 55363 & & 36991 & & 18372 & & 1921 & 1581130 \\
\hline 1941 & 49970 & & 36681 & & 13289 & & 1922 & 1424804 \\
\hline
\end{tabular}

Tabelle 1 Abiturienten deutscher, öffentlicher und privater Schulen ${ }^{744}$ in Gegenüberstellung mit den Geburtenzahlen jeweils 19 Jahre zuvor.

\begin{tabular}{|c|c|c|c|c|c|c|}
\hline $\mathrm{Jahr}^{745}$ & gesamt & männlich & weiblich & Physik gesamt & $\begin{array}{l}\text { Physik } \\
\text { männlich }\end{array}$ & $\begin{array}{l}\text { Physik } \\
\text { weiblich }\end{array}$ \\
\hline 1930 & 22572 & 17351 & 5221 & 275 & 239 & 36 \\
\hline 1931 & 22047 & 16921 & 5126 & 240 & 210 & 30 \\
\hline 1932 & 19203 & 15148 & 4055 & 197 & 163 & 34 \\
\hline 1933 & 15972 & 12879 & 3093 & 143 & 127 & 16 \\
\hline 1934 & 9298 & 7856 & 1442 & 92 & 86 & 6 \\
\hline 1935 & 10972 & 8840 & 2132 & & & \\
\hline 1936 & 6657 & 5183 & 1474 & & & \\
\hline 1937 & 8964 & 7622 & 1342 & & & \\
\hline 1938 & 8811 & 7135 & 1676 & & & \\
\hline 1939 & 12566 & 10483 & 2083 & & & \\
\hline 1940 & 22662 & 14985 & 7677 & & & \\
\hline
\end{tabular}

Tabelle 2 Die Studienanfänger an deutschen Universitäten. ${ }^{746}$

Welche Faktoren waren ausschlaggebend, dass immer weniger Abiturienten ein Studium anfingen - 1937 beispielsweise nur noch $21 \%$ ? Grüttner nennt zwei wesentliche Gründe:

1. Die hoffnungslose Lage auf dem akademischen Arbeitsmarkt. Sie führte dazu, dass ein Studium ohne Perspektive erschien; folglich kam es ab 1932 auch häufiger zu Studienabbrüchen, besonders bei den Frauen. Die allgemeine Wirtschaftskrise und die

\footnotetext{
740 Sommersemester plus nachfolgendes Wintersemester sind hier zusammengefasst.

741 Powels [1984] S. 144, Tab. 1.

742 Auf Grund der Verkürzung der Schulzeit an den höheren Schulen verließen 1937 zwei Abiturientenjahrgänge gleichzeitig die Schulen. Grüttner [1995] S. 105.

743 Auf Grund der Verkürzung der Schulzeit an den Mädchenschulen verließen 1940 zwei Abiturientenjahrgänge gleichzeitig die Schulen. Huerkamp [1996]a S. 63.

744 Abiturientenzahlen nach Titze [1987] S. 181, Tab. 83. Laut Huerkamp handelt es sich bei dieser Tab. 83 entgegen der Überschrift um die Abiturienten des deutschen öffentlichen und privaten Schulwesens. Huerkamp [1996]a Anmerkung 56 zu S. 59.

745 Sommersemester plus nachfolgendes Wintersemester sind hier zusammengefasst.

746 Errechnet nach Titze [1987] S. 189, 193, Tab. 89.
} 
Schwierigkeiten der Studienfinanzierung ließen ein Studium mehr denn je als Luxus erscheinen, den sich entsprechend weniger Menschen leisten konnten.

2. Die gewachsene Attraktivität anderer Berufe. Die expandierende Wirtschaft und vor allem die Wehrmacht lockte zahlreiche Abiturienten an. Die forcierte Aufrüstungspolitik ließ eine Offizierslaufbahn wieder lukrativ erscheinen. ${ }^{747}$

Von geringerer Bedeutung war das Ressentiment gegen den „Intellektualismus“, das zu einer anfänglichen, wissenschaftsfeindlichen Einstellung der NS-Regierung führte, die vor allem das Prestige der Universitäten schwächte. Die Einführung der halbjährigen Arbeitsdienstpflicht $1934^{748}$ und der allgemeinen Wehrpflicht 1935 hatten zur Folge, dass der Einstieg ins Berufsleben wie der Studienbeginn um bis zu zweieinhalb Jahre verzögert wurde, ${ }^{749}$ und daher manche Abiturienten auf ein Studium gänzlich verzichteten. Folglich sanken die Anfängerzahlen der Jahre ab 1935, und es kam nach 1937 nicht sofort zu dem auf Grund der geburtenstärkeren Nachkriegsjahrgänge $\mathrm{zu}$ erwartenden Anwachsen der Studienanfängerzahlen. ${ }^{750}$ Ein anderes Bild ergibt sich, wenn man nur die Frauen betrachtet, bei denen der bis zu zweieinhalb Jahre dauernde Wehrdienst keine Rolle spielte. Dort ist der Tiefstand tatsächlich 1937 erreicht. Danach ist ein Wachstum sowohl bei den Abiturientinnen als auch den Erstsemestern festzustellen. Was das Frauenstudium betrifft, sind allerdings die nicht-demografischen Einflüsse von größerer Wirkung als bei den Männern gewesen (siehe dazu Abschnitt 2.4).

In den Naturwissenschaften vollzog sich eine Schwerpunktverlagerung, die durch die unterschiedlichen Karrierechancen ausgelöst wurde. Das Chemiestudium gewann an Zustrom, während die stärker theoretisch ausgerichteten Fächer Mathematik und Physik an Bedeutung verloren. Eine monokausale Erklärung durch Theoriefeindlichkeit wäre jedoch zu vereinfachend, denn bis Kriegsbeginn verzeichneten Biologie, Geographie, Geologie und Mineralogie einen noch stärkeren Rückgang als die Physik. ${ }^{751}$ Die Physik verlor von 1932 bis zum Kriegsbeginn zwei Drittel ihrer Studenten. Dieser Verlust war auch in Göttingen zu verbuchen. Wie Diagramm 7 und Diagramm 8 zeigen, verläuft die Göttinger Entwicklung parallel zur gesamtdeutschen - bei den Frauen wie bei den Männern. Eine Untersuchung an

\footnotetext{
${ }^{747}$ Grüttner [1995] S. 104f. Huerkamp [1996]a S. 308 nennt die schlechten Berufsaussichten infolge der 'Überfüllungskrise' als den entscheidenden Faktor für den Rückgang der Studentenzahlen in den 30er Jahren.

748 Huerkamp [1996]a S. 83.

$749 \mathrm{Ab} 1935$ mussten die tauglichen Männer zusätzlich zum Arbeitsdienst bei der Reichswehr ein Jahr dienen, ab 1937 zwei Jahre. Huerkamp [1996]a S. 86.

750 Jarausch [1984] S. 179 gibt für 1938/39 an, dass 80,5 \% der männlichen Studienanfänger zum Arbeitsdienst und $60 \%$ zum Militärdienst mussten.
} 
22 der damals 23 existierenden Hochschulen ergab, dass das Maximum der Besucherzahlen der Physik-Anfängervorlesung im Jahr 1930 lag und bis zum WS 1937/38 auf etwa 40 \% zurückging. ${ }^{752}$

Der spürbare Nachwuchsmangel in der Physik wurde von Physikprofessoren 1936 als ein Argument in der Auseinandersetzung um die „Deutsche Physik“ genutzt. Die große Gruppe der Gegner der „Deutschen Physik“ versuchte, sich mit dem Studentenargument in der ideologischen Streitigkeit durchzusetzen. 75 Physiker unterzeichneten eine Eingabe an Reichserziehungsminister Rust, in der sie die Anerkennung der modernen theoretischen Physik als notwendig bezeichneten, da sie sonst ein noch stärkeres Fernbleiben der Studenten befürchteten. ${ }^{753}$

Das Erziehungsministerium bemühte sich ebenfalls um eine Erhöhung der Physikstudentenzahlen. Im August 1937 wies es die Studentenwerke an, die mittleren Semester sowie die neu zur Hochschule kommenden Studenten auf den starken Nachwuchsbedarf in Physik und Chemie hinzuweisen und eine Umstellung auf diese Fachgebiete zu empfehlen. ${ }^{754}$

Lorenz schlüsselt die akademischen Abschlussprüfungen in Physik nach Prüfungsorten für die Jahre 1933 und 1939 auf. Göttingen liegt in dieser Statistik an zweiter und dritter Stelle:

\begin{tabular}{|c|c|c|c|c|c|c|c|}
\hline \multirow[t]{5}{*}{ 1933: } & 1) & Berlin & $14,7 \%$ & \multirow{5}{*}{1939} & 1) & Wien & $27,6 \%$ \\
\hline & \multirow[t]{2}{*}{ 2) } & Wien & $12,6 \%$ & & 2) & Hamburg & $10,2 \%$ \\
\hline & & Göttingen & $12,6 \%$ & & 3) & Göttingen & $9,8 \%$ \\
\hline & 4) & Jena & $8,1 \%$ & & 4) & Berlin & $8,7 \%$ \\
\hline & 5) & München & $5,1 \%$ & & 5) & Jena & $7,1 \%$ \\
\hline
\end{tabular}

Tabelle 3 Anteile der Universitäten an den Abschlussprüfungen in Physik. ${ }^{755}$

\footnotetext{
751 Titze [1987] S. 142ff., Tab. 52-55.

752 Wien [1938/44]a S. 55.

753 Siehe die von Werner Heisenberg, Hans Geiger und Max Wien verfasste Denkschrift an Reichsminister Bernhard Rust, abgedruckt in Hoffmann [1989] S. 206-208; in englischer Übersetzung in Hentschel \& Hentschel (Hrsg.) [1996] S. 137-140.

754 Erlass des REM betreffend Bedarf an Physikern und Chemikern vom 17. August 1937. UAG, Rek. $4106^{\circ} \mathrm{u}$. b.

755 Lorenz [1943]b S. 26.
} 


\begin{tabular}{|l|l|l|l|}
\hline Jahr & \multicolumn{4}{|l|}{ Physik-Doktorprüfungen } & \\
\hline & zusammen & männl. & weibl. \\
\hline 1932 & 200 & 184 & 16 \\
\hline 1933 & 207 & 188 & 19 \\
\hline 1934 & 240 & 214 & 26 \\
\hline 1935 & 268 & 249 & 19 \\
\hline 1936 & 238 & 221 & 17 \\
\hline 1937 & 255 & 221 & 34 \\
\hline 1938 & 247 & 219 & 28 \\
\hline 1939 & 262 & 238 & 24 \\
\hline 1940 & 152 & 128 & 24 \\
\hline $1941^{756}$ & 75 & 69 & 6 \\
\hline
\end{tabular}

Tabelle 4 Anzahl der Physik-Doktorprüfungen in „Großdeutschland“ 1932-1941. ${ }^{757}$

Durch die hohen Studentenzugangszahlen vor 1933 nahm die Zahl der PhysikDoktorprüfungen bis 1939 zu (siehe Tabelle 4). Der hohe Frauenanteil der Physikdoktoranden liegt vor allem an der Universität Wien, die fast zwei Drittel aller Physikstudentinnen „Großdeutschlands“ promovierte (von 1932 bis 1941137 der gesamt 213). In Wien lag der Frauenanteil unter den Physik-Promovenden bei 35 \%. An den österreichischen Universitäten Wien, Innsbruck und Graz hielt der hohe Frauenanteil an den Promotionen bis zum Kriegsende an und sank dann jäh ab. ${ }^{758}$ An den restlichen Hochschulen des „Großdeutschen Reichs“ zusammen lag er bei 4,4 \%, an den bei Lorenz einzeln aufgelisteten 26 Universitäten ohne Wien bei 4,1\%,759 im ,Altreich“760 wie auch in Göttingen bei 3,4 \%. ${ }^{761}$

\begin{tabular}{|l|l|l|l|l|l|l|}
\hline Jahr & Physik-Diplomprüfungen & \multicolumn{2}{l|}{ Physik-Vorprüfungen } \\
\hline & zusammen & männl. & weibl. & zusammen & männl. & weibl. \\
\hline 1932 & 65 & 64 & 1 & 104 & 100 & 4 \\
\hline 1933 & 93 & 88 & 5 & 98 & 95 & 3 \\
\hline 1934 & 83 & 81 & 2 & 112 & 103 & 9 \\
\hline 1935 & 99 & 91 & 8 & 96 & 95 & 1 \\
\hline 1936 & 104 & 99 & 5 & 67 & 63 & 4 \\
\hline 1937 & 108 & 104 & 4 & 86 & 84 & 2 \\
\hline 1938 & 82 & 81 & 1 & 81 & 80 & 1 \\
\hline 1939 & 117 & 112 & 5 & 84 & 83 & 1 \\
\hline 1940 & 72 & 68 & 4 & 85 & 76 & 9 \\
\hline $1941^{762}$ & 35 & 35 & & 36 & 31 & 5 \\
\hline
\end{tabular}

Tabelle 5 Anzahl der Physik-Vor- und Diplomprüfungen an Technischen Hochschulen im „Altreich“ 1932-1941. ${ }^{763}$

\footnotetext{
756 Nur erstes Halbjahr.

${ }^{757}$ Lorenz [1943]b S. 128f., 142f. Hier sind auch die nichtbestandenen Prüfungen mitgezählt, die etwa 3-4 \% ausmachen; siehe S. 70f., 88f. Eine Gliederung der Nichbestandenen nach Geschlecht erlauben S. 84f, 86f.

758 Waldl [1968] S. 98f.

759 Lorenz [1943]b S. 172f.

760 Lorenz [1943]b S. 104f.

761 Lorenz [1943]b S. 172f.

762 Nur erstes Halbjahr.
} 
Entgegen den allgemein sinkenden Studentenzahlen ist an den Vordiplom- und Diplomprüfungszahlen in Physik an den Technischen Hochschulen kein deutliches Absinken bemerkbar (siehe Tabelle 5). Der Frauenanteil bei den Vorprüfungen war in diesen zehn Jahren im Mittel 4,6 \%, bei den Diplomprüfungen 4,1\%.

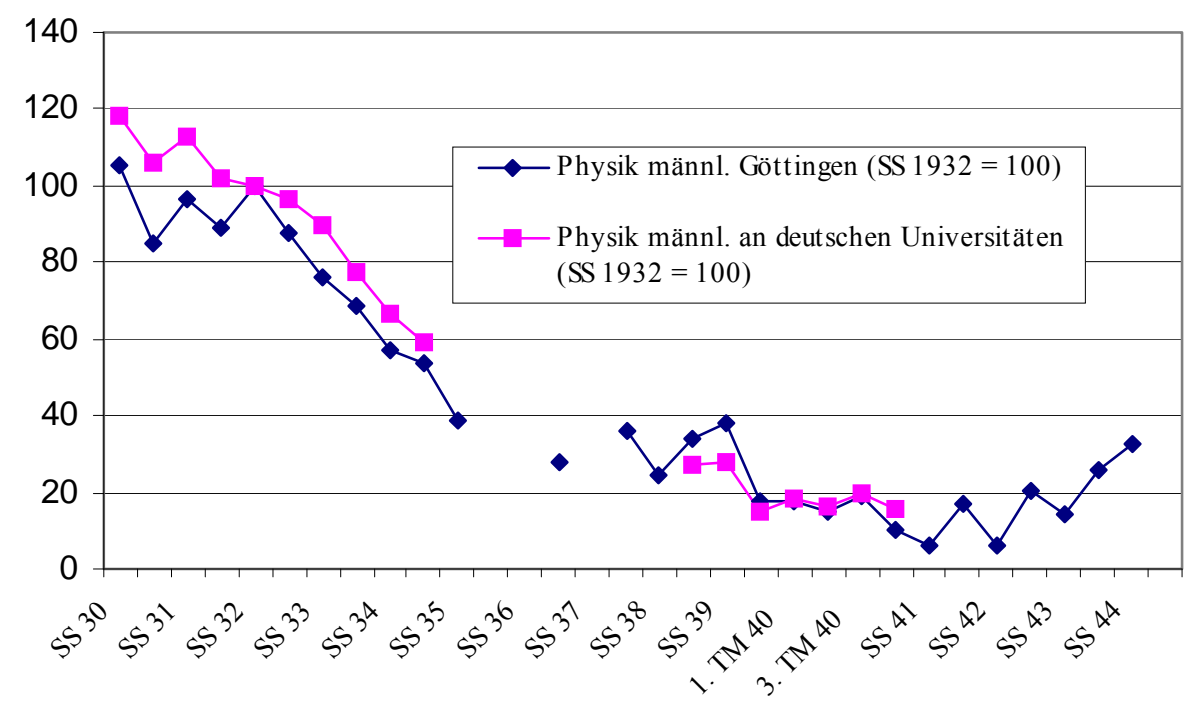

Diagramm 7 Vergleich der männlichen Physikstudenten der Universität Göttingen mit der gesamtdeutschen Entwicklung 1930-1944. ${ }^{764}$

\subsubsection{Studenten im Krieg}

Die 'Überfüllungskrise' der frühen 30er Jahre hatte sich schon vor Beginn des Krieges in einen Nachwuchsmangel verwandelt. Die dadurch hervorgerufenen negativen wirtschaftlichen Folgen zwangen die Regierung zu einer verstärkten Förderung des Studiums. Im August 1938 wurde der Hochschulzugang „für Begabte“ auch ohne Reifezeugnis ermöglicht. ${ }^{765}$ Das REM bemühte sich, durch Studienerleichterung und andere Anreize dieser Krise entgegenzusteuern. Die Studienbereitschaft nahm in den Kriegsjahren aber vor allem als Reaktion auf die veränderte Arbeitsmarktlage wieder zu. Während von 1933 bis 1939 im Mittel die Hälfte der Abiturienten studierwillig war, waren es im Jahr 1942 über $70 \%$. Obwohl viele potentielle männliche Studenten direkt nach dem Abitur zur Wehrmacht eingezogen wurden, stiegen die Studentenzahlen der Männer an - ein noch stärkerer Anstieg

763 Lorenz [1943]b S. 112f. Siehe auch die grafische Darstellung der bestandenen Abschlussprüfungen an den wissenschaftlichen Hochschulen des „Altreichs“ in den Naturwissenschaften: Lorenz [1943]b S. 12 und 13, Schaubild $1 \mathrm{f}$ und $1 \mathrm{~g}$.

764 Deutsche Zahlen nach Titze [1987]; Göttinger Zahlen nach Lorenz [1943]a und eigener Zählung aus den Matrikelverzeichnissen im UAG.

765 L. Mertens [1991] S. 99. 
zeigte sich bei den Frauen. Der Nachwuchsmangel in den akademischen Berufen ließ das Hochschulstudium wieder erfolgsversprechend erscheinen. Den größten Zulauf gab es in der Medizin, sodass für das Jahr 1940 ein globaler numerus clausus eingeführt wurde. Keine Fakultät durfte mehr als 130 \% ihrer Studentenzahl des WS 1938/39 haben. ${ }^{766}$ Durch den anfangs siegreichen Kriegsverlauf wurde bis Ende 1940 die Freistellung junger ungedienter Männer zum Studium großzügig gehandhabt. Danach mussten die Jahrgänge 1919 bis 1921 spätestens nach dem 4. Semester in den Kriegsdienst. Dafür wurden nun Soldaten, die seit 1937/38 dienten und an der Front waren, bevorzugt beurlaubt. Bis 1943 gab es auf diese Weise einen dauernden Wechsel in den Truppen und in der Studentenschaft. ${ }^{767}$

Die Göttinger Physik verzeichnete in den ersten beiden Kriegsjahren einen absoluten Tiefstand ihrer Studentenzahlen. Trotzdem waren die einführenden ExperimentalphysikVorlesungen überfüllt. Im Winter-Trimester 1940 nahmen insgesamt etwa 900 Studenten am physikalischen Unterricht teil; der Löwenanteil machten die zirka 700 Mediziner aus. ${ }^{768}$ Entsprechend stark belegt war auch das physikalische Praktikum für Mediziner, an dem 380 Studenten teilnahmen, statt den 80 in normalen Semestern. ${ }^{769}$ Demgegenüber waren den Physikprofessoren nur 25 Hauptfachstudenten der Physik bekannt. ${ }^{770}$ Diese äußerst niedrige Zahl - Anfang der 30er Jahre gab es über 200 Physikstudenten in Göttingen - wurde aber durchaus positiv bewertet: „Physik ist auch jetzt glücklicherweise noch kein Massenstudium geworden."771 Die Angst vor einem Massenstudium wird nach dem Krieg wieder zum wichtigen Thema unter den Professoren (siehe Abschnitt 2.3.2).

1938 war im Auftrag der Deutschen Physikalischen Gesellschaft das Heft „Der Physiker“ entstanden, welches das Anwerben des Nachwuchses unterstützen sollte. ${ }^{772}$ Zur Beschleunigung des Studiums führte das REM 1939 Trimester ein, die sich aber nicht bewährten und 1941 wieder abgeschafft wurden. Eine andere Maßnahme zur

\footnotetext{
766 Krönig \& Müller [1990] S. 10.

767 Krönig \& Müller [1990] S. 12f., 22.

768 Die Zahl der Medizinstudenten hatte sich während des 2. Weltkriegs seit dem WS 1938/39 bis zum Wintertrimester 1940 verdreifacht und bis zum Kriegsende verfünffacht. Siehe [Studentenzahlen] [1987].

769 Das Praktikum wurde 1938 insgesamt von 80 Studenten besucht. Siehe Joos an Kurator, 22. April 1939. UAG, Kur. XVI. V. C. h. 2. II.

770 Charlotte Lorenz [1943]a S. 232 führt 41 Physikstudenten für das 3. Trimester 1940 an, für das folgende 1. Trimester 1941 nur noch 26.

771 Siehe Joos an Rektor, 23. Februar 1940. UAG, Mat.Nat.Fak. 24a.

772 Eine Besprechung dieses Heftes findet sich in: 'Von der Physikertagung 1938', Physikalische Blätter 1 (1944), S. 81.
} 
Studienverkürzung war die Einführung des Diplomabschlusses in Physik im Jahr 1942, die von Max Wien schon 1938 gefordert worden war. ${ }^{773}$

Die militärischen Rückschläge wurden mit und nach Stalingrad zur Gewissheit. Die beschwörenden Durchhalteparolen der NSDStB-Funktionäre verloren an Glaubwürdigkeit und wurden von den Studenten immer weniger beachtet. Das Verhalten der Studenten bezüglich der politischen Beeinflussungen zeigte in der Endphase des Krieges vier typische Muster: 1) Es gab die politisch Indifferenten, die sich von Parteipolitik fern hielten und sich ganz auf ihr Studium konzentrierten. 2) Eine Gruppe wurde von NS-Funktionären „Liberalisten“ genannt. Diese zeichneten sich dadurch aus, dass sie Kritik übten und ihre bedrohte Freiheit $\mathrm{zu}$ verteidigen suchten. 3) Ein eigenes Muster bildeten die Offiziersstudenten, die sich vom NS distanzierten, aber ihre deutsche und nationale Einstellung betonten. 4) Schließlich gab es auch nationalsozialistische Studenten, von denen einige in den Augen der NS-Funktionäre bloß „Zweckidealisten“ gewesen seien, welche die politische Linientreue nur aufrecht erhielten, um persönliche Vorteile zu erlangen. Alle vier Typen zeigen eine Gemeinsamkeit: Als das Ende des Krieges nahte, rückten viele innerlich von dem ab, was sie als „Nationalsozialismus“ bezeichneten. ${ }^{774}$ Dieses innere Abrücken ist jedoch von einem aktiven Widerstand gegen den verbrecherischen Krieg weit entfernt. Die Unzufriedenheit der Studenten war sehr verbreitet und richtete sich vor allem gegen die Arbeitseinsätze und die politischen Pflichtübungen. Der innere Machtverlust der Parteikader führte auch dazu, dass die Kameradschaften des NSDStB, die mit politischer Duldung die Tradition der alten Studentenverbindungen fortsetzten, ein kaum noch kontrollierbares Eigenleben entwickelten.

Der Dissens mit der herrschenden Politik führte aber nur $\mathrm{zu}$ vereinzelten Widerstandshandlungen, die von der Mehrheit der Studenten isoliert blieben. Selbst nach der Kapitulation in Stalingrad konnten große Teile der Studentenschaft für eine Massenveranstaltung gegen die Widerstandskämpfer der Weißen Rose ${ }^{775}$ gewonnen werden. Die nationalsozialistische Propaganda wirkte sich durchaus auf die Mentalität der Studenten aus, wenn auch die politische Schulung nicht den gewünschten nationalsozialistischen Studententypus hervorbrachte. Vielmehr begünstigte die offizielle Zwangspolitisierung von

\footnotetext{
773 Wien [1938/44]b S. 89. In der Nachkriegszeit wurde die Einführung des Physik-Diploms an den Universitäten als ein schwerer „Mißgriff der Hitlerzeit“ angesehen, und auf der Vorstandssitzung der Deutschen Physikalischen Gesellschaft in der Britischen Zone 1948 in Clausthal eine Erklärung verabschiedet, die Doktorprüfung wieder anstelle der Diplomprüfung zu setzen, um dadurch wieder eine führende Schicht von Physikern zu schaffen. Diese Erklärung ist abgedruckt in Physikalische Blätter 4 (1948), S. $313 \mathrm{f}$.

774 Grüttner [1995] S. 422f.
} 
oben eine Skepsis gegenüber Politik von unten. Der vermeintlich unpolitische Student der Nachkriegszeit, der vor allem einer Parteipolitik ablehnend gegenüberstand, kündigte sich schon während der NS-Zeit an. ${ }^{776}$

Ab 1942 wurden Angehörige der Luftwaffe von der Universität Göttingen brieflich fernbetreut. 777 Ein Jahr später konnten sich die studierwilligen und zum Kriegsdienst eingezogenen Männer fernimmatrikulieren. ${ }^{778}$ Wer sich in Göttingen in Physik fernimmartrikulierte, bekam von der Universität Soldatenbriefe zugesendet, in denen einfache mathematische und physikalische Aufgaben gestellt waren. Diese Soldatenbriefe hatte Richard Becker entworfen (siehe Abschnitt 4.1); er übernahm auch die Korrektur der von den Soldaten eingesendeten Lösungen. Durch diese Fernbeziehung zur Universität konnte in der Nachkriegszeit eine reguläre Immatrikulation manchmal leichter erlangt werden. ${ }^{779}$

Auf das Anwachsen der Studentenzahlen gegen Kriegsende reagierte das REM, indem es im März 1943 die Rektoren ermächtigte, für überfüllte Fakultäten Zulassungsbeschränkungen einzuführen. ${ }^{780}$ Ein Jahr später bestärkte ein weiterer Erlass gegen die Überfüllung einzelner Hochschulen die Rektoren, die Zahl der Neuzulassungen nach eigenem Ermessen zu beschränken. ${ }^{781}$ Kopfermann als damaliger Göttinger Dekan erkundigte sich daraufhin bei den Institutsdirektoren nach der Auslastung ihrer Lehrveranstaltungen und der Größe der Hörsäle. Aus einem Antwortschreiben erfahren wir, dass im SS 1944 in Prandtls Vorlesung über Festigkeitslehre 25 Hörer, in der über Strömungslehre 10 saßen. Der Hörsaal fasste hundert Personen. ${ }^{782}$

Während in der Physik nicht von einer Überfüllung gesprochen werden konnte, war die Situation in den anderen Fächern angespannter. In einer Akte von 1944 wird sogar gesprochen von „Notstände[n], die den Lehr- und Forschungsbetrieb an der Universität Göttingen beeinträchtigen [...]. Die Studentenzahl liegt sehr erheblich über derjenigen der letzten Friedensjahre. Sie hat im WS 1943/44 3000 überschritten.“"783 In der Diskussion der

\footnotetext{
775 Zur Weißen Rose siehe Grüttner [1995] S. 457-471.

776 Grüttner [1995] S. 479f. Siehe auch Maßß [1998] zur politischen Einstellung der Nachkriegsstudentenschaft.

777 Becker an Rektor, 12. Mai 1942. UAG, Rek. Fernbetreuung 1941-1944.

778 Krönig \& Müller [1990] S. 28.

779 Siehe dazu das Beispiel zur Göttinger Physik bei Krönig \& Müller [1990] S. 134.

780 Grüttner [1995] S. 107f.

${ }^{781}$ Erlass des REM (Mentzel) vom 17. März 1944. UAG, Kur. XXX. A. a. Studierende. Allgemeine Vorschriften. VIII.

782 Prandtl an Dekan Kopfermann, 24. Juni 1944. MPG-Archiv, III, 61, 1738.

783 Bericht ohne Datum (vermutlich Februar 1944). In einer Auflistung der Studentenzahlen vom Oktober 1949 vom damaligen Rektor Rein sind für 19443394 Studenten genannt. Beides in: UAG, Rek. 1408. Auch an
} 
vom Ministerium angeregten Studienbeschränkung in der MathematischNaturwissenschaftlichen Fakultät betonte Dekan Kopfermann, dass ein numerus clausus für Physiker und Chemiker nicht, für Mediziner unter Umständen in Frage komme. Die meisten Göttinger Professoren der Naturwissenschaften waren gegen Studienbeschränkungen, obwohl sie ein Missverhältnis zwischen der Anzahl der Lehrenden und Lernenden verspürten. Pohl setzte sich für eine Vermehrung der Assistenten ein, Eucken jedoch sprach sich entschieden dagegen aus. ${ }^{784} \mathrm{Da}$ die Wehrmacht vermutlich keine Leute freigeben würde, überlegte man, Lehrkräfte von bombengeschädigten Instituten einzusetzen. In der Physik wurden aber doch keine 'fremden` Lehrkräfte eingesetzt.

Ab Sommer 1944 wurden die Studenten für die letzten Kriegsanstrengungen in großer Zahl herangezogen. Mehr als die Hälfte aller Studenten wurde zur Wehrmacht eingezogen oder vor allem in der Rüstungsindustrie zum Arbeitseinsatz abkommandiert. Erstimmatrikulationen wurden für das SS 1944 gesperrt, ausgenommen waren nur Versehrte und arbeitsunfähige Kriegerwitwen. Jene, die sich nicht neu einschreiben durften, waren zur Fernimmatrikulation zugelassen. Abkommandiert für den sogenannten „totalen Kriegseinsatz“ wurden alle Studentinnen und nicht der Wehrmacht angehörenden Studenten, die im SS 1944 im 1., 2. oder 3. Fachsemester waren, ausgenommen der Fächer Mathematik, Physik, Ballistik, Hochfrequenztechnik und Fernmeldetechnik. Studenten der Mathematik und Physik blieben nur dann ausgenommen, wenn sie nicht auf Lehramt studierten, sondern das Studium mit der Diplomprüfung oder der Promotion abschließen wollten. Außerdem traf es alle Studenten höherer Fachsemester, sofern sie nicht Medizin oder Naturwissenschaften studierten oder kurz vor einem Abschluss standen. Durch die zahlreichen Einziehungen der Studenten zum Kriegseinsatz kam es zu Schließungen einzelner Hochschulen oder Fachbereiche. Schwach besetzte Fakultäten wurden zusammengelegt. So wurden die naturwissenschaftlichen Fakultäten der Universitäten Bonn und Münster mit der entsprechenden Fakultät der Universität Göttingen zusammengelegt. 785

Eine unter dem Namen Osenberg-Aktion bekannt gewordene Rückrufinitiative von Soldaten zur Universität ging von dem Professor für Werkzeugmaschinentechnik an der TH Hannover und Leiter des 1943 eingerichteten Planungsamtes im RFR, Werner Osenberg, aus. Seit 1942

anderen Universitäten wuchsen die Studentenzahlen gegen Kriegsende stark an. Freiburg meldete im WS 1943/44 über 4000 Studenten. Siehe Schnabel [1991] S. 231-234.

784 Protokollbuch III der Math.-Nat. Fakultät, Sitzung vom 9. Dezember 1943, S. 295. GPMNF.

785 Erlass des REM (RV 391/44) Betr.: Totalen Kriegseinsatz, vom 1. September 1944; Erlass (W A 1200, RV), vom 14. September 1944; Erlass (W A 1220, RV (a)), vom 12. Oktober 1944, alle: UAG, Kur. XXX. A. a. Beih. 2. Betr. Totalen Kriegseinsatz. Siehe auch Grüttner [1995] S. 425. 
hatte er mehrfach auf die Notwendigkeit hingewiesen, Wissenschaftler für kriegswichtige Forschung von der Front zurückzuholen. Dies betraf vor allem fertig ausgebildete Forscher technischer und naturwissenschaftlicher Disziplinen. Auf eine Anfrage des Oberkommando der Kriegsmarine im Oktober 1943 wurden in Göttingen die zur Entlassung aus der Wehrmacht in Frage kommenden Studenten der Physik, Chemie und Hochfreuquenztechnik namentlich gemeldet. ${ }^{786}$ Bis Ende 1944 wurden in ganz Deutschland mindestens 3400 Wissenschaftler zur Rüstungsforschung freigestellt. Diese mussten dann eine Forschungstätigkeit von mindestens 53 Stunden in der Woche nachweisen. ${ }^{787}$ Neben der direkten Verwendung in der Rüstungsforschung gab es auch Umschulungsprogramme, die im Mai 1944 einsetzten. Ein Mangel herrschte vor allem in Physik, Hochfreuquenztechnik, Ballistik und Strömungsforschung. Einen im Jahr 1944 in Göttingen abgehaltenen Umschulungskurs Strömungslehre besuchten elf Teilnehmer, von denen im Oktober 1944 neun zum Fortsetzungskurs empfohlen wurden und einer an die Truppe zurückgeschickt wurde. ${ }^{788}$

Zusammenfassend lässt sich über die Studienbedingungen in der NS-Zeit sagen, dass die ersten Verschlechterungen von einer relativ raschen Verbesserung der Berufs- und Karrierechancen abgelöst wurden. Für die Studenten, die die geforderte politische Anpassung leisteten, stand die Möglichkeit zur relativ gesicherten Lebensplanung offen. „Nichtariern“ standen zunehmend administrative Hürden im Weg, die den meisten ein Studium verunmöglichten. Die erhoffte soziale Öffnung der Hochschulen kam nicht einmal im Ansatz zu Stande. In der Vorkriegszeit kam es sogar zu einer Verbürgerlichung der Studentenschaft, die erst durch die Kriegsumstände wieder abgeschwächt wurde. Diese Umstände, die Einberufung zur Front, die Bombadierung der Städte, das Beklagen der Todesopfer wirkten sich auf alle Lebensbereiche aus und erschwerten ein zielstrebiges Studieren. ${ }^{789}$

\footnotetext{
786 Oberkommando der Kriegsmarine an Rektor, 25. Oktober 1943. Für kriegswichtige Forschung sollten 1800 Studenten zur Fortsetzung des Studiums uk-gestellt werden. Die in Göttingen in Frage kommenden Studenten wurden von den einzelnen Professoren dem Dekanat telefonisch mitgeteilt. Siehe die vom Dekan hinzugefügte Anmerkung vom 2. November 1943 auf der von Prandtl erhaltenen Abschrift des erstgenannten Schreibens. MPG-Archiv, III, 61, 2160.

${ }^{787}$ Siehe „Richtlinien für den Einsatz der unter dem Stichwort: »Forschung« vom Wehrdienst freigestellten Fachkräfte," von Werner Osenberg. Ein Exemplar davon befindet sich im DLRA, GOAR, 2728. Allgemein zu Osenberg und seinem Rückholverfahren siehe Federspiel [2002]. Siehe auch Krönig \& Müller [1990] S. 30f., der von durch die Osenberg-Aktion zurückgerufenen Historikern, Philosophen und Altphilologen berichtet.

788 Prandtl an Osenberg, 23. Oktober 1944, DLRA, GOAR, 2728. Laut Federspiel [2002] S. 90 ist der Forschung bisher nicht bekannt gewesen, dass diese Umschulungskurse tatsächlich stattfanden.

789 Grüttner [1995] S. 477.
} 


\begin{tabular}{|l|l|l|l|l|l|l|}
\hline Semester & Universitäten & \multicolumn{4}{l|}{ Technische Hochschulen } \\
\hline & männl. & weibl. & zusammen & männl. & weibl. & zusammen \\
\hline SS 1939 & 458 & 42 & 500 & 509 & 19 & 528 \\
\hline HTM 1939 & 251 & 33 & 284 & 306 & 21 & 327 \\
\hline 1. TM 1940 & 310 & 49 & 359 & 322 & 28 & 350 \\
\hline 2. TM 1940 & 281 & 61 & 342 & 298 & 37 & 335 \\
\hline 3. TM 1940 & 320 & 83 & 403 & 299 & 56 & 355 \\
\hline WTM 1941 & 277 & 88 & 365 & 256 & 48 & 304 \\
\hline SS 1941 & 216 & 104 & 320 & 225 & 48 & 273 \\
\hline WS 1941/42 & 311 & 118 & 429 & 329 & 58 & 387 \\
\hline SS 1942 & 130 & 152 & 282 & 268 & 84 & 352 \\
\hline WS 1942/43 & 243 & 186 & 429 & 317 & 94 & 411 \\
\hline SS 1943 & 148 & 212 & 360 & 156 & 105 & 261 \\
\hline WS 1943/44 & 337 & 176 & 513 & 383 & 107 & 490 \\
\hline
\end{tabular}

Tabelle 6 Anzahl der Physikstudenten in „Großdeutschland“ 1939-1943. ${ }^{790}$

\begin{tabular}{|l|l|l|l|}
\hline Semester & \multicolumn{3}{|l|}{ Erstimmatrikulierte in Physik } \\
\hline & männl. & weibl. & zusammen \\
\hline 2. TM 1940 & 74 & 31 & 105 \\
\hline 3. TM 1940 & 148 & 43 & 191 \\
\hline WTM 1941 & 43 & 3 & 46 \\
\hline SS 1941 & 98 & 18 & 116 \\
\hline $\begin{array}{l}\text { WS } \\
1941 / 42\end{array}$ & 287 & 31 & 318 \\
\hline & & & \\
\hline $\begin{array}{l}\text { WS } \\
1943 / 44\end{array}$ & 181 & 42 & 223 \\
\hline SS 1944 & 185 & 119 & 304 \\
\hline
\end{tabular}

Tabelle 7 Die Erstimmatrikulierten an den wissenschaftlichen Hochschulen „Großdeutschlands“ in Physik 1940-44.791

\subsubsection{Das Kriegsende}

Trotz des immer deutlicher näherrückenden Kriegsendes versuchte die NS-Bürokratie eine gewisse Normalität aufrecht zu erhalten. Das REM kündigte noch Ende Februar 1945 an, dass das kommende Sommersemester am 16. April 1945 beginne und am 15. August ende. Die Prüfungen seien möglichst auf die erste Hälfte des Monats August zu legen. ${ }^{792}$ Der Einmarsch der amerikanischen Truppen in Göttingen noch vor dem angekündigten Semesterbeginn führte dazu, dass die Universität Göttingen, wie auch alle anderen deutschen Hochschulen, für die Studenten im SS 1945 geschlossen blieb. Die Studenten mussten sich in dieser unklaren Situation neu orientieren. Ihre Zukunft erschien fragwürdig. Einige Studenten verließen die Stadt. Eine Erfassung der ortsanwesenden Studenten wurde vom Senat mit der Begründung

\footnotetext{
790 Lorenz [1944] S. 12-15.

791 Lorenz [1944] S. 21-23.

792 Erlass des REM vom 20. Februar 1945. UAG, Kur. XXX. A. a. Studierende. Allgemeine Vorschriften. VIII.
} 
abgelehnt, eine sich etwa ergebende geringe Zahl könnte den Anspruch auf Wiedereröffnung der Universität gefährden. 793

Die Ablegung von Prüfungen war nach dem 8. April 1945 nicht mehr erlaubt. Doch die Besatzungsbehörde zeigte sich bald entgegenkommend, sodass schon im Juni 1945 die Prüfungen der vor dem 8. April gemeldeten Kandidaten und auch von zusätzlich 30 neuangemeldeten durchgeführt werden konnten. Doktordiplome konnten aber erst nach Wiedereröffnung der Universität ausgestellt werden. 794

Für die amerikanischen Soldaten wurden im Mai 1945 Kurse von Universitätsdozenten angeboten. Zur Rechtfertigung vor den deutschen Studenten, die bis zur Wiedereröffnung der Hochschulen warten mussten, wurde von Seiten der Universität der militärische Charakter dieser Kurse unterstrichen. ${ }^{795}$ Die deutschen Studenten wurden zum landwirtschaftlichen Arbeitseinsatz und zu Bibliotheksarbeiten aufgefordert. Die Studentinnen wurden besonders „für Kinderpflege und Küche auf dem Lande“ gesucht. Ausgenommen von den in Göttingen an sich freiwilligen Arbeitseinsätzen, die aber als Ehrenpflicht angesehen wurden, waren diejenigen, die mit Forschungsarbeit betraut oder in der Prüfungsvorbereitung waren. Der vertraute Terminus der Unabkömmlichkeit wurde hier in veränderter Bedeutung angewendet. Die in den Universitätsinstituten benötigten Studenten bekamen von Institutsleiter und Dekan die 'uk-Stellung' bestätigt, um nicht zum Arbeitseinsatz verpflichtet zu werden. Die Arbeitspflicht richtete sich zwar auch auf die Professoren, jedoch sahen diese ihren Beitrag durch ihre Forschungspflicht erfüllt. ${ }^{796}$ Die Stadt Göttingen betrachtete die Forschung nicht als das dringendste Bedürfnis in dieser Zeit und erreichte, dass doch einzelne Lehrkräfte zum Arbeitseinsatz hinzugezogen wurden. Strittig blieb dieser Punkt trotzdem. So versuchte der Senat beim Oberbürgermeister für Professor Botzenhart $\mathrm{zu}$ intervenieren, der nicht „fortdauernd“ herangezogen werden wollte. ${ }^{797}$

\footnotetext{
793 Protokoll der Senatssitzung vom 28. April 1945. UAG, Senatsprotokolle 1945-1949.

794 Protokolle der Senatssitzungen vom 19. und 20. Juni 1945. UAG, Senatsprotokolle 1945-1949.

795 Protokoll der Senatssitzung vom 5. Mai 1945. UAG, Senatsprotokolle 1945-1949.

796 Protokolle der Senatssitzungen vom 16. Mai, 19. Mai, 23. Mai, 2. Juni 1945. UAG, Senatsprotokolle 19451949.

797 Protokoll der Senatssitzung vom 16. Juni 1945. UAG, Senatsprotokolle 1945-1949. Die Hartnäckigkeit der Professoren gegen eine Verpflichtung selbst der Studenten zum Arbeitseinsatz zeigt sich auch in Bezug auf die neuimmatrikulierten Studenten in der Nachkriegszeit. So wurde die Koppelung der Neuimmatrikulation mit der Ableistung eines Arbeitseinsatzes, wie es Ministerialrat Wienert vorgeschlagen hatte, seitens der Universität missbilligt. Stattdessen trat die Universität mit einer eindringlichen Bitte an die Studentenvertretung heran, von sich aus Unterstützung zu sicher, da die Studenten sich doch als Mitglieder der Universität zu verstehen hätten. Die Professoren signalisierten eine gewisse Belohnung, indem sie auf den Wunsch der Studentenschaft, an der Selbstverwaltung der Universität beteiligt zu sein, hinwiesen. Protokoll der Senatssitzung vom 23. Juli 1947. UAG, Senatsprotokolle 1945-1949.
} 


\subsection{Die Nachkriegszeit}

\subsubsection{Zur politischen Haltung der Studenten nach dem verlorenen Krieg}

Jede allgemeine Äußerung über Eigenschaften einer größeren Gruppe von Menschen, vor allem wenn es sich um deren politische Überzeugungen handelt, ist mit entsprechender Vorsicht zu genießen. Einige deutlich zu Tage tretenden Tendenzen in der Nachkriegsstudentenschaft geben allerdings ein besseres Verständnis für die in den nächsten Kapiteln behandelten Abläufe. Wie schon angesprochen gab es gegen Kriegsende eine Abkehr der Studenten vom Begriff des Nationalsozialismus. „Wir waren im großen Ganzen nicht Nationalsozialisten, die Gegner ... nicht und [auch jene] nicht, die mitgelaufen sind. Doch das ist im Grunde recht wenig gewesen." So versuchte der Tübinger Student Bruno Heck die Abstandnahme vom Begriff und die Füllung mit neuen Inhalten: „Irgendwo sind wir dafür gewesen, nicht für den Nationalsozialismus, aber für den Nationalismus und für den Sozialismus." "798 Trotzdem zeigten sich die Studenten loyal gegenüber dem NS-Staat, was in den in der Studentenschaft vorherrschenden nationalkonservativen Tugenden begründet liegt: Treue gegenüber dem 'Vaterland', Gehorsam gegenüber dem Staat und Pflichterfüllung gegenüber der Obrigkeit. ${ }^{799}$ Dieser Wertekanon hatte eine lange Tradition und existierte unabhängig vom Nationalsozialismus. Auch nach dem Krieg behielten die Studenten diese Tugenden bei. ${ }^{800}$

Dies hängt auch damit zusammen, dass die Studenten der Nachkriegszeit vollständig im nationalsozialistischen Deutschland sozialisiert waren. Die „Hitlerjugend-Generation“ war in dem Bewusstsein aufgewachsen, etwas Besonderes zu sein, ein „Garant der Zukunft“. Dieses Gefühl wurde durch das Kriegsende zerstört; die Generation fühlte sich um ihre Zukunft betrogen. Ein allergisches Reagieren auf Verurteilungen statt Verstehen war die Folge. ${ }^{801}$ Aber von Seiten der Professoren kamen weniger Verurteilungen als Solidaritätsbekundungen.

Es gibt Anzeichen für einen mentalen Schulterschluss der Studenten mit den Professoren, der mit den von beiden geteilten nationalkonservativen Werten erklärt werden kann. ${ }^{802}$ Diese an

\footnotetext{
798 Zitiert nach Jarausch [1984] S. 213.

799 Siehe Grüttner [1995] S. 481.

800 Zur Charakterisierung der nationalkonservativen Grundhaltung der Studenten nach 1945 siehe Maaß [1998] S. $22 \mathrm{ff}$.

801 Siehe Rosenthal [1987], bes. S. 82-99, auch Rosenthal (Hrsg.) [1986] und Schörken [1990], bes. S. 137.

802 Siehe Maaß [1998] Kap. 2, bes. S. 23 und 46f.
} 
den Hochschulen der Nachkriegszeit überwiegende politische Haltung kann nach Maaß in sechs Charakteristika gefasst werden:

1) Festhalten an nationalkonservativen Leitfiguren der Weimarer Zeit

2) Antikommunistischer Konsens

3) Stolz auf Kriegsleistungen und Festhalten an militärischen Umgangsformen

4) Stolz auf deutsche Nation

5) Besinnung auf bildungsbürgerliche Vorbilder

6) Ablehnung von Parteipolitik, stattdessen Konzentration auf Fachwissenschaft. 803

Maaß vertritt die These, dass der nationalkonservative Konsens ein wesentlicher Grund für die Stabilität der akademischen Gemeinschaft Hochschule und für ein weitgehend konfliktfreies Miteinander zwischen Professoren- und Studentenmehrheit bis gegen Mitte der 60er Jahre war. ${ }^{804}$ Das Verhalten der Göttinger Studentenschaft bis zu Beginn der 50er Jahre und die in den Senatsprotokollen dokumentierte politische Haltung der Spitze der Studentenvertretung und die gute Zusammenarbeit der Professoren mit ihr stützen diese These. Die erste Studentenvertretung formierte sich aus korporierten Studenten. ${ }^{805}$ Es muss aber berücksichtigt werden, dass in der Phase der Restauration von den Professoren eine kritische Haltung der Studenten, oder gar politischer Aktionismus, nicht erwünscht war, und dass die Studenten in einem besonderen Abhängigkeitsverhältnis standen. Die strenge Aussiebung, die der numerus clausus mit sich brachte, und die dauernde Kontrolle der Studenten in Göttingen hemmten eine offene Auseinandersetzung um hochschulpolitische Fragen. Daher konnten Meinungen, die den Ansichten der Professoren nahe standen, gefahrloser vertreten werden, als eine Kritik des vorherrschenden Militarismus unter den Studenten oder das Hinterfragen der Verantwortung der Hochschulen und ihrer Würdenträger für die Kriegsfolgen. Es erscheint mir in dieser Hinsicht typisch, dass ein Student der Forstlichen Fakultät in Hannoversch Münden erst dann die große Anzahl von Offizieren unter den Studenten und deren militärisches Gehabe kritisierte, nachdem er zum Weiterstudium nicht mehr zugelassen worden war. ${ }^{806}$ Die Göttinger Quellen liefern Beispiele, wie die Professoren mit studentischer Kritik verfuhren: In der Regel wurde auf eine krankhafte Psyche des Kritikers verwiesen. Die Bezeichnungen variierten von „sehr weicher und ängstlicher Charakter“ bis „Wirrkopf mit Erlöserideen“. ${ }^{807}$ Festzuhalten bleibt, dass weniger

\footnotetext{
803 Siehe Maaß [1998] S. 34.

804 Maßß [1998] S. 46f.

805 Zum Wiederaufleben der Korporationen in Göttingen nach 1945 und deren Beteiligung an der Studentenvertretung siehe Bernhardi [1963].

806 Die aufschlussreiche Kritik über die Zustände an der Forstlichen Fakultät ist nachzulesen bei Maaß [1998] S. $35 \mathrm{f}$.

807 Siehe Schuler an Dekan Eucken, 10. April 1946. UAG, Math.-Nat. Fak. Nr. 19a; und Protokoll der Senatssitzung vom 2. Februar 1946. UAG, Senatsprotokolle 1945-1949.
} 
der Inhalt der Kritik, als der Charakter des Äußernden in Frage gestellt wurde. Dies war für davon betroffene Studenten wie auch für kritische Professorenkollegen besonders schmerzlich und folgenreich, da der 'richtige' Charakter nach damaliger Auffassung eine wesentliche Voraussetzung zur wissenschaftlichen Tätigkeit darstellte.

Unter den gemeinsamen politischen Haltungen bei Professoren und Studenten war der nationale Bezug des Denkens und Handelns besonders ausgeprägt. Als Argument für das Fortbestehen der Hochschulen, für die Notwendigkeit wissenschaftlicher Forschung wurde das Wohl Deutschlands, die Wiedergewinnung nationalen Ansehens der deutschen Kultur und Wissenschaft sowohl von Studenten wie von Professoren angeführt.808 Um den Hochschulzugang allen Begabten zu ermöglichen, nannte der Göttinger Rektor Rein folgendes Argument: „Hier geht es um die Zukunft unseres Landes!“"809 Und in der gleichen Sache beschloss die Hochschulkonferenz 1946: „Es muß gelingen, die Hochschulen den besten Kräften ohne Rücksicht auf Herkunft und Besitz zugänglich zu machen. Es geht um die Zukunft unseres Volkes!“ 810 Auch die Treuegelöbnisse der erstimmatrikulierten Studenten enthielten den Bezug zu „Volk und Vaterland“. 811 Auf dem Studententag in Heidelberg 1947 wurde folgender Leitsatz formuliert: „Wir bekennen uns zur Einheit des deutschen Volkes und wenden uns gegen alle separatistischen Bestrebungen." ${ }^{812}$

Statt von den Schrecken des nationalsozialistischen Rassenwahns sprachen die Professoren von den „Erfahrungen der Jahre, durch die wir gehen mußten“. ${ }^{813}$ In diesem Sinn fühlten sich Professoren und Studenten als gemeinsames 'Opfer der Zeitumstände' und sahen die Hauptaufgabe im Wiederaufbau Deutschlands, der in ihrem Denken nur gemeinsam zu schaffen war. „Die deutschen Universitäten und Hochschulen dienen dem deutschen Volk,“ wurde auf dem ersten Studententag 1946 verkündet. ${ }^{814}$ Es ist daher auch Ausdruck einer patriotischen und in diesem Sinn politischen Haltung, wenn die Studenten in Heidelberg sich „,in erster Linie mit den eigenen Sorgen beschäftigen“ und den Leitsatz formulieren: „Unsere Hauptaufgabe sehen wir Studenten aber in der Arbeit an uns selbst, in der Pflege des

\footnotetext{
${ }^{808}$ Zum vorwiegend positiven Bezug der Studenten zum 'Vaterland' siehe Maaß [1998] S. 38f.

${ }^{809}$ Rein auf der 5. Hochschulkonferenz, Bünde 16. August 1946. Heinemann (Hrsg.) [1990]c S. 191.

810 Beschluss der 6. Hochschulkonferenz, Bonn 24./25. September 1946. Heinemann (Hrsg.) [1990]d S. 558.

811 Siehe zum Wortlaut der Verpflichtungsformel für neu immatrikulierte Studenten Seite 241.

812 Beschluss des ersten Studententags der amerikanischen Zone in Heidelberg, 6.-8. Juli 1947. Neuhaus [1961] S. 118 .

813 Aus der Rede Herbert Schöfflers an die Göttinger Studenten vom 28. Oktober 1945, abgedruckt in Krönig \& Müller [1990] S. 342-348, hier S. 342. In Schöfflers Rede kam aber auch Dramatisches und Blutiges zur Sprache: Die Entwicklung der logischen Dinge in der Mathematik sei mit einem „Drama durch die Geschichte der Menschheit“ verbunden. Etwas überraschender folgende Wendung: „Wer weiß welche blutigen Kämpfe der Jahrhunderte hinter Namen wie Pfeffer und Muskat stehen?“. Ebenda S. 342f.
} 
akademischen Geistes und dem Streben nach einer wahren Bildung im Sinne der Universitas litterarum.“ 815

Nach dem Ende des Nationalsozialismus begriffen sich viele Studenten als 'unpolitische“ Zeitgenossen. Sie konzentrierten sich vorrangig auf die inhaltliche Seite ihres Studiums. ${ }^{816}$ In den zeitgenössischen Berichten wird diese Haltung vorwiegend positiv dargestellt. Eine Schülerin des Emigranten Richard Mises berichtete ihm nach Cambridge, Massachusetts, von ihren Eindrücken aus Göttingen im Jahr 1948:

„Im letzten Jahr bin ich verschiedentlich in Göttingen gewesen, eine der wenigen deutschen Universitäten, die unzerstört ist und in der man Leben und Arbeit spürt. [...] Man hat das Gefühl, als arbeiteten die Studenten verbissen und hartnäckig, Hunger und alle Entbehrungen wortlos ertragend, nur das Ziel des Examens im Auge. Es scheint nicht mehr viel Platz zu sein für studentische Freuden, fehlen ja auch die Voraussetzungen dafür völlig, ja kein Platz für irgendwelche Gedanken außerhalb des Studiums." 817

So einseitig aufs Studium konzentriert, wie es Mises beschrieben wurde, waren die Nachkriegsstudenten aber doch nicht. Ihre Interessen und Aktivitäten betrafen auch Kunst und Politik. Die als apolitisch begriffene Einstellung ist so zu verstehen, dass aktive politische Betätigung, vor allem parteipolitische, abgelehnt wurde. „Politische Diskussionen sind beliebt", schrieb der Diplomphysiker Friedrich Kaempffer 1945 in der GUZ. ${ }^{818}$ Am tagespolitischen Geschehen nahmen sie also durchaus Anteil. Teilweise löste dies bei den Professoren ein gewisses Unbehagen aus. So lehnten sie 1946 einen Vortrag des Assistenten von Max Schuler, Rainer Fuchs, über „Studenten und Politik“ ab. ${ }^{819}$ Leider wissen wir nichts über die Gründe der Ablehnung, aber dass Fuchs nach eigenen Angaben seit 1936 ISKMitglied gewesen sei, mag eine Rolle gespielt haben. Zur selben Zeit wurde in der Fakultätssitzung ein Schreiben von Dr. D. Kuchemann an die Universitätszeitung über die mathematisch-naturwissenschaftlichen Fakultät verlesen und einstimmig beschlossen, den Druck des Artikels zu verhindern. ${ }^{820}$ Auch in diesem Fall wissen wir leider nichts über den

\footnotetext{
814 Neuhaus [1961] S. 115.

815 Beschluss des ersten Studententags der amerikanischen Zone in Heidelberg, 6.-8. Juli 1947. Neuhaus [1961] S. 118.

816 Eine Beschreibung der unpolitischen Haltung der Nachkriegstudenten findet sich bei Krönig \& Müller [1990]. Kap. 12. Siehe auch den zeitgenössischen Bericht des Kontrolloffiziers L. H. Sutton [1946/83] S. 111f.

817 Brief von Hilde Heinicke (geb. Karselt) an Mises, 14. Januar 1948. HUA, HUG 4574.5, Correspondence, 1903-1953, box 4.

818 Kaempffer [1945].

819 Protokoll der Senatssitzung vom 21. Januar 1946. UAG, Senatsprotokolle 1945-1949.

820 Protokoll der Fakultätssitzung vom 11. Januar 1946. GPAMNFG, Protokollbuch III der mathematischnaturwissenschaftlichen Fakultät WS 1927/28 - SS 1946.
} 
Inhalt des Artikels. Der Fall zeigt aber, wie wirkungsvoll die Professoren Kritikäußerungen unterbinden konnten.

Unmittelbar nach Kriegsende bildeten sich auf ausdrückliche Anregung von Seiten der Professoren eine Vielzahl unpolitischer studentischer Gruppen. ${ }^{821}$ Die Bildung politischer Gruppen lehnten die Professoren mehrheitlich ab. Sie befürchteten, dass solche Gruppen in der Universität Unruhe stiften würden. Als positiven Aspekt erwog Smend, die Zulassung von Parteigruppen könne die Radikalisierung der Studentenschaft abfangen, doch schenkte er dieser Maßnahme wenig Hoffnung auf Erfolg. Er hielt die Universitätszeitung für ein geeignetes Ventil, politische Unruhen durch die Gestattung einer öffentlichen Diskussion abzufangen. Der Bonner Physikprofessor Heinrich Konen schlug vor, „,von den Studenten absolute Abstinenz in politischen Fragen $\mathrm{zu}$ fordern“. ${ }^{822}$ Die Göttinger mathematischnaturwissenschaftliche Fakultät vertrat den „Standpunkt, daß Politik vermieden werden soll, auch politische Betätigung der Studenten." 823 Die Studenten wurden für politisch unreif gehalten und seien deshalb vom politischen Leben fern zu halten. ${ }^{824}$ Die Militärregierung verbot zwar Korporationen alten Stils, schuf aber die Möglichkeit, Gesellschaften oder Clubs zur Diskussion politischer oder sozialer Fragen zuzulassen. ${ }^{825}$ Wenn eine Gruppe in Göttingen um Zulassung bat, mussten sich drei ihrer Mitglieder bei Rektor und Prorektor persönlich vorstellen. Trotz der ablehnenden Haltung seitens der Professoren beantragte schon Mitte Dezember 1945 die Christlich-Demokratische Studentengruppe als erste politische Vereinigung ihre Zulassung. ${ }^{826}$ Kurz darauf kam der Antrag einer sozialdemokratischen Gruppe. Beide wurden von der Militärregierung vorerst abgelehnt. ${ }^{827}$ Im April 1946 wurde die „Sozialistische Studentengruppe“ als erste zugelassen. ${ }^{828}$ Im Jahr

${ }^{821}$ Zur Bildung zahlreicher studentischer Gruppen siehe Krönig \& Müller [1990] S. 74 und Kap.14. Siehe auch Schöfflers dort abgedruckte Rede an die Göttinger Studenten (S. 342-348). Bernhardi [1963] S. 204 listet die unterschiedlichen Themenbereiche der Gruppen auf und gibt deren relative Größen an. Im September 1946 erlaubten die Briten die Bildung politischer Studentengruppen. Die Bedingungen, die dazu erlassen wurden, sind abgedruckt, ebenda, S. 259.

${ }^{822}$ Heinemann (Hrsg.) [1990]c S. 102. Zur Konens eigener, politisch zweifelhaften Haltung siehe Haude [1993] Kap. 11. Konen war einer von insgesamt zwei deutschen Rektoren, die von der britischen Militärregierung ihres Postens enthoben wurden. Der Entlassungsgrund war die von ihm vertretene Zulassungspolitik.

823 Protokoll der Fakultätssitzung vom 26. Oktober 1945. GPAMNFG, Protokollbuch III der mathematischnaturwissenschaftlichen Fakultät WS 1927/28 - SS 1946.

${ }^{824}$ Siehe zu den Ansichten der führenden deutschen Professoren über Studenten und Politik Heinemann (Hrsg.) [1990]c S. 100ff.

825 Siehe den Erlass der Militärregierung, abgedruckt in GUZ (1946), Nr. 4, S. 14.

826 Heinemann (Hrsg.) [1990]c S. 101.

827 Siehe Heinemann (Hrsg.) [1990]c S. 119.

828 Zur Zulassung der ersten politischen Studentengruppen in Göttingen siehe Bernhardi [1963] S. 211. 
1947 bestanden außerdem etwa 15 kleinere politische, aber nicht parteipolitische Gruppen. ${ }^{829}$ 1948 wurde dem Antrag des „Marxistischen Arbeitskreises“ auf Zulassung durch Fürsprache Professor Wenzels, der es nicht für ein getarntes kommunistisches Unternehmen hielt, unter der Auflage, sich in „Arbeitskreis zum Studium des Marxismus“ umzubenennen, stattgegeben. ${ }^{830}$ Die Sozialistische Studentengruppe hatte im selben Jahr etwa 60 Mitglieder, die Kommunistische 10 bis 15. In einem Bericht von General J. C. Haydon der Headquaters Intelligence Division über die Zustände an den Universitäten vom März 1949 heißt es diesbezüglich, die Universitäten Hamburg, Kiel und Göttingen seien stärker an der SPD und KPD-Seite als an der CDU-Seite vertreten. ${ }^{831}$

Die Existenz dieser kleinen linken Studentengruppen soll nicht darüber hinwegtäuschen, dass die vereinzelten kritischen Stimmen zum Nationalsozialismus und zum deutschen Krieg in der Studentenschaft wenig Gehör und Unterstützung fanden. Im November 1945 verurteilte ein Göttinger Dozent in seiner Vorlesung, an der etwa 400 Studenten teilnahmen, das HitlerRegime und machte es für die damalige Lage Deutschlands verantwortlich, worauf fast die gesamte Zuhörerschaft aufstand und den Raum verließ. ${ }^{832}$ Eine Bemerkung über Hitler führte in Göttingen zu dem Zwischenruf: „Es wird Zeit, dass wir wieder eine Feme bekommen.“833 Hier wurden Fememorde gefordert, wie sie in der Weimarer Republik zum Beispiel an Matthias Erzberger und Walther Rathenau begangen wurden. ${ }^{834}$ In Darmstadt machte Professor Mesmer im WS 1945/46 die Erfahrung, „daß man bei den Studenten auf Gescharre stößt, wenn man auch nur vorsichtige Andeutungen darüber macht, daß, nachdem nun einmal Deutschland und Nationalsozialismus identisch gewesen seien, Deutschlands Niederlage bejaht werden müsse und nicht als Unglück bedauert werden dürfe.“"835

Diese damals typische Form der Unmutsäußerung unter Studenten, das Scharren mit den Füßen, beschreibt auch der erste britische Kontrolloffizier für die Universität Göttingen, L. H. Sutton, in seinem zeitgenössischen Bericht shuffling feet. Er zeigt darin Verständnis für solche studentischen Proteste, die nach seiner Ansicht von unzureichender politischer Bildung

\footnotetext{
829 Siehe Heinemann (Hrsg.) [1990]c S. 279. Studentengruppen, die von Parteien begründet seien, wurden von den Rektoren grundsätzlich abgelehnt; siehe S. 280.

830 Protokoll der Senatssitzung vom 9. Juni 1948. UAG, Senatsprotokolle 1945-1949. Der „Arbeitskreis zum Studium des Marxismus" bestand von 1948 bis 1954. Bernhardi [1963] S. 211.

831 Siehe Maaß [1998] S. 43, Fußnote 79. Zur Bildung politischer Studentengruppen in Göttingen siehe Bernhardi [1963].

832 Siehe Maßß [1998] S. 24.

833 Zitat aus dem Artikel 'Lernen statt demonstrieren', Die Neue Zeitung, 2. Jg., Nr. 11 vom 3. Februar 1946. Siehe zu Berichten solcher Fememordforderungen in Göttingen Phillips [1983]c S. 9.

834 Auch an der TH Braunschweig forderten die Studenten im Protest gegen Hitler-Kritik Fememorde. Siehe Maaß [1998] S. 23f.
} 
herrühren. Er warnt davor, in jedem aufrührerischen Studenten einen überzeugten Nationalsozialisten zu wähnen. Bei den Göttinger Studenten des ersten Nachkriegssemesters unterscheidet er drei Typen: 1) Der liebe und freundliche Student mit guten Vorsätzen, der nur völlig ohne Einfluss auf die Regierung und das Verhältnis Deutschlands zur restlichen Welt sei. 2) Der politisch aktive und nationalistisch gesinnte Student, der Deutschland als den Verteidiger Europas gegen die Slaven verstehe. 3) Der Gangster, der vor allem in Kriegszeiten auftrete. Dieser dritte Typ, dem wenig intellektuelle Fähigkeiten zugesprochen wurden, sollte durch die politische und fachliche Überprüfung im Zulassungsverfahren von der Universität ferngehalten werden. Allen Typen gemeinsam sei eine erschreckende Unkenntnis in politischen Fragen; sie wüssten nichts über andere Länder, und sie seien hungrig auf jede neue Information. ${ }^{836}$

Die Berichterstattung des Neuen Hannoverschen Kuriers vom November 1945 über die Verhältnisse an der Universität Göttingen war in den Augen Suttons ein erster Gehversuch in kritischer Meinungsäußerung, der typischerweise übers Ziel hinaus schösse. In dem kurzen Bericht war zu lesen, dass ,die überwiegende Mehrheit der Studenten aus ehemaligen Offizieren“ bestehe und die ,politische Linie innerhalb der Studentenschaft [...] von Nazianschauungen geformt“ sei. Die Universität nehme „politische Funktionäre der Hitlerjugend und junge ehemalige Pg's als Studenten“ auf. ${ }^{837}$

Auch wenn diese Kritik möglicherweise überzogen war, so macht sie doch auf eines aufmerksam: Die Dominanz einer nationalkonservativen Einstellung in der Studentenschaft lag nicht nur an den politischen Überzeugungen der studierwilligen Jugendlichen, sondern auch an der speziellen Selektion durch die Professoren. Den Eigenheiten dieses Auswahlverfahrens wird daher im Folgenden besonderes Augenmerk gewidmet.

\footnotetext{
835 Handschriftlicher Entwurf eines Briefes von Kurt Hohenemser an Willy Prager, April 1946. KHP. 836 Siehe Sutton [1946/83]. Zur politischen Haltung der Nachkriegsstudenten siehe auch Respondek [1992] Kap. 9.

837 Siehe 'Der »Kurier« bemerkt: Universitäten', Neuer Hannoverscher Kurier, 30. November 1945, S. 2. Die Universität reagierte auf die Kritik an ihren Zuständen nicht durch eine Entgegnung, sondern ergriff Maßnahmen, um ähnliche künftige Berichterstattung zu verhindern. „Min. Grimme soll gebeten werden, studentische Zuschriften an den Neuen Hannoverschen Kurier zu verhindern. - die Universität auf der anderen Seite will ebenfalls schweigen.“ (Ein ähnliches Vorgehen gab es an der RWTH Aachen, deren Rektor Paul Röntgen im Februar 1946 eine Radiosendung des Nordwestdeutschen Rundfunks über die politisch zweifelhafte Haltung der dortigen Studenten verhinderte. Haude [1998] S. 51.) Als auch in der Neuen Zeitung, der Frankfurter Rundschau und der Rhein-Neckar-Zeitung (siehe dort den Artikel „Akademische Freiheit“, 6. Februar 1946.) 'Hetzartikel' gegen die Universität Göttingen im allgemeinen auftauchten, erwog der Senat, eine Berichtigung einzuklagen. Protokolle der Senatssitzungen vom 16. Januar 1946, 13. Februar 1946. UAG, Senatsprotokolle 1945-1949.
} 
Ein Vorherrschen der undemokratischen Haltung der Studenten blieb zumindest bis in die 50er Jahre bestehen, wie eine Frankfurter Umfrage der späten 50er Jahre von Habermas und anderen ergab. Sie stuften $13 \%$ der Befragten als unpolitisch ein, $11 \%$ als irrational, $19 \%$ als rational Distanzierte, $19 \%$ als naive Staatsbürger, $29 \%$ als reflektierte Staatsbürger und $9 \%$ als Engagierte. Das eigentlich demokratische Potential der Studenten lag noch unter zwei Fünftel. ${ }^{838}$ „Insgesamt stellten die Nachkriegsstudenten daher kaum ein Potential, von dem entscheidende [d.h. positive] politische Initiativen ausgegangen wären." ${ }^{839}$

\subsubsection{Aufnahmebedingungen in den ersten Nachkriegssemestern}

„Haltet uns die viele Mittelmäßigkeit vom Halse, bringt uns aber die Besten heran. Wo sie herkommen, ist uns gleichgültig. “840 So fasste der Göttinger Rektor Hermann Rein im Sommer 1946 die Haltung der Hochschullehrer in Bezug auf die Auswahlkriterien von Studenten zusammen. ${ }^{841}$ Erklären lässt sich diese Einstellung Reins damit, dass er selbst die NS-Zeit als „Diktatur der Mittelmäßigkeit oder gar der Minderwertigkeit“, die er ohnmächtig über sich ergehen lassen musste, interpretierte. ${ }^{842}$ In dieser Rhetorik ist die eben zitierte Maxime, die sich wie ein roter Faden durch das sich wandelnde Aufnahmeverfahren der Studenten zog, als eine Abkehr vom Nationalsozialismus zu verstehen, wenngleich die Wirkung eine andere war.

In der Nachkriegszeit herrschten völlig andere Verhältnisse für Studenten als in den Jahren zuvor. Da der Krieg viele am Studieren gehindert hatte, gab es in den ersten Nachkriegssemestern einen verstärkten Andrang zu den Universitäten. Zur Beseitigung kriegsbedingter Zerstörungen wurden die Studenten zu Aufbauarbeiten herangezogen. Von der Besatzungsbehörde wurden sie einer politischen Überprüfung unterzogen. Denn eine Maxime der alliierten Bildungspolitik war kurz gesagt: „German education shall be so controlled as completely to eliminate Nazi and militarist doctrines and to make possible the successful development of democratic ideas.“843 Die Universität Göttingen sah sich mit dem Problem konfrontiert, wie sie aus der großen Zahl an Bewerbern die Geeignetsten auswählen solle. Da die

\footnotetext{
838 Nach Jarausch [1984] S. 223.

839 Jarausch [1984] S. 222.

840 Rein auf der Hochschulkonferenz am 16. August 1946. Heinemann (Hrsg.) [1990]c S. 193. Reins Referat „Die Notwendigkeit und Möglichkeit des Zugangs aller Bevölkerungsschichten zu den Hochschulen“, aus dem das Zitat stammt, ist äußerst aufschlussreich für den Umgang der Professoren mit den Studenten. Ebenda S. 191200.

${ }^{841}$ Siehe auch den Leitartikel in der Göttinger Universitätszeitung vom 13.9.1946, „Die Hochschule den Besten!“, der bezeichnender Weise als redaktionelle Mitteilung ohne Autorennennung lief.

${ }^{842}$ Hermann Rein [1949] S. 9.
} 
Abiturzeugnisse der Bewerber kein geeignetes Auswahlkriterium darstellten, wurden mündliche Prüfungen aller Aufzunehmenden eingeführt. Dies versetzte die einzelnen Professoren in die Situation, selbst über die Auswahl der Studenten entscheiden zu können und selbst entscheiden $\mathrm{zu}$ müssen. Wie diese Überprüfungen abliefen und welche Auswirkungen die veränderten Voraussetzungen der Immatrikulation auf die Zusammensetzung der Studentenschaft hatten, soll im Folgenden gezeigt werden. Die hier erprobten Richtlinien und Vorgehensweisen werden auch deshalb besonders detailliert beschrieben, da sie aufgrund der frühen Wiedereröffnung der Göttinger Universität zum Vorbild für die anderen niedersächsischen Hochschulen wurden. ${ }^{844}$

Die gute Zusammenarbeit mit der britischen Militärregierung ermöglichte eine baldige Wiedereröffnung der Universität. Da das Sommersemester 1945 ausfiel, war der früheste Wiedereröffnungstermin das WS 1945/46. Die Sommermonate wurden genutzt, um die ersten Bewerber auf ihre Studieneignung zu prüfen; eine offizielle Immatrikulation durfte noch nicht vorgenommen werden. ${ }^{845}$ Diese Vorauswahl kann als Test für die große Aufgabe angesehen werden, die der Universität jeweils zu Beginn der nächsten Semester bevorstand. Es wurde hier im Kleinen probiert, die Eignung der angehenden Studenten in persönlichen Gesprächen festzustellen. Der Testcharakter des Verfahrens zeigt sich auch darin, dass es nur zu dem Besitz eines Vormerkscheins für die Studenten führte, der allein zum Studium noch nicht berechtigte. Er war für die neu in Göttingen angekommenen Bewerber jedoch Voraussetzung, um das Wohnrecht zu erwerben. Die schon im vorangegangenen Wintersemester in Göttinger Eingeschriebenen behielten ihr Wohnrecht, wenn sie sich zum Arbeitseinsatz meldeten. ${ }^{846}$

Mit der Vergabe des Vormerkscheins sollte lediglich eine privilegierte Studentengruppen bezeichnet werden, die im späteren Aufnahmeverfahren bevorzugt behandelt werden würde. Zur Erhaltung des Vormerkscheins, mussten die Studienbewerber zuerst einen Fragebogen ausfüllen. ${ }^{847}$ Bevorzugt zugelassen wurden Bewerber aus folgenden vier Gruppen:

1) Kriegsversehrte

2) Kriegerwitwen

3) Entlassene Soldaten, die mehr als drei Jahre ihrer akademischen Ausbildungszeit durch Wehrdienst eingebüßt hatten

\footnotetext{
843 Potsdamer Abkommen, 2. August 1945; zitiert nach Phillips [1983]b S. 1.

844 Wie eng sich zum Beispiel die TH Braunschweig an der Göttinger Praxis orientierte, zeigt Maaß [1998].

845 Fesefeldt [1962] S. 149.

846 Zum Vormerkungsverfahren siehe auch Heinemann (Hrsg.) [1990]c S. 50.

${ }^{847}$ In diesem Fragebogen wurde unter anderem gefragt nach: Beruf des Vaters, bisher studiert, Wehrdienst von bis, Kriegsversehrt, Berufsziel, ist das Studium finanziell gesichert, Fremdsprachenkenntnisse, sonstige Kenntnisse und Befähigungen (Schreibmaschine, Stenographie, Führerschein, Nähkenntnisse, Kochkenntnisse, usw.). UAG, Rundschreiben II.
} 
4) Studierende in den Abschlusssemestern. ${ }^{848}$

Die Bevorzugung der ersten drei Gruppen erklärt sich aus sozialen Gesichtspunkten. Hinzu kam im Verständnis der Professoren, dass die Soldaten wegen ihrer Kriegserfahrung eine zusätzliche Qualifikation besäßen: „Im übrigen werde vielfach die Meinung vertreten, dass die Kriegsteilnehmer die erforderliche Reifung im Felde erworben haben, auch wenn sie nicht die notwendige schulische Reife im vollen Umfang besäßen. “849

Die Vergabe des Scheins war in manchen Fällen an eine Vorprüfung gebunden, „namentlich dann, wenn angeblich die Zeugnisse verloren sind und nun festgestellt werden muß, ob man überhaupt einen Abiturenten oder Akademiker vor sich hat." 850 Zwei Prüfer wurden vom Dekan ausgewählt, die den Anwärter in Augenschein zu nehmen hatten. Die Bewerber mussten die Prüfer in den Privatwohnungen oder in den Instituten während der Sprechstunden aufsuchen und wurden dort in der Regel eine viertel bis halbe Stunde geprüft. Das Ergebnis der Prüfung wurde in ein Formular eingetragen, das dem Bewerber in einem verschlossenen Kuvert zur Weiterbeförderung mitgegeben wurde.

Der Dekan Eucken legte Kriterien fest, die bei der Prüfung zu berücksichtigen waren. So betonte er, dass auch aus der Gruppe der Kriegsversehrten ungeeignete Bewerber abgewiesen werden können. Bei Bewerbern aus der Gruppe der Abschlusssemester sollten Studentinnen besonders streng geprüft werden. ${ }^{851}$ Die Vormerkscheine wurden somit erst nach ,gründlicher Überprüfung der Eignung“652 ausgestellt und bedeuteten noch keine definitive Zugangsberechtigung zum Studium.

Die Universität Göttingen war bemüht, möglichst früh mit den Vorlesungen des WS 1945/46 zu beginnen, um wenigstens einige kohlenfreie Monate zu haben. Die Voraussetzungen dafür waren sehr gut. Die Universität blieb von Kriegsschäden großteils verschont. ${ }^{853}$ Nur ein Bombenangriff in den letzten Kriegstagen richtete beträchtlichen Schaden bei den in

\footnotetext{
848 „Merkblatt II für die Studierenden“. UAG, Rundschreiben II. Siehe auch die Auflistung der Bevorzugten in veränderter Reihenfolge: „Kriegsteilnehmer mit mehr als dreijähriger Dienstzeit, Versehrte ab Stufe II, Kriegerwitwen und Studierende in den Abschlusssemestern.“ aus „Mitteilung für die Studierenden“ vom 9. August 1945. UAG, Kur. XXX. A. a. Studierende. Allgemeine Vorschriften. VIII.

849 Dies berichtete Professor Creutzfeldt aus Kiel auf der ersten Hochschulkonferenz. Heinemann (Hrsg.) [1990]c S. 53

850 Protokoll der Senatssitzung vom 11. Juli 1945. UAG, Senatsprotokolle 1945-1949.

851 Dekan Eucken in einem Rundschreiben an die Institutsvorsteher der Math.-Nat. Fakultät, 19. Juli 1945. MPG-Archiv, III, 61, 1738.

852 Zitiert aus „Mitteilung für die Studierenden“ vom 9. August 1945. UAG, Kur. XXX. A. a. Studierende. Allgemeine Vorschriften. VIII.

8531945 waren von den 32 Hochschulen auf dem Gebiet der späteren Bundesrepublik und Westberlins 12 fast völlig zerstört, 8 konnten zu 25 bis $30 \%$ und 6 zur Hälfte genutzt werden; die übrigen 6 waren kaum oder gar nicht zerstört. Raiser [1966] S. 176. Zu den Bombenschäden in Göttingen siehe Bollnow [1950] S. 156.
} 
Bahnhofsnähe befindlichen geologischen, paläontologischen und zoologischen Instituten und am Theatrum Anatomicum an. Ein Jahr zuvor waren außerdem die Universitätsbibliothek und das psychologische Institut beschädigt worden. Während normalerweise die Vorlesungen eines Wintersemesters erst Ende Oktober begannen, konnte schon am 1. September 1945 die Universität wiedereröffnet werden und der Vorlesungsbetrieb am 17. September einsetzen. Damit war Göttingen die erste deutsche Universität, die nach dem Krieg in allen Fakultäten wieder ihre Tore öffnen konnte. Diese Vorreiterrolle und die geografische Lage nahe an der Grenze zur sowjetisch besetzten Zone bewirkten eine stark überregionale Sogwirkung auf Studenten aus dem gesamten ehemaligen Reichsgebiet. ${ }^{854} \mathrm{Mehr}$ als ein Fünftel der in Göttinger eingeschriebenen Studenten des WS 1945/46 kamen aus der sowjetischen Zone, Polen und Sowjetunion, nur knapp zwei Drittel aus der britischen Zone. ${ }^{855}$

Der große Andrang von Studenten machte eine Zulassungsbeschränkung notwendig. Noch Anfang September 1945 dachte man auf Grund des Wohnungsmangels an nur 3000 Studenten, ${ }^{856}$ die offizielle Beschränkung lag im ersten Nachkriegssemester bei 4500,857 doch schließlich nahm man 5000 auf; ein Großteil der etwa 12000 Bewerber musste trotzdem abgewiesen werden. ${ }^{858}$ Professor Plischke, der von November 1941 bis September 1943 Rektor gewesen war, übernahm am 4. September 1945 die Pressevertretung und hatte unter anderem die Aufgabe, die Studenten vor dem Zuzug nach Göttingen zu warnen. ${ }^{859}$

Aber nicht nur Göttingen musste mit dem Ansturm der Studenten kämpfen, auch die anderen wiedereröffneten Universitäten wurden mit diesem Problem konfrontiert. ${ }^{860}$ Die jungen Men-

$854 \mathrm{Zu}$ den allgemeinen Studienbedingungen und zur Atmosphäre siehe die Augenzeugenberichte von Kertz [1986], Gizler [1985] und Bahrdt [1988]. Durch die günstige Verkehrslage der Stadt an der Dreizonengrenze, durch Flüchtlinge, Vertriebene, Evakuierte und Rückwanderer hatte sich die ortsansässige Bevölkerung verdoppelt.

855 Siehe die prozentuale Auflistung der Herkunft der Göttinger Studenten in Heinemann (Hrsg.) [1990]c S. 99.

856 Schreiben des University Control Officier (UCO) vom 5. September 1945. UAG. Rek. 7101. Auch Smend nannte in Bezug auf die ursprünglichen Pläne zum numerus clauses die Zahl 3000 als angemessen. Siehe das Protokoll der zweiten Hochschulkonferenz in Bünde im Dezember 1945, in Heinemann (Hrsg.) [1990]c S. 96. 857 Siehe Rein [1948] S. 229.

858 „Die Zahl der Anmeldungen werden auf 12000 geschätzt.“ Protokoll der zweiten Hochschulkonferenz, in Heinemann (Hrsg.) [1990]c S. 96.

859 Protokoll der Senatssitzung vom 4. September 1945. UAG, Senatsprotokolle 1945-1949. Zu Plischke siehe auch den Artikel in den Göttinger Nachrichten vom 20. November 1941 anlässlich seiner Ernennung zum Rektor. Speziell gelobt wird dort Plischkes wissenschaftlicher „Einsatz der Völkerkunde im kolonialpolitischen Sektor“. „Besonders erfreulich ist, daß die rassen- und kulturgeschichtlichen Bildungswerte der Völkerkunde seit dem Neubau des Instituts [für Völkerkunde, 1936] aufs stärkste in die Öffentlichkeit getragen wurden. Dank dem Einsatz Prof. Plischkes und seiner Mitarbeiter sowie der Partei lernten bereits im ersten Jahre nicht weniger als 17500 Göttinger Besucher die Einrichtungen dieser Forschungsstätte [...] kennen. “ Zu Plischke und den Schwierigkeiten bei seiner Entnazifizierung siehe Brynjølfsson [1996] S. 43-48.

860 In Bonn wurden z. B. nur weniger als ein Sechstel der Bewerber aufgenommen. Siehe Kuhn, Rothe \& Mühlenbruch (Hrsg.) [1996] S. 85. In Heidelberg wurde die Universität im Januar 1946 wiedereröffnet. Die amerikanische Militärbehörde genehmigte eine Obergrenze von 3000 Studenten, beworben hatten sich 8000 . 
schen suchten in der Universität nach geistigem Halt. Ein damaliger Physikstudent erläuterte dies in einem Interview: Es war seine Sehnsucht nach ,,intellektueller Sauberkeit und Ehrlichkeit", die er durch das Studium befriedigen wollte. Diese 'saubere', ehrliche und aufrichtige Atmosphäre fand dieser Student gerade in den naturwissenschaftlichen Fächern der Göttinger Universität vor, und zwar nicht erst nach 1945, sondern auch während der NS-Zeit. Die Begrifflichkeit, die der Student zur Beschreibung des positiven Klimas wählte, benutzten Göttinger Physiker in einem aufschlussreichen Zusammenhang bereits in der unmittelbaren Nachkriegszeit. Richard Becker beantragte auf der Geschäftsversammlung der DPG im September 1947, dass die Gesellschaft dafür sorgen solle, dass Physiker, die sich in der NS-Zeit unkollegial verhalten hatten, keinen Einfluss bei der neuen Regierung bekämen. „Wir sind nicht begeistert von dem Entnazifizierungsgesetzt, halten es aber für unsere Pflicht, für Sauberkeit im Kreise der Kollegen zu sorgen." Unterstützt wurde Beckers Vorschlag von Walther Gerlach: „Wir müssen es für unsere Aufgabe halten, für Reinheit in unseren Reihen zu sorgen“. ${ }^{861}$ Die Grenzziehung, welche die Physiker in ihrer Gesellschaft 1947 durchführten, war eine zwischen erwünschten und unerwünschten Kollegen. Nach außen wurde sie als politisch motivierte Ausgrenzung ehemaliger Nationalsozialisten dargestellt. Doch wenn man den Blick nur auf die Nationalsozialisten unter den Physikern richtet, so gilt auch hier, dass die Erwünschten von den Unerwünschten geschieden wurden. Es gab unter den (weiterhin) angesehenen Physikern auch Nationalsozialisten, und diese konnten in einflussreichen Stellungen verbleiben. Der Begriff „Sauberkeit“ bedeutet in diesem Zusammenhang einen Kreis loyaler Kollegen, die sich für die Erhaltung eines hohen wissenschaftlichen Standards in ihrem Fach einsetzten. ${ }^{862}$ In diesem Sinn ist auch die Aussage des Studenten zu interpretieren, dass er eine saubere Atmosphäre in Göttingen vorgefunden habe.

Die Studenten suchten aber nicht nur nach einer von politischen Beeinflussungen vermeintlich freien, 'intellektuellen Insel'. Sie sahen sich auch dazu berufen, nach dem als Zusammenbruch empfundenen Kriegsende den Wiederaufbau Deutschlands in die eigene Hand zu nehmen. Viele mögen ihre Rolle im zerstörten Deutschland ähnlich empfunden haben wie Friedrich Meinecke, der mit seinem Buch „Die deutsche Katastrophe“ von 1946 dazu beitragen wollte, „ein neues, zwar gebeugtes, aber seelisch reineres Dasein zu beginnen

Siehe Pfetsch [1985/86] S. 369. In Hamburg bewarben sich 12000 zum Studium, von denen zirka 3300 angenommen wurden. Siehe Heinemann (Hrsg.) [1990]c S. 94; und GUZ (1946), Nr. 4, S. 14, wo von 11400 Bewerbern und 3481 Aufgenommenen die Rede ist.

861 Protokoll der Geschäftsversammlung vom 6.9.1947. DPG-Archiv, Nr. 40043.

862 Eine ähnliche Argumentationsfigur findet sich bei der Begründung der professionellen Wiederverwendbarkeit der Rasseforscher in der Nachkriegszeit, die sich angeblich „wissenschaftlicher und moralischer Sauberkeit" befleißigten. Siehe Sachse [2002]. 
und den Entschluss zu stärken, für die Rettung des uns verbliebenen Restes deutscher Volkund Kultursubstanz den uns verbliebenen Rest der eigenen Kraft einzusetzen."863 An die Studenten gerichtet schrieb Rektor Smend über die Verantwortung der Universitäten für das „deutsche Gesamtleben“ in der Göttinger Universitätszeitung: „An uns liegt es, ob dieser Anfang ein gutes oder schlechtes Vorzeichen sein wird für den Wiederaufstieg unseres Volkes im ganzen." $" 864$

In den ersten Nachkriegssemestern sah die Göttinger Universität eine ihrer Aufgaben im „Kampf gegen die Vermassung. “865 Sie fühlte eine ähnliche 'Gefahr der Vermassung“ wie in den frühen dreißiger Jahren. Damals gab es unter den Intellektuellen eine weit verbreitete Angst, nämlich „das Heraufkommen der Massen zur vollen sozialen Macht“, wie es Ortega y Gasset in seinem Buch Der Aufstand der Massen ausdrückte. Da dieses Buch in den Nachkriegsjahren recht populär war und auch von Göttinger Professoren sogar in offiziellen Eingaben zitiert wurde, ${ }^{866}$ soll kurz erläutert werden, welcher Begriff von „Masse“ und „Vermassung“ hier zu Grunde liegt. Die Massen stellten für Ortega y Gasset eine Bedrohung des öffentlichen Lebens dar. „Da die Massen ihrem Wesen nach ihr eigenes Dasein nicht lenken können noch dürfen und noch weniger imstande sind, die Gemeinschaft zu regieren, ist damit gesagt, daß Europa heute in einer der schwersten Krisen steht, die über Völker, Nationen, Kulturen kommen kann.“ Der Grund der Krise wurde im 'vermassten“ Menschen gesehen. Es war dies aber keine bloße Agitation gegen die Arbeiterklasse, denn „Masse bezeichnet hier keine gesellschaftliche Klasse, sondern eine Menschenklasse oder -art, die heute in allen gesellschaftlichen Klassen vorkommt“. Diesem Denken liegt eine strenge Dichotomie zwischen Masse und Elite zu Grunde, wobei Masse eine Charaktereigenschaft ist, die diejenigen besitzen, die „,sich schlechtweg für Durchschnitt“ halten. ${ }^{867}$ Dieses hier von Ortega y Gasset repräsentierte Denken war im Nachkriegsdeutschland bei Intellektuellen häufig anzutreffen. Der Kampf gegen die Vermassung an der Universität betraf also nicht nur 'zu große‘ Studentenzahlen, sondern auch die Auswahl nach bestimmten Menschentypen. ${ }^{868}$

\footnotetext{
863 Meinecke [1946] S. 7f.

864 GUZ (1945), Nr. 3, S. 1

865 Protokoll der Senatssitzung vom 1. September 1945. UAG, Senatsprotokolle 1945-1949.

866 In einem undatierten und nicht unterschriebenen Durchschlag der Denkschrift „Universität und

Währungsreform. Die Bedürfnisse der Naturwissenschaften“ findet sich folgendes Zitat von Ortega y Gasset: „Dabei bedürfen die Naturwissenschaften der Masse wie die Masse ihrer bei Todesstrafe; denn die heute lebende Zahl der Menschen kann auf unserem Planeten ohne Physikochemie nicht existieren. “ Eventuell hat diese Denkschrift Arnold Eucken verfasst. UAG, Rek. 1408.

867 Ortega y Gasset [1932]. Die Zitate finden sich auf S. 7, 11, 117.

868 Zur deutschen Nachkriegdiskussion von Wissenschaft, Technik und Massengesellschaft siehe Beyler [2003] S. 102-109.
} 
Dieser Kampf wurde an der Universität Göttingen mittels „,eines Systems von aufeinanderfolgenden Durchsiebungen“869 geführt: durch mündliche und schriftliche Prüfungen, durch Abschreckung, durch formale Ablehnungskriterien, durch eine Überwachung und Kontrolle der schon aufgenommenen Studenten. ${ }^{870}$ Er wurde nicht durch eine Ausscheidung der politisch Belasteten geführt. Die verschiedenen Mittel in der Abwehr der 'Massen' werden im Folgenden einzeln analysiert, beginnend mit der politischen Überprüfung.

\subsubsection{Entnazifizierung des Nachwuchses}

Die Entnazifizierung entstammte nicht einem deutschen Bedürfnis nach Ausschaltung von Vertretern einer verbrecherischen Politik. Dieser mangelnde deutsche Antrieb in der von der Militärregierung angeordneten politischen Überprüfung schlug sich auch in der Behandlung der Studenten nieder. Die ersten Richtlinien der Militärregierung zur Zulassung der Studenten (Instruction No. 12) wurden am 22. August 1945 erlassen und waren noch sehr allgemein gehalten. Vor allem höheren Führern in der SA und HJ, SS-Mitgliedern und Amtsträgern in der Partei war das Studium untersagt. Die Bewerber mussten eine Erklärung unterschreiben, dass sie diesen Gruppen nicht angehörten. ${ }^{871}$ Die Überprüfung der Studenten wurde den Universitäten anvertraut. ${ }^{872}$ Im Wintersemester 1945/46 wurden die Göttinger Studenten ohne systematische politische Überprüfung zugelassen. ${ }^{873}$ Wichtiger als politische Ansichten und Aktivitäten war den Professoren die materielle und geistige Not des akademischen Nachwuchses, die sie durch die Zulassung der Studienbewerber lindern wollten. Eine besonders fürsorgliche Behandlung erhielten die deutschen Ostflüchtlinge. Während des ersten Semesters mussten die Aufgenommenen die politischen Standardfragebögen ausfüllen.

\footnotetext{
${ }^{869}$ So formulierte es Rektor Smend auf der zweiten Hochschulkonferenz im Dezember 1945. Siehe Heinemann (Hrsg.) [1990]c S. 93.

870 Regierungsrat Wienert erläuterte auf der zweiten Hochschulkonferenz vier „Filter“, mit denen in Göttingen im WS 45/46 eine „Siebung“ der Studenten vorgenommen wurde. 1) schlagartige Anwesenheitsfeststellung, 2) Leistungsüberprüfung am Ende des Semesters, 3) Überprüfung der Vorbildung und Persönlichkeit bei fehlenden Reifezeugnissen, 4) Fleißzeugnisse von allen Studenten gefordert. Siehe Heinemann (Hrsg.) [1990]c S. 93f.

${ }^{871}$ Siehe Maaß [1998] S. 52. Dort sind in Fußnote 19 die sechs Gruppen der nicht Zuzulassenden angeführt. Neben dem Nachweis eines zum Studium berechtigenden Abschlusszeugnisses mussten die Bewerber ein polizeiliches Führungszeugnis vorlegen. Siehe „Bestimmungen über Immatrikulation und Rückmeldung zum WS 1945/46“, 24. August 1945, UAG, Kur. XXX. A. a. Studierende. Allgemeine Vorschriften. VIII. 872 Siehe Respondek [1992] S. 275ff.

873 Auf der ersten Hochschulkonferenz berichtete der Theologe Otto Weber über das Zulassungsverfahren der Universität Göttingen. Zu politischen Überprüfungen sagte er nur: „Studenten, denen die Militärregierung allgemein oder im Einzelfall das Studium untersagt, können nicht zugelassen werden." Siehe Heinemann (Hrsg.) [1990]c S. 49. Die dort in einer Fußnote angegebene Erläuterung der politischen Überprüfung bezieht sich nicht auf das WS 1945/46, sondern auf die folgenden Semester. Über das WS 1945/46 berichtet Kertz [1986] S. 25:

„Die Entnazifizierung spielte eine geringere Rolle.“ Auch in Heidelberg sollten aus der Sicht der Mediziner und Naturwissenschaftler Studenten aus politischen Gründen nicht ausgeschlossen werden. Pfetsch [1985/86] S. 377. In Hamburg wurden 1,6 \% der Bewerber aus politischen Gründen nicht aufgenommen. Krukowska [1993] S. 34.
} 
Im WS 1945/46 nahm die Universität Göttingen eine größere Zahl ehemaliger aktiver Offiziere und Parteimitglieder als Studenten in ihre Reihen auf. Der Rückblick eines damaligen Studenten liefert Motive dafür: „Die Georgia Augusta suchte die Kriegsteilnehmer, so gut sie es konnte, zu entschädigen, jedenfalls nicht weiter zu bestrafen, sondern ihnen einen Start ins zivile Leben zu ermöglichen. Die Professoren liebten ehemalige Soldaten und Offiziere, die mit unbezähmbaren Wissensdurst zum Studium kamen.“874 Dieser Praxis setzte die Militärregierung für das folgende Sommersemester einen Riegel vor. Zu Ostern 1946 wurden sämtliche Immatrikulationen aufgehoben und die Studenten einer politischen Überprüfung unterzogen, da die bisherigen Zulassungsbedingungen die Alliierten ,nicht befriedigen“ konnten. ${ }^{875}$ Die Rechtfertigung der Professoren, dass nach Leistungskriterien ausgewählt wurde, überzeugte die Briten nicht, da sie nicht den Eindruck hatten, dass das wissenschaftliche Niveau der Zugelassenen besonders hoch sei. Deshalb sollte in erster Linie die politische Qualifikation maßgebend für die Zulassung sein. ${ }^{876}$ Auf Grund ausgefüllter Fragebogen mussten sich die Studenten in fünf Gruppen einteilen lassen, von denen die beiden letzten (D und E) vom Studium ausgeschlossen waren:

A. niemals Mitglied der HJ, BDM, NSDAP, nie Antragsteller;

B. kein Mitglied aber Anwärter auf Mitgliedschaft, sowie diejenigen, die zwar Mitglied aber kein Führer in der HJ oder BDM waren;

C. kein ,aktivistisches Mitglied“ der NSDAP;

D. aktives Mitglied der NSDAP oder einer angeschlossenen Organisation;

E. „Diejenigen, die sonst unter die Entnazifizierungsbestimmungen der Militärkontrollbehörden fallen“" 877

Aus einer Statistik der politischen Fragebogen des WS 1945/46 geht hervor, dass in der Math.-Nat. Fakultät nur 15,4\% der Studenten in Gruppe A fielen, 63,9 \% in B, 3,3 \% in C und 17,4\% in D. Da die Fragebögen nicht sehr ernsthaft ausgefüllt wurden, ist für die tatsächliche Aufteilung eine Verschiebung nach C und $\mathrm{D}$ anzunehmen. ${ }^{878}$ Die Militärregierung wünschte, dass die Bewerber der Kategorien A und B bevorzugt aufgenommen würden, oder mit anderen Worten, dass die „Antinazis den anderen vorgezogen

\footnotetext{
${ }^{874}$ Kertz [1986] S. 31. Zur Integration der ehemaligen Offiziere in die westdeutsche Gesellschaft siehe Lockenour [2002].

875 Dekan der Rechts- und Staatswissenschaftlichen Fakultät an Kultusminister, 23. April 1947. UAG, Rek. 7101.

876 Siehe Heinemann (Hrsg.) [1990]c S. 117.

877 Aus: Militärregierung - Deutschland, Britisches Kontrollgebiet. Erziehungs-Anweisung an die deutschen Behörden Nr. 5. Zulassung von Studenten zu den Hochschulen (geltend für das Sommersemester 1946), UAG Rundschreiben der Georg-August-Universität 1945-50, abgedruckt in Krönig \& Müller [1990] S. 155. 878 UAG, Rek. 7101.
} 
werden““ ${ }^{879}$ Dies führte auf deutscher Seite zu Unmutsäußerungen. Auch der Göttinger AStA meldete sich im April 1946 zu Wort und kritisierte die Zulassungsbestimmungen scharf wegen ihrer einseitig politischen Kategorien. Das Fehlen von Leistungsgesichtspunkten führe zu einem „Hereinströmen ungeeigneter und unfähiger Elemente“. Bei der Klassifizierung nach politischen Kategorien sah der AStA eine Schwierigkeit in der Unterscheidung zwischen „wirklichen Nazis“ und den mit „unverdienter Härte betroffenen Studenten“. Eine Führerposition in HJ oder BDM alleine sei noch kein Beleg für nazistische Gesinnung, denn die Führer in Jugendverbänden hätten ihre Stellung nicht wegen politischer Leidenschaften erhalten, sondern „Begeisterung für das Neue, jugendlicher Idealismus und Tätigkeitsdrang, kindlicher Ehrgeiz und Geltungsbedürfnis“ habe sie zu Führern werden lassen. Die „skrupellose Parteiführung allerdings und ihre Propaganda [...] führten eine unwissende Jugend in masslose Verblendung hinein, in der sie heute hinausgerissen - von Führern und Idealen im Stich gelassen - in jäher Erkenntnis und gleichzeitig vor einem Nichts steht.“ Aber ganz unwissend war die Jugend auch nach Meinung des AStA nicht, denn die hauptamtlichen, hohen Führer (Bannführer usw.) seien auch politische Aktivisten und Fanatiker gewesen, während die unteren Ränge (Scharführer) anders zu behandeln seien. Der AStA sah durch die Entnazifizierung auch die 'Gefahr' der Verdrängung der männlichen Studenten durch weibliche, da die politische Betätigung, und damit die politische Belastung, der jungen Frauen „,naturgemäß“ geringer gewesen sei. ${ }^{880}$ Auch die Zulassung der besonders jungen Bewerber, die noch keine Möglichkeit hatten, in die Partei oder eine ihrer Gliederungen einzutreten, müsste beschränkt werden, da auch hier die politische Belastung geringer ausfalle und die älteren Jahrgänge verdrängt werden könnten. In einer langen, neun Punkte umfassenden Liste unterbreitete der AStA Vorschläge zur Durchführung der Erziehungsanweisung Nr. 5. Die Überprüfung der Studenten nur auf Grund der ausgefüllten Fragebogen genüge nicht, da sie nur ein ungenaues Bild liefere. Auch die formal nicht belasteten, deren ,nationalsozialistische Geisteshaltung“" aber bekannt sei, sollen ausgeschlossen werden. Besondere Berücksichtigung in der Beurteilung der Belasteten sollten finden: Vorzeitiges Ausscheiden aus der NSDAP, ihrer Gliederungen oder Verbänden, Kriegsversehrtheit, Verheiratung und Kinder (im Falle von Studentinnen, nur wenn diese Witwe ist), „wissenschaftliche Leistungsfähigkeit, wenn

\footnotetext{
879 So formulierte der Vertreter der Militärregierung, Mark, auf der Hochschulkonferenz im Februar 1946 den Zweck der Entnazifizierung der Studenten. Heinemann (Hrsg.) [1990]c S. 116. Die Delegation der britischen Association of University teachers schrieb in ihrem Bericht vom Mai 1947, es solle denjenigen ein Studium vorbehalten sein, ,die am meisten zu der Erwartung berechtigen, dass sie einen guten Gebrauch von ihm im Sinne einer Förderung sowohl des deutschen Wiederaufbaus wie der europäischen Sicherheit machen." Zitiert nach Phillips [1983]b S. 97.
} 
diese sich auch in Charakter und Persönlichkeit auswirkt", hohe Semesterzahl, wirtschaftliche Notlage („Für die Abweisung jedoch muss diese unerheblich bleiben“). Stärker Belastete, die schon die Mindestsemesterzahl studiert hatten, sollten als Gasthörer eingeschrieben werden. Für die abgewiesenen Studenten sollte es eine Einspruchsmöglichkeit geben. ${ }^{881}$

Die Angst, dass durch die Entnazifizierung intelligente Studenten nur deshalb aus den Universitäten verstoßen werden könnten, weil sie Parteiangehörige oder Führer von ParteiUnterverbänden gewesen waren, herrschte nicht nur bei der Studentenvertretung vor, sondern auch unter den Professoren. Ludwig Prandtl befürchtete durch die ,politische Auslese“ eine Bevorzugung der Mittelmäßigkeit, „während es doch gerade unsere Aufgabe sein muß, die überdurchschnittlich begabten jungen Leute zu fördern.“ In gleicher Stoßrichtung wie der AStA und auch zeitgleich mit dessen Denkschrift schlug Prandtl dem Rektor eine Berücksichtigung der Leistung vor, und zwar so, dass die politische Klassifizierung mit jener der Begabung kombiniert werden sollte:

„Hierbei wäre besonders darauf hinzuweisen, daß Jungens und Mädels unter 20 Jahren doch in politischen Dingen noch gänzlich unreif sind, und daß es deshalb falsch ist, Zulassung oder Nichtzulassung zur Universität abhängig zu machen von einem Entschluß der Jungen und Mädels, eine ihnen übertragene Stellung als Scharführer oder dergleichen anzunehmen oder abzulehnen, wobei die Ablehnung bei dem bekannten System der NSDAP sogar oft mit schwersten Unannehmlichkeiten verknüpft zu sein pflegte. In Wirklichkeit ist es doch so, daß gerade diejenigen, die sich durch schnelle Auffassung und größere Gewandtheit aus der Menge herausgehoben haben, den oberen Führern auffielen, und sie müßten dann keine frischen Jungens und Mädels gewesen sein, wenn sie sich über diese Anerkennung nicht einfach kindlich freuten. Und diese Zustimmung soll ihnen jetzt zum Verhängnis werden. Die Situation wäre vollständig gerettet, wenn die Bestimmung durchgesetzt würde, daß offensichtliche überdurchschnittliche Begabung in dem Sinne wirken soll, daß die Bewerber in die nächsthöhere Gruppe übergeführt werden, also B nach A, C nach B und D nach C. [...] Es kann auch zur Beschwichtigung der Militärregierung angeboten werden, daß alle diejenigen, die auf Grund der erbetenen neuen Bestimmungen in die höhere Gruppe versetzt worden sind, nach einem bzw. zwei Semestern nochmals überprüft werden, wobei auch charakterliche Eigenschaften zu berücksichtigen sein werden." 882

\footnotetext{
880 Das NS-Vorurteil, demnach Politik eine männliche Angelegenheit sei, überdauerte das Kriegsende, wie diese Äußerung verdeutlicht. Siehe Jarausch [1984] S. 203.

881 Am 1. April 1946 verfasste der AStA eine Denkschrift zur Entnazifizierung der Studentenschaft. Darin äußerte er sich positiv zu einer gerechten „Auslese“ nach Leistung und politischer Haltung, die als Auswahl der „Besten“ bei Entfernung ,nazistischer Elemente“ zu verstehen sei. Unterzeichnet war diese achtseitige Denkschrift von Moch. UAG, Math. Nat. 56.

882 Ludwig Prandtl an Rektor Rein, 1. April 1946 und mit Änderungen versehen, 2. April 1946. UAG, Rek. 7101. Die unter den Professoren anzutreffende Sorge einer Bevorzugung der Mittelmäßigkeit wird auch in Abschnitt 4.2.2 besprochen.
} 
Die Rhetorik von einer naiven, verblendeten Jugend, die zum aktiven Beitrag an Verbrechen bloß verleitet wurde, dürfte die Briten nicht unbedingt überzeugt haben; trotzdem stimmten sie Prandlts Vorschlag zu. In Übereinstimmung mit der Militärregierung wurden ehemalige 'zwangsweise“ NSDStB-Mitglieder nicht wie vorgesehen in Kategorie C eingestuft. ${ }^{883}$ Für die anderen Mitglieder von NS-Organisationen musste nach Prandtls Vorschlag verfahren werden.

Eine Mini-Mitläuferfabrik begann ihre mühselige Arbeit. Oft fehlten Fragebögen, die Glaubwürdigkeit der Angaben war zweifelhaft, die Einordnung in die Kategorien unklar. ${ }^{884}$ In 24 Sitzungen innerhalb von drei Monaten wurden 350 Einzelfälle geprüft; 68 persönliche Vorladungen fanden statt. 289 Fälle wurden höhergestuft, das waren über $80 \%$ der Belasteten. Das hohe Ausmaß der Hochstufungen erklärt sich aus der Struktur des Aufnahmeverfahrens. Der im Immatrikulationsausschuss sitzende Physiker Richard Becker fragte im April 1946 in der Fakultätssitzung nach, ob die weniger Belasteten unabhängig von ihrer wissenschaftlichen Eignung aufgenommen werden müssten, worauf ihm der Dekan Eucken nur die Möglichkeit der Höherstufung als Ausweg nannte. ${ }^{885}$ Die Angaben in den Fragebögen, die zur politischen Klassifizierung herangezogen wurden, wurden nicht auf deren Richtigkeit geprüft. Den politischen Klassifizierungen ist also nur bedingt Glauben zu schenken, denn in den Fragebögen der Studenten kamen öfters Falschangaben vor, die an anderen Universitäten auch zu Relegierungen führten. ${ }^{886}$ Es gibt einen Hinweis, dass auch in Göttingen „Tricks“ bei der Immatrikulation angewendet wurden. Dekan Eucken wurde bei den Immatrikulationsangelegenheiten von seinem Studenten Helmut Trawinski unterstützt. „Eucken versuchte zu helfen, und die ehemaligen Kriegsgefangenen kamen irgendwie - und

${ }^{883}$ Heinemann (Hrsg.) [1990]c S. 167.

${ }^{884}$ Dies berichtete Herr Mirbt laut Protokoll der Senatssitzung vom 6. April 1946. UAG, Senatsprotokolle 1945-1949.

885 Protokoll der Kommissionssitzung vom 11. April 1946. GPAMNFG, Protokollbuch III der mathematischnaturwissenschaftlichen Fakultät WS 1927/28 - SS 1946.

${ }^{886}$ Bei Krönig \& Müller [1990] S. 172f. sind einige Vorfälle von Fragebogenfälschungen der Jahre 1947/48 aufgeführt. An der Universität Marburg wurden deswegen 105 Studenten vom Studium ausgeschlossen, an der Universität Erlangen wurden 700 Studenten der Fragebogenfälschung verdächtigt, an der Universität Würzburg wurde 600 Studenten die Wiederzulassung verweigert. Zu Würzburg siehe auch die Rede von Prof. Seidlmayer [1949] S. 11, der zu den Bestrafungen der Studenten meinte: "Es ist wirklich höchste Zeit, dass damit endlich Schluß gemacht wird.“ Wie Maaß [1998] S. 70ff. für die TH Braunschweig zeigt, waren nicht nur die Studenten selbst an der Fragebogenfälschung beteiligt. Die dortige Sekretärin gab den Studenten Anleitungen zur Fälschung und schritt wenn nötig eigenhändig zu Aktenkorrekturen. Ihre politische Einstellung ist einerseits durch ihre frühere DNVP-Mitgliedschaft charakterisiert, andererseits durch die eigene Rechtfertigung ihres Tuns: Sie wollte „,deutschem Geist und deutscher Schaffenskraft ... helfen, dass der Körper nicht untergeht, der die intellektuelle Masse Deutschlands darstellt und der eben dieses Deutschland nicht ganz in Proletariat und verhungertem Herdenvieh versinken lassen soll.“ Daneben gab es Professoren, die bei korrekt ausgefüllten Fragebögen die Studenten bewusst entgegen den Anordnungen in eine weniger belastende Kategorie einstuften. Ebenda, S. 57. 
manchmal mit Tricks von Trawinski, über die Eucken hinwegsah, an der Universität unter." ${ }^{887}$ Der Immatrikulationsausschuss ${ }^{888}$ betonte, dass er die Einzelfälle ,gewissenhaft, aber zugleich wohlwollend“ geprüft habe. ${ }^{889}$ Studienbewerber, die 1946 in Braunschweig aus politischen Gründen zurückgewiesen wurden, wurden in Göttingen aufgenommen.890 Vermutlich wurden die Fähnlein-, Gefolgschafts-, Stamm- und Bannführer von den Hochschullehrern als Elite der Jugend begriffen, die sich somit von der verachteten Masse abhob. Dass unter ihnen nicht unbedingt die Dümmsten $\mathrm{zu}$ finden waren, meinte auch Minister Grimme in einem Plädoyer für eine Jugendamnestie im Februar 1946. ${ }^{891}$ Es ist daher in der wohlwollenden Behandlung dieser Jugendlichen kein innerer Widerspruch zu einer selbstgesetzten „strengen Auslese“ zu sehen. Man ist geneigt, zu glauben, dass in der Auslese nach jener Maxime verfahren wurde, die Friedrich Meinecke, der in der Nachkriegszeit in Göttingen weilte, ${ }^{892} 1946$ für die Deutschen hoffnungsvoll formulierte und forderte: „Mit Verantwortungsbewußtsein, mit reiner, humaner und vaterländischer Gesinnung!“"893

Für die Einsprüche gegen die Einstufung, welche die knapp $20 \%$ der Abgewiesenen erheben konnten, wurde von der Universität ein Ausschuss unter Vorsitz des Rektors Smend gebildet. ${ }^{894}$ Den durch das Entnazifizierungsverfahren aussortierten Studenten wurden außerdem Rehabilitierungskurse angeboten. ${ }^{895}$ Diese Kurse waren unter anderem dazu gedacht, Studenten, die kurz vor dem Examen standen, nach politischer Umschulung für ihren Beruf wiederzugewinnen. ${ }^{896}$

Bald konnte die Mitläuferfabrik ihre Produktion drosseln, denn mit der in der britischen Zone am 18. August 1946 erlassenen Zulassungsordnung war eine Jugendamnestie verbunden, die alle Jugendlichen ab Jahrgang 1919 betraf. Dadurch wurde ein Großteil der Klassifizierungsarbeit überflüssig. Die Studenten waren nur noch in drei Gruppen einzuteilen:

\footnotetext{
887 Becke-Goehring \& Eucken [1995] S. 52.

888 Der Ausschuss bestand aus dem Vorsitzenden Rektor Hermann Rein, Professor Richard Becker, Dozent Ziegler, Stadtsyndikus Kuss und Druckereileiter Arnholdt. Später kam ein Studenten-Ausschuss zur Entnazifizierung der Studentenschaft mit nur beratender Funktion dazu. Siehe: Protokoll der Senatssitzung vom 16. Februar 1946. UAG, Senatsprotokolle 1945-1949; UAG, Rek. 7101.

889 Siehe den Bericht des Immatrikulationsausschusses vom 10. Juli 1946. UAG, Rek. 7101. Die Praxis des Höherstufens scheint es zur selben Zeit auch an der TH Braunschweig gegeben zu haben. Siehe Maaß [1998] S. 56. ${ }^{890}$ Maaß [1998] S. 54.

${ }^{891}$ Heinemann (Hrsg.) [1990]c S. 178. Die Jugendamnestie sollte für die Jahrgänge ab 1912 gelten, damit die Begabtesten zum Zuge kommen können.

892 Rein [1948] S. 229.

893 Meinecke [1946] S. 157.

894 Dem Ausschuss gehörten noch Greve und der Vorsitzende des AStA Langmann an. Protokoll der Senatssitzung vom 21. Januar 1946. UAG, Senatsprotokolle 1945-1949.

895 Protokoll der Senatssitzung vom 10. Juli 1946. UAG, Senatsprotokolle 1945-1949.
} 
1) Nicht belastete Studenten, 2) Jahrgänge ab 1919, sofern diese nicht Kriegsverbrecher oder prominente Nazis waren, 3) Vor 1919 Geborene. Die dritte Gruppe wurde weiterhin nach politischer Belastung in vier Untergruppen untergliedert. Die Militärregierung schrieb vor, dass erst aus den ersten beiden Gruppen zuzulassen sei und nur bei noch freien Plätzen auch aus der dritten. ${ }^{897}$ In einem ersten Schritt sollte die akademische Qualifikation aller Kandidaten untersucht werden, und erst anschließend vom Sonderausschuss die zur Zulassung in Frage kommenden ausgewählt werden. ${ }^{898}$ Dies hätte den Vorteil gehabt, dass die politisch am wenigsten Belasteten hätten bevorzugt werden können. In der Praxis wurde hingegen die umgekehrte Reihenfolge angewendet, in der die deutschen 'Eignungsprüfer' aus den politisch Tragbaren die 'Geeignetsten' auswählen konnten. An der Universität Hamburg wurde genauso verfahren. In einem Bericht eines Mitglieds des Zulassungsausschuss vom Oktober 1948 heißt es, „dass fast alle Abgelehnten politisch so gut wie unbelastet sind [...] während sich unter den Zugelassenen immerhin allerlei Fälle für den Ausschuß befinden." 899

Entsprechend wenig Auswirkung hatte gesamt gesehen die Entnazifizierung auf die Immatrikulation gehabt. ${ }^{900}$ Ein Jahr nach der Jugendamnestie war die politische Belastung der Studenten laut Auskunft einer ,politischen Statistik der Studierenden für das Sommersemester 1947“ auffallend gering. Von den insgesamt 919 Studenten der Math.-Nat. Fakultät fielen 764 unter die Jungendamnestie. Die Restlichen wurden nach eventuellen Tricks bei der politischen Überprüfung und Höherstufungen wegen besonderer 'Begabung' wie folgt den Kategorien zugeordnet: 14 in die Kategorie A und 115 in die Kategorie B; lediglich 26 Studierende wurden als ehemalige Mitglieder der NSDAP oder ihrer Gliederungen entweder gleich in Kategorie C eingestuft, oder von D nach C oder B höhergestuft. 901

Die Anwesenheit vieler ehemaliger Offiziere unter den Studenten führte zu einer kritischen Stellungnahme eines ,antinazimilitaristischen Studentenausschusses“. Dieser vermutete mehr als das offiziell angegebene Drittel an Offizieren unter den Studenten und sendete Ende März

\footnotetext{
896 Siehe Heinemann (Hrsg.) [1990]c S. 130.

897 Siehe Maaß [1998] S. 58f. In Hamburg hielt man sich im Einvernehmen mit dem Kontrolloffizier nicht an die vorgeschriebene Reihenfolge. Krukowska [1993] S. 32.

898 Richtlinien für die Zulassung von Studenten von R. Herdman Pender, Director Eduction Branch, vom

18. Oktober 1946. UAG, Kur. XXX. A. a. Studierende. Allgemeine Vorschriften. VIII.

899 Schreiben des Mitglieds des Zulassungsausschuss der Universität Hamburg, Harriet Wegener vom

7. Oktober 1948 an den Syndikus der Universität Hamburg, zitiert nach Krukowska [1993] S. 33.

900 Siehe dazu Vollnhals (Hrsg.) [1991] S. 352; laut Schätzungen der Militärregierung konnten

Entnazifizierungsbestimmungen nach der Jugendamnestie nur mehr auf zirka $10 \%$ der Studierenden angewendet werden; siehe dazu Pingel [1985] S. 193.

901 Diese Statistik datiert vom 4. September 1947, Stichtag war der 1. September 1947. UAG, Kur. IX. 97 Bd. 1. 
1946 eine scharfe Kritik mit dem Titel „Zustände in Göttingen“ an die Hessischen Nachrichten, die diesen Beitrag jedoch nicht abdruckten, sondern dem Rektor der Universität Göttingen zur Stellungnahme weiterleiteten. Das Antwortschreiben des Rektors ist leider nicht überliefert. Dass der Rektor von einem Abdruck entschieden abgeraten haben wird, erscheint deshalb naheliegend, weil die Kritik nicht nur die Zulassungspraxis im Allgemeinen betraf, sondern auch Studentennamen von einem Oberst und Regimentskommandeur des Panzerregiments Hermann Göring und einem anderen Oberstleutnant genannt wurden und selbst die Professoren angegriffen und pauschal als „Nazis“ und „Charakterlumpen“ diffamiert wurden. ${ }^{902}$ Zur Veröffentlichung dieser „Zustände in Göttingen“ in den Hessischen Nachrichten kam es nicht, stattdessen lamentierte am 11. April 1946 der Journalist Kurt Eichner, dass sich ein Berg von Briefen junger Menschen, die über die Universitäten berichten, auf seinem Schreibtisch häufe. Er freue sich über die gesunde Kraft, die in der Jugend stecke, und forderte sie auf, im demokratischen Staat an ihrem Platz in der Gesellschaft mitzuarbeiten. ${ }^{903}$

Die Frankfurter Rundschau formulierte eine deutliche Kritik der Göttinger Zulassungspolitik. „Ein Student, der auf Grund seiner ehrenamtlichen Tätigkeit genaue Einblicke hat, schätzt, daß dort [in Göttingen] die reinen Nazi-Studenten 20 Prozent ausmachen, weitere 60 Prozent sympathisieren mit dem Nazismus.“ Die Aufnahme von ehemaligen Offizieren kritisierte derselbe Artikel vom Januar 1946 mit der Begründung, dass in der NS-Zeit „,ür die aktive Offizierslaufbahn nur die Bewerber mit Annahme rechnen konnten, die sich politisch stark in der HJ betätigt hatten. Dasselbe gilt für alle Reserveoffiziersanwärter, die sich freiwillig meldeten." 904

Wenn die Universität Göttingen die Veröffentlichung von mancher kritischer Stellungnahme verhindern konnte, so kamen doch einige Berichte über ihre Zulassungspolitik an die Öffentlichkeit. Die Militärregierung reagierte auf diesen öffentlichen Druck. Obwohl Rektor Smend im Oktober 1945 mit Major Beattie zur Übereinkunft kam, „dass eine starke Respektierung der militärischen Ehre der Studenten alles Übrige erleichtern werde,"905 und

\footnotetext{
902 Eine Abschrift befindet sich in UAG, Math. Nat. 56.

903 Artikel „Ihr sollt nicht abseits stehen“ von Kurt Eichner, Hessische Nachrichten, 11. April 1946, S. 2 unter der Rubrik ,Stimmen der Jugend“.

904 Siehe den Atikel von Wilhelm Karl Gerst 'Wer darf studieren', Frankfurter Rundschau, 29. Januar 1946.

905 In einer Aussprache zwischen Smend und Beattie im Oktober 1945 wurde auch die Behandlung der Studenten verhandelt. Smends Protokoll zufolge war Beatties Einstellung: 1) No importance of rumors. 2) Er erkenne Smends Meinung an, dass politische Gruppierungen bis dahin kaum vorlagen, und dass eine starke Respektierung der militärischen Ehre der Studenten alles Übrige erleichtern werde. 3) Jüngere Dozenten sollten sich der Studenten annehmen. Protokoll der Senatssitzung vom 30. Oktober 1945. UAG, Senatsprotokolle $1945-1949$.
} 
auch die Militärregierung im allgemeinen der Ansicht war, dass die Benachteiligung einer bestimmten Berufsgruppe ungerecht sei, ${ }^{906}$ hieß es in der von Control Officer Bird formulierten Regelung zur Zulassung vom September 1946 unter Punkt 3: „Frühere aktive Offiziere, die vor dem 1. Jan. 1919 geboren sind, sind nicht zuzulassen. Diese Bestimmung bezieht sich nicht auf die zum Sommersemester 1946 bereits ordnungsmässig zugelassenen früheren Offiziere.“907

Dass Bird die jungen Offiziere unangetastet ließ, widersprach den Zielen seiner vorgesetzten Stellen. Eine Vergleichsstatistik der vier Besatzungszonen, die vom Allied Education Committee erstellt wurde, zeigte, dass im Sommer 1946 in der britischen Zone deutlich mehr ehemalige aktive Offiziere sowie Reserveoffiziere zugelassen worden waren als in den anderen Zonen. ${ }^{908}$ Die Verantwortlichen in der britischen Erziehungsbehörde waren aber davon überzeugt, dass der deutsche Offizier keine Gewähr bietet, ein friedliebendes Deutschland aufzubauen. Die Offiziere stünden in einer Tradition, die ,wholly antagonistic to democracy“ sei. ${ }^{909}$ Es wurde als politisch falsches Zeichen angesehen, dass in der britischen Zone die meisten Offiziere zugelassen wurden. Deshalb gab der Direktor der Education Branch, R. Herdman Pender, einen Monat nach Birds obiger Anweisung bekannt: „Frühere aktive Offiziere der deutschen Wehrmacht dürfen als neue Studenten an Hochschulen oder Lehrerbildungsanstalten nicht zugelassen werden."910 Nun wurden auch die jüngeren aktiven Offiziere vom Studium ausgeschlossen, weiterhin aber nicht die schon immatrikulierten. Aus einer Statistik fürs WS 1946/47 geht hervor, dass in Göttingen rund 40 \% ehemalige Offiziere immatrikuliert waren, 6,7\% aktive und 33,2\% Reserveoffiziere, die Durchschnittsdienstzeit aller Studenten betrug 4 Jahre und 11 Monate. ${ }^{911}$ Im folgenden Semester war der Anteil der Offiziere etwas geringer. ${ }^{912}$ Das Verbot, aktive Offiziere zuzulassen, wurde schon im Februar

\footnotetext{
906 Siehe den Berichte „Die Universitäten in der Britischen Zone Deutschlands“ der Delegation der britischen Association of University Teachers, abgedruckt in Phillips [1983]b speziell S. 99 und die „Comments of the Control Commission" dazu, ebenda S. 169f.

907 UCO Bird an Rektor, 16. September 1946. UAG, Kur. XXX. A. a. Studierende. Allgemeine Vorschriften. VIII.

908 Siehe Phillips [1983]b S. 169, wo auch die genannte Vergleichstabelle abgedruckt ist. Wie die Änderungen der Zulassungsbedingungen 1946 sich an der Universität Münster auswirkten, zeigt Respondek [1992]

Kap. 10.6, und zur Aufnahme von ehemaligen Offizieren Kap. 10.8.2.

909 Siehe Phillips [1983]b S. 170.

910 Richtlinien für die Zulassung von Studenten vom Director Education Branch, R. Herdman Pender, vom 18. Oktober 1946. UAG, Kur. XXX. A. a. Studierende. Allgemeine Vorschriften. VIII.

911 UAG, Rek. 7101. Dort findet sich eine Liste über ehemaligen Dienstgrad und Versehrtenstufe der Studenten gegliedert nach Fakultäten.

912 Laut einer „politischen Statistik der Studierenden für das Sommersemester 1947“ vom 4. September 1947 waren an der Universität Göttingen 1605 ehemalige Offiziere bei insgesamt 4900 Studenten eingeschrieben somit $33 \%$. Soweit man den Angaben glauben schenken kann war in der Math.-Nat. Fakultät der Anteil mit 28 \% etwas geringer (32 ehemalige aktive Offiziere und 221 Reserveoffiziere bei 919 Studenten). Den größten
} 
1947 wieder aufgehoben. Eine sorgfältige Einzelüberprüfung sollte die untragbaren Kandidaten fern halten. ${ }^{913}$ Zum WS 1948/49 stieg der Anteil der aktiven Offiziere leicht an. ${ }^{914}$ Rektor Rein und zwei seiner Kollegen berichteten im April 1947, dass „keine der politischen Parteien bei der Zulassung aktiver Offiziere zum Studium Schwierigkeiten mache.“915

Eine Möglichkeit, auch politisch Untragbare aufzunehmen, bestand in der Zulassung von Gasthörern. Diese wurden „stillschweigend“ weder in das Kontingent des numerus clausus gezählt, noch bis zum WS 1946/47 politisch überprüft. ${ }^{916}$ Hier handelte es sich besonders um ältere Studenten, die nicht unter die Jugendamnestie fielen. Nach alter Gepflogenheit wurden nach 1945 auch die Doktoranden wieder als Gasthörer inskribiert. ${ }^{917}$ Im Prinzip gab es drei Gruppen von Gasthörern: a) Fremde, b) Doktoranden und Mitarbeiter, die für die Forschung wichtig sind und c) Examenskandidaten. ${ }^{918}$ Die Militärregierung verlangte ab WS 46/47 deren lückenlose Überprüfung. Da es bei der Aufnahme der Gasthörer öfter zu Schwierigkeiten gekommen war, wurden die Dekane vom Rektor angewiesen, dass für Nichtimmatrikulierte, wie zum Beispiel Gasthörer, auf keinen Fall irgendwelche Bescheinigungen fürs Arbeitsamt oder Bergungsamt auszustellen seien, sofern nicht durchsichtige und anerkannte Bindungen (wie zum Beispiel Doktorand) vorlägen. 919

Nachdem die Militärregierung im Jahr 1949 die Entnazifizierung durch die Aufhebung der Erziehungsanweisung Nr. 5 aufgegeben hatte, erklärte auch das Kultusministerium besondere Einrichtungen zur politischen Überprüfung der Zulassungsbewerber für überflüssig und überließ den Auslese- und Immatrikulationsausschüssen, „,von Fall zu Fall“ die politische Belastung von Studienbewerbern zu prüfen.920 Der Senat diskutierte daraufhin, ob den

\footnotetext{
Anteil aktiver Offiziere hatte die Theologische Fakultät mit 8,4 \%, den geringsten die Mediziner mit 1,9\%. UAG, Kur. IX. 97 Bd. 1. 
Ausschüssen feste Richtlinien für solche von-Fall-zu-Fall-Entscheidungen gegeben werden sollen. „Der Senat verzichtet darauf, bittet aber die Dekane, in allen Fällen, die nach dieser Richtung zu Zweifeln Anlass geben könnten, insbesondere also bei Bewerbern, die heute über 30 Jahre alt sind, von sich aus die ihnen geeignet erscheinenden Ermittlungen anzustellen und Zweifelsfragen gesondert dem Immatrikulationsausschuss zur Entscheidung vorzulegen."921 Eine Forderung der Gewerkschaft nach Einführung eines eigenen Ausschusses, bei dem Anzeigen über politisch belastete Studenten eingebracht werden sollten, lehnte die Universität schon Anfang 1948 mit der Begründung ab, dies würde „,eine bedenkliche Förderung des Denunziantentums zur Folge haben“".922

Damit war die Entnazifizierung der Studenten praktisch endgültig vom Tisch. Im Sommer 1951 wurde im Senat konsequenterweise beschlossen, „dass für die neu zu druckenden Anträge auf Zulassung zum Studium künftig die Fragen nach früherer politischer Betätigung bzw. nach Schädigung durch das NS-Regime in Fortfall kommen."923 Dass hier politisch Belastete und Opfer des NS in einem Atemzug genannt werden, erinnert an die Synchronisation des berüchtigten „131er“-Gesetzes zur Wiedereingliederung 'Entnazifizierter' in den öffentlichen Dienst mit dem 'Wiedergutmachungsgesetz' im Jahr 1951, dem selben Jahr, in dem der obige Senatsbeschluss gefasst wurde. ${ }^{924}$ Es gibt allerdings einen unschönen Unterschied: Während in der Versorgungs- und Wiedergutmachungsgesetzgebung sowohl Opfer wie Täter eine Besserstellung erfuhren, wurde bei den Studenten den Opfern eine Bevorzugung entzogen und gleichzeitig die politische Belastung unter den Mantel des Schweigens gehüllt. § 5 der Zulassungsordnung von 1948 regelte nämlich die Bevorzugung von Bewerbern gleicher fachlicher Eignung. Als erster Punkt sind „Bewerber mit Anrecht auf politische Wiedergutmachung“ aufgeführt. ${ }^{925} \mathrm{Da}$ die Universität nicht mehr danach fragte, konnten Bewerber dieser Gruppe nicht festgestellt und daher auch nicht bevorzugt werden.

\footnotetext{
921 Protokoll der Senatssitzung vom 25. Januar 1950. UAG, Senatsprotokolle 1949-1954.

922 Rektor Rein an Kultusminister Grimme, 13. Februar 1948. UAG, Kur. XXX. A. a. Studierende. Allgemeine Vorschriften. IX.

923 Protokoll der Senatssitzung vom 13. Juni 1951. Ein Auszug dieses Protokolls findet sich auch in UAG, Rek. 7101.

924 Zum „131er“-Gesetz und der Rehabilitierung und Versorgung der „131er“ siehe Frei [1996/99] bes. Kap. I.3.

925 Ein Exemplar der Zulassungsordnung befindet sich in UAG, Rek. 7101. Fünf Gruppen genossen eine Bevorzugung. Die erste wurde schon genannt. Es folgen Kriegsversehrte, Bewerber aus ,wirtschaftlich schlechter gestellten Volksschichten“, Bewerber mit erlittenem Zeitverlust durch Kriegsdienst oder Gefangenschaft und schließlich noch sonstige Kriegsgeschädigte. Der Senat beschloss am 13. Juni 1951 ebenfalls, dass ,die Frage nach früherem Wehrdienst beibehalten und die Frage nach aktivem Offiziersstand durch die Frage nach letztem Dienstgrad ersetzt werden" solle. Dadurch konnten diejenigen, die durch Kriegsdienst einen Zeitverlust erlitten hatten, weiterhin bevorzugt werden. UAG, Rk. 7101.
} 


\subsubsection{Abschreckung und formale Ablehnungskriterien}

Eine Strategie im „Kampf gegen die Vermassung“ bestand darin, bestimmten Gruppen von Studierwilligen jede Hoffnung auf ein mögliches Studium derart zu nehmen, dass sie erst gar nicht versuchten, das Aufnahmeverfahren zu bestehen. Die Universität konnte diese Strategie relativ autonom umsetzen und die Zulassungsbedingungen selbst festlegen, ohne an ministerielle Vorgaben gebunden zu sein. ${ }^{926}$ Die einzelnen Punkte wurden mit der britischen Militärbehörde abgesprochen, deren Einflussnahme in den Zulassungsvorschriften jedoch kaum zu erkennen ist. Im August 1945 teilte der Rektor den zukünftigen Studenten die Bedingungen für ein Studium in Göttingen in verschiedenen Ankündigungen schrittweise mit. ${ }^{927}$ Aus einem Mitteilungsblatt vom 9. August erfuhren die Bewerber, dass sie nicht in Göttingen studieren dürften, wenn es eine ihrem Heimatort näher liegende Hochschule gebe. Wenn sie kein normales Reifezeugnis vorweisen könnten, würden sie besonders überprüft. Vor allem Frauen waren davon betroffen: „Studentinnen, die auf Grund der genannten Bescheinigungen [Reifevermerke, Sonderreifevermerke und andere Ersatzprüfungen] oder des hauswirtschaftlichen Abiturs nach dem 1. November 1943 ihr Studium begonnen haben, müssen vorläufig ihr Studium unterbrechen."928 Während der erzwungenen Unterbrechung konnte das Reifezeugnis in einem sechsmonatigen Übergangskurs nachgeholt werden. Diese Maßnahme begründete Rektor Smend gegenüber der deutschen Hochschulbehörde mit „der Unzulänglichkeit der Vorbildung mancher nach bisherigem nationalsozialistischem Recht zuzulassender Studienanwärter"،.929 Auf diese Weise stellte Smend die Benachteiligung der Studentinnen als Korrektur einer vermeintlich falschen nationalsozialistischen Politik dar und schirmte sich dadurch gegen Kritik ab. Für viele Frauen bedeutete diese Maßnahme das Ende ihres Studiums. ${ }^{930}$ Neue Abiturientinnen sahen mit ihren meist formal unzureichenden Abiturzeugnissen wenig Chancen auf eine erfolgreiche Umsetzung ihrer Studienpläne. Dieses formale Ablehnungskriterium wurde im Laufe der Zeit durch Beschlüsse der Nordwestdeutschen Hochschulkonferenzen geregelt. Reifezeugnisse der hauswirtschaftlichen

\footnotetext{
926 Siehe Rektor Smend an den Oberpräsident in Hannover, 31. August 1945: „Ein zweiter Punkt, in dem wir verhältnismässig selbständig vorgehen mussten, war die Feststellung der Zulassungsbedingungen zur Universität. [...] Wir bitten auch hier um nachträgliche Genehmigung.“ UAG, Kur. XXX. A. a. Studierende. Allgemeine Vorschriften. VIII.. Siehe auch Krönig \& Müller [1990] S. 131.

927 Über die diese Bedingungen aushandelnden Senatssitzungen berichtet Fresefeldt [1962] S. 163.

928 Rektor Smend in einer „Mitteilung für die Studierenden“vom 9. August 1945. UAG, Kur. XXX. A. a. Studierende. Allgemeine Vorschriften. VIII. Siehe zur Beibehaltung dieser Regelung im SS 1946 Heinemann (Hrsg.) [1990]c S. 132.

${ }^{929}$ Schreiben Rektor Smend an den Herrn Oberpräsidenten in Hannover, 31. August 1945. UAG, Kur. XXX. A. a. Studierende. Allgemeine Vorschriften. VIII.
} 
Form, die vor 1947 erworben wurden, berechtigten erst nach Ablegung des „Kleinen Latinums“ zur Immatrikulation. „Wenn wir das Latein streichen, haben wir dieselbe Entwicklung wie im Dritten Reich,“ meinte der Göttinger Rektor Rein 1947.931 Später erworbene Reifezeugnisse berechtigten überhaupt nicht mehr zum Studium. Reifevermerke berechtigten ebenfalls nicht zur Immatrikulation. ${ }^{932}$

Vom Studium ausgeschlossen waren des Weiteren politisch besonders belastete Personen und Chemiestudenten des 2. bis 7. Semesters, da kein Gas für Laborexperimente vorhanden war. Da die Universität trotz dieser Einschränkungen zu viele Bewerber befürchtete, folgte in der oben zitierten Mitteilung folgende Warnung:

„Wegen besonders schlechter Berufsaussichten wird vor dem Studium der Medizin, der Physik (Diplom), der Chemie (Diplom) und der Germanistik gewarnt. Diese Warnung gilt insbesondere für Studentinnen. Selbst ausgezeichnet befähigte Studierende können kaum auf Verwirklichung ihrer Berufspläne hoffen." 933

Zwei Wochen später teilte der Rektor den künftigen Studenten schließlich detaillierte „Bestimmungen über Immatrikulation und Rückmeldung zum WS 1945/46“ mit. Die Warnung für Studentinnen wurde hier unmissverständlich in Form von Ablehnungsgründen formuliert: „Die Zulassung kann in der Regel nicht erfolgen [...] b) bei weiblichen Studierenden in Fachrichtungen mit besonders ungünstigen Berufsaussichten, namentlich wenn sie erst im Beginn des Studiums stehen.“ Die Klausel „,in der Regel“ ließ zwar Ausnahmen implizit zu; große Hoffnungen konnten sich die Frauen aber bei diesen Bestimmungen nicht machen. Unter den bevorzugt aufzunehmenden Bewerbergruppen wurden nun neben Kriegsgeschädigten ${ }^{934}$ auch Studenten berücksichtigt, „die durch politische Maßnahmen der vergangenen Regierung erhebliche Zeit zu ihrer Berufsausbildung eingebüsst haben". 935

\footnotetext{
930 Von den vielen Physikstudentinnen, die mit Kriegsende ihr Studium abbrachen, kam keine einzige später als Physikstudentin zurück an die Universität Göttingen. Siehe Abschnitt 2.4.2.

931 Rein auf der Hochschulkonferenz am 28. März 1947. Heinemann (Hrsg.) [1990]c S. 291. Rein war auch der Ansicht, die „Lateinlosigkeit“ verschärfe die Klassengegensätze. „Auf dem angestrebten Wege zum Europäertum ist die Vorbildung im Lateinischen wichtigste Voraussetzung.“

932 UAG, Rek. 7101. Siehe auch den Beschluss Nr. 5 der Hochschulkonferenz in Goslar, Februar 1946, Heinemann (Hrsg.) [1990]c S. 134.

933 Rektor Smend in „Mitteilungen für die Studierenden“ vom 9. August 1945, UAG, Kur. XXX. A. a. Studierende. Allgemeine Vorschriften. VIII. Zu anderen 'amtlichen` Prognosen mit negativ-warnendem Tenor siehe Krönig \& Müller [1990] S. 128 und Kap. 15.

934 Siehe die vier bevorzugten Gruppen für die Vergabe eines Vormerkscheins in Abschnitt 2.3.2.

935 „Bestimmungen über Immatrikulation und Rückmeldung zum WS 1945/46“, 24. August 1945. UAG, Kur. XXX. A. a. Studierende. Allgemeine Vorschriften. VIII.
} 
Die Richtlinien zeigen deutlich, dass die Universität vor allem eine Elite wissenschaftsbegeisterter Studenten aufnehmen wollte. Besondere soziale Rücksichtnahme galt den Ostvertriebenen, Kriegsversehrten und Kriegsrückkehrern. Frauen benötigten den Status der Kriegerwitwe, um einen akzeptierten Anspruch auf ein Studium anmelden zu können. Selbst wenn sich Frauen in der Studienabschlussphase befanden und damit eine formale Bevorzugung genossen, mussten sie eine besonders strenge Behandlung überstehen. Dies wurde schon bei den ersten Bewerberinnen um den Vormerkschein so gehandhabt. 936 Diese diskriminierende Praxis, die sich gerade in den Naturwissenschaften deutlich zeigte, mag einige potentielle Studentinnen abgeschreckt und von ihren ursprünglichen Studienplänen abgebracht haben.

Anders als an anderen Hochschulen wurden in Göttingen Aufräumarbeiten nicht zur Voraussetzung zum Studium und auch nicht zur Verpflichtung für bereits Studierende gemacht, was unter anderem daran lag, dass Göttingen im Krieg nicht so stark zerstört wurde. ${ }^{937}$ Es wurde jedoch erwartet, dass die Studenten sich am Arbeitseinsatz freiwillig beteiligten. Im Wintersemester 1947/48 wurden nur noch die jüngeren unter den Erstsemestern zu einem vom Akademischen Hilfswerk organisierten Arbeitseinsatz herangezogen. Der AStA forderte die Schaffung einer Rechtspflicht, die die Entfernung der Studenten, falls sie sich dem Arbeitsdienst entzögen, ermöglichen sollte. Daraufhin betonte der Senat, dass der Arbeitseinsatz den Charakter einer „kameradschaftlichen Ehrenpflicht“ haben sollte, deren Verletzung nur zum Verlust der Benefizien des Akademischen Hilfswerks und zur öffentlichen Anprangerung führen könne. ${ }^{938}$

In einem geringen Maße abschreckend könnte auch die Ankündigung eines verpflichtenden Vorstudiums gewirkt haben. Jedenfalls wurde das eingeführte Vorsemester als schwer verstimmende Strafe für die dazu Bestimmten empfunden. ${ }^{939}$ Schließlich bedeutete es eine Verlängerung des angestrebten Studiums um ein Semester, vorausgesetzt man konnte es mit positivem Erfolg absolvieren. Die Verringerung der Anfängerzahlen funktionierte hier aber weniger durch Abschreckung als vielmehr durch genaue Prüfung und Auswahl der Kandidaten.

\footnotetext{
936 Siehe die Erläuterungen zum Prüfungsverfahren des Dekans Eucken, dargestellt in Abschnitt 2.3.2.

937 In Braunschweig waren Aufräumarbeiten verpflichtend, Maaß [1998] S. 59; ebenso in Münster, Respondek [1992] Kap. 10.7.

938 Protokoll der Senatssitzungen vom 12. November 1947, 10. Dezember 1947. UAG, Senatsprotokolle 19451949.

939 Siehe Protokoll der Senatssitzung vom 10. Oktober 1945. UAG, Senatsprotokolle 1945-1949.
} 


\subsubsection{Prüfung und Überwachung der Studenten}

Das neu eingeführte sechsmonatige Vorstudium war eine Reaktion auf die schlechten Vorkenntnissen der Neubewerber. ${ }^{940}$ Hatte der Bewerber nur ein Ersatzreifezeugnis vorzuweisen, wurde er in der Regel zur Nachholung der Schulbildung an eine Schulbehörde verwiesen. ${ }^{941}$ Das Vorstudium wurde bei der Zulassung zum Studium nicht nur für alle Neubewerber verpflichtend vorgeschrieben, sondern auch für alle Erst- und Zweitsemester bei mehr als drei Jahre Studienunterbrechung. Die Fakultät konnte in Ausnahmefällen ein Überspringen des vorgeschriebenen Vorstudiums bewilligen. Sie konnte aber auch bestimmen, dass der Bewerber am Vorstudium teilzunehmen hatte, obwohl die formalen Kriterien für eine reguläre Immatrikulation erfüllt waren. Durch diese Möglichkeit, die klare Regelung zu umgehen, war den Professoren einiger Spielraum gegeben, sodass in jedem Einzelfall nach Belieben entschieden werden konnte. Gegen die Entscheidung der Fakultät gab es kein Einspruchsrecht. 942

Das im Göttinger Zentralinstitut für Erziehung und Unterricht durchgeführte Vorstudium bestand aus wöchentlich je vier Stunden Deutsch und Mathematik plus vier Stunden Englisch oder Französisch. Für Naturwissenschaftler wurde noch zusätzlich Physik und Chemie unterrichtet. Nebenher konnten die Teilnehmer schon reguläre Vorlesungen ihres Faches im Umfang von höchstens zehn Wochenstunden hören. Neben den allgemeinen Studiengebühren musste fürs Vorstudium eine Pauschale von RM 90,- bezahlt werden. ${ }^{943}$ Alle Studenten mussten zum Abschluss des Vorstudiums die Aufnahmeprüfung an der Fakultät ablegen. Dort wurden sie von den Lehrkräften geprüft und beurteilt und dann den Dekanen überwiesen, die eine Klausur veranstalteten, die nicht angelernten Gedächtnisstoff zum Gegenstand hatte und eventuell eine kurze Aussprache beinhaltete. ${ }^{944}$ Inwieweit diese Prüfungen sachlich und objektiv abliefen, kann nur spekuliert werden. Ein Student Göbel denunzierte laut Senatsprotokoll die deutschen Professoren in Zusammenhang mit Abschlussprüfungen

\footnotetext{
940 Berichte über die unterschiedliche Handhabung von Vorsemestern an den verschiedenen deutschen Hochschulen finden sich bei Krönig \& Müller [1990] Kap. 7.

941 Als Ersatzreifezeugnisse galten Reifevermerke, Sonderreifezeugnisse. War der abgelehnte Bewerber in Göttingen ansässig, wurde er ans dortige Zentralinstitut für Erziehung und Unterricht verwiesen. Ab SS 1946 konnten keine Immatrikulationen mit Reifevermerken vollzogen werden. Siehe Heinemann (Hrsg.) [1990]c S. $48,132$.

942 Bestimmungen über Immatrikulation und Rückmeldung zum WS 1945/46, vom 24. August 1945. UAG, Kur. XXX. A. a. Studierende. Allgemeine Vorschriften. VIII.

943 Siehe z. B. das Schreiben von Dr. Glaß vom 26. September 1945 des Zentralinstituts für Erziehung und Unterricht, oder das Schreiben des Oberpräsidenten aus Hannover vom 1. September 1945; beide in UAG Rek. 7101; außerdem Heinemann (Hrsg.) [1990]c S. 51.

944 Protokoll der Senatssitzung vom 16. Januar 1946. UAG, Senatsprotokolle 1945-1949.
} 
ausländischer Studenten als unsachlich. Diese Kritik wurde mit der Behauptung abgetan, Göbel sei ein „Wirrkopf mit Erlöserideen“. 945 Bestand der Kandidat die Klausur am Ende des Semesters, wurden ihm die parallel besuchten Vorlesungen anerkannt, und er konnte darauf aufbauend weiterstudieren. 946

Das Senatsprotokoll hielt fest, dass alle Fakultäten die Vorstudiumskurse für das Sommersemester 1946 für unnötig hielten. ${ }^{947}$ Daher wurde Ende 1946 das Vorstudium in Göttingen abgeschafft. 948 Die im Dezember 1946 vom Ministerium für Volksbildung, Kunst und Wissenschaft vorgeschlagenen Kurse für Studenten und Studienbewerber, die wegen Überfüllung der Universität nicht immatrikuliert werden konnten, fanden die prinzipielle Zustimmung des Senats. Die Einrichtung fachlicher Kurse wurde jedoch abgelehnt. 949

Zur Reduzierung der Studentenzahlen war das Vorstudium nur wenig geeignet. Es verschob das Problem bloß um ein Semester nach hinten. Vielleicht war dies mit ein Grund, warum es so bald aufgegeben wurde. Das entscheidende Instrument gegen die befürchtete 'Vermassung' war die Aufnahmeprüfung, die von der jeweiligen Fakultät durchgeführt wurde. Ich gehe im folgenden vor allem auf die Praxis der MathematischNaturwissenschaftlichen Fakultät ein, die einen vergleichsweise hohen Anspruch an die Bewerber setzte.

Die Richtlinien für das jeweils kurz vor Semesterbeginn stattfindende Aufnahmeexamen wurden bereits im Juni 1945 in einem Entwurf für einen Studien- und Prüfungsplan formuliert. In diesem Examen wollten die Professoren nicht nur das fachliche Wissen des Bewerbers feststellen, sondern sie wollten vor allem einen Eindruck erhalten, „ob eine für das Studium ausreichende Begabung und vor allem einige unerläßliche allgemeine Fähigkeiten vorhanden sind: rasches und logisches Denken, gute Beobachtungsgabe, Fähigkeit, sich zu konzentrieren."950 Für das vorwiegend mündliche Examen wurde eine Dauer von fünf Stunden veranschlagt. Die zu Prüfenden wurden in Gruppen von 12 bis 15 Anwärtern zusammengefasst. In der ersten Stunde wurden allgemeine Fragen aus dem Gesamtgebiet der Naturwissenschaft mündlich behandelt. Danach musste der Prüfling in einer Stunde eine schriftliche Schilderung eines bekannten oder vorgeführten Naturvorgangs verfassen. Dieser

\footnotetext{
945 Protokoll der Senatssitzung vom 2. Februar 1946. UAG, Senatsprotokolle 1945-1949.

946 Krönig \& Müller [1990] S. 133.

947 Protokoll der Senatssitzung vom 8. Mai 1946. UAG, Senatsprotokolle 1945-1949.

948 Krönig \& Müller [1990] S. 117.

949 Protokoll der Senatssitzung vom 8. Januar 1947. UAG, Senatsprotokolle 1945-1949.

950 Das Zitat wie die folgende Darstellung aus: „Erster Entwurf für einen zum Magister bezw. Doktor führenden Studien- und Prüfungsplan der Math.-Nat. Fakultät der Universität Göttingen (Juni 1945)“. UAG, Rek. 7101.
} 
erste Teil der Prüfung sollte einen Eindruck der allgemeinen Fähigkeiten vermitteln. Der zweite Teil bestand aus drei jeweils einstündigen, mündlichen Prüfungen in Mathematik und zwei beliebig zu wählenden naturwissenschaftlichen Fächern. Auf Grund erster Erfahrungen schlug der Dekan Eucken im April 1946 Richtlinien für die Aufnahmeprüfung vor. „Es soll im wesentlichen eine psychotechnische Prüfung in Verbindung mit Prüfung auf Begabung und logisches Denken sein."951 Die Durchführung der Prüfungen war den einzelnen Abteilungen aber weitgehend freigestellt. ${ }^{952}$

Diese detaillierte Regelung wurde nicht so starr angewendet, sondern es gab Möglichkeiten zur Abweichung durch die in der Nachkriegszeit so häufig angewendete von-Fall-zu-FallEntscheidung. Das letzte Wort hatte in jedem Fall der Dekan. Zum Beispiel konnten sich Bewerber, die einzelnen Professoren schon bekannt waren, einen Teil der Aufnahmeprozedur ersparen, wie folgender Bericht erläutert:

„Bereits im Juli 1945 habe ich mich bei den Professoren Pohl (Experimentalphysik) und Becker (Theoretische Physik) vorgestellt. Ich wurde von ihnen mehr ausgefragt als geprüft. Schon während des Krieges war ich in Göttingen 'fernimmatrikuliert', erhielt von Professor Becker Soldatenbriefe zugesandt und löste daraus mathematische und physikalische Aufgaben, die korrigiert wurden. Aufgrund der Beurteilung der beiden Professoren wurde ich am 5.9.1945 immatrikuliert." "953

Die Möglichkeit der Einzelfallentscheidung eröffnete der Protektion Tür und Tor. Persönliche Beziehungen zu Göttinger Professoren wurden bei den Bemühungen, einen Studienplatz in Göttingen zu bekommen, ausgenutzt. Eine Reihe solcher 'Empfehlungsschreiben` finden sich noch heute in den Akten. ${ }^{954}$ Ein Beispiel aus der Physik soll hier angeführt werden. Ursula Schleicher, geb. Bonhoeffer, bat Anfang 1949 um Zulassung ihres Sohnes zum Physikstudium in Göttingen. Sie richtete ihre Bitte an Rektor Raiser, der ihren Mann, der als Mittäter des 20. Juli 1944 von den Nationalsozialisten ermordet wurde, aus den Stuttgarter Jugendtagen und aus den Kriegsjahren in Berlin her kannte. Raiser antwortete ihr: „Er [ihr Mann] ist mir von da her in sehr lieber Erinnerung, und es ist mir eine ausgesprochene Freude, Ihrem Sohn behilflich sein zu können“. Von Richard Becker kam die Auskunft, dass

\footnotetext{
951 Dementsprechend sollten für jedes Prüfungsfach geeignete psychotechnische Methoden erprobt werden. Protokoll der Kommissionssitzung vom 11. April 1946. GPAMNFG, Protokollbuch III der mathematischnaturwissenschaftlichen Fakultät WS 1927/28 - SS 1946.

952 Protokoll der Fakultätssitzung vom 3. Mai 1946. GPAMNFG, Protokollbuch III der mathematischnaturwissenschaftlichen Fakultät WS 1927/28 - SS 1946.

953 Krönig \& Müller [1990] S. 134.

954 Siehe z. B. UAG, Rek. 7101. Ein Vater wollte zum Beispiel seinen Sohn zum Medizinstudium anmelden und wendete sich diesbezüglich an den ihn bekannten Rektor Rein. Dieser versprach eine bevorzugende Behandlung und antwortete: „Grüssen Sie Ihren Sohn von mir. Sobald er zurück ist, soll er sich an mich wenden!“
} 
Frau Schleichers Sohn sich wie alle Bewerber einer „,persönlichen Überprüfung“ stellen müsse, dass aber, ,wenn diese Vorstellung nicht zu einem ganz abnorm ungünstigen Ergebnis führt, seine Zulassung als gesichert angesehen werden kann.“955 Da der Vater des Bewerbers ein Opfer des NS-Regimes war, könnte man hierin eine Geste der Wiedergutmachung sehen. Dieser Aspekt stand aber nicht im Vordergrund, wie andere Protektionsfälle zeigen. Wichtig war das Vorhandensein einer persönlichen Verbindung, an die angeknüpft werden konnte. Dabei spielte die politische Überzeugung der Bekannten eine untergeordnete Rolle.

Welche Form die Aufnahmeprüfung im Jahr 1949 angenommen hat, nachdem die Göttinger Professoren schon vier Jahre Erfahrung hatten sammeln können, beschreibt der damaliger Student Weisse in einem Interview folgendermaßen. Da er von niemandem protegiert worden war, nahm er ohne Bevorzugung am regulären Prüfungsverfahren teil. Die Aufnahmeprüfung war rückblickend betrachtet die schwierigste Prüfung seines Lebens. Sein erster Prüfer war Richard Becker, der sehr nett war. Zuerst unterhielten sie sich über seinen „,background“, also über Familie, Herkunft, usw. Dann erst fing Becker an, fachlich zu prüfen. Jede Antwort von Weisse ergab eine Folgefrage. Das führte Becker so lange fort, bis Weisse keine Antwort wusste. Die Fragen waren sehr physikspezifisch, auch die dazugehörige Mathematik wurde abgefragt. Die erste Frage lautete: „Malen Sie die Kurve $y=x+1 / x$ an die Tafel.“ Am Schluss hatte Weisse den Eindruck, durchgefallen zu sein. ${ }^{956}$ Trotzdem nahm ihn Becker auf und schickte ihn zu Paul und Pick zu weiteren Prüfungen. Pauls Prüfungsstil unterschied sich zwar von Beckers, aber er bohrte ebenfalls so lange, bis Weisse nicht mehr weiter wusste. Bei Pick schließlich lief die Prüfung dann besser. Alle Prüfungen waren am selben Tag von 9 bis 13 Uhr. Eine große Gruppe war zu diesen Prüfungen geladen worden, seiner Erinnerung nach etwa 200 Bewerber. Nur zirka 20 davon sind aufgenommen worden. Die meisten kamen ihm hochnäsig vor. Ihr Verhalten lag vermutlich daran, dass alle sehr gute Abiturnoten in Mathematik und Physik hatten. Erst später hat er erfahren, dass nur diejenigen, die ein sehr gutes Abiturzeugnis hatten, zur Prüfung eingeladen worden waren. ${ }^{957}$

Wichtigstes Kriterium bei der Auswahl der naturwissenschaftlichen Studenten war die fachliche und menschliche Eignung. Daneben gab es formale Kriterien für zu bevorzugende

\footnotetext{
955 Ursula Schleicher an Rektor Raiser, 1. Februar 1949; Raiser an Schleicher, 15. Februar 1949; Becker an Raiser, 11. Februar 1949. Alle: UAG, Rek. 7101. Die ähnlichen Zulassungsbedingungen an anderen Hochschulen führten auch dort zu einer Vielzahl von Protektionsversuchen. Einige Beispiele für die TH Braunschweig liefert Maßß [1998] S. 68, 72f.; bezüglich der Universität Münster siehe Respondek [1992] S. $301 \mathrm{ff}$.

956 Karl Heinz Lindenberger sagte im Gespräch mit Klaus Schlüpmann über seine Aufnahmeprüfung 1949, Richard Becker habe ebenso gründlich wie betont „,kollegial“ geprüft. Siehe Schlüpmann [http].

957 Gespräch mit Weisse, 22. Mai 2001.
} 
Gruppen: entlassene Soldaten mit mindestens dreijähriger Dienstzeit, Kriegsversehrte ab Stufe II, Kriegerwitwen, Kriegswaisen, Studenten, die durch politische Zwangsmaßnahmen der nationalsozialistischen Regierung im Studium geschädigt waren und Studenten in den Abschlusssemestern, wobei wissenschaftliche Eignung vorausgesetzt wurde. ${ }^{958}$ „Allergrößte Zurückhaltung und schärfste Auslese“" wurde bei der Zulassung von Ausländern, die nicht zu den DP's (Displaced Persons) gehörten, angewendet, „,keinerlei Bevorzugung wird als richtig befunden." 959

In der Auswahl der Bewerber wurde auch deren Alter berücksichtigt. Der Wunsch der Studentenkonferenz, Studenten erst ab dem 21. Lebensjahr aufzunehmen, wurde nur von der Philosophischen, Juristischen und Medizinischen Fakultät umgesetzt - mit Ausnahme besonders qualifizierter Bewerber. In der Forstlichen Fakultät wurden Bewerber unter 24 Jahren nicht aufgenommen. In der Mathematisch-Naturwissenschaftlichen Fakultät wurden formale Kriterien wie Alter hinter das „Leistungsprinzip“ gereiht. Schon im Oktober 1945 sprach sich Pohl für eine, „rücksichtslose Auslese im Interesse einer wirklichen Qualitätsarbeit“ aus. ${ }^{960}$ Außerdem wurde eine Durchmischung der Studentenschaft mit jüngeren Jahrgängen für notwendig erachtet. Daher wurden abwechselnd in einem Semester vorrangig jüngere und im folgenden bevorzugt ältere Studenten aufgenommen. ${ }^{961}$

Studienbewerber, die in die Gruppe A der politischen Richtlinien der Militärregierung eingestuft wurden, wurden in allen Fakultäten (außer der Forstlichen) ohne Rücksicht aufs Alter aufgenommen. Als Folge der Bevorzugung der älteren Bewerber betrug im WS 1945/46 das Durchschnittsalter der männlichen Studenten 25,6 Jahre, das der Studentinnen 24,5 Jahre. ${ }^{962} 98 \%$ der im Herbst 1945 in Göttingen immatrikulierten männlichen Studenten waren Soldaten gewesen. ${ }^{963}$ Für das WS 1946/47 setzte der Dekan Eucken die Richtlinien für die Neuzulassungen fest. Es sollten vorrangig erste Semester aufgenommen werden, höhere nur, wenn die Studenten ,in Göttingen oder in einer der ostdeutschen (-polnisch-besetzten)

\footnotetext{
958 Siehe Regierungsrat Wienert am 26. November 1945, UAG, Rundschreiben der Georg-August-Universität II (1945-1950).

959 Protokoll der Senatssitzung vom 9. Juli 1947. UAG, Senatsprotokolle 1945-1949.

960 Protokoll der Fakultätssitzung vom 26. Oktober 1945. GPAMNFG, Protokollbuch III der mathematischnaturwissenschaftlichen Fakultät WS 1927/28 - SS 1946.

961 Die jüngeren Bewerber wurden in den Wintersemestern bevorzugt. Im SS 46 wurden in Mathematik, Physik und Chemie überhaupt keine Anfänger aufgenommen. Protokoll der Senatssitzung vom 3. April 1946. UAG, Senatsprotokolle 1945-1949.

962 Bollnow [1950] S. 159. Das Durchschnittsalter der ersten Semester betrug im SS 1946 bei den Männern 23, bei den Frauen 21,8 Jahre (Gesamtdurchschnitt 22,8; das war früher das Durchschnittsalter der Studenten überhaupt.
} 
Universitäten studiert haben, ferner die seit 1946 als Kriegsgefangene entlassen wurden u. die von zwei Göttinger Dozenten begutachtet wurden."964

Die aufwendigen Prüfungen der Bewerber wurden von zwei Ausschüssen betreut: dem Ausleseausschuss und dem Immatrikulationsausschuss. Der Ausleseausschuss war für die Überprüfung der Eignung in fachlicher und charakterlicher Hinsicht zuständig. ${ }^{965}$ Jede Fakultät hatte ihren eigenen Ausleseausschuss, der die Bewerber in Geeignete und Ungeeignete unterschied. ${ }^{966}$ Die Charakterprüfung wird im nächsten Abschnitt noch eingehend besprochen.

Der Immatrikulationsausschuss koordinierte die Ergebnisse der politischen Klassifizierung und der Ausleseausschüsse mit den festgelegten Aufnahmequoten der einzelnen Fakultäten und entschied, wer als Student aufgenommen und wer abgewiesen wurde. Er wurde im März 1946 gegründet. ${ }^{967}$ Diskutiert wurde beispielsweise die Behandlung der Jungvolk- und Jungmädelführer, außerdem wollte man über die Reaktion der Studenten anderer Universitäten auf die Zulassungsbedingungen der Militärregierung etwas erfahren, um es als „Material für eine grundsätzliche Stellungnahme zur Aufhebung bzw. Abänderung der

963 GUZ (1945/46), Nr. 1, S. 8ff. Über die Hälfte der ehemaligen Soldaten hatten eine Dienstzeit von 5 und mehr Jahren hinter sich. Zur Situation der Berufssoldaten siehe die Berichte in Krönig \& Müller [1990] S. 127. Siehe auch Bollnow [1950] S. 160; Mehnert \& Schulte [1949] S. 368.

964 Protokoll der Fakultätssitzung vom 31. Mai 1946. GPAMNFG, Protokollbuch III der mathematischnaturwissenschaftlichen Fakultät WS 1927/28 - SS 1946.

965 Der Ausleseausschuss bestand aus einem Vorsitzenden, den ein führendes Mitglied der Hochschule zu führen hatte. Dazu kamen zwei oder mehr weitere Hochschulmitglieder und eine gleiche Anzahl von Personen, die der Entnazifizierungsausschuss zu ernennen hatte und die nicht der Hochschule angehören durften. Ein Studentenvertreter bekam beratende Funktion im Ausschuss. So wurde die Zusammensetzung des „Sonderausschusses für Auslese von Studenten“ in einer Richtlinie des Director Education Branch, R. Herdman Pender, vom 18. Oktober 1946 vorgeschrieben. UAG, Kur. XXX. A. a. Studierende. Allgemeine Vorschriften. VIII. Ab April 1948 war die Zusammensetzung durch die ministerielle Ordnung geregelt. Der Ausleseausschuss bestand aus vier Mitgliedern: zwei Personen des Lehrkörpers, eine davon je nach Fachgebiet des Bewerbers wechselnd, einer Persönlichkeit des öffentlichen Lebens und einem vom AStA ernannten Studenten. Die Aufgabe dieses Ausschusses war, sich auf Grund einer persönlichen Vorladung einen Eindruck von der Eignung des Bewerbers zu verschaffen. Siehe $\S \S 7$ und 8 der Zulassungsordnung vom 5. April 1948. UAG, Kur. XXX. A. a. Studierende. Allgemeine Vorschriften. IX.

966 Alle Fakultäten hatten mit je einem einzigen Ausleseausschuss das Auskommen; die Math.-Nat. Fakultät benötigte hingegen gleich drei Ausschüsse, einen davon für die landwirtschaftliche Abteilung. Die beiden anderen waren wie folgt besetzt: Prof. Tollmien (Vertreter: Prof. Kopfermann), ein wechselndes Fakultätsmitglied, Dr. Pfauter (Stadtverwaltung, Vertreter: Arthur Levi) und ein vom AStA benannter Student der Fakultät. Der zweite Ausschuss bestand aus Prof. Firbas (Vertreter: Rippel), einem wechselnden Fakultätsmitglied, Willi Lagershausen (Vertreter: Werkmeister Nollau) und wieder einem Studenten der Fakultät. Undatierte Abschrift des Schreibens R 1914. UAG, Kur. XXX. A. a. Studierende. Allgemeine Vorschriften. IX.

967 Bei der Gründung bestand der Immatrikulationsausschuss aus den Mitgliedern Rein, Becker und Ziegler als Universitätsmitglieder und Stadtassessor Kuss sowie „Gewerkschaftsführer Arnold“ [sic]. Protokoll der Senatssitzung vom 23. März 1946. UAG, Senatsprotokolle 1945-1949. Vier Monate später war die Zusammensetzung der 5 Mitglieder wie folgt: Rektor Rein (ab Mai 1946 Raiser) als Vorsitzender, Prof. Becker, Dozent Ziegler, Stadtsyndikus Kuss, Druckereileiter Arnholdt. Aus Bericht des Immatrikulationsausschusses, 10. Juli 1946. UAG, Rek. 7101. 
Zulassungsbestimmungen“ ${ }^{\text {zu }}$ verwenden.968 Zusätzlich zum Ausschuss gab es Fakultätsberater bei Immatrikulationsfragen.969 Anfang 1948 wurde der Prorektor Richard Becker als Vorsitzender des Immatrikulationsausschusses bestimmt. ${ }^{970}$ Die von Control Officer Bird vorgeschlagene Hinzuziehung des Gewerkschaftlers Levi begegnete im Senat großen Bedenken. „Man fürchtet, dass die Anwesenheit des Herrn Lewy [sic] die zurückgewiesenen Bewerber geradezu in nazistisches Fahrwasser treiben könnte."971 Levi war ein jüdischer Remigrant, der im Oktober 1946 als 24-Jähriger aus England zurück nach Göttingen kam. In England war er gewerkschaftlich tätig gewesen. Er kehrte aus politischen Motiven mit dem Ziel zurück, an der Aufbauarbeit an einem anderen Deutschland mitzuwirken. Durch seine Beteiligung an der Entnazifizierung der Universität war er den Senatsmitgliedern bereits bekannt. Levi sagte später in einem Interview, er hätte es als Jude und Gewerkschaftler in Göttingen doppelt schwer gehabt. ${ }^{972}$ Eine dieser Schwierigkeiten war zum Beispiel, dass ihn der Senat nicht am Immatrikulationsausschuss beteiligte. Ob die angegebenen Befürchtungen, die Studenten würden dadurch in nazistisches Fahrwasser getrieben, der wahre Ablehnungsgrund waren, oder ob politische Animositäten oder gar die Angst vor zu großer Strenge mit im Spiel waren, sei dahingestellt. Später wurde die Zusammensetzung des Immatrikulationsausschusses durch $\S 10$ der Zulassungsordnung vom April 1948 geregelt. ${ }^{973}$ Die Persönlichkeiten des öffentlichen Lebens wurden vom Minister berufen. Erwünscht war bei ihnen ein geschulter „Blick für menschliche und geistige Qualitäten“.974

Die Ausmusterung der Ungeeigneten wollten die Professoren nicht nur auf die Neubewerber, sondern auch auf die höheren Semester anwenden. Eine generelle Entfernung der höheren Semester, die auf Grund ihrer 'Qualifikation' bei Neubewerbung nicht mehr aufgenommen

\footnotetext{
968 Protokoll der Senatssitzung vom 23. März 1946. UAG, Senatsprotokolle 1945-1949.

969 Dieser bestand aus folgenden Professoren: Jeremias, Raiser, Deuticke (evtl. Schödel), Rosemann, Waldschmidt, von Allesch, Eucken und Becker. Protokoll der Senatssitzung vom 30. März 1946. UAG, Senatsprotokolle 1945-1949.

970 Weitere Vertreter der Universität waren Bornkamm und Hans Neumann, und die Vertreter des öffentlichen Lebens waren Stadtdirektor Kuss und Oberbürgermeister Arnholdt. Protokoll der Senatssitzungen vom 14. Januar 1948. UAG, Senatsprotokolle 1945-1949.

971 Protokoll der Senatssitzungen vom 14. Januar 1948. UAG, Senatsprotokolle 1945-1949.

972 Zu Levi siehe Duwe \& Schäfer [1988].

973 Der Immatrikulationsausschuss setzte sich nach § 10 der Zulassungsordnung vom 5. April 1948 aus sechs Mitgliedern zusammen: drei Personen aus dem Lehrkörper a) dem Prorektor Becker als Vorsitzenden, b) Professor Wenzel (Rechts- und Staatswiss. Fakultät), c) den von den Fakultäten zu benennenden Mitgliedern ihrer „Auslese“-Ausschüsse, zwei Persönlichkeiten des öffentlichen Lebens d) Dr. Gentsch, e) Amtsgerichtsrat Dr. E: Schmidt, und einem vom AStA ernannten Studenten. Undatierte Abschrift des Schreibens R 1914. UAG, Kur. XXX. A. a. Studierende. Allgemeine Vorschriften. IX. Protokoll der Senatssitzung vom 28. April 1948. UAG, Senatsprotokolle 1945-1949.
} 
worden wären, wurde jedoch abgelehnt. Trotzdem bemühte sich der Senat um die Schaffung einer Rechtsgrundlage zur Exmatrikulation „ungeeigneter“ Studenten, die bis dahin in einem rechtlich ungeklärten Raum stattfand. ${ }^{975}$ Im WS 1945/46 mussten die Physikstudenten Fleißprüfungen ablegen, um $\mathrm{zu}$ Weiterstudium zugelassen $\mathrm{zu}$ werden. Bei diesen Semesterabschlussprüfungen wurde über mindestens acht Semesterwochenstunden (Vorlesungen oder Übungen) von mindestens zwei Dozenten geprüft. Bei Doktoranden genügte das Urteil des Doktorvaters. ${ }^{976}$ Diese Prüfungen dienten nicht nur der Auslese, sondern brachten auch Studenten und Professoren in engeren Kontakt zueinander. 977

Ein ministerieller Erlass aus Hannover vom März 1946 gestattete sehr großzügig die Entfernung ungeeigneter Studenten von der Universität: „Ich begrüße alle Maßnahmen, die bestimmt sind, Studierende, die sich als nicht geeignet zur Weiterführung des Studiums erweisen, vom Studium auszuschließen.“ Wer durch entsprechende Prüfungen durchfiel, sollte exmatrikuliert werden. Auch die britische Erziehungsbehörde stand solchen Maßnahmen positiv gegenüber und schlug selbst Pflichtprüfungen am Ende des zweiten oder dritten Semesters vor. ${ }^{978}$ Minister Grimme ersuchte um regelmäßige Bekanntgabe, wie viele auf diese Weise ausgeschieden wurden. ${ }^{979}$ Von den Göttinger Naturwissenschaftlern wurde dieser Erlass doch zu sehr als Freibrief verstanden. Zur Rechtfertigung der Reduzierung der Studentenzahlen in der mathematisch-naturwissenschaftlichen Fakultät wurde vom Dekan Eucken der Zustand des Jahres 1939 als das Normale bezeichnet, demgegenüber 1946 ein vierfach erhöhter Wert bestand. ${ }^{980}$ Im Sommer 1947 äußerte der Kultusminister seine Bedenken, dass gerade die mathematisch-naturwissenschaftliche Fakultät eine von ihm noch nicht genehmigte Studien- und Prüfungsordnung schon in Kraft gesetzt habe. „Die Gutachten, die ich mir über diese Studien- und Prüfungsordnung habe erstatten lassen, sind überwiegend kritisch. Man sieht in diesen Bestimmungen eine zu starke Einschränkung der

\footnotetext{
974 Siehe Zierold [1984] S. 26. Siehe dort auch S. 20-26, welche menschlichen und geistigen Fähigkeiten gemeint sind. Siehe auch hier den Abschnitt 2.3.6.

975 Protokoll der Senatssitzung vom 9. Februar 1946. UAG, Senatsprotokolle 1945-1949.

976 Protokoll der Fakultätssitzung vom 11. Januar 1946. GPAMNFG, Protokollbuch III der mathematischnaturwissenschaftlichen Fakultät WS 1927/28 - SS 1946.

977 Siehe den Zeitzeugenbericht von Kertz [1986] S. 27.

978 Siehe Phillips [1983]b S. 98, 169.

979 Erlass des Oberpräsidenten der Provinz Hannover, Abteilung Wissenschaft, Kunst und Volksbildung, 23. März 1946. UAG, Kur. XXX. A. a. Studierende. Allgemeine Vorschriften. VIII.

980 Protokoll der Fakultätssitzung vom 31. Mai 1946. GPAMNFG, Protokollbuch III der mathematischnaturwissenschaftlichen Fakultät WS 1927/28 - SS 1946. Siehe hierzu Diagramm 6, wo deutlich erkennbar die Zahlen von 1946 jenen von 1930-33 entsprachen.
} 
Studienfreiheit.“981 Der Kultusminister ersuchte um eingehenden Bericht, aus dem die angewendeten Bestimmungen der Studien- und Prüfungsordnung, die gemachten Erfahrungen und die vorgenommenen Änderungen ersichtlich sein sollten. Dieser Bericht vom Juli 1947 gibt uns ein ziemlich genaues Bild von den Aufnahmekriterien in der Math.-Nat. Fakultät und ihrem Wandel innerhalb der ersten zwei Jahre.

Zuerst war das Vertrauen in die richtige Auswahl durch die Aufnahmeprüfung noch nicht groß genug, sodass alle Neuanfänger nach den ersten Semestern in einem sogenannten Fortsetzungsexamen nochmals geprüft wurden. Diese Prüfung bestand aus einer 4-stündigen Klausur, in der nicht nur Stoff des Studienfaches, sondern auch die Allgemeinbildung geprüft wurde. Gegebenenfalls wurden die Kandidaten zusätzlich zu einer mündlichen Prüfung gebeten. ${ }^{982}$ Wer durchs Examen durchfiel, hatte keine Einspruchmöglichkeit und war vom Weiterstudium ausgeschlossen. Auf Grund dieser Prüfung waren nur einige Prozent der Studenten von der Universität verwiesen worden, sodass die Fakultät den Aufwand nicht für lohnenswert erachtete. Das Fortsetzungsexamen wurde deshalb abgeschafft, stattdessen wurde die Aufnahmeprüfung verschärft. Jeder Bewerber wurde von mindestens zwei Professoren auf seine Eignung geprüft. 983

Nach Abschaffung des Fortsetzungsexamens war das Diplomvorexamen die nächste Stufe, in der Studenten ausgesiebt wurden. In den Fächern Physik, Chemie, Mathematik, Psychologie und Landwirtschaft war dieses Examen schon lange üblich, in den anderen naturwissenschaftlichen Fächern wurde es unter der Bezeichnung „Zwischenexamen“ nach 1945 neu eingeführt. Üblicherweise wurde diese Prüfung nach dem 4. Semester abgelegt; wer sich bis zum Ende des 5. Semesters nicht gemeldet hatte, wurde von der Universität verwiesen. Voraussetzung zum Diplomvorexamen war die bestätigte Teilnahme an vorgeschriebenen Übungen und Vorlesungen (darunter auch Geschichte der Naturwissenschaften $)^{984}$. Die Prüfungen wurden nur mündlich abgehalten, und zwar in Hauptund Nebenfächern und in Geschichte der Naturwissenschaften. Die Physiker und Mathematiker mussten die Note „befriedigend“ erhalten, um weiterstudieren zu dürfen. Die

\footnotetext{
981 Niedersächsische Kultusminister an Kurator, 25. Juni 1947. UAG, Kur. XXX. A. a. Studierende. Allgemeine Vorschriften. VIII.

982 Wie die DP-Studenten bei diesen Prüfungen zu behandeln waren, war zuerst ungewiss, dann wurde beschlossen, sie den anderen Studenten gleich zu behandeln. Protokolle der Senatssitzungen vom 12. Februar 1947, 26. Februar 1947. UAG, Senatsprotokolle 1945-1949.

983 Eine drastische Auswirkung hatten die in Heidelberg von Walther Bothe eingeführten Semestralprüfungen, die alle nach dem zweiten Semester zu absolvieren hatten. Nur etwa ein Viertel der Studenten bestanden die Prüfung. Schmidt-Rohr [1996] S. 61.

984 Zur Geschichte der Naturwissenschaften siehe den Abschnitt 4.2.3.
} 
Chemiker mussten dagegen ein ,gut“ erzielen. ${ }^{985}$ Mit dieser Regelung war die Fakultät unzufrieden, da Fälle vorkamen, in denen Studenten mit guten Noten in den 'eigentlichen“ Studienfächern deshalb vom Studium ausgeschlossen wurden, weil sie in Geschichte der Naturwissenschaften schlecht abschnitten. Die Zwangsprüfung in Geschichte der Naturwissenschaften wurde daher wieder abgeschafft. Dieses Fach wurde ursprünglich mit der Begründung eingeführt, dass es den Studenten an allgemeiner Bildung fehlte, sie in der NS Zeit zu 'bloßen' Spezialisten ausgebildet worden seien, und dass sie deshalb leichter für die Ziele des Nationalsozialismus 'verführt' werden konnten. Die schnelle Abschaffung als Prüfungsfach lässt darauf schließen, dass die Professoren ihre eigene frühere Argumentation nicht so ernst nahmen, und dass ihnen gute Spezialisten durchaus lieber waren, als Durchschnittskandidaten mit breiter Bildung. ${ }^{986}$

Die letzte große Leistungsüberprüfung stellte das Diplomexamen, Staatsexamen und Doktorandum dar. In der Regel schloss das Studium nach 8 Semestern mit dem Staatsexamen für den höheren Schuldienst oder dem Diplomexamen ab. $987 \mathrm{Neu}$ eingeführt wurde das Doktorandum als Abschlussprüfung für diejenigen Studenten, die weder Diplom- noch Staatsexamen anstrebten, sondern gleich zur Doktorarbeit zugelassen werden wollten. Während es für Studenten, die Promotion und Staatsexamen als Abschluss anstrebten, bis dahin üblich gewesen war, dass sie zuerst die Doktorprüfung und anschließend das Staatsexamen ablegten, wobei die Dissertation die fürs Staatexamen vorgeschriebene Hausarbeit ersetzte, so musste nach der neuen Regelung die Reihenfolge umgedreht und sowohl Hausarbeit als auch Dissertation angefertigt werden. Die Zulassung zur Doktorarbeit wurde in jedem Fall vom Bestehen einer vorherigen Prüfung (z. B. Staatsexamen) abhängig gemacht, was nach Meinung der Fakultät eine ungünstige Regelung sei. Nach Ansicht der Professoren werde dadurch das Niveau der Doktorarbeiten in keiner Weise gehoben. „Die produktive Leistung bei der Durchführung einer Doktorarbeit liegt auf so gänzlich anderem Gebiete, daß derjenige, der dafür keine Fähigkeiten mitbringt, auch durch ein vorher

\footnotetext{
985 Von Ostern 1947 bis Dezember 1947 wurden 7 Studenten der Math.-Nat. Fakultät wegen nichtbestandenem Vordiplom- bzw. Zwischenexamen von der Universität verwiesen. Dekan Harder an Rektor, 8. Januar 1948. Vom WS 1947/48 bis WS 1948/49 wurden in der Math.-Nat. Fakultät 15 Studenten vom Weiterstudium durch Exmatrikulation ausgeschlossen. Rektor Raiser an Kultusminister, 19. Juni 1949. UAG, Kur. XXX. A. a. Studierende. Allgemeine Vorschriften. IX.

986 Siehe auch den Abschnitt 4.2. Die in den ersten Nachkriegsjahren an vielen deutschen Hochschulen eingeführten, verpflichtenden Veranstaltungen zur Erzielung einer allgemeineren, humanistischen Bildung hatten meist nur kurzen Bestand. Siehe Killy [1952] bes. S. 30.

987 Wenn Studenten über die übliche Zahl von Semestern studierten wurden sie in der Regel entweder exmatrikuliert oder auf die Gasthörerliste gesetzt, um Platz für neue Bewerber zu schaffen. Es wurde aber klein Zwang ausgeübt. Dekan Harder an Rektor, 8. Januar 1948. UAG, Kur. XXX. A. a. Studierende. Allgemeine Vorschriften. IX.
} 
abgelegtes Examen dafür nicht geeigneter wird.“ Auch die Einführung des Zwischenexamens wurde selbstkritisch bewertet: „Die Einteilung des Studiums nach freiem eigenem Ermessen ist kaum mehr möglich, sondern es ist $\mathrm{zu}$ einer gewissen Starrheit und Verschulung gekommen, die für die große Masse der Studenten zwar wohl belanglos ist (dem Durchschnittsstudenten schadet eine gewisse enge Führung wohl nicht), die aber für die Spitzenkandidaten, also gerade unsere wertvollsten Leute, eine unerfreuliche Einschränkung bedeutet." 988

Die vom Kultusminister kritisierte „Einschränkung der Studienfreiheit“ betraf wahrscheinlich vor allem jenen Punkt, den der Dekan selbst „ständige Überwachung der Studenten“ nannte. Die Studenten wurden nicht nur durch Prüfungen kontrolliert, es wurde im Dekanat auch eine Kartei geführt, „in der regelmäßig Eintragungen über die Anwesenheit, Examensleistungen usw.“ gemacht wurden. 989

„Wer an bestimmten Stichtagen nicht anwesend ist und keinen sehr triftigen Grund für seine Abwesenheit angeben kann, wird aus der Fakultät verwiesen. Außerdem findet eine ständige Kontrolle der Studenten in den Instituten statt. [...] Dadurch wird zwar gute Ordnung gehalten, aber doch auch wieder ein Zwang ausgeübt, der der freien Entfaltung der Kräfte des Einzelnen nach Neigung und Begabung entgegenwirkt. Trotzdem muß wohl zunächst an solchen Zwangsmaßnahmen festgehalten werden."

Der Kurator, der diesen Bericht ans Ministerium weiterleitete, nutzte diesen Punkt, um für mehr Stellen für Hilfskräfte und mehr Assistentenstellen zu werben, da erst durch eine ausreichende Zahl von „Gehilfen der Professoren“ eine gerechte, gesunde und wirksame Auslese zu erzielen sei. ${ }^{991}$

Die Überwachung der Studenten erwähnte auch Rektor Raiser, als er von seinem Kollegen Hellpach aus Heidelberg befragt wurde, wie in Göttingen mit „Scheinstudenten“ umgegangen werde. Hellpach beklagte, dass ,wir in der Studentenschaft mit mindestens $10 \%$ moralischem Gesindel, mindestens $30 \%$ intellektuell untauglichen u. somit mit bestenfalls $60 \%$ zum

\footnotetext{
988 Bericht des Dekans Harder an Kultusminister, 22. Juli 1947. UAG, Kur. XXX. A. a. Studierende. Allgemeine Vorschriften. VIII.

${ }^{989}$ Harder berichtete dem Rektor am 19. April 1947: „Jeder Student muß sich in jedem Semester auf dem Dekanat melden, worüber ein Vermerk in der Kartei gemacht wird. [...] durch die Kartei wird verhindert, daß die Studenten ihr Studium über Gebühr verlängern." UAG, Rek. 7101.

990 Bericht des Dekans Harder an Kultusminister, 22. Juli 1947. UAG, Kur. XXX. A. a. Studierende. Allgemeine Vorschriften. VIII.

${ }^{991}$ Kurator an Kultusminister, 11. August 1947. UAG, Kur. XXX. A. a. Studierende. Allgemeine Vorschriften. VIII.
} 
Studium Berufenen rechnen müssen!"992 Raiser berichtet, dass Studenten, die in Seminaren und Kursen durch „Gleichgültigkeit und Minderleistung“ auffielen, „aus der Matrikel gestrichen werden können, und schließlich werden unvorhergesehene Meldetermine eingeschoben“. Die Nichtanwesenden konnten von der Universität verwiesen werden. „Wir haben bei derartigen Razzien in den vergangenen Semestern immerhin eine ganz beträchtliche Zahl von Studienplätzen für wartende Anwärter freimachen können.“ Die Zwangsexmatrikulierten wurden sofort dem Arbeitsamt gemeldet. "Natürlich ist trotzdem damit zu rechnen, dass noch immer eine grosse Zahl von Scheinstudenten sich in der Stadt aufhält. Wir merken das daran, dass gerade aus der Zahl dieser Leute politische und kriminelle Beanstandungen stammen, welche der Universität zur Last gelegt werden.“ Raiser wollte diese Studenten nicht nur von der Universität, sondern sogar aus der Stadt vertreiben, was sich jedoch nicht so ohne Weiteres umsetzen ließ: „Die gegenwärtig bestehenden Aufenthalts- und Wohnungsgesetze scheinen es unmöglich zu machen, diese Studenten völlig aus der Stadt zu verweisen. “993

Ende 1947 haben sich die Aufnahmeprozeduren der verschiedenen Fakultäten etwas angeglichen. Das Vorgehen der Mathematisch-Naturwissenschaftlichen Fakultät musste bei dieser Anpassung nicht verändert werden, vielmehr richteten sich die anderen Fakultäten nach ihr aus. Jede Fakultät stellte mehrere verantwortliche Mitarbeiter auf, denen die Überprüfung der Papiere oblag. Alle Bewerber mussten nach wie vor persönlich vorstellig werden und sich der Prüfung durch ein mehrköpfiges Gremium aus der Dozentenschaft stellen. Dieses Gremium wurde von den Fachvertretern der einzelnen Abteilungen der Fakultät zusammengestellt. ${ }^{994}$ Dieses Verfahren blieb bis zur Abschaffung des numerus clausus 1953 bestehen. ${ }^{995}$

Um zusätzliche Plätze für neue Studenten zu erhalten, wurden die Examenssemester in der Medizinischen und Mathematisch-Naturwissenschaftlichen Fakultät zwangsexmatrikuliert. Diese Exmatrikulation war eine anerkannte Gepflogenheit und wurde als Notwendigkeit betrachtet, besaß aber keine Rechtsgrundlage. Die Erleichterungen des Akademischen Hilfswerks blieben den im Examen befindlichen, exmatrikulierten Studenten erhalten. Über den Vorschlag einer zwangsweisen Exmatrikulation bei zu langer Studiendauer konnten sich

\footnotetext{
992 Willy Hellpach, Psychologisches Institut der Universität Heidelberg, an Rektor Raiser, 29. März 1947. UAG, Rek. 7101.

993 Rektor Raiser an Hellpach, 12. Mai 1947. UAG, Rek. 7101.

994 Protokolle der Senatssitzungen vom 12. November 1947, 14. Januar 1948. UAG, Senatsprotokolle 19451949.
} 
die Fakultäten nicht einig werden.996 Laut Darstellung des Dekans Harder fand die Exmatrikulation der Studenten nicht ohne deren Willen statt. Jeder einzelne Fall wurde überprüft und entweder der Student im Normalkontingent belassen oder mit seiner Einwilligung auf die Gasthörerliste gesetzt. Zwangsexmatrikulationen gab es nur bei unzureichenden Leistungen in den Diplomvor- und Zwischenexamen. Zwischen Ostern und Dezember 1947 traf dies sieben Studenten. 997

Die in den ersten beiden Nachkriegsjahren von jeder Hochschule relativ eigenständig geregelten Aufnahmeverfahren sollten schließlich länderweit vereinheitlicht werden. Ansätze einer Demokratisierung und Beteiligung der Öffentlichkeit waren dabei erkennbar. Die Bestrebungen der Universität Göttingen als Demokratisierung zu bezeichnen, wäre allerdings doch zu euphemistisch, wie ein Ende 1947 vom Senat verfasster Entwurf einer Immatrikulationsordnung zeigt. Bei der Zusammensetzung des Immatrikulationsausschusses legte die Universität Wert auf eine Stimmenverteilung, die eine Zulassung eines Bewerbers gegen den Willen des Lehrkörpers unmöglich mache. Die Immatrikulation sei in erster Linie eine Sache der Hochschule. Trotzdem sollte die Öffentlichkeit am Ausschuss beteiligt sein, da „die Hochschule den Nachwuchs für eine beträchtliche Anzahl von Beamtenstellen und sonstige gehobene Berufe“ liefere, und der „Wunsch der Oeffentlichkeit nach einer Kontrolle des Zugangs zu diesen Berufen“ verständlich und statthaft sei. „Der von den Gewerkschaften erhobenen Forderung nach Beteiligung an den Immatrikulationsausschüssen glaubt die Kommission nicht stattgeben zu sollen.“ Eine einzige Persönlichkeit des öffentlichen Lebens sollte auf Vorschlag der Fakultät hinzugezogen werden; außerdem sollte ein Vertreter des AStA dem Ausschuss angehören. Die guten Erfahrungen mit dem AStA-Vertreter in den Senatssitzungen ließen ein harmonisches Arbeitsklima erhoffen: „Regelmässig wird bei gutwilliger Zusammenarbeit Uebereinstimmung zu erzielen sein.“998

Die von Kultusminister Grimme im Februar 1948 zur Diskussion vorgelegte „Ordnung der Zulassung zum Studium an den wissenschaftlichen Hochschulen in Niedersachsen“ wurde vom Senat in vielen Punkten kritisiert. Beispielhaft soll die Regelung der unter gleicher Eignung zu bevorzugenden Bewerber besprochen werden, da hier Mentalitäten zum Vorschein kommen, die bei der Besprechung der Charakterprüfung eine Rolle spielen

\footnotetext{
995 Siehe „Ergebnis einer Rundfrage betr. Zulassung zum Studium“ in: UAG, Rek. 7101. Siehe auch den Bericht einer Studentin, die 1950 die Aufnahmeprüfung für das Fach Jura absolvierte, Rühle [2000] S. 57f.

996 Protokoll der Senatssitzung vom 14. Januar 1948. UAG, Senatsprotokolle 1945-1949.

997 Dekan Harder an Rektor, 8. Januar 1948. UAG, Kur. XXX. A. a. Studierende. Allgemeine Vorschriften. IX.

998 Ende 1947 vom Senat verfasster „Entwurf einer Immatrikulationsordnung für die Georg-August-Universität in Göttingen“. UAG, Kur. XXX. A. a. Studierende. Allgemeine Vorschriften. IX.
} 
werden. Die Frage der bevorzugten Gruppen wurde schon in dem Ende 1947 verfassten Entwurf zur Immatrikulationsordnung breit diskutiert. „Schwierigkeiten hat die Regelung der Frage bereitet, inwieweit die sozialen Verhältnisse der Bewerber mit zu berücksichtigen sind.“ Die sozialen Verhältnisse spielten zwar eine gewichtige Rolle, jedoch müssten Eignung und Leistung ausschlaggebend bleiben. „Es wurde daher erwogen, eine Bestimmung aufzunehmen, dass bei gleicher Leistung und Eignung die sozialen Verhältnisse den Ausschlag geben müssten, diese Formulierung aber wieder verworfen, weil Fälle wirklich gleicher Eignung selten vorkommen, im übrigen bei der Würdigung der Persönlichkeit des Bewerbers und seiner Leistungen regelmässig die sozialen Verhältnisse in das Gesamturteil ohnehin einkalkuliert sind.“ Die einzelnen Bewerber seien zu unterschiedlich, als dass sich die „besonders wichtigen sozialen Momente“ in einem Punktssystem erfassen ließen, wie es zum Beispiel an den hessischen Hochschulen praktiziert wurde. Die Universität Göttingen wollte die Verantwortung für die von ihr vollzogene soziale Selektion selbst tragen. Einer expliziten Bevorzugung von Arbeiter- oder Bauernkindern konnte sie nicht zustimmen. In diese Richtung ging aber der Vorschlag von Kultusminister Grimme, in dem in $\S 5$ Abs. II geregelt ist, welche fünf Gruppen zu bevorzugen seien:

a) Bewerber mit Anrecht auf politische Wiedergutmachung

b) Kriegsversehrte der Versehrtenstufe III und IV,

c) Bewerber die aus wirtschaftlich schlechter gestellten Volksschichten stammen, da sie größere Schwierigkeiten zu überwinden hatten und daher die sonst gleichwertige Leistung charakterlich höher zu bewerten ist;

d) Bewerber, die durch Kriegsdienst oder Gefangenschaft grösseren Zeitverlust erlitten haben;

e) sonstige Kriegsgeschädigte, insbesondere Bewerber, die unter das Flüchtlingsgesetz fallen. ${ }^{999}$

Im Senat stieß erwartungsgemäß der Punkt c) auf Widerstand, der in seinem Wortlaut eine Förderung von begabten Arbeiter- und Bauernkindern darstellt, wenn es auch nicht explizit so formuliert ist. ${ }^{1000}$ Dieser Punkt sollte nach Meinung des Senats gestrichen werden.

„Der Senat ist der Auffassung, dass Eignung und Charakter nicht so getrennt beurteilt werden können, wie Abs. II Ziff. c dies offenbar vorsieht, die Dinge vielmehr notwendig in einem Gesamturteil zusammenfliessen. [...] Ferner muss die vorgesehene besondere Beurteilung nicht nur »Bewerber, die aus

\footnotetext{
999 Vom Niedersächsischen Kultusminister Grimme am 1. Februar 1948 zur Diskussion vorgelegte „Ordnung der Zulassung zum Studium an den wissenschaftlichen Hochschulen in Niedersachsen“. UAG, Kur. XXX. A. a. Studierende. Allgemeine Vorschriften. IX. Zur Diskussion dieser Zulassungsordnung an der TH Braunschweig siehe Maßß [1998] S. 66ff.

1000 Zum Vergleich hieß es in den „Richtlinien für die Zulassung zum Studium“ der DDR vom 20. März 1953: „Bevorzugt werden zum Studium zugelassen: 1. Arbeiter und deren Kinder [...] 2. Bauern und deren Kinder [...] 3. Schaffende Intelligenz und deren Kinder [...]. Der Anteil der Arbeiter und werktätigen Bauern und deren Kinder an der Gesamtzahl der von der Kommission ausgewählten Bewerber soll mindestens 50 \% [...] betragen." UAG, Kur. XXX. A. a. Studierende. Allgemeine Vorschriften. IX.
} 
wirtschaftlich schlechter gestellten Volksschichten stammen«, sondern jedem wirtschaftlich schlechter gestelltem Bewerber zugute kommen." 1001

Trotz der Kritik seitens des Senats hielt Grimme an seiner Formulierung der bevorzugt zu behandelnden Bewerber fest. Der Wortlaut der oben zitierten fünf Gruppen blieb unverändert bestehen. Der schon besprochene $\S 5$ listet auch die Kriterien auf, die bei der notwendigen Auswahl der Bewerber zu berücksichtigen seien:

- „die allgemein geistige Eignung für ein wissenschaftliches Studium ${ }^{1)}$,

- die besondere Begabung für das gewählte Studienfach,

- die menschlich-charakterliche Eignung für die Ausübung des gewählten akademischen Berufs und für eine verantwortungsbewusste Mitarbeit im öffentlichen Leben."

In Verbindung gebracht mit der Leistungsüberprüfung wurde die von der Universität sehr erwünschte Frage des Studienplatztausches, die vor allem in der MathematischNaturwissenschaftlichen Fakultät Schwierigkeiten bereitete. Zur Haltung des hohen Niveaus hielt die Fakultät an einer Prüfung der Tauschpartner fest. Ein Tausch auf Zeit, bei dem sich die von auswärts kommenden Studenten verpflichteten, nach einer gewissen Semesterzahl an ihre Ausgangsuniversität zurückzukehren, war möglich. „Das Problem ist seit Monaten mit grosser Zähigkeit behandelt worden, jedoch zu keiner Lösung zu bringen. Es bleibt nichts anderes übrig, als für diese Fakultät den Studienplatztausch von Fall zu Fall zu regeln. Der Senat ist einmütig der Ansicht, dass die Freizügigkeit des Univ. Wechsels f. d. Studierenden mit allen Mitteln zu fördern ist.“1003 Im Jahr 1948 waren die Professoren schon daran gewöhnt, mache Fragen für jeden Einzelfall neu entscheiden zu müssen.

Nach der Währungsreform wurde im Senat die Höhe der Prüfungsgebühren diskutiert. Während von Kleinschmidt, Martius und Rellich beklagt wurde, dass das Gesundheitsministerium die Herabsetzung der Prüfungsgebühren abgelehnt hatte, äußerte sich Pohl gegen eine generelle Herabsetzung. Er meinte, man müsse nach der Wichtigkeit der Prüfungen unterscheiden. Dr.-Prüfungen seien „nicht so sehr dringlich“. 1004

Die Debatte um eine Beurlaubung der Studenten zur Arbeitsaufnahme führte zu einer versteckten Einführung einer weiteren Ausmusterung der Studenten nach dem

1001 Stellungnahme des Senats, 13. Februar 1948; Hervorhebung original. UAG, Kur. XXX. A. a. Studierende. Allgemeine Vorschriften. IX.

1) z. B. geistige Beweglichkeit, Urteilsfähigkeit, geistiges Niveau, Weite des geistigen Horizontes. [Fußnote original]

1002 „Ordnung der Zulassung zum Studium an wissenschaftlichen Hochschulen“. Vom Niedersächsischen Kultusminister Grimme am 5. April 1948 erlassen. UAG, Kur. XXX. A. a. Studierende. Allgemeine Vorschriften. IX.

1003 Protokolle der Senatssitzungen vom 12. November 1947, 28. Januar 1948. UAG, Senatsprotokolle 19451949. 
Leistungsprinzip. Es wurde nämlich beschlossen, keine Beurlaubungen zuzulassen, sondern stattdessen die Exmatrikel zu geben, und dann „von Fall zu Fall nach Anhörung der Dozenten die bevorzugte Wieder-Immatrikulation der durch gute Leistungen Qualifizierten“ zu gewähren. 1005

Die glücklichen neuen Studenten, die alle Aufnahmehürden überwinden konnten, traten in einer „ernsten Feier“"1006, bei der der Lehrkörper im Talar in die alte Aula einzog, in die akademische Welt ein und wurden auf ihre neuen Aufgaben und Verantwortungen verpflichtet. Was aber waren im Denken der deutschen Professoren im Nachkriegsdeutschland die Aufgaben und Pflichten der Studenten? Auf der ersten Hochschulkonferenz schlug der Göttinger Rektor Smend die Grundzüge einer neuen Verpflichtungsformel vor, welche die Zustimmung der Konferenzteilnehmer fand. Auf drei Punkte sollten die Studenten verpflichtet werden: 1) Ehre und Ordnung der akademischen Gemeinschaft, 2) den Ernst und die Wahrhaftigkeit der wissenschaftlichen Arbeit, 3) Treue zu Volk und Vaterland. 1007

Volk und Vaterland, das waren zentrale Begriffe in der nationalsozialistischen Weltanschauung. Aber trotz des Endes der NS-Herrschaft wurde der Akademikernachwuchs weiterhin auf Volk und Vaterland verpflichtet. Dass es auch anders möglich war, zeigte die TH Hannover, die ein Gelöbnis ohne „Volk und Vaterland“, dafür mit Bekenntnis zu Pflichttreue und Kameradschaft und zur Achtung vor Gesetzen, Regeln und Anweisungen formulierte. Auch der erste Entwurf des Kultusministers Grimme war angemessen modern formuliert, wurde jedoch nach Rücksprache mit den Hochschulen verändert, sodass die 1948 verabschiedete gültige Formel, die Studenten verpflichtete, „in Treue zu Volk und Vaterland für die Sache der Menschheit zu wirken."1008

\footnotetext{
1004 Protokoll der Senatssitzung vom 7. Juli 1948. UAG, Senatsprotokolle 1945-1949.

1005 Protokoll der Senatssitzung vom 7. Juli 1948. UAG, Senatsprotokolle 1945-1949.

1006 Rein [1948] S. 229.

1007 Siehe Heinemann (Hrsg.) [1990]c S. 79. Konkret schüttelte der Rektor in der Immatrikulationsfeier in Vertretung aller neuen Studenten je einem Fakultätsvertreter die Hand und erklärte: „Ich verpflichte Sie, die Ehre und Ordnung der akademischen Gemeinschaft der Georg August-Universität in Ihrer gesamten Lebensführung zu wahren, Ich verpflichte Sie, Ihr Wissen im Dienste an der Wissenschaft zum Wohle der Menschheit in treuer Arbeit zu mehren, Ich verpflichte Sie, sich ständig der hohen Verantwortung bewusst zu sein, die Sie als Akademiker vor Ihrem Volk zu tragen haben, in stetiger Hilfsbereitschaft gegenüber den Hilfsbedürftigen ohne Ansehen seiner Person und in Erkenntnis Ihrer besonderen Pflicht für die Wiederherstellung des Ansehens unseres Vaterlandes." Verpflichtungsformel für neu immatrikulierte Studenten von 1945 bis 1948, abgedruckt in Rein [1946] S. 12. Siehe auch das Schreiben des Rektors Rein an den Niedersächsischen Kultusminister, 13. Februar 1948. UAG, Kur. XXX. A. a. Studierende. Allgemeine Vorschriften. IX.

1008 In $§ 11$ der Zulassungsordnung vom 5. April 1948 heißt es: „Bei der feierlichen Immatrikulation verpflichtet der Rektor die Aufzunehmenden, die Verfassung der Hochschule und die Satzung der Studentenschaft zu achten, Ehre und Ordnung der akademischen Gemeinschaft zu wahren, mit Ernst und
} 


\subsubsection{Die Charakterprüfung}

Der Charakter war neben dem fachlichen Wissen und Können von entscheidender Bedeutung in der Beurteilung der Kandidaten in den Aufnahmeprüfungen. Die Professoren stellten sich selbst die Aufgabe, die wissenschaftliche Eignung der Studienanwärter zu überprüfen, und sie hielten es für das Angemessenste, die Gesamtpersönlichkeit zu begutachten. Diese Einstellung ging konform mit der 1942 erlassenen Diplomprüfungsordnung, wonach in der mündlichen Prüfung „der Gesamteindruck des Prüflings bei der Urteilsbildung mitzuverwerten“" sei. 1009 Was aber waren die von den Professoren positiv eingeschätzten Tugenden des auszubildenden Akademikers? „Achtung vor dem akademischen Lehrer, Rücksicht und Hilfsbereitschaft gegenüber den Kommilitonen, Wahrhaftigkeit und Sauberkeit in allen menschlichen Beziehungen sind Grundelemente des akademischen Gemeinschaftslebens“, sprach Rektor Raiser 1950 zu den Studenten. ${ }^{1010}$ Man kann hier nicht nur die für den „einwandfreien Charakter“ erwünschten Tugenden sondern auch die Normen eines kollegialen Verhaltens erkennen, da das akademische Gemeinschaftsleben aus sozialen Verbindungen unter Kollegen bestand. Einen ähnlichen Tenor weist die Ansprache des Kultusministers Grimme vor den Studenten der Pädagogischen Hochschule Hannover auf. Unabdingbar sei die Forderung an die Studenten: „In Wachheit, Sauberkeit, Selbständigkeit des Denkens, in Zucht und Reinheit unseres Wollens Sucher der Wahrheit zu sein, unbekümmert, ob sie uns freundlich oder grausam, gefährlich oder nützlich ist.“1011

Die Charakterprüfung scheint ein zeittypisches Phänomen gewesen zu sein. Auch an anderen Hochschulen kam dieses Kriterium zur Anwendung. ${ }^{1012}$ Wie oben schon gezeigt, dachten die

\footnotetext{
Wahrhaftigkeit der Wissenschaft zu dienen und in Treue zu Volk und Vaterland für die Sache der Menschheit zu wirken." UAG, Kur. XXX. A. a. Studierende. Allgemeine Vorschriften. IX. Die Verpflichtungserklärung der TH Hannover und die erste Fassung des Kultusministeriums sind abgedruckt in Maaß [1998] S. 41. Minister Grimme sprach zwar 1946 nicht vom 'Vaterland', aber er sagte, es ginge bei der Erziehung der Jugend nicht nur um Wissen und Bildung, sondern es ,geht um Staat und Volk [...], um ganz Europa, ja, um die ganze Welt.“ Auch die Volksgemeinschaft erfuhr bei Grimme eine sprachliche Transformation. Das eigene Volk muss den Staat auf einer Grundlage errichten, die ,geistige Gemeinschaft heißt“. Siehe 'Erzieher wichtiger als Standartenführer', Neuer Hannoverscher Kurier, 15. Januar 1946, S. 2.

1009 Diplomprüfungsordnung für Studierende der Physik sowie für Studierende der Mathematik, § 3 Bewertung der Kenntnisse. BAB, R 4901, Nr. 500.

1010 Raiser [1950] S. 15.

1011 Minister Grimme in 'Erzieher wichtiger als Standartenführer', Neuer Hannoverscher Kurier, 15. Januar 1946, S. 2.

1012 In Hamburg war eine „einwandfreie Persönlichkeit“ Voraussetzung zur Einschreibung. In Bonn wurde in dreierlei Hinsicht geprüft: nach der politischen, der wissenschaftlichen und der Persönlichkeitsseite hin. Heinemann (Hrsg.) [1990]c S. 53, 94. Maaß [1998] schenkt der Charakterprüfung wenig Aufmerksamkeit. Möglicherweise kam sie an der TH Braunschweig weniger zum Tragen. Erwähnung findet die „menschlichcharakterliche" Eignung auf S. 66f. Maaß suggeriert, dass in Braunschweig eine Charakterprüfung erst mit der neuen Zulassungsordnung von 1948 Anwendung fand.
} 
Prüfer, dass Eignung und Charakter nicht getrennt zu beurteilen seien, sondern beides fließe notwendig in einem Gesamturteil zusammen. Sogar die sozialen Verhältnisse seien in einer Würdigung der Persönlichkeit und der Leistungen „ohnehin einkalkuliert“.

Auf welche Weise soziale Verhältnisse einflossen, zeigt ein Beispiel aus der Medizin. Der Göttinger Gynäkologe M. (vermutlich Martius ${ }^{1013}$ ) fing die Prüfungen mit der Frage an: „Und was ist Ihr Herr Vater?“ Einen positiven Verlauf der Prüfung konnte sich der Prüfling erhoffen, wenn er auf einen Vater mit Adelstitel, einen Generalstabsoffizier oder einen Professor verweisen konnte. ${ }^{1014}$ Diese Kategorie Fragen wirkte keinesfalls begünstigend auf eine soziale Öffnung der Universitäten, die in den ersten Nachkriegsjahren tatsächlich auch nicht erreicht wurde. Dies lag aber nicht nur am Vorgehen der Universitäten selbst. Zu berücksichtigen ist auch das Schulsystem der westdeutschen Länder. Nach 1945 fand eine Restauration der schulorganisatorischen Grundstruktur der späten Weimarer Zeit mit drei strikt getrennten Schularten statt. ${ }^{1015}$ Der Anteil von Studenten mit „akademisch gebildeten Vätern“ stieg in Göttingen von 22 \% im S 1945/46 auf 35,9 \% im WS 1947/48 und weiter auf $37,4 \%$ im WS 1948/49. 1016

Ein damaliger Physikprüfer erläuterte mir in einem Interview die Umstände, die zu der fast selbstverständlich und notwendig erscheinenden Charakterprüfung führten. Gerade in den ersten Nachkriegssemestern brachten die Bewerber wenig Vorwissen mit, sodass es wenig Sinn machte, ausführlich das Physikwissen abzufragen. Stattdessen fragte mein Interviewpartner nach Herkunft und Elternhaus, danach, was der (meist männliche) Prüfling im Krieg gemacht habe, wo er gekämpft habe. Außerdem fragte er, warum der Prüfling Physik studieren wolle. Wichtig war, dass er bei ihm ein „Kribbeln in den Fingern“ spüren konnte, eine Faszination für die Physik. Aber gesamt gesehen hat er weniger physikalische als menschliche Fragen gestellt. Die Noten des Abiturzeugnisses waren von geringer Bedeutung, entscheidender war, dass ein „einwandfreier Charakter“ gegeben war. Die Prüfungen waren

1013 Zu Martius siehe Bickenbach [1947].

1014 So äußerte sich Frau R. in einem Interview. Zitiert nach Clephas-Möcker \& Krallmann [1988] S. 188. Ilse Stein berichtete im Göttinger Tageblatt, 30. Oktober 1995, S. 13, 'Wenn ich operiere, besteht immer Lebensgefahr', dass Martius jede Prüfung mit dieser Frage einleitete. „War der Vater kein Arzt oder Förster, war es außerordentlich schwierig, eine Eins als Note zu erhalten.“

1015 Siehe Maaß [1998] S. 86. Zur sozialen Herkunft der westdeutschen Studenten siehe Kath [1952], [1954], [1957].

1016 Phillips [1983]c S. 14. 
improvisierend, denn die Prüfer hatten darin keine Erfahrung; es waren einfach lange Gespräche. ${ }^{1017}$

Obwohl die Vorgänge schon über 50 Jahre zurück liegen, erscheint diese Darstellung sehr glaubhaft. Die Frage nach Herkunft und Elternhaus in Zusammenhang mit der Bewertung des Charakters des Prüflings liefert eine interessante Parallele $\mathrm{zu}$ der damaligen wissenschaftlichen Charakterforschung, der Charakterologie. Dieser Zweig der Psychologie war in der NS-Zeit aus der Wehrmachtspsychologie hervorgegangen und genoss einen hohen Rang in der Psychologie auch und gerade in der Nachkriegszeit. Mit dem Begriff Charakter war ein Werdeprozess der seelischen Struktur gemeint. Da aber in dieser wissenschaftlichen Schule von der Vererblichkeit des Seelischen ausgegangen wurde, sind demzufolge der Erziehung des Menschen zu einer Persönlichkeit 'natürliche' Grenzen gesetzt. Diese Grenzen seien gegeben durch „Rasse, Blut und Volk“, oder in der Sprache der Nachkriegszeit, durch „Familie, Stamm, Volk und Menschheit“. Innerhalb dieser Denkwelt war es nur konsequent, wenn ein Prüfling, der aus äußeren Umständen wenig abprüfbares Vorwissen mitbrachte, ausführlich nach seiner „Herkunft“ befragt wurde, um die Veranlagung und 'natürliche Disposition“ für einen verantwortungsvollen akademischen Beruf herauszufinden. Die auf diese Weise erzielte Selektion konnte eine Bevorzugung von Abiturienten aus der bürgerlichen Schicht bewirkt haben, wie auch auf rassistischen und antisemitischen Kriterien beruht haben, je nachdem, welcher Prüfer an der Reihe war. Im Einzelnen bleibt es unklar, welche genauen Vorstellungen sich mit dem Begriff des „Charakters“ im Denken der Professoren verbanden. ${ }^{1018}$ Wie noch gezeigt wird, gab es 'linke“ wie 'rechte' Deutungen des Charakterbegriffs, wobei innerhalb der akademischen Elite die 'linke' Deutung vermutlich seltener vertreten wurde.

Die Charakterprüfung war ein Auswahlkriterium, das unabhängig von der Vorbildung der Geprüften angewendet wurde. Der Dekan Eucken, der für die Festlegung der Kriterien von Anfang an verantwortlich war, bewertete schon im April 1945, noch bevor Deutschland

1017 Ganz ähnlich wird über die Aufnahmeprüfungen der Staats- und Rechtswissenschaftlichen Fakultät berichtet: „Und die haben einem so ein bißchen auf den Zahn gefühlt, warum man studiert und so weiter und wollten so einen Eindruck haben praktisch. Ja, es war nicht direkt eine Prüfung, aber man wurde vorgeladen.“ So berichtet eine Studentin, die 1950 die Aufnahmeprüfung für das Fach Jura absolvierte, Rühle [2000] S. 57f. 1018 Zur Charakterologie, ihrer Entstehung, ihrer Inhalte vor wie nach 1945 siehe Mattes [1992]. Dort finden sich auch die Zitate, die aus Philipp Lersch, Der Aufbau des Charakters, aus den Auflagen von 1938 und 1951 stammen. Siehe auch Paul Heilwig: Charakterologie, Leipzig u. a.: Teubner, 1936, und die Besprechung dieses Buches durch Karl Gumpricht in: Die Tatwelt 13 (1937), S. 208-209. Robert Heiss: Die Lehre vom Charakter, Berlin u. a.: de Gruyter, 1936, und die Besprechung durch John Laird in: Die Tatwelt 13 (1937), S. 111-112. 
kapitulierte, Charakter und Wahrhaftigkeit bei der Auswahl der Studenten höher als die wissenschaftliche Leistung:

„Bei der Auswahl der akademischen Lehrer und bei der Beurteilung der Studenten sind allein entscheidend deren wissenschaftliche Leistungen, wobei allerdings unter allen Umständen ein völlig einwandfreier Charakter, vor allem unbedingte Wahrhaftigkeit vorausgesetzt wird.“1019

„Wahrhaftigkeit“ gehörte damals zum Ethos des Wissenschaftlers. ${ }^{1020}$ Die Forderung nach Wahrhaftigkeit bezog sich vor allem auf naturwissenschaftliche Forschung und weniger auf politische Handlungen, wo es Eucken selbst damit nicht so genau nahm. In diesem Sinn erläuterte zum Beispiel Walther Gerlach den Begriff der Wahrhaftigkeit. Die Suche nach der Wahrheit in der Naturwissenschaft war höchstes selbstgesetztes Ziel. Die Forderung beinhaltete auch, nichts zu verschweigen, was die Gültigkeit einer Aussage einschränken könnte. Fehler müssen zugegeben und offen gelegt werden; die Tatsache hat das Primat vor der Meinung. Die Wahrheitssuche war mit einem Ordnungsdenken verknüpft: „Die stetige Erweiterung und Vertiefung des Wissens zeigt uns die Freiheit unseres Denkens und beweist uns zur gleichen Zeit, daß Freiheit nicht Zügellosigkeit sein darf, sondern nur im Rahmen einer selbstgesetzten Ordnung fruchtbar wird, welche einzuhalten jeder sich verpflichtet. Der erste Grundsatz dieser Ordnung aber ist die innere Wahrhaftigkeit."1021 Neben dem Inhalt erinnert aber auch der Gestus dieser Sprache an frühere Aufrufe anderer Physiker. Um in der wissenschaftlichen Arbeit „tiefgehend und erfolgreich“ zu sein, müsse man eines suchen:

„den Geist restloser Klarheit, der Ehrlichkeit der Außenwelt gegenüber, zugleich der inneren Einheitlichkeit, den Geist, der jede Kompromißarbeit haßt, weil sie unwahrhaftig ist. Es ist das aber auch der Geist, den wir - als uns vorbildlich früh schon in den großen Forschern der Vergangenheit erkannt und verehrt haben, in Galilei, Kepler, Newton, Faraday. Wir bewundern und verehren ihn in gleicher Weise auch in Hitler, Ludendorff, Pöhner und ihren Genossen; wir erkennen in ihnen unsere allernächsten Geistesverwandten. “1022

Diesen letzten Satz hätte Eucken vermutlich nicht unterschrieben, weder 1924, als ihn Lenard und Stark formulierten, noch später; der Rest liegt aber nahe an dem, was Eucken dachte und schrieb. Es war die sprachliche und stilistische Verwandtschaft, die Eucken vermutlich nicht

\footnotetext{
1019 Entwurf zu einer grundsätzlichen Kundgebung der Universität von Arnold Eucken, 27. April 1945. UAG, Senatsprotokolle 1945-1949.

1020 Siehe zum Beispiel Rothacker [1943] S. 22: „Der deutsche Hochschullehrer ist Wissenschaftler und erfüllt gerade durch das Ethos der unbedingten Wahrhaftigkeit, das er als Forscher pflegt, zugleich seine große erzieherische Aufgabe.“

1021 Gerlach [1953] S. 5.

1022 Kundgebung für Hitler von Lenard und Stark, Mai 1924, wiederabgedruckt in Stark [1936] hier S. 110f.
} 
völlig bewusst war, aber bei kritischen Zeitgenossen Verbitterung auslöste. Die vor allem in national-konservativen Kreisen in der Nachkriegszeit unreflektierte Benutzung alten Vokabulars, wie zum Beispiel Euckens Begriff des „,völlig einwandfreien Charakters“,1023 wurde von dem sprachsensiblen Viktor Klemperer mit heftiger Kritik versehen:

„Wie viele Male zum Exempel habe ich seit dem Mai 1945 [...] von »charakterlichen« Eigenschaften oder vom »kämpferischen« Wesen der Demokratie sprechen hören! Das sind Ausdrücke aus dem Zentrum - das Dritte Reich würde sagen: »aus der Wesensmitte« - der LTI. Ist es Pedanterie, wenn ich mich hieran stoße [...]?“1024

Auch wenn es Eucken weder wollte noch meinte, so schwangen in dem Terminus „Charaktereigenschaften“ unvermeidlich nationalsozialistische Konnotationen mit. Klemperer war mit seiner Kritik kein Pedant, denn es ist durchaus anzunehmen, dass das Charakterideal der Deutschnationalen sich nur in Nuancen von jenem der Nationalsozialisten unterschied. Auch wenn es nicht völlig klar ist, welchen Inhalt der Begriff Charakter jeweils auszufüllen hat, so fällt beispielsweise auf, dass in Ehrungen bedeutender Physiker über die politischen Systeme hinweg immer wieder ähnliche Ideale zum Ausdruck kamen. Die „absolute Sauberkeit und Geradheit seines Wesens“, sei an Richard Becker so anziehend gewesen. „Dieser Charakter war die Grundlage für die Verehrung, die ihm entgegengebracht wurde.“1025 Dies wurde 1955 formuliert; 1936 hieß es in Bezug auf einen anderen Physiker: Das „Licht seines Geistes und die Kraft seines Charakters“ strahlten von Lenard vorbildlich aus. ${ }^{1026}$ Und an dem ehemaligen Göttinger Georg Joos wurden 1959 seine „hohen charakterlichen und menschlichen Eigenschaften" gelobt. ${ }^{1027}$ Offenbar besaßen die erfolgreichen deutschen Physiker das, was Eucken von ihnen forderte: einen einwandfreien Charakter. Bei Pohl hatte die Charakterprüfung eine lange Tradition, wenn sie auch bis 1945 mangels Aufnahmeprüfungen nicht auf die Studenten angewendet werden konnte. Sein früher Schüler Gudden berichtete 1944: „Nicht weniger wichtig als die Leistung war ihm der Charakter seiner Mitarbeiter“. 1028 Joos wies in einer Lobschrift zu Pohls Geburtstag auf einen

\footnotetext{
1023 Zum Beispiel konnten die NS-Kameradschaften (das waren die in nationalsozialistische Strukturen eingebundene Studentenverbindungen alten Stils) ihnen zugewiesene Mitglieder ablehnen, wenn sie charakterlich oder wissenschaftlich ungeeignet zu sein schienen. Jarausch [1984] S. 206.

1024 Klemperer [1957/99] S. 25.

1025 Leibfried [1955]b S. 400.

1026 Stark [1936] S. 112.

1027 Meißner [1959]a S. 320.

1028 Gudden [1944] S. 168.
} 
wichtigen Zweck dieser Sorgfalt hin, denn ,solche feste Charaktere braucht [...] die deutsche Physik schon um ihrer Vertretung nach außen willen."1029

Auch wenn die Nähe zur „Sprache des Dritten Reiches“ für manchen Zeitgenossen offensichtlich war, so galt im Bewusstsein der Sprecher der Charakterbegriff als überpolitischer Terminus, der deshalb scheinbar unbedenklich verwendet werden konnte. Bedenklich war auch weniger der Begriff, als die damit verknüpfte alte, nationalistische Haltung, die zum Beispiel bei den Studentenverbindungen klar nachweisbar ist. 1951 sahen sie ihre selbstgestellte Aufgabe im ,unveränderten [!] Ziel der Erziehung zur ehrenhaften, charaktervollen und vaterlandsbewussten Persönlichkeit". ${ }^{1030}$ Das in diesem Sinn beschriebene, unveränderte Ideal kann auch Eucken unterstellt werden, dessen eigener Charakter in einer schlagenden Verbindung mit geformt wurde. In diesen Zusammenhang muss auch Prandtls Stellungnahme zur Entnazifizierung der Studenten gesehen werden, in der er diejenigen bevorzugt wissen wollte, die schon im Nationalsozialismus positiv aufgefallen waren und deshalb in den Jugend-Verbänden leitende Stellen bekommen hatten. ${ }^{1031}$

Es entbehrt nicht einer gewissen Ironie, dass die Militärregierung diese revanchistische Tendenz gerade dann verstärkte, als sie diese erkannt hatte und zu bekämpfen begann. Gegenüber der Militärregierung wurde die Aufnahme von politisch belasteten Studenten dadurch gerechtfertigt, dass diese eine besonders hohe wissenschaftliche Eignung hätten. Um dem entgegenzusteuern forderte die britische Erziehungsbehörde, nicht nur fachliche Qualifikation zu berücksichtigen, sondern auch die für den Aufbau einer demokratischen Gesellschaft geeigneten Bewerber auszuwählen und auf deren außerfachliche Befähigung Wert zu legen. Dies war Teil des britischen Re-education-Programms, das die Erziehung zur Demokratie im Auge hatte. ${ }^{1032}$ In diesem Sinn ist Birds Anweisung an den Rektor zu verstehen, in der er mehr als nur eine Leistungsüberprüfung forderte: „Bei der Auswahl der Studenten haben die Fakultäten die Charaktereignung zu berücksichtigen und diejenigen auszuwählen, die abgesehen von ihrer akademischen Qualifikation des Vorzugs eines Platzes an der Universität am meisten würdig sind." ${ }^{1033}$ Mit dieser Formulierung erreichte Bird aber nur eine Verstärkung des schon etablierten Prüfungsverfahrens. Es muss aber berücksichtigt

\footnotetext{
1029 Joos [1954] S. 339.

1030 Bergmann [1951] S. 198.

1031 Siehe S. 215.

1032 Zur Re-education siehe Heinemann (Hrsg.) [1981] und [1990] und [1992]; Philips (Bearb.) [1991]; Pakschies [1979], [1981]; Welch [1989].

1033 CO Bird an Rektor, 16. September 1946; Hervorhebung original. UAG, Kur. XXX. A. a. Studierende. Allgemeine Vorschriften. VIII.
} 
werden, dass in der Übersetzung des englischen Originals ins Deutsche schon eine gewisse Umdeutung stattfand. Bird schrieb wörtlich: „Faculties will take into account suitability of type.“ Die Schwierigkeit der Übersetzung lag zugegebenermaßen darin, eine nicht nationalsozialistisch geprägte Entsprechnung für suitability of type zu finden. Die Delegation der britischen Association of University teachers forderte im Mai 1947 aber wörtlich eine Berücksichtigung von „,character and ability“ bei den Ausleseprüfungen. ${ }^{1034}$

Aber selbst deutsche kritische Stimmen waren in der Sprache ihrer Zeit gefangen und hatten es schwer, die passenden Worte zu finden. Ein Journalist des Neuen Hannoverschen Kuriers, der die Zulassungspraxis der Universität Göttingen wegen der Aufnahme vieler ehemaliger Offiziere und Parteimitglieder kritisierte, forderte stattdessen eine Auswahl „der künftigen Akademiker nach Befähigung, Charakter und politischer Sauberkeit."1035 Hier finden wir dieselbe Ironie, dass ein Kritiker genau jene Kriterien einfordert, die von jenen Prüfern, die Offiziere und Pg's aufnahmen, ohnehin berücksichtigt wurden, nur unter wahrscheinlich anderer Bedeutungszuweisung. In die selbe Richtung, wenn auch sprachlich etwas gespreizter, weist die Forderung von Mitscherlich, die er 1946 bei den Marburger Hochschulgesprächen aufstellte: „Das Problem der Platzfrage an den Universitäten ist nicht dadurch gelöst, daß man das Niveau heraufschraubt. Wir dürfen nicht nur hochspezialisierte Vertreter eines Faches herausbilden, sondern wir müssen eine neue Auslese schaffen. Dabei kann psychologisches und charakterologisches Wissen uns helfen."1036

Die im April 1948 vom Kultusminister Grimme erlassene neue „Ordnung der Zulassung zum Studium an den wissenschaftlichen Hochschulen in Niedersachsen“ regelte die bei der notwendigen Auslese zu berücksichtigen Kriterien. Neben ,allgemein-geistiger Eignung“ solle auch „die menschlich-charakterliche Eignung für die Ausübung des gewählten akademischen Berufs und für eine verantwortungsbewusste Mitarbeit im öffentlichen Leben“ berücksichtigt werden. ${ }^{1037}$ Der Leiter der Hochschulabteilung im Kultusministerium, Kurt Zierold, erläuterte 1948, wie die Forderung nach charakterlicher Eignung zu verstehen sei:

„Zeichnen wir das charakterliche Idealbild des Studenten, so wäre auszuwählen jener Mensch, der ein richtig Erkanntes und geistig Eingeordnetes verwirklichen kann, der jene Verwirklichungskraft hat, die unvereinbar ist mit egozentrischer Verkapselung und überwiegendem materialistischen Interesse, unvereinbar mit reinem Karriere-, Geld- und Machtstreben, unvereinbar mit persönlicher Geltungssucht und dem Wunsche nach der satten Sicherheit des Gewohnten. Ein

1034 Siehe den Bericht der Delegation in Phillips [1983]b S. 137.

1035 Siehe 'Der »Kurier« bemerkt: Universitäten“, Neuer Hannoverscher Kurier, 30. November 1945, S. 2.

1036 Mitscherlich [1947] S. 158. Hervorhebung original.

1037 Siehe $\S 5$ der erwähnten Ordnung. UAG, Kur. XXX. A. a. Studierende. Allgemeine Vorschriften. IX. 
Mensch, der offen ist, erschütterungsfähig, zur Leidenschaft der Hingabe bereit, klaren Willens, phrasenfeindlich und von intellektueller Redlichkeit, jung und zukunftsfroh, obwohl er der Begrenztheit alles nur Menschlichen inne ist."1038

Ein solcher Charakter war im Sinne des Ministeriums Voraussetzung, damit geistige Erkenntnisse verwirklicht werden können, „oder anders gesagt: um aus Kopfgedanken Herzgedanken werden zu lassen.“ Eine Forderung an den Charakter wurde als unpolitisch verstanden; man wollte sich von der ostdeutschen Regelung des Zulassungsverfahrens abgrenzen, wo explizit Arbeiterkinder bevorzugt wurden, also ein politisches Kriterium zum Einsatz kam. Zierold sprach die Hoffnung aus, dass die Charakterprüfung ebenfalls Kinder „unterer Volksschichten“ bevorzugen könne, da diese „in charakterlicher Beziehung, in Treue, Kameradschaft, Hilfsbereitschaft, Willenskraft, Volksverbundenheit, in jener Verwirklichungskraft, die wir forderten, niemandem nachstehen oder sogar dank ihrer vitalen Unverbrauchtheit manchem Sohn intellektueller Schichten überlegen“" seien. Bevorzugt würden sie aber nur, wenn sie in intellektueller und geistiger Hinsicht ihren Mitbewerbern ebenbürtig erschienen. ${ }^{1039}$

Das Zulassungsverfahren mit seiner Charakterprüfung fragt nicht explizit nach politischer Überzeugung oder sozialer Herkunft der Bewerber. Es ist jedoch anzunehmen, dass in den Köpfen der meisten Prüfer die Ansicht vorherrschte, dass die soziale Herkunft den Charakter mitformt und dass in der politischen Haltung sich ein Teil des Charakters widerspiegelt. Insofern war die Charakterprüfung politisch, wenn auch offiziell Politisches ferngehalten wurde. Negativ gesagt, wurde dadurch Politisches gerade dort nicht angewendet, wo es um Aspekte der Entnazifizierung ging. Die von Zierold genannten Tugenden „Treue, Kameradschaft, Hilfsbereitschaft, Willenskraft, Volksverbundenheit und Verwirklichungskraft“" sind auch typisch militärische Tugenden, und diese zu bevorzugen, widersprach der von alliierter Seite geforderten Entmilitarisierung. Die Charakterprüfung war auch ungeeignet, Bewerber mit nationalsozialistischer Überzeugung abzuhalten. Wenn man Zierolds charakterliches Idealbild betrachtet, so stellt man fest, dass auch überzeugte Nationalsozialisten unter den Göttinger Physikern diesem Bild entsprachen, was ihnen bei auftretenden Problemen in der Entnazifizierung von ihren Kollegen ausdrücklich beschieden wurde. Diese Physiker sollten nicht nur ihre Stellen behalten, sie bildeten auch das charakterliche Ideal für den Nachwuchs.

1038 Zierold [1984] S. 23f.

1039 Zitate aus Zierold [1984] S. 24f. 
In der Praxis hing die Bewertung des Charakters von den jeweiligen Prüfern ab. Entsprechend willkürlich erscheinen daher die Beurteilungen. Die Ergebnisse der Wissens- und Charakterprüfungen wurden dem Dekan schriftlich mitgeteilt, damit dieser eine Richtschnur hatte, wie mit dem Bewerber weiter zu verfahren sei. Zwei Göttinger Naturwissenschaftler beurteilten einen Bewerber folgendermaßen: $\mathrm{Er}$ „,machte einen durchaus freundlichen und kultivierten Eindruck. Seine Vorkenntnisse sind allerdings gering.“ Und der zweite: Er „machte einen für sein Alter überraschend jugendlichen Eindruck. Er hat mir gut gefallen. Seine Kenntnisse sind noch gering; er wußte aber, wer Helmholtz und Kepler waren." Beide Prüfer empfahlen seine Zulassung, jedoch musste der Bewerber erst das Vorstudium absolvieren. 1040

Die Charakterprüfung beinhaltete ein stark zufälliges Moment. Der Ausgang der Prüfung hing stark von der Persönlichkeit des Prüfers und seiner momentanen Laune ab. Manche hatten Pech, andere aber Glück, wie folgender Bericht zeigt: Zum Jahreswechsel 1947/48 bemühte sich Frau R. nach überstandener russischer Kriegsgefangenschaft um die Fortsetzung ihres Medizinstudiums in Göttingen. „Man wurde dort in der Universität aussortiert, und man wurde gefragt: »Sind Sie nicht Nazi, sind Sie nicht braun, warum sind Sie erst jetzt hier?«“" Sie war damals verwirrt, sah für sich keine Perspektive und litt unter Gedächtnisstörungen. Geprüft wurde sie von einer alten Mathematikprofessorin ${ }^{1041}$, der sie auch ihre Erinnerungslücken gestand. Darauf die Professorin: „»Haben Sie überhaupt schon was gegessen?«»Nein, ach Gott, das bin ich doch gewöhnt.«»Ich hab zu Hause noch einen Teller Suppe, kommen Sie mit.« Die teilte also mit mir die Suppe.“ Frau R. gestand ihre völlige Hilflosigkeit und war ganz überrascht, dass ihre Prüferin sie zum Studium zulassen wollte. „Sie hat mir dann also einen Platz in einem Studentenheim besorgt. [...] Die Professorin hat mich offiziell dann angemeldet und hat gesagt: »Sie müssen Medizin studieren.«“1042

Die Charakterprüfung bevorzugte nicht einen bestimmten Studententypus, da die Gruppe der prüfenden Dozenten über die Kriterien nicht völlig übereinstimmte. Da aber in der Professorenschaft eine national-konservative Einstellung vorherrschte, verwundert es nicht, dass eine ebensolche politische Einstellung bei den Studenten bevorzugt wurde. Der Bezirksvorstand des Deutschen Gewerkschafts-Bundes, Bezirk Niedersachsen, berichtete im April 1948 an den Kultusminister:

\footnotetext{
1040 Krönig \& Müller [1990] S. 133. Hervorhebung nicht original.

${ }^{1041}$ Es handelt sich hier ziemlich sicher um die apl. Professorin für Mathematik, Helene Braun, damals die einzige Frau unter den Dozenten der Math.-Nat. Fakultät. Siehe Vorlesungs- und Personalverzeichnis der Universität Göttingen.
} 
„Die Haltung des größten Teiles der Studentenschaft ist so, dass sie Anlass zur Sorge um die politische Entwicklung Deutschlands gibt. Das Verhalten der Studenten zeichnet sich aus durch übersteigerten Nationalismus und antidemokratische Einstellung. Wir sind uns bewusst, dass es sich hierbei nicht nur um die Universität Göttingen handelt, sondern dass die Entwicklung im wesentlichen an allen Universitäten die gleiche ist."1043

\subsubsection{Die Regelung des numerus clausus}

Der 1945 eingeführte numerus clausus war keine Göttinger Spezialität. Jede wiedereröffnende Hochschule in Deutschland musste damals eine Regelung finden, um mit der großen Anzahl an Bewerbern fertig zu werden. ${ }^{1044}$ Der numerus clausus war aus Sicht des Kultusministeriums unvermeidlich. ${ }^{1045}$ Er entsprang auch teilweise einem Bedürfnis der deutschen Professoren, ${ }^{1046}$ von denen manche ihn als eine „Wohltat“"1047 empfanden, als auch einer Forderung der Militärregierung, die bei einer großen Zahl von Studenten schwerwiegende politische Probleme befürchtete und auch die Gefahr sah, dass später arbeitslose Akademiker den Herd für neue Unruhen bilden könnten. Außerdem hatte auch die Abteilung Arbeitseinsatz (Manpower) ein Interesse an arbeitsfähigen jungen Menschen und wollte deshalb die Studentenzahl gering halten. ${ }^{1048}$ Ein pragmatischer Grund für den numerus clausus lag in der beschränkten Aufnahmefähigkeit der Hochschulen. Es fehlte an Räumen, Büchern, Papier, Studentenwohnungen, und hinzu kam in vielen Fächern ein durch die Entnazifizierung verkleinerter Lehrkörper. 1049

Um den numerus clausus auf den Bedarf an ausgebildeten Akademikern anpassen zu können, wurde im Januar 1946 eine „Zentralstelle für akademische Nachwuchs- und Berufsforschung“ eingerichtet, die ihren Sitz in Göttingen hatte. Leiter der Stelle war Regierungsrat Wienert. ${ }^{1050}$ Für das WS 1946/47 wurde wegen einem erwarteten Mangel an Lehrern der höheren Schulen das Kontingent für Lehramtskandidaten in der mathematisch-naturwissenschaftlichen Fakultät

\footnotetext{
1042 So äußerte sich Frau R. in einem Interview. Zitiert nach Clephas-Möcker \& Krallmann [1988] S. 191.

1043 Zitiert nach Maaß [1995]a S. 83.

1044 Eine ähnliche Ausgangslage wie Göttingen hatte die Universität Tübingen. Dort regulierte der numerus clausus die Studentenzahl auf etwa 3500. Er existierte genauso wie in Göttingen von 1945 bis 1953. Siehe Decker-Hauff \& Setzler (Hrsg.) [1977] S. 289.

1045 Siehe Zierold [1984] S. 20ff.

1046 Im Jahr 1948 hielten sich die positiven und ablehnenden Haltungen zum numerus clausus unter den deutschen Professoren etwa die Waage. Siehe Phillips [1995] S. 57. Auf vermehrte Ablehnung stieß er an der TH Braunschweig, Maaß [1998] S. 73f.

1047 Siehe Heinemann (Hrsg.) [1990]c S. 94.

1048 Siehe Maaß [1998] S. 73f.; Heinemann (Hrsg.) [1990]c S. 166f., 169.

1049 Siehe Phillips [1983]c S. 13.
} 
erhöht. Von den 524 Angemeldeten, die in die engere Wahl fielen, wurden 219 aufgenommen. ${ }^{1051}$ Zuerst gab es in Göttingen noch keinen offiziellen numerus clausus, sondern vom Senat festgelegte Quoten, die jedoch wesentlich überschritten wurden. ${ }^{1052} \mathrm{Im}$ September 1946 wurde dann der numerus clausus vom Universitätskontrolloffizier für die einzelnen Fakultäten wie folgt festgesetzt: ${ }^{1053}$

\begin{tabular}{|l|r|}
\hline Theologische Fakultät & 300 \\
\hline Medizinische Fakultät & 1300 \\
\hline Rechts- und Staatswissenschaftliche Fakultät & 1100 \\
\hline Math.-Naturwissenschaftliche Fakultät & 1050 \\
\hline Philosophische Fakultät & 1000 \\
\hline Forstliche Fakultät & 250 \\
\hline Zusammen & 5000 \\
\hline
\end{tabular}

Tabelle 8 Numerus clausus der einzelnen Fakultäten im WS 1946/47.

Vom WS 1945/46 bis zum SS 1948 beschränkte der numerus clausus die Anzahl der gesamten an der Universität immatrikulierten Studenten auf etwa 5000. Er wurde aber stets nur auf die deutschen Studenten bezogen. ${ }^{1054}$ Jede Fakultät bekam vom Universitätsoffizier Bird Quoten zugeschrieben, welche die Professoren innerhalb der Fakultäten selbst auf die einzelnen Fächer verteilen konnten. Dieses Verfahren hatte einige offensichtliche Nachteile. Nach der Auffüllung der im ersten Nachkriegssemester eingeräumten Plätze mussten die späteren Bewerber mit den wenigen frei gewordenen Plätze durch Abgänger Vorlieb nehmen. Im WS 1945/46 befanden sich 36,5 \% der Studenten im ersten Fachsemester. ${ }^{1055}$ Das führte dazu, dass in bestimmten Fächern in den folgenden Semestern manchmal kein einziger Student aufgenommen wurde. Auf Grund des unterschiedlichen Andrangs auf die

1050 Siehe Heinemann (Hrsg.) [1990]c S. 99 und den Bericht des Regierungsrats Wienert über die Arbeiten der Zentralstelle, S. $137 \mathrm{ff}$.

1051 Protokoll der Fakultätssitzung vom 17. August 1946. GPAMNFG, Protokollbuch III der mathematischnaturwissenschaftlichen Fakultät WS 1927/28 - SS 1946.

1052 Heinemann (Hrsg.) [1990]c S. 50.

1053 Rektor an Kultusminister, 16. Februar 1948. Die Zahlen haben sich im Laufe der Zeit nur leicht verändert und blieben bis 1949 gültig. Da die Theologen einen besonders eklatanten Nachwuchsmangel zu verzeichnen hatten, wurde Anfang 1947 deren Quote auf Kosten der philosophischen und der mathematischnaturwissenschaftlichen Fakultät von 300 auf 370 erhöht. Die Philosophen mussten 20, die Naturwissenschaftler 50 Plätze abgeben. Siehe Kultusminister an Rektor, 13. März 1947. UAG, Kur. XXX. A. a. Studierende. Allgemeine Vorschriften. VIII. Im SS 1947 bekam die Theologische Fakultät von der Philosophischen und von der Mathematisch-Naturwissenschaftlichen Fakultät 10 und 50 Plätze zugesprochen. Siehe Protokoll der Senatssitzung vom 22. Januar 1947. UAG, Senatsprotokolle 1945-1949. Im Jahr 1948 gaben die Phil. Fak. 25 und die Math.-Nat. Fak. 40 Plätze zugunsten der Theol. Fak. ab, deren Kontingent durch eine weitere Erhöhung der Gesamtzahl der Studienplätze um 10 auf 375 angewachsen war. UAG, Kur. XXX. A. a. Studierende. Allgemeine Vorschriften. IX.

1054 Referent des Rektors für studentische Angelegenheiten, Wienert, an Rektor, 11. März 1948. UAG, Rek. 7201.

1055 Siehe das Schaubild der Verteilung der Studentenschaft auf die Fachsemester von 1945-1949 in: Bollnow [1950] S. 159. 
verschiedenen Fächer wurden demgegenüber manche Quoten nicht voll ausgeschöpft. ${ }^{1056}$ Es kam zum Tausch von Plätzen nicht nur zwischen den Fächern innerhalb einer Fakultät, sondern auch zwischen den Fakultäten. Beurlaubte Studenten zählten nicht auf das Kontingent; bei der Wiederzulassung wurden diese in erster Linie berücksichtigt. Beurlaubungen wurden nur aus zwei Gründen erteilt: 1) an Kranke, 2) zur Vorbereitung auf eine Prüfung. 1057

Die Aufteilung der Quote auf die einzelnen Fächer wurde nicht starr gehandhabt, sondern in jedem Semester dem Bedarf angepasst. ${ }^{1058}$ Die Studentenzahlen und die Aufteilung des Kontingents der Math.-Nat. Fakultät sah für zwei exemplarische Semester folgendermaßen aus (die 200 Studenten der landwirtschaftlichen Abteilung sind hier nicht berücksichtigt, außerdem gab die Fakultät von ihren 1050 Plätzen 40 an die Theologische Fakultät ab):

\begin{tabular}{|l|l|l|}
\hline Fach & Studentenzahl, WS 1947/48 1059 & Kontingent, WS 1948/491060 \\
\hline Mathematik & 151 & 147 \\
\hline Physik & 203 & 190 \\
\hline Chemie & 184 & 200 \\
\hline Biologie & 129 & 127 \\
\hline Geographie & 38 & 38 \\
\hline Geologie & 18 & 18 \\
\hline Mineralogie & 17 & 18 \\
\hline Astronomie & 14 & 14 \\
\hline $\begin{array}{l}\text { Metallkund } \\
\text { e }\end{array}$ & 6 & 10 \\
\hline Geophysik & 7 & 6 \\
\hline Sport & 12 & 12 \\
\hline Psychologie & 26 & 22 \\
\hline Physiologie & 5 & 8 \\
\hline zusammen & 810 & 810 \\
\hline
\end{tabular}

Tabelle 9 Studentenzahlen und Kontingent der einzelnen Fächer der MathematischNaturwissenschaftlichen Fakultät, WS 1947/48 und WS 1948/49.

1056 Eine Kritik dieser Regelung des numerus clausus kam auch von studentischer Seite mit der Forderung, nicht die Gesamtzahl, sondern die Neuzulassungen zu beschränken. Siehe GUZ, 2. Jg., Nr. 12, vom 23.5.1947, S. 7. Zur Kritik der Professoren siehe Heinemann (Hrsg.) [1990]d S. 376-379. Der Göttinger Kurator Bojunga sprach sich aber noch 1948 gegen eine Umwandlung der Beschränkung von der Gesamtzahl auf die

Neuzulassungen aus, da er dadurch eine kurzfristige Erhöhung der Gesamtzahlen befürchtete. Siehe Kurator an Kultusminister, 5. März 1948. HStAH, Nds. 401 Acc. 92/85, Nr. 155.

1057 Referent des Rektors für studentische Angelegenheiten, Wienert, an Rektor, 11. März 1948. UAG, Rek. 7201.

1058 Siehe Rektor an Kultusminister, 26. Februar 1948 und 28. Januar 1949. HStAH, Nds. 401 Acc. 92/85, Nr. 155.

1059 Aus Dekan an Kurator, 30. Oktober 1947. UAG, Kur. XXX. A. a. Studierende. Allgemeine Vorschriften. IX.

1060 Aus Rektor an Kultusminister, 18. Januar 1949. UAG, Kur. XXX. A. a. Studierende. Allgemeine Vorschriften. IX. 
In die Immatrikulationszahlen wurden die Gasthörer nicht eingerechnet, insofern zählten sie nicht zum Kontingent des numerus clausus. Ein Zuzugs- und Wohnrecht mussten die Gasthörer über Institutsdirektor, Dekan und Rektor extra bei der Stadt beantragen. ${ }^{1061}$ Die bevorzugte Zulassung von Studenten, die aus langer Kriegsgefangenschaft heimkehrten, war mit verantwortlich, dass im Sommersemester 1947 der numerus clausus überschritten wurde. Für DP-Studenten, die außerhalb der nc-Quoten aufgenommen wurden, gab es eigene Zulassungsquoten, die zuerst jede Fakultät selbst festlegte. 1062 Später galt für sie ein Kontingent von $10 \%$ der deutschen Studenten. ${ }^{1063}$

Im WS 1947/48 gab es an der Universität Göttingen laut Angabe des Kurators 5947 Studenten, davon 150 Beurlaubte und 348 Gasthörer. Die verbleibenden 5444 waren sogenannte ordentliche Studenten, davon 5143 Einheimische. In den Gesamtstudentenzahlen waren aber die Examenskandidaten, die etwa $20 \%$ ausmachten, nicht mitgerechnet. ${ }^{1064}$ Der numerus clausus betrug 5010. ${ }^{1065}$ Wie diese Zahlen zeigen, hatte sich eine stillschweigende Umgehung des numerus clausus durch die vermehrte Aufnahme von Gasthörern eingespielt. 1066 Der UCO erfuhr bis dahin nur die Zahlen der ordentlichen deutschen Studenten. Ab 1948 verlangte Bird auch Informationen über die Zahl der Gasthörer. Folglich sanken die Gasthörerzahlen von über 400 im WS 1947/48 auf unter 100 im WS 1951/52 (siehe Tabelle 10). ${ }^{1067}$ Als Gasthörer konnten sich einschreiben berufstätige Personen oder „Personen mit einer durch eine Staats- oder Diplomprüfung abgeschlossenen Hochschulbildung, die von einem Dozenten der Universität mit Zustimmung des Dekans als Doktorand angenommen sind oder ihre Studien auf einzelnen Gebieten vervollständigen wollen." Nicht als Gasthörer zugelassen wurden all jene, die den Vorschriften der Immatrikulation genügten und noch keine Abschlussprüfung bestanden hatten. ${ }^{1068}$ Es handelte

\footnotetext{
1061 Protokoll der Senatssitzung vom 13. März 1946. UAG, Senatsprotokolle 1945-1949.

1062 Protokolle der Senatssitzungen vom 18. Dezember 1946, 7. Mai 1947. UAG, Senatsprotokolle 1945-1949.

1063 Rektor an Kurator, 5. März 1948. UAG, Kur. XXX. A. a. Studierende. Allgemeine Vorschriften. IX. Zu den von der Militärregierung festgelegten Quoten für ausländische Studenten siehe Heinemann (Hrsg.) [1990]c S. 103, 221. Zum Studium der displaced persons siehe Maaß [1998] Kap. 4.3.

1064 UAG, Rundschreiben der Georg-August-Universität III.

1065 Kurator an Kultusminister, 12. März 1948. UAG, Kur. XXX. A. a. Studierende. Allgemeine Vorschriften. IX. Diese Zahlen weichen von den in [Studentenzahlen] [1987] angegebenen, die auch in Tabelle 10 aufgelistet sind, leicht ab. Es ist schlechterdings nicht möglich, die Zahlen nach ihrem Wahrheitsgehalt zu beurteilen.

1066 Trotz der Überschreitung des vorgegebenen numerus clausus ersuchte die Universität Göttingen im Jahr 1947 im Unterschied zur TH Hannover und TH Braunschweig nicht um seine Erhöhung. Siehe Maaß [1998] S. 77. Begründet wurde die Göttinger Entscheidung mit den als zu hoch erachteten Studentenzahlen. Siehe Kurator an Kultusminister, 5. März 1948. HStAH, Nds. 401 Acc. 92/85, Nr. 155.

1067 Kurator an Kultusminister, 5. März 1948. UAG, Kur. XXX. A. a. Studierende. Allgemeine Vorschriften. IX. Gasthörerzahlen nach [Studentenzahlen] [1987].

1068 Mitteilung für Studierende für WS 1954/55. UAG, Kur. XXX. A. a. Studierende. Allgemeine Vorschriften. IX.
} 
sich also vor allem um ältere Studenten, die im Prinzip hätten politisch überprüft werden müssen.

Am 21. Februar 1949 wurde die Regelung des numerus clausus von der britischen Militärregierung den deutschen Ländern in eigener Verantwortung überlassen, infolgedessen nicht mehr die Gesamtzahl, sondern die Zahl der Neuzulassungen vom Kultusministerium festgesetzt wurde. Für die Universität Göttingen war diese Zahl 1176. Die Verteilung auf die einzelnen Fakultäten lag in der Hand der Universität. ${ }^{1069}$ Die Math.-Nat. Fakultät beschränkte die Zahl der Neuzulassungen auf 200. Außerdem sollte von Zwangsexmatrikulationen nach Vollendung der Pflichtsemesterzahl abgesehen werden. ${ }^{1070}$

Aber schon bevor die Verantwortung in deutschen Händen lag, wurden für das WS 1948/49 die Anzahlen der Neuzulassungen anstelle der Gesamtzahlen für die einzelnen Fakultäten beschränkt. In der Mathematisch-Naturwissenschaftlichen Fakultät wurden die Neuzulassungen auf 40-50 festgelegt, in der Theologischen auf 50-60, in der Juristischen 300, Medizinischen 120, Philosophischen 100 und Forstlichen 30. Eine Abstimmung der Zulassungszahlen mit dem Wohnungsangebot wurde im Senat abgelehnt. ${ }^{1071}$ Die Universität wollte mit der neuen Zulassungsregelung eine weitere Senkung der Gesamtstudentenzahlen erreichen und sprach sich, wie die obigen Zahlen schon andeuten, für eine „elastische Handhabung“ der Kontingentierung aus. ${ }^{1072}$

Auf der Hochschulkonferenz vom 21. Februar 1949 wurden die Jahreshöchstsummen für Neuzulassungen festgelegt. Das vorhin schon festgelegte Kontingent der Göttinger Math.Nat. Fakultät von 200 wurde bestätigt. ${ }^{1073}$ Im September 1949 hob die Militärregierung alle Zwangsbeschränkungen des Hochschulzugangs auf und gestattete dem Ministerium, notwendige Beschränkungen selbst zu treffen. ${ }^{1074}$

Die Universität glaubte immer noch, stark überhöhte Studentenzahlen aufzuweisen, und war deshalb weiterhin um eine Verringerung bemüht.1075 Die Studentenzahlen in Ost- und Westdeutschland zusammen hatten 1949 wieder etwa den Stand von 1931 erreicht, und es

1069 GUZ, Nr. 5, 11. März 1949, S. 14. Siehe auch die Empfehlung der Hochschulkonferenz vom März 1947, in Heinemann (Hrsg.) [1990]c S. 295; außerdem Maßß [1998] S. 80.

1070 GUZ, Nr. 8, 29. April 1949, S. 19. Diese Zahlen waren auch noch 1950 gültig. Siehe „Ergebnis einer Rundfrage betr. Zulassung zum Studium“ in: UAG, Rek. 7101.

1071 Protokoll der Senatssitzung vom 7. Juli 1948. UAG, Senatsprotokolle 1945-1949.

1072 Protokoll der Senatssitzung vom 8. Dezember 1948. UAG, Senatsprotokolle 1945-1949.

1073 Kultusministers an Kurator, 4. April 1949. UAG, Kur. XXX. A. a. Studierende. Allgemeine Vorschriften. IX.

1074 Bird an Rektor, 25. Oktober 1949. UAG, Kur. XXX. A. a. Studierende. Allgemeine Vorschriften. IX. 1075 Siehe Bollnow [1950] S. 158. 
wurden auch wieder ähnliche Stimmen laut, die vor einer drohenden Überfüllung der akademischen Berufe warnten. ${ }^{1076}$ Möglicherweise wollten die Göttinger Professoren dieser Gefahr vorbeugen.

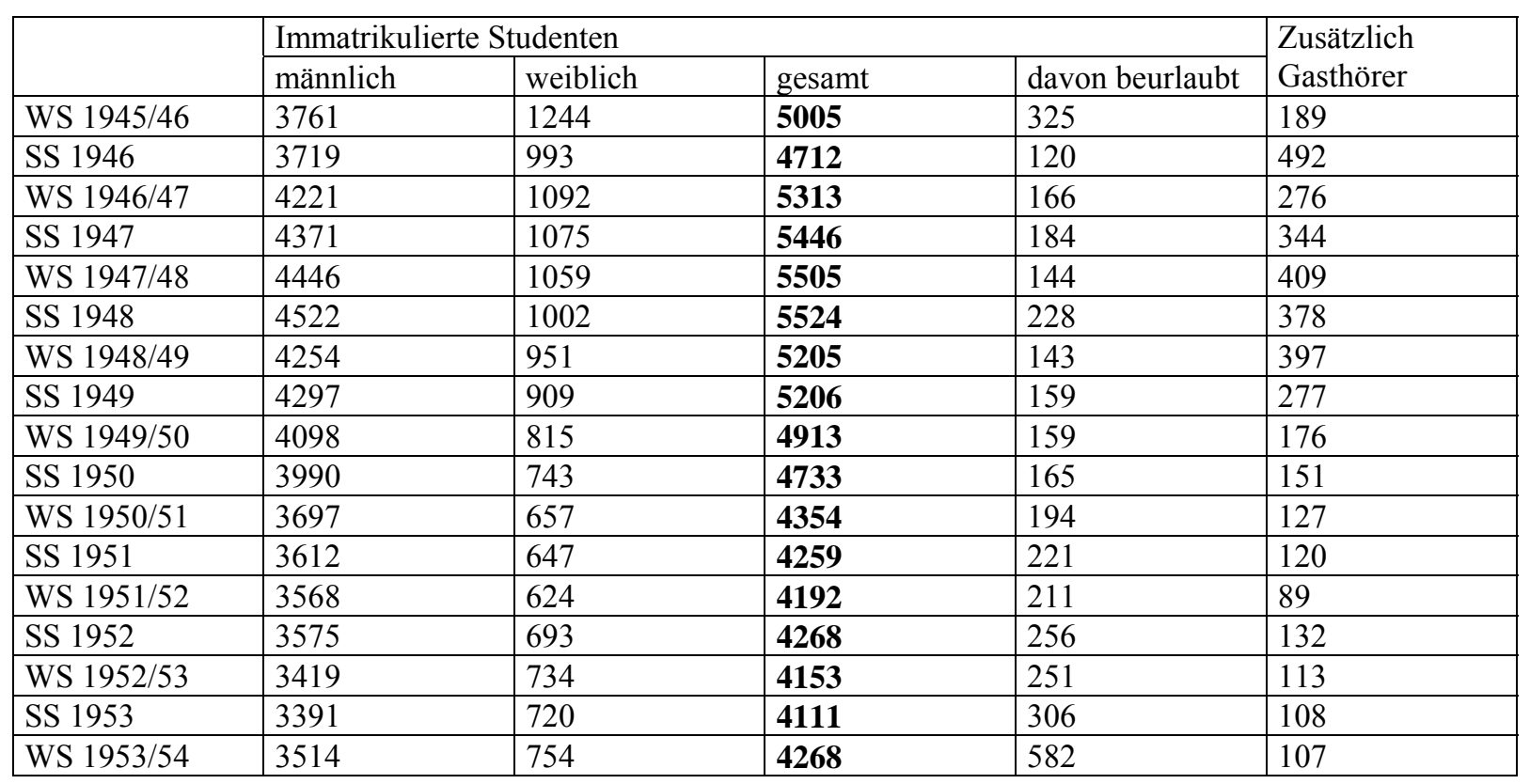

Tabelle 10 Studentenzahlen der Universität Göttingen 1945-1953.1077

Der Tiefstand der Studentenzahlen in Göttingen in den frühen 50er Jahren entspricht nicht dem bundesweiten Trend. Eine deutlich andere Entwicklung zeigt zum Beispiel die RWTH Aachen. Im WS 1946/47 waren dort 988 Studenten eingeschrieben. In den folgenden Wintersemestern stieg deren Zahl auf 1067, 1339, 2745 bis zum WS 1950/51 auf 3652 an. Zum Vergleich waren im WS 1932/33 in Aachen 940 Hörer und in Göttingen 3849 immatrikuliert. 1078

In Göttingen wurden im SS 1951 in der Physik von 87 Bewerbern 51 aufgenommen. Davon waren 40 Studienanfänger; 3 zugelassene Bewerber traten nachträglich zurück. Die Ablehnungsquote betrug im SS 1951 in der Physik 40 \%, in der Math.-Nat. Fakultät 39 \%. ${ }^{1079}$ Im SS 1952 wurden in der Math.-Nat. Fakultät von 281 Bewerbern 73 abgelehnt; 113 der zugelassenen 172 Studenten waren Studienanfänger. ${ }^{1080}$ Im WS 1953/54 wurden in der

\footnotetext{
1076 Siehe zum Beispiel den Artikel in der GUZ von Goldschmidt [1949].

1077 [Studentenzahlen] [1987] S. 10.

1078 Siehe Lohse [1993] S. 2, 46.

1079 Mitteilung des Dekans an den Rektor, 11. Mai 1951. In den Daten der gesamten Fakultät sind die Ausländer und die Abteilung Landwirtschaft ausgenommen. UAG, Rek. 7101.

1080 UAG, Rek. 7201.
} 
Math.-Nat. Fakultät von 195 Bewerbern 57 abgelehnt; nur 28 der zugelassenen 121 Studenten waren Studienanfänger. ${ }^{1081}$

\begin{tabular}{|l|l|l|l|}
\hline Semester & Zahl der Antragsteller ${ }^{1082}$ & Zahl der Neuzulassungen & $\begin{array}{l}\text { Neuzulassungen in } \\
\text { Prozent der Antragsteller }\end{array}$ \\
\hline WS 1945/46 & - & 539 & - \\
\hline SS 1946 & 903 & 248 & 27,5 \\
\hline WS 1946/47 & 980 & 272 & 27,8 \\
\hline SS 1947 & 251 & 96 & 38,2 \\
\hline WS 1947/48 & 692 & 209 & 30,2 \\
\hline SS 1948 & 2921083 & 140 & 47,9 \\
\hline WS $1948 / 49$ & 780 & 166 & 21,3 \\
\hline SS 1949 & 267 & 116 & 43,4 \\
\hline WS $1949 / 50$ & 648 & 307 & 47,3 \\
\hline SS 1950 & 403 & 218 & 54,1 \\
\hline WS $1950 / 51$ & 326 & 142 & 43,6 \\
\hline SS 1951 & 346 & 205 & 59,2 \\
\hline
\end{tabular}

Tabelle 11 Zahl der Antragsteller und Neuzulassungen deutscher Studenten der MathematischNaturwissenschaftlichen Fakultät. ${ }^{1084}$

Bis 1953 blieb der durch die Beschränkung der Neuzugänge geregelte numerus clausus erhalten. Die gesamten Studentenzahlen der Universität sanken kontinuierlich bis zum SS 1953 und wuchsen erst nach Aufgabe der Zulassungsbeschränkungen wieder an. In der Mathematisch-Naturwissenschaftlichen Fakultät war die Entwicklung ähnlich, wenn auch der Tiefstand schon im WS 51/52 erreicht war. Anders verliefen die Physikstudentenzahlen, die bis 1953 relativ konstant um die 200 gehalten wurden und nach 1953 besonders stark zu wachsen begannen.

1081 UAG, Rek. 7201.

1082 Die Zahlen der Antragsteller nennen nur die registrierten Bewerber. Die tatsächliche Bewerberzahl war größer, da manche Zulassungsgesuche gar nicht erst aufgenommen und notiert wurden.

1083 Nur Anträge von fortgeschrittenen Studenten wurden angenommen.

1084 UAG, Rek. 7201. 


\begin{tabular}{|c|c|c|c|c|c|c|c|c|c|}
\hline & \multicolumn{3}{|c|}{ Promotion } & \multicolumn{2}{|c|}{ (Haupt-) Diplom } & \multicolumn{2}{|c|}{ Diplomvorexamen } & \multicolumn{2}{|c|}{ Zwischenexamen } \\
\hline & $\begin{array}{l}\text { ges } \\
1085 \\
\end{array}$ & männl. & weibl. & männl. & weibl. & männl. & weibl. & männl. & weibl. \\
\hline 1932 & 13 & 9 & & & & & & & \\
\hline 1933 & 25 & 25 & & & & & & & \\
\hline 1934 & 14 & 13 & & & & & & & \\
\hline 1935 & 24 & 22 & 2 & & & & & & \\
\hline 1936 & 31 & 30 & & & & & & & \\
\hline 1937 & 17 & 18 & & & & & & & \\
\hline 1938 & 19 & 19 & 2 & & & & & & \\
\hline 1939 & 25 & 24 & 1 & & & & & & \\
\hline 1940 & 8 & 7 & 1 & & & & & & \\
\hline $1941^{1086}$ & 12 & 9 & & & & & & & \\
\hline 1942 & 8 & & & & & & & & \\
\hline 1943 & 3 & & & & & & & & \\
\hline 1944 & 6 & & & & & & & & \\
\hline 1945 & 5 & & & & & & & & \\
\hline 1946 & 4 & & & & & & & & \\
\hline 1947 & 5 & & & 7 & 1 & & & & \\
\hline 1948 & 9 & & & 9 & & & & & \\
\hline 1949 & 5 & & & 24 & & & & & \\
\hline 1950 & 7 & & & 42 & 4 & & & & \\
\hline & & & & & & & & & \\
\hline SS 52 & & 8 & & 20 & & 20 & 1 & & 1 \\
\hline WS $52 / 53$ & & 4 & & 14 & 1 & 22 & & 1 & 1 \\
\hline SS 53 & & 9 & & 21 & & 20 & & 1 & \\
\hline WS 53/54 & & 3 & & 11 & 1 & 21 & 1 & 1 & \\
\hline SS 54 & & 8 & & 10 & & 17 & & 1 & \\
\hline WS $54 / 55$ & & 8 & & 27 & & 23 & 1 & 2 & 1 \\
\hline SS 55 & & 10 & & 10 & & 14 & & & \\
\hline & & & & & & & & & \\
\hline WS 56/57 & & 12 & & 24 & & $34^{1087}$ & 1 & & \\
\hline SS 57 & & 2 & & 15 & & 31 & & & \\
\hline
\end{tabular}

Tabelle 12 Übersicht über die an der Universität Göttingen abgelegten Prüfungen in Physik. 1088

Der in obiger Tabelle 12 ersichtliche Rückgang der Promotionszahlen ab dem Jahr 1940 zeigt sich erstaunlicherweise ebenfalls sehr deutlicher bei den US-amerikanischen Zahlen zu Physik-Ph.D's. ${ }^{1089}$

1085 Nach Rosenow [1987/98] S. 579. Diese Zahlen resultieren aus seiner eigenen Auswertung der Karteikarten im UAG und fassen die Fächer experimentelle, theoretische und angewandte Physik, sowie Geophysik und Astrophysik zusammen. Meine eigenen Recherchen zeigten allerdings, dass die Karteikarten lückenhaft sind. 1086 Nur erstes Halbjahr.

1087 Ab hier hieß es nicht mehr Diplomvorexamen, sondern Vordiplom. Ein Zwischenexamen in Physik scheint es ab diesem Zeitpunkt nicht mehr gegeben zu haben.

1088 Für die Jahre bis 1941 siehe Lorenz [1943]b S. 172f. Zahlen ab 1947 aus: UAG, Rek. 7201. In den oben angeführten Zahlen sind auch diejenigen der ausländischen Prüflinge enthalten. Diese sind: Promotion: 1933 vier, 1934 einer, 1936 drei, 1937, 1938 und 1939 je einer, 1940 drei, 1941 einer; WS 52/53, SS 53 und WS 54/55 je einer, SS 55 zwei, SS 57 einer. Diplom: 1948, 1950, SS 53, SS 55 je einer. Diplomvorexamen: SS 55 einer. Bei allen ausländischen Prüflingen nach 1947 handelte es sich um Männer.

1089 Siehe Physics in a new era, S. 90, Figure 5.7. 


\subsubsection{Die Normalisierung und das starke Wachstum nach 1953}

Zum Abschluss dieses Kapitels folgt noch ein kurzer Ausblick auf die Entwicklung der Studentenzahlen nach Wegfall des numerus clausus im Jahr 1953. ${ }^{1090}$ Alle Immatrikulations-, Auslese- und politischen Ausschüsse waren überflüssig geworden. Die Bearbeitung der Zulassungen erfolgte mit Ausnahme für das Fach Chemie ausschließlich durch das Sekretariat. ${ }^{1091}$ Die Studentenzahlen stiegen bis Ende der 50er Jahre in der MathematischNaturwissenschaftlichen Fakultät kontinuierlich auf über 1500 an, sodass der Leiter des I. Physikalischen Instituts und damalige Dekan, Rudolf Hilsch, sich Ende Mai 1959 an den Rektor wandte, um „Maßnahmen zur Verringerung der Studentenzahlen“ zu diskutieren. ${ }^{1092}$ Um sein Argument zu belegen, dass die Zunahme der Studentenzahlen ganz wesentlich auf das Konto der Physik gehe, nannte Hilsch unter anderem folgende Zahlen: In der Physik stieg die Zahl eingeschriebener Studenten von 270 im WS 1954/55 auf 641 im SS 1959. Diese Steigerungsrate von zirka $140 \%$ war deutlich höher als etwa die der Chemie mit $40 \%$ und auch höher als die der Fakultät insgesamt mit 86\% Zuwachs.

Der Anstieg der Studentenzahlen in den fünfziger Jahren war eine zu erwartende Entwicklung, insofern als in dem über lange Zeit kontinuierlichen Wachstumsprozess der Wissenschaften die kriegsbedingte Stagnation wieder ausgeglichen werden musste. Die Entwicklung der deutschen Studentenzahlen (die Göttinger verlaufen ab Mitte der fünfziger Jahre parallel dazu) wird besser verständlich, wenn man sie in die allgemeine quantitative Wissenschaftsentwicklung einordnet, die beispielsweise Derek de Solla Price für eine großen Zeitraum bis Anfang der sechziger Jahre untersuchte. Er hat gezeigt, dass das Wachstum der Wissenschaften über mehrere hundert Jahre entlang einer exponentiellen Kurve verlief. ${ }^{1093}$ Dies trifft auf die Anzahl der Wissenschaftler wie der Zeitschriften oder Publikationen zu. Auch die Studentenfrequenz auf deutschen Hochschulen weist bis in die siebziger Jahre einen derartigen Verlauf auf, mit der Ausnahme, dass die politischen Verhältnisse das Wachstum zwischen 1930 und 1950 verhinderten. Das Besondere liegt also weniger an der Entwicklung zur Massenuniversität in der frühen Bundesrepublik, sondern an dem von den Professoren und dem Ministerium mittels des numerus clausus erreichten Aufschub. Gerade in Göttingen

\footnotetext{
1090 In Münster wurde der numerus clausus bereits im Herbst 1952 aufgehoben, Respondek [1992] S. 351.

1091 UAG, Rek. 7101.

1092 Unter anderem wurde daran gedacht, zum kommenden WS den Zugang für Neuanfänger ganz zu sperren und im darauffolgenden SS ,wesentlich zu beschränken“, worunter er eine Verringerung der

Neueinschreibungen um mindestens 50\% verstand. Siehe das Schreiben Hilsch an den Rektor, 26. Mai 1959. UAG, Rek. 7112-2/2.

1093 Solla Price [1963/74]. Der Wendepunkt des Wachstums wurde grob um 1970 erreicht.
} 
waren die ersten Nachkriegsjahre von dem Bestreben der Professoren dominiert, eine Elite auszubilden und die Gemeinschaft der Forschenden und Lernenden überschaubar klein zu halten. Wie die künftige Elite aus den vielen Bewerbern ausgewählt wurde, haben die oberen Abschnitte bereits dargestellt. Ein weiterer wichtiger Punkt, die deutliche Veränderung in der geschlechtlichen Zusammensetzung der Studentenschaft, wird im Folgenden letzten Abschnitt näher untersucht.

\subsection{Frauen in der Physik}

Frauen studierten unter anderen Voraussetzungen als ihre männlichen Kommilitonen. Ihre Schulbildung unterschied sich meist von jener der Jungen, da die Gymnasien nach Geschlechtern getrennt waren. Auf Grund gesellschaftlicher Erwartungen und Einschränkungen wurden Frauen meist in anderen Fächer ausgebildet - in Schule wie Universität. Die Studentinnenfrequenz war stärker von politischen Maßnahmen beeinflusst als die Studentenzahlen der Männer. Deutlich wird dies auch am Übergang in die Nachkriegszeit, der in der bisherigen Forschung noch wenig Beachtung gefunden hat. Eine verkürzte, aber typische Darstellung der Studentinnenfrequenz hebt den Aufschwung des Frauenstudiums gegen Ende der Weimarer Republik hervor, um dann fortzufahren:

„Ab 1933 bremsten restriktive Maßnahmen der Nationalsozialisten diese positive Tendenz. So wurde z. B. der Anteil von Studentinnen an deutschen Hochschulen auf zehn Prozent beschränkt. Auch nach dem Krieg blieben die Quoten weiblicher Abiturienten und Studierender lange Zeit relativ gering."1094

In dieser Darstellung wird verschwiegen, dass die Studentinnenzahlen im Krieg stark anstiegen (z. B. in Göttingen von 126 Studentinnen 1938 auf 2175 im Jahr 1944) und nach 1945 stagnierten oder sogar zurückgingen (in Göttingen fielen die Studentinnenzahlen auf 1244 im WS 1945/46 und weiter auf 624 im WS 1951/52). Im Folgenden wird auf die speziellen Studienbedingungen der Frauen eingegangen, und die besondere Zurückdrängung der Frauen in Göttingen nach 1945 in ihren lokalen Bedingungen erklärt. 1095

\subsubsection{Das Frauenstudium von 1930 bis 1945}

Das Frauenstudium erlebte einen zahlenmäßig großen Aufschwung in der Weimarer Republik zwischen 1925 und 1931. Gegen Ende der 20er Jahre mehrten sich jedoch Aversionen gegen

1094 Hille [1993] S. 216. 
studierende Frauen vor allem unter den männlichen Studienkollegen. Den Studentinnen wurde vorgeworfen, vom 'natürlichen' Zustand, ihrer 'weiblichen' Aufgabe in Familie und Kindererziehung, abzuirren, für das Studium geistig nicht fähig zu sein, die Universität als Heiratsinstitut zu missbrauchen, und ihnen wurde prophezeit, dass sie durchs Studium ihre Weiblichkeit verlieren würden. Hinter diesen Angriffen steckten teilweise Ängste der Männer vor Konkurrenz, die vor allem in der Zeit einer Überfüllungskrise akademischer Berufe stärker wahrgenommen wurden. ${ }^{1096}$ Der Ruf nach einer Beschränkung des Frauenstudiums, nach einem eigenen numerus clausus für Frauen, wurde laut. ${ }^{1097}$ Diese vor 1933 herrschende Stimmung war in weiten Teilen der Studentenschaft verbreitet und sollte daher nicht als eine typisch nationalsozialistische Anschauung deklariert werden. Der NSDStB nahm keine offizielle Position zum Frauenstudium ein; er machte sich aus populistischen Gründen zum Sprachrohr der eben skizzierten Meinungen der männlichen Studentenschaft, verhielt sich aber ambivalent gegenüber dem Frauenstudium. Eine Folge dieser nicht festgelegten Haltung war, dass der NSDStB bei Wahlen gleiche Attraktivität auf männliche Studenten wie Studentinnen ausübte. ${ }^{1098}$ Das alles macht auch verständlich, warum nach der Machtübernahme erst mit einer gewissen Verzögerung Maßnahmen gegen das Frauenstudium ergriffen wurden. ${ }^{1099}$

Zum Ende der Weimarer Republik studierten über 17000 Frauen an deutschen Universitäten, was einem Anteil von 18,6\% entsprach. Die Studentinnen bevorzugten besonders die größeren Städte als Studienort. In Berlin, Köln und Hamburg lag ihr Anteil im Sommersemester 1932 über 20\%, in Göttingen nur bei 15\%. Bei der Fächerwahl standen Medizin und die philologischen Fächer an der Spitze der Beliebtheit. In den Naturwissenschaften in Göttingen waren Frauen verhältnismäßig stark mit 17,1 \% vertreten. Während die Biologie mit 45,9 \% einen sehr hohen Frauenanteil aufwies, ${ }^{1100}$ bildete die Physik nach Chemie (15,6\%) und Mathematik (14,8\%) mit 7,8\% das Schlusslicht. ${ }^{1101}$ Der geringe Frauenanteil unter den Physikstudenten in Göttingen ist typisch und findet sich auch

\footnotetext{
1095 Einen breit angelegten Literaturüberblick zum Thema Frauen in der Physik gibt Margarete Maurer [1993].

$1096 \mathrm{Zu}$ der eindeutigen, wenn auch fälschlichen, männlichen Wahrnehmung der Frauen als Konkurrenz auf dem akademischen Arbeitsmarkt siehe Huerkamp [1994].

1097 Grüttner [1995] S. 112f.

1098 Hentschel \& Hentschel (Hrsg.) [1996] S. xlvii.

1099 Grüttner [1995] S. 114f.

1100 Gründe für die Beliebtheit des Biologiestudiums (v. a. Zoologie und Botanik) unter Frauen liefert NaglerSpringmann [1997] S. 165f. Im Nationalsozialismus wurde der Biologieunterricht in Mädchenschulen aufgewertet; dazu Huerkamp [1996]a S. 61.

1101 Mertens [1989] S. 8f; Lorenz [1943]a S. 232f.
} 
bei anderen deutschen Universitäten. ${ }^{102}$ Ein Grund dafür liegt im niedrigen Stellenwert der Physik in der gymnasialen Mädchenausbildung und den geringen Berufsaussichten für Physikerinnen.

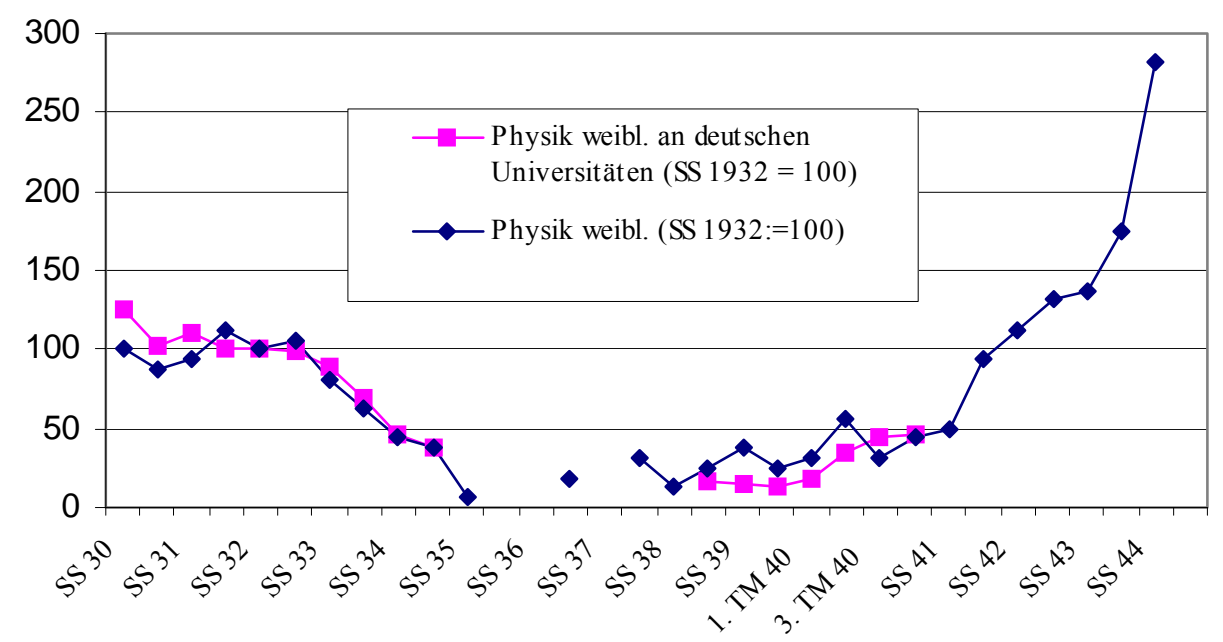

Diagramm 8 Vergleich der Physikstudentinnen der Universität Göttingen mit der gesamtdeutschen Entwicklung 1930-1944. ${ }^{1103}$

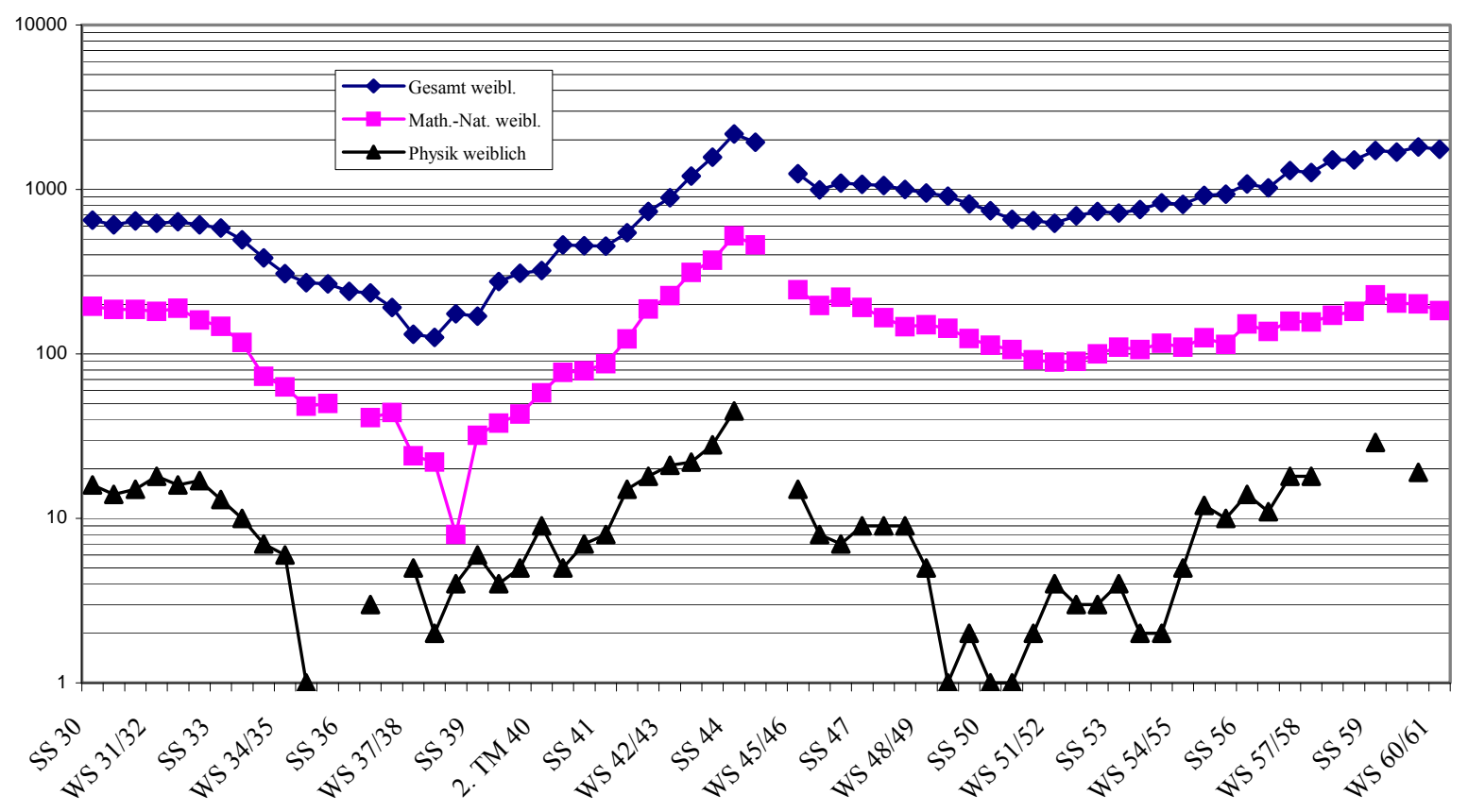

Diagramm 9 Absolute Studentinnenzahlen der Universität Göttingen gesamt, der Math.-Nat. Fakultät und der Physik 1930-1960.1104

1102 An den deutschen Universitäten insgesamt lag 1932 der Anteil der Physikstudentinnen bei $9 \%$. Titze [1987] S. 148. Die geringe Präsenz von Studentinnen in der Physik wird teils auf die Mentalität der großbürgerlichen Familien zurückgeführt. Siehe die Untersuchung der Münchner Verhältnisse bei NaglerSpringmann [1997] S. 175.

1103 Deutsche Zahlen nach Titze [1987]; Göttinger Zahlen nach Lorenz [1943]a und nach eigener Zählung aus den Matrikelverzeichnissen im UAG. 
Der Rückgang der Studentinnenzahlen verlief in Göttingen wie auch in ganz Deutschland ab 1930/31 zuerst flach und nach der Regierungsübernahme der Nationalsozialisten deutlich steiler. Trotz steigender Abiturientinnenzahlen entschlossen sich weniger Frauen zum Studium. Während im Jahr 1931 von hundert Abiturientinnen noch 53,7 ein Studium begonnen hatten, waren es im folgenden Jahr nur noch 37,4 (siehe Tabelle 1). Wie Diagramm 8 zeigt, verlaufen die Physikstudentinnenzahlen in Göttingen bis 1941 weitgehend parallel zu den gesamtdeutschen Zahlen.

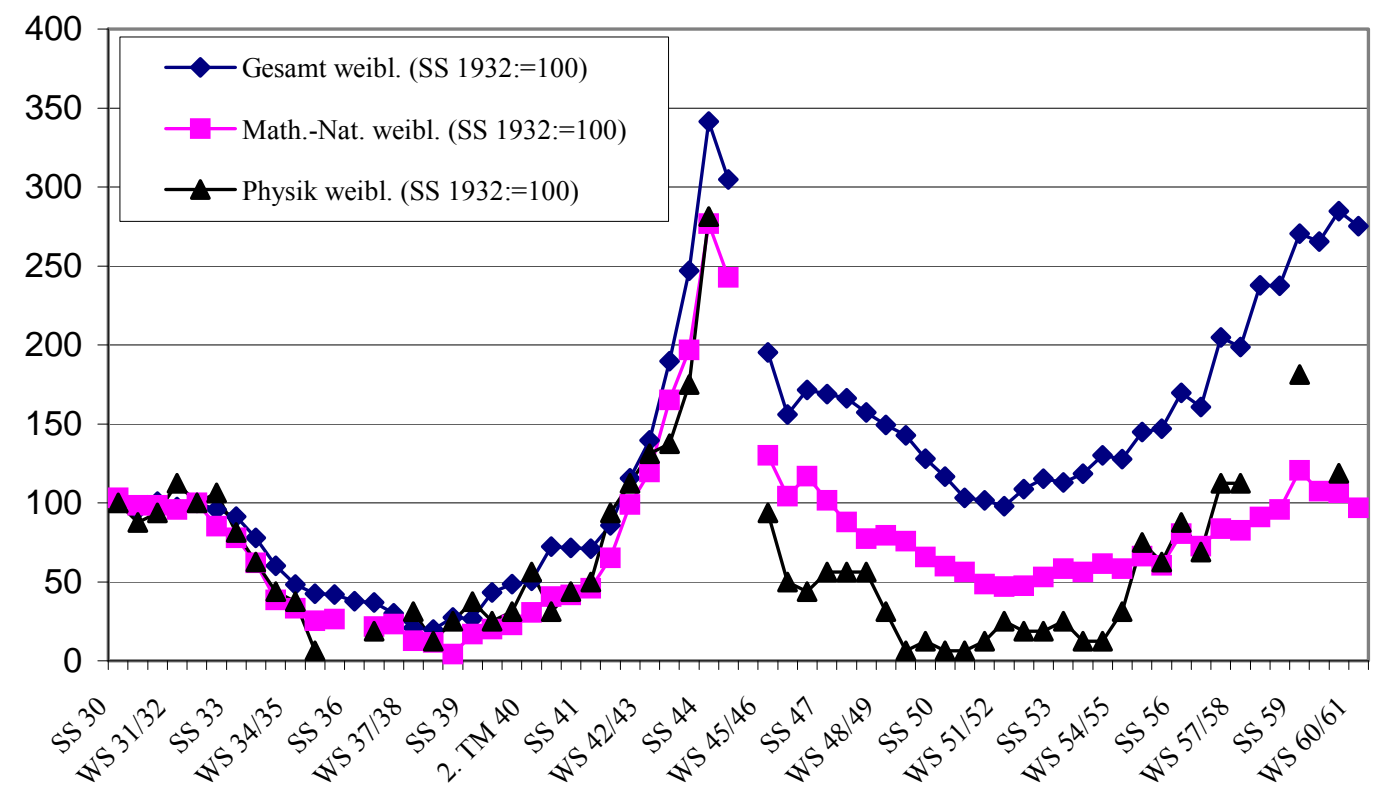

Diagramm 10 Unterschiedliche Entwicklung der Studentinnenzahlen in der Physik, der Mathematisch-Naturwissenschaftlichen Fakultät und der gesamten Universität Göttingen von 1930 bis 1960 bezogen auf das SS 1932. ${ }^{1105}$

Wie ich im Abschnitt 2.2.1 ausführlich dargestellt habe, waren für diesen Rückgang vor allem demografische Gründe verantwortlich. Bei den Frauen spielten darüber hinaus politische Faktoren eine große Rolle, obgleich einschränkend bemerkt werden muss, dass eine politische Steuerung des Frauenstudiums nicht erfolgreich durchgeführt wurde. Das Regime änderte seine frauenpolitischen Zielsetzungen bezüglich des Hochschulstudiums etwa um 1936/37. In der ersten, ideologischen Phase der NS-Herrschaft richtete die Politik sich gegen das Frauenstudium und verstärkte die Zurückdrängung der Frauen aus den Universitäten.

Die ersten studentenpolitischen Maßnahmen an den Universitäten setzte das Regime in der Bekämpfung 'linker' Wissenschaftler und in den rassistisch motivierten Vertreibungen. Fragen des Frauenstudiums spielten eine untergeordnete Rolle. Ende 1933 wurden erste 
Schritte zur Zurückdrängung der Studentinnen gesetzt. Von Anfang 1934 an existierte ein Jahr lang ein numerus clausus für deutsche Hochschulen, der die Zahl der Abiturienten mit Hochschulreife auf 15000 beschränkte. ${ }^{1106}$ Der Anteil der Frauen davon durfte in keinem Land $10 \%$ überschreiten. Diese Regelung wurde „eher lax“ gehandhabt ${ }^{1107}$ und existierte zu kurz, um einen gravierenden Einfluss auf die längere Entwicklung des Frauenstudiums ausgeübt zu haben. ${ }^{1108}$ Es wurden im SS 1934 entgegen der Reglementierung 11,7\% der Abiturienten ${ }^{1109}$ der Hochschulreifevermerk gegeben und 12,5\% Frauen unter den Erstimmatrikulierten zugelassen. ${ }^{1110}$ Abiturienten, denen 1934 die Hochschulreife nicht zuerkannt worden war, konnten nachträglich zum Studium zugelassen werden. ${ }^{111}$

Auch andere Maßnahmen, speziell Frauen vom Studieren abzuhalten, wie zum Beispiel durch 'geeignete' Beratung in Berufsberatungsstellen, griffen laut Powels nicht und wurden von den Frauen meist umgangen. ${ }^{112}$ Die angekündigte „politische Auslese“ durch die Verpflichtung zum Arbeitsdienst erwies sich bei Männern wie Frauen als „kaum wirkungsvoll“. ${ }^{1113}$ Bis 1934 war die Teilnahme am Werkhalbjahr freiwillig und daher auch entsprechend gering. Aber selbst nachdem ein sechsmonatiger Dienst zur Studienvoraussetzung gemacht worden war, blieb das Studium allen Abiturienten offen - allen, außer den „Nichtariern“. Diese waren vom Arbeitsdienst ausgeschlossen. Bei den anderen hatte die durch den Dienst angestrebte „Auslese“ keine nennenswerte Wirkung. Die Frauen hatten in gewisser Weise Glück, da es nicht genügend Arbeitsmöglichkeiten für sie gab, sodass bis 1936 die Dienstzeit oft nur drei bis vier Monate betrug. ${ }^{1114}$

Im Jahr 1935 wurde für alle männlichen Studenten des 1. bis 7. Semesters, die noch keinen freiwilligen oder aus gesundheitlichen Gründen keinen verpflichtenden Arbeitsdienst abgeleistet hatten, ein zusätzlicher Arbeitsdienst eingeführt. Für Frauen gab es dies nicht. ${ }^{1115}$

\footnotetext{
1105 Zur Quellenangabe siehe Fußnote 715.

1106 Diese Beschränkung verfügte eine Verordnung des Innenministers Frick vom 28. Dezember 1933, die aber erst am 12. Januar 1934 bekannt gegeben wurde und sich dann auf den Abiturientenjahrgang 1934 auswirkte. Mit Erlass vom 9. Februar 1935 hob der Reichsminister für Wissenschaft, Erziehung und Volksbildung, Rust, die Verordnung wieder auf. Huerkamp [1996]a S. 80-82.

1107 Grüttner [1995] S. 115.

1108 Dazu ausführlich Huerkamp [1996]b.

1109 Grüttner [1995] S. 116.

1110 Pauwels [1984] S. 21.

1111 Grüttner [1995] S. 103.

1112 Pauwels [1984] S. 21-26.

1113 Huerkamp [1996]a S. 82-86. Grüttner [1995] S. 227-237. Siehe auch Mertens [1991] S. 109f.

1114 Huerkamp [1996]a S. 83, 85. Davon abweichende Angaben zur Verkürzung der Dienstzeit für Frauen finden sich bei Powels [1984] S. 23 und Mertens [1989] S. 9.

1115 Huerkamp [1996]a S. 85. Leider gibt Huerkamp keine Auskunft, inwieweit diese Maßnahme sich auf jüdische Studenten auswirkte.
} 
1935 wurde ein Reichsarbeitsdienst-Gesetz verabschiedet, das beide Geschlechter gleichermaßen und die gesamte Bevölkerung, nicht nur Studenten, betraf. Entgegen der gesetzlichen Vorgabe herrschte beim Arbeitsdienst der Frauen aber noch lange das Prinzip der Freiwilligkeit, hingegen war der Dienst für angehende Studentinnen verpflichtend. Dieses Ungleichgewicht wirkte sich auf die Studierwilligkeit der Frauen aus. Während alle Männer zum Dienst mussten, egal ob sie studieren wollten, konnten Frauen dem Dienst entkommen, falls sie sich gegen das Studium entschieden.

In der Hochschulpolitik versuchte man dem Ausbleiben der Studentinnen aus wirtschaftspolitischen Überlegungen ab 1936/37 entgegenzusteuern, indem speziell das Frauenstudium gefördert wurde, sogar in als 'männlich' angesehenen Fächern wie Jura. ${ }^{1116}$ 1936 liest man in Die deutsche Studentenschaft: „Zu sagen: eine Frau studiert nicht Jura oder nicht Physik ist Unsinn.“1117 Im September 1936 forderte der „Völkische Beobachter“ Eltern auf, talentierten Töchtern ein Studium zu ermöglichen. Ein Jahr später wendete sich Reichserziehungsminister Rust an Oberschülerinnen und warb für ein Studium. Seit 1938 beteiligten sich Reichsstudentenführung und Reichsstudentenwerk an dieser Werbung. ${ }^{118}$

Zusammenfassend stellt Grüttner fest: „Zwischen 1935 und 1944 gab es für Abiturientinnen, die ein Universitätsstudium anfangen wollten, im allgemeinen keine administrativen Einschränkungen mehr."1119 Dem ist zu entgegnen, dass durch die Neuorganisation der Mädchenschulausbildung ab 1935/37 die Mädchen schlechter aufs Studium vorbereitet wurden. Ziel dieser Maßnahme war unter anderem die Verringerung der Studentinnenzahlen. ${ }^{1120}$

Die politische Organisation der Studentinnen war die im NSDStB angesiedelte „Arbeitsgemeinschaft Nationalsozialistischer Studentinnen“ (ANSt). 1933 waren nur 4,1\% der Studentinnen im ANSt organisiert, 1937 waren es dann 34,4 \% (in Göttingen 40,6 \%), was auf die bevorzugte Zulassung von BDM-Mitgliedern, die dann automatisch ANStMitglieder wurden, zurückzuführen ist. ${ }^{1121}$ Die organisatorische Erfassung der Studentinnen stieg relativ rasch an, im Sommer 1939 auf 71 \%. Im Vergleich dazu waren die Männern zur

\footnotetext{
1116 Pauwels [1984] S. 29.

1117 Wilhelmine Dreißig: 'Frauenarbeitsdienst und Frauenstudium', in: Die Deutsche Studentenschaft. Wissen und Dienst vom 19. August 1936, S. 10-11, S. 11, hier zitiert nach Mertens [1989] S. 10.

1118 Güttner [1995] S. 120.

1119 Grüttner [1995] S. 116.

1120 Weyrather [1981] S. 146, 160. Huerkamp [1996]a S. $61 \mathrm{ff}$.

1121 Grüttner [1995] S. 501; Clephas-Möcker \& Krallmann [1992] S. 180 geben an, dass $193775 \%$ aller

Studentinnen in die ANSt eingetreten waren.
} 
selben Zeit zu 51 \% im NSDStB organisiert. ${ }^{1122}$ Diese Zahlen sind aber nicht als eine stärkere nationalsozialistische Überzeugung unter den Frauen zu deuten. Es waren die speziellen Aufnahmeverfahren, die zum Mitgliederwachstum im ANSt führten. Von den Studentinnen wurde oft die Zugehörigkeit zum ANSt als unvermeidliche Pflichtübung angesehen. ${ }^{1123}$

Obwohl die Einteilung in typisch 'männliche' und auch 'weibliche' Fachgebiete an Gewicht verlor, und trotz der gezielten Förderung, sanken die Studentinnenzahlen an deutschen Hochschulen stetig bis 1938. Dazu kam noch die geringere Bereitschaft unter den Frauen, die Schule mit dem Abitur abzuschließen. 1933 war der Höchststand mit 6609 Abiturientinnen erreicht, 1937 der Tiefpunkt mit nur noch knapp ein Drittel davon. Jedoch war die Abiturientinnenrate (also ihr Anteil an der weiblichen Bevölkerung ihres Jahrgangs) 1937 ungefähr auf dem Stand von 1929. ${ }^{1124}$ Der Rückgang der Studentinnen in den Jahren 1931 bis 1938 von 19394 auf 5920 hat nach Powels vor allem psychosoziale Gründe; Titze erklärt ihn durch ein komplexes Zusammenwirken eigendynamischer und politischer Einflüsse. ${ }^{1125} \mathrm{Im}$ Jahr 1932 wollten noch 63,9 \% der Abiturientinnen ein Studium beginnen. Dieser Wert sank Mitte der 30er Jahre auf $35 \%$, hingegen blieb bei den Männern während der gesamten 30er Jahre der Studienwunsch bei der Hälfte bis drei Viertel der Abiturienten erhalten (siehe Tabelle 1).

Vergleicht man die Entwicklungen beider Geschlechter, so sieht man, dass bei den Frauen die nicht-demografischen Faktoren auf den Rückgang der Studentenzahlen deutlichere Auswirkungen hatten. Die Zahl der männlichen Studenten sank zwischen dem SS 1932 und dem SS 1938 um 54,4 \%, die Zahl der weiblichen um 68,3 \%. ${ }^{1126}$ Für das stärkere Sinken der Frauenzahlen führt Grüttner fünf Gründe an: 1) Die Maßnahmen des NS-Staates gegen berufstätige Akademikerinnen ließen ein Studium wenig aussichtsreich erscheinen. Beispielsweise legte das Kultusministerium im Jahr 1934 das Verhältnis von Männern zu Frauen im Lehrkörper von Schulen auf 3:2 fest. Damit schwand bei den studierenden Lehramtskandidatinnen die Aussicht auf Anstellung. ${ }^{1127}$ 2) Die Wirtschaftskrise in den 30er Jahren traf die Frauen unter den Studenten stärker als die Männer. Das Studium von Frauen erschien als Luxus, auf den die zahlenden Eltern in Krisenzeiten verzichteten. Nur noch

\footnotetext{
1122 Grüttner [1995] S. 352.

1123 Grüttner [1995] S. 355f., $411 \mathrm{ff}$.

1124 Huerkamp [1996]a S. 60. Zahlen nach Titze [1987] S. 173, Tab. 78.

1125 Powels [1984] S. 39f, 45; Titze [1995] S. 43. Studentinnenzahlen deutscher Universitäten nach Titze [1987] S. 43 , Tab. 6.

1126 Siehe auch Pauwels [1984] S. 40, Fig. 3 (wobei hier in der Legende männl. und weibl. Studentenzahlen vertauscht angegeben sind), S. 147f, Tab. 6.

1127 Soden [1979] S. 31. 
reiche Eltern leisteten sich ein Studium für ihre Töchter, was in der Verschiebung der sozialen Herkunft der Studentinnen zu den höheren Schichten abzulesen ist. ${ }^{1128}$ 3) Studentinnen wurden bei der Vergabe von Stipendien benachteiligt. 4) Die Vertreibung der „Nichtarier“ verringerte ebenfalls die Frauenquote, da Frauen in dieser Gruppe stärker repräsentiert waren. 5) Die Propaganda mit ihrer Aufwertung der Mutterrolle beeinflusste Abiturientinnen und Eltern gegen ein Studium. ${ }^{129}$ Huerkamp fügt noch die stärkere Auswirkung der Arbeitsdienstpflicht auf Frauen an. ${ }^{1130}$

In den Naturwissenschaften wurden die Frauen etwas deutlicher zurückgedrängt:1131 Zwischen 1932 und 1938 von 3010 auf 482, dies ist ein Abfall um 84 \%. Der Frauenanteil in den Fächern Mathematik und Physik fiel im selben Zeitabschnitt stetig von 5,9\% auf 1,2\%. ${ }^{1132}$ Dieser allgemeine Trend spiegelt sich auch in den Göttinger Studentenzahlen wider. Hier schwand die Zahl der männlichen Studenten von 1932 bis 1938 um 68,5 \%, die Zahl der weiblichen um 77,6\%. ${ }^{1133}$ In den Naturwissenschaften ging die Studentenzahl um 78,5 \% zurück, bei den Frauen sogar um 87,3 \%. In der Physik betrug der Abfall allgemein $67 \%$ und bei den Frauen 75 \%. Die verbliebenen vier Physikstudentinnen im WS 1938/39 machten einen Anteil von 5,9\% aus. ${ }^{1134}$ Wie in Diagramm 8 erkennbar ist, verlaufen in der Physik die Göttinger Zahlen parallel zu den gesamtdeutschen.

Für das seltenere Antreffen von Frauen in den Naturwissenschaften lassen sich zwei Gründe anführen. Erstens lag es an der reduzierten Schulausbildung für Mädchen in diesen Fächern. Ab 1935 wurde je eine Stunde Mathematik und Englisch zu Gunsten von Handarbeitsunterricht gestrichen. Die Mädchen durften keine höheren Jungenschulen besuchen, wenn es eine Mittelschule für Mädchen in ihrem Bezirk gab. Ausnahmen wurden jedoch zugelassen, und so stieg der Anteil der Mädchen, die Jungenschulen besuchten, in den 30er Jahren weiter an. ${ }^{1135}$ Nach der „Neuordnung des höheren Schulwesens“ von 1937/38 boten die Mädchenschulen in der Oberstufe nur noch einen sprachlichen oder hauswirtschaftlichen Zweig an. Durch diese Maßnahmen hatten die Mädchen eine

\footnotetext{
1128 Zur sozialen Herkunft der Studenten siehe Güttner [1995] S. 136-140.

1129 Güttner [1995] S. 116ff.

1130 Huerkamp [1996]b S. 340.

1131 Siehe Güttner [1995] S. 491, Tab. 20.

1132 Pauwels [1984] S. 33, 149, Tab. 8.

1133 Titze [1995] S. 239.

1134 Lorenz [1943]a S. 232f. Da es für das Sommersemester 1938 leider keine Studentenzahlen der Physik gibt, ist hier der Aball zwischen SS 1932 und WS 1938/39 angegeben.

1135 Huerkamp [1996]a S. 65ff. Im Jahr 1927 gingen von allen Mädchen 2,5 \% an Jungenschulen, 1932 waren es 4,6 \% und 1937 5,3 \%. Von allen Abiturientinnen kamen im Jahr 1932 13,8 \% von Jungenschulen; 1938 waren es mehr als ein Viertel.
} 
vergleichsweise schlechtere Ausbildung, besonders in naturwissenschaftlichen Fächern. ${ }^{1136}$ Im Physikunterricht sollten laut Lehrplan von 1938 Fragen des täglichen Lebens von Hausfrauen und Mütter im Vordergrund stehen, wie beispielsweise technische Haushaltsgeräte sowie die Anwendung der Physik in der Gesundheitspflege und der Optik. ${ }^{1137}$ Es dauerte eine gewisse Zeit, bis diese Maßnahme Auswirkungen zeigte. Vor allem in der Nachkriegszeit wurde die Neuregelung der Schulausbildung für die Frauen zum entscheidenden Nachteil (dazu mehr im Abschnitt 2.4.2).

Zweitens war die geringere Präsenz in den Naturwissenschaften möglicherweise eine Folge der geringeren Berufschancen für Frauen in diesen Sparten. Der Anreiz, ein solches Fach zu studieren, wurde dadurch abgeschwächt. ${ }^{1138}$ Außerdem war das Studium der Naturwissenschaften teurer als zum Beispiel ein Studium geisteswissenschaftlicher Fächer; die Kolleggelder waren etwa doppelt so hoch. Dieser ökonomische Druck schränkte die Möglichkeiten der Studienplanung besonders für Frauen ein. Den Söhnen bezahlten die Eltern eher ein teures Studium, da die Aussichten auf eine entsprechende berufliche Verwirklichung größer waren.

Die durch die Propaganda verstärkte Rollenzuweisung wirkte sich auf die Mentalität der jungen, studierwilligen Frauen, genauso wie auf deren Eltern, aus und beeinflusste somit die Studienfachwahl. Zumindest blieb das Medizinstudium eine akzeptierte Alternative. Über $55 \%$ der Frauen studierten 1938 Medizin, Pharmazie oder Zahlheilkunde. Die abnehmende Attraktivität der kulturwissenschaftlichen Fächer bis 1939 wurde gelegentlich als Flucht aus den als politisch geltenden Wissenschaften beschrieben. Diese These greift aber zu kurz. ${ }^{1139}$ Es drängt sich dann die Frage auf, wieso die Flucht aus den politisch weniger exponierten Fächern Mathematik und Physik noch deutlicher war? Die politischen Vorgaben spielten eine geringere Rolle als angenommen, denn die Physik wurde immer seltener gewählt, obwohl die NS-Politik bereits ihre anfängliche Stoßrichtung für eine Bevorzugung der anwendungsorientierten Fächer und gegen reine Grundlagenforschung aufgegeben und korrigiert hatte. Bestehen blieb aber der politische Widerspruch, dass Frauen einerseits in technische und naturwissenschaftliche Berufe gelockt wurden, und ihnen andererseits als angestammter Platz in der Gesellschaft der in der Ehe neben dem Mann zugewiesen wurde.

\footnotetext{
1136 Weyrather [1981] S. 145f.

1137 Bäumer-Schleinkofer [1994] S. 287.

1138 Powels [1984] S. 41.

1139 Güttner [1995] S. 127f. 
Verheiratete Frauen wurden bis 1938 aus den Berufen vertrieben, ${ }^{1140}$ auch das Studium wurde von den Eltern oft nur bis zur Heirat finanziert. Meist folgte nach der Heirat der Studienabbruch. ${ }^{1141}$

Im WS 1939/40 waren im gesamten Reich nur noch 19 Frauen in Physik eingeschrieben, was aber immerhin einen Anteil von 8,1\% ausmachte. ${ }^{1142}$ In Göttingen studierten gerade noch vier Frauen Physik. ${ }^{1143}$ Es ist schwierig, konkrete Gründe für das Absinken der Frauenzahlen in der Physik auszumachen. Da die Entwicklung in der Physik parallel zur Gesamtentwicklung verläuft, dürften die für das absolute Absinken der Frauenzahlen allgemein angeführten Gründe auch hier gültig sein. Aber selbst die Begründung eines fächerübergreifenden Trends stößt mancherorts auf Schwierigkeiten. An der Universität Würzburg sanken die Zahlen der männlichen Studenten stärker als die der weiblichen. Laut Hessenauer lassen sich dafür keine schlüssigen Erklärungen finden. ${ }^{1144}$ Als Ursache für die Verdrängung der Frauen aus der Physik in Berlin führt Vogt die Etablierung der „Deutschen Physik" und die Vertreibung bedeutender Physiker an. ${ }^{1145}$

Im Jahr 1938 kamen nach Ableistung des Arbeitsdienstes die ersten geburtenstärkeren Nachkriegsjahrgänge an die Universitäten, und damit stiegen die Zahlen der immatrikulierten Frauen wieder leicht an. Im WS 1938/39 schrieben sich 1898 Frauen neu ein, während es im vorausgegangenen Semester nur 1511 Frauen waren. An der Universität Göttingen waren im SS 1938 insgesamt 128 Frauen, im WS 1938/39 160 Frauen und im dritten Trimester 1940 bereits 447 Frauen eingeschrieben. ${ }^{1146}$ Im Jahr 1939 wurde der Pflichtarbeitsdienst für Frauen neu geregelt. Die Studentinnen brauchten ihn nicht mehr vor dem Studium zu absolvieren, sondern konnten ihn auf die Semesterferien oder ans Ende des Studiums verlegen. ${ }^{1147}$ Wer sich in einem kriegswichtigen Fach wie Chemie oder Physik einschrieb, wurde vorzeitig aus dem Arbeitsdienst entlassen. ${ }^{1148}$

Der Vergleich der Entwicklung der Studentinnenzahlen mit den politischen Vorgaben zum Frauenstudium in den 30er Jahren zeigt, dass die beiden Faktoren schlecht korrelieren. Daraus

1140 Das Beschäftigungsverbot als Bedingung des Ehestandsdarlehens wurde 1938 aufgehoben. Soden [1979] S. 32 .

${ }^{1141}$ Eine Heirat war bis in die 60er Jahre bei manchen Studentinnen die Ursache für den Studienabbruch. Siehe Gerstein [1965].

1142 Mertens [1991] S. 111.

1143 Lorenz [1943]a S. 232.

1144 Siehe dazu die Untersuchung zur Universität Würzburg von Hessenauer [2000], bes. S. 324.

1145 Vogt [2000] S. 198.

1146 Titze [1995] S. 239.

1147 Mertens [1989] S. 10. 
schließt Powels, dass es keine wirksame politische Steuerung des Frauenstudiums gab. Ein Effekt der NS-Frauenpolitik war aber, dass sich die soziale Herkunft der Studentinnen im Vergleich zur Weimarer Republik noch stärker zu den höheren Schichten verlagerte. ${ }^{1149}$ Die Steuerungsversuche der NS-Politik waren nach Huerkamp weniger stark für die Studien- und Fächerwahl von Bedeutung als es die Marktkräfte und die traditionellen Orientierungen der jungen Frauen waren. ${ }^{1150}$

Während des Krieges stiegen die Frauenzahlen in allen Fächern stark an - auch in der Physik. Das lag weniger daran, dass die eingezogenen Männer Plätze an den Universitäten freigemacht hatten, sondern mehr an einer speziellen Förderung des Frauenstudiums. Huerkamp spricht sogar von einer ,ideologische[n] Aufwertung des Frauenstudiums durch die NS-Propaganda“. ${ }^{1151}$ Die Einrichtung einer Reichsberatungsstelle für Frauenberufe im Jahr 1939 erlaubte eine Verstärkung der Studienpropaganda. ${ }^{1152}$ Ab Januar 1940 wurde auch den Absolventinnen von Oberschulen mit hauswirtschaftlichem Abitur das Studium aller Fächer außer Medizin erlaubt, ohne dass sie dazu die ab 1939 eingerichtete Ergänzungsprüfung in Physik, Mathematik, Geschichte und in zwei Sprachen ablegen mussten. ${ }^{1153} \mathrm{Ab}$ Februar 1942 waren Kriegerwitwen und Frauen mit Kindern vom Arbeitsdienst befreit. Im selben Jahr wurde im Langemarck-Studium eine Vorstudienausbildung für Frauen eingerichtet, in der 20 bis 32 Jahre alte Frauen eine zweijährige, kostenlose Ausbildung zur Hochschulreife erhielten. Ab Sommer 1941 folgte dem Arbeitsdienst noch ein sechsmonatiger Kriegshilfsdienst. Beide Dienste waren ab Mai 1944 nicht mehr Voraussetzung zum Studium. ${ }^{154}$ Frauen hatten es im Vergleich zu Männern in mancher Sicht leichter, ein Studium anzufangen. In der Regel absolvierten sie ein ordentliches Abitur, während Männer öfter einen Not-Reifevermerk erhielten. Die Vorbildung war in vielen Fächern nach formalen Kriterien etwas besser, jedoch nicht in den meisten Naturwissenschaften. Außerdem war der zeitliche Abstand des Studienbeginns zum Abitur im Mittel geringer. ${ }^{1155}$

Im Krieg fungierten die Universitäten für Frauen zum Teil als Zufluchtsstätten. Nach der Verkündung der allgemeinen Dienstpflicht für Frauen zwischen 17 und 25 Jahren kurz nach

\footnotetext{
1148 Nagler-Springmann [1995] S. 215.

1149 Powels [1984] S. 45ff.

1150 Huerkamp [1996]a S. 306.

1151 Huerkamp [1996]a S. 89.

1152 Jarausch [1984] S. 203.

1153 Weyrather [1981] S. 160.

1154 Powels [1984] S. 96ff.
} 
dem Überfall auf Polen im September 1939 wurden die Hochschulen als Fluchtburgen genutzt. Der je halbjährige Arbeits- und Kriegshilfsdienst konnte durch Anmeldung zum Studium meist auf wenige Monate verkürzt werden. ${ }^{1156}$ Ein Studium ersparte Frauen auch die Teilnahme an Kampagnen wie „Frauen helfen siegen“ vom März 1941, oder dem vom Generalbevollmächtigten für den Arbeitseinsatz, Fritz Sauckel, im Januar 1943 anberaumten großen Arbeitseinsatz, der alle nicht erwerbstätigen Frauen zwischen 17 und 45 Jahren betraf. Damit erklärt sich teilweise, wieso im Sommersemester 1943 die Zahl der immatrikulierten Frauen um $78 \%$ gegenüber dem vorhergehenden Semester hochschnellte. In diesem Semester schrieben sich mehr Frauen neu ein, als im SS 1939 an allen deutschen Hochschulen studiert hatten. In einem SD-Bericht von 1942 wird die Zunahme des Frauenstudiums einerseits als „durchaus zweckmäßig“, andererseits als „Flucht vor der Fabrik in die Hörsäle“ beschrieben. Das Studium werde nicht wirklich ernsthaft und gründlich betrieben. ${ }^{1157}$ Der Göttinger Rektor Plischke berichtete im Juli 1943 dem REM, dass die neu eingeschriebenen Studentinnen ihn um sofortige Immatrikulation baten, damit sie nicht zum Kriegseinsatz herangezogen würden. Unter ihnen befänden sich zahlreiche junge, verheiratete, kinderlose Frauen, deren Männer zum Kriegsdienst eingezogen seien. Auf Plischkes Frage, ob sie auch in Friedenszeiten studieren wollten, bekam er ausweichende Antworten. ${ }^{1158}$

Im Zuge der „totalen Mobilmachung“ für den Krieg ab 1943 stand auch zeitweise die Fortführung des Hochschulstudiums zur Disposition. Manche Kräfte in der Partei wünschten sich eine Verpflichtung zum Arbeitseinsatz vor allem von Studentinnen, Erstsemestern und Studenten geisteswissenschaftlicher Fächer. Der außerordentliche Nachwuchsmangel in den akademischen Berufen ließ es aber ganz anders kommen: Das Frauenstudium blieb unangetastet, und Erstimmatrikulationen waren weiterhin in allen Fächern möglich. Nur ungeeignete Studenten sollten zwangsweise beurlaubt und für den Arbeitseinsatz gemeldet werden. Diese Maßnahme war besonders gegen jene Frauen gedacht, die vor den Rüstungsarbeiten ins Studium 'geflüchtet' waren, traf aber im SS 1944 nur 0,6\% aller Studenten. Also ließ die „totale Mobilmachung“ die Hochschulen ziemlich unberührt. ${ }^{1159}$ Erhebliche Auswirkungen auf das Frauenstudium hatte allerdings der „totale Kriegseinsatz“ im WS 1944/45. Für Studentinnen gab es kaum Ausnahmen, von diesem Einsatz befreit zu werden. Entweder sie studierten Mathematik, Physik, Ballistik, Hochfrequenztechnik oder

\footnotetext{
1155 Krönig \& Müller [1990] S. 49f.

1156 Huerkamp [1996]a S. 90.

1157 Zitiert nach Güttner [1995] S. 122.

1158 Plischke an Regierungsdirektor F. Koch, REM, 3. Juli 1943, zitiert nach Güttner [1995] S. 122.

1159 Güttner [1995] S. 415f.
} 
Fernmeldetechnik, jedoch nicht aufs Lehramt, oder sie waren in einem anderen naturwissenschaftlichen Fach oder in der Medizin im 4. oder höheren Semester, oder sie standen unabhängig vom Fach unmittelbar vor dem Abschluss. Alle anderen Frauen mussten zum Arbeitseinsatz. Laut Grüttner traf es 26403 Studentinnen. Wieviele Frauen eine Erstimmatrikulation in den noch möglichen Fächern wählten, kann heute nicht mehr gesagt werden, da es für das WS 1944/45 sowohl für ganz Deutschland als auch für die Universität Göttingen keine Daten gibt. Im SS 1944 waren in Göttingen etwa die Hälfte aller Physikstudentinnen im 1. bis 3. Fachsemester und hatten durch ihre Fächerwahl das Glück, nicht arbeitsverpflichtet zu werden, was ihnen bei den meisten anderen Fächern widerfahren wäre. ${ }^{1160}$

Weitere Gründe, die Frauen zum Studium bewegten, lagen in der Unsicherheit der eigenen Zukunft, der Aussicht, bei Verlust des männlichen Lebenspartners auf eigenen Füßen stehen zu müssen und sich dementsprechend eine eigene berufliche Zukunft sicherstellen zu wollen. Verheiratete Frauen entschlossen sich nun eher zur Fortsetzung ihres Studiums statt zum bis dahin üblichen Studienabbruch bei Heirat. In diesem Sinn wirkte der Krieg als Katalysator für das Frauenstudium. ${ }^{1161}$ Die Studentinnenanzahl stieg im 'Altreich' von knapp 6000 im Jahr 1939 auf über 41000 im Jahr 1944. Im SS 1944 schrieben sich über 11000 Frauen neu ein mehr als je zuvor. 1939 lag der Anteil der Frauen unter den Studienanfängern bei 9\%, 1944 hingegen bei $64 \% .{ }^{1162}$ Gegen Ende des Kriegs studierten ungefähr gleich viele Frauen wie Männer an deutschen Hochschulen. In Chemie waren es sogar 63,3 \% Frauen; praktisch ein gleich hoher Anteil wie in den Naturwissenschaften allgemein. ${ }^{1163}$ Auch die Göttinger Physik erlebte im SS 1944 die höchsten Physikstudentinnenzahlen. Dies lag aber weniger an Neueinschreibungen im ersten Fachsemester, wie es die allgemeine Entwicklung suggeriert. Die 45 Physikstudentinnen damals waren im Mittel im 4,5. Fachsemester inskribiert; nur etwa 8 bis 10 Studentinnen standen im ersten Fachsemester (siehe Diagramm 12).

Wegen des großen Andrangs der Frauen an die Universitäten ermächtigte das REM die Rektoren im März 1943, Zulassungsbeschränkungen einzuführen, die sich besonders gegen weibliche Studienanfänger richten sollte. ${ }^{1164}$ Auf Aufforderung des Sicherheitsdienstes der SS

1160 Siehe auch den Abschnitt 2.2.2; zu den Göttinger Physikstudentinnen Tabelle 13 und Grüttner [1995] S. 425.

1161 Powels [1984] S. 99f.

1162 Jarausch [1984] S. 203.

1163 Powels [1984] S. 101. Für das Jahr 1939 gibt Powels 6342 Studentinnen an, Titze [1987] S. 43, Tab. 6, der diesbezüglich die verlässlichere Quelle darstellt, jedoch 5777. Zu Studentinnen in der Chemie siehe Roloff [1992]. Nach Jarausch [1984] S. 204 war der Frauenanteil in den Naturwissenschaften 63,5 \%.

1164 Grüttner [1995] S. 107f. 
berichtet Rektor Plischke im Sommer 1943 über das Frauenstudium an der Universität Göttingen:

„Eine Überprüfung der in Göttingen studierenden Frauen, die laufend im Gang ist, hat bis jetzt ergeben, dass der weitaus grösste Teil mit Eifer, Fleiss und Pflichtbewusstsein dem Studium nachgeht. Es steht auch eindeutig fest, dass gerade die Studentinnen meist $\mathrm{zu}$ viel Vorlesungen belegen, oft über 30 Wochenstunden. [...] Massgebend für das Studium ist für den weitaus grössten Teil die Sicherstellung der Zukunft durch einen Beruf. Unverkennbar nimmt dadurch auch seit etwa zwei Semestern die Zahl derjenigen Studentinnen zu, die auf den Lehrberuf zustreben." 1165

Damals, im SS 1943, studierten in Göttingen 22 Frauen Physik im Hauptfach, mehr als je zuvor. Wenn man Plischkes Bericht Glauben schenken darf, waren unter ihnen nur wenige 'Scheinstudentinnen'. Die Stoßrichtung gegen die Studentinnen bekräftigte ein weiterer ministerieller Erlass vom März 1944 gegen die Überfüllung einzelner Hochschulen. Die Rektoren seien dafür verantwortlich, dass ,in keiner Fachrichtung mehr Studierende zugelassen werden als nach den Erfordernissen eines geregelten, erfolgreichen Unterrichts verantwortet werden kann. Bei einer Beschränkung der Zahl der Neuzulassungen liegt es durchaus im Sinne meiner Anordnungen, wenn hierbei die weiblichen Studierenden zuletzt berücksichtigt werden [...]." $1166 \mathrm{Zu}$ einer kritischeren Beurteilung des Frauenstudiums als Plischke kam 1944 der neue Göttinger Rektor Hans Drexler in seinem Antwortschreiben ans Ministerium:

„Die Erfahrungen der letzten beiden Jahre haben gezeigt, dass die Abiturientinnen aus dem hauswirtschaftlichen Zweig der höheren Schulen an Vorbildung und Leistung den übrigen bei weitem nachstehen. Es ist daher beabsichtigt, sofern der Andrang in dem bisherigen Umfang anhält, die genannten Abiturientinnen von der Annahme auszuschliessen. Eine Schwierigkeit liegt nur darin, dass in einigen Städten des Gaues, z. B. in Goslar, überhaupt nur der hauswirtschaftliche Zweig vorhanden ist. Angesichts der dauernd zunehmenden Überfüllung werden wir uns aber in Zukunft auch über diese Bedenken hinwegzusetzen gezwungen sehen." ${ }^{1167}$

Auch in der Mathematisch-Naturwissenschaftlichen Fakultät wurde die vom Ministerium angeregte Studienbeschränkung diskutiert. Zur nachrangigen Aufnahme von Studentinnen ist im Fakultätsprotokoll nur eine Äußerung vermerkt: „Eucken gegen Vermehrung d. Ass.,

\footnotetext{
1165 Rektor Plischke an den Sicherheitsdienst des Reichsführers-SS, SD-Abschnitt, Braunschweig, Leitaußenstelle Göttingen, 12. Juni 1943. Zitiert nach Wegeler [1996] S. 255.

1166 Erlass des REM (Mentzel) vom 17. März 1944. UAG, Kur. XXX. A. a. Studierende. Allgemeine Vorschriften. VIII.

1167 Rektor an REM, 19. Juli 1944. UAG, Kur. XXX. A. a. Studierende. Allgemeine Vorschriften. VIII.
} 
gegen Frauenstudium.“1168 Der Chemiker Eucken war im SS 1944 von 127 Chemiestudentinnen und 'nur' 91 männlichen Studenten umgeben. ${ }^{1169}$ Die Vertreibung der Studentinnen schwebte zu Kriegsende als latente Drohung über der Universität, wurde aber noch nicht durchgesetzt. Einige Professoren wären zu diesem Schritt bereit gewesen; sie sahen sogar eine gewisse Notwendigkeit darin. Die Umsetzung wurde schließlich auf die Nachkriegszeit verschoben.

Trotz der deutlichen Anzeichen auf eine künftige Zurückdrängung der Frauen konnten die Frauen gegen Ende des Kriegs besser studieren als je zuvor. Im Unterschied zur ausgehenden Weimarer Republik wurden sie von ihren männlichen Kommilitonen seltener als zukünftige Konkurrenz auf dem Arbeitsmarkt angesehen und entsprechend weniger angefeindet. Jedenfalls berichteten Studentinnen rückblickend überwiegend, sie hätten sich nicht benachteiligt gefühlt. Diesen Befund kann ich für Göttingen durch eigene Interviews mit ehemaligen Physikstudentinnen bestätigen. Es ist aber kritisch anzumerken, dass manche Diskriminierung von den Studentinnen nicht als solche wahrgenommen wurde. Eine Studentin berichtete folgendes Erlebnis aus dem Jahr 1941:

„Joos kam an meinen Arbeitsplatz, beim Physikalischen Praktikum. Meine Aufgabe war Das ballistische Galvanometer. 1941 - Krieg - Er in Hauptmannsuniform, zum Universitätsdienst beurlaubt, fragte mich: »Was ist Ballistik?« Meine prompte Antwort: »Die Lehre vom Schießen.« - »Mal herhören!« forderte er die Anwesenden auf, »hier weiß eine Dame, was die Lehre vom Schießen ist!« Einige Wochen später meldete ich mich bei ihm zur Fleißprüfung. Am Schluß fragte er mich: »Wann lassen Sie sich Ihre Doktorarbeit geben?«"1170

Während sich das Klima für die Studentinnen innerhalb der Universität besserte, tauchten in der Bevölkerung vermehrt kritische Stimmen auf, die neidisch über die Frauen aus „,besseren Schichten“" klagten, die sich der Dienstverpflichtung in der Kriegswirtschaft durchs Studium entziehen konnten. ${ }^{1171}$

Es ist bemerkenswert, dass die Frauen im Krieg besonders naturwissenschaftliche Fächer wählten. In Chemie, Physik, Mathematik und Geologie stieg in gesamt Deutschland ihr Anteil von $11 \%$ im Jahr 1939 auf 64 \% im Jahr 1943 und lag damit über dem durchschnittlichen

\footnotetext{
1168 Protokoll der Fakultätssitzung vom 9. Dezember 1943; Hervorhebung original. GPAMNFG, Protokollbuch III der mathematisch-naturwissenschaftlichen Fakultät WS 1927/28 - SS 1946.

1169 Zahlen nach eigener Zählung aus den Matrikelverzeichnissen im UAG.

1170 Mitteilung einer damaligen Physikstudentin, die anonym bleiben möchte.

1171 Güttner [1995] S. 124f.
} 
Frauenanteil an allen Fächern, der damals 45 \% betrug. ${ }^{1172}$ Die konkreten Zukunftsaussichten für die Zeit nach dem Studium scheinen auf die Kriegsstudentinnen wenig Einfluss gehabt zu haben. ${ }^{1173}$ Auch in Göttingen gab es gegen Kriegsende eine erstaunlich große Anzahl an Physikstudentinnen. Im Sommersemester 1944 gab es unter den 110 Studenten 48 Frauen, was einem Anteil von $44 \%$ entspricht. Diese Entwicklung scheint typisch zu sein, aber leider gibt es nur wenig geschlechtlich differenzierte Vergleichszahlen von Physikstudenten der späten Kriegsjahre. Als ein Beispiel kann hier die TH Wien angeführt werden. Dort war der Anteil der Frauen, die technische Physik studierten, im Studienjahr 1944/45 30 \%, während er an der gesamten TH $22,1 \%$ betrug. 1174

Aus einer Untersuchung der Physikerinnen in Berlin von Annette Vogt geht hervor, dass die Frauen bei der Fächerwahl zur Promotion in Physik bis 1945 zu 93 \% Experimentalphysik (oder einfach „Physik“) wählten und nur 7\% theoretische Physik oder Philosophie der Physik. Gesamt waren es 46 Promotionen, 29 vor 1933 und 17 in der NS-Zeit. ${ }^{1175}$ Die Berufswahl verschob sich mit der Zeit. Eine Anstellung an der Universität konnten bis 1936 nur vier von 40 Promovendinnen finden, hingegen in den folgenden Jahren bis 1945 drei von acht. Während vor 1936 acht Physikerinnen in der Industrie unterkamen, war es nachher nur eine einzige. Den Lehrerberuf wählten drei Physikpromovendinnen vor und eine einzige nach 1936. ${ }^{1176}$ Eine Auflistung der Physikpromotionen an der Universität Freiburg der Jahre 1911 bis 1952 zeigt, dass bis 1925 neun Frauen promovierten und in den folgenden Jahren nur noch eine einzige, diese im Jahr 1951.1177

Bei den Studentinnen der Naturwissenschaften lag Anfang der 30er Jahre das Lehramt als Berufswunsch deutlich an erster Stelle. Die tatsächliche Berufswahl wich vom Wunsch gelegentlich ab. Das Lehramtsstudium und das Staatsexamen diente als Rückversicherung, falls der unsichere Weg einer Hochschullaufbahn oder einer Anstellung in der Industrie scheitern sollte. Selbst einzelne Männer, die später Physikordinarius wurden, schlossen ihr Physikstudium zuerst mit dem Staatsexamen ab, und entschlossen sich erst danach und auf Grund gezielter Förderung $\mathrm{zu}$ einer akademischen Karriere. ${ }^{1178}$ Frauen sind verständlicherweise auf eine solche Rückversicherung noch stärker angewiesen als Männer.

\footnotetext{
1172 Weyrather [1981] S. 148.

1173 Huerkamp [1996]a S. 89.

1174 Mikoletzky [1997]a S. 178, 180.

1175 Vogt [2000] S. 196f. Die beiden Promotionen in der Geophysik habe ich hier ausgeklammert.

1176 Vogt [2000] S. 204f.

1177 Nauck [1953] S. 69f.
} 
Von welchen Zufällen die spätere Berufswahl abhängt, zeigt das Interview mit der theoretischen Physikerin Ursula Schotte: „Das Studium hat mir großen Spaß gemacht, aber man hat dadurch noch keinen Einblick in das, was man in der Forschung später leisten muß. Vielleicht habe ich immer noch im Hinterkopf gehabt, daß man auch Lehrerin werden könnte. Das hätte ich vielleicht auch gemacht, wenn ich nicht einen Physiker geheiratet hätte, der in der Forschung tätig ist, und der mich eigentlich braucht als Gesprächspartnerin."1179 Demgegenüber machte sich eine Göttinger Physikstudentin der vierziger Jahre keine Illusionen, „in der Männerwelt der Physiker je mehr zu werden, als eine Technische Assistentin besserer Qualifikation." 1180

Eine überschwängliche Gesamteinschätzung des Frauenstudiums in der NS-Zeit liest sich bei Grüttner so: „Mit einiger Verspätung und oft mit starkem Widerwillen mußten die Nationalsozialisten schließlich den historischen Durchbruch akzeptieren, den das Frauenstudium im ersten Drittel des Jahrhunderts erzielt hatte."1181 Es handelte sich aber keineswegs um einen historischen Durchbruch, sondern um eine kriegsbedingte Sondererscheinung, die nach 1945 wieder rückgängig gemacht wurde. Ich schließe mich der bei Jarausch gegebenen Bilanz über das Frauenstudium in den Kriegsjahren an: „Trotz gegenläufiger Ideologie erzwangen die Kriegsumstände und der Akademikermangel eine begrenzte Emanzipation der studierenden Frauen im »Dritten Reich«““.1182 Eine Bestätigung dafür gibt eine Stellungnahme des Freiburger Rektors, der das Frauenstudium zu Kriegsende verteidigte, da ,wir ohne den Einsatz jeder fähigen Frau auch im akademischen Berufsleben schon heute und erst recht in Zukunft nicht auskommen können, dass also das Frauenstudium grundsätzlich aus zwingenden staatspolitischen Gründen sogar mit allen Kräften gefördert werden muss, solange Männer in genügender Anzahl nicht zur Verfügung stehen."1183

\subsubsection{Die Verdrängung der Physikstudentinnen nach 1945}

Die Forschung zum Frauenstudium hat sich bisher nur wenig mit der veränderten Ausgangslage für studierwillige Frauen in der unmittelbaren Nachkriegszeit beschäftigt.

\footnotetext{
1178 Bei den Göttinger Physikern gilt das zum Beispiel für Karl-Heinz Hellwege, Peter Brix, Hans Kopfermann, Erwin Meyer und Friedrich Hund.

1179 Schotte [1981] S. 159.

1180 Bericht einer anonym bleibenden Physikstudentin, die sich nach drei Jahren Forschungstätigkeit in einem Göttinger Physikinstitut 1947 für den Schuldienst entschied.

1181 Grüttner [1995] S. 478.

1182 Jarausch [1984] S. 204.

1183 Zitiert nach Schnabel [1991] S. 232. 
Überhaupt gibt es kaum tiefer greifende Studien zu Studentinnen der Nachkriegszeit. ${ }^{1184}$ Ein Vergleich der Göttinger Ergebnisse mit anderen Universitäten oder einer allgemeinen Entwicklung ist daher leider nur grob und in Ansätzen möglich. Ziel dieses Abschnittes ist es daher, genaue Daten zumindest für die Göttingen Physik zu präsentieren und eine Erklärung mit lokal beschränkter Gültigkeit1185 für diese Entwicklung zu geben.

Die Studentinnen wurden nach Kriegsende häufig zum Thema hochschulpolitischer Gespräche. Vereinzelt finden sich Fürsprecher für das Frauenstudium, wie der damalige Heidelberger Dozent Alexander Mitscherlich: „Auch die Frauen müssen sozial eingegliedert werden. Es ist eine politische und soziale Realität, dass ein unendlicher Überschuß an Frauen in Europa vorhanden ist.“1186 Im ersten Nachkriegsjahrzehnt bestand die westdeutsche Gesellschaft zu fast 60 \% aus Frauen. ${ }^{1187}$ In Göttingen dominierte eine reservierte Haltung der Professoren gegenüber dem Frauenstudium. Wie sich das Kriegsende hier auf die allgemeinen Studienbedingungen auswirkte, wurde in den vorigen Abschnitten gezeigt. Die wesentliche Neuerung bestand in der Einführung eines numerus clausus, wodurch der Zugang zur Universität nicht mehr allen frei stand. Die Professoren wählten sich ihren akademischen Nachwuchs selbst aus. Entscheidend waren aber nicht allein die fachlichen Leistungen wie zum Beispiel Zeugnisnoten, wo Frauen oft bessere Ergebnisse präsentierten, ${ }^{1188}$ sondern eine eigenartige Mischung aus Fachwissen und Charaktereigenschaften. Für das Frauenstudium in Göttingen bedeutete dies einen einschneidenden Rückgang. Der Anteil der Studentinnen unter allen Studenten der Universität sank von 44,5 \% im SS 1944 auf 24,9 \% im ersten Nachkriegssemester und weiter auf 14,9 \% im WS 1951/52. Die absoluten Studentinnenzahlen gingen in den genannten Semestern wie folgt zurück: 2175, 1244 und

\footnotetext{
${ }^{1184}$ Für die 50er Jahre: Brentano [1963]. Einen knappen Überblick gibt Metz-Göckel, Roloff \& Schlüter [1989]. Abschnitte zum Frauenstudium enthalten Respondek [1992] Kap. 10.5, Maaß [1998] Kap. 4.2, in Bezug zur geplanten Hochschulreform Phillips [1995] Kap. 5.9, wo das Fehlen eines eigenen Abschnitts zum Frauenstudium im „Blauen Gutachten“ diskutiert wird. Einen lebendigen Einblick in die besonderen Bedingungen für Studentinnen von den Anfängen des Frauenstudiums bis in die 50er Jahre bieten in Bezug auf Heidelberg Lauterer-Pirner \& Schepers-S.-W. [1985/86]. Leider sind dort die 40er Jahre nach dem Kriegsende ausgespart. Einen guten Einblick in die Lebensentwürfe und Alltagserfahrungen von Studentinnen der frühen 50er Jahre anhand des Beispiels der Göttinger Rechtswissenschaften gibt die Magisterarbeit von Stefanie Rühle [2000].

1185 Zum Beispiel gab es laut Protokoll der ersten Hochschulkonferenz in Hamburg „keine weitergehenden Beschränkungen“ für Studentinnen, ,also andere Regelung als in Göttingen“, Heinemann (Hrsg.) [1990]c S. 54. 1186 Mitscherlich [1947] S.157.

1187 Boehling [1994] S. 69.

${ }^{1188}$ Siehe Respondek [1992] S. 311.
} 
624. ${ }^{1189}$ Zum Vergleich stieg die Studentinnenzahl an der Universität Freiburg von WS 1945/46 bis zum SS 1952 von 370 auf 1125. ${ }^{1190}$

Wie Diagramm 10 und Diagramm 11 zeigen, erfolgte die Zurückdrängung der Frauen in Göttingen je nach Fachrichtung in unterschiedlichem Ausmaß. Dies verdeutlicht auch der 1950 gegebene Bericht von Bollnow, der exemplarisch einige Entwicklungen skizziert:

„In der Philosophischen Fakultät betrug er [der Frauenanteil] 1941/42 67 \%. Er sank vom WS $1945 / 46$ bis WS $1948 / 49$ von $38 \%$ auf $28 \%$. In der Kunstgeschichte bildeten sie noch 1945/46 fast $80 \%$ (gegen $44 \%$ 1948/49). In der gleichen Zeit sank ihr Anteil in Geschichte von $45 \%$ auf $16 \%$, in der Germanistik von $52 \%$ auf $34 \%$, in der Chemie von $16 \%$ auf 3,5\%, während er in den neueren Sprachen konstant blieb."1191

Die Physik und die Chemie waren am stärksten betroffen. Nicht nur die Anteile der Studentinnen sanken in diesen Fächern nach 1945 am stärksten, auch die absoluten Zahlen gingen drastisch zurück. In der Chemie ist der Rückgang anhand dreier Semester deutlich zu sehen: Im SS 1944, SS 1946 und WS 1948/49 gab es 127, 28 und 9 Chemiestudentinnen. Die entsprechenden Zahlen der männlichen Chemiestudenten lauten 91, 135 und 153.1192 Am Beispiel der Physik werden im Folgenden die einzelnen Gründe für die Verdrängung und ihre Mechanismen gezeigt.

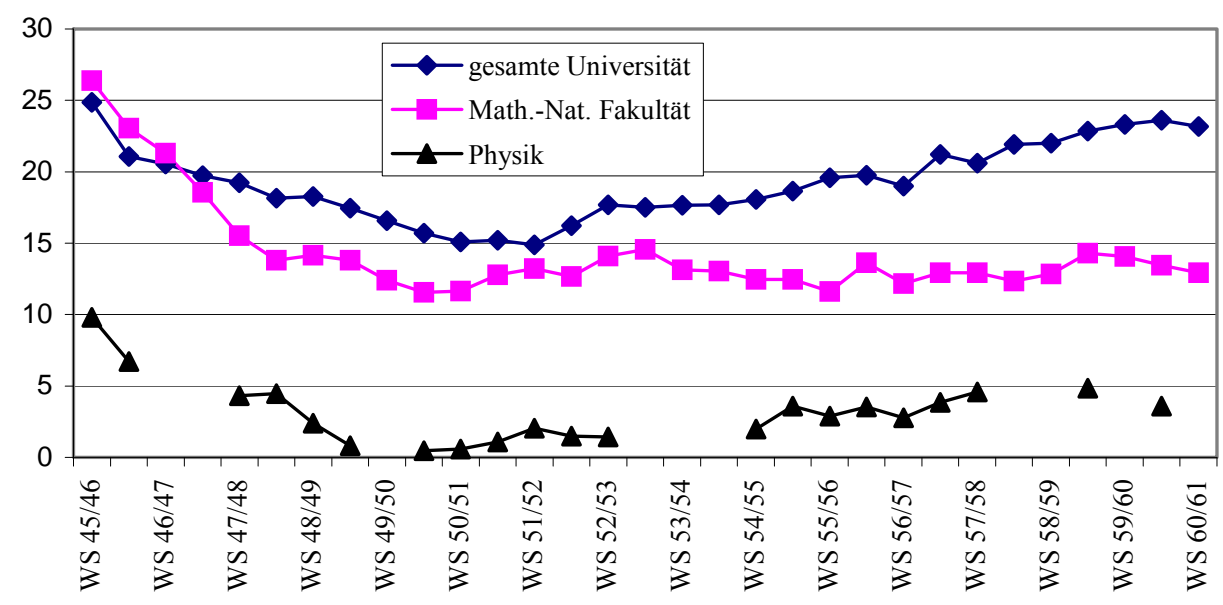

Diagramm 11 Frauenanteil unter den Studenten der Physik, der Math.-Nat. Fakultät und der Universität Göttingen insgesamt 1945-1960 (Angaben in Prozent). ${ }^{1193}$

\footnotetext{
1189 Anteile errechnet nach [Studentenzahlen] [1987].

1190 Nauck [1953] S. 27.

1191 Bollnow [1950] S. 158f.

1192 Zahlen nach eigener Zählung aus den Studentenverzeichnissen im UAG.

1193 Zur Quellenangabe siehe Fußnote 715.
} 
Schon im Sommer 1945 wurden in der Mathematisch-Naturwissenschaftlichen Fakultät die Weichen gegen das Frauenstudium gestellt. Bei den ersten Prüfungen der Studienbewerber wurden ehemalige Soldaten bevorzugt. In der Physik war es aber nicht so, dass dadurch die zum Kriegsdienst beurlaubten Physikstudenten wieder in großer Zahl nach Göttingen zurückkehrten. Im WS 1942/43 wie auch im SS 1944 gab es jeweils 61 zur Wehrmacht Beurlaubte. Zieht man Doppelnennungen ab, bleiben 84, von denen zumindest 6 nachweislich in Russland ihr Leben ließen. Von den verbleibenden 78 kehrten 22 zwischen dem WS 1945/46 und dem WS 1948/49 an die Universität Göttingen zurück, 14 davon zur Physik. ${ }^{1194}$ Dies stellte also keine große Gruppe dar, die eine gravierende Zurückdrängung der Studentinnen erklären könnte.

Bei den Aufnahmeprüfungen wurden aber auch jene Studenten bevorzugt, die in den Abschlusssemestern standen. In dieser Gruppe befanden sich auch Studentinnen, wie Dekan Eucken anmerkte, „doch wird es zweckmäßig sein, bei diesen einen besonders strengen Maßstab anzulegen, da bei der gegenwärtigen Wirtschaftslage nur ganz hervorragend tüchtige weibliche akademisch gebildete Kräfte einige Aussicht darauf haben werden, eine Anstellung zu finden." 1195 Hier ist ein wichtiger Grund für die unterschiedlich starke Zurückdrängung der Studentinnen in den einzelnen Fächern ausgesprochen: Es war die realistische Sorge der Professoren um die berufliche Zukunft ihrer Studenten und Studentinnen. Da Frauen in der Physik und Chemie besonders schlechte Berufsaussichten hatten, bevorzugten die Professoren für die wenigen freien Studienplätze, die sie zu vergeben hatten, aus Effizienzüberlegungen Männer, die sowohl für die Erlangung einer Industriestelle als auch fürs Aufsteigen in einer Hochschullaufbahn höhere Erfolgschancen besaßen. Anders gesagt, wurde Studentinnen nur wegen „Rücksichtnahme auf gewisse Frauenberufe“ ein Anrecht aufs Studium zugestanden. ${ }^{1196}$

Diese Ungleichbehandlung der Frauen stieß in der Mathematisch-Naturwissenschaftlichen Fakultät nicht auf allgemeine Zustimmung, wie das Sitzungsprotokoll vom 13. August 1945 zeigt:

\footnotetext{
1194 Daten der Beurlaubten aus den Matrikelverzeichnissen ermittelt. Die in Russland Verstorbenen wurden anhand Die Toten der Georgia Augusta 1939-1945 identifiziert; beides UAG.

1195 Dekan Eucken in einem Rundschreiben an die Institutsvorsteher der Math.-Nat. Fakultät, 19. Juli 1945. MPG-Archiv, III, 61, 1738.

1196 Protokoll der ersten Hochschulkonferenz, Heinemann (Hrsg.) [1990]c S. 49. Dort heißt es auch: „Im übrigen können Studentinnen aus denjenigen Fächern, in denen wirkliche Berufsaussichten bestehen, zum Studium kommen, soweit sie nicht anderen Studenten die Plätze wegnehmen.“
} 
„Er [Eucken] tritt für eine Beschränkung der Zahl der Studentinnen ein. Auf eine Frage von Herrn Harder[1197] werden Schätzungen über die möglichen Anzahlen von Studenten in den einzelnen Fakultäten genannt. Herr Gallwitz[1198] tritt für eine Gleichberechtigung der Studentinnen ein. Herr v. Allesch[1199] schneidet die Frage nach der Rechtsgrundlage für eine Unterscheidung zwischen Frauen und Männern an. Herr Prandtl betont, dass die Erfolgsaussichten für das Fortkommen in Beruf massgebend einkalkuliert werden müssen, und dass in diesem Sinne bei Frauen ein schärferer Masstab [sic] angelegt werden müsse.“ 1200

Für die Naturwissenschaftler wie Prandtl und Eucken war die Universität nicht nur Bildungs-, sondern auch Ausbildungsstätte, und dies rechtfertige die Ungleichbehandlung. Die Diskussion um eine Beschränkung des Zugangs speziell für Frauen wurde nicht nur in Göttingen in Erwägung gezogen. In Marburg, Tübingen, Hamburg und Freiburg kam es tatsächlich zu einer administrativen Einschränkung des Frauenstudiums. In Göttingen geschah dies verborgener durch die von Fall zu Fall Entscheidungen der Professoren. Die abgewiesenen Studentinnen wurden von der „Dozentin Dr. med. Winkler“ und „Frau Professor Kaehler“ beraten. ${ }^{1201}$ Eine Folge der Ablehnung von weiblichen Studienbewerbern war, dass es im Winter 1945/46 in Göttingen eine ,große Zahl von Hausgehilfinnen [gab], die früher Studentinnen waren“. ${ }^{1202}$

Das 'Berufsargument' führte aber nicht zu einem Studienverbot für Frauen in Physik und Chemie. Vereinzelt wurden Physikstudentinnen zugelassen, auch während Euckens Zeit als Dekan, obwohl er das letzte Wort in Fragen der Zulassung hatte und seine Zustimmung bei Frauen hätte verweigern können. ${ }^{1203}$ Der Rückgang der Physikstudentinnen kann nicht allein mit den Einstellungen und Handlungen einzelner wichtiger Persönlichkeiten erklärt werden. Vielmehr scheinen hier strukturelle Faktoren eine entscheidende Rolle gespielt zu haben. Außerdem könnte die kollektive Mentalität der prüfenden Professoren die Zurückdrängung der Frauen verstärkt haben. Um diesen Fragen nachgehen zu können, werden erst genaue Daten zur Studienfrequenz und zum Studienverlauf der Physikstudentinnen präsentiert. Für

\footnotetext{
1197 Professor der Botanik und Euckens Nachfolger als Dekan.

1198 Professor der Landwirtschaftlichen Maschinenkunde.

1199 Professor der Psychologie und Philosophie.

1200 Protokoll der Fakultätssitzung vom 13. August 1945. GPAMNFG, Protokollbuch III der mathematischnaturwissenschaftlichen Fakultät WS 1927/28 - SS 1946.

1201 Protokoll der Senatssitzung vom 5. Juni 1946. UAG, Senatsprotokolle 1945-1949.

1202 Heinemann (Hrsg.) [1990]c S. 52.

1203 Zeitzeugen berichten von Euckens ablehnender Haltung bei der Aufnahme von Studentinnen. Siehe Krönig \& Müller [1990] S. 132f., Grun [1995]c, der Eucken als ,einen unnahbaren, emotionslosen Menschen, der am liebsten das Frauenstudium abschaffen wollte“ beschreibt, sowie Kertz [1986] S. 25: Von Eucken, war bekannt, dass er Studentinnen grundsätzlich abwies.“ In der Eucken Biografie von Becke-Goehring \& Eucken [1995] S. 52 wird Eucken bezüglich seines „Skeptizismus“ zum Frauenstudium mit folgender Aussage zitiert:
} 
das erste Nachkriegssemester gibt folgende Tabelle genaue Auskunft über die Aufteilung der eingeschriebenen Physikstudenten.

\begin{tabular}{|l|l|l|l||l|}
\hline \multirow{2}{*}{} & \multicolumn{2}{|l|}{ Hauptfach } & Lehramt & Zusammen \\
\cline { 2 - 5 } & männl. & weibl. & $\begin{array}{l}\text { männl. und } \\
\text { weibl. }\end{array}$ & männl. und weibl. \\
\hline Vorstudium & 50 & & 14 & 64 \\
\hline mittlere Semester & 52 & 4 & 11 & 67 \\
\hline $\begin{array}{l}\text { kurz vor } \\
\text { Abschluss }\end{array}$ & 12 & 4 & 3 & 19 \\
\hline Doktoranden & 2 & 1 & & 3 \\
\hline insgesamt & 116 & 9 & $\begin{array}{l}28 \\
\text { (davon 6 Frauen) }\end{array}$ & $\begin{array}{l}153 \\
\text { (davon 15 Frauen) } 1204\end{array}$ \\
\hline
\end{tabular}

Tabelle 13 In Göttingen immatrikulierte Physikstudenten im Wintersemester 1945/46. ${ }^{1205}$

Nachdem in den Jahren 1941 bis 1944 der Frauenanteil unter den Physikstudenten bei etwa $40 \%$ gelegen hatte, fiel er im WS 1945/46 auf $10 \%$ und somit auf einen ähnlichen Wert, wie in den Jahren 1930 bis 1933 (damals 8-9 \%). Bei diesen Verhältnissen blieb es aber nicht. Die Physikstudentinnen wurden sukzessive weniger, bis im SS 1949 nur noch eine einzige übrig blieb. Die Betrachtung der rückläufigen Zahlen alleine suggeriert allerdings ein falsches Bild von der Nachkriegsentwicklung. Es konnten sich nämlich durchaus neue Studentinnen einschreiben; sie blieben aber nur wenige Semester in der Physik. Leider gibt es kaum statistisches Material für die zweite Hälfte der Vierzigerjahre. Zu den Neuimmatrikulationen des SS 1946 bemerkte die Mathematisch-Naturwissenschaftliche Fakultät, dass ein genauer Überblick erschwert sei, die „Damen“ aber überwiegen. Von 250 Neuzulassungen seien 80 „Damen“, während rund 700 abgelehnt werden mussten. ${ }^{1206}$ Das heißt, dass auf Grund der kurzen Verweildauer mehr Physikstudentinnen zwischen 1945 und 1952 neu aufgenommenen wurden als die Zahlen vermuten lassen, dass aber nur eine oder zwei von ihnen ihr Physikstudium in Göttingen zum Abschluss brachte. Die tatsächlichen Verhältnisse lassen sich am besten bildlich darstellen.

Aus den Quellen im Göttinger Universitätsarchiv konnten 99 Hauptfachstudentinnen der Physik der Jahre 1942 bis 1955 ermittelt und deren offizielle Verweildauer im Fach Physik einigermaßen verlässlich rekonstruiert werden. In Diagramm 12 sind die Physikstudentinnen

\footnotetext{
„Ach, die Damen suchen hier doch nur einen Mann und brechen das Studium dann vorzeitig ab, nachdem sie die Studienplätze für Neueintretende blockiert haben."

1204 Aus dem Studentenverzeichnis des UAG waren 9 Hauptfach Physikstudentinnen zu identifizieren. Da es damals üblich war, Doktoranden zu exmatrikulieren, ist es fraglich, ob diese neun mit den in der Tabelle angegebenen Hauptfachstudentinnen identisch sind.

1205 UAG Mat.Nat.Fak., Ord. 19b.

1206 Protokoll der Fakultätssitzung vom 31. Mai 1946. GPAMNFG, Protokollbuch III der mathematischnaturwissenschaftlichen Fakultät WS 1927/28 - SS 1946. Siehe auch Tabelle 11.
} 
derart untereinander grafisch angeordnet, dass jeder Studentin eine Zeile zugeordnet wurde. Soweit möglich wurde auch das Fachsemester und eventuelle Wechsel zu anderen Fächern angegeben.

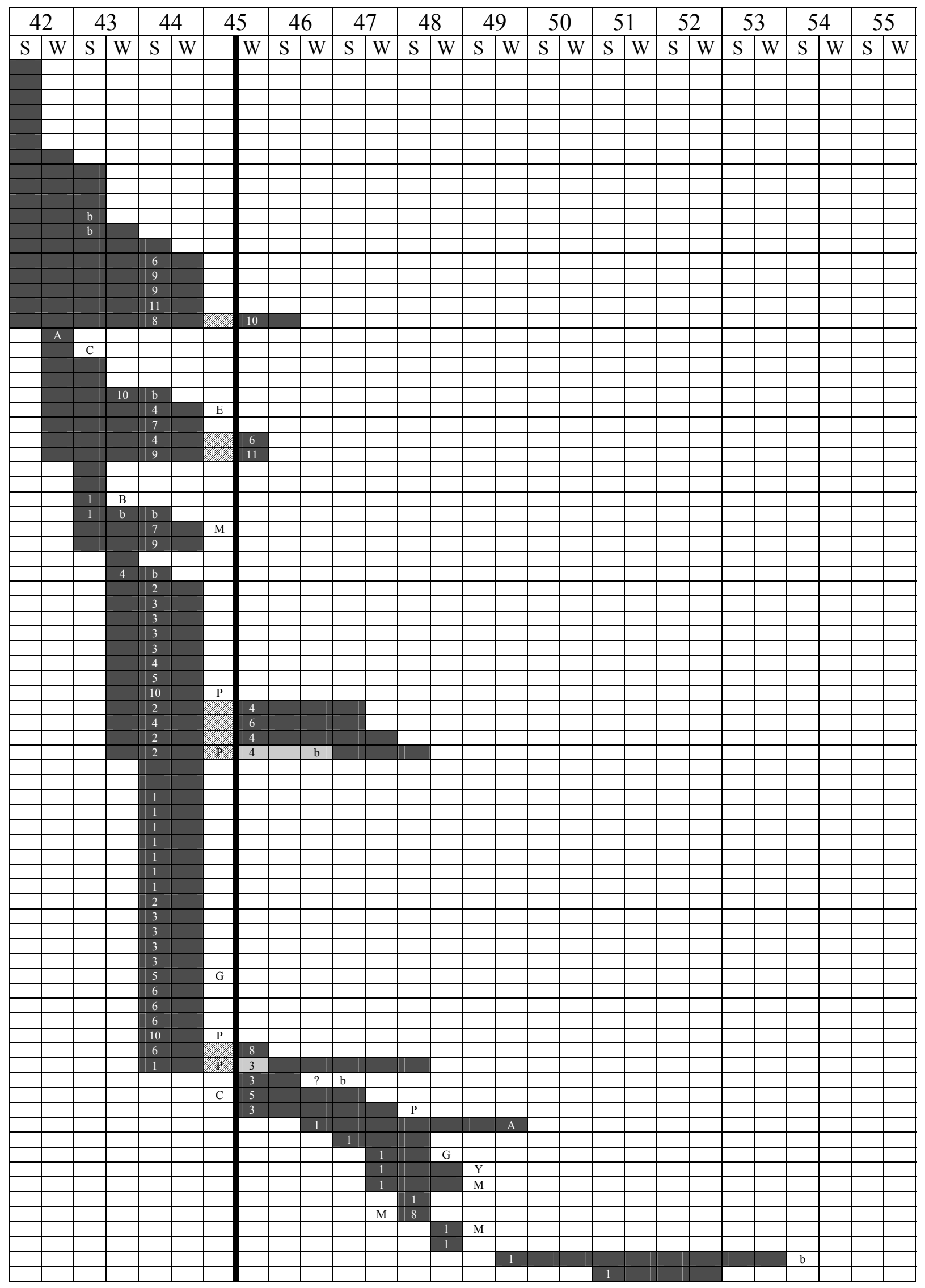




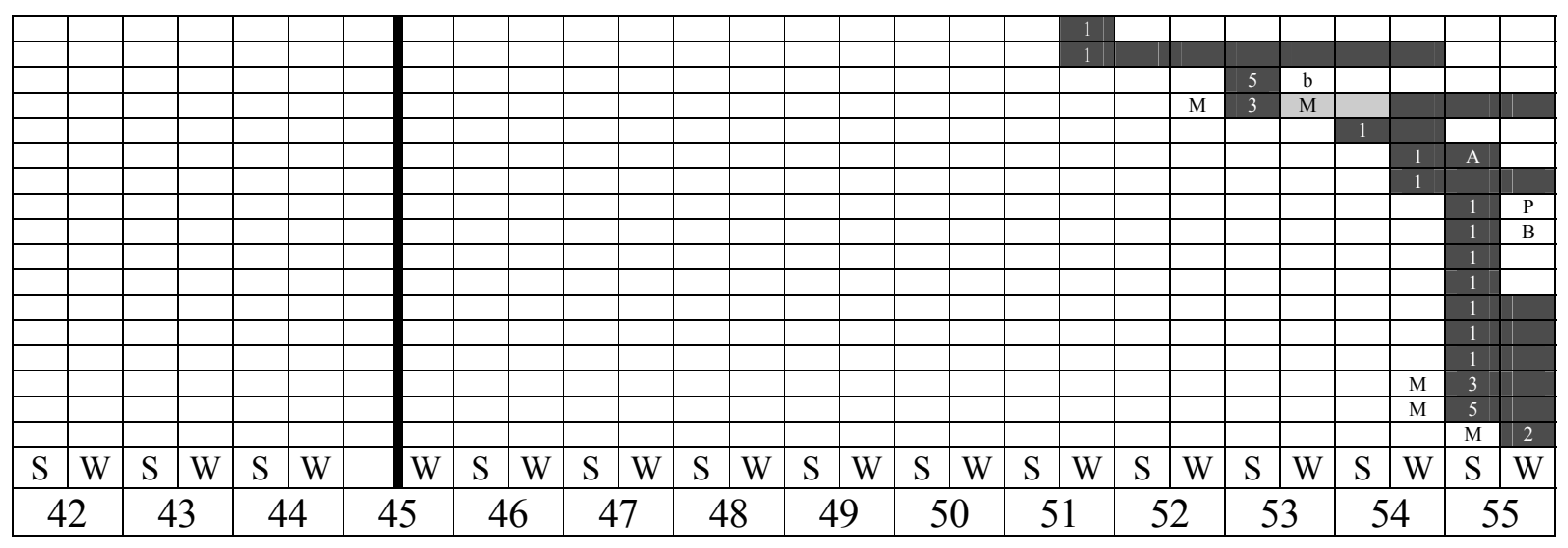

Diagramm 12 Die Verweildauer der Göttinger Physikstudentinnen zwischen 1942 und 1955. Beurlaubungen sind durch „, b“ gekennzeichnet. „A“ bedeutet Ausländerin. Die anderen Großbuchstaben geben den Wechsel zu oder von einem anderen Fach an: B steht für Biologie, C für Chemie, E für Medizin, G für Geografie, M für Mathematik, P für ein Fach der philosophischen Fakultät, Y für Psychologie. Die hell unterlegten Flächen markieren bei unterbrochenem Physikstudium das Verbleiben an der Universität Göttingen in einem anderen Fach. Die Schraffur in der ersten Hälfte 1945 soll andeuten, dass hier kein Vorlesungsbetrieb stattfand. Die Angaben im WS 1944/45 sind mangels Quellen unverlässlich. ${ }^{207}$

Wie ist die in obigem Diagramm dargestellte Nachkriegsentwicklung zu interpretieren? Sicherlich ist der Rückgang der Physikstudentinnen nicht bloß eine Nachwirkung der nationalsozialistischen Herrschaft und Weltanschauung, eine Argumentation, die für die geringen Studentinnenzahlen in Deutschland bis in die 50er Jahre teilweise angeführt wird. ${ }^{1208}$ Vorurteile gegenüber Frauen spielten bestimmt eine Rolle, aber diese waren nicht typisch nationalsozialistisch. Eine Auswirkung der nationalsozialistischen Bildungspolitik, unter der die jungen Frauen in der Nachkriegszeit zu leiden hatten, waren die schlechten Studienchancen mit einem hauswirtschaftlichen Reifezeugnis (siehe S. 223f.). Die Regelung, dass diese Zeugnisse nicht nur wegen des Lateinmangels, sondern letztlich aus Prinzip nicht als Studienberechtigung anerkannt wurden, wurde auf den Hochschulkonferenzen von Männern durchgesetzt, die als Nachkriegsrektoren eine gewisse Distanz zum Nationalsozialismus meist zu recht behaupten konnten. Es ist also nur indirekt eine nationalsozialistische Nachwirkung, und sie war keinesfalls zwangsläufig. Wie gezeigt konnten vor 1945 sehr viele Frauen mit diesen Abschlusszeugnissen ein Studium beginnen. Die Benachteiligung der Frauen nach 1945 war eine freie Entscheidung der Professoren. 1946 kritisierte die SPD diese Diskriminierung. Die auf der Frauen-Arbeitstagung formulierte und an die Kultusminister gerichtete Forderung nach Gleichberechtigung der Frauen beim Studienzugang blieb aber wirkungslos. ${ }^{209}$

\footnotetext{
1207 Die Daten sind aus den Matrikelverzeichnissen in UAG soweit möglich ermittelt. Einschränkend wirken die lückenhaften Angaben zur Fächerwahl (siehe dazu Fußnote 715). Außerdem ist die vollständige Erfassung der Studentenschaft in den Verzeichnissen zweifelhaft.

1208 Hinterberger [1996] S. 46; Mertens [1991] S. 123.

1209 Der Antrag der Frauen-Arbeitstagung ist abgedruckt bei Maaß [1998] S. 100.
} 
$\mathrm{Zu}$ der Behinderung durch ein als unzureichend erachtetes Zeugnis kam noch der strenge Maßstab bei den Aufnahmeprüfungen hinzu, der dazu führte, dass in den ersten beiden Nachkriegssemestern keine einzige Frau sich als Erstsemester einschreiben konnte. ${ }^{1210}$ Daher gab es auch keine Frauen im Vorstudium in Physik als Hauptfach (siehe Tabelle 13). Von den zehn im Studentenverzeichnis angeführten Physikstudentinnen des WS 1945/46 befand sich also keine im ersten Semester. Nur sieben von ihnen studierten bereits zu Kriegszeiten in Göttingen. ${ }^{1211}$ Was geschah mit den 38 anderen Physikstudentinnen des SS 1944 beim Übergang in die Nachkriegszeit? Um diese Frage zu diskutieren, stellen wir die Studentinnen des SS 1944 mit ihrer Aufgliederung nach Fachsemestern, wie sie bei fortgesetztem Studium im WS 1945/46 ausgesehen hätte, mit den tatsächlichen Studentinnen des WS 1945/46 gegenüber.

\begin{tabular}{|l|l|l|l|l|l|l|l|l|l|l|l|l|l|}
\hline Fachsemester & 1 & 2 & 3 & 4 & 5 & 6 & 7 & 8 & 9 & 10 & 11 & 12 & 13 \\
\hline $\begin{array}{l}\text { Hypothetische Anzahl der Physikstudentinnen } \\
\text { (Basis SS 1944) }\end{array}$ & & & 8 & 5 & 8 & 4 & 2 & 5 & 2 & 1 & 4 & 2 & 1 \\
\hline Tatsächliche Anzahl der Physikstudentinnen 1213 & & & 2 & 2 & 1 & 2 & & 1 & & 1 & 1 & & \\
\hline
\end{tabular}

Tabelle 14 Gegenüberstellung der Physikstudentinnen des SS 1944 mit denen des WS 1945/46.

Jene 15 hypothetischen Studentinnen, die im WS 1945/46 im 8. oder höheren Fachsemester standen, befanden sich, falls sie ihr Studium nicht abgebrochen hatten, in der Abschlussphase und konnten gemäß der Göttingen Gepflogenheit noch vor der Abschlussprüfung exmatrikuliert werden, um neuen Studenten Plätze frei zu machen. Dass von diesen 15 nur noch drei im WS 1945/46 immatrikuliert waren, sagt daher wenig aus. Von den möglichen 27 Studentinnen, die im 1. bis 7. Fachsemester gestanden hätten, setzten im WS 1945/46 nur vier ihr Physikstudium in Göttingen fort; eine von ihnen war Waltrud Betz, die Tochter des Göttinger Professors für angewandte Mechanik, Albert Betz. Dazu kamen noch drei weitere Studentinnen anderer Hochschulen, die sich im 3. und 5. Semester befanden. Sieben der 27 wechselten in Göttingen in ein anderes Fach, zwei davon kehrten in den folgenden Semestern wieder zur Physik zurück. Zusammengefasst lässt sich sagen, dass von den 45 Physikstudentinnen des SS 1944 mit Kriegsende 31 Göttingen verließen. Genauer betrachtet

\footnotetext{
1210 Maaß [1998] S. 104 zufolge gelang es auch an der TH Braunschweig im ersten Nachkriegssemester keiner einzigen Frau jedoch vielen Männern, als Erstsemester ins Matrikelbuch eingetragen zu werden.

1211 Da vom WS 1944/45 kein Studentenverzeichnis existiert, ist es möglich wenn auch unwahrscheinlich, dass von den drei Studentinnen, die in Diagramm 12 erst im WS 1945/46 das erste Mal aufscheinen, schon 1944/45 in Göttingen studierten.

1212 Hier fehlen drei Physikstudentinnen, deren Fachsemester nicht ermittelt werden konnte.

1213 Hier sind nur die zehn in den Matrikelverzeichnissen angeführten Studentinnen aufgelistet, obgleich in Tabelle 13 eine Anzahl von 15 Studentinnen genannt ist.
} 
blieben von den 27 sich im SS 1944 in den ersten oder mittleren Semestern befindenden Physikstudentinnen nur neun nach 1945 in Göttingen im selben Fach.

Eine Hürde, die vor allem in den Naturwissenschaften besonders groß war, bestand in den Leistungsüberprüfungen nach den ersten Semestern und in der ständigen Überwachung. Es scheint so, als könne das in Diagramm 12 anzutreffende Muster auf diese Auslesemethode zurückgeführt werden. Man erkennt deutlich, dass bis zum WS 1949/50 bis auf eine einzige alle der nach 1945 erstimmatrikulierten Studentinnen nur maximal drei Semester verweilten. Die eine Studentin, die sich im WS 1946/47 einschreiben konnte und sieben Semester blieb, war Ausländerin und zählte damit nicht zum Kontingent des numerus clausus. Sie nahm also keinem Mann den Platz weg. 1214

Wenn die zwischen 1946 und 1948 erstimmatrikulierten Physikstudentinnen auch nur wenige Semester Physik studierten, so konnten doch vier von den sieben ihr Studium in einem anderen Fach fortsetzen. Bei den anderen ist das weitere Schicksal ungewiss, ein Studienabbruch denkbar. ${ }^{1215}$ Allen gemeinsam ist, dass sie die ersten Aufnahmehürden, insbesondere die Leistungs- und Charakterprüfung überstanden hatten. Es gibt aber Anzeichen, dass diese Form der Überprüfung die Frauen benachteiligt hat. Betrachten wir zuerst die Zahlen der Studienanfängerinnen in der Physik, die sich ins erste Semester einschrieben (siehe Tabelle 15).

\begin{tabular}{|l|c|c|c|c|c|c|c|c|c|c|c|c|c|c|c|}
\hline Semester & $43 / 44$ & 44 & $45 / 46$ & 46 & $46 / 47$ & 47 & $47 / 48$ & 48 & $48 / 49$ & 49 & $49 / 50$ & 50 & $50 / 51$ & 51 & $51 / 52$ \\
\hline $\begin{array}{l}\text { Anzahl der Physik- } \\
\text { studentinnen im } \\
\text { 1. Semester }\end{array}$ & 4 & 8 & 0 & 0 & 1 & 1 & 3 & 1 & 2 & 0 & 1 & 0 & 0 & 1 & 2 \\
\hline
\end{tabular}

\begin{tabular}{|l|c|c|c|c|c|c|c|c|c|c|c|c|c|c|c|}
\hline Semester & 52 & $52 / 53$ & 53 & $53 / 54$ & 54 & $54 / 55$ & 55 & $55 / 56$ & 56 & $56 / 57$ & 57 & $57 / 58$ & & & \\
\hline $\begin{array}{l}\text { Anzahl der Physik- } \\
\text { studentinnen im } \\
\text { 1. Semester }\end{array}$ & 0 & 0 & 0 & 0 & 1 & 2 & 7 & 0 & 4 & 0 & 6 & 2 & & & \\
\hline
\end{tabular}

Tabelle 15 Anzahl der Physikstudentinnen im ersten Semester von 1943 bis 1957.

Wie Tabelle 15 zeigt, schrieben sich in den ersten fünf Nachkriegssemestern fünf Studentinnen als Erstsemester in Physik ein, demgegenüber stehen im selben Zeitraum

\footnotetext{
1214 Die Göttinger Physik scheint kein Einzelfall gewesen zu sein. Auf eine geringe Aufnahme und Verweildauer von Studentinnen in den ersten Nachkriegsjahren deuten auch die Ergebnisse von Maaß in Bezug auf die TH Braunschweig hin. Von den Studentinnen, die zwischen 1945 und 1955 ihren Studienabschluss erworben haben, studierten bereits $83 \%$ vor 1945. Maaß [1998] S. 105.

1215 Zum vorzeitigen Abgang von Studentinnen von der Universität siehe die Studie von Gerstein [1965], die zu dem Ergebnis kommt, dass Ende er 50er Jahre 57 \% der Studentinnen und 34 \% der männlichen Studenten die Universität vorzeitig verließen (S. 14). Gründe zum Studienabbruch von Frauen in der unmittelbaren Nachkriegszeit nennen auch Kuhn, Rothe \& Mühlenbruch (Hrsg.) [1996] S. 85.
} 
mindestens 143 Ersteinschreibungen männlicher Studenten. ${ }^{1216}$ In den Nachkriegssemestern wurden, solange der numerus clausus existierte (bis 1953), durchschnittlich 0,7 Frauen pro Semester als Studienanfängerin in Physik aufgenommen, in den folgenden acht Semestern im Mittel drei. Laut mündlicher Auskunft eines Physikstudenten, der im WS 1949/50 in Göttingen sein Studium begann, wurden damals von den Bewerbern nur solche zur Aufnahmeprüfung eingeladen, die in Mathematik und Physik mit „sehr gut“ das Abitur bestanden hatten. Von den etwa 200 zur Prüfung Eingeladenen wurden nur etwa ein Zehntel zum Physikstudium zugelassen. In seiner Erinnerung sei unter den Bewerbern keine einzige Frau gewesen. Tatsächlich wurde Ilse Horeis in seinem Semester als Studienanfägerin in Physik neu eingeschrieben. Auch erscheint die Zahl 200 der eingeladenen Bewerber zu hoch, dafür die Aufnahmequote von nur $10 \%$ zu niedrig. Möglicherweise sind durch den zeitlichen Abstand die tatsächlich schweren Bedingungen für Studienbewerber überzeichnet erinnert. Die Quellen weisen für die Mathematisch-Naturwissenschaftliche Fakultät eine Aufnahmequote von 47,3 \% für das WS 1949/50 auf (siehe Tabelle 11). Leider gibt es nur vereinzelte Angaben zu den Aufnahmequoten in der Physik. Im SS 1951 war sie mit 40 \% auf praktisch gleichem Niveau wie in der Fakultät insgesamt (siehe Seite 256). Als Vergleich kann auch Hamburg dienen. Dort gab es im WS 1949/50 64 Bewerber in der Physik, denen 16 freie Plätze gegenüber standen, das heißt $25 \%$ konnten aufgenommen werden. ${ }^{1217}$

Die geringen Neueinschreibungen von Frauen deuten darauf hin, dass in der Aufnahmeprüfung auch Vorurteile gegenüber Frauen in der Wissenschaft und speziell Frauen in der Physik eine Rolle gespielt haben könnten. Es ist bewusst von Vorurteilen die Rede und nicht von eventuellen schlechten Erfahrungen mit Studentinnen. Vorurteile können selbst dann weiter bestehen, wenn sie eigentlich durch die eigene Erfahrung als widerlegt gelten müssten. Während Physikprofessoren auf der einen Seite ihre Studentinnen in ihren Fähigkeiten schätzten und förderten und dabei gute Erfahrungen machten, konnten sie auf der anderen Seite von der 'Naturwidrigkeit' von Frauen in der Physik überzeugt sein. Ein Beispiel für diesen Widerspruch ist Max Plancks Äußerung zum Frauenstudium. Er gesteht ein, nur gute Erfahrungen gemacht zu haben, fügt aber einschränkend hinzu, dass Amazonen auch auf geistigem Gebiet naturwidrig seien. ${ }^{1218}$

1216 Da für die Semester WS 1945/46, WS 1946/47, SS 1947, WS 1947/48 keine Fächerangaben in den Matrikelverzeichnissen angegeben sind, fehlen in obiger Zahl eventuelle Studenten, die sich in diesen Semestern in Göttingen in Physik neu einschrieben und nur ein Semester kurz blieben.

1217 Hamburger Zahlen nach Krokowska [1993] S. 18.

1218 Planck, 1897, zitiert nach Kleinert [1978] S. 32. Kleinert zieht hier meiner Meinung nach den Fehlschluss, Planck sei frei von Vorurteile gegen begabte Physikerinnen gewesen, da er Lise Meitner mit großem 
Es gibt zwar keine Studie über die Vorurteile der Göttinger Physiker, dafür aber eine Arbeit von Hans Anger über die „Probleme der deutschen Universität“, die auf Interviews mit 138 Professoren der Universitäten Frankfurt, Heidelberg, Kiel und Bonn aus dem Jahr 1954 basiert, in der auch Fragen zum Frauenstudium und zu Hochschullehrerinnen gestellt wurden. Auch wenn hier vier andere Hochschulen untersucht wurden, sind die Resultate zumindest der Tendenz nach auf Göttingen übertragbar. ${ }^{1219}$ In Angers Studie zeigen zwei Drittel der Hochschullehrer eine negative Einstellung zum Frauenstudium. Das restliche Drittel zeichnete sich durch eine bestenfalls neutrale Haltung aus. In der Mehrzahl reproduzierten die Professoren ein von der tatsächlichen Erfahrung unbeeinflusstes Frauenstereotyp.

Ein eklatanter Unterschied zwischen den Geschlechtern wurde in den Studienmotiven gesehen. Drei Viertel der Professoren, die sich zu den Studienmotiven äußerten, behaupteten diesbezüglich Differenzen. Während bei den Männern drei Motive mit gleicher Wertigkeit genannt wurden (Berufsausbildung, soziales Geltungsstreben und materielle Gründe), wurde den Frauen am häufigsten ein „Heiratsmotiv“ unterstellt. Bei den männlichen Studenten wurden solche zum Studium konträren Motive niemals genannt. Die Professoren sahen das Studium von Frauen als Ersatz für die Heirat oder als Anbahnung selbiger an. Um die vermeintliche Richtigkeit des Heiratsmotivs bei Frauen zu unterstreichen, argumentierte ein Dozent 'wissenschaftlich“ induktiv: „Wenn sie nicht hübsch genug ist, um mit Sicherheit Heiratsaussichten zu haben, geht sie auf die Universität. Das zeigt sich daran, daß wir nur sehr wenig hübsche Studentinnen haben.“" 1220 Zwischen den Zeilen steht hier, dass zu einer 'vollwertigen' Frau auch eine weibliche Attraktivität gehört. 'Wenig hübsche‘ Studentinnen wurden deshalb nicht für voll genommen - ihnen fehle ein Stück 'Weiblichkeit' ${ }^{1221}$

Unter Naturwissenschaftlern stärker ausgeprägt als bei Professoren anderer Fächer fand sich die Ansicht, Frauen seien ihrem 'Wesen' nach als Dozentin und als Studentin schlecht geeignet. Auf die Frage, ob es zu viele oder zu wenige Studentinnen gebe, antwortete ein Naturwissenschaftler:

„Das regelt sich ganz von selbst. Es sind weder zuviele noch zuwenige. Wieviel gibt es denn überhaupt? ... Was sagen Sie? 20 Prozent? Doch so viele? Das ist ja

\footnotetext{
Wohlwollen gefördert habe. Meiner Lesart zufolge zeigt Planck hier sehr deutlich den nicht aufgelösten Widerspruch zwischen konkreter Erfahrung und allgemeiner Überzeugung.

1219 Zum Folgenden siehe Anger [1960] S. 451-502.

1220 Anger [1960] S. 459.

1221 Dass sich auch Kommilitoninnen, die sich selbst für hübsch genug hielten, von ihnen abgrenzten, zeigt Rühle [2000] S. 94f.
} 
schrecklich! Aber die heiraten ja doch wieder weg. Sie sind nur eine unnütze Belastung der Universität." 1222

Dazu ein anderer Naturwissenschaftler: „In unserem Gebiet ist das in Ordnung. Sie studieren ein bis zwei Semester und verschwinden dann meist sehr bald."1223 In Göttingen war es ähnlich. Wenn man nicht nur das Verschwinden von der Universität, sondern auch den Wechsel in ein anderes Fach mit einrechnet, verweilten drei Viertel der Physikstudentinnen, die erst ab 1945 bis zum Ende des numerus clausus hier studierten, nicht länger als drei Semester in der Physik.

Die folgende Antwort könnte von einem Physiker stammen, da er nur eine Frau unter hundert Studenten seines Faches wusste. Er meinte auf die Frage nach zu vielen oder zu wenigen Studentinnen schlicht: „Bei uns ist es gut so.“1224 Auch die schlechten Berufsaussichten der Studentinnen kamen zur Sprache. Ein Chemiker gab an, dass die Industrie keine Chemikerinnen mehr anstelle, wofür zwei Gründe verantwortlich seien: „Nun, sie sind dafür einfach weniger geeignet, und später heiraten sie ja doch, und man muß einen Neuen anstellen“.1225 Wie oben gezeigt, führte eine ähnliche Einstellung unter den Göttinger Naturwissenschaftlern dazu, Frauen einem strengeren Maßstab bei der Prüfung zu unterwerfen. Die Frauen waren sich ihrer Außenseiterrolle und den damit verbundenen Schwierigkeiten bewusst. In diesem Zusammenhang bezeichneten es die Professoren in Angers Interviews mit positiver Färbung als „Idealismus“, wenn die Frauen trotzdem studieren wollten.

Bei der Frage nach den Leistungen der Studentinnen äußerte sich fast die Hälfte der Professoren über allgemeine Eigenschaften, Fähigkeiten und Interessen der Frauen, statt über die konkreten Prüfungserfahrungen zu berichten. Besonders die Naturwissenschaftler beriefen sich seltener auf praktische Erfahrungen. Diejenigen, die doch über eigene Erlebnisse berichteten, führten oft keine oder nur geringe Differenzen in den Leistungen von Studenten und Studentinnen an, behauptete aber Unterschiede in den Fähigkeiten. In den meisten Köpfen der Prüfer herrschte das Vorurteil, Frauen könnten keine geistigen Spitzenleistungen erbringen - Frauen würden diesen 'Mangel' durch größeren Fleiß ersetzen. Rein intellektuelle Fähigkeiten seien bei Frauen geringer und seltener, ihnen liege weniger das abstrakte Denken

\footnotetext{
1222 Anger [1960] S. 465.

1223 Anger [1960] S. 465.

${ }^{1224}$ Anger [1960] S. 465.

1225 Anger [1960] S. 460. 
und jedes Denken überhaupt, es mangle ihnen an Kritikfähigkeit, sie besäßen weniger Erfindungsgabe, eine dürftigere wissenschaftliche Phantasie.

Auf der positiven Seite sprachen sie den Frauen ein besseres Gedächtnis und eine größere Lernfähigkeit zu. Frauen seien fleißiger, eifriger, sorgfältiger, zuverlässiger und gewissenhafter als Männer. Zwei Drittel der Professoren behaupteten solche 'typischen“ Unterschiede zwischen Männern und Frauen. Bessere Leistungen der Frauen wurden außerdem mit dem geringen Frauenanteil an den Universitäten erklärt. Es sei eben nur eine Elite zugelassen worden.

Mit diesem Wissen über die allgemeine Einstellung der Professoren zu den Leistungen und Fähigkeiten der Studentinnen entdeckt man in folgender Begründung des Göttinger Dekans Harder gegen die Bindung der Vergabe der Doktorarbeit an die Absolvierung des Doktorandums mit der Note „gut“ eine verborgene Inschutznahme der männlichen Studenten gegen typisch 'weibliches' Auswendiglernen:

„Da die Ausführung einer Doktorarbeit aber weniger sehr umfangreiches Wissen als vielmehr ausgesprochenes wissenschaftliches Können zur Voraussetzung hat, so konnte es vorkommen, daß Leute mit gutem Gedächtnis die Note "gut« spielend erreichten, während zu wissenschaftlichem Denken durchaus begabte Kandidaten es $\mathrm{u}$. U. nur $\mathrm{zu}$ »befriedigend « brachten und damit von der Ausführung einer Doktorarbeit ausgeschlossen waren. Es gingen der Wissenschaft daher ausgesprochen fähige Kräfte verloren." 1226

Deshalb wurde die Notenbeschränkung fallen gelassen und nur das Bestehen des Doktorandums gefordert.

Die in Angers Studie zitierten Antworten offenbaren eine Voreingenommenheit eines großen Teils der Professorenschaft zu Hochschullehrerinnen. Warum es davon so wenige gebe, lautet eine Frage an die Professoren. Die Mehrzahl der Antworten erklärten nicht die Seltenheit, sondern behaupteten die Unmöglichkeit von Hochschullehrerinnen, und diese Unmöglichkeit wurde aus der 'Natur des weiblichen Geschlechts' abgeleitet. Ein Naturwissenschaftler meinte: „Die Frau basiert zu sehr auf dem Gefühlsleben. Dies ist auf der Universität aber völlig ausgemerzt. Deshalb gibt es dort auch keinen Platz für Frauen.“1227 Zugespitzter formulierte es ein anderer Professor: „Weil zu einem Hochschullehrer die ganze Fülle einer männlichen Begabung gehört.“1228 Die negative Einstellung der Professoren zu weiblichen

\footnotetext{
${ }^{1226}$ Bericht des Dekans Harder an den Niedersächsischen Kultusminister, 22. Juli 1947. UAG, Kur. XXX. A. a. Studierende. Allgemeine Vorschriften. VIII.

1227 Anger [1960] S. 481.

1228 Anger [1960] S. 481.
} 
Lehrkräften war noch ausgeprägter als jene zu Studentinnen. Die Frauen an den Universitäten gerieten so in ein Dilemma unterschiedlicher Verhaltenserwartungen: Sie sollten gleichzeitig 'weiblich' und wissenschaftlich leistungsfähig sein, wobei dies von den Professoren als prinzipiell unvereinbar hingestellt wurde. ${ }^{1229}$

Anger stellte einen Zusammenhang zwischen der politischen Einstellung der Dozenten und deren Ansichten zum Frauenstudium fest. Die ,antipolitischen“ Professoren betrachteten als stärkstes Studienmotiv der Frauen den sogenannten „Heiratsmarkt“. Außerdem hielten sie in der Regel Studentinnen im eigenen Fach für ungeeignet. Demgegenüber hebt sich die Haltung der politisch „engagierten“ Professoren der Tendenz nach positiv ab, wenn sie auch nicht sonderlich profiliert ist. Eine weitere Korrelation findet sich zum Thema „Korporationen“. Die extremen Gegner des Frauenstudiums zeigten eine besonders korporationsfreundliche Haltung. Auch wer die Frage, warum es so wenig Hochschullehrerinnen gebe, mit Lachen quittierte, gehörte meist zu den Befürwortern der traditionellen Verbindungen.

Was bedeuten Angers Ergebnisse für die Göttinger Physik? Die oben dargestellte Mentalität und besonders die aufgezeigten Verbindungen mit anderen politischen Ansichten lassen sich auf Göttinger Professoren übertragen. Dabei ist nicht nur statistisch davon auszugehen, dass zwei Drittel des Lehrkörpers eine negative Einstellung zum Frauenstudium besaßen, sondern es lassen sich auch individuelle Zuordnungen treffen. Zum Beispiel war Arnold Eucken ein Professor, der dem Frauenstudium strikt ablehnend gegenüber stand. Eucken zeigt darüber hinaus eine Reihe anderer Eigenschaften, die Anger für diesen Typus von Professoren herausfand. Er war politisch nationalkonservativ eingestellt (vor 1933 Mitglied der DNVP) ${ }^{1230}$ und bis 1933 aktives Mitglied der schlagenden Verbindung Saxonia. ${ }^{1231}$ Er war der Ansicht, dass eine „Frau das schwere Studium der Physik [nicht] durchhalten könne.“ Deshalb versagte er auch der eigenen Tochter das von ihr gewünschte Physikstudium, erklärte sich aber mit einem Chemiestudium einverstanden. ${ }^{1232}$ Trotz seiner Vorurteile gegen das Frauenstudium führte Eucken in den fünf Nachkriegsjahren bis zu seinem Tod mindestens drei Frauen zur Promotionen. ${ }^{1233}$ Eucken ähnelt sehr dem von Anger beschriebenen Typus des extremen Gegners des Frauenstudiums. Dass Eucken 1945 und 1946 zum Dekan gewählt

\footnotetext{
1229 Siehe dazu auch Rühle [2000] S. 109-111.

1230 Laut eigenen Angaben im Fragebogen der Militärregierung. HStAH, Nds. 171 Hildesheim 7932.

1231 Eucken trat 1902 in das Corps Saxonia ein. „Arnold ist dann auch im Corps recht aktiv, schlägt vier Mensuren, nimmt an Commers und Stiftungsfest teil und übernimmt sogar eine Charge. [...] Im Wintersemester 1903 ficht Eucken dann nochmals zwei Mensuren." Becke-Goehring \& Eucken [1995] S. 11.

1232 Becke-Goehring \& Eucken [1995] S. 56.

1233 Laut den leider unvollständigen Karteikarten Math.-Nat. Promotionen im UAG waren dies: Ingrid Delitsch 1946, Ursula Jakobshagen 1946, Gertraud Quirin 1949.
} 
wurde, lässt auf eine gewisse Akzeptanz dieser Einstellung unter seinen Kollegen schließen. Euckens Überzeugungen bezüglich Fähigkeiten und gesellschaftlicher Rolle der Frauen können in abgeschwächter Form als typisch für die Göttinger Physikerschaft der 40er Jahre angesehen werden. Man kann das Argument auch umkehren. Wenn man die geringe Zulassung von Physikstudentinnen währen Euckens Dekanszeit auf seine Vorurteile zurückführt, dann sind die genauso geringen Zulassungsquoten von 1949 bis 1953 ein Anzeichen für ähnliche Ansichten unter Euckens Kollegen. Die Förderung von Frauen im Einzelfall bedeutet nicht, dass Professoren ihre Vorurteile abgelegt hätten. Ein Beispiel hierfür ist Eucken als Betreuer von Doktorandinnen. Auch wenn Diagramm 12 detaillierte Daten zur Studentinnenfrequenz bietet, so bleibt es unmöglich festzustellen, welchen quantitativen Anteil die Vorurteile gegenüber Frauen in der geringen Zulassung von Studentinnen hatten. Es erscheint letztendlich nur plausibel, dass es einen Einfluss gab. Aber nicht einmal dafür lässt sich ein exakter Nachweis führen.

Mit Wegfall des numerus clausus stiegen die absoluten Zahlen der Physikstudentinnen stark an. Der numerus clausus ermöglichte das Fernhalten von Frauen; er selbst war aber nicht das Instrument der Verdrängung. Durchgesetzt wurde sie in Göttingen nicht administrativ, sondern im Zuge der Aufnahme- und Studienfortsetzungsprüfungen. Dass ein numerus clausus in der Nachkriegszeit nicht zwangsläufig zur radikalen Verdrängung der Frauen aus der Physik führen musste, zeigt das Beispiel der TU Berlin-Charlottenburg. Dort waren im WS 1948/49 230 Studenten in Physik eingeschrieben, darunter 19 Frauen (8,3 \%). Der Frauenanteil an der gesamten TU betrug damals 8,9\%. Auch die TU Berlin hatte wegen Raummangels und Rücksichtnahme auf die berufliche Zukunft der Absolventen einen strengen numerus clausus eingeführt. ${ }^{1234}$

Auch ohne ihn numerus clausus konnte der Frauenanteil rückläufig sein. Die TH's in Österreich zeigen eine zu Göttingen ähnliche Entwicklung der Gesamtstudentenzahlen; besonders die unterschiedlichen Verläufe von Männern und Frauen decken sich erstaunlich gut. Mikoletzkys erklärt den Rückgang bis Mitte der 50er Jahre mit demografischen und ökonomischen Gründen. Ihren Ausführungen zufolge gab es anscheinend keinen numerus clausus. ${ }^{1235}$ Ein Blick auf die USA zeigt auch dort einen Rückgang der Physikstudentinnen bis in die 50er Jahre. ${ }^{1236}$ Diese Daten legen eine größeren allgemein-gesellschaftlichen

\footnotetext{
1234 Becker [1949] S. 40.

1235 Mikoletzky [1997]b S. 262f., Grafik 6.1.

1236 Kistiakowsky [1980].
} 
Einfluss nahe, als hätte das Frauenstudium gerade in der Mitte des 20. Jahrhunderts an Attraktivität eingebüßt.

Konservative männliche Studenten unterstützten die Zurückdrängung von Frauen in den Universitäten. Im September 1946 beantragte der Vorsitzende des Göttinger AStA die „Bevorzugung älterer Kriegsversehrter bei der Immatrikulation vor jungen Bewerbern, insbesondere jungen Mädchen“..1237 In der Studentenschaft war auch die Ansicht einer 'vorsichtigen Gleichberechtigung' vorhanden. Zum Thema Frauenstudium erklärte der erste Studententag folgendes:

„Die deutschen Universitäten und Hochschulen dienen dem deutschen Volk. Der Staat fordert die Mitarbeit der Frau im öffentlichen und kulturellen Leben. Darum ist ihr die Hochschule genauso zugänglich wie allen, die dem öffentlichen Leben dienen wollen. Gleichberechtigt stehen Studenten und Studentinnen neben- und miteinander in der Hochschule, um sich das Rüstzeug für die später zu erfüllenden Aufgaben zu erwerben. Der numerus clausus bedingt eine scharfe Auslese nach Befähigung und menschlicher und fachlicher Eignung, der alle Studierenden gleichermaßen unterworfen sind. Wir sind überzeugt, daß sich auf diesem Wege ein gesundes Zahlenverhältnis organisch ergibt." 1238

Es bleibt offen, was die Studenten unter einem 'organischen' Ergebnis verstanden haben. Die Vorstellung, dass Frauen und Männer der Auslese „gleichermaßen“ unterworfen waren, klingt etwas gutgläubig.

Fast unabhängig vom Standpunkt des Betrachters wurde das Frauenstudium in der Nachkriegszeit meist als Problem aufgefasst. Die Gegner des Frauenstudiums führten Schlagworte wie Überfüllung der Hochschule, Nachteile der männlichen Kriegsteilnehmer, Frauenüberschuss und geringe Aufnahmefähigkeit der akademischen Berufe an. Ein Plädoyer des nordrhein-westfälischen Kultusministers Teusch im „Deutschen Hochschulführer 1950“ für mehr Frauen an den Hochschulen trug den Titel „Probleme des Frauenstudiums“. Teusch hielt die Frauen für das Studium und die akademische Lehre für unbedingt geeignet und unentbehrlich. Er begründete dies mit dem „Wesen der Frau“, das angeblich nach Synthese verlange und daher gegen eine intellektualistische Spezialisierung der Hochschule helfe. ${ }^{1239}$ Durch diese auch unter Befürwortern des Frauenstudiums verbreiteten Denkschemata war es für Frauen praktisch unmöglich, unter gleichen Voraussetzungen wie ihre männlichen Studienkollegen zu studieren. Die damaligen Studentinnen mögen aber diese Unterschiede

\footnotetext{
1237 Protokoll der Senatssitzung vom 26. September 1946. UAG, Senatsprotokolle 1945-1949.

1238 Beschluss des ersten Studententags in der britischen Zone, Göttingen 3.-5. Juli 1946. Neuhaus [1961]

S. $115 \mathrm{f}$.

1239 Teusch [1950] S. 8.
} 
nicht unbedingt wahrgenommen haben. ${ }^{1240}$ Viele teilten die Vorurteile vom 'Wesen der Frau'. 1241

Ein Indiz dafür, dass nicht nur in Göttingen in der Nachkriegszeit die Frauen speziell aus der Physik verdrängt wurden liefert Hinterberger mit ihrer Studie über Physikerinnen an der Universität Bonn. Dort war der gesamte Frauenanteil im ersten Nachkriegssemester mit 22 \% ähnlich hoch wie in Göttingen (25\%). ${ }^{1242}$ Hinterberger gibt zwar keine Angaben über die Zahlen der Physikstudentinnen, dafür lässt sich aus ihrer Studie die Verdrängung der Frauen an den Zahlen der Promotionen ablesen. Es gab zwischen 1939 und 1946 fünf Promotionen von Frauen in der Physik; die nächste Promotion folgte erst im Jahr 1959 und dann wieder 1968. ${ }^{1243}$ Während der weibliche Anteil an Physikpromotionen in Bonn in der NS-Zeit 10 \% betrug, stagnierte er in der BRD-Zeit bis 1980 bei $1 \%$. ${ }^{1244}$ Hinterberger kommt zu dem resignierenden Schluss: „In den ersten Jahrzehnten nach dem Zweiten Weltkrieg waren Frauen im Fach Physik an der Bonner Universität so gut wie nicht vertreten, obwohl die Voraussetzungen für ein gleichberechtigtes Studium gegeben und auch ausreichend Kapazitäten vorhanden waren."1245 In Bonn, und vermutlich nicht nur dort, scheint es eine doppelte Verdrängung der Frauen aus der Physik gegeben zu haben. Erstens wurden sie aus den Naturwissenschaften verdrängt und in den Naturwissenschaften vor allem aus der Physik. Während in den 30er Jahren ein Viertel der naturwissenschaftlichen Promotionen von Frauen in der Physik stattfanden, waren es in den 50er Jahren nur $1 \%{ }^{1246}$

Die Vorbehalte gegenüber Frauen in der Physik beeinflussten nicht nur die Zulassung von Studentinnen negativ. Sie erzeugten in den 40er und 50er Jahren auch ein Klima in den Physikinstituten, das keine günstigen Bedingungen für wissenschaftliche Karrieren von Frauen darstellte. Die Zahlen der Habilitationen von Frauen in der Physik deuten dies an. In der Weimarer Republik wurden drei Frauen in Physik habilitiert: Lise Meitner 1922 in Berlin, Hertha Sponer 1925 in Göttingen und Hedwig Kohn 1930 in Breslau. Die nächsten Habilitationen folgten erst in der Nachkriegszeit: in der BRD 1959 Erika Böhm-Vitense, in

\footnotetext{
1240 Siehe zum Beispiel Interviews mit Nachkriegsstudentinnen der Universität Jena in Bürgel [1999] S. 220f.

1241 Siehe Maaß [1998] Kap. 4.2, besonders S. 103. Mitte der 60er Jahre scheint sich das (Selbst-)Bewusstsein und die Wahrnehmungsfähigkeiten der Frauen gewandelt zu haben. Siehe dazu die Abschnitte „Die

Diskriminierung der Studentin im Bereich der Universität“ und „Die Vorurteile gegenüber der Leistungsfähigkeit der Frau“" in Gerstein [1965].

1242 Hinterberger [1996] S. 46; [Studentenzahlen] [1987] S. 10.

1243 Hinterberger [1996] S. 45.

1244 Hinterberger [1996] S. 56, Tab. 9.

1245 Hinterberger [1996] S. 57.

1246 Hinterberger [1996] S. 56, Tab. 10.
} 
der DDR (bzw. SBZ) 1947 Iris Runge ${ }^{1247}$ und 1954 Katharina Dornberger-Schiff und Liselott Herforth. 1248

Trotz aller Vorbehalte gegen Frauen an der Universität im allgemeinen und als Physikstudentinnen im besonderen wurden die anwesenden Physikstudentinnen ernst genommen und in ihrer wissenschaftlichen Ausbildung gefördert. Auch die Qualität ihrer Arbeit scheint die Professoren zufriedengestellt $\mathrm{zu}$ haben. Ein Hinweis dafür gibt der überproportionale Anteil der Frauen als Hilfskräfte in der Praktikumsbetreuung. ${ }^{1249}$ Die Betreuung der Praktika brachte nicht nur den Vorteil, mit den Dozenten in näheren Kontakt zu kommen und Erfahrung im Unterrichten zu sammeln, sondern auch eine geldliche Vergütung. Untersucht habe ich die geschlechtliche Zusammensetzung der Hilfskräfte der Praktik für Mediziner und für Naturwissenschaftler (Anfänger- und Fortgeschrittenenpraktikum) in den Jahren 1943 bis 1958. ${ }^{1250}$ Bis Kriegsende waren etwa gleich viele Frauen wie Männer als Hilfskräfte eingesetzt, insgesamt zwischen 8 und 13 pro Semester. Der Anteil der Physikstudentinnen betrug in dieser Zeit etwa $40 \%$. Allerdings wurden nicht alle gleich hoch bezahlt. Jene, die nur das Medizinerpraktikum betreuten, bekamen nur einen halb so hohen Lohn. Dies betraf aber ausschließlich Männer, sodass die Frauen gesamt gesehen besser bezahlt wurden.

Im ersten Nachkriegsjahrzehnt waren insgesamt etwa $5 \%$ der Physikstudenten als Hilfskräfte in der Praktikumsbetreuung eingesetzt. Im WS 1945/46 waren es vier Frauen und sieben Männer. Dieses Verhältnis nahm bis zum SS 1950 ständig ab, wo es null zu neun betrug. Von da an fehlten die Frauen in der Praktikumsbetreuung mit nur zwei Ausnahmen: Im SS 1953 und im WS 1956/57 gab es jeweils eine Frau. Die bis 1950 eingesetzten Frauen waren aber nicht die regulären Studentinnen, die in Diagramm 12 aufgeführt sind, sondern oft exmatrikulierte Studentinnen, die im Abschluss standen oder auch schon ihren Doktortitel hatten. Es waren Frauen, die sieben bis acht Jahre vorher ihr Studium begonnen hatten. Mit diesem Wissen wird es verständlich, warum in den 50er Jahren keine Frauen in der Praktikumsbetreuung zu finden sind: Es gab keine Studentinnen, die in den späten 40er Jahren ihr Studium begonnen und es in Göttingen zu Ende gebracht hatten.

\footnotetext{
1247 Promotion im Jahr 1922.

1248 Boedeker \& Meyer-Plath [1974]. Kohns Jahr der Habilitation nach Vogt [2000] S. 199.

1249 Im Fach Jura scheint es ähnlich gewesen zu sein. Dort gab es mehr Mitarbeiterinnen der Professoren in den Seminaren als es ihrem Anteil unter den Studenten entsprach. Rühle [2000] S. 94.

1250 Die Daten sind entnommen aus UAG, Kur. XVI. V. C. h. 2. II-IV.
} 


\begin{tabular}{|l|l|l|l||l|l|l|l|}
\hline & $\begin{array}{l}\text { Physik } \\
\text { gesamt }\end{array}$ & $\begin{array}{l}\text { Physik } \\
\text { männlich }\end{array}$ & $\begin{array}{l}\text { Physik } \\
\text { weiblich }\end{array}$ & & $\begin{array}{l}\text { Physik } \\
\text { gesamt }\end{array}$ & $\begin{array}{l}\text { Physik } \\
\text { männlich }\end{array}$ & $\begin{array}{l}\text { Physik } \\
\text { weiblich }\end{array}$ \\
\hline SS 30 & 216 & 200 & 16 & WS 45/46 & 153 & 138 & 15 \\
\hline WS 30/31 & 176 & 162 & 14 & SS 46 & 119 & 111 & 8 \\
\hline SS 31 & 198 & 183 & 15 & WS 46/47 & & & 7 \\
\hline WS 31/32 & 187 & 169 & 18 & SS 47 & & & 9 \\
\hline SS 32 & 206 & 190 & 16 & WS 47/48 & 208 & 199 & 9 \\
\hline WS 32/33 & 184 & 167 & 17 & SS 48 & 201 & 192 & 9 \\
\hline SS 33 & 157 & 144 & 13 & WS 48/49 & 210 & 205 & 5 \\
\hline WS 33/34 & 141 & 131 & 10 & SS 49 & 122 & 121 & 1 \\
\hline SS 34 & 115 & 108 & 7 & WS 49/50 & & & 2 \\
\hline WS 34/35 & 108 & 102 & 6 & SS 50 & 210 & 209 & 1 \\
\hline SS 35 & 74 & 73 & 1 & WS 50/51 & 171 & 170 & 1 \\
\hline WS 35/36 & & & & SS 51 & 185 & 183 & 2 \\
\hline SS 36 & & & & WS 51/52 & 195 & 191 & 4 \\
\hline WS 36/37 & 56 & 53 & 3 & SS 52 & 201 & 198 & 3 \\
\hline SS 37 & & & & WS 52/53 & 210 & 207 & 3 \\
\hline WS 37/38 & 74 & 69 & 5 & SS 53 & & & 4 \\
\hline SS 38 & 48 & 46 & 2 & WS 53/54 & & & 2 \\
\hline WS 38/39 & 68 & 64 & 4 & SS 54 & & & 2 \\
\hline SS 39 & 78 & 72 & 6 & WS 54/55 & 252 & 247 & 5 \\
\hline Herbst TM 39 & 38 & 34 & 4 & SS 55 & 333 & 321 & 12 \\
\hline 1. TM 40 & 38 & 33 & 5 & WS 55/56 & 347 & 337 & 10 \\
\hline 2. TM 40 & 38 & 29 & 9 & SS 56 & 397 & 383 & 14 \\
\hline 3. TM 40 & 41 & 36 & 5 & WS 56/57 & 395 & 384 & 11 \\
\hline 1. TM 41 & 26 & 19 & 7 & SS 57 & 469 & 451 & 18 \\
\hline SS 41 & 19 & 11 & 8 & WS 57/58 & 393 & 375 & 18 \\
\hline WS 41/42 & 47 & 32 & 15 & SS 58 & & & \\
\hline SS 42 & 29 & 11 & 18 & WS 58/59 & & & \\
\hline WS 42/43 & 60 & 39 & 21 & SS 59 & 598 & 569 & 29 \\
\hline SS 43 & 49 & 27 & 22 & SS 60 & 531 & 512 & 19 \\
\hline WS 43/44 & 77 & 49 & 28 & WS 60/61 & & & \\
\hline SS 44 & 107 & 62 & 45 & & & & \\
\hline WS 44/45 & & & & & & \\
\hline
\end{tabular}

Tabelle 16 Zahl der Physikstudenten in Göttingen, 1930-1960. 


\section{Physik für Krieg und Frieden - Forschungsthemen im Wandel der Zeit}

Die Rahmenbedingungen für die Forschung haben sich zwischen 1940 und 1950 radikal gewandelt. Im Krieg flossen Forschungsgelder für militärische Projekte in die Physikinstitute. Auf diese Weise kamen neue Forschungsthemen nach Göttingen; auch die personellen Ressourcen wurden in manchen Instituten fast ausschließlich für Rüstungsforschung ${ }^{1251}$ eingesetzt. Die Göttinger Physik wies trotz des Eingespanntseins für Kriegszwecke auch Eigenschaften eines normalen Universitätsbetriebs auf. So wie in der Lehre die physikalischen Grundlagen weiterhin in fast unveränderter Art behandelt wurden, gab es auch in der Forschung eine weiterlaufende Grundlagenforschung. Auf diese Tatsache wurde vor allem nach Kriegsende hingewiesen, als die Alliierten über den Fortbestand der Forschungen $\mathrm{zu}$ entscheiden hatten. Die durch die alliierte Forschungskontrolle untersagten militärisch relevanten Forschungen verschwanden nun aus der Göttinger Forschungslandschaft oder wurden mittels geschickter Argumentation in einen neuen, friedlichen Kontext gestellt. Diese drei Muster von Verlaufsformen werden im Folgenden an einzelnen Beispielen dargestellt. Zuerst wird gezeigt, in welchen Bereichen in Göttingen Rüstungsforschung betrieben wurde. Dann wird die Kontinuität bestimmter Forschungen besprochen und mit der Pohl-Schule ein Bespiel für ein von den sich wandelnden Rahmenbedingungen wenig beeinflusstes Programm der Grundlagenforschungen gegeben. In diesem Beispiel ist weder eine Nazifizierung noch eine Entnazifizierung zu erkennen. Dieses Forschungsprogramm besaß eine Dynamik, die scheinbar von der äußeren politischen Entwicklung abgekoppelt war. Zuletzt wird gezeigt, wie die Forschungskontrolle mit Hilfe der Mediziner umgangen werden konnte.

\subsection{Die NS-Zeit - Rüstungsforschung}

Die Verquickung von wissenschaftlicher Forschung und militärischen Zielen ist an vielen Beispielen untersucht worden. Detaillierte Studien liegen $\mathrm{zu}$ außeruniversitären Forschungseinrichtungen vor, doch zeigen diese, dass „,nach wie vor kaum generalisierende Aussagen über die Geschichte der Rüstungsforschung möglich sind. Vielmehr wird deutlich, dass je nach sektoraler Verortung und je nach zeitlichem Bezug ganz unterschiedliche 
Entwicklungen sichtbar werden." 1252 Von den physiknahen Forschungsrichtungen fanden das Uranprojekt, ${ }^{1253}$ die Raketenentwicklung ${ }^{1254}$ und die Luftfahrtforschung ${ }^{1255}$ besondere Aufmerksamkeit. Die universitäre physikalische Forschung ist auf ihre militärische Relevanz hin noch wenig untersucht. ${ }^{1256}$ Bei der Behandlung der Physik im Nationalsozialismus stehen meist neben den personellen Eingriffen ideologische Auseinandersetzungen innerhalb der Physikerschaft, der Streit um die „Deutsche Physik“, im Vordergrund. Im Krieg, als die praktische Nützlichkeit der Physik für die Rüstung zum staatlichen Maßstab wurde, verlor die „Deutsche Physik“ an Bedeutung. Die meisten Physiker gehörten zu den Kritikern der „Deutschen Physik“, vor allem auch jene, die ernsthaft einen effizienten Einsatz der Physik für die deutschen Kriegsziele anstrebten. ${ }^{1257}$ Eine generelle ideologische Beeinflussung der Wissenschaft durch den Nationalsozialismus wurde in neueren wissenschaftshistorischen Arbeiten speziell in der Rüstungsforschung nachgewiesen. ${ }^{1258}$ Demgegenüber betonten die Forscher kurz nach 1945, sie hätten großenteils normale Wissenschaft betrieben. In dieser Hinsicht äußerte sich zum Beispiel der Göttinger Rektor Hermann Rein: „Die meisten Laboratorien widmeten sich hartnäckig bis zuletzt Problemen, die keinen Zusammenhang mit Krieg und Politik erkennen ließen.“"1259 Gegen den verständlichen Versuch der beteiligten Wissenschaftler, sich von Verantwortung frei zu sprechen, indem sie auf die gleichsam 'neutrale' Grundlagenforschung hinwiesen, die sie angeblich 'nur' betrieben hätten, setzen neuere Untersuchungen an einem grundsätzlicheren Punkt ein. Die Trennung zwischen

1251 Der Begriff Rüstungsforschung wird hier in einem weiten Sinn verstanden in Anlehnung an Helmuth Maier (Hrsg.) [2002] S. 8f. So ist darunter die gesamte naturwissenschaftlich-technische Forschung und Entwicklung zu verstehen, die zur Errichtung eines autarken Wehrstaates diente.

1252 Siehe die Beiträge in Kaufmann (Hrsg.) [2000]; Maier (Hrsg.) [2002]. Zitat aus Maier (Hrsg.) [2002] S. 25. 1253 Walker [1990/92], [1995], [2000]; in biografischer Fokussierung auf Heisenberg: Powers [1993]; Rose [1998].

1254 Neufeld [1994], [1997]; auf die Bedeutung der Hochschulen in der Raketenentwicklung nimmt Bezug Pula [1998].

1255 Siehe Trischler [1992], [1994], [2000]; Budrass [1998], [2002]. Wenig kritisch: Benecke \& Quick (Hrsg.)

[1957]. Zu luftfahrtmedizinischer Forschung siehe Roth [2000].

1256 Nur ansatzweise auch auf militärische Relevanz eingehend: Breger [1985/86]; Lemmerich [1987]a;

Renneberg [1991]b; Rosenow [1987/98]; Cassidy [1979].

1257 Zur „Deutschen Physik“ siehe die mittlerweile klassischen Darstellungen Beyerchen [1980/82]; Richter [1980]; und die neueren Interpretationen von Simonsohn [1992]; Hentschel \& Hentschel (Hrsg.) [1996] S. lxxv; Eckart [1993] S. 198-206, und seine noch unpublizierte Studie über die Wirkung der „Deutschen Physik“ in München; Litten [2000] S. 377-384. Eine frühe Behandlung der „Deutschen Physik“ aus der Sicht eines Physikers, die jedoch von der problematischen Annahme einer prinzipiellen Reibung zwischen (richtiger) Physik und nationalsozialistischer Ideologie ausgeht, ist Scherzer [1965]. Die ideologische und militärische Beeinflussung der Physik durch den NS in faschismuskritischer Sicht untersucht Schlicker [1983]. Eine überzeugende Darstellung von Georg Joos, eines Gegners der „Deutschen Physik“, der sich besonders für den Kriegseinsatz seiner Wissenschaft eingesetzt hat, geben Lemuth \& Stutz [2003]. Ein weiteres Beispiel hierfür ist Pascual Jordan; siehe Hoffmann [2003].

1258 Diese Beeinflussung wurde an überzeugenden Beispielen dargelegt von Albrecht [1994]. Siehe auch Maier [2002]; Ciesla [2000]. 
Grundlagenforschung und militärischer Forschung, oder jene zwischen angewandter und 'reiner' Forschung ist ein historisches Konstrukt, das bestimmten Legitimationszwecken diente. Einen gelungener Nachweis, wie sehr die sogenannte Grundlagenforschung mit kriegsrelevanter Forschung zusammenhing, diese „weitgehende Homogenität von »Grundlagen-« und Kriegsforschung“, lieferte Moritz Epple am Beispiel Ludwig Prandtls und des KWI für Strömungsforschung. 1260

Es stellt auch eine vor allem politische Aussage dar, als Professor R. C. Evans 1947 in seinem Bericht über die Naturforschung in Deutschland mit speziellem Bezug auf die physikalische Forschung in Göttingen behauptete: „Auf dem Gebiet der Grundlagenforschung, auf jeden Fall auf meinem eigenen Spezialgebiet, sind diese Leistungen nicht eindrucksvoll."1261 Demgegenüber habe die angewandte Wissenschaft in Deutschland große Leistungen vollbracht. Hinter dieser Darstellung von Evans stand wohl das Bestreben, die Wissenschaftspolitik im Nationalsozialismus als eine die Grundlagenforschung vernachlässigende $\mathrm{zu}$ charakterisieren, die kurzsichtig auf militärische Anwendungen ausgerichtet gewesen sei. ${ }^{1262}$ Die deutschen Physiker selbst boten die gesamte Physik der Staatsführung als Instrument zur Erreichung militärischer Ziele an. Sie wiesen auf den engen Zusammenhang zwischen physikalischem Grundlagenwissen und der militärischen Anwendung während des Kriegs hin. ${ }^{1263}$ Zum Beispiel fand die Physik als Beitrag zur Wehrpflicht auch Anwendung in der Ausbildung junger Männer. 1944 erschien der zweite Band von Physik in der Kriegsmarine, ein Werk, das „ohne Vorbild ist“ und die physikalischen Grundlagen in einer einfach verständlichen Weise darbietet, um all jenen Deutschen, die dem „Seegeltungsgedanken“ anhingen, eine geeignete Einführung zu geben. ${ }^{1264}$ In den ersten Nachkriegsjahren war es nicht mehr angebracht, physikalisches Wissen mit deutschem Expansionsstreben in einen so engen Zusammenhang zu bringen; stattdessen bot es sich an, die Physik als 'ideologiefreie' Grundlagenwissenschaft darzustellen.

\footnotetext{
1259 Rein [1948] S. 229.

1260 Diese Verbindung zeigt Epple [2002] (Zitat S. 309) und am Beispiel der reinen und angewandten Mathematik Epple \& Remmert [2000].

1261 Evans [1947] S. 14.

1262 In die gleiche Richtung argumentierte auch Werner Heisenberg nach 1945, der sogar meinte, das „Dritte Reich“ habe die Grundlagenforschung ab 1933 im ganzen verkümmern lassen. „Man hat sich darauf beschränkt, die Ergebnisse der Wissenschaft bis 1933 auf die Rüstung anzuwenden“. Heisenberg [1949]b S. 1.

1263 Siehe dazu beispielsweise Pascual Jordans positive Bezugnahmen auf die Kriegsrelevanz der Physik einschließlich der reinen Forschung in seinen Aufsätzen, die in Hoffmann [2003] wiederabgedruckt sind. 1264 Kreutzer \& Müller [1944].
} 
Auch der erste Jahrgang der Physikalischen Blätter aus dem Jahr 1944 ist mit Blick auf die Verflechtung von allgemeiner Physik und Rüstungsforschung $\mathrm{zu}$ interpretieren. ${ }^{1265}$ Der Grundtenor der Physikalischen Blätter im Krieg war, die allgemeine Bedeutung der physikalischen Forschung und Ausbildung zu betonen. Diese allgemeine Bedeutung schloss 1944 die militärische Relevanz der Physik mit ein, wenngleich auch die Argumentation implizit teilweise auf eine Forschungspolitik in der Nachkriegszeit zugeschnitten war. Die lange Kriegsdauer wurde mit einer vernachlässigten Forschung in Zusammenhang gebracht. Das Augustheft stand unter dem Motto „Forschung auch im Krieg?“, und liefert Gründe für die forcierte Forschung selbst im „totalen Krieg““.1266 Zitiert wurden auch angelsächsische Berichte, wie beispielsweise folgender aus dem Jahr 1941: „Die wirkungsvollste Offensive der Vereinigten Staaten besteht darin, Grundlagenforschung $\mathrm{zu}$ betreiben und damit neue Möglichkeiten zu schaffen." 1267 Die Hochschulphysiker richteten sich in den Physikalischen Blättern an staatliche Stellen, um sich Mittel für ihre Institute zu sichern. Befürchtet wurde von ihnen, dass die Industrie durch die anwendungsorientierte Forschung im Krieg auf Kosten der Hochschulen mehr staatliche Unterstützung bekäme. Deshalb wurde die Trennung zwischen Grundlagenforschung und Zweckforschung als unzweckmäßig dargestellt und die enge Verbindung und Überlappung beider betont. ${ }^{1268}$ Die argumentative Kopplung von Kriegsrelevanz und Bedeutung für die Nachkriegszeit findet sich in dem Satz: „Forschung ist nicht nur kriegsentscheidend, sie ist wie der Nachwuchs lebensentscheidend für den Bestand der ganzen Nation." 1269 Auf Grund der militärischen Siege der Alliierten im Laufe des Jahres 1944 verbreitete sich in der Physikerschaft wie in der gesamten Bevölkerung die Meinung, dass der Krieg für Deutschland kaum noch zu gewinnen sei. Die 1944 publizierten Texte beabsichtigten wohl eine Stärkung der Forschung, um den Frieden statt des Krieges für Deutschland zu gewinnen. ${ }^{1270}$ Trotz dieses aktuellen Zwecks bestanden die ersten Hefte fast ausschließlich aus Wiederabdrucken alter Aufsätze und Reden aus den 30er und frühen 40er Jahren. Auch Nature Artikel von 1942 wurden übersetzt und gekürzt wiedergegeben. Die 1944 gedruckten Artikel lassen eine Rhetorik erkennen, die für die Nutzung der Physik in Friedenszeiten dienlich war. Es sollte wohl die Glaubwürdigkeit der Aufsätze erhöhen, dass

\footnotetext{
1265 Zur Interpretation des ersten Jahrgangs der Physikalischen Blätter als ,politische Gratwanderung“ siehe Dreisigacker \& Rechenberg [1995] S. F-139f.

1266 Siehe Heft 8 Physikalische Blätter 1 (1944).

${ }^{1267}$ Heft 8 Physikalische Blätter 1 (1944), S. 99. Zitat aus Journal for applied Physics 12 (1941), S. 439.

1268 Siehe zum Beispiel Zenneck [1944]. Den Zusammenhang zwischen Technik und Grundlagenforschung betonend Ramsauer [1938/44]; Niemeier [1944]; Brüche [1944].

1269 'Forschung tut Not', Physikalische Blätter 1 (1944), S. 5. Siehe auch Ernst Brüche: 'Zur Einführung', ebenda, S. 2-4.

1270 Dazu siehe Abschnitt 3.7.2.
} 
diese Rhetorik, die vielfach aus anderen Zeiten und Zusammenhängen stammte, gleichsam 'zufällig' für die damalige Situation geeignet erschien.

Die Argumentation galt der Stärkung des gesamten physikalischen Potentials Deutschlands. ${ }^{1271}$ Die deutschen Wissenschaftler zogen eine Parallele zwischen dem offiziell behaupteten Überlebenskampf des deutschen Volkes und dem Konkurrenzkampf der deutschen gegen ausländische Physik. ${ }^{1272}$ Die an die Wissenschaftspolitiker gerichteten Appelle sind im Inhalt und Ausdruck an die herrschende staatliche Doktrin angepasst: „Es ist eine Tatsache, daß neben der politischen und biologischen Kraft der Völker die Beherrschung und Weiterentwicklung der wissenschaftlich-technischen Mittel heute die unabdingbare Voraussetzung für die Selbstbehauptung eines großen Volkes wie des deutschen und mit ihm der europäischen Lebensraumgemeinschaft ist. Daraus ergeben sich für das neue Deutschland besonders große Verantwortungen und Aufgaben auch im Bereich der naturwissenschaftlichen Grundlagenforschung." 1273

Sowohl die zeitgenössische Einschätzung wie die neuere Forschung sieht also die Grundlagenforschung eng mit den deutschen Rüstungsanstrengungen verbunden. Zur Differenzierung soll hier aber nicht jede Forschung primär als den deutschen Kriegszielen dienend angesehen werden, sondern unterschieden werden zwischen spezieller Auftragsforschung für militärische Dienststellen und gewöhnlicher physikalischer Forschung, die vermutlich auch ohne Krieg betrieben worden wäre.

\subsubsection{Forschung im Auftrag des Militärs an den Göttinger Physikinstituten}

Ein Grund für die bisher geringe Beschäftigung mit kriegsrelevanter Forschung an Universitätsinstituten liegt vermutlich in der schlechten Quellenlage. Dies trifft zumindest für die Physikinstitute der Universität Göttingen zu. Die Akten des Universitätsarchivs geben leider keine genaue Auskunft über die von den Physikern im Auftrag des Militärs betriebenen Forschungen. ${ }^{1274}$ Durch mehr oder weniger zufällige Quellenfunde können hier zwar einzelne Hinweise angeführt werden, die aber zusammen nur ein unvollständiges Bild der Göttinger Rüstungsforschung geben.

\footnotetext{
1271 Siehe 'Der Ruf nach physikalischer Forschung', Physikalische Blätter 1 (1944), S. 36.

1272 Siehe zum Beispiel Niemeier [1944].

1273 Niemeier [1944] S. 109.

1274 Eine Auskunft über das für Rüstungsforschung eingesetzte Personal an der Universität Göttingen gibt die Kuratorialakte „Sicherstellung von Kräften an Universitätsinstituten für kriegswichtige Aufgaben“. Über die Inhalte der Forschung oder die Auftraggeber erfährt man aber hierin nichts. UAG, Kur. 2018.
} 
Einen ersten gedrängten aber doch guten Überblick liefert die von Prandtl gegebene Auflistung „Kriegsarbeit von Instituten der Mathematisch-Naturwissenschaftlichen Fakultät der Universität Göttingen“ vom Februar 1943. Das Erste Physikalische Institut führte einen Auftrag der Dringlichkeitsstufe SS und zwei Aufträge der Stufe S für die Luftwaffe aus, betreute daneben 10 auswärts ausgeführte SS-Aufträge, ebenfalls für die Luftwaffe. Die wissenschaftlichen Mitarbeiter waren Erich Mollwo (leitend) und Fritz Stöckmann. Außerdem arbeitete Hans König in Pohls Institut im Auftrag der LFM. Im zweiten Physikalischen Institut wurden in der Abteilung 1 (altes Göttinger Institut) ein SS-Auftrag der Kriegsmarine, ein SS-Auftrag der Luftwaffe und ein geheimes Preisausschreiben der Luftwaffe bearbeitet. Die wissenschaftlichen Mitarbeiter waren Karl-Heinz Hellwege (leitend) als Bearbeiter einer Arbeit „Schwarzes Flugzeug“ (Teilproblem der Arbeit von Hans König) und Dietrich Meyer. Für den Forschungsauftrag der Dringlichkeitsstufe SS der Forschungsführung des RLM wurde 1943 eine zusätzliche wissenschaftliche Assistentin angestellt, die Hellwege bei der Durchführung fotografisch-technischer Arbeiten unterstützte. ${ }^{1275}$ Die Abteilung 2 (altes Kieler Institut) bearbeitete einen SS-Auftrag des Heeres, einen SS-Teilauftrag der Kriegsmarine und einen SS-Teilauftrag der Luftwaffe. Die wissenschaftlichen Mitarbeiter waren Wilhelm Walcher (leitend), Wolfgang Paul (Assistent) und Schaefer (Mitarbeiter). Im Institut für angewandte Elektrizität wurde ein SS-Auftrag des Nachrichtenmittelversuchskommandos Kiel vom Bearbeiter Eickhoff ausgeführt, der vom Versuchskommando nach Göttingen abkommandiert worden war. ${ }^{1276}$ Das Institut für angewandte Mechanik führte zwei SS-Aufträge der Luftwaffe und einen SS-Auftrag des Heereswaffenamts aus. Die wissenschaftlichen Mitarbeiter waren Johann Hoch und Gerhard Lyra, dazu zwei Arbeitsurlauber. ${ }^{1277}$

Prandtls Bericht gibt den Stand von 1943 wieder. Das zweite Physikalische Institut war, schon bevor Kopfermann 1942 nach Göttingen kam, mit Militäraufträgen reichlich bestückt.

\footnotetext{
1275 Siehe Antrag Kopfermanns an Kurator, 3. Dezember 1942 und Hellwege an Oberpräsidenten in Hannover, 8. Januar 1943. UAG, Kur. XVI. V. C. h. 1. III.

1276 Siehe auch den Hinweis des damaligen Dekans Correns vom August 1941, dass das Institut für angewandte Elektrizität völlig in den Aufgaben der Landesverteidigung aufgehe, zitiert in Abschnitt 1.2.4.

1277 Prandtls Auflistung „Kriegsarbeit von Instituten der Mathematisch-Naturwissenschaftlichen Fakultät der Universität Göttingen“, 17. Februar 1943. Der Anlass dieser Auflistung war ein Gespräch mit dem Oberpräsidenten in Hannover, bei dem Prandtl die naturwissenschaftliche Fakultät vertrat. Die uk-Stellung einiger Mitarbeiter war durch eine sogenannte $30 \%$-Aktion gefährdet, die wehrpflichtige Forscher zum Kriegsdienst abziehen sollte. Prandtl wandte sich deshalb im Januar 1943 an die Forschungsführung der Luftwaffe, um auf jene Institute hinzuweisen, an denen Arbeiten im Auftrag der Luftwaffe durchgeführt wurden. In dem Gespräch mit dem Oberpräsidenten im Februar 1943 setzte sich Prandtl für die Anerkennung der uk-Stellungen in den Instituten ein. Prandtl an Flieger-Oberstabsing. Wolff in der Forschungsführung des R.d.L. und Ob.d.L., 20. Januar 1943. MPG-A, Nachlass Prandtl, III, 61, 2160. Zu den Forschungen im Institut für angewandte Mechanik siehe Abschnitt 5.3.2.4.
} 
Der damalige Institutsdirektor Georg Joos wies darauf im Frühjahr 1941 besonders hin, als er in eine physikalische Streitfrage mit einem Kollegen verwickelt war. Joos beklagte, dass sein Kontrahent Fredenhagen keinerlei Kriegsaufträge zu bearbeiten hätte, „während ich durch Arbeiten für Heereswaffenamt, Kriegsmarine und Reichsluftfahrtministerium bis an die Grenze der Leistungsfähigkeit belastet bin."1278 Gerichtliche Schritte gegen Fredenhagen könne Joos nicht unternehmen, da er seine Zeit „restlos für wehrtechnische Aufgaben widmen muss [...]. Denn ich hielte es für Landesverrat, wenn wegen derartiger Streitereien die deutsche Rüstung auch nur um ein millionstel [sic] geschädigt würde." 1279 Schon im Frühjahr 1939 setzte sich Joos zusammen mit seinem Schüler Hanle in einem Akt der Selbstmobilisierung mit dem Kultusministerium in Verbindung, um auf die wirtschaftlichen und militärischen Anwendungsmöglichkeiten der Kernspaltung aufmerksam zu machen. ${ }^{1280}$ Gleich zu Kriegsbeginn, im September 1939, wurde Joos mit kriegsrelevanten Forschungen beauftragt. Gegenüber dem Kurator gab er an, dass er „für die Marine Fragen des Empfangs elektrischer Wellen unter Wasser bearbeitet.“ Zu diesem Zweck reiste er zur ArtillerieBeobachtungsschule in Jüterbog. ${ }^{1281}$

Die Geheimhaltung der Forschungen führte dazu, dass sogar die engen Kollegen nicht wussten, woran der Kollege im Nachbarinstitut arbeitete. Joos fühlte sich zu Spekulationen veranlasst, als Pohl 1940/41 für drei Wochen nach München zog:

„Er [Pohl] sagte mir, er wolle sich nicht dauernd beurlauben lassen, müsse aber praktisch ganz fürs R.L.M. arbeiten. Wenn ich nun etwas Sherlock Holmes spielen möchte, würde ich so kombinieren: Pohl bezeichnet sich meist als den Erfinder des T-Schutzes. Steinheil will ihn einführen und kommt nicht zu Rande, also wird über das R.L.M. Pohl zu Hilfe geholt. Das sind natürlich nur theoretische Kombinationen, die nur theoretisches Interesse haben. Pohl, der sonst vieles mit mir bespricht, deutet nicht einmal an, wo er in München arbeitet. Das hätte er ohne Verletzung des bekannten Befehls ohne weiteres tun können. "1282

Leider erlaubt es die Quellenlage nicht, festzustellen, ob Joos' Spekulationen zutreffen. Pohl selbst schrieb im Dezember 1940, dass seine Arbeiten für das RLM gute Fortschritte machten. ${ }^{1283}$ Weitere Verbindungen von Pohl zum RLM können ebenfalls nachgewiesen werden. Laut Angaben von König hatte Pohl ein gutes Verhältnis zu Adolf Baeumker im

\footnotetext{
1278 Joos an Dekan, 10. März 1941. UAG, Rek. PA Joos.

1279 Joos an Fredenhagen, 7. März 1941. UAG, Rek. PA Joos.

1280 Walker [1990/92] S. 30. Zum Konzept der Selbstmobilisierung, das auf Ludwig [1974] zurück geht, siehe Mehrtens [1994]a, der es aber nur auf die dem Blitzkrieg folgende Phase anwendet.

1281 Joos an Kurator, 27. September 1939. GPAMNFG, Lehrkörper (ausgeschieden), Joos.

1282 Joos an Bauersfeld, 9. Februar 1941. BACZ, PA 2105.
} 
RLM. ${ }^{1284} 1943$ war Pohl als Obmann der Forschungsgruppe „Allgemeine Wissenschaften“ in der Forschungsführung des RLM vorgesehen, außerdem sollte er das Fachgebiet Physik als Beauftragter vertreten. $\mathrm{Ob}$ er diese Funktionen dann tatsächlich wahrgenommen hatte, geht aus den Quellen nicht hervor. ${ }^{1285}$ Die in Pohls Institut verfolgte Forschung zu Halbleitern stand in Zusammenhang mit rüstungstechnischen Zielen. Pohls Assistent Stöckmann bestätigte dies im Rückblick 1950: „Vor allem durch die Bedürfnisse der Kriegsführung und die Entdeckung neuer praktischer Anwendungsmöglichkeiten ist die Erforschung der Halbleiter beträchtlich gefördert worden." 1286 Wie diese Förderung in Göttingen konkret aussah, ist mangels Quellen schwer zu sagen. Einen Zusammenhang mit der deutschen Radarentwicklung dürften die ab 1943 durchgeführten Untersuchungen am Germanium aufweisen. Der in Gräfelfing an Radardetektoren forschende Heinrich Welker erwähnte 1943 in einem Bericht, dass es noch genauer Leitfähigkeitsmessungen bedürfe, um die präparative Beeinflussbarkeit des Germaniums zu studieren. ${ }^{1287}$ Möglicherweise war dieser hier angemeldete rüstungstechnische Bedarf der Auslöser dafür, dass ab 1943 Joseph Stuke in Pohls Institut Leitfähigkeitsmessungen an reinem Germanium durchführte. ${ }^{1288}$ Das Germanium war jedenfalls ein für das Forschungsprogramm der Pohl-Schule untypischer Kristall; er wurde in Göttingen ausschließlich in den letzten Kriegsjahren untersucht. Ungewöhnlich ist auch, dass Stuke die Ergebnisse seiner 1947 eingereichten Dissertation anscheinend nicht in einer Zeitschrift veröffentlicht hat. Stattdessen bespricht erst im Jahr 1950 Stöckmann in seinem zusammenfassenden Bericht über die Elektrizitätsleitung in Halbleitern Stukes Messungen. ${ }^{1289}$ Es gibt offenbar nur eine einzige Publikation in einer Zeitschrift speziell über die in Pohls Institut durchgeführten Arbeiten am Germanium, nämlich jene von Hans König über Struktur und Aufbau dünner Germaniumschichten aus

\footnotetext{
1283 Das geht aus einer Abschrift eines Briefes von Pohl an Fleischmann, 10. Dezember 1940, hervor. NARA, RG 77, entry 22, box 166.

1284 Interview mit Hans König, 10. Februar 2001. Gestützt wird diese Aussage auch durch Briefe Fleischmanns an Pohl, in denen Pohl als Vermittler zu Baeumker um Hilfe gebeten wurde. NARA, RG 77, entry 22, box 166. 1285 „Verzeichnis der bisher vorgesehenen Forschungsgruppen und Fachgebiete sowie der dafür ins Auge gefassten Persönlichkeiten“, 13. Januar 1943. BAB, R 26 III.

1286 Stöckmann [1950]c S. 85.

1287 Germanium wurde als Halbleitermaterial für Radardetektoren benutzt. Der Bericht „Germanium als Detektormaterial“ aus dem Jahr 1943 befindet sich im NL Welker. Hier zitiert nach Eckert [1993] S. 219. Zur Entwicklung des Radars in Deutschland während des Kriegs siehe neben Eckert [1993] S. 217-222 auch Handel [2003]. Einen Überblick über die gesamte deutsche Entwicklung, ohne jedoch näher auf Hochschulforschungen und speziell Göttingen einzugehen, geben Brandt [1950/62], Reuter [1971] und Trenkle [1979].

1288 Nahegelegt wird das durch die von König gemachten Angaben im Interview. Demnach hatte er gute Kontakte zu Siemens und speziell auch zu Heinrich Welker, als er über Siliziumschichten, Einkristalle und Germanium geforscht hat. Interview mit Hans König, 10. Februar 2001.

1289 Stuke [1947]; Stöckmann [1950]c bes. S. 86.
} 
dem Jahr 1944. ${ }^{1290}$ Im Interview gab König allerdings an, dass er im Rahmen kriegsrelevanter Forschung Siliziumdetektoren entwickelte, welche die Luftwaffe für die Radarentwicklung benötigte. Untersucht wurde unter anderem die Oberflächenstruktur von Siliziummonoxyd. ${ }^{1291}$ Die Quellen bestätigen, dass König am deutschen Radarprojekt beteiligt war, jedoch werden nur seine Untersuchungen am Germanium genannt. Im FIATBericht über die deutsche Detektorenentwicklung wird Königs Beitrag mehrfach erwähnt. König habe an der Mitte September 1944 in Berlin-Wannsee stattgefundenen Besprechung über Detektorkristalle teilgenommen und dort über seine Untersuchungen an Germaniumoberflächen referiert. ${ }^{1292}$ Stukes Doktorarbeit über Germanium wurde von König angeregt. Der 1947 verfasste Text lässt den militärischen Kontext dieser Forschung unerwähnt. ${ }^{1293}$ Die ursprünglich auf ein klar militärisches Ziel zugeschnittene (Anwendungs-) Forschung erschien im Nachkriegskontext als reine Grundlagenforschung. Es ist durchaus angebracht, diese Forschung so zu bezeichnen. An diesem Beispiel sieht man aber, welch große Bedeutung auch sie für den Krieg hatte. ${ }^{1294}$

Prandtls Bericht von 1943 ließ ein Göttinger Physikinstitut unerwähnt: das Institut für theoretische Physik. Das verwundert etwas, da auch in diesem Institut Rüstungsforschung im Auftrag der Forschungsführung der Luftwaffe betrieben wurde. Das Institut hatte im Krieg 100000 RM erhalten, um Forschungen zur Geschossentwicklung durchzuführen. Die Mauser-Werke lieferten eine Anzahl von Maschinengewehrläufen für Erprobungszwecke, die Günther Leibfried als Sachbearbeiter in Göttingen zur Entwicklung, Erprobung und Fertigung von Flak-Geschossen benutzte. Schon allein aus der über zwei Jahre währenden, großzügigen

\footnotetext{
1290 König [1944]a.

1291 Interview mit Hans König, 10. Februar 2001.

1292 Siehe Seiler [1948] S. 281f, 284 zu Königs Beiträgen zur Detektorentwicklung. Königs Assistent Walkenhorst war an diesen Arbeiten ebenfalls beteiligt.

1293 Stuke [1947]. Dass König diese Arbeit anregte, wird in der Danksagung vermerkt. Stukes Arbeit ist auch in Bezug auf das Zitationsverhalten untypisch für die Pohlschule. Zum Vergleich mit den in Abschnitt 3.3.1 durchgeführten Zitationsanalysen sei hier das Zitierverhalten von Stuke angeführt. Von den 14 zitierten Arbeiten stammen drei aus der Pohl-Schule: Gudden [1934]; Lehfeldt [1933]a; Gudden \& Pohl [1920]c Zeitschrift für Physik 3 (1920), S. 123. Die anderen zitierten Arbeiten sind: Bidwell, C. C. [1922] Phys. Rev. 19 (1922), S. 447; Meissner, W. \& B. Voigt [1930] Ann. d. Phys. (5) 7 (1930), S. 892; Nitka, H. [1937] Phys. Zs. 38 (1937), S. 896; Benedict, G. [1918] Metallurgie 7 (1918), S. 531; Bridgman, P. W. [1935] Proc. Amer. Acad. 70 (1935), S. 304; Kapitza, P. [1929] Proc. Roy. Soc. Lond. A. 123 (1929), S. 319; Königsberger, J. \& O. Reichenheim [1906] Phys. Zs. 7 (1906), S. 570; Schulze, A. [1930] Phys. Zs. 31 (1930), S. 1062; Becker, K. [1926] Zs.f. Phys. 40 (1926), S. 37; Teal, G. K., I. R. Fisher \& A. W. Treptow [1946] Journ. Appl. Phys. 17 (1946), S. 879; Lark-Horowitz, K., A. E. Middleton, E. P. Miller, J. Wallerstein, E. Conwell, V. F. Weisskopf, A. Johnson \& W. W. Scanlon [1946] Phys. Rew. 69 (1946), S. 258. Von diesen Arbeiten werden nur die beiden letzten, die neue Ergebnisse der Halbleiterforschung aus den USA berichten und Bidwell [1922] auch von der Pohl-Schule zitiert. Für eine Dissertation aus der Pohl-Schule wäre das Verhältnis 3 : 11 (Anzahl der zitierten Arbeiten der Pohl-Schule im Verhältnis zu den anderen) höchst ungewöhnlich.

1294 Die wichtige Schnittstelle zwischen Grundlagenforschung und technischer Anwendung behandelt auch am Beispiel der Mikroelektronik und der Entwicklung von Radardetektoren Kaiser [1995].
} 
finanziellen Unterstützung lässt sich schließen, dass der damalige Forschungsauftrag tatsächlich militärisch verwertbare Ergebnisse lieferte und keine nur vorgegebene Kriegswichtigkeit zur Erreichung von uk-Stellungen der Mitarbeiter darstellte. ${ }^{1295}$ Neben der Geschossentwicklung wurden im Auftrag des Sperrversuchskommandos des OKM Gegenmaßnahmen zu den alliierten magnetischen Minen erforscht. Unter der Leitung von Becker analysierte Döring die Stromkreise der alliierten Minen und berechnete danach das magnetische Feld von Such-Elektroden (sweeper-electrodes) auf Kabeln. Im Auftrag der Luftwaffe widmete er sich auch der theoretischen Behandlung von Explosionen, speziell der Detonation und chemischen Änderungen während der Explosion. Er untersuchte Druckwellen in der Luft und Schockwellen in Flüssigkeiten. ${ }^{1296}$ Die zuletzt genannten Arbeiten führte er als Professor in Posen durch. Es war vermutlich nur ein Zufall, dass Dörings Lehrer Becker im Ersten und Döring selbst im Zweiten Weltkrieg an einer Ausgestaltung der Theorie der Detonation arbeiteten. Döring wies in einem Aufsatz über den Detonationsvorgang in Gasen speziell auf diese Gemeinsamkeit hin und betonte dadurch seine Zugehörigkeit zur Becker'schen Schule. Becker hatte seine ersten Ergebnisse im Jahr 1916 erstmals in Sommerfelds Kolloquium öffentlich vorgetragen. Deshalb war es Döring eine besondere Freude, seine eigene erste Abhandlung auf diesem Gebiet seinem hochverehrten wissenschaftlichen Großvater Sommerfeld zum 75. Geburtstag widmen zu können. ${ }^{1297}$

Der Institutsdirektor Becker führte selbst Aufträge des OKM über die Ausbreitung elektromagnetischer Wellen, hervorgerufen durch einen unter Wasser befindlichen Dipol, aus. ${ }^{1298}$ Außerdem wurde er zum Leiter des Ausschusses Hafthohlladung („Committee on hollow charges“) ernannt. Diesem Ausschuss gehörten außerdem Beckers Assistent Döring an, von der Marine Dr. Bauer und Dr. Buchmann, vom HWA Erich Schumann und Dr. Trinks, von der Luftwaffe Professor Hubert Schardin. Die Hafthohlladung war ein Vorgänger der Panzerfaust. Durch die Anbringung der Sprengladung in einem Hohlraum hatte diese Waffe eine höhere Zerstörungswirkung. Beckers Forschungen in diesem Zusammenhang galten einer genauen Vorhersage der Detonationsgeschwindigkeit. Er berechnete die Druckverteilung in der durch eine Bombenexplosion hervorgerufenen

1295 Siehe Leibfrieds Lebenslauf von 1956. UAG, Rek. PA Leibfried. Siehe auch Leibfried an den Kurator, 11. April 1951; UAG, Kur. XVI. V. C. i.2. Dieses Schreiben ist zitiert in Hentschel \& Rammer [2003] S. 38.

1296 BIOS Final Report No. 79, Applied Mathematical Research in Germany, with Particular Reference to Naval Applications, S. 55.

1297 Döring [1943].

1298 BIOS Final Report No. 79, Applied Mathematical Research in Germany, with Particular Reference to Naval Applications, S. 60. 
Ausbreitung sphärischer Wellen. ${ }^{1299}$ Bei Becker hatte die Detonation als Forschungsthema eine lange Tradition. Schon im Ersten Weltkrieg, genauer von 1913 bis 1919, arbeitete er in der Sprengstoffindustrie. Die aus der dortigen Forschung gewonnenen Erkenntnisse verwertete er in seiner 1922/23 erfolgten Habilitation an der Universität Berlin. In seinem Einsatz für militärische Belange beschränkte er sich nicht nur auf Forschungsbeiträge. Er stellte seine Arbeitskraft auch in entsprechenden Ausschüssen zur Verfügung. Im Ersten Weltkrieg war dies das Waffen- und Munitionsbeschaffungsamt in Berlin, im Zweiten Weltkrieg unter anderem der Vorsitz des Ausschusses Hafthohlladung. ${ }^{1300}$

Beckers Hauptforschungsthema in den dreißiger Jahren, der Magnetismus, fand auch eine militärische Verwertung. Becker befasste sich mit magnetischen Minen, berechnete dazu das magnetische Feld von Schiffen. Magnetische Minen wurden vernichtet, indem durch sie ein elektrischer Strom geschickt wurde, der von zwei Minenabweisern erzeugt wurde. Ein Problem, mit dem sich Becker befasste, war die küstennahe Minenräumung, bei der die Leitfähigkeit der Landmasse mit berücksichtigt werden musste. Versuche dazu wurden im Sperr-Versuchskommando in Kiel unter der Leitung von Dr. Hagemann durchgeführt. ${ }^{1301}$ Beckers Forschungen wurden vom Staat gewürdigt. Am 30. Januar 1942 wurde Becker das Kriegsverdienstkreuz zweiter Klasse verliehen. Am 1. März 1942 wurde er zum korrespondierenden Mitglied der Deutschen Akademie der Luftfahrtforschung ernannt. ${ }^{1302}$ Als geheime Kommandosache im Auftrag der Luftwaffe führte Becker „Untersuchungen über Brandschrapnelle“ in Göttingen durch. ${ }^{1303}$ Aus den Quellen geht nicht hervor, wozu die Brandschrapnelle entwickelt und ob sie eingesetzt wurden. Ein Schrapnell ist im allgemeinen ein Artilleriegeschoss, das bei Explosion eine große Zahl von Kleinstgeschossen zerstreut. Im Zweiten Weltkrieg wurden auch Schrapnellminen eingesetzt, die bei Zündung etwa eineinhalb Meter in die Luft sprangen, explodierten und eine Vielzahl kleiner Stahlkugeln und Splitter in die Umgebung schleuderten. ${ }^{1304}$

Vage Hinweise auf militärische Forschungen kann man den im Auftrag der Alliierten verfassten FIAT-Berichten entnehmen. In diesen Berichten sind die während des Kriegs in

\footnotetext{
${ }^{1299}$ CIOS Report, Item No. 2, File No. XXXII-85, Aerodynamische Versuchsanstalt and the Kaiser Wilhelm Institute für Strömungsforschung Göttingen, S. 13. NARA, RG 319, Box 689. Zur Theorie des Hohlraumeffekts siehe Döring \& Schardin [1948] S. 120-125.

1300 Siehe hierzu auch Abschnitt 1.2.2.

${ }^{1301}$ CIOS Report, Item No. 2, File No. XXXII-85, Aerodynamische Versuchsanstalt and the Kaiser Wilhelm Institute für Strömungsforschung Göttingen, S. 13. NARA, RG 319, Box 689.

1302 UAG, Kur. PA Becker.

1303 „Aufstellung f. Kriegswirtschaftstellen v. 8.1.45. Sachgebiet Sprengstoffe“. Auftragsnummer OKL-Nr. SS 4942-6134-2786/44. BAB, R 26 III.
} 
Deutschland durchgeführten Forschungen zusammengefasst. Dass aber diese Berichte keine 'neutrale' Beschreibung von Forschungen sind, sondern auch politische Ziele durch die Art der Darstellung und die darin vorgenommene Entkontextualisierung verfolgt wurden, zeigte Mark Walker am Beispiel des Uranprojekts. In den FIAT-Beiträgen über Kernphysik und kosmische Strahlung lösten die deutschen Physiker ihre Forschungen vom militärischen Kontext und beschrieben ihre Uranmaschine als „friedliche“ Maschine, ohne zu erwähnen, dass beim Betrieb der Maschine Kernsprengstoffe erzeugt werden. ${ }^{1305}$ Von den Göttingern gibt es etliche Beiträge $\mathrm{zu}$ den FIAT-Berichten, die mit entsprechender Vorsicht $\mathrm{zu}$ interpretieren sind. ${ }^{1306}$ Die Bemühung um eine Reinwaschung der deutschen Forschungen macht es für den Nichtspezialisten schwer, die militärische Relevanz der jeweiligen Arbeiten aus diesen Berichten zu entnehmen.

Einen ähnlichen Zweck wie die FIAT-Berichte verfolgte eine Initiative von Mr. Goody, dem kommissarischen Leiter der AVA, der im Oktober 1945 dem Göttinger Dekan Eucken den Wunsch einer Anzahl englischer Naturwissenschaftler übermittelte, ,allmählich mit den deutschen Fachgenossen wieder in einen wissenschaftlichen Konnex zu treten. Um einen solchen anzubahnen, will man in England zunächst über die Ergebnisse wichtiger Forschungsarbeiten unterrichtet werden, die im Laufe der letzten Jahre in einer Anzahl Göttinger Institute ausgeführt, aber bis jetzt noch nicht oder nur unvollständig in Fachzeitschriften veröffentlicht sind.“1307 Daraufhin wurden folgende Kurzberichte, die jeweils nicht länger als zwei Maschinschreibseiten sein sollten, eingesandt:

\begin{tabular}{|l|l|l|}
\hline Inst. f. angew. Mech. & Schuler & Sammelbericht (Zeitmessung-Pendeluhren-Kreisellehre-Regelungstechnik) \\
\hline \multirow{3}{*}{ II. Physik. Institut } & Hellwege & Termaufspaltung und elektrische Dipolstrahlung \\
\cline { 2 - 3 } & Severin & Spektren kristallwasserhaltiger fester Salze des Erbiums \\
\cline { 2 - 3 } & Dietrich Meyer & Wechselwirkung zwischen 4f Elektronen und Kristallgitter \\
\cline { 2 - 3 } & Yu Kang Chow & Kramersche Entartung und J-Werte im Spektrum des kristallinen NdF3 \\
\hline Inst. f. angew. Elektr. & Zahn \& Severin & Sammelbericht (Beugung elektromagnetischer Wellen an metallischen Blenden) \\
\hline
\end{tabular}

Tabelle 17 Liste der Forschungsberichte Göttinger physikalischer Institute vom November 1945. 1308

\footnotetext{
1304 http://www.lexikon-der-wehrmacht.de/Waffen/minen-R.htm\#Schutzenmine\%2044.

1305 Walker [1990/92] S. 250-252.

1306 Wenn man nur jene Göttinger berücksichtigt, die im Krieg zumindest zeitweise in Göttingen forschten, sind dies: Becker [1948]; Betz [1948]b, [1948]c; Döring \& Schardin [1948]; Houtermans [1948]; Joos [1948]; Kopfermann [1948]; Küssner \& Billing [1948]; Paul [1948]c; Prandtl [1948]a; Tollmien [1948]; Walcher [1948].

1307 Laut Rundschreiben Euckens an alle mathematisch-naturwissenschaftlichen Institute, 1. November 1945.

UAG, Math. Nat. 56.

1308 UAG, Math. Nat. 56.
} 
Leider sind die Berichte selbst nicht überliefert. Eigenartigerweise sind in dieser Tabelle die drei Ordinarien Becker, Kopfermann und Pohl, sowie deren enge Mitarbeiter nicht vertreten. In den hier aufgelisteten Instituten wurde nach den vereinzelten Belegen, die aus den Quellen zu entnehmen sind, in hohem Ausmaß Rüstungsforschung betrieben. Im II. Physikalischen Institut trifft dies vor allem auf Hellwege und seinen Kreis zu. Trotzdem scheinen die eingereichten Berichte jenen Teil der Forschung $\mathrm{zu}$ präsentieren, der für die alliierten Wissenschaftler als bedeutsam und zugleich wohl auch als wissenschaftspolitisch unverfänglich gelten sollte. Drei der Kurzberichte betrafen noch unpublizierte Doktorarbeiten, die unter der Leitung Hellweges entstanden. Die später publizierten Versionen sind: Severin [1947], Dietrich Meyer [1948] und Chow [1948]. Hellweges eigener Bericht dürfte inhaltlich mit seinen späteren Publikationen Hellwege [1949]b-f in Verbindung stehen. Aus dem Sammelbericht von Zahn und Severin dürfte die Publikation Severin [1947] hervorgegangen sein. Zu Schuler siehe Kapitel 5. Wenn diese Berichte und die damit in Zusammenhang stehenden Publikationen auch auf Forschungen der Kriegszeit Bezug nehmen, so ist darin wohl nur verschleiert die militärische Relevanz zu erkennen. Mit dem veränderten politischen Kontext änderte sich auch die Verwertung und Präsentation ein und derselben Forschungsergebnisse.

Wie dieser keineswegs vollständige Überblick über Rüstungsforschungen an den Göttinger Physikinstituten zeigt, drückte die eingangs zitierte Bemerkung des Rektors Rein, dass die meisten Laboratorien sich bis zuletzt hartnäckig Problemen widmeten, die keinen Zusammenhang mit Krieg und Politik erkennen ließen, bestenfalls eine halbe Wahrheit aus. Wie zuletzt gesehen, war selbst die theoretische Physik stark an militärischer Forschung beteiligt. Die fachlichen Grenzen zwischen reiner und angewandter, oder zwischen theoretischer und experimenteller Forschung zerflossen unter den Bedingungen des Kriegs. So kam es, dass theoretische Physiker sich an der Entwicklung von Maschinengewehren beteiligten und auch Versuche mit diesen Waffen durchführten. Mit dem Kriegsende verschwanden diese ungewöhnlichen Forschungsthemen, nicht zuletzt weil die zugehörigen Auftrag- und Geldgeber nicht mehr existierten. Dass für die militärischen Anwendungen die Grundlagen der Physik eine Vorbedingung darstellten, dass also auch Grundlagenforschung betrieben und die gesamte Physik gefördert werden muss, um rüstungstechnische Verbesserungen zu erzielen, darauf wiesen die deutschen Physiker immer wieder hin. Es ist daher kein Widerspruch, wenn neben der Zweckforschung auch Grundlagenforschung betrieben wurde. Diese zweite Komponente erschien in der Nachkriegszeit als der erwünschte Teil der Forschung, während die erste Forschungsbeschränkungen unterlag. Um die 
physikalische Forschung als Ganzes wieder in Gang zu bringen, verwiesen die Göttinger Physiker in ihren Berichten im Herbst 1945 auf die unverfänglichen Anteile ihrer Arbeiten.

\subsection{Kontinuität in der Forschung - der Übergang in die Nachkriegszeit}

„When can we resume our research work again?“, das war die drängende Frage der deutschen Naturwissenschaftler, die sie den alliierten Offizieren bei den ersten Inspektionen im Frühjahr 1945 stellten. Die Göttinger Physiker bildeten in dieser Hinsicht keine Ausnahme. ${ }^{1309}$ Ist dieser Gleichklang der deutschen Wissenschaftler, den Goudsmit lakonisch feststellte, diese Fixierung auf die Forschung, ein erstes Anzeichen für einen gleich mit Kriegsende einsetzenden Verdrängungsprozess durch Flucht in die Arbeit? Goudsmit fiel jedenfalls auf, dass seine deutschen Kollegen überhaupt kein Gefühl der Verantwortung zeigten, diese lieber auf den Gauleiter oder die Parteiführung abschoben. ${ }^{1310}$ Die weitere Entwicklung, mit der auch unter Physikern verbreiteten Unfähigkeit zu trauern, legt diesen Schluss nahe. ${ }^{1311}$ Hier soll aber nicht die mentale Verarbeitung, sondern die sachliche Entwicklung behandelt werden. Die Entscheidung über die Fortsetzung der Forschungen lag in den Händen der Besatzer, und deren Ziel war zuerst eine Entnazifizierung und Entmilitarisierung der deutschen Forschungslandschaft.

\subsection{1 Überwachung der Forschungstätigkeit in den ersten Monaten der Besatzung}

Das erklärte Ziel der Alliierten, Deutschland $\mathrm{zu}$ entmilitarisieren, führte $\mathrm{zu}$ einer weitreichenden Forschungskontrolle und -überwachung. Verschiedene Phasen lassen sich identifizieren. Unmittelbar nach dem militärischen Sieg überwog die Identifizierung und Ausbeutung der kriegsrelevanten deutschen Forschung und die Festnahme und Evakuierung ausgewählter Wissenschaftler. Danach folgte eine systematische Erfassung der deutschen Forschungstätigkeit in unzähligen Berichten durch FIAT, und gleichzeitig verlief die

\footnotetext{
1309 Siehe den Bericht von Goudsmit vom 23. April 1945 über das Gespräch mit Kopfermann und Houtermans in Göttingen, 17. April 1945. NARA, RG 77, Entry 22, Box 167.

1310 Brief von Goudsmit an Franck, 18. Dezember 1945. NBL, Goudsmit papers, box 9, folder 75.

1311 Eine Anwendung von Alexander und Margarete Mitscherlichs Analyse der deutschen

Nachkriegsgesellschaft (Die Unfähigkeit zu trauern) auf die Wissenschaft und Technik unternahm Kaiser [1997]. Zur Mentalität der Physiker speziell in der unmittelbaren Nachkriegszeit siehe die in Vorbereitung befindliche Studie von Klaus Hentschel.
} 
personelle Entnazifizierung, die schon etwas früher als die Forschungskontrolle durch gesetzliche Vorschriften geregelt wurde. ${ }^{1312}$

Die Bedingungen dafür, dass die Forschung in den Physikinstituten rasch wieder aufgenommen werden konnte, waren in Göttingen besonders gut. Während die AVA weitgehend demontiert wurde, blieben die Physikinstitute der Universität von größeren Eingriffen verschont. Von der Alsos-Mission ${ }^{1313}$ wurden im Institut für angewandte Elektrizität und im II. Physikalischen Institut einige Senderröhren und Magnete für Ultrakurzwellen beschlagnahmt, die fast alle Eigentum der Kriegsmarine waren. Die anderen Institute erlitten praktisch keine Konfiskationen, wenngleich auch Listen abhanden gekommener Gegenstände (wie private Radioapparate und dergleichen) aufgestellt wurden. Ob diese Verluste auf das Konto der Besatzer zu zählen sind, bleibt aber fraglich. ${ }^{1314}$ Dieser geringe Eingriff war nicht der Regelfall, wie der Bericht von Walther Bothe aus Heidelberg vom November 1945 zeigt: „Mein Institut ist jetzt praktisch ganz ausgeräumt, einschliesslich aller geeichten Messapparaturen, an denen die Arbeit und Erfahrungen von vielen Jahren hingen. Geblieben ist mir vorläufig nur das Zyklotron und zwei Räume, in denen unsere Apparate gestapelt sind."1315 Die Arbeit an dem Zyklotron war Bothe zu diesem Zeitpunkt noch untersagt.

Von den in Deutschland durchgeführten physikalischen Forschungen genoss vor allem das Uranprojekt die besondere Aufmerksamkeit der Alliierten. Die mit der Ermittlung aller diesbezüglichen Aktivitäten beauftragte Alsos-Mission suchte, die vorrückenden alliierten Truppen begleitend, all jene Orte auf, in denen das Uranprojekt betrieben wurde und wo daran beteiligte Wissenschaftler vermutet wurden. In der sogenannten „Strassburg Summary“ listeten die Alliierten 242 deutsche Wissenschaftler auf und bewerteten in einer Zehn-PunkteSkala ihre Bedeutung für das Uranprojekt. Unter den 24 wichtigsten Personen (6 bis 10 Punkte) befand sich nur ein Physiker aus den Göttinger Universitätsinstituten. Dies war Wilhelm Walcher (6 Punkte), dessen Arbeiten zur Isotopentrennung von Bedeutung waren. Aus dieser Gruppe wurden sechs Physiker inhaftiert und zusammen mit vier weiteren, als weniger bedeutend Eingestuften, über Umwege in das nahe Cambridge gelegene Farm-Hall

\footnotetext{
$1312 \mathrm{Zu}$ unterschiedlichen Phaseneinteilungen des alliierten Zugriffs auf die deutsche Wissenschaft siehe Ash [1995]b S. 905-908; Heinemann [2001] S. 171f.

1313 Alsos ist das griechische Wort für "groves" und war der Deckname der Nachrichteneinheit des Manhattan Projects, die die Uranforschungen in Deutschland zu untersuchen hatte. Leiter des Manhattan Projects war General Leslie Groves. Zur Alsos-Mission siehe Walker [1990/92] S. 187-215; Goudsmit [1947/83].

$1314 \mathrm{Zu}$ solchen Listen abhanden gekommener Instrumente und Gegenstände siehe Schuler, Kopfermann, Zahn und Prandtl an den Dekan 14. und 15. Juni 1945. UAG, Mat. Nat. 24a.

1315 Bothe an Pohl, 7. November 1945. Bothe Nachlass, MPG-A, III, 6, 11, 1.
} 
gebracht, wo sie bis Anfang 1946 interniert blieben. ${ }^{1316}$ In der 30 Wissenschaftler umfassenden mittleren Gruppe (3 bis 5 Punkte) waren mit Siegfried Flügge und Houtermans zwei Göttinger zu finden. Flügge kam allerdings erst im Juni 1945 nach Göttingen, sodass er in der ersten Bewertung Göttingens durch die Alliierten nicht bei dieser Stadt mitgezählt wurde. 27 Wissenschaftler wurden mit 2 Punkten bewertet, darunter Becker, Döring, Paul und Pohl. Der Kernphysiker Kopfermann bekam mit nur einem Punkt die niedrigste Bewertung, ebenso Erich Mollwo. Neben den Personen wurden auch die Städte von 1 bis 10 Punkten bewertet. Göttingen rangierte mit nur einem Punkt ganz unten, während 22 andere Städte zwei oder mehr Punkte bekamen. ${ }^{1317}$

Die Universität Göttingen war also, was die physikalische Forschung betrifft, ohne Berücksichtigung der AVA, von geringerem Interesse für die Alliierten. Als Frederick Seitz in seiner Funktion als FIAT-Mitarbeiter zusammen mit Samuel Goudsmit von der Alsos Mission im Frühjahr 1945 die Göttinger Institute inspizierte, stand er vor Pohls Institut und wunderte sich über das dort angebrachte „Off-limits“ Schild, das nur den Besatzungsoffizieren Eintritt gestattete. In dieser Situation sprach ihn Pohls Assistent Mollwo an und bat ihn, ob er ihm nicht Zugang zum Institut verschaffen könne. Die Begegnung zwischen zwei Festkörperphysikern, die sich fachlich kannten und schätzten, führte zu einem konstruktiven kollegialen Verhältnis. ${ }^{1318}$ Beide waren darum bemüht, dass die wissenschaftliche Forschung wieder ermöglicht und fortgesetzt werden müsse. Seitz verschaffte den Göttingern wieder Zugang $\mathrm{zu}$ ihren Instituten. ${ }^{1319}$ Auf einem langen Spaziergang konnte Pohl Seitz davon überzeugen, dass er sich in den Kriegsjahren weniger um Forschung als um die Aktualisierung seiner Lehrbücher gekümmert habe. Die militärische Relevanz der in seinem Institut durchgeführten Forschungen herunterspielend und die grundlegende Physikausbildung betonend, erreichte Pohl die wohlwollende Unterstützung der alliierten Offiziere zur Wiederherstellung normaler Forschungsbedingungen. Seitz erinnert

\footnotetext{
1316 Siehe Hoffmann (Hrsg.) [1993].

1317 "Analysis of Importance of Persons and Cities Mentioned in the »Strassburg Summary«" von W. A. Shurcliff, 21. Februar 1945. NARA, RG 77, Entry 22, Box 167.

1318 Seitz [1994] S. 160, 171. Zur Entstehung von kollegialen Verhältnissen zwischen alliierten „Wissenschaftlern in Uniform“ und deutschen Forschern siehe Heinemann [2001] S. 171.

1319 Die Institute hatten für die Physiker nicht nur einen praktischen, sondern auch einen hohen ideellen Wert. Dass sie selbst keinen und die Alliierten ungehinderten Zutritt hatten, war ihnen ein Dorn im Auge. Schon am 25. April 1945 wurde über den Erfolg des Kurators gegen das Eindringen von Soldaten in durch off limits geschützte Institute berichtet. Protokoll der Senatssitzung vom 25. April 1945. UAG, Senatsprotokolle 19451949.
} 
sich: „Among other things we agreed to establish inter-laboratory links and to meet again when normal relationships had been established."1320

Eine ähnliche Begebenheit ist für Hans Kopfermann und das II. Physikalische Institut dokumentiert. Am 17. April 1945 kamen Samuel Goudsmit und Major R. R. Furman nach Göttingen und befragten Kopfermann und Houtermans über ihre Kriegstätigkeit und Beteiligung am Uranprojekt. In diesem Gespräch gelang es vor allem Houtermans, die deutschen Kernphysiker als „Anti-Nazis“ darzustellen, die versuchten, den Krieg in den Dienst der Wissenschaft zu stellen. Die einzigen Ausnahmen waren in seiner Sicht Abraham Esau und Dr. H. Beuthe, die er als extreme Nazis charakterisierte. ${ }^{1321}$ Diese schwarz-weiß Darstellung erweckt zumindest heute den Eindruck, als wurden hier zwei 'schwarze Schafe" geopfert, um den Rest der Physiker moralisch zu rehabilitieren. Da Houtermans selbst Verfolgter der Nationalsozialisten war (siehe Abschnitt 1.3.4.4), besaßen seine Aussagen einige Glaubwürdigkeit. Kopfermann scheint, soweit das aus dem Bericht von Goudsmit zu entnehmen ist, in dieser Beziehung zurückhaltender gewesen zu sein. Seine Forschungen im Krieg konzentrierten sich dem Bericht zufolge auf Massenspektroskopie und Hyperfeinstruktur. ${ }^{1322}$ Für Goudsmit bestätigte sich somit die im „Strassburg Summary“ gegebene Einschätzung, dass Kopfermann keine Bedeutung für das deutsche Uranprojekt hatte, und wurde möglicherweise sogar dahingehend erweitert, dass er überhaupt eine geringe Rolle in den deutschen Kriegsanstrengungen spielte.

Das Verhältnis zwischen Kopfermann und Goudsmit war weniger eines des siegreichen Offiziers zum unterlegenen Wissenschaftler als ein kollegiales zwischen zwei Kernphysikern. ${ }^{1323}$ Dass Kopfermann ein gutes Verhältnis zu vielen deutschen Emigranten unterhielt und dass er in seinem 1940 erschienen Buch Kernmomente diese, einschließlich Goudsmit, zitierte und deren Forschungsbeiträge positiv erwähnte, war einer Besprechung über die Zukunft der deutschen Forschung auf sachlichem Niveau zuträglich. ${ }^{1324}$ Kopfermann verhandelte nicht nur mit dem Leiter der Alsos-Mission, Goudsmit, sondern auch mit dessen

\footnotetext{
1320 Frederick Seitz, Memorial Symposium in honor of Heinz Pick, Stuttgart, November 5, 1985, S. 7. NBL.

$1321 \mathrm{Zu}$ Esau siehe Hoffmann \& Stutz [2003].

1322 Bericht von Goudsmit vom 23. April 1945 über das Gespräch mit Kopfermann und Houtermans in Göttingen, 17. April 1945. NARA, RG 77, Entry 22, Box 167.

1323 „I have a very high opinion of Kopfermann even though he became a member of the Nazi party during the war and there are several arguments in his favor." Goudsmit an Weisskopf, 11. Februar 1948. NBL, Samuel Abraham Goudsmit, papers, box 24, series III, 257, Weisskopf.

$1324 \mathrm{Zu}$ den Beziehungen Kopfermanns zu den Emigranten siehe Abschnitt 1.3.6. Goudsmit wurde gleich auf der ersten Seite des Vorworts in „Kernmomente“ erwähnt: „In der Darstellung wurde deshalb, S. Goudsmit folgend, überwiegend von einfachen Modellen und ihrer korrespondenzmäßigen Behandlung Gebrauch gemacht." Kopfermann [1940].
} 
Mitarbeitern Smythe, Gerard Kuiper und Major Fisher. Der zuletzt Genannte leitete die positiven Verhandlungsergebnisse an die zuständigen britischen Behörden weiter (Major Wilson, 126 Mil. Gov. Det.). ${ }^{1325}$ So konnte Kopfermann erreichen, dass bereits im Mai 1945 die physikalischen Institute überwiegend als entmilitarisiert freigegeben wurden. ${ }^{1326}$ In einem privaten Brief beschrieb Kopfermann die Situation folgendermaßen: „Die Institute wurden alle besetzt und gründlich durchgesehen. In ungewöhnlich großzügiger Weise wurde uns dann erlaubt, Friedensforschung wieder aufzunehmen. Bei den Kommissionen waren eine Reihe mir bekannter amerikanischer Kollegen, die sich reizend benommen haben." 1327

Nicht alle Göttinger Wissenschaftler konnten so gute Kontakte zu den Alliierten herstellen. Der Dekan Eucken nahm zum Beispiel Äußerungen von alliierter Seite, die auf eine „,künftige Einschränkung der Forschungsfreiheit" hindeuteten, mit größerer Besorgnis auf. Ihm fehlte der vertrauensvolle Kontakt, der zu einer gelasseneren Interpretation geführt hätte. Eucken konnte dann „durch Herrn Kopfermann beruhigend aufgeklärt“ werden. ${ }^{1328}$ Man erkennt an dieser Episode zum einen, wie wichtig die persönlichen Kontakte zwischen den als Sieger und Inspekteure kommenden Wissenschaftlern und ihren deutschen Kollegen waren, zum anderen, dass hier der Zufall eine Rolle spielt, nämlich inwiefern hier Kollegen aufeinander trafen, die sich schon kannten und ein gutes Verhältnis unterhielten, und daher zum Dritten, dass das Ausmaß des alliierten Eingriffs in die deutsche Forschungslandschaft nicht vorgegeben war, sondern Ergebnis von in gewissen Grenzen offenen Verhandlungen war. Es bestätigt sich hier, worauf Mitchell Ash hingewiesen hat, dass vom Übergang der nazifizierten in die entnazifizierte Wissenschaft der Aushandlungsprozess zwischen den beteiligten Personen, der mehrere Jahre dauern konnte und dessen Ausgang von vielen politischen und wissenschaftlichen Faktoren abhing, die wesentliche Komponente zum Verständnis der Wissenschaftsentwicklung in dieser Zeit des politischen Umbruchs ist. Eine erreichte Kontinuität der Forschung war keine bloße Fortsetzung, sondern konnte in dieser Situation nur eine Umwidmung alter Vorhaben in einen neuen Kontext sein. ${ }^{1329}$ Die hier

\footnotetext{
1325 Kopfermann an Education Control Officier L. H. Sutton, 11. Dezember 1945. UAG, Math. Nat. 56. 1326 Mitteilung von Kopfermann, Senatssitzung 16. Mai 1945. UAG, Senatsprotokolle 1945-1949.

1327 Kopfermann an Charlotte Gmelin, 29. Mai 1945. Zitiert nach Schlüpmann [http] Kap. „Letzte Züge der Diktatur und erste Maßnahmen der Vier Mächte, S. 384. Ganz ähnlich verlief zum Beispiel die Besetzung des KWI für Chemie in Tailfingen. Im Juni 1945 kamen alliierte Professoren zur Inspektion, die „Zusammenkunft verlief auf kollegial-freundschaftlicher Basis“. Folge war, dass das Institut uneingeschränkt weiterarbeiten konnte. Das Zitat stammt von Josef Mattauch, hier wiedergegeben nach Heinemannn [1990]b S. 417. 1328 Protokoll der Senatssitzung vom 2. Mai.1945. In der folgenden Senatssitzung vom 5. Mai konnte Eucken dann seinen Kollegen berichten, dass ,kein Anlaß zur Befürchtung weitgehender Einschränkungen der physikalischen Forschungsarbeit besteht.“ UAG, Senatsprotokolle 1945-1949.

1329 Ash [1995]a, [1995]b.
} 
besprochenen ersten Kontakte im Frühjahr 1945 stellen somit nur den Beginn dieses Prozesses dar.

Am 24. Juni 1945 wurde unerwartet auf Anordnung der Militärregierung in Hannover die Einstellung der Forschungstätigkeit in allen Göttinger Instituten verfügt. Die zentrale Stelle in Hannover wollte darüber informiert werden, wer die Forschungen bisher autorisiert habe, welche Forschungsarbeit danach geleistet und von wem sie überwacht wurde, und wie viele Personen an der Forschung beteiligt seien. ${ }^{1330}$ Dieser Erlass galt nur solange, bis die Überprüfung der Institute und Seminare abgeschlossen war. Ende August konnten die mathematisch-naturwissenschaftlichen Institute wieder ihre Forschungsarbeit aufnehmen. ${ }^{1331}$

Mitte Juli 1945 beschlagnahmte die Army School einige Universitätsinstitute, und der Göttinger Townmajor Templin setzte einen Räumungstermin auf den 23. August fest. Nach einer heftigen Beschwerde seitens der Universität in Hannover bei Major Beattie und Major Ruddy und dem folgenden persönlichen Besuch von Capt. Godfrey in Göttingen wurden der Townmajor Templin und der befehlgebende Offizier abgelöst. ${ }^{1332}$ Damit konnte die Fortsetzung der Forschung erfolgreich wieder erreicht werden, und gleichzeitig wurden auch in personeller Hinsicht die Weichen für eine konstruktive Zusammenarbeit mit den Besatzungsbehörden gestellt.

Ende 1945 erfolgte die Gründung des German Scientific Advisory Councils. Colonel Blount besprach sich hier in der ersten stattfindenden Sitzung am 1. Januar 1946 mit den Göttinger Professoren Carl Correns, Arnold Eucken, Otto Hahn, Werner Heisenberg, Hermann Rein und Adolf Windaus sowie mit Ernst Telschow über den Wiederaufbau der deutschen Forschung. ${ }^{1333}$

\subsubsection{Gesetzliche Bestimmungen der Forschungskontrolle}

Das alliierte Kontrollratsgesetz Nr. 25 wurde am 7. Mai 1946 erlassen. Ziel des Gesetzes war die Sicherstellung der Entwaffnung und Entmilitarisierung in der wissenschaftlichen Forschung. Die Physik betreffend waren Forschungen der angewandten Kernphysik, des Raketenantriebs, der angewandten Aero- und Hydrodynamik und verschiedenste

1330 Zum 26. Juni 1945 musste die Universität der Militärregierung melden, dass alle Forschungstätigkeiten in Göttinger Instituten vollständig eingestellt wurden. Siehe Rektor Smend an Dekan Eucken, 26. Juni 1945. UAG, Math. Nat. Fak. 24a.

1331 Gizler [1985] S. 16.

1332 Protokoll der Senatssitzung vom 21. Juli 1945. UAG, Senatsprotokolle 1945-1949.

1333 Heinemannn [1990]b S. 422. 
Anwendungen elektromagnetischer, infraroter und akustischer Strahlung für vor allem militärisch verwertbare Zwecke verboten. Die Nutzung von Radioaktivität für andere als medizinische Zwecke war genehmigungspflichtig. ${ }^{1334}$ Das Gesetz gab die Verantwortung der Forschungskontrolle nicht einer alliierten Behörde, sondern den einzelnen Kommandeuren und deren Mitarbeitern der einzelnen Zonen. Dies erlaubte gewisse individuelle Regelungen zwischen den vier Zonen. Die Briten drängten auf eine strikte Entnazifizierung der Wissenschaftler, da sie damit eine Kontrolle der Forschungsinhalte, die sie für schwer durchführbar erachteten, umgehen konnten. Das Verbot angewandter Forschung allein war keine genügende Sicherheitsvorkehrung, da auch Grundlagenforschung mit bestimmten Anwendungen in Verbindung stand. Die als politisch vertretbar eingestuften deutschen Wissenschaftler konnten wieder ungehindert forschen, egal welchen Arbeiten sie früher nachgegangen waren. „Little that they do in the laboratory can be a threat to security, and the rest can be controlled by the authorities." 1335

Nach Manfred Heinemann wandte sich die britische Research Branch schon ab Herbst 1945 einer zukunftsgerichteten Wissenschaftspolitik zu. Die Forschungsoffiziere hatten das Kapitel der personellen Entnazifizierung für sich persönlich bereits abgeschlossen. Colonel Bertie K. Blount berichtete, dass die Verfolgung von Mitläufern nicht ihre Sache sei. Im September/Oktober 1945 errichtete die Militärregierung in Göttingen eine Wissenschaftsabteilung zur Kontrolle der Forschung. ${ }^{1336}$ Da das Kontrollratsgesetz Nr. 25 in den Instanzzuständigkeiten unklar formuliert war, verzögerte sich seine Wirkung. Auf die Phase der Ausbeutung folgte ab 1947 eine der Forschungsüberwachung mit dem Ziel eines kontrollierten Wiederaufbaus deutscher Forschung. Als Kontrollsystem dafür wurde das von 1948 bis 1955 wirkende militärische Sicherheitsamt geschaffen. Das Gesetz Nr. 25 führte mit seinen nur schrittweise gelockerten Forschungsverboten zu einer bewussten Verzögerung mancher, nicht nur militärischer Forschungsrichtung. Eine gewisse Erleichterung brachte das dem Gesetz Nr. 25 im September 1949 folgende Gesetz Nr. 23, wonach Grundlagenforschung in der Kernphysik wie in der Hydro- und Aerodynamik nicht mehr zulassungspflichtig waren. Der Kontrollbehörde musste allerdings regelmäßig über die Forschungstätigkeit berichtet werden. Eine große Entscheidungsbefugnis besaßen die einzelnen Kontrolloffiziere, was sich für Göttingen positiv auswirkte. Ab 1950 gab es eine gemeinsame Kontrolltätigkeit der

\footnotetext{
1334 Einen Abdruck des Gesetzes findet man zum Beispiel in den Physikalischen Blättern 2 (1946), S. 49-52.

1335 „Report on the activities of Roger Adams, scientific advisor to the Deputy Military Governor of Germany“, 5. März 1946, zitiert nach Cassidy [1994] S. 224.

1336 Heinemannn [1990]b S. 419.
} 
Westalliierten. Mit der beginnenden Remilitarisierung ab 1950/51 und verstärkt mit der Wiederbewaffnung 1952 nahm die Forschungskontrolle merklich ab. ${ }^{1337}$

Das Kontrollratsgesetz Nr. 25 verbot zwar militärische Forschung, klassifizierte Projekte aber auch nach einem eventuellen friedlichen Nutzen. Forschungseinrichtungen „of a purely military character“ seien zu zerstören oder zu entfernen, andererseits seien Einrichtungen „having a possible peace time application“ zu erhalten oder umzuwandeln. Dies gab den einzelnen Kontrollbehörden einen Entscheidungsspielraum, der allerdings in Widerspruch zu anderen Kotrollratsdirektiven stand (z. B. ACC Directive 22). Die Auslegung der widersprüchlichen Bestimmungen wurde jeweils in den Zonen vollzogen. ${ }^{1338}$

Göttingen war von den Verboten weniger stark betroffen, da mit Colonel Bertie Blount und Ronald G. J. Fraser Offiziere die Kontrolle besaßen, die an einem konstruktiven Wiederaufbau der deutschen Forschung interessiert waren. Blount hatte schon vor dem Krieg Beziehungen zu Deutschland. Er promovierte 1931 bei dem Chemiker Walther Borsche in Frankfurt und fühlte sich auch deshalb mit den deutschen Naturwissenschaftlern kollegial verbunden. ${ }^{1339}$ Von den Göttinger Physikern noch stärker als Kollege wahrgenommen wurde Ronald Fraser, der selbst Physiker und ein Spezialist für Molekularstrahlen war. ${ }^{1340}$ In Fragen der Forschungspolitik vertrat er eine dem Londoner Physiker und späteren Wissenschaftshistoriker John Desmond Bernal nahestehende, gewissermaßen utilitaristische Auffassung vom Zweck der Forschung, die sich am sozialen Nutzen zu orientieren habe. ${ }^{1341}$ Fraser blieb bis Ende 1948 in der Research Branch und wechselte dann als Verbindungsoffizier für den International Council of Scientific Unions zur 1946 gegründeten UNESCO nach Paris. ${ }^{1342}$ Wie die Göttinger es erreichten, vom Gesetz untersagte Forschungen durchführen zu können, wird in Abschnitt 3.7 behandelt.

1337 Zur Forschungskontrolle und -überwachung siehe im Überblick Stamm [1989]; Cassidy [1994] und [1996]; besonders in Bezug auf die MPG Heinemann [2001]. Detaillierter sind die frühen Studien von Stamm [1981] zur Institutionalisierung der Forschungsförderung nach 1945, und von Osietzky [1984] zu außeruniversitären Forschungseinrichtungen. Zur Ausbeutung der deutschen Wissenschaften siehe für den Westen Gimbel [1990] und für den Osten Mick [2000].

1338 Cassidy [1994] S. 229f. Mehr zum Kontrollratsgesetz Nr. 25 und den Auswirkungen in der Göttinger Physik folgt im Abschnitt 3.7.

1339 Zu Blount siehe Osietzky [1984] S. 98; Alter [1990] S. 745.

1340 Über Molekularstrahlen verfasste Fraser zwei Bücher: Fraser [1931] und [1937].

${ }^{1341}$ Eine ausführliche Darstellung Bernals über den Wert und die Funktion der Wissenschaft von marxistischem Standpunkt aus findet sich in Bernal [1939/86]; siehe auch Bernal [1947]. Dass Fraser Bernals Ansichten nahe stand, berichtet Osietzky [1984] S. 98, 105. Bei der Frage von Neugründungen von Instituten in Deutschland zeigte sich Fraser besonders an einem Institut für Bauwesen interessiert, das nach Bernals Vorstellungen gebildet werden sollte.

1342 Heinemann [2001] S. 182. 


\subsubsection{Die Fortsetzung der Forschung in den Göttinger Instituten}

Nachdem in den ersten Monaten der Besatzung eine Basis für die Fortsetzung von Friedensforschung geschaffen worden war, sandten die Göttinger Physiker im September 1945 folgende Liste an das Military Government, um die Genehmigung zur Wiederaufnahme eigenständiger wissenschaftlicher Forschungen für die angegebenen Themen zu erhalten. Die Einsendung dieser Liste wurde vom Dekan Eucken als formelle Notwendigkeit bezeichnet. 1343

\begin{tabular}{|c|c|c|}
\hline Institute & Subject of the scientific research & Responsible Workers \\
\hline$[\ldots]$ & {$[\ldots]$} & {$[\ldots]$} \\
\hline \multirow{2}{*}{$\begin{array}{l}\text { Institut für angewandte } \\
\text { Mechanik }\end{array}$} & Mechanical vibrations and waves & Dr. Stellmacher \\
\hline & Gyroscope, regulators, measurement of time & Prof. Schuler \\
\hline$[\ldots]$ & {$[\ldots]$} & {$[\ldots]$} \\
\hline $\begin{array}{l}\text { Erstes Physikalisches } \\
\text { Institut }\end{array}$ & Investigations of optical properties and electric conductivity of crystals & $\begin{array}{l}\text { Prof. Pohl, Prof. Mollwo, } \\
\text { Dr. Stöckmann }\end{array}$ \\
\hline \multirow{6}{*}{$\begin{array}{l}\text { Zweites Physikalisches } \\
\text { Institut }\end{array}$} & Mass spectroscopy & Dr. Walcher, Dr. Paul, Brix \\
\hline & Research on atomic spectra & $\begin{array}{l}\text { Prof. Kopfermann, } \\
\text { Dr. Meyer }\end{array}$ \\
\hline & Research on fast electrons and hard X-rays & Prof. Kopfermann, Dr. Paul \\
\hline & Research on spectra of the ions of rare earth crystals & Dr. Hellwege \\
\hline & Research on gaseous discharges & Dr. Walcher \\
\hline & Research on natural and artificial radioactivity & $\begin{array}{l}\text { Prof. Kopfermann, } \\
\text { Dr. Paul, Dr. Walcher }\end{array}$ \\
\hline \multirow[t]{3}{*}{$\begin{array}{l}\text { Institut für Theoretische } \\
\text { Physik }\end{array}$} & $\begin{array}{l}\text { Theoretical work on the following fields of investigation: thermodynamics, } \\
\text { electromagnetic field, quantumtheory of radiation }\end{array}$ & Prof. Becker \\
\hline & Theory of electron, astrophysics & Prof. Flügge \\
\hline & Ferromagnetism, quantumtheory of radiation & Prof. Döring \\
\hline $\begin{array}{l}\text { Institut für Angewandte } \\
\text { Elektrizität }\end{array}$ & $\begin{array}{l}\text { Works out of the sphere of the piecoelectricity, dielectric constants, conductibility } \\
\text { of electrolyts, transformation of amorph metals into crystalline form }\end{array}$ & Dr. Severin \\
\hline
\end{tabular}

Tabelle 18 Liste der Forschungsprojekte physikalischer Institute vom September 1945. ${ }^{1344}$

Auf Vorschlag Kopfermanns wurde folgender, in holprigem Englisch formulierter Zusatz unter der Auflistung der physikalischen Institute eingefügt: "All these themes have been gone into in detail by an Allied Scientific Committee, and been agreed by them as de-militarised research themes for the case of research to be reopened." 1345 Ende November genehmigte der Kontrolloffizier L. H. Sutton alle aufgelisteten Forschungsvorhaben mit Ausnahme jener des II. Physikalischen Instituts. Offensichtlich bestand zwischen Sutton und Kopfermann zu diesem Zeitpunkt noch nicht jenes Vertrauensverhältnis, das Kopfermann mit den ersten Forschungsinspektoren erreicht hatte. Sutton wünschte genauere Angaben über das verwendete physikalische Instrumentarium, er wollte wissen, ob die angegebenen

1343 Dekan Eucken an die Institutsdirektoren, 6. September 1945. UAG, Math. Nat. 56.

1344 Die Liste wurde am 22. September 1945 an das Military Government gesandt. UAG, Math. Nat. 56. 
Wissenschaftler schon zuvor am selben Institut diesen Forschungen nachgegangen waren, bevor der Forschungsstopp erlassen wurde, und außerdem sollte Kopfermann angeben, welches „Allied Scientific Committee“ die Forschungen genehmigt habe. ${ }^{1346}$ In seiner Antwort bekräftigte Kopfermann zu Beginn, dass es sich bei allen Themen im wesentlichen um Grundlagenforschung handle. Wie erbeten listete er die physikalischen Instrumente auf, mit denen die in der vorigen Tabelle aufgeführten sechs verschiedenen Forschungsthemen des II. Physikalischen Institut durchgeführt wurden: ${ }^{1347}$

1) Massenspektrometer, konstruiert von Walcher und Paul, ${ }^{1348}$

2) mehrere Glas- und Quarz-Spektrographen sowie Fabry-Pérot-Etalons, ${ }^{1349}$

3) Elektronenbeschleuniger zur Herstellung harter Röntgenstrahlen und schneller Elektronen, bestellt vom gynäkologischen Institut der Universität bei den SiemensReiniger-Werken, ${ }^{1350}$

4) zwei konkave Beugungsgitter,

5) gewöhnliches Hoch-Vakuum-Gerät und Entladungsröhren,

6) einen $100 \mathrm{kV}$ Hochspannungsgenerator mit passender Entladungsröhre, GeigerMüller-Zählrohre und Verstärker, sowie eine ( $\mathrm{Ra} \alpha+\mathrm{Be})$-Quelle von etwa $100 \mathrm{mg}$ Radium-Äquivalent. ${ }^{1351}$

Alle Forschungen seien von den genannten Physikern bis zur Besetzung Göttingens durch alliierte Truppen durchgeführt worden. Für die unter Punkt 3 und 6 angeführten Themen waren nur vorbereitende Arbeiten durchgeführt worden. „It may be added that all research work the continuation of which is proposed has in the past being considered [sic] as fundamental research exclusively and was not underlying any restriction concerning publishing of any details of apparatus and results." Kopfermann bemühte sich also weiterhin, die Forschungen in seinem Institut ausschließlich als Grundlagenforschung darzustellen. Um auch Sutton davon zu überzeugen, wies Kopfermann darauf hin, dass diese Sichtweise auch von Goudsmit, Smythe und Kuiper vertreten wurde und deren Genehmigung der Forschungsarbeiten von Major Fisher an Major Wilson vom 126 Military Government Detachment weitergegeben wurde. In dieser Abteilung der Militärregierung saß nun der

\footnotetext{
1345 Eingefügt nach Vorschlag Kopfermanns vom 12. September 1945. UAG, Math. Nat. 56.

1346 Schreiben Suttons betreffend „Research-work in the Faculty of Science”, 23. November 1945. UAG, Math. Nat. 56. Siehe auch Protokoll der Fakultätssitzung vom 30. November 1945. GPAMNFG, Protokollbuch III der mathematisch-naturwissenschaftlichen Fakultät WS 1927/28 - SS 1946. Obwohl die Forschungsthemen im November 1945 genehmigt wurden, teilte Eucken der Fakultät im Mai 1946 mit, dass die Institute für angewandte Mechanik und angewandte Elektrizität eine Forschungserlaubnis noch nicht erhalten hätten. Protokoll der Fakultätssitzung vom 3. Mai 1946. GPAMNFG, Protokollbuch III der mathematischnaturwissenschaftlichen Fakultät WS 1927/28 - SS 1946.

1347 Kopfermann an Sutton, 11. Dezember 1945. Auch das folgende Zitat ist diesem Schreiben entnommen. UAG, Math. Nat. 56.

$1348 \mathrm{Zu}$ den Massenspektrographen siehe die Beschreibungen in Walcher [1938], [1939], [1943]a, [1948].

1349 Zu den Fabry-Pérot-Etalons siehe Kopfermann [1940] S. 79f.

$1350 \mathrm{Zu}$ dem in 1947 in Göttingen aufgestellten Betatron und den damit durchgeführten Forschungen in Zusammenarbeit mit dem gynäkologischen Institut unter Prof. Heinrich Martius siehe Abschnitt 3.7.2.
} 
Kontrolloffizier Sutton, der sich mit Kopfermanns Erläuterungen offenbar zufrieden gab und die Forschungen genehmigte. Dass Kopfermann sogar die Umgehung der im Kontrollratsgesetz Nr. 25 festgeschriebenen Forschungsbeschränkungen erreichen konnte, wird weiter unten in Abschnitt 3.7.2 dargestellt.

Trotz Genehmigung der angegebenen Forschungen auch der Institute der angewandten Physik Ende 1945, die auch militärische relevante Themen wie Kreiselforschung und Regelungstechnik beinhalteten, kam es ein Jahr später zu einer grundlegenden Umgestaltung der Institute und ihrer fachlichen Ausrichtung. Die Gründe hierfür lagen aber weniger in der Forschungskontrolle als in einem zufälligen zeitlichen Zusammentreffen verschiedener anderer Faktoren, auf die in den Abschnitten 5.4.4 und 5.5 genauer eingegangen wird.

In Tabelle 18 fällt auf, dass im I. Physikalischen Institut alle Mitarbeiter an demselben Thema forschten, während in den anderen Instituten eine differenziertere Zuordnung von Themen und Wissenschaftler erkennbar ist. Dies ist eine Folge der Eigenart der Forschungsorganisation in diesem Institut und hängt mir der Machtposition des Institutsdirektors Pohl zusammen. In Pohls Institut wurde neben militärischer Auftragsarbeit ein lange angelegtes Programm der Grundlagenforschung durchgeführt. Die Fragestellungen dieser Forschung ergaben sich zu jedem Zeitpunkt aus den experimentellen Ergebnissen der zuvor durchgeführten Arbeiten und scheinen unabhängig von politischen und weltgeschichtlichen Ereignissen, ja sogar teilweise unabhängig von physikalischen Fortschritten anderer verwandter Programme, gewesen zu sein. Wegen dieser Unabhängigkeit konnte das Pohl'sche Forschungsprogramm ohne große Probleme in der Besatzungszeit fortgeführt werden. Das interessante Eigenleben der Pohl-Schule wird im folgenden Abschnitt eingehend untersucht.

\subsection{Die Pohl-Schule der experimentellen Festkörperphysik}

Das Besondere an der Forschung im I. Physikalischen Institut ist die Konstanz des Themas und der Fragestellung über drei Jahrzehnte. Weitgehend abgekoppelt von den bedeutenden Entwicklungen in der theoretischen Physik, die das physikalische Weltbild grundlegend veränderten, pflegte Pohl eine betont auf das Experiment konzentrierte Schule einer Forschungsrichtung, die später den Namen Festkörperphysik erhielt. Im Zentrum stand die Untersuchung der elektrischen und fotochemischen Eigenschaften von 
Alkalihalogenidkristallen. Um Pohls Forschungsprogramm einordnen zu können, wird zuerst ein kurzer Überblick über die wichtigsten Entwicklungslinien in der beginnenden Festkörperphysik gegeben.

Von einer physikalischen Subdisziplin der Festkörperphysik kann man erst in den vierziger Jahren und vor allem nach dem Zweiten Weltkrieg sprechen. Davor fehlte den vielen Physikern, die sich mit der Untersuchung der Eigenschaften fester Körper befassten, ein eigener sozialer, institutioneller und kognitiver Rahmen. Sie kamen aus den unterschiedlichen, damals existierenden Subdisziplinen, und ihre Erforschung der Festkörper war in diesen jeweiligen disziplinären Rahmen eingebettet. ${ }^{1352}$ Unter festen Körpern verstand man bis in die vierziger Jahre nur Kristalle. Die elektrischen Eigenschaften erklärte man sich Anfang des 20. Jahrhunderts mit dem Modell eines freien Elektronengases, doch die klassische Physik reichte zur Erklärung mikroskopischer Vorgänge in Kristallen nicht aus. Rasche Fortschritte im Verständnis wurden mit der Anwendung der neuen Quantenmechanik auf den Festkörper ab 1926 erzielt. Pauli erkannte, dass auf das freie Elektron in Metallen die Fermi-Dirac-Statistik anzuwenden sei. Eine Weiterentwicklung dieser Elektronentheorie fand durch Paulis Lehrer Sommerfeld statt. ${ }^{1353}$ Eine ganze Reihe junger Theoretiker rund um Sommerfeld befasste sich in Folge mit der Ausarbeitung einer quantenmechanischen Theorie der Metalle (Heisenberg, Peierls, Bethe, Eckart, Houston, Pauling). Einen für die Zukunft besonders bedeutenden Beitrag lieferte Felix Bloch im Jahr 1928 mit seiner quantenmechanischen Studie der Wellenfunktion von Elektronen in Gittern. Damit schuf er die Grundlage der vielleicht wichtigsten Theorie der Festkörperphysik, nämlich des Bändermodells. Eine Verallgemeinerung und Vertiefung erfuhr das Modell durch Rudolf Peierls und Léon Brillouin. Alan Wilson aus Cambridge wandte 1931 dieses Modell zur Erklärung der Halbleiter an. Er beschrieb den Halbleiter als einen Isolator mit einem Zwischenraum zwischen zwei Bändern, den Elektronen mittels Anregung überwinden konnten. Wilsons Modell war ein Schritt zu einer besseren Berechnung der Festkörper und brachte eine Annäherung von Theorie und Experiment. Es wird heute sogar als Geburtsakt der Halbleiterphysik bezeichnet. ${ }^{1354}$ Eine erste Anwendung fand das Modell durch Wigner und Seitz in Princeton und durch Slater am MIT; weiter ausgearbeitet wurde es neben anderen

1352 Zur Formung einer eigenen Subdisziplin „Festkörperphysik“ siehe Kragh [1999] Chap. 24. Die Festkörperphysik vor den 40er Jahren zeigt strukturelle Ähnlichkeiten mit der Spektroskopie bis etwa 1930. Die Frage, wie und ob sich die Spektroskopie zu einer Disziplin entwickelte, analysierte eingehend und unter Angabe klarer Kategorien der Disziplinbildung, die Vergleiche mit anderen Entwicklungen vereinfachen und begünstigen, Hentschel [2002].

1353 Siehe Eckert [1993] Kap. 6.

1354 Madelung [2003] S. 180. 
durch Frenkel, Joffe und Nordheim. Eines der erfolgreichsten Institute, das sich Anfang der dreißiger Jahre den Festkörpern zuwandte, war jenes von Nevill Mott geleitete an der Universität in Bristol. Einen ersten Abschluss der quantenmechanischen Theorie des Festkörpers markiert der fast 300 Seiten lange Artikel von Sommerfeld und Bethe im Handbuch der Physik 1933.

Der schon lange bekannte gleichrichtende Effekt der Halbleiter erfuhr eine theoretische Erklärung erst um 1940 durch Walter Schottky, Mott und Davydov. In diesem Jahr erschien auch eine der ersten Monografien zur Festkörperphysik: Frederick Seitz' Modern Theory of Solids. Für die beiden Halbleitertypen der Elektronen- und Löcherleitung führte Jack Scaff 1941 die Bezeichnungen n-type und p-type ein. Während des Krieges wurden Halbleiter zu einem wichtigen Faktor in der Radarentwicklung. In solcher militärisch ausgerichteter Forschung stellte sich zuerst in den USA eine p-n-Verbindung als ausgezeichneter Gleichrichter heraus. Die wichtigste Erfindung in Verbindung mit Halbleitern war der Transistor. Schon 1939 entwickelte William Shockley in den Bell Laboratories das Konzept des Feldeffekt-Transistors, das allerdings erst in den 50er Jahren umgesetzt werden konnte. Einen funktionierenden Spitzen-Transistor entwickelten Shockley, Walter Brattain und John Bardeen 1947/48, wofür die drei Forscher 1956 mit dem Nobelpreis ausgezeichnet wurden. ${ }^{1355}$

Wie dieser kurze Abriss zur Geschichte der Festkörperphysik zeigt, kamen die wesentlichen Fortschritte durch Beiträge der theoretischen Physik zustande. Die Beiträge der Göttinger Physiker um Pohl werden in solchen Kurzfassungen der Entwicklungsgeschichte wenn überhaupt dann nur am Rande erwähnt. Hilsch und Pohl werden zum Beispiel von Helge Kragh in Zusammenhang mit der Entwicklung des Transistors erwähnt. Schon 1938 bauten sie einen Dreielektrodenkristall, mit dem sie eine mehr als 100-fache Verstärkung des Stromes erzielten. Diese Triode hatte aber wegen der geringen Wanderungsgeschwindigkeit der Elektronen keinen praktischen Wert und wurde von Pohl auch nicht weiterentwickelt. ${ }^{1356}$ Die Bedeutung der Göttinger Arbeiten lag vor allem darin, dass sie relativ unabhängig von den theoretischen 'Grundlagen' ein umfangreiches, hauptsächlich phänomenologisches Wissen ansammelten. Die Untersuchung der elektrischen Eigenschaften von Nichtmetallen

\footnotetext{
1355 Diese kurze Darstellung der frühen Festkörperphysik basiert vor allem auf Kragh [1999] Chapter 24 und Kant [1988].

1356 Kragh [1999] S. 371. Bei Kant [1988] findet Pohl keine Erwähnung. Eine Beschreibung und Abbildung des Dreielektrodenkristalls geben Eckert \& Schubert [1986] S. 126f., deren historische Studie der Kristall-

Forschungen auch ausführlich auf die Pohl-Schule eingeht. Die Halbleiterforschung in Deutschland wird mit starkem Bezug auf die Nachkriegszeit behandelt von Handel [2003] und Madelung [2003].
} 
zeigte, welch große Auswirkung geringste Verunreinigungen und Unregelmäßigkeiten eines Kristalls auf dessen Leitfähigkeit ausüben. Je nach Art der Verunreinigung besaß der Halbleiter unterschiedliche Leitungseigenschaften.

In Pohls Institut wurden mehrere Gruppen von eng miteinander verknüpften Forschungsthemen der Festkörperphysik durchgeführt. Am Beginn standen lichtelektrische Erscheinungen von Kristallen. Danach folgten Arbeiten über die optischen Eigenschaften der mit verschiedenen Metallen aktivierten Alkalihalogenidphosphore und über die Lichtabsorption der reinen Alkalihalogenide, sowie Untersuchungen zur Fotochemie dieser Kristalle. Die bekanntesten Arbeiten der Pohl-Schule sind jene über die Farbzentren der Alkalihalogenide. Der ab 1930 benutzte Name „Farbzentren“ rührt daher, dass einzelne atomare Zentren in kleinsten Konzentrationen kräftige Färbungen bei sonst farblosen Kristallen hervorrufen. Bis man allerdings zu dieser Erklärung der schon seit Mitte des 19. Jahrhunderts bekannten Farberscheinungen gelangte, war eine langjährige und konsequente Verfolgung eines gezielt darauf ausgelegten Forschungsprogramms notwendig. Es konnte geklärt werden, dass die Färbung auf schmale Absorptionsbanden im sichtbaren Bereich zurückgeht (Gyulai 1925). Die Absorption wurde gedeutet als der Übergang zwischen zwei ungestörten Energiestufen des Kristalls (Smakula 1930). ${ }^{1357}$ Die Farbzentren sind einerseits Spender und andererseits Empfänger von Elektronen (Pick 1938). Unter Einbeziehung der thermodynamischen Fehlordnungen der Kristalle kam die Pohl-Schule um $1938 \mathrm{zu}$ dem einfachen Modell, dass das Farbzentrum aus einem in einer Anionenlücke eingelagerten Elektron besteht. ${ }^{1358}$ Bei Anlegen eines elektrischen Feldes bewegen sich diese Elektronen: Man beobachtet eine wandernde Farbzentrenwolke. ${ }^{1359}$

Neben den Leitungsvorgängen im Inneren eines Halbleiters waren auch die Eigenschaften der Kontakte zwischen Halbleitern und Metallen sowie zwischen zwei Halbleitern von Interesse, da diese sich grundlegend vom Verhalten der Kontakte zwischen zwei Metallen unterschieden. Die Pohl-Schule widmete sich der genauen Messung dieser verschiedenen Phänomene. Das so gewonnene, verlässliche Datenmaterial konnte aufgrund des entwickelten theoretischen Verständnisses ab den vierziger Jahren systematisch angewendet werden. Durch Hinzufügung von Fremdatomen (Dotieren) konnte die Leitfähigkeit von Halbleitern gezielt

\footnotetext{
1357 Später beschreibt man die Absorption als eine Anregung von Elektronen der Zentren von einem Grundzustand in einen höheren angeregten Zustand.

1358 Siehe zum Beispiel Pohl [1940]a S. 190, 270. In Pohl [1938] S. 38 heißt es noch, die Färbung „entsteht im einfachsten Fall durch neutrale Alkaliatome, die irgendwie lose im Kristallinnern gebunden sind. Wir nennen sie kurz Farbzentren."

1359 Dieser eindrucksvolle Demonstrationsversuch findet sich beschrieben in Pohl [1940]a S. 274. 
beeinflusst werden. Eine technische Anwendung erfuhren die Halbleiter bereits in den vierziger Jahren zum Beispiel als Heißleiter, Trockengleichrichter und Widerstandsfotozellen.

Es gab mehrere Gründe, warum Pohl und seine Mitarbeiter einem derart eigenständigen Forschungsprogramm über drei Jahrzehnte treu blieben und dabei kaum eine Verzahnung mit den theoretischen Fortschritten erreichten. Zuerst muss die dominierende Rolle Pohls genannt werden, die seine Mitarbeiter in eine bestimmte Richtung zwang. Gerlach schrieb 1978 über Pohl: „Das Institut war sein Reich, er herrschte nicht, er beherrschte alles [...]“. ${ }^{1360}$ Der Einfluss erreichte eine unglaubliche Tiefe. Seine Schüler übernahmen nicht nur die Experimentiermethoden, sondern auch seine Art im „Sehen der Probleme“ und seinen Stil des Schreibens. „Nach wenigen Minuten des Vortrags, nach wenigen Seiten des Lesens in einem Lehrbuch erkennt man den Pohlschüler.“1361 Die Dominanz von Pohl bewirkte, dass seine Institutsmitarbeiter eine einheitliche Forschungsrichtung verfolgten. Er kontrollierte die Arbeiten und beteiligte sich an der Abfassung, ohne dass er immer auch als Mitautor aufgeführt war. In einer Würdigung von Pohls Schaffen heißt es daher 1944: „Will man sich über den Gesamtumfang der bisherigen wissenschaftlichen Leistung Pohls ein Bild machen, so darf man in Referatenblättern nicht nur unter dem Namen Pohl suchen, sondern muß das Gesamtschaffen des Göttinger I. Physikalischen Instituts heranziehen.“1362

Pohls Credo, „Theorien kommen und gehen, Tatsachen bleiben“, gab er auch den Mitarbeitern deutlich zu spüren. Pohl riet ihnen, sich „nicht in Diskussionen mit Theoretikern einzulassen, davon verstünden wir doch nichts."1363 Der Hintergrund, der zu diesem Ratschlag führte, mag in den von Born, Franck und Pohl gemeinsam abgehaltenen Kolloquia gelegen haben, wo es ,ständig kleine Gefechte zwischen den extremen Experimentalisten aus Pohls Schule und meinen [Borns] Theoretikern“ gab. ${ }^{1364}$ Pohl zeigte Härte gegenüber den Theoretikern, wenn sie die Experimentalphysik nicht genügend beachteten. Borns Schüler Max Delbrück ließ er in der mündlichen Doktorprüfung durchfallen, weil er einige Fragen aus der ,praktischen Physik“ nicht beantworten konnte. ${ }^{1365}$ Andererseits bestand ein Kandidat, der auf die Frage, was Trägheit sei, wortlos ein Blatt Papier unter einem Aschenbecher wegzog. Born war schockiert, doch Pohl fand es fantastisch klar. ${ }^{1366}$

\footnotetext{
1360 Gerlach [1978] S. 219.

1361 Achilles [1977] S. 159.

1362 Gudden [1944] S. 167.

1363 Mollwo in einem unveröffentlichten Manuskript, 1981, zitiert nach Eckert \& Schubert [1986] S. 122.

1364 Born [1975] S. 289.

1365 Born [1975] S. 322.

1366 Achilles [1977] S. 159.
} 
Es ist einsichtig, weshalb sich die vom Patriarchen abhängigen Forscher an die im Institut geltenden 'Spielregeln' hielten. Warum aber stand Pohl selbst der Theorie so skeptisch gegenüber? Ein Grund lag in seinem zu schnellen Studium, das ihm eine „völlig unzureichende Ausbildung“" auf den Weg mitgab. ${ }^{1367} 1903$ legte er das Abitur am humanistischen Gymnasium Johanneum in Hamburg ab, und schon im Juni 1906 promovierte er bei Emil Warburg an der Universität Berlin. Er bedauerte immer wieder seinen Mangel an mathematischen Fertigkeiten, der durch das kurze, sehr experimentell ausgerichtete Studium verschuldet sei und ihm den Weg zur theoretischen Physik verschlossen habe. „Ich habe mich immer sehr wenig um die Theorie gekümmert; mich hat immer sehr viel mehr die experimentelle Tatsache interessiert.“1368 Gerlach sprach sogar von einem ,auf Mathematik verzichtenden Denken“ Pohls. ${ }^{1369}$ Pohls Abneigung zur Theorie schloss aber nicht aus, dass theoretische Modelle in seinem Institut häufig diskutiert wurden. ${ }^{1370}$ Auch die mathematische Auswertung der Experimente war eine Selbstverständlichkeit. Allerdings wurde in den Veröffentlichungen eine vorsichtige Formulierung bei theoretischen Interpretationen gewählt, um die Gültigkeit der Arbeit nicht durch Spekulationen einzuengen. Beispielsweise schloss er an die Deutung eines Phänomens die Einschränkung an, was „,wirklich erfolgt, soll dahingestellt bleiben. Vielleicht handelt es sich um ..."1371

Noch ein weiterer Grund ist für die Eigenständigkeit von Pohls Forschungsprogramm verantwortlich. Als Pohl in einem Interview zu den Arbeiten von Wilson der frühen dreißiger Jahre gefragt wurde, in denen das Bändermodell in Bezug auf Halbleiter formuliert wurde, antwortete er offen, dass er Wilsons Arbeiten nicht zur Kenntnis genommen hatte. „Ich habe immer sehr wenig Literatur gelesen. Aber es geht auch so."1372 Pohl kokettierte mit seiner betonten Beschränkung aufs Experiment und den damit gefundenen 'Tatsachen'. Er zeigte aber ein gutes Gespür dafür, welche Datenerfassungen von allgemeinerem physikalischen Interesse waren. Frederick Seitz bemerkte 1946 mit Erstaunen, dass die Göttinger genau diejenigen Experimente ausgeführt hatten, die für eine Interpretation der Halbleiterphänomene auf Basis der modernen Atomtheorie notwendig waren, obwohl sie an

\footnotetext{
1367 Dies schrieb Pohl 1966, zitiert nach Eckert \& Schubert [1986] S. 116.

1368 Interview mit Pohl, 7. Juli 1974, NBL. Mollwo [1978] S. 16 berichtet: „Immer wieder pflegte er seine Mitarbeiter zum Messen anzuhalten.“

1369 Gerlach [1978] S. 219.

1370 Siehe Stöckmann [1978] S. 33.

1371 Pohl [1938] S. 39. Siehe auch Eckert \& Schubert [1986] S. 122f.

1372 Interview mit Pohl, 7. Juli 1974, NBL. Joos berichtet, dass „,es geht auch so“ ein von Pohl oft gebrauchter Trostspruch war. Joos [1954] S. 339. Siehe auch Mollwo [1978] S. 17.
} 
dieser Theorie gar kein tieferes Interesse besaßen. ${ }^{1373}$ Trotz der weitgehenden Ignoranz der theoretischen Erkenntnisse in Pohls Forschungsprogramm waren seine Untersuchungen für die Weiterentwicklung der (theoretischen) Festkörperphysik von großem Nutzen. Mott und Gurney schreiben 1940: „The properties of these coloured crystals have been studied in great detail by R. W. Pohl and his co-workers, and the results that they have achieved enable a fairly complete theoretical picture to be given of these phenomena in alkali-halides." 1374 Der Erfolg lag auch daran, dass Pohl es verstanden hatte, fähige Mitarbeiter an sich zu binden. Laut Heinz Pick sei er aber im Schlepptau seiner Mitarbeiter gegangen und nicht die tragende Figur in der Forschung gewesen. Die entscheidenden Impulse seien meist von den Mitarbeitern gekommen. Pohl griff die neuen Ideen schnell auf und förderte deren Umsetzung mit Begeisterung. Pohl sei aber kein kreativer Forscher gewesen. ${ }^{1375}$ Picks Urteil bezieht sich auf die letzten 15 Jahre von Pohls Zeit als Institutsdirektor; zuvor mag Pohl wohl eine aktivere Rolle in der Forschung eingenommen haben.

Während die Erforschung von Ionenkristallen, wie sie im Göttinger Institut ausgiebig gepflegt wurde, in den zwanziger Jahren eine relativ neue Forschungsrichtung darstellte, an der nur eine beschränkte Zahl von Physikern beteiligt waren, so zeigte sich nach den Erfolgen der theoretischen Erklärung der Phänomene in Halbleitern ab den vierziger Jahren, als sich die Festkörperphysik als eigenständige Subdisziplin etablierte, ein reges internationales Interesse an den Kristalleigenschaften. Diese veränderte Situation fiel in jene Zeitspanne, die Pohls letztes Jahrzehnt seiner Amtszeit als Institutsdirektor markiert, und es stellt sich die Frage, wie die Göttinger darauf reagierten. Um diese Frage zu klären, untersuche ich im folgenden die Arbeiten der Pohl-Schule aus dieser Zeit auf ihre Zitiergewohnheiten. Damit soll gezeigt werden, wie sich diese starke Schulbildung in den Publikationen niederschlug. Unterschiede in den Arbeiten der Dozenten zu jenen der Doktoranden werden genauso untersucht wie die Frage, wann und von wem deutsche wie angloamerikanische theoretische Arbeiten zur Kenntnis genommen wurden.

\footnotetext{
1373 „It is a rather remarkable characteristic of this [Pohl's and his co-workers'] work that, although the investigators have never had a very deep interest in the fundamental interpretation of the properties of the discolored alkali halides in terms of modern atomic theory, the experiments they have carried out have been exactly those that are needed to furnish the basis for such an interpretation. This fact indicates that they possess a very deep intuitive sense concerning the physically important quantities which enter into the problem." Seitz [1946] S. 384. Eine deutsche Übersetzung davon findet sich bei Eckert \& Schubert [1986] S. 122.

1374 Mott \& Gurney [1940] S. 111.

1375 Interview mit Pick, 2. Oktober 1981. NBL.
} 


\subsubsection{Analyse der Zitiergewohnheiten der Pohl-Schule}

\subsubsection{Zur Methode}

Die Pohl-Schule besteht aus Pohl selbst und denjenigen seiner Mitarbeiter, die einen wesentlichen Teil ihrer Ausbildung bei ihm erfahren haben; das sind insbesondere seine Doktoranden und Assistenten. ${ }^{1376}$ Nicht dazugerechnet werden Gastwissenschaftler am Institut, die dort nur kurzzeitig einer bestimmten Forschungsfrage nachgingen und ihre Ausbildung anderswo erfahren haben. In den Jahren 1919 bis 1953 sind insgesamt 388 Veröffentlichungen aus dem I. Physikalischen Institut hervorgegangen, ${ }^{1377}$ aus denen 71 ausgewählt und analysiert wurden, die von der oben definierten Personengruppe aus den Jahren 1938 bis 1954 stammen. Aus thematischen Gründen aus der Untersuchung ausgeschlossen wurden jene Arbeiten, die keinen Fragen physikalischen Inhalts nachgehen, wie zum Beispiel Rezensionen ${ }^{1378}$ oder Beiträge zu Fragen des Physik-Schulunterrichts ${ }^{1379}$. Eine weitere Beschränkung liegt darin, dass nur Zeitschriftenaufsätze analysiert wurden; Bücher und unpublizierte Arbeiten wurden ignoriert. Der physikalische Inhalt der Aufsätze spielte bei der Auswahl keine Rolle. Die meisten Arbeiten widmen sich den vielfältigen Eigenschaften der Alkalihalogenidkristalle. Pohl publizierte aber gelegentlich auch zu grundlegenden physikalischen Fragen wie zum Beispiel zum Aufbau des Maßsystems und den Eigenschaften von Einheiten. ${ }^{1380}$ Auch wenn diese Arbeiten vermutlich mehr aus der Auseinandersetzung mit seiner Einführungsvorlesung und den daraus entstandenen Lehrbüchern entsprangen, wurden sie in die Zitationsanlyse mit einbezogen. Da Pohl darin äußerst sparsam zitiert, bleibt insgesamt die Verlässlichkeit der Schlüsse zur eigentlichen Pohl-Schule der Kristallphysik erhalten. Durch den Verzicht auf eine inhaltliche Aussortierung eröffnet sich die Möglichkeit, über die 'Breite' und 'Belesenheit' der PohlSchule im Untersuchungszeitraum Aussagen zu machen.

Eine Schwierigkeit ergibt sich in der Erfassung der Zitate. Nicht nur Pohl selbst war in der Offenlegung der benutzten Quellen unpräzise. Es scheint ein Charakteristikum der PohlSchule zu sein, dass nicht alle benutzten Arbeiten explizit genannt werden. Manchmal wird

\footnotetext{
1376 Zur Pohl-Schule sind auch jene zu rechnen, die zwar anderswo promovierten, aber eine erhebliche Zeit unter Pohl gearbeitet haben. Ein Beispiel ist Ostap Stasiw, der 1929 bei Bothe promovierte und von 1931 bis 1937 Mitarbeiter von Pohl war, 1938 in Göttingen habilitiert wurde und schon 1937 Leiter des

Forschungslaboratoriums von Zeiss-Ikon in Dresden wurde.

1377 Die Gesamtzahl ist entnommen aus Minnigerode [1978] S. 56.

1378 Zum Beispiel Pohl [1940]d.

1379 Zum Beispiel Pohl [1952]b.
} 
im Text ein Name nur beiläufig erwähnt, wie zum Beispiel: „Im Anschluß an Hecht machen wir die Annahme, daß [...]", ${ }^{1381}$ ohne dass die entsprechende Arbeit von Hecht zitiert wird. Pohl selbst verfuhr in dieser Hinsicht noch strenger. Da es ihm anscheinend besonders um die physikalische Frage und nicht um die Ansichten einzelner Forscher ging, vermied er manchmal sogar die Namensnennung. Zum Beispiel schrieb Pohl, nachdem er festgestellt hatte, dass der Begriff der Dosis in der Physik nicht eindeutig definiert war: „Selbst das führende Lehrbuch der physikalischen Meßtechnik ließ uns im Stich“, ohne den Autor des Lehrbuchs zu nennen. ${ }^{1382}$ Beschränkt man sich nur auf die in den Fußnoten oder Literaturlisten eindeutig belegten Quellen, verliert man andere, offensichtlich zugrunde gelegte Arbeiten. Trotz dieses Mangels sind in den folgenden Listen nur die eindeutigen Zitate aufgenommen.

Dabei sind die Arbeiten zwei Gruppen zugeordnet: 1. Arbeiten von Pohlschülern oder aus Pohls Institut, 2. alle anderen Arbeiten. Die erste Gruppe umfasst mehr als die Pohl-Schule, wie sie oben definiert wurde. Hinzugezählt werden auch die Arbeiten von nur kurzzeitigen Mitarbeitern und Gästen im Institut, da diese Arbeiten unter Pohls Kontrolle durchgeführt wurden. Meßaufbau, verwendete Apparate und die Durchführung der Messungen waren ihm vertraut. Es ist anzunehmen, dass er deswegen diesen Arbeiten größeres Vertrauen schenkte. Da die Gäste nicht zur Pohl-Schule zu zählen sind, wurden auch nur die von ihnen in Göttingen durchgeführten Arbeiten, nicht aber ältere oder spätere, zur ersten Gruppe gezählt. ${ }^{1383}$ Anders wurde mit den eigentlichen Pohl-Schülern verfahren. Von diesen wurden auch spätere, nach ihrem Weggang von Göttingen verfasste Arbeiten weiterhin in die erste Gruppe gereiht. ${ }^{1384}$ Die Zuordnung der Arbeiten geschah auf Grund der Angaben in den jeweiligen Aufsätzen. Eine gute Hilfe war auch die Liste von 87 Arbeiten aus dem Göttinger Institut am Ende von Pohls Überblicksartikel von 1938. ${ }^{1385}$

\footnotetext{
1380 Siehe Pohl [1942]a, [1942]b, [1943], [1948], [1951]a, [1951]b; Pohl \& Stöckmann [1944]a, [1944]b.

1381 Rögener [1940] S. 222.

1382 Pohl [1951]a.

1383 Zum Beispiel wurde von Lenz nur die Arbeit [1927]b, die er auf Einladung Pohls in Göttingen verfasste, in die erste Gruppe aufgenommen, nicht aber Lenz [1924], [1925], [1927]a, die von der Pohl-Schule ebenfalls zitiert wurden.

1384 Zum Beispiel Gudden [1928], [1930], [1933].

1385 Siehe Pohl [1938] S. 52-54.
} 


\subsubsection{Die Daten}

Analysierte Arbeiten (71): ${ }^{1386}$

Ackermann [1940]; Akpinar [1940]; Domanic [1943]; Dorendorf [1951]; Dorendorf \& Pick [1950]; Fritzsche [1952]; Gericke [1950]; Harten [1949]a, [1949]b, [1950]; Heiland \& Kelting [1949]; Hilsch \& Pohl [1938]; Hoch [1940]; Intemann \& Stöckmann [1951/52]; Karabascheff [1941/42]; Kelting \& Witt [1949]; Kerkhoff [1951]; Martienssen [1951/52], [1952]; Martienssen \& Pick [1952]; Mollwo [1939], [1941], [1942], [1943]a, [1943]b, [1944], [1948]a, [1948]b, [1948/49]; Mollwo \& Stöckmann [1948]a, [1948]b; Petroff [1950]; Pick [1938], [1939], [1940], [1948], [1949], [1951], [1954]; Pick \& Pohl [1951]; Pick \& Weber [1950]; Pohl [1938], [1940]b, [1940]c, [1942]a, [1943], [1948], [1949], [1951]a, [1951]b, [1951]c, [1952]a; Pohl \& Stöckmann [1944]a, [1944]b, [1947], [1948], [1949]; Rögener [1940]; Rohn [1949]; Stöckmann [1946], [1949], [1950]a, [1950]b, [1950]c, [1951]a, [1951]b, [1952]; Thomas [1940]; Weber [1951]a; Witt [1950], [1952].

Das zeitliche Mittel der analysierten Arbeiten liegt bei 1947, sofern man alle Arbeiten gleich gewichtet.

\begin{tabular}{|c|c|c|c|}
\hline Aufsatz & $\begin{array}{l}\text { Zitierte Arbeiten der Pohl-Schule } \\
\text { (A) }\end{array}$ & andere zitierte Arbeiten (B) & $A: B$ \\
\hline $\begin{array}{l}\text { Hilsch \& Pohl } \\
\text { [1938] }\end{array}$ & Hilsch \& Pohl [1930]b, [1936]a. & $\begin{array}{l}\text { Zintl \& Harder [1931, [1935]; Schneider \& O’Bryan } \\
\text { [1937]. }\end{array}$ & $2: 3$ \\
\hline Pick [1938] & $\begin{array}{l}\text { Smakula [1930]a; Rögener [1937]; Hilsch \& Pohl } \\
\text { [1930]a, [1934], [1936]; Schaitberger [1937]; } \\
\text { Kleinschrod [1936]; Glaser \& Lehfeldt [1936]; } \\
\text { Glaser [1937]. }\end{array}$ & Smekal [1936]; Wolff [1936]. & $9: 2$ \\
\hline Pohl [1938] & $\begin{array}{l}\text { Gudden \& Pohl [1920]b, [1925]a; Hilsch [1927]a, } \\
\text { [1935], [1936], [1937]a, [1937]b; Lehfeldt [1933]a, } \\
\text { [1935]; Gudden [1930]; Gyulai [1925]b, [1926], } \\
\text { [1927]; Flechsig [1925], [1926], [1928], [1931]; } \\
\text { Pohl [1926], [1932], [1933], [1934]a, [1934]b, } \\
\text { [1935]a, [1935]b, [1936], [1937]a, [1937]b; Hilsch } \\
\text { \& Ottmer [1926]; Ottmer [1928]; Hilsch \& Pohl } \\
\text { [1929], [1930]a, [1930]b, [1930]c, [1931], [1932], } \\
\text { [1933]a, [1933]b, [1933]c, [1934], [1936]; Smakula } \\
\text { [1930]a, [1930]b, [1934]; Fesefeldt [1930]; } \\
\text { Gundelach [1930]; Mollwo [1931], [1933], [1935]a, } \\
\text { [1935]b, [1935]c, [1937]; Stasiw [1932], [1933], } \\
\text { [1934]a, [1934]b, [1935], [1936]a, [1936]b; Korth } \\
\text { [1932], [1933], [1935]; Blau [1933]; Bauer [1934]; } \\
\text { Mollwo \& Roos [1934]; Lüpke [1934]; Thiele } \\
\text { [1936]; Glaser \& Lehfeldt [1936]; Glaser [1936]a, } \\
\text { [1936]b, [1937]; Kleinschrod [1936]; Hohls [1937]; } \\
\text { Rögener [1937]; Pick [1938]. }\end{array}$ & $\begin{array}{l}\text { Schneider \& O'Bryan [1937]; Boer [1937]b; Eggert \& } \\
\text { Noddack [1927]; Sheppard \& Trivelli [1921]. }\end{array}$ & $74: 4$ \\
\hline $\begin{array}{l}\text { Mollwo } \\
{[1939]}\end{array}$ & $\begin{array}{l}\text { Pohl [1938]; Hilsch \& Pohl [1937]a; Mollwo } \\
\text { [1937]; Hilsch [1937]a; Honrath [1937]. }\end{array}$ & $\begin{array}{l}\text { Narayanaswamy [1935]; Krishnan \& Narayanaswamy } \\
\text { [1935]; Mukhopadhyya [1938]. }\end{array}$ & $5: 3$ \\
\hline Pick [1939] & $\begin{array}{l}\text { Pohl [1926], [1938]; Voßnack [im Druck]; Blau } \\
\text { [1933]; Rögener [1937]; Mollwo [1933]; Lüpke } \\
\text { [1934]; Korth [1935]; Stasiw [1936]a; Glaser \& } \\
\text { Lehfeldt [1936]; Pick [1938]. }\end{array}$ & $\begin{array}{l}\text { Koch \& Wagner [1937]; Schottky [1933], [1935]; Jost } \\
\text { [1936]a, [1937]; Jost \& Nehlep [1936]; Mott \& } \\
\text { Littleton [1938]a; Boer [1937]a; Mott [1938]. }\end{array}$ & $11: 9$ \\
\hline $\begin{array}{l}\text { Ackermann } \\
{[1940]}\end{array}$ & $\begin{array}{l}\text { Korth [1933]; Maslakowez [1928]; Pohl \& } \\
\text { Pringsheim [1912]. }\end{array}$ & Kohlrausch [1931/37]. & $3: 1$ \\
\hline $\begin{array}{l}\text { Akpinar } \\
{[1940]}\end{array}$ & $\begin{array}{l}\text { Korth [1935]; Mollwo [1939]; Kleinschrod [1936]; } \\
\text { Fesefeldt [1932]; Lüpke [1934]; Hilsch \& Pohl } \\
\text { [1929]; Maslakowez [1928]; Kyropoulos [1926]; } \\
\text { Koch [1929]. }\end{array}$ & - & $9: 0$ \\
\hline Hoch [1940] & $\begin{array}{l}\text { Gudden \& Pohl [1920]b, [1921]a, [1921]b, [1923]a, } \\
\text { [1923]b, [1925]c; Hilsch \& Pohl [1938]; Mollwo } \\
\text { [1933]. }\end{array}$ & Lenard [1928]; Riehl [1937]; Gisolf [1939]a. & $8: 3$ \\
\hline Pick [1940] & Pick [1938]; Domanic [erscheint demnächst]. & - & $2: 0$ \\
\hline Pohl [1940]b & Pohl [1940]a. & - & $1: 0$ \\
\hline Pohl [1940]c & Pohl [1940]a. & Classen [1905]. & $1: 1$ \\
\hline
\end{tabular}

1386 Die Titel und Erscheinungsorte dieser Arbeiten finden sich im Literaturverzeichnis. 


\begin{tabular}{|c|c|c|c|}
\hline $\begin{array}{l}\text { Rögener } \\
{[1940]}\end{array}$ & $\begin{array}{l}\text { Glaser \& Lehrfeldt [1936]; Glaser [1937]; Flechsig } \\
\text { [1928]. }\end{array}$ & - & $3: 0$ \\
\hline $\begin{array}{l}\text { Thomas } \\
{[1940]}\end{array}$ & $\begin{array}{l}\text { Pohl [1938]; Hilsch \& Pohl [1938]; Rögener [1937]; } \\
\text { Kleinschrod [1939]; Hilsch [1937]a. }\end{array}$ & - & $5: 0$ \\
\hline $\begin{array}{l}\text { Mollwo } \\
{[1941]}\end{array}$ & $\begin{array}{l}\text { Mollwo [1932], [1937], [1939]; Apkinar [1940]; } \\
\text { Honrath [1937]. }\end{array}$ & Siedentopf [1905]. & $5: 1$ \\
\hline $\begin{array}{l}\text { Karabascheff } \\
{[1941 / 42]}\end{array}$ & $\begin{array}{l}\text { Pohl [1934]a, [1938]; Hilsch \& Pohl [1938]; } \\
\text { Lehfeldt [1933]a; Stasiw [1932], [1933]; Mollwo \& } \\
\text { Roos [1934]; Mollwo [1933]; Rögener [1937]; } \\
\text { Smakula [1934]. }\end{array}$ & - & $10: 0$ \\
\hline $\begin{array}{l}\text { Mollwo } \\
{[1942]}\end{array}$ & - & Greinacher [1941]. & $0: 1$ \\
\hline Pohl [1942]a & - & - & $0: 0$ \\
\hline Pohl [1942]b & - & Ulich [1941]. & $0: 1$ \\
\hline $\begin{array}{l}\text { Domanic } \\
{[1943]}\end{array}$ & $\begin{array}{l}\text { Pick [1938]; Glaser \& Lehfeldt [1936]; Rögener } \\
\text { [1937]; Thomas [1940]; Glaser [1937]. }\end{array}$ & - & $5: 0$ \\
\hline $\begin{array}{l}\text { Mollwo } \\
{[1943] \mathrm{a}}\end{array}$ & Bauer [1934]. & $\begin{array}{l}\text { Wood [1904]; Selenyi [1911]; Leistner [1924]; Leistner } \\
\text { \& Möbius [1924]; Schult [1927]; Boer [1933]; Lau } \\
\text { [1929]; Voigt [1902]. }\end{array}$ & $1: 8$ \\
\hline $\begin{array}{l}\text { Mollwo } \\
{[1943] b}\end{array}$ & $\begin{array}{l}\text { Stasiw [1933]; Mollwo \& Roos [1934]; Pick [1939]; } \\
\text { Kleinschrod [1936]; Smakula [1934]; Rögener } \\
\text { [1937]; Mollwo [1935]a, [1935]b , [1939]; } \\
\text { Karabascheff [1941/42]; Pohl [1927] ?. Aufl. 1943. }\end{array}$ & $\begin{array}{l}\text { Koch \& Wagner [1937]; Schottky [1935]; Jost [1936]a, } \\
\text { [1937]; Jost \& Nehlep [1936]; Wartenberg [1926]. }\end{array}$ & $11: 6$ \\
\hline Pohl [1943] & Pohl [1942]b. & - & $1: 0$ \\
\hline $\begin{array}{l}\text { Mollwo } \\
{[1944]}\end{array}$ & $\begin{array}{l}\text { Hilsch \& Pohl [1928], [1930]b; Fesefeldt \& Gyulai } \\
\text { [1929]; Fesefeldt [1930]; Fritsch [1935]; Bauer } \\
\text { [1934]; Gudden \& Pohl [1923]b. }\end{array}$ & $\begin{array}{l}\text { Gisolf, Groot \& Kröger [1941]; Gisolf [1939]a, } \\
\text { [1939]b; Pfund [1934]; Langmuir, Estermann \& Stern } \\
\text { [1923]; Reinders \& Hamburger [1932]. } 1387\end{array}$ & $7: 6$ \\
\hline $\begin{array}{l}\text { Pohl \& } \\
\text { Stöckmann } \\
{[1944] \mathrm{a}}\end{array}$ & Pohl [1930] 7. Aufl., [1927] 10. Aufl., [1943]. & - & $3: 0$ \\
\hline $\begin{array}{l}\text { Pohl \& } \\
\text { Stöckmann } \\
{[1944] \mathrm{b}}\end{array}$ & ( & Kohlrausch [1943]. & $0: 1$ \\
\hline $\begin{array}{l}\text { Stöckmann } \\
{[1946]}\end{array}$ & Gudden \& Pohl [1925]b; Hilsch \& Pohl [1937]a. & - & $2: 0$ \\
\hline $\begin{array}{l}\text { Pohl \& } \\
\text { Stöckmann } \\
{[1947]}\end{array}$ & $\begin{array}{l}\text { Gudden \& Pohl [1920]b, [1921]a, [1921]c, [1923]b, } \\
\text { [1924]; Hilsch \& Pohl [1937]a, [1939]; Hilsch } \\
\text { [1939]; Lehfeldt [1935]; Stasiw [1932]; Hecht } \\
\text { [1932]; Pohl [1932]; Mollwo [1935]a, [1943]b. }\end{array}$ & - & $14: 0$ \\
\hline $\begin{array}{l}\text { Mollwo } \\
{[1948] \mathrm{a}}\end{array}$ & $\begin{array}{l}\text { Hilsch \& Pohl [1929]; Bauer [1934]; Smakula } \\
\text { [1927]; Fesefeldt [1930]; Hilsch [1927]a. }\end{array}$ & Forro [1929]a. & $5: 1$ \\
\hline $\begin{array}{l}\text { Mollwo } \\
{[1948] \mathrm{b}}\end{array}$ & Mollwo \& Stöckmann [1948]a; Mollwo [1944]. & - & $2: 0$ \\
\hline $\begin{array}{l}\text { Mollwo \& } \\
\text { Stöckmann } \\
{[1948] \mathrm{a}}\end{array}$ & $\begin{array}{l}\text { Pohl [1938]; Hilsch \& Pohl [1937]a, [1939]; Pohl \& } \\
\text { Stöckmann [1947]; Glaser [1936]a; Mollwo [1944], } \\
\text { [?]; Gudden \& Pohl [1923]a. }\end{array}$ & $\begin{array}{l}\text { Fritsch [1935]; Baumbach \& Wagner [1933]; Skaupy } \\
\text { [1920]; Schottky [1943]; Seitz [1940]; W. Meyer } \\
\text { [1933]; Hartmann [1936]; Boer \& Verwey [1937]; } \\
\text { Miller [1941]. }\end{array}$ & $8: 9$ \\
\hline $\begin{array}{l}\text { Mollwo \& } \\
\text { Stöckmann } \\
{[1948] b}\end{array}$ & $\begin{array}{l}\text { Mollwo \& Stöckmann [1948]a; Mollwo [1948]b; } \\
\text { Hilsch \& Pohl [1937]a, [1939]; Pohl \& Stöckmann } \\
\text { [1947]; Gudden [1934]. }\end{array}$ & $\begin{array}{l}\text { James [1947]; Schottky [1944]; Fritsch [1935]; } \\
\text { Baumbach \& Wagner [1933]; W. Meyer [1933]; } \\
\text { Wilson [1932]a; Nordheim [1934]; Fröhlich [1936]. }\end{array}$ & $6: 7$ \\
\hline Pick [1948] & $\begin{array}{l}\text { Pohl \& Stöckmann [1947]; Mollwo \& Stöckmann } \\
\text { [1948]a; Mollwo [1948]b; Gudden \& Pohl [1921]b, } \\
\text { [1923]a; Pick [1949]. }\end{array}$ & Hinterberger [1942]. & $6: 1$ \\
\hline Pohl [1948] & - & - & $0: 0$ \\
\hline $\begin{array}{l}\text { Pohl \& } \\
\text { Stöckmann } \\
{[1948]}\end{array}$ & ( & Nyquist [1928]; Bay [1947]; Barnes \& Czerny [1932]. & $0: 3$ \\
\hline $\begin{array}{l}\text { Mollwo } \\
{[1948 / 49]}\end{array}$ & Pohl [1940]a 4./5. Aufl. & ( & $1: 0$ \\
\hline $\begin{array}{l}\text { Harten } \\
{[1949] \mathrm{a}}\end{array}$ & Mollwo \& Stöckmann [1948]a. & $\begin{array}{l}\text { Wright [1900]; Jentzsch [1912]; Woronkoff \& } \\
\text { Pokrowski [1924]; Schulz [1928]; Kortüm \& Kortüm- } \\
\text { Seiler [1947]; Springer [1940]; Pokrowski [1924], } \\
\text { [1926]a, [1926]b; Leontowitsch [1928]; Littmann } \\
\text { [1940]. }\end{array}$ & $1: 11$ \\
\hline $\begin{array}{l}\text { Harten } \\
{[1949] \mathrm{b}}\end{array}$ & $\begin{array}{l}\text { Hecht [1930]; Glaser [1936]b; Thomas [1940]; } \\
\text { Mollwo [1933]; Kleinschrod [1936]; Pick [1938], } \\
\text { [1939]; Smakula [1929]; Glaser \& Lehfeldt [1936]; } \\
\text { Pohl [1938]; Hilsch \& Pohl [1933]c. }\end{array}$ & $\begin{array}{l}\text { Ferguson [1944]; Röntgen [1921]; Becquerel [1885]; } \\
\text { Czasar [1940]a, [1940]b; Kirkpatrik [1932]; Przibram } \\
\text { [1926], [1931]; Helbig [1934]; Estermann, Leivo \& } \\
\text { Stern [1949]. }\end{array}$ & $11: 10$ \\
\hline
\end{tabular}

${ }^{1387}$ Hier erkennt man die Zusammenarbeit zwischen Mollwo und König. Mollwo zitiert hier 'fremde' Arbeiten, die auch in Königs unmittelbar im Anschluss an den Mollwo-Artikel abgedruckt zwei Arbeiten (siehe König [1944]a und [1944]b) Erwähnung finden, nicht aber in irgend einer anderen Arbeit aus der Pohl-Schule. 


\begin{tabular}{|c|c|c|c|}
\hline $\begin{array}{l}\text { Heiland \& } \\
\text { Kelting [1949] }\end{array}$ & $\begin{array}{l}\text { Pohl [1938]; Stasiw [1936]a; Pick [1939]; Blau } \\
\text { [1933]; Kelting \& Witt [1949]; Mollwo [1933]; } \\
\text { Rögener [1937]; Kleinschrod [1936]; Thomas } \\
\text { [1940]; Mollwo \& Roos [1934]. }\end{array}$ & - & $10: 0$ \\
\hline $\begin{array}{l}\text { Kelting \& } \\
\text { Witt [1949] }\end{array}$ & $\begin{array}{l}\text { Kyropoulos [1926]; Koch [1929]; Stasiw [1933], } \\
\text { [1934]a; Pick [1939]; Hilsch \& Pohl [1937]a; Pohl } \\
\text { \& Stöckmann [1947]; Mollwo [1943]b; Korth } \\
\text { [1933]; Lehfeldt [1933]a; Pohl [1927] 13./14. Aufl.. }\end{array}$ & Biltz \& Biltz [1940]; Koch \& Wagner [1937]. & $11: 2$ \\
\hline Pick [1949] & Pohl \& Pringsheim [1912]; Pick [1948]. & $\begin{array}{l}\text { Liebig [1835]; Hauser \& Biesalski [1910]; Rosenheim } \\
\text { \& Löwenstamm [1903]; Kohlschütter [1903]; } \\
\text { Kohlschütter \& Fleischmann [1912]; Wartenberg } \\
\text { [1930]. }\end{array}$ & $2: 6$ \\
\hline Pohl [1949] & - & - & $0: 0$ \\
\hline $\begin{array}{l}\text { Pohl \& } \\
\text { Stöckmann } \\
{[1949]}\end{array}$ & $\begin{array}{l}\text { Gudden \& Pohl [1920]a, [1920]b, [1921]a, [1923]a, } \\
\text { [1924], [1925]c; Hilsch \& Pohl [1937]a, [1939]; } \\
\text { Pohl \& Stöckmann [1947]; Stuke [1947]; Gudden } \\
\text { [1930]; Hecht [1932]; Flechsig [1931]; Lehfeldt } \\
\text { [1935]; Mollwo [1948]b; Stöckmann [1949]. }\end{array}$ & $\begin{array}{l}\text { Frerichs [1947]; Kallmann \& Warminsky [1948]a, } \\
\text { [1948]b; Rittner [1948]; Beadeker [1909]; Stettner } \\
\text { [1941]; Heerden [1945]. }\end{array}$ & $16: 7$ \\
\hline Rohn [1949] & $\begin{array}{l}\text { Pohl \& Pringsheim [1912]; Hilsch \& Pohl [1929], } \\
\text { [1930]b; Bauer [1934]; Mollwo [1943]a. }\end{array}$ & Murmann [1933]. & $5: 1$ \\
\hline $\begin{array}{l}\text { Stöckmann } \\
\text { [1949] }\end{array}$ & $\begin{array}{l}\text { Flechsig [1931]; Hecht [1932]; Gudden \& Pohl } \\
\text { [1920]a, [1920]b, [1921]a, [1923]a, [1923]b; Pohl } \\
\text { [1928]; Lehfeldt [1935]; Hilsch \& Pohl [1935], } \\
\text { [1937]a, [1937]b, [1939]; Glaser \& Lehfeldt [1936], } \\
\text { [1937]; Pohl \& Stöckmann [1947]. }\end{array}$ & $\begin{array}{l}\text { Lenz [1925], [1927]a; Stetter [1941]; Jentschke [1948]; } \\
\text { Heerden [1945]; Hofstadter, Millen \& Ridgway [1947]; } \\
\text { Hofstadter [1947]a, [1947]b, [1948]; Wouters \& } \\
\text { Christian [1947]; Davidson \& Larsch [1948]; Ahearn } \\
\text { [1948]a, [1948]b; Wooldrige, Ahearn \& Burton [1947]; } \\
\text { Curtiss \& Brown [1947]; Friedman, Birks \& Gauvin } \\
\text { [1948]; Lonsdale [1948]; Frerichs [1947]; Kallmann \& } \\
\text { Warminsky [1948]b; Broser \& Kallmann [1947]a, } \\
\text { [1947]b, [1948]a, [1948]b, [1948]c; Collins \& Hoyt } \\
\text { [1948]. }\end{array}$ & $16: 24$ \\
\hline $\begin{array}{l}\text { Dorendorf \& } \\
\text { Pick [1950] }\end{array}$ & $\begin{array}{l}\text { Pohl [1938]; Rögener [1937]; Petroff [1950]; } \\
\text { Heiland [1950]; Ottmer [1928]; Mollwo [1931], } \\
\text { [1937]; Kelting \& Witt [1949]. }\end{array}$ & $\begin{array}{l}\text { Becquerel [1885]; Molnar [1940]; Alexander \& } \\
\text { Schneider [1949]; Boer [1937]a; Mott [1938]. }\end{array}$ & $8: 5$ \\
\hline $\begin{array}{l}\text { Gericke } \\
{[1950]}\end{array}$ & $\begin{array}{l}\text { Pohl [1937]a; Glaser \& Lehfeldt [1936]; Glaser } \\
\text { [1937]; Flechsig [1925]. }\end{array}$ & - & $4: 0$ \\
\hline Harten [1950] & $\begin{array}{l}\text { Pohl [1938]; Glaser \& Lehfeldt [1936]; Glaser } \\
\text { [1937]; Harten [1949]b (4x); Kelting \& Witt [1949]. }\end{array}$ & Czasar [1940]a, [1940]b. & $5: 2$ \\
\hline Petroff [1950] & $\begin{array}{l}\text { Ottmer [1928]; Miescher [1933]; Kleinschrod } \\
\text { [1936]; Smakula [1930]b; Hilsch \& Pohl [1935], } \\
\text { [1936]. }\end{array}$ & Seitz [1946]; Molnar [1940]; Burstein \& Oberly [1949]. & $6: 3$ \\
\hline $\begin{array}{l}\text { Pick \& Weber } \\
{[1950]}\end{array}$ & Kelting \& Witt [1949]. & Biltz \& Biltz [1940]. & $1: 1$ \\
\hline $\begin{array}{l}\text { Stöckmann } \\
{[1950] \mathrm{a}}\end{array}$ & $\begin{array}{l}\text { Mollwo \& Stöckmann [1948]a, [1948]b; Mollwo } \\
\text { [1943]b, [1948]b; Heiland [1948]. }\end{array}$ & $\begin{array}{l}\text { Sommerville [1912]; Jander \& Stamm [1931]; Guillery } \\
\text { [1932]; Baumbach \& Wagner [1933]; Fritsch [1935]; } \\
\text { Meyer \& Neldel [1937]; Miller [1941]; Hahn, Russel \& } \\
\text { Miller [1949]; Seitz [1940]; Hauffe [noch } \\
\text { unveröffentlicht]; Leverenz [1948]; Meyer, Möglich \& } \\
\text { Schottky [1939]; Mott \& Gurney [1940]; Garlick \& } \\
\text { Wilins [1945]; Wagner \& Grünewald [1938]; Bevan, } \\
\text { Shelton \& Anderson [1948]; E. E. Hahn [1949]. }\end{array}$ & $5: 17$ \\
\hline $\begin{array}{l}\text { Stöckmann } \\
{[1950] \mathrm{b}}\end{array}$ & $\begin{array}{l}\text { Gudden [1928]; Gudden \& Pohl [1921]c, [1921]d, } \\
\text { [1923]a, [1923]b; Hecht [1932]; Pohl [1938]; Hilsch } \\
\text { \& Pohl [1937]a, [1937]b, [1939]; Pohl \& } \\
\text { Stöckmann [1947]; Mollwo \& Stöckmann [1948]b; } \\
\text { Pohl \& Stöckmann [1949]; Pick [1948]; Stöckmann } \\
\text { [1949]. }\end{array}$ & $\begin{array}{l}\text { Smith [1873]; Justi [1948]; Schottky [unveröffentlicht]; } \\
\text { Shockley [1938]; Hughes \& Du Bridge [1932]; } \\
\text { Hofstadter [1949]; MacKay [1948]; Kallmann \& } \\
\text { Warminsky [1948]b. }\end{array}$ & $15: 8$ \\
\hline $\begin{array}{l}\text { Stöckmann } \\
{[1950] \mathrm{c}}\end{array}$ & $\begin{array}{l}\text { Gudden [1930], [1933]; Stasiw [1932], [1933]; } \\
\text { Mollwo [1943]b; Heiland [1948]; Pohl [1938]; } \\
\text { Stuke [1947]; Mollwo \& Stöckmann [1948]b; } \\
\text { Engelhardt [1933]; Gudden \& Pohl [1923]b; Hilsch } \\
\text { \& Pohl [1930]a, [1930]c, [1932], [1937]a, [1939]; } \\
\text { Gyulai [1925]a; Lenz [1927]b; Pohl \& Stöckmann } \\
\text { [1947]; Pick [1948]; Stöckmann [1949], [1950]c. }\end{array}$ & $\begin{array}{l}\text { Faraday [1834]; Wagner [1933]a, [1933]b, [1933]c, } \\
\text { [1935], [1938]; Königsberger [1923]; Beaderke [1908], } \\
\text { [1909], [1912]; Wilson [1931], [1932]a, [1932]b; Lark- } \\
\text { Horovitz [1946], [1949]; Teal, Fisher \& Treptow } \\
\text { [1946]; Busch \& Labhard [1946]; Baumbach \& Wagner } \\
\text { [1933]; Bidwell [1922]; Hinterberger [1946]; Peierls } \\
\text { [1929]; Heisenberg [1931]; Pearson \& Bardeen [1949]; } \\
\text { Torrey \& Whitmer [1948]; Becker \& Fan [1949]; Koch } \\
\text { [1949]; Schottky [1938], [1939]a, [1940], [1942]; } \\
\text { Schottky \& Spenke [1939]; Nordheim [1932]; } \\
\text { Hartmann \& Schottky [1936]; Spenke [1949]; Schottky } \\
\text { \& Deutschmann [1929]; Schmidt [1941]; Schweickert } \\
\text { [1939]; Ryder \& Shockley [1949]; Haynes \& Shockley } \\
\text { [1949]; Bardeen \& Brattain [1948], [1949]; Mott } \\
\text { [1939]a, [1939]b; Lehovec [1946], [1947], [1948]; } \\
\text { Becquerl [1839]; West \& Carroll [1947]; Haynes } \\
\text { [1947]; Lenz [1924], [1925], [1927]a; Klick [1949]; } \\
\text { Klick \& Maurer [1949]; MacKay [1948]; Seitz [1942]; } \\
\text { Bethe [1942]; Sachs [1942]; Herzfeld [1944]; Lark- }\end{array}$ & $22: 63$ \\
\hline
\end{tabular}




\begin{tabular}{|c|c|c|c|}
\hline & & Horovitz u. Mitarb. [1948], [1949], [1950]a, [1950]b. & \\
\hline Witt [1950] & $\begin{array}{l}\text { Glaser \& Lehfeldt [1936]; Glaser [1937]; Harten } \\
\text { [1949]b. }\end{array}$ & $\begin{array}{l}\text { Stetter [1941]; Heerden [1945]; Jentschke [1948]; } \\
\text { Hofstadter [1949]; Schintlmeister [1943]; Jaffé [1906]. }\end{array}$ & $3: 6$ \\
\hline $\begin{array}{l}\text { Dorendorf } \\
{[1951]}\end{array}$ & $\begin{array}{l}\text { Ottmer [1928]; Pick [1940]; Dorendorf \& Pick } \\
\text { [1950]; Petroff [1950]; Mollwo [1937]; Korth } \\
\text { [1933]; Thomas [1940]; Kleinschrod [1936]. }\end{array}$ & $\begin{array}{l}\text { Molnar [1940]; Alexander \& Schneider [1949]; Casler, } \\
\text { Pringsheim \& Yuster [1950]a, [1950]b; Goldstein } \\
\text { [1897]; Röntgen [1921]; Burstein \& Oberly [1950]. }\end{array}$ & $8: 7$ \\
\hline $\begin{array}{l}\text { Kerkhoff } \\
{[1951]}\end{array}$ & $\begin{array}{l}\text { Lehfeldt [1933]a; Kelting \& Witt [1949]; Pick \& } \\
\text { Weber [1950]. }\end{array}$ & $\begin{array}{l}\text { Tubandt, Reinhold \& Liebold [1931]; Wagner \& Ronge } \\
{[1950] .}\end{array}$ & $3: 2$ \\
\hline Pick [1951] & $\begin{array}{l}\text { Pohl [1938]; [1940]a 7./8. Aufl. 1948; Hilsch \& } \\
\text { Pohl [1930]a, [1932], [1936]; Miescher [1933]; } \\
\text { Umrath [1933]; Lehfeldt [1933]a, [1933]b; Stasiw } \\
\text { [1950], [1951]; Stasiw \& Teltow [1941]; Hecht } \\
\text { [1932]; Lüpke [1934]; Dorendorf \& Pick [1950]; } \\
\text { Dorendorf [1951]; Petroff [1950]; Korth [1935]; } \\
\text { Akpinar [1940]; Pick [1938]. }\end{array}$ & $\begin{array}{l}\text { Gurney \& Mott [1940]; Eggert \& Noddack [1923]; } \\
\text { Meidinger [1925]; Sheppard, Trivelli \& Loveland } \\
\text { [1925]; James [1945]; Eggert \& Rathes [1928]; Teltow } \\
\text { [1949]a, [1949]b; Tubbant \& Eggert [1920]; Koch \& } \\
\text { Wagner [1937]; Frenkel [1926]; Mitchell [1949]a, } \\
\text { [1949]b, [1951]; Löhle [1933]; Schottky [1939]b; } \\
\text { Evans \& Webb [1938]; Molnar [1940]; Pashley [1951]; } \\
\text { Mott [1948]. }\end{array}$ & $22: 18$ \\
\hline $\begin{array}{l}\text { Pick \& Pohl } \\
{[1951]}\end{array}$ & $\begin{array}{l}\text { Dorendorf \& Pick [1950]; Dorendorf [1951]; Weber } \\
\text { [1951]a, [1951]b; Hilsch \& Pohl [1930]a, [1932]; } \\
\text { Umrath [1933]; Pick [1951]; Hahn [unveröffentl.]; } \\
\text { Akpinar [1940]; Stasiw \& Teltow [1941]; Stasiw } \\
\text { [1951]. }\end{array}$ & $\begin{array}{l}\text { Eggert \& Noddack [1923]; Sheppard, Trivelli \& } \\
\text { Loveland [1925]; Casler, Pringsheim \& Yuster [1950]b; } \\
\text { Molnar \& Hartman [1950]; Pashley [1951]. }\end{array}$ & $12: 5$ \\
\hline Pohl [1951]a & - & - & $0: 0$ \\
\hline Pohl [1951]b & - & - & $0: 0$ \\
\hline Pohl [1951]c & Pohl [1930] 10./11. Aufl. 1947. & Töpler [1908]; Wiener [1890]. & $1: 2$ \\
\hline $\begin{array}{l}\text { Stöckmann } \\
{[1951] \mathrm{a}}\end{array}$ & Stöckmann [1950]c. & $\begin{array}{l}\text { Weise [1949]; Becker, Green \& Pearson [1946], } \\
\text { [1947]; Verwey, Haaijman \& Romeijn [1947], [1948]; } \\
\text { Verwey, Haaijman, Romeijn \& Oosterhout [1950]; } \\
\text { Bumbach \& Wagner [1934]; Wagner [1935], [1950]; } \\
\text { Verwey \& Boer [1936]a, [1936]b; Boer \& Verwey } \\
\text { [1937]; Jonker \& Santen [1950]; Verwey \& Haaijman } \\
\text { [1941]; Verwey \& Heilmann [1947]; Snoek [1946]; } \\
\text { Hund [1935]; Dressnandt [1940]; Mott [1949]; } \\
\text { Schottky [1939]b; Hauffe \& Vierk [1950]; Hauffe \& } \\
\text { Block [im Druck]; Domenicali [1950]; Wagner \& Koch } \\
\text { [1936]. }\end{array}$ & $1: 23$ \\
\hline $\begin{array}{l}\text { Stöckmann } \\
{[1951] \mathrm{b}}\end{array}$ & - & - & $0: 0$ \\
\hline $\begin{array}{l}\text { Weber } \\
{[1951] \mathrm{a}}\end{array}$ & $\begin{array}{l}\text { Thomas [1940]; Dorendorf [1951]; Pohl [1940]a } \\
\text { 7./8. Aufl. 1948. }\end{array}$ & Strong \& Brice [1935]; Molnar \& Hartmann [1950]. & $3: 2$ \\
\hline $\begin{array}{l}\text { Intemann \& } \\
\text { Stöckmann } \\
{[1951 / 52]}\end{array}$ & $\begin{array}{l}\text { Stöckmann [1950]a; Mollwo [1944]; Bauer [1937]; } \\
\text { Mollwo \& Stöckmann [1948]b. }\end{array}$ & $\begin{array}{l}\text { Fritsch [1935]; Miller [1941]; Hahn, Russel \& Miller } \\
\text { [1949]; E. E. Hahn [1949], [1951]; Evans [1940]; } \\
\text { Volger [1950]. }\end{array}$ & $4: 7$ \\
\hline $\begin{array}{l}\text { Martienssen } \\
{[1951 / 52]}\end{array}$ & $\begin{array}{l}\text { Kelting \& Witt [1949]; Pohl [1938], [1951]; Hilsch } \\
\text { \& Pohl [1929], [1930]b, [1933]a, [1933]b, [1934], } \\
\text { [1935], [1936]; Ottmer [1928]; Arsenjewa [1929]; } \\
\text { Mollwo [1933], [1937]; Pick [1938]; Schaitberger } \\
\text { [1937]; Thomas [1940]; Martienssen [1951]; } \\
\text { Dorendorf \& Pick [1950]; Dorendorf [1951]; Petroff } \\
\text { [1950]; Glaser [1936]b; Harten [1949]b. }\end{array}$ & $\begin{array}{l}\text { Seitz [1946]; Delbecq, Pringsheim \& Yuster [1951]; } \\
\text { Molnar [1940]; Burstein \& Oberly [1950]; Casler, } \\
\text { Pringsheim \& Yuster [1949], [1950]a, [1950]c; } \\
\text { Alexander \& Schneider [1949]; Hippel [1936]. }\end{array}$ & $23: 9$ \\
\hline $\begin{array}{l}\text { Fritzsche } \\
{[1952]}\end{array}$ & $\begin{array}{l}\text { Mollwo \& Stöckmann [1948]a , [1948]b; } \\
\text { Stöckmann [1950]a; Mollwo [1944], [1950]; Helwig } \\
\text { [1951], [1952]; Intemann \& Stöckmann [1951/52]. }\end{array}$ & 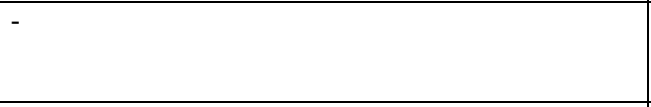 & $8: 0$ \\
\hline $\begin{array}{l}\text { Martienssen } \\
{[1952]}\end{array}$ & $\begin{array}{l}\text { Thomas [1940]; Martienssen [1951/52]; Martienssen } \\
\text { \& Pohl [1952]; }\end{array}$ & $\begin{array}{l}\text { Delbecq, Pringsheim \& Yuster [1951]; Markham } \\
\text { [unveröffentl.]; Duerig \& Markham [unveröffentl.]; }\end{array}$ & $3: 3$ \\
\hline $\begin{array}{l}\text { Martienssen \& } \\
\text { Pick [1952] }\end{array}$ & $\begin{array}{l}\text { Hilsch \& Pohl [1933]b, [1934]; Lüpke [1934]; } \\
\text { Akpinar [1940]; Pick \& Pohl [1951]; Thomas } \\
\text { [1940]; Pohl [1952]a. }\end{array}$ & - & $7: 0$ \\
\hline $\begin{array}{l}\text { Martienssen \& } \\
\text { Pohl [1952] }\end{array}$ & $\begin{array}{l}\text { Thomas [1940]; Martienssen [1951/52]; Harten } \\
\text { [1949]b; Pick \& Pohl [1951]. }\end{array}$ & Delbecq, Pringsheim \& Yuster [1951]. & $4: 1$ \\
\hline Pohl [1952]a & Pohl [1929]. & - & $1: 0$ \\
\hline $\begin{array}{l}\text { Stöckmann } \\
{[1952]}\end{array}$ & $\begin{array}{l}\text { Gudden \& Pohl [1920]b; Stöckmann [1950]a, } \\
\text { [1950]c, [1951]b, [1951]c; Pohl [1938]; Glaser } \\
\text { [1937]; Birus [1942]; Pick [1951]; Mollwo \& } \\
\text { Stöckmann [1948]b; Fritzsche [1952]; Witt [1950]; } \\
\text { Hilsch [1937]b; Lehfeldt [1935]. }\end{array}$ & $\begin{array}{l}\text { Lenard, Schmidt \& Tomaschek [1928]; Pringsheim } \\
\text { [1928]; Riehl [1941]; Verneuil [1886]; Lecoq de } \\
\text { Boisbaudran [1886]a, [1886]b, [1886]c; Klatt \& Lenard } \\
\text { [1889]; Muto [1935], [1937]; Seitz \& Johnson [1937]a, } \\
\text { [1937]b, [1937]c; Schön [1938], [1939]; Riehl \& Schön } \\
\text { [1939]; Rothschild [1934], [1936]; Brauer [1939]a, } \\
\text { [1939]b, [1946], [1947], [1950]a [1950]b, [1950]c, } \\
\text { [1951]a, [1951]b; Urbach, Pearlman \& Hemmendinger } \\
\text { [1946]; Ellickson [1946]; Antonow-Romanowski, } \\
\text { Lewschin, Morgenstern \& Trapeznikowa [1946]a, } \\
\text { [1946]b, [1946]c; Kröger, Hellingman \& Smit [1949]; } \\
\text { Kröger \& Dikhoff [1950]; Bube [1950], [1951]; } \\
\text { Mitchell [1951]; Stookey [1949]; Haase [1950]; } \\
\text { Hüniger \& Rudolph [1941]; Schön [1937], [1948], }\end{array}$ & $14: 53$ \\
\hline
\end{tabular}




\begin{tabular}{|c|c|c|c|}
\hline & & $\begin{array}{l}\text { [1951]; Hippel [1936]; Seitz [1938], [1939], [1950]b; } \\
\text { Möglich \& Rompe [1940]; Birus, Möglich \& Rompe } \\
\text { [1943]; Adirowitsch [1948]a, [1948]b, [1949], [1951]; } \\
\text { Schottky [1944]; Groot [1939]; Fassbender [1949]; } \\
\text { Broser \& Warminsky [1950], [1951]; Goos [1939]; } \\
\text { Streck [1939]a, [1939]b; Randall \& Wilkins [1945]a, } \\
\text { [1945]b, [1945]c; Garlick \& Gibson [1947]; Franck } \\
\text { [1948]; Bull \& Garlick [1950]; Leverenz [1948], } \\
\text { [1950]; Urbach [1930]a, [1930]b; Garlick \& Wilkins } \\
\text { [1945]; Garlick, Wells \& Wilkins [1948]; Meyer \& } \\
\text { Neldel [1937]; Klasens [unveröffentl.]; Haynes \& } \\
\text { Shockley [1948], [1951]; Kröger [1948]; Fonda \& Seitz } \\
\text { [1948]; Garlick [1949]; Förster [1951]; Pringsheim } \\
\text { [1949]; Bandow [1950]. }\end{array}$ & \\
\hline Witt [1952] & $\begin{array}{l}\text { Mollwo [1934]; Glaser [1937]; Hilsch [1937]; Pick } \\
\text { \& Weber [1950]; Kelting \& Witt [1949]; Kerkhoff } \\
\text { [1951]. }\end{array}$ & $\begin{array}{l}\text { Estermann, Leivo \& Stern [1949]; Wagner \& Ronge } \\
\text { [1950]. }\end{array}$ & $6: 2$ \\
\hline Pick [1954] & $\begin{array}{l}\text { Mette \& Pick [1953]; Hilsch \& Pohl [1930]b; Witt } \\
\text { [1953]; Kelting \& Witt [1949]; Hilsch [1927]b; Pick } \\
\text { \& Wissman [im Druck]; Mollwo \& Roos [1934]; } \\
\text { Meyeren [1930]; Karabascheff [1941/42]; Heiland } \\
\text { [1950]; Pick [1951]; Martienssen \& Pick [1953]. }\end{array}$ & $\begin{array}{l}\text { Seitz [1940]; Pauling [1948]; Slater [1951]; Laszlo } \\
\text { [1925]; Tsujikawa \& Kanda [1950]; Bayliss \& Riviere } \\
\text { [1949]; Vartanian [1950]; Carlswell [1953]; Brattain \& } \\
\text { Briggs [1949]; Fan \& Becker [1949]; Henisch (Hrsg.) } \\
\text { [1951]; Minor [1903]; Ingersoll [1910]; Försterling \& } \\
\text { Fréedericksz [1913]; Schneider \& O’Bryan [1937]; } \\
\text { Apker \& Taft [1950]; Pfann \& Olsen [1953]; Frenkel } \\
\text { [1926]; Wagner \& Schottky [1931]; Cottrell [1953]; } \\
\text { T'Ing-Sui Kê [1949]; Bowen [1938]; Bowen \& } \\
\text { Mickiewicz [1947]; Forro [1929]b; Shockley [1950]; } \\
\text { Pearson \& Bardeen [1949]; Baedeker [1908], [1909], } \\
\text { [1912]. }\end{array}$ & $11: 30$ \\
\hline
\end{tabular}

\section{Zitierte Arbeiten (zusätzlich zu den im Literaturverzeichnis angeführten):}

\section{Arbeiten aus Pohls Institut und von Pohl-Schülern:}

Arsenjewa, A. [1929] Zeitschrift für Physik 57 (1929), S. 166.

Bauer, G. [1934] Annalen der Physik (5) 19 (1934), S. 434.

Bauer, G. [1937] Annalen der Physik (5) 30 (1937), S. 433.

Birus, Karl [1942] Ergebn. exakt. Naturwiss. 20 (1942), S. 183.

Blau, Marietta [1933] Nachrichten von der Gesellschaft der Wissenschaften zu Göttingen, Mathematisch-

Physikalische Klasse (1933), S. 401. ${ }^{1388}$

Domanic, Fahri [erscheint demnächst] wahrscheinlich: Annalen der Physik (5) 43 (1943), S. 187.

Engelhardt, E. [1933] Annalen der Physik (5) 17 (1933), S. 501.

Fesefeldt, Hans [1930] Zeitschrift für Physik 64 (1930), S. 623.

Fesefeldt, Hans [1932] Nachrichten von der Gesellschaft der Wissenschaften zu Göttingen, MathematischPhysikalische Klasse, Fachgruppe II (1932), S. 353.

Fesefeldt, Hans \& Zoltán Gyulai [1929] Nachrichten von der Gesellschaft der Wissenschaften zu Göttingen, Mathematisch-Physikalische Klasse (1929), S. 226.

Flechsig, W. [1925] Zeitschrift für Physik 33 (1925), S. 372.

Flechsig, W. [1926] Zeitschrift für Physik 36 (1926), S. 605.

Flechsig, W. [1928] Zeitschrift für Physik 46 (1928), S. 788.

Flechsig, W. [1931] Physikalische Zeitschrift 32 (1931), S. 843.

Fritsch, O. [1935] Annalen der Physik (5) 22 (1935), S. 375.

Fritzsche, H. [1952] Diplomarbeit Göttingen, 1952.

Glaser, Günther [1936]a Nachrichten von der Gesellschaft der Wissenschaften zu Göttingen, MathematischPhysikalische Klasse, 2 (1936), S. 109.

Glaser, Günther [1936]b Annalen der Physik (5) 27 (1936), S. 217.

Glaser, Günther [1937] Nachrichten von der Gesellschaft der Wissenschaften zu Göttingen, MathematischPhysikalische Klasse, (N. F.) Phys. 3 (1937), S. 31.

Glaser, Günther \& W. Lehfeldt [1936] Nachrichten von der Gesellschaft der Wissenschaften zu Göttingen, Mathematisch-Physikalische Klasse, (N. F.) Phys. 2 (1936), S. 91.

Glaser, Günther \& W. Lehfeldt [1937] Nachrichten von der Gesellschaft der Wissenschaften zu Göttingen, Mathematisch-Physikalische Klasse (1937), S. 31.

Gudden, Bernhard [1928] Lichtelektrische Erscheinungen, Berlin 1928.

Gudden, Bernhard [1930] Erlanger Berichte 62 (1930), S. 289.

1388 Zum Gastaufenthalt von Marietta Blau in Pohls Institut 1932/33 siehe Rosner \& Strohmaier (Hrsg.) [2003]. 
Gudden, Bernhard [1934] Ergebn. exakt. Naturwiss. 13 (1934), S. 223.

Gudden, Bernhard \& Robert Wichard Pohl [1920]a Zeitschrift für Physik 2 (1920), S. 361. Gudden, Bernhard \& Robert Wichard Pohl [1920]b Zeitschrift für Physik 3 (1920), S. 98. Gudden, Bernhard \& Robert Wichard Pohl [1921]a Zeitschrift für Physik 4 (1921), S. 206. Gudden, Bernhard \& Robert Wichard Pohl [1921]b Zeitschrift für Physik 5 (1921), S. 176. Gudden, Bernhard \& Robert Wichard Pohl [1921]c Zeitschrift für Physik 6 (1921), S. 248. Gudden, Bernhard \& Robert Wichard Pohl [1921]d Zeitschrift für Physik 7 (1921), S. 65. Gudden, Bernhard \& Robert Wichard Pohl [1923]a Zeitschrift für Physik 16 (1923), S. 42. Gudden, Bernhard \& Robert Wichard Pohl [1923]b Zeitschrift für Physik 17 (1923), S. 331. Gudden, Bernhard \& Robert Wichard Pohl [1924] Zeitschrift für Physik 21 (1924), S. 1.

Gudden, Bernhard \& Robert Wichard Pohl [1925]a Zeitschrift für Physik 31 (1925), S. 651. Gudden, Bernhard \& Robert Wichard Pohl [1925]b Zeitschrift für Physik 34 (1925), S. 245. Gudden, Bernhard \& Robert Wichard Pohl [1925]c Zeitschrift für Physik 35 (1925), S. 240. Gundelach, E. [1930] Zeitschrift für Physik 66 (1930), S. 775.

Gyulai, ${ }^{1389}$ Zoltán [1925]a Zeitschrift für Physik 32 (1925), S. 103.

Gyulai, Zoltán [1925]b Zeitschrift für Physik 33 (1925), S. 251.

Gyulai, Zoltán [1926] Zeitschrift für Physik 37 (1926), S. 889.

Gyulai, Zoltán [1927] Zeitschrift für Physik 46 (1927), S. 80.

Hahn, Rosemarie [unveröffentl.] Diplomarbeit Göttingen.

Hecht, K. [1930] Dissertation Göttingen, 1930.

Hecht, K. [1932] Zeitschrift für Physik 77 (1932), S. 235.

Heiland, Gerhard [1948] Dissertation Göttingen, 1948.

Helwig, Gerhard [1951] Dissertation Göttingen, 1951.

Hilsch, Rudolf [1927]a Zeitschrift für Physik 44 (1927), S. 421.

Hilsch, Rudolf [1927]b Zeitschrift für Physik 44 (1927), S. 860.

Hilsch, Rudolf [1935] Zeitschrift für technische Physik 16 (1935), S. 341.

Hilsch, Rudolf [1936] Zeitschr.f. angew. Chem. 49 (1936), S. 69.

Hilsch, Rudolf [1937]a Annalen der Physik (5) 29 (1937), S. 407.

Hilsch, Rudolf [1937]b Physikalische Zeitschrift 38 (1937), S. 1031.

Hilsch, Rudolf [1939] Die Naturwissenschaften 27 (1937), S. 489.

Hilsch, Rudolf \& R. Ottmer [1926] Zeitschrift für Physik 39 (1926), S. 644.

Hilsch, Rudolf \& Robert Wichard Pohl [1928] Zeitschrift für Physik 48 (1928), S. 384.

Hilsch, Rudolf \& Robert Wichard Pohl [1929] Zeitschrift für Physik 57 (1929), S. 145.

Hilsch, Rudolf \& Robert Wichard Pohl [1930]a Zeitschrift für Physik 64 (1930), S. 606.

Hilsch, Rudolf \& Robert Wichard Pohl [1930]b Zeitschrift für Physik 59 (1930), S. 812.

Hilsch, Rudolf \& Robert Wichard Pohl [1930]c Nachrichten von der Gesellschaft der Wissenschaften zu Göttingen, Mathematisch-Physikalische Klasse (1930), S. 176.

Hilsch, Rudolf \& Robert Wichard Pohl [1931] Zeitschrift für Physik 68 (1931), S. 721.

Hilsch, Rudolf \& Robert Wichard Pohl [1932] Zeitschrift für Physik 77 (1932), S. 421.

Hilsch, Rudolf \& Robert Wichard Pohl [1933]a Nachrichten von der Gesellschaft der Wissenschaften zu Göttingen, Mathematisch-Physikalische Klasse, Fachgruppe II (1933), S. 322.

Hilsch, Rudolf \& Robert Wichard Pohl [1933]b Nachrichten von der Gesellschaft der Wissenschaften zu Göttingen, Mathematisch-Physikalische Klasse, Fachgruppe II (1933), S. 406.

Hilsch, Rudolf \& Robert Wichard Pohl [1933]c Zeitschrift für Physik 87 (1933), S. 78.

Hilsch, Rudolf \& Robert Wichard Pohl [1934] Nachrichten von der Gesellschaft der Wissenschaften zu Göttingen, Mathematisch-Physikalische Klasse, (N. F.) Phys. 1 (1934), S. 115-127.

Hilsch, Rudolf \& Robert Wichard Pohl [1935] Nachrichten von der Gesellschaft der Wissenschaften zu Göttingen, Mathematisch-Physikalische Klasse, Neue Folge 1 (1935), S. 269.

Hilsch, Rudolf \& Robert Wichard Pohl [1936] Nachrichten von der Gesellschaft der Wissenschaften zu Göttingen, Mathematisch-Physikalische Klasse, (N. F.) Phys. 2 (1936), S. 139.

Hilsch, Rudolf \& Robert Wichard Pohl [1937]a Zeitschrift für Physik 108 (1937), S. 55.

Hilsch, Rudolf \& Robert Wichard Pohl [1937]b Nachrichten von der Gesellschaft der Wissenschaften zu Göttingen, Mathematisch-Physikalische Klasse (1937), S. 45.

Hilsch, Rudolf \& Robert Wichard Pohl [1938] Annalen der Physik (5) 32 (1938), S. 155.

Hilsch, Rudolf \& Robert Wichard Pohl [1939] Zeitschrift für Physik 112 (1939), S. 252.

Hohls, H. W. [1937] Annalen der Physik (5) 29 (1937), S. 433.

Honrath, W. [1937] Annalen der Physik (5) 29 (1937), S. 421.

Kleinschrod, F. G. [1936] Annalen der Physik (5) 27 (1936), S. 97.

1389 Zoltán Gyulai war von 1924-26 Gastwissenschaftler in Göttingen. 
Koch, Werner [1929] Zeitschrift für Physik 57 (1929), S. 638.

Korth, K. [1932] Nachrichten von der Gesellschaft der Wissenschaften zu Göttingen, MathematischPhysikalische Klasse (1932), S. 576.

Korth, K. [1933] Zeitschrift für Physik 84 (1933), S. 677.

Korth, K. [1935] Nachrichten von der Gesellschaft der Wissenschaften zu Göttingen, MathematischPhysikalische Klasse, (N. F.) Phys. 1 (1935), S. 221-227.

Kyropoulos, S. [1926] Zeitschrift für anorganische Chemie 154 (1926), S. 308.

Lehfeldt, W. [1933]a Zeitschrift für Physik 85 (1933), S. 717.

Lehfeldt, W. [1933]b Nachrichten von der Gesellschaft der Wissenschaften zu Göttingen, MathematischPhysikalische Klasse (1933), S. 171.

Lehfeldt, W. [1935] Nachrichten von der Gesellschaft der Wissenschaften zu Göttingen, MathematischPhysikalische Klasse, Neue Folge 1 (1935), S. 171.

Lenz, H. [1927]b Annalen der Physik (4) 83 (1927), S. 941.

Lüpke, A. D. v. [1934] Annalen der Physik (5) 21 (1934), S. 1.

Martienssen, Werner [1951] Die Naturwissenschaften 38 (1951), S. 482.

Martienssen, Werner \& Erich Mollwo [1953] Zeitschrift für Physik 135 (1953), S. 309.

Maslakowez, I. [1928] Zeitschrift für Physik 51 (1928), S. 696.

Mette, H. \& Heinz Pick [1953] Zeitschrift für Physik 134 (1953), S. 566.

Meyeren, Wilhelm v. [1930] Zeitschrift für Physik 61 (1930), S. 321.

Miescher, E. [1933] Nachrichten von der Gesellschaft der Wissenschaften zu Göttingen, MathematischPhysikalische Klasse, Fachgruppe II (1933), S. 329.

Mollwo, Erich [1931] Nachrichten von der Gesellschaft der Wissenschaften zu Göttingen, MathematischPhysikalische Klasse (1931), S. 97.

Mollwo, Erich [1932] Nachrichten von der Gesellschaft der Wissenschaften zu Göttingen, MathematischPhysikalische Klasse (1932), S. 254.

Mollwo, Erich [1933] Zeitschrift für Physik 85 (1933), S. 56.

Mollwo, Erich [1934] Nachrichten von der Gesellschaft der Wissenschaften zu Göttingen, MathematischPhysikalische Klasse, Neue Folge 1 (1934), S. 79.

Mollwo, Erich [1935]a Nachrichten von der Gesellschaft der Wissenschaften zu Göttingen, MathematischPhysikalische Klasse, Neue Folge 1 (1935), S. 203-207

Mollwo, Erich [1935]b Zs. f. techn. Phys. 16 (1935), S. 346.

Mollwo, Erich [1935]c Nachrichten von der Gesellschaft der Wissenschaften zu Göttingen, MathematischPhysikalische Klasse, Neue Folge 1 (1935), S. 215.

Mollwo, Erich [1937] Annalen der Physik (5) 29 (1937), S. 394.

Mollwo, Erich [1950] Forsch. u. Fortschr. 26 (1950), 3. Sonderheft.

Mollwo, Erich [1951] Z. physik. Chem. 198 (1951), S. 258.

Mollwo, Erich \& W. Roos [1934] Nachrichten von der Gesellschaft der Wissenschaften zu Göttingen, Mathematisch-Physikalische Klasse, Neue Folge 1 (1934), S. 107.

Ottmer, R. [1928] Zeitschrift für Physik 46 (1928), S. 798.

Pick, Heinz \& Walter Wissman [im Druck] Zeitschrift für Physik 138 (1954), S. 436.

Pohl, Robert Wichard [1926] Die Naturwissenschaften 14 (1926), S. 214.

Pohl, Robert Wichard [1928] Die Naturwissenschaften 16 (1928), S. 477.

Pohl, Robert Wichard [1929] Festrede zur Reichsgründungsfeier der Universität Göttingen am 18.1.28.

Veröffentlicht in der Festschrift zur Vierteljahrhundert-Feier der Gelehrtenschule des Johanneums zu Hamburg. Hamburg 1929.

Pohl, Robert Wichard [1932] Die Naturwissenschaften 20 (1932), S. 932.

Pohl, Robert Wichard [1933] Die Naturwissenschaften 21 (1933), S. 261.

Pohl, Robert Wichard [1934]a Physikalische Zeitschrift 35 (1934), S. 107.

Pohl, Robert Wichard [1934]b Zeitschrift f. Metallkde. 26 (1934), S. 217.

Pohl, Robert Wichard [1935]a Kolloid-Zeitschrift 71 (1935), S. 257.

Pohl, Robert Wichard [1935]b Zeitschrift für technische Physik 16 (1935), S. 338.

Pohl, Robert Wichard [1936] Elektrotechn. Zeitschr. 57 (1936), S. 321.

Pohl, Robert Wichard [1937]a Annalen der Physik (5) 29 (1937), S. 239.

Pohl, Robert Wichard [1937]b Nachrichten von der Gesellschaft der Wissenschaften zu Göttingen, Mathematisch-Physikalische Klasse, Neue Folge III (1939), S. 71.

Pohl, Robert Wichard [1951] in Mitchell, J. W.: Photographic Sensitivity, London 1951, S. 4.

Pohl, Robert Wichard \& P. Pringsheim [1912] Verh. dtsch. phys. Ges. 14 (1912), S. 506.

Rögener, Heinz [1937] Annalen der Physik (5) 29 (1937), S. 386.

Schaitberger, G. [1937] Nachrichten von der Gesellschaft der Wissenschaften zu Göttingen, MathematischPhysikalische Klasse, (N. F.) Phys. 2 (1937), S. 181. 
Smakula, Alexander [1927] Zeitschrift für Physik 45 (1927), S. 1.

Smakula, Alexander [1929] Nachrichten von der Gesellschaft der Wissenschaften zu Göttingen, MathematischPhysikalische Klasse 1 (1929), S. 110.

Smakula, Alexander [1930]a Zeitschrift für Physik 59 (1930), S. 603.

Smakula, Alexander [1930]b Zeitschrift für Physik 63 (1930), S. 762.

Smakula, Alexander [1934] Nachrichten von der Gesellschaft der Wissenschaften zu Göttingen, MathematischPhysikalische Klasse, Neue Folge 1 (1934), S. 55.

Stasiw, Ostap [1932] Nachrichten von der Gesellschaft der Wissenschaften zu Göttingen, MathematischPhysikalische Klasse, Nr. 26 (1932), S. 261.

Stasiw, Ostap [1933] Nachrichten von der Gesellschaft der Wissenschaften zu Göttingen, MathematischPhysikalische Klasse (1933), S. 387.

Stasiw, Ostap [1934]a Nachrichten von der Gesellschaft der Wissenschaften zu Göttingen, MathematischPhysikalische Klasse, Neue Folge 1 (1934), S. 147.

Stasiw, Ostap [1934]b Nachrichten von der Gesellschaft der Wissenschaften zu Göttingen, MathematischPhysikalische Klasse, Neue Folge 1 (1934), S. 199.

Stasiw, Ostap [1935] Zeitschrift für technische Physik 16 (1935), S. 343.

Stasiw, Ostap [1936]a Nachrichten von der Gesellschaft der Wissenschaften zu Göttingen, MathematischPhysikalische Klasse, (N. F.) Phys. 2 (1936), S. 1-7.

Stasiw, Ostap [1936]b Nachrichten von der Gesellschaft der Wissenschaften zu Göttingen, MathematischPhysikalische Klasse, (N. F.) Phys. 2 (1936), S. 131.

Stasiw, Ostap [1950] Zeitschrift für Physik 127 (1950), S. 522.

Stasiw, Ostap [1951] Zeitschrift für Physik 130 (1951), S. 39.

Stasiw, Ostap \& Joachim Teltow [1941] Nachrichten der Akademie der Wissenschaften in Göttingen, Mathematisch-Physikalische Klasse (1941), S. 100.

Stöckmann, Fritz [1951]c Z. physik. Chem. 198 (1951), S. 215.

Thiele, W. [1936] Annalen der Physik (5) 25 (1936), S. 561.

Umrath,W. [1933] Dissertation Göttingen, 1933.

Voßnack, Renate [im Druck] Annalen der Physik (5) 35 (1939), S. 107.

Weber, Heinrich [1951]b Die Naturwissenschaften 38 (1951), S. 140.

Witt, Horst [1953] Zeitschrift für Physik 134 (1953), S. 117.

\section{Andere Arbeiten:}

Adirowitsch, E. J. [1948]a Ber. Akad. Wiss. USSR 63 (1948), S. 111.

Adirowitsch, E. J. [1948]b Ber. Akad. Wiss. USSR 63 (1948), S. 635.

Adirowitsch, E. J. [1949] Nachr. Akad. Wiss. USSR, physik. Ser. 13 (1949), S. 101.

Adirowitsch, E. J. [1951] Abh. sowj. Physik 1 (1951), S. 71.

Ahearn, A. J. [1948]a Physical Review 73 (1948), S. 524.

Ahearn, A. J. [1948]b Physical Review 73 (1948), S. 1113.

Alexander, I. \& E. E Schneider [1949] Nature 164 (1949), S. 653.

Antonow-Romanowski, W. W., W. L. Lewschin, Z. L. Morgenstern \& Z. A. Trapeznikowa [1946]a Ber. Akad. Wiss. USSR 54 (1946), S. 19.

Antonow-Romanowski, W. W., W. L. Lewschin, Z. L. Morgenstern \& Z. A. Trapeznikowa [1946]b Ber. Akad. Wiss. USSR 54 (1946), S. 775.

Antonow-Romanowski, W. W., W. L. Lewschin, Z. L. Morgenstern \& Z. A. Trapeznikowa [1946]c Ber. Akad. Wiss. USSR 54 (1946), S. 783.

Apker, L. \& E. Taft [1950] Physical Review 79 (1950), S. 964.

Baedeker, K. [1908] Physikalische Zeitschrift 9 (1908), S. 431.

Baedeker, K. [1909] Annalen der Physik (4) 29 (1909), S. 566.

Baedeker, K. [1912] Physikalische Zeitschrift 13 (1912), S. 1080.

Bandow, F. [1950] Lumineszenz, Stuttgart 1950.

Bardeen, J. \& W. H. Brattain [1948] Physical Review 74 (1948), S. 230.

Bardeen, J. \& W. H. Brattain [1949] Physical Review 75 (1949), S. 1208.

Barnes, R. B. \& M. Czerny [1932] Zeitschrift für Physik 79 (1932), S. 436.

Baumbach, H. H. v. \& C. Wagner [1933] Zeitschrift für physikalische Chemie (B) 22 (1933), S. 199.

Baumbach, H. H. v. \& C. Wagner [1934] Zeitschrift für physikalische Chemie (B) 24 (1934), S. 59.

Bay, Z. [1947] Hungarica Acta Physica 1 (1947), S. 1.

Bayliss, N. S. \& J. C. Riviere [1949] Nature 163 (1949), S. 765.

Becker, J. A., C. B. Green \& G. L. Pearson [1946] Electr. Engng. 65 (1946), S. 711.

Becker, J. A., C. B. Green \& G. L. Pearson [1947] Bell System techn. J. 26 (1947), S. 170.

Becker, M. \& H. J. Fan [1949] Physical Review 76 (1949), S. 1530. 
Becquerel, E. [1839] C. R. Acad. Sci. Paris 9 (1839), S. 561.

Becquerel, H. [1885] C. r. Acad. Sci. Paris 101 (1885), S. 205.

Bethe, H. A. [1942] MIT, Rad. Lab. Report (1942), 43/12.

Bevan, D. J., J. P. Shelton \& J. S. Anderson [1948] J. chem. Soc. London (1948), S. 1729.

Bidwell, C. C. [1922] Physical Review 19 (1922), S. 447.

Biltz, H. \& W. Biltz [1940] Ausführung quantitativer Analysen, Leipzig 1940.

Birus, K., F. Möglich \& R. Rompe [1943] Physikalische Zeitschrift 44 (1943), S. 122.

Boer, J. H. de [1933] Zeitschrift für physikalische Chemie (B) 21 (1933), S. 198.

Boer, J. H. de [1937]a Rec. Trav. Chim. Pays Bas 56 (1937), S. 301.

Boer, J. H. de [1937]b Elektronenemission und Adsorptionserscheinungen, Leipzig 1937.

Boer, J. H. de \& E. J. W. Verwey [1937] Proc. physic. Soc. 49 extra part. (1937), S. 59.

Lecoq de Boisbaudran [1886]a C. R. Paris 103 (1886), S. 468.

Lecoq de Boisbaudran [1886]b C. R. Paris 103 (1886), S. 679.

Lecoq de Boisbaudran [1886]c C. R. Paris 103 (1886), S. 1107.

Bowen, E. J. [1938] Nature 142 (1938), S. 1081.

Bowen, E. J. \& E. Mickiewicz [1947] Nature 159 (1947), S. 706.

Brattain, W. H. \& H. B. Briggs [1949] Physical Review 75 (1949), S. 1705.

Brauer, P. [1946] Zeitschrift für Naturforschung 1 (1946), S. 70.

Brauer, P. [1947] Zeitschrift für Naturforschung 2a (1947), S. 238.

Brauer, P. [1950]a Zeitschrift für Naturforschung 5a (1950), S. 156.

Brauer, P. [1950]b Zeitschrift für Naturforschung 5a (1950), S. 158.

Brauer, P. [1950]c J. Opt. Soc. America 40 (1950), S. 353.

Brauer, P. [1951] a Zeitschrift für Naturforschung 6a (1951), S. 561.

Brauer, P. [1951]b Zeitschrift für Naturforschung 6a (1951), S. 562.

Broser, I. \& H. Kallmann [1947]a Zeitschrift für Naturforschung 2a (1947), S. 439.

Broser, I. \& H. Kallmann [1947]b Zeitschrift für Naturforschung 2a (1947), S. 642.

Broser, I. \& H. Kallmann [1948]a Zeitschrift für Naturforschung 3a (1948), S. 6.

Broser, I. \& H. Kallmann [1948]b Annalen der Physik (6) 4 (1948), S. 61.

Broser, I. \& H. Kallmann [1948]c Annalen der Physik (6) 4 (1948), S. 85.

Broser, I. \& R. Warminsky [1950] Annalen der Physik (6) 7 (1950), S. 289.

Broser, I. \& R. Warminsky [1951] Zeitschrift für Naturforschung 6a (1951), S. 85.

Bube, R. H. [1950] Physical Review 80 (1950), S. 655.

Bube, R. H. [1951] J. Chem. Physics 19 (1951), S. 985.

Bull, C. \& G. F. J. Garlick [1950] Proc. Physic. Soc. A 63 (1950), S. 1283.

Burstein, E. \& J. J. Oberly [1949] Physical Review 76 (1949), S. 1254.

Burstein, E. \& J. J. Oberly [1950] Physical Review 79 (1950), S. 903.

Busch, G. \& H. Lebhard [1946] Helv. phys. Acta 19 (1946), S. 463.

Carswell, D. J. [1953] J. Chem. Physics 21 (1953), S. 1890.

Casler, R., P. Pringsheim \& Ph. Yuster [1949] Quarterly Report of Argonne National Laboratory, 1949.

Casler, R., P. Pringsheim \& Ph. Yuster [1950]a J. chem. Physics 18 (1950), S. 887.

Casler, R., P. Pringsheim \& Ph. Yuster [1950]b J. chem. Physics 18 (1950), S. 1564.

Casler, R., P. Pringsheim \& Ph. Yuster [1950]c J. chem. Physics 18 (1950), S. 12.

Classen, J. [1905] Vorlesung über die Natur des Lichtes, Leipzig 1905.

Collins, C. B. \& R. C. Hoyt [1948] Physical Review 73 (1948), S. 1259.

Cottrell, A. H. [1953] Dislocations and Plastic Flow in Crystals, Oxford 1953.

Curtiss, L. F. \& B. W. Brown [1947] Physical Review 72 (1947), S. 643.

Czasar, E. [1940]a Strahlentherapie 62 (1940), S. 322.

Czasar, E. [1940]b Strahlentherapie 62 (1940), S. 522.

Davidson, N. \& L. E. Larsch [1948] Physical Review 74 (1948), S. 220.

Delbecq, J., P. Pringsheim \& Ph. Yuster [1951] J. chem. Physics 19 (1951), S. 574.

Domenicali, C. A. [1950] Physical Review 78 (1950), S. 458.

Dressnandt, H. [1940] Zeitschrift für Physik 115 (1940), S. 369.

Duerig, H. W. \& J. J. Markham [unveröffentl.] 'Color Centers in Alkali Halides at $5^{\circ} \mathrm{K}$ '.

Eggert, J. \& W. Noddack [1923] Zeitschrift für Physik 20 (1923), S. 299.

Eggert, J. \& W. Noddack [1926] Zeitschr.f. Elektrochem. 32 (1926), S. 496.

Eggert, J. \& W. Raths [1928] Handbuch der Physik, Bd. XIX, 1928.

Ellickson, R. T. [1946] J. opt. Soc. America 36 (1946), S. 264.

Estermann, I., W. J. Leivo \& O. Stern [1949] Physical Review 75 (1949), S. 627.

Evans, C. H. \& J. H. Webb [1938] J. opt. Soc. America 28 (1938), S. 249.

Evans, J. [1940] Physical Review 57 (1940), S. 47. 
Fan, H. Y. \& M. Becker [1949] Physical Review 76 (1949), S. 1530.

Faraday, M. [1834] Poggendorff Ann. 61 (1834), S. 225.

Fassbender, J. [1949] Annalen der Physik (6) 5 (1949), S. 33.

Ferguson, J. N. [1944] Physical Review 66 (1944), S. 220.

Fonda, G. R. \& F. Seitz [1948] Cornell Symposium on Solid Luminescent Meterials, New York 1948.

Forro, M. [1929]a Zeitschrift für Physik 56 (1929), S. 534.

Forro, M. [1929]b Zeitschrift für Physik 58 (1929), S. 613.

Förster, Th. [1951] Fluoreszenz organischer Verbindungen, Göttingen 1951.

Försterling, K. \& V. Fréedericksz [1913] Annalen der Physik (4) 40 (1913), S. 201.

Franck, J. [1948] Annalen der Physik (6) 3 (1948), S. 62.

Frenkel, J. [1926] Zeitschrift für Physik 35 (1926), S. 652.

Frerichs, R. [1947] Physical Review 72 (1947), S. 594.

Friedman, H., L. S. Birks \& H. P. Gauvin [1948] Physical Review 73 (1948), S. 186.

Fröhlich, H. [1936] Elektronentheorie der Metalle, Berlin 1936.

Garlick, G. F. J. [1949] Luminescent Materials, Oxford 1949.

Garlick, G. F. J. \& A. F. Gibson [1947] Proc. Roy. Soc. London A 188 (1947), S. 485.

Garlick, G. F. J. \& M. H. F. Wilkins [1945] Proc. Roy. Soc. London A 184 (1945), S. 406.

Garlick, G. F. J., A. F. Wells \& M. H. F. Wilkins [1948] J. Chem. Physics 17 (1948), S. 399.

Gisolf, J. H. [1939]a Physica 6 (1939), S. 84.

Gisolf, J. H. [1939]b Trans. Faraday Soc. 35 (1939), S. 94.

Gisolf, J. H. [1939]c Trans. Faraday Soc. 35 (1939), S. 171.

Gisolf, J. H., W. de Groot \& F. A. Kröger [1941] Physica 8 (1941), S. 805.

Goldstein, E. [1897] Wiedemanns Ann. 60 (1897), S. 491.

Goos, F. [1939] Annalen der Physik (5) 34 (1939), S. 77.

Greinacher, H. [1941] Helvetica Physica acta 14 (1941), S. 552.

Groot, W. de [1939] Physica 6 (1939), S. 275.

Guillery, P. [1932] Annalen der Physik (5) 14 (1932), S. 212.

Gurney, R. W. \& N. F. Mott [1938] Proc. Roy. Soc. London A, 164 (1938), S. 151.

Haase, G. [1950] Umschau 50 (1950), S. 286.

Hahn, E. E. [1949] Dissertation Univ Pennsylvenia, 1949.

Hahn, E. E. [1951] J. Appl. Phys. 22 (1951), S. 855.

Hahn, E. E., B. R. Russell \& P. H. Miller [1949] Physical Review 75 (1949), S. 1631.

Hartmann, W. [1936] Zeitschrift für technische Physik 17 (1936), S. 436.

Hartmann, W. \& W. Schottky [1936] Die Naturwissenschaften 24 (1936), S. 558.

Hauffe, K. [1950] Annalen der Physik (6) 8 (1950), S. 201.

Hauffe, K. [noch unveröffentlicht].

Hauffe, K. \& J. Block [im Druck] Z. phys. Chem. (1951?)

Hauffe, K. \& A. L. Vierk [1950] Z. phys. Chem. 196 (1950), S. 160.

Hauser \& Biesalski [1910] Chemiker-Zeitung 34 (1910), S. 1079.

Haynes, J. R. [1947] in Fonda-Seitz: Luminescent Materials, New York 1947.

Haynes, J. R. \& W. Shockley [1948] Report of a Conference on Strength of Solids, London 1948.

Haynes, J. R. \& W. Shockley [1949] Physical Review 75 (1949), S. 691.

Haynes, J. R. \& W. Shockley [1951] Physical Review 82 (1951), S. 935.

Heerden, P. J. van [1945] Dissertation Utrecht, 1945.

Heisenberg, W. [1931] Annalen der Physik (5) 10 (1931), S. 888.

Helbig, K. [1934] Zeitschrift für Physik 91 (1934), S. 573.

Henisch, H. H. (Hrsg.) [1951] Semi-Conducting Materials, London 1951.

Herzfeld, K. F. [1944] NDRC-Report (1944), 14-284.

Hinterberger, H. [1942] Zeitschrift für Physik 119 (1942), S. 1-21.

Hinterberger, H. [1946] Z. Naturforschg. 1 (1946), S. 13.

Hippel, A. v. [1936] Zeitschrift für Physik 101 (1936), S. 680.

Hofstadter, R. [1947]a Physical Review 72 (1947), S. 747.

Hofstadter, R. [1947]b Physical Review 72 (1947), S. 1120.

Hofstadter, R. [1948] Physical Review 73 (1948), S. 631.

Hofstadter, R. [1949] Nucleonics 4 (1949), H. 4/5.

Hofstadter, R., J. C. D. Millen \& S. C. Ridgway [1947] Physical Review 72 (1947), S. 977.

Hughes, A. L. \& L. A. Du Bridge [1932] Photoelectric Phenomena, New York 1932.

Hund, F. [1935] Physikalische Zeitschrift 36 (1935), S. 728.

Hüniger, M. \& J. Rudolph [1941] Zeitschrift für Physik 117 (1941), S. 81.

Ingersoll, L. R. [1910] Astrophysic. J. 32 (1910), S. 282. 
T’Ing-Sui Kê [1949] J. Appl. Physics 20 (1949), S. 274.

Jaffé, J. [1906] J. Phys. 5 ( 1906), S. 263.

Jander, W. \& W. Stamm [1931] Z. anorg. allg. Chem. 199 (1931), S. 165.

James, T. H. [1945] J. Photographic Soc. Amer. 2 (1945), No. 2.

James, H. M. [1947] Physical Review 71 (1947), S. 137.

Jentschke, W. [1948] Physical Review 73 (1948), S. 77.

Jonker, G. H. \& J. H. van Santen [1950] Physica 16 (1950), S. 337.

Jost, W. [1936]a Physikalische Zeitschrift 36 (1936), S. 757.

Jost, W. [1937] Diffusion und chemische Reaktion in festen Stoffen, Leipzig 1937.

Jost, W. \& G. Nehlep [1936] Zeitschrift für physikalische Chemie (B) 32 (1936), S. 1.

Justi, E. [1948] Leitfähigkeit und Leistungsmechanismus fester Stoffe, Göttingen 1948.

Kallmann, H. \& R. Warminsky [1948]a Annalen der Physik (6) 4 (1948), S. 57.

Kallmann, H. \& R. Warminsky [1948]b Annalen der Physik (6) 4 (1948), S. 69.

MacKay, K. G. [1948] Physical Review 74 (1948), S. 1606.

Kirkpatrik, P. [1932] Rev. Sci. Instr. 3 (1932), S. 430.

Klasens, H. A. [unveröffentl.] 1952?

Klatt, V. \& Ph. Lenard [1889] Annalen der Physik (3) 38 (1889), S. 90.

Klick, C. C. [1949] Dissertation Pittsburg, 1949.

Klick, C. C. \& R. J. Maurer [1949] Physical Review 76 (1949), S. 179.

Koch, E. \& C. Wagner [1937] Zeitschrift für physikalische Chemie (B) 38 (1937), S. 295.

Koch, W. [1949] Forschungen und Fortschritte, Sonderheft Festkörpertagung 1949.

Kohlrausch, K. W. F. [1931/37] Smekal-Raman-Effekt, Erg.-Bd., 1931/37.

Kohlrausch, K. W. F. [1943] Praktische Physik, Bd. 1, 18. Aufl.

Kohlschütter, V. [1903] Ber. dtsch. chem. Ges. 36 (1903), S. 1151.

Kohlschütter, V. \& E. Fleischmann [1912] Liebigs Ann. 387 (1912), S. 88.

Königsberger, J. [1923] in L. Graetz: Handbuch der Elektrizität und des Magnetismus, Bd. 3, Leipzig 1923.

Krishnan, K. S. \& L. K. Narayanaswamy [1935] Curr. Sc. 3 (1935), S. 417.

Kröger, F. A. [1948] Some Aspects of the Luminescence of Solids, New York 1948.

Kröger, F. A. \& J. Dikhoff [1950] Physica 16 (1950), S. 297.

Kröger, F. A., J. E. Hellingman \& N. W. Smit [1949] Physica 15 (1949), S. 990.

Kröger, F. A. \& N. W. Smit [1950] Physica 16 (1950), S. 317.

Langmuir, J., J. Estermann \& O. Stern [1923] Zeitschr. f. phys. Chemie 106 (1923), S. 399.

Lark-Horovitz, K. [1946] Physical Review 69 (1946), S. 258.

Lark-Horovitz, K. [1949] Electrical Engineering (1949), S. 1047.

Lark-Horovitz, K. \& Mitarb. [1948] Physical Review 74 (1948), S. 1255.

Lark-Horovitz, K. \& Mitarb. [1949] Physical Review 76 (1949), S. 442.

Lark-Horovitz, K. \& Mitarb. [1950]a Physical Review 78 (1950), S. 645.

Lark-Horovitz, K. \& Mitarb. [1950]b Physical Review 78 (1950), S. 815.

Laszlo, H. G. [1925] Z. physik. Chem. 118 (1925), S. 369.

Lau, E. [1929] Zeitschrift für Instrumentenkunde 49 (1929), S. 57.

Lehovec, K. [1946] Z. Naturforschg. 1 (1946), S. 258.

Lehovec, K. [1947] Z. Naturforschg. 2a (1947), S. 398.

Lehovec, K. [1948] Physical Review 74 (1948), S. 463.

Leistner, K. [1924] Annalen der Physik (4) 74 (1924), S. 325.

Leistner, K. \& W. Möbius [1924] Annalen der Physik (4) 74 (1924), S. 700.

Lenard, P. [1928] Handb. d. Exp.-Physik.

Lenard, Ph, F. Schmidt \& R. Tomaschek [1928] Handbuch der Experimentalphysik, Bd. 23, Leipzig 1928.

Lenz, H. [1924] Physikalische Zeitschrift 25 (1924), S. 435.

Lenz, H. [1925] Annalen der Physik (4) 77 (1925), S. 449.

Lenz, H. [1927]a Annalen der Physik (4) 82 (1927), S. 775.

Leverenz, H. W. [1948] in: Fonda \& Seitz [1948].

Leverenz, H. W. [1950] Introduction to Luminescence of Solids, New York 1950.

Liebig, Justus [1835] Ann. Pharmaz. 14 (1835), S. 134.

Löhle, F. [1933] Nachrichten von der Gesellschaft der Wissenschaften zu Göttingen, MathematischPhysikalische Klasse (1933), S. 271.

Lonsdale, Kathleen [1948] Physical Review 73 (1948), S. 1467.

Markham, J. J. [unveröffentl.] 'Speculations on the Formation of F-Centers during Irridation'.

Meidinger, W. [1925] Zeitschrift für physikalische Chemie 114 (1925), S. 89.

Meyer, W. [1933] Zeitschrift für Physik 85 (1933), S. 278.

Meyer, W., F. Möglich \& W. Schottky [1939] Z. Elektrochem. 45 (1939), S. 68. 
Meyer, W. \& H. Neldel [1937] Z. techn. Phys. 18 (1937), S. 588.

Miller, P. H. [1941] Physical Review 60 (1941), S. 890.

Minor, R. S. [1903] Annalen der Physik (4) 10 (1903), S. 581.

Mitchell, J. W. [1949]a Phil. Mag. (7) 40 (1949), S. 249.

Mitchell, J. W. [1949]b Phil. Mag. (7) 40 (1949), S. 667.

Mitchell, J. W. [1951] in: Photographic Sensitivity, London 1951, S. 242-257.

Möglich, F. \& R. Rompe [1940] Zeitschrift für Physik 115 (1940), S. 707.

Molnar, J. P. [1940] Dissertation MIT, 1940.

Molnar, I. P. \& C. D. Hartmann [1950] Physical Review 79 (1950), S. 1015.

Mott, N. F. [1938] Science Progress 32 (1938), S. 128.

Mott, N. F. [1939]a Proc. Roy. Soc. London A 171 (1939), S. 144.

Mott, N. F. [1939]b Proc. Roy. Soc. London 171 (1939), S. 281.

Mott, N. F. [1948] Photographic J. B 88 (1948), S. 119.

Mott, N. F. [1949] Proc. physic. Soc. A 62 (1949), S. 416.

Mott, N. F. \& R. W. Gurney [1940] Electronic Processes in Ionic Cristals, Oxford 1940.

Mott, N. F. \& M. J. Littleton [1938]a Trans. Faraday Soc. 34 (1938), S. 485.

Mukhopadhyay, B. [1938] Zs.f. Krist. 100 (1938), S. 308.

Murmann, H. [1933] Zeitschrift für Physik 80 (1933), S. 161.

Muto, T. [1935] Sci. Pap. Inst. Physic. Chem. Res. 28 (1935), S. 171.

Muto, T. [1937] Sci. Pap. Inst. Physic. Chem. Res. 32 (1937), S. 5.

Narayanaswamy, L. K. [1935] Trans. Farad. Soc. 31 (1935), S. 1411.

Nordheim, L. W. [1932] Zeitschrift für Physik 75 (1932), S. 434.

Nordheim, E. [1934] in Müller-Poillet, Lehrbuch der Physik, Bd. 4, Braunschweig 1934.

Nyquist, H. [1928] Physical Review 32 (1928), S. 113.

Pauling, L. [1948] The Nature of the Chemical Bond, Ithaca 1948.

Pashley, D. W. [1951] in Mitchell, J. W.: Photographic Sensitivity, London 1951, S. 39-45.

Pearson, G. L. \& J. Bardeen [1949] Physical Review 75 (1949), S. 865.

Peierls, R. [1929] Zeitschrift für Physik 53 (1929), S. 255.

Pfann, W. G. \& K. M. Olsen [1953] Physical Review 89 (1953), S. 322.

Pfund, A. H. [1934] Journ. Opt. Soc. Amer. 24 (1934), S. 99.

Pringsheim, P. [1928] Fluoreszenz und Phosphoreszenz, Berlin 1928.

Pringsheim, P. [1949] Fluorescence and Phosphorescence, New York 1949.

Przibram, K. [1926] Wiener Berichte II a 135 (1926), S. 197.

Przibram, K. [1931] Zeitschrift für Physik 68 (1931), S. 403.

Randall, J. T. \& M. H. F. Wilkins [1945]a Proc. Roy. Soc. London A 184 (1945), S. 347.

Randall, J. T. \& M. H. F. Wilkins [1945]b Proc. Roy. Soc. London A 184 (1945), S. 365.

Randall, J. T. \& M. H. F. Wilkins [1945]c Proc. Roy. Soc. London A 184 (1945), S. 390.

Reinders, W. \& L. Hamburger [1932] Zeitschr.f. wiss. Photogr. 31 (1932), S. 32.

Riehl, N. [1937] Annalen der Physik (5) 29 (1937), S. 636.

Riehl, N. [1941] Physik und technische Anwendungen der Lumineszenz, Berlin 1941.

Riehl, N. \& M. Schön [1939] Zeitschrift für Physik 114 (1939), S. 682.

Rittner, E. S. [1948] Physical Review 73 (1948), S. 1212.

Röntgen, W. C. [1921] Annalen der Physik (4) 64 (1921), S. 1.

Rosenheim \& Löwenstamm [1903] Z. anorg. Chem. 34 (1903), S. 62.

Rothschild, S. [1934] Physikalische Zeitschrift 35 (1934), S. 557.

Rothschild, S. [1936] Physikalische Zeitschrift 37 (1936), S. 757.

Ryder, E. J. \& W. Shockley [1949] Physical Review 75 (1949), S. 310.

Sachs, H. A. [1942] NDRC-Report (1942), 14-129.

Schintlmeister, J. [1943] Die Elektronenröhre als physikalisches Meßgerät, Berlin 1943.

Schmidt, A. [1941] Zeitschrift für Physik 117 (1941), S. 757.

Schneider, E. G. \& H. M. O’Bryan [1937] Physical Review 51 (1937), S. 293.

Schön, M. [1937] Verh. dtsch. physik. Ges. (3) 18 (1937), S. 70.

Schön, M. [1938] Physikalische Zeitschrift 39 (1938), S. 940.

Schön, M. [1939] Naturwiss. 27 (1939), S. 432.

Schön, M. [1951] Z. Naturforschg. 6a (1951), S. 251.

Schottky, W. [1933] Physikalische Zeitschrift 34 (1933), S. 863.

Schottky, W. [1935] Zeitschrift für physikalische Chemie (B) 29 (1935), S. 353.

Schottky, W. [1938] Die Naturwissenschaften 26 (1938), S. 843.

Schottky, W. [1939]a Zeitschrift für Physik 113 (1939), S. 367.

Schottky, W. [1939]b Z. Elektrochem. 45 (1939), S. 42. 
Schottky, W. [1940] Physikalische Zeitschrift 41 (1940), S. 570.

Schottky, W. [1942] Zeitschrift für Physik 118 (1942), S. 539.

Schottky, W. [1943] Leuchten und Struktur fester Stoffe, Verlag Oldenbourg 1943.

Schottky, W. [1944] unveröffentlichter Bericht zur Theorie der Phosphore, 1944.

Schottky, W. [unveröffentlicht] Untersuchungen zu Arbeiten von Hilsch und Pohl.

Schottky, W. \& W. Deutschmann [1929] Physikalische Zeitschrift 30 (1929), S. 839.

Schottky, W. \& E. Spenke [1939] Wiss. Veröff. Siemens-Werken 18 (1939), S. 225.

Schult, E. [1927] Annalen der Physik (4) 82 (1927), S. 1025.

Schweickert, H. [1939] Verh. dtsch. physik. Ges. (3) 20 (1939), S. 99.

Seitz, F. [1938] J. Chem. Physics 6 (1938), S. 150.

Seitz, F. [1939] Trans. Faraday Soc. 35 (1939), S. 74.

Seitz, F. [1940] The Modern Theory of Solids, New York 1940.

Seitz, F. [1946] Rev. Mod. Phys. 18 (1946), S. 384.

Seitz, F. [1950]a Physical Review 79 (1950), S. 529.

Seitz, F. [1950]b Physical Review 80 (1950), S. 239.

Seitz, F. \& R. P. Johnson [1937]a J. Appl. Physics 8 (1937), S. 84.

Seitz, F. \& R. P. Johnson [1937]b J. Appl. Physics 8 (1937), S. 186.

Seitz, F. \& R. P. Johnson [1937]c J. Appl. Physics 8 (1937), S. 264.

Selenyi, P. [1911] Annalen der Physik (4) 35 (1911), S. 444.

Sheppard, S. E. \& A. P. Trivelli [1921] Phot. Journ. 61 (1921), S. 403.

Sheppard, S. E., A. P. H. Trivelli \& R. P. Loveland [1925] J. Franklin Inst. 200 (1925), S. 51.

Shockley, W. [1938] J. Appl. Physics 9 (1938), S. 635.

Shockley, W. [1950] Electrons and Holes in Semiconductors, New York 1950.

Siedentopf, H. [1905] Physikalische Zeitschrift 6 (1905), S. 885.

Skaupy, F. [1920] Zeitschrift für Physik 1 (1920), S. 259.

Slater, J. C. [1951] Quantum Theory of Matter, New York 1951.

Smekal, A. [1936] Physikalische Zeitschrift 37 (1936), S. 554.

Smith, W. [1873] Amer. J. Sci. 5 (1873), S. 301.

Snoek, J. L. [1946] Philips' techn. Rdsch. 8 (1946), S. 353

Sommerville, A. [1912] Physical Review 34 (1912), S. 311.

Spenke, E. [1949] Zeitschrift für Physik 126 (1949), S. 67.

Stettner, G. [1941] Verh. dtsch. physik. Ges. 22 (1941), S. 13.

Stookey, S. O. [1949] Ind. Engng. Chem. 41 (1949), S. 856.

Streck, E. [1939]a Annalen der Physik (5) 34 (1939), S. 96.

Streck, E. [1939]b Annalen der Physik (5) 35 (1939), S. 58.

Strong, I. \& R. T. Brice [1935] J. opt. Soc. Amer. 25 (1935), S. 209.

Teal, K. G., J. R. Fisher \& A. W. Treptow [1946] J. appl. Physics 17 (1946), S. 879.

Teltow, Joachim [1949]a Annalen der Physik (6) 5 (1949), S. 63.

Teltow, Joachim [1949]b Annalen der Physik (6) 5 (1949), S. 71.

Töpler, M. [1908] Annalen der Physik (4) 27 (1908), S. 1043.

Torrey, H. C. \& C. A. Whitmer [1948] Crystal Rectifiers, New York u. a. 1948.

Tsujikawa, I. \& E. Kanda [1950] Sci. Rep. Tôhoku Univ. A 2 (1950), S. 420.

Tubandt, C. \& J. Eggert [1920] Z. anorg. Chem 110 (1920), S. 196.

Ulich, H. [1941] Kurzes Lehrbuch der physikalischen Chemie, 3. Aufl. 1941.

Urbach, F. [1930]a Wiener Ber. II A 139 (1930), S. 363.

Urbach, F. [1930]b Wiener Ber. II A 139 (1930), S. 483.

Urbach, F., D. Pearlman \& H. Hemmendinger [1946] J. opt. Soc. America 36 (1946), S. 372.

Vartanian, A. T. [1950] Dokl. Akad. Nauk. USSR 71 (1950), S. 641.

Verneuil, A. [1886] C. R. Paris 103 (1886), S. 600.

Verwey, E. J. W., \& J. H. de Boer [1936]a Rec. Trav. chim. Pays-Bas 55 (1936), S. 531.

Verwey, E. J. W., \& J. H. de Boer [1936]b Strukturber. 4 (1936), S. 170.

Verwey, E. J. W. \& P. W. Haaijman [1941] Physica 8 (1941), S. 979.

Verwey, E. J. W., P. W. Haaijman \& F. C. Romeijn [1947] J. chem. Physics 15 (1947), S. 181.

Verwey, E. J. W., P. W. Haaijman \& F. C. Romeijn [1948] Chem. Weekblad 44 (1948), S. 705.

Verwey, E. J. W., P. W. Haaijman, F. C. Romeijn \& G. W. van Oosterhout [1950] Philip's Res. Rep. 5 (1950), S. 173.

Verwey, E. J. \& E. L. Heilmann [1947] J. chem. Physics 15 (1947), S. 174.

Voigt, Woldemar [1902] Nachrichten von der Gesellschaft der Wissenschaften zu Göttingen, MathematischPhysikalische Klasse (1902), Heft 4, S. 259.

Volger, J. [1950] Physical Review 79 (1950), S. 1023. 
Wagner, C. [1933]a Zeitschrift für physikalische Chemie (B) 21 (1933), S. 42.

Wagner, C. [1933]b Zeitschrift für physikalische Chemie (B) 21 (1933), S. 469.

Wagner, C. [1933]c Z. Elektrochem. 38 (1933), S. 543.

Wagner, C. [1935] Physikalische Zeitschrift 36 (1935), S. 721.

Wagner, C. [1938] Trans. Faraday Soc. 34 (1938), S. 851.

Wagner, C. [1950] J. chem. Physics 18 (1950), S. 62.

Wagner, C. \& K. Grünewald [1938] Zeitschrift für physikalische Chemie (B) 40 (1938), S. 455.

Wagner, C. \& W. Koch [1936] Zeitschrift für physikalische Chemie (B) 32 (1936), S. 439.

Wagner, C. \& G. Ronge [1950] Journ. chem. Phys. 18 (1950), S. 74.

Wagner, C. \& W. Schottky [1931] Zeitschrift für physikalische Chemie (B) 11 (1931), S. 163.

Wartenberg, H. v. [1926] Zs. f. Elektrochemie 32 (1926), S. 330.

Wartenberg, H. v. [1930] Z. anorg. Chem. 190 (1930), S. 185.

Weise, E. [1949] Technische Halbleiter-Widerstände, Leipzig 1949.

West, W. \& B. H. Carroll [1947] J. chem. Physics 15 (1947), S. 429.

Wiener, O. [1890] Wiedermanns Ann. Physik 40 (1890), S. 203.

Wilson, A. H. [1931] Proc. Roy. Soc. London 133 (1931), S. 458.

Wilson, A. H. [1932]a Proc. Roy. Soc. London 134 (1932), S. 282.

Wilson, A. H. [1932]b Proc. Roy. Soc. London 136 (1932), S. 487.

Wolff, H. [1936] Physikalische Zeitschrift 37 (1936), S. 552.

Wood, R. W. [1904] Phil. Mag. 7 (1904), S. 385.

Wooldrige, E. E., A. J. Ahearn \& J. A. Burton [1947] Physical Review 71 (1947), S. 913.

Wouters, Louis F. \& R. S. Christian [1947] Physical Review 72 (1947), S. 1127.

Zintl, E. \& A. Harder [1931] Zeitschrift für physikalische Chemie (B) 14 (1931), S. 265.

Zintl, E. \& A. Harder [1935] Zeitschrift für physikalische Chemie (B) 28 (1935), S. 478.

\subsubsection{Ergebnisse}

Die wichtigsten Ergebnisse lassen sich in folgenden Punkten zusammenfassen:

1) Die Pohl-Schule zitiert bevorzugt Arbeiten aus dem eigenen Institut

2) Bei den jüngeren Mitarbeitern ist diese Tendenz stärker ausgeprägt

3) Pohl selbst zitiert äußerst sparsam

4) Heute als grundlegend angesehene theoretische Arbeiten wurden erst mit langer zeitlicher Verzögerung zitiert

5) Die angloamerikanischen Arbeiten wurden verstärkt erst nach 1945 zur Kenntnis genommen

6) Die Pohl-Schule zitiert keine Arbeiten der Göttinger Kollegen aus den benachbarten Physikinstituten

Zu 1) Von den insgesamt 893 Zitaten nennen 492 Arbeiten aus dem eigenen Institut (das Verhältnis A : B ist also 492 : 401). Die Bevorzugung der Göttinger Forschungsergebnisse in den Zitaten schlägt sich auch in der Liste der meistzitierten Arbeiten nieder: Von den 30 Publikationen, die mindestens fünfmal zitiert wurden, stammen bis auf eine einzige (Molnar [1940]) alle aus Pohls Institut. Mit dreizehnmal am häufigsten zitiert wurde ein Überblicksartikel von Pohl aus dem Jahr 1938 über die Forschungsarbeiten seines Institut. Bei Pohls Gästen wurde zwischen den in Göttingen entstandenen und den übrigen Arbeiten 
unterschieden. Zitiert wurden vom Pohl-Kreis bevorzugt jene Arbeiten, die im eigenen Institut entstanden sind. ${ }^{1390}$

\begin{tabular}{|l|r|}
\hline Pohl [1938] & 13 \\
\hline Glaser \& Lehfeldt [1936] & 9 \\
\hline Hilsch \& Pohl [1937]a & 9 \\
\hline Rögener [1937] & 9 \\
\hline Thomas [1940] & 9 \\
\hline Pohl \& Stöckmann [1947] & 8 \\
\hline Glaser [1937] & 7 \\
\hline Gudden \& Pohl [1920]b & 7 \\
\hline Hilsch \& Pohl [1939] & 7 \\
\hline Kelting \& Witt [1949] & 7 \\
\hline Kleinschrod [1936] & 7 \\
\hline Mollwo [1933] & 7 \\
\hline Pick [1938] & 7 \\
\hline Gudden \& Pohl [1923]a & 6 \\
\hline Gudden \& Pohl [1923]b & 6 \\
\hline Hilsch \& Pohl [1930]b & 6 \\
\hline Mollwo \& Stöckmann [1948]a & 6 \\
\hline Mollwo \& Stöckmann [1948]b & 6 \\
\hline Bauer [1934] & 5 \\
\hline Hecht [1932] & 5 \\
\hline Hilsch \& Pohl [1929] & 5 \\
\hline Hilsch \& Pohl [1930]a & 5 \\
\hline Hilsch \& Pohl [1936]a & 5 \\
\hline Lehfeldt [1933]a & 5 \\
\hline Lehfeldt [1935] & 5 \\
\hline Lüpke [1934] & 5 \\
\hline Mollwo \& Roos [1934] & 5 \\
\hline Molnar [1940] & \\
\hline Pohl [1940]a & 5 \\
\hline Stasiw [1933] & 5 \\
\hline
\end{tabular}

Tabelle 19 Liste der meistzitierten Arbeiten

Das Zitierverhalten veränderte sich im Laufe der Zeit. In den 50er Jahren wurden mehr auswärtige Arbeiten angeführt als zuvor. Legt man einen Zeitschnitt im Jahr 1950, so sehen die Verhältnisse wie folgt aus: In den 44 Arbeiten bis einschließlich 1949 ist das Verhältnis A : B 292 : 132, in den 27 späteren Arbeiten 200 : 269. Dieser Wandel ist begleitet von einer Zunahme der absoluten Zahl der Zitate pro Arbeit. Vor 1950 gibt es im Mittel 9,6 Zitate pro Aufsatz, danach 17,3. Für diesen Trend verantwortlich waren besonders die langjährigen Mitarbeiter Pohls, Pick und vor allem Stöckmann. In den acht Arbeiten von Stöckmann als alleinigem Autor finden sich im Mittel 37,8 Zitate. Auch die mit der Zeit stärkere Zurkenntnisnahme der auswärtigen Arbeiten liegt besonders an Stöckmann. Ohne seine Aufsätze ist A : B insgesamt 406 : 183, vor $1950274: 108$ und danach immer noch mit einem Übergewicht auf den Göttinger Arbeiten 143 : 105. Stöckmanns Zitierverhalten legt den Schluss nahe, dass er im Laufe seiner Göttinger Assistentenzeit immer selbständiger in der

1390 Auch in Bezug auf Doktorarbeiten aus Pohls Institut kann man dieses Verhalten erkennen. Ein Beispiel ist Wilhelm Meyeren, dessen Göttinger Dissertation (Meyeren [1930]) einmal von Pick zitiert wurde. Er studierte in München, Göttingen und Berlin, war nach seiner Promotion Assistent an der TH Karlsruhe und habilitierte sich dort 1938 mit einer Arbeit über die Anregung von Gasen durch Elektronenstoß. Seine späteren Arbeiten wurden von den Göttingern nicht zitiert. - In diese Kategorie gehört auch Zoltán Gyulai, der in Siebenbürgen 
Forschung wurde, sich von Pohl schrittweise 'abnabelte' und die 'äußere Welt' stärker als alle anderen Institutsmitarbeiter zur Kenntnis nahm.

$\mathrm{Zu}$ 2) Betrachtet man einige Arbeiten der jüngeren Mitarbeiter, vor allem deren publizierte Doktorarbeiten, zeigt sich im Zitierverhalten eine deutliche Konzentration auf die Göttinger Arbeiten mit einer ähnlichen zeitlichen Entwicklung. Von den 20 ausgewählten Aufsätzen stammen elf aus den Jahren vor 1950. ${ }^{1391}$ Bei ihnen ist A : B 61 : 9. Mehr als die Hälfte dieser Aufsätze zitieren überhaupt keine auswärtige Arbeit. ${ }^{1392}$ Nach 1950 sind dies nur noch zwei von sieben; ${ }^{1393}$ das Verhältnis A : B wandelte sich zu 47 : 32.

Zu 3) Die nur unter Pohls Namen erschienenen Aufsätze im Untersuchungszeitraum zeigen zwei Extreme im Zitierverhalten. Auf der einen Seite steht sein Überblicksartikel von 1938, in dem er 74 der in seinem Institut zustandegekommenen Arbeiten explizit zitiert und insgesamt 87 am Ende auflistet. Auf der anderen Seite finden sich elf Aufsätze mit im Mittel jeweils weniger als einem einzigen Zitat. Sie behandeln hauptsächlich grundsätzliche Fragen zu physikalischen Einheiten, welche Größen als Grundgrößen anzusehen sind, welche Bedeutung das Mol in der Physik hat, ${ }^{1394}$ aber auch Themen des Physikunterrichts. ${ }^{1395}$ In einem dieser Aufsätze erörtert Pohl die Bedeutung von Kristallfehlern für die Physik fester Körper, behandelt also ein Thema seines langjährigen Forschungsprogramms. Aber selbst hier gibt es nur ein einziges Zitat, und dies betrifft eine von ihm verfasste, in einer Festschrift seines Hamburger Gymnasiums publizierte Festrede zur Reichsgründungsfeier der Universität Göttingen aus dem Jahr 1928. ${ }^{1396}$

Pohl zitierte entweder seine eigenen Lehrbücher oder Aufsätze und Lehrbücher anderer Autoren, die allerdings meist aus seiner Studienzeit stammten, also zum Zeitpunkt der Zitation bereits etwa 40 Jahre alt waren. Die einzige Ausnahme betrifft das Lehrbuch der physikalischen Chemie von H. Ulich von 1941, das Pohl zur Bekräftigung seiner Definition

und Ungarn studierte und von 1924 bis 1926 in Göttingen bei Pohl forschte. Nur seine Arbeiten aus dieser Zeit wurden zitiert.

1391 Folgende 20 Aufsätze wurden herangezogen: Ackermann [1940]; Akpinar [1940]; Domanic [1943]; Dorendorf [1951]; Dorendorf \& Pick [1950]; Fritzsche [1952]; Gericke [1950]; Heiland \& Kelting [1949]; Hoch [1940]; Intemann \& Stöckmann [1951/52]; Karabascheff [1941/42]; Kelting \& Witt [1949]; Kerkhoff [1951]; Petroff [1950]; Pick [1938]; Rögener [1940]; Rohn [1949]; Thomas [1940]; Weber [1951]a; Witt [1950]. 1392 Es sind dies: Akpinar [1940]; Domanic [1943]; Heiland \& Kelting [1949]; Karabascheff [1941/42]; Rögener [1940]; Thomas [1940].

1393 Bei diesen beiden handelt es sich allerdings um publizierte Diplomarbeiten, nämlich Gericke [1950] und Fritzsche [1952].

1394 Pohl [1942]a, [1942]b, [1943], [1948], [1949], [1951]a, [1951]b, [1951]c. Zu dieser Kategorie sind auch die beiden Arbeiten Pohl \& Stöckmann [1944]a, [1944]b zu zählen, die ein ähnliches Zitierverhalten zeigen.

1395 Pohl [1940]b, [1940]c.

1396 Pohl [1952]a. 
des Mol als individuelle Masseneinheit anführt. ${ }^{1397}$ An anderer Stelle begründet Pohl die Zurückhaltung in der Namensnennung bei der Diskussion verschiedener Standpunkte in Fragen der physikalischen Einheiten: „Namen werden absichtlich nicht genannt. Diesen Ausführungen liegen keinerlei polemische Absichten zugrunde.“1398 Man könnte diese rücksichtsvolle Haltung als „Pohl’sche Sachlichkeit“ bezeichnen.

$\mathrm{Zu}$ 4) Alan Wilsons theoretische Arbeiten aus den frühen dreißiger Jahren, die das Bändermodell begründeten, wurden erst nach 1945 zitiert. Der Grund hierfür liegt vermutlich in der allgemeinen Skepsis der Pohl-Schule gegenüber quantenmechanischen „Vorstellungen“. Wilson wurde dementsprechend nur in insgesamt zwei Aufsätzen zitiert: in Mollwo \& Stöckmann [1948]b und in Stöckmann [1950]c. Im ersten Aufsatz, „Eine quantitative Deutung der elektrischen und lichtelektrischen Leitfähigkeit von Zinkoxyd auf Grund des Massenwirkungsgesetzes“, finden sich Hinweise, warum das erfolgreiche theoretische Modell nicht Eingang in die Pohl-Schule gefunden hat. Es handelt sich um einen Aufsatz, der im Anschluss an in derselben Zeitschrift dargelegten experimentellen Ergebnisse eine quantitative Deutung dieser wagt. Die getrennte Behandlung von Daten und Deutung erfährt darin eine eigene Begründung: „Obwohl die experimentellen Untersuchungen und unsere Deutungsversuche in steter Wechselwirkung miteinander ausgeführt wurden, bringen wir in der vorliegenden Arbeit unsere Deutung getrennt von den experimentellen Ergebnissen, da diese auf jeden Fall auch unabhängig von allen theoretischen Vorstellungen ihre Gültigkeit behalten."1399 Dies ist so zu verstehen, dass Mollwo und Stöckmann die Gültigkeit ihrer vorhergenden Publikationen durch eine möglicherweise unzutreffende Deutung nicht gefährden wollten. In den vorhergehenden Arbeiten teilten sie „sauber reproduzierbare Gesetzmäßigkeiten“ mit, deren Deutung, auch wenn diese aus der PohlSchule kommt, nur den Charakter des Möglichen besaß. ${ }^{1400}$

Der Fortschritt in der theoretischen Festkörperphysik führte zu neuen Modellen und Deutungen, die auch in Göttingen nicht unbemerkt blieben. 1948 schien eine besondere Begündung erforderlich, warum die neuen theoretischen Erkenntnisse nicht als Standard benutzt wurden: „Es ist seit einigen Jahren üblich, bei der Beschreibung von lichtelektrischen Leitungsvorgängen in festen Körpern das aus wellenmechanischen Vorstellungen folgende

\footnotetext{
1397 Pohl [1942]b S. 533.

1398 Pohl [1942]a S. 127.

1399 Mollwo \& Stöckmann [1948]b S. 240.

1400 In der Zusammenfassung der vorhergehenden Arbeit schrieb Mollwo: „Die in dieser Arbeit wiedergegebenen Ergebnisse sind hier absichtlich ohne jede Deutung gelassen. Eine solche bringt die folgende
} 
Bändermodell zu benutzen. Wir schließen uns in der vorliegenden Arbeit diesem Brauch nicht an“. ${ }^{1401}$ Drei Gründe führen sie an, die diese Verweigerung rechtfertigen sollen. 1. suchen sie nach Konzentrationen der Ladungsträger und nicht nach deren Energieniveaus, wofür das Bändermodell besonders geeignet wäre. 2. können sie die auftretenden Störniveaus im ZnO chemisch identifizieren, weshalb sie ,die qualitative Veranschaulichung im Niveauschema entbehren können.“ 3. ist die genauere Rechnung durch „wellenmechanische Verfahren [...] uninteressant [...], so lange man die erste Näherung nicht kennt, die sich aus der klassischen Rechnung ergibt.“1402 Mollwo und Stöckmann behandeln die elektrische und lichtelektrische Leitfähigkeit des $\mathrm{ZnO}$ also klassisch, indem sie die Gesetze des chemischen Gleichgewichts und der Reaktionskinetik auf die Dissoziation des neutralen Zink in ein einwertiges und zweiwertiges Ion anwenden. Die gemessenen Ströme werden ausschließlich auf das Vorhandensein der Zinkionen zurückgeführt. Für diese klassische Rechnung müssen sie allerdings eine Zusatzannahme in Form eines die Reaktionen beschleunigenden Katalysators machen. Die 'tatsächliche Existenz' dieses Katalysators stellen sie aber gleich wieder selbst in Frage:

„Die Einführung des Katalysators erscheint etwas gekünstelt, letzten Endes soll er aber auch nur als ein mögliches Bild aufgefaßt werden. Wir möchten die Frage völlig offen lassen, ob statt dessen vielleicht die Geschwindigkeitskonstanten, die Beweglichkeiten der optisch abgespaltenen Elektronen oder die Querschnitte der Strombahn der lichtelektrischen Ströme (etwa durch Elektronendiffusion) während der Belichtung $\mathrm{i}_{\mathrm{o}}{ }^{-2 / 3}$ proportional werden. Alle Annahmen führen hinsichtlich des gemessenen Stromes $i_{L}$ zum gleichen Ergebnis. Der Kürze halber sprechen wir weiterhin stets nur vom Katalysator." 1403

Am Ende vergleichen sie ihre klassisch gewonnenen Ergebnisse mit einer „Beschreibung der Erscheinungen mit Hilfe des Energieschemas“ - also einer Beschreibung auf quantenmechanischer Grundlage. Dabei betonen sie, dass das von Wilson durch strenge Rechnung gefundene Ergebnis für die Elektronenkonzentration bei der thermischen Dissoziation einer Störstelle sich nicht „nur mit den Methoden der modernen Theorie deuten“ lasse. Der Pohlschüler Gudden gab schon 1934 eine ,anschauliche Deutung der Wilsonschen Formel“", ${ }^{1404}$ auf die Mollwo und Stöckmann nochmal verweisen, da diese ,,anscheinend im allgemeinen nicht bekannt“ sei. Abschließend halten sie fest: „Wir sehen in diesen Gründen

\footnotetext{
Arbeit. In dieser beschränken wir uns vollkommen auf die Tatsachen.“ Mollwo [1948]b S. 239; das Zitat im Haupttext findet sich auf S. 230.

1401 Mollwo \& Stöckmann [1948]b S. 241.

1402 Mollwo \& Stöckmann [1948]b S. 241.

1403 Mollwo \& Stöckmann [1948]b S. 243.

1404 Siehe Gudden [1934] S. 252.
} 
eine ausreichende Rechtfertigung für unseren Verzicht auf die Anwendung der modernen Theorie, um so mehr als die Ergebnisse der klassischen Rechnung keine prinzipiell ungeklärte Frage zurücklassen.“1405

Auch in dem zweiten Aufsatz, in dem Wilson zitiert wird, zeigt sich die Skepsis gegenüber diesen theoretischen Vorstellungen. Ohne auf das Modell näher einzugehen, bemerkte Stöckmann, dass die daraus abgeleiteten Eigenschaften der Eigenleitung von Halbleitern lange Zeit nicht nachgewiesen werden konnten. „Infolgedessen fehlte $\mathrm{zu}$ den aus den Wilsonschen Arbeiten folgenden weitreichenden Modellvorstellungen über die energetischen Verhältnisse in einem Halbleiter immer noch der entscheidende experimentelle Beweis.“1406 Dieser wurde unter anderem in Göttingen von Joseph Stuke an Untersuchungen am Germanium erbracht. Doch bei der „Deutung“ der neuen Ergebnisse bedient sich Stöckmann wieder dem klassischen Bild des Massenwirkungsgesetzes. Das Bändermodell fand auch in diesem Aufsatz keine Verwendung. Stöckmann zitiert zwar bei der Besprechung von Stukes Ergebnissen auch Arbeiten über Germanium und Silizium, die während des Krieges in den USA und der Schweiz durchgeführt und nach 1945 publiziert wurden, doch lässt er die in München von Heinrich Welker durchgeführten Leitfähigkeits- und Hall-Effektmessungen am Germanium, die 1948 publiziert wurden, unerwähnt. ${ }^{1407}$ Der Sommerfeldschüler Welker stützte seine theoretische Erklärung für die durch Dotierung des Germanium erzielten hohe Elektronenbeweglichkeiten auf das quantenmechanische Bändermodell. ${ }^{1408}$ Vielleicht bewirkte das gespannte Verhältnis zwischen dem Pohlkreis und den Münchnern dieses Zitierverhalten. Wie Pick im Interview sagte, gab es „durchaus lebhafte Gefühle“ zwischen den beiden Lagern. ${ }^{1409}$

Die Pohlschule hing dem klassischen Bild von Elektronen, die als Teilchen durch ein Kristallgitter wandern, an und fand die Wellenmechanik zu wenig anschaulich. Um die Anschaulichkeit im wahren Wortsinn $\mathrm{zu}$ erreichen, enthalten ihre Arbeiten meist viele Diagramme und Abbildungen, unter anderem vom Gitteraufbau der Kristalle und Aussehen von Störstellen wie Versetzungen und Fehlordnungen. Obwohl sich auch das Bändermodell in Diagrammform veranschaulichen ließe, wurde es, wenn überhaupt, nur im Text erwähnt. Es dauerte bis 1954, als Pohl in der neunten Auflage seiner „Optik und Atomphysik“ im neu

\footnotetext{
1405 Mollwo \& Stöckmann [1948]b S. 254.

1406 Stöckmann [1950]c S. 86.

1407 Ringer, W. \& H. Welker [1948] 'Leitfähigkeit und Hall-Effekt von Germanium', Zeitschrift für Naturforschung 3a (1948), S. 20-29.

$1408 \mathrm{Zu}$ Welkers Forschungen im Kontext der deutschen Festkörperphysik siehe Eckert [1993] S. 212-220.

1409 Interview mit Heinz Pick, 2. Oktober 1981. NBL.
} 
eingefügten Kapitel 19 zur Quantenoptik fester Körper das Bändermodell zur qualitativen Erklärung von Leitungsvorgängen benutzte. Im Vorwort schreibt er: „Im XIX. Kapitel werden meine früheren Mitarbeiter in ganz knapper Fassung manches von dem finden, um das wir uns in früheren Jahren gemeinsam bemüht haben." 1410 Dieses Kapitel ist eine komprimierte Darstellung des Pohl'schen Forschungsprogramms. Während Pohl früher seine „Tatsachen“ ausschließlich klassisch „deutete“, gesteht er nun ein: „Man kann die Tatsachen in chemischer Ausdrucksweise oder an Hand eines Niveauschemas beschreiben. Beides hat seine Berechtigung."1411 Für Pohl scheinen beide Modelle gleiche Gültigkeit zu haben. Trotzdem benutzt Pohl zur Beschreibung fast aller Phänomene die klassische Variante. Doch erhält man den Eindruck, als wären die beiden Modelle beliebig austauschbar, wie folgende Äußerung bei der Besprechung der fotochemischen und elektrischen Eigenschaften der Kristallphosphore zeigt: „Dabei soll zur Abwechslung einmal nicht das photochemische Bild, sondern die Darstellung im Niveauschema [...] benutzt werden.“"1412 Doch auch hier benutzt Pohl weitgehend klassische Vorstellungen. Er schreibt daher selbst von einer „halb photochemischen Betrachtungsweise“.1413 Die Übergänge zwischen verschiedenen Energieniveaus erklärt er durch Ortswechsel von Elektronen und Defektelektronen. Die Löcherleitung lässt sich im klassischen Bild allerdings nicht befriedigend verstehen. Löcher verhalten sich nach Pohl wie Elektronen mit positiver Ladung, doch zur bildlichen Veranschaulichung schlägt er vor: „Man kann mit gleichem Recht sagen, ein Teilchen [Elektron] diffundiere nach rechts, oder ein Loch nach links.“ 1414 Dieses Bild führt allerdings bei reinen p-Leitern zu einem falschen Vorzeichen beim Hall-Effekt. Diese Schwierigkeit ignorierte Pohl, obwohl sie ihm durchaus bekannt war. ${ }^{1415}$ Stöckmann verabschiedete sich von diesem einfachen Bild der Löcherleitung und erwähnte in einem Aufsatz 1950, dass Peierls und Heisenberg schon 1929 und 1931 eine theoretische Erklärung für das anomale

\footnotetext{
1410 Pohl [1940]a 9. Aufl. 1954, S. IV.

1411 Pohl [1940]a 9. Aufl. 1954, S. 320.

1412 Pohl [1940]a 9. Aufl. 1954, S. 329.

1413 Pohl [1940]a 9. Aufl. 1954, S. 330.

1414 Pohl [1940]a 9. Aufl. 1954, S. $318 f$.

1415 Pohls Kollege Georg Joos schreibt zum Beispiel in seinem Lehrbuch der theoretischen Physik in der 5. Aufl. 1943, S. 684: „Bei manchen Metallen, z. B. Zn, ist das Vorzeichen [des Hall-Effekts] entgegengesetzt, als ob positive Ladungsträger am Strom beteiligt wären. Die Bändertheorie erklärt dies zwanglos“. In der folgenden Erklärung bleibt Joos allerdings auf einer anschaulichen Stufe und deutet nur an, dass das Phänomen auch „streng abgeleitet werden“ könne. 1948 schreibt Pohl zum anomalen Vorzeichen des Hall-Effekts bei Zn in seinem Lehrbuch zur Elektrizitätslehre kurz: „Es ergibt sich so, als ob Elektronen mit einer positiven Ladung wandern. Das kann man bisher nur deuten, wenn man die Elektronen als Wellenbündel behandelt." Pohl [1927], 13. u. 14. Aufl. 1948, S. 208. In der Auflage von 1941 gab Pohl noch keine Erklärung für das verkehrte Vorzeichen. Im Interview gab Pohl an, dass er vom Hall-Effekt nichts mehr wissen wollte, nachdem Gudden bei Messungen des Hall-Effekts der einzig damals brauchbare reine Diamant zu Bruch gegangen war. Interview mit Pohl, 7. Juli 1974, NBL.
} 
Vorzeichen beim Hall-Effekt gaben. Ohne das wellenmechanische Bild zu benutzen, gab Stöckmann eine halbklassische Deutung. Das klassische Bild geht von Elektronen aus, die durch das Gitter wandern und dadurch eine Leitfähigkeit des Materials verursachen. Da aber die äußeren Elektronenhüllen der Gitterbausteine miteinander verflochten sind, verlieren die Elektronen ihre Individualität; sie sind nicht mehr einzelnen Atomen zuzuordnen.

„Das an die Störstelle angelagerte Elektron fehlt daher nicht einem bestimmten Gitterbaustein, sondern dem Elektronengefüge des Kristallgitters als ganzem. Das muß so beschrieben werden, als ob die Störstelle nicht ein Elektron angelagert hat, sondern als ob sie eine freie positive Ladung abgegeben hat, die sich im übrigen etwa wie ein freies Elektron benimmt. Diese positive Ladung darf wie ein freies Elektron als selbständiges Individuum angesehen werden und erhält den Namen Defektelektron". ${ }^{1416}$

Stöckmann untnimmt hier keinen Versuch, ein Bild für das wandernde Loch, das sich wie ein freies Elektron benimmt, zu entwerfen. Er akzeptiert es als Ergebnis aus der Quantenmechanik. Nachdem das Defektelektron in seinen Eigenschaften wie ein gewöhnliches Elektron identifiziert wurde, wendet Stöckmann darauf konsequenterweise die bewährten Methoden an und errechnet Dissoziationsgleichgewichte für Defektelektronen mit Hilfe des Massenwirkungsgesetzes. Auch den „wellenmechanischen Tunneleffekt“ erwähnt Stöckmann als Tatsache ohne weitere Erläuterung. Ein kurzer Verweis auf Wilson und Nordheim genügte. Doch mehr als eine mögliche Erklärung für die 'Überwindung' eines Potentialberges wollte Stöckmann damit nicht erreichen. ${ }^{1417}$ Es erscheint so, als ob hier und in dem oben zitierten Absatz die größtmögliche Benutzung der Quantenmechanik erfolgte, die in der Pohl-Schule zu dieser Zeit zulässig war. Das von Nevill Mott und Ronald Gurney 1940 verfasste Standardwerk zur Festkörpertheorie, das die meisten Eigenschaften der Alkalihalogenidkristalle mit Hilfe der Quantenmechanik erklären konnte, wurde von den Göttingern nur einmal zitiert. ${ }^{1418}$ Stöckmann bezieht sich 1950 auf dieses Buch an einer Stelle seines Aufsatzes, wo er bei seinen Berechnungen eine unter Benutzung quantenstatistischer Methoden hergeleitete Formel einführt. ${ }^{1419}$ Das Bändermodell bleibt auch in diesem Aufsatz unerwähnt.

\footnotetext{
1416 Stöckmann [1950]c S. 87. Hervorhebung original.

1417 „Für Fragen des Kontaktwiderstandes zwischen 2 Metallen ist der Tunneleffekt [...] wahrscheinlich von erheblicher Bedeutung." Stöckmann [1950]c S. 106.

1418 Im Vorwort zur 1. Aufl. von Mott \& Gurney [1940/48] schreiben sie: „We were first attracted to the subject by the very detailed and complete experimental inverstigations of the properties of alkali-halide crystals with colour centres which have been carried out in recent years; we have found that an explanation based on quantum mechanics can be given of the great majority of these properties."

1419 Stöckmann [1950]a S. 573. 
Obwohl Pohl das Niveauschema als mögliches Erklärungsmodell in sein Lehrbuch aufgenommen hatte, beschrieben seine Schüler die Vorgänge im Halbleiter weiterhin im klassischen Bild, wie selbst der Überblicksartikel zur Festkörperphysik von Heinz Pick in den Naturwissenschaften von 1954 zeigt. ${ }^{1420}$ Bei den Gästen in Pohls Institut findet sich das Niveauschema als selbstverständliche Interpretation der Messungen an Halbleitern, wie weiter unten am Beispiel von Luise Meyer-Schützmeister noch gezeigt wird.

Eine schnellere Aufnahme und Akzeptanz fanden Schottkys theoretische Modelle. Insgesamt wurden 15 Arbeiten von ihm zitiert. Schottkys Raumladungstheorie der Sperrschicht konnte mit Hilfe der von der Pohl-Schule zur Erklärung von Leitungsvorgängen gewöhnlich benutzten (foto)chemischen Reaktionsgleichgewichte für Dissoziationsvorgänge von freien Elektronen beschrieben werden. Zum Beispiel kommt in der Grenzschicht zwischen Halbleiter und Metall eine positive Raumladung im Halbleiter dadurch zu Stande, dass ,eine gewisse Anzahl von Elektronen in das Metall fließt." "1421 Durch das klassische Bild ließ sich also die Sperrschicht einigermaßen gut veranschaulichen. Neben der Benutzung des theoretischen Modells von Schottky gab es auch einen fachlichen Austausch der Göttinger Experimentatoren mit dem bei Siemens arbeitenden Theoretiker. ${ }^{1422}$

Zu 5) In den Nachkriegsjahren wurden deutlich mehr angloamerikanische Arbeiten zitiert als zuvor. Das spiegelt die Verlagerung des Forschungsschwerpunkts wider: Wesentliche Fortschritte in der theoretischen wie experimentellen Festkörperphysik kamen in den vierziger Jahren aus den Bell Laboratories, den Universitäten in Princeton und Purdue, dem MIT und der Universität Bristol. Die von dort stammenden neueren Arbeiten wurden von den Göttingern rasch aufgegriffen. Im Zuge dessen kamen aber auch die älteren Aufsätze aus den dreißiger Jahren ins Blickfeld der Pohl-Schule. Zum Beispiel wurden Arbeiten von Frederick Seitz (Princeton) aus den späten dreißiger Jahren das erste Mal erst 1952 zitiert. ${ }^{1423}$ Seitz' frühe Monografie von 1940 wird in den hier untersuchten Arbeiten der Göttinger nur dreimal zitiert: in Mollwo \& Stöckmann [1948]a, Stöckmann [1950]a und Pick [1954]. Ein anderes Beispiel ist William Shockley (MIT und Bell). Seine Arbeiten der Jahre 1948 bis 1951 fanden unmittelbar Aufnahme durch die Göttinger. Doch eine schon 1938 publizierte Arbeit fand erst im Jahr 1950 Erwähnung. ${ }^{1424}$ Eine späte Rezeption betraf also nicht nur theoretische

\footnotetext{
1420 Pick [1954].

1421 Stöckmann [1950]c S. 105.

1422 Stöckmann bedankte sich in seinem Überblicksaufsatz über die Theorie der lichtelektrischen Leitung in Mischleitern bei Schottky für wertvolle Hinweise. Stöckmann [1950]b S. 210.

1423 Stöckmann [1952] zitiert Seitz [1938], [1939] und Seitz \& Johnson [1937]a, [1937]b, [1937]c.

1424 Shockley [1938] zitiert in Stöckmann [1950]b.
} 
Arbeiten, wie jene von Wilson aus den Jahren 1931/32, sondern auch die eben besprochenen Aufsätze von Experimentalphysikern.

Wie am Beispiel von Nevill Mott (Bristol) zu sehen ist, konnten englischsprachige Arbeiten der dreißiger Jahre von den Göttingern durchaus schnell rezipiert werden. Seine Aufsätze von 1938 wurden schon 1939 zitiert. ${ }^{1425}$ Das hängt vermutlich damit zusammen, dass im Juli 1937 in Bristol eine von Mott organisierte Tagung über Elektrizitätsleitung in festen Körpern stattfand, an der auch Pohl teilnahm. ${ }^{1426}$ Nach einer längeren Pause wurde Mott wieder in den Jahren 1950/51 zitiert; dann sowohl neue wie alte Aufsätze. ${ }^{1427}$ - Der internationale Gedankenaustausch auf Tagungen konnte über 10 Jahre lang nicht stattfinden. Erst 1949 kamen deutsche und ausländische Festkörperphysiker wieder zusammen, als in Göttingen eine Diskussionstagung anlässlich Pohls 65. Geburtstag veranstaltet wurde. Aus Pittsburgh kamen Frederick Seitz und Robert I. Maurer, aus Bristol Nevill F. Mott und aus Twickenham I. W. Davisson. ${ }^{1428}$ Dieser Kontakt brachte den Göttingern einen bestimmten Ausschnitt der angloamerikanischen Forschungen stärker ins Bewusstsein. Es ist daher auch nicht verwunderlich, dass die einzige Zitation einer Arbeit von Maurer im Jahr 1950, also unmittelbar nach der Tagung, erfolgte. ${ }^{1429}$ Bei Seitz liegen die Verhältnis ähnlich: Seine Arbeiten, darunter auch Aufsätze aus den Jahren 1938 und 1939, wurden in insgesamt sieben verschiedenen Aufsätzen der Göttinger zitiert, aber nur einer davon erschien vor der Tagung, ${ }^{1430}$ alle anderen sind aus den Jahren $1950 \mathrm{ff}$.

Zu 6) Zwischen der Pohl-Schule und den näheren Göttinger Fachkollegen scheint es fast keine fachliche Zusammenarbeit gegeben zu haben. Dies legt zumindest das Zitierverhalten der Pohlschule nahe. Die Arbeiten der Göttinger Physikprofessoren Prandtl, Reich, Born, Franck, Schuler, Joos, Becker, Zahn, Kopfermann und Meyer wurden nicht zitiert. Die einzige Ausnahme war ein Aufsatz von Franck aus dem Jahr 1948. Franck war nicht der einzige Emigrant, dessen Arbeiten aus der Emigrationszeit wahrgenommen wurden. Auch Hippel und Nordheim zählen dazu, wobei von Nordheim auch ein Aufsatz aus dem Jahr 1932 einmal zitiert wurde, allerdings erst 1950. Nordheim war Schüler von Max Born. Seine

\footnotetext{
1425 Pick [1939] zitiert Mott [1938] und Mott \& Littleton [1938]a.

1426 Siehe den zusammenfassenden Bericht Pohl [1938], den er für die Tagung in Bristol verfasst hatte.

1427 Dorendorf \& Pick [1950] zitieren Mott [1938]; Stöckmann [1950]a zitiert Mott \& Gurney [1940];

Stöckmann [1950]c Mott [1939]a und [1939]b; Pick [1951] Gurney \& Mott [1938] und Mott [1948]; Stöckmann [1951]a Mott [1949].

1428 König [1949]b.

1429 Siehe Stöckmann [1950]c, der Klick \& Maurer [1949]zitiert.

1430 Stöckmann [1948]a. Bei Mott liegen die Verhältnisse zwar ähnlich wie bei Seitz (fünf von sechs Zitationen nach der Tagung), hingegen wurde er schon vor 1945 zitiert.
} 
Arbeiten galten unter anderem der Weiterentwicklung der quantenmechanischen Elektronentheorie, daher wurden sie von der Pohl-Schule erst recht spät rezipiert. Eine Chance der Zusammenarbeit hätte es mit Max Born gegeben, der sich schon vor seiner Göttinger Zeit die Aufgabe stellte, die Eigenschaften der festen Körper vom Bau der Kristallgitter her zu verstehen. In Göttingen widmete er sich vor allem der Ausarbeitung der Quantenmechanik. Doch in seinem Exil in Edinburgh lieferte er wieder wertvolle Beiträge zur Theorie der Kristalle. ${ }^{1431}$ Mott und Littleton führten Berechnungen auf der Basis von Borns Behandlung der Wechselwirkung von Ionen in Ionenkristallen durch und konnten so zeigen, dass von verschiedenen Möglichkeiten der Störstellen in Alkalihalogenidkristallen der Einbau von zwischengelagerten Atomen weniger als ein Prozent ausmachen kann. ${ }^{1432}$ Diese Arbeit wurde von der Pohl-Schule rasch zur Kenntnis genommen. ${ }^{1433}$ Doch zu einer Zusammenarbeit mit Born oder einer Benutzung seiner Theorien durch die Pohl-Schule scheint es nicht gekommen zu sein, was weniger an den physikalischen Inhalten als am unterschiedlichen Forschungsstil gelegenen haben mag. Mit Borns Nachfolger Becker gab es ebenfalls keine Zusammenarbeit. Becker nahm die Arbeiten aus Pohls Institut kaum zur Kenntnis. Das berichtete jedenfalls Pick im Interview. Am Tag von Pohls Emeritierung kam Becker zu Pick, der vertretungsweise die Institutsleitung übernahm, und fragte: „Na, Pick, zeigen Sie mal, was macht ihr denn eigentlich hier?"1434

Auf der unteren Ebene der Institutsmitarbeiter kam es zur Zusammenarbeit von Pohlschülern und Joosschülern. Ein Beispiel betrifft Ostap Stasiw (I. Institut) und Joachim Teltow (II. Institut). Beide gingen von Göttingen $\mathrm{zu}$ Zeiss nach Dresden. Die dortige Forschungstätigkeit führte $\mathrm{zu}$ gemeinsamen Publikationen. ${ }^{1435} \mathrm{Zu}$ einer tatsächlichen Zusammenarbeit innerhalb der Göttinger Institute scheint es nur zwischen Eugen Saur (II. Insitut) und Stasiw gekommen zu sein. ${ }^{1436} \mathrm{Zu}$ der Zeit, als Joos Direktor der II. Physik war, gab es offenbar mehr Kontakte zwischen den beiden Experimentalphysikinstituten als zuvor und danach. Die Joosschülerin Adelheid Gott führte Untersuchungen an

\footnotetext{
1431 Siehe Hund [1987] S. 62, 70.

1432 Mott \& Littleton [1938]. Siehe auch Seitz [1946] S. 394.

1433 Siehe Pick [1939].

1434 Interview mit Heinz Pick, 2. Oktober 1981. NBL.

1435 Ostap Stasiw \& Joachim Teltow [1941]a 'Zur Photochemie des Silberchlorids mit Fremdionenzusätzen', Nachrichten der Akademie der Wissenschaften in Göttingen, Mathematisch-Physikalische Klasse (1941), S. 9399; dieselben [1941]b 'Untersuchung der primären Photochemie des Silberbromids mit geringen Zusätzen von Silbersulfid bei verschiedenen Wellenlängen', ebenda, S. 100-109; dieselben [1941]c 'Zur Deutung der Photochemie der Silberhalogenidkristalle', ebenda, S. 110-118. dieselben [1944] 'Zur Photochemie der Silberhalogenide', ebenda (1944), S. 155-163.

1436 Saur \& Stasiw [1938]. Saur hatte auch zu Pohl selbst einen offenbar guten Kontakt. Im Vorwort zu Pohl [1940]a wird ihm für seine Hilfe gedankt.
} 
Alkalihalogenidkristallen durch, wobei sie die Kristalle von Pohl und Mollwo sowie von dem Pohl-Schüler Alexander Smakula von der Firma Zeiss in Jena zur Verfügung gestellt bekam. Der verwendete Interferenzmessapparat war ebenfalls ein Zeiss-Produkt. Am Ende des Aufsatzs bedankte sie sich bei Joos für die Bereitstellung der Institutshilfsmittel und sein förderndes Interesse und bei Pohl und Mollwo für wertvolle Diskussionen. ${ }^{1437}$ In den häufig anzutreffenden Danksagungen am Ende der Aufsätze waren sonst keine weiteren derartigen Beispiele von Hilfeleistungen zwischen den Pohlschülern und Mitgliedern anderer Institute zu finden.

\subsubsection{Vergleich des Zitationsverhaltens der Pohl-Schule mit Außenstehenden}

Zur Überprüfung, inwiefern sich eine Schulebildung in den Zitationen der Arbeiten aus dem Pohl-Kreis widerspiegelt, werden im folgenden ausgewählte Arbeiten zur Festkörperphysik, die nicht aus der Pohl-Schule stammen, auf ihr Zitationsverhalten untersucht. Dabei handelt es sich zum einen um Arbeiten aus Pohls Institut, die allerdings von Gästen durchgeführt wurden. Zum anderen wird ein Überblicksartikel zu Farbzentren in Alkalihalogenidkristallen von Frederick Seitz vom Carnegie Institute of Technology, Pittsburgh, Pennsylvania, untersucht. In beiden Fällen handelt es sich um Arbeiten, die verwandte Themen des Pohl'schen Forschungsprogramms behandeln. Die Auswahl des auswärtigen Aufsatzes erfolgte bewusst nach thematischen Gesichtspunkten. Die Untersuchung der Farbzentren war das zentrale Forschungsthema der Pohl-Schule.

Die Analyse der Zitationen wird nach dem gleichen Schema durchgeführt, wie es oben an der Pohl-Schule geschehen ist. Zuerst werden vier Arbeiten aus dem I. Physikalischen Institut untersucht und anschließend getrennt davon jene von Seitz. Durch die Trennung bekommt man zwei unterschiedliche Gruppen zitierter Literatur, die man jeweils mit dem Kanon der von der Pohl-Schule benutzten Literatur vergleichen kann.

1437 Gott [1942]. 


\begin{tabular}{|c|c|c|c|}
\hline $\begin{array}{l}\text { Krenzien } \\
{[1949] \mathrm{a}}\end{array}$ & $\begin{array}{l}\text { Hilsch \& Pohl } \\
{[1930] \mathrm{b} ; \text { Hilsch }} \\
{[1932] .}\end{array}$ & Becker [1929]; Katz [1937], [1938]a, [1938]b; Schneider \& O’Bryan [1937]. & $2: 5$ \\
\hline $\begin{array}{l}\text { Krenzien } \\
{[1949] \mathrm{b}}\end{array}$ & Krenzien [1949]a. & $\begin{array}{l}\text { Baeyer [1908]a, [1908]b; Gehrts [1911]; Farnsworth [1925]; Lenard [1918]; Lenard } \\
\text { \& Becker [1927]; Bothe [1933]; Ruthemann [1941], [1948]. }\end{array}$ & $1: 9$ \\
\hline $\begin{array}{l}\text { Krenzien } \\
{[1949] \mathrm{c}}\end{array}$ & $\begin{array}{l}\text { Gudden \& Pohl } \\
\text { [1926]; Pick [1948]; } \\
\text { Mollwo \& Stöckmann } \\
\text { [1948]b. }\end{array}$ & Hinterberger [1942]. & $3: 1$ \\
\hline $\begin{array}{l}\text { Meyer- } \\
\text { Schützmeister } \\
{[1951]}\end{array}$ & Engelhardt [1933]. & $\begin{array}{l}\text { Condon [1938]; Fowler [1933], [1936]; Apker, Taft \& Dickey [1948]a, [1948]b; } \\
\text { Lenard [1902]; Lukirsky \& Prilezaev [1928]; Millican [1921]; Du Bridge [1933]; } \\
\text { Wilson [1931], [1932]a; Bardeen [1947]; Dünnwald \& Wagner [1933]; Klemm \& } \\
\text { Schüth [1931/32]; Le Blanc, Sachse \& Schöpel [1933]; Hartmann [1936]; } \\
\text { Baumbach, Dünnwald \& Wagner [1933]; Dressnandt [1940]. }\end{array}$ & $1: 18$ \\
\hline
\end{tabular}

Arbeiten aus Pohls Institut, die nicht von der Pohl-Schule zitiert wurden:

Gudden, Bernhard \& Robert Wichard Pohl [1926] Zeitschrift für Physik 37 (1926), S. 881.

Hilsch, Rudolf [1932] Zeitschrift für Physik 77 (1932), S. 427.

\section{Andere Arbeiten:}

Apker, L., E. Taft \& J. Dickey [1948]a Physical Review 73 (1948), S. 46.

Apker, L., E. Taft \& J. Dickey [1948]b Physical Review 74 (1948), S. 1462.

Baeyer, O. v. [1908]a Verh. dtsch. phys. Ges. 10 (1908), S. 96.

Baeyer, O. v. [1908]b Verh. dtsch. phys. Ges. 10 (1908), S. 953.

Bardeen, J. [1947] Physical Review 71 (1947), S. 717.

Baumbach, H. H., H. Dünnwald \& C. Wagner [1933] Zeitschrift für physikalische Chemie (B) 22 (1933), S. 226.

Becker, A. [1929] Annalen der Physik (5) 2 (1929), S. 249.

Blanc, M. le, H. Sachse \& H. Schöpel [1933] Annalen der Physik (5) 17 (1933), S. 334.

Bothe, W. [1933] Handbuch der Physik, Bd. XXII/2, 1933.

Bridge, L. A. du [1933] Physical Review 43 (1933), S. 727.

Condon, E. U. [1938] Physical Review 54 (1938), S. 1089.

* Dressnandt, H. [1940] Zeitschrift für Physik 115 (1940), S. 369.

Dünnwald, H. \& C. Wagner [1933] Zeitschrift für physikalische Chemie (B) 22 (1933), S. 212.

Farnsworth, H. E. [1925] Physical Review (2) 25 (1925), S. 41.

Fowler, R. H. [1933] Proc. Roy. Soc. Lond. A 140 (1933), S. 505.

Fowler, R. H. [1936] Statistical Mechanics, Teddington 1936.

Gehrts, A. [1911] Annalen der Physik (4) 36 (1911), S. 995.

Hartmann, W. [1936] Zeitschrift für Physik 102 (1936), S. 709.

* Hinterberger, H. [1942] Zeitschrift für Physik 119 (1942), S. 1-21.

Katz, H. [1937] Z. techn. Phys. 18 (1937), S. 555.

Katz, H. [1938]a Annalen der Physik (5) 33 (1938), S. 160.

Katz, H. [1938]b Annalen der Physik (5) 33 (1938), S. 169.

Klemm, W. \& W. Schüth [1931/32] Z. anorg. allg. Chem. 203 (1931/32), S. 104.

Lenard, P. [1902] Annalen der Physik (4) 8 (1902), S. 149.

Lenard, P. [1918] Quantitatives über Kathodenstrahlen aller Geschwindigkeiten, Heidelberg 1918.

Lenard, P. \& A. Becker [1927] Handbuch der Experimentellen Physik, Bd. 14, 1927.

Lukirsky, P. \& S. Prilezaev [1928] Zeitschrift für Physik 49 (1928), S. 236.

Millican, R. A. [1921] Physical Review 18 (1921), S. 236.

Ruthemann, G. [1941] Naturwiss. 29 (1941), S. 648.

Ruthemann, G. [1948] Annalen der Physik (6) 2 (1948), S. 113.

* Schneider, E. G. \& H. M. O’Bryan [1937] Physical Review 51 (1937), S. 293.

* Wilson, A. H. [1931] Proc. Roy. Soc. Lond. A 133 (1931), S. 458.

* Wilson, A. H. [1932]a Proc. Roy. Soc. Lond. A 134 (1932), S. 277.

Analyse des Artikels von Frederick Seitz: 'Color Centers in Alkali Halide Crystals', Review of Modern Physics 18 (1946), S. 384-408.

\begin{tabular}{|l|l|l|l|}
\hline Seitz & Pohl [1938]; Mollwo [1935]a, [1937]; & Mott \& Gurney [1940]; Seitz [1940]; Goldstein [1896]; Molnar [1940]; \\
[1946] & Kleinschrod [1936]; Smakula [1930]a; & Landau [1933]; Frenkel [1926]; Schottky [1935]; Wagner \& Schottky \\
& Rögener [1937], [1940]; Pick [1939]; & [1931]; Jost [1933], [1934], [1936]b, [1937]; Mott \& Littleton [1938]a, \\
& Glaser [1937]; Domanic [1943]; Lehfeldt & [1938]b; Tubandt [?]; Einstein [1905]; Koch \& Wagner [1937]; Love \\
& [1933]a; Glaser \& Lehfeldt [1936]. & [1945]; Birge [1941], [1945]; Hutchison \& Johnston [1940], [1942]; \\
& & Hutchison [1944], [1945]; de Boer [1937]a; Tibbs [1939].
\end{tabular}


Arbeiten aus Pohls Institut, die nicht von der Pohl-Schule zitiert wurden:

Rögener, H. [1940].

\section{Andere Arbeiten:}

Birge, R. T. [1941] Reports on Progress in Physics 8 (1941), S. 90.

Birge, R. T. [1945] Am. J. Phys. 13 (1945), S. 63.

* Boer, J. H. de [1937]a Rec. Trav. Chim. Pays Bas 56 (1937), S. 301.

Einstein, A. [1905] Ann. d. Phys. 17 (1905), S. 549.

* Frenkel, J. [1926] Zeitschrift für Physik 35 (1926), S. 652.

Goldstein, E. [1896] Zeits. f. Instrumentenkunde 16 (1896), S. 211.

Hutchison, D. A. [1944] Phys. Rev. 66 (1944), S. 144.

Hutchison, D. A. [1945] J. Chem. Phys. 10 (1945), S. 383.

Hutchison, D. A. \& H. L. Johnston [1940] J. Am. Chem. Soc. 62 (1940), S. 3165.

Hutchison, D. A. \& H. L. Johnston [1942] Phys. Rev. 62 (1942), S. 32.

Jost, W. [1933] J. Chem. Phys. 1 (1933), S. 466.

Jost, W. [1934] Zeitschrift für physikalische Chemie (A) 169 (1934), S. 129.

Jost, W. [1936]b Zeitschrift für physikalische Chemie (B) 32 (1936), S. 1.

* Jost, W. [1937] Diffusion und chemische Reaktion in festen Stoffen, Leipzig 1937.

* Koch, E. \& C. Wagner [1937] Zeitschrift für physikalische Chemie (B) 38 (1937), S. 295.

Landau, L. [1933] Zeits. Sowjetunion 3 (1933), S. 664.

Love, A. E. H. [1945] Elasticity, New York 1945.

* Molnar, J. P. [1940] Dissertation MIT, 1940.

* Mott, N. F. \& R. W. Gurney [1940] Electronic Processes in Ionic Cristals, Oxford 1940.

* Mott, N. F. \& M. J. Littleton [1938]a Trans. Faraday Soc. 34 (1938), S. 485.

Mott, N. F. \& M. J. Littleton [1938]b Trans. Faraday Soc. 34 (1938), S. 500.

* Schottky, W. [1935] Zeitschrift für physikalische Chemie (B) 29 (1935), S. 353.

* Seitz, F. [1940] The Modern Theory of Solids, New York 1940.

Tibbs, S. R. [1939] Trans. Faraday Soc. 35 (1939), S. 1471.

Tubandt, C. [?] Handbuch der Experimental Physik, Vol. XII, 1932/33.

* Wagner, C. \& W. Schottky [1931] Zeitschrift für physikalische Chemie (B) 11 (1931), S. 163.

Zeichenerklärung:

* diese Arbeit wurde auch von der Pohl-Schule zitiert

\subsubsection{Auswertung des Vergleichs}

Krenzien [1949]a bedankte sich bei Pohl für die ,gastliche Aufnahme in seinem Institut“. Obwohl der Titel der Arbeit (,Zum Durchgang langsamer Elektronen durch Alkalihalogenidkristalle“) zeigt, dass Krenzien ein Thema des Pohl'schen Forschungsprogramms bearbeitete, liefert die Analyse der Zitate, dass seine Fragestellung aus einem anderen Kontext entnommen ist. Seine Versuchsanordnung orientiert sich an einer von Hilsch benutzten. Auch seine Ergebnisse vergleicht Krenzien mit jenen von Hilsch 1932 gefundenen. Um die Abhängigkeit der Streuzahlen vom Winkel der einstrahlenden Elektronen zu erklären, greift Krenzien auf die Welleneigenschaften der Elektronen zurück und ordnet ihnen die ihrer Energie entsprechende de Broglie-Wellenlänge zu. Obwohl er damit die Winkelabhängigkeit plausibel machen konnte, fügte er eine starke Einschränkung der Gültigkeit des benutzten Modells hinzu, die vermutlich Pohls skeptischer Einstellung geschuldet war: „Trotzdem steht es außer Frage, daß sich [...] kein einfacher Zusammenhang 
zwischen den de-Broglie-Wellenlängen im Maximum der Durchlässigkeit und den Gitterkonstanten zeigt."1438 Die Behandlung der Elektronen als Wellen war in der PohlSchule unüblich. Insofern entfernte sich Krenzien mit seiner Deutung von der Praxis des I. Instituts. In Pohls Lehrbuch werden zwar Materiewellen ausführlich besprochen, doch bleibt Pohl trotz der experimentellen Evidenzen skeptisch. ${ }^{1439}$ Wie gewöhnlich geht Pohl auch bei den Materiewellen von den experimentellen 'Tatsachen' aus. „Unabhängig von aller Spekulation ist also eine Tatsache völlig gesichert: Man kann mit Korpuskularstrahlen [...] Beugungserscheinungen erhalten. Folglich muß man auch bewegten materiellen Teilchen eine Wellenlänge zuordnen.“1440 Da man aber für Materiewellen nur die Wellenlänge, nicht aber die Phasengeschwindigkeit oder die Frequenz messen kann, wird die Frequenz mit Hilfe der Energiegleichung definiert: $v=\frac{E}{h}$. Nach Festlegung der Frequenz lässt sich auch die Phasengeschwindigkeit definieren, die jedoch „in allen Fällen nur eine Rechengröß darstelle. Mit dieser Darstellung legt Pohl nahe, dass es sich hier nur um eine Deutung der Erscheinungen handle, und dass die Realität der Welle nicht gesichert sei. Er sagt deshalb: Die Entdeckung der Beugungserscheinungen an Elektronenstrahlen ,verlangte gebieterisch ein Wellenbild“. 1441 Pohl meint damit, die Welle sei keine Tatsache, sondern nur eine bildliche Deutung. Zusätzlich ergebe sich das Problem, dass die Anschaulichkeit der Wellenmetapher nur bedingt brauchbar sei. Denn selbst bei Wasserwellen erkennen wir nach Pohl nur eine räumlich und zeitlich wechselnde Anordnung und Verteilung ungeheurer Mengen von Individuen, deren Lage und Geschwindigkeiten im einzelnen unbekannt bleiben. Die Übertragung der Wellenvorstellung auf elektrische Wellen im Vakuum ,ist schon eine weitgehende Abstraktion“, und das gilt sinngemäß auch für Materiewellen. „Wir beobachten stets nur die Verteilung zahlloser Individuen in charakteristischen, mit Wellen beschreibbaren Verteilungen, z. B. in Beugungsfiguren. Die Wellen für sich allein sind eine Abstraktion."1442 Aus dieser Auffassung Pohls kann man den Schluss ziehen, dass bei der Beschreibung von Leitungsvorgängen in Halbleitern das Wellenbild unangebracht sei, da keine nur mit Wellen beschreibbaren Phänomene vorzufinden seien, also diese Abstraktionsleistung unnötig sei. Daher stellte Krenziens Deutung der Winkelabhängigkeit der Streuung einen Ausbruch aus den durch Pohl vorgegebenen Erklärungsschemata dar.

\footnotetext{
1438 Krenzien [1949]a S. 373.

1439 Siehe das Kapitel „Der Dualismus von Welle und Korpuskel“ in Pohl [1940]a.

1440 Pohl [1940]a S. 294. Hervorhebung original.

1441 Pohl [1940]a S. 295. Hervorhebung original.

1442 Pohl [1940]a S. 296. Hervorhebung original.
} 
Der kurze Aufsatz Krenzien [1949]b scheint eine Folgeuntersuchung an Krenzien [1949]a zu sein. Wieder untersucht er die Streuung langsamer Elektronen, doch diesmal nicht an Alkalihalogenidschichten, sondern an Aluminiumschichten. Der Untersuchungsgegenstand lag also außerhalb des Pohl'schen Forschungsprogramms. Der Hauptzweck der Publikation lag in der Korrektur von in der Literatur lange benutzten falschen Werten. Es ist daher verständlich, dass das Zitationsverhalten hier von jenem der Pohl-Schule abweicht.

Krenzien [1949]c behandelt die lichtelektrische Leitfähigkeit von Bleitellurid und stellt somit ein Thema aus Pohls Forschungsprogramm dar. Kurz zuvor untersuchte Pick die lichtelektrische Leitfähigkeit von Bleisulfid. ${ }^{1443}$ Das Zitationsverhalten zeigt die Verwandtschaft der beiden Aufsätze: Es wird praktisch auf die gleiche Literatur zurückgegriffen.

Die letzte hier untersuchte Arbeit aus dem I. Institut ist eine Untersuchung des äußeren Fotoeffekts von Luise Meyer-Schützmeister. ${ }^{1444}$ Angeregt wurde diese Arbeit von Krenzien. Meyer-Schützmeister konnte als Gastwissenschaftlerin ihre Experimente in Pohls Institut durchführen; ihre eigentliche institutionelle Heimat war die ebenfalls in Göttingen angesiedelte biochemische Abteilung der Medizinischen Forschungsanstalt der Max-PlanckGesellschaft. Die Untersuchung des Fotoeffekts an Halbleitern war Teil des Pohl'schen Forschungsprogramms. Schon in den frühen zwanziger Jahren arbeitete Pohl mit Gudden zu diesem Fragenkomplex, doch in der späteren Zeit gab es nur wenige Arbeiten darüber. ${ }^{1445}$ Das Zitierverhalten von Meyer-Schützmeister weicht stark von den Gewohnheiten der PohlSchule ab. Dies liegt aber nicht so sehr am Thema der Arbeit. Gleich zu Beginn entwickelt sie ihre Fragestellung aus Arbeiten angloamerikanischer Herkunft. Dass sie hierbei mit Edward Condon und Ralph Fowler zwei Theoretiker anführt, zeigt ganz deutlich, dass sie aus einer anderen Schule stammt. ${ }^{1446}$ Entsprechend anders sieht auch die Diskussion ihrer Ergebnisse aus. Sie deutet ihre Messungen wie selbstverständlich anhand von Elektronenenergieschemata. Zur Bekräftigung dafür, dass es sich dabei um eine altbewährte Methode handelt, führt sie zwei Begründer der quantenmechanischen Elektronentheorie an, nämlich Ralph Fowler und Alan Wilson. Damit hebt sie sich von der Pohl-Schule ab, die die 'neue' Theorie wie gezeigt nur zögerlich akzeptierte und Wilson nur dreimal und Fowler gar

\footnotetext{
1443 Pick [1948].

1444 Meyer-Schützmeister [1951].

1445 Zum Beispiel Stöckmann [1946].

1446 Meyer-Schützmeister war Schülerin von Hans Geiger und erwarb ihren Dr.-Ing. 1943 an der TH Berlin.

Nach Assistenzjahren in Berlin kam sie in der Nachkriegszeit nach Göttingen. 1948 richtete sie ein Isotopenlabor in der Medizinischen Forschungsanstalt der MPG ein. Siehe Brix \& Richter [1981]. 
nicht zitierte. Zur Veranschaulichung der Verhältnisse bei den untersuchten Halbleiterkathoden stellt sie die Energieschemata in Diagrammform dar. Auch solche Diagramme werden von der Pohl-Schule nicht benutzt.

In Seitz Aufsatz über die Farbzentren in Alkalihalogenidkristallen werden die Pionierleistungen der Göttinger auf diesem Gebiet angemessen gewürdigt. Dies steht vermutlich in Zusammenhang mit einem Regierungsauftrag, den Seitz im Frühjahr 1945 erhielt. Seine Aufgabe war es, verschiedene angewandte Forschungen, die in Europa während des Kriegs durchgeführt wurden, zu überblicken und $\mathrm{zu}$ überprüfen. ${ }^{1447}$ Es ist also nicht verwunderlich, dass sein Aufsatz über die Farbzentren die deutschen Forschungen besonders behandelt. In den ersten drei Kapiteln (Darkening with X-Rays; Additive Coloring; Properties of Cristals Containing F-Centers) werden mit einer Ausnahme nur Göttinger Arbeiten zitiert. ${ }^{1448}$ In der Interpretation der Messdaten bleibt Seitz in dem von der Pohl-Schule vorgegeben Rahmen. Nur an einer Stelle fügt er eine sehr schematische grafische Darstellung von Energiniveaus ein, in denen die verschiedenen Bänderstrukturen von F-Zentren und F'Zentren gezeigt werden. ${ }^{1449}$ Nur in diesem Punkt weicht er vom Stil der Pohl-Schule deutlich $\mathrm{ab}$.

Vergleicht man die gesamte zitierte Literatur der Arbeiten von Seitz, Krenzien und MeyerSchützmeister mit jener der Pohl-Schule, so kann man folgende Schlüsse ziehen: Die von Krenzien und Meyer-Schützmeister benutzte Literatur zeigt nur wenig Überschneidung mit dem großen Kanon der von der Pohl-Schule zitierten. Es sind insgesamt nur vier Autoren, die in beiden Gruppen auftauchen. Dies lässt darauf schließen, dass die Gäste ihren Forschungen selbständig nachgingen und ihre Ergebnisse in jenen Forschungskontext stellen konnten, dem sie selbst angehörten. - Der Artikel von Seitz weist zwar eine größere Überlappung in der benutzten Literatur auf, trotzdem wurden die meisten der von ihm zitierten Arbeiten, die nicht aus Pohls Institut stammen, von den Göttingern niemals angeführt. Unter den gemeinsam zitierten Arbeiten befinden sich drei, die von den Göttingern erst in den fünfziger Jahren erstmals angeführt wurden: Frenkel [1926]; Molnar [1940] und Mott \& Gurney [1940].

\footnotetext{
1447 Frederick Seitz, Memorial Symposium in honor of Heinz Pick, Stuttgart, November 5, 1985, S. 5. NBL. 1448 Die Ausnahme ist Molnar [1940]. Seine Arbeit war für die Göttinger aus zwei Gründen bedeutend: Er verfolgte dieselbe Fragestellung und fand bei Bestrahlung der Kristalle eine neue Bande, die die Göttinger noch nicht entdeckt hatten. Wegen dieser neuen Daten fand Molnar nicht nur in Seitz' Artikel Eingang, sondern auch in spätere Göttinger Arbeiten. Molnar [1940] ist die einzige nicht aus der Pohl-Schule stammende Arbeit, die unter den dreißig meistzitierten zu finden ist.

1449 Seitz [1946] S. 392, Fig. 13.
} 


\subsubsection{Schlussfolgerungen - die Pohl-Schule als Denkkollektiv}

Die Pohl-Schule bildet in ihrem Physikverständnis wie in ihrer sozialen Verbundenheit eine harmonische Einheit und kann daher als Denkkollektiv im Sinn von Ludwik Fleck aufgefasst werden. Flecks Erkenntnistheorie liefert ein begriffliches Instrumentarium, das ideal geeignet ist, die Eigenschaften der Pohl-Schule treffend zu erfassen, insbesondere das 'Wesen' der von der Pohl-Schule als forschungsleitend begriffenen „Tatsachen“ aufzuspüren. Im folgenden werden also die aus der Zitationsanalyse gewonnenen Merkmale denksoziologisch gedeutet. ${ }^{1450}$

Ein Denkkollektiv zeichnet sich durch den intensiven Meinungsaustausch seiner Mitglieder aus. ${ }^{1451}$ Dies ist bei der Pohl-Schule in starkem Maße gegeben. Pohl ist der Mittelpunkt und die bestimmende Figur; zusammen mit seinen Mitarbeitern und Doktoranden bildet er den engeren Kreis des Kollektivs - bei Fleck esoterischer Kreis genannt. Die Gäste des Instituts und die Festkörperphysiker anderer Universitäten, mit denen die Pohl-Schule in Kontakt stand, gehören ebenfalls zum Denkkollektiv, und zwar formen sie den sogenannten exoterischen Kreis. ${ }^{1452}$ Dieses so um Pohl strukturierte Denkkollektiv bildet einen eigenen Denkstil aus. Darunter versteht man ein abgeschlossenes Meinungssystem, einen bestimmten Wissensbestand, die Art, Dinge zu sehen und in das eigene Ordnungsschema einzusortieren. Der Denkstil begleitet den Forscher ständig bei seiner Arbeit. Er erzeugt eine gerichtete Wahrnehmung, die den Wissenschaftler dazu führt, den Sinn, die wesentliche Gestalt, die geschlossene Einheit in seinem Untersuchungsgegenstand zu erkennen. Der Denkstil der Pohl-Schule ist in vielen Punkten identisch mit jenem der damaligen Physiker allgemein. In bestimmten Fragen erweist er sich aber als eigenartig. Eine solche Eigenart ist die Stellung zur theoretischen Physik und speziell zur Quantenmechanik. Die Pohl-Schule zeigt eine lang wirkende Beharrungstendenz gegen die Übernahme der theoretischen Erkenntnisse. Diese Abwehr kann man als Folge der unterschiedlichen Denkstile der Theoretiker und der PohlSchule interpretieren. Als die Quantenmechanik Mitte der zwanziger Jahre entwickelt wurde, war Pohl ein anerkannter Fachmann, der bereits ein klar umrissenes Forschungsprogramm in Göttingen entwickelt hatte. Seine frühen Arbeiten galten Röntgenstrahlen, ${ }^{1453}$ außerdem

\footnotetext{
1450 Fleck [1935/99].

${ }^{1451}$ Fleck kennt verschiedene Größen von Denkkollektiven, von zwei Menschen im Gedankenaustausch (S. 60, 135) bis zu stabilen Gruppen in der Wissenschaft oder auch Religionsgemeinschaften (S. 136, 141). Es ist eine der Schwächen von Flecks Werk, dass er in der Festlegung der Größe so undeutlich ist.

1452 Zur Unterscheidung von esoterischem und exoterischem Kreis siehe Fleck [1935/99] S. 138f.

1453 Pohl [1912]. 
untersuchte er zusammen mit Peter Pringsheim den Fotoeffekt an Metalloberflächen. ${ }^{1454}$ In dieser Zeit, in der die 'klassische' Physik langsam umgestoßen wurde, für viele Experimentalphysiker aber noch prägenden Einfluss hatte, formte Pohl seinen Denkstil. Damit soll nicht gesagt werden, dass dies später automatisch zu einer ablehnenden Haltung gegenüber der Quantenmechanik führen musste. Pohl war schon damals neueren theoretischen Erklärungen gegenüber vorsichtig und suchte seinen Halt in den experimentellen 'Tatsachen'. Schon früh war Pohl bemüht, eine physikalische Erscheinung als Teilchen oder als Welle zu beschreiben; ein Sowohl-als-auch schien ihm nicht zu behagen. In seinem Buch über Röntgenstrahlen von 1912 hat er die Korpuskulartheorie der Röntgenstrahlen von Bragg nicht behandelt, „da ich keine Möglichkeit sehe, auch nur die wichtigsten Eigenschaften der Strahlen mit ihrer Hilfe zu deuten."1455 Für Pohl waren Röntgenstrahlen eben keine Teilchen sondern Strahlen, genauer eine „Ätherstrahlung“. ${ }^{1456}$ Doch selbst als er die Interferenzfiguren von Friedrich, Knipping und Laue bekommen hatte, die deutliche Beugungsmuster zeigen, blieb er auch hier in der Interpretation skeptisch, ob die periodische elektromagnetische Welle eine allgemeine Eigenschaft der Röntgenstrahlung sei. „Durch den Nachweis der Interferenz muß es als sicher gelten, daß Röntgenstrahlen periodischen Charakter besitzen können; aber erst weitere Versuche werden zeigen, wann und in welchen Fällen unperiodisch gebremste Elektronen Impulse weißen Röntgenlichts emittieren oder periodisch beschleunigte, schwingende Elektronen eine monochromatische Röntgenspektrallinie erzeugen." 1457

In Göttingen wurde Pohls Mitarbeiterkreis schrittweise in diesen Denkstil eingeführt. Große Energien steckte Pohl in die Ausbildung der Studenten. In seiner Verantwortung lag der Einführungszyklus in die Experimentalphysik, den er völlig neu gestaltete und wofür er internationale Anerkennung erfuhr. Ihm ging es besonders darum, die experimentellen Tatsachen anschaulich zu machen. ${ }^{1458}$ Man kann dieses Bestreben noch heute in seinen Lehrbüchern erkennen. Viele Demonstrationsexperimente wurden mittels Schattenwurf an die Wand projiziert, sodass alle Hörer das Experiment gut beobachten konnten. Solche Schattenrisse sind entweder als Fotografie oder schematisiert in seinen Lehrbüchern zu

\footnotetext{
1454 Pohl \& Pringsheim [1914].

1455 Pohl [1912] S. VI.

1456 Pohl [1912] S. 18.

1457 Pohl [1912] S. 155f. Hervorhebung nicht original. Siehe dazu auch Pohls vorsichtigen Abwägungen auf S. $149 \mathrm{f}$.

1458 Im Vorwort von Pohl [1927], seinem ersten Lehrbuch, das aus den Göttinger Einführungsvorlesungen entstanden ist, schreibt er: „Auswahl und Anordnung des Stoffes sind so getroffen, daß die Zusammenhänge zwischen den experimentellen Tatsachen deutlich hervortreten.“
} 
finden. Mit den Büchern und den sehr eindrucksvollen Vorlesungen erhielten die Studenten ihre Einführungsweihe in die Pohl'sche Experimentalphysik. Diesen allgemein bei Einführungen in ein Wissensgebiet anzutreffenden Vorgang hat Fleck treffend beschrieben: „Man präpariert ein[en] Intellekt für ein Gebiet, man nimmt es in eine in sich geschlossene Welt auf, man erteilt ihm eine Art Einführungsweihe." 1459 Wenn der Student sich auf Pohls Stil einließ und im Institut eine Arbeit unter seiner Anleitung durchführte, erlernte er in dieser Jahre dauernden Formung nicht nur allgemeine Grundlagen der Physik, sondern auch, zwischen Tatsachen und Deutungen im Pohl'schen Sinn zu unterscheiden. Entscheidend sind in seinem Denken die messbaren Größen. Diese bilden den festen Boden der Tatsachen, während abgeleitete Größen, deren Werte sich nur aus der Rechnung ergeben, einen unsicheren Charakter aufweisen können. In den Lehrbüchern stellt Pohl klar heraus, welche die grundlegenden Versuche sind, auf denen seine Tatsachenwelt beruht. ${ }^{1460}$ Die Unterscheidung zwischen Tatsachen und (vorläufiger) Deutung kommt am deutlichsten im dritten Band, der Optik, zur Geltung. Dort lautet eine Abschnittsüberschrift „Lichtreflexion bei schwacher Absorption und schrägem Einfall. Die Tatsachen“. ${ }^{1461}$ Wie zu erwarten gibt Pohl in diesem Abschnitt die experimentell gewonnenen Daten zur Reflexion an. In einem Diagramm veranschaulicht er die Abhängigkeit der Reflexion von der Schwingungsebene des einfallenden Lichts. Der Hintergrund dafür, warum dieser Abschnitt den Zusatz „Die Tatsachen“ bekam, wird im folgenden Abschnitt „Die Fresnelschen Formeln“ klar. Hier erscheinen zu Beginn zwei Formeln, die zwar das vorher behandelte Datenmaterial richtig wiedergeben, aber offenbar etwas anderes als Tatsachen sind. Pohl schreibt: „Die Fresnelschen Formeln lassen sich - unabhängig von den näheren Vorstellungen über die Natur des Lichtes - aus zwei Voraussetzungen herleiten“..1462 Die Formeln sind eine mathematisch korrekte Beschreibung der Tatsachen. Den Tatsachenstatus besitzen aber nur die Messdaten. Ein ähnliches Schema findet sich bei den aufeinander folgenden Abschnitten „Lichtreflexion bei starker Absorption. Die Tatsachen“ und „Einschaltung. Allgemeines über die mathematische Behandlung von Schwingungen und Wellen“. ${ }^{1463}$ Hier werden die Tatsachen an Hand einer Torsions-Wellenmaschine demonstriert (eine lange Reihe kleiner Hanteln auf einem Silberdraht); danach wird davon säuberlich getrennt der mathematische

\footnotetext{
1459 Fleck [1935/99] S. 73.

${ }^{1460}$ Um nur ein Beispiel zu nennen sei aus Pohl [1927] 6. u. 7. Aufl. 1941 das Kapitel über Kräfte und Energie im elektrischen Feld angeführt. Dort heißt es nach einem kurzen § 27 Vorbemerkungen: „§ 28 Grundversuch. Wir beginnen, wie stets, mit einer experimentellen Erfahrung."

1461 Pohl [1940]a $\S 83$.

1462 Pohl [1940]a S. 135.

1463 Pohl [1940]a $\S 87$ und 88.
} 
Apparat ausgebreitet. Auf der einen Seite eine im wahrsten Sinn anschauliche Maschine, auf der anderen Seite rein formale Beziehungen mit komplexen Rechengrößen. Dass die mathematische Behandlung nicht Teil der Tatsachen ist, liegt aber nicht daran, dass es sich um komplexe Größen $\left(e^{i \omega t}\right)$ handelt. „Man suche hinter dem Wort »komplexe Amplitude« ja nichts geheimnisvoll Gelehrtes und klage nicht über einen Mangel an »Anschaulichkeit«. Es handelt sich [...] lediglich um eine formale Schreibweise für den in Gl. (120) enthaltenen Tatbestand.“1464 Pohl versuchte, den Studenten mit dem mathematischen Formalismus vertraut zu machen und eine Vorstellung für die Gleichungen zu geben. Trotzdem weist seine Sprache darauf hin, dass es sich um etwas Abstraktes handelt, etwas nicht Messbares. An der Formulierung erkennt man den Status der Größe. Selbst bei Betonung der Nützlichkeit einer Größe spürt man die in Pohls Denken herrschende Wertung als Nicht-Tatsache, wie das Beispiel der komplexen Brechzahl zeigt: „Sie leistet als formale Rechengröße ausgezeichnete Dienste, sie ist bei keiner Behandlung irgendwelcher Wellenabsorption zu entbehren." 1465

Ein drittes und ebenso deutliches Beispiel für die Trennung zwischen Tatsachen und Auswertung findet sich in den Abschnitten „Dispersion und Absorption, Tatsachen“ und "Qualitative Deutung der optischen Dispersionskurven“.1466 Der Bergriff „Qualitative Deutung“ stellt ein wichtiges Unterscheidungskriterium dar. Wenn die Pohl-Schule diese Formulierung benutzt, verlässt sie nach eigenem Verständnis den Bereich der Tatsachen. In dem Beispiel aus dem Lehrbuch benutzt Pohl die zuvor gefundenen Tatsachen aus den mechanischen Wellenversuchen und nutzt das so gewonnene Bild, um ein neues Phänomen, nämlich die Dispersion, zu erklären. Mit der distanzierten Sprache will er erreichen, dass man die Modellvorstellung nicht mit der Wirklichkeit verwechselt. ${ }^{1467}$ Dies liegt ihm nicht nur beim Licht, sondern bei allen Wellenerscheinungen am Herzen. Auch der Wellenmechanik räumt er nur den Charakter einer möglichen Deutung und nicht den Status einer Tatsache ein.

Die Untersuchung des erkenntnistheoretischen Status des „Wellenbildes“ bei Pohl ist aufschlussreich, um das Wesen von Pohls „Tatsachen“ erfassen zu können. Einiges dazu habe ich bereits in der Diskussion von Krenziens Benutzung der de Broglie-Wellenlänge gebracht. Wie gezeigt, waren für Pohl elektromagnetische Wellen im Vakuum eine weitgehende Abstraktion. Das gilt natürlich auch für Licht, obwohl für Pohl Licht gar keine elektromagnetische Welle ist. Trotzdem spricht er bei Beugungs- und

\footnotetext{
1464 Pohl [1940]a S. 145. Hervorhebung original.

1465 Pohl [1940]a S. 147.

1466 Pohl [1940]a §§ 105 und106.
} 
Interferenzerscheinungen des Lichts von Wellen, doch meint er ,mit dem Worte Welle oder Wellenzug [...] stillschweigend eine mathematische Welle“, und zwar im Unterschied zu physikalischen Wellen, die es tatsächlich gibt. ${ }^{1468}$ In der Erklärung von Lichtphänomenen bedient er sich konsequent den aus der Mechanik gewonnenen Versuchsergebnissen mit Wellen, um dann die Beobachtungen am Licht als Analogie zu präsentieren. Er vermeidet peinlichst Formulierungen, die Licht als physikalisch existierende Wellen ausgeben könnten. „Über die physikalische Natur des Lichtvektors brauchen wir einstweilen keine Aussage zu machen. Wir beschränken uns, wie bisher, bei der Darstellung der optischen Eigenschaften auf das unbedingt Notwendige." 1469 Wellen dienen ihm zur bildlichen Darstellung und zur Beschreibung von Lichteigenschaften.

Zusätzlich zu der Ansicht, dass diese Wellen gar nicht die Natur des Lichts ausmachen, führt die Benutzung des Wellenbildes aber noch zu einer weiteren Schwierigkeit. Dort, wo sich die Quantennatur des Lichts zeigt, versagt diese Deutung; stattdessen muss man von einem korpuskularen Bild ausgehen, um Phänomene wie Fotoeffekt, Fluoreszenz und Phosphoreszenz zu erklären. Pohl legt sich auch hier nicht fest, indem er etwa die Natur des Lichts als korpuskular behauptet. „Nach der Entdeckung der Planckschen Konstanten $h$ genügte das Wellenbild nicht mehr allein für eine Darstellung der Lichtstrahlung. Neben ihm mußte das korpuskulare Bild der Photonen entwickelt werden.“1470 Es „ergab sich“ für die Lichtteilchen auch eine Energie und ein Impuls. Den Dualismus von Welle und Korpuskel zusammenfassend schreibt Pohl:

„Die Amplitude dieser Wellen hat keine physikalische Bedeutung, sondern erst das Ergebnis der Rechnung, die mit der Beobachtung vergleichbare statistische Verteilung der atomaren Individuen. Das gilt in gleicher Weise für die Wellen des Lichtes wie die Materiewellen. Aus diesem Grunde haben wir von vornherein in diesem Buche alle unnötigen Aussagen über die Amplituden der Lichtwellen vermieden, und zum Schluß auch die Aussage Lichtwelle = elektrische Welle auf ihren wahren Gehalt zurückgeführt." 1471

Die im letzten Satz gemeinte Einschränkung betrifft das Teilchenbild des Lichts, das in dem Bild der elektrischen Welle nicht enthalten ist. Die Amplitude einer Lichtwelle definiert Pohl als eine der Wurzel aus dem Ausschlag des Strahlungsmessers proportionale Größe. ${ }^{1472}$ Er

\footnotetext{
1467 “Die Verwechslung mathematischer und physikalischer Wellen führt zu mancherlei Scheinproblemen”, schreibt er beispielsweise warnend bei der Besprechung von Interferenzerscheinungen. Pohl [1940]a S. 59. 1468 Pohl [1940]a S. 59.

1469 Pohl [1940]a S. 114.

1470 Pohl [1940]a S. 292f. Hervorhebung original. Siehe auch S. $288 f$.

1471 Pohl [1940]a S. 297. Hervorhebung original.

1472 Pohl [1940]a S. 16.
} 
vermeidet also, eine bestimmte bildliche Vorstellung mit der Definition zu verknüpfen. Stattdessen zieht er sich auf die vom Experimentator gefundenen Messgrößen, auf das Erfahrungsgemäße zurück. Er war sichtlich bemüht, viele Phänomene auf eine 'unverfängliche“ Art zu erklären, ohne sich auf das „Wesen“ der Erscheinungen allzu sehr festzulegen, wenngleich man den Eindruck erhält, dass er beständig nach dem „Wesen“ von Erscheinungen suchte.

Beim Welle-Teilchen-Dualismus kam Pohl wie auch viele seiner Kollegen in Erklärungsnöte. Einig waren sich die Physiker in den vierziger Jahren, dass Licht weder nur Welle oder Teilchen ist, sondern eben beides als Eigenschaft enthält. Prägnant formuliert hat dies Wolfgang Finkelnburg in seiner Atomphysik, nämlich, „daß Welle und Teilchen also nur zwei Erscheinungsformen derselben physikalischen Realität sind“. ${ }^{1473}$ In dem Ringen um eine Antwort, mit welcher Art von physikalischer Realität man es denn zu tun habe, verfolgte Pohl zum Teil einen anderen Weg als seine Kollegen. Während damals weitgehend Konsens darüber herrschte, das tatsächliche Wesen des Lichts offen zu lassen, ging Pohl noch einen Schritt weiter und bezweifelte die physikalische Realität der Lichtwellen. ${ }^{1474}$ Die Frage nach dem Wesen des Lichts konnte Pohl nur negativ beantworten, indem er feststellte, was es nicht ist. Manche Kollegen hielten demgegenüber schon die Fragestellung für verkehrt. Pascual Jordan stellt 1941 in einer populärwissenschaftlichen Abhandlung die Frage: „Was ist das Licht? Wellenvorgang oder Teilchenstrahl? Aber allmählich sind wir $\mathrm{zu}$ der Einsicht gekommen, daß das Wort »ist« hier einfach nicht paßt; daß man vielmehr fragen muß, was aus Strahlung werden kann, je nach der Art der Beobachtungs-Auseinandersetzung mit dem Objekt. Werden kann aber beides daraus“. 1475

Pohl wollte aber eine Antwort auf die Frage nach dem Wesen. Und da er sie nicht geben konnte, blieb er in Bezug auf das Verständnis der Lichtphänomene unzufrieden: „Wir können über die Lichtstrahlung vielerlei sehr bestimmte Aussagen machen. Diese lassen sich aber noch nicht $\mathrm{zu}$ einem restlos geschlossenen und allseitig befriedigenden Bilde zusammenfassen.“1476

\footnotetext{
1473 Finkelnburg [1948/51] S. 161. Hervorhebung original.

1474 Während Pohl dem Licht die Wellennatur absprach, behauptete Gerthsen, dass „dem Licht sowohl Wellenals auch Quantennatur zuzuschreiben“" sei. Gerthsen [1948] S. 467. Ähnlich verfährt auch Tomaschek [1934/43] Bd. 3, §§ 36, 42-44, der allerdings der Wellennatur stärker anhängt und den Lichtquanten zusätzlich ein Verhalten zuschreibt, ,als ob sie korpuskularer Natur wären“ (S. 207). Jemand, der Pohl weitgehend in der Interpretation folgt und auch seine Abbildungen übernimmt, ist Westphal [1928/47] §§ 251, 334, 352.

1475 Jordan [1941] S. 29. Hervorhebung original. Auf S. 38 heißt es weiter: "In Wahrheit ist das Licht weder Welle noch Korpuskel, sondern ein »Drittes«, das sich der gedanklichen Nachbildung in einer anschaulichen Vorstellung entzieht und nur in abstrakt-mathematischen Begriffen beschreibbar ist.“

1476 Pohl [1940]a S. 1.
} 
Die Diskussion von Wellenerscheinungen hat gezeigt, was im Pohl'schen Denken keine Tatsache ist. Daraus folgte auch die ablehnende Haltung gegenüber wellenmechanischen Interpretationen von Halbleitereigenschaften. Der Pohl'sche Denkstil zeigte gegenüber Neuerungen im physikalischen Weltbild, die nicht auf seinen stilgemäßen Tatsachen fußten, eine deutliche Beharrungstendenz. Fleck behauptete: „Solches stilgemäße, geschlossene System ist keiner Neuerung unmittelbar zugänglich: es wird alles stilgemäß umdeuten."1477 Tatsächlich begegneten uns schon solche Umdeutungen. Die von Wilson abgeleiteten quantenmechanischen Erklärungen wurden von Gudden 1934 anschaulich (um)gedeutet, das heißt, in den Pohl'schen Denkstil übersetzt. Noch 1948 beriefen sich Mollwo und Stöckmann auf diese Deutung und sahen es dadurch für gerechtfertigt an, die Experimente weiterhin im traditionellen, stilgemäßen Sinn zu deuten.

Pohls Denkstil ist geprägt durch mehr beschreibende als deutende Erfassung von physikalischen Vorgängen. Wir haben oben seinen Denkstil anhand von Darstellungen aus seinen Büchern der vierziger Jahre beschrieben. Der Vergleich dieser Darstellungen mit früheren zeigt, dass seine Zurückhaltung gegenüber klaren Deutungen, der Festlegung auf eine bestimmte physikalische Natur einer Größe, im Lauf der Zeit größer wurde. Wir haben deutlich gesehen, wie viel Wert Pohl 1940 darauf legt, dass Licht keine elektrische Welle ist. Doch in seiner ersten Auflage der Elektrizitätslehre von 1927 schreibt er euphorisch: „Die Identität des Lichtes mit kurzen elektrischen Wellen ist über allen Zweifel erhaben." 1478 Pohl hatte sich im Urteil seines eigenen Denkstils $\mathrm{zu}$ schnellfertig festgelegt. Es kamen experimentelle Beweise der Teilcheneigenschaft von Licht, die Pohl akzeptieren musste. Es gab auch schon vor 1927 warnende Stimmen, die auf die Begrenztheit des Wellenbildes hinwiesen. Max Planck, den Pohl sehr verehrte, ${ }^{1479}$ trug 1919 über „das Wesen des Lichts“ vor. Er sah die Huygens'sche Wellentheorie für Licht durch die Entdeckung neuer Tatsachen ernstlich bedroht. Den Lichtquanten musste eine gewisse reale Existenz zugesprochen werden, und es war nicht klar, ob sich die Quanten wie Wellen ausbreiten und dadurch ins

${ }^{1477}$ Fleck [1935/99] S. 45. An anderer Stelle (S. 143) schreibt er ausführlicher: "Die Prinzipien eines fremden Kollektivs empfindet man [...] als willkürlich, ihre eventuelle Legitimierung als petitio principii. [...]

Einzeltatsachen und Einzelbegriffe werden - je nach der Verwandtschaft der Kollektive - entweder als freie Erfindung angesehen, die einfach unbeachtet bleiben [...], oder aber - bei weniger divergenten Kollektiven anders gedeutet, d. h. in eine andere Denksprache übersetzt und übernommen.“

1478 Pohl [1927] S. 251. Diese Satz ist in Pohl [1927] 5. Aufl. 1940, S. 251 ohne Kommentar verschwunden, während vorhergehender und nachfolgender Satz unverändert blieben. Selbst die Abschnittsüberschrift „Die Wesensgleichheit der elektrischen Wellen und der Lichtwellen. Das gesamte Spektrum elektrischer Wellen“ blieb unverändert.

1479 Pohl widmete seine „Optik“, Pohl [1940]a, ,als Zeichen der Verehrung“ Max Planck. 
Endlose verdünnt würden. ${ }^{1480}$ Bothe führte 1926 Experimente durch, deren Ergebnisse gegen die Verdünnung sprachen und den elementaren Emissionsakt von einzelnen Lichtkorpuskeln nachwiesen. ${ }^{1481}$ Es scheint so, als habe Pohl diesen Versuch seines Kollegen 1927 noch nicht entsprechend gewürdigt.

Diese Erfahrung, sich zur Zurücknahme einer Deutung gezwungen zu fühlen, mag dazu beigetragen haben, dass er noch vorsichtiger wurde und die Natur der Dinge möglichst lange offen lies. Wenn es allerdings experimentelle Evidenzen gab, konnte er theoretisch abgeleiteten Beziehungen durchaus zustimmen. So begründete er 1940 die Gültigkeit der Formel $\mathrm{E}=\mathrm{mc}^{2}$ wie folgt: Massen aller Art stehen in einem fundamentalen Zusammenhang mit der Energie und der Lichtgeschwindigkeit, „und zwar als Folgerung einer Erfahrungstatsache, nämlich des Relativitätsprinzips.“1482 Pohl hatte eine dezidierte Meinung über die Gültigkeit verschiedener Theorien. Während die Quantentheorie in seinem Verständnis Tatsachen beschreibt ( $h$ war eine anerkannte Naturkonstante, die man messen konnte) ${ }^{1483}$, war die Quantenmechanik bloß ein Bild, das man sich von bestimmten Naturvorgängen machte. Dieses Bild erschien ihm bis Anfang der 50er Jahre als nicht notwendig, stattdessen zog er 'klassische' Interpretationen vor. Als die Quantenmechanik Mitte der 20er Jahre entwickelt wurde, dürfte sie für Pohl nur eine Modeerscheinung gewesen sein. Gegenüber Moden war er prinzipiell kritisch eingestellt. Am Ende seiner Hochschullehrerlaufbahn formulierte er diesen Standpunkt in seinem Lehrbuch: Wichtig war ihm, ,aus der unendlichen Stoffülle, unbekümmert um Modeströmungen, die grundlegenden Dinge herauszugreifen und die inneren Zusammenhänge in der Fülle der Erscheinungen mit unseren heutigen Vorstellungen $\mathrm{zu}$ beschreiben. - Nach hundert Jahren wird auch die Darstellung dieses Buches den Leser ebenso seltsam anmuten, wie uns Physikbücher früherer Generationen."1484 Die Vorläufigkeit des momentanen Kenntnisstandes war ihm stets bewusst und mit ein Grund für seine Geringschätzung bestimmter Theorien.

Einen 'intimen' Zugang zu Pohls Denkstil liefern Randnotizen, die er in einem Buch seines Theoretikerkollegen Becker angebracht hat. Es handelt sich um das Buch „Vorstufen zur Theoretischen Physik“. ${ }^{1485}$ Pohls Notizen, Unter- und Anstreichungen stammen mit großer

\footnotetext{
1480 Planck [1919].

1481 Siehe die anerkennende Darstellung des Versuchs in Pohl [1940]a S. 289.

1482 Pohl [1940]a 2. u. 3. Aufl. 1941, S. 289. Hervorhebung original.

1483 Zur Messung von $h$ siehe Pohl [1940]a S. 198-202.

1484 Vorwort zur 9. Aufl. von Pohl [1940]a 9. Aufl. 1954, S. III.

1485 Durch Zufall habe ich Pohls privates Exemplar von Becker [1950]a in einem Göttinger Antiquariat erstanden. Es enthält Anmerkungen von Pohl auf den Seiten 2-3, 6, 16, 21, 36, 87-88, 100-103, 107, 112, 116117, 122, 137-138. Das Buch hat 172 Seiten. Auf der Innenseite des Buchumschlags ist „S. 36 87/88“vermerkt.
} 
Wahrscheinlichkeit aus der Zeit um 1950/51. Der Zeitraum lässt sich eingrenzen durch das Erscheinungsjahr des Buches 1950 und durch einen publizierten Aufsatz von Pohl aus dem Jahr 1951. Einige der im Buch angebrachten Korrekturen betreffen Probleme, die Gegenstand des Aufsatzes sind. Pohl ging der Frage nach, ob es einen Wesensunterschied zwischen Grundgrößen und abgeleiteten Größen gibt. Er verneinte dies und stellte auch klar, dass die Anzahl der Grundgrößen Konvention ist, und man nicht „eine bestimmte Zahl (z. B. Drei) zum Dogma erheben“ sollte. ${ }^{1486}$ Wie die Unterstreichungen im Buch zeigen, war Pohl daran interessiert, wie sein Kollege Größen einführt, und ob er mit den Einheiten korrekt umgeht. Besondere Aufmerksamkeit findet Beckers Benutzung des Mols. Pohl hat über die Definition des Mols in den letzten Kriegsjahren publiziert und sich dafür ausgesprochen, dass es nicht als bloße Zahl, sondern als eine Masseneinheit aufzufassen sei. ${ }^{1487}$ Entsprechend kritisiert er Beckers Umgang mit dem Mol bei der Behandlung der idealen Gasgleichung, zum Beispiel, dass Becker die Loschmidtsche Konstante als , $\approx 6 \cdot 10^{23 ،}$ angibt, statt als $\approx 6 \cdot 10^{23} \mathrm{Mol}^{-1} .{ }^{1488}$ Was Pohl hier fordert, und das ist auch ein Charakteristikum seines Denkstils, ist eine korrekte Verwendung von physikalischen Größen und Einheiten und die konsequente Umsetzung von einmal akzeptierten Definitionen. So notiert er zu dem Satz (in dem es um die ideale Gaskonstante $R$ ging) „Wählt man als Gasquantum ein Mol [...], so erhält man bei allen Gasen denselben Zahlenwert $R$ für $r^{\text {‘: }}$,R ist doch eine Grösse, kein Zahlenwert!“1489 Auch klare Begriffe wünschte Pohl. Als Becker von einer „Menge des [...] Gasquantums“ sprach, setzte Pohl ein Fragezeichen daneben, und einige Seiten weiter unterstrich er das Wort „Gasmenge“ und schrieb „gut“ an den Rand. ${ }^{1490}$ Klare Begriffe bildeten für Pohl neben den experimentell gewonnenen 'Tatsachen' die Grundlage, oder den festen Boden der Physik. Teil des Bemühens um klare Begriffe war es, komplexe Sachverhalte möglichst einfach darzustellen, sie dadurch erst richtig zu erfassen. „Simplex sigillum veri“ (Einfach ist das Zeichen des Wahren) steht über dem Eingang zu Pohls großem Hörsaal. ${ }^{1491}$ Das Ringen der Pohl-Schule um zutreffende Interpretationen in der Physik ist geprägt durch die Suche nach

\footnotetext{
1486 Pohl [1951]b S. 247.

1487 Pohl [1942]a, [1942]b, [1943]; Pohl \& Stöckmann [1944]a.

1488 Becker [1950]a S. 102.

1489 Randbemerkung von Pohl in Becker [1950]a S. 101. Über das Wort „Gasquantum“ schrieb er klein „,menge“. Über Definitionen des Mols, einer Loschmidt'schen Konstante und einer Avogadro’schen Konstante korrespondierte Pohl auch mit seinem alten Freund Max Born. Siehe Pohl an Born, 8. Oktober 1956; Pohl an Born, 6. November 1956. StB-B, NL Born, 591. Born an Pohl, 16. Oktober 1956. StB-B, NL Born, 1095. 1490 Becker [1950]a S. 88, 103.

1491 Von respektlosen Institutsmitgliedern wurde dieser Spruch mit Bezug auf die damalige primitive Experimentiertechnik übersetzt mit „Siegellack ist das einzig Wahre“. Siehe Mollwo [1978] S. 18.
} 
einfachen Zusammenhängen, nach klaren Ausdrucksformen. Bei Pohl war diese Eigenschaft am ausgeprägtesten: „Er dachte, sprach und schrieb einfach“, ${ }^{1492}$ sagte Mollwo im Rückblick.

Neben vielen kritischen Anmerkungen gibt es in Beckers Buch auch positive Vermerke von Pohl. Ein Ausrufezeichen steht neben einem Absatz, der folgendermaßen beginnt: „Machen Sie selbst folgenden Versuch“. ${ }^{1493}$ Pohl war offenbar positiv überrascht, dass in einem Buch der theoretischen Physik eine Anleitung $\mathrm{zu}$ einem konkreten Versuch gegeben wird. Zustimmung fand auch der Satz: „Jede Definition einer physikalischen Größe ist gleichbedeutend mit einer Vorschrift zu ihrer Messung.“1494

Ein weiterer Aspekt der Tatsachen im Pohl'schen Denkstil ist noch zu erwähnen. Die Tatsachen bilden zwar den festen Boden, auf dem die Interpretationen aufgebaut werden, doch Pohl kennt auch „ungeklärte Tatsachen“. ${ }^{1495}$ Dies sind Messergebnisse, die verlässlich sind, weil sie in sorgfältigen, mehrfach wiederholten Experimenten gefunden wurden, sich aber in das bisherige, stilgemäße Erklärungsschema nicht einfügen lassen. Diese Tatsachen besitzen einen erkenntnistheoretisch höheren Status als die bisherigen 'Theorien', die vielleicht nicht ganz zutreffend sind und eventuell an die neuen Daten angepasst werden müssen. Die ungeklärten Tatsachen finden sich nur in Zeitschriftenaufsätzen, nicht aber in den Lehrbüchern. Dort werden die neuen Tatsachen zwar als Fakten erwähnt, aber keine Deutungen gegeben oder dabei auftretende Schwierigkeiten besprochen. Soweit es sich um 'verstandene' Tatsachen handelt, werden soweit möglich stilgemäße Deutungen gegeben; nur bei Unvereinbarkeit mit der Schulvorstellung wird auf alternative Interpretationen, und wenn es sein muss auch auf die Quantenmechanik verwiesen (siehe die obige Besprechung des Hall-Effekts). ${ }^{1496}$

Pohls Auffassung der Physik, sein Denkstil, prägte sich den Studenten über seine Lehrbücher und Vorlesungen ein. Besonders betraf dies jene Studenten, die im I. Physikalischen Institut ihre Abschlussarbeit durchführten. Um sich ein kleines Zubrot zu verdienen, wurden sie gerne mit Korrekturleseaufgaben der neuen Auflagen der Lehrbücher beauftragt. Dies führte auf

\footnotetext{
1492 Mollwo [1978] S. 18.

1493 Becker [1950]a S. 6.

1494 Becker [1950]a S. 100. Diesen Satz unterstrich Pohl und setzte ein ,gut“ daneben.

1495 Pohl [1938] S. 41.

1496 Auf diesen Umgang mit ungeklärten Tatsachen wies auch Fleck [1935/99] S. 164 hin: „Versteht man unter Tatsache Feststehendes, Bewiesenes, so ist sie nur in der Handbuchwissenschaft vorhanden: vorher im Stadium des losen Widerstandsavisos der Zeitschriftenwissenschaft ist sie eigentlich Anlage der Tatsache. Nachher, im Stadium des alltäglichen, populären Wissens ist sie schon zu Fleisch geworden: sie wird zum unmittelbar wahrnehmbaren Dinge, zur Wirklichkeit.“
} 
ökonomische Weise dazu, sich intensiv mit Pohls Sicht der Physik auseinander zu setzen. Die Wirkung, die die Übernahme eines Denkstils zeigt, hat Fleck überzeugend festgehalten:

„Jede didaktische Einführung ist also wörtlich eine Hinein-Führung, ein sanfter Zwang. [...] Die Einweihung in einen Denkstil, also auch die Einführung in eine Wissenschaft sind erkenntnistheoretisch jenen Einweihungen analog, die wir aus der Ethnologie und Kulturgeschichte kennen. Sie wirken nicht nur formell: der heilige Geist senkt sich auf den Neuling herab und bis jetzt Unsichtbares wird ihm sichtbar. Dies ist die Wirkung der Aneignung eines Denkstils." ${ }^{1497}$

$\mathrm{Zu}$ der didaktischen Einführung kam noch der persönliche Kontakt im Institut. Besonders intensiv war der Kontakt mit den Assistenten, wie die rückblickenden Berichte von Stöckmann und Mollwo belegen: „Unzählig viele Male war dabei ich sein Gesprächspartner, oft bis spät in die Nacht hinein, oder auch an Sonntag-Vormittagen“. 1498 „Probleme besprach er [...] auf mehr oder weniger langen Spaziergängen zu zweit, die er oft unvermutet und nicht immer zur besonderen Freude seiner Assistenten, oft aber auch ganz systematisch veranstaltete.“1499 Pohls Physikauffassung ist Folge vieler Diskussionen. Sein Denkstil war nicht sein persönlicher Besitz; vielmehr formte er sich erst durch die Auseinandersetzungen mit seinen Schülern, durch das gemeinsame Ringen um verlässliche Deutungen. In den Danksagungen am Ende von Aufsätzen war es in der Pohl-Schule gute Tradition, all jenen zu danken, die in Diskussionen mit Kritik und Rat weitergeholfen haben. Bei Pohl selbst finden sich solche Hinweise in den Vorwörtern seiner Lehrbücher, wo er seinen Assistenten für „manche freimütige und lehrreiche Kritik“ dankte. ${ }^{1500}$ Insofern hat es seine Berechtigung, wenn die Pohlschule als Denkgemeinschaft charakterisiert wird, wobei Pohl und seine Assistenten den Kern des Kollektivs darstellen. ${ }^{1501}$

Das Kollektiv schuf sich seine eigene Physik. Es besaß ein eigenes Sehen der Probleme und benutzte einen charakteristischen Schreibstil in der Darstellung. Die Pohl-Schule versuchte, möglichst klare und eindeutige Begriffe $\mathrm{zu}$ benutzen, und vor allem auch deren erkenntnistheoretischen Status anzugeben. Der Sprachstil sollte klar erkennen lassen, wann man es mit festen Tatsachen und vagen Deutungen zu tun hat. In dem Bemühen, zu einem anschaulichen Gesamtbild der Physik zu gelangen, ist Pohl in der Sicht seiner Kollegen

\footnotetext{
1497 Fleck [1935/99] S. 137.

1498 Stöckmann [1978] S. 37.

1499 Mollwo [1978] S. 18. Auch Pick berichtet im Interview, dass er viele stundenlange Spaziergänge mit Pohl unternommen hat. Interview mit Heinz Pick, 2. Oktober 1981. NBL.

1500 Vorwort in Pohl [1940]a.

1501 Dieser Kern ist eine sehr kleine Gruppe. In den 33 Jahren in Göttingen gab es nur fünf langjährige Assistenten: Gudden, Hilsch, Mollwo, Pick und Stöckmann.
} 
teilweise $\mathrm{zu}$ weit gegangen. ${ }^{1502}$ Aber gerade diese Überschreitungen des üblichen Interpretationsrahmens machten die Pohl-Schule für alle identifizierbar. So war für die anderen Physiker der Denkstil der Pohlschule als Eigenart deutlich erkennbar. Noch 1976 stellt Mollwo fest: „Oft und oft hat man mir im In- und Ausland versichert, daß die Pohlsche Schule unverkennbar von anderen Physikern zu unterscheiden wäre. Sie durch persönlichen Kontakt zusammenzuhalten war ihm [Pohl] ein deutliches Anliegen."1503 Der lange bestehende Zusammenhalt der Schule verlieh ihr entsprechende Macht, die sich bei Besetzungsfragen an deutschen Universitäten entsprechend bemerkbar machte (siehe Abschnitt 1.3.5.1). Der enge persönliche Kontakt wirkte sich aber auch auf das Denken der Schule aus. Der kollektiv geprägte Denkstil war nichts Statisches und bedurfte des ständigen engen Gedankenverkehrs in der Gruppe. Wie Fleck darlegt, wandelt sich der Denkstil mit jeder neu erkannten Tatsache ein klein wenig - bei größeren, tiefgreifenden Entdeckungen entsprechend stärker. Der Forscher verspürt aber ein Widerstreben, allzu schnell den Denkstil zu ändern. Ein Beispiel für die Beharrungstendenz, das Bemühen, möglichst wenig Eingriff in den Denkstil vorzunehmen, liefert eine Entdeckung von Pick aus dem Jahr 1937.

Bei Bestrahlung des Kristalls mit Licht spaltet ein Lichtquant nur ein einzelnes Elektron ab. Von dieser Tatsache ging auch die Pohl-Schule aus. Demzufolge erwartete man eine Quantenausbeute (Verhältnis der die Bindung wechselnden Elektronen zu absorbierten Lichtquanten) von höchstens 1, eher etwas darunter (Messungen aus dem Jahr 1930 ergaben Werte zwischen 0,15 und 0,65). Pick maß nun aber als Quantenausbeute 2, das heißt ein Lichtquant löscht zwei F-Zentren aus. Im Interview erinnert sich Pick: „Ich sehe noch Herrn Hilsch: »Ach, Herr Pick, was haben Sie denn da für einen Blödsinn - geben Sie mal her.«"1504 Auf Anordnung Pohls wiederholten Pick und Hilsch gemeinsam die Messungen und bestätigten das Ergebnis. In der Publikation schrieb Pohl (alias Pick): „Die Quantenausbeute $\eta_{0}=2$ war überraschend. "1505 Die Deutung hielt an der Tatsache fest, dass nur ein einziges Elektron pro Lichtquant abgespalten wird. Wie konnte aber ein einzelnes Elektron zwei $F$ Zentren in zwei $F^{\prime}$-Zentren umwandeln? Der eine Teil der Erklärung beinhaltet den normalen Vorgang: Ein Lichtquant spaltet ein Elektron aus dem F-Zentrum ab. Das diffundierende Elektron wird von einem Ion eingefangen und bildet ein $F^{\prime}$-Zentrum. Dies war die stilgemäße Erklärung, wie sich $F$ - in $F^{\prime}$-Zentren verwandeln. Nun musste ein Trick angewendet werden,

\footnotetext{
1502 Siehe für eine solche Kritik beispielsweise Gerlach [1978] S. 217.

1503 Mollwo [1978] S. 18f.

1504 Interview mit Heinz Pick, 2. Oktober 1981. NBL.

1505 Pick [1938] S. 373.
} 
um aus Eins Zwei zu machen. Dieser bestand darin, dass das wandernde Elektron in der Nähe eines anderen F-Zentrums von einem „(irgendwie ausgezeichneten) positiven“ Ion eingefangen wird, und das dadurch erzeugte $F^{\prime}$-Zentrum mit dem benachbarten $F$-Zentrum „eine Art von Molekül“ bildet, das optisch wie $2 F^{\prime}$-Zentren erscheint. Somit erhält man das gewünschte Ergebnis: Es erscheinen zwei $F^{\prime}$-Zentren und es verschwanden ebenfalls zwei $F$ Zentren; eines durch Abspalten eines Elektron, das zweite ging in dem molekülähnlichen Gebilde auf. 1506

Diese Erklärung besitzt doch einen gewissen Ad-hoc-Charakter. Die Pohl-Schule vertrat die an den eigenen Denkstil angepasste Deutung, obwohl sie den zur selben Zeit vertretenen Auffassungen von Adolph Smekal widersprach. 15071939 fand Pick neue Begriffe für das molekülähnliche Ding. Das Elektron wurde laut Pick in der Nachbarschaft eines F-Zentrums durch ein Dipolfeld eingefangen. „Man kann von zwei eng benachbarten Farbzentren im Gebiet einer negativen Überschußladung sprechen, oder von einem negativen Molekülion. Wir nennen das Gebilde $2 F^{\prime}$-Zentren. Wir könnten aber mit gleichem Recht von einem Zentrum mit doppelter Absorptionswahrscheinlichkeit sprechen.“"1508 Man beachte, dass Pick nur Varianten anbietet, wie man über das Ding sprechen kann; er sagt aber nicht, was es ist. Die Deutung erschien nicht so verlässlich, dass sie gleich in Pohls Lehrbuch Eingang gefunden hätte. Dort wird zwar 1941 Picks Diagramm abgebildet, das den Verlauf der Quantenausbeute über der Temperatur zeigt, doch dass sie über $-100^{\circ} \mathrm{C}$ den Wert 2 besitzt, wird im Text gar nicht erwähnt, also auch nicht als eine zu deutende Besonderheit hervorgehoben. ${ }^{1509}$ Erst 1954 gibt Pohl in seinem Lehrbuch eine Deutung für den Wert 2 der Quantenausbeute. Diese unterscheidet sich deutlich von der Ad-hoc-Deutung aus dem Jahr 1937. Das molekülähnliche Gebilde verschwand, dafür übernahmen die Farbzentren sowohl die Funktion des Elektronenspenders wie des -fängers (dies war der Pohl-Schule prinzipiell schon 1937 bekannt). ${ }^{1510}$ Das durch Bestrahlung frei gewordene Elektron wird nun von einem anderen $F$-Zentrum eingefangen (und nicht mehr in dessen Nachbarschaft) und wandelt dieses in ein $F^{\prime}$-Zentrum um. Die 1937 geltende Annahme, dass sich zwei $F^{\prime}$-Zentren bilden müssten, wurde aufgegeben. In der neuen Deutung führt die Bestrahlung mit einem Lichtquant zum Verschwinden von zwei $F$-Zentren und zur Bildung nur eines einzigen $F^{\prime}$ -

\footnotetext{
1506 Siehe dazu die nicht vollständig gleichlautenden Deutungen in Pohl [1938] S. 43, 45 (eingegangen am 22. August 1937) und Pick [1938] S. 374 (eingegangen am 28. Oktober 1937). Die Vorstellung eines Moleküls findet sich erst bei Pick [1938].

1507 Pick [1938] S. 374.

1508 Pick [1939] S. 80f.

1509 Pohl [1940]a S. 271.
} 
Zentrums. ${ }^{1511}$ Diese einfachere Erklärung gaben Mott und Gurney schon 1940 und Frederick Seitz 1946. ${ }^{1512}$ Seitz' Deutung von Picks Messergebnissen ist besonders klar formuliert: Ein $F^{\prime}$-Zentrum resultiert aus der Hinzugabe eines Elektrons zu einem F-Zentrum. Die Reaktion lautet für ihn kurz: $2 F \rightarrow F^{\prime}{ }^{\prime}{ }^{1513}$ Es gibt einen Grund, warum die Pohl-Schule 1937 das molekülähnliche Gebilde eingeführt und nicht damals schon die Reaktion $2 F \rightarrow F$, angenommen hat. Pick untersuchte zwei Prozesse: den Abbau von F-Zentren und den Aufbau von $F^{\prime}$-Zentren jeweils in Abhängigkeit der absorbierten Lichtquanten. Für beide Prozesse suchte er die Quantenausbeute. Doch maß er nur den Abbau der F-Zentren und schloss aus der Veränderung der beiden Absorptionskurven (von F-Zentrum und $F^{\prime}$-Zentrum), dass gleich viele Zentren ausgelöscht wie gebildet werden müssen. Innerhalb des Denkstils der Pohl-Schule war dieser Schluss zwingend. Deshalb war $2 F \rightarrow F^{\prime}$ keine Erklärungsoption.

Die Beharrungstendenz des Denkstils zeigt sich im Positiven wie im Negativen, in der Beibehaltung gewohnter Erklärungsschemata wie in der fortgesetzten Ablehnung bestimmter 'Theorien“. Ein Charakteristikum des Positiven ist zum Beispiel: „Das Sichere und Bleibende unserer physikalischen Wissenschaft liegt in den experimentellen Tatsachen. In diesen gibt es nicht Umsturz und Wiederverzichten auf schon Erworbenes, sondern nur fortschreitende Erschließung neuer Gebiete.“1514 Diese Sätze, deren Inhalt (überspitzt gesagt: Theorien kommen und gehen, Tatsachen bleiben) typisch für die Pohl-Schule ist, stammen aber von Pascual Jordan, den wir im ersten Kapitel als abstrakten Theoretiker und Formalmathematiker kennen gelernt haben. ${ }^{1515}$ Es ist also Teil eines allgemeineren Denkstils der Physiker, die experimentellen Tatsachen als Grundlage ihrer Wissenschaft anzusehen. Daher gelingt eine Abgrenzung des Denkstils der Pohl-Schule besser über die negative Seite der abgelehnten Erklärungsmodelle. Dies wurde am Beispiel der Wellenmechanik ausführlich gezeigt. Dass die Pohl-Schule nicht in quantenmechanischen Kategorien denken wollte, mag mit ein Grund dafür gewesen sein, dass sie in der Nachkriegszeit gegenüber der internationalen Forschung etwas in Rückstand geriet. Solange die Pohl-Schüler in Göttingen saßen, gab es kaum Kontakt

\footnotetext{
1510 Siehe Glaser \& Lehfeldt [1936].

1511 Pohl [1940]a 9. Aufl. 1954, S. 322. Die 7. und 8. Aufl. 1948 behandelt den Abschnitt noch genauso wie 1940.

1512 Mott \& Gurney [1940/48] S. 129f.

1513 Seitz [1946] S. 390.

1514 Jordan [1936/45] S. IV. Hervorhebung original.

1515 Der von Pohl häufig benutzte Spruch „,Theorien kommen und gehen, Tatsachen bleiben“ geht auf seinen Heidelberger Lehrer Quincke zurück; siehe Mollwo [1978] S. 17. Es zeigt sich eine deutliche Parallele zu Ernst Machs Erkenntnis- und Wissenschaftstheorie, von der Jordan stark beeinflusst war, beispielsweise in der Aussage: „Das Ziel der Naturwissenschaft ist der Zusammenhang der Erscheinungen. Die Theorien aber sind wie dürre Blätter, welche abfallen, wenn sie den Organismus der Wissenschaft eine Zeit lang in Athem gehalten haben." Mach [1872] S. 46.
} 
zu den Theoretikern. Das änderte sich nach deren Wegberufung. Pick zufolge war die Zeit ab Mitte der 50er Jahre in der Farbzentrenforschung durch eine lebhafte Zusammenarbeit der Experimentatoren mit den Theoretikern gekennzeichnet, wobei er es offen lässt, inwieweit die Pohl-Schule daran beteiligt war. War bei Pohl die Übernahme von quantenmechanischen Interpretationen bis Mitte der 50er Jahre nur zaghaft vorhanden, vollzog sie sich bei den Schülern später doch deutlich. Pick stellte anlässlich des Pohl Gedächtnis-Kolloquiums die Farbzentrenphysik in quantenmechanischer Interpretation dar. Er gab Schaubilder der Wellenfunktion des F-Elektrons im Grundzustand und in angeregtem Zustand. ${ }^{1516}$ Wenn man also im Rückblick die Frage stellt, warum die Pohl-Schule die weitgehend anerkannte Quantenmechanik nicht schon im ersten Nachkriegsjahrzehnt sich zu eigen gemacht hat, so liegt die Antwort im spezifischen Denkstil dieser Schule.

Manche Stilmerkmale blieben den Schülern auch nach dem Verlassen des Göttinger Instituts erhalten. Ein Beispiel dafür ist die spezifische Wahl des Forschungsprogramms von Erich Mollwo in Erlangen. Genau wie Pohl wählte er eine als ideal angesehene Modell-Substanz, deren Eigenschaften er dreißig Jahre lang erforschte. ${ }^{1517}$ Bei Pohl waren es die Alkalihalogenide, bei Mollwo das Zink-Oxyd, das ein II-VI-Halbleiter ist. Mollwo hielt an dieser Modell-Substanz fest, obwohl die III-V-Halbleiter allgemein größere Aufmerksamkeit auf sich zogen. „Sein Credo war: Kennt man nur einen Halbleiter, den aber genau und umfassend, so kann einen bei anderen Halbleitern nicht mehr viel überraschen."1518 Wie Pohl ging Mollwo einem lang angelegten Forschungsprogramm nach, und wieder war es kein 'Modethema', sondern die Fortführung der in Göttingen begonnenen Untersuchungen.

\subsection{Forschungen ohne militärische Aufträge}

Einen umfassenden Überblick über die publizierten Forschungen der Göttinger Physiker gibt der erste Teil der Literaturliste am Ende dieser Arbeit. Auf einzelne Forschungen und Aufsätze wird im folgenden Abschnitt eingegangen. Die diskutierten Arbeiten sind bewusst aus Pohls Institut entnommen, um das aus einer erkenntnistheoretischen Analyse gewonnene Bild der Pohl-Schule in inhaltlicher Hinsicht zu erweitern.

\footnotetext{
1516 Pick [1978].

${ }^{1517}$ Lohmann [1994]b S. 233.

1518 Lohmann [1994]a S. 1158. 


\subsubsection{Behandlung grundsätzlicher physikalischer Fragen während des Krieges}

Betrachtet man die von Pohl während des Kriegs publizierten Zeitschriftenaufsätze, so fällt auf, dass sie einerseits Unterrichtsversuche und andererseits grundsätzliche Fragen zum physikalischen Einheitensystem betreffen. Keine seiner Veröffentlichungen deutet auf eine militärische Forschung hin. Als ein Beispiel sei der 1944 zusammen mit Stöckmann publizierte Aufsatz „Zur Anwendung des Gleichheitszeichens“ erwähnt. ${ }^{1519}$ Darin wird der in der Literatur eingerissene Brauch kritisiert, aus dimensionsrichtigen Gleichungen dimensionierte Proportionalitätsfaktoren wegzustreichen und trotzdem das Gleichheitszeichen stehen zu lassen. Dieser im März 1944 eingereichte Aufsatz zeigt, dass zu einer Zeit, wo andernorts fieberhaft neue Waffen entwickelt wurden, ${ }^{1520}$ Pohl und Stöckmann sich mit ganz und gar nicht rüstungsrelevanten Fragen beschäftigten, die zumindest den Herren in der Forschungsorganisation als nebensächlich erscheinen mussten. Gleiches trifft auf Pohls Auseinandersetzung mit dem Begriff des Mols zu. Pohl plädierte dafür, das Mol als individuelle Masseneinheit aufzufassen. Dies führte zu Differenzen zwischen Pohl und Eucken, die durch eine zweite Publikation aus dem Weg geräumt werden konnten. ${ }^{1521}$ Unabhängig von Krieg oder Frieden widmeten die Physiker ihre Zeit und Energie grundsätzlichen physikalischen Fragen. Dies scheint unabhängig von der politischen Überzeugung der Fall gewesen zu sein, also auch bei jenen Physikern, die sich in patriotischem Eifer für einen deutschen militärischen Sieg einsetzten.

Pohls Aufsätze im Krieg beinhalten also keine aus Experimenten gewonnenen Ergebnisse. Dass in Pohls Institut neben der ausführlich besprochenen Farbzentrenphysik noch andere Grundlagenforschung, und zwar in enger Verschränkung mit militärischer Forschung durchgeführt wurde, zeigen die Publikationen von Hans König. Dieser untersuchte Eisenkristalle auf deren magnetische Eigenschaften, um herauszufinden, wie viele Elementarzellen notwendig sind, damit aus paramagnetischem Eisen ferromagnetisches wird. Er dampfte Eisen auf eine stark gekühlte Kollodiumhaut auf und maß an dieser Schicht die Drehung der Polarisationsebene von durchgehendem Licht (Faraday-Effekt), die auf ferromagnetisches Verhalten schließen ließ. Mit einem Elektronenstrahl konnte er aus der Linienbreite der Interferenzringe die Kristallgröße ermitteln. Der Abstand der Beugungsringe

\footnotetext{
1519 Pohl \& Stöckmann [1944]b.

1520 Siehe zum Beispiel Albrecht [1994].

1521 Pohl [1943]; Pohl \& Stöckmann [1944]a. Die Differenzen zwischen Pohl und Eucken sind erwähnt in Pohls Gutachten zum Habilitationsgesuch von Stöckmann, 22. Februar 1950. GPAMNFG, Lehrkörper (ausgeschieden), Stöckmann.
} 
gab Auskunft über die Gitterkonstante und die Schärfe des Bildes über die Anzahl der Elementarzellen. Seine Messungen ergaben, dass etwa 64 Elementarzellen erforderlich waren, um einen ferromagnetischen Kristall zu bilden. Die Ergebnisse dieser Untersuchungen reichte König erst im Sommer 1946 zur Publikation bei den von Eucken herausgegebenen Naturwissenschaften ein. ${ }^{1522}$

Mit demselben Versuchsaufbau machte König eine Entdeckung, die er 1942 unmittelbar veröffentlichte. Als er den Apparat ohne Präparat testete, erhielt er dabei manchmal ein scharfes Beugungsbild, das von irgendwelchen Kristallen herrühren musste. Er diskutierte den Effekt unter anderem mit Pohl, Eucken und Laue, aber keiner konnte ihm sagen, um was es sich handelt. Schließlich fand König heraus, dass in der Fotoplatte Wasser war, das verdampfte und in der auf $-150^{\circ} \mathrm{C}$ gekühlten Hochvakuumröhre Eiskristalle bildete. Das Überraschende war allerdings, dass sich bei diesen Bedingungen neue, bisher unbekannte Eiskristalle bildeten, die ein Beugungsbild vom Diamanttyp ergaben. Bei diesem Cristobaliteis bilden die O-Atome ein Diamantgitter, wobei jedes O-Atom von vier H-Atomen in Form eines Tetraeders umgeben ist. Eucken und Pohl waren über die Entdeckung begeistert. König konnte über das neue Eiskristall in der Akademie der Wissenschaften vortragen. Der Vortrag wurde in den Nachrichten der Akademie auf Vorschlag von Carl Correns veröffentlicht. ${ }^{1523}$

Königs im Krieg publizierte Grundlagenforschung entsprang aus einer Zufallsentdeckung. Das auftretende Beugungsbild war ein unerwünschter Schmutzeffekt, der die eigentlich intendierte Forschung störte. Für König war es ein glücklicher Umstand, dass er sich durch die Entlarvung des Störeffekts bei seinen Kollegen einen guten Namen als Physiker machen konnte.

\subsection{Experimentierende Theoretiker - Beckers Forschungsstil}

Das von Richard Becker geleitete Institut für theoretische Physik zeichnete sich unter anderem dadurch aus, dass seine Assistenten und Doktoranden selbst Experimente durchführten. Ein Grund dafür liegt in den von Becker vorzugsweise bearbeiteten Themen wie Magnetismus und plastische Deformation. Da es mit den Göttinger Experimentalphysikern zu keiner Zusammenarbeit kam, sicherte sich Becker so eine Eigenständigkeit und Unabhängigkeit in der Themenwahl. 1939 schrieb er an Born: „,...] mit

1522 König [1946]a. Siehe dazu auch Becker [1948] S. 29f. 
Joos vertrage ich mich auch so weit ganz gut; von einer Zusammenarbeit ist aber nicht die Rede."1524 Dass es auch mit Pohl zu keiner Zusammenarbeit kam, mag neben den unterschiedlichen Forschungsgebieten auch an persönlichen Gründen gelegen haben.

Anlässlich der Habilitation seines langjährigen Assistenten Döring lobte ihn Becker in folgender Weise: „In wissenschaftlicher Hinsicht zeichnet sich Herr Dr. Döring dadurch aus, daß er die Methoden der theoretischen Physik in absolut sicherer Weise beherrscht und gleichzeitig mit den Problemen und Möglichkeiten der experimentellen Forschung durchaus vertraut ist. Dadurch ist er auch imstande, als Vortragender die Gegenstände seines Faches in ganz besonders klarer und anschaulicher Weise darzustellen.“1525 Nicht nur Döring war mit dem Experimentieren vertraut, sondern auch Beckers Schüler Georg Thiessen, der 1940 eine experimentelle Überprüfung eines speziellen Teils der von Becker und Döring formulierten Theorie des Ferromagnetismus durchführte. In einem Nickeldraht unter starker innerer Spannung maß Thiessen die durch Spannungsänderung verursachte Änderung des relativen elektrischen Widerstands, der Anfangssuszeptibilität sowie der Remanenz. Der mit 24 Seiten recht lange Aufsatz wird vom experimentellen Teil dominiert, wenngleich auch eine theoretische Einführung gegeben wird. Am Ende dankt Thiessen Becker für die Aufgabenstellung und das große Interesse sowie Döring und Heinz Haake für wertvolle Ratschläge. ${ }^{1526}$ Becker selbst untersuchte ebenfalls auf experimentellem Weg zusammen mit einem anderen seiner Schüler, Hans Polley, den Einfluss innerer Spannungen auf das Einmündungsgesetz bei Nickel. Interessanterweise wurden die Untersuchungen vorzeitig abgebrochen, wie die Autoren selbst angeben, und die vorläufigen Ergebnisse Ende März 1940 zur Veröffentlichung eingesandt. ${ }^{1527}$ Es ist anzunehmen, dass militärische Aufträge für den Abbruch der Untersuchung verantwortlich waren.

Der engste Schüler von Becker in seiner Göttinger Zeit war Günther Leibfried. Wie früher schon dargelegt war Leibfried eigentlich Schüler von Joos, bei dem er sein experimentelles Rüstzeug erlernte. Joos war sowohl Experimental- als auch theoretischer Physiker. Insofern waren für Leibfried gute Voraussetzungen für einen Wechsel ins Institut für theoretische Physik gegeben. Dass Leibfried als promovierter Experimentalphysiker zu Becker kam, war insofern günstig, als Becker seine Schüler nicht selbst experimentell ausbilden konnte, von

\footnotetext{
1523 Siehe König [1942]. Informationen nach Interview mit König vom 10. Februar 2001.

1524 Brief Becker an Born, 23. Juli 1939. StB-B, Nachlass Born 34.

1525 Aus dem Gutachten Beckers zu Dörings Habilitation, 9. Dezember 1938. GPAMNFG, Lehrkörper (ausgeschieden), Döring.

1526 Thiessen [1940].

1527 Becker \& Polley [1940].
} 
ihnen aber das Experimentieren verlangte. ${ }^{1528}$ Dies zeigt sich in Leibfrieds 1949 eingereichter Habilitationsschrift „Theoretische und experimentelle Beiträge zur Dynamik der Versetzungen bei plastischer Deformation“. Für seine Untersuchungen entwickelte Leibfried eine neue Apparatur zur Beobachtung kleinster plastischer Deformationen. Um die Längenänderung eines auf Zug beanspruchten Drahtes festzustellen, konstruierte er eine geistreiche Spiegelanordnung, mit der er Deformationen von der Größenordnung von Angström messen konnte. Diese Messapparatur besprach er in einem eigenen Aufsatz, übrigens ein acht Seiten langer Aufsatz eines Theoretikers, in dem keine einzige mathematische Gleichung vorkommt. 1529

\subsection{Die Entnazifizierung und die besondere Produktivität von Physikern}

Diejenigen Physiker, die durch die Entnazifizierung oder auch durch den Verlust der nun nicht mehr innerhalb Deutschlands liegenden Hochschule stellungslos waren, entwickelten in den ersten Nachkriegsjahren mitunter eine erstaunliche Produktivität. Ein Motiv für diesen Arbeitseifer lag darin, dass sie sich möglicherweise genötigt fühlten, ihren Kollegen ihren immer noch vorhandenen fachlichen Wert besonders unter Beweis zu stellen. Auf diese Weise reagierte beispielsweise Wolfgang Finkelnburg, der seine Stelle an der Universität Straßburg verloren hatte und sich im Sommer 1947 immer noch auf Stellungssuche befand. Er schrieb an Pohl in der Hoffnung, durch seine Unterstützung wieder eine Hochschulstellung in Deutschland zu bekommen. In diesem Brief verwies er besonders auf seine vier Bücher und über 60 Veröffentlichungen, die ihm im Konkurrenzkampf mit den jüngeren Dozenten eigentlich zum Vorteil gereichen müssten. Auch die Nachkriegszeit verbrachte er in produktiver Tätigkeit: Zwei neue Lehrbücher befanden sich 1947 im Erscheinen. ${ }^{1530}$

Ein weiterer Grund für den Arbeitsfleiß lag im Fortfall der Unterrichtsverpflichtung, der mehr Zeit und Muße zur schriftstellerischen Tätigkeit ließ. Am Beispiel von den vier 'Göttinger' Physikern Hellwege, König, Sauter und Jordan wird dieses zeittypische Phänomen in jeweils individuellen Ausformungen näher beleuchtet. Hellwege wurde 1945 entlassen und hatte bis 1949 Lehrverbot. Trotzdem konnte er im II. Physikalischen Institut seinen spektroskopischen Untersuchungen nachgehen. Seine Zeitschriftenaufsätze aus dieser stellungslosen Zeit

\footnotetext{
1528 Siehe die unter Joos' Leitung durchgeführten experimentellen Arbeiten Leibfried [1940]a-b.

1529 Leibfried [1950]b. Dort findet sich auch eine Abbildung der Versuchsanordnung.
} 
behandelten vor allem die unterschiedlichsten Aspekte der Elektronenterme und der Strahlung von Atomen in Kristallen. ${ }^{1531}$ Daneben schrieb er auch sein erstes Lehrbuch, eine Einführung in die Physik der Atome. ${ }^{1532}$ Der reiche literarische Ertrag Hellweges bestätigte seinen Kollegen das Bild, dass er vor allem ein ernsthafter, der Physik zugewandter Wissenschaftler sei, der seine Karriere nicht mittels politischem Aktivismus durchgesetzt hätte. Seine soliden Arbeiten qualifizierten ihn für ein Ordinariat, das er schließlich 1952 in Darmstadt erhielt.

Dort hatte kurz zuvor sein Göttinger Kollege Hans König den Lehrstuhl für Experimentalphysik übernommen. König befand sich nach dem verlorenen Krieg in einer ähnlichen Situation wie Hellwege. Auch er war ab 1945 stellungslos und in der Zeit der Entnazifizierung bestrebt, sich den Ruf des ernsthaften Wissenschaftlers zu sichern. Das Bild des sachlichen Physikers sollte jenes des überzeugten Nationalsozialisten überdecken. Beide Bilder waren vor 1945 vorhanden. Schon seine Forschungen während des Kriegs, verbunden mit einer zufälligen Entdeckung, gaben ihm das Profil des gewissenhaften Grundlagenforschers. Das im Krieg in Göttingen aufgestellte Elektronenmikroskop wurde in der Nachkriegszeit sein wichtigstes Instrument, mit dem er vor allem den Aufbau von verschiedenen Kristallen untersuchte. So entstanden in den Jahren 1946 bis 1948 zwölf Aufsätze, die er hauptsächlich in den beiden Zeitschriften „Optik“ und, mit Euckens Unterstützung, in den „Naturwissenschaften“ publizierte. Im Interview berichtete er von dem außergewöhnlichen Arbeitsfleiß in den ersten Nachkriegsjahren.

Bei Fritz Sauter wirkte sich die Entlassung aus seinem Ordinariat in München 1945 auf andere Weise aus. Sauter verlor zwar seine Hochschulstellung, konnte aber weiterhin im Auftrag der Franzosen in Saint-Louis Physik betreiben. Auch die Ausrichtung der Forschung blieb im Laboratoire de Recherches de Saint-Louis, das aus einer Zweigstelle des Laboratoire Central de l'Armement hervorging, Rüstungsforschung. ${ }^{1533}$ Die Rückkehr zur deutschen Hochschule gelang Sauter erst 1949 als Privatdozent. Entsprechend kam seine Publikationstätigkeit nach dem Krieg erst 1949 wieder in Schwung. Auffällig bei Sauter sind seine zahlreich verfassten Rezensionen: Allein 1949 und 1950 besprach er elf Bücher, vorwiegend solche der theoretischen Physik. ${ }^{1534}$ Unter den besprochenen Werken befand sich mit Finkelnburgs Einführung in die Atomphysik auch ein Buch eines seiner Konkurrenten, der

\footnotetext{
1530 Finkelnburg an Pohl, 15. August 1947. Dienstzimmernachlass Pohl. Siehe zu Finkelnburgs Bemühungen und den Gründen für das Scheitern den Abschnitt 1.3.5.1.

${ }^{1531}$ Hellwege [1947]a-d, [1949]b-f.

1532 Hellwege [1949]a.

1533 Siehe http://www.isl.tm.fr/de/generalite/pages/histo_d.html.

1534 Sauter [1949]d-f, [1950]d-k.
} 
ebenfalls auf der Suche nach einer Wiederanstellung war. Das Urteil über Finkelnburgs Buch fiel durchaus positiv aus. ${ }^{1535}$

Eine besonders umfangreiche literarische Tätigkeit entfaltete Pascual Jordan. Von 1945 bis 1947 weilte er in Göttingen und hoffte vergebens auf eine dortige Unterbringung, bis er schließlich an der Universität Hamburg eine Gastprofessur übernahm und dort 1953 einen ordentlichen Lehrstuhl bekam. In Göttingen versuchte er ,angesichts des schwierigen Existenzkampfes"1536 sich durch die Publikation mehrerer populärwissenschaftlicher Bücher finanziell über Wasser zu halten; vier erschienen 1947, ein weiteres folgte 1949. ${ }^{1537}$ Daneben publizierte er zahlreiche wissenschaftliche Aufsätze, die einen weit gestreuten Themenbereich abdeckten. So befasste er sich mit der Weiterentwicklung der Relativitätstheorie. Die Erweiterung der projektiven Relativitätstheorie war auch das Thema, mit dem sich Jordans Schüler Ludwig in Göttingen habilitierte. ${ }^{1538}$ In Zusammenarbeit mit Houtermans widmete sich Jordan einem Thema der Radioaktivität. ${ }^{1539}$ Einen weiteren Themenkomplex betreffen Fragen der Sternentstehung und der Höhenstrahlung. ${ }^{1540}$ Neben diesen Spezialthemen widmete er sich auch grundsätzlichen und philosophischen Betrachtungen der Physik, die er besonders in seinen Büchern breit darstellte. ${ }^{1541}$ Hier finden sich auch politische Aussagen wie die folgende, die 1941 abgedruckt und in den Neuauflagen nach 1945 gestrichen wurde: „wir sind nicht gewillt, in der Verknüpfung zwischen Wissenschaft und militärischer Macht einen Mißbrauch zu sehen, nachdem militärische Macht ihre zwingende, aufbauende Kraft im Schaffen eines neuen Europas erwiesen hat."1542 Ebenfalls im Zusammenhang mit dem politischen und kulturellen Klima steht Jordans Beschäftigung mit Fragen, die wir heute der Biophysik zurechnen. Schon in den dreißiger Jahren begann Jordan die Quantenmechanik und die Biologie $\mathrm{zu}$ verbinden. Auch in den ersten Nachkriegsjahren beschäftigten ihn biophysikalische Fragestellungen. ${ }^{1543}$ Inhaltliche Analysen von Jordans Arbeiten und Einschätzungen der philosophischen und politischen Bedeutung seines Versuchs, eine

\footnotetext{
1535 Sauter [1949]f.

1536 So beschrieb er seine Lebensumstände in einem Brief an Laue vom 25. November 1946. MPG-A, Nachlass Laue, III, 50, 972.

1537 Jordan [1947]a-d, [1949]a.

1538 Siehe zu diesem Themenbereich Jordan [1945]a, [1946]b, [1947]e und Jordan \& Müller [1947]. Zu Ludwig siehe Abschnitt 1.3.5.2.

1539 Houtermans \& Jordan [1946].

1540 Jordan [1944]a-b, [1945]b, [1946]a, [1946]c, [1947]a, [1947]f, [1948]g.

1541 Jordan [1947]b, [1947]d, [1948]a, [1949]c.

1542 Jordan [1941] S. 9. Dieser Satz ist schon in der 3. Aufl. von 1943 gestrichen worden.

1543 Jordan [1941], [1944]c, [1947]c, [1947]g, [1948]e-f, [1949]b. 
Quanten-Biologie zu etablieren, liegen heute mehrere vor. ${ }^{1544}$ Hier geht es aber vor allem um die Auswirkung, die seine unsichere berufliche Situation in der Nachkriegszeit auf seine wissenschaftliche Produktivität hatte. Diese war bei Jordan wie bei den zuvor Besprochenen überdurchschnittlich hoch. Da sich der von König berichtete besondere Arbeitsfleiß anscheinend besonders auf physikalische Arbeiten konzentrierte, kann man vermuten, dass eine Besinnung und Auseinandersetzung mit dem eigenen Anteil an den von Deutschland verübten Verbrechen damit verdrängt wurde. Statt in die abgründige Vergangenheit schauten diese stellungslosen Physiker in eine unsichere Zukunft, für die sie sich besonders zu qualifizieren hatten.

\subsection{Forschungsbeschränkungen bewirken Innovationen - Physiker und Mediziner}

Nachdem im April 1945 die Physikinstitute von den Alliierten geschlossen worden waren, begann ein Verhandlungsprozess um die Fortsetzung der physikalischen Forschungen. In diesem Prozess wendeten die Göttinger als Taktik die Zusammenarbeit mit den Medizinern an. Von den Alliierten wurde medizinische Forschung aus pragmatischen Gründen bevorzugt wieder zugelassen. ${ }^{1545}$ Durch eine neu eingegangene Kooperation mit den Medizinern machten sich die Physiker zu Nutznießern dieser Bevorzugung. An zwei Beispielen werde ich zeigen, wie ein politisch stark Belasteter die Fortsetzung der Forschungstätigkeit dadurch erreichen konnte, und wie später die gesetzlichen Forschungsbeschränkungen umgangen wurden.

\subsubsection{Hans König und die Untersuchung von Bakterien}

Wie mir Hans König im Interview berichtete, wurden von der Militärregierung vor allem jene Forschungen problemlos genehmigt, die in Zusammenhang mit Seuchenbekämpfung standen. Damit er seine Arbeiten mit dem Elektronenmikroskop fortsetzen konnte, besorgte er sich mit Unterstützung von Anneliese Winkler vom Hygiene-Institut gefährlich klingende Bakterien und beantragte deren Untersuchung als neues Forschungsprogramm. Zwei erste kürzere Aufsätze zu dem neuen Thema stellte König bereits im Dezember 1945 fertig. Darin

\footnotetext{
1544 Beyler [1994], [1996]b, [1999]; Wise [1994].

1545 Eine Directive on the Control of German Education and Youth Activities (PRO, FO 1050/157) aus der ersten Hälfte des Jahres 1945 bestimmte: "If the question of priority arises, attention should be directed first to the reopening of faculties or institutions directly concerned with medical, dental, veterinary, agricultural, building and mining education." Zitiert nach Haude [1993] S. 9.
} 
diskutiert er die Schwierigkeiten, die eine Untersuchung von organischen Präparaten mit Elektronenbestrahlung ergeben können, besonders die Veränderung von Bakterien und Viren durch die Strahlung. ${ }^{1546}$ In dem zweiten Aufsatz bespricht er ein von ihm neu entwickeltes Verfahren, nicht das Untersuchungsobjekt selbst, sondern einen Abdruck davon im Elektronenmikroskop zu analysieren und dabei ein plastisches Bild der ursprünglichen Oberfläche zu erhalten. ${ }^{1547}$ Man könnte annehmen, dass mit diesen Veröffentlichungen, die das neue Forschungsprogramm belegten, der Zweck erfüllt sei, und König sich wieder seinen eigentlichen Themen widmen konnte. Wie die Publikationen der folgenden Jahre zeigen, wandte er sich tatsächlich den ihn schon früher interessierenden Fragen zu und veröffentlichte über dünne Eisenschichten und die Bestimmung von Gitterkonstanten im Elektronenmikroskop. Doch auch die Bakterienuntersuchungen beschäftigten ihn weiterhin. Zusammen mit der Bakteriologin Anneliese Winkler publizierte er 1948 in den „Naturwissenschaften“ einen längeren Aufsatz „Über Einschlüsse in Bakterien und ihre Veränderung im Elektronenmikroskop“. ${ }^{1548}$ Die elektronenmikroskopische Untersuchung von Bakterien war damals noch ein junges und wenig erforschtes Gebiet und war deshalb für den jungen Physiker auf dem Weg zur Professur ein geeignetes Tätigkeitsfeld. Auch seine Schüler ließ König an Bakterien forschen, wie Veröffentlichungen mit Mechthild Knoch zeigen. ${ }^{1549}$ Die Forschungsergebnisse trug König häufig auch bei den Medizinern vor. Mit Gerhard Schubert von der Strahlenbiologischen Abteilung der Universitäts-Frauenklinik in Göttingen gab es auch eine Zusammenarbeit. ${ }^{1550}$ Wenngleich die Untersuchung von Bakterien nicht zu Königs Hauptthema wurde, induzierte die in der Besatzungszeit eingeführte Forschungskontrolle durch die Zusammenarbeit Königs mit dem Hygiene-Institut neue Forschungsthemen in den Physikinstituten.

\subsubsection{Neuer Teilchenbeschleuniger trotz Verbot der angewandten Kernphysik}

Ein ungewöhnliches Projekt ist der Gegenstand dieses Abschnitts. Kopfermann startete die Entwicklung eines für physikalische Grundlagenforschung und medizinische Anwendungen konzipierten Teilchenbeschleunigers mitten im Krieg im Jahr 1943. Knapp vor Kriegsende wurde das Gerät von Siemens-Reiniger in Erlangen fertiggestellt, konnte aber nicht mehr

\footnotetext{
1546 König [1946]d.

1547 König [1946]e.

1548 König \& Winkler [1948].

1549 Winkler, Knoch \& König [1951]; Knoch \& König [1951].

1550 Interview mit Hans König, 10. Februar 2001. 
nach Göttingen geliefert werden. 1947 gelang trotz des Verbots der angewandten Kernphysik die Aufstellung in Kopfermanns Institut.

Die Finanzierung der Betatronentwicklung wurde vom RFR übernommen. Leiter des RFR war ab 1943 Walther Gerlach, der in der letzten Kriegsphase eine doppelte Forschungspolitik verfolgte. Einerseits förderte er die Kriegsproduktion, und andererseits traf er Vorbereitungen für die Nachkriegszeit und genehmigte Grundlagenforschung ohne militärische Relevanz mit der Begründung, Deutschland müsse nicht nur den Krieg, sondern auch den Frieden gewinnen. Auf der gleichen Linie liegt ein Befehl Himmlers vom Mai 1944. Es sollte eine wissenschaftliche Forschungsstätte eingerichtet werden, in der die Physiker und Chemiker unter den KZ-Häftlingen zu Rechen- und Konstruktionsarbeiten, „sowie aber auch zu Grundlagen-Forschungen angesetzt" werden sollten. Sogar Forschungen, die 1939 aus Kriegsgründen abgebrochen worden waren, sollten wieder aufgenommen werden, wie zum Beispiel Rechnungen zur langfristigen Wettervorhersage. ${ }^{1551}$ Wie es scheint, stellte sich auch die SS Mitte 1944 schon auf eine Friedenszeit nach dem Krieg ein. Diese 1943/44 einsetzende Aufweitung der forschungspolitischen Ziele nutzte Kopfermann für sein Beschleunigerprojekt. ${ }^{1552}$ Der RFR bewilligte das Projekt und gab mehrere Geräte in Auftrag, eines davon für Kopfermann in Göttingen.

Bereits im Sommer 1943 hoffte Kopfermann, noch im selben Jahr ein Rheotron, wie der Beschleuniger damals genannt wurde, für sein Institut $\mathrm{zu}$ bekommen. Mit dem Ziel, kernphysikalische Messtechnik zu erlernen, schickte er seinen Assistenten Wolfgang Paul im September 1943 in Otto Hahns Institut nach Berlin. ${ }^{1553}$ Bei Siemens-Reiniger leitete Konrad Gund die Betatronentwicklung; in Göttingen wurde in Zusammenarbeit mit ihm gerechnet und experimentiert. Am 10. Mai 1944 telegrafierte Gund nach Göttingen: „Schleuderstrahl!“ Umgehend reiste Paul nach Erlangen und machte sich mit dem Betatron vertraut. Daraufhin wurde auch die Konstruktion eines größeren Geräts in Angriff genommen. ${ }^{1554}$ Etwa zur selben Zeit war die Kopfermann-Schülerin Maria Kemmerich aus kriegswichtigen Gründen auf drei Monate bei der Firma Siemens-Reiniger in Erlangen beschäftigt. Sie hatte besondere Messungen für eine von der Luftwaffe gegebene Untersuchung durchzuführen. So stellte es

\footnotetext{
1551 Siehe Schlüpmann [http] Kap. „Die Wiege der Nachkriegsphysik“.

1552 Zur Beschleunigerentwicklung bei Siemens siehe Eckert \& Osietzki [1989] speziell S. 55-57 zum Göttinger Betatron.

1553 Kopfermann an Hahn, 7. Juli 1943; Hahn an Kopfermann, 9. Juli 1943; Kopfermann an Hahn, 31. Juli 1943. MPG-A, Nachlass Hahn, III, 14 A, 2221.

1554 Schlüpmann [http] Kap. „Die Wiege der Nachkriegsphysik“.
} 
jedenfalls Kopfermann dar. Es ist aber anzunehmen, dass die Messungen von Kemmerich ebenfalls im Zusammenhang mit dem Betatron standen. ${ }^{1555}$

Kaum war Deutschland besiegt und eine konstruktive Beziehung zu den Besatzern hergestellt, dachte Kopfermann schon an die Fortsetzung seiner Arbeiten mit dem Betatron. Mit seinem Assistenten Paul fuhr er schon im Mai 1945 mit dem Fahrrad nach Erlangen zu Siemens. Es gab für ihn scheinbar kein Bedürfnis, vom Vergangenen Abstand zu nehmen und sich Zeit zur Besinnung zu gönnen. Ganz im Gegenteil wurde an der alten Arbeit weitergemacht, fast so, als wäre nichts gewesen. Optimismus kennzeichnete seine damalige Verfassung: „Ich selbst bin ja nicht tot zu kriegen und glaube fest an die Zukunft.“1556 Die fehlende Aussprache mit Freunden und der starre Blick nach vorne führte mit Kopfermanns Worten geradezu zur Arbeitswut. Kopfermanns Optimismus war in Bezug auf das Betatron nicht ohne weiteres selbstverständlich. Die Situation um die Beschleunigerentwicklung im Nachkriegsdeutschland war besonders schwierig, da zum einen die Forschung in der angewandten Kernphysik generell verboten war. Zum anderen beschlagnahmten die alliierten Militärs viele fertige oder halbfertige Geräte, einige wurden in die Sowjetunion abtransportiert. 1557 In Erlangen waren bei Kriegsende drei Geräte in unterschiedlichem Entwicklungsstand vorhanden: jenes für Kopfermann war betriebsfertig, ein weiteres $6 \mathrm{MeV}$ Gerät war im Aufbau und ein verbessertes Gerät mit etwas höherer Energie befand sich noch in weniger fortgeschrittenem Stadium. ${ }^{1558}$ Die Radfahrt nach Erlangen diente vor allem dazu, sich über die Lage bei Siemens in der neuen Situation einen Überblick zu verschaffen. ${ }^{1559}$

Das Betatron stand in Erlangen den Göttingern noch prinzipiell zur Verfügung. Schwierigkeiten bereitete aber die Genehmigung, es von der amerikanischen Zone in die britische zu bekommen. Die Amerikaner hatten ein allgemeines Interesse an den in Deutschland befindlichen Beschleunigern. ${ }^{1560}$ In einem Schreiben an Goudsmit über die Situation der Betatrons in Deutschland merkte Lewis H. Strauss vom Navy Department, Office of Research and Inventions in Washington D.C. im Mai 1946 an, dass noch „such tricky questions as reparations and the extraction from the British zone“ $\mathrm{zu}$ klären seien.

\footnotetext{
1555 Kopfermann an Kurator, 14. Juni 1944. UAG, Kur. XVI. V. C. h. 2. II. Erste Publikationen über das $6 \mathrm{MeV}$ Betatron ist Gund [1946]; Kopfermann \& Paul [1946]. Konrad Gund promovierte 1946 bei Kopfermann.

1556 Brief von Kopfermann zitiert bei Schlüpmann [http] Kap. „Problematische 'Wandlung““.

${ }^{1557}$ Zur Situation der Beschleuniger am KWI für Chemie in Berlin siehe Weiss [1994]b, zu jener am KWI für medizinische Forschung in Heidelberg Schmidt-Rohr [1996].

1558 Kollath [1947] S. 183.

1559 Brix [1994] S. 1154.
} 
Goudsmit wollte eines der deutschen Betatrons für eigene Versuche im niedrigen Energiebereich (bis $10 \mathrm{MeV}$ ) in den USA nutzen und erkundigte sich nach Möglichkeiten eines Abtransports. ${ }^{1561}$ Doch mittlerweile hatten sich hohe politische Stellen in die Betatronfrage eingeschaltet, sogar General Clay mischte sich in die Diskussion ein, und um über die Betatrons verfügen zu können, war die Zustimmung aller vier Besatzungsmächte erforderlich. Dies teilte Albert M. Stone, Office of the Assistant Naval Attaché for Research der amerikanischen Botschaft in London, im Januar 1947 Goudsmit mit. Groves war der Meinung, dass jenes ,instrument originally intended for Gottingen be shipped there for obvious advantages resulting from happy guests." 1562 Stone schrieb des Weiteren, Goudsmit hätte ein Betatron einfach mitnehmen sollen, als er 1945 in Deutschland war und dies mit weniger Umständen möglich war. ${ }^{1563}$ Die Nutzung der Erlanger Geräte war Anfang 1947 insofern entschieden, als dass eines der Universität Göttingen zur Verfügung stand. „Any attempt to overrule this assignment not advisable", lautete eine entschiedene Stellungnahme aus London, die über das US Navy Department an Goudsmit weitergeleitet wurde. ${ }^{1564}$

Die britischen Stellen setzten sich in dieser Konkurrenzsituation stark für die Interessen der Göttinger Physiker ein. Ein selbst gestelltes Hindernis hätte das Gesetz Nr. 25 darstellen können. Doch über die Inbetriebnahme hatte die in Göttingen sitzende Research Branch zu entscheiden, und $\mathrm{zu}$ ihr hatten die Göttinger gute Beziehungen. Wie wichtig solche Beziehungen für die deutsche Wissenschaft im allgemeinen und die Göttinger Physik im besonderen war, beschreibt Heisenberg in einen Brief an Bohr im Sommer 1948. Die Research Branch bestand 1946 aus dem Leiter Brigadegeneral Frank Spedding (Chef der Planungsabteilung in der Economic Subdivision der britischen Militärregierung), ferner aus dem Chemiker Oberst Bertie Blount, dem Physiker Ronald Fraser und einigen jüngeren Herren. Etwa im Frühjahr 1947 kehrte Blount nach England und zurück, und im Sommer 1947 wurde Spedding nach Berlin versetzt. Im Winter 1947/48 kam Blount als Nachfolger für Spedding nach Göttingen zurück. Blount half den Göttingern vor allem bei den großen Fragen

\footnotetext{
1560 Siehe hierzu den geheimen Bericht „Inventory of Nuclear Physics Laboratory Equipment in Germany“ des Office of the Military Attaché, Manhattan Engineer District, American Embassy, London, vom 9. August 1946. NARA, RG 77, entry 22, box 166.

${ }^{1561}$ Lewis H. Strauss an Goudsmit, 28. Mai 1946; Goudsmit an Alan T. Waterman, Navy Department, Office of Research and Inventions, Washington D.C., 16. August 1946. Beide NBL, Goudsmit papers, box 28, folder 55. 1562 Schreiben von General Groves, 19. Februar 1946. NARA, RG 77, entry 22, box 160.

1563 Albert M. Stone, Office of the Assistant Naval Attaché for Research der amerikanischen Botschaft in London, an Goudsmit, 29. Januar 1947. Dort heißt es auch: „Too bad we're not still in the good old days when you could just send me a crate of cigarettes and a bottle of whiskey: the cigarettes for a betatron, the whiskey for Army trucking!". NBL, Goudsmit papers, box 28, folder 55.

1564 Alan T. Waterman, Navy Department, Office of Naval Research, Washington D.C., an Goudsmit, 5. Februar 1947. NBL, Goudsmit papers, box 28, folder 55.
} 
der Wissenschaftsorganisation. Er unterstützte sie bei den Verhandlungen mit den amerikanischen und französischen Dienststellen und setzte sich für die Zukunft der MPG ein. ${ }^{1565}$ Demgegenüber habe Fraser „der Wissenschaft in unserer Zone durch seine unermüdliche Hilfe in vielen Einzelfragen, z. B. dem Wiederaufbau der Physikalisch Technischen Reichsanstalt, bei der Beschaffung von Kopfermanns Betatron, durch die Diskussion über die deutschen Atomenergiearbeiten, durch die Beschaffung von ausländischer Literatur und vieles andere sehr große Dienste geleistet.“ Da Frasers Vertrag bei der Research Branch mit Jahresende 1948 auslief, hoffte Heisenberg, dass sich eine Möglichkeit fände, Fraser ,weiter zugunsten einer fruchtbaren Verbindung der deutschen Wissenschaft mit der des Auslandes“ einzusetzen. Heisenberg schätzte „Fraser als einen Freund der deutschen Wissenschaft und als einen Mann, der richtige Vorstellungen über den zukünftigen Wiederaufbau Mitteleuropas hat“..1566

Wie dieser rückblickende Bericht von Heisenberg andeutet, konnte Kopfermann ein konstruktives Verhältnis zu Fraser aufbauen. Dies lag auch daran, dass die beiden enge Fachgenossen waren. Frasers Buch über Molekularstrahlen ${ }^{1567}$ wurde in Kopfermanns Institut zur Einstiegslektüre der Atomstrahlgruppe. Um das gesetzliche Forschungsverbot zu umgehen, wurde besonders betont, dass das Betatron für strahlenbiologische und medizinische Untersuchungen ausgelegt sei. Natürlich konnte und wollte Kopfermann damit auch physikalische Forschung betreiben. Auch konnte er Fraser in dieser Hinsicht nichts vormachen. Es galt weniger, Fraser zu überzeugen, als einen gangbaren offiziellen Weg zu finden. Denn es ist anzunehmen, dass Fraser davon überzeugt war, dass Kopfermann mit dem Beschleuniger keine militärisch bedeutende Forschung betreiben werde, und somit das Gerät keine Gefährdung der Sicherheit darstellte. Vielmehr fand er in der Research Branch eine Mitstreiterin für die Fortsetzung eines im Krieg begonnenen Projekts. Als das Betatron im September 1947 nach Göttingen gebracht wurde, schilderte Kopfermann dem Kurator noch einmal die Schwierigkeiten, die zu überwinden waren: „Diese Schleuder ist nach endlosen Verhandlungen mit der amerikanischen Militärregierung mit Hilfe des englischen Research

\footnotetext{
$1565 \mathrm{Zu}$ Blounts „,außerordentlich großem“ Einsatz für die KWG siehe Oexle [1994] S. 45ff., zu Speddings positver Einstellung zur Wiederingangsetzung der deutschen Wissenschaft ebenda S. 58.

1566 Heisenberg an Bohr, 24. Juli 1948. MPG-A, Nachlass Hahn, III, 14A, 1003. Eine ähnliche Einschätzung der Bedeutung Frasers vermittelt ein Bericht von Hans Bethe über seinen Besuch Deutschlands vom 31. August 1948. Dort heißt es: „The work at Goettingen has been very much furthered by Dr. Fraser, the British representative, who has shown an extremely understanding attitude.“ NBL, Goudsmit papers, box 28, folder 49. Welch große Bedeutung Fraser für die Göttinger Physik hatte, geht auch aus einem Brief des Stuttgarter Physikers Erich Regener an Max Laue hervor, der wehmütig schrieb: „Wir haben hier keinen Dr. Fraser.“ Zitiert nach Walcher [1995] S. F-112.
}

1567 Fraser [1937]. 
Branch unter der tatkräftigen Unterstützung von Herrn Dr. Fraser [...] in Göttingen eingetroffen und im Zweiten Physikalischen Institut aufgestellt worden."1568

Die Arbeit an der Zwille, wie der neue Teilchenbeschleuniger auch genannt wurde, konnte also fortgesetzt werden. Das Gerät wurde als medizinisches Gerät deklariert. Wolfgang Paul wurde sogar kurzfristig Mitglied der medizinischen Fakultät, arbeitete mit den Medizinern zusammen, konnte aber auch eigentliche kernphysikalische Forschung betreiben. Kopfermann wurde Mitglied des Kuratoriums des Instituts für Medizinische Physik und Biophysik, das durch ihn, den Physiologen Hermann Rein und den Gynäkologen Heinrich Martius gebildet war.

Im Vergleich mit der internationalen Beschleunigerentwicklung war das Göttinger Betatron ein kleines Gerät, das in seiner Leistung nicht dem aktuellen Forschungsstand entsprach. Als Neuerungen wurden in den USA die ersten Synchrotrone in Betrieb genommen, 1946 ein 350 $\mathrm{MeV}$ Synchrotron in Berkeley und kurz vorher eine $75 \mathrm{MeV}$ Anlage in den General Electric Research Laboratories in Schenectady. ${ }^{1569}$ Aber auch wenn man das Göttinger $6 \mathrm{MeV}$ Betatron nicht mit den moderneren Synchrotrons, sondern mit anderen Betatrons der Zeit vergleicht, stellt man fest, dass der Entwicklungsstand 1945 bei etwa $50 \mathrm{MeV}$ angelangt war. ${ }^{1570}$

Wenn auch das Göttinger Betatron in der Beschleunigungsleistung hinter dem damaligen technischen Entwicklungsstand zurückhing, so hatte es auf Grund seiner speziellen Konstruktion doch besondere Vorteile im Einsatz. Im Unterschied zu anderen Apparaten konnten hier die hochbeschleunigten Elektronen in einem gebündelten Strahl aus dem Vakuumgefäß heraus geführt werden. Diese Besonderheit, die einen Vorsprung gegenüber der angelsächsischen Entwicklung brachte, betonte Kopfermann extra. Zwei wesentliche Vorteile brachte die Herausführung des Strahls: 1571

- die Energie der Elektronen war auf etwa $1 \%$ homogen, und

- man erhielt eine für medizinische Anwendungen hohe Dosisleistung von $1000 \mathrm{r} / \mathrm{min}$ in einem Abstand von $1 \mathrm{~m}$.

\footnotetext{
1568 Kopfermann an Kurator, 24. September 1947. UAG, Kur. XVI. V. C. h. 1. III. Bei Eckart \& Osietzki [1989] S. 57 wird anderslautend angegeben, dass das Betatron in der Frauenklinik aufgestellt wurde. 1569 Morrison [1947] S. 178.

1570 Siehe Livingston \& Blewett [1962] S. 6, Fig. 1.1, wo die Wachstumsrate der Energie von Teilchenbeschleunigern verschiedener Bautypen angegeben ist und auch eine Grenzkurve eingezeichnet ist. Dass diese Grenzkurve nicht nur bis 1960, sondern bis 1990 Gültigkeit besitzt, zeigt Kragh [1999] S. 303, Fig. 20.2. Im Jahr 1942 wurden in den USA schon $20 \mathrm{MeV}$ Betatrons betrieben, Wachsmann [1947] S. 373. 1571 Zur Herausführung des Elektronenstrahls siehe Gund [1947]; Gund \& Reich [1949].
} 
Bei anderen Beschleunigern, wo der Elektronenstrahl nicht herausgeführt werden konnte, ließ man die Elektronen im Innern auf eine Antikathode aufprallen, und konnte so die Bremsstrahlung für therapeutische Zwecke nutzen. Die auf diese Art gewonnene harte Röntgenstrahlung hatte zwei Nachteile: erstens ein kontinuierliches Energiespektrum, und zweitens eine um drei Größenordnungen kleinere Dosisleistung. Der Unterschied der Beschleunigertypen wirkte sich ganz entscheidend in der medizinischen Anwendung bei der Krebsbekämpfung aus. Während die Intensität der Röntgenstrahlung nach einer e-Funktion mit der Tiefe abnimmt, besitzen Elektronen eine wohldefinierte Reichweite, die von der Energie abhängt und daher genau eingestellt werden kann. Ein weiterer Vorteil der Elektronenbestrahlung ist, dass die Körperoberfläche geschont werden kann und die maximale Dosis gezielt auf den Krankheitsherd verabreicht werden kann. Die tieferen Gewebeschichten bleiben vollkommend geschont. Zur Bestimmung der relativen Tiefendosis wurden Messungen an einem $\mathrm{KCl}$ Kristall durchgeführt. Hier kam es zu einer gegenseitigen Befruchtung der Forschungen des I. und II. Instituts. Heinz Pick stellte den Kristall her, Berger und Paul führten die Messungen durch und konnten bei der Auswertung der Daten auf das umfangreiche Wissen der Pohl-Schule zurückgreifen. Gemessen wurde die Verteilung der Farbzentren nach Beschuss mit Elektronen wohldefinierter Energie, um daraus auf die Verteilung der Ionisationsdichte rückzuschließen. Das Maximum der Ionisation lag im Inneren und war um etwa das Zweifache höher als an der Oberfläche. Die relativ geringe Energie von maximal $6 \mathrm{MeV}$ ließ aber nur die Behandlung von Krankheitsherden zu, die weniger als $3 \mathrm{~cm}$ tief lagen. ${ }^{1572}$

Auf dem Gynäkologenkongress in Karlsruhe 1949 berichtete der Göttinger Gynäkologe Heinrich Martius über die mit der Bestrahlung von schnellen Elektronen gewonnenen Ergebnisse. Er sprach sich optimistisch aus, dass den schnellen Elektronen vielleicht eine höhere Effektivität auch verschiedenem Gewebe gegenüber innewohne als den klassischen Röntgenstrahlen. ${ }^{1573}$

Auch rein physikalische Probleme wurden mit dem Betatron bearbeitet. Die Elektronen einheitlicher, aber beliebig variierbarer Energie erlaubten es, Elektronenstoßexperimente mit Atomkernen zu machen. Wolfgang Paul ist es gelungen, das Deuteron durch Elektronenstoß zu spalten. Untersucht wurde auch der Durchgang schneller Elektronen durch Materie, was

\footnotetext{
1572 Zu den Einsatzgebieten des Betatrons siehe ausführlich Kopfermann [1949] und kurz zusammengefasst Kopfermann an Hahn, 29. September 1949. MPG-A, Nachlass Hahn, III, 14 A, 2221. Zur medizinischen Anwendung siehe Gund \& Wachsmann [1948]. Die Untersuchungen der Ionisationsverteilung im KCl Kristall sind nachzulesen in Berger \& Paul [1949].
} 
neue physikalische Probleme erwarten ließ. Auch verschiedene biologische Reaktionen von Tieren und Pflanzen wurden von Paul und Schubert untersucht, indem sie sowohl mit schnellen Elektronen des Betatrons als auch mit 200 keV-Röntgenstrahlen bestrahlt wurden. ${ }^{1574}$

Die 25000 RM für die Anschaffung des Betatrons wurden vom Kultusministerium zur Verfügung gestellt; auch der Etat des II. Physikalischen Instituts wurde für das Rechnungsjahr 1947 um 5000 RM erhöht. ${ }^{1575}$ Aus einem Schreiben des Kurators von 1950 ergibt sich folgende Übersicht über die dem II. Physikalischen Institut zur Verfügung gestandenen Etats für Lehrmittel: 1576

\begin{tabular}{|l|c|c|c|c|c|c|}
\hline Jahr & 1938 & 1942 & 1947 & 1948 & 1949 & 1950 \\
\hline Etat & 10950 & 9850 & 3170 & 9000 & 10000 & 10000 \\
\hline
\end{tabular}

1952 wurde dieser Etat auf 13000 DM erhöht; nach Weggang Kopfermanns nach Heidelberg bekam im Jahr 1955 sein Nachfolger Flammersfeld 30000 DM und 1956 bereits 34500 DM zur Verfügung gestellt. 1577

Wenn man an heutige Teilchenbeschleuniger denkt, hat man riesige Anlagen vor Augen die nur noch im Stil der big science betrieben werden können. Demgegenüber war das Göttinger Betatron genau das Gegenteil. Der Beschleuniger war eine einfache, wenig Raum beanspruchende und verhältnismäßig billige Apparatur. Insgesamt wog es etwa $350 \mathrm{~kg}$ und hatte die handlichen Ausmaße von 76 x 44 x $20 \mathrm{~cm}^{3} .{ }^{1578}$ Auch die Anzahl der Mitarbeiter, die am Betatron forschten, blieb gering. Wolfgang Paul wurde im Institut der Beschleunigerspezialist und war auch für die Zusammenarbeit mit den Medizinern verantwortlich. Mit dem Weggang von Paul 1952 endete diese Zusammenarbeit. Paul nahm das kleine Betatron mit nach Bonn, verwendete es dann aber doch nicht mehr, da es zu

\footnotetext{
1573 Kepp [1949] S. 341.

1574 Kopfermann [1949] und Kopfermann an Hahn, 29. September 1949. MPG-A, Nachlass Hahn, III, 14 A, 2221. Zur Spaltung des Deuterons siehe Paul [1949]; zum Durchgang schneller Elektronen durch Materie Paul \& Reich [1950], zur biologischen Wirkung Paul \& Schubert [1950]; Dittrich, Paul, Riedel \& Schubert [1949]; Bruns, Dittrich, Paul \& Schubert [1950]; Schmermund, Bleek \& Heinrich [1950]; Czech, Czech \& Schmermund [1950]; Bode, Paul \& Theismann [1950]; Kepp [1950]; Dittrich, Fass, Höhne \& Schubert [1950]; Bleek, Dittrich, Fass, Paul, Schmermund, Schubert \& Stadtmüller [1950]; Bode, Paul \& Schubert [1950]; Dittrich, Höhne, Paul \& Schubert [1950]. Eine rückblickende Übersicht liefert Markus [1973]. 1575 Siehe Kopfermanns Antrag vom 24. September 1947 und die Bewilligung vom Kultusministerium vom 19. Dezember 1947. Zur Erhöhung des Etats siehe Schreiben des Kurators, 10. Februar 1948. UAG, Kur. XVI. V. C. h. 1. III.

1576 Kurator an Kultusministerium, 3. Juni 1950. Diese Liste enthält die Sondermittel für das II. Physikalische Institut, und zwar die Haushaltsmittel für Lehrmittel pp. bei Titel 300 (früher Titel 51). Leider gibt es im UAG keinen Aktenbestand, der eine systematische Auflistung der Etats der einzelnen Institute enthält. UAG, Kur. XVI. V. C. h. 1. III.

1577 Alle Angaben nach UAG, Kur. XVI. V. C. h. 1. III.

1578 Wachsmann [1947] S. 374; Gund \& Wachsmann [1948].
} 
veraltet war. ${ }^{1579}$ Stattdessen konstruierte er ein $500 \mathrm{MeV}$ Elektronsynchrotron. Es galt nicht nur für die Arbeiten am Göttinger Betatron, dass nur wenige Spezialisten daran beteiligt waren. Ganz allgemein hielt Kopfermann in seinem Institut die Arbeitsgruppen und die von ihnen durchgeführten Forschungen klein und verweigerte sich in gewisser Weise dem Trend zur Großforschung. Victor Weisskopf charakterisierte Kopfermanns Forschungsstil in einem Nachruf als ,the style of chamber music in science.“1580 Dies galt auch für die anderen Göttinger Physikinstitute der Zeit.

1579 Knop [1973] S. 20f.

1580 Weisskopf [1964] S. 183. 


\section{Das Lehrangebot: mehr als ein Spiegel der Forschungsthemen}

Welchen Einfluss hatten die politischen Umbrüche auf die Lehre in der Physik? Gab es 1945 eine Neuorientierung der Lehre? Mit diesen Fragestellungen liegt der Schwerpunkt dieses Kapitels auf den Änderungen im Lehrangebot. Demgegenüber muss aber gleich zu Beginn festgestellt werden, dass der weitaus größte Teil des Physikcurriculums von politischen Einflüssen unberührt blieb: Die Einführungsvorlesung, die Praktika und auch viele weiterführende Vorlesungen wurden unverändert fortgeführt. Die größte Kontinuität zeigt die von Pohl nicht nur für Physiker, sondern auch für Mediziner und andere Naturwissenschaftler gehaltene Einführungsvorlesung, deren Inhalt sich aus Pohls laufend überarbeiteten und aktualisierten Lehrbüchern gut erschließen lässt. Einen Überblick über das Göttinger Curriculum geben Tabelle 22 und Tabelle 23 am Ende dieses Kapitels. ${ }^{1581}$ Neben der dominanten Kontinuität der grundlegenden Lehre gab es charakteristische Veränderungen zumeist in Randgebieten des Curriculums, die teils auf die jeweilige politische Lage zurückzuführen sind. Im folgenden werden vor allem diese Diskontinuitäten getrennt für die NS-Zeit und die Nachkriegszeit untersucht.

\subsection{Veränderung des Lehrangebots im Nationalsozialismus}

Auffällig ist die Diskontinuität von Vorlesungen zur Relativitätstheorie. Sie wurde zwischen den Jahren $1934{ }^{1582}$ und 1946 zumindest offiziell gar nicht gelesen, wenngleich unklar bleibt, inwieweit sie beispielsweise in Vorlesungen über Elektrodynamik doch mit behandelt wurde, wie dies Otto Heckmann und Fritz Sauter nach 1945 behauptet haben. ${ }^{1583}$ Die Vermeidung des Begriffs „Relativitätstheorie“ in den Titeln der Vorlesungen und Seminare kann als Zugeständnis an die offiziell verfemte und mit dem Namen Einstein verbundene Theorie

1581 Dieses Angebot an Lehrveranstaltungen im Gesamten zu untersuchen, wäre eine umfangreiche Forschungsarbeit, die hier nicht geleistet werden kann. Zur Kopfermann-Schule, ihrem Ausbildungsstil und ihrem Erfolg vor allem in der Nachkriegszeit siehe Schlüpmann [http]. Die von Pohl eingeführten Neuerungen in der Einführungsvorlesung und ihre internationale Verbreitung werden gerade von Roland Wittje in Norwegen untersucht.

1582 Im SS 1934 las Max Schuler eine Einführung in die Relativitätstheorie, allgemeinverständlich. Zu Schuler siehe Kapitel 5.

1583 Siehe Heckmann [1976] S. 32, der behauptete, er habe zusammen mit Sauter im SS 1936 ein Seminar über Elektrodynamik bewegter Körper gehalten, in dem es um die spezielle Relativitätstheorie gegangen sei. Laut Vorlesungsverzeichnis war der Titel des Seminars im SS 36 Ausgewählte Fragen der Quantenmechanik, und für 
gelten. ${ }^{1584}$ Obwohl die Relativitätstheorie bereits im November 1940 im Zuge des Münchener Schlichtungsgesprächs zwischen Vertretern der „Deutschen Physik“ und einigen der etablierten Physiker wieder 'hoffähig' geworden war, ${ }^{1585}$ hielt Richard Becker erst im SS 1946 wieder eine Vorlesung mit dem Titel „Relativitätstheorie“. Beckers Vermeidung der expliziten Nennung der Relativitätstheorie bis 1945 lag vermutlich nicht nur an der Kopplung mit dem Namen Einstein, sondern auch an einer durch fachfremde Personen damals durchaus gängigen Verwechslung mit einem allgemeinen Relativismus. ${ }^{1586}$ Deshalb bezeichnete Fritz Sauter in einem Bericht zu einer 1942 in Seefeld stattgefundenen Tagung, auf der es unter anderem um die Geltung der Relativitätstheorie ging, „die Schaffung einer eigenen unmissverständlichen Bezeichnung [der Relativitätstheorie] für [...] äusserst wünschenswert“, um solche Verwechslungen zu vermeiden. ${ }^{1587}$ Mit dem Wissen um diese letzten Endes nur noch begrifflichen Auseinandersetzungen wird Beckers Verhalten verständlich, der den Inhalt seiner Seminare zur theoretischen Physik nicht näher bezeichnete und damit eventuelle Schwierigkeiten von vornherein vermied.

Neben der Relativitätstheorie war auch die Quantenmechanik politisch verrufen. Doch in diesem Fall war der Begriff nicht so sehr belastet, dass er nicht in einem Vorlesungstitel auftreten durfte. Trotzdem wurden entsprechende Vorlesungen während der NS-Zeit seltener angeboten als danach: Quantentheorie (einschließlich Quantenmechanik) wurde bis $1945 \mathrm{im}$ Mittel jedes dritte Semester gelesen (in 23 Semestern und Trimestern 9 Mal); nach dem Krieg gab es ab dem SS 1946 einen wahren Schub mit insgesamt sieben Veranstaltungen in den nächsten sechs Semestern, der einen gewissen Nachholbedarf anzeigt. Auch der neu nach

\footnotetext{
die Semester davor und danach sind die Seminare mit Sauter nicht näher bezeichnet. Zu Heckmanns 'flexibler' Selbstdarstellung siehe Hentschel \& Renneberg [1995].

1584 Beim Versuch, eine „Deutschen Physik“ zu etablieren, bekam die Relativitätstheorie unter anderem das Etikett eines ,großen jüdischen Weltbluff“. Zur „Deutsche Physik“ siehe Beyerchen [1980/82]; Richter [1980]; Walker [1990/92] S. 79-101; Eckert [1993] S. 196-206; Hentschel \& Hentschel (Hrsg.) [1996] S. lxxv; Litten [2000] S. 377-384.

1585 Nach Punkt 2 der Vereinbarung, die am 15. November 1940 zwischen Harald Volkmann, Bruno Thüring, Wilhelm Müller, Rudolf Tomaschek und Ludwig Wesch als Vertreter der „Deutschen Physik“ und Carl Friedrich Weizsäcker, Otto Scherzer, Georg Joos, Otto Heckmann und Hans Kopfermann auf der anderen Seite getroffen wurde, gehörten die in der speziellen Relativitätstheorie zusammengefassten Erfahrungstatsachen zum festen Bestandteil der Physik. Siehe Flitner (Hrsg.) [1965]; Beyerchen [1980/82] S. 238-242.; Richter [1980] S. 127; Walker [1990/92] S. 88.

1586 Hentschel [1990] bes. Kapitel 2.

1587 Die hier zitierte Formulierung stammt aus einer ersten Fassung des von Fritz Sauter verfassten Berichts und wurde von Carl Friedrich Weizsäcker abgeändert, da er sie als ,zu starke Konzession an die Gegenseite empfunden“ habe. Das „Physiker-Lager“ in Seefeld (Tirol) fand im November 1942 statt. Die verschiedenen Fassungen des Berichts und ein Schreiben von Weizsäcker an Sauter vom 21. Juni 1943 befinden sich in NBL, Goudsmit papers, box 25, folder 12, Seefield.
} 
Göttingen berufene Mathmatiker Franz Rellich beteiligte sich an diesem Angebot im WS 1946/47 mit der Vorlesung über Spezielle Eigenwertprobleme der Quantenmechanik. ${ }^{1588}$

Obwohl bedeutende Fortschritte in der Physik in den frühen dreißiger Jahren aus den angelsächsischen Ländern kamen, wurde ein von Born und Franck im SS 1931 eingeführter englischer Sprachkurs nur bis zum WS 1934/35 angeboten. Auch wenn die Göttinger Physiker damit nicht der internationalen Wissenschaft und der internationalen Gelehrtenrepublik absagten, wie dies ihr Historikerkollege Ulrich Kahrstedt öffentlich tat, so war es doch ein Symbol, das sich gegen die Internationalisierung des Faches richtete. ${ }^{1589}$ Eine Folge der rassistischen Vertreibungspolitik des Nationalsozialismus war, dass philosophisch orientierte Vorlesungen für Hörer aller Fakultäten wegfielen, die vor allem von Mathematikern wie Weyl, Courant und Hilbert, aber auch von Physikern wie Born angeboten worden waren. ${ }^{1590}$

Die von der NS-Regierung in Angriff genommene Kriegsvorbereitung wurde in der Lehre der Göttinger Physik durch eine Häufung von anwendungs- und technikbezogenen Vorlesungen begleitet. In der angewandten Physik bedeutete dies keine wesentliche Änderung im Curriculum, da hier militärisch relevante Forschungsthemen eine lange Tradition hatten und demzufolge schon vor 1933 ihren Niederschlag auch in der Lehre fanden. Als Vorlesungen finden sich zum Beispiel Ballistik (Wilhelm Flügge, SS 1934) oder automatische Steuerung von Maschinen, Schiffen und Flugzeugen (Max Schuler, SS 1935). Die letztgenannte Vorlesung hielt Schuler zum ersten Mal schon im SS 1932. Ein Blick auf das Vorlesungsangebot der experimentellen und theoretischen Physik zeigt, daß die Förderung der Kriegswirtschaft sich auch hier auf den Physikunterricht auswirkte. So wurde beispielsweise im SS 1938 Maschinenzeichnen und Normenkunde für Physiker angeboten, im folgenden WS Werkstoffkunde für Physiker; leider sind die Vortragenden dieser Vorlesungen nicht namentlich genannt. An anderer Stelle zeigt sich, daß auch die Kernphysiker für die technische Ausbildung sorgten: Im WS 1943/44 lasen Kopfermann und Wolfgang Paul Physikalische Technik- und Werkstoffkunde. Neben diesen auf die praktische Verwertbarkeit im Krieg abgestimmten Vorlesungen findet sich auch eine Vorlesung, die eine Verbindung zwischen Physik und Staatsaufgaben herstellte und den sozialdarwinistisch anmutenden Titel Physik als Waffe im Daseinskampf trug, gehalten von Georg Joos im WS 1936/37. Leider ist

\footnotetext{
1588 Im vorhergehenden Semester las er über Singuläre Eigenwertprobleme.

1589 Zu Kahrstedts Festrede in der Aula vom Januar 1934 mit dem Gelöbnis einer deutschen Wissenschaft an Stelle einer internationalen siehe Wegeler [1996] S. 147-162.

1590 Siehe Tabelle 20.
} 
kein Vorlesungsmanuskript dazu bekannt, jedoch lässt sich aus einem Vortrag von Joos über Physik und Energiewirtschaft, den er im Mai 1934 in Jena gehalten hatte, plausibel rekonstruieren, um welche Art „Daseinskampf“ es sich gehandelt haben mag. ${ }^{1591}$ Aus den versiegenden Energiequellen auf der Erde erwachse dem Physiker die Aufgabe, alternative Energien für die Zukunft ausfindig zu machen. Joos sah eine Chance in der Ausnutzung der in den Atomkernen steckenden Bindungsenergie. Die Physiker befänden sich aber in einem weltweiten Wettlauf um die neuen Erkenntnisse. Jener Staat, dem zuerst die Lösung des Problems gelingen möge, würde der Herr der Welt sein. ${ }^{1592}$ Wie dieses Beispiel zeigt, sah Joos zumindest in der Frage der Atomenergie die Physik als eine Waffe zur Erringung der Weltherrschaft.

Eine stärkere Auswirkung als die eben besprochene inhaltliche Verschiebung und Neuerung in der Lehre ist in der allgemeinen Verdünnung im Lehrangebot zu sehen. Dies lässt sich durch zwei Ursachen erklären: Zum einen waren die mit Beginn der dreißiger Jahre drastisch sinkenden Studentenzahlen verantwortlich (siehe Abschnitt 2.2), zum anderen der schrumpfende Lehrkörper, zuerst 1933 durch die Entlassungen und im Krieg durch Abkommandierungen.

Zwischen 1939 und 1942 sind reichsweit neue Studien- und Prüfungsordnungen in Kraft getreten. In den Naturwissenschaften zeigten diese generell eine kriegsbedingte Entideologisierung. Künftige Physik- und Chemielehrer mussten allerdings Auskunft geben können über die Bedeutung ihrer Disziplin für den „Lebenskampf des deutschen Volkes“. ${ }^{1593}$ Noch deutlicher als bei den Lehramtsstudiengängen ist der Trend zur Entpolitisierung in den Diplomstudienordnungen zu sehen. Neu war an der im November 1942 in Kraft getretenen Diplomstudienordnung in der Physik vor allem die einheitliche Ausrichtung des physikalischen Studiums an den Universitäten und Technischen Hochschulen. Anstatt vertiefender Kenntnisse in den verschiedenen Gebieten der technischen und angewandten Physik wurde einer physikalischen Allgemeinbildung Vorrang gegeben mit dem Ziel, eine unerwünschte Spezialisierung einzuschränken. ${ }^{1594}$

\footnotetext{
1591 Diesen Versuch haben Oliver Lemuth und Rüdiger Stutz überzeugend unternommen. Ich danke beiden für die Einsicht in ihr Manuskript ,„Patriotic Scientists« - Jenaer Physiker und Chemiker zwischen berufsständischen Eigeninteressen und »vaterländischer Pflichterfüllung«“". Mittlerweile publiziert in Hoßfeld, John, Lemuth \& Stutz (Hrsg.) [2003].

1592 Siehe dazu ausführlich Lemuth \& Stutz [2003].

1593 Zitiert nach Grüttner [1995] S. 196.

1594 Erlass des REM, 7. August 1942, betr. Neuordnung des Studiums der Physik und der Mathematik. BAB, R 4901, Nr. 500. Zum Problem einer Spezialisierung siehe Abschnitt 4.2.1.
} 
Wegen der schlechten Mathematikkenntnisse der Studienanfänger suchten die Göttinger Professoren 1938 eine Verbesserung des mathematischen Unterrichts an ihrer Universität zu erreichen. Während es vorher keine regelmäßige mathematische Einführungsvorlesung speziell für Naturwissenschaftler gab, wurde im WS 1937/38 die Vorlesung Einführung in die höhere Mathematik für Naturwissenschaftler mit Übungen neu geschaffen. Dieser zweisemestrige Vorlesungszyklus war jeweils vierstündig und wurde zuerst gemeinsam von Becker und Kaluza, später auch von Joos gehalten. ${ }^{1595}$ Die Vorlesung überschnitt sich zeitlich nicht mit der parallel angebotenen über Differential- und Integralrechnung. Es ist aber nicht anzunehmen, dass die Studenten der Naturwissenschaften beide Vorlesungen belegen sollten. Für den zweiten Turnus im WS 1938/39 wurden Gelder für einen zusätzlichen Dozenten, der die Übungen betreute, vom Mathematischen Institut zur Verfügung gestellt. Gleichzeitig wurden die Übungen um eine Stunde verlängert. Der Krieg führte zu einer weiteren Verschlechterung der von den neuen Studenten mitgebrachten Vorkenntnisse. Deshalb führte Richard Becker im SS 1942 eine Arbeitsgemeinschaft zur Wiederholung und Befestigung des Schulpensums in Mathematik für Studierende der Naturwissenschaften ein, in der fortgeschrittene Studenten die Neulinge in kleinen Gruppen unterrichteten. ${ }^{1596}$ Becker und Joos bekamen im Zuge der neuen Mathematikvorlesung für Naturwissenschaftler das Recht, auch im Fach angewandte Mathematik Prüfungen abzunehmen. ${ }^{1597}$ Die neu eingeführte Vorlesung blieb allerdings auf die NS-Zeit beschränkt. Obwohl besonders in der Nachkriegszeit über die schlechten Kenntnisse der Studienbewerber geklagt wurde, gab es nach 1945 nur ein stark reduziertes Angebot an einführenden Vorlesungen in die Mathematik speziell für Naturwissenschaftler. Erst im WS 1947/48 wurde von dem Dozenten Ernst Graeser eine dreistündige derartige Vorlesung angeboten, die in den folgenden Wintersemestern wiederholt wurde.

Ein weiterer Versuch zur Auffrischung der Kenntnisse von Abiturienten, die erst nach längerem Kriegsdienst ihr Studium beginnen konnten, stellte die Ende 1943 an den Hochschulen eingerichtete „fachliche Grundausbildung“ dar. Für die Naturwissenschaften war hier Mathematik das wichtigste Fach. Physik und Chemie waren vom Ministerium nicht unbedingt vorgesehen gewesen, wurden aber zum Beispiel an der Universität Wien

\footnotetext{
1595 Der Inhalt der Vorlesung dürfte sich bei Joos und Kaluza aus ihrem Lehrbuch Joos \& Kaluza [1938] erschließen lassen, bei Becker aus seinen Soldatenbriefen, die weiter unten besprochen werden.

1596 Siehe dazu Abschnitt 4.1.

1597 Protokoll der Besprechung betreffend den Unterricht für höhere Mathematik für Naturwissenschaftler am 4. Mai 1938. GPAMNFG, Protokollbuch III der mathematisch-naturwissenschaftlichen Fakultät WS 1927/28 SS 1946. Siehe auch Schreiben Becker an REM, 31. Mai 1938. UAG, Rek. 5250 / 8A. Institut für theoretische Physik, Feb. 1934-Dez. 1959.
} 
angeboten. In Göttingen war das Angebot viel spärlicher. Die Teilnahme daran war freiwillig. ${ }^{1598}$ Das Ministerium wollte über den Erfolg dieser neuen Einrichtung informiert werden und bekam vom Göttinger Dekan Kopfermann einen nüchternen Bericht. Im Sommersemester 1944 kam aus Mangel an Beteiligung keine der vom REM erwünschten fachlichen Grundausbildung in den Naturwissenschaften zu Stande. Die Fakultät sah in dem schon vorhandenen und jedes Semester angebotenen Kurs Einführung in die mathematische Behandlung der Naturwissenschaften die „,beste und einzig wirklich notwendige Grundlage für das Studium der Naturwissenschaften“. Wegen der geringen Vorkenntnisse der Studienanfänger wurde in diesem Kurs hauptsächlich auf die Schulmathematik zurückgegriffen. Zusätzliche Kurse in Physik und Chemie erschienen der Fakultät als nicht erforderlich. ${ }^{1599}$

In direktem Zusammenhang mit dem Krieg standen die von Richard Becker verfassten Göttinger Soldatenbriefe für Physiker und Mathematiker. In der Einführung zur ersten Nummer, die im September 1943 erschien, ist zu lesen: „Diese Briefe richten sich an Soldaten, die die Absicht haben, Mathematik oder Physik zu studieren, mit diesem Studium aber noch gar nicht oder eben erst angefangen haben."1600 Diese Briefe enthalten Übungsaufgaben, deren Lösung der Soldat an Becker zu schicken hatte, um sie vom Professor selbst korrigiert zurückzuerhalten. Auf diese Weise entstand ein persönlicher Kontakt zwischen Professor und (noch-nicht-)Student, der sich in der Nachkriegszeit beim streng angewendeten numerus clausus bedeutend auswirken konnte. Insgesamt erschienen bis Kriegsende fünf Soldatenbriefe, die zusammen einen Umfang von 160 Seiten ergeben. ${ }^{1601}$ Beckers Ziel war, eine Verbindung zwischen der Physik und der Mathematik herzustellen. Er führte den Studenten in sehr lebendiger Sprache von zuerst einfach erscheinenden Problemen zur Beherrschung von komplexen Aufgaben heran. Immer wieder bemüht er sich, die Phantasie anzuregen, um die Problemstellungen und deren Lösung zu „erleben“. „Sie müssen dann die Größe $U$ geradezu an Ihren Fingerspitzen fühlen, erst dann haben Sie den Begriff der

\footnotetext{
1598 Erlass des REM zur „,fachlichen Grundausbildung“ vom 2. Oktober 1943. UAG, Kur. XXX. A. a. Studierende. Allgemeine Vorschriften. IX.

1599 Dekan Kopfermann an REM, 20. September 1944. UAG, Kur. XXX. A. a. Studierende. Allgemeine Vorschriften. VIII.

1600 Göttinger Soldatenbriefe für Physiker und Mathematiker, im Auftrag der Georg-August-Universität Göttingen herausgegeben von Prof. Becker, [...] Nr. 1, September 1943, S. 1. Mein herzlicher Dank gilt Dr. Eva Opitz für die Überlassung sämtlicher Soldatenbriefe.

1601 Die jeweils 32 Seiten starken Hefte erschienen im September 1943, November 1943, Januar 1944, Mai 1944 und Februar 1945.
} 
potentiellen Energie »erfaßt«.“1602 Es ging Becker nicht nur darum, dass durch das Lösen vieler Aufgaben Rechentechniken eingeübt wurden, sondern vor allem, dass an einzelnen Beispielen die Prinzipien eingehend verstanden wurden, sodass sie sich der Student in Beckers Worten „,ins Gefühl bringen“ konnte. ${ }^{1603}$ Typisch hierfür ist beispielsweise die Einführung in die Differentialrechnung: „Sie müssen die Differentialrechnung nicht lernen, sondern nach Möglichkeit selbst erfinden. Wenn Ihnen das an Hand der folgenden Hinweise gelingt, so haben Sie schon viel gewonnen." 1604 Wichtig war ihm, dass jede physikalische (und auch mathematische) Gleichung anschaulich verstanden werden musste. Als Lösung genügte ihm nicht das Anschreiben von Gleichungen. Diese mussten vielmehr interpretiert werden, am besten grafisch und sprachlich. „Nur dadurch werden Sie wirklich mit der Materie vertraut.“"1605 Den letzten Soldatenbrief vom Februar 1945 eröffnet ein sieben Seiten langer Abschnitt Vom Gebrauch der deutschen Sprache in Physik und Mathematik. Hierin fordert er den Soldaten auf, die Lösungen der Übungsaufgaben „von vornherein gewissermaßen wie einen Aufsatz niederzuschreiben, eventuell sogar mit einer Disposition."1606 Dahinter steckte die Überzeugung, dass nur das wirklich verstanden wurde, was auch in vollständigen deutschen Sätzen niedergeschrieben oder vorgetragen werden konnte.

Mit den Soldatenbriefen erreichte Becker eine weiterführende Ausbildung der in der Wehrmacht kämpfenden jungen Männer, die diesen vermutlich eine willkommene Ablenkung und geistige Beschäftigung war. Auch wenn gegen Ende des Kriegs die Physikstudentenzahlen in Göttingen wieder stiegen waren viele immer noch zur Wehrmacht eingezogen. Zum Beispiel waren im SS 194462 männliche und 45 weibliche Physikstudenten in Göttingen anwesend, weitere 61 waren wegen Wehrdienst beurlaubt. Es kann als besondere Pflichtauffassung interpretiert werden, dass Becker seinen Lehrauftrag nicht nur bezüglich der anwesenden Studenten, sondern auch der abwesenden und erst künftigen wahrnahm. Hinzu

1602 Soldatenbrief Nr. 1, S. 22. Das „Erleben“ von Mathematik fordert Becker auch bei der Einführung von Sinus und Kosinus, bei der er die übliche Abbildung des Einheitskreises gibt, ,,in welcher Sie sich die Gerade $A B$ [=Radius] wirklich als Stange vorstellen müssen, die Sie um den Punkt $A$ drehen, damit Sie erleben, wie sin und cos sich mit der Bogenlänge $D B$ ändern." Soldatenbrief Nr. 3, S. 65.

1603 Soldatenbrief Nr. 2, S. 33.

1604 Soldatenbrief Nr. 1, S. 13.

1605 Soldatenbrief Nr. 2, S. 33. Ein Beispiel zur Forderung nach plastischer Vorstellung sei aus Soldatenbrief Nr. 5, S. 131 zitiert: „Die ganze Physik besteht nur aus Aussagen über die Ergebnisse von Messungen. Um also ein zunächst mit ein paar Buchstaben angedeutetes Gesetz [...] zu verstehen, müssen Sie sich möglichst plastisch vorstellen, was Sie alles tun müßten, um dieses Gesetz zu bestätigen. [...] Solange Ihnen aber nicht mindestens grundsätzlich eine solche Messung vor Augen steht, bleibt jede physikalische Formel eine nutzlose Anhäufung von Buchstaben. Das Auswendiglernen von solchen Buchstabenhäufungen ist eine völlig sinnlose Beschäftigung und hat mit dem Lernen von Physik nicht das mindeste zu tun."

1606 Soldatenbrief Nr. 5, S. 130. 
kam vermutlich, dass sich Becker mit den Soldaten gefühlsmäßig verbunden sah, denn für ihn war der Einsatz fürs „Vaterland“, ob als Soldat an der Front oder als Wissenschaftler in der Rüstungsforschung, eine patriotische Pflicht. Außerdem kämpften sein eigener Sohn und sein bester Student in der Wehrmacht, sodass man davon ausgehen kann, dass seine Gedanken häufig bei den Soldaten waren. ${ }^{1607}$ Die zuweilen väterliche und einfühlsame Sprache dieser Soldatenbriefe, die den Namen „Briefe“ zurecht tragen, scheint mit dieser Gefühlslage zu korrespondieren. Vielleicht mag es auch an dieser einmaligen Entstehungssituation und dem besonderen Einsatzzweck gelegen haben, dass diese Briefe eine didaktisch hochwertige Einführung in die mathematischen Methoden der Physik geworden sind. Der persönliche Ton und die ausführliche Hilfestellung bei elementaren Aufgaben waren einer späteren Publikation hinderlich. In etwas erweiterter Form und auf höherem fachlichen Niveau publizierte Becker vier Jahre nach Kriegsende eine Vorstufe zur Theoretischen Physik, die ähnliche Aufgaben und Themen wie die Briefe enthält. Doch ist in der Publikation alles formaler und damit trockener dargestellt, sodass die Besonderheit der Briefe, nämlich eine anschauliche Einführung ins physikalische Denken mit einer expliziten Hinzuziehung der Phantasie, der Gedankenexperimente auf einfachstem Niveau, hier weitgehend verloren ging. Während im Lehrbuch vor allem fertige Physik dargeboten wird, waren die Briefe eine Anleitung für den Weg dorthin. An ihnen kann man aber erahnen, warum die Schüler Beckers im Rückblick seine didaktischen Fähigkeit so überaus lobend herausstellen.

\subsubsection{Veränderungen in der Organisation des physikalischen Praktikums}

Unter James Franck war das Physikalische Praktikum dreiteilig: a) für Mediziner, b) für Chemiker und Naturwissenschaftler, c) für Physiker und Mathematiker. Die beiden ersten Gruppen wurden wöchentlich vier Stunden, die letzte Gruppe 7 Stunden betreut. Im Herbst 1933 wurde das physikalische Praktikum auf Veranlassung Pohls im Sinne seiner Unterrichtsmethodik umgestaltet. Mit der Leitung des Praktikums war der vormalige Assistent Francks, Günther Cario, betraut. Statt das Praktikum an einem Tag für alle abzuhalten und über hundert Studenten gleichzeitig auszubilden, wurde es auf die ganze Woche verteilt und dadurch eine intensivere Betreuung ermöglicht. Es wurden kleine Gruppen von vier Studenten gebildet, die täglich von 8-11 Uhr von einem Assistenten betreut

1607 Beide starben im Krieg. 
wurden. „Auf diese Weise entwickelt sich das Praktikum zu einer Art Arbeitsgemeinschaft Zwischen den vier Studierenden und dem Assistenten."1608

Inwieweit es noch eine Trennung der verschiedenen Teilnehmer (Mediziner, Naturwissenschaftler und Physiker) gab, geht aus den Quellen nicht hervor. Nach der durch Pohl veranlassten Umgestaltung und der folgenden Lehrstuhlübernahme durch Joos wurde im Vorlesungsverzeichnis bis zum WS 1938/39 nur noch global ohne weitere Untergliederung ein Physikalisches Praktikum angekündigt. Die tägliche Durchführung wurde von Joos auf vier Tage in der Woche reduziert. Als normale Teilnehmerzahlen für die Vorkriegssemester nannte Joos 80 Mediziner und 50 Chemiker; zu den Physikern machte Joos keine Angaben. Deren Zahl dürfte aber deutlich unter 20 gelegen haben. 1936 gab es insgesamt nur 56 Physikstudenten, 1939 waren es nur noch 38 (laut Joos sogar nur 25). ${ }^{1609}$ Da einzelne Praktikumsaufgaben für die Mediziner entweder $\mathrm{zu}$ schwierig oder für deren Zwecke unbrauchbar waren, richtete Joos im SS 1939 ein spezielles Praktikum für Mediziner neu ein, das beim ersten Durchgang bereits von 50 Studenten belegt wurde. ${ }^{1610}$ Im Krieg ging zwar die Zahl der Physikstudenten zurück, wegen der großen Anzahl von Medizinern aber nicht die der Praktikumsteilnehmer, sodass neue Hilfskräfte eingestellt werden mussten. Im WinterTrimester 1940 nahmen am physikalischen Praktikum bereits 380 Mediziner und 170 Chemiker teil. ${ }^{1611}$ Die Suche nach geeigneten Hilfskräften gestaltete sich im Krieg wegen der vielen zum Militär Berufenen mitunter schwierig. 1942 beantragte Hellwege die Einstellung des in Kabul geborenen Afghanen M. Jusuf als Hilfskraft. Um politische Einwände abzuwehren, verwies Hellwege auf die ,afghanischen traditionellen Abwehrkämpfe gegen England und Rußland“. Außerdem erscheine Jusufs „Freundschaft für deutsches Geistes- und Kulturleben [...] aufrichtig““. ${ }^{1612}$

Eine Erweiterung erfuhr das Praktikum unter dem neuen Institutsdirektor Kopfermann. Die Zahl der gestellten Aufgaben wuchs, und wie mir Studenten berichteten, stieg auch die Qualität der Experimentiervorrichtungen und Fragestellungen. Im Unterschied zu vorher, als die Studenten am fertigen Versuchsaufbau nur die Messungen durchzuführen hatten, mussten sie nun auch den Aufbau der Versuche aus den erforderlichen Einzelteilen selbst zu Wege bringen. Ab dem WS 1944/45 kam zu dem bestehenden allgemeinen Praktikum und dem für

\footnotetext{
1608 Aus Lebenslauf von Günther Cario, ohne Datum, vermutlich November 1934. UAG, Rek. 3306.

1609 Joos an Rektor, 23. Februar 1940. UAG, Mat. Nat. Fak. 24a.

1610 Joos an Kurator, 22. April 1939. UAG, Kur. XVI. V. C. h. 2. II.

1611 Joos an Rektor, 23. Februar 1940. UAG, Mat.Nat.Fak. 24a.

1612 Hellwege an Kurator, 17. Februar 1942. Siehe auch den Antrag Kopfermanns vom 9. Dezember 1942 zur

Anstellung weiterer vier Hilfskräfte. UAG, Kur. XVI. V. C. h. 2. II.
} 
Mediziner ein Physikalisches Praktikum für Fortgeschrittene hinzu. Insgesamt standen 124 Aufgaben zur Verfügung, davon 27 aus der Mechanik, 16 aus der Wärmelehre, 34 aus der Elektrizitätslehre, 30 aus der Optik und 17 aus der Atomphysik. 18 Aufgaben waren für das Fortgeschrittenen-Praktikum; die meisten davon (11) stammten aus der Atomphysik, dem Schwerpunkt des II. Physikalischen Instituts. Das 'normale' Praktikum umfasste zweimal drei Semesterwochenstunden, die einzeln für RM 7,50 belegt werden konnten, oder zusammen für RM 15. Der Besuch des Praktikums erstreckte sich über mehrere Semester. Die Prüfungen wurden nicht vom Leiter Kopfermann, sondern von seinen Assistenten abgenommen. Am Ende bekam man bescheinigt, welche Arbeiten man erfolgreich absolviert hatte; in einem mir vorliegenden Zeugnis aus dem Jahr 1947 waren dies 43 Aufgaben.

\subsubsection{Versuch einer Bewertung der Lehre während der NS-Zeit}

Für die NS-Zeit wird in der historischen Forschung allgemein ein Niveauverlust der fachlichen Lehre festgestellt. Auslöser dieses Absinkens waren: Entlassung zahlreicher nicht mehr erwünschter Dozenten, Aufhebung der Lehrfreiheit und Überlastung der Studentenschaft durch fachfremde Ansprüche. ${ }^{1613}$ Diese Punkte treffen alle auch auf die Göttinger Physik zu. Haben wir es demzufolge mit einem Niedergang der Lehre zu tun?

Diese Frage muss verneint werden. Wie in Abschnitt 1.2.3 schon angedeutet wurde, konnten die 1933 vakant gewordenen Lehrstühle mit Physikern nachbesetzt werden, die sich besonders um die Ausbildung der Studenten verdient gemacht hatten. Auch die Berufung Kopfermanns 1942 führte zu einer weiteren Verbesserung der Lehre, wie an der schrittweisen Qualitätssteigerung des Praktikums gezeigt wurde. Becker, Joos, Kopfermann und Pohl werden von den ehemaligen Studenten für ihre didaktisch guten Vorlesungen gelobt. Allen gemeinsam war ein Bemühen um eine anschauliche Darstellung physikalischer Gesetzmäßigkeiten; nicht nur in den Vorlesungen, ${ }^{1614}$ diese Anschaulichkeit wurde auch in ihren Lehrbüchern angestrebt. In die gleiche Richtung zielten die 1938 eingeführten Mathematikvorlesungen für Physiker. Dort wurde den Physikern und anderen

\footnotetext{
1613 Grüttner [1995] S. 476.

1614 Ein Student berichtet über Pohls Vorlesung, dass sie ein „Kunstgenuss“ gewesen sei. Pohl verstand es, die Dinge plastisch darzustellen. Als der Magnetismus besprochen wurde, hat er einen riesigen Magnet aufgebaut, der einen Pendel mit einer Kupferscheibe bremste. Jeder einzelne Student durfte das Pendel hin- und herschieben, um die Kräfte selbst zu spüren. Es waren ungefähr 300 Studenten. - Das besondere Bemühen um Anschaulichkeit wurde Pohl als übertrieben angelastet (siehe zum Beispiel das Interview mit Heinz Pick, 2. Oktober 1981. NBL). Trotzdem hatten seine Lehrbücher einen hohen Wert; vor allem hielt sie Pohl bei den vielen Neuauflagen jeweils auf dem aktuellen Stand der Forschung. Beispielsweise bezeichnete Sommerfeld Pohls Optiklehrbuch als originell und modern; siehe Sommerfeld [1940].
} 
Naturwissenschaftlern das mathematische Rüstzeug im Vergleich zu den Vorlesungen der 'reinen' Mathematiker in weniger formalistischer Weise beigebracht. Ein eindrucksvolles Beispiel der Verbindung von anschaulicher Mathematik und Physik liefern Beckers Soldatenbriefe.

Abgesehen von der durch Pohl geschaffenen Kontinuität gab es durch die vom Nationalsozialismus bewirkte personelle Umgestaltung eine Änderung im Stil der Lehre. Dies wirkte sich positiv für eine solide Grundausbildung in der Physik aus, vor allem auch für Nichtphysiker. Aber auch die wenigen Physikstudenten, die eine Universitätslaufbahn anstrebten, fanden in den Göttinger Instituten eine anregende Atmosphäre. Darauf wurde besonders in Interviews hingewiesen. Es zeigt sich zum Beispiel, dass glänzende Forscher anderer Universitäten selbst überdurchschnittlich gute Physikstudenten nicht begeistern und an sich binden konnten. Wolfgang Paul berichtete, dass er als Student 1934 nach Leipzig ging, das mit Heisenberg, Hund und Debye ,im Prinzip [...] glänzend besetzt“ gewesen sei. Es hat ihm dort aber „überhaupt nicht gefallen“, genauer gesagt habe ihm „der Stil des Institutes nicht gefallen“, außerdem sei Debye gerade weggegangen. Paul zog unversehens weiter an die TH Berlin, wo er sich bei Kopfermann und Becker bedeutend wohler fühlte. ${ }^{1615}$ Er folgte seinen Lehrern nach Göttingen, wurde dort Dozent, später erfolgreicher Professor in Bonn und erhielt sogar den Nobelpreis für Physik. Diese Episode zeigt, dass die Göttinger Schule nicht nur eine solide und breite Physikausbildung bot, sondern auch höchst erfolgreiche Physiker hervorbrachte und - was vielleicht noch wichtiger ist - sie auch anziehen konnte. Göttingen hatte auch in der NS-Zeit einen guten Ruf, wenngleich sich dieser zum Teil aus den zwanziger Jahren speiste. Studenten, die in Prag beziehungsweise in Hamburg studiert hatten, berichteten in Interviews, dass sie wegen des guten Rufes 1938 bzw. 1941 nach Göttingen wechselten. Was sie dort hielt, war die Atmosphäre am Institut. ${ }^{1616}$

\footnotetext{
1615 Steiner [1995] S. 197. Pauls Kritik bezieht sich vermutlich auf Heisenbergs Seminare, in denen sich die Teilnehmer wie in einem sportlichen Wettbewerb gegenseitig zu übertrumpfen versuchten. Zur Atmosphäre in Heisenbergs Seminaren siehe die Berichte von Zeitzeugen in Kleint \& Wiemers (Hrsg.) [1993]. Ein anderer Student der theoretischen Physik berichtet, er habe in der Nachkriegszeit in Göttingen neben Vorlesungen von Becker und Sauter auch eine von Heisenberg gehört, nämlich jene über spezielle Probleme der Theorie des Neutrons (WS 1950/51), doch er besuchte sie nur wenige Male, denn er habe nichts verstanden. Bei Laue habe er Relativitätstheorie gehört. Das war die schlechteste Vorlesung, die er je gehört habe. Laue konnte nicht vortragen, schrieb die Tafel voll, verhedderte sich. Am Anfang war der Hörsaal voll, zum Schluss saß er mit noch zwei oder drei anderen Studenten da. Ein anderer Student, der den Besuch der Vorlesung recht bald aufgegeben hatte, begründete dies mit Laues langweiligem Stil.

1616 Ein Student von Becker und Sauter berichtet zum Beispiel über die Atmosphäre in der theoretischen Physik, dass es recht familiär zuging. Das Seminar zur theoretischen Physik lief im kleinen Rahmen ab. Am runden Tisch saßen Becker, Sauter, Leibfried, zwei oder drei Doktoranden und zwei Studenten. Einer hielt einen Vortrag, dann gab es zur Diskussion Tee und Kekse. Das Besondere an Göttingen wurde dem Studenten bewusst, als er Sauter nach Köln folgte. Der Wechsel war für ihn wie ein Kulturschock. Die Studenten saßen
} 
Es ist also nicht zutreffend, von einem Niedergang der Lehre in der NS-Zeit zu sprechen. Doch schließt dies nicht bestimmte Veränderungen aus, auf die noch näher einzugehen ist. Schon angesprochen wurde eine Änderung im Stil der Lehre. Die stärkere Ausrichtung auf anschauliche Fassung der Physik (wie auch der Mathematik durch Physiker) stellt einen Kontrast zur bis 1933 vorhandenen, mehr formalistischen Behandlung dar. Dies gilt besonders auch für die theoretische Physik mit der Ablösung Borns durch Becker. Mit der mehr auf Anschaulichkeit ausgerichteten Lehre war auch eine Verschiebung in der Themengewichtung verbunden. Während Göttingen unter Max Born ein Zentrum der modernen Quantenmechanik gewesen war, lagen unter Becker die Schwerpunkte in der Lehre mehr auf anderen Gebieten, vor allem auf der Elektrodynamik und Thermodynamik. ${ }^{1617}$ Die besondere Qualität Beckers lag in der Art, wie er den Studenten anhand derjenigen Gebiete der Physik, die schon lange Zeit eine feste und gültige Gestalt angenommen haben (wie zum Beispiel Mechanik und Elektrizitätslehre), in die fundamentalen Gedankengänge der Physik heranführte. Auch in diesen 'alten' Gebieten der theoretischen Physik zeigt sich ein Stilunterschied zwischen Becker und zum Beispiel dem Born- und Heisenberg-Schüler Friedrich Hund. Erkennbar ist dies an Beckers kritischer Besprechung der Einführung in die theoretische Physik von Hund. Becker kritisierte, dass Hund sich zu wenig den allgemeinen physikalischen Gedankengängen widme und zu viel Raum der Entwicklung grundlegender mathematischer Techniken gewähre. "Es kann bezweifelt werden, ob auf diese Weise das Eindringen in den Stoff wirklich erleichtert wird.” Insbesondere bemängelte Becker im Kapitel Mechanik das Fehlen der "allgemeinsten Grundbegriffe wie etwa Druck oder Spannung”. ${ }^{1618} \mathrm{Zu}$ Beckers Stil gehörte es auch, dass der wesentliche Gehalt einer Theorie in einigen Sätzen qualitativ erläutert werden konnte. Falls dies nicht möglich sei, käme ihm die Theorie von vornherein verdächtig vor. Dieser Stil prägte auch die Nichtphysiker unter seinen Schülern, wie der rückblickende Bericht eines späteren Chemieprofessors belegt. ${ }^{1619}$ Becker war eine prägende Figur für seine engeren Schüler. An Döring sieht man, wie Beckers Stil weitergegeben wurde. Dörings Schüler charakterisierten seinen Vorlesungsstil wie folgt: „Jeder nur formalen Darstellung abhold, hat er ihnen [den Studenten] vorgeführt, wie man auch zunächst verwickelt erscheinende Probleme auf ihre einfachsten physikalischen

dort mit Anzug im großen Hörsaal, und der Dozent wurde mit Herr Professor angesprochen. In Göttingen wurde entschieden weniger Wert auf solche Formalitäten gelegt.

1617 Siehe zum Beispiel das Interview mit Heinz Pick, 2. Oktober 1981. NBL. Peter Urban bezeichnete Beckers Lehrbuch der Wärmelehre (Becker [1955]) in Acta phys. Austriaca 11 (1958), S. 107 als ,das beste seiner Art“. Zitiert nach Schlüpmann [http]Kap. „Endstation Heidelberg“.

1618 Becker [1950]c.

1619 Wicke [1984] S. 42. 
Grundstrukturen zurückführt und diese dann mit den Hilfsmittel der Mathematik ökonomisch behandelt.“"1620

Eine Veränderung in der Lehre betrifft die Quantität des Angebots. Deutlich weniger Vorlesungen gab es in der Zeit unmittelbar nach den Entlassungen 1933 bis die Lehrstühle und Assistentenstellen nachbesetzt waren sowie in den ersten Kriegsjahren. Aber auch in den Jahren 1936 bis 1939 war das Abgebot dünner als bis 1933, was wahrscheinlich mit den gesunkenen Studentenzahlen zusammenhing (von 1932 bis 1937 gingen die Studentenzahlen in der Physik etwa um den Faktor 3 zurück, bis 1941 um den Faktor 8). In gewisser Weise kompensiert wurde das geringe Angebot durch das günstigere Verhältnis der Zahl der Dozenten zu jener der Physikstudenten. Die Vorlesungen waren aber nicht so schlecht besucht, wie es die Entwicklung der Physikstudentenzahlen erwarten ließ. Selbst Physikspezialvorlesungen, wie die von Georg Joos im Jahr 1938 angebotenen „,angewandte Optik“ und „tiefe Temperaturen“ wurden von je 40 Studenten besucht. In diesem Semester waren insgesamt nur 48 Physikhauptfachstudenten eingeschrieben; die Vorlesungen zogen wahrscheinlich auch Studenten anderer Fächer an. ${ }^{1621}$

Wie zu Beginn dieses Abschnitts erwähnt, wird als ein Argument für den allgemeinen Niveauverlust in der Lehre die Aufgabe der Lehrfreiheit angeführt. In der Göttinger Physik ist allerdings keine besondere Einflussnahme von außen auf die Lehrinhalte festzustellen. Die ideologischen Kämpfe innerhalb der deutschen Physikerschaft, die durch die "Deutsche Physik" verursacht wurden, blieben ohne Auswirkung auf Göttingen. Es gibt keinen Hinweis, dass auch nur einer der Göttinger der "Deutschen Physik" nahe stand. Vor allem gibt es keine Anzeichen, dass sich in den einführenden Grundveranstaltungen wie der von Pohl und seinen Assistenten gehaltenen Einführungsvorlesung und den Praktika inhaltlich etwas auf Grund von politischer Einflussnahme veränderte. Die sonstigen Änderungen im Angebot an Spezialvorlesungen wie der Wegfall philosophisch orientierter Vorlesungen sind großteils auf die personellen Veränderungen im Lehrkörper zurückzuführen. Die merkliche Zunahme von technikorietierten und rüstungsrelevanten Vorlesungen ist auch nicht als Anzeichen für eine eingeschränkte Lehrfreiheit zu interpretieren, sondern scheint vielmehr auf ein patriotisches Selbstverständnis der Professoren zurückführbar zu sein, zu dem das Eintreten für ein militärisch starkes Deutschland dazu gehörte.

\footnotetext{
1620 Simon \& Zehler [1981].

1621 Joos an Kurator, 22. April 1939. UAG, Kur. XVI. V. C. h. 2. II. Zu der Entwicklung der Studentenzahlen siehe Abschnitt 2.2.
} 
Die Zusatzbelastungen der Studenten durch Arbeits- und Wehrdienst, sowie durch Dienste in Partei-Gliederungen, wirkten sich insofern auf die Lehre aus, als die Studentenzahlen zurückgingen, da das Studium damit allgemein an Attraktivität verlor. Von den geringeren Studentenzahlen auf eine qualitativ schlechtere Lehre $\mathrm{zu}$ schließen, ist allerdings problematisch, vor allem wenn man berücksichtigt, dass Anfang der dreißiger Jahre die Professoren genau umgekehrt argumentierten und auf Grund der 'Überfüllung' der Universitäten eine Qualitätsminderung der Ausbildung befürchteten. Die Göttinger Physikprofessoren waren Ende der dreißiger Jahre froh, dass das Physikstudium kein Massenstudium sei, und sie sich optimal um die einzelnen Studenten kümmern konnten.

Wenn man den Begriff Lehre etwas weiter fasst und nicht nur die Ausbildung der Studenten bis zum Examen darunter versteht, sondern auch die Ausbildung des akademischen Nachwuchses in Hinblick auf eine Universitätslaufbahn, so wird ersichtlich, dass Göttingen hierin eine hohe Qualität aufzuweisen hatte, und zwar kontinuierlich von der NS-Zeit bis in die Nachkriegszeit. Es kann hier nur angedeutet werden, welche Faktoren zu dieser guten und erfolgreichen Ausbildung geführt haben. Die Atmosphäre in den Instituten, die auch die Bereitschaft zu einem intensiven Arbeitseinsatz begünstigte, in der Nachkriegszeit mitunter zur Flucht in die Arbeit führen konnte, spielt hier eine bedeutende Rolle. Allgemein forderten die Göttinger Professoren von ihren Mitarbeitern einen hohen Standard in der wissenschaftliche Arbeit. Pohls Schüler berichten zum Beispiel, dass sie zäh, oft bis in die späte Nacht hinein arbeiteten. Um die geforderte Genauigkeit zu erreichen, mussten manche Messungen zwanzigmal und öfter wiederholt werden. „Die Arbeitszeit unterlag keiner (oberen) Beschränkung, und häufig kam Pohl nach dem Abendessen zum Besuch der Nachtarbeiter."1622 Auch im Nachbarinstitut bei Kopfermann sah die Situation ähnlich aus. Auch dort gab es bestimmte Rituale der Ausbildung. Sein Schüler Peter Brix berichtet darüber: ,Jeder Vortrag mußte etwa dreimal geprobt werden; zuletzt kam Kopfermann hinzu. Die Didaktik, der Tafelplan und die Zeit sollten stimmen; die Physik mußte restlos verstanden sein."1623 Das Verstehen der Physik war Anliegen aller Institutsmitglieder und brachte sie näher zusammen, auch im Privatleben zum Beispiel in Form gemeinsamer Urlaubsreisen. Eine besondere Art, die Physik verstehen zu wollen, kennzeichnete Kopfermanns Stil, der geprägt war „durch sein bohrendes, nie sich zufriedengebendes Prüfen aller Fragen, besonders der eigenen Ideen - »ich verstehe wieder einmal gar nichts, könnt ihr, Kinder, es mir nicht

1622 Glaser an Teichmann, 1982, zitiert nach Eckert \& Schubert [1986] S. 121.

1623 Brix [1994]a S. 1154. 
erklären?« haben seine Mitarbeiter oft gehört!“1624 Über den Menschen Kopfermann sagte Wolfgang Paul: „Er verstand es wirklich, Wissenschaft als Tätigkeit des Geistes zu lehren und verborgene Fähigkeiten in jungen Menschen zu wecken.“1625 Dass diese Eigenschaften Kopfermanns $\mathrm{zu}$ einer erfolgreichen Ausbildung des wissenschaftlichen Nachwuchses führten, beschreibt auch sehr anschaulich Walther Gerlach: „wer Kopfermanns Glück erlebt hat, wenn ihm an den runden Geburtstagen seiner Schüler und Freunde Hochschätzung entgegenschlug, hat einen unauslöschbaren Eindruck von einer seltenen Harmonie wissenschaftlicher und menschlicher Größe. Es mag als ein »quantitatives Maß« der Bedeutung dieser zwei Faktoren für den Fortgang der Wissenschaft angesehen werden, daß heute 20 - wenn nicht mehr - Kopfermann-Schüler führende Stellen in Hochschul- und Forschungsinstituten des In- und Auslandes innehaben." ${ }^{1626}$

Die Ordinarien schufen die Basis einer soliden Grundausbildung. In der Nachkriegszeit wurde diese durch zahlreiche hinzugekommene Dozenten bereichert.

\subsection{Spezielle Neuerungen im Lehrangebot nach 1945}

In diesem Abschnitt werden exemplarisch einige für die Nachkriegszeit typischen Neuerungen im Göttinger Lehrangebot der Physik besprochen. Mit der Forschungsbeschränkung der Militärregierung war eine einschneidende Veränderung im Lehrangebot verbunden, die man als negative Neuerung bezeichnen könnte: Durch die erzwungene Schließung der AVA fiel die flugspezifische Forschung und mit ihr auch die entsprechende Lehre weg. Obwohl die AVA schon 1953 wieder ihre Tore öffnete, wurde erst im WS 1955/56 mit Tragflügeltheorie (Ludwieg) wieder eine erste einschlägige Vorlesung angeboten. Aber nicht nur durch den Wegfall der AVA veränderte sich das Profil in der Lehre stark. Der Forschungsschwerpunkt verlagerte sich von der angewandten zur Grundlagenforschung. Diese Neuausrichtung der angewandten Physik in Forschung und Lehre wird in Zusammenhang mit den forschungs- und besonders personalpolitischen Hintergründen in den Abschnitten 5.4.4 und 5.5 besprochen.

Der im ersten Kapitel beschriebene Zuwachs an Personal in der unmittelbaren Nachkriegszeit wirkte sich in Form eines umfangreicheren und breiter gestreuten Lehrangebots aus. Dadurch erfuhren die Studenten auch unterschiedliche Stile in der Behandlung physikalischer Fragen.

1624 Gerlach [1965] S. 199.

1625 Zitiert nach Brix [1994]a S. 1157.

1626 Gerlach [1965] S. 199. 
Zum Beispiel konnten sie bei Vorlesungen zur Relativitätstheorie zwischen den Dozenten Becker, Sauter, Ludwig, Laue und Weizsäcker wählen. Einen deutlichen stilistischen Unterschied gab es zwischen den Vorlesungen Beckers und Ludwigs. ${ }^{1627}$ Während Becker mehr Wert auf die Grundprinzipien legte und um ein anschauliches Verständnis bemüht war, ging Ludwig stärker formalistisch vor. ${ }^{1628}$ Beckers Stil mag zwar den Anschein des Altmodischen haben, hinderte ihn aber nicht, auch moderne Vorlesungen zu halten. Ein Beispiel sind seine Quantenmechanikvorlesungen aus der Nachkriegszeit. Die folgende Einschätzung stützt sich auf den Berichte eines Physikstudenten und späteren Ordinarius, der damals Quantenmechanik bei Flügge, Rellich, Becker und Heisenberg gehört hat. Im Gegensatz zu Heisenbergs Vorlesung, die geschichtlich angelegt war und die Entstehung der Quantenmechanik mit behandelte, ging Becker gleich auf den neuesten Stand der Forschung ein. Seine axiomatisch angelegte Vorlesung, in der mehr mit Operatoren gearbeitet wurde, war fortschrittlicher als jene von Heisenberg. ${ }^{1629}$ Für den Studenten war sie sogar eine „Meisterleistung“.

Heisenberg und die anderen am Max-Planck-Institut für Physik arbeitenden Physiker boten vor allem Spezialvorlesungen für fortgeschrittene Studenten an. Ein Grund für die Vorlesungstätigkeit dieser Wissenschaftler mag unter anderem die Suche nach geeigneten Doktoranden gewesen sein. ${ }^{1630}$ Heisenberg las zum Beispiel über die Quantentheorie der Wellenfelder (WS 46/47), über Quantenmechanik (WS 48/49) und über Theoretische Wärmelehre (SS 47). Karl Wirtz deckte mit seinen Vorlesungen einen vorher wenig wahrgenommenen Bereich ab: Einführung in die Theorie der chemischen Bindungen (WS 47/48), Quanteneffekte in der Molekülphysik (SS 48), Aus der Kinetik der Flüssigkeiten (SS 49), Mesonen in der kosmischen Strahlung (WS 48/49). Über Kosmische Strahlung hielt Wirtz auch gemeinsam mit Haxel ein Seminar ab (SS 49). Haxel selbst hatte über Physik der Röntgenstrahlen (WS 49/50) gelesen, bevor er auf eine Professur in Heidelberg wechselte. ${ }^{1631}$ Auch Weizsäcker und Laue beteiligten sich an der Lehre mit physikalischen Spezialvorlesungen: Weizsäcker beispielsweise mit Quantentheorie des Elektrons und des Lichts (WS 47/48) und Relativitätstheorie (SS 53); Laue mit Theorie der Supraleitung (WS 49/50). Diese beiden übernahmen aber noch eine andere Aufgabe, die in der Nachkriegszeit

\footnotetext{
1627 Siehe zum Unterschied zwischen der Becker-Schule und Günther Ludwig den Abschnitt 1.3.5.2.

1628 Ein Student Ludwigs, der Relativitätstheorie bei beiden gehört hat, nannte Beckers Vorlesung einfachen, „alt hergebracht“. Im Unterschied zu Becker wählte Ludwig von Beginn an die Darstellung mit Indizes.

1629 Zu Beckers Beschäftigung mit der Quantenmechanik in der Nachkriegszeit siehe zum Beispiel Becker [1945]; Becker \& Leibfried [1946], [1949].

1630 Siehe Vogt [2000] S. 202.
} 
kurzzeitig einige Bedeutung erhielt: Sie engagierten sich innerhalb des studium generale und boten Vorlesungen zur Geschichte der Physik und über naturphilosophische Themen für Hörer aller Fakultäten an. Auf diese Besonderheit, die typisch für die Nachkriegszeit war, wird im Folgenden näher eingegangen.

\subsubsection{Das studium generale als Reaktion auf den Kriegsschock}

Im September 1945 behauptete der Göttinger Senat über die Lehrpraxis an der eigenen Universität, „dass ein auf das Praktische gerichteter Lehrbetrieb uns wesensfremd ist“. ${ }^{1632}$ Stattdessen war die Universität bemüht, ihren kulturellen Wert in den Vordergrund zu stellen. In der breiten Debatte um notwendige Reformen der deutschen Universitäten in der Nachkriegszeit tauchte oft die Forderung nach einem studium generale auf. Der Student sollte nicht nur in einem engen Fachgebiet ausgebildet werden, sondern er sollte auch eine Allgemeinbildung erhalten, die ihm ein Verständnis für das ganze Gebäude der Wissenschaft geben sollte. Dadurch könne er sein Fachwissen besser einordnen und Verantwortung für sein Tun als Wissenschaftler übernehmen lernen. Als gefährliche Gegenentwicklung sahen die Professoren die fortschreitende Spezialisierung in den Wissenschaften. Diese Gefahr war zwar nichts Neues, diente in der Nachkriegszeit aber auch als Abgrenzung gegen falsche Zielsetzungen des Nationalsozialismus, denen die Universitäten angeblich unterworfen worden waren. Diese Haltung der deutschen Professoren wird beispielsweise in den Entwürfen zu einer offiziellen Stellungnahme der Universität Göttingen vom Frühjahr 1945 deutlich. ${ }^{1633}$

Auch die Göttinger Naturwissenschaftler beteiligten sich in dieser Weise an der neuen Standortbestimmung der Universität. Betrachten wir als ein Beispiel hierfür die Ansichten von Arnold Eucken. Für ihn befand sich die Universität in einer Krise, da sich die Wissenschaft in "zahllose, beziehungslose Einzelfächer" verzweigt und aufgespalten hatte. Dies laufe aber der "Grundforderung der Wissenschaften nach Universalität diametral entgegen.” Ein Wesensmerkmal der Universität sei die Suche nach Wahrheit. Der Sinn von Unterricht und Forschung sei daher die geistige Formung des ganzen Menschen, denn nur auf dieser Grundlage könne Wahrheit als solche erkannt werden. Noch in einer anderen Hinsicht konkretisierte Eucken, weshalb die Ausrichtung auf das Praktische selbst in den

\footnotetext{
${ }^{1631} \mathrm{Zu}$ Haxel siehe Abschnitt 1.3.4.7.

1632 Protokoll der Senatssitzung vom 4. September 1945. UAG, Senatsprotokolle 1945-1949.

1633 Siehe hierzu die Entwürfe von Weber, Schöffler, Schmucker und Eucken, die in Abschnitt 1.3.1 besprochen wurden.
} 
Naturwissenschaften nicht genüge. Es liege nämlich ein besonderer Bildungswert in den Naturwissenschaften; vor allem die Ergebnisse naturwissenschaftlicher Forschung allgemeiner Art dienen zur Gestaltung eines Weltbildes. ${ }^{1634}$ Diese positive Funktion der Universität sei von einer fortschreitenden Spezialisierung bedroht. ${ }^{635}$ Diese an Eucken beispielhaft gezeigte Argumentation war typisch für die Nachkriegszeit.

Doch hatte die Klage um eine negativ verstandene Spezialisierung in den Wissenschaften eine lange Geschichte. Als Zeitalter der Spezialisierung wurde das 19. Jahrhundert mit seiner fortschreitenden Entwicklung der Einzelwissenschaften gesehen. Deutliche Kritik wurde schon im ersten Drittel des 20. Jahrhunderts laut, beispielsweise von José Ortega y Gasset. ${ }^{1636}$ Die Debatten in der Nachkriegszeit, die um die Rolle der Wissenschaft und der Wissenschaftler in Bezug auf die Verbrechen der NS-Zeit geführt wurden, enthielten den Vorwurf an die Hochschulen, sie hätten reine Spezialisten ausgebildet, die keinen Blick für größere Zusammenhänge mehr haben konnten. Auch Karl Jaspers behauptete, dass ein Spezialistentum zu einer Verengung des Wissens geführt habe. Deshalb konnten die Nationalsozialisten die Spezialisten leicht 'verführen'. Dieser Argumentation zu Folge müsse die Universität zur Gesundung wieder dahin gelangen, dass die „Gesamtheit unserer Welt lebendig ist im einzelnen Gelehrten“. 1637

Die Spezialisierung wurde generell als ein Merkmal der Moderne verstanden. Die Naturwissenschaftler und speziell Physiker nahmen in dieser Debatte um die Spezialisierung der Wissenschaften und die in ihr liegende Gefahr teilweise einen von ihren geisteswissenschaftlichen Kollegen abweichenden Standpunkt ein. Richard Beyler hat diese Unterschiede zwischen Geisteswissenschaftlern und Physikern herausgearbeitet. ${ }^{1638}$ Jedoch gab es auf keiner Seite ein kohärentes Bild; die Kritik setzte an unterschiedlichen Punkten an und zielte in verschiedene Richtungen. Eine gemeinsame Basis war aber die Einsicht, dass die Naturwissenschaften einer direkten Verbindung $\mathrm{zu}$ den allgemeinen kulturellen Werten

\footnotetext{
1634 Auch im Nationalsozialismus wurde von Physikern auf die 'kulturelle' Bedeutung der Physik hingewiesen. Der Heidelberger Ordinarius August Becker behauptete, grundlegende Kenntnisse in der Physik - wie sie angeblich typischerweise deutsche Physiker erforschten - seien notwendig, um potentielle Energie in Sprengstoffe zu übersetzen, kinetische Energie in Raketen, den Zusammenhalt von Molebändern in Helme und Panzer usw. Siehe Remy [2002] S. 92.

1635 Eucken [1946].

1636 Die Entwicklung der Wissenschaften zwänge den Forscher, seinen Arbeitskreis immer enger zu fassen. Ortega y Gasset befürchtete, dass dieser dadurch den Kontakt zu den übrigen Teilen der Wissenschaft verliere. Er sah die westliche Kultur, die Errungenschaften des Abendlandes in Gefahr. Als positives Bild stellte er der Spezialisierung das Idealbild des Universalgelehrten gegenüber. Die allgemeine Bildung war das höhere Gut im Vergleich zur Gelehrsamkeit in einem kleinen Bereich. Siehe Ortega y Gasset [1931] bes. Kap. XII.

1637 Jaspers zitiert nach Pfetsch [1986] S. 370.

1638 Beyler [1996]. 
bedurften. Während die Geisteswissenschaftler die Rettung in der klassischen humanistischen Bildung, im Festhalten an kultureller Tradition suchten, sahen manche Naturwissenschaftler einen Ausweg auch in einer ausgewogenen Mischung zwischen humanistischer und naturwissenschaftlicher Ausbildung. ${ }^{1639}$ Eine Abwehrstrategie gegen Vorwürfe an eine rein zweckgerichtete Naturwissenschaft bestand für Physiker in einer klaren Unterscheidung zwischen Technik und Naturwissenschaft. Die Technik habe durch ihre rein sachlichen Aufgaben zu Zerstörung und „der Katastrophe“ geführt; die Naturwissenschaft sei etwas Anderes. ${ }^{1640}$ Sie war nicht nur anwendbares, instrumentelles Wissen, sondern selbst eine Art von Humanismus. ${ }^{1641}$

Wie bereits gezeigt, wurde in der Studienreformdiskussion das studium generale als geeignetes Mittel gegen die Spezialisierung angesehen. Aber so, wie das vermeintliche Problem ein altes war, so war es auch dieser Lösungsansatz. In seinen „Gedanken zur Hochschulreform“ von 1919 forderte der spätere Preußische Kultusminister Carl Heinrich Becker eine universitäre Erziehung, die statt zum partikularistischen Denken zum Allgemeinen und Universalen ausgerichtet sei. ${ }^{1642}$ Das studium generale erfülle diese Aufgabe in der Weimarer Republik in Form von Vorlesungen für Hörer aller Fakultäten. Auch zu Beginn des Nationalsozialismus waren solche Vorlesungen Teil einer Studienreform. ${ }^{1643} 1945$ wurde eine zusätzliche, nichtspezialisierte Ausbildung aufs Neue als Lösungsweg vorgeschlagen. Es scheint, als sei dies eine typische akademische Reaktion auf politische Umbrüche gewesen. Die Inhalte des zusätzlichen Angebots legten zu jeder Zeit die vortragenden Professoren fest, ohne an bestimmte Richtlinien gebunden $\mathrm{zu}$ sein. Die Göttinger Vorlesungsverzeichnisse zeigen, wie breit und unterschiedlich das Angebot war. In dieser Vielfalt fand allerlei Platz, auch philosophisch ausgerichtete Vorlesungen naturwissenschaftlicher Themen, zeitgemäßes wie unzeitgemäßes (siehe Tabelle 20). So liest man beispielsweise: Menschliche Abstammungslehre und Rassenkunde, Erbberatung und Eheberatung, Menschliche Erblichkeit und Rassenhygiene, Der Untergang des Abendlandes, biologisch gesehen, Das Bevölkerungsproblem, Aktuelle Fragen der Soziologie in

\footnotetext{
1639 Gerade in Krisenzeiten schienen humanistische Werte eine Trost spendende Kraft besessen zu haben. Der theoretische Physiker Buchwald ordnete seinen Vortrag über die Geschichte der Deutschen Physikalischen Gesellschaft 1944 unter die fünf Überschriften von Goethes Stanzen „Urworte orphisch“. Hermann [1995] S. F103.

1640 Siehe hierzu das Beispiel Friedrich Hund bei Beyler [1996] S. 395.

1641 Siehe hierzu das Beispiel Clemens Münster bei Beyler [1996] S. 396. In der Nachkriegszeit verstärkte sich die Auffassung, physikalisches Wissen als Kulturgut zu verstehen. Das ging so weit, dass man in der Physik auch dann einen kulturellen Wert erkannte und die entsprechenden populärwissenschaftlichen Physikbücher kaufte, wenn man die Inhalte der Physik nicht mehr verstand. Siehe Carson [2003].

1642 Schneider [1983] S. 56.
} 
biologischer Sicht. Das ist zugegebenermaßen keine repräsentative oder ausgewogene Auswahl des Vortragangebots. Allgemein signalisieren nur die wenigsten Titel eine deutlich rassistische Themenbehandlung. Das Bemerkenswerte an der hier präsentierten Liste ist, dass keiner der Vorträge aus der NS-Zeit stammt. Vielmehr sind sie abwechselnd den Vorlesungsverzeichnissen aus der Zeit davor und danach entnommen (1931-32 und 1947$50)$.

Ein indoktrinierender Charakter der öffentlichen Vorlesungen kam besonders in der Frühphase des Nationalsozialismus zur Geltung. Als wollte die Universität Göttingen die Studenten mit einer neuen weltanschaulichen Ideologie impfen, gab sie der öffentlichen Vortragsreihe im WS 1933/34 den Titel „Rasse, Volk und Staat“. Einen gleichnamigen Vortrag hielt in dieser Reihe der Völkerkundler und spätere NS-Rektor, Hans Plischke; andere Vorträge behandelten Rassenhygiene, die Gestaltung des Volkskörpers durch Erbgut, Abstammungstheorie und Weltanschauung, wehrpolitische Fragen und ähnliches. Neben 16 Vorträgen innerhalb dieser Reihe gab es noch 50 weitere Vorlesungen für Hörer aller Fakultäten, bei denen teilweise wieder Rassenkunde und Rassenhygiene des deutschen Volkes das Thema war. Herman Nohl las über nationale Erziehung und Oberst a. D. Bernhard Schwertfeger über Wehrwissenschaft. ${ }^{1644}$ Das Ziel dieser Vorlesungen und speziell der erstgenannten Vortragsreihe erscheint naheliegend, galt es doch, die neue Weltsicht wissenschaftlich zu legitimieren und den Studenten eine 'Orientierung' zu geben. Nach zwölf Jahren Diktatur sollte die Jugend aufs Neue umerzogen werden, wobei die deutschen Professoren mehrheitlich ein humanistisches Bildungsideal als Rettung empfanden. Es bleibt fraglich, inwieweit das neue Weltbild, das den Studenten vermittelt werden sollte, ein demokratisches war. Die Begründungen der öffentlichen Vorlesungen waren einem akademisch aristokratischen Selbstverständnis verpflichtet. ${ }^{1645}$ Zusätzlich zur methodischen Ähnlichkeit der weltanschaulichen Einflussnahme auf die Studenten waren auch die beteiligten Professoren nach den politischen Umbrüchen 1933 wie 1945 teilweise dieselben geblieben. Im WS 1945/46 las beispielsweise Herman Nohl über Wilhelm Dilthey. ${ }^{1646}$ Der Zweck der öffentlichen Vorlesungen war beide Male, eine breitere Ausbildung zu erreichen, nur die Richtung unterschied sich erheblich.

\footnotetext{
1643 Krönig \& Müller [1990] S. 200f.

1644 Dem Kriegsgeschichtler Schwertfeger verlieh die philosophische Fakultät 1928 den Ehrendoktortitel. Siehe Dahms [1987/98] S. 34.

1645 Zur Betonung dieser Tradition beschloss der Senat im April 1946 die „Dr.-Diplome wieder lateinisch“ auszustellen und zur Verkündung des Rektorwechsels wieder einen lateinischen Aushang anzubringen. Protokoll der Senatssitzung vom 10. April 1946. UAG, Senatsprotokolle 1945-1949.
} 


\begin{tabular}{|c|c|}
\hline Semester & Vorlesungen für Hörer aller Fakultäten \\
\hline WS $31 / 32$ & $\begin{array}{l}\text { Einleitung in die Philosophie auf Grund moderner Naturwissenschaft (Hilbert) } \\
\text { Kosmogonie (Kienle) }\end{array}$ \\
\hline SS 32 & Die mathematisch-physikalische Erkenntnisweise (Weyl) \\
\hline WS $32 / 33$ & $\begin{array}{l}\text { Grundlagen der Logik, allgemeinverständlich (Hilbert) } \\
\text { Probleme und Methoden der Mathematik (Courant) } \\
\text { Unterhaltungsmathematik (Lietzmann) }\end{array}$ \\
\hline SS 33 & $\begin{array}{l}\text { Das Unendliche in der Mathematik (Hilbert) } \\
\text { Unsere Stellung zum Weltganzen (Kienle) } \\
\text { Moderne Strömungen in der Wissenschaft der unbelebten Natur (Born) } \\
\text { Wissen und Denken (Hilbert) } \\
\text { Grundlagen der Analysis: Das Rechnen mit ganzen, rationalen, irrationalen, komplexen Zahlen } \\
\quad \text { (Landau) } \\
\text { Die mathematische Denkweise, erläutert an typischen Beispielen (Courant) } \\
\text { Mathematik und bildende Kunst (Lietzmann) }\end{array}$ \\
\hline WS $33 / 34$ & $\begin{array}{l}\text { Wetter und Wettervorhersage (Angenheister) } \\
\text { Die Bedeutung der Chemie für die heutigen wirtschaftlichen Aufgaben (Wedekind) }\end{array}$ \\
\hline SS 34 & Technik der Römer, mit besonderer Berücksichtigung deutscher Altertümer (Kyropoulos) \\
\hline WS $45 / 46$ & $\begin{array}{l}\text { Physikalische und biologische Grundlagen der Strahlentherapie (Kepp, Witt) } \\
\text { Die Lösung technischer Probleme im lebenden Organismus (Rein) } \\
\text { Die Bedeutung chemischer Forschung für Biologie und Medizin (N.N.) } \\
\text { Sterne, Nebel und Weltall (ten Bruggencate) }\end{array}$ \\
\hline SS 46 & $\begin{array}{l}\text { Das Wesen des mathematischen Problems (Lyra) } \\
\text { Aus der Welt der Atome (N.N. oder Kopfermann) } \\
\text { Die Geschichte der physischen Welt (Weizsäcker) }\end{array}$ \\
\hline WS $46 / 47$ & $\begin{array}{l}\text { Übersicht über Methoden und Ergebnisse der Physik (Flügge) } \\
\text { Entstehung und Schicksale chemischer Entdeckungen (Brockmann) } \\
\text { Anschauliche Mathematik (Kaluza) } \\
\text { Aus der Geschichte der Physik (Flügge) } \\
\text { Geschichte der Biologie in Übersicht (Schmucker) }\end{array}$ \\
\hline SS 47 & $\begin{array}{l}\text { Kernphysikalische Anwendungen in Medizin und Biologie (Schubert) } \\
\text { Lebensbilder großer Naturforscher (Eucken) } \\
\text { Sonne und Erde (Bartels) }\end{array}$ \\
\hline WS $47 / 48$ & $\begin{array}{l}\text { Sterne, Nebel, Weltall (ten Bruggencate) } \\
\text { Aus der Geschichte der Physik (Laue) } \\
\text { Geschichte der Chemie und Pharmazie, II. Teil (Lockemann) } \\
\text { Ausgewählte Kapitel aus der Geologie der Ozeane (Andrée) } \\
\text { Aus der Geschichte der Mineralogie, Geologie und Physischen Geographie, II. Teil (Andrée) } \\
\text { Geschichte der Geographie (Creutzburg) }\end{array}$ \\
\hline SS 48 & $\begin{array}{l}\text { Aus der Geschichte der Physik (Laue) } \\
\text { Lebensbilder großer Naturforscher und Techniker (Eucken) } \\
\text { Geschichte der Geographie im 19. Jahrhundert und bis zur Gegenwart (Creutzburg) } \\
\text { Geographie weltpolitisch wichtiger Gebiete, Fortsetzung (Mortensen) }\end{array}$ \\
\hline WS 48/49 & Das Atom (Weizsäcker) \\
\hline SS 49 & $\begin{array}{l}\text { Aus der Geschichte der Physik (Laue) } \\
\text { Vorlesungsreihe „Grundlegende Tatsachen der heutigen Naturwissenschaft“: } \\
\text { Physik und Biologie (Pohl) } \\
\text { Die Realität der Molekeln (Eucken) } \\
\text { Das periodische System der Elemente (Goubeau) } \\
\text { Organische Moleküle (Brockmann) } \\
\text { Gesetz und Zufall in der Physik (Becker) } \\
\text { Ordnung und Unordnung in den Kristallen (Correns) } \\
\text { Physik der Sonne (ten Bruggencate) } \\
\text { Sonne und Erde (Bartels) }\end{array}$ \\
\hline
\end{tabular}

$1646 \mathrm{Zu}$ Nohl und seiner Nachkriegskarriere siehe Linnemann [2002].

1647 Die zuerst genannten Vorträge von Hilbert, Kienle und Born fanden im Rahmen der öffentlichen

Vorlesungsreihe „Die geistige Lage der Gegenwart im Spiegel der Wissenschaft“ statt. 


\begin{tabular}{|c|c|}
\hline & $\begin{array}{l}\text { Bewegungen der Erdkruste (Bederke) } \\
\text { Pflanzen und Hormone (Harders) } \\
\text { Die Pflanzendecke seit der Eiszeit (Firbas) } \\
\text { Die Sprache der Tiere (Autrum) }\end{array}$ \\
\hline WS 49/50 & $\begin{array}{l}\text { Das Gesetz der Wüstenbildung (Mortensen) } \\
\text { Vorlesungsreihe „Grundlegende Tatsachen der heutigen Naturwissenschaft“: } \\
\text { Die Pflanzendecke seit der Eiszeit (Firbas) } \\
\text { Die Grenzen der Lebewesen (Rippel) } \\
\text { Die Entstehung der Individualität in der Entwicklung des Tierkörpers (Henke) } \\
\text { Vererbung und Züchtung (Rudorf) } \\
\text { Ökonomie und Veredelung der Nährstoffe (Lenkeit) } \\
\text { Die Bedeutung des Wirkungsgrads lebender Organe und Gewebe für die physiologische } \\
\quad \text { Forschung (Rein) } \\
\text { Stoff und Energie (Feher) } \\
\text { Physik und Technik des Ultraschalls (Meyer) } \\
\text { Werden und Wirken der Wirbel in Flüssigkeits- und Gasströmungen (Tollmien) } \\
\text { Die Elektronenschleuder und ihre Anwendung in Physik und Medizin (Kopfermann) } \\
\text { Kosmische Höhenstrahlung (Haxel) } \\
\text { Das Alter der Erde (Houtermans) }\end{array}$ \\
\hline SS 50 & Der biblische Wunderglaube und die Naturwissenschaft (Lyra) \\
\hline WS 50/51 & Sterne und Nebel (Haffner) \\
\hline WS 51/52 & Feldtheorien (Weizsäcker) \\
\hline WS 53/54 & $\begin{array}{l}\text { Sterne und Atome (Biermann) } \\
\text { Kinetik der Erregungsvorgänge (Bonhoeffer) }\end{array}$ \\
\hline WS 54/55 & Kants Theorie der Entstehung des Planetensystems (1755) (Weizsäcker) \\
\hline
\end{tabular}

Tabelle 20 Vorlesungen naturwissenschaftlichen Inhalts für Hörer aller Fakultäten, 19311955.

Der Begriff studium generale fasst eine ganze Reihe unterschiedlicher Aktivitäten mit leicht differierenden Zielsetzungen zusammen. Neben Vorlesungen für Hörer aller Fachrichtungen versteht man darunter auch Einrichtungen wie den dies academicus, Ringvorlesungen, Arbeitskreise, besondere Studentenheime und Kolloquia. Als drei Haupttendenzen lassen sich wissenschaftliche, gesellschaftliche und politische Zielrichtungen unterscheiden. ${ }^{1648}$ Jede Hochschule gestaltete ihr individuelles studium generale, das selten fest institutionalisiert wurde und deren Teilnahme den Studenten meist freigestellt blieb. ${ }^{1649}$ In Göttingen bestand es aus den Vorlesungen für Hörer aller Fakultäten. Besonders großen Zustrom fanden die Veranstaltungen des Philosophen Nicolai Hartmann und des Physikers Carl Friedrich Weizsäcker. Wie Tabelle 20 zeigt, beteiligten sich die Dozenten der Naturwissenschaften in beträchtlichem Ausmaß am studium generale. Beispielsweise brachte Eucken in seiner Vorlesung über Lebensbilder großer Naturforscher den fachfremden Studenten die

1648 Killy [1952] bes. S. $19 f$.

1649 Eine institutionalisierte Form erhielt das studium generale an den Universitäten Freiburg und Münster, sowie an der TH Berlin; siehe Killy [1952]. In Heidelberg gab es als eine Einrichtung des studium generale das Collegium Academicum, das als Mittel zur politischen und Persönlichkeitsbildung verstanden wurde. Zur geringen Präsenz des studium generale in Heidelberg siehe Pfetsch [1986] S. 376. 
Errungenschaften der Naturwissenschaften in biografischer Aufbereitung nahe. ${ }^{1650}$ Diese Methode ist in ihren Inhalten recht flexibel. Die NS-Schulpolitik versuchte eine Propaganda zugunsten der Bedeutung deutscher Forscher in den Schulunterricht einzubringen, wozu eine nationale Wissenschaftsgeschichte in biografischer Form dienen sollte. ${ }^{1651}$ Selbst wenn vermutlich in Euckens Vorlesung auch deutsche Forscher gewürdigt wurden, so soll damit nicht unterstellt werden, dass sie eine nationalsozialistische Ausrichtung hatte. ${ }^{1652}$ Ohne genaue Kenntnis des Vorgetragenen lässt sich schlechterdings nichts über den Wert der Vorlesung im Rahmen der Re-education sagen. Das Engagement für das studium generale war auch auf Seiten der Studenten deutlich vorhanden. Das Interesse der Studenten der Naturwissenschaften an geisteswissenschaftlichen Vorlesungen richtete sich vor allem auf Philosophie und Geschichte. ${ }^{1653}$ Eine große Anziehungskraft besaß daneben die Theologie. So finden sich in einem Studienbuch eines Hauptfachstudenten der Physik auch theologische Vorlesungen wie Die Kirche und Die Lehre von der Schrift (beide Gogarten, ${ }^{1654}$ WS 45/46 und SS 46), Die Theologie Karl Barths (Wiesner, ${ }^{165}$ SS 46), Calvin und der Calvinismus (Weber, ${ }^{1656}$ SS 47). ${ }^{1657}$

Neben den allgemeinen öffentlichen Vorlesungen ohne thematische Bindung gab es in Göttingen auch eine öffentliche, politisch-historische Vorlesungsreihe, auf die nach Senatsbeschluss vom November 1947 künftig „eindringlicher“ hingewiesen wurde, sodass diese Reihe im Vorlesungsverzeichnis ab dem WS 1947/48 gleich an erster Stelle besonders angekündigt wurde. In dieser Vorlesungsreihe sprachen auch Minister und ausländische Wissenschaftler. ${ }^{1658}$ Im SS 1949 und im WS 1949/50 gab es eine von der mathematischnaturwissenschaftlichen Fakultät angebotene Vorlesungsreihe über Grundlegende Tatsachen der heutigen Naturwissenschaft (siehe Tabelle 20). Die Hochzeit des studium generale in Göttingen begann mit dem Kriegsende und dauerte bis in die frühen fünfziger Jahre. Danach nahm das Interesse wie das Angebot ab. Noch in die Aufschwungsphase fiel die 1947 erfolgte Gründung der Zeitschrift Studium Generale, die unter anderem von den Göttinger Professoren

\footnotetext{
1650 Zur Bedeutung einer hagiografischen Wissenschaftsgeschichte in dieser Zeit siehe Abschnitt 4.2.3.

1651 Siehe Bäumer-Schleinkofer [1994] S. 288f.

1652 Wahrscheinlich war Johannes Kepler einer der 'großen Naturforscher', die Eucken in der Vorlesung vorstellte. Jedenfalls beschäftigte er sich im Krieg näher mit ihm, wie Eucken [1940] belegt.

1653 Siehe Krönig \& Müller [1990] S. 202.

1654 Friedrich Gogarten, Professor für systematische Theologie.

1655 Werner Wiesner, Professor für systematische Theologie.

1656 Otto Weber, Professor für reformierte Theologie.

1657 Das Studienbuch wurde mir dankenswerter Weise von einem damaligen Studenten zur Verfügung gestellt.
} 
Rein, Smend und Weizsäcker herausgegeben wurde. Die in der ersten Ausgabe enthaltene Begründung für die Zeitschriftsgründung bedient sich derselben Argumente, die wir schon kennengelernt haben. Das erste Heft beginnt mit einem Aufsatz von Weizsäcker, der den Titel Das Experiment trägt. Ausgehend von naturwissenschaftlichen Überlegungen gelangt er zu grundsätzlichen moralischen und religiösen Fragen. ${ }^{1659}$ Weizsäcker war eine der aktivsten Figuren in der Diskussion um das studium generale nach 1945. Er beteiligte sich auch an der Ausarbeitung des sogenannten Blauen Gutachtens zur Hochschulreform aus dem Jahr 1948. Es wird stark vermutet, dass er der Autor des dortigen Abschnittes über das studium generale ist. ${ }^{1660}$ Auf diesen sieben Seiten begegnen uns dieselben Sorgen um das „Zeitalter äußerster [...] Spezialisierung“ und dieselben Hoffnungen an eine allgemeine Bildung. Weil Weizsäcker in Göttingen eine bedeutende Rolle spielte, und seine Vorlesung zur Geschichte der Natur im nächsten Abschnitt näher besprochen wird, seien hier zentrale Passagen seiner Argumentation für ein studium generale wiedergegeben:

„Es ist außerdem eine vornehme Pflicht der akademisch gebildeten Menschen, sich in besonderem Maße für die Gestaltung unserer Übergangszeit und für die Wahrung und Verbreitung der unveräußerlichen Güter der abendländischen Kultur verantwortlich zu fühlen. [...] Hochgradiges Spezialistentum aber, selbst wenn es entsprechend der technisch-fachwissenschaftlichen Differenziertheit unseres Zeitalters in engem Konnex mit der Forschung in Fakultäten, Technischen Hochschulen und Instituten auftritt, erfordert in verstärktem Maße jenes Wissen um die allgemeinen Zusammenhänge, wenn es nicht zu einer sinnlosen Isolierung einzelner Fach- und Berufsgruppen und damit zu einer unheilvollen Aufspaltung und Vernichtung des abendländischen Kulturerbes führen soll. [... Es ist notwendig,] den jungen Akademikern [... die] religiösen Fundamente des gesellschaftlichen Zusammenlebens zum Bewußtsein $\mathrm{zu}$ bringen. Ohne tiefe ethische Bindung droht alles Menschenwerk und der Fortschritt der Wissenschaft in einer Hybris zu enden und der Selbstvernichtung preisgegeben zu sein." 1661

Wenn man Weizsäcker wörtlich nimmt, so war für ihn das studium generale ein Mittel zur Rettung des abendländischen Kulturerbes. In Göttingen beteiligte er sich selbst an diesem

\footnotetext{
1658 Die einzelnen Vorträge wurden durch extra Aushang angekündigt und nicht im Vorlesungsverzeichnis angeführt. Siehe auch das Protokoll der Senatssitzung vom 12. November 1947. UAG, Senatsprotokolle 19451949.

1659 Weizsäcker [1947]a Er schließt den Aufsatz mit der Vermutung, dass es in dem „großen Experiment“, das die Neuzeit darstellt, ,nur auf die Liebe“ ankomme. Zur Bedeutung der Liebe, die hier als christliche Liebe zu verstehen ist, in Weizsäckers Denken siehe den folgenden Abschnitt 4.2.2.

$1660 \mathrm{Zu}$ dieser Vermutung siehe Phillips [1995] S. 65.

1661 Aus dem Gutachten zur Hochschulreform von 1948, zitiert nach Phillips [1995] Anhang, S. 78. Eine ähnliche Argumentation für die Notwendigkeit eines Wissens um allgemeine Zusammenhänge findet sich bereits bei Weizsäcker [1945/83]a bes. S. 222.
} 
Programm. ${ }^{1662}$ Die Universität ernannte ihn zum Honorarprofessor, weil er nicht nur über theoretische Physik, sondern auch über ,,allgemeinere naturwissenschaftliche Probleme [...] für einen grösseren Kreis von Studierenden“ ungewöhnlich erfolgreich Vorlesungen halten konnte. Die Fakultät hoffte auch, die kommende Lücke auf dem Gebiet der Geschichte der Naturwissenschaften durch den sich damals abzeichnenden Weggang von Siegfried Flügge, mit Weizsäcker wieder schließen zu können. ${ }^{1663}$ Diese Wünsche erfüllten sich nicht, da Weizsäcker, wie er selbst sagte, „erst noch gründlichere Studien treiben“ müsse, um eine Geschichte der Physik lesen zu können. ${ }^{1664}$ Statt Weizsäcker übernahm dann Laue diese Aufgabe, jedoch verglichen mit Weizsäckers Vorlesungen weit weniger erfolgreich (siehe Abschnitt 4.2.3).

Wie im Abschnitt 1.3.6.1 gezeigt, wünschten manche Emigranten, dass Weizsäcker aus politischen Gründen nicht vor jungem Publikum vortragen sollte. Die Göttinger nahmen einen gegenteiligen Standpunkt ein. Die Argumentation der Fakultät, warum Weizsäcker politisch unbedenklich sei, benutzt eine fragwürdige politische Rechtfertigung Heisenbergs in bedenklicher Übertragung auf Weizsäcker:

„Nach Ansicht der Fakultät liegen gegen Professor v. Weizsäcker keinerlei politische Bedenken vor. Prof. v. W. gehörte längere Zeit und gehört auch jetzt wieder dem engsten Mitarbeiterstab Professor Heisenbergs an, der, wie erinnerlich vor dem Krieg schweren politischen Angriffen seitens des »schwarzen Korps« und der SS ausgesetzt war." 1665

Diese nichtssagende Stellungnahme zu Weizsäckers politischer Haltung ist insofern typisch für die Zeit der Persilscheine, als in ihr fast beliebig herbeigezogenene 'Argumente' eine Aussage über die politische Dimension der Handlungen der betreffenden Person ersetzten und sogar als inhaltlich gleichwertiger Ersatz dafür dargestellt wurden. Am 28. September 1946 genehmigte die Militärregierung die Beschäftigung Weizsäckers. ${ }^{1666}$ Die Physikordinarien waren der Auffassung, dass Weizsäckers wie auch Heisenbergs Ernennung zum

\footnotetext{
1662 Schon im WS 1944/45 hat er in Straßburg eine Vorlesung über Naturphilosophie angekündigt, die aber nicht mehr stattfinden konnte. Siehe Kant [1997] S. 25.

1663 Dekan Eucken an Weizsäcker, 18. Oktober 1946 und Eucken an Ministerium für Volksbildung, Kunst und Wissenschaft, 4. November 1946. GPAMNFG, Lehrkörper (ausgeschieden), Weizsäcker. Im SS 1946 erhielt Weizsäcker für die öffentliche Vorlesung Geschichte der physikalischen Welt als Ausgleich für die ausbleibenden Kolleghonorare eine einmalige Pauschalvergütung von vermutlich RM 600. Einen entsprechenden Antrag stellte Eucken am 2. April 1946 an den Kurator. GPAMNFG, Lehrkörper (ausgeschieden), Weizsäcker.

1664 Weizsäcker an Dekan Eucken, 29. Oktober 1946. GPAMNFG, Lehrkörper (ausgeschieden), Weizsäcker. 1665 Dekan Eucken an Rektor, 24. Mai 1946. GPAMNFG, Lehrkörper (ausgeschieden), Weizsäcker. 1666 Laut Auskunft des Kurators vom 14.Oktober 1946. GPAMNFG, Lehrkörper (ausgeschieden), Weizsäcker.
} 
Honorarprofessor eine „ganz ungewöhnliche Bereicherung“ für den Lehrplan war. ${ }^{1667}$ Ungewöhnlich war die Bereicherung im Falle Weizsäckers auch deshalb, weil er in seinen öffentlichen Vorlesungen mit naturwissenschaftlichen Themen den jungen Akademikern auch die religiösen Fundamente des gesellschaftlichen Zusammenlebens zum Bewusstsein bringen wollte. In der bisherigen Forschung wurde Weizsäckers Einsatz in dieser Richtung weitgehend unkritisch behandelt. Seine Vorlesung über die Geschichte der Natur gilt ihr als großes Ereignis. ${ }^{1668}$ Dass Weizsäcker darin aber auch auf problematische Weise mit der deutschen Geschichte umging, wird verschwiegen. Der folgende Abschnitt wird daher auf diesen Aspekt besonderes Gewicht legen.

\subsubsection{Weizsäckers Geschichte der Natur}

Der große Zuspruch, den Weizsäckers Vorlesung über die Geschichte der physikalischen Welt für Hörer aller Fakultäten im SS 1946 erfuhr, hing besonders mit der Person Weizsäckers zusammen. ${ }^{1669}$ Das Thema für sich genommen ließ mit seinem Bezug auf die physikalische Welt nicht unbedingt eine neue Standortbestimmung nach dem Ende des Nationalsozialismus erwarten. Doch das Bedürfnis nach neuer Orientierung war in großem Maß vorhanden, und Weizsäcker berücksichtigte und befriedigte es in seiner Vorlesung. ${ }^{1670}$ Darauf beruhte meiner Ansicht nach sein Erfolg. Weizsäcker integrierte den Menschen in eine Naturgeschichte, um die Probleme seiner Gegenwart auf weitgehend naturwissenschaftliche Weise abzuleiten. Sowohl das Thema wie auch Weizsäckers Rolle als Physiker suggerierten eine sachliche, objektive Behandlung, die ihrerseits eine naturwissenschaftliche, vernunftgeleitete Orientierung erhoffen ließ. Weizsäcker bezog sich gleich in seinen einleitenden Worten auf das Bedürfnis der Studenten nach einem „Weltbild [...], das uns in der Verworrenheit unseres Daseins einen Halt böte." 1671

\footnotetext{
1667 Becker und Kopfermann an Dekan Eucken, 3. Oktober 1946. GPAMNFG, Lehrkörper (ausgeschieden), Weizsäcker.

1668 Kertz [1986] S. 37; Krönig \& Müller [1990] S. 202.

1669 Ein Student berichtete: „Weizsäcker kam 1946 nach Göttingen, es hatte sich wie ein Lauffeuer herumgesprochen, daß man dahin gehen mußte. Wir hörten damals die Geschichte der Natur. Der Raum war so brechend voll - alles, alles kam da hin.“ Zitiert nach Krönig \& Müller [1990] S. 202.

1670 Das Bedürfnis nach neuer Orientierung wurde von Weizsäcker zwar den Studenten in den Mund gelegt, dürfte aber bei ihm selbst in gleichem Maß vorhanden gewesen sein. Die Geschichte der eigenen Familie dürfte bei Weizsäcker Fragen nach dem Verhältnis eines bürgerlich liberalen Weltbildes zum Nationalsozialismus aufgeworfen haben. Er suchte anscheinend nach einer vom Nationalsozialismus unbelasteten Basis der eigenen Überzeugungen.

1671 Weizsäcker [1948/56] S. 5.
} 
Die vorwiegend nationalkonservativ eingestellte Studentenschaft ${ }^{1672}$ fand in Weizsäcker eine willkommene Leitfigur. Die Studenten strömten in diese Vorlesung. Die Physiker unter ihnen hatten den Vorteil, dass sie sich vom Institut Hocker organisieren konnten, um im völlig überfüllten Hörsaal sich einen zusätzlichen Sitzplatz zu verschaffen. Versuche, durch Radioübertragung in Nebenräume die Vorlesung einem größeren Publikum zugänglich zu machen, scheiterten. Man wollte Weizsäckers Sprachklang und Gestik direkt erleben. Ein männlicher Interviewpartner merkte an, dass diese Veranstaltung auch von Frauen besucht wurde. Im Gegensatz zu Physik-Spezialvorlesungen, an denen allein schon wegen der schwindenden Physikstudentinnenzahlen in der Nachkriegszeit kaum Frauen teilnahmen, waren Weizsäckers allgemeine Vorlesungen eben auch für Frauen gedacht. ${ }^{1673}$

Wie konnte Weizsäcker der Suche nach Orientierungsmarken der Studenten mit Vorträgen über die Geschichte der physikalischen Welt gerecht werden? In 12 Vorträgen spannte er den Bogen von den Ursprüngen des Universums bis zur Notwendigkeit der Religion als letzten Ausweg in der modernen Welt. ${ }^{1674}$ Wie zu zeigen sein wird, waren diese Vorträge als Reaktion auf den Nationalsozialismus entstanden. Weizsäcker suchte einen Umgang mit der durch die Shoah und den verlorenen Krieg geschaffenen Situation, doch er spricht dieses Motiv an keiner Stelle explizit aus. Ich werde im Folgenden die wesentlichen Abschnitte kurz darstellen, in denen zwischen den Zeilen der Versuch einer Geschichtsbewältigung unternommen wurde. Meiner Interpretation liegt sein aus den Vorträgen entstandenes, erstmals 1948 publiziertes Buch Die Geschichte der Natur zu Grunde. Die dort versammelten Gedankengänge finden sich zum Teil schon in früheren Schriften Weizsäckers, auf die ich in der Deutung der Vorlesung zurückkommen werde. ${ }^{1675}$

1672 Laut Maßß [1998]; siehe auch Abschnitt 2.3.1.

1673 Weizsäckers Vorlesungen für Hörer aller Fakultäten zogen eine bestimmte Schicht von Studentinnen aus reichem Elternhaus an, weshalb sie von den Physikstudenten scherzhaft „Pelzmantelkolleg“ genannt wurden. 1674 Im ersten Vortrag legte Weizsäcker die Ziele seiner Unternehmung dar: „Ich fordere Sie auf, mit mir in dieser Vorlesung von unserem Standort als Menschen der Gegenwart aus schrittweise in die fernste Vergangenheit zurückzukehren, die uns bekannt geworden ist. Von dort aus wollen wir dann wieder schrittweise die Entstehung unserer Welt verfolgen, bis wir den Boden gedanklich nachgebaut haben, auf dem wir heute stehen und von dem wir ausgegangen sind.“ An anderer Stelle schreibt er: „Wir versuchen nun, vom äußersten Punkt der kosmischen Geschichte durch die Stufen des Werdens der Gestalten zu unserem heutigen menschlichen Standort zurückzufinden.“ Und etwas später: „Erst wenn wir die Naturgeschichte bis zum Menschen fortführen, zeigt sich, daß wir nach uns selbst fragen, wenn wir nach der Natur fragen. Es zeigt sich aber auch, daß es sinnvoll ist, den Umweg über die Natur zu gehen, wenn die Fragen nach uns selbst uns bedrängen." Weizsäcker [1948/56] S. 14, 53, 104.

1675 Siehe Weizsäcker [1943]a bes. das Kapitel Die Unendlichkeit der Welt. Sehr aufschlussreich sind auch seine Geschichtskonstruktion, Weizsäcker [1945/83]a, und seine Beurteilung des deutschen Geistes, Weizsäcker [1945/83]b, sowie ein später geschriebener, unbeendeter Brief über den Nationalsozialismus, Weizsäcker [1952/83]. 
Weizsäcker betrachtete die Beschäftigung mit der Geschichte als notwendig, denn in ihr sind die Tatsachen geschaffen worden, die die Gegenwart bestimmen: „die Geschichte ist das Schicksal."1676 Weizsäcker meinte in diesem Zusammenhang vor allem die Geschichte der natürlichen Welt, aus der der Mensch hervorgegangen ist. Dieser Zugang wird dadurch gerechtfertigt, dass es für ihn keinen prinzipiellen Bruch in der Naturgeschichte von den Anfängen des Universums, der Entstehung von einfachsten Lebewesen bis zum Auftauchen des Menschen gab. Die Geschichte der Natur ist in dieser Sicht geprägt durch Naturgesetze, denen sowohl die unbelebte Natur wie alle Lebewesen unterliegen. ${ }^{1677}$ In der Konstruktion dieser Geschichte bediente er sich einer naturwissenschaftlichen Methode. ${ }^{1678}$ Die Behauptung, dass eine derart konstruierte Geschichte unser Schicksal sei, kann als eine Relativierung der menschlichen Verantwortung verstanden werden; auf die Frage, in welcher Weise der Mensch Verantwortung zu tragen habe, kam Weizsäcker am Ende seiner Vorlesung noch zu sprechen.

Die Probleme der Menschheit wurden laut Weizsäcker verursacht durch den von Darwin behaupteten ständigen Kampf ums Dasein. Aus dem Darwinismus, der naturwissenschaftlichen Gesetzmäßigkeit des Lebens, leitete Weizsäcker auch menschliche Verhaltensweisen ab: „Das Leben entwickelt sich weiter, weil jedes lebende Wesen auf der Schwelle des Todes steht. In dieser paradoxen Lage ist das Individuum: Es tötet, um zu leben, und lebt, um zu sterben. [...] Und dies ist nicht nur ein objektiver Vorgang an fernliegenden physikalischen Gebilden. Es ist unser Schicksal“..1679 Weizsäcker betonte immer wieder die 'natürliche Selbstverständlichkeit' des Tötens. Das dürfte zum Erfolg seiner Vorlesung beigetragen haben. Die zahlreichen, gerade aus dem Krieg heimgekehrten Studenten konnten

1676 Weizsäcker [1948/56] S. 11.

1677 Siehe auch Fußnote 1674. Auch der Mensch unterliege dem „Zweck“ der Natur: „Der letzte Zweck der Organe, den wir nachweisen können, scheint stets die Erhaltung des Individuums oder der Art zu sein. Wenn zu irgendeinem Zeitpunkt viele Arten von Lebewesen in den Kampf ums Dasein eintreten, so bleiben schließlich sicher die in diesem Sinne zweckmäßigsten übrig. Zweckmäßigkeit ist damit also zu einem objektiven Begriff geworden. Die Zwecke der Natur sind wirklich, auch wenn es kein Bewußtsein gibt, das sie denkt."Weizsäcker [1948/56] S. 90.

1678 Weizsäcker bespricht das Problem der Trennung zwischen Geistes- und Naturwissenschaften. Er möchte beide als zwei Halbkreise verstanden wissen, die zusammen als Vollkreis, der mehrmals durchlaufen werden müsse, erst „die Wirklichkeit als Eines, die Wissenschaft als Ganzes [...] sehen“ lassen. Dahinter steht die Ansicht, dass beide Wissenschaften voneinander abhängig seien: Die Naturwissenschaft könne als Voraussetzung der Geisteswissenschaft angesehen werden, da der Mensch aus der Natur komme und ihren Gesetzen unterliege. Umgekehrt könne die Geisteswissenschaft auch als Voraussetzung der Naturwissenschaft angesehen werden, denn die Naturwissenschaft ist eine geistige Produktion und erst der menschliche Geist machte es möglich, dass Begriffe von der Natur gedacht werden konnten. Weizsäcker konzentrierte sich darauf, von der Natur im ganzen und von ihrer Geschichtlichkeit zu reden, wobei die Herkunft des Menschen aus ihr die Hauptfrage darstellte. Weizsäcker [1948/56] S. 8f.

1679 Weizsäcker [1948/56] S. 94f. 
daraus eine naturalisierende Rechtfertigung für ihr eigenes Töten konstruieren. ${ }^{1680}$ Weizsäcker unterstützte dies ferner, indem er den naturwissenschaftlich begründeten Kampf ums Dasein auf Völker und Kulturen ausdehnte und sich hierbei auf Oswald Spengler bezog, der „der Lehre vom gesetzmäßigen Aufstieg und Niedergang der Kulturen Ansehen verschafft" hat. ${ }^{1681}$ Diese Wellenbewegung der Kulturen, das Untergehen 'alter Völker', und der Aufstieg 'junger Völker' lasse sich nach Weizsäcker naturwissenschaftlich verstehen. Das Universum entwickelte sich von einer schöpferischen Undifferenziertheit über die Entfaltung der Gestalten bis zu einem wahrscheinlich kommenden Wärmetod. Diese Gestalt des geschichtlichen Ablaufs müsse auch das organische Leben aufweisen. Als großes Problem in der Geschichte der Menschheit sah er die Zivilisation. Diese führe nämlich zu einer „Selbstdomestikation“ der Menschen. Was damit gemeint ist, erklärte er an Hand der Arbeiten von Konrad Lorenz über die Wild- und Hausgänse. Die Hausgans sei an die Gefangenschaft besser angepasst als die Wildgans, würde aber einen harten Winter ohne menschliche Fürsorge nicht überleben. „Um den Kampf ums Dasein in der Domestikation gut $\mathrm{zu}$ bestehen, muß das Tier eben nur noch »wahllos und maßlos fressen und zeugen« (Lorenz).“1682 Anschließend übertrug er diese naturwissenschaftlichen Erkenntnisse auf die menschliche Gesellschaft. Die ethischen und ästhetischen Werturteile der Menschen seien notwendig gewesen für das Leben in „kleinen Gemeinschaften“. Doch der „Staat der Zivilisation nimmt den Gemeinschaften die Notwendigkeit, sich selbst zu verteidigen. [...] In der neuen Form des Kampfes ums Dasein bedeutet moralische Minderwertigkeit eine Chance für das Individuum. Ein Menschentyp, der nicht offen verbrecherisch, aber von unedler Hemmungslosigkeit im kleinen ist, setzt sich durch."1683 Diese Behauptung spiegelt das Bild wider, das Konservative in der Nachkriegszeit gerne vom Nationalsozialismus zeichneten: als Herrschaft der minderwertigen, unedlen Menschen. ${ }^{1684}$ Demgegenüber lautete die gängige

\footnotetext{
1680 Weizsäcker beschrieb die aktuellen Probleme seiner Zeit als welche der gesamten Menschheit. Er sprach nicht von Tätern und Opfern, sondern suggerierte 'natürliche' Ursachen hinter verbrecherischen Handlungen. Er schwieg vom letzten Krieg; gleichzeitig war er bemüht, das Töten als etwas Natürliches zu begreifen: „Alle Wesen wollen leben, denn wenn ihnen der Trieb zum Leben nicht erblich wäre, so wären sie längst ausgestorben. Sie töten, um zu leben und leben, um zu sterben. Dasein ist ein nie befriedigender Durst nach Sein und nach Lust, der ein nie beendetes Leiden hervorbringt. Sind das Sätze aus der Biologie oder des Buddhismus? Sie sind beides. Sie sind wahr."Weizsäcker [1948/56] S. 121.

1681 Weizsäcker [1948/56] S. 108.

1682 Weizsäcker [1948/56] S. 111.

1683 Weizsäcker [1948/56] S. 112. Hier weist Weizsäcker auch darauf hin, welche Gefahr die Zivilisation für die Menschheit bedeute: „Indem die Umwelt ungefährlicher wird und die Zahl der Menschen zunimmt, wird der Mitmensch der Hauptgegner im Kampf ums Dasein."

1684 Weizsäcker fasste den Nationalsozialismus als eine „Herrschaft des Kleinbürgertums“ auf. Hitler war für ihn ,einer der dumpfen Vielen“, dessen „menschliche Atmosphäre“ ihm als die der „Mediokrität“ erschien. Weizsäcker [1952/83] S. 277, 280, 289. Zum Topos des Minderwertigen siehe allgemein das erfolgreiche Buch von E. J. Jung: Herrschaft der Minderwertigen, 1927.
} 
Selbstrechtfertigung, dass man anständig geblieben sei. Es ist diese Einstellung der damaligen Intellektuellen, ${ }^{1685}$ die zu der üblichen charakterlichen Beurteilung der Wissenschaftler bei Berufungsverfahren und zur Charakterprüfung der Studenten führte. ${ }^{1686}$ Gegen diese „,neuen Gefahren der Zivilisation“, also der Belohnung unmoralischen Verhaltens, habe der Mensch keine „Schutzinstinkte“. Hinzu komme, dass er wegen seiner natürlichen Anlage besonders mit Waffen hemmungslos umgehe. Es scheint demzufolge so, als stünde die Menschheit vor dem Abgrund. Aber einen Weg zurück gebe es laut Weizsäcker nicht. „Der Mensch ist ein Experiment, das nicht auf halbem Weg abgebrochen werden kann. Da es begonnen ist, muß es zu Ende geführt werden.“1687

Die Religion diente ihm als Mittel, über die moralische Komponente des menschlichen Handelns zu sprechen. Er fragte rhetorisch, wer für Geschehenes die Verantwortung tragen könne. „Wenn das Wissen und die aus dem Wissen folgende Macht überhaupt gut sein können, dann nur in der Hand guter Menschen.“"1688 Über gut und böse wird aber Weizsäcker zufolge nicht wissenschaftlich entschieden, sondern auf einer „religiösen Ebene“. Die Religion ist für ihn aber auch „die Voraussetzung unseres Seins und Denkens“. ${ }^{689}$ Das Christentum - „unser Schicksal“ - liefert die Grundlage, um allgemein über Schuld zu sprechen: „Was ist Schuld? Schuld ist zunächst, was Leiden hervorbringt. Schuld ist, was wir uns im Kampf ums Dasein täglich gegenseitig antun. Das Individuum tötet, um zu leben.“1690 Mit der Formulierung, „was wir uns [...] antun“, kommt zwar das konkrete Wir in die Debatte, doch werden Täter und Opfer vermischt und auf die gleiche Ebene gestellt. Die Menschheit macht sich schuldig und ist gleichzeitig Opfer. Das Wir hätte hier das Publikum im Hörsaal sein können. Vermutlich wurde es von einigen Zuhörern auch so gedacht. Und für die Studenten mit dieser Lesart bot er gleich anschließend einen Ausweg an. Bei der Schuld handele es sich nämlich nicht nur um das Töten: „Schuld ist Mangel an Liebe.“1691

1685 Diese Einstellung findet sich auch bei Emigranten wie dem Schriftsteller Carl Zuckmayer: siehe Zuckmayer [2002].

1686 Siehe Abschnitt 2.3.6.

1687 Weizsäcker [1948/56] S. 113.

1688 Weizsäcker [1948/56] S. 6.

1689 Weizsäcker [1948/56] S. 117.

1690 Und auf der folgenden Seite liest man: „Mit äußerlicher Objektivität betrachtet, sind Erbleiden und Erbschuld uralte biologische Tatsachen. Alle Wesen kämpfen den Kampf ums Dasein. Alle müssen leiden und sterben, alle müssen leidenmachen und töten." Weizsäcker [1948/56] S. 122, 123.

1691 Weizsäcker [1948/56] S. 122. 
Die Liebe eröffne den Weg zur Buße nach den in „Verwirrung“ geratenen Forderungen ${ }^{1692}$ an den Menschen. So könnte Weizsäcker von seinen Studenten verstanden worden sein. Darauf läuft auch eine zentrale Stelle seiner Vorlesung hinaus:

„Die Verzweiflung, die in der christlichen Lehre von der Erbsünde liegt, hat hier [in der Unmöglichkeit, die instinktiven Regungen zu verändern,] ihre Wurzel in der Erfahrung. Ich sehe, daß ich meine Instinkte ändern muß, ich kann sie aber trotzdem nicht ändern. [...] Der Konflikt besteht zwischen zwei objektiv aufweisbaren Tatbeständen: den Kampfinstinkten gegen den Mitmenschen, den wir nun einmal haben, und den Bedingungen, die erfüllt sein müssen, wenn die Menschheit leben soll. [...] Er drückt eben die Tatsache aus, daß der Mensch ein Wesen ist, das so, wie es ist, nicht bleiben kann. Zur Unschuld des Tieres kann er nicht zurück, er muß vorwärts in eine neue Unschuld oder untergehen. Und die eine Möglichkeit, die ihm offensteht, ist nun freilich in dem Satz ausgesprochen: Gott ist die Liebe."1693

In Weizsäckers biologistischer Sicht erscheint der Mensch wie jedes Lebewesen vor allem als Kämpfer. ${ }^{1694}$ Die Natur habe den Menschen nicht für ein Leben in Zivilisation geschaffen, deshalb brauche er die religiöse Liebe zum Überleben: „Jeder weiß ja, daß er helfen müßte, wenn er die Not sähe, und eben darum sieht er weg. Liebe ist die Haltung der Seele, die sehend den Kampf ums Dasein aufhebt.“1695

Weizsäckers zentrale Aussage am Ende seiner Vorlesung lautete: Die Menschheit müsse den Weg zur Religion finden, wenn sie in Frieden weiterleben will. An den werdenden Wissenschaftler richtete er die eher kryptische Botschaft, dass jede Erkenntnis den Menschen in die Bindung der Liebe führen müsse. Lieblose Erkenntnis wäre teuflisch und führe zur Vernichtung der Liebe. ${ }^{1696}$

Trotz dieser eigenartigen Botschaften erfüllte Weizsäckers Vorlesung die allgemein dem studium generale zugewiesenen Ziele: Sie vermittelte kein Spezialwissen, sondern versuchte, die Bedeutung einer Naturgeschichte für den zeitgenössischen Menschen herauszuarbeiten. Außerdem mögen ihre Inhalte zur Verteidigung abendländischer Kulturgüter gedient haben. Weizsäckers politische Aussagen waren typisch für die konservative Geisteselite in der Nachkriegszeit. Friedrich Meinecke schrieb zum Beispiel 1946: „Die Orte, wo wir uns seelisch wieder anzusiedeln haben, sind uns gewiesen. Sie heißen Religion und Kultur des

\footnotetext{
1692 Weizsäcker [1948/56] S. 114.

1693 Weizsäcker [1948/56] S. 124.

1694 Später nannte er seine Betrachtungsweise ,geschichtliche Anthropologie“. Siehe Weizsäcker [1977].

1695 Weizsäcker [1948/56] S. 124.

1696 Weizsäcker [1948/56] S. 126.
} 
deutschen Geistes.“1697 Weizsäckers Ansichten werden besser verständlich, wenn man seine weiteren in der unmittelbaren Nachkriegszeit verfassten Texte in die Analyse mit einbezieht. ${ }^{1698}$ Daraus ergibt sich, dass bei ihm das Plädoyer für ein religiöses Leben mit seiner Auffassung zusammenhing, dass der Nationalsozialismus - genauso wie der Kommunismus - eine falsche Religion gewesen sei. ${ }^{1699}$ Da aber seiner Meinung nach das Leben in der modernen, zivilisierten Welt nur dann Sinn habe, wenn man „die Wirklichkeit der Götter“ als „die beherrschenden Mächte des menschlichen Daseins“ anerkenne und danach lebe, war es für ihn entscheidend, die richtige Religion zu finden. ${ }^{1700}$ Diese war für ihn das Christentum; in dieser Richtung müsse alle Bemühung gehen, dort liege alle Hoffnung. 1701

Nationalsozialismus und Kommunismus waren für ihn Zeiterscheinungen, die mit dem Aufkommen des „modernen Massenstaates“ zusammenhingen. Für das Aufkommen des Nationalsozialismus gab es laut Weizsäcker Kräfte, „die teils spezifisch deutsch, teils spezifisch für unsere Zeit [waren. ...] Die zeitgemäße Komponente scheint mir die wichtigere.“1702 Eine der Zeiterscheinungen ist der „Typus des Massenmenschen“. Sein Leben in der „reinen Realität“ sei durch Sinnlosigkeit gekennzeichnet. Der Nihilismus sei seine einzig überzeugende Weltanschauung. ${ }^{1703}$ Es scheint, als liege hierin eine Begründung, warum Weizsäcker den Kampf der Deutschen gegen den Bolschewismus rechtfertigte. Er spricht in diesem Zusammenhang von einer Schuld des Westens und einer Schuld der Deutschen. Wenn die Verantwortlichen des Westens seit Versailles oder besser seit dem politischen Aufstieg Deutschlands den Mensch im Deutschen klarer gesehen hätte, hätten viele Fehler vermieden werden können, auf die sich Hitler mit sachlichem Recht berufen konnte. Eine Schuld der Deutschen sah er aber darin, dass Hitler nicht der Degen des Westens gegen den Osten werden konnte. ${ }^{1704}$

Weizsäcker war zwar in seiner Vorlesung nicht so konkret auf den Nationalsozialismus und die Verantwortung oder Schuld der Deutschen eingegangen, doch die Art, wie er die Geschichte der Menschheit kritisch beurteilte, beinhaltete schon all die Ideologeme, die zu der oben dargestellten Deutung führten: die Gefahr der Zivilisation, das Aufkommen des

\footnotetext{
1697 Meinecke [1946] S. 164.

1698 Siehe die in Fußnote 1675 angegebenen Aufsätze Weizsäckers.

1699 Weizsäcker [1952/83] S. 292, 296, 298.

1700 Weizsäcker [1948/56] S. 119, 120.

1701 Weizsäcker [1952/83] S. 301.

1702 Weizsäcker [1952/83] S. 281.

1703 Weizsäcker [1945/83]a S. 236.
} 
Massenmenschen, die Herrschaft eines Menschentyps von „unedler Hemmungslosigkeit“. Seine sozialdarwinistische Naturalisierung der Geschichte diente implizit zur Rechtfertigung des deutschen Krieges, der als Verteidigung der abendländischen Kultur gegen eine bolschewistische Bedrohung interpretiert werden konnte. Die Religion war für Weizsäcker die einzige Möglichkeit, dem Leben in der Moderne einen Sinn zu geben. Wie diese Religiosität in der Zukunft auszusehen habe, darüber machte er keine konkreten Aussagen. Die Hoffnung liege in der christlichen Liebe. Es bedürfe wenigstens einiger Menschen, die die Gefahren der Zukunft kannten und Mittel der Abhilfe wussten. Weizsäcker suggerierte, nur eine geistige Elite könne die Menschheit sicher in die Zukunft führen. Dieses elitäre oder akademisch aristokratische Selbstverständnis zeigt auch, wie die Forderungen an das studium generale, nämlich dass junge Akademiker zu einem sozial und staatsbürgerlich denkenden Menschen erzogen werden sollen, von den Professoren verstanden wurde.

Dieses Selbstverständnis vermittelte auch Weizsäckers Mentor und Freund, Werner Heisenberg, 1946 in einer Rede an Göttinger Studenten. Heisenberg warnte vor bedrohlichen, großen Volksmassen, die sich mit Hilfe der Politik gegen eine Geisteselite durchsetzen konnten und Unheil anrichteten. ${ }^{1705}$ Die Angst vor einer Vermassung sowie Heisenbergs Umgang damit erinnern an die populären Schriften Ortega y Gassets. ${ }^{1706}$ Eine „Ordnung der Welt" könne nur von der Wissenschaft, die zwischen wahr und falsch zu unterscheiden erlaube, ausgehen, und „,von den Menschen, denen der Blick dorthin nicht versperrt ist.“1707 Drei Jahre später hielt Heisenberg anlässlich der 100-Jahrfeier des Max-Gymnasiums in München eine Rede, die ein eindringliches Bekenntnis zur humanistischen Bildung und zur abendländischen Kultur - zur Sendung des Abendlandes - war. ${ }^{1708}$

Im Aufleben des studium generale im ersten Nachkriegsjahrzehnt und in der Beteiligung der Physiker daran zeigt sich das Bedürfnis der Professoren wie Studenten, eine Fachausbildung um die Vermittlung alter kultureller Werte zu bereichern. Ziel war es, einen positiven Bezug zur deutschen Geistesgeschichte herzustellen, und die eigene wissenschaftliche Betätigung in diese Tradition zu stellen. Hierzu dienten auch Vorlesungen über die Geschichte der Physik. Doch auch diese Vorlesungen gab es mit einer ähnlichen Zielsetzung schon vor 1945.

\footnotetext{
1704 Weizsäcker [1952/83] S. 306f.

1705 Heisenberg [1946/47] S. 388, 390. Zum elitären Selbstverständnis siehe Carson [1999].

1706 Ortega y Gasset [1931].

1707 Heisenberg [1946/47] S. 392f.

1708 Heisenberg [1949]c.
} 


\subsubsection{Vorlesungen über die Geschichte der Physik}

Die neuere Forschung hat sich der Frage gewidmet, wie sich die Wissenschaftsgeschichte und hier besonders die Physik- und Astronomiegeschichte - im Nationalsozialismus als politisches Instrument benutzen ließ. An den Beispielen von Kopernikus, dem „deutschen“ Astronom, und von Galilei als dem Kämpfer gegen eine wissenschaftsfeindliche katholische Kirche konnte Volker Remmert darlegen, wie die Wissenschaftsgeschichte im Nationalsozialismus politischen Nutzen entfaltete. ${ }^{1709}$ Ähnliches gilt auch für die Lehre in der Physik.

Die Lehrpläne von 1938 führten Physikgeschichte als festen Bestandteil in den Schulunterricht ein. Auch in den Schulbüchern finden sich entsprechende Abschnitte zur Physikgeschichte. In der NS-Zeit diente diese Art Wissenschaftsgeschichte, die besonders die Leistungen der „arischen“ Forscher herausstellte und eine Art „Arisierung“ umstrittener Figuren wie etwa Kopernikus praktizierte, einer gezielten Propaganda. ${ }^{1710}$ Auch in die 1942 neu erstellte Diplomstudienordnung fand die Geschichte der Naturwissenschaften Eingang. „Von den Studierenden wird erwartet, daß sie sich während des Studiums ihrer Neigung entsprechend in allgemeinen Geisteswissenschaften und anderen Wissensgebieten fortbilden, um so einen Überblick über das gesamte Gebiet der Naturwissenschaften bzw. der Technik sowie der Allgemeinbildung zu gewinnen. Hierzu gehört im besonderen auch der Besuch von Vorlesungen und Übungen sowie eigenes Arbeiten über Geschichte der Naturwissenschaften." $" 1711$

Dass es bis zum Kriegsende keine eigenen Vorlesungen zur Geschichte der Physik in Göttingen gab, lag vermutlich am Mangel an geeigneten Dozenten. In der Ausrichtung der Lehre ist hier 1945 insofern kein Bruch zu bemerken, als nach dem Krieg bloß das vorher formulierte Programm fortgesetzt, das heißt, nun auch in die Tat umgesetzt wurde. Nur die Diskussion um eine Hochschulreform konstruierte daraus eine Zielsetzung, die gegen die frühere NS-Bildungspolitik gerichtet sei. Die sachlich gehaltenen Studienpläne der Nachkriegszeit zeigen die Kontinuität zu den in der Diplomstudienordnung von 1942 festgelegten Zielen. In einem Göttinger Entwurf eines Studien- und Prüfungsplanes der

\footnotetext{
1709 Remmert [2001].

1710 Zur Physikgeschichte im nationalsozialistischen Schulunterricht als Mittel der politischen Indoktrination siehe Bäumer-Schleinkofer [1994].

1711 Studienordnung für Studierende der Physik sowie für Studierende der Mathematik, Richtlinien, I, 4. BAB, R 4901, Nr. 500. Diese Bemühung um breitere Bildung mittels historischer Vorlesungen war nicht nur auf die Physik beschränkt. Zum Beispiel war an der Universität Freiburg Geschichte der Medizin eine Pflichtvorlesung in der NS-Zeit. Schnabel [1991] S. 228.
} 
mathematisch-naturwissenschaftlichen Fakultät vom Juni 1945 heißt es: Neben der Fachausbildung sollte der Student veranlasst werden, ,sich zusätzlich zunächst mit der allgemeinen Geschichte der Naturwissenschaften, später, nach eigener Wahl, je nach seiner individuellen Neigung, mit einem allgemeinen geisteswissenschaftlichen Fach eingehender beschäftigen."1712 Die Physikgeschichte als ein Teil der Naturwissenschaftsgeschichte sollte wieder gegen die Spezialisierung Abhilfe schaffen und zu einer breiteren Bildung der Physikstudenten führen. Die Geschichte der Naturwissenschaften sollte den kulturellen Wert der Naturwissenschaft erkennbar machen und dadurch festigen. Verfechter einer Wissenschaftsgeschichte in der Nachkriegszeit betonten, dass eine erwünschte, wirklich allgemeine Bildung nur dann zu erreichen sei, wenn auch die geschichtliche Entwicklung der naturwissenschaftlichen und technischen Welt vermittelt werde. Auch auf die Bedeutung der Wissenschaftsgeschichte für die Vermittlung eines Bewusstseins für Kultur wurde hingewiesen. Die 'großen Männer' der Wissenschafts- und Technikgeschichte leisteten demnach einen gleichrangigen Beitrag zur eigenen Kultur wie bedeutende Dichter, Philosophen und Künstler. ${ }^{1713}$ Diese Argumentation erklärt die in der Nachkriegszeit wieder verbreitete wissenschaftshistorische Hagiografie, die auf Wurzeln bei Ostwald und Lenard zurückgreifen konnte. ${ }^{1714}$

Nachdem in Göttingen der Beschluss gefasst worden war, die Physikgeschichte in den Lehrplan aufzunehmen, musste noch ein geeigneter Dozent dafür gefunden werden. Im ersten Kapitel wurde schon beschrieben, wie Siegfried Flügge im Juni 1945 nach Göttingen kam und auf welche Weise er eine Anstellung an der Universität fand. Flügges Diätendozentur wurde im August 1945 mit Hinweis auf sein großes Ansehen in der Kernphysik begründet, obwohl Flügge die Geschichte der exakten Naturwissenschaften lehren sollte. Die Fakultät stand nämlich vor dem Problem, dass ,trotz vielfacher Bemühungen ein Fachgenosse, für den die Geschichte der exakten Naturwissenschaften berufsmäßig das Hauptfach bildet, nicht ausfindig gemacht werden konnte."1715 Eine inoffizielle Anfrage wurde durch Vermittlung Max Schulers an Hans Schimank gerichtet, der in Hamburg Professor für Geschichte der Physik war. Im Oktober 1945 erklärte sich Schimank dem Göttinger Angebot grundsätzlich „nicht abgeneigt“", doch wollte er noch genaueres über die Bedingungen, wie zum Beispiel Etat und zur Verfügung stehende Assistentenstellen, erfahren. Vermutlich hätte die Fakultät

\footnotetext{
1712 UAG, Rek. 7101.

1713 Ein komprimiertes und deutliches Eintreten für Wissenschaftsgeschichte als Bildungsmittel gab zum Beispiel Hans Schimank [1951].

1714 Siehe Ostwald [1909]; Lenard [1929/43].

1715 Dekan Eucken an Rektor, 28. August 1945. UAG, Math.-Nat. Fak. 19a.
} 
Schimanks Erwartungen nicht gerecht werden können, doch so weit kam es gar nicht, denn als seine Antwort im Oktober 1945 Max Schuler erreichte, war in Göttingen schon Flügge angestellt worden. ${ }^{1716}$ Dieses Provisorium wurde von Becker in seinem Antrag an die Fakultät nur als „Notlösung“ bezeichnet. Die Fakultät erwartete sich zweierlei: Zum einen versprachen sich die Physiker von Flügges Anwesenheit im Institut reichen Gewinn für ihre eigenen physikalischen Arbeiten. Zum anderen sollte Flügge einerseits die Lehre in seinem Spezialgebiet der Kernphysik vertreten, andererseits aber auch erfolgreich Vorträge über die geschichtliche Entwicklung der Physik sowie über das Leben hervorragender Naturforscher halten. ${ }^{1717}$ In der Tat entsprach er auch im letzten Punkt den Erwartungen. Das ist doch erstaunlich, da Flügge als damals 33-Jähriger, aufstrebender Physiker, der seinen Forschungsschwerpunkt in der theoretischen Kernphysik hatte, über die er selbstverständlich ebenfalls Vorlesungen hielt, sich aus dieser Tätigkeit wenig Lorbeeren für seine weitere Karriere erhoffen konnte. Obwohl sich also für Flügge die Lehre in Physikgeschichte nur aus der speziellen Nachkriegssituation ergab, und es auch von Anfang an klar war, dass es sich für ihn dabei nur um eine kurze Übergangslösung handelte, nahm er das Fach offenbar ernst und hielt auch unter heutigen Gesichtspunkten gute Vorlesungen.

Im SS 1946 las Flügge laut Vorlesungsverzeichnis „Ausgewählte Kapitel aus der Geschichte der Physik“ und im folgenden Wintersemester für Hörer aller Fakultäten eine „Übersicht über Methoden und Ergebnisse der Physik“. Diese letztgenannte Vorlesung trägt in einer mir freundlicherweise zur Verfügung gestellten Mitschrift den abweichenden Titel „Die Grundlegung der modernen Naturwissenschaft im 17. Jahrhundert“. 1718 Auf Grund dieser 27 Seiten umfassenden Mitschrift, die leider nur die erste Hälfte des Semesters abdeckt, lässt sich die Vorlesung recht gut rekonstruieren. ${ }^{1719}$

Das 17. Jahrhundert wird als die erste große Blütezeit der Naturwissenschaft angesehen. Das Besondere in diesem Jahrhundert war die experimentelle Untersuchung von Naturvorgängen

\footnotetext{
1716 Siehe Schimank an Schuler, 30. Oktober 1945. UH-HSGS, NL Schimank, Korr. Schuler.

1717 Antrag Beckers an den Dekan für eine Dozentur Flügges vom 24. August 1945. Den Antrag unterzeichneten ebenfalls Kopfermann und Pohl; befürwortet wurde er von Bruggencate, Prandtl, Herglotz, Schuler, Kaluza, Correns und Mortensen. UAG, Kur. Math.-Nat. Fak. 19a.

1718 Mein Dank gilt Hanswalter Giesekus für die Leihgabe seiner Mitschrift.

1719 Es ist mir anhand der Mitschrift leider nicht gelungen, herauszufinden, welches oder welche Werke zur Physikgeschichte Flügge als Grundlage seiner Vorlesung benutzte. Die in der Universitätsbibliothek Göttingen vorhandenen, und daher auch Flügge damals zur Verfügung stehenden deutschsprachigen Werke weichen im Aufbau und auch in den Inhalten in Einzelheiten deutlich von Flügges Darstellung ab, und kommen daher kaum in Frage. Es sind dies: Poggendorff [1879]; Heller [1882-1884]; Rosenberger [1882-1890]; Hoppe [1926]. Möglicherweise entnahm Flügge seine Kontinuitätsthese in Bezug auf den Übergang vom Mittelalter zur frühen Neuzeit dem umfangreichen Werk Pierre Duhems. In dessen zehnbändigen Le système du monde: historie des
} 
und die Anwendung der Logik auf das Naturgeschehen in Form mathematischer Theorien. In der Grundlegung der modernen Naturwissenschaft unterschied Flügge zwei Epochen: Die erste ist charakterisiert durch das Auftreten genialer Einzelgänger, die folgende durch die Gruppierung gewisser Forscher um einzelne Mittelpunkte. Solche waren in Frankreich der Hof Ludwig XIV. und in England die Royal Society. Flügge machte in diesem Zusammenhang auf die Problematik der 'Staatsnähe' aufmerksam, die ganz allgemein einerseits eine wesentliche Unterstützung sichert, andererseits auch eine Abhängigkeit bedeutet.

In der Behandlung der Vorläufer der modernen Naturwissenschaft stellte Flügge die Lehre Aristoteles vor und würdigte auch die positiven Leistungen der Scholastik. Flügge betonte das schrittweise Abgehen von den aristotelischen Lehren im Mittelalter, indem er auf Albertus Magnus (1193-1280), Petrus Peregrinus (13. Jh.), Albertus Saxonicus (um 1316-1390), Nicolaus Cusanus (1401-1464) und Nicolaus Kopernicus (1473-1543) und deren Verdienste näher einging. In Flügges Darstellung gibt es keinen erklärten Gegensatz zwischen der Scholastik und einem mit Kopernikus beginnenden neuen Weltbild, sondern einen kontinuierlichen Übergang. „Copernicus tat nur etwas, was in der Luft lag,“ ist in der Mitschrift festgehalten. Am Ende des Abschnittes zu Kopernikus lesen wir:

„Wir sehen so, daß Kopernikus mit seiner Entdeckung, so grundlegend sie für die Folge werden sollte, doch im Rahmen seiner Zeit blieb. Wir sind allzuleicht geneigt, die Vorarbeiten zu übersehen, welche die Kontinuität der Forschung erst deutlich macht. Ein Genie, was den Rahmen seiner Zeit völlig sprengen würde, kann von seiner Generation nie verstanden und als solches erkannt werden.“

Diese Sichtweise wandte Flügge auch auf die folgende Epoche an. Kepler und Galilei erfuhren eine eingehende, biografisch angelegte Würdigung. Sie waren aber keine wissenschaftlichen Revolutionäre, sondern trieben die angestoßene Entwicklung nur weiter. Flügge verstand die Forscher als Kinder ihrer Zeit. Er versuchte, selbst die heute als 'falsch' erkannten Ansichten als einen damals schlüssigen Weg zum Erkenntnisgewinn verständlich zu machen. So stellte er bei der Besprechung von Keplers Schriften die Astrologie als einen ernstzunehmenden Wissenschaftszweig dar, um deren Weiterentwicklung sich Kepler genauso bemühte, wie um die Astronomie. Beide Bemühungen wurden von Flügge positiv gewertet. Er zeigte auch dort Kontinuitäten im Denken auf, wo man bei flüchtigem Lesen einen Bruch erkennen könnte. „Als Ursache seiner Forschung gibt er [Kepler] an, die 
Gedanken Gottes bei der Weltschöpfung nachzudenken. - Dies ist ja, wenn auch meist anders formuliert, auch heute noch der Grund unseres Erkenntnisdranges. Auch uns ist die Frage nach dem »Warum« der Naturgesetze eine Frage, die den wissenschaftlichen Raum durchbricht."

Flügges Geschichte der Physik ist in ihrer Methode erstaunlich modern und vielgestaltig. ${ }^{1720}$ Das zeigt sich schon an der Art, wie Kepler, Galilei und Guericke behandelt werden (danach bricht die Mitschrift ab, sodass die sicherlich folgenden Huygens und Newton leider fehlen). Das Experiment erfährt in Flügges Darstellung gleiche Aufmerksamkeit, wie die Theorie. Der philosophische und gesellschaftliche Kontext wird ernst genommen. Es wird nicht nur darauf hingewiesen, dass Galilei in eine Konflikt mit der Kirche geriet, sondern auch, dass er in ein internationales wissenschaftliches Kommunikationsnetz eingebunden war, dass er es verstand, einen erfolgreichen Schülerkreis um sich zu sammeln, der seinerseits die Gründung der Accademia del Cimento erreichte. Diese Akademie schaffte mit ihrem experimentellen Programm eine Verbreiterung der Forschungsbasis. Auch die Entwicklung neuer Instrumente und der damit gewonnenen neuen Erkenntnisse behandelte Flügge. Er beschreibt auch die Auswirkungen von Reformation und Gegenreformation auf die Ausübung der Wissenschaft, zeigt die damit verbundene Verlagerung der Zentren der europäischen Forschung. In den biografischen Abschnitten vermeidet er es, Heldengeschichten zu konstruieren. ${ }^{1721}$ Auch der Anteil der deutschen Forscher wird nicht besonders in den Vordergrund gestellt - dadurch hob er sich von mancher älterer deutscher Physikgeschichte deutlich ab. ${ }^{1722}$

Flügge erfüllte den Auftrag seiner Dozentur, die Geschichte der Naturwissenschaften zu lehren, zur Zufriedenheit der Studenten wie der Fakultät, doch war seine Lehrtätigkeit in Göttingen, wie von Beginn an geplant, nur eine Übergangslösung. 1947 erhielt er ein Ordinariat für theoretische Physik in Marburg, und die Göttinger Fakultät musste sich wieder um einen neuen Dozenten bemühen. Der am MPI für Physik arbeitende Max Laue erklärte sich bereit, sich am Unterricht der Universität zu beteiligen. Dass er prädestiniert dafür war, Vorlesungen zur Geschichte der Physik zu lesen, wird im folgenden noch erläutert. Die Fakultät ernannte ihn wie kurz zuvor auch Heisenberg zum ordentlichen Honorarprofessor.

\footnotetext{
1720 Flügges Darstellung der Physikgeschichte und seine Interpretationen weichen deutlich von denen Kistners [1906] und Hoppes [1926] ab.

1721 Flügge kam später zu einer etwas anderen Bewertung der Physik in der frühen Neuzeit, wie sein Buch „Wege und Ziele der Physik“ zeigt. Die Scholastik habe zwar wesentliche Elemente zum Neubau der Physik beigesteuert (Logik, Mathematik). Doch weil es eine hochentwickelte Tradition der Aristotelischen Naturphilosophie gab, sei die Leistung eines Galilei oder Kepler besonders hoch zu bewerten, da sie einen neuen Standpunkt durchzusetzen hatten. Flügge [1974] bes. S. 2 f.

1722 Siehe zum Beispiel Kistner [1906].
} 
Die Ernennung wurde in beiden Fällen mit dem internationalen Rang der Nobelpreisträger gerechtfertigt, nur dass sich die Würdigung Laues in dem Hinweis unterschied, „daß Herr v. Laue einer der leidenschaftlichsten und bekanntesten Gegner des nationalsozialistischen Regimes war." 1723

Mit der Ablösung Flügges durch Laue im WS 1947/48 war zwar immer noch kein Fachmann für Physikgeschichte gefunden, wohl aber jemand, der sich im letzten Kriegsjahr intensiv in das Thema eingearbeitet hatte. Auslöser dafür war im Januar 1944 die Anfrage des Bonner Philosophen und Psychologen Erich Rothacker an Laue, eine 50-seitige Geschichte der Physik für eine geplante, zweibändige Geschichte der Wissenschaften zu verfassen. Nachdem sich Laue versichert hatte, auch die Geschichte der Kristallphysik, die ihm sehr am Herzen lag, mit behandeln zu dürfen, sagte er zu und sandte schon im Juli 1944 ein 130 Seiten starkes Manuskript ein. Er vertiefte sich in die Arbeit über die Geschichte der Physik, „um sich von den äußeren Ereignissen abzulenken.“ Die Bombardierung von Berlin richtete im März 1944 auch in Laues Haus Verwüstungen an, sodass er im April nach Hechingen zum dorthin verlagerten KWI für Physik umzog. Als Teil der von Rothacker herausgegebenen Geschichte der Wissenschaften (II. Naturwissenschaften) erschien Laues Beitrag separat als eigenes kleines Buch 1946 im Universitäts-Verlag in Bonn. ${ }^{1724}$

Als Laue im WS 1947/48 das erste Mal eine Vorlesung über die Geschichte der Physik anbot, konnte er also auf sein schon erschienenes Buch zurückgreifen. Das in seinem Nachlass befindliche „Notizbuch zur Geschichte der Physik“ zeigt aber, dass er für die Vorlesung offenbar eine andere Gliederung des Stoffes wählte. Während das Buch in 14 Kapitel streng thematisch gegliedert ist, von Zeitmessung und Mechanik bis Wärmestrahlung und Quantenphysik, beginnt die Vorlesung mit kurzen Notizen zu 20 Forschern aus der Antike bis ins 16. Jahrhundert, die in seinem Buch teilweise unerwähnt bleiben. ${ }^{1725}$ Es folgt eine ausführliche Behandlung von Galileis Leistungen, der Laue mehr Platz einräumte als all den eingangs Genannten zusammen. Diese Gewichtung folgte aus Laues Zielsetzung seiner Geschichte der Physik. Er wollte „das Werden und die Wandlungen einiger für die heutige

\footnotetext{
1723 Dekan Harder an Kultusministerium, 9. Juli 1947. UAG, Rek. PA Laue.

1724 Siehe den Briefwechsel Laue - Rothacker in ULB Bonn, Abt. Handschriften und Rara, Rothacker I. Das Zitat stammt aus Laue an Rothacker, 22. Juli 1944. Die erste Anfrage Rothackers datiert vom 10. Januar 1944. Zu Laues Umzug nach Hechingen siehe Herneck [1979] S. 71f.

1725 Neben Archimedes, Ptolemäus, Kopernikus und Kepler finden sich hier auch die Seefahrer Vasco da Gama und Christoph Kolumbus. Keinem widmete Laue mehr als eine halbe Seite des A5-Heftes. Zwei Kurzbiografien betrafen Physiker, die nach dem 16. Jahrhundert geboren waren: Benjamin Franklin und Ernst Chladni. MPGArchiv, Nachlass Laue, III, 50, 15.
} 
Physik wichtigen Ideen und Erkenntnisse“ ins Zentrum seiner Darstellung stellen. ${ }^{1726}$ Durch den deutlichen Bezug auf die moderne Physik verloren die Leistungen der Antike und des Mittelalters an Bedeutung. „Was sich aber sonst an Mechanik bei Aristoteles findet und die ganze Scholastik hindurch als unwidersprochene Wahrheit galt, war für die aufkeimende Wissenschaft des 16. Jahrhunderts lediglich das größte aller $\mathrm{zu}$ überwindenden Hemmnisse.“1727 Dieser ideengeschichtliche Zugang Laues entsprach den Vorstellungen des Auftraggebers Rothacker, wie sie in dessen programmatischen Text über „Wissenschaftsgeschichte und Universitätsgeschichte“ als Ziel der Wissenschaftsgeschichtsschreibung formuliert sind. Die Wissenschaftsgeschichte solle keine Geschichte kumulierenden Wissens sein, sondern die Entdeckungen in den Vordergrund stellen. Als letzten Sinn der Wissenschaftsgeschichte sah Rothacker, dass sie den „heroischen und schöpferischen Eroberungsprozeß der geistigen Formen [...] schildert“. ${ }^{1728}$

Laue suchte nach jenen Fortschritten in der Geschichte der Physik, die auch Mitte des 20. Jahrhunderts noch Geltung besaßen. In Galilei sah er den ersten wirklich bedeutenden Vertreter der Physik, der mit modernen Methoden eine systematische Forschung betrieb. „Erst mit dem beginnenden 17. Jahrhundert [...kann] man von einer kontinuierlich fortschreitenden Forschung reden“. ${ }^{1729}$ Gerade im Vergleich mit Flügge wird deutlich, wie sich unterschiedliche Zielsetzungen in der Darstellung der Physikgeschichte niederschlugen. Flügge nahm jede Epoche für sich ernst und wollte die schrittweise und für ihn kontinuierlich ablaufende Entwicklung verständlich machen, während Laue nur das für seine eigene Zeit Bedeutende in der (kürzeren) Entstehung darstellte. Dies führte bei Laue zu einer Geringschätzung des Mittelalters, die sich im Laufe seiner Beschäftigung mit der Physikgeschichte noch verstärkte. ${ }^{1730}$

Laues Buch Geschichte der Physik unterschied sich von früheren Darstellungen anderer Autoren. Von den gewichtigen Werken Poggendorffs, Hellers, Rosenbergers und Hoppes

\footnotetext{
1726 Laue [1946] S. 9.

1727 Laue [1946] 3. Aufl. 1950, S. 20f.

1728 Rothacker [1943] S. 20. Es sei darauf hingewiesen, dass Rothacker sich schon 1932 öffentlich zum Nationalsozialismus bekannte, und dass seine Kulturanthropologie eine rassistische Gestalt aufweist. Deshalb findet sein Werk in der neueren Forschung besondere Aufmerksamkeit. Volker Böhnigk findet in Rothacker ein Beispiel eines fachlich hoch angesehenen Wissenschaftlers, der den Rassismus (gleichsam das Grundelement einer NS-Wissenschaftsauffassung) zur Grundlage seiner philosophischen Lehren machte. Siehe Böhnigk [2002].

1729 Laue [1946] S. 10. Siehe auch in der 3. Aufl. 1950, S. 31.

1730 Der oben zitierte Satz, dass die Leistungen der Scholastik nur ein Hemmnis für die moderne Wissenschaft waren, findet sich in der dritten Auflage seines Buches von 1950, noch nicht aber in der ersten von 1946.
} 
unterschied sie sich schon allein im Umfang. ${ }^{1731}$ Aber auch von der handlichen Geschichte der Physik von Adolf Kistner aus dem Jahr 1906 hob sich Laues Werk deutlich ab. Kistner gliederte seine Darstellung nach Epochen und Jahrhunderten und stellte die wichtigsten Entdeckungen in der Physik chronologisch dar. Vor allem gegen Ende des Buches konzentrierte sich Kistner auf die Nennung 'großer Männer' und ihrer Leistungen und verwendete wenig Platz für inhaltliche Erläuterungen der physikalischen Erkenntnisse. ${ }^{1732}$ Demgegenüber liefert Laue ein spannend zu lesendes Buch, das teilweise den Charakter eines Physiklehrbuches, teilweise den eines historischen Vorspannes damaliger Zeitschriftenaufsätze aufweist. Er wollte nicht die historische Entwicklung mit all ihren Verzweigungen verständlich machen, sondern ihm ging es um eine historische Darstellung, wie die Theorien der Physik seiner Zeit entstanden sind. In der dritten Auflage von 1950 bespricht er die neuesten Erkenntnisse bis ins Jahr 1949. In der geschichtlichen Entwicklung findet Laue Beweise für die objektive Wahrheit der Physik:

„Immer wieder kommt es in ihrer Geschichte vor, daß sich zwei bis dahin völlig unabhängige, von verschiedenen Menschengruppen gepflegte physikalische Gedankenkreise [...] unversehens zusammenfinden und zwanglos zusammenfügen. Wer ein solches aufs höchste überraschende Ereignis auch nur von Ferne miterleben durfte, oder wenigstens es nachzuleben imstande ist, zweifelt nicht mehr, daß die zusammenkommenden Theorien, wenn nicht volle Wahrheit, so doch einen bedeutenden Kern objektiver, von menschlichen Zutaten freier Wahrheit enthalten. [...] Das Ideal für eine Geschichte der Physik muß es sein, solche Geschehnisse möglichst klar herauszustellen." ${ }^{1733}$

Mit diesem selbstgesetzten Ziel verfasste Laue nicht nur eine Geschichte, sondern auch eine Rechtfertigung und Verteidigung des damaligen gesicherten Wissens der Physik. Ein Ziel dieser Auffassung von Physikgeschichte war es, eine Erfolgsgeschichte der Physik vorzulegen. Die Irrwege in der Physik, die ja immer erst im Nachhinein als solche erkennbar werden, hatten hier keinen Platz. Der Erfolg des kleinen Buches zeigt, dass es einen Bedarf an einer derartigen Darstellung der Physikgeschichte gab. Schon nach vier Jahren wurde das Buch in leicht erweiterter Fassung zum dritten Mal aufgelegt. Albert Einstein las das Buch mit „großem Entzücken“ und lobte Laue: „Es ist wirklich verdienstlich, daß einer, der die ganze Linie so verständnisvoll übersieht, den Philologen und Wortkrämern die Darstellung

1731 Poggendorff [1879]; Heller [1882-1884]; Rosenberger [1882-1890]; Hoppe [1926].

1732 Kistner [1906].

1733 Laue [1946] 3. Aufl. 1950, S. 14f. Hervorhebung original. 
der Geschichte des menschlichen Gedankens aus der Hand nimmt und das große Drama hinstellt, gereinigt vom Staub der belanglosen Einzelheiten."1734

Im krassen Gegensatz zum Erfolg des Buches standen Laues Vorlesungen, die von den Studenten eher gemieden wurden. Laut Aussagen damaliger Studenten lag dies an Laues besonders schlechtem Vortragsstil. Ein Teilnehmer an Laues Vorlesung über Supraleitung berichtete, dass zur ersten Vorlesung der Hörsaal noch gut gefüllt war, doch nach wenigen Durchgängen nur noch ein kleiner Rest von zwei bis drei Studenten übrig blieb, der teils aus Anstand bis zum Ende durchhielt. Es ist anzunehmen, dass die Physikgeschichte-Vorlesungen ähnlich schlecht besucht waren.

Laues Vorlesung vom WS 1947/48 orientierte sich an den großen Persönlichkeiten der Physik. Neben Galilei behandelte sie ausführlich René Descartes, Otto von Guericke, Isaac Newton und Ludwig Lange. Nur kurz widmete er sich Huygens, Torricelli, Boyle, Mariotte, Pascal, Hooke, Leibniz. ${ }^{1735}$ Ungewöhnlich ist die nicht nur beiläufige Erwähnung Ludwig Langes. Er war ein für Laue zu unrecht vergessener, scharfer Kritiker des absoluten Raumes und der absoluten Zeit Newtons sowie ein Wegbereiter der Relativitätstheorie Einsteins. ${ }^{1736}$ Gegen Ende der Vorlesung im WS 1947/48 scheint Laue vom biografischen Aufbau zum thematischen, den er auch im Buch verfolgte, übergewechselt zu sein. Im SS 1948 begann die Vorlesung mit „Elektrizität und Magnetismus“, was dem fünften Kapitel des Buches entspricht. ${ }^{1737}$

Von 1947 bis 1950 bot Laue Vorlesungen über die Geschichte der Physik an. 1951 wechselte er als Direktor des KWI für physikalische Chemie nach Berlin-Dahlem. In Göttingen gab es für ihn keinen Nachfolger, der die Geschichte der Physik in der Lehre weiter gepflegt hätte. Dies ist ein Anzeichen dafür, dass die Bemühungen um ein studium generale, um eine breite Bildung der angehenden Naturwissenschaftler als eine der Aufgaben der Universität, bereits an Gewicht und Bedeutung verloren haben. Die Physikausbildung kehrte nach der kurzzeitigen Aufrüttelung 1945 zu einer Normalität zurück, die in der Lehre eine klare Betonung auf die 'eigentliche' Fachausbildung setzte und gelegentlich randständige Vorlesungen, wie sie vorher das studium generale brachte, einstreute. - An den Beispielen Weizsäcker, Flügge und Laue konnten dank der guten Quellenlage die Inhalte der in der

\footnotetext{
1734 Einstein an Laue, 15. Mai 1947. Zitiert nach Herneck [1979] S. 72.

1735 Über Galilei schrieb er neuneinhalb Seiten, über Newton drei, Descartes und Guericke je zwei und Lange eineinhalb. Siehe das "Notizbuch zur Geschichte der Physik", MPG-Archiv, Nachlass Laue, III, 50, 15. 1736 Siehe Laue [1946] S. 73 und Laue [1948]f.

1737 “Notizbuch zur Geschichte der Physik“ MPG-Archiv, Nachlass Laue, III, 50, 15.
} 
Nachkriegszeit neu angebotenen Vorlesungen im Detail besprochen werden. Dies ist leider in Bezug auf die ebenfalls neuen Didaktikvorlesungen nicht möglich, daher wird im folgenden Abschnitt vor allem der Frage nachgegangen, wie es zu diesem neuen Vorlesungsangebot in Göttingen kam.

\subsubsection{Ernst Lamla und die Didaktik der Physik}

Dass an der Universität Göttingen von 1947 bis 1959 Vorlesungen über die Didaktik der Physik angeboten wurden, war mehr die Folge glücklicher Zufälle als konkreter Planung der Fakultät. Dieses Vorlesungsangebot kam nur deshalb zustande, weil der theoretische Physiker Ernst Lamla, der in der Weimarer Republik in der Schulverwaltung tätig war, der Universität in der Nachkriegszeit zur Verfügung stand. Lamla wurde 1933 aus dem Staatsdienst in den Ruhestand versetzte, suchte in der Nachkriegszeit eine neue Anstellung und fand sie 1947 in Göttingen als Schuldirektor. Doch der Weg dahin war keinesfalls geradlinig.

Ernst Lamla wurde 1888 in Berlin geboren. Er studierte ab 1907 Physik, Mathematik, Chemie und Mineralogie an der Universität Berlin und schloss sein Studium 1912 mit einer Promotion in theoretischer Physik bei Max Planck ab. Von 1918 bis 1921 war er Assistent am Institut für theoretische Physik unter Planck und Laue. Als junger Wissenschaftler hatte er an der Berliner Universität unter anderem Kontakt zu den nur wenig älteren Physikprofessoren Pohl, Franck und Born, sowie zu dem jüngeren Kollegen Bothe. Lamla verließ dann jedoch die Universität und startete eine Laufbahn in der preußischen Schulverwaltung. 1932 stieg er zum Vizepräsidenten des Provinzialschulkollegiums in Magdeburg auf. Aus politischen Gründen verlor er 1933 diese Stellung, betätigte sich dann zuerst als selbständiger Physiker und half nebenbei Studenten bei der Vorbereitung aufs Staatexamen oder die Doktor-Prüfung. Ab 1938 war er als freier Mitarbeiter der Deutschen Versuchsanstalt für Luftfahrt in BerlinAdlershof tätig und führte Forschungsaufträge theoretischer Art für das dortige Institut für Gasdynamik durch. Ebenfalls ab 1938 gab er auch Physikunterricht in einer Berliner Lehranstalt für medizinisch-technische Assistentinnen. Im November 1943 wurde sein Berliner Wohnhaus von Bomben zerstört, im Mai 1944 auch sein Ausweichquartier. Nach Verlust seines gesamten Besitzes ging er im März 1945 nach Sonthofen im Allgäu, wohin das Institut für Gasdynamik umgezogen war. Dort erlebte er das Ende des Krieges. ${ }^{1738}$

Nachdem das nationalsozialistische Deutschland besiegt worden war, stand für Lamla eine neue berufliche Zukunft offen. Seine Bemühungen gingen in verschiedene Richtungen; 
entscheidend waren die Hilfestellungen durch frühere Kollegen aus der Physik und der Politik. Sein altes kollegiales Netz diente ihm als „Ressource“ (Ash) für seinen Wiedereinstieg in die akademische Welt. In den USA erkundigte er sich noch 1945 bei James Franck, doch dieser sah wenig Chancen, für ihn dort eine Anstellung zu finden. ${ }^{1739}$ Im August 1945 wandte sich Lamla an das Bayerische Kultusministerium. Daraufhin wurde er kommissarischer Syndikus der Bayerischen Akademie der Wissenschaften. In der Zwischenzeit bekleidete er eine Assistentenstelle an der TH Stuttgart. Dann bekam er das Angebot, die Vertretung des Lehrstuhls für theoretische Physik an der Universität München zu übernehmen. Er wäre dazu bereit gewesen, falls er als Syndikus der Bayerischen Akademie bestätigt worden wäre. Doch das Kultusministerium lehnte ihn ab, da Lamla nicht in Bayern geboren war. ${ }^{1740}$ Da Lamla den negativen Ausgang befürchtete, ${ }^{1741}$ wandte er sich schon 1945 an seinen früheren Kollegen und SPD-Parteigenossen aus der Weimarer Republik, den vormaligen Kultusminister Adolf Grimme, der in der Nachkriegszeit zuerst Regierungsdirektor in Hannover, 1946 Volksbildungsminister des Landes Hannover und 1947 schließlich wieder Kultusminister wurde. Grimme bat er um Unterstützung bei der Erlangung einer Professur für Physik, am besten theoretische Physik, an einer Universität oder TH in der britischen Zone. Als besondere Qualifikation gab Lamla an, dass er als alter Schulfachmann sich auch um die Ausbildung der Studienräte kümmern könne und wolle. ${ }^{1742}$ Grimme konnte ihm aber nur eine Direktorstelle an einer Schule in Aussicht stellen. In die Autonomie der Universitäten wollte Grimme nicht eingreifen, deshalb müsse sich Lamla selbst direkt an die entsprechenden Fakultäten wenden. ${ }^{1743}$ Diesen Schritt versuchte er mit Unterstützung von Max Laue, der sich Mitte 1946 diesbezüglich an Walther Bothe in Heidelberg wandte, jedoch eine negative Antwort erhielt. ${ }^{174}$ Eine fixe Zusage bekam Lamla aus Mülheim, wo er für die Direktorstelle einer höheren Lehranstalt vorgesehen war. Damit verbunden war auch die

\footnotetext{
1738 Lamla an Grimme, 6. Dezember 1945. GStA, I, HA. Rep. 92, Grimme, 1992.

1739 Franck an Lamla, 10. November 1945. GStA, I, HA. Rep. 92, Grimme, 1992.

1740 Siehe Physikalische Blätter 3 (1947), S. 206, „Theoretische Physik an der Universität München“.

${ }^{1741}$ Im Dezember 1945 schrieb er über seine Bemühungen beim Bayerischen Kultusministerium an Grimme: „Ich glaube aber, daß die negative Liebe der Bayern zu den Preußen den Ausschlag geben wird.“ Lamla an Grimme, 6. Dezember 1945. GStA, I, HA. Rep. 92, Grimme, 1992.

1742 Lamla an Grimme, 6. Dezember 1945. GStA, I, HA. Rep. 92, Grimme, 1992.

1743 Grimme an Lamla, 28. Januar 1946. GStA, I, HA. Rep. 92, Grimme, 1992. Im April 1946 sah Grimme eine Chance, Lamla als Nachfolger von Walter Lietzmann als Schulleiter der Oberrealschule für Jungen (spätere Felix-Klein-Gymnasium) in Göttingen einzusetzen. Grimme an Lamla, 9. April 1946; ebenda. 1744 "Lieber Herr v. Laue, [...] Ich habe Ihnen noch nicht für Ihren freundlichen Hinweis auf Herrn Lamla gedankt. Ich kenne ihn gut und schätze ihn sehr, aber es lag der Fakultät daran, als ersten Theoretiker in Heidelberg gleich jemanden zu bekommen, der nun auch mit den letzten Entwicklungen der theoretischen Physik möglichst eng vertraut ist. So hat sich die Fakultät nicht entschliessen können, die praktisch schon fertige Berufungsliste noch einmal umzuwerfen." Bothe an Laue, 17. August 1946. MPG-Archiv, Nachlass Laue, III, 50,330 .
} 
Aussicht, an der Universität Köln eine Honorarprofessur zu bekommen. Erst in diesem Moment, im Frühjahr 1947, kam von Grimme das Angebot, in Göttingen die Leitung des städtischen Gymnasiums zu übernehmen. Laue wurde bei Grimme vorstellig, um für Lamla eine Honorarprofessur an der Universität Göttingen in die Wege zu leiten. Grimme musste sich persönlich an den Oberbürgermeister von Mülheim, Diederichs, wenden, damit dieser Lamla, der dort schon zugesagt hatte, wieder freigab. Am 1. Juli 1947 wurde Lamla schließlich Direktor des städtischen Gymnasiums in Göttingen. ${ }^{1745}$ Auch wenn Lamla gerne nach Göttingen ging, so war sein Weg dahin doch von vielen Zufällen und unvorhersehbaren Ereignissen beeinflusst. Was jedoch von Anfang an für die Option Göttingen fest stand, war eine Verbindung zur Universität.

Die Erreichung einer Honorarprofessur an der Universität wurde von Lamla taktisch geplant. Im Ministerium hatte er mit Grimme den wichtigsten Unterstützer, doch sollte von dort kein Druck auf die Universität ausgeübt werden. Stattdessen nutzte er die in seiner Assistentenzeit gesponnenen kollegialen Verbindungen aus. In Absprache mit seinem früheren Berliner Kollegen Pohl konnte Lamla erreichen, dass Pohl selbst einen entsprechenden Antrag in der Fakultät einbrachte. ${ }^{1746}$ Im Fakultätsprotokoll ist knapp vermerkt: „Antrag wird von Herrn Pohl begründet (im Namen der Physiker). Fakultät stimmt einstimmig zu."1747 Max Laue, wieder ein früherer Kollege an der Berliner Universität, bei dem Lamla bis 1921 Assistent war, steuerte ein Gutachten bei, in dem er besonders die wissenschaftlichen Qualitäten Lamlas hervorhob. Lamla handhabe die schwierigen, rechnerisch umständlichen Annäherungsmethoden in der dynamischen Theorie der Raumgitterinterferenzen mit Meisterschaft. „Seine Arbeiten sind von nicht zu übertreffender Klarheit und sprechen m. E. das abschließende Wort über dieses Thema."1748

Da durch dieses Verfahren die Autonomie der Fakultät in Personalentscheidungen gewahrt worden war, konnte Ende Oktober 1947 vom Dekan auf dem üblichen Dienstweg ein Antrag an das Ministerium gestellt werden. Der Kurator, der vom Ministerium vorher eingeweiht worden war, hatte schon Mitte Oktober die Zustimmung des Universitätskontrolloffiziers zur

\footnotetext{
1745 Dass Lamla die Direktorstelle übernehmen sollte, war auch ein Anliegen der Göttinger SPD. Siehe den Schriftwechsel zwischen Ministerialrat Rönnebeck und dem Göttinger Ortsverein der SPD vom Sommer 1947. GStA, I, HA. Rep. 92, Grimme, 1992.

1746 Siehe den Brief Lamla an Grimme, 9. November 1947, in dem er das taktische Vorgehen beschreibt und die Absprache mit Pohl erwähnt. GStA, I, HA. Rep. 92, Grimme, 1992.

1747 Protokoll der Fakultätssitzung vom 24. Oktober 1947. GPAMNFG, Protokollbuch IV der mathematischnaturwissenschaftlichen Fakultät WS 1946/47 - WS 1949/50.

1748 Gutachten von Laue vom 10. Oktober 1947. HStAH, Nds. 401 Acc. 92 / 85, Nr. 330.
} 
Ernennung Lamlas eingeholt. Am 17. Dezember 1947 wurde Lamla schließlich von Grimme zum Honorarprofessor an der Universität Göttingen ernannt. 1749

Seine Veranstaltungen zur Didaktik der Physik, die in Tabelle 21 für die Jahre bis 1955 aufgelistet sind, stellten ein völlig neues Angebot im Göttinger Curriculum dar. Bis 1947 sind aber keine Bemühungen der Fakultät erkennbar, das traditionelle Lehrangebot durch spezielle Didaktikvorlesungen zu bereichern. Vermutlich war man der Auffassung, dass Pohls sehr anschaulich gehaltene Experimentalvorlesungen den Lehramts-Studenten ein gutes Beispiel für einen didaktisch durchdachten Physikunterricht seien. Pohl maß die didaktische Qualität seiner eigenen Vorlesungen am Verständnis, das er vor allem bei den Medizinstudenten für Physik erreichen konnte. Trotz der diesbezüglich sehr erfolgreichen Vorlesung Pohls blieb noch ein Bedarf an Veranstaltungen, die die Didaktik der Physik nicht nur beispielhaft vorführten, sondern selbst zum Thema hatten und den Lehramtsstudenten eine Anleitung zum Unterrichten der Physik gaben. Es war Lamlas Initiative zu verdanken, dass diese Lücke gefüllt wurde, die die Fakultät bislang nicht als solche wahrgenommen hatte. Noch in einer weiteren Hinsicht, die nicht die Universität betraf, wirkte sich Lamlas Anwesenheit in Göttingen aus. Lamla war auch daran beteiligt, dass das städtische Gymnasium 1947 in MaxPlanck-Gymnasium umbenannt wurde. Noch am Sterbetag Max Plancks telegrafierte Grimme an die Schulleitung und ordnete die neue Namensgebung an. Für Lamla war es eine große Freude, Direktor einer Schule zu sein, die den Namen seines wissenschaftlichen Lehrers trug. 1750

\begin{tabular}{|l|l|}
\hline WS 48/49 & Didaktische Fragen aus dem Gebiet der Mechanik \\
\hline SS 49 & Übungen über didaktische Fragen aus dem Gebiet der Mechanik und der Wärmelehre \\
\hline WS 49/50 & Übungen über didaktische Fragen aus dem Gebiet der Wärmelehre und Optik \\
\hline SS 50 & Übungen über didaktische Fragen aus dem Gebiet der Optik und der Elektrizitätslehre \\
\hline WS 50/51 & $\begin{array}{l}\text { Probleme der Atomistik im Unterricht } \\
\text { Übungen über didaktische Fragen aus dem Gebiet der Atomistik }\end{array}$ \\
\hline WS 51/52 & Didaktik der Physik I mit Übungen \\
\hline SS 52 & Didaktik der Physik II mit Übungen \\
\hline WS 54/55 & Didaktik der Physik II mit Übungen \\
\hline SS 55 & Didaktik der Physik II mit Übungen \\
\hline WS 55/56 & $\begin{array}{l}\text { Physik im Unterricht } \\
\text { Didaktik der Physik I }\end{array}$ \\
\hline
\end{tabular}

Tabelle 21 Lehrangebot zur Didaktik der Physik von Ernst Lamla, 1948-1955.

1749 HStAH, Nds. 401 Acc. 92 / 85, Nr. 330.

1750 Hennig, Johannson, Ohlemacher \& Winters [1986] S. 94-96. 
Experimentelle und theoretische Physik

\begin{tabular}{|c|c|c|c|c|c|c|}
\hline Vorlesungsgruppen & WS $31 / 32$ & SS 32 & WS $32 / 33$ & SS 33 & WS 33/34 & SS 34 \\
\hline $\begin{array}{l}\text { Experimentalphysik } \\
\text { Einführungsvorlesung } 1751\end{array}$ & (Pohl) & 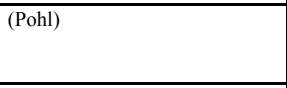 & $($ Pohl) & (Pohl, Hilsch) & (Pohl, Hilsch) & (Pohl, Hilsch) \\
\hline $\begin{array}{l}\text { Praktika und dazugehörige Seminare und } \\
\text { Vorlesungen } 1752\end{array}$ & (Franck) & (Franck) & (Franck) & (Franck) & (N.N.) & (N.N., Cario) \\
\hline $\begin{array}{l}\text { Atom- und Kernphysik, Spektroskopie, } \\
\text { Optik und andere Spezialvorlesungen }\end{array}$ & $\begin{array}{l}\text { Optik + UE (Nordheim) } \\
\text { Grenzgebiete zw. Physik u. Chemie } \\
\text { (Sponer) } \\
\text { Gasentladungen (Hippel) } \\
\text { Exp. Grundl. d. Wellenmechanik } \\
\text { (Kuhn) }\end{array}$ & $\begin{array}{l}\text { Fluorescenz von Gasen } \\
\text { (Franck) } \\
\text { Exp. Spektroskopie u. Atombau } \\
\text { (Cario) } \\
\text { Bandenspektren (Sponer) } \\
\text { Kinetische Theorie d. Materie } \\
\text { u. ihre exp. Grundl. (Kuhn) }\end{array}$ & $\begin{array}{l}\text { Ultrarote Spektren u. Ramanspektren } \\
\text { (Kuhn) } \\
\text { Optik (Cario) } \\
\text { Glühelektronenemission u. } \\
\text { lichtelektrischer Effekt (Hippel) } \\
\text { Mechanik + UE (Schuler) }\end{array}$ & $\begin{array}{l}\text { Energieaustausch bei elementaren } \\
\text { Stoßprozessen (Franck) } \\
\text { Exp. Einf. in d. Atomphysik (Cario) } \\
\text { Radioaktivität u. Kernphysik (Sponer) } \\
\text { Elektrizititatsleitung in Flüssigkeiten } \\
\text { (Hippel) } \\
\text { ttomspektren u. periodisches System } \\
\text { (Kuhn) }\end{array}$ & $\begin{array}{l}\text { Atomtheor. Fragen d. atmosphärischen } \\
\text { u. kosmischen Physik (Cario) } \\
\text { Beugungserscheinungen u. Struktur d. } \\
\text { Materie (Sponer) } \\
\text { Physik d. Gasentladungen (Hippel) } \\
\text { Mechanik + UE (Schuler) }\end{array}$ & $\begin{array}{l}\text { Molekülspektren u. ihre Anwend. auf } \\
\text { chem. Probleme (Spponer) } \\
\text { Gasentladungen (N.N.) }\end{array}$ \\
\hline Wärmelehre und Thermodynamik & $\begin{array}{l}\text { Exp. Grundl. d. Wärmelehre (Cario) } \\
\text { Wärmelehre + UE (Hertz) }\end{array}$ & & $\begin{array}{l}\text { Kinetische Theorie d. Wärme u. } \\
\text { statistische Mechanik (Hertz) }\end{array}$ & Thermodynamik + UE (Heitler) & $\begin{array}{l}\text { Kinetische Theorie d. Wärme + UE } \\
\text { (Stobbe) } \\
\text { Einf. in d. Thermodynamik (Prandtl) }\end{array}$ & \\
\hline Quantentheorie, Relativitätstheorie & Relativitätstheorie (Heitler) & $\begin{array}{l}\text { Quantentheorie u. Atomphysik } \\
+ \text { UE (Born) }\end{array}$ & Quantenmechanik (Heitler) & $\begin{array}{l}\text { * Allg. Infinitesimalgeometrie u. } \\
\text { Relativitätstheorie (Weyl) }\end{array}$ & & $\begin{array}{l}\text { Quantentheorie (N.N.) } \\
\text { Einf. in d. Relativitatstsheorie, } \\
\text { allgemeinverstanndlich (Schuler) } \\
\end{array}$ \\
\hline $\begin{array}{l}\text { Sonstige Veranstaltungen der theoretischen } \\
\text { Physik }\end{array}$ & $\begin{array}{l}\text { SE über Struktur d. Materie (Born, } \\
\text { Hilbert, Weyl) }\end{array}$ & $\begin{array}{l}\text { Einf. in d. theor. Physik + UE } \\
\text { (Hertz) } \\
\text { Mechanik + UE (Heitler) } \\
\text { SE über Struktur d. Materie } \\
\text { (Born, Weyl) } \\
\text { Elektronentheorie d. Metalle } \\
\text { (Nordheim) } \\
\end{array}$ & $\begin{array}{l}\text { Theorie d. Elektrizität u. d. Magne- } \\
\text { tismus + UE (Born) } \\
\text { Mechanik II (Nordheim) } \\
\text { SE über Struktur d. Materie (Born, } \\
\text { Weyl) }\end{array}$ & $\begin{array}{l}\text { Einf. in d. theor. Physik u. } \\
\text { Vektorrechnung (Hertz) } \\
\text { Optik + UE (Born) } \\
\text { Elektrt. u. magn. Eigenschaften d. } \\
\text { Materie (Nordheim) }\end{array}$ & $\begin{array}{l}\text { SE über Struktur d. Materie (Stobbe, } \\
\text { Weyl) } \\
\text { Feld-u. Wellen-Mechanik (Weyl) }\end{array}$ & \\
\hline Mathematik & $\begin{array}{l}{ }^{*} \text { Math. Behandlung d. Naturwiss. }{ }^{+} \\
\text {UE (Seyfarth) }\end{array}$ & & $\begin{array}{l}{ }^{*} \text { Math. Behandlung d. Naturwiss. }+ \\
\text { UE (Seyfarth) }\end{array}$ & $\begin{array}{l}{ }^{*} \text { Grundl. d. Analysis (Landau) } \\
*^{*} \text { Differentialgl. u. Meth. d. math. } \\
\text { Physik + UE (Courant) }\end{array}$ & $\begin{array}{l}\text { * Anwend. d. Math. auf Naturwiss. } \\
\text { (Seyfarth) } \\
\text { * Differentialgl. u. Meth. d. math. } \\
\text { Physik + UE (Cauer) } \\
\end{array}$ & \\
\hline $\begin{array}{l}\text { Geschichte, Philosophie und Methoden der } \\
\text { Physik, Didaktik }\end{array}$ & $\begin{array}{l}\text { Prinzipien d. Physik (Born) } \\
\text { * Kausalität u. Physik (Hertz) } \\
\text { * Einleitung in d. Philosophie auf } \\
\text { Grund moderner Naturwiss. } \\
\text { (Hibert) } \\
\text { Kosmogonie (Kienle) }\end{array}$ & $\begin{array}{l}\text { * Philosophische } \\
\text { Voraussetzungen d. Naturwiss. } \\
\text { (Hertz) } \\
\text { * Die math.-phys. } \\
\text { Erkenntnisweise (Weyl) }\end{array}$ & $\begin{array}{l}\text { Grundlagen d. Logik, } \\
\text { allgemeinverständlich (Hilbert) } \\
\text { Probleme u. Meth. d. Math. } \\
\text { (Courant) }\end{array}$ & $\begin{array}{l}\text { Unsere Stellung zum Weltganzen } \\
\text { (Kienle) } \\
\text { Moderne Strömungen in d. Wissen- } \\
\text { schaft d. unbelebten Natur (Born) }\end{array}$ & & $\begin{array}{l}\text { Technik d. Römer, mit bes. Berücksichti- } \\
\text { gung deutscher Altertümer (Kyropoulos) }\end{array}$ \\
\hline Sonstige Veranstaltungen & $\begin{array}{l}\text { Phys. PS (Cario, Hippel) } \\
\text { Phys. SE (Born, Franck) } \\
\text { Englischer Sprachkurs }\end{array}$ & $\begin{array}{l}\text { Phys. PS (Cario, Hippel) } \\
\text { Phys. SE (Born, Franck) } \\
\text { Englischer Sprachkurs }\end{array}$ & $\begin{array}{l}\text { Phys. PS (Cario, Hippel) } \\
\text { Phys. SE (Born, Franck) } \\
\text { Englischer Sprachkurs }\end{array}$ & $\begin{array}{l}\text { Phys. PS (Cario, Hippel) } \\
\text { Phys. SE (Born, Franck) } \\
\text { Englischer Sprachkurs }\end{array}$ & Phys. PS (Cario, Hippel) & Englischer Sprachkurs \\
\hline
\end{tabular}

* Im Vorlesungsverzeichnis bei den mathematischen Veranstaltungen angekündigt.

Tabelle 22 Das Lehrangebot der experimentellen und theoretischen Physik 1931-1955. ${ }^{1753}$

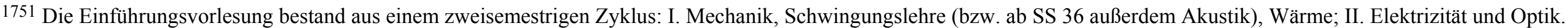
1752 Ein nur in Klammern angegebener Name bedeutet hier, dass es sich um das Praktikum der Physiker, Mathematiker, Naturwissenschaftler und Mediziner handelt. Namentlich angegeben sind nur diejenigen, die im Vorlesungsverzeichnis als dafür Verantwortliche aufscheinen. Zu den strukturellen Veränderungen des Praktikums siehe Abschnitt 4.1.1.

1753 Die Tabelle basiert vorwiegend auf den publizierten Vorlesungsverzeichnissen der Universität Göttingen. Diese im Voraus gedruckten Angaben spiegeln nicht immer das tatsächliche Lehrangebot wider. Dies gilt insbesondere für das SS 1933, in dem einige Vorlesungen von dann emigrierten Wissenschaftlern angekündigt waren. In diesem Fall

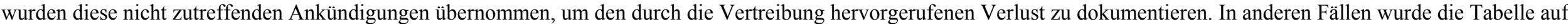

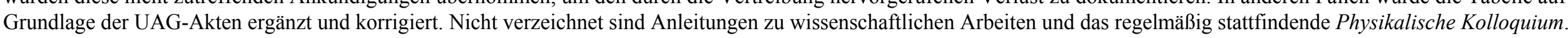




\begin{tabular}{|c|c|c|c|c|c|c|}
\hline Vorlesungsgruppen & WS 34/35 & SS 35 & WS $35 / 36$ & SS 36 & WS $36 / 37$ & SS 37 \\
\hline Experimentalphysik Einführungsvorlesung & (Pohl, Hilsch) & $\begin{array}{l}\text { (Pohl, Hilsch) } \\
\end{array}$ & (Pohl, Hilsch) & (Pohl, Hilsch) & (Pohl, Hilsch) & (Pohl, Hilsch) \\
\hline $\begin{array}{l}\text { Praktika und dazugehörige Seminare und } \\
\text { Vorlesungen }\end{array}$ & (N.N., Cario) & (N.N., Cario) & (Joos) & $\begin{array}{l}\text { (Joos) } \\
\text { Praktikum d. quantitativen u. } \\
\text { qualitativen Spektralanalyse } \\
\text { (Mannkopff) }\end{array}$ & (Joos) & (Joos) \\
\hline $\begin{array}{l}\text { Atom- und Kernphysik, Spektroskopie, Optik } \\
\text { und andere Spezialvorlesungen }\end{array}$ & $\begin{array}{l}\text { Exp. Atomphysik I: Licht-Emmission u. - } \\
\text { Absorption (Cario) } \\
\text { Quantitative u. qualitative Verfahren d. optischen } \\
\text { Spektralanalyse (Mannkopff) } \\
\text { Energieaustausch bei elementaren Stoßprozessen } \\
\text { (Sponer) }\end{array}$ & $\begin{array}{l}\text { Exp. Atomphysik II : } \\
\text { Radioaktivität (Cario) }\end{array}$ & $\begin{array}{l}\text { Der metallische Zustand (Joos) } \\
\text { Ausgew. Kapitel d. Optik (Cario) } \\
\text { Atomsspektren u. Atombau } \\
\text { (Mannkopff) }\end{array}$ & $\begin{array}{l}\text { Atomtheor. Fragen d. atmosphärischen } \\
\text { u. kosmischen Physik (Cario) } \\
\text { Magnetische Eigenschaften d. Stoffe } \\
\text { (Joos) }\end{array}$ & $\begin{array}{l}\text { Atomphys. Fragen d. atmosphärischen } \\
\text { u. kosmischen Physik (Cario) } \\
\text { Bandenspektren u. chem. Bindung } \\
\text { (Mannkopff) } \\
\text { Die Grundl. d. Konstruktion optischer } \\
\text { Instrumente (Joos) } \\
\text { Elektrizität t. Magnetismus + UE } \\
\text { (N.N.) }\end{array}$ & $\begin{array}{l}\text { Kernphysik (Joos) } \\
\text { Bandenspektren u. chem. } \\
\text { Bindung (Mannkopff) } \\
\text { Kursus d. quantitativen } \\
\text { Spektralanalyse (Mannkopff) }\end{array}$ \\
\hline Wärmelehre und Thermodynamik & & & & $\begin{array}{l}\text { Theoretische Physik V: Thermodynamik } \\
\text { u. Statistik + UE (Sauter) }\end{array}$ & $\begin{array}{l}\text { Ausgew. Fragen d. Thermodynamik u. } \\
\text { Statistik (Sauter) }\end{array}$ & \\
\hline Quantentheorie, Relativitätstheorie & & & $\begin{array}{l}\text { Theor. Physik IV: Atomphysik u. } \\
\text { Quantentheorie + UE (Sauter) }\end{array}$ & $\begin{array}{l}\text { Theor.-phys. SE: Ausgew. Fragen d. } \\
\text { Quantenmechanik (Sauter) }\end{array}$ & & $\begin{array}{l}\text { SE zur Quantenmechanik } \\
\text { (Becker) }\end{array}$ \\
\hline $\begin{array}{l}\text { Sonstige Veranstaltungen der theoretischen } \\
\text { Physik }\end{array}$ & \begin{tabular}{|l} 
Theor. Physik II: Elektrodynamik + UE (Fues) \\
Elektronentheorie d. Metalle (Sauter) \\
Kernphysik u. Radioaktivitatt (Sauter) \\
SE über Fragen d. neueren Physik (Fues, Sauter) \\
\end{tabular} & $\begin{array}{l}\text { Theor. Physik III: Optik + } \\
\text { UE (Sauter) } \\
\text { Theor.-phys. SE (Sauter) }\end{array}$ & \begin{tabular}{|l|l} 
Theor-phys. SE (Sauter) \\
\end{tabular} & & Theor.-phys. SE (Sauter) & $\begin{array}{l}\text { Optik aller Wellenlängen } \\
\text { (Becker) }\end{array}$ \\
\hline Mathematik & $\begin{array}{l}\text { VO, Besprechungen u. UE über Fragen d. angew. } \\
\text { Math. für Anf., insbes. Naturwiss. (Seyfarth) }\end{array}$ & & $\begin{array}{l}\text { * Math. Hilfsmittel d. Naturwiss. } \\
\text { (Seyfarth) } \\
{ }^{*} \text { Differentialgl. d. theor. Physik, } \\
\text { spez. Funktionen (Sauter, Ullrich) } \\
\end{array}$ & $\begin{array}{l}\text { * Math. Fragen d. Theorie u. Berech- } \\
\text { nung d. Flugzeuge (Cauer) }\end{array}$ & & \\
\hline $\begin{array}{l}\text { Geschichte, Philosophie und Methoden der } \\
\text { Physik, Didaktik }\end{array}$ & & & & & & \\
\hline Sonstige Veranstaltungen & Englischer Sprachkurs (Miss Bennett Jones) & & Phys. SE (Cario) & Phys. SE (Cario) & $\begin{array}{l}\text { Physik als Waffe im Daseinskampf } \\
\text { (Joos) } \\
\text { Phys. PS (Cario) }\end{array}$ & \\
\hline
\end{tabular}

\begin{tabular}{|c|c|c|c|c|c|c|}
\hline Vorlesungsgruppen & WS $37 / 38$ & SS 38 & WS 38/39 & SS 39 & WS 39/40 & 1. TM 40 \\
\hline Experimentalphysik Einführungsvorlesung & (Pohl, Hilsch) & (Pohl, Hilsch) & (Pohl, Hilsch) & (Pohl, Hilsch) & (Pohl, Hilsch) & (Pohl, Pick) \\
\hline $\begin{array}{l}\text { Praktika und dazugehörige Seminare und } \\
\text { Vorlesungen }\end{array}$ & (Joos) & 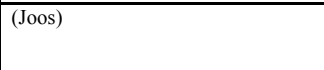 & (Joos) & (Joos, Hanle) & (Joos, Hanle) & (Joos, Hanle) \\
\hline $\begin{array}{l}\text { Atom- und Kernphysik, Spektroskopie, } \\
\text { Optik und andere Spezialvorlesungen }\end{array}$ & $\begin{array}{l}\text { Quantitative u. qualitative Spekt- } \\
\text { ralanalyse (Mannkopff) } \\
\text { Spektroskopie (Joos) }\end{array}$ & $\begin{array}{l}\text { Kernphysik (Hanle) } \\
\text { Ausgew. Abschnitte d. angew. } \\
\text { Optik (Joos) } \\
\text { Elektrizität in Metallen } \\
\text { (Mannkopff) }\end{array}$ & $\begin{array}{l}\text { SE ̈̈ber Kernphysik u. } \\
\text { Höhenstrahlung (Hanle) } \\
\text { Ultrarote Spektren (Mannkopff) } \\
\text { Gasentladungen (Hanle) } \\
\text { Physik d. tiefen Temperaturen } \\
\text { (Joos) } \\
\end{array}$ & $\begin{array}{l}\text { SE über Kernphysik u. Höhenstrahlung } \\
\text { (Hanle) } \\
\text { Magneto- u. Elektrooptik (Hanle) } \\
\text { Ausgew. Kapitel d. Kristallphysik (Joos) }\end{array}$ & $\begin{array}{l}\text { Kursus d. quantitativen u. qualitativen } \\
\text { Emissionsspektralanalyse (Mannkopff) } \\
\text { Wechselwirkung zw. Licht u. Materie (Hanle) } \\
\text { Physik d. Atomkerns (Jos) } \\
\text { Atombau u. Spekttrallinien (Mannkopff) }\end{array}$ & $\begin{array}{l}\text { Spektroskopie (Hellwege) } \\
\text { Wechselwirkung zw. Licht u. } \\
\text { Materie (Hanle) }\end{array}$ \\
\hline Wärmelehre und Thermodynamik & $\begin{array}{l}\text { Theorie d. Wärme u. Statistik } \\
\text { (Becker) }\end{array}$ & & & & $\begin{array}{l}\text { Wärmetheorie u. statistische Mechanik + UE } \\
\text { (Becker) }\end{array}$ & \\
\hline Quantentheorie, Relativitätstheorie & Quantenmechanik (Becker) & & $\begin{array}{l}\begin{array}{l}\text { SE über Quantentheorie } \\
\text { (Becker) }\end{array} \\
\end{array}$ & $\begin{array}{l}\text { Die exp. Grundl. d. neueren } \\
\text { Quantentheorie (Mannkopff) }\end{array}$ & & $\begin{array}{l}\text { Grundzüge d. Quantentheorie + } \\
\text { UE (Becker) }\end{array}$ \\
\hline $\begin{array}{l}\text { Sonstige Veranstaltungen der theoretischen } \\
\text { Physik }\end{array}$ & & $\begin{array}{l}\text { Mechanik mit Anwend. auf d. } \\
\text { Physik (Becker) } \\
\text { SE über neuere Probleme d. Physik } \\
\text { (Becker) }\end{array}$ & $\begin{array}{l}\text { Elektrizität u. Magnetismus + } \\
\text { UE (Becker) }\end{array}$ & $\begin{array}{l}\text { Elektronentheorie + UE (Becker) } \\
\text { SE über spez. Fragen d. theor. Physik } \\
\text { (Becker) }\end{array}$ & SE für theor. Physik (Becker) & $\begin{array}{l}\text { SE zur theor. Physik (Becker) } \\
\text { Spez. Probleme d. theor. Physik } \\
\text { (Döring) }\end{array}$ \\
\hline Mathematik & \begin{tabular}{|l|} 
* Einf. in d. höhere Math. für \\
Naturwiss. (Becker, Kaluza)
\end{tabular} & $\begin{array}{l}\text { * Einf. in d. höhere Math. für } \\
\text { Naturwiss. II (Becker, Kaluza) }\end{array}$ & $\begin{array}{l}\text { * Einf. in d. höhere Math. für } \\
\text { Naturwiss. + UE (Becker) }\end{array}$ & $\begin{array}{l}\text { * Einf. in d. höhere Math. für Naturwiss. } \\
\text { II + UE (Becker) }\end{array}$ & $\begin{array}{l}\text { * Einf. in d. höhere Math. für Naturwiss. } \\
\text { (Kaluza) }\end{array}$ & $\begin{array}{l}\text { * Einf. in d. höhere Math. für } \\
\text { Naturwiss. II + UE (Kaluza) }\end{array}$ \\
\hline \multicolumn{7}{|l|}{$\begin{array}{l}\text { Geschichte, Philosophie und Methoden der } \\
\text { Physik, Didaktik }\end{array}$} \\
\hline Sonstige Veranstaltungen & & $\begin{array}{l}\text { Maschinenzeichen u. Normenkunde } \\
\text { für Physiker (N.N.) }\end{array}$ & $\begin{array}{l}\text { Werkstoffkunde für Physiker } \\
\text { (N.N.) }\end{array}$ & $\begin{array}{l}\text { Einzelthemen aus d. neueren phys. } \\
\text { Literatur, erläutert mit Exp. (Mollwo) }\end{array}$ & $\begin{array}{l}\text { Einzelthemen aus d. neueren Physik, erläutert } \\
\text { mit Exp. (Mollwo) }\end{array}$ & \\
\hline
\end{tabular}

* Im Vorlesungsverzeichnis bei den mathematischen Veranstaltungen angekündigt. 


\begin{tabular}{|c|c|c|c|c|c|}
\hline $\begin{array}{c}\text { Vorlesungsgruppen } \\
\end{array}$ & 2. u. 3. TM 40 & 1. TM 41 & SS 41 & WS $41 / 42$ & SS 42 \\
\hline Experimentalphysik Einführungsvorlesung & (Pohl, N.N.) & (Pohl, Mollwo) & (Pohl, Mollwo) & (Pohl, Mollwo) & (Pohl, Mollwo) \\
\hline Praktika und dazugehörige Seminare und Vorlesungen & (Joos, Hanle) & (Joos, Hanle) & (Hanle, Hellwege) & (Hellwege) & (N.N.) \\
\hline $\begin{array}{l}\text { Atom- und Kernphysik, Spektroskopie, Optik und andere } \\
\text { Spezialvorlesungen }\end{array}$ & $\begin{array}{l}\text { Einf. in d. Kernphysik (Hanle) } \\
\text { Atomphysik (Hellwege) }\end{array}$ & $\begin{array}{l}\text { Kristallphysik (Hellwege) } \\
\text { Gasentladungen (Hanle) }\end{array}$ & $\begin{array}{l}\text { Spektroskopie (Hellwege) } \\
\text { Wechselwirkung zw. Licht u. Materie } \\
\text { (Hanle) }\end{array}$ & $\begin{array}{l}\text { Wechselwirkung zw. Licht u. Materie } \\
\text { (Hellwege) }\end{array}$ & Atomphysik (Hellwege) \\
\hline Wärmelehre und Thermodynamik & & & $\begin{array}{l}\text { Thermodynamik + UE (Becker) } \\
\end{array}$ & & \\
\hline Quantentheorie, Relativitätstheorie & & & & Quantentheorie + UE (Becker) & $\begin{array}{l}\text { Quantenmechanik d Elektrons (Becker) } \\
\end{array}$ \\
\hline Sonstige Veranstaltungen der theoretischen Physik & $\begin{array}{l}\text { SE zur theor. Physik (Becker) } \\
\text { Elektrizitiät u. Magnetismus (Becker) } \\
\text { Spez. Probleme d. theor. Physik (Döring) }\end{array}$ & $\begin{array}{l}\text { SE zur theor. Physik (Becker) } \\
\text { Spez. Probleme d. theor. Physik (Döring) } \\
\text { Optik aller Wellenlängen + UE (Becker) } \\
\end{array}$ & $\begin{array}{l}\text { SE zur theor. Physik (Becker) } \\
\text { Spez. Probleme d. theor. Physik } \\
\text { (Döring) }\end{array}$ & $\begin{array}{l}\text { SE zur theor. Physik (Becker) } \\
\text { Elektrizität u. Magnetismus (Döring) }\end{array}$ & $\begin{array}{l}\text { Optik aller Wellenlängen + UE } \\
\text { (Döring) }\end{array}$ \\
\hline Mathematik & $\begin{array}{l}\text { * Einf. in d. höhere Math. für Naturwiss. } \\
\text { II + UE (Kaluza) }\end{array}$ & $\begin{array}{l}* \text { Einf. in d. Math. für Physiker II + UE (Joos) } \\
*^{*} \text { Partielle Differentialgl. d. math. Physik (Görtler) }\end{array}$ & & $\begin{array}{l}\text { * Einf. in d. höhere Math. für } \\
\text { Naturwiss. I (Kaluza) }\end{array}$ & $\begin{array}{l}\text { * Einf. in d. höhere Math. für } \\
\text { Naturwiss. II (Kaluza) }\end{array}$ \\
\hline \multicolumn{6}{|l|}{$\begin{array}{l}\text { Geschichte, Philosophie und Methoden der Physik, } \\
\text { Didaktik }\end{array}$} \\
\hline Sonstige Veranstaltungen & & & $\begin{array}{l}\text { Potential u. oszillierende Funktionen mit } \\
\text { Anwend. in d. Geophysik (Bungers) }\end{array}$ & Phys. PS (Hellwege, Döring) & Phys. PS (Hellwege, Döring) \\
\hline
\end{tabular}

\begin{tabular}{|c|c|c|c|c|c|}
\hline Vorlesungsgruppen & WS $42 / 43$ & SS 43 & WS 43/44 & SS 44 & WS 44/45 \\
\hline Experimentalphysik Einführungsvorlesung & (Pohl, Mollwo) & (Pohl, Mollwo) & (Pohl, Mollwo) & (Pohl, Mollwo) & (Pohl, Mollwo) \\
\hline $\begin{array}{l}\text { Praktika und dazugehörige Seminare und } \\
\text { Vorlesungen }\end{array}$ & $\begin{array}{l}\text { (Kopfermann) } \\
\text { Praktikum d. quantitativen Spektralanalyse } \\
\text { (Mannkopff) }\end{array}$ & (Kopfermann) & $\begin{array}{l}\text { (Kopfermann, Hellwege) } \\
\text { Praktikum d. quantitativen } \\
\text { Emissionspektralanalyse (Mannkopff) } \\
\end{array}$ & (Kopfermann) & (Kopfermann, Hellwege, Walcher) \\
\hline $\begin{array}{l}\text { Atom- und Kernphysik, Spektroskopie, Optik } \\
\text { und andere Spezialvorlesungen }\end{array}$ & $\begin{array}{l}\text { Einf. in d. Kernphysik (Kopfermann) } \\
\text { Molekül- u. Kristallphysik (Hellwege) }\end{array}$ & $\begin{array}{l}\text { Elektro- u. Magneto-Optik (Mannkopff) } \\
\text { Gasentladungen (Valcher) } \\
\text { Tiefe Temperaturen (Hellwege) }\end{array}$ & $\begin{array}{l}\text { Elektronentheorie d. Metalle (Kopfer- } \\
\text { mann) } \\
\text { Physik d. Röntgenstrahlen (Walcher) }\end{array}$ & $\begin{array}{l}\text { Atom- u. Molekülkräfte (Walcher) } \\
\text { Wechselwirkung zw. Licht u. Materie } \\
\text { (Hellwege) }\end{array}$ & $\begin{array}{l}\text { Optische Abbildungen u. spektroskopische Apparate } \\
\text { (Mannkopff) } \\
\text { Wechselwirkung zw. Licht u. Materie (Hellwege) } \\
\text { Ultraschall (Kopfermann) }\end{array}$ \\
\hline Wärmelehre und Thermodynamik & $\begin{array}{l}\text { Wärmelehre u. kinetische Theorie d. } \\
\text { Materie + UE (Becker) }\end{array}$ & & & & \\
\hline Quantentheorie, Relativitätstheorie & & $\begin{array}{l}\text { Quantenmechanik des Elektrons (Becker) } \\
\end{array}$ & & & \\
\hline $\begin{array}{l}\text { Sonstige Veranstaltungen der theoretischen } \\
\text { Physik }\end{array}$ & $\begin{array}{l}\text { SE zur theor. Physik (Becker, Döring) } \\
\text { Elektronentheorie d. Metalle (Döring) }\end{array}$ & $\begin{array}{l}\text { SE zur theor. Physik (Becker) } \\
\text { Atomphysik + UE (Becker) }\end{array}$ & \begin{tabular}{|l|} 
SE zur theor. Physik (Becker) \\
Elektrizitatt u. Magnetismus + UE \\
(Becker)
\end{tabular} & $\begin{array}{l}\text { SE zur theor. Physik (Becker) } \\
\text { Mechanik als Grundlage d. theor. Physik } \\
+ \text { UE (Becker) }\end{array}$ & $\begin{array}{l}\text { SE für theor. Physik (Becker) } \\
\text { Optik aller Wellenlängen + UE (Becker) }\end{array}$ \\
\hline Mathematik & $\begin{array}{l}{ }^{*} \text { Einf. in d. Math. für Naturwiss. I (Becker, } \\
\text { Döring) }\end{array}$ & $\begin{array}{l}\text { * Einf. in d. Math. für Naturwiss. II } \\
\text { (Becker) }\end{array}$ & $\begin{array}{l}\text { * Einf. in d. höhere Math. für Naturwiss. } \\
\text { I (Kaluza) }\end{array}$ & $\begin{array}{l}\text { * Einf. in d. höhere Math. für Naturwiss. } \\
\text { II (Kaluza) }\end{array}$ & $\begin{array}{l}\text { *'Math. für Naturwiss. I+ UE (Becker) } \\
\text { * Spez. Funktionen d. math. Physik (Wittich) } \\
\end{array}$ \\
\hline \multicolumn{6}{|l|}{$\begin{array}{l}\text { Geschichte, Philosophie und Methoden der } \\
\text { Physik, Didaktik }\end{array}$} \\
\hline Sonstige Veranstaltungen & Phys. PS (Kopfermann, Hellwege) & $\begin{array}{l}\text { Phys. PS (Kopfermann, Hellwege, } \\
\text { Walcher) }\end{array}$ & $\begin{array}{l}\text { Phys. PS (Kopfermann, Hellwege) } \\
\text { Phys. Technik-u. Werkstoffkunde } \\
\text { (Kopfermann, Paul) }\end{array}$ & $\begin{array}{l}\text { Phys. PS (Kopfermann, Walcher) } \\
\text { Übungsstunden zur Physik (Becker) }\end{array}$ & Phys. PS (Kopfermann, Walcher) \\
\hline
\end{tabular}

* Im Vorlesungsverzeichnis bei den mathematischen Veranstaltungen angekündigt. 


\begin{tabular}{|c|c|c|c|c|}
\hline Vorlesungsgruppen & WS 45/46 & SS 46 & WS 46/47 & SS 47 \\
\hline Experimentalphysik Einführungsvorlesung & (Pohl, Mollwo) & (Pohl, Mollwo) & (Pohl, Mollwo) & (Pohl, Mollwo) \\
\hline Praktika und dazugehörige Seminare und Vorlesungen & (Kopfermann, Hellwege, Walcher, Paul) & (Kopfermann, Walcher, N.N.) & (Kopfermann, Walcher, N.N.) & (Kopfermann, Paul, Walcher) \\
\hline $\begin{array}{l}\text { Atom- und Kernphysik, Spektroskopie, Optik und } \\
\text { andere Spezialvorlesungen }\end{array}$ & $\begin{array}{l}\text { Meth. u. Apparate d. Spektroskopie (Mannkopff) } \\
\text { Emission, Absorption u. Dispersion d. Lichtes (Kopfer- } \\
\text { mann), } \\
\text { Physik d. freien Elektronen u. Ionen (Walcher) } \\
\text { Elektr. u. magnet. Eigenschaften d. Materie (Hellwege) }\end{array}$ & $\begin{array}{l}\text { Metallelektronen (Walcher) } \\
\text { Exp. Grundl. d. Atomphysik (Paul) } \\
\text { Natürliche u. künstliche Radioaktivität } \\
\text { (Houtermans) } \\
\text { SE über Neutronen (Kopfermann) } \\
\text { Elektrizitätsdurchgang durch Gase (Mannkopff) }\end{array}$ & $\begin{array}{l}\text { Molekülspektren u. chem. Bindung (Mannkopff) } \\
\text { Physik d. Röntgenlichts (Houtermans) } \\
\text { Metalleletkronen (Walcher) } \\
\text { Spektroskopie u. Atombau (Paul) }\end{array}$ & $\begin{array}{l}\text { Molekëilspektren u. chem. Bindung (Mannkopff) } \\
\text { Metallelelektronen (Walcher) } \\
\text { Atomphysik (Kopfermann) } \\
\text { Radioaktivitâtu t. Geologie (Houtermans) }\end{array}$ \\
\hline Wärmelehre und Thermodynamik & Theorie d. Wärme + UE (Becker) & & & Theor. Wärmelehre + UE (Heisenberg) \\
\hline Quantentheorie, Relativitätstheorie & & $\begin{array}{l}\text { Quantenmechanik + UE (Flügge) } \\
\text { Relativitatstsheorie (Becker) }\end{array}$ & $\begin{array}{l}\text { Quantentheorie II: Diracsche Theorie (Flügge) } \\
\text { Quantentheorie d. Wellenfelder [-] (Heisenberg) } \\
\text { siehe auch Mathematik }\end{array}$ & Quantentheorie + UE (Becker) \\
\hline Sonstige Veranstaltungen der theoretischen Physik & SE für theor. Physik (Becker) & $\begin{array}{l}\text { SE über theor. Physik (Becker, Döring, Flügge) } \\
\text { Elektriziziăt u. Magnetismus + UE (Becker) }\end{array}$ & $\begin{array}{l}\text { Mechanik + UE (Becker) } \\
\text { SE über Elektronen u. Strahlung (Becker) } \\
\end{array}$ & SE über spez. Fragen d. theor. Physik (Becker) \\
\hline Mathematik & Math. Meth. d. Physik (Döring) & * Spez. Funktionen d. math. Physik (Magnus) & $\begin{array}{l}\begin{array}{l}\text { Spez. Eigenwertprobleme d. Quantenmechanik } \\
\text { (Rellich) }\end{array} \\
\text { (a) }\end{array}$ & $\begin{array}{l}\text { * Analytische Geometrie u. lineare Algebra für Naturwiss. } \\
\text { (Magnus) }\end{array}$ \\
\hline $\begin{array}{l}\text { Geschichte, Philosophie und Methoden der Physik, } \\
\text { Didaktik }\end{array}$ & $\begin{array}{l}\text { Geschichte d. Physik [-] (S. Flügge) } \\
\text { Sterne, Nebel u. Weltall (ten Bruggencate) }\end{array}$ & $\begin{array}{l}\text { Ausgew. Kapitel aus d. Geschichte d. Physik } \\
\text { (Flügge) } \\
\text { Das Wesen d. math. Problems (Lyra) } \\
\text { Aus d. Welt d. Atome (N.N. oder Kopfermann) } \\
\text { Die Geschichte d. physischen Welt (Weizsäcker) } \\
\end{array}$ & $\begin{array}{l}\text { Übersicht über Meth. u. Ergeb. d. Physik (Flügge) } \\
\text { Aus d. Geschichte d. Physik (Flügge) } \\
\text { Anschauliche Mathematik (Kaluza) }\end{array}$ & $\begin{array}{l}\text { Kosmogonie (Weizsäcker) } \\
\text { Lebensbilder großer Naturforscher (Eucken) } \\
\text { Sonne u. Erde (Bartels) }\end{array}$ \\
\hline Sonstige Veranstaltungen & $\begin{array}{l}\text { Phys. PS (Kopfermann) } \\
\text { Phys. u. biolog. Grundl. d. Strahlentherapie (Kepp, Witte) } \\
\text { Repetitorium d. Exp.-physik für Kriegsteilnehmer (N.N.) }\end{array}$ & Phys. PS (Kopfermann) & & $\begin{array}{l}\text { Phys. PS (Houtermans, Mannkopff) } \\
\text { Kernphys. Anwend. in Medizin u. Biologie (Schubert) }\end{array}$ \\
\hline
\end{tabular}

\begin{tabular}{|c|c|c|c|c|}
\hline Vorlesungsgruppen & WS 47/48 & SS 48 & WS 48/49 & SS 49 \\
\hline Experimentalphysik Einführungsvorlesung & (Pohl, Mollwo) & (Pohl, Mollwo) & (Pohl) & (Pohl) \\
\hline $\begin{array}{l}\text { Praktika und dazugehörige Seminare und } \\
\text { Vorlesungen }\end{array}$ & (Kopfermann, Houtermans, Paul) & (Kopfermann, Houtermans, Paul) & $\begin{array}{l}\text { (Kopfermann, Houtermans, Paul) } \\
\text { Praktikum d. chem. Analyse durch Emissions- } \\
\text { spektren (Mannkopff) }\end{array}$ & \begin{tabular}{|l|} 
(Kopfermann, Houtermans, Paul) \\
Praktikum d. quantitativen Emissionsspektralanalyse (Mannkopff)
\end{tabular} \\
\hline $\begin{array}{l}\text { Atom- und Kernphysik, Spektroskopie, Optik } \\
\text { und andere Spezialvorlesungen }\end{array}$ & $\begin{array}{l}\text { Ergeb. u. Meth. d. Ultrarotspektroskopie (Mannkopff) } \\
\text { Physik d. Neutrons (Houtermans) } \\
\text { Erzeugung energiereicher Elektronen u. ihre Anwend. } \\
\text { (Paul) } \\
\text { Einf. in d. Theorie d. chem. Bindungen (Wirtz) }\end{array}$ & $\begin{array}{l}\text { Durchgang von Strahlung durch Materie } \\
\text { (Kopfermann) } \\
\text { Elektronenbeugung an fester, flüssiger u. } \\
\text { gasförmiger Materie (König) } \\
\text { Aufbau u. Umwandlungen d. Atomkerne } \\
\text { (Houtermans) }\end{array}$ & $\begin{array}{l}\text { Durchgang von Strahlung durch Materie } \\
\text { (Houtermans) } \\
\text { Ultrarotspektroskopie (Mannkopff) } \\
\text { Mesonen in d. kosmischen Strahlung + UE } \\
\text { (Wirtz) } \\
\text { Elektronenübermikroskopie (König) }\end{array}$ & $\begin{array}{l}\text { Ultrarotspektroskopie (Mannkopff) } \\
\text { Radioaktivität (Houtermans) } \\
\text { Dispersion u. Absorption d. Lichtes (Kopfermann) } \\
\text { Kosmische Strahlung (Haxel) } \\
\text { Seminaristische Übungen über Probleme d. kosmischen Strahlung (Wirtz, } \\
\text { Haxel) } \\
\text { Ausgew. Kapitel aus d. Kristallphysik (Hellwege) } \\
\text { Elektrische Leitungsvorgänge in nichtmetallischen festen Körpern (Pick) } \\
\text { Aus d. Kinetik d. Flüssigkeiten (Wirtz) }\end{array}$ \\
\hline Wärmelehre und Thermodynamik & & & Theorie d. Wärme + UE (Becker) & \\
\hline Quantentheorie, Relativitätstheorie & $\begin{array}{l}\text { Quantentheorie d. Elektrons u. d. Lichts (Weizsäcker) } \\
\text { Kursus über Einzelfragen d. Quantentheorie (Becker, } \\
\text { Ass.) }\end{array}$ & $\begin{array}{l}\text { Einf. in d. Quantentheorie d. Atombaus + UE } \\
\text { (Heisenberg) } \\
\text { Quanteneffekte in d. Molekülphysik + SE } \\
\text { (Wirtz) }\end{array}$ & $\begin{array}{l}\text { Quantenmechanik + UE (Heisenberg) } \\
\text { Spezielle Relativitatatstheorie + UE (Ludwig) }\end{array}$ & Allgemeine Relativitätstheorie (Ludwig) \\
\hline $\begin{array}{l}\text { Sonstige Veranstaltungen der theoretischen } \\
\text { Physik }\end{array}$ & $\begin{array}{l}\text { SE zur theor. Physik (Becker) } \\
\text { Optik + UE (Becker) }\end{array}$ & $\begin{array}{l}\text { SE zur theor. Physik (Becker) } \\
\text { Statistische Mechanik (Ludwig) } \\
\text { Theorie d. Elektrizitatt + UE (Becker) }\end{array}$ & SE zur theor. Physik (Becker) & $\begin{array}{l}\text { SE zur theor. Physik (Becker, Ludwig) } \\
\text { Atomphysik + UE (Becker) }\end{array}$ \\
\hline Mathematik & * Math. für Naturwiss. (Graeser) & $\begin{array}{l}\text { * Ausgew. Meth. d. math. Physik mit geophys. } \\
\text { Anwend. (Bartels) }\end{array}$ & * Math. für Naturwiss. (Graeser) & \begin{tabular}{|l} 
Einf. in d. math. Meth. d. Physik (Ludwig) \\
\end{tabular} \\
\hline $\begin{array}{l}\text { Geschichte, Philosophie und Methoden der } \\
\text { Physik, Didaktik }\end{array}$ & $\begin{array}{l}\text { Aus d. Geschichte d. Physik (Laue) } \\
\text { Sterne, Nebel, Weltall (ten Bruggencate) }\end{array}$ & $\begin{array}{l}\text { Der begriffliche Aufbau d. theor. Physik } \\
\text { (Weizsäker) } \\
\text { Aus d. Geschichte d. Physik (Laue) } \\
\text { Lebensbilder großer Naturforscher u. } \\
\text { Techniker (Eucken) }\end{array}$ & \begin{tabular}{|l} 
Didaktische Fragen aus d. Gebiet d. Mechanik \\
(Lamla) \\
Das Atom (Weizsäcker)
\end{tabular} & $\begin{array}{l}\text { Aus d. Geschichte d. Physik (Laue) } \\
\text { UE über didaktische Fragen aus d. Gebiet d. Mechanik u. d. Wärmelehre } \\
\text { (Lamla) } \\
\text { Vorlesungsreihe: Grundlegende Tatsachen d. heutigen Naturwiss. (siehe } \\
\text { Abschnitt 4.2) }\end{array}$ \\
\hline Sonstige Veranstaltungen & & & $\begin{array}{l}\text { Phys. PS (Houtermans, Hellwege) } \\
\text { Phys. Grundl. d. Strahlengenetik (Paul) }\end{array}$ & \begin{tabular}{|l|} 
Phys. PS (Hellwege) \\
Wissenschaftliche Photographie (König)
\end{tabular} \\
\hline
\end{tabular}

* Im Vorlesungsverzeichnis bei den mathematischen Veranstaltungen angekündigt. 


\begin{tabular}{|c|c|c|c|}
\hline Vorlesungsgruppen & WS 49/50 & SS 50 & WS 50/51 \\
\hline Experimentalphysik Einführungsvorlesung & (Pohl, Pick) & (Pohl, Pick) & (Pohl, Pick, Stöckmann) \\
\hline Praktika und dazugehörige Seminare und Vorlesungen & (Kopfermann, Houtermans, Paul) & (Kopfermann, Houtermans, Paul) & (Kopfermann, Houtermans, Paul) \\
\hline $\begin{array}{l}\text { Atom- und Kernphysik, Spektroskopie, Optik und } \\
\text { andere Spezialvorlesungen }\end{array}$ & $\begin{array}{l}\text { Spektroskopie aller Wellenlängen (Hellwege) } \\
\text { Kursus d. quantitativen Spektralanalyse (Mannkopff) } \\
\text { Spertraphotometrie + UE (Mannkopff) } \\
\text { Physik d. Röntgenstrahlen (Haxel) } \\
\text { Durchgang von Strahlung durch Materie (Houtermans) } \\
\text { Exp. Grundl. d. Atomphysik (Paul) } \\
\text { Chem. Bindungen (Wirtz) } \\
\text { Physik d. Oberfllähen (König) } \\
\end{array}$ & $\begin{array}{l}\text { Molekularstrahlen (Kopfermann) } \\
\text { Tiefe Temperaturen (Houtermans) } \\
\text { Kosmische Strahlung (Wirtz) } \\
\text { Kristallphosphore (iik) } \\
\text { Eisf. in d. Physik d. Atome (Hellwege) } \\
\text { Ferromagnetismus (König) }\end{array}$ & $\begin{array}{l}\text { Kursus d. quantitativen Emissionsspektralanalyse (Mannkopff) } \\
\text { Spektralphotometrie +UE (Mannkopff) } \\
\text { Molekiulspektroskopie (Mannkopff) } \\
\text { Kosmische Strahlung (Wirtz) } \\
\text { Wechselwirkung von Licht mit Materie (Hellwege) } \\
\text { Exp. Meth. d. Kerrphysik (Paul) } \\
\text { Radioaktive Meth. d. Mineralogie u. Geologie (Houtermans) } \\
\text { Physik dünner Schichten (König) }\end{array}$ \\
\hline \multicolumn{4}{|l|}{ Wärmelehre und Thermodynamik } \\
\hline Quantentheorie, Relativitätstheorie & Quantentheorie + UE (Becker) & & Relativitätstheorie (Sauter) \\
\hline Sonstige Veranstaltungen der theoretischen Physik & $\begin{array}{l}\text { SE zur theor. Physik (Becker, Ludwig) } \\
\text { Theorie d. Supraleitung (Laue) } \\
\text { Elastizitätstheorie d. Kristalle u. ihre molekulare Deutung (Ludwig) } \\
\text { Molekülstruktur (Sauter) }\end{array}$ & $\begin{array}{l}\text { Elektrizitäta u. Magnetismus }+ \text { UE (Becker) } \\
\text { SE über spez. Fragen d. theor. Physik (Becker) } \\
\text { Theorie d. Atomkers (Heisenberg) } \\
\text { Kinetische Gastheorie (Sauter) }\end{array}$ & $\begin{array}{l}\text { SE zur theor. Physik (Becker) } \\
\text { Gittertheorie d. Kristalle + UE (Leibfried) } \\
\text { Elektronentheorie d. Metalle (Sauter) } \\
\text { Theorie d. Neutronen (Heisenberg) } \\
\text { Optik aller Wellenlängen + UE (Becker) }\end{array}$ \\
\hline Mathematik & $\begin{array}{l}\text { * Math. für Naturwiss. (Graeser) } \\
\text { * Einf. in d. höhere Analysis, insbes. für Naturwiss. (Rellich) }\end{array}$ & & " Höhere Analysis für Naturwiss. + UE (Kaluza) \\
\hline $\begin{array}{l}\text { Geschichte, Philosophie und Methoden der Physik, } \\
\text { Didaktik }\end{array}$ & $\begin{array}{l}\text { UE über didaktische Fragen aus dem Gebiet d. Wärmelehre u. Optik (Lamla) } \\
\text { Vorlesungstreihe: Grundlegende Tatsachen d. heutigen Naturwiss. (siehe } \\
\text { Abschnitt 4.2) }\end{array}$ & \begin{tabular}{|l} 
Zur Geschichte d. Physik (Laue) \\
UE über didaktische Fragen aus d. Gebiet d. Optik u. d. Elektrizitattslehre \\
(Lamla) \\
Der biblische Wunderglaube u. d. Naturwiss. (Lyra) \\
\end{tabular} & $\begin{array}{l}\text { Probleme d. Atomistik im Unterricht (Lamla) } \\
\text { UE über didaktische Fragen aus d. Gebiet d. Atomistik (Lamla) }\end{array}$ \\
\hline Sonstige Veranstaltungen & $\begin{array}{l}\text { Phys. PS (Hellwege) } \\
\text { SE für Fortgeschrittene (Wirtz) }\end{array}$ & $\begin{array}{l}\text { Phys. PS (Hellwege) } \\
\text { SE fü Fortgeschrittene (Wirtz) } \\
\text { Hydrodynamik im Kosmos (Weizsäcker) } \\
\end{array}$ & $\begin{array}{l}\text { Phys. PS (Hellwege) } \\
\text { SE für Fortgeschrittene (Wirtz) }\end{array}$ \\
\hline
\end{tabular}

\begin{tabular}{|c|c|c|c|}
\hline Vorlesungsgruppen & SS 51 & WS $51 / 52$ & SS 52 \\
\hline Experimentalphysik Einführungsvorlesung & (Pohl, Pick, Stöckmann) & (Pohl, Pick, Stöckmann) & (Pohl, Pick, Stöckmann) \\
\hline Praktika und dazugehörige Seminare und Vorlesungen & \begin{tabular}{|l} 
(Kopfermann, Houtermans, Paul) \\
\end{tabular} & $\begin{array}{l}\text { (Kopfermann, Houtermans, Paul, Krüger) } \\
\end{array}$ & $\begin{array}{l}\text { (Kopfermann, Houtermans, Paul) } \\
\end{array}$ \\
\hline $\begin{array}{l}\text { Atom- und Kernphysik, Spektroskopie, Optik und } \\
\text { andere Spezialvorlesungen }\end{array}$ & \begin{tabular}{|l} 
Moleküllspektren (Mannkopff) \\
Quantitative Emissionsspektralanalyse (Mannkopff) \\
Emission, Absorption u. Dispersion von Licht (Kopfermann) \\
Kosmische Strahlung II (Wirtz) \\
Elektrizitätsleitung in nichtmetallischen Festkörpern (Pick) \\
Symmetrie, Eigenschwingungen u. Elektronenterme von Molekeln u. Kristallen \\
(Hellwege) \\
Physik d. Vakuums (Houtermans) \\
Elektronenbugung an fester, flüssiger u. gasforrmiger Materie (König) \\
\end{tabular} & $\begin{array}{l}\text { Molekülspektren u. Molekülbau (Mannkopff) } \\
\text { Spektralphotometrie (Mannkopff) } \\
\text { Hyperfeinstruktur u. Kernmomente (Kopfermann) } \\
\text { PS Elementarprozessed. Atomphysik (Kopfermann) } \\
\text { Beschleunigungsanlagen für lonen u. Elektronen (Paul) } \\
\text { Einf. in d. Physik d. Atome (Hellwege) } \\
\text { Spez. Probleme d. Atomphysik (Wirtz) } \\
\text { SE zur Atomphysik (Wirtz) } \\
\text { Elektronenmikroskopie (König) }\end{array}$ & $\begin{array}{l}\text { Kursus d. quantitativen Emissionsspektralanalyse (Mannkopff) } \\
\text { Elektrizitätsbeweegung in Gasen (Mannkopff) } \\
\text { Kristallphosphore (Stöckmann) } \\
\text { Einfi. in d. Physik d. Molekeln (Hellwege) } \\
\text { Atomspektren (Kopfermann) } \\
\text { Exp. Grundl. d. Kernphysik (Krüger) }\end{array}$ \\
\hline Wärmelehre und Thermodynamik & \begin{tabular}{|l|l|l} 
Theorie d. Wärme + UE (Sauter) \\
\end{tabular} & & \\
\hline Quantentheorie, Relativitätstheorie & \begin{tabular}{|l|l} 
Relativitätstheorie (Weizsäcker) \\
\end{tabular} & $\begin{array}{l}\text { Quantenmechanik + UE (Leibfried) } \\
\end{array}$ & $\begin{array}{l}\text { Grundl. d. Atom- u. Quantentheorie (Sauter) } \\
\end{array}$ \\
\hline Sonstige Veranstaltungen der theoretischen Physik & $\begin{array}{l}\text { SE zur theor. Physik (Sauter, Leibfried) } \\
\text { Elementare Wellenmechanik + UE (Leibfried) }\end{array}$ & $\begin{array}{l}\text { Theor-phys. SE (Becker, Sauter, Leibfried) } \\
\text { Mechanik als Grundl. d. theor. Physik + UE (Becker) } \\
\text { Statistische Probleme d. Physik + UE (Sauter) }\end{array}$ & $\begin{array}{l}\text { Theor-phys. SE (Becker, Sauter, Leibfried) } \\
\text { Elektrodynamik + UE (Becker) } \\
\text { Schwingungs- u. Ausglechsprobleme d. Physik + UE (Leibfried) } \\
\text { Spez. Probleme aus d. Theorie d. Atomerers (Heisenberg) } \\
\text { Kinetische Theorie d. Flüssigkeiten (Wirtz) }\end{array}$ \\
\hline Mathematik & \begin{tabular}{|l} 
* Höhere Analysis für Naturwiss. + UE (Deuring) \\
* Spez. Funktionen d. math. Physik (Graeser)
\end{tabular} & $\begin{array}{l}* \text { Math. für Naturwiss. (Graeser) } \\
* \text { * Himmelsmechanik (Siegels) }\end{array}$ & $\begin{array}{l}\text { * Höhere Analysis für Naturwiss. + UE (Schneider) } \\
\text { * SE über math. Fragen aus d. Quantentheorie d. Wellenfelder } \\
\text { (Heisenberg, Rellich) }\end{array}$ \\
\hline $\begin{array}{l}\text { Geschichte, Philosophie und Methoden der Physik, } \\
\text { Didaktik }\end{array}$ & & $\begin{array}{l}\text { Didaktik d. Physik I+UE (Lamla) } \\
\text { Feldtheorien (Weizsäcker) }\end{array}$ & Didaktik d. Physik II +UE (Lamla) \\
\hline Sonstige Veranstaltungen & $\begin{array}{l}\text { Phys. PS (Hellwege) } \\
\text { SE für Fortgeschrittene (Wirtz) }\end{array}$ & Phys. PS (Hellwege) & SE für Fortgeschrittene (Wirtz) \\
\hline
\end{tabular}

* Im Vorlesungsverzeichnis bei den mathematischen Veranstaltungen angekündigt. 


\begin{tabular}{|c|c|c|c|c|c|c|c|}
\hline Vorlesungsgruppen & WS 52/53 & SS 53 & WS 53/54 & SS 54 & WS $54 / 55$ & SS 55 & WS 55/56 \\
\hline $\begin{array}{l}\text { Experimentalphysik } \\
\text { Einführungsvorlesung }\end{array}$ & (N.N., Pick, Stöckmann) & (N.N., Pick) & (Hilsch, Pick) & (Hilsch, Buckel) & (Hilsch, Buckel) & (Hilsch, Buckel) & (Hilsch, Buckel) \\
\hline $\begin{array}{l}\text { Praktika und dazugehörige Seminare } \\
\text { und Vorlesungen }\end{array}$ & (Kopfermann, Paul, Krüger) & $\begin{array}{l}\text { (Kopfermann, Mannkopff, } \\
\text { Krüger) }\end{array}$ & (N.N., Mannkopff, Krüger) & (Flammersfeld, Mannkopff) & (Flammersfeld, Mannkopff) & (Flammersfeld, Mannkopff) & $\begin{array}{l}\text { (Flammersfeld) } \\
\text { (Fla }\end{array}$ \\
\hline $\begin{array}{l}\text { Atom- und Kernphysik, } \\
\text { Spektroskopie, Optik und andere } \\
\text { Spezialvorlesungen }\end{array}$ & $\begin{array}{l}\text { Atomspektren (Kopfermann) } \\
\text { Exp. Grundl. d. Kernphysik (Paul) } \\
\text { Ausgew. Kapitel aus d. Exp.-physik } \\
\text { d. Neutrons (Wirtz) }\end{array}$ & $\begin{array}{l}\text { Kursus d. quantitativen } \\
\text { Emissionsspektralanalyse } \\
\text { (Mannkopff) } \\
\text { Elektrizitätsbewegung in } \\
\text { Gasen (Mannkopff) } \\
\text { Exp. Grundl. d. Atomphysik } \\
\text { (Krüger) } \\
\text { Chem. Bindung (Wirtz) }\end{array}$ & $\begin{array}{l}\text { Kursus d. quantitativen } \\
\text { Emissionsspektralanalyse } \\
\text { (Mannkopff) } \\
\text { Probleme aus d. } \\
\text { Neutronenphysik (Wirtz) }\end{array}$ & $\begin{array}{l}\text { Spektrochem. Analyse } \\
\text { (Mannkopff) } \\
\text { Ausgew. Kapitel aus d. } \\
\text { Festkörperphysik (Pick) } \\
\text { Einf. in d. Kernphysik } \\
\text { (Flammersfeld) } \\
\text { Einf. in d. Neutronenphysik } \\
\text { (Wirtz) }\end{array}$ & $\begin{array}{l}\text { Kursus d. spektrochem. Analyse } \\
\text { (Mannkopff) } \\
\text { Spez. Probleme d. } \\
\text { Neutronenphysik + SE (Wirtz) }\end{array}$ & $\begin{array}{l}\text { Spektroskopie u. Kernphysik } \\
\text { (Mannkopff) }\end{array}$ & $\begin{array}{l}\text { Spektrochem. Analyse } \\
\text { (Mannkopff) } \\
\text { Kernphysik (Flammersfeld) } \\
\text { Neutronen- und Reaktorphysik } \\
\text { (Wirtz) }\end{array}$ \\
\hline Wärmelehre und Thermodynamik & & $\begin{array}{l}\text { Theorie d. Wärme + UE } \\
\text { (Becker) }\end{array}$ & & & & & \\
\hline Quantentheorie, Relativitätstheorie & $\begin{array}{l}\text { Quantentheorie + UE (Becker) } \\
\text { siehe auch Geschichte... }\end{array}$ & & Relativitätstheorie (Weizsäcker) & $\begin{array}{l}\text { Quantentheorie + UE } \\
\text { (Leibfried) }\end{array}$ & & & Quantentheorie (Leibfried) \\
\hline $\begin{array}{l}\text { Sonstige Veranstaltungen der } \\
\text { theoretischen Physik }\end{array}$ & $\begin{array}{l}\text { Theor--phys. SE (Becker, Sauter, } \\
\text { Leibfried) } \\
\text { Elastische u. plastische Eigen- } \\
\text { schaften von Metallen (Leibfried) } \\
\text { Elektronentheorie d. Metalle } \\
\text { (Sauter) }\end{array}$ & $\begin{array}{l}\text { Theor--phys. SE (Becker, } \\
\text { Leibfried) } \\
\text { Metallelektronen (Leibfried) }\end{array}$ & $\begin{array}{l}\text { Theor--phys. SE (Becker, } \\
\text { Leibfried) } \\
\text { Statistische Mechanik + UE } \\
\text { (Becker) } \\
\text { Optik + UE (Leibfried) } \\
\text { Theorie d. Supraleitung (Koppe) } \\
\text { Kosmische Strahlung } \\
\text { (Heisenberg) } \\
\end{array}$ & $\begin{array}{l}\text { Elektrodynamik + UE } \\
\text { (Becker) } \\
\text { Theor.-phys. SE (Becker, } \\
\text { Leibfried) }\end{array}$ & $\begin{array}{l}\text { Theor.-phys. SE (Becker, } \\
\text { Leibfried) } \\
\text { Einf. in d.theor. Kernphysik } \\
\text { (Lüders) } \\
\text { Atomtheorie d. Kristallgitter + } \\
\text { UE (Leibfried) } \\
\text { Elektronentheorie + UE (Becker) }\end{array}$ & $\begin{array}{l}\text { Theor.-phys. SE (Becker, Leibfried) } \\
\text { Mechanik als Grundl. d. theor. } \\
\text { Physik + UE (Becker) } \\
\text { Meth. d. theor. Physik (Leibfried) } \\
\text { Theorie d. Kernreaktionen (Lüders) }\end{array}$ & $\begin{array}{l}\text { Theor.-phys. SE. (Leibfried) } \\
\text { Mesonenphysik (Lüders) }\end{array}$ \\
\hline Mathematik & * Math. für Naturwiss. (Graeser) & $\begin{array}{l}\text { * Höhere Analysis für } \\
\text { Naturwiss. + UE (Stellmacher) }\end{array}$ & $\begin{array}{l}\text { * Math. für Naturwiss. } \\
\text { (Graeser) } \\
\text { * Störungstheorie d. } \\
\text { Spektralzerlegung (Rellich) }\end{array}$ & $\begin{array}{l}\text { * Potentialtheorie u. } \\
\text { Funktionen d. math. Physik } \\
\text { (Graeser) }\end{array}$ & * Math. für Naturwiss. (Graeser) & $\begin{array}{l}\text { * Nichtlineare partielle } \\
\text { Differentialgl. Stoß- u. } \\
\text { Expansionswellen (Friedrichs) } \\
\text { * Potentialtheorie u. spez. } \\
\text { Funktionen d. math. Physik } \\
\text { (Graeser) }\end{array}$ & \\
\hline $\begin{array}{l}\text { Geschichte, Philosophie und } \\
\text { Methoden der Physik, Didaktik }\end{array}$ & $\begin{array}{l}\text { Theorie d. Kosmogonie } \\
\text { (Weizsäcker) } \\
\text { UE über zeitgenössische } \\
\text { Philosophie d. Quantenwissen- } \\
\text { schaften (Weizsäcker) }\end{array}$ & $\begin{array}{l}\text { Theorie d. Kosmogonie II } \\
\text { (Weizsäcker) } \\
\text { UE zur Philosophie d. math. } \\
\text { Wissenschatten (Weizsäcker) }\end{array}$ & $\begin{array}{l}\text { SE über Philosophie d. math. } \\
\text { Wissenschaften (Weizsäcker) }\end{array}$ & $\begin{array}{l}\text { *SE Ëber Philosophie d. } \\
\text { math. Wissenschaften } \\
\text { (Weizsäcker) }\end{array}$ & $\begin{array}{l}\text { Kants Theorie d. Entstehung d. } \\
\text { Planetensystems (1755) } \\
\text { (Weizäcker) } \\
\text { SE über Philosophie d. math. } \\
\text { Wissenschaften (Weizsäcker) } \\
\text { Disaktikk d. Physik II +UE } \\
\text { (Lamla) }\end{array}$ & $\begin{array}{l}\text { SE über Philosophie d. math. } \\
\text { Wissenschaften (Weizsäcker) } \\
\text { Didaktik d. Physik II + UE (Lamla) }\end{array}$ & $\begin{array}{l}\text { Geschichte d. modernen Physik } \\
\text { (seit 1880) (Flammersfeld) } \\
\text { Philosophie d. mathematischen } \\
\text { Wissenschaften (Weizsäcker) } \\
\text { Physik im Unterricht (Lamla) } \\
\text { Didaktik d. Physik I (Lamla) }\end{array}$ \\
\hline Sonstige Veranstaltungen & SE für Fortgeschrittene (Wirtz) & $\begin{array}{l}\text { SE für Fortgeschrittene } \\
\text { (Wirtz) }\end{array}$ & $\begin{array}{l}\text { SE für Fortgeschrittene (Wirtz) } \\
\text { (a) }\end{array}$ & $\begin{array}{l}\text { SE für Fortgeschrittene } \\
\text { (Wirtz) }\end{array}$ & & SE für Fortgeschrittene (Wirtz) & $\begin{array}{l}\text { Tieftemperaturphysik (Buckel) } \\
\end{array}$ \\
\hline
\end{tabular}

* Im Vorlesungsverzeichnis bei den mathematischen Veranstaltungen angekündigt. 
Angewandte Physik

\begin{tabular}{|c|c|c|c|c|c|c|c|c|c|}
\hline Vorlesungsgruppen & WS 31/32 & SS 32 & WS $32 / 33$ & SS 33 & WS $33 / 34$ & SS 34 & WS 34/35 & SS 35 & WS 35/36 \\
\hline $\begin{array}{l}\text { Elektrizität und } \\
\text { Elektrophysik }\end{array}$ & $\begin{array}{l}\text { Angew. Elektrizität } \\
\text { I(Reich) } \\
\text { SE über angew. } \\
\text { Elektrizität (Reich) }\end{array}$ & $\begin{array}{l}\text { Elektrische Schwingungen u. } \\
\text { drahtlose Telegraphie (Reich) }\end{array}$ & $\begin{array}{l}\text { Neueste Fortschritte d. } \\
\text { Elektrophysik (Reich) } \\
\text { SE über angew. Elektrizität } \\
\text { (Reich) }\end{array}$ & Angew. Elektrizität I (Reich) & $\begin{array}{l}\text { Elektrische Schwin- } \\
\text { gungen u. drahtlose } \\
\text { Telegraphie (Reich) } \\
\text { Elektrische Meßmeth. } \\
\text { (Reich) } \\
\text { Theor. Grundl. } \\
\text { elektrischer Meßmeth. } \\
\text { (Reich) }\end{array}$ & $\begin{array}{l}\text { Neueste Fortschritte d. } \\
\text { Elektrophysik (Reich) } \\
\text { Ausgew. Kapitel d. } \\
\text { elektrischen Meßkunde } \\
\text { (Gerdien) }\end{array}$ & $\begin{array}{l}\text { Angew. Elektrizität I } \\
\text { (Reich) }\end{array}$ & $\begin{array}{l}\text { Elektromagnetische Schwin- } \\
\text { gungen u. drahtlose Telegra- } \\
\text { phie (Reich) } \\
\text { Ausgew. Kapitel l. } \\
\text { elektrischen Meßkunde } \\
\text { (Gerdien) }\end{array}$ & $\begin{array}{l}\text { Neueste Fortschritte } \\
\text { d. Elektrophysik } \\
\text { (Reich) }\end{array}$ \\
\hline Praktika & $\begin{array}{l}\text { Elektrophys. P. } \\
\text { (Reich) } \\
\text { P. zur Kreisellehre } \\
\text { (Schuler) } \\
\text { P. zur Festig- } \\
\text { keitslehre (Prager) } \\
\end{array}$ & Elektrophys. P. (Reich) & $\begin{array}{l}\text { Elektrophys. P. (Reich) } \\
\text { Schwingungsp. (Hohenemser) }\end{array}$ & $\begin{array}{l}\text { Elektrophys. P. (Reich) } \\
\text { Mechanikp. (Schuler) }\end{array}$ & $\begin{array}{l}\text { Elektrophys. P. (Reich) } \\
\text { Mechanikp. (Schuler) }\end{array}$ & $\begin{array}{l}\text { Elektrophys. P. (Reich) } \\
\text { P. d. Festigkeitslehre } \\
\text { (Flügge) } \\
\text { Mechanikp. (Schuler) }\end{array}$ & $\begin{array}{l}\text { Elektrophys. P. (Reich) } \\
\text { Mechanikp. (Schuler) }\end{array}$ & $\begin{array}{l}\text { Elektrophys. P. (Reich) } \\
\text { Mechanikp. (Schuler) }\end{array}$ & $\begin{array}{l}\text { Elektrophys. P. } \\
\text { (Reich) } \\
\text { Mechanikp. } \\
\text { (Schuler) }\end{array}$ \\
\hline Mechanik & $\begin{array}{l}\text { Einff in d. } \\
\text { Mechanik (Prandtl) }\end{array}$ & & Aeromechanik (Prandtl) & & & & Aeromechanik (Prandtl) & $\begin{array}{l}\text { SE über ausgew. Fragen d. } \\
\text { Mechanik (Schuler) }\end{array}$ & 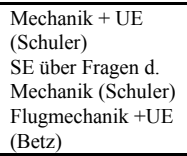 \\
\hline Festigkeitslehre, Statik & $\begin{array}{l}\text { Festigkeitslehre } \\
\text { (Prager) }\end{array}$ & $\begin{array}{l}\text { Stabilitätsprobleme d. } \\
\text { Elastizitätstheorie (N.N.) } \\
\text { Elastokinetik (N.N.) } \\
\end{array}$ & Flugzeugstatik (Prager) & $\begin{array}{l}\text { Graphische Statik + UE } \\
\text { (Flügge) }\end{array}$ & $\begin{array}{l}\begin{array}{l}\text { Festigkeitslehre + UE } \\
\text { (Flügge) } \\
\text { Schalentheorie (Flügge) }\end{array} \\
\text { She }\end{array}$ & & $\begin{array}{l}\text { Ausgew. Kapitel d. } \\
\text { Flugzeugstatik (Flügge) }\end{array}$ & $\begin{array}{l}\text { SE über ausgew. Fragen d. } \\
\text { Flugzeugstatik (Flügge) }\end{array}$ & $\begin{array}{l}\text { Knicken, Kippen, } \\
\text { Ausbeulen (Flügge) }\end{array}$ \\
\hline $\begin{array}{l}\text { Hydro- und } \\
\text { Aerodynamik, } \\
\text { Strömungslehre }\end{array}$ & & $\begin{array}{l}\text { Hydrodynamik u. } \\
\text { Aerodynamik (Prandtl) } \\
\text { Aoredynamische Messungen } \\
\text { + UE (Betz) }\end{array}$ & & $\begin{array}{l}\text { Ausgew. Abschnitte d. } \\
\text { Strömungslehre (Prandtl) }\end{array}$ & Theorie d. Fliegens (Betz) & $\begin{array}{l}\text { Hydrodynamik u. } \\
\text { Aerodynamik (Prandtl) }\end{array}$ & & $\begin{array}{l}\text { Ausgew. Abschnitte d. } \\
\text { Strömungslehre (Prandtl) } \\
\text { UE zur Tragflügeltheorie } \\
\text { (Betz) }\end{array}$ & \\
\hline $\begin{array}{l}\text { Sonstige } \\
\text { Veranstaltungen }\end{array}$ & $\begin{array}{l}\text { Theorie u. Anwend. } \\
\text { d. Kreisels } \\
\text { (Schuler) }\end{array}$ & $\begin{array}{l}\text { Autom. Steuerung von } \\
\text { Maschinen, Schiffen u. } \\
\text { Flugzeugen (Schuler) } \\
\text { Technische Elektrochemie } \\
\text { (Kyropoulos) }\end{array}$ & $\begin{array}{l}\text { Physik d. Öle u. ihrer Anwend. } \\
\text { (Kyropoulos) } \\
\text { Technische Elektrochemie } \\
\text { (Kyropoulos) }\end{array}$ & Einkristalle (Kyropoulos) & $\begin{array}{l}\text { Molekulare Polarisation, } \\
\text { ihr Vorkommen u. ihre } \\
\text { techn. Anwend. } \\
\text { (Kyropoulos) } \\
\text { Technische } \\
\text { Elektrochemie } \\
\text { (Kyropoulos) }\end{array}$ & $\begin{array}{l}\text { Molekulare Polarisation, ihr } \\
\text { Vorkommen u. ihre techn. } \\
\text { Anwend. (Kyropoulos) } \\
\text { Einf. in d. Ballistik } \\
\text { (Flügge) } \\
\text { Technik d. Römer, mit bes. } \\
\text { Berücksichtigung deutscher } \\
\text { Altertümer (Kyropoulos) } \\
\text { Theorie u. Anwend. d. } \\
\text { Kreisels (Schuler) } \\
\end{array}$ & $\begin{array}{l}\text { Mechanische } \\
\text { Schwingungslehre } \\
\text { (Schuler) } \\
\text { Physik d. Oberflä- } \\
\text { chenerscheinungen u. } \\
\text { ihrer Anwend. } \\
\text { (Kyropoulos) }\end{array}$ & $\begin{array}{l}\text { Autom. Steuerung von } \\
\text { Maschinen, Schiffen u. } \\
\text { Flugzeugen (Shuler) } \\
\text { Physik d. Kohlen- } \\
\text { wasserstoffhydrierung } \\
\text { (Kyropoulos) } \\
\text { Ausgew. Meth. zur } \\
\text { Bestimmung d. Molekülbaus } \\
\text { (Kyropoulos) }\end{array}$ & $\begin{array}{l}\text { Einf. in d. } \\
\text { Thermodynamik } \\
\text { (Prandtl) } \\
\text { Molekularkräfte u. } \\
\text { ihre Anwend. } \\
\text { (Kyropoulos) }\end{array}$ \\
\hline Mathematik & $\begin{array}{l}\text { * Anschauliche u. } \\
\text { nuttrliche Math. } \\
\text { (Prandt) }\end{array}$ & $\begin{array}{l}\text { * Math. Instrumente (Prager) } \\
\text { * Anfängerpraktikum über } \\
\text { praktische Analysis u. math. } \\
\text { Instrumente (Cuuer, Prager) }\end{array}$ & $\begin{array}{l}\text { * Konforme Abbildung (Betz) } \\
\text { * Anwend. A. Funktionentheorie } \\
\text { auf d. Theorie d. Elektrizität u. } \\
\text { Elektrotechnik (Cauer) } \\
\text { * Potentialtheoretische Ansätze d. } \\
\text { Kontinuummsmechanik (Flugge) } \\
\text { * Praktikum d. angew. Math. } \\
\text { (Bernstein, Betz, Prandtl, Schuler, } \\
\text { Cauer, Flügge, Hohenemser, } \\
\text { Prager) }\end{array}$ & $\begin{array}{l}\text { * Darstellende Geometrie + } \\
\text { UE (Hohenemser) } \\
\text { * Ausgleichsrechnung(Schuler) } \\
\text { * Praktikum d. angew. Math. } \\
\text { (Bernstein, Betz, Prandtl, } \\
\text { Schuler, Cauer, Flügge, } \\
\text { Hohenemser) } \\
\text { * SE über math. Behandlung } \\
\text { elektrotechnischer Probleme } \\
\text { (Cauer) }\end{array}$ & $\begin{array}{l}\text { *SE über Anwend. d. } \\
\text { Math. auf Probleme d. } \\
\text { Elektrotechnik (Cauer) }\end{array}$ & $\begin{array}{l}{ }^{*} \text { SE über math. Probleme } \\
\text { d. Elektrotechnik (Cauer) }\end{array}$ & $\begin{array}{l}\text { Konforme Abbildung } \\
\text { (Betz) } \\
\text { SE über math. Fragen d. } \\
\text { Gadynamik (Flügge, } \\
\text { Rellich) } \\
\text { SE über math.Fragen d. } \\
\text { Elektrotechnik (Cauer) }\end{array}$ & & \\
\hline
\end{tabular}

* Im Vorlesungsverzeichnis bei den mathematischen Veranstaltungen angekündigt.

Tabelle 23 Das Lehrangebot der angewandten Physik 1931-1955. ${ }^{1754}$

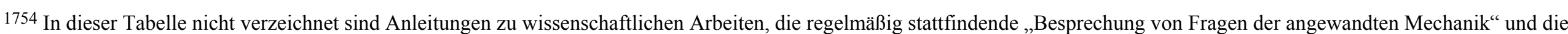
vom SS 1934 bis zum SS 1941 im Vorlesungsverzeichnis unter „Angewandte Physik und Mechanik“ aufgeführten Veranstaltungen über Medizinische Physik und Biophysik. Die Anmerkungen von Fußnote 1753 gelten hier entsprechend. 


\begin{tabular}{|c|c|c|c|c|c|c|c|}
\hline Vorlesungsgruppen & SS 36 & WS $36 / 37$ & SS 37 & WS $37 / 38$ & SS 38 & WS 38/39 & SS 39 \\
\hline $\begin{array}{l}\text { Elektrizität und } \\
\text { Elektrophysik }\end{array}$ & $\begin{array}{l}\text { Angew. Elektrizität I (Reich) } \\
\text { SE über angew. Elektrizität (Reich) } \\
\text { Ausgew. Kapitel d. elektrischen } \\
\text { Meßkunde (Gerdien) }\end{array}$ & $\begin{array}{l}\text { Elektrische Schwingungen u. } \\
\text { drahtlose Telegraphie (Reich) } \\
\text { SE über angew. Elektrizität } \\
\text { (Reich) }\end{array}$ & $\begin{array}{l}\text { Neueste Fortschritte d. } \\
\text { Elektrophysik (Reich) } \\
\text { SE über angew. Elektrizität } \\
\text { (Reich) } \\
\text { Ausgew. Kapitel d. elektrischen } \\
\text { Meßkunde (Gerdien) } \\
\end{array}$ & $\begin{array}{l}\text { Angew. Elektrizität I (Reich) } \\
\text { SE über angew. Elektrizität (Reich) }\end{array}$ & $\begin{array}{l}\text { Elektrische Schwingungen u. } \\
\text { drahtlose Telegraphie (Reich) } \\
\text { SE über angew. Elektrizität } \\
\text { (Reich) } \\
\text { Ausgew. Kapitel d. elektrischen } \\
\text { Meßkunde (Gerdien) }\end{array}$ & $\begin{array}{l}\text { Neueste Fortschritte d. } \\
\text { Elektrophysik (Reich) } \\
\text { SE über angew. Elektrizizität } \\
\text { (Reich) }\end{array}$ & $\begin{array}{l}\text { Angew. Elektrizität I (Reich) } \\
\text { SE über angew. Elektrizität (Reich) }\end{array}$ \\
\hline Praktika & $\begin{array}{l}\text { Elektrophys. P. (Reich) } \\
\text { Mechanikp. (Schuler) }\end{array}$ & $\begin{array}{l}\text { Elektrophys. P. (Reich) } \\
\text { Mechanikp. (Schuler) } \\
\end{array}$ & $\begin{array}{l}\text { Elektrophys. P. (Reich) } \\
\text { Mechanikp. (Schuler) } \\
\end{array}$ & \begin{tabular}{|l|} 
Elektrophys. P. (Reich) \\
Mechanikp. (Schuler) \\
\end{tabular} & $\begin{array}{l}\text { Elektrophys. P. (Reich) } \\
\text { Mechanikp. (Schuler) } \\
\end{array}$ & $\begin{array}{l}\text { Elektrophys. P. (Reich) } \\
\text { Mechanikp. (Schuler) } \\
\end{array}$ & $\begin{array}{l}\text { Elektrophys. P. (Reich) } \\
\text { Mechanikp. (Schuler) } \\
\end{array}$ \\
\hline Mechanik & $\begin{array}{l}\text { SE über Fragen d. angew. Mechanik } \\
\text { (Schuler) }\end{array}$ & $\begin{array}{l}\text { Mechanik + UE (Schuler) } \\
\text { SE über Fragen d. angew. } \\
\text { Mechanik (Schuler) } \\
\text { SE über Flugmechanik (Betz, } \\
\text { Flügge) }\end{array}$ & $\begin{array}{l}\text { SE über Fragen d. angew. } \\
\text { Mechanik (Schuler) } \\
\text { Aeromechanik (Prandtl) }\end{array}$ & $\begin{array}{l}\text { Mechanik + UE (Schuler) } \\
\text { SE über Fragen d. angew. Mechanik } \\
\text { (Schuler) }\end{array}$ & $\begin{array}{l}\text { SE über Fragen d. angew. } \\
\text { Mechanik (Schuler) }\end{array}$ & $\begin{array}{l}\text { SE über Fragenn d. angew. } \\
\text { Mechanik (Schuler) }\end{array}$ & $\begin{array}{l}\text { Mechanik + UE (Schuler) } \\
\text { SE über Fragen d. angew. Mechanik } \\
\text { (Schuler) }\end{array}$ \\
\hline Festigkeitslehre, Statik & $\begin{array}{l}\text { SE über ausgew. Kapitel d. } \\
\text { Flugzeugstatik (Flügge) }\end{array}$ & & Festigkeitslehre (Flügge) & Graphische Statik (Flügge) & & & Elastizität u. Festigkeit (Betz) \\
\hline $\begin{array}{l}\text { Hydro- und Aerodynamik, } \\
\text { Strömungslehre }\end{array}$ & $\begin{array}{l}\text { Hydrodynamik u. Aerodynamik } \\
\text { (Prandl) } \\
\text { Aerodynamische Messungen (Betz) }\end{array}$ & $\begin{array}{l}\begin{array}{l}\text { Hydrodynamik u. Aerodynamik II } \\
\text { (Prandtl) }\end{array}\end{array}$ & siehe Mathematik & $\begin{array}{l}\text { Strömungslehre (Prandtl) } \\
\end{array}$ & $\begin{array}{l}\text { Hydrodynamik u. Aerodynamik I } \\
\text { (Prandtl) } \\
\text { Tragflügel u. Flügelräder (Betz) }\end{array}$ & $\begin{array}{l}\text { Hydrodynamik u. } \\
\text { Aerodynamik II (Prandtl) } \\
\text { UE ur Tragfluggeltheorie } \\
\text { (Betz) }\end{array}$ & $\begin{array}{l}\text { Hydrodynamik u. Aerodynamik III } \\
\text { (Prandtl) }\end{array}$ \\
\hline Sonstige Veranstaltungen & $\begin{array}{l}\text { Kreisellehre (Schuler) } \\
\text { Flug-. Fahrzzeugmotoren } \\
\text { (Kyropoulos) } \\
\text { Polare Molekeln nebst Anwend. } \\
\text { (Kyropoulos) }\end{array}$ & & $\begin{array}{l}\text { Mechanische Schwingungslehre } \\
\text { (Schuler) }\end{array}$ & $\begin{array}{l}\text { Die gasgefülltte Röhre mit } \\
\text { Steuergitter als exp. Hilfsmittel } \\
\text { (Glaser) }\end{array}$ & $\begin{array}{l}\text { Die techn. Physik d. } \\
\text { lichtelektrischen Zelle (Glaser) } \\
\text { Theorie d. autom. Steuerung } \\
\text { (Schuler) }\end{array}$ & $\begin{array}{l}\text { Die Gasentladung als } \\
\text { Lichtquelle (Glaser) } \\
\text { Theorie u. Anwwend. d. } \\
\text { Kreisels (Schuler) }\end{array}$ & $\begin{array}{l}\text { Die Sonde in d. Gasentladung } \\
\text { (Glaser) }\end{array}$ \\
\hline Mathematik & $\begin{array}{l}\text { * Math. Fragen d. Theorie u. } \\
\text { Berechnung d. Flugzeuge (Cauer) }\end{array}$ & $\begin{array}{l}\text { *Gewöhnl. Differentialgl. + UE } \\
\text { (Tollmien) }\end{array}$ & $\begin{array}{l}\text { * Partielle Differentialgl. + UE } \\
\text { (Tollmien) } \\
\text { Rechenmeth. d. Hydrodynamik } \\
\text { (Betz) }\end{array}$ & $\begin{array}{l}\text { Konforme Abbildung (Betz) } \\
\text { * Graphische u. numerische Meth. } \\
\text { (Tollmien) }\end{array}$ & & $\begin{array}{l}\text { * Äußere Ballistik + UE } \\
\text { (Kaluza) }\end{array}$ & $\begin{array}{l}\text { * Differentialgl. d. Mechanik u. } \\
\text { Variationsrechnung (Herglotz) }\end{array}$ \\
\hline
\end{tabular}

\begin{tabular}{|c|c|c|c|c|c|c|c|}
\hline Vorlesungsgruppen & WS 39/40 & 1. TM 40 & 2. u. 3. TM 40 & SS 41 & 1. TM 41 & WS 41/42 & SS 42 \\
\hline $\begin{array}{l}\text { Elektrizität und } \\
\text { Elektrophysik }\end{array}$ & $\begin{array}{l}\text { Elektrische Schwingungen u. drahtlose Telegra- } \\
\text { phie (Reich) } \\
\text { SE über angew. Elektrizität (Reich) }\end{array}$ & $\begin{array}{l}\text { Neueste Fortschritte d. Elektrophysik } \\
\text { (Reich) } \\
\text { SE über angew. Elektrizität (Reich) }\end{array}$ & $\begin{array}{l}\text { Neueste Fortschritte d. angew. } \\
\text { Elektrizität (Reich) } \\
\text { SE über angew. Elektrizität } \\
\text { (Reich) }\end{array}$ & $\begin{array}{l}\text { Ausgew. Kapitel d. angew. } \\
\text { Elektrizität (Ruprecht) } \\
\text { SE über angew. Elektrizität } \\
\text { (Ruprecht) }\end{array}$ & $\begin{array}{l}\text { Neueste Fortschritte d. } \\
\text { angew. Elektrizität (Reich) } \\
\text { SE über angew. Elektrizität } \\
\text { (Reich) }\end{array}$ & $\begin{array}{l}\text { Angew. Elektrizizität (Zahn) } \\
\text { SE über angew. } \\
\text { Elektrizititat (Zahn) }\end{array}$ & $\begin{array}{l}\text { Angew. Elektrizität I } 1755 \\
\text { (Zahn) } \\
\text { SE über angew. Elektrizität } \\
\text { (Zahn) }\end{array}$ \\
\hline Praktika & $\begin{array}{l}\text { Elektrophys. P. (Reich) } \\
\text { Mechanikp. (Schuler) }\end{array}$ & $\begin{array}{l}\text { Elektrophys. P. (Reich) } \\
\text { Mechanikp. (Schuler) }\end{array}$ & Elektrophys. P. (Reich) & $\begin{array}{l}\text { Elektrophys. P. (Ruprecht) } \\
\text { Mechanikp. (Schuler) }\end{array}$ & $\begin{array}{l}\text { Elektrophys. P. (Reich) } \\
\text { Mechanikp. (Schuler) }\end{array}$ & \begin{tabular}{|l|} 
Elektrophys. P. (Zahn) \\
Mechanikp. (Schuler)
\end{tabular} & $\begin{array}{l}\text { Elektrophys. P. (Zahn) } \\
\text { Mechanikp. (Schuler) }\end{array}$ \\
\hline Mechanik & $\begin{array}{l}\text { SE über Fragen d. angew. Mechanik (Schuler) } \\
\text { Flugmechanik + UE (Betz) } \\
\text { Aeromechanik (Prandtl) }\end{array}$ & $\begin{array}{l}\text { SE über Fragen d. angew. Mechanik } \\
\text { (Schuler) }\end{array}$ & $\begin{array}{l}\text { SE über Fragen d. angew. } \\
\text { Mechanik (Schuler) }\end{array}$ & $\begin{array}{l}\text { SE über Fragen d. angew. } \\
\text { Mechanik (Schuler) }\end{array}$ & $\begin{array}{l}\text { SE über Fragen d. angew. } \\
\text { Mechanik (Schuler) }\end{array}$ & $\begin{array}{l}\text { SE über Fragen d. angew. } \\
\text { Mechanik (Schuler) }\end{array}$ & $\begin{array}{l}\begin{array}{l}\text { SE über Fragen d. angew. } \\
\text { Mechanik (Schuler) } \\
\text { Einf. in d. Aeromechanik } \\
\text { (Prandtl) }\end{array} \\
\end{array}$ \\
\hline Festigkeitslehre, Statik & $\begin{array}{l}\text { Festigkeitslehre u. Elastizitätstheorie (Schuler) } \\
\text { Schalentheorie (N.N.) }\end{array}$ & $\begin{array}{l}\text { Elastizitïtstsheorie d. zweidim. } \\
\text { Spannungszustände (Schultz-Grunow) }\end{array}$ & $\begin{array}{l}\text { Festigkeitslehre (Schultz-Grunow) } \\
\end{array}$ & & & \begin{tabular}{l|}
$\begin{array}{l}\text { Statik u. Festigkeitslehre } \\
\text { (Prandt)) }\end{array}$ \\
\end{tabular} & \\
\hline $\begin{array}{l}\text { Hydro- und Aerodynamik, } \\
\text { Strömungslehre }\end{array}$ & siehe Mathematik & $\begin{array}{l}\text { Hydrodynamik u. Aerodynamik I b } \\
\text { (Prandtl) } \\
\text { Gasdynamik (Betz) }\end{array}$ & $\begin{array}{l}\text { Hydrodynamik u. Aerodynamik II } \\
\text { (Prandt)) }\end{array}$ & & & & $\begin{array}{l}\text { Besprechung von } \\
\text { Potentialströmungen (Betz) }\end{array}$ \\
\hline Sonstige Veranstaltungen & $\begin{array}{l}\text { Trockengleichrichter in Physik u. Technik } \\
\text { (Glaser) }\end{array}$ & $\begin{array}{l}\text { Neuere techn.-phys. Probleme d. } \\
\text { Gasentladungen (Glaser) } \\
\text { Mechanische Schwingungslehre } \\
\text { (Schuler) } \\
\end{array}$ & $\begin{array}{l}\text { Steuerbare Entladungen (Glaser) } \\
\text { Kurs über Flugzeuginstrumente } \\
\text { (Schuler) }\end{array}$ & $\begin{array}{l}\text { Mechanische } \\
\text { Schwingungslehre (Schuler) }\end{array}$ & $\begin{array}{l}\text { Einf. in d. Thermodynamik } \\
\text { (Prandtl) } \\
\text { Theorie un Anwend. } \\
\text { Kreisels + UE (Schuler) } \\
\end{array}$ & $\begin{array}{l}\text { Theorie u. Anwend. d. } \\
\text { Kreisels (Schuler) }\end{array}$ & \begin{tabular}{|l|}
$\begin{array}{l}\text { Theorie d. autom. Steuerung } \\
\text { (Schuler) }\end{array}$ \\
\end{tabular} \\
\hline Mathematik & $\begin{array}{l}{ }^{*} \text { Geometr. Meth. d. angew. Mathematik } \\
\text { (Kaluza) } \\
\text { * Konforme Abbildung mit bes. Berücksichtu- } \\
\text { gung d. math. Strömungslehre (Graeser) }\end{array}$ & $\begin{array}{l}\text { * Grundzüge d. Luftfahrtnavigation } \\
\text { (Kaluza) }\end{array}$ & $\begin{array}{l}\text { *Anwend. d. Ausgleichsrechnung } \\
\text { + UE (Schuler, Kaluza) }\end{array}$ & $\begin{array}{l}\text { *Analytische Mechanik } \\
\text { (Herglotz) }\end{array}$ & & & \\
\hline
\end{tabular}

* Im Vorlesungsverzeichnis bei den mathematischen Veranstaltungen angekündigt.

1755 Elektrische und magnetische Meßinstrumente, Grundlagen der Elektrotechnik. 


\begin{tabular}{|c|c|c|c|c|c|c|c|c|}
\hline Vorlesungsgruppen & WS $42 / 43$ & SS 43 & WS $43 / 44$ & SS 44 & WS $44 / 45$ & WS $45 / 46$ & SS 46 & WS 46/47 \\
\hline $\begin{array}{l}\text { Elektrizität und } \\
\text { Elektrophysik }\end{array}$ & $\begin{array}{l}\text { SE über angew. } \\
\text { Elektrizität (Zahn) }\end{array}$ & $\begin{array}{l}\text { SE über angew. Elektrizitït (Zahn) } \\
\text { Die Elektronenröhren u. ihre } \\
\text { Anwend., spez. bei phys. } \\
\text { Messungen (Zahn) }\end{array}$ & $\begin{array}{l}\text { SE über angew. Elektrizität } \\
\text { (Zahn) } \\
\text { Ausgew. Kapitel d. } \\
\text { Hochfrequenztechnik (Zahn) }\end{array}$ & $\begin{array}{l}\text { Ausgew. Kapitel d. } \\
\text { Elektrizitättslehre (Zahn) }\end{array}$ & & Angew. Elektrizitätslehre (Zahn) & $\begin{array}{l}\text { Elektronenröhren u. Verstärker } \\
\text { (Zahn) }\end{array}$ & $\begin{array}{l}\text { Ausgew. Kapitel d. } \\
\text { Hochfrequenztechnik (Zahn) }\end{array}$ \\
\hline $\begin{array}{l}\text { Praktika } \\
\end{array}$ & $\begin{array}{l}\text { Elektrophys. P. (Zahn) } \\
\text { Mechanikp. (Schuler) }\end{array}$ & $\begin{array}{l}\text { Elektrophys. P. (Zahn) } \\
\text { Mechanikp. (Schuler) } \\
\end{array}$ & $\begin{array}{l}\text { Elektrophys. P. (Zahn) } \\
\text { Mechanikp. (Schuler) }\end{array}$ & $\begin{array}{l}\text { Elektrophys. P. (Zahn) } \\
\text { Mechanikp. (Schuler) } \\
\end{array}$ & \begin{tabular}{|l} 
Elektrophys. P. (Zahn) \\
Mechanikp. (Schuler) \\
\end{tabular} & $\begin{array}{l}\text { Elektrophys. P. (Zahn) } \\
\text { Mechanikp. (Schuler) }\end{array}$ & $\begin{array}{l}\text { Elektrophys. P. (Zahn) } \\
\text { Mechanikp. (Schuler) } \\
\end{array}$ & $\begin{array}{l}\text { Elektrophys. P. (Zahn) } \\
\text { Mechanikp. (N.N.) } \\
\end{array}$ \\
\hline Mechanik & $\begin{array}{l}\text { Mechanik + UE } \\
\text { (Schuler) } \\
\text { SE über Fragen d. } \\
\text { angew. Mechanik } \\
\text { (Schuler) }\end{array}$ & $\begin{array}{l}\text { SE über Fragen d. angew. } \\
\text { Mechanik (Schuler) }\end{array}$ & $\begin{array}{l}\text { Mechanik + UE (Schuler) } \\
\text { SE über Fragen d. angew. } \\
\text { Mechanik (Schuler) }\end{array}$ & $\begin{array}{l}\text { SE über Fragen d. angew. } \\
\text { Mechanik (Schuler) }\end{array}$ & $\begin{array}{l}\text { Mechanik + UE } \\
\text { (Schuler) } \\
\text { SE über Fragen d. } \\
\text { angew. Mechanik } \\
\text { (Schuler) }\end{array}$ & $\begin{array}{l}\text { Einf. in d. Mechanik (Prandtl) } \\
\text { SE über Fragen d. angew. Mechanik } \\
\text { (Schuler) }\end{array}$ & $\begin{array}{l}\text { SE über Fragen d. angew. } \\
\text { Mechanik (Schuler) }\end{array}$ & Mechanik (Wieghardt) \\
\hline Festigkeitslehre, Statik & & & & $\begin{array}{l}\text { Elastizität u. Festigkeit } \\
\text { (Prandtl) } \\
\text { siehe Mathematik } \\
\end{array}$ & & Einf. in d. Festigkeitslehre (N.N.) & & \\
\hline $\begin{array}{l}\text { Hydro- und Aerodynamik, } \\
\text { Strömungslehre }\end{array}$ & $\begin{array}{l}\text { Hydrodynamik u. } \\
\text { Aerodynamik (Prandtl) } \\
\text { Gasdynamik } \\
\text { (Oswatitsch) }\end{array}$ & $\begin{array}{l}\text { Hydrodynamik u. Aerodynamik II } \\
\text { (Prandtl) } \\
\text { Gasdynamik II (Oswatitsch) }\end{array}$ & $\begin{array}{l}\text { Hydrodynamik u. } \\
\text { Aerodynamik III (Prandtl) }\end{array}$ & $\begin{array}{l}\text { Ausgew. Abschnitte d. } \\
\text { Strơmungslehre (Prandtl) }\end{array}$ & $\begin{array}{l}\text { Hydrodynamik u. } \\
\text { Aerodynamik I (Prandtl) } \\
\text { Turbulenz (Oswatitsch) } \\
\text { Tragflügel u. Flügelräder } \\
\text { (Betz) }\end{array}$ & $\begin{array}{l}\text { Charakteristikenverfahren d. } \\
\text { Hydrodynamik (Oswatitsch) } \\
\text { Elementare Stömungslehre (Betz) }\end{array}$ & $\begin{array}{l}\begin{array}{l}\text { Reibende Strömung mit Turbulenz } \\
\text { (Prandtl) } \\
\text { siehe Mathematik }\end{array} \\
\end{array}$ & $\begin{array}{l}\text { Ausgew. Abschnitte d. } \\
\text { Stömungslehre (Prandtl) } \\
\text { Wichtige Begriffe d. } \\
\text { Stömungslehre (Betz) }\end{array}$ \\
\hline Sonstige Veranstaltungen & & $\begin{array}{l}\text { Mechanische Schwingungslehre + } \\
\text { UE (Schuler) }\end{array}$ & & $\begin{array}{l}\text { Thermodynamik (Oswatitsch) } \\
\text { Der Kreisel u. seine Anwend. } \\
\text { in d. Technik + UE (Schuler) }\end{array}$ & & $\begin{array}{l}\text { Mechanische Schwingungslehre + } \\
\text { UE (Schuler) }\end{array}$ & $\begin{array}{l}\text { Physikalische Dimensionen } \\
\text { (Oswatitsch) } \\
\text { Anwend. d. Kreiselgesetze in } \\
\text { Astronomie, Physik u. Technik } \\
\text { (Schuler) }\end{array}$ & \\
\hline Mathematik & & & Konforme Abbildung (Betz) & $\begin{array}{l}\begin{array}{l}* \text { *Graphische Statik + UE } \\
\text { (Görtler) }\end{array} \\
\end{array}$ & & & $\begin{array}{l}\text { * Rechenmeth. d. Strömungslehre } \\
\text { (Betz) }\end{array}$ & $\begin{array}{l}\text { Dimensionsanalysis } \\
\text { (Oswatitsch) }\end{array}$ \\
\hline
\end{tabular}

\begin{tabular}{|c|c|c|c|c|c|c|c|c|}
\hline Vorlesungsgruppen & SS 47 & WS 47/48 & SS 48 & WS 48/49 & SS 49 & WS 49/50 & SS 50 & WS 50/51 \\
\hline $\begin{array}{l}\text { Elektrizität und } \\
\text { Elektrophysik }\end{array}$ & Elektroakustik (Meyer) & \begin{tabular}{|l} 
Elektroakustik (Meyer) \\
\end{tabular} & $\begin{array}{l}\text { Elektrische Meßtechnik } \\
\text { (Meyer) } \\
\text { Die Elektronenröhre als } \\
\text { Hilfsmittel bei phys. } \\
\text { Messungen (Zahn) } \\
\end{array}$ & $\begin{array}{l}\text { Phys. Grundl. d. Hochfre-- } \\
\text { quenztechnik (Meyer) }\end{array}$ & & Elektro-Akustik (Meyer) & Elektrische Meßtechnik (Meyer) & $\begin{array}{l}\text { Phys. Grundl. d. } \\
\text { Hochfrequenztechnik } \\
\text { (Meyer) } \\
\text { Elektrostriktion u. Piezo- } \\
\text { Elektrizität (Schoch) } \\
\end{array}$ \\
\hline Praktika & $\begin{array}{l}\text { Elektrophys. P. (N.N.) } \\
\text { Mechanikp. (N.N.) }\end{array}$ & $\begin{array}{l}\text { Mechanik- u. } \\
\text { Elektrophys.- P. } \\
\text { (Meyer) } \\
\end{array}$ & $\begin{array}{l}\begin{array}{l}\text { Mechanik- u. Elektrophysik- P. } \\
\text { (Meyer) }\end{array}\end{array}$ & $\begin{array}{l}\text { Mechanik- u. Elektrophy- } \\
\text { sik- P. (Meyer) }\end{array}$ & Elektrophys.- P. (Meyer) & Elektrophys.- P. (Meyer) & Elektrophys.- P. (Meyer) & Elektrophys.- P. (Meyer) \\
\hline Mechanik & & $\begin{array}{l}\text { Einf. in d. Mechanik + } \\
\text { UE (Tollmien) }\end{array}$ & $\begin{array}{l}\text { Mechanik deformierbarer } \\
\text { Körper (Tollmien) }\end{array}$ & siehe Strömungslehre & siehe Strömungslehre & $\begin{array}{l}\text { Allg. Mechanik + UE } \\
\text { (Tollmien) }\end{array}$ & $\begin{array}{l}\text { Mechanik deformierbarer Körper } \\
\text { (Tollmien) }\end{array}$ & siehe Strömungslehre \\
\hline Festigkeitslehre, Statik & $\begin{array}{l}\text { Analytische u. graphische } \\
\text { Statik (Prandtl) } \\
\text { Elastizitä tu. Plastizität } \\
\text { (Wieghardt) }\end{array}$ & & & & & $\begin{array}{l}\text { siehe Mathematik } \\
\end{array}$ & & \\
\hline $\begin{array}{l}\text { Hydro- und Aerodynamik, } \\
\text { Strömungslehre }\end{array}$ & $\begin{array}{l}\text { Strömungen kompressibler } \\
\text { Medien (N.N.) } \\
\text { Elementare Stömungslehre: } \\
\text { Energie- u. Impulsgesetze } \\
\text { (Betz) }\end{array}$ & & & $\begin{array}{l}\text { Mechanik u. Thermody- } \\
\text { namik d. Strömungen } \\
\text { (Tollmien) }\end{array}$ & $\begin{array}{l}\text { Mechanik u. Thermody- } \\
\text { namik d. Strömungen } \\
\text { (Tollmen) }\end{array}$ & & $\begin{array}{l}\text { Turbulenz (Tollmien) } \\
\text { UE in strommungstechn. Berechnungen } \\
\text { (Betz) }\end{array}$ & $\begin{array}{l}\text { Mechanik u. Thermodynamik } \\
\text { d. Strömungen (Tolllieien) } \\
\text { Theorie d. Strömungs- } \\
\text { maschinen + UE (Betz) }\end{array}$ \\
\hline Sonstige Veranstaltungen & $\begin{array}{l}\text { Allg. Schwingungs- u. } \\
\text { Wellenlehre (N.N.) }\end{array}$ & $\begin{array}{l}\text { Der Kraftbegriff u. d. } \\
\text { Kraftmessung (Betz) } \\
\text { Einf. in d. Kreisellehre } \\
\text { (Wieghardt) }\end{array}$ & $\begin{array}{l}\text { Theorie d. phys. Dimensionen } \\
\text { (Wieghardt) }\end{array}$ & $\begin{array}{l}\text { Theorie d. phys. } \\
\text { Dimensionen (Wieghardt) } \\
\text { Ultraschall (Meyer, Schoch) }\end{array}$ & $\begin{array}{l}\text { Schwingungs- u. } \\
\text { Wellentehre (Meyer) } \\
\text { Theorie d. Kreisels (Schuler) }\end{array}$ & $\begin{array}{l}\text { Anwend. d. Kreiselgesetze in } \\
\text { Physik u. Technik (Schuler) }\end{array}$ & Die Theorie d. Reglers (Schuler) & Theorie d. Kreisels (Schuler) \\
\hline Mathematik & & & * Konforme Abbildung (Betz) & $\begin{array}{l}\text { * Konforme Abbildung } \\
\text { (Betz) }\end{array}$ & $\begin{array}{l}\text { * Graphische Meth. d. prakt. } \\
\text { Analysis (Tollmien) }\end{array}$ & $\begin{array}{l}\text { Rechenmeth. d. } \\
\text { Hydrodynamik + UE (Betz) } \\
\text { * Praxis d. Gleichungen } \\
\text { (Tollmien) }\end{array}$ & $\begin{array}{l}\text { * Interpolation u. Quadratur mit } \\
\text { Anwend. auf Differential- u. Integralgl. } \\
\text { (Tollmien) }\end{array}$ & $\begin{array}{l}\text { * Graphische Meth. d. prakt. } \\
\text { Analysis (Tollmien) }\end{array}$ \\
\hline
\end{tabular}

* Im Vorlesungsverzeichnis bei den mathematischen Veranstaltungen angekündigt. 


\begin{tabular}{|c|c|c|c|c|c|c|c|c|c|c|}
\hline Vorlesungsgruppen & SS 51 & WS 51/52 & SS 52 & WS $52 / 53$ & SS 53 & WS 53/54 & SS 54 & WS 54/55 & SS 55 & WS 55/56 \\
\hline $\begin{array}{l}\text { Elektrizität und } \\
\text { Elektrophysik }\end{array}$ & & Elektroakustik (Meyer) & $\begin{array}{l}\text { Elektrische Meßtechnik } \\
\text { (Meyer) }\end{array}$ & $\begin{array}{l}\text { Phys. Grundl. d. } \\
\text { Hochfrequenztechnik } \\
\text { (Meyer) }\end{array}$ & $\begin{array}{l}\text { Elektrische u. } \\
\text { akustische Filter } \\
\text { (Tamm) }\end{array}$ & Elektroakustik (Meyer) & \begin{tabular}{|l} 
Elektrische \\
Meßtechnik (Meyer) \\
Leitungen d. \\
Höchstre- \\
quenztechnik \\
(Severin)
\end{tabular} & $\begin{array}{l}\text { Phys. Grundl. d. } \\
\text { Hochfrequenztechnik } \\
\text { (Meyer) } \\
\text { Elektronische } \\
\text { Impulstechnik u. ihre } \\
\text { phys. Grundl. (Tamm) } \\
\text { Halbleiterdioden u. - } \\
\text { Trioden (Severin) } \\
\end{array}$ & $\begin{array}{l}\text { Höchstfrequenztechnik } \\
\text { (Severin) }\end{array}$ & $\begin{array}{l}\text { Elektroakustik } \\
\text { (Meyer) } \\
\text { Elektrische u. } \\
\text { akustische Filter } \\
\text { (Tamm) }\end{array}$ \\
\hline Praktika & \begin{tabular}{|l}
$\begin{array}{l}\text { Elektrophys.- P. } \\
\text { (Meyer) }\end{array}$ \\
\end{tabular} & $\begin{array}{l}\text { Elektrophys.- P. } \\
\text { (Meyer) }\end{array}$ & $\begin{array}{l}\text { Elektrophys.- P. (Meyer) } \\
\text { Röhrenp. (Meyer) }\end{array}$ & $\begin{array}{l}\text { Elektrophys.- P. } \\
\text { (Moyer) } \\
\text { Röhrenp. (Meyer) }\end{array}$ & \begin{tabular}{|l|} 
Elektrophys.- P. \\
(Meyer) \\
Röhrenp. (Meyer)
\end{tabular} & $\begin{array}{l}\text { Elektrophys.- P. } \\
\text { (Moyer) } \\
\text { Röhrenp. (Meyer) }\end{array}$ & \begin{tabular}{|l|} 
Elektrophys.- P. \\
(Meyer) \\
Röhrenp. (Meyer)
\end{tabular} & $\begin{array}{l}\text { Elektrophys.- P. (Meyer, } \\
\text { Severin) } \\
\text { Röhrenp. (Meyer, } \\
\text { Severin) } \\
\end{array}$ & $\begin{array}{l}\text { Elektrophys.- P. (Meyer, } \\
\text { Severin) } \\
\text { Röhrenp. (Meyer, } \\
\text { Severin) }\end{array}$ & \begin{tabular}{|l|} 
Elektrophys.- P. \\
(Meyer, Severin) \\
Röhrenp. (Meyer, \\
Severin) \\
\end{tabular} \\
\hline Mechanik & \begin{tabular}{|l}
$\begin{array}{l}\text { Allg. Mechanik + UE } \\
\text { (Tollmien) }\end{array}$ \\
\end{tabular} & $\begin{array}{l}\text { Mechanik } \\
\text { deformierbarer Körper } \\
\text { (Tollmien) }\end{array}$ & $\begin{array}{l}\text { siehe Strömungslehre } \\
\text { siehe Mathematik }\end{array}$ & $\begin{array}{l}\text { Allg. Mechanik + } \\
\text { UE (Tollmien) }\end{array}$ & $\begin{array}{l}\text { Mechanik } \\
\text { deformierbarer Körper } \\
\text { (Tollmien) }\end{array}$ & siehe Strömungslehre & \begin{tabular}{|l} 
Allg. Mechanik + UE \\
(Tollmien) \\
Analytische Mechanik \\
(Schäfer) \\
\end{tabular} & $\begin{array}{l}\text { Mechanik } \\
\text { deformierbarer Körper } \\
\text { (Tollmien, Schäfer) }\end{array}$ & siehe Strömungslehre & 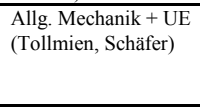 \\
\hline \multicolumn{11}{|l|}{ Festigkeitslehre, Statik } \\
\hline $\begin{array}{l}\text { Hydro- und } \\
\text { Aerodynamik, } \\
\text { Strömungslehre }\end{array}$ & $\begin{array}{l}\text { UE in strömungstechn. } \\
\text { Berechnungen (Betz) }\end{array}$ & & $\begin{array}{l}\text { Mechanik u. Thermodynamik } \\
\text { d. Strömungen (Tollmien) } \\
\text { UE in stromunungtechn. } \\
\text { Berechnungen (Betz) }\end{array}$ & $\begin{array}{l}\text { Theorie d. } \\
\text { Strömungsmaschinen } \\
\text { + UE (Betz) } \\
\text { Gasdynamik } \\
\text { (Schäfer) }\end{array}$ & $\begin{array}{l}\text { UE in strömungstechn. } \\
\text { Berechnungen (Betz) }\end{array}$ & $\begin{array}{l}\text { Mechanik u. } \\
\text { Thermodynamik d. } \\
\text { Stromungen (Tollmien) } \\
\text { Strömungsmessungen } \\
\text { (Betz) }\end{array}$ & \begin{tabular}{|l|} 
UE in \\
strömungstechn. \\
Berechnungen (Betz) \\
Turbulenz (Tollmien)
\end{tabular} & Turbulenz II (Tollmien) & $\begin{array}{l}\text { Mechanik u. } \\
\text { Thermodynamik d. } \\
\text { Strömungen (Tollmien, } \\
\text { Schäfer) } \\
\text { Statistische Analyse d. } \\
\text { Turbulenz (Tollmien) } \\
\text { UE in strömungstechn. } \\
\text { Berechnungen (Betz) }\end{array}$ & $\begin{array}{l}\text { Strömungsmessungen } \\
\text { (Betz) } \\
\text { Hydrodynamische } \\
\text { Miscellen (Tollmien) } \\
\text { Tragflügeltheorie } \\
\text { (Ludwieg) }\end{array}$ \\
\hline $\begin{array}{l}\text { Sonstige } \\
\text { Veranstaltungen }\end{array}$ & $\begin{array}{l}\text { Schwingungs- u. } \\
\text { Wellenlehre (Meyer) }\end{array}$ & $\begin{array}{l}\text { Theorie anharmonischer } \\
\text { u. nichtlinearer } \\
\text { Schwingungen (Schäfer) } \\
\text { Theorie d. autom. } \\
\text { Regler (Schuler) }\end{array}$ & $\begin{array}{l}\text { Ausgew. Kapitel aus d. } \\
\text { Physik d. Ultraschalls } \\
\text { (Tamm) }\end{array}$ & $\begin{array}{l}\text { Die phys. Grundl. d. } \\
\text { Fernsehens (Tamm) }\end{array}$ & $\begin{array}{l}\text { Schwingungs- u. } \\
\text { Wellenlehre (Meyer) } \\
\text { Der Kreisel als } \\
\text { Meßgerart in Physik u. } \\
\text { Technik (Schuler) } \\
\text { Kreiseltheorie (Schäfer) }\end{array}$ & $\begin{array}{l}\text { Theorie rheolinearer u. } \\
\text { nichtlinearer } \\
\text { Schwingungen } \\
\text { (Schäfer) } \\
\text { Der Kreisel als } \\
\text { Meßgerăt in Physik u. } \\
\text { Technik (Schuler) } \\
\text { Grundl. d. Regeltechnik } \\
\text { (Tamm) }\end{array}$ & Ultraschall (Tamm) & & $\begin{array}{l}\text { Schwingungs- u. } \\
\text { Wellenlehre (Meyer) } \\
\text { Die phys. Grundl. d. } \\
\text { Fernsehens (Tamm) }\end{array}$ & \\
\hline Mathematik & $\begin{array}{l}\text { *Graphische Meth. d. } \\
\text { prakt. Analysis } \\
\text { (Tollmien) }\end{array}$ & $\begin{array}{l}\text { * Konforme Abbildung } \\
\text { + UE (Betz) } \\
\text { * Praxis d. Gleichungen } \\
\text { (Tollmien) }\end{array}$ & $\begin{array}{l}\text { * Elektrische Netzwerke } \\
\text { (Stöhr) } \\
\text { * Interpolation u. Quadratur } \\
\text { mit Anwend. auf } \\
\text { Differential- u. Integralgl. } \\
\text { (Tollmien) } \\
\text { Singularitäten- (Integralgl.- } \\
\text { )Meth. mit Anwend. in d. } \\
\text { Mechanik (Schäfer) }\end{array}$ & $\begin{array}{l}\text { *Approximation } \\
\text { empirischer } \\
\text { Funktionen } \\
\text { (Tollmien) }\end{array}$ & $\begin{array}{l}\text { *Graphische Meth. d. } \\
\text { prakt. Analysis } \\
\text { (Tollmien) }\end{array}$ & $\begin{array}{l}\text { * Praxis d. Gleichungen } \\
\text { (Tollmien) }\end{array}$ & & $\begin{array}{l}\text { * Konforme Abbildung } \\
\text { (Betz) }\end{array}$ & $\begin{array}{l}\text { * Graphische Meth. d. } \\
\text { prakt. Analysis } \\
\text { (Tollmien) }\end{array}$ & $\begin{array}{l}\text { * Praxis d. } \\
\text { Gleichungen } \\
\text { (Tollmien) }\end{array}$ \\
\hline
\end{tabular}

* Im Vorlesungsverzeichnis bei den mathematischen Veranstaltungen angekündigt. 


\section{Das Institut für angewandte Mechanik - Kollegialität auf dem Prüfstand}

„Von allen Göttinger Universitätsinstituten hat wohl das ehemalige »Institut für angewandte Mechanik« die vielseitigste Geschichte." ${ }^{1756}$

Von den Göttinger Physikinstituten erfuhr das Institut für angewandte Mechanik durch die politischen Zäsuren sowohl von 1933 wie auch von 1945 die tiefgreifendsten Veränderungen. Beide Male wurde das Personal komplett ausgetauscht und die Forschung neu ausgerichtet. Einen bemerkenswerten Unterschied zu den anderen Physikinstituten stellt die Tatsache dar, dass die nach 1933 und nach 1945 abgesetzten Institutsleiter an der Universität verblieben und nicht in die Emigration gezwungen beziehungsweise durch die Entnazifizierung entlassen wurden.

Das Institut existierte bis 1947 unter dem Namen „Institut für angewandte Mechanik“, wurde dann mit dem Institut für angewandte Elektrizität vereinigt und erhielt den Namen „III. Physikalisches Institut“. In der ersten Zeit ist es vor allem von zwei Personen geprägt worden: Ludwig Prandtl, der es bis 1934 leitete, und Max Schuler, der darauf hin die Leitung übertragen bekam. 1947 übernahm Erwin Meyer die Leitung der 'III. Physik'. Diese drei Direktoren bestimmten nicht nur die inhaltliche Ausrichtung des Instituts, sondern auch die Kriterien für die Auswahl des wissenschaftlichen Nachwuchses. Auch diesbezüglich gab es hier stärkere Änderungen als in den anderen Physikinstituten. Es lag also nicht nur an den veränderten politischen Umständen, dass die Karrieren des akademischen Nachwuchses unter den drei Direktoren anders und auch unterschiedlich erfolgreich verliefen. Diese Beeinflussung ging so weit, dass dadurch der einzige Versuch eines 1933 entlassenen Göttinger Physikers, 1945 in seine frühere Stelle wieder eingesetzt zu werden, zum Scheitern gebracht wurde.

\subsection{Die Geschichte des Instituts bis Anfang der dreißiger Jahre}

Die Geschichte des Instituts für angewandte Mechanik ist bisher noch nicht zusammenfassend dargestellt worden. Von den Göttinger Professoren wurde sie zuweilen geschönt dargestellt, um bestimmte wissenschaftspolitische Ziele zu legitimieren. Es ist daher notwendig, sich 
zuerst einen Überblick über die Geschichte zu verschaffen, wie sie sich aus den Quellen darstellt, und hierbei besonders die Entstehungsgeschichte zu betrachten. ${ }^{1757}$

\subsubsection{Die Ursprünge des Instituts}

$\mathrm{Zu}$ den Ursprüngen des Instituts gehört das Bemühen des Mathematikers und Wissenschaftsorganisators Felix Klein, die angewandte Physik und Mathematik in Göttingen zu fördern. ${ }^{1758}$ Klein wurde 1886 nach Göttingen berufen; zwei Jahre später wurde die „Göttinger Vereinigung zur Förderung der angewandten Physik“ mit Klein als Vorsitzendem gegründet. Durch Kleins Initiative wurde 1897 eine Abteilung für technische Physik eingerichtet und an das physikalische Institut angegliedert. Mit der neuen Abteilung erfuhr das am Leinekanal gegenüber der Bibliothek befindliche physikalische Institut eine bauliche und inhaltliche Erweiterung. ${ }^{1759}$ Von 1849 bis 1897 bestand es nur aus zwei Abteilungen: ${ }^{1760}$ der Abteilung für Experimentalphysik und der Abteilung für mathematische Physik. Direktor der Experimentalphysik war bis 1874 Wilhelm Weber und danach Eduard Riecke. ${ }^{1761}$ Hier wurden galvanische Messungen und erdmagnetische Beobachtungen durchgeführt sowie ein physikalisches Praktikum abgehalten, für das ab 1866 eine Assistentenstelle und ab 1872 eine Hilfsassistentenstelle eingerichtet wurde. Die mathematische Physik leitete zuerst Johann Benedikt Listing und ab 1883 Woldemar Voigt. ${ }^{1762}$ Hier waren die räumlichen Verhältnisse sehr beschränkt: Ein Saal im Erdgeschoss und zwei Zimmer unterm Dach. Ab 1886 wurde das Institut vergrößert, und damit mehr Möglichkeiten geschaffen, den Studenten Experimente in den Vorlesungen vorzuführen und sie auch selbst experimentieren zu lassen. ${ }^{1763}$

\footnotetext{
1756 Abendpost vom 5. Februar 1949, S. 7: „Kreiselkompaß und Ausgleichspendel““. Zitiert nach einem Zeitungsausschnitt in UAG, Rek. 5250 / 7 A.

${ }^{1757}$ Für die frühe Geschichte wurden vor allem die ausführlichen Berichte der jährlichen Chroniken der Universität Göttingen als Quelle benutzt.

1758 Zu Klein siehe Tobies [1981], [1987]; Spangenberg [2000]; Manegold [1968]; Kneser [1949]; Lietzmann [1949]; Prandtl [1949].

17591898 kam auch eine Abteilung für Geophysik unter der Leitung von Emil Wiechert hinzu, die sich ab 1902 als Institut für Geophysik verselbständigte und nicht mehr Teil des physikalischen Instituts war.

${ }^{1760}$ Bevor 1849 die zwei Abteilungen gegründet wurden, gab es an der Universität Göttingen ein physikalisches Kabinet, das von 1799 bis 1842 im alten Museumsgebäude untergebracht war und dann ins ehemalige Werlhof'sche Haus (heute Michaelishaus genannt) verlegt wurde.

${ }^{1761}$ Ab 1902 bis zur Umgestaltung der Physikinstitute 1905 hieß Rieckes 'Institut' Abteilung für Experimentalphysik und für angewandte Electrizitätslehre.

1762 Die Abteilung für mathematische Physik wurde unter Voigt gelegentlich auch Abteilung für theoretische Physik bezeichnet (siehe zum Beispiel die Universitätschroniken für die Jahre 1892 und 1893).

1763 Zur Geschichte der Physikinstitute ausführlicher, doch mit Lücken in Bezug auf die technische Physik und angewandte Mechanik, siehe Hund [1987].
} 
In der 1897 neu hinzugekommenen Abteilung für technische Physik bestand die erste maschinelle Ausstattung aus einem 15 PS-Gasmotor und einer 15 PS starken Dampfmaschine. ${ }^{1764}$ Die Leitung der mit einer außerordentlichen Professur ausgestatteten technischen Physik hatte im ersten halben Jahr Richard Mollier, ihm folgte Eugen Meyer. Im Jahr 1898 wurden eine Kältemaschinenanlage mit Kohlensäurebetrieb, eine Generatorgasanlage, eine 15 PS starke Gasturbine, ein 2 PS Petroleummotor sowie ein 20 PS Dieselmotor aufgestellt. Nach der Berufung Meyers auf ein Ordinariat an der TH BerlinCharlottenburg übernahm Hans Lorenz im Jahr 1900 die Leitung. Unter ihm wurden Einrichtungen für die Festigkeitslehre und Hydraulik angeschafft. Ende 1902 kamen eine Zerreißmaschine und eine Torsionsmaschine sowie eine elektrisch angetriebene Pumpe mit Windkessel hinzu. Im Jahr 1904 wurde Ludwig Prandtl als außerordentlicher Professor Nachfolger von Lorenz. Ein Jahr später zogen die physikalischen Institute in die Neubauten in der Bunsenstraße, und die „technische Physik“ konnte zusammen mit der ,angewandten Mathematik“ die dadurch frei gewordenen Gebäude in der Hospitalstraße 12 beziehen. Die Zusammengehörigkeit der beiden 'Institute‘ kam in der Bezeichnung „Institut für angewandte Mathematik und Mechanik“ zum Ausdruck. Der vorige Name „technische Physik“ wurde aufgegeben, um sich von der angewandten Elektrizitätslehre deutlicher abzugrenzen. Der Begriff Mechanik sollte dabei in seinem weitesten Sinne - auch die Thermodynamik umfassend - verstanden werden. Der beiden Abteilungen gemeinsame Hörsaal hatte 70 Sitzplätze, die treppenförmig aufstiegen. Über der breiten Wandtafel hing ein großer, herab klappbarer Rechenschieber. ${ }^{1765}$

Neben diesem einen Ursprung des Instituts, nämlich der Erweiterung des physikalischen Instituts um die technische Physik 1897, hat es seinen zweiten Ursprung in der Sammlung mathematischer Instrumente und Modelle. Die Sammlung war hervorgegangen aus einem der ältesten Universitätsinstitute, der sogenannten Modell- und Maschinenkammer. Zwischen 1832 und 1879 war Georg Ulrich Direktor der Sammlung, die ursprünglich in der Bibliothek und dann bis 1860 im akademischen Museum Aufstellung fand. 1865 wurde ihr ein geräumiger Saal im neuen Auditorienhaus eingeräumt. Ulrichs Nachfolger wurde Hermann Amandus Schwarz, und die Modell- und Maschinenkammer bekam den Namen Sammlung mathematischer Instrumente und Modelle. Sie diente hauptsächlich dem Unterricht der höheren Mathematik und Geometrie. Ab 1889 befanden sich im mathematischen Zeichensaal sechs Arbeitsplätze für Studierende, wovon jeder Platz mit einem Arbeitstisch, Stuhl, 
Reißzeug, Reißbrett, rechtwinkligen Dreiecken, Kurvenlinealen sowie mit einer Beleuchtungseinrichtung ausgestattet war. Nach dem Weggang von Schwarz übernahm Felix Klein 1891 die Direktion der Sammlung. Er übergab die brauchbaren Instrumente den verschiedenen Instituten, um Raum für die Anschaffung neuer Instrumente und Modelle zu schaffen. 1891 wurde auch eine Assistentenstelle eingerichtet, die ab Oktober 1894 Arnold Sommerfeld - der spätere Ordinarius in München und Nestor der Atomphysik - innehatte. Klein und Sommerfeld verfassten in den folgenden Jahren ein vierbändiges Werk über den Kreisel. ${ }^{1766}$ Über die Entwicklung der Sammlung schrieb Klein 1899:

„Die Sammlung hat entsprechend der steigenden Frequenz und der allgemeinen Entwicklung, welche das Studium der angewandten Mathematik z. Z. an den Universitäten findet, im laufenden Jahre eine beträchtliche Erweiterung erfahren. Es sind nämlich für den Unterricht in darstellender Geometrie (der von Prof. Schilling übernommen wurde) sowie der Geodäsie (Prof. Wiechert) einige Räume in der früheren Wohnung des Directors der Frauenklinik (Hospitalstrasse 12) zur Verfügung gestellt worden, während es gleichzeitig durch besondere Bewilligung ermöglicht wurde, den Bestand der Sammlung an geeigneten Demonstrationsmitteln und Instrumenten wesentlich zu vervollständigen.“1767

Im Jahr 1900 wurden zum ersten Mal geodätische Übungen mit 24 Praktikanten abgehalten. 1902 wurden der Sammlung nautische Instrumente, wie sie auf Schnelldampfern eingesetzt wurden, geschenkt. Im Jahr 1903 wurde die Sammlung „entsprechend dem gesteigerten Umfang des Betriebes“ in zwei Abteilungen geteilt:

- Abteilung A für mathematische Modelle (unter Direktion von Klein) und

- Abteilung B für graphische Übungen und mathematische Instrumente (unter Direktion von Schilling)

Im Jahr 1904 wechselte Schilling an die TH Danzig, und Carl Runge übernahm die Abteilung B. Die nächste Umgestaltung geschah ein Jahr später, indem die Abteilung B als Institut für angewandte Mathematik verselbständigt wurde, während die Abteilung A unter Kleins Leitung wie bisher fort bestand.

\subsubsection{Neuorganisierung der Physikinstitute 1905}

Mit dem Umzug der Physikinstitute in die neuen Bauten in der Bunsenstraße im Jahr 1905 war eine Neuorganisation verbunden. Im Zuge dieser Neuordnung wurden die Institute umbenannt: Das von Prandtl geleitete 'Institut' bekam nun den Zusatz „für angewandte

1765 Runge \& Prandtl [1906].

1766 Zum Werk über den Kreisel von Klein \& Sommerfeld siehe Fußnote 1783. 
Mechanik“. Max Schuler behauptete 1944, dass aus historischen Gründen der richtige Name „Institut für Mechanik“ lauten müsse. Um diese Frage zu klären, wird im folgenden die Umstrukturierung der Physik und die Neubenennung der Institute im Überblick dargestellt. Im Jahr 1904 war das physikalische Institut der Universität Göttingen in drei Abteilungen gegliedert:

A Abteilung für Experimentalphysik und angewandte Elektrizitätslehre (Riecke) ${ }^{1768}$

B Abteilung für mathematische Physik (Voigt)

C Abteilung für technische Physik (Prandtl; vorher Lorenz).

Auch nach dem Umzug blieb die Anzahl der Abteilungen drei. Doch die Elektrizitätslehre bekam nun eine eigenes Gebäude und wurde unter der Leitung Hermann Theodor Simons eine eigenständige Abteilung. ${ }^{1769}$ Die neue Gliederung sah im Jahr 1905 wie folgt aus:

A Abteilung für Experimentalphysik (Riecke)

B Abteilung für mathematische Physik (Voigt)

C Abteilung für angewandte Elektrizität (Simon). ${ }^{1770}$

Prandtls Abteilung für technische Physik, die in den alten Gebäuden am Leinekanal blieb, wurde ebenfalls neu organisiert. Sie wurde eine Abteilung des neu gegründeten Instituts für angewandte Mathematik und Mechanik, welches als zweite Abteilung auch die von Runge geleitete angewandte Mathematik (frühere Abteilung B der Sammlung mathematischer Instrumente und Modelle) umfasste. Die im Michaelishaus verbliebenen Bereiche wurden also zusammengefasst unter dem Namen „Institut für angewandte Mathematik und Mechanik“. Sie gliederten sich wie folgt:

- Abteilung A für angewandte Mathematik (Runge)

- Abteilung B für angewandte Mechanik (Prandtl).

Wie man hieran erkennt, ist Schulers spätere Behauptung, im Namen des Instituts für angewandte Mathematik und Mechanik beziehe sich das ,angewandte“ nur auf die Mathematik und nicht auf die Mechanik, falsch. Die angewandte Mechanik hatte in Göttingen seit ihrem ersten Auftreten 1905 nie einen anderen Namen. Zu Schulers Versuch, das Institut umzubenennen, um dadurch seinen Einflussbereich in der Göttinger Physik zu vergrößern, siehe Abschnitt 5.3.2.5. Mit der Entpflichtung Runges wurde die angewandte Mathematik 1925 mit dem Mathematischen Institut vereinigt und unter die Leitung des neu berufenen

${ }^{1767}$ Felix Klein über die Sammlung mathematischer Instrumente und Modelle, in: Chronik der Georg-AugustUniversität zu Göttingen für das Rechnungsjahr 1899.

1768 Die angewandte Elektrizitätslehre wurde von Rieckes Assistenten Hermann Theodor Simons geleitet. 1769 Simon war seit 1898 Assistent bei Riecke. Von 1900 bis 1901 war er als Physikdozent und Leiter des physikalischen Laboratoriums in Frankfurt am Main. Anschließend übernahm er als Extraordinarius die Leitung der Elektrizitätslehre in Rieckes Institut. Gemeinsam mit Riecke gründete er 1899 die Physikalische Zeitschrift und war als deren Herausgeber tätig. 
Gustav Herglotz gestellt. Damit wurde Prandtls Abteilung zum eigenständigen „Institut für angewandte Mechanik“.

Unter Prandtl bekam die angewandte Mechanik in Forschung und Lehre einen festen Platz innerhalb der Göttinger Physik. Eine erste offizielle Anerkennung seiner Leistungen erhielt Prandtl 1907, indem er zum ordentlichen Professor ernannt wurde. Im Jahr 1906 erhielt seine Abteilung 3500 Mk. von der Göttinger Vereinigung zur Förderung der angewandten Physik und Mathematik. Die Firma Fr. Krupp schenkte dem Institut „,wertvolle Probestäbe“. Die wissenschaftlichen Arbeiten behandelten hauptsächlich Probleme der Gasdynamik und der Festigkeitslehre. Im Unterricht wurde ein breites Spektrum an Themen abgedeckt. Bis 1906 wurden folgende Vorlesungen gehalten: Allgemeine Maschinenlehre, Maschinentechnik, Technologie (für Hörer aller Fakultäten, insbesondere Juristen), landwirtschaftliche Maschinenlehre, technische Mechanik, dynamische Aufgaben der Technik, Festigkeitslehre, Hydrodynamik, Hydraulik und Gasdynamik, Thermodynamik, technische Wärmelehre, Wärmemotoren, Theorie der mechanischen Meßinstrumente und technisches Zeichnen. ${ }^{1771}$ 1906 kam Theodor Kármán nach Göttingen und promovierte zwei Jahre später bei Prandtl. Er blieb noch insgesamt sechs Jahre als Prandtls Mitarbeiter am Institut. In den Jahren 1907/08 fand eine Neuordnung der Praktika statt: Das Wärmemaschinen-Praktikum wurde in das allgemeine physikalische Praktikum eingegliedert. Als Praktikum für Erstsemester wurde das Mechanik-Praktikum eingeführt, welches erstmals im SS 1907 im Umfang von 3 Wochenstunden abgehalten wurde. Gegenstände waren Statik und Dynamik, Reibung, Festigkeit, Hydraulik und Aerodynamik. Durch diese Erweiterung der Praktikums war die Anstellung eines zweiten Assistenten notwendig geworden; sie wurde ermöglicht durch das Entgegenkommen der Göttinger Vereinigung, die - neben ihren regelmäßigen Aufwendungen für das Institut - eine Vergütung für einen Hilfsassistenten aussetzte. Im Jahr 1908 wurden folgende Apparate angeschafft: eine Manometer-Eichvorrichtung mit Quecksilbersäule (bis 12 Atmosphären), Ergänzungen zur hydraulischen Presse, ein Mikromanometer für Wasserdruck und ein 2,8 PS Elektromotor mit stark veränderlicher Tourenzahl und Schalteinrichtungen.

Im Jahr 1909 wurde das Arbeitsgebiet durch die Hinzunahme des Fachgebiets Luftschifffahrt erweitert. Die Göttinger Vereinigung bezahlte einen weiteren Hilfsassistenten, und die Staatsregierung gab eine Zuwendung von dreimal 4000 Mk. auf drei Jahre verteilt. Mit dem

1770 Die Bezeichnung der Abteilung C für angewandte Elektrizität wurde zwischen 1916 und 1920 in Institut für angewandte Elektrizität geändert.

1771 Siehe Runge \& Prandtl [1906] S. 110. 
Institut in Verbindung stand die von der Motorluftschiffstudiengesellschaft errichtete Modellversuchsanstalt für Motorluftschifffahrt und Flugtechnik, die im Jahr 1909 unter Prandtls Leitung den Betrieb aufnahm und den Grundstein der späteren AVA darstellt. ${ }^{1772}$ Im Jahr 1910 wurde eine vollständige kinematographische Einrichtung (Aufnahmeapparat, Kopiervorrichtung und Wiedergabeapparat), ein Chronograph, eine größere Serie Stereoskopbilder, Diapositive und drei Kinofilme von den Ahlborn'schen Aufnahmen von Flüssigkeitsbewegungen angeschafft. Die Bezahlung erfolgte aus dem für Luftschifffahrtszwecke bewilligten staatlichen Extraordinariums. Im Jahr 1912 wurde ein Luftschraubenversuchswagen gekauft, der auf einer neugebauten, zwei Kilometer langen Versuchsstrecke in Arenshausen eingesetzt wurde. Mit den Luftschraubenversuchen wurde der damalige Hilfsassistent Albert Betz beauftragt. Im Jahr 1913 bekam die Abteilung für angewandte Mechanik eine Luftverflüssigungsanlage von Carl von Linde zum Geschenk. Die Modellversuchsanstalt ging im September 1913 in den Besitz der Universität über und wurde dem Institut für angewandte Mechanik als Abteilung für wissenschaftliche Aeronautik angegliedert.

Zu Beginn des Ersten Weltkriegs beziehungsweise kurz danach wurden sämtliche Assistenten in den Dienst des Heeres eingezogen. Im Jahr 1915 wurde der Praktikumsbetrieb eingestellt, ein Neubau einer großen Modellversuchsanstalt für Aerodynamik wurde errichtet, und im Mai und Juni wurden die Assistenten Betz und Wieselburger für die Arbeit in der neuen Anstalt vom Heeresdienst zurückgestellt. Die Luftfahrtforschung konnte im Ersten Weltkrieg ihre Nützlichkeit für den kriegsführenden Staat unter Beweis stellen. ${ }^{1773}$ Das Personal der AVA wuchs sprunghaft an. Das Universitätsinstitut für angewandte Mechanik konnte aber von diesem Aufschwung nicht profitieren.

\subsubsection{Das Institut in den zwanziger Jahren}

Während der Kriegsjahre ruhte der Betrieb in der Abteilung für angewandte Mechanik. $\mathrm{Zu}$ Ostern 1919 wurde er wieder in vollem Umfang aufgenommen. Trotz des Aufschwungs der angewandten Forschung während des Krieges, von dem vor allem die AVA profitierte, konnte Prandtl auf die Anfrage des theoretischen Physikers Richard Becker, ob Prandtl ihm einen jungen Ingenieur mit gründlicher allgemeiner und naturwissenschaftlicher Bildung vermitteln könnte, im September 1920 nur antworten: „Ihrem Wunsche, Ihnen einen jungen Ingenieur

1772 Zur Geschichte der AVA siehe Rotta [1990], und zur politischen Verortung Trischler [1992].

1773 Zur Luftfahrtforschung im Ersten Weltkrieg siehe Trischler [1992] Kap. 2. 
nachzuweisen, bin ich leider nicht in der Lage nachzukommen. In Göttingen wachsen nur Mathematiker und Physiker.“1774

Im August 1920 bekam Prandtl einen Ruf an die TH München, und in einem Brief an Kármán schrieb er, dass „Sie ohne Zweifel meine Nachfolgerschaft im Institut für angewandte Mechanik und meinen Lehrstuhl angeboten bekommen“ werden. ${ }^{1775}$ Dazu kam es aber nicht, denn Prandtl lehnte den Ruf nach München ab und erreichte dadurch, dass er an der Universität Göttingen vom persönlichen zum planmäßigen ordentlichen Professor aufstieg. ${ }^{1776}$ Als der Ruf nach München 1922 mit günstigeren Bedingungen erneuert wurde, nahm er ihn an. Seine Übersiedlung verzögerte sich jedoch, und im Mai 1923 bot ihm die KWG an, zusätzlich zur AVA ein Kaiser-Wilhelm-Institut für Hydrodynamik einzurichten und mit laufendem Etat auszustatten, falls er in Göttingen bliebe. Prandtl nahm das Angebot der KWG an, sagte am 4. Dezember 1923 in München endgültig ab und blieb bis zu seinem Lebensende in Göttingen. Das neue Kaiser-Wilhelm-Institut für Strömungsforschung wurde im Juli 1925 eingeweiht. Prandtl blieb bis 1946 Direktor dieses Instituts. ${ }^{1777}$

In der Abteilung für angewandte Mechanik kamen folgende Einrichtungen nach dem Ersten Weltkrieg neu hinzu: 1921 ein 6,5 m langes Gerinne zum Studium turbulenter Flüssigkeitsströmungen, 1923/24 ein Torsionsapparat für Zug- und Verdrehbeanspruchungen (zum Teil aus Mitteln der Notgemeinschaft), eine von der Helmholtz-Gesellschaft finanzierte Hilfseinrichtung für Metallmikrophotographie und ein Glühofen. Die Arbeiten des Instituts behandelten Anfang der 20er Jahre Fragen der Strömungslehre, der Elastizitäts- und Festigkeitslehre. Mit den angeschafften Maschinen arbeitete vor allem der 1919 nach Göttingen gekommene Árpád Nádai1778, der 1920 Prandtls Assistent am Institut für angewandte Mechanik wurde. Sein Forschungsgebiet war die Festigkeitslehre. Mit seinen

\footnotetext{
1774 Prandtl an Becker, 28. September 1920. DLR-Archiv, GOAR 1364.

1775 Prandtl an Kármán, 11. August 1920. DLR-Archiv, GOAR 1364.

1776 Mit Erlass vom 21. November 1921 wurde Prandtl ein neu geschaffenes Ordinariat für technische Physik, Aeronautik usw. verliehen. Sein Besoldungsdienstalter als planmäßiger ordentlicher Professor wurde auf den 1. April 1921 festgesetzt. Unter Vorwegnahme sämtlicher Dienstaltersstufen wurde ihm ein Grundgehalt von 16200 M bewilligt. UAG, Kur. PA Prandtl.

1777 Zu Prandtls Vita siehe Rotta [1980]; Betz [1953/62]; Busemann [1959]; Görtler [1953]b; sowie die von seiner Tochter verfasste Biografie: Vogel-Prandtl [1993].

1778 Árpád Nádai, geboren 1883 in Budapest, studierte an der TH Zürich Maschinenbau, 1906 Diplom, 1 1⁄2 Jahre Konstrukteur in Budapest und München, ging 1909 an die TH Charlottenburg und promovierte dort 1911. Von 1910-1912 war er Assistent am Lehrstuhl der technischen Mechanik und am Festigkeitslaboratorium der TH bei Eugen Meyer und Assistent am Materialprüfungswesen bei Rudolff. 1913 übersiedelte er in die Schweiz. 1914 zum Kriegsdienst eingezogen, kämpfte er in Italien. 1918 wurde er aus dem Militärdienst entlassen, 1919 kam er nach Göttingen, wo er von 1920-1929 Assistent am Institut für angewandte Mechanik war. Anschließend ging er in die USA nach East Pittsburgh. Siehe Chronik der Georg August-Universität für die Rechnungsjahre 1921-23, S. 36f.
} 
experimentellen Arbeiten erforschte er besonders Phänomene der Plattenbiegung und die Fließeigenschaften der Metalle. 1923 habilitierte er sich für das Fach ,angewandte Mechanik“.

Um 1925 sind einige ältere Maschinen entfernt und die Werkstatt vergrößert worden. Neu angeschafft wurden eine 20-Tonnen-Universalprüfmaschine, ein großes Pendelschlagwerk, eine große mikrophotographische Einrichtung. Alle Geräte wurden von der HelmholtzGesellschaft und der Notgemeinschaft finanziert. Die Forschungsarbeiten Ende der 20er Jahre beschäftigten sich hauptsächlich mit Elastizitätstheorie, Plastizitätstheorie und Fragen der Festigkeit beim allgemeinen Spannungszustand. Die Forschungen zur Hydrodynamik sind an das KWI für Strömungsforschung verlagert worden. Der Assistent am Universitätsinstitut, Árpád Nádai, konnte zahlreiche Untersuchungen mit Unterstützung der HelmholtzGesellschaft durchführen. ${ }^{1779}$ Der dem Institut zur Verfügung stehende Flächenraum betrug etwa 700 qm. Er umfasste 18 Räume des Gebäudes am Leinekanal 3, zu denen in erster Linie zwei große Maschinenhallen für Versuche, eine Mechanikerwerkstatt und ein großer Bibliotheksraum gehörten. Die übrigen Räume waren aufgeteilt zwischen dem Personal des Institutes, den Praktikanten und den Doktoranden. Es waren Arbeitsplätze für 20 Praktikanten und 6 Doktoranden vorhanden. ${ }^{1780}$

\subsubsection{Max Schuler und das Institut in der Weimarer Republik}

Max Schuler war bereits 41 Jahre alt, als er $1923 \mathrm{zu}$ Prandtl ins Institut für angewandte Mechanik kam. Nach einer erfolgreichen Karriere in der Industrie, in der er bis zum Firmendirektor aufgestiegen war, führte ihn sein Wunsch, wieder wissenschaftliche Forschung zu betreiben, zu einer beruflichen Neuausrichtung. An der Universität Göttingen startete er eine Hochschullehrerlaufbahn.

1779 Aus dieser Förderung resultierten folgende Publikationen: Árpád Nádai: 'Beobachtungen der Gleitflächenbildung an plastischen Stoffen', Proc. First Int. Congress Applied Mechanics, Delft 1924, S. 318325; ders.: 'Über die Gleit- und Verzweigungsflächen einiger Gleichgewichtszustände bildsamer Massen und die Nachspannungen bleibend verzerrter Körper', Z. Phys. 30 (1924), S. 106-138; ders.: 'Über die unter einer Belastung sich bildenden Gleitflächen der festen Körper', Z. techn. Phys. 5 (1924), S. 369-378; ders.: 'Die Fließgrenze des Eisens', Schweiz. Bauztg. 83 (1924), S. 157-160, 172-175; ders.: 'Mechanik der bildsamen Körper', in: Hütte, des Ingenieurs Taschenbuch, 25. Aufl., 1. Band, S. 318-331, Berlin 1925; ders.: 'Neue Beiträge zum ebenen Problem der Plastizität', ZAMM 5 (1925), S. 141-142; ders.: 'Zur Mechanik der bildsamen Formänderungen', Ber. Werkstoffaussch. VDEh. 56 (1925); ders.: 'Versuche über die Fließgrenze des Eisens', Verhandl. des 2. Internat. Kongresses für angewandte Mechanik, Zürich 1926, Zürich 1927; ders.: 'Darstellung ebener Spannungszustände mit Hilfe von winkeltreuen Abbildungen', Z. Phys. 41 (1927), S. 48-50. Siehe auch: „Die Helmholtz-Gesellschaft zur Förderung der physikalisch-technischen Forschung in zwanzig Jahren ihres Wirkens“. DLR-Archiv, GOAR 1152.

1780 Die Raumverhältnisse gab Schuler in einer Beschreibung des Instituts vom 14. Januar 1938 an. UAG, Math.-nat. Fak. 24 a. 
Schuler wurde 1882 in Zweibrücken in der Pfalz als Sohn des Bankiers Oskar Schuler geboren. Er wuchs in einem katholischen Elternhaus auf. Seine Mutter starb, als er 15 Jahre alt war. Nach der Schulausbildung in München mit Abitur am humanistischen Wilhelmsgymnasium im Jahr 1901 studierte er an der TH München Maschinenbau und schloss das Studium im August 1907 mit der Diplomhauptprüfung ab. Danach trat er in die Firma seines Cousins Hermann Anschütz-Kaempfe ein. Zuerst war Schuler in der auf die Entwicklung von Kreiselgeräten spezialisierten Firma Anschütz \& Co in Kiel von 1907-1910 Leiter des Versuchslaboratoriums, 1910 wurde er Prokurist, und von 1914-1922 war er Teilhaber und wissenschaftlicher Direktor. Im Herbst 1922 trat Schuler aus der Firma Anschütz \& Co aus. Mehrere deutsche und amerikanische Patente sind aus seiner Tätigkeit hervorgegangen. ${ }^{1781}$

1914 heiratete er Else Treitschke, die Tochter des Brauereibesitzers Friedrich Treitschke. Da sie evangelisch war, trat Max Schuler anlässlich der Hochzeit aus der katholischen Kirche aus. Vor der Hochzeit mit Max Schuler war sie mit dem Firmeninhaber Hermann AnschützKaempfe verheiratet. Else und Max Schuler adoptierten zwei Kinder: den im September 1912 geborenen Wolfgang und die im Februar 1919 geborene Ilse. Die beruflichen Beziehungen der Cousins Schuler und Anschütz-Kaempfe dürften durch die privaten Verhältnisse in Mitleidenschaft gezogen worden sein. Jedenfalls zog sich Anschütz-Kaempfe aus der geschäftlichen Leitung zurück und schied als persönlich haftender Gesellschafter im Jahr 1914 aus. Die neuen Geschäftsleiter wurden Max Schuler und Wolfgang Otto. ${ }^{1782}$ Otto war der Cousin von Else Schuler und seit der Gründung 1905 Teilhaber der Firma Anschütz \& Co. Anschütz-Kaempfe wich den neuen Gesellschaftern aus und ging ab 1916 für den größten Teil des Jahres nach München zurück. Er heiratete Tico Mewes (gest. 1916) aus Istanbul und im März 1919 Reta Stöve. Nach seinem Tod heiratete Wolfgang Otto die Witwe Reta. Nachdem Schuler 1923 nach Göttingen gegangen war, wurde Oskar Richter sein Nachfolger in der Firma. Richter war mit Anschütz-Kaempfes jüngster Schwester verheiratet.

Schuler hatte schon während seines Studiums an der Germaniawerft in Kiel gearbeitet und dabei die Versuche von Anschütz-Kaempfe kennen gelernt, einen Kreiselkompaß für Unterseeboote zu konstruieren. Als er im Alter von 25 Jahren in seine Firma eintrat, machte er sich an die Konstruktion eines Kreiselkompasses und stütze sich dabei hauptsächlich auf

1781 Zu Schulers Laufbahn bei Anschütz \& Co siehe Bludau \& Kaltenbach [1955].

1782 Bludau \& Kaltenbach [1955] S. 36. 
das Lehrbuch von Klein und Sommerfeld ${ }^{1783}$ und auf die Berechnungen seines Lehrers August Föppl. Bei der Konstruktion des Drehstrommotors zum Antrieb des Kreisels kamen ihm die Vorlesungen von J. Ossanna ${ }^{1784}$ zugute, die er an der TH München gehört hatte. 1908 gelang es endlich, einen Kreiselkompass herzustellen, der an Bord von Schiffen erfolgreich arbeitete. ${ }^{1785}$ In den Jahren 1910-16 hielt er regelmäßig Unterrichtskurse über den Kreiselkompass für die Marine Akademie in Kiel. Während seiner Tätigkeit bei AnschützKaempfe fertigte Schuler seine Dissertation über die Einwirkung periodischer Momente auf den Kreiselkompass an. Er hatte diese bereits 1914 fertig gestellt, konnte sie aber zur Promotion nicht verwerten, weil die Materie von der Marinebehörde als geheim erklärt worden war. Erst im November 1920 konnte die Arbeit von der TH München angenommen werden. Im Januar 1921 fand die mündliche Prüfung statt. ${ }^{1786}$ Betreut wurde sie durch August Föppl ${ }^{1787}$, Korreferent war Robert Emden ${ }^{1788}$.

Schulers Forschungen lieferten wichtige Beiträge zum Verständnis von Kreiselkompassen. Im ersten Jahrzehnt des 20. Jahrhunderts war es eine umstrittene Frage, ob ein Kreiselkompass als Navigationsgerät auf Schiffen überhaupt brauchbar sei. Ihr Einsatz führte bei Richtungsund Geschwindigkeitsänderungen des Schiffes zu erheblichen Anzeigefehlern. Schuler konnte nachweisen, dass der Kreiselkompass fehlerlos arbeitet, wenn man ihn so konstruiert, dass seine Schwingungszeit 84 Minuten beträgt; dies entspricht der Schwingungszeit eines Pendels

1783 Felix Klein \& Arnold Sommerfeld: Über die Theorie des Kreisels, 3 Bände, Leipzig: Teubner, 1897-1903. Ein vierter Band über „Die technischen Anwendungen der Kreiseltheorie“ (für den Druck ergänzt und bearbeitet von Fritz Noether) ist 1910 erschienen, für den Schuler seine Rechnungen zur Verfügung stellte. Siehe undatierten Lebenslauf (wahrscheinlich 1924). UAG, Kur. PA Schuler.

1784 Hier ist Giovanni Ossanna gemeint (der auch den deutschen Vornamen Johann benutzte), der 1901 auf den eigens für ihn geschaffenen Lehrstuhl für Elektrische Maschinen an die TH München berufen worden war und der ein Buch über Theorie und Konstruktion elektrischer Maschinen verfasste (herausgegeben in München vom Akademischen Elektro-Ingenieur-Verein, ohne Datum). Siehe die biografische Würdigung Ossannas von Lothar Schoen: http://www.regione.taa.it/giunta/enel/schoen_td.htm.

1785 Eine Beschreibung dieses Kreiselkompasses findet sich in: Hermann Anschütz-Kaempfe: 'Der Kreisel als Richtungsweiser auf der Erde mit besonderer Berücksichtigung seiner Verwendbarkeit auf Schiffen', Jahrbuch der Schiffbautechnischen Gesellschaft 10 (1909), S. 352-369. Hierzu schrieb Schuler einen mathematischen Anhang: Max Schuler: 'Mathematischer Anhang zu dem Vortrage von Dr. Anschütz-Kaempfe über »Der Kreisel als Richtungsweiser auf der Erde mit besonderer Berücksichtigung seiner Verwendbarkeit auf Schiffen «", ebenda, S. 561-576. Zu Schulers Forschungstätigkeit bei Anschütz-Kaempfe siehe seinen undatierten Lebenslauf (wahrscheinlich 1924). UAG, Kur. PA Schuler.

1786 Die Dissertation wurde veröffentlicht in Schuler [1922]a.

1787 August Föppl wurde 1892 Extraordinarius für Landwirtschaftlichen Maschinenbau an der Universität Leipzig und war von 1894 bis 1921 Professor für Technische Mechanik an der TH München. Er verfasste unter anderem ein sechsbändiges Werk „Vorlesungen zur Technischen Mechanik“. Föppl hinterließ eine große Zahl an Schülern, die einige Lehrstühle besetzten, so zum Beispiel seine Söhne Ludwig und Otto, als auch seine Schwiegersöhne Prandtl und Thoma. Föppls Kreiselversuche bildeten den Ausgangspunkt für Schulers weitere Arbeiten über den Kreisel. Siehe Magnus (Hrsg.) [1993] S. 137, 201.

1788 Robert Emden war ab 1899 Privatdozent an der TH-München, dort 1907 ao. Professor und 1924 Honorarprofessor, später Professor in Zürich. Verfasste Bücher über Gaskugeln (1907), Grundlagen der Ballonführung (1907) und Thermodynamik der Himmelskörper (1926). 
von der Länge des Erdradius. Jedoch traten durch das Schlingern des Schiffes bei schwerem Seegang weiterhin Fehler auf, die durch Verwendung eines Mehrkreiselkompasses, dessen Kreisel in unterschiedlicher Orientierung angeordnet sind, behoben werden konnten. Die hierzu erforderlichen Berechnungen und die theoretischen Erklärungen fasste er in seiner Dissertation zusammen.

Dass Schulers Forschungen im Ersten Weltkrieg von militärischer Bedeutung waren, ergibt sich schon aus der Tatsache, dass die Marine seine Dissertation für geheim erklärte. Schuler war bei Beginn des Krieges Leutnant der Reserve der Feldartillerie und stieg 1918 in Würdigung seiner Verdienste um die Kriegstechnik zum Hauptmann der Landwehr auf. Während des Krieges wurde er von der Marine zum Bau von Kreiselkompassen für Unterseeboote reklamiert. Die Marine stellte ihm auch die Aufgabe, einen künstlichen Horizont für Flugzeuge zu bauen, der in Wolken und bei Nebel und möglichst unabhängig von den Flugzeugbewegungen die wahre Lotlinie anzeige. Aus den Quellen geht nicht hervor, ob der von Schuler entwickelte „Fliegerhorizont“ auch Anwendung fand. ${ }^{1789}$ Eine andere Aufgabenstellung betraf Fernlenkboote, an denen gegen Ende des Krieges gearbeitet wurde. Die Marine wünschte einen Kreiselapparat, der das Schiff selbständig auf einem eingestellten Kurs steuert. „Ich unterzog mich dieser Aufgabe, konnte sie aber durch den Kriegsabbruch nicht zu Ende führen. Doch machte ich mir die Erfahrungen, die ich bei diesen Versuchen gesammelt hatte, zunutze, um nach dem Kriege eine automatische Steuerung für Handelsschiffe zu bauen." ${ }^{1790}$ Da sie sich rasch bewährte, wurde die automatische Steuerung ab 1922 auf zahlreichen großen Handelsdampfern eingesetzt.

Als er die Entwicklungsarbeiten für die Marine durchführte, war er häufig bei Probefahrten mit auf See. Bei einer dieser Fahrten verursachte ein Zusammenstoß seines Fahrzeuges mit einem eben auftauchenden U-Boot eine schwere Rückenmarkerschütterung, die ihm sein ganzes weiteres Leben gelegentlich zu schaffen machte. ${ }^{1791}$ Auch epileptische Anfälle, die Schuler zu verheimlichen suchte, traten danach auf. ${ }^{1792}$

\footnotetext{
1789 Schulers trug am 22. Februar 1928 im Kolloquium des KWI für Strömungsforschung über seine Forschungen zur Luftnavigierung vor. Siehe das von ihm verfasste, fünfseitige Protokoll dazu in den Protokollbüchern der Jahre 1928-1935, die sich ohne Signatur im Magazin der Bibliothek der DLR in Göttingen befinden.

${ }^{1790}$ Lebenslauf von Schuler, ohne Datum, wahrscheinlich aus dem Jahr 1924. UAG, Kur. PA Schuler.

1791 Die Verletzung ging damals mit einer völligen Querschnittslaesion einher. Auf Grund der Contusion des Rückenmarks neigte er zu Ohnmachtsanfällen, Durchfällen und Darmstörungen. Siehe das ärztliche Attest des Direktors der Medizinischen Klinik und Poliklinik, Rudolf Schoen, vom 16. Mai 1946. HStAH, Nds. 401, Acc. 112/83, Nr. 986. Siehe auch Dekan an Ministerium, 10. Januar 1928. UAG, Kur. PA Schuler.

1792 Dies geht zum Beispiel aus einem Vermerk des Kurators hervor: „Nach einer vertraulich gemachten Mitteilung des Herrn Rektors leidet Prof. Schuler zeitweise auch an epileptischen Anfällen, sodass seine
} 


\subsubsection{Schulers Weg nach Göttingen}

Einen Kontakt zwischen Schuler und Prandtl gab es schon im Jahr 1920, als Schuler in einem Patentprozess Prandtl als Sachverständigen benannte. ${ }^{1793}$ Im September 1922 äußerte Schuler den Wunsch, zur Universität Göttingen zu kommen, um sich dort „,in der modernen Physik wieder auf das Laufende zu bringen“, aber auch, um dort Vorträge über sein Spezialgebiet, den Kreisel, zu halten. Er fragte bei Prandtl an, ob einer Habilitation prinzipielle Schwierigkeiten entgegenstehen würden, weil er an einer technischen Hochschule und nicht an einer deutschen Universität promoviert hatte. ${ }^{1794}$ Prandtl, der ja genauso wie Schuler an der TH München promoviert hatte, konnte Schuler beruhigend aufklären, das keine formalen Bedenken bestünden. Jedoch hatte Prandtl gerade einen Ruf an die TH München erhalten, und er sah eine „sehr grosse Wahrscheinlichkeit“, dass er zum 1. April 1923 dorthin wechseln würde. Deshalb hätte über eine Habilitation Schulers sein Nachfolger mit zu entscheiden. $\mathrm{Ob}$ mit dieser Sachlage Göttingen überhaupt noch einen Reiz für Schuler besaß, bezweifelte Prandtl. ${ }^{1795}$ Schuler hatte vorher schon von Max Born erfahren, dass Prandtl Göttingen wahrscheinlich verlassen werde. Da Schulers Pläne noch nicht fest standen, und er vor allem an Prandtls Vorträgen interessiert war, ${ }^{1796}$ schrieb er an ihn: „Da ich aus Ihrem Briefe ersehe, dass Sie nach München zu gehen beabsichtigen, so würde mich dies natürlich sehr locken ebenfalls dort weiter zu studieren." Bedenken hatte Schuler allerdings wegen der schlechten Wohnungssituation in München. ${ }^{1797}$

Es scheint aber, dass die Person Prandtl in Schulers Entscheidung über seine berufliche und akademische Zukunft eine große Rolle spielte. Göttingen verlor an Attraktivität zum einen durch Prandtls geplanten Weggang, weit mehr aber durch eine Mitteilung über Prandtls vermutlichen Nachfolger. Dies hätte nämlich nach dem Willen der Fakultät der theoretische Physiker Erwin Madelung aus Frankfurt werden sollen. Prandtl kommentierte diese Entscheidung lakonisch: „Die Berufung Madelung's ist, wie ich zugeben muss, etwas eigenartig, da er bisher ein anderes Fach vertreten hat, aber sie wird von hiesigen Kollegen

\footnotetext{
Entpflichtung auch aus diesem Grunde wünschenswert erscheint." Siehe den handschriftlichen Vermerk des Kurators, Nr. 1996 II, zum Emeritierungsgesuch von Schuler, ohne Datum, vermutlich Mitte Mai 1946. UAG, Kur. PA Schuler.

1793 Siehe den Briefwechsel Schuler-Prandtl vom November/Dezember 1920. DLR-Archiv, GOAR 1365.

1794 Schuler an Prandtl, 8. September 1922. MPG-Archiv, III, 61, 1512.

1795 Prandtl an Schuler, 27. September 1922. MPG-Archiv, III, 61, 1512.

1796 Schuler an Prandtl, 8. September 1922. MPG-Archiv, III, 61, 1512.

1797 Schuler an Prandtl, 8. Oktober 1922. Gegenüber Prandtl begründete Schuler seine Entscheidung gegen München später mit der ergebnislosen Wohnungssuche. Schuler an Prandtl, 7. Februar 1923. MPG-Archiv, III, $61,1512$.
} 
aus anderen Gründen, die ich nicht erörtern kann, sehr stark befürwortet."1798 Prandtls Andeutung lädt $\mathrm{zu}$ verschiedenen Spekulationen ein. Man könnte vermuten, dass verschiedene persönliche Bindungen eine Rolle spielten, besonders, weil Prandtl nicht bereit war, näheres über die Gründe zu sagen. Madelung war Pohls Schwager, und er war mit Franck zusammen im Ersten Weltkrieg im Pionierregiment 36 mit der Untersuchung von Gaskampfstoffen beschäftigt. Am Ende des Kriegs kam er in der von Ladenburg geleiteten Schallmessabteilung der Artillerie-Prüfungskommission mit Born zusammen. Es existierten also zu allen Göttinger Physikordinarien persönliche Beziehungen. Doch es gab daneben auch gewichtige inhaltliche Gründe für eine Berufung Madelungs nach Göttingen. ${ }^{1799}$ Vielleicht wollte die Fakultät der Göttinger Physik ein besonderes Profil geben durch die Besetzung zweier Ordinariate mit theoretischen Physikern. Eventuell wollte sie ein Gegengewicht zur Universität Berlin schaffen, wo zu dieser Zeit mit Max Laue und Max Planck zwei Nobelpreisträger theoretische Physik lehrten. Plausibler erscheint, dass sie mit ihm als Bindeglied die experimentelle und theoretische Physik zu einer intensiveren Zusammenarbeit bringen wollte. Madelung erfuhr seine Ausbildung zum Experimentalphysiker in Göttingen, wo er 1905 bei Simon promovierte. Es folgte eine Assistentenzeit bei Riecke, wo er sich in der theoretischen Physik mit dem atomaren Aufbau der Kristalle beschäftigte. Er lieferte Pionierarbeiten zur Gittertheorie der Kristalle und habilitierte sich 1912 in Göttingen. Max Born urteilte im Rückblick, dass Madelungs Arbeiten von 1910 den Beginn der Gitterdynamik markieren. Mit Born und Landé beschäftigte er sich auch im Krieg während seiner Tätigkeit in der Schallmessabteilung weiterhin mit Kristallphysik. Im Zuge seiner Berechnungen der elektrostatischen Energie von Kristallen fand er eine Konstante, die für jeden Gittertyp einen charakteristischen Wert besitzt und als Madelung-Konstante bekannt wurde. Born war an diesen Rechnungen unmittelbar beteiligt und von Madelungs Leistung tief beeindruckt. ${ }^{1800}$ In der Göttinger Physik, die von experimenteller wie theoretischer Seite ein Interesse an der Kristallphysik hatte, hätte Madelung eine Brücke zwischen der formalistischen Ausrichtung bei Born und der betont experimentellen bei Pohl schlagen können. Jedoch wurden die Pläne der Fakultät überholt durch die Entscheidung der KWG, für Prandtl ein neues Institut zu errichten und damit seinen Verbleib in Göttingen zu sichern. Diese Lösung begünstigte Max Schulers Pläne, in Göttingen eine akademische Laufbahn

\footnotetext{
1798 Prandtl an Schuler, 10. Februar 1923. MPG-Archiv, III, 61, 1512.

1799 Zu Madelungs Laufbahn und Forschungen siehe Ulrich E. Schröders Beitrag auf: http://www.physik.unifrankfurt.de/paf/paf73.html

1800 Siehe Born [1975] S. 253. 
einzuschlagen. Zum SS 1923 kam er in die kleine Universitätsstadt und hörte wieder Vorlesungen.

\subsubsection{Max Schulers Sonderstellung im Institut}

Schuler war nun frei von Verpflichtungen und widmete sich seinen wissenschaftlichen Untersuchungen zum Kreiselkompass. In seinem ersten halben Jahr hielt er drei Vorträge in Göttingen: Im Juli 1923 über „Das störungsfreie Pendel“ in der Physikalischen Gesellschaft zu Göttingen und über „Das Glätten von Funktionen mittels Differenzentabelle“ im Seminar von Carl Runge. Im November sprach er in Prandtls Seminar über „Die Stabilitätsverhältnisse bei automatischer Steuerung“. ${ }^{1801}$ Seine in dieser Zeit verfolgten Versuche, die Genauigkeit des Kreiselkompasses weiter zu steigern, hatten das Ziel, ihn für Vermessungszwecke verwendbar zu machen. Schuler prüfte die Weisung des Kreisels nach dem astronomisch bestimmten Meridian, um so einen mechanischen Beweis für die Erddrehung zu erhalten. Diese Messungen und ihre Ergebnisse reichte er der Fakultät im Januar 1924 als Habilitationsschrift mit dem Titel „Die Bestimmung der Erdachse mit dem Kreisel“ ein. Die Habilitationskommission bestand aus Prandtl als Hauptreferenten, Runge, Wiechert, Born, Pohl, Courant, Meinardus und Seedorf. Im Gutachten hob Prandtl Schulers theoretische Leistungen bei der Firma Anschütz \& Co. hervor, wenngleich er anschließend die vielen praktischen Anwendungen aufzählte. Prandtl hielt fest, Schuler sei „als Privatgelehrter“ nach Göttingen gekommen, ,um seine durch seinen Werdegang etwas einseitigen Kenntnisse auf eine breitere Basis zu stellen.“ Da die Dynamik der starren Körper bei Prandtl etwas zu kurz komme, sei es günstig, wenn Schuler dieses Gebiet in Vorlesungen vertrete. Der Theoretiker Born meinte kurz: „Ich habe von Herrn Dr. Schuler den allerbesten Eindruck gewonnen, nicht nur als Theoretiker und Experimentator, sondern auch als Lehrer. Seine Vorträge im Kolloquium waren musterhaft. Ich würde seinen Eintritt in den Lehrkörper mit Freude begrüßen.“ Die Probevorlesung fand am 5. Mai 1924 zum Thema „Der Kreisel als Richtungsweiser" statt. Am 13. Juni 1924 wurde ihm die venia legendi für das Fach angewandte Mechanik erteilt. ${ }^{1802}$

Es ist wichtig, festzuhalten, dass Schuler nicht nur in der angewandten Physik, sondern sogar in der theoretischen Physik durch Born wissenschaftliche Anerkennung fand. Dies war für jemand, dessen wissenschaftliche Herkunft der Maschinenbau war, keine Selbstverständlichkeit und von besonderem Wert für eine akademische Laufbahn in der

1801 Lebenslauf von Schuler, ohne Datum, wahrscheinlich aus dem Jahr 1924. UAG, Kur. PA Schuler. 
Göttinger Physik. Bedeutung erlangte diese 'Rückendeckung' auch deshalb, weil Schuler Bedenken wegen seiner technischen Herkunft hatte. Dies erkennt man unter anderem am Stil eines außergewöhnlich umfangreichen Lebenslaufs, den er anlässlich der Habilitation verfasste. Schulers inhaltliche Auswahl in der Darstellung der eigenen Biografie, Auslassungen wie Ausschweifungen, lassen Rückschlüsse auf sein Selbstverständnis ziehen. Der Lebenslauf gibt neben den reinen Daten des beruflichen Werdegangs auch einen umfangreichen Überblick über die Geschichte des Kreiselkompasses. Die einzelnen Fortschritte in der Konstruktion immer genauerer Kreiselkompasse, auch Beiträge anderer Forscher werden ausführlich ausgebreitet. Schuler verknüpft seine komplette wissenschaftliche Laufbahn, seine Interessen und Leistungen ausschließlich mit der Geschichte des Kreiselkompasses. Er stellt sich in erster Linie als erfahrenen Instrumentenbauer dar, der als erster komplizierte mathematische Berechnungen richtig durchführte. Obwohl er diese 'rechnende Seite' in den Vordergrund stellte, später nannte er sich auch einen Theoretiker, erweckt die Darstellung beim Leser mehr das Bild eines Praktikers. Insofern mag sein Lebenslauf nur schlecht auf die Erwartungshaltung der Universität Göttingen abgestimmt gewesen sein. Die Bedeutung seiner Leistungen unterstrich Schuler, indem er auf die Anwendungen in der Technik und die ihm ausgestellten Patente hinwies. Doch die Ausführlichkeit, mit der er die technischen Anwendungen seiner Arbeiten schilderte, dürfte die Fakultät vermutlich nicht so sehr interessiert haben. Was im langen Lebenslauf aber zum Beispiel fehlt, ist eine Erwähnung irgend welcher anderen wissenschaftlichen Interessen außer des Kreisels, denen er möglicherweise während seines Studiums nachgegangen war. Gesamt gesehen wirkt der Lebenslauf unbeholfen und ausschweifend, wenn man bedenkt, dass er von einem erfahrenen, 42-jährigen Mann verfasst wurde, der über 12 Jahre Teilhaber und wissenschaftlicher Direktor einer großen Firma war und sich für die Lehrbefugnis an einer Universität bewarb. Man erhält den Eindruck, Schuler sei ein Spezialist eines eng umgrenzten Gebiets, der für seine neu gewählte Arbeitsumgebung nicht die nötige Selbstsicherheit mitbringe und glaube, sich ausführlich erklären und rechtfertigen zu müssen. Seine Erklärungen betreffen aber nur seine Industrietätigkeit, obwohl er schon ein Jahr lang in Göttingen wissenschaftliche Forschungen betrieb. Den angemessenen Stil der Darstellung seiner akademischen Qualifikation hat er bis dahin noch nicht gefunden. Seine späteren Lebensläufe der dreißiger Jahre unterscheiden sich grundlegend von dem besprochenen. Sie sind nicht nur kürzer und sachlicher, sie enthalten 
auch eine Einteilung seiner Arbeiten in theoretische und solche, die praktische Apparate betreffen. Diese Darstellungsweise entsprach besser dem Stil der Göttinger Physik.

In das erste Göttinger Jahr fällt seine im Rückblick bedeutendste Publikation, jedenfalls wenn man die Bedeutung an der Anzahl der Einträge im Science Citation Index der Jahre 1955 bis 1995 misst. Es ist dies ein kurzer Aufsatz in der Physikalischen Zeitschrift mit dem Titel „Die Störung von Pendel- und Kreiselapparaten durch die Beschleunigung des Fahrzeuges“". ${ }^{1803}$ In dieser Arbeit lieferte er eine physikalische Ableitung dafür, dass sich der Kreiselkompass bei einer Einstellung auf eine Schwingungsdauer von 84 Minuten bei jeder Änderung der Fahrzeugsgeschwindigkeit ohne Schwingungen in die neue Gleichgewichtslage einstellt, da in diesem Fall der Beschleunigungsausschlag ebenso groß wird wie der Fahrtfehler. Dieses Prinzip wurde später Schuler-Prinzip oder auch 84-Minuten-Prinzip genannt und bekam grundlegende Bedeutung für die Trägheitsnavigation, speziell im Zweiten Weltkrieg für die Steuerung von Raketen. Erst durch die amerikanische Raketenforschung wurde seine Arbeit auch im englischsprachigen Raum rezipiert. 1950 schrieb Walter Wrigley vom MIT: „Although Schuler's article [from 1923] must have been reasonably well-known on the European continent, [...] it has been relatively unknown in America until recently, and is not widely known even now."1804 Und 1969 äußert sich ganz ähnlich Frank Coffman Bell: „About 1950 some engineers working on inertial navigation in America were becoming aware of his work and his 1923 paper. The notion soon became popular in several navigation engineering circles that Schuler's idea and the concept of inertial navigation were one and the same, especially with respect to the two artificial horizons involved. No English translation of Schuler's 1923 paper appears to have been available before 1956, and only two are known to the author to exist at this time, perhaps in very limited availability. " 1805 Sein Prinzip wurde dann im angelsächsischen Sprachraum als Schuler-tuning bekannt.

Die Organisation der Forschung und Lehre im Institut für angewandte Mechanik war mit der Aufnahme Schulers in den Lehrkörper relativ klar geregelt. Prandtl übernahm die Hydro- und Aerodynamik, Nádai die Festigkeitslehre und Schuler sein Spezialgebiet, die Kreisellehre. Veranstaltungen zur allgemeinen (angewandten) Mechanik boten alle drei Dozenten an. Bei der Ausbildung des wissenschaftlichen Nachwuchs war die Aufteilung entsprechend: Die

\footnotetext{
1803 Siehe Schuler [1923].

1804 Wrigley [1950] S. 282.

1805 Bell [1969] S. 495. Die erwähnten Übersetzungen sind: Fisher, G. H.: Translation of Schuler's original paper published in Physikalische Zeitschrift, 1923, Engineering Report No. 3. Kearfott Division, General Precision, Inc., Little Falls, N. J., 1956; Slater, J. M.: The Disturbance of Pendulum and Gyroscopic Apparatus
} 
'Strömungsforscher' wurden am KWI bei Prandtl beschäftigt, die 'Festigkeitsforscher' am Institut für angewandte Mechanik, wo auch Schuler seine Schüler in der Kreisel- und Schwingungsphysik arbeiten lassen konnte. Schuler stellte zu diesem Zweck Instrumente und Kreiselapparate als Unterrichtsmodelle aus seinem privaten Besitz im Institut auf.

\begin{tabular}{|l|l|l|}
\hline Semester & Titel der Vorlesung & Stunden \\
\hline SS 1924 & Der Kreisel als Meßinstrument & 1 \\
\hline WS 1924/25 & Angewandte Schwingungslehre & 1 \\
\hline SS 1925 & $\begin{array}{l}\text { Die Theorie des Kreisels } \\
\text { Übungen zur Mechanik, gemeinsam mit Prof. Courant und Dr. Nádai }\end{array}$ & 2 \\
& Einführung in die Mechanik & 2 \\
\hline DS 1925/26 & Semwendung der Kreiselgesetze in Physik und Technik & 1 \\
& Kinematik & 1 \\
\hline SS 1926 & Angewandte Schwingungslehre & 2 (14tägig) \\
\hline WS 1926/27 & Die Relativitätstheorie von Einstein & 1 \\
\hline SS 1927 & Die Theorie des Kreisels & 1 \\
\hline WS 1927/28 & $\begin{array}{l}\text { Vorlesung über Mechanik } \\
\text { Übungen zur Mechanik }\end{array}$ & 1 \\
\hline SS 1928 & $\begin{array}{l}\text { Anwendung der Kreiselgesetze in Astronomie, Physik und Technik } \\
\text { Praktikum zur Anwendung der Mechanikgesetze }\end{array}$ & 2 \\
\hline WS 1928/29 & $\begin{array}{l}\text { Die Theorie der Beobachtungsfehler in Physik und Astronomie } \\
\text { Die Relativitätstheorie von Einstein }\end{array}$ & 4 \\
\hline SS 1929 & $\begin{array}{l}\text { Angewandte Schwingungslehre } \\
\text { Festigkeitspraktikum }\end{array}$ & 2 \\
\hline WS 1929/30 & $\begin{array}{l}\text { Vorlesung über Mechanik } \\
\text { Übungen zur Mechanik }\end{array}$ & 2 \\
\hline SS 1930 & $\begin{array}{l}\text { Anwendung der Kreiselgesetze in Astronomie, Physik und Technik } \\
\text { Praktikum in der elementaren Mechanik, gemeinsam mit Dr. Prager }\end{array}$ & 2 \\
\hline WS 1930/31 & Die Ausgleichung der Beobachtungsfehler in Physik und Astronomie & 2 \\
\hline SS 1931 & $\begin{array}{l}\text { Mechanische Schwingungslehre } \\
\text { Praktikum zur Schwingungslehre }\end{array}$ & 2 \\
\hline WS 1931/32 & $\begin{array}{l}\text { Theorie und Anwendung des Kreisels } \\
\text { Praktikum zur Kreisellehre } \\
\text { Übungen zur Mechanik 1806 }\end{array}$ & 2 \\
\hline
\end{tabular}

Tabelle 24 Schulers Lehrveranstaltungen an der Universität Göttingen von 1924 bis 1932. ${ }^{1807}$

\subsubsection{Trotz früher Ernennung zum Professor eine Karriere mit Hindernissen}

Die Fakultät versuchte, Schulers akademische Laufbahn $\mathrm{zu}$ beschleunigen. Obwohl normalerweise eine Frist von sechs Jahren zwischen der Erteilung der Lehrbefugnis und einer Ernennung zum Professor liegen müsste, beantragte die Fakultät bereits nach knapp vier Jahren, im Januar 1928, beim Ministerium die Verleihung der Dienstbezeichnung eines nichtbeamteten außerordentlichen Professors und die Erteilung eines Lehrauftrages an

by Acceleration of the Vehicle, by Dr. Maximilian Schuler, translated. Inertial Navigation Division, Autonetics, a division of North American Aviation, Inc., Downey, Calif., 1960.

1806 Diese Übungen, die nicht im Vorlesungsverzeichnis aufgeführt waren, hat Schuler in Ergänzung zu Prandtls Mechanik-Vorlesung gehalten. Prandtl an Kurator, 13. November 1931. MPG-Archiv, III, 61, 1735. 
Schuler. Die Verkürzung der Frist begründete die Fakultät einerseits mit Schulers 1917 durch einen Zusammenstoß mit einem U-Boot verursachten „Kriegsbeschädigung“, die laut ministeriellem Erlass eine Verkürzung erlaube, und andererseits damit, dass er bereits als „gereifter Mann“ nach Göttingen gekommen sei. Der Lehrauftrag wurde mit Schulers erfolgreicher Lehrtätigkeit begründet: „er versteht durch die anschauliche Art seines Vortrages das Interesse der Studenten zu fesseln und nimmt auch sonst an allen fachlichen Angelegenheiten einen sehr regen Anteil.“ Da Schuler vier Jahre lang seine Lehrtätigkeit ohne jegliche Vergütung bestritten hatte, würde ein Lehrauftrag, „der zweckmäßig den Titel »Für Theorie und Anwendung des Kreisels« erhalten würde“, eine verdiente Anerkennung bedeuten. Bei der engen Ausrichtung seiner Forschungen legte die Fakultät besonderes Gewicht auf die Feststellung, dass die Kreiselfragen „nur mit durchaus wissenschaftlichen Methoden bearbeitet werden“ könnten, und Schuler auch „seit langem die Anerkennung seiner wissenschaftlichen Fachkollegen erworben" habe. 1808 Das Ministerium ernannte Schuler am 26. April 1928 zum nichtbeamteten außerordentlichen Professor für angewandte Mechanik an der Universität Göttingen, lehnte aber gleichzeitig den Antrag auf einen besoldeten Lehrauftrag ab.

Im Oktober 1928 wurde Schuler auf der Berufungsliste für den Lehrstuhl für Statik und Dynamik an der Deutschen Technischen Hochschule in Prag an zweiter Stelle zusammen mit Herbert Wagner (TH Danzig) genannt. Berufen wurde der erstgereihte Wilhelm Müller. Zu Schulers Qualifizierung steht in der Berufungsliste: „Obwohl die von Schuler erzielten Resultate die verdiente Würdigung in der wissenschaftlichen Welt vollauf gefunden haben, so muß doch andererseits betont werden, daß seine ganze Persönlichkeit auf ein sehr enges Arbeitsgebiet eingestellt ist. Auch seine Vorlesungstätigkeit beschränkt sich mit Ausnahme einer gelegentlich populären Einführungsvorlesung in die Relativitätstheorie auf Gegenstände seines engeren Arbeitsgebietes." 1809 Die Nennung auf der Berufungsliste wird in Schulers Universitäts-Personalakten nicht erwähnt. Es scheint so, als ob sie auch für seine weitere Karriere und die Bemühungen um einen Lehrauftrag keine positiven Auswirkung hatte.

1807 Für die folgenden Semester siehe Tabelle 23.

1808 Dekans an Ministerium, 10. Januar 1928, UAG, Kur. PA Schuler.

1809 Bericht der allgemeinen Abteilung für die Besetzung der durch die Berufung von Professor Pöschl frei gewordenen Lehrkanzel für Statik und Dynamik an der Deutschen Technischen Hochschule Prag, beschlossen am 11. Oktober 1928. An der Abfassung des Berichts beteiligt waren: Proff. Weiß, Carda, Funk, Mack, Tuma, Pöschl, Fiedler, Nowak, Gessner und Körner. Zitiert nach Litten [2000] S. 44. 
Schuler hatte an der Universität Göttingen nur ein recht bescheidenes Einkommen, das aus den Vorlesungshonoraren bestand. ${ }^{1810}$ Seinen Lebensunterhalt bestritt er aus den Einnahmen aus seinen Patenten. Anfang Mai 1929 beantragte die Fakultät wieder einen besoldeten Lehrauftrag mit dem Titel „Für Theorie und Anwendung des Kreisels“ für Schuler, der am 5. Juni 1929 vom Ministerium aus Mangel an Mitteln abgelehnt wurde. Daraufhin protestierte Schuler mit einem Schreiben an den Kurator. Er wies darauf hin, dass der Kultusminister Carl Heinrich Becker die Universitäten in einer öffentlichen Rede kritisierte, dass sie die Verbindung mit dem Leben verloren hätten, weil sie im Unterschied $\mathrm{zu}$ den technischen Hochschulen keine Persönlichkeiten aus der Wirtschaft berufen würden. Schuler sehe sich gezwungen, an eine andere Hochschule zu wechseln, falls die Universität Göttingen seine Lehrtätigkeit nicht finanziell honoriere. Dies würde jedoch den Zielen des Ministers entgegen stehen. Trotz der schlüssigen Argumentation blieb Schulers Protest erfolglos. ${ }^{1811}$ Am 19. Juli 1929 beantragte die Fakultät erneut einen besoldeten Lehrauftrag für Schuler mit dem geänderten Titel „Für technische Mechanik, besonders für Schwingungslehre und Kreisellehre“, 1812 der am 17. Dezember 1929 vom Ministerium aus Mangel an Mittel wiederum abgelehnt wurde. ${ }^{1813}$ Als Entschädigung erhielt Schuler im August 1929 vom Ministerium eine einmalige Vergütung von RM 400,--

Die Akte betreffend die Erteilung eines besonderen, nicht besoldeten Lehrauftrags an Schuler wurde in den Jahren 1930-32 mindestens zwölfmal verschiedenen Stellen vorgelegt. Auf den entsprechenden Aktenvermerken in der vom Kurator Valentiner geführten Personalakte sind verschiedene Notizen des Kurators zu finden. 11. Dezember 1930: „1) Leider immer noch wenig Aussicht. Ich muß gewisse Professoren dafür interessieren.“ 19. Mai 1931: „1) Hr. Prof. Pohl hat sich über Hr. Schuler sehr günstig ausgesprochen. Ich möchte noch weitere Erkundigungen einziehen." 1814 Einen unbesoldeten Lehrauftrag für Schuler beantragte die Fakultät schließlich im Juli 1932,1815 der jedoch postwendend vom Ministerium abgelehnt wurde, da die Erteilung eines unbesoldeten Lehrauftrags an nichtbeamtete außerordentliche Professoren ,,aus grundsätzlichen Überlegungen leider unmöglich ist”. 1816

\footnotetext{
1810 Beispielsweise erhielt Schuler im SS 1929 an Vorlesungshonorar RM 47,50, außerdem noch einen Zuschlag von $50 \%$ (= RM 23,75).

1811 Schuler an Kurator, 12. Juli 1929. UAG, Kur. PA Schuler.

1812 Dekan an Ministerium, 19. Juli 1929. UAG, Kur. PA Schuler.

1813 Abgelehnt durch Erlass vom 17. Dezember 1929. UAG, Kur. PA Schuler.

1814 Notizen von Valentiner in UAG, Kur. PA Schuler.

1815 Dekan an Ministerium, 11. Juli 1932. UAG, Kur. PA Schuler.

1816 Erlass des Ministers vom 3. August 1932. UAG, Kur. PA Schuler. 
Obwohl Schuler von seinen Physikerkollegen wie auch vom Kurator hilfreiche Unterstützung fand, gelang es bis 1933 nicht, ihm ein regelmäßiges, gesichertes Einkommen durch die Universität zu ermöglichen.

\subsubsection{Erweiterung von Schulers Forschungsthemen}

Um 1926/27 kamen zur Kreiselphysik zwei weitere Forschungsthemen hinzu, denen sich Schuler intensiv widmete. Das erste Thema ist ein mit der Kreiselphysik verwandtes Problem und betrifft den Ausgleich der Schlingerbewegung von Schiffen. Versuche dazu wurden mit Kreiseln (sogenannten Schlingerkreisel) durchgeführt. Eine andere Möglichkeit, deren nähere Untersuchung Schuler unternahm, war, sogenannte Schlingertanks im Schiffsrumpf anzubringen. ${ }^{1817}$ Eines der von Schuler später angegebenen Ziele dieser Forschungen war es, die Schlingerbewegung bei Kriegsschiffen zu verringern, um damit die Treffsicherheit der Geschütze zu erhöhen. ${ }^{1818}$ Über gekoppelte Schwingungssysteme unter besonderer Berücksichtigung des Schlingertankproblems promovierte Schulers erster Doktorand, Erich Hahnkamm. ${ }^{1819}$

Als zweites neues Forschungsthema behandelte Schuler Fragen der genauen Zeitmessung. Mit einer neuen Konstruktionsidee schaffte er es, eine Pendeluhr zu bauen, die ganz wesentlich genauer war als die bis dahin bekannten astronomischen Pendeluhren. Schuler verband damit das Ziel, die Genauigkeit seines Uhrenpendels so weit zu steigern, dass damit die Schwankungen in der Länge des Tages messbar werden. Er schaffte dies durch die von ihm erdachte Konstruktion eines Ausgleichspendels (auch Minimumpendel genannt). Seine Uhr war damals die genaueste Pendeluhr der Welt. Zu Forschungszwecken wurde eine Schuler-Uhr, wie sie dann genannt wurde, in der Universitätssternwarte aufgestellt. ${ }^{1820}$ Als Hilfsassistenten, der die Messungen der Uhr betreute, beschäftigte er Thomas Gengler, den späteren NS-Kreisleiter von Göttingen. Auch an diesem Thema ließ er in den dreißiger Jahren Doktoranden forschen. Aus den langjährigen Messungen konnte man aus den merkwürdigen Gangsprüngen der Schuler-Uhr neue Erkenntnisse über das Verhalten von Invar-Stahl

\footnotetext{
1817 Schulers Publikationen zu diesem Themengebiet sind: Schuler [1927]c, [1928], [1929]c.

1818 Siehe Schulers spätere Darstellung über „Die Bedeutung des Instituts für angewandte Mechanik an der Universität Göttingen“ vom 19. Juli 1938. UAG, Math.-nat. Fak. 24 a.

1819 Laut Doktorurkunde war die mündliche Prüfung in angewandter Mechanik, Physik, Chemie und Mathematik am 30. Juli 1930 und wurde mit „Genügend“ beurteilt. Die Dissertation erhielt die Note „Sehr gut“. Die Urkunde wurde am 26. April 1932 ausgestellt. Siehe UAG, Kur., XVI. V. C. e. 1. Siehe auch seine Publikationen, die aus der Doktorarbeit hervorgingen: Hahnkamm [1933]a, [1933]b.

1820 Siehe Schulers Publikationen über Messungen mit seiner Uhr und Fragen der Zeitmessung allgemein: Schuler [1927]a, [1927]b, [1929]b, [1929]d, [1931]b, [1931]c, [1931]d, [1932]b, [1935]b, [1935]c, [1938]a, [1938]b, [1938]c, [1939]a, [1939]b, [1947/48], [1950]b, [1951]b; Schuler \& Gockel [1938], [1939].
} 
gewinnen. Außerdem konnten durch kombinierte Messungen von Pendel- und Quarzuhren sehr geringe Schwankungen der Schwerebeschleunigung nachgewiesen werden. ${ }^{1821}$ Über die vorläufigen Ergebnisse in seinen beiden neuen Forschungsthemen trug Schuler auf der Tagung des Ausschusses für mechanische Schwingungen des VDI im Mai 1929 vor. ${ }^{1822}$

In Schulers Angebot an Lehrveranstaltungen sticht eine Vorlesung heraus, die sich von seinen Interessen in der angewandten Mechanik deutlich abhebt. Es ist dies die erstmals im WS 1926/27 angebotene Vorlesung über Relativitätstheorie. Es ist anzunehmen, dass der persönliche Kontakt zu Einstein, der noch in Schulers Kieler Zeit bei Anschütz-Kaempfe bestand, sein Interesse an der Relativitätstheorie geweckt hat. ${ }^{1823}$ Die Beschäftigung mit der Relativitätstheorie kräftigte auch sein Selbstbild vom Theoretiker. Über einen geplanten Vortrag in Hamburg im April 1927 vor der Gesellschaft für technische Physik über die Bekämpfung der Schlingerbewegungen des Schiffes erhoffte sich Schuler, dass „bei der Aussprache sich Herren beteiligen werden, die durch ihre praktische Erfahrung mir als Theoretiker wiederum Anregung und Winke geben können." ${ }^{1824}$ Auch in der Wahrnehmung Max Borns war Schuler ein „Theoretiker und Experimentator“. ${ }^{1825}$ Als Born im WS 1927/28 verreist war, übernahm Schuler seine große Mechanikvorlesung - wohlgemerkt die Vorlesung über theoretische Mechanik, nicht jene über experimentelle, die Pohl regelmäßig hielt. 1826

\subsection{Das Institut unter Willy Prager, 1929-1933}

Nach Ausscheiden des Assistenten Nádai im Juli 1929 übergab Prandtl diese Stelle dem 26 Jahre jungen Willy Prager. Damit blieb die fachliche Kontinuität im Institut gewahrt. Prager studierte ab 1921 an der TH Darmstadt Bauingenieurwesen, legte dort 1925 die Diplomprüfung ab und war anschließend planmäßiger Assistent für Mechanik. Im folgenden Jahr promovierte er mit einer Arbeit über die Kinematik des Raumfachwerks; bereits als 24Jähriger habilitierte er sich für Mechanik. Die eingereichte Habilitationsschrift trug den Titel: „Zur Theorie elastisch gelagerter Konstruktionen“. Er blieb noch zwei Jahre an der TH Darmstadt, ab 1928 mit einen Lehrauftrag. Seine Vorlesungstätigkeit in Darmstadt behandelte

\footnotetext{
1821 Einen kurzen Überblick über die Forschungsergebnisse gibt Magnus [1972]b.

1822 Seine Vorträge behandelten: „Eine Berichtigung der Gleichungen des Schlingertanks“ und „Ein neues Pendel mit unveränderlicher Schwingungszeit (Mit Vorführung auf der Sternwarte)“. Zusammen mit Prandtl führte er die Gäste auf einer Besichtigungstour durch das Institut für angewandte Mechanik. UAG, Sek. 335.53. 1823 Zur Verbindung Schuler-Einstein siehe Lohmeier \& Schell (Hrsg.) [1992] und den dort auf S. 148ff. abgedruckten Brief Schulers an Einstein.

1824 Schuler an Schimank, 17. April 1927. UH-HSGS, NL Schimank, Korr. Schuler.

1825 Siehe Borns Gutachten zu Schulers Habilitation, zitiert in Abschnitt 5.1.4.2.
} 
unter anderem Elastizitätstheorie, Strömungslehre, Flugzeugstatik und Himmelsmechanik. Die Umhabilitierung Pragers nach Göttingen für das Fach Mechanik fand im Juni 1929 statt. ${ }^{1827}$ In Prandtls Gutachten zeigt sich, dass er neben den fachlichen Qualitäten Pragers auch die charakterlichen eigens würdigte: „Bezüglich seiner menschlichen Eigenschaften trage ich noch nach, daß er ein feiner, sehr zurückhaltender und bescheidener Mann ist, von dem ich sicher bin, daß er mit Jedem sehr gut auskommen wird."1828 Die Einschätzung Prandtls bestätigte sich zumindest in dem gutem Verhältnis, dass Prager zu den Mathematikern herstellen konnte. Beispielsweise konnte er die bis dahin belastete Beziehung des Instituts zu Richard Courant wieder auf eine konstruktive und für beide Seiten befriedigende Basis stellen. Über die positiven Veränderungen und Pragers Anteil daran berichtet ein Brief des damaligen Hilfsassistenten am Institut, Gustav Mesmer, ${ }^{1829}$ an Prandtl vom November 1929: „Z. Zt. sieht alles viel freundlicher aus als im vorigen Jahr, als das Institut unter persönlichen Anfeindungen litt. Herr Dr. Prager, den wir alle sehr gern haben, hat die Beziehungen zu Herrn Prof. Courant u.s.w. in trefflicher Weise wieder aufgenommen, das Interesse an unseren Dingen scheint wieder zu wachsen. Das Mechanikpraktikum hat zwar nur sechs Teilnehmer, aber immerhin mehr als im Vorjahr. (Da waren es fünf!)“1830 Auch in Courants Gutachten zu Pragers Habilitationsschrift äußert sich schon eine Hoffnung auf ein wiederhergestelltes gutes Verhältnis: „Herr Prager ist ein Mann, welcher moderne mathematische Methoden in viel höherem Masse beherrscht als die meisten seiner engeren Fachgenossen. Ich hoffe von seiner Göttinger Wirksamkeit eine günstige Rückwirkung auf den Betrieb der angewandten Mathematik." 1831 Auch bei den Studenten kam der immerhin erst 26 Jahre junge Prager gut an. Über Pragers Vorlesung vom WS 1929/30 schrieb Mesmer an Prandtl: „Die Vorlesung über »Statik unbestimmter Systeme« gefällt mir sehr gut, sie ist eine sehr schöne Ergänzung zu Ihrer »Graphischen Statik« - und Herrn Dr. Pragers Vortrag

\footnotetext{
1826 Schuler an Schimank, 13. Oktober 1927. UH-HSGS, NL Schimank, Korr. Schuler.

1827 Die Habilitationskommission wurde am 31. Mai 1929 zusammengestellt und bestand aus: Prandtl, Courant, Herglotz, Born, Reich, Angenheister, Prodekan und Dekan. Der öffentliche Probevortrag zum Thema „Über eine Zuordnung ebener und räumlicher Fachwerke“ fand am 27. Juli 1929 statt. GPAMNFG, Lehrkörper (ausgeschieden), Prager.

1828 Gutachten Prandtl, GPAMNFG, Lehrkörper (ausgeschieden), Prager.

1829 Unter der Betreuung Nádais promovierte Gustav Mesmer mit der Arbeit „Vergleichende spannungsoptische Untersuchungen und Fließversuche unter konzentriertem Druck“, Korreferent war Prandtl. Mesmer studierte Mathematik und Naturwissenschaften in Tübingen, München und Göttingen, 1929-33 Hilfsassistent am Institut für angewandte Mechanik Göttingen; 1939 Habilitation TH Aachen, 1940 ordentlicher Professor TH Darmstadt, dort 1949 Rektor, 1950 Professor Washington University, St. Louis, MO, USA, 1957 Gastprofessor TH Darmstadt, Gastprofessor Universität Kabul, Afghanistan, 1974 emeritiert. Siehe Lebenslauf in seiner Dissertation; Kürschner; MPG-Archiv, III, 14 A, 2900.

1830 Brief Mesmer an Prandtl, 26. November 1929. MPG-Archiv, III, 61, 1056.

1831 GPAMNFG, Lehrkörper (ausgeschieden), Prager.
} 
ist sehr anschaulich und klar."1832 Im Rückblick schätzte Kurt Hohenemser Pragers Vorlesungen als die besten ein, die er je gehört habe. ${ }^{1833}$

Als Prager im August 1929 Nádais Assistentenstelle übernahm, wurde das zum Nádai’schen Lehrauftrag gehörende Festigkeitspraktikum auf Veranlassung Prandtls zuerst Schuler übertragen. Einen diesbezüglichen schriftlichen Antrag hatte Prandtl schon am 9. März 1929 an den Kurator gestellt. ${ }^{1834}$ Diese neue Verteilung der Aufgaben lag, wie sich aus den Notizen des Kurators ergibt, daran, dass Schuler ein vergüteter Lehrauftrag zukommen sollte - wenn auch nur vertretungsweise und nur für ein Semester. Es war dann auch das einzige Semester, in dem Schuler ein Festigkeitspraktikum abhielt. ${ }^{1835}$ Diese Aufgabe übernahm anschließend der fachlich geeignetere Prager. Schuler betreute im SS 1930 zusammen mit Prager ein Praktikum zur elementaren Mechanik. In den Jahren bis 1934 bot Schuler nur noch Praktika seiner Spezialgebiete Kreisel- und Schwingungslehre an, danach, nach der Entlassung und Abwehr aller von Prandtl vorgeschlagenen Assistenten, auch wieder das Mechanikpraktikum (siehe Tabelle 23 und Tabelle 24).

Prandtl war von Pragers wissenschaftlichen und menschlichen Qualitäten so sehr überzeugt, dass er ihm die Verwaltung des Instituts überließ - wenn auch nur inoffiziell. Prandtl erschien gewöhnlich einmal in der Woche am Institut und ließ sich von Prager die Fortschritte in den Forschungsarbeiten der Institutsmitarbeiter berichten. ${ }^{1836}$ Mit dem Gewinn Pragers für Göttingen kam es zu einer Verjüngung im Institut. Die Situation, dass sehr junge Wissenschaftler bezahlte Forschungsarbeiten durchführen konnten und diese auch das Institutsleben prägten, mag gerade für den eine Generation älteren Schuler, der als 'Gast' im Institut unbezahlte Forschung betrieb, unangenehm gewesen sein. Auffällig war auch, wie schnell der junge Wissenschaftlernachwuchs aus der Gruppe der 'Festigkeitsforscher' Karriere machen konnte, während Schuler selbst und auch seine ersten Doktoranden erheblich langsamer vorwärts kamen. Auf zwei der schnellen Karrieren wird im folgenden näher eingegangen, da sie auch die angespannte Beziehung der angewandten Physik zur 'reinen“ Physik in Göttingen offenbaren.

\footnotetext{
1832 Brief Mesmer an Prandtl, 26. November 1929. MPG-Archiv, III, 61, 1056.

1833 Siehe Rammer [2002] S. 79f.

1834 Siehe Notiz des Kurators vom 31. April 1929. UAG, Kur. PA Schuler.

1835 Siehe Kurator an Schuler, 13. Mai 1929. UAG, Kur. PA Schuler.

1836 Siehe die verleumderische Darstellung von Erich Hahnkamm vom 18. November 1933, die zumindest in der Kritik an Prandtls seltenen Besuchen zutreffen dürfe. UAG, Kur. XVI. V. C. h. 11 I. Eine Bestätigung erbrachte das Interview mit Hohenemser. Rammer [2002] S. 82f. Auch Prandtls eigenen Aussagen zu Folge hatte er nur wenig Zeit für die Aufgaben am Institut für angewandte Mechanik aufgewendet.
} 


\subsubsection{Spannungen zwischen 'reiner' und angewandter Physik}

$\mathrm{Zu}$ einer prinzipiellen Auseinandersetzung in der Fakultät führte das Habilitationsverfahren von Wilhelm Flügge. Der am 18. März 1904 in Greiz (Thüringen) geborene Wilhelm Flügge war der ältere Bruder des theoretischen Physikers Siegfried Flügge. Er ging in Dresden zur Schule, wo er Ostern 1921 das Abitur ablegte. Danach studierte er an der TH Dresden Bauingenieur, absolvierte im Juni 1925 sein Diplom bei Professor Max Foerster und war dort anschließend Assistent von Professor Kurt Beyer. Im November 1927 promovierte er zum Dr.-Ing. bei den Professoren Beyer und Erich Trefftz mit einer Arbeit über Kreisplatten unter Einzellasten. Von Ende 1927 bis Oktober 1930 arbeitete als Ingenieur bei der Baufirma Dyckerhoff \& Widmann. Zur Erweiterung seine Mathematik- und Mechanikkenntnisse kam er im Mai 1930 an die Universität Göttingen und besuchte dort Vorlesungen. Er erhielt ein Stipendium der Notgemeinschaft und arbeitete am Institut unter Prandtls Aufsicht über Zylinderknickung und die Theorie elastischer Schalen. Er reichte sein Gesuch um Zulassung zur Habilitation am 27. Oktober 1931 ein und legte seine Arbeit über Zylinderknickung bei. ${ }^{1837}$ Als Kommission fungierten die Herren Prandtl, Weyl, Herglotz, Reich, Pohl, Prager, Prodekan Schermer und Dekan Born. Erst auf Anregung Prandtls wurde Prager von der drittletzten auf die zweite Stelle der Kommission gesetzt, da Prager ,als der einzig eigentliche Fachmann außer“ Prandtl anzusehen war. ${ }^{1838}$ In der geänderten Reihenfolge wurden die Gutachten abgegeben. Schon Prandtl konnte in seiner Stellungnahme dem Gesuch nicht uneingeschränkt zustimmen, wenngleich sein abschließendes Urteil positiv ausfiel:

„Flügge ist ein starkes Talent; ohne Zweifel wird er sich auch bei anderen Aufgaben erneut bewähren. Vorläufig ist es aber ein ziemlich enges Gebiet, auf dem er sich bisher betätigt hat, und dieses Gebiet gravitiert mehr nach der technischen Hochschule als nach der Universität. Ich zweifle nicht, daß er später seinen Weg zur technischen Hochschule zurück finden wird. Vorläufig möchte er aber in Göttingen bleiben und sich hier seine Sporen im Dozieren verdienen. Ich möchte deshalb diesem vorzüglichen Manne gerne vorwärts helfen und beantrage daher Zulassung zu den weiteren Habilitationsleistungen." 1839

Prager bescheinigte Flügge, dass er die Theorie elastischer Schalen - eines der schwierigsten Gebiete der technischen Elastizitätslehre - in ausgezeichnetem Maße beherrsche. „Wenn auch die Arbeiten alle diesem verhältnismäßig kleinen Gebiet der technischen Mechanik angehören, so gewinnt man doch die Überzeugung, dass der Verfasser auch auf anderen

1837 Siehe zum Vorhergehenden Flügges undatierten Lebenslauf, vermutlich 27. Oktober 1931. GPAMNFG, Lehrkörper (ausgeschieden), Flügge.

1838 Prandtl an Dekan Born, 14. November 1931. GPAMNFG, Lehrkörper (ausgeschieden), Flügge. 
Gebieten ähnliche Erfolge erzielen wird." 1840 Weyl imponierte der Mut und die Zähigkeit, mit der Flügge das Problem anging

„- auf Grund des voll beherrschten »klassischen« Vorrats von Ideen, der aber weder Mehrung noch eine originelle Wendung erfährt. Dies scheint einer der Wege zu sein, auf welchem der Praxis im Gebiete der Elastizität heute am besten vorwärts geholfen werden kann. Wo sich der Drang nach Verbindung von Technik und Theorie mit einer solchen Entschiedenheit und so viel Talent äussert wie bei Herrn Flügge - der offenbar erhebliche persönliche Opfer bringt, um sich hier zu habilitieren - sollte die Fakultät sich zur Förderung bereit finden."1841

Diese vielen vorgebrachten Einschränkungen - enges Gebiet, das eher an eine TH gehöre, persönliches Vorwärts-Helfen als Motiv der Unterstützung, persönliche Opfer Flügges als Entschuldigung - mögen nun Pohl, der Flügge selbst nicht persönlich kannte, dazu veranlasst haben, grundsätzliche Bedenken zu äußern.

„Hier scheint der Termin der Habilitations-Absicht recht früh gewählt zu sein, denn Herr Flügge hat sich in seinen bisherigen 4 Arbeiten nur auf einem kleinen Teilgebiet der angewandten Mechanik betätigt. - Es möchte sich ja mancher Tüchtige und Energische unter den jüngeren Herren sehr früh habilitieren, um sich dadurch den Übergang zur Technik zu erleichtern. Aber ich habe in diesen Fällen das Bedenken, daß dies Verfahren von Bewerbern anderer Fächer unserer Fakultät als Bevorzugung empfunden werden muß. Liegt für eine sofortige Habilitation Dr. Flügges ein dringendes Unterrichtsbedürfnis vor, etwa auch vom Standpunkt der angewandten Mathematik? Vielleicht kann Herr Kollege Herglotz gebeten werden, seine Entscheidung noch näher zu begründen, wenn sich die Mitglieder der Kommission einmal $\mathrm{zu}$ einer mündlichen Aussprache zusammenfinden könnten.“" 1842

Mit der Bitte an Herglotz, der sein Einverständnis zur Hablitation Flügges schon gegeben hatte, wollte Pohl wahrscheinlich das Unterrichtsbedürfnis in der angewandten Mathematik ausloten. Daraufhin schaltete sich auch der Dekan Born ins Verfahren ein.

„Auf Grund der Bedenken des Koll. Pohl, die ich selber teile, bitte ich Herrn Koll. Herglotz um eine frdl. Ergänzung seines Gutachtens. Habilitation auf Grund eines kleinen Teilgebiets der Elastizitätslehre, die selbst wieder ein beschränktes Teilgebiet der Mechanik ist, scheint mir nicht möglich, oder nur dann, wenn in den Arbeiten des Kandidaten eine ganz ungewöhnliche, geniehafte wissenschaftliche Leistung zum Ausdruck kommt. Ich bitte Herrn Koll. Herglotz hierüber seine Meinung zu sagen.“1843

1839 Gutachten Prandtl, 18. November 1931, GPAMNFG, Lehrkörper (ausgeschieden), Flügge.

1840 Gutachten Prager, 23. November 1931, GPAMNFG, Lehrkörper (ausgeschieden), Flügge.

1841 Gutachten Weyl, 28. November 1931, GPAMNFG, Lehrkörper (ausgeschieden), Flügge.

1842 Gutachten Pohl, 17. Dezember 1931, GPAMNFG, Lehrkörper (ausgeschieden), Flügge.

1843 Eintrag Born in Flügges Akte, 5. Januar 1932, GPAMNFG, Lehrkörper (ausgeschieden), Flügge. 
Mit der Geniehaftigkeit spielte Born möglicherweise auf Heisenberg an, den er selbst ungewöhnlich jung mit 22 Jahren zur Habilitation geführt hatte. Das erste Gutachten von Herglotz lautete vollständig: „Für Zulassung“. Vom verlangten zweiten wurde leider die erste Zeile abgeschnitten. Es beginnt mit: „,- die vorliegenden Arbeiten überraschen nicht durch Universalität oder geniehafte Konzeption."1844 Des weiteren ist von der seltenen Kraft Flügges die Rede, mit der er trotz methodischer Schwierigkeiten zu konkreten, kontrollierbaren Resultaten gelangte. Letztlich stimmte Herglotz für die Zulassung Flügges. Die Akte ging wieder zu Pohl, der seine Bedenken wiederholte, obwohl er eine Woche vorher für die Zulassung des noch jüngeren Hohenemser votierte. Pohl wünschte eine mündliche Aussprache darüber, ob erstens ein dringendes Unterrichtsbedürfnis eine Habilitation schon jetzt erforderlich mache, und ob zweitens die Fakultät im Augenblick der damaligen „Abbaumaßnahmen“ mit der Habilitation eines nicht durch eine Assistentenstelle gesicherten Privatdozenten nicht ein bedenkliches Risiko übernehme. ${ }^{1845}$ Es ist überraschend, dass Pohl mit keinem Wort auf den Parallelfall Hohenemser eingeht, zu dem er mit Ausnahme der fehlenden Assistentenstelle dieselben Fragen hätte aufwerfen können. Bei der folgenden Zusammenkunft der Kommission konnte Prandtl klärend eingreifen. Er erklärte, dass Flügges Habilitation keineswegs zu früh stattfinde, da er sein Studium vor über sechs Jahren abgeschlossen habe, dass Flügge deshalb so wenig publiziert habe, weil er praktisch tätig war, und dass ein eigentliches Bedürfnis für seine Lehrtätigkeit zwar nicht vorliege, jedoch Flügge an die Fakultät keine Versorgungsansprüche stellen wolle und vor habe, sich später an eine technische Hochschule umzuhabilitieren, sodass er nur kurz Göttinger Privatdozent bleiben wolle. ${ }^{1846}$

In dem schwierigen Verfahren, in dem Pohl mit der Unterstützung Borns ernsthafte Bedenken anmeldete, Prandtl seinen Gastwissenschaftler verteidigte, der seine Ausbildung gar nicht bei ihm, sondern an der TH Dresden erfahren hatte, und in dem die Mathematiker zwischen die Fronten gerieten, sich aber vorsichtig zustimmend verhielten, kam die Kommission Ende Januar $1932 \mathrm{zu}$ folgendem eeeSchluss:

„Auf Grund vorstehenden Gutachtens erklärt sich die Kommission mit der Zulassung des Herrn Flügge einverstanden unter der Bedingung, daß ihm nach Erfüllung aller Habilitationsbedingungen die Bestimmung der Habilitationsordnung $\S 7$ vorgehalten wird, wonach er keinerlei Ansprüche auf

\footnotetext{
1844 Herglotz erstes Gutachten stammt vom 1. Dezember 1931, das zweite vom 8. Januar 1932. GPAMNFG, Lehrkörper (ausgeschieden), Flügge.

1845 Eintrag Pohl, 18. Januar 1932. GPAMNFG, Lehrkörper (ausgeschieden), Flügge.

1846 Erklärung von Prandtl, 28. Januar 1932. GPAMNFG, Lehrkörper (ausgeschieden), Flügge.
} 
Beförderung (verstanden als materielle Hilfe jeder Art, Stipendien u. dergl.) an die Fakultät zu stellen hat." 1847

Die gelungene Abwehr der schweren Einwände von Pohl und Born, von denen nur noch die Befürchtung eines materiellen Risikos für die Universität übrig blieb, jedoch keine Bedenken bezüglich der wissenschaftlichen Qualifikation, ist auf die gewichtige Stimme Prandtls in der Fakultät zurückzuführen. Dies wird auch bei späteren Habilitationsverfahren noch deutlich werden. Flügge konnte im Februar 1932 seinen öffentlichen Probevortrag über „Stabilitätsprobleme der Elastizitätstheorie“ halten und erhielt daraufhin die venia legendi fürs Fach angewandte Mechanik. ${ }^{1848}$

Praktisch gleichzeitig mit Flügge leitete der um zwei Jahre jüngere Kurt Hohenemser sein Habilitationsverfahren in die Wege. Hohenemser war Pragers erster inoffizieller Doktorand an der TH Darmstadt. Er promovierte dort im Dezember 1929 mit der Arbeit „Praktische Wege zur angenäherten Schwingungsberechnung elastischer Systeme“. ${ }^{1849}$ Das Thema wurde von Prager vorgeschlagen, offiziell betreut wurde die Arbeit von Wilhelm Schlink, Korreferent war Alwin Walther. Von August 1929 bis April 1930 war Hohenemser außerplanmäßiger Assistent von Schlink am Aerodynamischen Institut der TH Darmstadt, anschließend folgte er seinem Lehrer Prager nach Göttingen. Auf Vermittlung Prandtls bekam er ein Stipendium der Notgemeinschaft und führte Untersuchungen über die Grenzen des plastischen Bereichs in Körpern, die teils elastisch, teils bildsam verformt sind, durch. ${ }^{1850}$ Außerdem arbeitete er mit Prager über Stabschwingungen; ihre Ergebnisse legten sie in dem Buch „Dynamik der Stabwerke“ vor. ${ }^{1851}$

Hohenemser assistierte Prager im WS 1930/31 bei der Abhaltung der Vorlesung zur praktischen Analysis und im SS 1931 bei der Vorbereitung und Durchführung des Festigkeitspraktikums. Im November 1931 ersuchte der erst 25-jährige Hohenemser um

1847 Abschlusserklärung vom Dekan Born, 28. Januar 1932. GPAMNFG, Lehrkörper (ausgeschieden), Flügge.

1848 Der Probevortrag fand am 18. Februar 1932 statt. GPAMNFG, Lehrkörper (ausgeschieden), Flügge.

1849 Veröffentlicht in Hohenemser [1930]. Prandtl schrieb an Hohenemser am 3. April 1930, er habe seine Dissertation mit Interesse durchgesehen, allerdings feststellen müssen, dass er für die „verwendeten Integralsgleichungsmethoden zu wenig Vorkenntnisse habe“, um die Arbeit richtig zu verstehen. MPG-Archiv, III, 61, 692.

${ }^{1850}$ Siehe den Briefwechsel Hohenemser-Prandtl vom 15. März 1930 bis 8. April 1930. MPG-Archiv, III, 61, 692.

1851 Kurt Hohenemser: 'Fließversuche an Rohren aus Stahl bei komplizierter Zug- und Torsionsbeanspruchung', ZAMM 11 (1931); ders.: 'Neuere Versuchsergebnisse über das plastische Verhalten der Metalle', ZAMM 11 (1931); ders. \& Willy Prager: 'Beitrag zur Mechanik des bildsamen Verhaltens von Flußstahl', ZAMM 12 (1932) (diese Arbeit wurde von der Helmholtz-Gesellschaft zur Förderung der physikalisch-technischen Forschung finanziert); dies.: 'Über die Anzahl der Knotenpunkte bei erzwungenen und freien Stabschwingungen', ZAMM 11 (1931). dies.: Dynamik der Stabwerke. Eine Schwingungslehre für Bauingenieure, Berlin: Springer, 1933. 
Erteilung der venia legendi und reichte seine Habilitationsschrift „Variationsprobleme in der Mechanik elastisch-bildsamer Körper“ ein. ${ }^{1852}$ Die Schwierigkeiten in dieser Arbeit lagen unter anderem daran, dass als Nebenbedingungen Ungleichungen auftraten, für deren Behandlung geeignete mathematische Methoden gefunden werden mussten. Die Habilitationskommission bestand aus den selben Professoren wie bei Flügges Verfahren; auch hier wurde aus fachlichen Überlegungen Prager nachträglich an die zweite Stelle vorgerückt. ${ }^{1853}$ Im Gutachten von Prandtl heißt es zu Beginn: „Herr Dr. Hohenemser [...] fiel mir sehr bald durch sein eindringendes Verständnis und durch die äußerst gewandte Beherrschung der mathematischen Methoden auf. Später konnte ich auch seine experimentelle Geschicklichkeit des öfteren feststellen." Nach dem Referieren seiner Arbeiten kommt Prandtl zu dem Schluss: „Nach dieser Schilderung der wissenschaftlichen Persönlichkeit Dr. Hohenemsers ist es klar, daß er einen sehr erwünschten Zuwachs unseres Lehrkörpers bedeuten wird.“1854 Das folgende Gutachten von Prager behandelt ausschließlich Hohenemsers veröffentlichte Arbeiten und enthielt sich jedes Werturteils, da „die Mehrzahl der eingereichten Arbeiten teils auf meine Anregung hin teils in Zusammenarbeit mit mir entstanden“" 1855 waren. Demgegenüber gab Courant ein deutliches Urteil zu Hohenemser ab:

„Auf grund genauerer persönlicher Bezugnahme und auf grund der vorgelegten Abhandlungen kann ich mich dem Votum der Kollegen Prandtl und Prager voll anschliessen. Herr Hohenemser ist ein aufstrebendes Talent mit weit gespannten Interessen und Kenntnissen. Mehrere seiner Arbeiten, vor allem auch die Habilitationsschrift beweisen eine erstaunliche Fähigkeit, binnen kurzer Zeit in eine schwierige mathematische Disziplin bis zu einer wirklichen methodischen Beherrschung einzudringen und dann fruchtbare Anwendungen auf dem Gebiete der Mechanik zu machen. Obwohl Herr H. nach seinem Entwicklungsgang durchaus von der Technik herkommt, sind seine Bestrebungen entschieden nach rein wissenschaftlicher Erkenntnis gerichtet. Ich glaube, dass die von ihm eingeschlagene Arbeitsrichtung grosse Zukunftsaussichten hat und auch für die reine Mathematik noch manche Anregungen bringen wird. Daher begrüsse ich gerade als Mathematiker die Gewinnung von Herrn H. als Privatdozenten." 1856

Dies schrieb Courant zwei Wochen, bevor Pohl seine Kritik an Flügges Habilitation äußerte. Für die Auseinandersetzung mit dieser Kritik bemerkenswert ist Courants Betonung der auf die rein wissenschaftliche Erkenntnis gerichteten Arbeitsweise Hohenemsers. Nach dieser

\footnotetext{
1852 Sein Gesuch datiert vom 12. November 1931. Die Habilitationsschrift wurde veröffentlicht in Hohenemser [1932]b.

1853 Am 17. November 1931 wurde Prager auf die zweite Stelle der Kommission nach Prandtl gereiht. GPAMNFG, Lehrkörper (ausgeschieden), Hohenemser.

1854 Gutachten Prandtl, 23. November 1931, GPAMNFG, Lehrkörper (ausgeschieden), Hohenemser.

1855 Gutachten Prager, 24. November 1931, GPAMNFG, Lehrkörper (ausgeschieden), Hohenemser.

1856 Gutachten Courant, 6. Dezember 1931, GPAMNFG, Lehrkörper (ausgeschieden), Hohenemser.
} 
äußerst positiven Beurteilung stimmte die Habilitationskommission ohne weitere gutachterliche Äußerungen, und schließlich auch die anderen Fakultätsmitglieder einstimmig für die Zulassung Hohenemsers zu den weiteren Leistungen. ${ }^{1857}$ Hohenemser wurde, obwohl er wie Flügge aus demselben Fach kam und obwohl er zwei Jahre jünger war, nicht in die generelle Debatte um frühzeitige Habilitationen hineingezogen. Ihm wurde im Unterschied zu Flügge nicht vorgehalten, dass er mit seiner Forschungsrichtung an eine TH gehöre. Dies ist insofern wichtig festzuhalten, da die Fakultät 1945 Hohenemsers beantragte Lehr- und Forschungstätigkeit in Göttingen mit Argumenten ablehnte, die 1931/32 gegen Flügge, nicht aber gegen Hohenemser vorgebracht wurden. Zu der günstigeren Beurteilung mag Courants Gutachten mit der Hoffnung auf große Zukunftsaussichten der Hohenemser'schen Arbeitsrichtung auch für die reine Mathematik eine Rolle gespielt haben. Es könnte sogar sein, dass Pohl dieses Gutachten vor sich liegen hatte, als er am 17. Dezember 1931 seine Kritik niederschrieb. Pohl erhielt Hohenemsers Akte nämlich, nachdem Reich am 17. Dezember unterschrieben hatte, also eventuell noch am selben Tag. Aber selbst wenn er sie erst später bekam, wird ihm die Parallelität zum Fall Flügge aufgefallen sein. Trotzdem stimmte er am 12. Januar 1932 ohne Einschränkung für die Zulassung Hohenemsers zu den weiteren Habilitationsleistungen. Eine Woche danach wiederholte er seine Bedenken im Fall Flügge. Es scheint demnach so, als seien Hohenemsers breitere fachliche Ausrichtung, seine zahlreicheren Publikationen und das günstigere Urteil der Mathematiker hier ausschlaggebend gewesen. Hohenemsers Probevortrag „Über ein heuristisches Prinzip zur Begründung statistischer Ansätze in der Mechanik“ fand wie auch Flügges Vortrag am 18. Februar 1932 statt. Die Themenwahl war allerdings ungeschickt, da Hohenemser einem Ansatz von Richard Mises folgte, der von den Göttinger Mathematikern stark kritisiert wurde. Sein Vortrag fand daher keine uneingeschränkt positive Aufnahme. ${ }^{1858}$

Am 3. März 1932 wurde Hohenemser die venia legendi erteilt und im SS 1932 hielt er eine eigene Vorlesung über Schwingungsphysik, im folgenden WS ein Schwingungspraktikum ab. Seine Forschungstätigkeit war von einer großen literarischen Produktivität begleitet. In die Göttinger Zeit von 1930 bis 1933 fallen über 20 wissenschaftliche Publikationen. Die Vielfalt

\footnotetext{
${ }^{1857}$ Für die Zulassung zu den weiteren Habilitationsleistungen unterschrieben folgende Kommissionsmitglieder ohne jeden zusätzlichen Kommentar: Herglotz (8.12.31), Reich (17.12.31), Pohl (12.1.32), Schermer (?) (14.1.32), Born (19.1.32), Eucken (23.1.32), Bernstein (23.1.32), Goldschmidt (25.1.32), Franck (25.1.32) und Seedorf (29.1.32). GPAMNFG, Lehrkörper (ausgeschieden), Hohenemser.

$1858 \mathrm{Zu}$ Mises 'Ansatz in der Wahrscheinlichkeitsrechnung und der Kritik aus Göttingen siehe Rammer [2002] S. 91. Über die Kritik an seinem Probevortrag berichtet Hohenemser in seinen Erinnerungen, einem über 60 Seiten starken Manuskript mit dem Titel: „Woran ich mich noch erinnere“, das er im Kloster in Bildhausen von 1945 bis 1947 ausgelöst durch den Verlust seines Besitzes schrieb; siehe S. 50. KHP.
} 
seiner wissenschaftlichen Interessen zeigt sich zum Beispiel in zwei Ausätzen über grundlegende Fragen der Wahrscheinlichkeitstheorie. ${ }^{1859}$ Im Rückblick des Jahres 1946 urteilt Hohenemser über seine Göttinger Zeit:

\begin{abstract}
„Die drei Göttinger Jahre von 1930 bis 1933 waren die arbeitsmässig befriedigensten meines seitherigen Lebens. Ich war bis auf das letzte Jahr, in welchem ich ein kleines Praktikum und eine kleine Spezialvorlesung über Schwingungslehre hielt, frei von regelmässigen Pflichten irgendwelcher Art, verfügte über die reiche persönliche Anregung durch Prager und über die bisher ungekannten und reichen Hilfsmittel des Institutes für angewandte Mechanik und des mathematischen Institutes, vor allem dessen Bibliothek, und musste lediglich zur Erhaltung des Stipendiums selbstgewählte Forschungsarbeiten durchführen und darüber berichten." 1860
\end{abstract}

Auch das private Leben war für ihn durch die Bekanntschaft mit vielen anregenden Menschen sehr befriedigend. Er nahm zusammen mit Mesmer und Prager an verschiedenen Tanzabenden teil, auch an den von Prandtl und Landau veranstalteten, wo er beispielsweise mit Prandtls Tochter tanzte. Er besuchte auch Kammermusikabende bei Richard Courant. Courants Frau, Levy ${ }^{1861}$, Rudolf Lüneburg und andere musikalische Mathematiker spielten die Instrumente, während sich Courant selbst langweilte, da er nach Hohenemsers Erinnerung völlig unmusikalisch war. Fast täglich war Hohenemser Gast an einem vegetarischen Mittagstisch von Frau Schmalz, an dem er eine Reihe Nelsonschüler kennen lernte, so Heinrich Düker, Erna Siem, Albert Steen, Hedwig Schulz. ${ }^{1862}$ Der Nationalsozialismus brachte eine grundlegende Veränderung der Lebenssituation für Hohenemser und viele der genannten Personen.

\title{
5.3 Das Institut im Nationalsozialismus
}

Zum Jahreswechsel 1932/33 wurden im Institut für angewandte Mechanik personalpolitische Entscheidungen notwendig. Willy Prager nahm einen Ruf als Ordinarius an die TH Karlsruhe an und schied damit aus der Göttinger Assistentenstelle aus. Schon im Januar 1933 beantragte Prandtl, die Assistentenstelle Hohenemser zu übertragen. ${ }^{1863}$ Doch auf die Neubesetzung zum 1. April 1933 folgte ein politischer Machtkampf zwischen Prandtl und nationalsozialistischen Studenten, der so weit führte, dass schließlich auch die Direktorstelle zur Disposition stand.

\footnotetext{
1859 Hohenemser [1931]a, [1931/32]. In diesen Aufsätzen kombinierte er die Ansätze von Richard Mises und Hans Reichenbach und formulierte zum ersten Mal das Prinzip des geringsten Prophezeiungsrisikos.

1860 „Woran ich mich noch erinnere“, S. 49. KHP.

1861 Wahrscheinlich ist der Mathematiker Hans Lewy gemeint.

1862 „Woran ich mich noch erinnere“, S. 51f. KHP.
} 


\subsubsection{Politische Unruhen im Institut - der Leitungswechsel Prandtl-Schuler}

Der 1933 eskalierende politische Streit beruhte auf Spannungen, die es im Institut schon vorher zwischen nationalsozialistischen Studenten und einer Freundesgruppe um Willy Prager und Kurt Hohenemser gab. Besonders hervorgetreten war der aktive Nationalsozialist Erich Hahnkamm, der Hilfsassistent bei Schuler war. Hahnkamm wurde am 31. Oktober 1905 in Brunsbüttelkoog als Sohn eines Reichsbahnobersekretärs geboren. Er studierte Physik, Mathematik und Chemie in Wien und Göttingen. Bei Schuler fertigte er eine Doktorarbeit über „Gekoppelte Schwingungssysteme unter besonderer Berücksichtigung des Schlingertankproblems“ an. Seine 1930 abgelegte mündliche Doktorprüfung wurde mit „Genügend“ beurteilt. 1864 Von 1930 bis 1931 war er Praktikumsassistent bei Franck. Nach eigenen Angaben verlor er diese Stelle, weil Franck bekannt geworden sei, dass er ein Nationalsozialist war. ${ }^{1865}$ Hahnkamm gehörte schon vor 1933 einigen rechtsradikalen Verbindungen an: 1919 Deutschnationaler Jugendbund, 1923 Wehrwolf, 1924 Stahlhelm, 1925 Völkischer Studentenbund Wien, 1. Dezember 1931 NSDAP. Nach dem Rauswurf bei Franck wurde er 1932 Hilfsassistent bei Schuler. Schuler hatte allerdings Schwierigkeiten, Gelder für Hahnkamms Hilfstätigkeiten bewilligt zu bekommen. Hahnkamm fühlte sich deshalb gegenüber Prandtls Schülern zurückgesetzt. $\mathrm{Zu}$ der ungleichen finanziellen Unterstützung kamen noch deutliche politische Differenzen zur Gruppe der Prandtl-Schüler hinzu. ${ }^{1866}$

Um diese Situation zu entschärfen, versuchten Kurt Hohenemser und der Mathematiker Rudolf Lüneburg durch die Veranstaltung einer politischen Diskussionsrunde mit Hahnkamm ins Gespräch zu kommen. Laut Hohenemsers unmittelbar nach dem Krieg niedergeschriebenen Erinnerungen nahmen neben Lüneburg, der politisch links stand und

1863 Prandtl an Kurator, 23. Januar 1933. UAG, Kur. PA Hohenemser.

1864 Die mündliche Prüfung in angewandter Mechanik, Physik, Chemie und Mathematik war am 30. Juli 1930.

Die Doktorurkunde wurde am 26. April 1932 ausgestellt; die Dissertation wurde mit „Sehr gut“ beurteilt. UAG, Kur., XVI. V. C. e. 1. Siehe auch Erich Hahnkamm: 'Erzwungene Schwingungen reibungsgekoppelter

Schwingungssysteme‘, Zeitschrift für angewandte Mathematik und Mechanik 13 (1933), S. 183-202.

1865 Hahnkamm an REM, 6. Dezember 1935. Hahnkamm schreibt: „Schließlich möchte ich noch erwähnen, dass ich die Hilfsassistentenstelle, die ich am II. physikalischen Institut durch einige Semester bekleidete, verlor, nachdem man herausbekommen hatte, dass ich Parteigenosse war - übrigens der einzige unter allen Mitarbeitern beider physikalischer Institute.“ UAG, Rek. 5250 / 7 A.

1866 Auf die Mischung von nationalsozialistischer Überzeugung und finanzieller Schlechterstellung lässt auch der 10-seitige „Bericht des Dr. Erich Hahnkamm über das Institut für angewandte Mechanik“ vom 21. Juni 1934 schließen. GSTA PK, I. HA Rep. 76 Kultusministerium, Vc Sekt. 21 Tit. 23 Nr. 18 Bd. 3, Das Kaiser-WilhelmInstitut für Strömungsforschung in Göttingen, 1933-34. 
zeitweilig mit dem Kommunismus sympathisierte, ${ }^{1867}$ und Hohenemser, der der SPD nahe stand, ${ }^{1868}$ noch Mesmer und Prager regelmäßig teil,

„sowie öfters auch der grosse Nazifanatiker Hahnkamp [sic] [...], auf den wir es besonders abgesehen hatten. Merkwürdigerweise hat er den Inhalt dieser Gespräche später nicht benutzt, um einen von uns damit hereinzulegen, so wie er auf Grund von Protokollen über andere Gespräche zum Beispiel Mesmer denunzierte. Mesmer war bei diesen Diskussionen meistens am undiszipliniertesten und redete am meisten Allgemeinplätze, eine Unsitte, die sich abzugewöhnen gerade der Hauptsinn solcher Veranstaltungen sein sollte. Ich habe jedenfalls durch die scharfen und wohlüberlegten Lüneburgschen Einwände gelernt, in meinen Behauptungen sehr vorsichtig $\mathrm{zu}$ sein, und allgemeine Behauptungen zu unterlassen." 1869

In diesen Zusammenkünften wurden auch Hitlers Ziele diskutiert und möglicherweise auch Ausschnitte aus „Mein Kampf“" gelesen. Hahnkamm verhielt sich sehr still, sodass es nicht zu der erhofften inhaltlichen Auseinandersetzung mit ihm kam. ${ }^{1870}$ Die übrigen Teilnehmer waren sich in ihrer Kritik an Hitler weitgehend einig und äußerten diese auch offen. Hahnkamm machte sich während der Diskussionen Notizen, die er später, wie noch zu zeigen sein wird, vermutlich doch als Grundlage von Denunziationen verwendete. ${ }^{1871}$ Der Versuch der linken Wissenschaftler am Institut, durch offene Gespräche die Spannungen abzubauen, scheiterte. Nach dem Regierungswechsel im Januar 1933 gingen die Nationalsozialisten in die Offensive.

\subsubsection{Prager als erstes Opfer von Denunziationen}

Prager sollte zum 1. April 1933 einem Ruf als ordentlicher Professor für technische Mechanik an die TH Karlsruhe folgen. Er teilte dem Dekan schon Anfang Januar die Annahme des Karlsruher Ordinariats mit. ${ }^{1872}$ Am 2. Februar wurde die Anstellungsurkunde ausgestellt.

\footnotetext{
1867 Zu Lüneburg siehe Siegmund-Schltze [1998] S. 154-158.

1868 Hohenemser gab in seinem Fragebogen der Militärregierung (ohne Datum) an, 1932 und 1933 SPD gewählt zu haben. HStAH, Nds. 401, Acc. 92 / 85, Nr. 135.

1869 „Woran ich mich noch erinnere“, S. 52. KHP.

${ }^{1870}$ Hahnkamm selbst beschreibt die Situation in seinem 10-seitigen „Bericht des Dr. Erich Hahnkamm über das Institut für angewandte Mechanik“ vom 21. Juni 1934 ähnlich: „Ende 1932 war der Gegensatz zwischen den Juden und mir so stark gesteigert, dass diese mich schliesslich zu politischen Diskussionsabenden einluden. Nunmehr wurden mir die Zusammenhänge völlig klar, da wir in die Wohnung des bekannten ISK-Mannes Lüneburger [sic] gebeten wurden. Als Erörterungsgrundlage wurden Schriften des ISK-Gründers Nelson benutzt. Unter Anderen nahmen an diesen Abenden Teil: Dr. Heesch, Dr. Mesmer, Dr. Hohenemser, Dr. Prager." Obwohl der gesamte Bericht eine Reihe von Verdrehungen und Fehlern enthält, erscheint der zitierte Ausschnitt glaubwürdig. GSTA PK, I. HA Rep. 76 Kultusministerium, Vc Sekt. 21 Tit. 23 Nr. 18 Bd. 3 , Das Kaiser-Wilhelm-Institut für Strömungsforschung in Göttingen, 1933-34.

1871 Angaben zur Diskussionsgruppe stammen aus einem Gespräch mit Hohenemser vom August 2000. Siehe Rammer [2002] S. 81f.

1872 Prager an Dekan, 9. Januar 1933, GPAMNFG, Lehrkörper (ausgeschieden), Prager.
} 
Doch Prager wurde schließlich in Karlsruhe von Studenten ausgepfiffen und am Halten seiner Vorlesung gehindert. ${ }^{1873}$ Es spricht einiges dafür, dass die Karlsruher Studenten aus Göttingen, vermutlich von Hahnkamm, informiert worden waren und daraufhin ihren Protest organisierten. ${ }^{1874}$ Schon Ende März scheint es dort zu Unruhen gekommen zu sein, wie aus einem Schreiben von Prandtl an Eugen Fehrle, Leiter der Hochschulabteilung des Kultusministeriums, hervorgeht. Dort schreibt Prandtl:

„Was die Verständigung mit den Karlsruher Studenten betrifft, so können Sie die Stellung von Herrn Prager sehr erleichtern, wenn Sie ihnen sagen, daß es sich um einen blonden Mann mit gerader Nase handelt, der zu drei-vier [sic] Teilen rein deutschen Geblütes ist und der mit einer Deutschen verheiratet ist. Sie können den Studenten auch sagen, daß Herr Prager sich im Unterricht an der hiesigen Universität ganz glänzend bewährt habe und auch in der Forschung bereits einen sehr guten Namen habe." 1875

Prandtl versuchte offenbar durch ein Eingehen auf die rassistischen Vorurteile der nationalsozialistischen Studenten die Gemüter zu besänftigen und die Karriere seines Schülers zu retten. Mit dieser Eingabe billigte er indirekt die Auswahl von Forschern nach Haarfarbe, Nasenform und 'deutschem Blut'. Die Probleme bei Pragers Berufung lagen aber nicht nur an den Krawall schlagenden Studenten, sondern auch an neuen gesetzlichen Bestimmungen. Durch eine Verordnung vom 28. März 1933 wurde vom Staatsministerium „im Namen des badischen Volkes“ eine rechtliche Grundlage für den Entzug der Karlsruher Professur geschaffen. In Artikel I dieser Verordnung heißt es: „Sämtliche Beförderungen, Ernennungen und Versetzungen von Beamten, welche vor dem 12. März 1933 ausgesprochen sind und erst an einem nach dem Tag der Verkündung dieser Verordnung liegenden Zeitpunkt wirksam werden sollten, werden hiermit aufgehoben."1876 Am 30. März bekam Prager diese Verordnung vom Minister des Kultus und Unterrichts mit dem Hinweis übersendet, dass sämtliche Verhandlungen und Abmachungen bezüglich seiner Berufung gegenstandslos

1873 Nach Auskunft von Hohenemser an Klaus Hentschel vom 12. November 1998.

1874 Eine Bestätigung dieser Annahme liefert der 10-seitige „,Bericht des Dr. Erich Hahnkamm über das Institut für angewandte Mechanik“ vom 21. Juni 1934. Dort heißt es: „Als die nahende nationalsozialistische Revolution die Lage der Juden in wachsendem Masse gefährdete, versuchte man für Herrn Prager noch schnell eine Professur in Karlsruhe zu ergattern. Dies ist für einige Tage auch tatsächlich gelungen. Das wurde aber rückgängig gemacht durch die Karlsruher Studentenschaft, die von uns ins Bild gesetzt wurde. Wie erheiternd wirkte es auf mich, als an einem schönen Märzmorgen Herr Prager mir eindringlich versicherte, er habe bei der letzten Wahl »Deutschnational« gewählt.“ GSTA PK, I. HA Rep. 76 Kultusministerium, Vc Sekt. 21 Tit. 23 Nr. 18 Bd. 3, Das Kaiser-Wilhelm-Institut für Strömungsforschung in Göttingen, 1933-34.

1875 Prandtl an Eugen Fehrle, Leiter der Hochschulabteilung des Ministeriums des Kultus und Unterrichts in Karlsruhe, 27. März 1933. DLR-Archiv, GOAR 3670.

1876 Verordnung des Staatsministeriums, unterzeichnet vom Beauftragten des Reichs, Robert Wagner, 28. März 1933. DLR-Archiv, GOAR 3670. 
seien. ${ }^{1877}$ Dadurch befand sich Prager in einer völlig ungeklärten Rechtslage. Auf seine Göttinger Assistentenstelle konnte er nicht zurückkehren, da die Nachbesetzung schon rechtskräftig erfolgt war. Prandtl erklärte sich sofort bereit, sich um ein Notgemeinschaftsstipendium für Prager zu bemühen. Prager hoffte außerdem, durch ein publik Werden des ungerechten Vorgehens gegen ihn, „dessen Bekanntwerden sicher nicht zum Segen des neuen Systems sich auswirken kann“, die Karlsruher Professur doch übernehmen zu können. ${ }^{1878}$ Doch all diese Bemühungen fruchteten nicht. Pragers Verhalten zeigt eine extreme Anpassungsbereitschaft an die vorhandenen politischen Verhältnisse. Auch im Exil verhielt er sich extrem anpassungswillig. ${ }^{1879}$

Während das Ministerium in der Verhandlung mit Prager sachlich war und als vorläufige Lösung eine Beurlaubung für das Sommersemester erwog, bediente sich die „Studentenschaft durchaus unsachlicher Methoden". ${ }^{1880}$ Prager erhoffte sich eine Besserung seiner Lage durch Fürsprache politisch einflussreicher Personen. Am 30. März bat er Prandtl, sich für ihn bei Philipp Lenard einzusetzen. „Ich wäre Ihnen nun sehr dankbar, wenn Sie entweder selbst [...] einflußreich an Herrn Lenard schreiben wollten oder Herrn Pohl veranlassen könnten, dies zu tun.“1881 Prager lieferte für Pohl bzw. Prandtl auch entsprechende 'Argumente', mit denen Lenard von seinen 'Qualitäten' zu überzeugen sei. So bemühte er sich zu zeigen, wie wenig 'jüdischer Einfluss' in seiner Familie vorhanden war. Gleichsam als Kompensation führte er an, dass die Familie der Großmutter väterlicherseits sogar einen katholischen Bischof stellte. Außerdem fügte er hinzu, dass vor seiner Berufung Auskünfte von Herren eingeholt wurden, „die wie Herr Gerdien als Judenfresser bekannt sind oder wie Herr Reul als stark rechts stehend oder nationalsozialistisch. Diese Auskünfte sollen sehr günstig für mich gewesen sein und liegen beim Ministerium vor. Auch auf diese Tatsache könnte Herr Lenard hingewiesen werden." Prager ließ die nationalsozialistischen Kriterien gelten und nahm sogar positiv auf die „,ölkische Sache“ Bezug. Besonders widerlich fand er hingegen, dass „die ganze Erregung auf die Tätigkeit solcher zurückgeht, die ihre nationalsozialistische Gesinnung vor

1877 Ministers des Kultus und Unterrichts, Staatskommissar (gez. Wacker), an Willy Prager, 30. März 1933. DLR-Archiv, GOAR 3670.

1878 Siehe den Brief von Prager an Mesmer, 31. März 1933. Mesmer wandte sich an einen Herrn Muhs in Hildesheim, um Pragers Fall bekannt zu machen und auch, um juristischen Rat zu erhalten. Der Brief an Herrn Muhs ist nicht erhalten, die Information stammt aus einem Brief von Mesmer an Prager, 1. April 1933. KHP. 1879 Schon im ersten Jahr seiner Lehrtätigkeit an der Universität Istanbul hielt er seine Vorlesungen auf türkisch. 1941 emigrierte er weiter in die USA. Viele Beziehungen zu Deutschen hat er völlig abgebrochen, auch zu ehemaligen Freunden. Die spärlichen Briefe, die er in der Nachkriegszeit an seine Familie und enge Freunde sandte, schrieb er auf englisch. Auch gegenüber anderen Emigranten in den USA weigerte er sich, deutsch zu sprechen.

1880 Brief von Prager an Prandtl vom 30. März 1933. DLR-Archiv, GOAR 3670.

1881 Brief von Prager an Prandtl vom 30. März 1933. Hervorhebung original. DLR-Archiv, GOAR 3670. 
wenigen Wochen entdeckt haben und nun bekunden müssen. Ich weiss wirklich nicht, ob es der völkischen Sache nicht viel dienlicher wäre, sich derartige Leute als Opfer auszusuchen, wenn die kochende Volksseele ein solches braucht, auch wenn sie einwandfrei arischer Abstammung sein sollten, was übrigens zum mindesten bei einem der Herren zweifelhaft ist.“1882 Prandtl ging auf Pragers Vorschlag ein und verfasste an Lenard ein Schreiben, das wegen seiner antisemitischen Klischees hier nur wenig gekürzt wiedergegeben wird:

„Hochverehrter Herr Geheimrat! Darf ich Sie für die folgende Angelegenheit interessieren? In Karlsruhe ist im Zusammenhang mit dem Regierungswechsel folgende scheußliche Sache passiert. Der hiesige Privatdozent Dr. W. Prager (kein Jude, siehe unten), hat auf Weihnachten einen Ruf als ordentlicher Professor der Mechanik an der Technischen Hochschule Karlsruhe erhalten, hat ihn Anfang Februar angenommen, seine hiesige Assistentenstelle aufgegeben (die auch schon wieder besetzt ist), in Karlsruhe eine Wohnung und ein Dienstmädchen gemietet, den Umzug eingeleitet usw. Da wird ihm von der neuen Regierung plötzlich eröffnet, daß er die Stelle nicht bekommen könne, weil die Studentenschaft an seinem jüdischen Namen Anstoß nimmt. Prager ist einer der glänzendsten jungen Leute auf dem Gebiet der technischen Mechanik und wird sicher noch einmal eine Zierde derjenigen Hochschule werden, die ihn beruft. Er ist blond, mit gerader Nase, macht einen durchaus arischen Eindruck und vor allem ist er auch ein prachtvoller Charakter, beliebt bei Jedermann, der ihn kennt. Der Name stammt natürlich von einem jüdischen Ahnen, aber ich möchte hervorheben, daß bereits seine vier Großeltern sämtlich christlich waren, 3 davon, so wie mir versichert wird, einwandfrei deutschen Geblütes. Er unterhält keinerlei verwandtschaftliche Beziehungen mit irgendeiner jüdischen Linie seines Namens und ist von ganz einwandfrei nationaler Gesinnung. Auch die Art, wie er den gegen ihn geführten Schlag trägt, ist prachtvoll.“1883

Anschließend bat er Lenard, sich für Prager einzusetzen. Um Prandtls Argumentation besser verstehen zu können, sei auf ein Schreiben hingewiesen, das Prandtl von einem überaus engagierten Nationalsozialisten namens Engberding erhalten hatte. Dieses Schreiben war eine Reaktion auf Prandtls Versuch, in vermeintlich geschickter Ausnutzung nationalsozialistischer Vorurteile die rassistischen Entlassungen in der Wissenschaftlichen Gesellschaft für Luftfahrt etwas hinauszuzögern. Prandtl schrieb, er sehe keine Veranlassung, die fragliche Angelegenheit in ,jüdischer Hast“ zu erledigen. Prandtls Strategie ging jedoch überhaupt nicht auf. Die sechsseitige Antwort des Marine-Baurat Engberding vom 30. März 1933 zeigt, dass sich ein militanter Nationalsozialist hierdurch nur angegriffen fühlte und seine Sache nur noch energischer vorantrieb. „Ein Nationalsozialist tut nichts in $» j u ̈ d i s c h e r$ Hast«! Wohl aber packt er die Dinge, wo es nötig ist, rasch und energisch an und lässt sich

1882 Prager an Prandtl, 30. März 1933. Hervorhebung original. DLR-Archiv, GOAR 3670.

1883 Prandtl an Lenard, 1. April 1933. DLR-Archiv, GOAR 3670. 
durch nichts von dem einmal als richtig erkannten Wege abbringen!“1884 Engberding versicherte auch, dass er nicht in Eigeninteresse handle, auch die persönliche Ehrenhaftigkeit der „Juden“ nicht anzweifle, sondern dass es sich ausschließlich um eine zu lösende grundsätzliche „Rassenfrage“ handle. Diese inhaltliche Position von einem in der ersten Zeit des NS-Regimes einflussreichen Nationalsozialisten mag Prandtl in der Taktik, wie er sich für betroffene Wissenschaftler am besten einsetzen sollte, beeinflusst haben. Vermutlich deshalb bezog sich Prandtl später vor allem im positiven Sinn auf nationalsozialistische Klischees.

Für den Fall, dass seine Bemühungen scheitern sollten, versuchte Prandtl, wenigstens Pragers Göttinger Privatdozentur aufrecht zu erhalten. „Es soll nicht so aussehen, als ob Sie sich vor irgendwelchen Leuten verkriechen sollten“, schrieb er an Prager. ${ }^{1885}$ Prandtl dachte bei der Finanzierung Pragers zuerst an ein Notgemeinschaftsstipendium und in zweiter Linie an ein Rockefeller-Stipendium. Prager bat die Universität Göttingen um die Aufrechterhaltung seiner Dozentur und um die Ankündigung einer Vorlesung über praktische Analysis für das SS 1933. ${ }^{1886}$ Dieser Bitte wurde allerdings nicht entsprochen. Anfang Mai 1933 teilte der Dekan Reich dem Rektor offiziell mit, dass Pragers Berufung vom Badischen Ministerium rückgängig gemacht worden sei. ${ }^{1887}$ Prager sah wenig Chancen, an einer Hochschule unterzukommen und schrieb bereits Ende Mai an den Dekan, „dass ich vorübergehend eine Stelle in der Industrie angenommen habe. Wenn ich auch augenblicklich von meiner Venia legendi ohnedies keinen Gebrauch mache, so möchte ich doch unter allen Umständen vermeiden, dass meine vorübergehende Abwesenheit von Göttingen als freiwilliges Ausscheiden aus dem Lehrkörper der Georgia Augusta gedeutet wird. Ich bitte daher Ew. Spektabilität, mich zunächst bis zum 1. Juli dieses Jahres zu beurlauben. “1888 Dem Wechsel in die Industrie waren erfolglose Versuche Prandtls vorausgegangen, entscheidende Politiker der neuen Regierung für den Fall Prager zu interessieren.

\subsubsection{Prandtls Einsatz für Prager bei höchsten Politikern}

Als Prandtl am 4. April vom Badischen Kultusministerium eine negative Antwort bezüglich Pragers Wiederernennung an der TH Karlsruhe bekam und außerdem der Weg über Lenard

\footnotetext{
1884 Marine-Baurat z. D. Engberding an Prandtl, 30. März 1933, DLR-Archiv, GOAR 3683.

1885 Prandtl an Prager, 1. April 1933. DLR-Archiv, GOAR 3670.

1886 Siehe den Ratschlag Prandtls an Prager, 7. April 1933 (MPG-Archiv, III, 61, 1272.), und das Schreiben Pragers an den Dekan, ohne Datum, GPAMNFG, Lehrkörper (ausgeschieden), Prager.

1887 Dekan Reich an Rektor, 2. Mai 1933. UAG, Sek. 316.6.

1888 Prager an Dekan, 26. Mai 1933. Hervorhebung original. Bei der Industriestelle handelte es sich um eine Anstellung als Statiker bei den Fieselerwerken in Kassel. GPAMNFG, Lehrkörper (ausgeschieden), Prager.
} 
nicht fruchtete, ${ }^{1889}$ blieben ihm als aussichtsreiche Beschwerdeinstanzen nur noch die zentralen Regierungsstellen in Berlin übrig. Mit dem am 7. April verkündeten Gesetz zur Wiederherstellung des Berufsbeamtentums verschärfte sich die Problematik um Pragers Hochschullaufbahn. Da der $\S 3$ die Entfernung der Beamten „nicht arischer Abstammung“ vorsah, zielte Prandtls Strategie darauf, Prager als „Deutschstämmigen“ gelten zu lassen und von den Bestimmungen auszunehmen. Zweifel an Pragers „rein deutscher Abstammung“ erwuchsen aus Angaben über seine Familie, die Prager im Zuge seiner geplanten Berufung nach Karlsruhe dem Ministerium einreichte. Dort gab er an, dass sein Großvater väterlicherseits die österreichische Staatsangehörigkeit besaß und aus einer deutschen Familie stammte. „Ob mein Großvater ursprünglich noch jüdischen Glaubensbekenntnisses war, ist nicht mehr festzustellen. Bei seinem Tode war er jedenfalls Katholik, er ist auch auf dem katholischen Filaretfriedhof in Bukarest beerdigt. Da sein älterer Bruder bis an sein Lebensende der jüdischen Glaubensgemeinschaft angehörte, ist anzunehmen, dass auch mein Großvater ursprünglich dieser Glaubensgemeinschaft angehörte und wohl erst bei seiner Heirat zum römisch-katholischen Glauben übertrat."1890 Auf Grund dieser Angaben zur Religionszugehörigkeit des Großvaters galt Prager für das Badische Ministerium als „Nichtarier“. 1891

Am 11. April schrieb Prandtl an den Vizekanzler und Reichskommissar für das Land Preußen Franz von Papen. Prandtl erhoffte sich offenbar am ehesten von dem parteilosen und früher dem Zentrum zugehörigen Papen eine Unterstützung in der Causa Prager. Da das Berufsbeamtengesetz offen ließ, was exakt unter dem Begriff „nicht arisch“ zu verstehen ist, argumentierte Prandtl in ähnlicher Weise wie zuvor Lenard gegenüber, weshalb Prager trotz eines vermeintlich jüdischen Großelternteils als Deutscher anzusehen sei. Prandtl würde eine dem eigenen Verständnis widersprechende Regelung, „die Menschen treffen würde, die zu drei Vierteilen deutschstämmig sind und natürlich auch in ihrem Wesen sehr stark im Deutschtum verankert sind, entschieden zu weit gehen.“ Auf den konkreten Fall bezogen betonte er, dass Prager ,weder in seiner Erscheinung noch in seinem Charakter irgendeinen jüdischen Zug an sich hat [...]. Hier würde mit dem Schlag, der gegen das Judentum geführt

1889 Prandtl an Eugen Fehrle, Leiter der Hochschulabteilung des Ministeriums des Kultus und Unterrichts in Karlsruhe, 31. März 1933. In diesem Schreiben wies Prandtl auf die besonders große Härte der Anwendung des neuen Gesetzes auf Prager hin. Die negative Antwort datiert vom 4. April 1933. DLR-Archiv, GOAR 3670. 1890 Siehe „Angaben über die Familie des Dr.-Ing. W. Prager, Karlsruhe“, 29. März 1933. Dass diese Angaben zu einem ans Ministerium gerichteten Schreiben zugehörig waren, geht aus einem späteren Schreiben des Ministeriums hervor. Siehe Schreiben vom 26. November 1934 an den Reichsstatthalter in Baden; beides GLAK, 235, Nr. 2390, PA Prager. 
wird, wirklich zuviel gutes Deutschtum getroffen." 1892 Da dieses Schreiben von der am selben Tag erlassenen Durchführungsverordnung zum Berufsbeamtengesetz gewissermaßen überholt wurde (siehe Abschnitt 5.3.1.3) und den gewünschten Erfolg nicht einbrachte, machte Prandtl Ende April eine ähnliche Eingabe bei Innenminister Wilhelm Frick. Seine Sorgen galten der Behandlung der „Halbjuden und Viertelsjuden“. „Besonders bezüglich der Viertelsjuden ist zu sagen, daß sie Dreiviertelsdeutsche sind, und daß man ihnen in weitaus den meisten Fällen bitter Unrecht tut, wenn man sie den Volljuden gleichbehandelt, während sie doch in ihrem Empfinden und in ihrer ganzen Art sich bisher überwiegend als vollgültige Deutsche gefühlt haben.“ In der Charakterisierung Pragers näherte sich Prandtl dem, was Nationalsozialisten als Tugenden eines guten Deutschen glaubten. „Ich weiß auch von gelegentlichen Vorkommnissen, daß der junge Gelehrte sich früher von jüdischen Fachkollegen distanzierte und sich selbst für einen Deutschen hielt." Prandtl bat den Minister, dass man bei Vorhandensein eines ,jüdischen Einschlags“ nicht nach starrem Schema verfahren, sondern den Einzelfall prüfen solle. Er begründete dies mit einem mehr soziologischen als rassistischen Antisemitismus:

„M. E. ist bei dem Kampf Deutschlands gegen das Judentum das Rassenproblem garnicht das vordringlichste, sondern die Gefährlichkeit des jüdischen Bevölkerungsteils liegt in seiner Geschlossenheit und in dem unheimlichen Zusammenhalten und Zusammenwirken. Wer (besonders von den Halbjuden usw.) sich von der Judenschaft lossagt und sich selbst als Deutschen empfindet und im Deutschtum aufgehen will, dem sollte man nach meiner Ansicht dazu helfen, ihm dies zu ermöglichen, und ihn nicht durch Maßnahmen wie die jetzt beabsichtigte sozusagen in das Judentum zurückstoßen. Vom bevölkerungspolitischen Standpunkt aus erlaube ich mir dazu zu bemerken, daß nach meinen sehr zahlreichen Feststellungen aus der Vermischung von deutschem und jüdischem Blut ungewöhnlich viele hochbegabte Menschen hervorgehen, die für uns höchst wertvoll sind, sobald es gelingt, sie vom Judentum innerlich zu 1ösen.“" 1893

Auf dieses Schreiben antwortete am 10. Mai an Stelle des Ministers der Sachverständige für Rasseforschung, Achim Gercke. Er belehrte Prandtl, dass man nicht von „Dreivierteldeutschen“" sprechen könne, denn es seien nur die Ahnen zu drei Viertel deutsch. Wie groß der jüdische Einfluss sei, könne nicht einfach errechnet werden. Außerdem stellte er pointiert fest: „Das Gesetz lässt Ausnahmen nicht zu.“ Nach Gercke verlange eine

\footnotetext{
1891 Siehe das Schreiben des Kultusministeriums (gez. Fehrle) an Pragers Vorgänger in Karlsruhe, Professor Max Tolle, 29. April 1933. GLAK, 235, Nr. 2390, PA Prager.

1892 Prandtl an Vizekanzler von Papen, 11. April 1933. DLR-Archiv, GOAR 3670.

1893 Alle vorigen Zitate aus Schreiben Prandtl an den Reichsminister des Innern, Wilhelm Frick, 27. April 1933. DLR-Archiv, GOAR 3670.
} 
„Reinigung“ des „deutschen Volkes“ in „rassischer Hinsicht“ Opfer. ${ }^{1894}$ Prandtl scheiterte also damit, den Nationalsozialisten einen 'milderen Antisemitismus' abzuringen. Trotz dieser klaren Entscheidung auf höchster Ebene versuchte Prandtl im Juni 1933 erneut, Prager an der Universität zu halten und ihm seine frühere Assistentenstelle wieder zu übertragen, da die Kündigung des planmäßigen Assistenten Hohenemser zu erwarten war. Prandtl fügte noch hinzu, dass sich auch die Hörer stark für Prager eingesetzt hätten, um ihn als Dozenten wieder zu gewinnen. ${ }^{1895}$ Auch dieser letzte Versuch blieb erfolglos. Gustav Mesmer vertrat Prager in der Abhaltung der angekündigten Vorlesungen.

\subsubsection{Die Scheinlegalität von Pragers Entlassung}

Der Fall Prager ist typisch für die unter dem Deckmantel einer Scheinlegalität durchgeführten Entlassungen in der Formierungsphase des Nationalsozialismus. Das Berufsbeamtengesetz ließ es offen, wer als „nicht arisch“ zu gelten hatte. Eine erste Klärung brachte die Durchführungsverordnung vom 11. April 1933. Danach „genügte“ es für die „nichtarische Abstammung“, „,wenn ein Elternteil oder ein Großelternteil nicht arisch ist". ${ }^{1896}$ Für Prager brachte diese Verordnung keine befriedigende Klärung, denn es wurde nicht genau definiert, wann ein Großelternteil als „nicht arisch“ anzusehen ist. Im Mai bekam Prager einen Fragebogen zur Durchführung des Berufsbeamtengesetzes vom Ministerium zugesandt, den er „mit tunlichster Beschleunigung ausgefüllt“ vorzulegen hatte. ${ }^{1897}$ In diesem Fragebogen stellte sich Prager auf den Standpunkt, ,,arischer Abstammung“ zu sein. ${ }^{1898}$ Trotzdem wurde er im Juli 1933 auf Grund des sogenannten Arierparagrafen des Berufsbeamtengesetzes „zuruhegesetzt“, 1899 die Gehaltszahlungen wurden Ende Oktober 1933 eingestellt. ${ }^{1900}$ Die

\footnotetext{
1894 Schreiben des Sachverständigen für Rasseforschung beim Reichsministerium des Innern, Achim Gercke, an Prandtl, 10. Mai 1933. DLR-Archiv, GOAR 3670.

1895 Prandtl an Kurtor, 1. Juni 1933. Eine handschriftliche Bemerkung, vermutlich vom Kurator, hielt auf diesem Schreiben aber fest: „Dr. Prager ist jüdischer Abstammung und kein Frontkämpfer“. UAG, Kur. PA Hohenemser.

1896 Walk (Hrsg.) [1996] S. 13.

1897 Kultusminister (gez. Fehrle, Baumgratz, Dr. Grüninger) an Prager, 17. Mai 1933. GLAK, 235, Nr. 2390, PA Prager.

1898 Nach Brief Prager an Prandtl, 5. Juli 1933. MPG-Archiv, III, 61, 1272. Siehe auch den Fragebogen in GLAK, 235, Nr. 2390, PA Prager.

1899 Minister (gez. Frank, Dr. Fehrle, Baumgratz, Dr. Grüninger) an Prager, 28. Juli 1933: „Der Herr Reichsstatthalter hat Sie [...] zum ordentlichen Professor [...] ernannt, Ihnen ein Grundgehalt von jährlich 7000 RM [...] bewilligt, Ihnen die Zeit seit 1. April 1928 auf das [...] Dienstalter angerechnet und ausgesprochen, daß Sie gemäß § 3, Abs. 1 [Arierparagraf] des Reichsgesetzes vom 7. April 1933 zur Wiederherstellung des Berufsbeamtentums mit dem Tag der Eröffnung zuruhegesetzt werden.“ GLAK, 235, Nr. 2390, PA Prager. 1900 Minister (gez. Dr. Fehrle, Dr. Mayer, Dr. Grüninger) an Pragers Rechtsanwälte, 8. August 1933. GLAK, 235, Nr. 2390, PA Prager.
} 
Beschwerden von Pragers Rechtsanwälten brachten keine Klärung der Sachlage. ${ }^{1901}$ Eine Änderung der rechtlichen Lage brachte der Runderlass des Innenministers vom 26. Oktober 1934, demnach für ein Gutachten, ob eine Person ,arischer Abstammung“ ist, nur der Sachverständige für Rassenforschung in Frage komme. ${ }^{1902}$ Ab diesem Zeitpunkt hatte also Achim Gercke als Sachverständiger ein entscheidendes Wort mitzureden, jener Gercke, der bereits im Mai 1933 Prandtls Eingabe an Frick negativ beantwortet hatte. Möglicherweise hat Prandtls Schreiben, in dem er ja behauptete, Prager sei „Dreiviertelsdeutscher“, Gercke in seiner Entscheidung beeinflusst. Die Überprüfung von Pragers Abstammung dauerte bis März 1935 und schrieb schließlich seine ,nichtarische Abstammung“ fest. Der katholische Großvater Sigismund Prager ${ }^{1903}$ wurde mit dem Juden Samuel Präger identifiziert, obwohl es dafür keine Belege gab. „Doch kann an der Identität [...] nach den ganzen Umständen des Falles kein Zweifel bestehen“, hieß es in dem Gutachten der Reichsstelle für Sippenforschung. ${ }^{1904}$ Eine Beschwerde der Rechtsanwälte mit der Begründung, dass „auch Namen und Anzahl der Geschwister des Samuel Präger nicht mit Namen und Anzahl der Geschwister des Grossvaters Siegmund Prager übereinstimmen“, hatte keinen Erfolg. ${ }^{1905}$ Doch auch diese Entscheidung offenbart in zweifacher Weise die Scheinlegalität von Pragers Entlassung. Zum einen wurde Prager schon ein Jahr vorher, am 26. März 1934, vom Preußischen Minister für Wissenschaft, Erziehung und Volksbildung die Lehrbefugnis „vorbehaltlich der Nachprüfung auf Grund des noch ausstehenden Gutachtens des Sachverständigen für Rasseforschung“ entzogen. ${ }^{1906}$ Zum anderen war aber die Definition Pragers als „nicht arisch“ durch die kurz danach festgesetzten Regelungen der Nürnberger Gesetze überholt. Ihnen zu Folge galten Großeltern dann als jüdisch, wenn sie der jüdischen Religionsgemeinschaft angehörten. ${ }^{1907}$ Da dies bei sämtlichen Großeltern Pragers nicht der Fall war, war er nach der seit Ende 1935 geltenden nationalsozialistischen Rassendefinition „arisch“. Die Personalakte gibt leider keine Auskunft, ob die geänderte Gesetzeslage sich zum

\footnotetext{
1901 Siehe das Schreiben der Rechtsanwälte Kaufmann und Klaas an den Reichsstatthalter in Baden, 24. Mai 1933, in dem sie bekundeten, dass $\S 3$, Abs. 1 (Arierparagraf) für Prager bezüglich seiner Abstammung nicht in Anwendung komme. GLAK, 235, Nr. 2390, PA Prager.

1902 Walk (Hrsg.) [1996] S. 95.

1903 Es gibt unterschiedliche Schreibweisen des Vornamen des Großvaters. Willy Prager schreibt in seinen Angaben über seine Familie „Sigismund“, in der Heiratsurkunde von Willy Pragers Vater heißt er „Sigmund“, und Pragers Rechtsanwälte wie auch die „Rasseforscher“ schreiben „Siegmund“. GLAK, 235, Nr. 2390, PA Prager.

1904 Gutachten der Reichsstelle für Sippenforschung (= Nachfolger des Sachverständigen für Rasseforschung) an den Kultusminister, 22. März 1935. GLAK, 235, Nr. 2390, PA Prager.

1905 Rechtsanwälte Kaufmann und Klaas an Ministerium, 20. Mai 1935. GLAK, 235, Nr. 2390, PA Prager.

1906 Erlass des Ministers (U I Nr. 16217.34) vom 26. März 1934, UAG, Math.-Nat. Fak. Nr. 19a.

1907 Siehe die Verordnungen zum Reichsbürgergesetz und zum Gesetz zum Schutze des deutschen Blutes und der deutschen Ehre, beide vom 14. November 1935. Walk (Hrsg.) [1996] S. 139f.
} 
Vorteil Pragers auswirkte. In einem Nachruf heißt es, er habe die Rechtsstreitigkeit letztlich gewonnen und die ausgebliebenen Gehaltszahlungen rückerstattet bekommen. ${ }^{1908}$

Die Rechtsstreitigkeit der Jahre 1934/35 hatte keine Auswirkung auf die schon 1933 praktisch vollzogene Verdrängung aus den deutschen Hochschulen. Die im Mai 1933 angetretene Industriestelle bei dem Flugzeughersteller Fieseler in Ihringhausen bei Kassel behielt er bis Ende September 1933.1909 Mit 1. Oktober 1933 nahm er den Ruf auf eine ordentliche Professur für Mechanik an der Universität Istanbul an. Bis April 1934 bat Prager mehrmals um Verlängerung seines Urlaubs, um weiterhin zum Lehrkörper der Universität Göttingen zu gehören. ${ }^{1910}$ Durch den Krieg sah sich Prager zur weiteren Emigration veranlasst. 1941 kam er in die USA und war dort bis 1973 Professor der angewandten Mechanik an der Brown University in Providence. ${ }^{1911}$

\subsubsection{Die Entlassung Hohenemsers und die Wiederbesetzung der Assistentenstelle}

Kurt Hohenemser trat am 1. April 1933 die Nachfolge Pragers als Assistent am Institut für angewandte Mechanik an. Er bekam gleichzeitig auch Befugnisse übertragen, die zur Führung der Institutsgeschäfte notwendig waren. ${ }^{1912}$ Doch Hohenemser machte sich keine Illusionen über seine Zukunft als Hochschullehrer im nationalsozialistischen Deutschland. Am selben Tag, also noch vor Inkrafttreten des Berufsbeamtengesetzes, besprach er sich mit seinem Freund Gustav Mesmer. Dieser berichtete darüber an Prager nach Karlsruhe:

\footnotetext{
1908 Hodge [1980] S. 225.

1909 Zu Fieseler siehe Fieseler [1979].

1910 GPAMNFG, Lehrkörper (ausgeschieden), Prager.

${ }^{1911}$ Für die Professur in den USA setzte sich vor allem der zwei Jahre zuvor von Istanbul nach Boston (erst Wetergaard College, dann Harvard University) gekommene Richard Mises ein. Albert Einstein empfahl Prager der Brown University auf Vorschlag von Mises und Kármán. Auch Hermann Weyl setzte sich für Prager ein. An der Brown University wurde Prager der erste Direktor des im Sommer 1941 neu eingerichteten Programms für „Advanced Instruction and Research in Mechanics“. 1946 schuf Prager dort eine "Graduate Division of Applied Mathematics", die eine Brücke zwischen Mathematik und Ingenieurswissenschaft darstellte. Er war ihr erster Direktor bis 1953. Von 1963-65 war er Berater des IBM Forschungslabors in Zürich, von 1965-68 Professor der angewandten Mechanik an der University of California, San Diego. Danach kehrte er bis zu seiner Pensionierung 1973 an die Brown University zurück. Zu Pragers Biografie siehe Hopkins [1980]; Hodge [1980]; International Biographycal Dictionary of Central European Émigrés 1933-1945, Vol. II, S. 923; Deutsche Biographische Enzyklopädie, Generallandesarchiv Karlsruhe: Personalakte Willy Prager; Washington, Library of Congress, Veblen papers, Box 32, Prager; DLR-Archiv, GOAR 3664. Zur Emigration deutscher Naturwissenschaftler in die Türkei siehe Erichsen [1991]; allgemein zur Emigration in die Türkei Widmann [1973]; Grothusen (Hrsg.) [1987].

1912 So genehmigte ihm der Minister „die Anweisungsbefugnis für die sächlichen Ausgabefonds der Instituts sowie die Befügnisse zur Bescheinigung der Richtigkeit der Rechnungen und der bestimmungsmäßigen Verwendung der Beschaffungen." Preußische Minister für Wissenschaft, Kunst und Volksbildung an Kurator, 25. März 1933. UAG, Kur. PA Hohenemser. Dass Hohenemser tatsächlich die Institutsgeschäfte wahrnahm, geht aus einem Schreiben Prandtls vom 26. Juli 1933 hervor: „Für die Vertretung in der Leitung [...] hat sich Herr Professor Dr. Goldschmidt bereiterklärt. Da Herr Dr. Hohenemser, der in Göttingen anwesend sein wird,
} 
„Jupp [= Kurt Hohenemser] ist ja total pessimistisch, er hat mit dem Obernazi Hahnkamm gesprochen, und was da herauskam, ist ja wirklich unglaublich: Es heisst, dass jeder, bei dem auch nur ein Fünkchen jüdisches Blut nachgewiesen werden kann, vom Lehrbetrieb in Deutschland ausgeschlossen werden soll. Grosse Kartotheken über alle Dozenten sind aufgestellt worden, und es scheint aussichtslos, der Entdeckung zu entgehen. [...] [Hohenemser] denkt ja schon die tollsten Sachen aus, z. B. Japan!“1913

Eigentümlicherweise wurde Hohenemser am 3. April noch auf die Weimarer Verfassung vereidigt. Vier Tage später wurden die gesetzlichen Grundlagen für seine Entlassung geschaffen. Der Protestant Hohenemser wurde wegen seines jüdischen Vaters zum Mischling ersten Grades erklärt. Deshalb wurde ihm Anfang Mai 1933 vom Dekan „empfohlen“, bis zur entgültigen Entscheidung seiner Rechtslage die venia legendi nicht auszuüben. ${ }^{1914}$ Außerdem wurde ihm noch im April auf polizeiliche Anordnung das Betreten des Universitätsgeländes untersagt. ${ }^{1915}$ Auf eine Beschleunigung seiner Entlassung drängten nationalsozialistische Studenten am Institut. Aus einer vertraulichen Mitteilung des Kurators Valentiner an Prandtl geht hervor, dass es einer Gruppe von Studenten (,wohl ein Dutzend“) vor allem darauf ankam, dass Heinz Schlechtweg an die Stelle Hohenemsers als Assistent trete. ${ }^{1916}$ Dies widersprach aber Prandtls Plänen, der stattdessen am 1. Juni 1933 beantragte, Prager die Assistentenstelle wieder $\mathrm{zu}$ übertragen. Dieses Vorhaben stellte sich jedoch als undurchführbar heraus. Unterdessen wurde von Studenten weiter Druck auf Prandtl ausgeübt. „Nachdem die nationale Revolution jetzt gründlich Wandel auch in unserem Institut zu schaffen versprach, bin ich mehrfach zu Herrn Prof. Prandtl hingegangen mit der Bitte, uns einen vaterländisch denkenden Assistenten zum Leiter des Instituts zu machen. Ich wurde abgewiesen mit den Worten: »Sie sind auch so ein brauner Fanatiker.« [...] Meine

die laufenden Geschäfte wahrnimmt, würde Herr Professor Goldschmidt nur in besonderen über die Befugnisse von Dr. Hohenemser hinausgehenden Fällen bemüht werden müssen.“ MPG-Archiv, III, 61, 2162.

1913 Brief von Mesmer an Prager, 1. April 1933. Von diesem Brief ist nur die erste Seite erhalten. KHP.

1914 Dekan Reich an Kurator, 9. Mai 1933. UAG, Kur. PA Hohenemser. Kurz zuvor gab der Mathematiker Weyl als Vorlesungsänderung bekannt, dass die von Prager angekündigte Praktische Analysis von Hohenemser gelesen werde. Diese Angabe wurde nachträglich vom Kurator verbessert. Daraus ergibt sich, dass einerseits Schuler für Hohenemser Darstellende Geometrie mit Übungen und andererseits Prandtl gemeinsam mit Mesmer für Prager Praktische Analysis lasen. UAG, Math.-Nat. Fak. Nr. 19a.

1915 Mündliche Auskunft von Kurt Hohenemser, 20. August 2000. In den Akten des Universitätsarchivs und des Prüfungsamts konnte kein Hinweis auf dieses Verbot gefunden werden. Einen indirekten Hinweis gibt die Formulierung in Prandtls Schreiben an den Kurator vom 13. April 1933: „Für den Fall, daß es nötig sein sollte, wird Herr Professor Betz mich in der Führung der Geschäfte des Institutes für angewandte Mechanik vertreten können, soweit nicht der Assistent, Dr. Hohenemser, die Dinge wahrnehmen kann." MPG-Archiv, III, 61, 2162. 1916 Kurator Valentiner an Prandtl, 10. Juli 1933. UAG, Kur. PA Hohenemser. Hahnkamm berichtet über die Beschwerde beim Kurator: „Daraufhin stellte ich den Herrn Kurator vor die Wahl, den Juden [Hohenemser] unverzüglich zu entfernen oder wir würden zur Selbsthilfe greifen.“ „Bericht des Dr. Erich Hahnkamm über das Institut für angewandte Mechanik" vom 21. Juni 1934. GSTA PK, I. HA Rep. 76 Kultusministerium, Vc Sekt. 21 Tit. 23 Nr. 18 Bd. 3, Das Kaiser-Wilhelm-Institut für Strömungsforschung in Göttingen, 1933-34. 
nachhaltigen Forderungen, diesen Juden [Hohenemser] sobald wie möglich zu entlassen, lehnte Herr Prof. Prandtl ab“, berichtete Hahnkamm rückblickend über sein Engagement. ${ }^{1917}$ Im Juli gab Prandtl dem Kurator eine vertrauliche Auskunft über seine Pläne:

„Es ist mir bekannt, daß eine kleine Gruppe von Mitarbeitern bzw. Gästen des Instituts für angewandte Mechanik sich für Herrn Schlechtweg einsetzt, und es war mir interessant zu hören, daß der Widerspruch gegen das Verbleiben von Herrn Hohenemser also wirklich, wie ich selbst schon vermutet habe, von dieser Seite kommt. Die Herren sind auch bei mir in dem gleichen Sinne vorstellig geworden, ich mußte ihnen aber erwidern, daß ich nicht beabsichtige im Falle einer Entlassung von Herrn Dr. Hohenemser die Assistentenstelle Herrn Schlechtweg $\mathrm{zu}$ geben, daß ich vielmehr die Stelle für Herrn Dr. Prager freizuhalten wünsche. Ich füge noch hinzu, daß ich auch wenn Herr Prager nicht zu gewinnen wäre, sie nicht Herrn Dr. Schlechtweg, sondern Herrn Dr. Flügge zu geben beabsichtigen würde." ${ }^{1918}$

Schlechtweg arbeitete als Notgemeinschaftsstipendiat am Institut bei Prager und Prandtl. Im Juni 1932 befürwortete Prandtl die Aufnahme Schlechtwegs in die Gesellschaft für angewandte Mathematik und Mechanik. ${ }^{1919}$ Er hat ihn durchaus für einen fähigen Wissenschaftler gehalten. Nur an einer Stelle kam in der Abwehr Schlechtwegs als Assistenten auch eine vorsichtige wissenschaftliche Kritik zur Sprache. Prandtl war nach Kenntnisnahme einer „Darlegung“ von Hahnkamm und Schlechtweg „nicht davon überzeugt, ob Herr Dr. Schlechtweg das von ihm angegebene Programm in einer wirklich befriedigenden Weise würde durchführen können.“"1920 Prandtls ablehnende Haltung lag vermutlich weniger an Schlechtwegs wissenschaftlicher Befähigung, selbst wenn auch Hohenemser von Schlechtwegs theoretischen Fähigkeiten wenig hielt, ${ }^{1921}$ sondern eher an dessen schlechtem Charakter. Dieser offenbarte sich zum Beispiel in einem Zeitschriftenartikel aus dem Jahr 1934 und der sich daran anschließenden Kontroverse. Schlechtweg beginnt den Artikel mit dem Satz: „Es soll hier darauf hingewiesen werden, daß die in dieser Zeitschrift kürzlich

1917 „Bericht des Dr. Erich Hahnkamm über das Institut für angewandte Mechanik“ vom 21. Juni 1934. Hahnkamm berichtet, dass er Prandtl nicht mehr weiter behelligte, als dieser Flügge als Assistenten beantragt hatte, „da ich es für aussichtslos hielt, einen derartigen Gegner der nationalsozialistischen Weltanschauung [gemeint ist Prandtl] von der Sinnlosigkeit seines Widerstandes zu überzeugen.“ GSTA PK, I. HA Rep. 76 Kultusministerium, Vc Sekt. 21 Tit. 23 Nr. 18 Bd. 3, Das Kaiser-Wilhelm-Institut für Strömungsforschung in Göttingen, 1933-34.

1918 Prandtl an Kurator, 11. Juli 1933. MPG-Archiv, III, 61, 2162.

1919 Prandtl an Mises, 18. Juni 1932. MPG-Archiv, III, 61, 1082.

1920 Prandtl an Kurator, 17. Oktober 1933. UAG, Kur. XVI. V. C. h. 11 I. Die erwähnte „Darlegung“ von Hahnkamm und Schlechtweg ist leider weder im UAG, noch im MPG-Archiv, wo ein Durchschlag von Prandtls Schreiben existiert (III, 61, 2162), vorhanden.

1921 Hohenemser sagte im Interview über Schlechtweg: „Ja, natürlich, ich hatte auch mit Schlechtweg Kontakt und mit Gebelein. Ich hatte mit all den Leuten Kontakt. Schlechtweg kann ich mir sogar noch vorstellen. Er war ein sehr großer Mensch. Aber der war theoretisch glaube ich nicht sehr bewandert. Schlechtweg war einer von den weniger Begabten." Interview mit Kurt Hohenemser, 19./20. August 2000. NBL. 
mitgeteilten Versuchsergebnisse von Hohenemser und Prager in Widerspruch stehen zu den seitherigen Erfahrungen auf diesem Gebiet.“1922 Diese Arbeit wollte er als „Mitteilung aus dem Institut f. angew. Mechanik“ veröffentlichen, ohne sie Prandtl vorher vorzugelegen. Dies widersprach der allgemeinen Gepflogenheit, und brachte Schlechtweg scharfe Ermahnungen seitens Prandtls ein. Im Versuch einer Rechtfertigung diffamierte Schlechtweg Prager vehement. Prager habe nur jenen „Untergebenen“ wissenschaftliche Unterstützung gegeben, die „fest auf dem Boden der jüdisch-marxistischen Weltauffassung“ stünden. ${ }^{1923}$ Diese Beschimpfungen führten dazu, dass sich Prandtl von Schlechtweg künftig distanzierte. Er vereitelte auch Schlechtwegs späteren Habilitationsversuch in Göttingen im Mai 1936. Schlechtweg war inzwischen nach Essen zu Krupp gewechselt. Als Habilitationsschrift sollten seine früheren Göttinger Arbeiten ersatzweise anerkannt werden. Dies stellte kein prinzipielles Problem dar, doch Prandtl informierte den Dekan, er habe ,auf Grund meiner persönlichen Kenntnis vom Charakter von Dr. Schlechtweg die allergrößten Bedenken, ihn als Privatdozent hierher zu ziehen. Er ist ein Mensch, der mit Ellenbogen arbeitet und sich überall mehr Rechte herausnimmt, als ihm zukommen." Schlechtweg habe als wissenschaftlicher Gast am Institut einem Studenten selbständig ein ungeeignetes Doktorthema gegeben, ohne Prandtl zu informieren. ${ }^{1924}$ Prandtl erwähnte auch Schlechtwegs Publikation von 1934 mit dem Angriff auf Prager und Hohenemser.

„Da der angegriffene die Schlechtwegschen Ausführungen zu widerlegen imstande war, hat Schlechtweg von dem Schriftleiter Dr. Rosbaud [...] verlangt, daß er das letzte Wort haben müsse und mußte sich belehren lassen, daß das letzte Wort immer dem Angegriffenen zukäme. Als Schlechtweg erkannte, daß er dabei den Kürzeren zog, hat er schließlich auf den ganzen Angriff verzichtet. Dr. Rosbaud hat mir seinen Briefwechsel mit Dr. Schlechtweg gezeigt, der auf die Manieren von Herrn Schlechtweg ein sehr ungünstiges Licht wirft.“1925

Mit diesen schwerwiegenden Einwänden konnte Prandtl die Fakultät überzeugen, den Antrag abzulehnen. ${ }^{1926}$

\footnotetext{
1922 Heinz Schlechtweg: 'Zur Frage der Ermüdungsfestigkeit bei mehrachsigen Spannungszuständen. Bemerkung zu einer gleichnamigen Arbeit von K. Hohenemser und W. Prager', Zeitschrift für Metallwirtschaft 13 (1934). Zitiert nach einem Sonderdruck, der sich in Prandtls Nachlass befindet. MPG-Archiv, III, 61, 1454. 1923 Schlechtweg an Prandtl, 25. März 1934. Prandtls Antwort vom 29. März beginnt ohne Anrede: „Ihr Brief vom 25.3. gibt mir an mehreren Stellen Gelegenheit, mich sehr erheblich über Sie zu wundern." MPG-Archiv, III, 61, 1454.

1924 Wahrscheinlich war Baumann der genannte Doktorand, der 1934 bei Schuler promovierte und ein für Schulers Doktoranden ungewöhnliches Thema der Kontinuumsmechanik behandelte.

1925 Prandtl an Dekan, 20. Mai 1936, GPAMNFG, Lehrkörper (ausgeschieden), Schlechtweg.

1926 Der Dekan teilte Schlechtweg am 14. Juli 1936 mit: „Da Ihre Bewerbung um den Dr. phil. habil. voraussichtlich auf Schwierigkeiten stossen wird, möchte ich Ihnen vorschlagen, Ihr Gesuch wieder zurückzuziehen. Herr Professor Schuler will Ihnen noch Näheres mitteilen.“ Schuler dürfte ihm die aussichtslose
} 
Im August 1933 musste Prandtl akzeptieren, dass sowohl Hohenemser wie auch Prager für die Assistentenstelle nicht mehr in Frage kamen. Dass ihm die Besetzung aber wichtig war, zeigt ein Schreiben, das er aus dem Urlaub an den Kurator sandte, und in welchem er darauf bestand, dass Flügge als Nachfolger von Hohenemser zu bestellen sei. ${ }^{1927}$ Hohenemsers Zukunft war zu diesem Zeitpunkt noch nicht geklärt. Er bat deshalb den Dekan um eine ordnungsgemäße Befreiung vom Abhalten von Vorlesungen. Die erbetene Klärung der Verhältnisse bekam Hohenemser am 8. September, indem ihm vom Minister die Lehrbefugnis entzogen wurde; zum 1. Oktober wurde er als Assistent entlassen. ${ }^{1928}$ Er konnte im Oktober 1933 in den Fieseler-Werken bei Kassel Nachfolger von Prager als Statiker und Aerodynamiker werden.

\subsubsection{Hohenemsers gescheiterter Emigrationsversuch}

Hohenemser wandte sich mit einem Stellengesuch im Mai 1933 direkt an Professor C. E. Inglis vom Engineering Laboratory in Cambridge, der ihm in seinem Department eine Möglichkeit zu eigener Forschungstätigkeit anbieten konnte, jedoch keine Möglichkeit für eine bezahlte Dozentur sah. ${ }^{1929}$ Deshalb richtete sich Hohenemser an das Academic Assistance Council (AAC) ${ }^{1930}$ in London und bat um Unterstützung bei der Finanzierung einer akademischen Stelle in England. ${ }^{1931}$ Das AAC erkundigte sich bei Inglis und bekam die positive Antwort : “...the fact, that Dr. Hohenemser was first assistant at Göttingen University under Professor Prandtl is a very high testimony of his ability, and for a man of 27 years of age the number of scientific papers he has published is quite remarkable. Concerning the excellence of his intellectual qualifications I have no doubt whatsoever." 1932 Das AAC bot daraufhin Hohenemser ein Stipendium in Höhe von $£ 200$ an. Im Herbst 1933 schien es so, als würde einer baldigen Emigration unter diesen Bedingungen nichts im Wege stehen. Hohenemser schob sie aber bis Anfang 1934 auf, da er bis Ende Dezember von der Universität Göttingen noch bezahlt wurde, und er diese Einnahme nicht durch eine Ausreise

Lage deutlich vor Augen geführt haben, denn am 4. August zog Schlechtweg sein Gesuch zurück. GPAMNFG, Lehrkörper (ausgeschieden), Schlechtweg.

1927 Prandtl an Kurator, aus dem Urlaub, 2. August 1933. UAG, Kur. IX. 83.

1928 Hohenemser an Dekan, 23. August 1933, GPAMNFG, Lehrkörper (ausgeschieden), Hohenemser. REM (gez. i. V. Stuckart) an Hohenemser, 8. September 1933, HStAH, Nds. 401, Acc. 92 / 85, Nr. 135, Dekan an Rektor, 26. September 1933, UAG, Math.-Nat. Fak. Nr. 19a, Kurator an Hohenemser, 29. September 1933. Die Dienstbezüge wurden ihm bis Ende Dezember weitergezahlt. HStAH, Nds. 401, Acc. 92 / 85, Nr. 135.

${ }^{1929}$ Inglis an Hohenemser, 6. Juni 1933. Bodleian Library, Oxford, MS SPSL 243/8, corr. Hohenemser.

1930 Das im April 1933 in London gegründete AAC war eine Hilfsorganisation für in Deutschland vertriebene Wissenschaftler und wurde 1936 in Society for the Protection of Science and Learning (SPSL) umgenannt. Siehe Hentschel \& Hentschel (Hrsg.) [1996] S. lxif.

${ }^{1931}$ Hohenemser an AAC, 1. Juni 1933. Bodleian Library, Oxford, MS SPSL 243/8, corr. Hohenemser. 
verlieren wollte. Das Angebot auf das Stipendium bestand für ihn auch noch Anfang 1934. Obwohl er in Deutschland eine Anstellung gefunden hatte, wollte er sich die Emigrationsmöglichkeit weiterhin offen halten, da seine Stelle bei Fieseler nicht sehr sicher erschien. Im November 1933 schrieb er an Prandtl: "Leider sind bereits wieder Schwierigkeiten im Anzug, die durch meine nichtarische Großmutter verursacht werden und es kann sein, daß das Intermezzo noch kürzer dauern wird als beabsichtigt war.”1933

Hohenemser ersuchte um weiteren Aufschub, doch das ACC bat ihn, er solle seine Stelle in Deutschland möglichst lange $\mathrm{zu}$ behalten versuchen und das Stipendium für andere, notdürftigere Wissenschaftler frei geben. Hohenemser verzichtete daraufhin auf seine Ansprüche "in order to liberate money for the assistance of another person who is, at the present moment more urgently in need of it." 1934 Im Sommer 1934 reiste er nach Cambridge zum internationalen Kongress für angewandte Mechanik und versuchte vor Ort aufs Neue, eine Finanzierung vom ACC zu erhalten. "I earnestly wish to leave Germany if there is any possibility." 1935 Dieser letzte Versuch zur Emigration scheiterte. Ein Grund dafür war wieder, dass er eine wenn auch unsichere Stelle in Deutschland besaß und das ACC mit Anträgen hilfebedürftiger Forscher überhäuft wurde. Ein im Interview rückblickend genannter Grund für seine Emigrationsanstrengung war, dass er seinen Eltern außerhalb Deutschlands eine Existenz sichern wollte. Deshalb schlug er das Angebot auf das Stipendium aus, da es für den Lebensunterhalt von vier Personen nicht ausreichte. ${ }^{1936}$

\subsubsection{Prandtls Verwicklung in eine politische Auseinandersetzung an der AVA}

Die Auseinandersetzungen am Universitätsinstitut für angewandte Mechanik um die Besetzung der Assistentenstelle waren für Prandtl nur ein Nebenschauplatz in den politischen Kämpfen der Jahre 1933/34. Viel wichtiger für ihn waren die Geschehnisse am KWI für Strömungsforschung und an der AVA. Um Prandtls nachgiebiges Handeln am Universitätsinstitut besser $\mathrm{zu}$ verstehen, wird kurz sein Verhalten in dem für ihn bedeutenderen Streit beschrieben. ${ }^{1937}$

\footnotetext{
1932 Inglis an AAC, 21. Juli 1933. Bodleian Library, Oxford, MS SPSL 243/8, corr. Hohenemser.

1933 Hohenemser an Prandtl, 2. November 1933. MPG-Archiv, III, 61, 692.

1934 Hohenemser an AAC, 21. Dezember 1933. Bodleian Library, Oxford, MS SPSL 243/8, corr. Hohenemser.

1935 Hohenemser an AAC, 5. Juli 1934. Bodleian Library, Oxford, MS SPSL 243/8, corr. Hohenemser.

1936 Rammer [2002] S. 87.

1937 Zum Fall Nikuradse siehe Tollmien [1987/98] S. 693-695; Trischler [1992] S. 189-192; und sehr knapp Epple [2002] S. 313. Die hier gegebene Darstellung stützt sich auf die Aktenbestände: MPG-Archiv, I, 44, 161163; SUBG, Cod. Ms. L. Prandtl 10; und besonders für die sich nach Entscheidung des Falls Nikuradse anschließenden politischen Auseinandersetzungen: GStAPK, I. HA Rep. 76 Kultusministerium, Vc Sekt. 21 Tit. 23 Nr. 18 Bd. 3, Das Kaiser-Wilhelm-Institut für Strömungsforschung in Göttingen, 1933-1934.
} 
Im Frühjahr 1933 wurde ein Mitarbeiter am KWI für Strömungsforschung, der Georgier Johann Nikuradse, der Spionage und des Bücherdiebstahls verdächtigt. Der Verdacht wurde dem Obmann der NSBO der AVA mitgeteilt, der eine Untersuchung veranlasste und dem SSStandartenführer und Polizeidirektor Gnade einen ersten Bericht übergab. Dieses Vorgehen gegen einen bei bestimmten Personen unbeliebten Ausländer war ein politischer Angriff, der mit Hilfe von NS-Organisationen eingeleitet wurde. Doch auf überraschende Weise wurden die Rollen von Angreifer und Verteidiger rasch umgepolt. Nikuradse arbeitete schon seit mehreren Jahren für die NSDAP und war an der Aufstellung von „Judenlisten“ von Professoren und Assistenten der Universität Göttingen beteiligt. Die Unterstützung, die er aus NS-Kreisen erfuhr, führte dazu, dass Nikuradse von Gnade und dem ins Verfahren hinzugezogenen Leiter des Geheimdienstes der SS, Hauptmann a. D. Weniger, entlastet wurde und jenen Mitarbeitern, die ihn verdächtigt hatten, mit Kündigung gedroht wurde. Prandtl sah sich daraufhin veranlasst, von der KWG ein Disziplinarverfahren gegen Nikuradse durchführen zu lassen. Die Untersuchung führte der Universitätsrichter Wolff und der Universitätskurator Valentiner. Doch trotz dieser außenstehenden und vermeintlich unparteiischen Richter verlief das Verfahren weiterhin unsachlich. Mehrere Zeugen wurden vernommen und zu Verdachtsmomenten gegenüber Nikuradse befragt. Daraufhin sprach der Universitätsrichter Wolff Nikuradse von allen Anschuldigungen frei und entschied, dass sieben Zeugen zur Wiederherstellung des Arbeitsfriedens zu entlassen seien, da sie als Unruhestifter anzusehen seien. Mit diesem Urteil folgte Wolff einem Gutachten des Leiters des Geheimdienstes Weniger, der Zugang zu allen Akten hatte. Hinter diesem Urteil ist aber nicht unbedingt politischer Druck zu vermuten, denn Nikuradse soll sich, laut Bericht von drei Zeugen schon vor der Untersuchung Wolff als Richter gewünscht haben.

Prandtl protestierte gegen diese Entscheidung. An den Oberregierungsrat Baeumker im Luftfahrtministerium schrieb er Ende September 1933: „Im übrigen, unter uns gesagt, es ist ein Unding, daß ich in dem Moment, wo wir unsere Mitarbeiterschaft weiter auszubauen haben werden, plötzlich sieben deutsche Mitarbeiter entlasse, weil sie zu einem am Institut arbeitenden Ausländer in Gegensatz geraten sind. [...] Der ganze Komplex ist deshalb schwierig, weil das Gegeneinanderarbeiten von lokalen Parteiinstanzen mit hereinspielt. Einzelheiten werden deshalb besser mündlich berichtet."1938 Prandtl konnte schließlich bei der Generalverwaltung der KWG erreichen, dass Generaldirektor Friedrich Glum Ende Oktober 1933 nach Göttingen kam, um die Sache selbst zu untersuchen. Glum milderte das

1938 Prandtl an Baeumker, 26. September 1933. SUBG, Cod. Ms. L. Prandtl 10. 
Urteil ab, bestätigte aber die Notwendigkeit der Entlassung von dreien der 'Unruhestifter'; die anderen vier wurden verwarnt, durften aber weiter an den Instituten der KWG beschäftigt werden. Obwohl Prandtl Glums Entscheidung weiterhin für ungerecht hielt, setzte er seine Unterschrift unter die Kündigungsschreiben. Zu diesem Schritt mag wohl mit beigetragen haben, dass er durch seinen Einsatz für die sieben Mitarbeiter selbst politisch verdächtig erschien, schließlich hätten diese das Ansehen des Deutschen Reiches geschädigt. Der politische Kleinkrieg in seinem Institut zerstörte nicht seine Freude über das Ende der Weimarer Republik und die 'großen Maßnahmen' der neuen Regierung. In einem privaten Brief an seinen Schwager Ludwig Föppl vom November 1933 meinte Prandtl, „daß man gerade jetzt [...] als Deutscher den Kopf wieder höher tragen kann“. 1939 Diese Haltung Prandtls wird in der Forschung paradoxer Weise als „dem Nationalsozialismus sicher zunächst eher distanziert“ gegenüberstehend beschrieben. Später soll Prandtl aber den Nationalsozialismus offen verteidigt haben. ${ }^{1940}$

Prandtl hatte anfangs die Hoffnung, dass mit Glums Entscheidung der Fall erledigt sei. Diesen Standpunkt vertrat er ganz deutlich bei einer Betriebsversammlung Ende Oktober: „Es muß jetzt wirklich Ruhe im Institut eintreten und ein Strich unter die Vergangenheit gemacht werden. Nur so kann die Arbeitsfähigkeit wieder den Stand der früheren Jahre zurück erlangen, was wir doch alle wünschen müssen. "1941 Erst der Protest der 'rehabilitierten "vier Mitarbeiter, ihre akademische Laufbahn sei gefährdet, da ihnen zu Unrecht vorgeworfen worden sei, das Ansehen des Deutschen Reiches geschädigt zu haben, veranlasste Prandtl, sich weiter für die Abänderung des Urteils einzusetzen. Er wandte sich an verschiedene Stellen, am eindringlichsten an den Präsidenten der KWG, Max Planck. In mehreren, sehr ausführlichen, bis zu 17 Seiten langen Briefen versuchte er Planck davon zu überzeugen, dass das Urteil auf ungenügender Prüfung der Sachlage beruhe und revidiert werden müsse. Prandtl selbst führte eine umfangreiche Untersuchung durch und befragte zusätzliche Zeugen. Das Ergebnis war, dass für ihn die Glaubwürdigkeit von Nikuradse „,nahe den Nullpunkt gesunken ist.“1942 Dieser Einsatz blieb allerdings erfolglos. Plancks zahlreiche Antwortschreiben bekräftigten immer wieder den einen Standpunkt, dass Prandtl doch die ganze Angelegenheit endlich ruhen lassen solle. Während Planck sich vor allem um die Arbeitsfähigkeit des Instituts sorgte, und diese durch die Wiedereinstellung von vier

1939 Prandtl an Föppl, 29. November 1933. MPG-Archiv, III, 61, 2145.

1940 Diese Ansicht vertritt Tollmien [1987/98] S. 696.

1941 Aktennotiz von Prandtl von einer Aussprache bei der Betriebsversammlung vom 31. Oktober 1933. SUBG, Cod. Ms. L. Prandtl 10.

1942 Prandtl an Planck, 14. Dezember 1933. SUBG, Cod. Ms. L. Prandtl 10. 
Mitarbeitern nicht gefährdet sah, fühlte sich Prandtl auch für die berufliche Zukunft seiner Leute verantwortlich.

Prandtl musste es hinnehmen, dass er selbst durch persönliche Vorsprache bei der KWG und beim Kultusministerium Anfang Januar 1934 keine nach seiner Auffassung gerechte Entscheidung des Falls Nikuradse erreichen konnte. Dass er Nikuradse schließlich kündigte, brachte ihm weitere politische Schwierigkeiten. Die Göttinger Polizei erwog deshalb sogar, „Prandtl im Interesse des Arbeitsfriedens und der Staatssicherheit die Betriebsführung zu entziehen."1943 Die Erfahrung, dass Prandtl trotz größtem Einsatz in seinem Institut nicht mehr das letzte Wort in Personalangelegenheiten hatte, wirkte sich auch auf die Anfang 1934 sich verschärfende Auseinandersetzung im Universitätsinstitut für angewandte Mechanik aus.

\subsubsection{Prandtls entgültiger Verlust des Instituts}

Als Prandtl im Herbst 1933 drei seiner Mitarbeiter an der AVA entlassen musste, spitzte sich auch die Auseinandersetzung um die Wiederbesetzung der Assistentenstelle im Institut für angewandte Mechanik zu. Im September 1933 beantragte Prandtl, die planmäßige Assistentenstelle Flügge zu übertragen, „der wegen seiner wissenschaftlichen Befähigung in erster Linie dafür in Frage kommt. [...] Er ist arisch und nach allem, was mir über ihn bekannt ist, national zuverlässig.“"1944 Drei Wochen später gab Prandtl eine zusätzliche Begründung, warum er auf Flügge Wert lege. Er war durch die Inanspruchnahme am KWI gezwungen, „die inneren Obliegenheiten des Instituts für angewandte Mechanik in einem höheren Umfang dem Assistenten zu überlassen [...] als das im Normalfall eines Instituts der Universität zutreffen würde.“ Deshalb legte er besonderen Wert darauf, „einen reifen jungen Gelehrten als Assistenten $\mathrm{zu}$ haben, der auch den Studierenden gegenüber bereits die nötige wissenschaftliche Autorität besitzt und in der Lage ist, diesen gegenüber die Belange des Institutsdirektors mit dem erforderlichen Nachdruck wahrzunehmen." ${ }^{1945}$ Ein Zeichen von Flügges Reife war auch, dass er seit 1933 Redaktionsmitglied des „Zentralblattes für Mechanik“"war, das er dann bis zum Kriegsende leitete.

1943 Kriminal-Sekretär Ippensen und Kriminal-Kommissar a. Pr. Lange, 15. Juni 1934. GStAPK, I. HA Rep. 76 Kultusministerium, Vc Sekt. 21 Tit. 23 Nr. 18 Bd. 3, Das Kaiser-Wilhelm-Institut für Strömungsforschung in Göttingen, 1933-1934. Diese Quelle scheint Moritz Epple unbekannt gewesen zu sein, denn Epple [2002] S. 313 behauptet, Prandtls eigene Stellung sei in dieser Affäre zu keinem Zeitpunkt bedroht gewesen.

1944 Prandtl an Kurator, 22. September 1933. Vier Tage zuvor bat er den Kurator von Würzburg aus, Flügge vertretungsweise die Assistentenstelle zu übertragen. UAG, Kur. XVI. V. C. h. 11 I.

1945 Prandtl an Kurator, 10. Oktober 1933. UAG, Kur. XVI. V. C. h. 11 I. 
Die Kritik, die Prandtl wegen seiner Abwehr der nationalsozialistischen Forderungen auch von Seiten der Geheimen Staatspolizei erfuhr, führte offenbar zu einer vorübergehenden Abschwächung seiner Haltung, zumindest den Studenten gegenüber. Dies geht aus einem Schreiben Hahnkamms von Anfang Oktober an den Kurator hervor: „Unsere teilweisen Befürchtungen, dass unser Lehrer und Vorsteher, Herr Professor Prandtl, mit unserem Handeln und Denken nicht einverstanden wäre, und dass sich daraus gewisse Unannehmlichkeiten entwickeln könnten, haben sich $\mathrm{zu}$ unserer aller Freude nicht bewahrheitet. Wir sind alle über das allgemeine Verständnis und die Liebenswürdigkeit, die Herr Professor Prandtl mir bei kürzlichen Besprechungen entgegengebracht hat, ausserordentlich erfreut.“1946

Hahnkamm scheint die Rolle eines Rädelsführers unter den nationalsozialistischen Studenten am Institut eingenommen zu haben. Sein parteipolitisches Engagement unterstrich er durch zahlreiche Mitgliedschaften. Zu der Parteimitgliedschaft von 1931 kamen noch hinzu: 1933 SS (SS/Fliegerst. Göttingen), ohne Jahresangabe NSFK, NSDStB, NSDDB, DAF, NSV, NSLB, NSBDT, Reichsluftschutzbund, NS.-Altherrenbund d. D. Studenten. ${ }^{1947}$ Hahnkamm sah sich gegen Ende des Jahres schon als Nachfolger von Hohenemser. So stellte er es jedenfalls gegenüber dem Kurator dar, bei dem er sich Mitte November über die fehlende Vergütung seiner Arbeit beschwerte. In diesem Schreiben lästerte er auch über Prandtl, der „höchstens alle drei Wochen für eine Stunde im Institut zu sehen“ sei, und bat, Schuler „zum Leiter unseres Instituts [zu] ernennen“. 1948 Damit weitete sich der Konflikt auch auf die Stelle des Institutsdirektors aus. Die Besetzung der Assistentenstelle blieb noch ungeklärt. Der schon entlassene Hohenemser erhielt seine Gehaltszahlungen noch bis Ende Dezember. Am 30. Oktober 1933 setzte der Preußische Minister Flügge als seinen Nachfolger ein. ${ }^{1949}$ Diese Anweisung scheint der Kurator aber nicht umgesetzt zu haben. Ende Dezember schrieb der Rektor an den Kurator: „Mir ist aus der Dozentenschaft mitgeteilt worden, daß bereits vor Wochen Dr. Flügge für diese Stelle beantragt sei. Auf Grund der mir bisher vorliegenden Erkundigungen würde es sich nicht empfehlen, die Ernennung Dr. Flügges zum 1. Januar

\footnotetext{
1946 Hahnkamm an Kurator, 4. Oktober 1933. UAG, Kur. XVI. V. C. h. 11 I.

1947 In einem Lebenslauf vom Juni 1934 schreibt er über sich: „Politisch bin ich Mitkämpfer für die nationale Erhebung seit dem Jahre 1922."UAG, Kur. XVI. V. C. e. 1. Die Angaben zu den politischen Mitgliedschaften entstammen MPG-Archiv, III, 61, 2015; BAB, Parteipolitische Erhebung, Hahnkamm; BAB, BDC, PK-Akte Hahnkamm; BAB, ZA V 13, S. 290-291; Auskunft Landesarchiv Berlin, 31. März 2000).

1948 Hahnkamm an Kurator, 18. November (original „Nebelung“) 1933. UAG, Kur. XVI. V. C. h. 11 I.

1949 Erlass des Ministers vom 30. Oktober 1933. UAG, Kur. XVI. V. C. h. 11 I.
} 
auszusprechen.“1950 Wie es scheint, rechnete der Kurator schon mit der Ernennung Hahnkamms. Doch Prandtl wollte Flügge unbedingt durchsetzen.

Die schlechten Erfahrungen, die er in den Verhandlungen mit dem Kurator und dem Kultusministerium in der Streitsache Nikuradse gemacht hatte, ließen ihn nun einen anderen Lösungsweg suchen. Er versuchte, im direkten Gespräch mit Schuler und Flügge einen Kompromiss auszuhandeln. Dabei war er bereit, auf die Institutsleitung zu verzichten und Schuler als seinen Nachfolger vorzuschlagen. Etwa Anfang Februar 1934 setzte Prandtl einen sieben Punkte umfassenden Vertrag auf, der die Rechte und Pflichten von Prandtl, Schuler und Flügge festschrieb und von allen dreien unterzeichnet werden sollte. Dieser Vertragsentwurf räumte Schuler offenbar noch nicht genug Rechte ein, denn es wurde ein neuer Fünf-Punkte-Vertrag aufgesetzt, der dann tatsächlich von allen am 24. Februar 1934 unterschrieben wurde. Prandtl verpflichtete sich darin, Schuler als seinen Nachfolger vorzuschlagen und für ihn einen besoldeten Lehrauftrag und eine weitere Hilfskraft zu beantragen. Dafür stand ihm das Recht zu, eigene Doktoranden am Institut arbeiten zu lassen. Schuler erklärte sich bereit, die gesamte Verwaltung des Instituts zu übernehmen und für die Leitung und den Weiterausbau des Lehrbetriebs zu sorgen. Schuler war einverstanden, Flügge als Assistenten zu übernehmen. Außerdem sicherte er Flügge das Recht zu, sich seine wissenschaftlichen Arbeitsthemen selbst zu wählen und ihm ausreichende Möglichkeiten für diese Arbeiten zur Verfügung zu stellen. Im Vertrag wurde auch festgehalten, dass Flügge in seiner Eigenschaft als Institutsassistent Schuler unterstand und diesem bei der Durchführung des Praktikums behilflich sein musste. Aus dem ursprünglichen Vertragstext gestrichen wurde der Passus, dass Prandtl als Schiedsrichter in Streitfragen das letzte Wort zu sagen habe. Ebenfalls fortgefallen war der Satz: „Im Falle des Ausscheidens von Dr. Flügge wird eine neue Vereinbarung zu treffen sein." ${ }^{1951}$

Vor allem durch die Abänderungen im Vertragstext verlor Prandtl praktisch den gesamten Einfluss auf sein Institut. Er tat dies vermutlich in der Hoffnung, einem seiner fähigen Mitarbeiter eine Stelle zu sichern und außerdem die fachliche Kontinuität im Institut zu wahren. Flügge war ja als Spezialist von Schalenkonstruktionen ein Vertreter der Festigkeitslehre. Es ist aus den Quellen nicht zu entnehmen, auf welche Weise Schuler eine so günstige Verhandlungsposition erreichte, dass er die weitreichenden Abänderungen

\footnotetext{
1950 Rektor an Kurator, 21. Dezember 1933. UAG, Kur. XVI. V. C. h. 11 I.

1951 Siehe den nicht unterzeichneten 7-Punkte-Vertrag, ohne Datum (DLR-Archiv, GOAR 3664.), sowie die unterzeichnete Einverständniserklärung vom 24. Februar 1934 und den Briefentwurf Prandtls an Schuler,
} 
durchsetzen konnte. ${ }^{1952}$ Belegt sind mehrere eindeutige und verleumderische Eingaben von Schulers Hilfsassistenten Erich Hahnkamm. Ob auch sein früherer Hilfsassistent Thomas Gengler, der mittlerweile zum Göttinger Kreisleiter aufgestiegen war, Druck auf Prandtl ausübte, bleibt offen. ${ }^{1953}$ Zwei Tage nach Vertragsunterzeichnung reichte Prandtl wie vorher festgelegt seinen Rücktritt als Institutsdirektor ein. In der Formulierung lässt er aber deutlich spüren, dass dieser Schritt nicht freiwillig geschah:

„Aus einer Reihe von Vorkommnissen der letzten Zeit glaube ich schließen zu müssen, daß man höheren Orts meinen Rücktritt von der Leitung des Instituts für angewandte Mechanik wünscht. Ich werde mich diesem Wunsch nicht entziehen. Als eine zur Zeit erreichbare Zwischenlösung schlage ich vor, Herrn Professor Dr.-Ing. M. Schuler hier mit der Leitung des Instituts zu beauftragen und ihm einen besoldeten Lehrauftrag hierfür zu gewähren, und ihm ferner noch neben dem Institutsassistenten eine weitere Hilfskraft, etwa aus dem Assistenzleistungsfonds, zur Verfügung zu stellen. [...] Bei den Einrichtungen des Instituts an Apparaten und Maschinen ist im letzten Jahrzehnt die Festigkeitsforschung besonders stark betont worden. Es wird sich deshalb empfehlen, für die planmäßige Assistentenstelle einen jungen Forscher dieser Richtung zu wählen. Dies war auch der Grund, warum ich großen Nachdruck darauf legte, für die planmäßige Assistentenstelle unseren hiesigen Privatdozenten Dr.-Ing. W. Flügge zu gewinnen. Ich möchte hier betonen, daß Herr Professor Schuler sein ausdrückliches Einverständnis dazu gegeben hat, daß Dr. Flügge jetzt die planmäßige Assistentenstelle bekommt."1954

Der Rektor unterstützte Prandtls Antrag, und obwohl Schuler etwas drängelte und schon vor der ministeriellen Entscheidung vertretungsweise mit der Institutsleitung beauftragt werden wollte, sah es für kurze Zeit so aus, als ob ein befriedigender Kompromiss gefunden worden war. ${ }^{1955}$ Mit 1. April 1934 wurde Flügge neuer Assistent; acht Tage später wurde Schuler die Institutsleitung übertragen. Kritik an der Besetzungen der Assistentenstelle kam sogleich von der NS-Dozentenschaft, die fürs Erste jedoch keine Konsequenzen hatte. ${ }^{1956}$ Ende Mai bat Flügge, ihn für die Teilnahme des im Juli 1934 in Cambridge stattfindenden Kongresses für angewandte Mechanik zu beurlauben. Schuler, der sich selbst zwar als Wissenschaftler der

15. Februar 1934. MPG-Archiv, III, 61, 1512, außerdem Prandtl an Dekan, 14. Februar 1934. MPG-Archiv, III, $61,1737$.

1952 Es gibt einen Hinweis auf einen anderen Verhandlungsvorteil Schulers. Noch auf dem alten Vertrag fußend beantragte Prandtl am 14. Februar 1934 beim Dekan, Schuler die stellvertretende Leitung des Instituts für angewandte Mechanik zu übertragen, um ihn in Göttingen zu halten. Schuler habe nämlich eine Anfrage der DVL in Berlin-Adlershof wegen Übernahme einer Abteilungsleiterstelle erhalten. Prandtl schickte diesen Antrag offenbar nicht ab, denn auf ihm ist oben „Ungültig!“ vermerkt. MPG-Archiv, III, 61, 1737.

1953 Zur Bedeutung des Göttinger Kreisleiters, Gengler, siehe Tollmien [1998].

1954 Prandtl an Dekan Reich, 26. Februar 1934. UAG, Kur. PA Schuler. Dieses Schreiben befindet sich außerdem in UAG, Rek. 5250 / 7A.

1955 Rektor an REM, 28. Februar 1934. UAG, Kur. PA Schuler. Schuler an Kurator, 8. März 1934. UAG, Rek. $5250 / 7 \mathrm{~A}$

1956 NS-Dozentenschaft, Vogel, an Kurator, 17. März 1934, UAG, Kur. XVI. V. C. e. 1. 
angewandten Mechanik betrachtete, jedoch nicht an den vierjährlich stattfindenden internationalen Kongressen teilnahm, unterstützte den Antrag 'seines ‘ Assistenten, da die Teilnahme im wissenschaftlichen Interesse liege. ${ }^{1957}$ Doch Ende Juni erlebte Flügge zwei böse Überraschungen. Zum einen wurde ihm von der NSDAP die Teilnahme am MechanikKongress mit der Begründung nicht gestattet, er sei politisch unzuverlässig und seine Einstellung zu Staat und Bewegung sei völlig undurchsichtig. ${ }^{1958}$ Viel schwerer wog allerdings die zweite Entscheidung: Ihm wurde zum 1. Oktober 1934 gekündigt. Das Ministerium gab sich nicht einmal die Mühe, irgendeinen Vorwand für die Kündigung zu konstruieren, kündigte ihn also ohne Angabe eines Grundes, verlangte aber explizit, die Stelle mit Erich Hahnkamm zu besetzen. ${ }^{1959}$

Prandtl war entmachtet. Mit dieser ministeriellen Entscheidung war Schuler der Weg frei gegeben, das Institut völlig nach seinen Wünschen umzugestalten und die Forschung entsprechend auszurichten. Prandtl äußerte seinen Unmut über diese Kündigung: „Es erscheint untragbar, daß wir den besten Leuten, die wir haben, und die wir für die künftige Entwicklung von Wissenschaft und Technik notwendig brauchen, das Fortkommen in der Wissenschaft unmöglich machen, bloß weil irgend ein Mißgünstiger unwahre Nachrichten über sie an die entscheidende Dienststelle hat gelangen lassen." 1960 Flügge hatte durch die äußerst eigenartige Kündigung erhebliche Probleme, eine neue Stelle zu finden. Sein ursprüngliches und schon anlässlich seiner Habilitation formuliertes Ziel war, an einer TH als Hochschullehrer tätig zu werden. Schon im März 1934 kam er für die ordentliche Professur für Mechanik der TH Aachen in Vorschlag. Dieses Ordinariat erhielt schließlich der leidenschaftliche Antisemit Wilhelm Müller, der später in München Nachfolger von Sommerfeld wurde. Es ist zu vermuten, dass auch schon bei der Aachener Berufung politische Kriterien eine entscheidende Rolle spielten. ${ }^{1961}$ Die wertvolle Unterstützung von Prandtl war Flügge aber sicher, der ihn schon 1934 für einen ,ganz besonders befähigten jungen Gelehrten und für einen der besten Kandidaten für Mechanik- oder Statiklehrstühle an deutschen Technischen Hochschulen“ hielt und von seiner „durch und durch charaktervollen Gesinnung“ überzeugt war. ${ }^{1962}$

\footnotetext{
1957 Flügge an Kurator mit einem Zusatz von Schuler, 26. Mai 1934. UAG, Kur. PA Flügge.

1958 NSDAP, Gauleitung Südhannover-Braunschweig, an Kurator, 8. Juni 1934. UAG, Kur. PA Flügge.

1959 Ministerium (gez. Vahlen) an Kurator, 27. Juni 1934. UAG, Kur. XVI. V. C. e. 1.

1960 Prandtl an Kurator, 27. Juli 1934. Es ist anzunehmen, dass der von Prandtl erwähnte Missgünstige wohl Erich Hahnkamm war. MPG-Archiv, III, 61, 1735; und UAG, Kur. XVI. V. C. e. 1.

1961 Litten [2000] S. 52ff.

1962 Prandtl an Kurator, 27. Juli 1934. MPG-Archiv, III, 61, 1735; und UAG, Kur. XVI. V. C. e. 1. 
Trotz Prandtls Unterstützung hatte Flügge wegen der bezeichnenden Kündigung durch das Ministerium wenig Aussichten auf eine erfolgreiche Hochschullehrerlaufbahn. Deshalb bewarb er sich 1934 bei der Deutschen Versuchsanstalt für Luftfahrt in Berlin Adlershof, die aber erst über die Entlassungsgründe aufgeklärt werden wollte. ${ }^{1963}$ Erst nach mehreren Bitten um Aufklärung, die Flügge ans Ministerium richtete, ${ }^{1964}$ erfuhr er, dass „wegen Umgestaltung des Instituts“ eine weitere Verwendung von ihm nicht mehr möglich war, einer Beschäftigung bei der DVL aber nichts entgegenspreche. ${ }^{1965}$ Flügge wurde dann aber an der AVA als Assistent angestellt, wo er als Mitarbeiter von Betz anscheinend ohne Probleme unterkam. ${ }^{1966}$ Dort blieb er bis Ende 1937, um schließlich doch zur DVL zu wechseln. Seine Göttinger Dozentur erlosch mit Ende des WS 1938/39.1967 Die ursprünglich geplante Hochschullehrerlaufbahn hatte damit ein vorläufiges Ende gefunden. Auch eine Berufung Flügges auf den Lehrstuhl für Luftfahrzeugbau an der TH Aachen wurde abgewehrt, obwohl er 1942 an erster Stelle der Berufungsliste stand. Erst in der Nachkriegszeit konnte er zum Universitätsprofessor in den USA aufsteigen. ${ }^{1968}$

Der von Prandtl erwähnte Missgünstige, der seine Konkurrenten denunzierte, könnte Erich Hahnkamm gewesen sein. Konkrete Belege seiner politischen Angriffe sind, soweit sie Eingang in die Akten gefunden haben, bereits zitiert worden. Dass Hahnkamm auch bei der Entlassung Flügges seine Hände im Spiel hatte, legt sein Bericht über das Institut vom Dezember 1935 nahe, den er an das Reichserziehungsministerium sandte.

„Obgleich mir Stellungen in den vergangenen Jahren angeboten worden sind, die mir wesentlich mehr eingebracht hätten als die Assistentenstelle, habe ich sie abgeschlagen, zumal die Erlangung der Assistentenstelle nach der Machtergreifung durch den Nationalsozialismus aus den Händen der Juden und nachfolgenden Liberalisten für mich als Nationalsozialisten eine Prestigefrage war. Durch alle diese von mir bekämpften Verhältnisse bin ich nicht nur wissenschaftlich gehindert worden, sondern habe auch oft schwere wirtschaftliche Not gelitten [...]. Trotzdem möchte ich in keiner Weise für die erlittenen

\footnotetext{
1963 DVL (gez. Kröplin) an Rektor, 9. August 1934, UAG, Kur. XVI. V. C. e. 1.

1964 Flügge an Kurator, 23. Juli 1934. UAG, Kur. XVI. V. C. e. 1; und MPG-Archiv, III, 61, 456.

1965 Minister an Kurator, 14. September 1934. UAG, Kur. XVI. V. C. e. 1.

1966 Siehe Prandtl an Georgii, 7. Oktober 1941. MPG-Archiv, III, 61, 1978.

1967 Flügge an Dekan, 6. Dezember 1937; REM (gez. Dames) an Flügge, 27. Januar 1939. GPAMNFG, Lehrkörper (ausgeschieden), Flügge.

1968 Gegen Kriegsende ist Flügges Abteilung der DVL nach Saulgau in Süddeutschland verlegt worden, wo sie „ohne Verluste in die neue Zeit hinübergekommen“ war. Von 1946 bis 1948 war er Gruppenleiter am Centre Technique, Office National d'Etudes et de Recherches Aéronautiques, zunächst in Wasserburg am Bodensee, von 1947-48 in Paris. Ab 1948 war er Professor am Department of Engineering Mechanics, Stanford University, California. UAG, Kur. PA Flügge; UAG, Kur. XVI. V. C. e. 1; GPAMNFG, Lehrkörper (ausgeschieden), Flügge; BAB, ZB II, 5356; BAB, Dr.-Ing. Flügge Wilhelm; BAB, BDC, Ing. 904 Wilhelm Flügge; MPGArchiv, I, 44, 566; Poggendorff.
} 
Nachteile entschädigt werden. Lohn genug ist mir der Sieg der Bewegung, für die ich leidenschaftlich gekämpft habe."1969

Wie das Beispiel Hahnkamm zeigt, gaben die Maßnahmen zur nationalsozialistischen Umgestaltung der Universität sogar Hilfsassistenten die Möglichkeit, entscheidenden Einfluss auf die Personalpolitik auszuüben. Nach Ausschaltung seiner Konkurrenten Prager, Hohenemser und Flügge konnte Hahnkamm selbst die Assistentenstelle einnehmen. Seinen Triumph genoss er bei der Übergabe der Institutsleitung an Schuler, bei der er „eine völlig unakademische Ansprache hielt, in welcher der neue nationalsozialistische Geist, der jetzt in die Wissenschaft eingezogen sei, mit den üblichen Phrasen gerühmt wurde. “1970

Um das Bild von Hahnkamms politischen Aktivitäten der Jahre 1933/34 abzurunden, sei noch erwähnt, dass er im Frühjahr 1934 auch Gustav Mesmer denunzierte, dessen politische Einstellung er aus den von Hohenemser und Lüneburg angeregten Diskussionsrunden kannte. Der Anlass der Denunziation war ein Nachspiel des Falls Nikuradse, in den Mesmer verwickelt war. Hahnkamm wurde von der Polizei vorgeladen und zu Mesmers politischem Verhalten befragt. Im Gegensatz zu den erheblichen Vorwürfen, die er seinen direkten Konkurrenten machte, blieb er in diesem Fall sachlicher, wenn auch der Inhalt geeignet war, Mesmer ernsthaft $\mathrm{zu}$ schaden. Er gab beispielsweise zu Protokoll, dass Mesmer ein entschiedener Gegner des Nationalsozialismus sei, der „nicht verstehe, wie man Wissenschaftler von deutschen Hochschulen entfernen könne, weil sie Juden wären."1971 Die politische Auseinandersetzung verlief für Mesmer relativ glimpflich. Zwar konnte er genauso wie Flügge nicht an dem Kongress in Cambridge im Sommer 1934 teilnehmen, da ihm im Juni der Pass entzogen wurde. ${ }^{1972}$ Dafür wurde aber seine weitere Hochschulkarriere nicht im gleichen Ausmaß behindert. Mesmer konnte sich an der TH Aachen habilitieren und wurde 1940 auf Fürsprache Prandtls ordentlicher Professor an der TH Darmstadt. Eine kollegiale

\footnotetext{
1969 Hahnkamm an REM, 6. Dezember 1935. UAG, Rek. 5250 / 7 A.

1970 Kurt Hohenemser: „Bericht über die seitherigen Vorgänge betreffend meine Rehabilitierung an der Universität Göttingen“, 5. April 1946. Von Hahnkamms Ansprache erfuhr Hohenemser von Prandtl und Mesmer, die bei der Zeremonie anwesend waren. KHP.

1971 Zeugenaussage von Erich Hahnkamm, Göttingen 8. Februar 1934. GStAPK, I. HA Rep. 76

Kultusministerium, Vc Sekt. 21 Tit. 23 Nr. 18 Bd. 3, Das Kaiser-Wilhelm-Institut für Strömungsforschung in Göttingen, 1933-1934.

1972 Siehe den Bericht der Ortspolizeibehörde Göttingen, 20. Juli 1934, Betrifft: Fall Mesmer: "Polizeilicherseits war ihm Ende Juni der Pass entzogen worden, weil er die Absicht hatte, nach Holland und England zu fahren." GStAPK, I. HA Rep. 76 Kultusministerium, Vc Sekt. 21 Tit. 23 Nr. 18 Bd. 3, Das Kaiser-Wilhelm-Institut für Strömungsforschung in Göttingen, 1933-1934.
} 
Verbindung zu Prandtl ${ }^{1973}$ und vor allem eine enge freundschaftliche zu Hohenemser blieb über die Jahre bestehen. ${ }^{1974}$

\subsubsection{Das Institut unter Schulers Leitung}

Max Schuler bekam die Institutsleitung nur auf Grund der Initiative nationalsozialistischer Studenten. Unter normalen Verhältnissen hätte Prandtl ihn nicht für diese Stelle vorgeschlagen. Selbst unter politischem Druck war er nur bereit, ihn als Zwischenlösung zu befürworten. Dies lag aber nicht etwa daran, dass Schuler charakterlich ungeeignet oder wissenschaftlich minder qualifiziert gewesen sei. Für die Fakultät war Schuler ein ehrenwerter Kollege mit ausgezeichneter wissenschaftlicher Qualifikation in seinen Spezialgebieten. Die Universität förderte aus diesen und nicht aus politischen Gründen stets Schulers Karriere, doch sollte die Institutsleitung nur eine Zwischenlösung bleiben, da Prandtl den Forschungsschwerpunkt des Instituts in der Festigkeitslehre sichern wollte. Die Ausstattung des Instituts an Maschinen und Instrumenten war von Anfang an darauf ausgerichtet. Schulers Forschungen der Kreisel- und Schwingungsphysik waren eine willkommene Ergänzung aber kein Ersatz der vorhandenen Forschungsschwerpunkte. Im Vergleich mit den personellen Änderungen an den anderen Physikinstituten zeigt sich eine Besonderheit dieses Falles: Eine internationale Koryphäe ihres Fachs wurde durch einen weniger bedeutenden Forscher ersetzt, ohne dass Prandtl von den neuen Gesetzen betroffen gewesen wäre und die Universität hätte verlassen müssen.

\subsubsection{Schulers Laufbahn im Nationalsozialismus}

Im Sommersemester 1933 übernahm Schuler Lehrveranstaltungen seiner vertriebenen Kollegen. Zusätzlich zu seiner geplanten Vorlesung über Ausgleichsrechnung und dem Mechanik-Praktikum hielt er eine Vorlesung über Darstellende Geometrie plus Übungen im Umfang von sieben Semesterwochenstunden ab. Für diesen besonderen Einsatz bekam er eine Vergütung in Höhe von RM 960,-. In einem erneuten Antrag der Fakultät auf einen Lehrauftrag vom Juli 1933 wurde besonders seine Eignung für wehrwissenschaftliche Vorlesungen betont; der Lehrauftrag sollte Dynamik der Apparate und Maschinen heißen. Die

1973 Siehe zum Beispiel die Briefe Mesmer-Prandtl von September 1944 bis Juni 1945 in: MPG-Archiv, I, 44, 1082.

1974 Mündliche Auskunft von Hohenemser, August 2000. 
Formulierung dieser Eingabe folgte wörtlich einem Entwurf Prandtls. ${ }^{1975}$ Auch dieser Antrag blieb erfolglos. Im März 1934 versuchte Schuler persönlich durch eine Eingabe an den Kurator, eine Vorlesungsunterstützung bewilligt zu bekommen. „Ich erlaube mir darauf hinzuweisen, daß ich im abgelaufenen Semester bisher von der Universität gar kein Gehalt noch Zuwendungen bekommen habe, obwohl ich meine volle Arbeitskraft in den Dienst der Universität gestellt habe. Ich wäre Ihnen, sehr geehrter Herr Geheimrat, sehr dankbar, wenn Sie für mich etwas, wenn auch nur eine Kleinigkeit, erreichen könnten."1976 Auch dieser Versuch schlug fehlt, doch dem folgenden Antrag der Fakultät vom Mai 1934 auf einen vergüteten Lehrauftrag wurde Folge geleistet. ${ }^{1977}$

Das Jahr 1934 markiert einen bedeutenden Schritt in Schulers Laufbahn. Am 9. April 1934 bekam er die Leitung des Instituts für angewandte Mechanik, und mit Wirkung vom 1. Mai 1934 wurde ihm ein Lehrauftrag für angewandte Mechanik mit einer monatlichen Vergütung von 422 RM 57 Pf bewilligt. Beides geschah auf Antrag Prandtls, der sich damit an die zwischen ihm, Schuler und Flügge vereinbarte Regelung hielt. Damit hatte zwar Schuler schon mehr erreicht, als er bis 1933 erhoffen konnte, doch empfand er seinen Aufstieg noch als unvollkommen. Das lag daran, dass er in seiner neuen Stellung als Institutsleiter, ohne jedoch eine planmäßige Stelle zu besitzen, einen seltsamen Eindruck vermittelte. Besonders störte ihn, dass er in der Fakultät wenig Mitspracherecht genoss, dass er den anderen Institutsleitern deutlich untergeordnet war. Seine Bestrebungen galten folglich der Erreichung einer planmäßigen Professur mit dem Ziel, letztlich ein Ordinariat zu bekommen. Den Gipfel der Hochschullehrerlaufbahn konnte Schuler dann allerdings nicht erreichen. Auch der Schritt zur planmäßigen Professur verzögerte sich. Der politische Rückenwind, den er in der Formierungsphase der NS-Herrschaft genoss, flaute merklich ab. Seine politische Anpassung blieb auf einem Niveau, das vereinzelte Zweifel in den sonst positiven politischen Beurteilungen über ihn nicht vollständig ausräumen konnte. Im November 1933 wurde er förderndes Mitglied der SS, im Juli 1934 trat er dem NSLB und ein Jahr später der NSV bei. Außerdem wurde er bis 1938 noch Mitglied des NSBDT, der DAF, des Reichsluftschutzbunds und des Altherrenbunds der Deutschen Studenten. ${ }^{1978}$ In einer politischen Beurteilung der Ortsgruppe Hainberg vom Juli 1938 wurde Schulers Verhalten

\footnotetext{
1975 Dekan an Ministerium für Wissenschaft, Erziehung und Volksbildung, 21. Juli 1933. UAG, Kur. PA Schuler. Prandtls Entwurf, 14. Juli 1933. MPG-Archiv, III, 61, 1512.

1976 Schuler an Kurator, 19. März 1934. UAG, Kur. PA Schuler.

1977 Dekan Reich an Kurator, 7. Mai 1934. UAG, Kur. PA Schuler.
} 
„der Bewegung gegenüber vor der Machtübernahme“ als „unsicher, zurückhaltend“ beschrieben. Zur aktuellen Einstellung Schulers „zur Bewegung und zum Staat“ heißt es: „Sch. ist ehrlich bemüht, die heutige Zeit zu verstehen. Vielleicht in seinem Wesen noch etwas deutschnational.“1979 Seltsamerweise urteilte dieselbe Stelle zwei Jahre später über Schulers Verhalten „der Bewegung gegenüber vor der Machtübernahme“: „fördernd unterstützt". Sein aktuelles Verhalten sei dadurch charakterisiert, dass er nicht aktiv tätig sei, die Parteiveranstaltungen besuche, gerne und angemessen bei Sammlungen gebe und regelmäßig Plaketten kaufe. Schulers Ehefrau gehöre der NS-Frauenschaft oder dem Frauenwerk an, die Kinder seien Mitglieder von NSDAP-Gliederungen, der allgemeine Leumund der Familie sei gut, die wirtschaftlichen Verhältnisse geordnet. Lebensführung und Charakter von Schuler seien einwandfrei. Die politische Zuverlässigkeit konnte ohne Einschränkungen bejaht werden. ${ }^{1980}$ Ganz allgemein hatten diese Beurteilungen eine nicht zu vernachlässigende Wirkung auf die Karrieren der Beurteilten, obwohl ihnen auf Grund der schematischen Durchführung mittels vorgegebener Formulare nicht allzu viel Glauben zu schenken ist. Anders verhält es sich mit dem Gutachten des Kreisleiters Thomas Gengler, der Schuler durch jahrelange Zusammenarbeit gut kannte. ${ }^{1981}$ Gengler gab der Gestapo 1940 folgende Auskunft: „Prof. Dr. Maximilian Schuler, Göttingen, verhielt sich vor der Machtübernahme politisch stark zurückhaltend. Er ist auch nach keiner Seite aktiv irgendwie hervorgetreten. Nach der Machtübernahme bekannte sich Prof. Schuler sehr bald zum Werk des Führers und war zur Mitarbeit stets bereit. Die Familienangehörigen von Prof. Schuler gehören alle Gliederungen der Partei an. Er selbst ist Mitglied der N.S.V." 1982 An den günstigen politischen Zeugnissen wird es also nicht gelegen haben, dass sein beruflicher Aufstieg nur langsam vorwärts kam. Aber wie noch zu zeigen ist, mangelte es ihm auch nicht an der nötigen Unterstützung durch die Fakultät.

\footnotetext{
1978 Die Angaben zu den Mitgliedschaften entstammen einem Schreiben Schulers vom 31. Oktober 1938. UAG, Kur. PA Schuler; sowie BAB, R 21 / 10.018; BAB, BDC, NSLB-Kartei, Schuler, Max; HStAH, Nds. 171 Hildesheim, 7876.

1979 Politische Beurteilung Schulers durch die Ortsgruppe Hainberg auf Anforderung der Deutschen Volksbildungsstätte Göttingen, 30. Juli 1938. Siehe auch das Schreiben der Volksbildungsstätte Göttingen an das Personalamt der NSDAP, Göttingen, 8. Juli 1938; sowie das Schreiben des Kreisleiters an den Leiter der Deutschen Volksbildungsstätte, Pg. Dr. Geißel, 6. August 1938. BAB, PK-Akte, Schuler, Max, 1110016005. 1980 Politische Beurteilung Schulers durch die Ortsgruppe Hainberg auf Anforderung der Gestapo Göttingen, 1. März 1940. BAB, PK-Akte, Schuler, Max, 1110016005.

1981 Zum engen Verhältnis Schulers zu Gengler siehe Schuler an Kurator Valentiner, 29. Juni 1933. UAG, Kur. XVI. V. C. f. 2.

1982 Auskunft über die politische Haltung Schulers vom Göttinger Kreisleiter Gengler an die Geheime Staatspolizei Göttingen, 11. März 1940. Siehe auch die ähnliche lautende Auskunft Genglers an den Kreisamtsleiter Ambronn in Göttingen, 10. Oktober 1941. BAB, PK-Akte, Schuler, Max, 1110016005.
} 
Für Schulers Karriere setzte sich vor allem Prandtl ein. Er tat dies, obwohl er aus Schulers Umfeld heraus und durch die von Schuler selbst geforderten Verschärfungen ihrer Vereinbarung in dem von ihm 30 Jahre geleiteten Institut entmachtet worden war. Prandtls Verhalten ist erklärungsbedürftig. Zu beschreiben ist es zunächst als eines, das von kollegialer Loyalität gekennzeichnet ist. Die Frage lautet somit, wieso die tragfähige kollegiale Beziehung zwischen Prandtl und Schuler durch die Ereignisse der Jahre 1933/34 nicht zerstört wurde. Ein entscheidender Faktor, der sich allerdings aus den Quellen schwer bestimmen lässt, war Schulers Charakter. Hätte Schuler einen ähnlichen Charakter wie zum Beispiel Schlechtweg gehabt, der in Prandtls Verständnis mit unangebrachten Methoden mehr Vorteile für sich erkämpfte, als ihm zustanden, so hätte Prandtl vermutlich auch Schulers akademische Karriere in Göttingen zu verhindern versucht. Schulers Methoden waren in Prandtls Urteil offenbar legitim. Prandtl scheint zwischen den Aktionen der Nationalsozialisten, die auf ihn Druck ausübten, und den Handlungen Schulers, der davon Nutznießer war, klar unterschieden zu haben. Hinzu kommt, dass Prandtl wie Schuler keine Nationalsozialisten im engeren Sinn waren, auch wenn sie sich ,zum Werk des Führers“ bekannt haben mögen, sondern beide als Deutschnationale zu charakterisieren sind. Bei Prandtl ist dies nachweisbar: Für die Kommunalwahlen im März 1933 unterstützte er öffentlich die deutschnationale Liste Kampfbund Schwarz-Weiß-Rot. ${ }^{1983}$ Schulers deutschnationale Haltung wurde in politischen Beurteilungen ausgesprochen. Auch wenn solche Charakterisierungen im allgemeinen nur bedingt glaubwürdig sind, so erscheint sie in diesem Fall doch plausibel. Zumindest in keinem Widerspruch zu dieser Deutung stehen Schulers Handlungen zur Vorbereitung seiner Teilnahme an der internationalen Tagung für Zeitmesskunde und technisches Messwesen im Juli 1937 in Paris. Schuler sollte dort die deutsche Gruppe führen. Zur Unterstützung beantragte er beim Ministerium einen Diplomaten als Begleitung und begründete dies folgendermaßen:

„Es wäre doch immerhin möglich, daß bei einer dieser Sitzungen seitens ausländischer Gäste, ein scharfer Angriff gegen Deutschland fallen würde. Ich wäre dann verpflichtet, im Namen der deutschen Teilnehmer solche Angriffe zurückzuweisen. Sollten sich diese Angriffe weiter verschärfen, so würde ich mit allen deutschen Teilnehmern geschlossen den Saal verlassen. Ich erwarte zwar nicht, daß etwas derartiges eintritt, aber es wäre mir doch sehr erwünscht für alle Fälle einen Diplomaten zur Seite zu haben, der mir mit seiner Sprachkenntnis und Erfahrung die nötige Unterstützung zuteil werden läßt. Es kommt mir vor allem

1983 Tollmien [1987/98] S. 705, Fußnote 57; Dahms [1987/98] S. 42. Der Kampfbund Schwarz-Weiß-Rot war eine Listenverbindung von DVP, Stahlhelm und DNVP. 
darauf an, durch ein richtiges und gutes Auftreten die Würde unseres Volkes zu wahren." 1984

Neben der ähnlichen politischen Einstellung weisen beider Biografien noch eine Reihe weiterer Gemeinsamkeiten auf. Beide waren römisch-katholischer Konfession, und beide waren Bayern, wenn man davon absieht, dass Schuler in der Pfalz geboren war, jedoch seine gesamte Schulzeit in München absolvierte. ${ }^{1985}$ Sie studierten beide an der TH München und promovierten bei August Föppl. Zu einer Begegnung an der Hochschule kam es aber nicht, da der sieben Jahre ältere Prandtl bereits eine Professur an der TH Hannover übernommen hatte, als Schuler sein Studium begann. Zur gemeinsamen akademischen Herkunft kam noch eine Ähnlichkeit im äußeren Erscheinungsbild hinzu, die vor allem durch die gleichartigen Bärte hervorgerufen wurde.

Es wäre sicherlich eine unzutreffende Vereinfachung, die kollegiale Verbundenheit mit einer der angeführten Gemeinsamkeiten in kausalen Zusammenhang zu bringen. Andererseits ist eine begünstigende Wirkung doch anzunehmen. Es ist nicht überraschend, dass sich die katholischen Bayern, die beide von der gleichen $\mathrm{TH}$ kamen und an einer vorwiegend protestantischen, preußischen Universität lehrten, emotional verbunden fühlten. $\mathrm{Zu}$ den aus den Biografien herrührenden Verbindungen kam die gegenseitige Wertschätzung der wissenschaftlichen Leistungen hinzu. Dies war aber gerade in der Formierungsphase des Nationalsozialismus ein weniger entscheidendes Kriterium, wie der Vergleichsfall Schlechtweg gezeigt hat. Prandtl lehnte Schlechtweg ab, obwohl er seine Göttinger Forschungsarbeiten sogar als Ersatz einer Habilitationsschrift für geeignet hielt. Es wäre also falsch, Schulers Unterstützung bloß auf seine fachlichen Leistungen zurückzuführen. Die wissenschaftliche Qualifikation war ein notwendiger aber kein hinreichender Grund.

Prandtls Fürsprache war gefordert, als Schuler sich 1938 um eine beamtete Stelle bemühte. Die Fakultät fragte Prandtl nach seiner Meinung $\mathrm{zu}$ dem Vorschlag, ein planmäßiges Extraordinariat für angewandte Mechanik für Schuler zu schaffen. ${ }^{1986}$ Prandtl äußerte sich positiv, denn Schuler habe es verstanden, „dem Institut frisches Leben zuzuführen, insbes. gehen dauernd schöne Dissertationen aus dem Institut hervor. [...] Ich halte es danach, sowohl aus Billigkeitsgründen, wie auch der Anerkennung für bereits erwiesene Leistungen

\footnotetext{
1984 Schuler an REM, 1. Juli 1937. Der Antrag auf Zuteilung eines Diplomaten wurde abgelehnt. BAB, R 4901, Nr. 3035.

1985 Schulers süddeutsche Herkunft war für die Göttinger auch daran zu erkennen, dass er seinen Dackel Seppel nannte, der seiner Frau hieß Resi.

1986 Dekan Lenkeit an Prandtl, 19. Juli 1938. UAG, Math.-nat. Fak 24 a.
} 
wegen für gerechtfertigt, wenn Herr Schuler jetzt in seiner Eigenschaft als Institutsdirektor Beamteneigenschaft verliehen wird!“"1987 Noch vor dem Eintreffen von Prandtls Antwort verfasste die Fakultät einen entsprechenden Antrag ans Ministerium. Begründet wurde der Antrag damit, dass die Aufwertung des Instituts ,mit Rücksicht auf die Aufgaben der Fakultät in Technik und Rüstung“ geboten sei. Bei den „lebensnahen Anwendungen“ spiele die angewandte Mechanik eine „hervorragende Rolle“. ${ }^{1988}$ Die Rhetorik brachte nicht den gewünschten Erfolg. Erst mit der 1939 geschaffenen finanziellen Verbesserung des Mittelbaus durch Zahlung von Diäten für ausgewählte Privatdozenten und außerordentliche Professoren kam der nächste Karriereschritt für Schuler. Die neue Reichshabilitationsordnung ermöglichte es Schuler, zum beamteten Dozenten neuer Ordnung mit Diäten ernannt zu werden. Sein diesbezüglicher Antrag vom Mai 1939 wurde von allen Universitätsstellen unterstützt; ${ }^{1989}$ auch der NSD-Dozentenbund befürwortete den Antrag, da in ,politischer und charakterlicher Hinsicht [...] gegen seine Person keine Bedenken“ bestünden. ${ }^{1990}$ Schuler scheint sich der beamteten Stelle schon sicher gewesen zu sein, denn noch bevor sein Antrag beantwortet wurde, ging er einen Schritt weiter und beantragte die Ernennung zum Ordinarius. ${ }^{1991}$

Am 28. September 1939 wurde Schuler ins Beamtenverhältnis berufen und zum außerplanmäßigen Professor ernannt. Nach elf Jahren als nichtbeamteter außerordentlicher Professor hatte er nun endlich eine bezahlte Stelle. Neue Aufgaben kamen auf Schuler wegen des kurz zuvor begonnenen Kriegs zu. Anfang September wurde er zum Luftschutzwarndienst einberufen. ${ }^{1992}$ Drei Wochen später kam eine Anfrage des Wehrbezirks-Kommandos Göttingen auf „U- und Sicherstellung“ des Hauptmanns der Landwehr außer Dienst, Max Schuler, für Peenemünde. Daraufhin wurde Schuler vom Wehrwirtschaftsinspektor in Hannover für die Heeresversuchsanstalt Peenemünde freigegeben. ${ }^{1993}$ Schuler konnte also in seinem Institut in Göttingen bleiben und Forschungsaufgaben für das

\footnotetext{
1987 Prandtl an Dekan Lenkeit, 21. Juli 1938. UAG, Math.-nat. Fak 24 a.

1988 Dekan Lenkeit an den Minister für Wissenschaft, Erziehung und Volksbildung, 20. Juli 1938. UAG, Math.nat. Fak 24 a; sowie UAG, Rek. PA Schuler.

1989 Schuler an REM, 30. Mai 1939; Dekan an REM, 4. Juli 1939. Die Fakultät beantragte wieder, ein planmäßiges Extraordinariat einschließlich einer Direktorstelle einzurichten und Schuler zum Diätendozenten zu ernennen. Rektor an REM, 21. August 1939. UAG, Kur. PA Schuler.

${ }^{1990}$ Hochschulgruppe Göttingen des NSD-Dozentenbundes an Rektor, 17. August 1939. UAG, Rek. PA Schuler.

1991 Schuler an Kurator und Dekan, 17. Juni 1939. GPAMNFG, Lehrkörper (ausgeschieden), Schuler.

1992 Schuler an Dekan, 9. September 1939, GPAMNFG, Lehrkörper (ausgeschieden), Schuler.

1993 Wehrbezirks-Kommando Göttingen an Kurator, 29. September 1939. GPAMNFG, Lehrkörper (ausgeschieden), Schuler.
} 
Raketenforschungszentrum übernehmen. ${ }^{1994}$ Die Bemühungen um ein Ordinariat wurden kurz darauf durch einen Ruf an die Universität Hamburg unterstützt. Dort wurde ihm eine ordentliche Professur in Verbindung mit einer Direktorstelle angeboten. ${ }^{1995}$ Seine Kollegen Prandtl und Albert Betz setzten sich für ihn ein und versuchten, eine Verbesserung seiner Göttinger Position zu erreichen. Sie argumentierten, die angewandte Mechanik in Göttingen verdiene unabhängig von Schulers Entscheidung ein Ordinariat. Denn anders ließe sich im Falle seines Wegganges kein vollwertiger Nachfolger finden. Diesen Antrag unterstützten Pohl und Joos, wobei sie besonders auf Schulers Wissen in seinen technischen Sonderfächern hinwiesen. ${ }^{1996}$ Der Dekan Lenkeit fügte hinzu, dass der gerade in Fertigstellung befindliche Ausbau des Instituts für angewandte Mechanik genau auf Schulers Bedürfnisse ausgelegt sei. ${ }^{1997}$ Nach einer Rücksprache im Ministerium betonte der Dekan in einem neuen Antrag, die Angelegenheit sei „außerordentlich wichtig“, der fehlende planmäßige Lehrstuhl sei eine „akute Gefahr für das Bestehen des Instituts“, und dieses Institut sei doch aus einer „organisch gewachsenen Arbeitsgemeinschaft“ entstanden. Schließlich gipfelt die Darstellung in der Behauptung, dass es sich um ,eine Lebensfrage für die traditionelle Arbeitsrichtung der Fakultät" handle. ${ }^{1998}$ Der Kurator versuchte, persönliche Beziehungen auszunutzen, und richtete ,persönlich die Bitte“ an den Ministerialbeamten Dames, Schuler zum ordentlichen Professor zu ernennen und für Göttingen zu erhalten. ${ }^{1999}$ Dames war selbst Physiker und hatte in Göttingen ab Dezember 1933 die Assistentenstelle am II. Physikalischen Institut inne gehabt, bevor er ins Ministerium wechselte. ${ }^{2000}$ Demnach kannte er Schuler persönlich. Nachdem das Ministerium drei Monate lang nicht reagiert hatte, richtete sich Schuler selbst wieder an den Kurator, um auf seine unbefriedigende Stellung hinzuweisen. ${ }^{2001}$ Diesem erneuten Drängen des 'nur' mit der Verwaltung des Instituts Beauftragten folgte fünf Tage später die offizielle Ernennung zum Institutsdirektor mit der Aussicht auf baldige Einrichtung eines Extraordinariats. ${ }^{2002}$ Dieser zuletzt genannte Punkt bereitete allerdings Schwierigkeiten, da eigentlich kein geeigneter freier Lehrstuhl verfügbar war. Im Januar 1942 schrieb Schuler

\footnotetext{
1994 Zu Peenemünde siehe Neufeld [1997].

1995 Laut eines Schreibens von Schuler an Kurator vom 18. Februar 1940 handelte es sich bei dem Angebot um die Direktorstelle des Instituts für Uhrentechnik und Feinmechanik in Hamburg. UAG, Kur. PA Schuler.

1996 Prandtl und Betz an Dekan Lenkeit, 9. November 1939, mit einer angefügten Unterstützungserklärung von Pohl und Joos. UAG, Rek. PA Schuler.

1997 Dekan an REM, 24. November 1939. UAG, Kur. PA Schuler.

1998 Dekan an REM, 22. Dezember 1939. UAG, Kur. PA Schuler.

1999 Kurator an Prof. Dr. Dames, Reichsministerium für Wissenschaft, Erziehung und Volksbildung, 5. Januar 1940. UAG, Kur. PA Schuler.

2000 UAG, Rek. 5250 / 6 A.

2001 Schuler an Kurator, 1. Februar 1940. UAG, Kur. PA Schuler.

2002 REM (gez. Mentzel) an Schuler und Kurator, 6. Februar 1940. UAG, Kur. PA Schuler.
} 
an den Hamburger Wissenschaftshistoriker Hans Schimank: „Diese Sachen mit den Fakultäten und Ministerien kenne ich zur Genüge. Es ist furchtbar! Überall Intrigen und keine Entschlusskraft.“2003 Als Zwischenlösung bekam Schuler mit Wirkung vom 1. Januar 1941 das freie Extraordinariat für mathematische Statistik und Versicherungsmathematik, das allerdings für seinen ursprünglichen Zweck noch benötigt wurde. Nach der Vertreibung des Direktors des Instituts für mathematische Statistik, Felix Bernstein, 1933 wurde der Lehrstuhl nicht nachbesetzt. Um dies aber zu ermöglichen, sollte Schulers Extraordinariat zu gegebener Zeit in ein Ordinariat umgewandelt und ein neues Extraordinariat für Wirtschaftsmathematik angemeldet werden. ${ }^{2004}$ Schulers Wunsch nach einem Ordinariat führte der Kurator auf Folgendes zurück: „Ich habe weiter aus der Unterredung die Überzeugung gewonnen, daß Professor Schuler den größten Wert darauf legt, eine vollgültige Stellung innerhalb der Fakultät zu haben. Ich glaube, daß Professor Schuler sich in der Vergangenheit zurückgesetzt, vielleicht sogar gekränkt gefühlt hat.“2005 Der letzte Schritt zum Ordinariat wurde Schuler aber erst für die Zeit nach dem Krieg zugesagt. Damit blieb Schuler auf der Zwischenlösung sitzen und verhinderte dadurch die Besetzung der Wirtschaftsmathematik. Es ist interessant zu sehen, dass es an der Universität Hamburg einen ähnlich gelagerten Fall gab. Der dortige Professor der angewandten Physik, Hans Georg Möller, kämpfte seit 1927 für seine Ernennung zum Ordinarius. Das erwünschte planmäßige Ordinariat erhielt er schließlich zum 1. April 1943.2006 Für Schuler bestanden also reelle Chancen auf eine Beförderung, jedoch erwies sich das Ministerium in seinem Fall weniger entgegenkommend. Immerhin bewilligte das Ministerium einen Neubau für Schulers Institut in der Bürgerstraße 42, der im Sommer 1940 bezogen werden konnte. Damit rückte Schuler vom Stadtzentrum in unmittelbare Nachbarschaft zu den anderen Physikinstituten. ${ }^{2007}$

\footnotetext{
2003 Schuler an Schimank, 1. Januar 1942. UH-HSGS, NL Schimank, Korr. Schuler.

2004 Zu den komplizierten Verhältnissen der Lehrstuhlbesetzungen siehe REM an Kurator, 5. April 1940; Dekan an REM, 3. Mai 1940; REM an Schuler, 29. Mai 1940; REM an Schuler, 22. Februar 1941; Aktenvermerk des Kurators, 19. Februar 1940. UAG, Kur. PA Schuler. Max Schuler an REM, 2. Mai 1940. UAG, Rek. PA Schuler. REM (gez. Dames) an Kurator, 15. Februar 1940; Dekan Lenkeit an REM, 30. März 1940. UAG, Math. Nat. 56. REM an Rektor, 16. Oktober 1943. Dekan Correns an REM, 5. November 1943. Nach Auskunft des Ministeriums gab es 1943 vier Ordinariate für Mathematik aber kein einziges Extraordinariat. Das Ordinariat Courant war besetzt durch Kaluza, das Ordinariat Weyl durch Hasse, das Ordinariat Herglotz durch Herglotz, das Ordinariat Landau durch Tornier. Dieser Lehrstuhl wurde mit Inhaber mit 1. Oktober 1936 an die Universität Berlin verlegt. Das Ordinariat Siegel war vakant; es wurde am 28. Oktober 1937 von Bonn nach Göttingen verlegt. Im Tausch dafür wurde das Extraordinariat Bernstein von Göttingen nach Bonn verlegt. Das Extraordinariat für Wirtschaftsmathematik wurde 1937 durch Umwandlung einer Oberassistentenstelle gegründet. Es wurde seit 22. Februar 1941 für Professor Schuler in Anspruch genommen. UAG, Math.-Nat. 56. 2005 Kurator an REM, 9. Mai 1940. UAG, Kur. PA Schuler.

2006 Renneberg [1991]b S. 1106f.

2007 Siehe Schuler an Dekan, 8. Juli 1940. UAG, Math.-nat. Fak. 24 a. Schreiben Schulers vom 8. Juli 1940. UAG, Rek. 5250 / 7A.
} 
Der langsame Aufstieg Schulers in seiner akademischen Laufbahn und das Ausbleiben des Ordinariats lag an den für ihn nur teilweise günstigen Bedingungen am Institut. Zwar wirkte sich der politische Machtwechsel 1933 für ihn positiv aus, indem er die Institutsleitung bekam, die ihm andernfalls nicht erreichbar gewesen wäre, doch hatte er das Pech, dass kein Lehrstuhl für angewandte Mechanik frei war. Ganz anders hätte es ausgesehen, wenn - rein hypothetisch - Prandtl sein Lehrstuhl entzogen worden wäre. So aber hatte Schuler gegen das Ministerium anzukämpfen, das sich gegen ein zusätzliches Ordinariat in der angewandten Physik neben den schon vorhandenen Professuren von Prandtl, Betz ${ }^{2008}$ und Reich wehrte.

\subsubsection{Schuler als Nutznießer der Judenverfolgung}

Schulers Biografie hat durch den Nationalsozialismus eine besondere Formung erfahren, die sich in vielen Lebensbereichen für ihn meist günstig auswirkte. Ein Beispiel hierfür ist der Kauf eines Hauses im Jahr 1939. Als Schuler 1923 nach Göttingen zog, wohnte er zuerst sechs Jahre in einem bürgerlichen Haus mit einer großen Fensterfront Am weißen Stein 17, dann vier Jahre Am Goldgraben 26/II, bis er im Oktober 1933 in das Haus Hainholzweg 68 zog. Alle drei Wohnsitze liegen im Ostviertel Göttingens, einer typischen Wohngegend für Universitätsprofessoren. Im Hainholzweg wohnten zwischen 1937 und 1954 in naher Nachbarschaft unter anderem die Professoren Max Reich (Hausnummer 62), Theodor Kaluza und Nikolai Hartmann (64), Gustav Herglotz (70). Auf Anfrage der Gauleitung Hannover vom März 1939 betreffs „Übernahme eines jüdischen Grundstücks“ gab die Göttinger Kreisleitung bekannt, dass nichts Nachteiliges in politischer Hinsicht über Schuler bekannt sei und gegen die Übernahme keine Bedenken bestünden. ${ }^{2009}$ Schuler profitierte von der Entrechtung der „Nichtarier“. Im April 1939 ging das dem jüdischen Rechtsanwalt Walter Proskauer gehörende Haus Hainholzweg 68 in Schulers Besitz über. Die fortgeschrittene Entrechtung der Juden bedingte den günstigen Kaufpreis von RM 30000. Laut Auskunft von Schulers Schwiegersohn war Schuler der Ansicht, einen angemessenen Preis bezahlt zu haben, außerdem habe Schuler den Betrag sofort bar ausbezahlt, um Walter Proskauer in seiner Bemühung um eine Auswanderung zu unterstützen. ${ }^{2010}$ Proskauers Pläne scheiterten allerding; er wurde 1943 nach Auschwitz oder Theresienstadt deportiert (die Angaben in der

\footnotetext{
2008 Albert Betz war ab 1926 nicht beamteter außerordentlicher und ab 1940 außerplanmäßigen Professor für angewandte Mechanik. Zusätzlich wurde er 1937 vom Luftfahrtministerium zum ordentlichen Professor im Reichsdienst ernannt.

2009 BAB, PK-Akte, Schuler, Max, 1110016005.

2010 Auskunft von Friedrich Schlögl, 25. Juni 2004.
} 
Literatur sind hier widersprüchlich). ${ }^{2011}$ Schuler war unverfroren genug, im Juni 1939 einen „Zuschuß zur teuren Wohnung“ zu beantragen. ${ }^{2012} 1953$ wurde vor dem Wiedergutmachungsamt ein Vergleich zwischen Schuler und dem Sohn Walter Proskauers geschlossen und die Rückgabe des Hauses durchgeführt. ${ }^{2013}$

\subsubsection{Schulers Assistenten}

Die fachliche Ausrichtung der Assistenten entsprach dem Themenspektrum, das Schuler nach Übernahme des Instituts durchsetzte. Der Forschungsschwerpunkt verlagerte sich zur Kreiseltheorie, Schwingungslehre, Zeitmessung mit dem freien Pendel und zur Theorie der Wasserwellen. Die Forschungsstelle für Zeitmessung, die sich bis dahin in den Räumen der Universitätssternwarte befand, wurde dem Institut für angewandte Mechanik angegliedert. Von der Deutschen Forschungsgemeinschaft wurde dem Institut eine neue Uhrenanlage mit freischwingendem Ausgleichspendel für Versuche zur genauen Zeitmessung und Schweremessung zur Verfügung gestellt. Die Helmholtzgesellschaft stiftete hierzu einen thermostatisch geheizten Versuchsaum. ${ }^{2014}$

Die Übereinstimmung der Forschungsthemen der Assistenten mit jenen des Institutsleiters erscheint vollkommen natürlich. Es bedeutete im konkreten Fall aber auch, dass Schuler keinen eigenen Doktoranden an einem Thema aus der Festigkeitslehre arbeiten ließ, obwohl die Ausstattung des Instituts an Apparaten und Maschinen besonders geeignet dafür war. ${ }^{2015}$ Die Aufmerksamkeit auf Schulers Assistenten zu richten, ist aber aus einem anderen Grund interessant. In auffälliger Weise finden sich unter ihnen mehrere Wissenschaftler mit ausgeprägtem Engagement für den Nationalsozialismus. Außerdem waren sie häufig in bestimmter Weise Außenseiter und wählten in der Regel keine akademische Laufbahn. Dies trifft bereits auf die bisher erwähnten Assistenten Gengler und Hahnkamm zu.

Obwohl der planmäßige Assistent Erich Hahnkamm 1935 mit der Abfassung einer Habilitationsschrift begonnen hatte, ${ }^{2016}$ verzichtete er auf eine akademische Laufbahn und

\footnotetext{
2011 Schäfer-Richter \& Klein [1992] S. 209f. nennen eine Deportation nach Auschwitz. Nach Bruns-Wüstefeld [1997] S. 246 wurde Proskauer im März 1943 nach Theresienstadt gebracht, das er nicht überlebte.

2012 Schuler an Kurator, 4. Juni 1939. UAG, Kur. PA Schuler.

2013 Bruns-Wüstefeld [1997] S. 245f.

2014 Chronik der Georg-August-Universität Göttingen, 1931-1938, unveröffentlicht, UAG.

2015 Schuler schreibt selbst in seiner Darlegung „Die Bedeutung des Instituts für angewandte Mechanik an der Universität Göttingen.“ vom 19. Juli 1938 nach Aufzählung der durchgeführten Forschungsarbeiten aus seinen Spezialgebieten über die Festigkeitslehre: „Für dieses Forschungsgebiet ist das Institut mit guten Versuchsmaschinen ausgerüstet, und es besteht ein gutes Zusammenarbeiten mit dem Physikalisch-Chemischen Institut und dem Institut für allgemeine Metallkunde." UAG, Math.-nat. Fak. 24 a.

2016 Siehe Hahnkamm an REM, 6. Dezember 1935. UAG, Rek. 5250 / 7 A.
} 
wechselte 1936 ins Reichsluftfahrtministerium als Referent im Technischen Amt. Dort war er mit der Leitung der für Nacht- und Wolkenflug unentbehrlichen Kreiselgeräte-Entwicklung beauftragt ${ }^{2017}$ und wurde 1939 zum Flieger-Stabsingenieur ernannt. Später wurde er Betriebsleiter einer Filiale der Firma Horn in Leipzig, die unter anderem Kreiselgeräte herstellte. Er verstarb 1944.

Nachdem Hahnkamm die planmäßige Assistentenstelle übernommen hatte, nahm er Einfluss auf weitere Stellenbesetzungen im Institut. Als seinen Nachfolger auf der Hilfsassistentur wünschte Schuler 1934 Helmut Baumann. Dieser wurde aber von Hahnkamm in übler Weise denunziert und schied als Kandidat aus. Hahnkamm schlug seinen Kollegen Spaeth vor, der seit 1928 Mitglied der SA war. Schuler ließ sich darauf ein und stellte einen entsprechenden Antrag, doch das Ministerium beendete die Auseinandersetzung, indem es die Hilfskraft am Institut im Etat strich. ${ }^{2018}$ Als Hahnkamm im April 1936 aus seiner Stelle ausschied, meldete sich umgehend der früher von ihm für diese Stelle favorisierte Heinz Schlechtweg mit einem Habilitationsgesuch. Wie bereits gezeigt, wurde dieses Gesuch von Prandtl entschieden abgelehnt, sodass es Schlechtweg zurückzog und für die Assistentenstelle nicht mehr geeignet erschien. Schuler beantragte, die Stelle mit Heinrich Gockel zu besetzen, der mit einem DFGStipendium an der Schuler-Uhr in der Sternwarte arbeitete und 1936 bei Reich mit der Arbeit „Die Dämpfung von Piezokristallen unter besonderer Berücksichtigung der kristallographischen Eigenschaften“ promoviert wurde. Doch zwei Wochen später zog Schuler seinen Antrag zurück und organisierte für Gockel wieder ein DFG-Stipendium. Erst im Sommer 1940, als eine zweite Assistentenstelle für das Institut bewilligt wurde, wurde Gockel planmäßiger Assistent. ${ }^{2019}$ Als Hahnkamms Nachfolger beantragte Schuler den Prandtl-Schüler Heinrich Mußmann. ${ }^{2020}$ Die Dozentenschaft war mit Mußmann „einverstanden“ und ab Juli 1936 war er mit der Verwaltung der Assistentenstelle beauftragt, blieb jedoch nur weniger als ein Jahr auf dieser Stelle. Interessant ist die Verbindung zwischen Mußmann und Schlechtweg. Zusammen arbeiteten sie bis 1933 am Institut in der

\footnotetext{
2017 Hahnkamm an Kurator, 11. März 1936. UAG, Kur. XVI. V. C. e. 1.

2018 Siehe die entsprechenden Schreiben von Rektor Neumann an Kurator, 14. November 1934; Kurator, 12. Dezember 1934; Erlass des REM, 6. Dezember 1934. UAG, Rek. 5250 / 7 A.

2019 Zu Gockels Arbeiten mit der Schuler-Uhr siehe Gockel [1937]. In dieser Arbeit hat Gockel drei Einflüsse auf die Genauigkeit der Spannungsstabilisatoren, die zum Betrieb der Schuler-Uhr verwendet wurden, untersucht. 1. Raumtemperatur, 2. Netzschwankungen und 3. Alterung der Stabilisatoren. Siehe auch Schuler \& Gockel [1938]; Gockel [1938], [1939].

2020 Heinrich Mußmann studierte ab 1929 in Göttingen Mathematik und Physik. Er war Doktorand von Prager, promovierte 1936 bei Prandtl mit der Arbeit „Die elastische Nachwirkung und ihr Zusammenhang mit der optischen Nachwirkung“. Im Jahr 1933 wurde er vom Stahlhelm in die SA überführt. Alle Angaben aus seinem undatierten Lebenslauf. UAG, Kur. XVI. V. C. e. 1.; MPG-Archiv, III, 61, 1735.
} 
Forschergruppe zur Festigkeitslehre. Vermutlich blieb nach Schlechtwegs Weggang der Kontakt bestehen, denn 1940 publizierten sie gemeinsam in den Annalen der Physik. ${ }^{2021}$

Nächster planmäßiger Assistent wurde 1937 Karl Stellmacher, der schon ab April 1937 die Stelle vertretungsweise übernommen hatte. Stellmachers wissenschaftliche Laufbahn erfuhr durch die veränderten Umstände als Folge der Einschnitte 1933 und 1945 mehrere Wendungen. Seine Tätigkeit in Schulers Institut erwies sich letztlich als Sackgasse. - Nach seinem schlechten Reifezeugnis 1927, in dem er nur in Mathematik ein „sehr gut“, daneben aber viermal „genügend“ bekam, legte er Ende 1933 eine ebenso schlechte Prüfung mit Gesamturteil „genügend“ für das Lehramt für die Fächer Mathematik, Physik und Chemie in Göttingen ab. Richard Courant stellte ihm eine Aufgabe $\mathrm{zu}$ hyperbolischen Differentialgleichungen, ein Thema, das er nach Unterbrechung erst in der Nachkriegszeit wieder aufnehmen konnte. Obwohl er seinen Betreuer Courant wegen Emigration verloren hatte, arbeitete Stellmacher aus eigenem Entschluss an diesem Thema nach der Staatsprüfung weiter. Nach zwei Jahren fand sich in Herglotz ein neuer Betreuer, der ihn mit seiner Arbeit „Ausbreitungsvorgänge der Gravitation (Die Frage nach der Kausalität in der allgemeinen Relativitätstheorie)“ zur Promotion führte (Urteil schriftlich „,sehr gut“, mündlich „gut“). ${ }^{2022}$ Mit dem folgenden Wechsel in Schulers Institut änderte er seine Arbeitsrichtung und beschäftigte sich hauptsächlich mit Kreiselproblemen. Von Sommer 1939 bis Sommer 1944 war er Soldat. Nach der Emeritierung Schulers im Sommer 1946 übernahm er vertretungsweise die Institutsleitung. „Vor dem Krieg begonnene umfangreiche Untersuchungen über den zwei-Kreisel-Horizont waren inzwischen überholt, und es gab niemand mehr, der sich dafür interessierte“, schrieb er über seine damalige Situation in einem Lebenslauf. Er wandte sich dann wieder der reinen Mathematik zu. Im April 1948 wurde er als wissenschaftlicher Assistent in das Mathematische Institut übernommen, habilitierte sich im selben Jahr im Fach Mathematik mit einer Arbeit über partielle hyperbolische Differentialgleichungen und wurde Privatdozent. Erst im Juni 1955 wurde er - immer noch in Göttingen - im Alter von 46 Jahren zum außerplanmäßigen Professor ernannt. Noch im selben Jahr ging er in die USA als research associate im Institute for Fluid Dynamics and Applied Mathematics of the University of Maryland in College Park. Innerhalb eines Jahres wurde er dort full professor. ${ }^{2023}$

\footnotetext{
${ }^{2021}$ Mußmann \& Schlechtweg [1940].

2022 Die Dissertation wurde publiziert in Stellmacher [1937].

2023 Zitat aus seinem Lebenslauf von Juli 1948. GPAMNFG, Lehrkörper (ausgeschieden), Stellmacher; HStAH, Nds. 401, Acc. 112 / 83, Nr. 899.
} 
Der einzige Assistent Schulers, der später ordentlicher Professor für angewandte Mechanik wurde, ist Kurt Magnus. Er studierte von 1932 bis 1937 Mathematik und Physik in Göttingen, promovierte bei Schuler mit einer Arbeit über „Schwingungen kraftgekoppelter Kreisel“2024 und wurde Ende 1937 planmäßiger Assistent am Institut. Im November 1933 trat er 21-jährig in die SA, Sturm 1/82 Göttingen, ein. Ein Jahr später wurde er zur Hitlerjugend überwiesen, in der er nacheinander einige Ämter übernahm: Sportwart, Kameradschaftsführer, Gefolgschaftsführer, Stammführer, stellvertretender Führer des Standortes Göttingen, Leiter der Hauptstelle III (Kulturarbeit, weltanschauliche Schulung usw.), Schulbeauftragter im Bannstab 82. Letzter Dienstgrad: Hauptgefolgschaftsführer. ${ }^{2025}$ Die fachliche Ausbildung in seinem Spezialgebiet der Mechanik erhielt er nicht nur bei Schuler, sondern auch bei dem Mathematiker Herglotz. Magnus bearbeitete das Manuskript zur Herglotz'schen Vorlesung „Analytische Mechanik“. ${ }^{2026}$ Ein auch nur oberflächlicher Vergleich mit dem Schuler'schen Vorlesungs-Manuskript zeigt, dass die Herglotz'sche Vorlesung weit formeller angelegt war und bedeutend tiefer in die mathematische Behandlung der Mechanik eindrang. Magnus beherrschte dadurch die mathematischen Problemstellungen besser als die anderen Schüler Schulers. Im Auftrag des RLM betrieb Magnus wissenschaftliche Forschungen zu Luftfahrtgeräten. Im März 1942 wurde er als technischer Physiker zur Firma Dr.-Ing. Hans Heymann, Werkstätten für Schwingungsforschung, Darmstadt, zur Durchführung spezieller kriegswichtiger Forschungsaufgaben dienstverpflichtet. Nach den langen Arbeitstagen mit vorwiegend technisch-praktischer Tätigkeit fand er noch Zeit, eine Habilitationsschrift anzufertigen. Im April 1942 reichte er die Arbeit „Über die Anwendungen der allgemeinen Bewegungsgleichungen starrer Körper in bewegten Bezugssystemen“2027 ein, die teilweise auf dem Stoff von Herglotz' Vorlesung aufbaute. Zusätzlich benutzte Magnus das von Mises entwickelte Hilfsmittel der Motorrechnung. ${ }^{2028}$ Die Arbeit hatte Bedeutung für alle Maschinen und Instrumente, die in Flugzeugen eingebaut waren. Im Habilitationsverfahren zeigte sich allerdings, dass die Physiker der Arbeit wegen der knappen Darstellung nicht folgen konnten. Dies galt insbesondere für Prandtl und Becker. Bei Kaluza hinterließ die Arbeit den Eindruck von großer Geschicklichkeit, Sicherheit und Reife. Kaluza konnte der

\footnotetext{
2024 Prüfungsfächer der mündlichen Prüfung waren: angewandte Mechanik, angewandte Mathematik und angewandte Elektrizitätslehre. GPAMNFG, Lehrkörper (ausgeschieden), Magnus.

2025 Ab 9. März 1942 war er wegen Dienstverpflichtung beurlaubt. Außerdem war er noch Mitglied der DAF und der NSV. Alle Angaben aus seinem Lebenslauf vom April 1942, GPAMNFG, Lehrkörper (ausgeschieden), Magnus.

${ }^{2026}$ Dieses Exemplar befindet sich heute in der Göttinger Universitätsbibliothek.

2027 Diese Arbeit ist veröffentlicht in Magnus [1942].

2028 Siehe Magnus an Herglotz, 18. April 1942, SUB, Handschriftenabteilung, Cod. Ms. G. Herglotz F 87, Magnus.
} 
dichten Darstellung folgen und sprach sich für die Zulassung zur Habilitation aus. Dass auch Herglotz die Arbeit lobte, scheint in diesem Zusammenhang naheliegend. Allgemein fand die Arbeit bei den Mathematikern mehr Anklang als bei den Physikern. Mit Magnus Probevortrag über „die Entwicklung der Kreisel-Unterrichtsmodelle (mit Versuchen)“2029 kam des Verfahren zu einem positiven Ende. Im Februar 1943 wurde er zum Dozenten für angewandte Mechanik ernannt. ${ }^{2030}$

Im April 1943 wurde er zum Torpedowaffenplatz Gotenhafen abkommandiert. In Gotenhafen-Hexengrund war er der Abteilung E III zugeteilt und für die Kreiselgeräte der Torpedos zuständig. Außerdem hatte er eine Gastdozentur an der TH Danzig. Seine ersten Eindrücke in Gotenhafen hielt er in einem Brief an Herglotz fest:

„Ich habe hier den Sprung in die reinste technische Praxis gemacht und hoffe, dabei beweisen zu können, daß Theorie nicht immer grau zu sein braucht, sondern daß sie ein recht gutes und kaum zu entbehrendes Handwerkszeug ist. [...] Nachdem mich erst einzelne meiner Kollegen in mathematischen Fragen um Rat gefragt hatten, gebe ich jetzt schon in einem kleinen Kreise so eine Art mathematisch-physikalisches Seminar, bei dem wir einfache Fragen behandeln, die irgendwie im Laufe der täglichen Arbeit auftauchen. Diese Tätigkeit macht mir sehr viel Freude und bietet eine kleine Entschädigung für die Tatsache, daß mir sonst kaum Ruhe und Zeit bleibt, mich mit rein wissenschaftlichen Fragen $\mathrm{zu}$ beschäftigen. Hoffentlich gestatten es mir die äußeren Verhältnisse bald wieder, meine Tätigkeit an der Universität Göttingen aufzunehmen. Denn meine augenblickliche Beschäftigung als technischer Physiker erst in einem Industriebetrieb und nunmehr an einer Luftwaffendienststelle betrachte ich lediglich als »Lehr- und Wanderjahre«."2031

Magnus‘ Hochschullaufbahn wurde durch den Krieg und anschließend auf Grund der Entnazifizierung erheblich verzögert. An seiner Biografie erkennt man aber, wie wichtig für die Nachwuchswissenschaftler der angewandten Mechanik eine enge Beziehung zu den Mathematikern war. Diese hatte sich schon bei Prager und Hohenemser vorteilhaft ausgewirkt und begünstigte auch den positiven Ausgang von Magnus‘ Habilitation.

Als letzter von Schulers Assistenten ist noch Johann Hoch zu erwähnen. In ähnlicher Weise wie Hahnkamm ist auch Hoch als politischer Flüchtling zu bezeichnen, der Unterschlupf in Schulers Institut fand. Der Österreicher Hoch war seit 1932 Mitglied der NSDAP. Er wurde

${ }^{2029}$ Magnus entwickelte in Göttingen ein eigenes Kreiselmodell für den Unterricht, das er in seinem erstmals 1945 erschienenen Buch Magnus [1945/65] beschreibt. Für die dritte Auflage 1965 hat Magnus allerdings „gewisse Änderungen des allgemeinen Stils“ unternommen.

${ }^{2030}$ Am 29. Juli 1942 wurde ihm der Grad eines Dr. rer. nat. habil. verliehen. Die öffentliche Lehrprobe fand am 17. Dezember 1942 statt und die Dozentur wurde ihm am 23. Februar 1943 verliehen. Zu Magnus Biografie siehe GPAMNFG, Lehrkörper (ausgeschieden), Magnus; BAB, DOK / K, 291/4; Magnus [1993] bes. S. 245250 . 
von seinem Physikstudium in Wien wegen politischer Betätigung für „Grodeutschland“ relegiert und saß deshalb sogar Gefängnisstrafen ab. 1936 entging er einer erneuten Verhaftung nach eigenen Angaben durch „Flucht nach Deutschland“, wo er noch im selben Jahr eingebürgert wurde. In Göttingen setzte er sein Studium fort und schloss es 1941 mit einer Doktorarbeit bei Schuler über das sphärische Pendel bei linearer Reibung ab. Im WS 1939 wurde er Hilfsassistent bei Schuler und blieb dies bis Anfang 1942. Hoch konnte wegen wehrwichtigen Forschungsarbeiten offenbar eine uk-Stellung erhalten, wurde zum Februar 1942 zur Heeres-Versuchsanstalt Peenemünde zur Mitarbeit an der Raketenentwicklung abkommandiert, konnte diese Forschungen aber zumindest teilweise, wenn nicht hauptsächlich, in Göttingen durchführen. ${ }^{2032}$

Der Krieg führte wie auch in den anderen Physikinstituten dazu, dass kaum Kandidaten für die Nachbesetzung von Assistentenstellen vorhanden waren, da die meisten Nachwuchswissenschaftler entweder Kriegsdienst leisteten oder für geheime Forschungsarbeiten reklamiert waren. Zum Zuge kamen dann vermehrt Ausländer, die keine geheimen Forschungsarbeiten durchführen durften. Beispielsweise wurde Hochs Hilfsassistentenstelle mit einem Luxemburger nachbesetzt. ${ }^{2033}$ Die beiden planmäßigen Assistenten Gockel und Stellmacher standen Schuler während des Krieges nicht zur Verfügung. Gockel wurde zum Militär eingezogen, und Stellmacher von der Marine zuerst eingezogen, dann aber uk-gestellt, um an Schulers Institut Berechnungen im Auftrag der Kriegsmarine durchzuführen. Gerade gegen Ende des Krieges war Schuler auf die Unterstützung durch seine Hilfsassistenten angewiesen, da die Studentenzahlen wieder spürbar anstiegen, und er 45 Praktikanden und 70 Teilnehmer in den Übungen hatte. ${ }^{2034}$

\subsubsection{Forschungen für Kriegszwecke}

Die Rüstungsforschung der Göttinger Physikinstitute wurde bereits in Abschnitt 3.1 dargestellt. In Schulers Institut hatten militärische Forschungen im Krieg eine zentrale Stellung. Aus verschiedenen Eingaben Schulers geht hervor, dass sämtliche seiner deutschen

\footnotetext{
2031 Magnus an Herglotz, 7. April 1943, SUB, Handschriftenabteilung, Cod. Ms. G. Herglotz F 87, Magnus. 2032 Lebenslauf Johann Hoch, 20. August 1939. Siehe auch Schuler an Dekan, 27. Juli 1939. UAG, Kur. XVI. V. C. e. 1. Die mündliche Doktorprüfung war am 23. Juli 1941, Korreferent war Kaluza, mündliche Prüfer Schuler, Prandtl, Kaluza, Pohl und Ruprecht. UAG, Math. Nat. 56, Meldungen zur Doktorprüfung XIII. Anfang 1943 setzte sich Prandtl beim RLM unter anderem für die uk-Stellung von Schulers Mitarbeiter Hans Hoch ein. Prandtl an Flieger-Oberstabsing. Wolff in der Forschungsführung des RdL und ObdL, 20. Januar 1943. MPGArchiv, III, 61, 2160.

2033 Schuler an Kurator, 20. Februar 1942. Lebenslauf Roger Johann Bleche. UAG, Kur. XVI. V. C. e. 1. 2034 Informationen über Gockel und Stellmacher, sowie über die Notwendigkeit der Hilfsassistenten aus: Schuler an Kurator, 8. November 1944 und 21. November 1944. UAG, Kur. XVI. V. C. e. 1.
} 
Mitarbeiter Arbeiten im Auftrag der Wehrmacht, des RLM und der Marine durchführten. Die Inhalte der Forschungen lassen sich aus den benutzten Quellen einigermaßen rekonstruieren. Im Wesentlichen handelte es sich um die Entwicklung von Geräten zur (automatischen) Steuerung von Flug- und Wassergeschossen, insbesondere Raketen und Torpedos.

Kurt Magnus war bis 1942 am Institut im Auftrag des RLM in drei Forschungsbereichen tätig: 1) Wissenschaftliche Untersuchungen an Kreiselgeräten, 2) Forschungsaufgaben auf dem Kreiselgebiet und 3) Automatische Steuerung von Torpedos. ${ }^{2035}$ Seine Vorträge im Kolloquium der angewandten Mechanik spiegeln die Auftragsforschung wider. ${ }^{2036}$ Auch Johann Hoch war schon vor seiner Abkommandierung 1942 mit Rüstungsforschung beschäftigt. Schuler bestätigte dem Kurator, dass Hoch 1939 für seine wehrwichtigen Forschungstätigkeiten eine Vergütung „von anderer Stelle“ bekam, also nicht von der Universität. ${ }^{2037}$ Das Thema seiner Arbeiten dürfte im Zusammenhang mit der Entwicklung von Kreiselgeräten zur Flugzeugsteuerung gestanden haben. ${ }^{2038}$ Eine Auflistung der Kriegsarbeiten der Göttinger naturwissenschaftlichen Institute von Prandtl aus dem Jahr 1943 führt Hoch und Lyra als wissenschaftliche Bearbeiter des Instituts für angewandte Mechanik an. 2039

Gerhard Lyra war Mathematiker und promovierte 1938 bei Kaluza mit einer Arbeit „Über einen Satz zur Theorie der C-summierbaren Reihen“. In Schulers Institut arbeitete er ab April 1940 im Auftrag des Oberkommandos des Heeres bzw. der Heeresversuchsanstalt Peenemünde über automatisch gesteuerte Luftkörper und an Stabilitätsuntersuchungen. ${ }^{2040} \mathrm{Er}$

2035 BAB, R 26 / III / 9, Forscher Kartei, Magnus.

${ }^{2036}$ Er trug vor über Dämpfungsarten für die Schwingungen des Fliegerhorizontes (1. Februar 1939), über neuere Arbeiten auf dem Gebiet der Selbststeuerung von Flugzeugen (28. Juni und 12. Juli 1939), über Untersuchungen zur Verminderung von Rüttelschwingungen an Kreiselgeräten (15. Januar 1940), über Schwingungsgleichungen mit periodisch veränderlichen Koeffizienten (Über K. Klotter: Stabilisierung und Labilisierung durch Schwingungen) (26. November 1941), und über die allgemeinen Bewegungsgleichungen starrer Körper relativ zu einem bewegten Bezugssystem (24. Februar 1943). MPG-Archiv, III, 61, 2164.

2037 Schulers an Kurator, 17. November 1939. UAG, Kur. XVI. V. C. e. 1.

2038 Im Kolloquium hielt er Vorträge über neuere Arbeiten zur Theorie der automatischen Flugzeugsteuerung (7. Februar 1940), über sphärische Pendelschwingungen viskoser Reibung (16. Oktober 1940), über die Schwingungsdauer eines Stabpendels im Schwerefeld der Erde (16. Dezember 1942), über die Stabilität des schweren unsymmetrischen Kreisels und Betrachtungen zur Stabilität eines Flugkörpers (12. Januar 1944), und über den stabilisierenden Einfluss der Beschleunigung von Flugkörpern (29. November 1944). MPG-Archiv, III, $61,2164$.

2039 Siehe: „Betr.: Kriegsarbeit von Instituten der Mathematisch-Naturwissenschaftlichen Fakultät der Universität Göttinger", Prandtl an Flieger-Oberstabsing. Wolff in der Forschungsführung des R.d.L. und Ob.d.L., 20. Januar 1943. MPG-Archiv, III, 61, 2160.

2040 Siehe Schulers Gutachten zu Lyras Habilitation, 10. Juli 1941, GPAMNFG, Lehrkörper (ausgeschieden), Lyra. BAB, R 26 / III / 9, Forscher Kartei, Lyra. Lyra trug im Kolloquium für angewandte Mechanik vor über Berechnung der Längsbewegung eines Flugzeugs nach Richter und W. Müller (19. Juni 1940), über

A. Weigand: Die Berechnung freier nicht-linearer Schwingungen mit Hilfe der elliptischen Funktion (28. Januar 1942), über die Theorie der Moazagotl-Strömung (17. Juni 1942), über F. N. Scheubel: Der Einfluss des 
war ab November 1939 Assistent am Mathematischen Institut. 1942 habilitierte er sich mit der Arbeit „Zur Theorie der C.- und H.-Summierbarkeit negativer Ordnung“ und wurde zum Dozenten für das Fach Mathematik ernannt. Pohl war bis zur Habilitation von Lyras Prüfungsleistungen enttäuscht. Lyra blieb bis 1955, als er zum Diätendozenten ernannt wurde, Assistent am Mathematischen Institut. ${ }^{2041}$

Schuler ließ auch in Doktorarbeiten eindeutig militärische Fragestellungen bearbeiten. Zum Beispiel promovierte Heinz Rathmann 1941 mit einer Arbeit über Zielfehler und Treffwahrscheinlichkeit beim Schießen längs der Flugrichtung (Schießen auf bewegte Ziele). ${ }^{2042}$ Schuler selbst arbeitete zum einen an denselben drei Aufträgen wie Magnus, die oben aufgelistet sind. ${ }^{2043}$ Für die Arbeiten zur automatischen Steuerung von Torpedos sind ihm von der Forschungsführung des Reichsministers der Luftwaffe insgesamt 35000 RM zur Verfügung gestellt worden. ${ }^{2044} \mathrm{Im}$ Auftrag des Heereswaffenamtes hatte Schuler Untersuchungen von Kreiselgeräten durchzuführen. Außerdem war er auch Leiter des Ausschusses Kreiselfragen des VDI. ${ }^{2045}$ Nach Auskunft des Reichsforschungsrats vom Dezember 1944 hatte Schuler zwei Forschungsaufträge auf dem Gebiet der Raketenforschung: 1) geh. Kods. RLM.-SS-6133-0803/März/April 44 und 2) „Feuerlilie“ geh. Kods. RLM.-SS-6133-0803/44. ${ }^{2046}$ Im Jahre 1944 brauchte die Marine dringend einen kleinen Kreiselkompass für ein Ein- oder Zweimann-Unterseeboot. Dafür bildete sie einen Ausschuss, der alle Stellen einbezog, die zu einer schnellen Verwirklichung des Projekts beitragen konnten. In dem Ausschuss waren Schuler sowie Vertreter der Deutschen Seewarte in Hamburg, der Firma Anschütz und der Firma Kreiselgeräte GmbH vertreten. ${ }^{2047}$

Dichtegradienten der Atmosphäre auf die Längsbewegung des Flugzeugs (16. Juni 1943) und über M. Eichler: über die Dämpfung von Schwingungen bei zeitlich veränderlichen Kräften (29. November 1944). MPG-Archiv, III, 61, 2164.

2041 Zur Biografie Gerhard Lyras siehe Lebenslauf vom 17. Juni 1941; Habilitationsgutachten; Göttinger Tageblatt vom 26.10.1956, Nachruf der Universität, Dezember 1975. UAG, Kur. PA Lyra; UAG, Rek. PA Lyra; GPAMNFG, Lehrkörper (ausgeschieden), Lyra.

2042 Referenten waren Schuler und Kaluza. UAG, Karteikarten, Math.-Nat. Promotionen. Die mündliche Prüfung fand am 3. Dezember 1941 statt mit den Prüfern Schuler, Zahn, Kaluza, i. V. Mollwo. UAG, Math. Nat. 56, Meldungen zur Doktorprüfung XIII.

2043 Siehe Fußnote 2035.

2044 Dieser Auftrag wurde am 22. Oktober 1944 gestellt, Auftragsnummer SS 4942-6133-1803 / 44, Bedarf-Gr. 2851, Auftragssteuerungsnummer 2851 / 42 und ist unterzeichnet von i. A. Gerritzen. Die Arbeiten hätten diesem Schreiben zufolge bis zum 30. September 1945 durchgeführt werden müssen. UAG, Rek. PA Schuler. 2045 Der 1939 gegründete Arbeitsausschuss Kreiselfragen war eine Abteilung des VDI Fachausschusses für Schwingungs- und Schalltechnik. BAB, R 26 / III / 9, Forscher Kartei, Schuler.

2046 Schreiben RFR (gez. Dr. Engeroff) an OKM, 7. Dezember 1944. BAB, R 26 III.

2047 Angaben aus Gievers [1971] S. 285 und 290. Gievers erwähnt auch ein ausführliches Gutachten von Schuler über den Übergrundkompass der Firma Kreiselgeräte GmbH aus dem Jahr 1946. 


\subsubsection{Gescheiterte Institutsumbenennung - Schulers Kollegen wehren ab}

Mitte 1944 startete Schuler einen Versuch, den Einflussbereich seines Instituts zu erweitern. Beim REM beantragte er die Umbenennung des Instituts für angewandte Mechanik in „Institut für Mechanik“ und begründete dies mit fünf Punkten. Zuerst konstruierte er eine falsche Geschichte zur Namensgebung bei Gründung des Instituts und behauptete, im Institut für angewandte Mathematik und Mechanik beziehe sich ,angewandte“ nur auf die Mathematik. ${ }^{2048}$ Dann gab er an, dass er ,vor allen Dingen die mathematische Seite der Mechanik“" behandle, und sich damit sein Institut von den Instituten für Mechanik der technischen Hochschulen unterscheide, aber nicht dadurch, dass es stärker auf Anwendungen ausgelegt sei. Mit der Umbenennung wolle er den Studenten klar machen, dass nicht nur ein Sondergebiet, sondern ,die allgemeine Mechanik im Anschluss an die angewandte Mathematik des mathematischen Institutes besonders gepflegt wird.“2049 Schulers Antrag hatte eine heftige Ablehnung des Dekans Kopfermann zur Folge, der Schulers Forschungen eindeutig der angewandten Mechanik zuordnete und die anderen Physikordinarien, die ebenfalls die Mechanik in ihren Vorlesungen behandelten, nicht beschnitten wissen wollte. ${ }^{2050}$ Der Kurator befand die Angelegenheit nicht für kriegswichtig, wollte sie deshalb nicht dem Minister zur Entscheidung vorlegen und bat den Rektor, die Sache bis nach Kriegsende zurückzustellen. ${ }^{2051}$

\subsection{Entnazifizierung des Instituts - missglückte Versuche konstruierter Kontinuität}

Der allgemeine Ablauf der personellen Entnazifizierung und der Forschungskontrolle der Physikinstitute wurde schon in den Abschnitten 1.3.2 und 3.2 dargestellt. Im Zentrum dieses Abschnitts steht eine heftige Auseinandersetzung um die Wiedergutmachungsansprüche von Kurt Hohenemser, die die Geschichte des Instituts in den ersten zwei Nachkriegsjahren geprägt hat. Der anfangs zwischen Schuler und Hohenemser entfachte Streit erlangte schnell Bedeutung auf den höheren Entscheidungsebenen, und brachte die Universität Göttingen zu einer grundsätzlichen Auseinandersetzung mit Fragen der personellen Entnazifizierung und Wiedergutmachung, zwei Komplexen, die die Universitätsleitung stets miteinander gekoppelt

\footnotetext{
2048 Dass dem nicht so ist, habe ich in Abschnitt 5.1.2 gezeigt.

2049 Schuler an Ministerium, 18. Juli 1944. UAG, Math.-nat. Fak. 24 a.

2050 Kopfermann an Ministerium, 10. Oktober 1944, zitiert in Hentschel \& Rammer [2003] S. 48f. UAG, Math.nat. Fak. 24 a.

${ }^{2051}$ Kurator an Rektor, 19. Oktober 1944. UAG, Math.-nat. Fak. 24 a. 
dachte. Hohenemser wurde zu einem Präzedenzfall für die Universität. Er markiert die Grenzziehung zwischen zugestandener und strikt verweigerter Wiedergutmachung. Dieser Fall ist also von allgemeiner Bedeutung für das Verständnis des Übergangs der Wissenschaft vom Nationalsozialismus in die Nachkriegszeit. Leider erschließt sich die Tiefe des Falls nur auf Grund guter Kenntnis der Vorgeschichte. So kam Anikó Szabó in ihrem materialreichen und sehr wertvollen Buch über die Wiedergutmachung an niedersächsischen Hochschulen auf vorwiegender Grundlage der Nachkriegsakten zu falschen Interpretationen. ${ }^{2052}$ Die 1947 erfolgte völlige Umstrukturierung der angewandten Physik in Göttingen, die damals rein fachlich begründet wurde, ist nicht unabhängig von der Auseinandersetzung mit dem Fall Hohenemser zu deuten. Vielmehr lässt die folgende Darstellung die Interpretation zu, dass die Schließung der angewandten Mechanik in Göttingen das letzte Glied in der Kette der Abwehrmaßnahmen gegen Hohenemser bildete.

\subsubsection{Der Konflikt zwischen Schuler und Hohenemser}

\subsubsection{Schuler bemüht sich um seine Assistenten}

Die deutsche Niederlage im Zweiten Weltkrieg hatte für Schuler negative Folgen. Seine Hoffnung auf die vom REM versprochene ordentliche Professur wurde zerstört, sein Institut geplündert, es gab keine Forschungsgelder für seine Zeitmessanlage und die angewandte Forschung seines Gebiets wurde verboten. Sein Gesundheitszustand war den Umständen entsprechend schlecht. Im April und Mai 1945 litt er unter einer schweren Lungenentzündung, hinzu kamen Herzbeschwerden. Von 1939 bis 1947 verlor er 20 kg an Körpermasse. ${ }^{2053}$ In dieser Situation hoffte Schuler, seine Schüler, die in verschiedenen militärischen Projekten teilweise außerhalb Göttingens eingesetzt gewesen waren, wiederzugewinnen und die wissenschaftliche Arbeit mit ihnen fortsetzen zu können.

Zunächst galt es, für eine Rückkehr seiner Schüler die passenden Verhältnisse zu schaffen. Das vorhandene Personal sollte weiter Beschäftigung finden, für Rückkehrer sollten Stellen reserviert werden. Von den beiden planmäßigen Assistentenstellen war nur eine mit Karl

\footnotetext{
2052 Szabó [2000] S. 214-232. Um nur ein Beispiel einer Fehlinterpretation anzuführen: Szabó folgt der offiziellen Nachkriegsdarstellung, nach der Prandtl sein Institut 1934 freiwillig abgegeben habe und Schuler deshalb zu seinem Nachfolger vorgeschlagen habe, weil er am KWI und an der AVA so beansprucht war. Szabó geht sogar einen Schritt weiter und behauptet, Schuler wäre wahrscheinlich ,ohnehin bald Institutsdirektor geworden“" (S. 218).

2053 Siehe amtsärztliches Zeugnis des staatlichen Gesundheitsamts für Stadt und Kreis Göttingen, 26. Mai 1939. Fragebogen der Militärregierung von 1947. UAG, Kur. PA Schuler. Attest von Dr. Arnold Bunnemann, 16. Mai 1946. HStAH, Nds. 401, Acc. 112/83, Nr. 986.
} 
Stellmacher besetzt. ${ }^{2054} \mathrm{Da}$ von seinen Schülern einige politisch stark belastet waren, musste Schuler in Anbetracht der Entnazifizierungsbestimmungen taktisch geschickt vorgehen, um seine personalpolitischen Ziele zu erreichen. Genau in dieser heiklen Phase kam Hohenemser nach Göttingen.

\title{
5.4.1.2 Hohenemser durchkreuzt Schulers Pläne
}

Hohenemser kam am 19. Juni 1945 mit dem Vorhaben nach Göttingen, sich um die Wiederaufnahme seiner 1933 gezwungenermaßen unterbrochenen Lehrtätigkeit an der Universität zu kümmern. Zu Mittag traf er sich mit Prandtl, danach besuchte er das Institut, erhielt jedoch keinen Einlass. Erst drei Tage später traf er Schuler im Institut an. Bei diesem Treffen konnte Hohenemser sein Anliegen, nämlich die Bedingungen für seine Wiedereinstellung zu erkunden, nicht umsetzten.

\begin{abstract}
„Dort empfing mich Schuler in geradezu unverschämter Weise, begrüßte mich nicht einmal, sondern fuhr mich nur an, was ich bei ihm wolle. Leider war ich auf einen derartigen Empfang nicht vorbereitet und fand daher nicht die Geistesgegenwart, ihm gehörig die Meinung zu sagen. Er schien mir allerdings geistig ziemlich gestört zu sein und faselte unsinniges Zeug, so zum Beispiel, daß er täglich damit rechne, von den Engländern erschossen zu werden. Nach kurzer Zeit entließ er mich unter dem Vorwand, keine Zeit zu haben."2055
\end{abstract}

Schuler empfand Hohenemsers Besuch als persönlichen Angriff und Bedrohung. In sein Tagebuch notierte er: „22.6. Besuch von Hohenemser, der mich aus dem Institut werfen will und mein Nachfolger werden will!“2056 Schuler sah sich im Sommer 1945 gegenüber Hohenemser offenbar in einer Verteidigungsposition. Allein das Auftauchen des „Nichtariers“ Hohenemser in seinem Institut erschien wie ein Angriff gegen die herrschenden Verhältnisse am Institut. Eine einvernehmliche Lösung war daraufhin unmöglich. Ein

\footnotetext{
2054 Siehe Schuler an Kurator, 31. Mai 1945. UAG, Kur. XVI. V. C. e. 1.

2055 Handschriftlicher Entwurf eines Briefes von Hohenemser an Prager, 3. Juni 1946. KHP. Zum Vergleich seien noch weitere Beschreibung dieses Zusammentreffens von Hohenemser angeführt: „Herr Prof. Schuler [...] hat mich bei meinem Besuch in derartig unverschämter Weise empfangen und nach kurzer Zeit wieder verabschiedet", schreibt er an Courant, 21. Mai 1946. Zurückhaltender formuliert er gegenüber dem Rektor am 29. Mai 1946: ,[...] das unfreundliche und abweisende Verhalten von Herrn Prof. Schuler bei meinem Besuch [...]“ (GPAMNFG, Lehrkörper (ausgeschieden), Hohenemser.). Gegenüber Prandtl formuliert er Schulers Verhalten recht deutlich: „die unerwartet unfreundliche Abfertigung“ (16. April 1946). Er schreibt an prandtl auch, er wolle sich bei Schuler nicht entschuldigen, „da Herr Prof. Schuler mich vorigen Sommer, ohne dass ich ihm jemals etwas getan hätte, sehr vor den Kopf gestossen hat, indem er mich wie einen sehr lästigen Besucher behandelte. [...] Wenn ich sehe, dass Herr Prof. Schuler künftig mir gegenüber wenigstens die primitivsten Höflichkeitsformen wahrt, wird es mir leichter fallen, eine versöhnende Bemerkung des Bedauerns über meinen Angriff zu machen.“ Hohenemser an Prandtl, 20. Mai 1946. MPG-Archiv, III, 61, 692.

2056 Freundliche Auskunft von Schulers Schwiegersohn Friedrich Schlögl, 22. Juni 2001. Hervorhebung original.
} 
weiterer Grund für die ablehnende Haltung Schulers kann in einem alten Streit zwischen den beiden aus dem Jahr 1933 gelegen haben. ${ }^{2057}$

\subsubsection{Rückblick: Hohenemsers Leben und Überleben im Nationalsozialismus}

Nach seiner Beschäftigung bei Fieseler nahm Hohenemser 1935 eine Anstellung bei Anton Flettner in Berlin an. Dort arbeitete er bis Kriegsende zuerst in leitenden Stellungen an der Entwicklung der Flettner-Hubschrauber. Auf Anordnung der Partei verlor er seine Stellen und durfte als „Nichtarier“ nur noch als persönlicher Berater Flettners fungieren und in den letzten Jahren nicht einmal über eine einzige Hilfskraft mehr verfügen, obwohl er, sowohl was die Theorie wie auch die Konstruktionsideen betraf, maßgebend an der erfolgreichen Entwicklung der Geräte beteiligt war. ${ }^{2058}$ Der Flettner Hubschrauber F1-282 zählte nach Kriegsende zu den besten der Welt und wurde von den Alliierten getestet und anerkennend beschrieben. ${ }^{2059}$

Hohenemsers väterliche Familie war von der Judenverfolgung noch in viel stärkerem Ausmaß betroffen. Hohenemsers Eltern lebten in einer sogenannten Mischehe; der Vater Richard Hohenemser war Jude und von Geburt an blind. Die SS hatte mit der Beschlagnahme ihres Berliner Hauses gedroht, doch so weit kam es nicht: Am 8. April 1942 nahmen sich Richard und Alice Hohenemser das Leben. Für Kurt Hohenemser kam dieser Schritt überraschend, und er war unendlich schmerzhaft. Kurt Hohenemser hing sehr an seinem Vater, dessen phänomenales Gedächtnis er bewunderte, dessen Geigenspiel er schätzte und der ihm mit seinem philosophischen Wissen und seiner denkerischen Schärfe ein Vorbild war. Sein nüchterner Bericht über den Selbstmord an seine Tante Muriel in England beschreibt in analytischer Schärfe die durch die Judenverfolgung entstandene Situation in der Gesellschaft:

„Mother and Father passed their last years in complete solitude and Father did not even dare to visit us for fear of getting me into trouble. Nobody really has been

\footnotetext{
2057 Es gibt einen Hinweis auf diesen Streit in Prandtl an Kurator, 18. September 1933: „In der Streitsache Hohenemser - Schuler besitze ich einen Bericht von Dr. Hohenemser. Demnach hat er lediglich die Absicht gehabt, meiner Interessen, beziehungsweise diejenigen des Instituts, zu wahren gegenüber etwas, was er als einen unberechtigten Übergriff ansah."UAG, Kur. XVI. V. C. h. 11 I.

2058 Zeugnis über Hohenemsers Tätigkeit von Anton Flettner, 18. Januar 1946. HStAH, Nds. 401, Acc. 92 / 85, Nr. 135. Hohenemsers an Courant, 21. Mai 1946. Library of Congress, Veblen papers, Box 4. Hohenemser an Odqvist, 4. Juni 1946. KHP. Zu Hohenemsers Forschungstätigkeit siehe die zahlreichen Berichte, die er 1944 und 1945 publizierte.

2059 Siehe den Bericht von William E. Cobey: Evaluation and Test of the Flettner-282 German Helicopter (Project No. DA-30), Technical Report No. F-TR-1193-ND. Dieser Bericht wurde von der Prewitt Aircraft Company zusammengestellt und zieht den Schluss: “[...] ,,performance of this helicopter is relatively good, maintenance is nil, and the flying characteristics are good.“ Der Autor empfahl, ,that all eligible and interested helicopter organisations be permitted to have their pilots fly this helicopter." Zur Entwicklung der deutschen Hubschrauber bis 1945, besonders in Bezug auf Bautypen und Produktionsbedingungen, siehe Coates [2002].
} 
rude to them, but they were outcasts, they did not belong to the community, they were without right [sic], without protection, every day they could be brought away to never come back again: nobody would have been astonished, everybody wondered that they still lived in their flat. The feeling [sic] of the neighbours towards them were similar to those in the case of a hopeless sick person. One goes shyly out of the way of this person and is relieved when at last the death of that person has taken away the bad conscience which life shows when confronted of the process of dying. Nobody was surprised when we found that the parents had poisoned themselves with gas. It was the thing that was expected by them. There was no revolting against a government which denied the right of living to a certain group of citizens who were not hated, were even respected. That these people had to leave the world by law of government was not regarded as the effect of having a criminal government; it was regarded as fate, and fate comes from God and may not be criticised [sic].“2060

Auch Hohenemsers selbst von der Judenverfolgung betroffene Tante Paula begriff den Suizid der Eltern als Schicksal. In ihrem Kondolenzbrief schrieb sie: „Immer klarer wird mir, daß sie eigentlich nicht anders handeln konnten, daß es ein harmonischer $u$. folgerichtiger Abschluß ihres gemeinsamen Lebens war u. daß dies etwas Versöhnliches hat.“2061 1944 nahm sich Paula Hohenemser selbst das Leben. $\mathrm{Zu}$ den ganz wenigen Dingen, die Hohenemser auf seiner Flucht aus Schlesien Anfang 1945 retten konnte, zählt auch der Abschiedsbrief seiner Kusine Elisabeth Schumacher, geborene Hohenemser. Sie wurde wegen ihrer Mitarbeit in der von der Gestapo „Rote Kapelle“ genannten Widerstandsgruppe 1942 zum Tod verurteilt und hingerichtet. ${ }^{2062}$

„Liebe, liebe Käthe, Kurt u. Änne! Ein köstliches Päckchen erfreute mich noch am Sonnabend so sehr u. ein wunderbares Bild von meinem Verönchen [2063]. Es war wie lebendig bei mir, so zärtlich und lieb. Habt Dank! Und habt wohl. Wir werden uns nie in diesem Leben wiedersehen u. ob in einem anderen, das werde ich bald erfahren. Ich bin gespannt darauf. [...] Ihr Lieben! Ich wünsche Euch und den Kindern, daß Ihr durchhalten möget durch diese schwere Zeit und daß Ihr noch eine bessere Zukunft erleben möget. Es sterben so viele Menschen täglich, stündlich. Da müssen wir ganz still sein u. sind sehr ruhig, fast froh. Ihr müßt wissen, daß es immer für die schwerer ist, die bleiben, $u$. darum schmerzt es mich an Euch zu denken. Grüßt alle lieben Menschen. Der guten Änne wünsche ich, daß ihre treue Zähigkeit belohnt werde, Euch wünsche ich, daß Ihr Euren Kindern

\footnotetext{
2060 Durchschrift des Briefes von Hohenemser an seine Tante Muriel, 17. Mai 1946. KHP.

2061 Kondolenzbrief von Paula Pauli, geb. Hohenemser, an Kurt Hohenemser, 20. Mai 1942. Paula Pauli starb 1944. KHP.

2062 Die Rote Kapelle ist ein Sammelbegriff der deutschen militärischen Abwehr für verschiedene Gruppen in Frankreich, Belgien, Holland und der Schweiz. Davon abzugrenzen ist die Rote Kapelle in Deutschland. Dies war eine Widerstandsgruppe um Arvid Harnack und Harro Schulze-Boysen. Im Jahr 1941 nahm sie Verbindung zu Russland auf. Von August 1942 bis März 1943 wurden 126 zur Roten Kapelle zählende Widerstandskämpfer verhaftet, über 50 davon wurden hingerichtet. Siehe Coppi; Danyel \& Tuchel (Hrsg.) [1994]; Griebel, Coburger \& Scheel (Hrsg.) [1992]; Coppi \& Andresen (Hrsg.) [1999]; Kesaris (Hrsg.) [1979]. Hohenemser hatte selbst eine lose Verbindung zur Gruppe, siehe Rammer [2002] S. 89.

2063 Veronika ist die 1940 geborene Tochter von Kurt und Käthe Hohenemser.
} 
noch lange den Weg ins Leben bahnen könnt. Daß Ihr mich lieb behalten werdet, das weiß ich, und verzeihen werdet Ihr mir auch. Daß ist alles, was ich noch brauche. [...] Ich habe Euch sehr lieb. Habt wohl und wenn es Euch möglich ist, schreibt meiner Mutter. Eure Elisabeth. Leider bin ich nicht mehr allein, um mich richtig konzentrieren zu können. Und ich weiß jetzt, daß Eure Eltern einen schönen, wunderschönen Tod hatten."2064

Über Elisabeth sagte Kurt Hohenemser, sie sei eine gute Freundin seiner Mutter und besonders seiner Frau Käthe gewesen und gewiss die wertvollste Persönlichkeit der Hohenemserfamilie. ${ }^{2065}$ Hohenemser hatte selbst eine lose Verbindung zur „Roten Kapelle“, die ihm eine Vorladung bei der SS einbrachte. Auf Intervention seines Arbeitgebers Flettner konnte die politische Verfolgung abgewehrt werden. ${ }^{2066}$ Die Vernichtungspolitik des Nationalsozialismus kostete den meisten Familienangehörigen der Hohenemsers das Leben. „Meine Eltern und die meisten volljüdischen in Deutschland verbliebenen Mitglieder meiner väterlichen Familie nahmen sich 1942/43 das Leben, andere kamen im Lager um. Nur ein einziger Bruder meines Vaters blieb zufällig am Leben. Sie können sich denken, wie es einem da das Herz erfreut, hier überall auf die Juden schimpfen zu hören, die jetzt »alle« wiederkämen und sich wie immer überall vordrängten“, schrieb Hohenemser im Mai 1946 an Courant. ${ }^{2067}$ Der schmerzliche Verlust seiner Familie und Freunde prägte Hohenemsers Haltung gegenüber den Nutznießern des Nationalsozialismus. Hinzu kam seine materielle Lage nach dem Krieg.

Die Firma Flettner wurde im Herbst 1943 von Berlin nach Schlesien verlegt. Aus Oberweistritz flüchtete Hohenemser vor der heranrückenden Front im Januar 1945 und verlor dabei fast sein gesamtes Hab und Gut, darunter seine wissenschaftliche Bibliothek und eine Stradivari Violine seines Vaters. Er fand mit seiner Familie Unterschlupf in einem Kloster in Bildhausen bei Münnerstadt in Oberfranken. Dort bewohnte er mit seiner Schwiegermutter, seiner Frau und den beiden Kindern zwei Dachkammern. Das Klosterleben bot zumindest den Vorteil, dass die Familie nicht hungern musste. Hohenemsers Gesundheit war während der gesamten Kriegszeit stark angeschlagen. „Vor der Gefahr der Einberufung war ich zwar sicher, da selbst im 5ten Kriegsjahr der Militärarzt meinen Gesundheitszustand so kümmerlich fand, daß er mich untauglich schrieb, obwohl damals halbe Leichen zum

\footnotetext{
2064 Abschiedsbrief von Elisabeth Schumacher, geborene Hohenemser, vom 22. Dezember 1942. KHP. Zu Elisabeth Schumacher siehe Coppi; Danyel \& Tuchel (Hrsg.) [1994] S. 254-261; Griebel, Coburger \& Scheel (Hrsg.) [1992] S. 102f.

2065 Hohenemser an seine Tante Muriel, 17. Mai 1946. KHP.

2066 Siehe Rammer [2002] S. 89.

2067 Hohenemser an Courant, 21. Mai 1946. Library of Congress, Veblen papers, Box 4.
} 
Kriegsdienst eingezogen wurden.“2068 Auch im Kloster litt er noch unter starken Magenbeschwerden. Seine erste Fahrt nach Göttingen im Juni 1945 dauerte vier Tage. Auf Güterzügen kam er in kleinen Etappen nur langsam voran.

Mit der Kenntnis von Hohenemsers und Schulers Situation im Sommer 1945 wird ihr Verständigungsproblem bei ihrer ersten Wiederbegegnung begreiflich. Am Tag nach der misslungenen Begegnung, dem 23. Juni 1945, besuchte Hohenemser den Maschinenmeister Brandt des Instituts für angewandte Mechanik. „Erzählung von Schulers Heil Hitler“, notierte er zu diesem Besuch in sein Notizbuch. Er traf sich auch mit Rellich und diskutierte mit ihm Heisenbergs Quantentheorie, dann ging er zu Herglotz. Am Nachmittag erhielt er vom Institutsmechaniker Hoffmann einen langen Bericht über das Institut. Über die Assistenten erfuhr er, Stellmacher sei vergesslich und untüchtig, Magnus aus Travemünde der einzig tüchtige im Institut. Hohenemser notierte sich auch die personellen Verhältnisse am Institut, bis hinunter zu den Gehilfen und der Verwaltung. Am 24. Juni formulierte er seine Anträge an das Kuratorium (siehe unten) und besprach sich anschließend mit Prandtl. „Prandtl war zwar persönlich nett aber hatte durchaus kein Verständnis für meinen Wunsch, in Göttingen wieder rehabilitiert zu werden. Ich sollte es doch an einer T.H. versuchen, dort paßte ich besser hin, und er könne auch in Göttingen nichts für mich tun, da er das Institut für angewandte Mechanik an Schuler habe abgeben müssen."2069 Am folgenden Tag war Hohenemser dreimal beim Rektor und übergab ihm persönlich seine Anträge, an denen dieser bei der Durchsicht nichts beanstandete. ${ }^{2070}$ Aber schon $\mathrm{zu}$ diesem Zeitpunkt beurteilte der Rektor die Chancen für eine Wiederverleihung der Assistentenstelle sehr skeptisch. ${ }^{2071}$ Abends trat Hohenemser die Rückreise zum Kloster an, wo er drei Tage später eintraf. ${ }^{2072}$

\subsubsection{Der Kampf der Universität gegen Hohenemsers Rehabilitierung}

Hohenemser wünschte an der Universität Göttingen seine Forschungstätigkeit wieder aufzunehmen. Es gibt hier eine interessante strukturelle Parallele zu Schulers Beginn seiner wissenschaftlichen Laufbahn in Göttingen: Beide hatten im Alter von etwa 40 Jahren eine erfolgreiche Karriere in der Industrie hinter sich und wollten an die Universität zurückkehren. In beiden Fällen hatte Prandtl eine entscheidende Rolle inne. Der Unterschied zeigt sich im

\footnotetext{
2068 Handschriftlicher Entwurf eines Briefes von Hohenemser an Odqvist, 4. Juni 1946. KHP.

2069 Handschriftlicher Entwurf eines Briefes von Hohenemser an Prager, 3. Juni 1946. KHP.

2070 So schreibt Hohenemser in seinem „Bericht über die seitherigen Vorgänge betreffend meine Rehabilitierung an der Universität Göttingen“. KHP.

2071 Laut eines Briefes von Hohenemser an Prager, 3. Juni 1946. KHP.
} 
Ausgang: Bei Schuler glückte der Versuch, bei Hohenemser scheiterte er. Am Beginn der Auseinandersetzung steht folgende Bemerkung Hohenemsers, die er seinen Anträgen auf Wiedererteilung der Lehrbefugnis und auf Wiedereinsetzung in die planmäßige Assistentenstelle hinzufügte:

„Die Leitung des Instituts für angewandte Mechanik hatte damals Herr Professor Prandtl. Durch Vermittlung von Herrn Gengler, des Assistenten von Professor Schuler und nachmaligen Kreisleiters von Göttingen, wurde die Leitung des Instituts für angewandte Mechanik Herrn Professor Prandtl entzogen und Herrn Professor Schuler übertragen, welcher sie zur Zeit ausübt.“"2073

Es war seine kindliche Anhänglichkeit an den verehrten Lehrer und die Empörung über dessen politisch durchgesetzte Entmachtung im Institut, die ihn zu dieser Bemerkung veranlasste. Prandtl riet ihm davon ab, teilte ihm gleichzeitig mit, dass er für ihn nichts tun könne, da er das Institut habe abgeben müssen. Prandtls Entmachtung von 1934 gefährdete also Hohenemsers Wiedergutmachung. Was als nicht ganz uneigennützige Rehabilitierung einer politisch zurückgesetzten Koryphäe gedacht war, wurde von der Universität vor allem als Angriff gegen den Kollegen Schuler gelesen. Die beiden zitierten Sätze wurden offiziell zum Stein des Anstoßes. Schon zwei Tage nach Antragstellung wurde im Senat festgehalten, dass Stellenbesetzungen zur Zeit nicht möglich seien und deshalb Hohenemsers Antrag auf Wiedereinsetzung in die Assistentenstelle einstweilen abzulehnen sei. Über die Frage der venia legendi habe die Fakultät zu entscheiden. ${ }^{2074}$ Daraufhin ersuchte der Dekan Eucken seine Kollegen Prandtl, Herglotz und Schuler um Stellungnahme und bekundete bei dieser Gelegenheit bereits eigene Bedenken. „An sich wäre unseres Erachtens nach den gegenwärtigen Bestimmungen die Wiedererteilung der venia legendi an Hohenemser durchaus korrekt, vielleicht sogar notwendig, wenn nicht schwerwiegende Bedenken dagegen sprechen“. Ein solches Bedenken erkannte Eucken in dem ,außerordentlich schweren Vorwurf gegen ein Fakultätsmitglied“, ohne anzugeben, worin der Vorwurf bestand. Jedenfalls wünschte er, näheres über den Leitungswechsel zu erfahren. ${ }^{2075}$

Diese Nachfrage stellte das kollegiale Verhalten auf den Prüfstand, schließlich war Hohenemser früher Kollege von allen drei befragten Professoren und hatte noch eine Woche zuvor Gespräche mit ihnen geführt. Herglotz antwortete kurz und zurückhaltend, ohne sich

\footnotetext{
2072 Notizbucheintragungen von Hohenemser, Juni 1945. KHP.

2073 Hohenemser an Kurator, 25 Juni 1945. UAG, Math.-nat. Fak. 19 a; HStAH, Nds. 401, Acc. 92 / 85, Nr. 135.

2074 Protokoll der Senatssitzung vom 27. Juni 1945. UAG, Senatsprotokolle 1945-1949.

2075 Dekan Eucken an Prandtl, Herglotz und Schuler, 30. Juni 1945. UAG, Math.-nat. Fak. 19 a.
} 
damit in größere Schwierigkeiten zu verstricken: „Die Restituierung von Hrn Hohenemser in Stellung eines Dozenten erscheint mir an sich ordnungsgemäss. Über die seinerzeitigen Vorgänge beim Direktorwechsel des Institutes für angew. Mechanik ist mir nichts bekannt geworden."2076 Bei Schuler war statt kollegialer Verbundenheit offene Feindschaft vorhanden. Seine Auskunft war eine ausführliche Selbstrechtfertigung, die gleichzeitig Hohenemsers Aussagen gründlich uminterpretierte und verunstaltete. Er konstruierte aus Hohenemsers Antrag eine schwerste Verleumdung und Beleidigung. Der Antrag enthalte laut Schuler die Behauptung, er habe seine Stellung nicht wegen seiner Kenntnisse bekommen, sondern nur auf Grund Genglers Unterstützung. Diesen frei erfundenen Vorwurf widerlegte Schuler ausführlich und sprach sich folglich entschieden gegen Hohenemsers Anträge aus. Am Ende gab er sich gütig: „Wenn Hohenemser sich bei einer anderen Hochschule um die Venia legendi oder um eine Assistentenstelle bewirbt, so werde ich ihm keine Schwierigkeiten machen.“2077

Einen schwierigen Balanceakt hatte Prandtl zu bestehen, der zu seinem Kollegen Schuler wie seinem früheren Assistenten Hohenemser ein gutes Verhältnis hatte. Er sah sich mit dem Dilemma konfrontiert, nicht beiden Seiten gleichzeitig gerecht werden zu können. Die Frage Euckens wahrheitsgemäß in allen Einzelheiten zu beantworten, wäre eine Bloßstellung Schulers gewesen. Vor Hohenemser wollte er aber aus Gründen der persönlichen Verbundenheit sein Gesicht auch nicht verlieren. Prandtl fand einen Kompromiss, der dem Dekan die Vorgehensweise relativ offen ließ. Er präsentierte Eucken ein 'Argument', Hohenemser abzuweisen, indem er behauptete, dass Hohenemser zwar ein gediegenes Wissen erweise, aber „nicht als Fachmann besonders hohen Ranges gelten kann“.2078 Da der Senat kurz zuvor beschlossen hatte, eine Rückkehr auf die früheren Stellen „nur im Zuge eines Berufungsverfahrens mit dem Ziel der Ergänzung durch die Besten“ zuzulassen, lieferte Prandtl mit seiner Aussage ein offiziell verwendbares 'Argument'. Prandtl war auch der Meinung, dass man Schuler nicht zumuten könne, Hohenemser als Assistenten zu übernehmen. Damit nahm auch Prandtl den Standpunkt ein, dass sich Hohenemser unkollegial verhalten habe und sich dadurch den Zugang zu seinem früheren Institut selbst

\footnotetext{
2076 Herglotz an Dekan Eucken, 30. Juni 1945. UAG, Math.-nat. Fak. 19 a.

2077 Schuler an Dekan Eucken, 30. Juni 1945. UAG, Math.-Nat. Fak. 19a.

2078 Zu diesem Urteil mag vielleicht Gerhard Sissingh beigetragen haben, der bei Flettner genauso wie

Hohenemser für die theoretische Behandlung der Hubschrauberprobleme zuständig war, bevor er zur AVA nach Göttingen wechselte. Dort hat er im Juni 1944 einen Vortrag zur Einführung in die Aerodynamik der Drehflügelflugzeuge gehalten. Da Sissingh und Hohenemser ein gespanntes Verhältnis hatten, mag Sissingh ihn in Göttingen diskreditiert haben. Bis 1933 war Prandtl mit Hohenemsers wissenschaftlicher Tätigkeit zufrieden,
} 
verbaut habe. Zuletzt bestätigte er Hohenemsers Darstellung zum Leitungswechsel. Er habe nur unter Druck und keineswegs freiwillig die Leitung abgegeben. „Die Verhandlungen mit mir wurden durch den damaligen Dozentenvertreter der Fakultät, Dr. O. Kuhn, geführt“.2079 Hohenemser erfuhr von Prandtls Stellungnahme diesen letzten Punkt. Er schloss daraus, dass Prandtl also ,,anständig““ war. ${ }^{2080}$

Eucken hätte sich mit Bezug auf Prandtl auf den Standpunkt stellen können, dass die wesentliche Aussage Hohenemsers, nämlich der unfreiwillige Rücktritt von der Institutsleitung und die folgende Übertragung auf Schuler, korrekt war, wenn auch die Beteiligung Genglers zweifelhaft bleibt. Eucken traf aber eine andere Auswahl der ihm dargebotenen Äußerungen. Er bekräftigte in seinem Schreiben an den Rektor, dass Hohenemsers Bemerkungen ,namentlich unter den heutigen Verhältnissen als schwere beleidigende Vorwürfe [...] aufgefaßt werden müssen“. Außerdem erwiesen sie sich bei einer Nachprüfung an Hand des vorhandenen Aktenmaterials angeblich als falsch. Dies war der erste Schritt in Euckens Strategie, Hohenemser als unglaubwürdig darzustellen. Im Namen der Fakultät hielt Eucken eine „fruchtbare kollegiale Zusammenarbeit“ mit Hohenemser für ausgeschlossen. „Doch bestehen diesseits keine Bedenken, ihm diese für eine andere Hochschule zu erteilen.“2081

In dieser ersten Stellungnahme wird klar ausgesprochen, dass das Verhalten Hohenemsers in den Augen der Professoren ein Verstoß gegen die Kollegialität darstellte. Die Verbundenheit der Göttinger Professoren mit ihrem Kollegen Schuler verhinderte eine Aufklärung des Leitungswechsels, da damit eine Entwürdigung Schulers verbunden gewesen wäre. Deshalb wurde auch die bestätigende Äußerung Prandtls unterdrückt. In diesem Fall ordnete Eucken seine vermeintlich höchstrangige Forderung nach unbedingter Wahrhaftigkeit unter die unausgesprochene Forderung nach Abwehr 'unkollegialer' Wissenschaftler. Am selben Tag, als Eucken das obige Schreiben an den Rektor verfasste, wurde im Senat, also auch von Eucken und Smend, beschlossen: „In Rehabilitationsfällen kann eine Stelle nur dann verliehen werden, wenn sie frei ist - auf eine besetzte besteht kein Anspruch.“2082 Damit wurde die Basis für die Konstruktion des nächsten offiziellen Ablehnungsgrunds geschaffen.

und es ist nicht anzunehmen, dass er sich mit dessen späteren Arbeiten intensiv auseinandergesetzt hat, um die fachliche Qualität angemessen beurteilen zu können. MPG-Archiv, III, 61, 2164.

2079 Prandtl an Dekan Eucken, 3. Juli 1945. UAG, Math.-Nat. Fak. 19a. Hier ist vermutlich der Zoologe Otto Kuhn gemeint. Siehe Schappacher [1987/98] S. 531. Leider sind zu den Verhandlungen zwischen Prandtl und Kuhn keine Akten überliefert.

2080 Hohenemser an Prager, 3. Juni 1946. KHP.

2081 Dekan Eucken an Rektor Smend, 7. Juli 1945. UAG, Math.-nat. Fak. 19 a.

2082 Protokoll der Senatssitzung vom 7. Juli 1945. UAG, Senatsprotokolle 1945-1949. 
Bevor die Universität sich in der Causa Hohenemser ans Ministerium wandte, besprachen sich Rektor Smend und Kurator Bojunga. ${ }^{2083}$ Sie kamen zu dem Schluss, dass man die Anträge Hohenemsers aus rechtlichen und taktischen Gründen nicht so leicht abweisen könne. Der Rektor bat die Fakultät um erneute Stellungnahme. Hohenemser habe ein Recht auf Rehabilitierung, ihm das zu verweigern würde der Universität wahrscheinlich nur eine Niederlage gegenüber dem Oberpräsidenten einbringen. Er habe sein Recht durch seine unerfreulichen Bemerkungen nicht verwirkt. „Herrn H. wird nicht nachzuweisen sein, dass er diese Äusserungen wider besseres Wissen getan hat, geneigt, wie er durch die damalige Lage geworden sein mag, alle Dinge soweit irgend möglich, als parteipolitisch bestimmt zu deuten.“ Deshalb schlug Smend vor, die Wiedererteilung der venia legendi beim Oberpräsidenten zu beantragen, dafür aber "Hohenemser selbst den Antrag auf Wiederverleihung des Assistentenstelle als zur Zeit unerfüllbar und mit dem nachdrücklichen Hinweise auf die Unrichtigkeit und Unerfreulichkeit seiner Bemerkungen über die Vorgänge beim Leitungswechsel im Institut für angewandte Mechanik zurückzugeben.“2084

Es ist bemerkenswert, wie in dieser universitätsinternen Kommunikation zwischen Rektor und Fakultät eine Sprachregelung über die Vorgänge in der NS-Zeit gesucht wurde. Die Personalentscheidungen in der Formierungsphase des Nationalsozialismus „,als parteipolitisch bestimmt zu deuten“, sollte nur als eine voreingenommene und unzutreffende Ansicht eines Außenstehenden denkbar sein. Die Fakultätsmitglieder sollten hingegen den Standpunkt vertreten, der Kern der Universität hätte einer politischen Vereinnahmung stand gehalten. Deshalb musste Hohenemsers Hinweis nicht nur als unerfreulich, sondern vielmehr als unrichtig zu gelten haben. In dieser Sicht war Hohenemsers Antrag eine Gefahr für die neu zu konstruierende Identität der Nachkriegsuniversität. Es sind daher zwei Ebenen der Abwehr Hohenemsers zu unterscheiden: Die Universitätsleitung sah durch ihn die Konstruktion einer positiven Nachkriegsidentität der Hochschule gefährdet. ${ }^{2085}$ Die Fakultät und speziell die Fachkollegen fürchteten um das ruhige und geordnete Arbeitsklima, da in ihrem Verständnis der an der Vergangenheit rührende Hohenemser eine kollegiale Zusammenarbeit unmöglich mache.

Trotz Euckens eindeutiger Stellungnahme gegen eine Wiederaufnahme Hohenemsers in den Göttinger Lehrkörper ging er auf Prandtls 'Angebot', ihn fachlich als nicht herausragend zu

${ }^{2083} \mathrm{Zu}$ Smend siehe Campenhausen [1987]; Huber [1976].

${ }^{2084}$ Schreiben Rektor Smend an Dekan Eucken, 12. Juli 1945. UAG, Math.-Nat. Fak. 19 a. 
diskreditieren, nicht ein. Das ist bemerkenswert, denn Eucken war bei Habilitationen und in Berufungsangelegenheiten ein steter Mahner, den wissenschaftlichen Standard hoch zu halten. Eine zu geringe Zahl an Publikationen oder zu enge fachliche Ausrichtung wurde von ihm regelmäßig kritisiert. Eucken hat vermutlich einen Blick in die Personalakte Hohenemser geworfen und vielleicht auch die Habilitationsgutachten (wieder) gelesen und seine eigene Unterschrift darunter gefunden. Eucken müsste erkannt haben, dass Hohenemser ein sehr produktiver Wissenschaftler war, dessen Interessen laut Gutachten rein wissenschaftlich ausgerichtet waren und sich auf unterschiedliche Gebiete erstreckten. In diesem Punkt blieb Eucken fair, indem er Hohenemsers Qualifikation unangetastet ließ. Hohenemser sollte die akademische Laufbahn an einer anderen Hochschule nicht schwerer gemacht werden, als es der Vorwurf der Unkollegialität schon machte.

Die taktischen Überlegungen des Rektors Smend überzeugten die Fakultät nicht. Besonders der Dekan Eucken konnte sich mit dem Gedanken, Hohenemser in den Göttingen Lehrkörper aufzunehmen, nicht anfreunden. Er hielt sich im Namen der Fakultät verpflichtet, ,auf die große Gefahr in Bezug auf das kollegiale Zusammenarbeiten hinzuweisen [...] da eine Zusammenarbeit mit ihm in unserem Kreise nach den von ihm gemachten Bemerkungen völlig ausgeschlossen erscheint. Wir halten daher nachdrücklichst an unserem Vorschlag fest, Herrn H. einer anderen Universität oder Hochschule zuzuweisen.“2086 Am selben Tag, dem 14. Juli 1945, wurde im Senat beschlossen, zunächst Hohenemsers „Kommen abzuwarten, mit ihm zu verhandeln und ihn zur Zurücknahme der beanstandeten Äußerung zu veranlassen. Außerdem die freien Diätendozenturen festzustellen und anderweitig festzulegen.“2087 Über die freie zweite Assistentenstelle im Institut wusste der Senat offenbar nicht Bescheid, aber solange Schuler behauptete, es sei keine Stelle frei, da er sie für 'seine Rückkehrer' reservierte, brauchte sich der Senat damit auch nicht auseinander zu setzen.

Am 24. Juli machte sich Hohenemser mit dem Fahrrad und auf Güterzügen auf den Weg nach Göttingen. „Fulda an 20 Uhr. Kein Postamt. Nacht auf Pritsche“, notierte er in sein Notizbuch. Am 27. Juli traf er sich mit Prandtl und erfuhr: „Fakultät einverstanden, aber keine

\footnotetext{
2085 Auf die Verfälschungen der Geschichte im Zuge der Konstruktion einer vorzeigbaren Nachkriegsidentität der Hochschulen hat kürzlich besonders Remy [2002] hingewiesen, der diese Konstruktion etwas hochtrabend einen „Mythos“ nennt.

2086 Dekan Eucken an Rektor Smend, 14. Juli 1945. UAG, Math.-nat. Fak. 19 a.

2087 Protokoll der Senatssitzung vom 14. Juli 1945. UAG, Senatsprotokolle 1945-1949. Im August 1945 besaß die mathematisch-naturwissenschaftliche Fakultät drei freie Diätendozenturen, die vor allem an „wissenschaftlich verdiente, z. Z. stellenlose Herren“ hätten vergeben werden sollen. Protokolle der Fakultätssitzungen vom 17. August 1945 und 27. August 1945. GPAMNFG, Protokollbuch III der mathematisch-naturwissenschaftlichen Fakultät WS 1927/28 - SS 1946.
} 
Stelle“. ${ }^{2088}$ Tags drauf besprach er sich mit dem Rektor Smend. Hier erfuhr er, dass aus den Akten keine Anhaltspunkte für die Richtigkeit seiner Behauptung zu entnehmen seien. Er musste sich von Smend sagen lassen, er schütte seinen Unrat in die Universität aus, störe ihren Frieden, benähme sich ebenso unmöglich wie die Nazis und könne nicht mehr in den Lehrkörper aufgenommen werden, wenn er nicht den Beweis für seine Anschuldigungen gegen Herrn Schuler erbringe. Daraufhin wollte Hohenemser seine Bemerkungen im Antrag zurücknehmen - eine eigenartige Übereinstimmung mit dem Senatsbeschluss -, was Smend aber mit der Begründung zurückwies, dass es sich um eine Urkunde handele, die sich nicht zurückziehen lasse. 2089 Den Abend verbrachte Hohenemser bei Herglotz. Am nächsten Tag traf er die Institutsangestellten Hoffmann und Brandt, und abends wieder Prandtl. Die Rückreise war erneut beschwerlich: „Endlose Fahrt bis Gießen, an $23^{0}$ statt $19^{0}$, Nacht auf dem Bahnhof und im Güterwagen."2090 Von den Göttinger Ordinarien haben zumindest Prandtl und Herglotz Hohenemsers Sicht kennen gelernt. Doch waren sie nicht bereit, Hohenemser gegen Schuler zu unterstützen. Herglotz war als angewandter Mathematiker nicht nur ein naher Fachgenosse Schulers, sondern als Bewohner des Hauses Hainholzweg 70 auch privat sein unmittelbarer Nachbar.

Hohenemser empfand seine Bemerkungen nun als ungeschickt und unglücklich. Er entschuldigte sich bei Prandtl für die dadurch hervorgerufenen Unannehmlichkeiten und erklärte:

„Sie haben wohl recht mit Ihrer Vermutung, dass die Bemerkung in meinem Antrag mehr einem Gefühl des Unwillens über jene Vorgänge als der vernünftigen Überlegung entsprang. Tatsächlich hat mich die Art, in welcher man eine Persönlichkeit wie Sie behandelt hat, weit mehr empört als mein eigenes Schicksal, dass ja immerhin gesetzmässig vorgeschrieben war. Wenn man 1934 in Cambridge erlebt hat, welche Hochachtung, Wärme und Ehrfurcht Ihnen von den Fachgenossen der ganzen Welt entgegengebracht wurde und dann an die Vorgänge in Göttingen dachte, bei denen irgendwelche unbedeutenden jungen Leute dank ihrer politischen Betätigung Ihre Stellung untergraben konnten, dann ist es vielleicht verzeihlich, wenn der lange unterdrückte Unwillen über jene Dinge sich an einer ungeeigneten Stelle Luft machte.“2091

Das „Gefühl des Unwillens“ gegenüber Prandtls Verlust des Instituts als Auslöser für die unvorsichtige Bemerkung ist durchaus ernst $\mathrm{zu}$ nehmen. Hohenemser zeigte Zeit seines

\footnotetext{
2088 Eintrag in Notizbuch. KHP.

2089 Darlegung des Gesprächs ist folgenden Briefen entnommen: Hohenemsers an Courant, 21. Mai 1946

(Library of Congress, Veblen papers, Box 4.), Hohenemser an Prager, 3. Juni 1946 (KHP). Siehe auch

Hohenemser an Rektor, 29. Mai 1946. GPAMNFG, Lehrkörper (ausgeschieden), Hohenemser.

2090 Eintrag in Notizbuch. KHP.

2091 Durchschrift des Briefes von Hohenemser an Prandtl, 30. Juli 1945. KHP.
} 
Lebens eine überschwängliche Verehrung für seine wissenschaftlichen Lehrer und Vorbilder. Dies traf schon in gewissem Sinn bei seinem Physiklehrer in der Schule zu und war besonders stark ausgeprägt bei Willy Prager. Auch Prandtl gegenüber empfand er große Verehrung, die im Sommer 1945 noch uneingeschränkt vorhanden war, dann allerdings auf Grund Prandtls Einsatz für Schuler schwand. Trotzdem hingen in Hohenemsers Zimmer in St. Louis bis zu seinem Tod neben vielen Familienfotos nur zwei Fotografien von Wissenschaftlern: von Albert Einstein und von Ludwig Prandtl.

Hohenemser kam der Forderung des Rektors nach Beweisen für seine Behauptungen nach und gab eine erstaunlich detailreiche Präzisierung der Vorgänge zum Leitungswechsel ab, die die Rolle Hahnkamms und dessen Umfeld anstatt Genglers betonte und auch in allen anderen Punkten dem entspricht, was auf Grund der Quellenlage heute über die Vorgänge rekonstruierbar ist (siehe Abschnitt 5.3.1). Da er ohne Akteneinsicht seine Darlegung nicht beweisen konnte, führte er mehrere Zeugen an und bat den Rektor um eine Untersuchung des Leitungswechsels. Er betonte, dass er gegen Schuler sachlich nichts vorzubringen habe, und dass er keinerlei Anhaltspunkte für seine etwaige Mitbeteiligung am Leitungswechsel habe. ${ }^{2092}$

Smend ließ sich darauf nicht ein. Er notierte auf Hohenemsers Antrag handschriftlich: „1) Antrag auf Wiederherstellung der venia an den Oberpräsidenten, 2) Antrag auf Wiedereinsetzung in die planmäßige Assistentenstelle abzulehnen, da nicht frei, 3) Antrag auf Untersuchung der Vorgänge beim Übergang der Leitung des Instituts für angewandte Mechanik [abzulehnen], da gar kein Anlaß für eine solche Untersuchung vorliegt.“2093 Diese drei Punkte wurden laut Smend am selben Tag im Senat beschlossen, ohne dass der Beschluss in das Senatsprotokoll Eingang fand. Das weitere Vorgehen der Universität im Fall Hohenemser lässt sich sehr einfach beschreiben: Sie tat nichts. Fünf Monate, bis Dezember 1945, blieb sein Antrag unbearbeitet liegen. Auch der vom Senat beschlossene „Antrag auf Wiederherstellung der venia an den Oberpräsidenten“ blieb aus.

In dieser Zeit wurden, wie in Abschnitt 1.3.4 dargestellt, viele unkomplizierte Berufungen und Stellenvergaben durchgeführt. Es sei nur an die Vergabe einer Dozentur an Siegfried Flügge erinnert, der aus fachlichen Gründen eigentlich nicht dafür in Frage kam (siehe Abschnitt 1.3.4.3). Auch einem Prandtl-Schüler wurde unbürokratisch ein Arbeitsplatz zur Verfügung gestellt, als der Ordinarius an der TH Dresden, Walter Tollmien, nach dem

2092 Hohenemser an Rektor Smend, 30. Juli 1945. UAG, Kur. PA Hohenemser. 
verheerenden Bombenangriff im Februar 1945 nach Göttingen kam. Tollmien war kein 'Außenseiter', sondern ein im Amt befindlicher Kollege, der seine Karriere mit den üblichen Anpassungen in der NS-Zeit gemacht und 1937 ein Ordinariat bekommen hatte. Von ihm war keine Ruhestörung zu befürchten. Aber auch 'Außenseiter', oder genauer gesagt, aus der „Volksgemeinschaft“ ausgegliederte, wurden in der zweiten Hälfte des Jahres 1945 in Göttingen rehabilitiert. In der Physik ist Fritz Houtermans ein Beispiel (siehe Abschnitt 1.3.4.4). Von den im Nationalsozialismus in Göttingen entlassenen Privatdozenten aller Fächer wurde aber nur ein einziger 1945 wieder durch Übertragung einer Stelle rehabilitiert. Diese Rehabilitierung des Psychologen Heinrich Düker liefert einen interessanten Vergleich zum Fall Hohenemser.

\subsubsection{Die geglückte Rehabilitierung Heinrich Dükers}

Zuerst sind einige Gemeinsamkeiten zwischen Hohenemser und Düker zu nennen. Sie waren beide in Göttingen politisch aktiv, Düker als Mitglied des ISK in stärkerem Maß als Hohenemser. Über die politischen Interessen lernten sie einander kennen. In Berlin hielt Düker eine Grabrede bei der Beerdigung von Hohenemsers Eltern 1942. Die bedeutendste Gemeinsamkeit ist ihre linke politische Einstellung und klare Gegnerschaft zum Nationalsozialismus, bei Düker verbunden mit Widerstandstätigkeit, weshalb er zu drei Jahren Gefängnis verurteilt und später ins KZ Sachsenhausen eingeliefert wurde. Die Biografien weisen aber auch entscheidende Unterschiede auf. Düker wurde 'erst' 1936 die Lehrbefugnis entzogen, und zwar aus politischen Gründen nach $\S 18$ der Reichshabilitationsordnung. Düker blieb als „Arier“ offiziell Teil der „Volksgemeinschaft“ ein wesentlicher Unterschied zu Hohenemser. In Dükers Bemühung um Wiederaufnahme der Lehrtätigkeit in Göttingen zeigt sich noch ein weiterer entscheidender Unterschied. ${ }^{2094}$

Düker erfuhr eine uneingeschränkte Unterstützung durch den Institutsdirektor des Psychologischen Instituts, Johannes von Allesch. Dieser bescheinigte Düker Ende August 1945, dass er eine „hervorragende Forscherpersönlichkeit“ sei, und dass seine Rehabilitation „nicht nur das ihm zugefügte Unrecht wiedergutmachen, sondern auch der Universität Göttingen bedeutenden Gewinn bringen“w werde. Deshalb stellte Allesch Anträge auf 1) Wiedereinsetzung in die Dozentur, 2) Aushändigung der Ernennung zum außerplanmäßigen

2093 Handschriftlicher Eintrag am Ende des Schreibens Hohenemser an Rektor Smend, 30. Juli 1945, unterschrieben von Smend. UAG, Kur. PA Hohenemser.

2094 Zu Düker siehe Paul [1987/98] bes. S. 508-512; Dahms [1987/98] S. 46. 
Professor, und 3) Erteilung einer Diätenstelle. ${ }^{2095}$ Im Fall Düker spielten antisemitische Vorbehalte keine Rolle. Auf Antrag Euckens wurde zwei Tage nach Alleschs Antragstellung im Senat beschlossen, Düker ,,auf eine Diätendozentur zu übernehmen, wobei aber keine der dieser Fakultät zur Verfügung stehenden Dozenturen verwendet werden soll.“2096

Dükers Wiedereinsetzung konnte schnell und glatt durchgeführt werden, obwohl in der Fakultät keine Stelle für ihn frei gewesen war oder verwendet werden sollte. Seine Eingliederung in den Lehrkörper erfolgte so weitgehend, dass er im Januar 1946 in einen Universitätsausschuss zur Beurteilung von Entlassungen berufen wurde. ${ }^{2097}$ Düker war mit Hohenemser auch in der Nachkriegszeit in Kontakt, verstand aber den Unterschied in ihren Wiedergutmachungsfällen nicht. Im November 1945 schrieb er Hohenemser, dass es einen Kampf gekostet habe, seine Rechte zu bekommen und riet ihm: „Ihnen steht eine bezahlte Dozentur zu. Setzen Sie sich nur ordentlich dahinter. Wenn es sein muß, werden Sie energisch. Mit Bescheidenheit und Feinheit kommen Sie heute nicht weit. Die große Zeit hat in dieser Hinsicht zu verheerend gewirkt."2098 Düker wusste nicht, dass Hohenemser von Prandtl fachlich diskreditiert wurde, während er selbst in diesem Punkt volle Unterstützung erfuhr. Auch die unterschiedliche Auswirkung eines möglicherweise in der Fakultät vorhandenen Antisemitismus scheint Düker nicht bedacht zu haben. Sein Rat, energischer vorzugehen, war aber auf alle Fälle hilfreich. Denn während der Fall Hohenemser auf Eis gelegt war, bemühte sich Schuler weiterhin um personelle Kontinuitäten im Institut.

\subsubsection{Angestrebte Kontinuitäten in Schulers Institut scheiterten}

Schuler besaß im Sommer 1945 zwei von der Universität bezahlte wissenschaftliche Mitarbeiter: die Hilfskraft Friedrich Karl Rubbert und seinen Assistenten Karl Ludwig Stellmacher. Rubbert wurde im Juli 1945 die „vorsorgliche“ Kündigung ausgesprochen, da mit Rückkehr der Inhaber der planmäßigen Stellen zu rechnen sei. ${ }^{2099}$ Auf diese Weise diente Rubbert als Platzhalter für konstruierbare Kontinuitäten. Vom Kurator war es dem Institutsdirektor überantwortet worden, eine Verlängerung der Hilfskräfte zu beantragen, oder

\footnotetext{
2095 Direktor des Psychologischen Instituts, Allesch an Dekan Eucken, 27. August 1945. GPAMNFG, Lehrkörper (ausgeschieden), Düker.

2096 Protokoll der Senatssitzung vom 29. August 1945. UAG, Senatsprotokolle 1945-1949.

2097 Der Viererausschuss bestand aus Rein, Pohl, E. Schmidt und Düker. Er beurteilte zusammen mit Rektor und Dekan Entlassungsfragen. Protokoll der Senatssitzung vom 21. Januar 1946. UAG, Senatsprotokolle 19451949.

2098 Düker an Hohenemser, 7. November 1945, Hervorhebung original. KHP.

2099 Die vorsorgliche Kündigung war ein vorgedrucktes Formular, bei dem nur der Name des Betroffenen einzusetzen war, und das durch entsprechende Formulierung für alle Institute, Seminare und Kliniken der Universität anwendbar war. UAG, Kur. XVI. V. C. e. 1.
} 
Rückkehrer einzustellen. Schuler hatte also freie Hand in der Zusammenstellung seiner Belegschaft. Dass er die vorhandenen Möglichkeiten, Hohenemser einzustellen, nicht nutzte und auch nicht bekannt gab, sei nur der Vollständigkeit halber erwähnt. Im September 1945 beantragte er, seinen während des Kriegs in Peenemünde und der Luftfahrtindustrie arbeitenden ehemaligen Schüler Rainer Fuchs ${ }^{2100}$ vertretungsweise „mit monatlicher Kündigung“ die unbesetzte zweite Assistentenstelle zu übertragen. ${ }^{2101}$ Schuler dachte vermutlich an seine begabten Schüler Hoch und Magnus, deren Rückkehr an die Universität er erhoffte, als er die Stellen mit Rubbert und Fuchs in Vertretung von Rückkehrern besetzte. Für den anlaufenden Lehrbetrieb benötigte er dringend diese Hilfskräfte. ${ }^{2102}$

\subsubsection{Schulers Mitarbeiter „,»spielten« wieder Universität“}

Der frühere Assistent am Institut, Kurt Magnus, kam im Spätherbst 1945 nach einer halbjährigen Internierungszeit in Travemünde zurück nach Göttingen und hoffte, hier wieder Fuß fassen zu können, da er ja immer noch als Privatdozent dem Lehrkörper angehörte, wenn er auch keine Stelle bekleidete und somit keine Bezüge bekam. Er selbst beschreibt den Göttinger Wiedereinstieg so:

„Tatsächlich traten die Alltagssorgen jener Tage - um das Essen, um Heizung und Unterkunft - in den Hintergrund, nachdem sich einige Mitarbeiter der ehemaligen Göttinger Institutsmannschaft wieder zusammengefunden hatten, um, von unserem so verehrten Institutschef unterstützt, einen neuen Anfang zu versuchen. Wir »spielten« wieder Universität wie zuvor, diskutierten, hielten Kolloquien ab, organisierten Seminare - und noch im Wintersemester 45/46 konnte ich vor wenigen Hörern wieder eine Vorlesung halten. Es gab zwar keine Bezahlung dafür, aber wir waren ja bescheiden geworden und lebten von der Hoffnung und dem Glauben an eine bessere Zukunft.“2103

Aber noch vor Ablauf des Wintersemesters wurde Magnus von der Militärregierung die Arbeit an der Universität Göttingen untersagt. Magnus erhob Einspruch und behauptete, sich in der Hitlerjugend nur sportlich betätigt zu haben. ${ }^{2104}$ Eucken fügte dem Einspruch hinzu, dass die Fakultät keine Bedenken gegen sein Verbleiben in der Dozentenstelle habe, da er an der Universität nicht durch irgendwelche politische Aktivität aufgefallen sei. ${ }^{2105}$ Schuler

\footnotetext{
2100 Zu Fuchs siehe UAG, Kur. XVI. V. C. e. 1.

2101 Schuler an Kurator, 14. September 1945. UAG, Kur. XVI. V. C. e. 1.

2102 Schuler an Kurator, 7. September 1945. UAG, Kur. XVI. V. C. e. 1.

2103 Magnus [1993] S. 19.

$2104 \mathrm{Zu}$ Magnus‘ Ämtern in der HJ siehe Abschnitt 5.3.2.3.

2105 Stellungnahme zu Magnus` Einspruch vom Dekan Eucken, 4. Februar 1946. Später wurde darauf handschriftlich vermerkt: „K. Magnus ist am 23.II.46 entlassen worden!“ GPAMNFG, Lehrkörper (ausgeschieden), Magnus.
} 
beurteilte Magnus als exzellenten Wissenschaftler, der seine Lehrtätigkeit gegen jede politische Betätigung scharf abgegrenzt habe. ${ }^{2106}$ Magnus bemühte sich erfolglos, Hilfe von einem britischen Offizier zu bekommen, den er aus seiner Internierungszeit kannte. Von der Militärregierung wurde ihm sein Bankkonto gesperrt. Um sich außerhalb der Universität ein Standbein zu verschaffen, eröffnete er ein „Physikalisch-technisches Büro“. Durch die Vermittlung seines Kollegen Johann Hoch fand er ein anderes, gut bezahltes Betätigungsfeld.

\subsubsection{Verschobene Kontinuität: Schulers frühere Assistenten bauen wieder Raketen}

Johann Hoch kam Anfang 1946 wieder nach Göttingen. Leider geben die Quellen keine Auskunft darüber, wie und wo Hoch das Kriegsende erlebte, und was er in der Zeit bis Anfang 1946 machte. Laut Magnus hatte es ihn „aus der Bahn geworfen“. ${ }^{2107}$ Er nutzte seine Kontakte zu den früheren Raketenbauern und bekam eine Anstellung bei der neu in Angriff genommenen Raketenentwicklung in Bleicherode. Er überredete Magnus, sich daran zu beteiligen. Dort wurde unter sowjetischer Leitung die Rekonstruktion der A 4 Rakete, die in Peenemünde entwickelt worden war, in Angriff genommen. Magnus und Hoch waren für die Steuerungselemente, die Kreiselgeräte, zuständig. Am 22. Oktober 1946 wurden alle Mitarbeiter des Bleicheroder Werkes, der Zeiss Werke und anderer Firmen in einer groß angelegten Verschleppungsaktion in Zügen nach Russland gebracht. ${ }^{2108}$ Dort lebten sie zwar in relativem Luxus, mussten sich aber unter eingeschränkter Bewegungsfreiheit an der russischen Raketenentwicklung beteiligen. Erst in den frühen fünfziger Jahren durften sie nach Deutschland zurückkehren. Hoch starb allerdings vorher an einer Operation in Russland. 2109 Im November 1953 kam Magnus zurück und schlug (wieder) eine Universitätslaufbahn ein. ${ }^{2110}$ Diese begann 1954 in Freiburg und erreichte 1966 ihren Höhepunkt mit der Berufung auf ein Ordinariat für Mechanik an die TH München. ${ }^{211}$

\footnotetext{
2106 Schuler an Dekan, 1. April 1946, GPAMNFG, Lehrkörper (ausgeschieden), Magnus.

2107 Magnus [1993] S. 20. Er schreibt im Vorwort, dass er manche Namen geändert hat. Johann Hoch wird von ihm Dr. John genannt. Zur Identifizierung von Johann Hoch diente das Buch über die Beteiligung der Deutschen an der sowjetischen Raketenentwicklung von Werner Albring [1991].

2108 Siehe Mick [2000].

2109 Mick [2000] S. 148.

2110 Siehe hierzu Magnus [1993].

2111954 war er wissenschaftlicher Mitarbeiter in der Abteilung für angewandte Mathematik des Mathematischen Instituts der Universität Freiburg. 1955 wurde er dort zum Dozenten und 1956 zum außerplanmäßigen Professor ernannt. 1958 wurde er als ordentlicher Professor Nachfolger von Richard Grammel an der TH Stuttgart, wo er bis 1966 blieb. 1962/63 war er Gastprofessor im Department of Mechanical Engineering der University of Kansas in Lawrence (Kansas). 1963 wurde er Herausgeber des ,IngenieurArchivs“, das Grammel gegründet und bis dahin herausgegeben hatte. 1966 wurde er auf den Lehrstuhl B für Mechanik in der Fakultät für Maschinenwesen der TH München berufen. 1972 und 1974 war er Prodekan und Dekan, 1980 wurde er emeritiert. Siehe Truckenbrodt [1982].
} 
Bei allen Brüchen, die die Biografien von Magnus und Hoch aufzuweisen haben, ist doch auf der inhaltlichen Seite der Forschung über das Jahr 1945 hinweg eine 'verschobene، Kontinuität festzustellen. Sie waren weiterhin in der Rüstungsforschung an der Entwicklung von Kreiselgeräten tätig, allerdings verschob sich ihr angestrebter Arbeitsplatz von der Universität Göttingen erst in die SBZ und weiter nach Russland. Die Entnazifizierung verhinderte die Wiederaufnahme ihrer Hochschullaufbahn in den Jahren 1945/46. Ihre Namen fanden jedoch in keine Statistik zur Entnazifizierung der Universität Göttingen Eingang, da sie 1945 keine Stelle besaßen und damit auch keine verlieren konnten. Obwohl Schuler seine früheren Schüler nicht zurückgewinnen konnte, war angeblich trotzdem kein Platz für Hohenemser im Institut vorhanden.

\subsubsection{Hohenemsers schwache Einbindung ins Göttinger kollegiale Netz}

Ein entscheidender Grund, warum Hohenemsers Rehabilitierung von der Fakultät abgewehrt wurde, war seine schwache Einbindung ins Göttinger kollegiale Netz. Ihm fehlte ein mächtiger Fürsprecher, der sich in der Fakultät für seine Ansprüche stark gemacht hätte. Dabei fehlte es Hohenemser nicht an Kontakten zu Göttinger Hochschullehrern. Im Sommer 1945 traf er sich beispielsweise mit Herglotz, Rellich, Tollmien, Jordan und Nohl. ${ }^{2112}$ Diese Kontakte brachten ihm keine große Hilfe ein, auch wenn sich Herglotz stets positiv zu Hohenemsers Wiedergutmachung geäußert hat, aber offenbar nur auf spezielle Anfrage und dann recht zurückhaltend. Herglotz hielt der strikt ablehnenden Haltung Euckens, die von Schuler durch entsprechende 'Argumente' gefördert wurde, wenig entgegen. Der frühere Fürsprecher aus der Mathematik, Richard Courant, der sich 1932/33 entschieden positiv über Hohenemsers akademische Zukunft ausgesprochen hatte, musste 1933 selbst die Universität verlassen und fehlte 1945 spürbar. Der einzig vorhandene und in der Logik des damaligen, patriarchal-hierarchischen Universitätssystems vor allem in Frage kommende Förderer war Prandtl. Ein Problem bestand für Prandtl darin, dass er das Institut für angewandte Mechanik hatte abgeben müssen, was auch 1945 noch die Folge hatte, dass er in Personalangelegenheiten des Instituts nicht eingreifen wollte. Dass er Hohenemser am liebsten an eine Technische Hochschule abweisen wollte, ${ }^{2113}$ lässt sich am besten sozialpsychologisch verstehen. Das in Abbildung 3 gezeigte Triplet der Beziehungen Prandtl - Schuler - Hohenemser gilt als nicht balanciert. Eine solche Konstellation führte bei Prandtl

\footnotetext{
2112 Siehe Einträge in Hohenemsers Notizbuch. KHP.

2113 Diesen Standpunkt vertrat Prandtl schon im Sommer 1945 Hohenemser gegenüber. Siehe Hohenemser an Prager, 3. Juni 1946. KHP.
} 
zu emotionalem Stress. ${ }^{2114}$ Es gibt zwei Möglichkeiten der Ausbalancierung: Eine der beiden positiven Verbindungen müsste $\mathrm{zu}$ einer negativen werden, oder alle drei müssten positiv sein. Es ist anzunehmen, dass Prandtl die letzte Möglichkeit für unwahrscheinlich hielt, andererseits aber auch keine der positiven Beziehungen abbrechen wollte. Zur Vermeidung des Stresses bot sich für Prandtl nur noch an, eine physische Distanz zu Schuler oder Hohenemser herzustellen. Der einfachste Ausweg schien, Hohenemser an eine TH zu verweisen. Es gibt aber auch Anzeichen dafür, dass die Beziehung Prandtl - Hohenemser 1945 unter der Auseinandersetzung mit Schuler gelitten hat. Während Prandtl in seinen Briefen von 1933 bis 1944 und ab April 1946 stets die Begrüßungsformel „Lieber Herr Hohenemser!“ benutzte, wechselte er im Dezember 1945 zu dem eher distanzierten „Sehr geehrter Herr Dr. Hohenemser!“‘2115

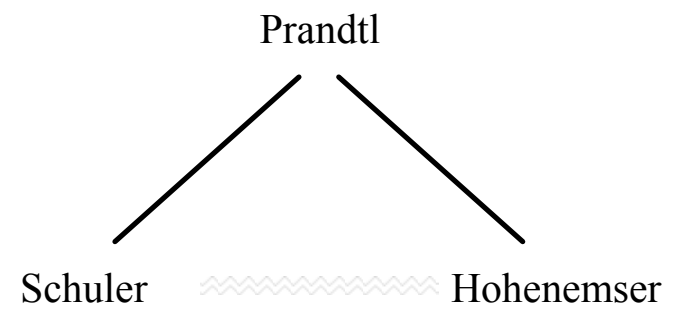

Abbildung 3 Sozialpsychologisches Triplet von Prandtl, Schuler und Hohenemser. Gerade Linien bezeichnen eine positive Verbindung, gezackte eine negative.

\subsubsection{Der Fall Hohenemser gelangt 1946 ans Ministerium}

Als vier Monate nach der Antragstellung vergangen waren und von der Universität noch immer keine Nachricht gekommen war, erbat Hohenemser Ende November 1945 vom Rektor eine Bestätigung, dass seine Anträge in Bearbeitung seien. ${ }^{2116}$ Gleichzeitig wurde auch Prandtl aktiv und mahnte Anfang Dezember im Dekanat die Bearbeitung der Wiedererteilung der Lehrbefugnis an. ${ }^{2117}$ Eucken reagierte mit einer äußerst seltsamen Stellungnahme. Die Fakultät erhebe keine grundsätzlichen Einwendungen gegen eine Wiedererteilung der venia legendi, ,nachdem Dr. Hohenemser die beleidigenden Äußerungen gegen Professor Schuler zurückgenommen hat.“ Abgesehen davon, dass es sich bei Hohenemsers Äußerungen nicht um eine Beleidigung handelte, da über Schuler nur zutreffend gesagt wurde, dass er die Institutsleitung übertragen bekam, so überrascht doch, dass Eucken behauptete, Hohenemser

2114 Zum theoretischen Hintergrund dieser Interpretation siehe Jansen [1999] S. 34f.

2115 Siehe den Briefwechsel in MPG-Archiv, III, 61, 692.

2116 Hohenemser an Rektor Smend, 27. November 1945. UAG, Kur. PA Hohenemser. 
habe die Äußerungen zurückgenommen, wo ihm doch Rektor Smend dies ausdrücklich als unmöglich erklärt hatte. Eucken erreichte mit dieser verleumderischen Behauptung, dass Hohenemser fortan als unglaubwürdig galt. Eucken wies in seiner Stellungnahme auch darauf hin, dass Hohenemser in Göttingen nicht benötigt werde, da im Fach angewandte Mechanik „bereits zwei Dozenten, Dr. K. Magnus und Dr. K. Wieghardt vorhanden sind und erfahrungsgemäß eine Überzahl von Dozenten für den Lehrbetrieb eher schädlich als nützlich ist. “2118 Dieses 'Argument' sieht auf den ersten Blick überzeugend aus, war aber insofern ein Vorwand, als es auch dann kein Bedürfnis und auch weiterhin keine Möglichkeit für Hohenemser als Dozent in Göttingen gab, als Magnus zwei Monate später entlassen wurde. Hohenemser auf die angewandte Mechanik festzulegen übersah, dass er die Lehrbefugnis auch für angewandte Mathematik besaß. In diesem Fach gab es einen dringenden Unterrichtsbedarf in nummerischem Rechnen, wie Eucken im Februar 1946 seinem Kollegen Herglotz mitteilte. Da der kurz vor der Berufung auf die Professur für angewandte Mathematik stehende Rellich selbst ein 'reiner' Mathematiker sei, kämen hier laut Eucken vor allem die jüngeren Dozenten zum Zuge. ${ }^{2119}$ Es gab also sogar einen Bedarf an Hohenemsers Unterrichtsfächern. Dies wurde im Zuge der 'Argumentation' gegen Hohenemser später erneut Thema. Hier genügt die Erkenntnis, dass Eucken bloß Vorwände gesucht hat, um Hohenemser abzuwehren.

Zu Weihnachten 1945 beantragte der Rektor beim Oberpräsidenten, „die Zurücknahme der Entziehung der Lehrbefugnis erwirken zu wollen."2120 Dieses Schreiben ging seinen Amtsweg über den Kurator. Der stellvertretende Kurator Freytag (Kurator Bojunga wurde zwischenzeitlich wieder seines Amtes enthoben) ${ }^{2121}$ brachte vermutlich ohne genaue Kenntnis des Falles seine eigene Sichtweise mit ein, als er begründete, warum er Hohenemsers Antrag auf Wiedereinsetzung in die Assistentenstelle nicht stattzugeben vermag. Dies sei nicht wünschenswert, da Hohenemser den Institutsdirektor „ohne jeden Grund angegriffen hat““.2122 Wie Freytag zu der Einsicht gelangte, dass Hohenemser grundlos handelte, bleibt ungewiss.

\footnotetext{
2117 Prandtl an Hohenemser, 1. Dezember 1945. KHP.

2118 Dekan Eucken an Rektor Smend, 13. Dezember 1945. GPAMNFG, Lehrkörper (ausgeschieden), Hohenemser.

2119 Eucken an Herglotz, 9. Februar 1946. GPAMNFG, Lehrkörper (ausgeschieden), Rellich. Rellich wurde zum 1. Mai 1946 nach Göttingen berufen.

2120 Rektor Smend an Kurator, 24. Dezember 1945. HStAH, Nds. 401, Acc. 92 / 85, Nr. 135.

2121 Freytag wurde Ende Oktober, Anfang November nach Besprechung des Rektors Smend mit Major Beattie als geschäftsführender Kurator eingesetzt. Protokoll der Senatssitzung vom 30. Oktober 1945. UAG, Senatsprotokolle 1945-1949.

2122 Geschäftsführender Kurators Freytag an den Oberpräsidenten in Hannover, Hauptabteilung Kultus, 5. Januar 1946. HStAH, Nds. 401, Acc. 92 / 85, Nr. 135.
} 
Dass er es als Angriff formulierte, zeigt die Mentalität der Beamten, die während der NS-Zeit ihren Dienst versehen hatten und sich entsprechend anpassen mussten. Dass diese Anpassung auch Nutzen brachte, wollte man nach 1945 nicht vorgehalten bekommen. Der feine Unterschied zwischen dem Vorwurf einer persönlichen Initiative zur Förderung der Karriere mit politischen Mitteln und der Kritik der politischen Einflussnahme auf die Entziehung einer Stelle wurde geflissentlich übersehen. Hohenemser musste immer wieder auf diesen Unterschied hinweisen. Trotzdem blieb die Wahrnehmung bestehen, er habe Schuler beleidigt. Gerade der Kurator, der leichten Zugang zu den Kuratorialakten des Instituts für angewandte Mechanik und den entsprechenden Assistentenakten hatte, hätte sich ein genaues Bild über die Hintergründe des Leitungswechsels verschaffen und feststellen können, dass Hohenemsers Grundaussage richtig war. Stattdessen verleumdete er Hohenemser und leistete seinen Beitrag zum Scheitern der Wiedergutmachung.

In der Diskussion um die Rückberufung von Emigranten beschloss die Fakultät im Januar 1946, „eine namentliche Liste der erwünschten Dozenten aufzustellen. Assistenten sollen, als nicht unter den Begriff »teacher« fallend, nicht genannt werden.“2123 Bezeichnend ist nicht nur die Vorsorge Euckens, Hohenemser als Assistent nicht auf die Liste setzen zu müssen, sondern auch die Spezifizierung, nur die erwünschten Dozenten aufzunehmen. ${ }^{2124}$

Hohenemser erfuhr von der Göttinger Rektorenkonferenz und von einer Liste unverschuldet amtsenthobener Hochschullehrer. Im Januar 1946 bat er den Rektor, in diese Liste aufgenommen zu werden. Dem Schreiben legte er Zeugnisabschriften über seine Tätigkeit seit der Promotion und eine Liste seiner insgesamt 37 wissenschaftlichen Veröffentlichungen bei. ${ }^{2125}$ Rektor Smend setzte Hohenemser auf die genannte Liste und leitete das Schreiben ans Ministerium nach Hannover (das eigentlich noch Oberpräsidium hieß, dann wieder Kultusministerium) weiter. ${ }^{2126}$ Dort trafen noch andere Informationen über den Fall Hohenemser ein.

\subsubsection{Hohenemser bekam Unterstützung von früheren Bekannten}

Im Februar 1946 setzte sich Oberregierungsrat Theo Hüpeden, der früher Hohenemsers Nachbar in Kassel war, für ihn beim Oberpräsidenten Kopf in Hannover ein.

\footnotetext{
2123 Protokoll der Kommissionssitzung, Mittwoch 23. Januar 1946. GPAMNFG, Protokollbuch III der mathematisch-naturwissenschaftlichen Fakultät WS 1927/28 - SS 1946.

2124 Zur allgemeinen Diskussion um Rückberufungen, den Entscheidungen der Universität und ihren Folgen siehe Abschnitt 1.3.3.

2125 Hohenemser an Rektor, 21. Januar 1946. HStAH, Nds. 401, Acc. 92 / 85, Nr. 135.

2126 Rektor Smend an Kurator, 8. Februar 1946. HStAH, Nds. 401, Acc. 92 / 85, Nr. 135.
} 
„Seine Wiedereinstellung ist aber bisher von Göttingen verweigert worden, weil Herr Hohenemser mit irgend einem mir unbekanntem Herrn der neuen Aera im Sommer vorigen Jahres einen persönlichen Konflikt hatte. So wie ich die Angelegenheit kennen gelernt habe, handelt es sich dabei wirklich um eine Belanglosigkeit, die das Rektorat einer Hochschule von dem Range Göttingens heute unter keinen Umständen zur Begründung der Ablehnung eines tüchtigen Mannes gelten lassen dürfte. Darf ich, sehr geehrter Herr Oberpräsident, wohl bitten in der Angelegenheit Hohenemser $\mathrm{zu}$ intervenieren und wenn irgend möglich dafür zu sorgen, daß Herr Hohenemser rehabilitiert wird. Es ist m. E. auch aus politischen Gründen für uns unhaltbar, wenn ein politisch absolut zuverlässiger Mensch heute aus belanglosen persönlichen Motiven heraus in die Ecke gestellt wird.“2127

Diese Bitte scheint keinen besonderen Einfluss auf die Entscheidung des Ministeriums genommen zu haben. Es waren auch, anders als von Hüpeden behauptet, durchaus keine belanglosen Motive, die die Universität zu ihrer Abwehrhaltung brachte. Doch über die Nachkriegsidentität der Universität, und wie sie auszusehen hat und herzustellen ist, wurde in diesem Fall nicht offen debattiert. Die Leitung der Hochschulabteilung im niedersächsischen Kultusministerium hatte im fraglichen Zeitraum Kurt Zierold. Während der NS-Zeit war Zierold Vorsitzender der „Reichsanstalt für Film und Bild in Wissenschaft und Unterricht“ und war damit in einem Bereich tätig, der von starker parteipolitischer Einflussnahme geprägt war. ${ }^{2128}$

Zum neuen Kultusminister Adolf Grimme hatte Hohenemser Beziehungen über gemeinsame Bekannte (Tillmanns), aber er scheint nicht persönlich versucht zu haben, diese für seine Wiedereinstellung auszunutzen. Grimme hatte wie Hohenemser Kontakte zur „Roten Kapelle“. Wegen dieser Verbindung wurde Grimme 1942 zu drei Jahren Zuchthaus verurteilt. ${ }^{2129}$ Nach Kriegsende befreit wurde Grimme zuerst Regierungsdirektor in Hannover und dann im August 1946 Volksbildungsminister im ersten Kabinett des Landes Hannover (später Niedersachsen). Nach der Landtagswahl im Frühjahr 1947 übernahm Grimme das Kultusministerium. ${ }^{2130}$ Im April 1946 setzte sich Hertha Tillmanns bei Grimme für Hohenemser ein. ${ }^{2131}$ Einer eventuellen Förderung Hohenemsers stand aber entgegen, dass Grimme sich mit Rektor Smend menschlich sehr verbunden fühlte. Er gratulierte ihm

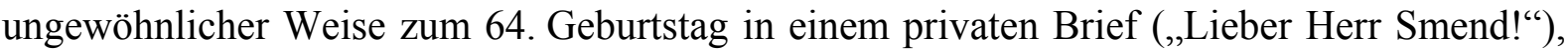

\footnotetext{
2127 Oberregierungsrat Theo Hüpeden an Oberpräsident Kopf, 1. Februar 1946. In der Antwort vom 4. Februar 1946 heißt es, dass in der Angelegenheit Hohenemser ,die weitere Verfolgung veranlaßt“ wurde. HStAH, Nds. 401, Acc. 92 / 85, Nr. 135.

2128 Angaben nach Munzinger-Archiv.

2129 Angaben nach Munzinger-Archiv.

2130 Angaben nach Munzinger-Archiv.

2131 Hertha Tillmanns an Adolf Grimme, 10. April 1946. HStAH, Nds. 401, Acc. 92 / 85, Nr. 135.
} 
den er mit den Worten schloss: „Menschen, wie Sie, braucht unser armes geschlagenes Volk so dringend. “2132 Außerdem war der geschäftsführende Kurator Hans-Waldemar Freytag einer der besten Jugendfreunde „und besonders lieber Kamerad“ von Grimme. Es war dann auch Grimme, der dem „nur ganz kurze Zeit in der Partei gewesenen“ Freund auf den Kuratorposten in Göttingen setzte. ${ }^{2133}$ Vermutlich hatten die Eingaben des Rektors und Kurators bei Grimme mehr Gewicht als die Bitte Hertha Tillmanns. Sie wandte sich nicht nur an Grimme, sondern mündlich und schriftlich auch an Zierold. ${ }^{2134}$ Doch es scheint so, als habe sich das Ministerium die Strategie der Universität zu eigen gemacht. Es ließ sich jedenfalls mit der Bearbeitung sehr viel Zeit. Zwei Monate vergingen, ohne dass Hohenemser eine Nachricht bekam. Er entschloss sich zu seiner dritten Reise nach Göttingen.

\subsubsection{Hohenemser sprach im Ministerium vor}

Einen Tag hielt er sich in Göttingen auf, besprach sich unter anderem mit Düker, dem Mechanikermeister Hoffmann und dem Kurator, ${ }^{2135}$ und reiste dann weiter zum Oberpräsidium in Hannover. Dort hatte er eine Besprechung mit Ministerialrat Zierold, der ihm kund tat, dass keine Stelle für ihn frei sei, worauf Hohenemser energischer als für ihn üblich auftrat ${ }^{2136}$ und eine beschleunigte Erledigung seiner Wiedergutmachung forderte. Als mögliches Arbeitsprogramm schlug er dem Oberpräsidium vor, die Forschung zur Kontinuumsmechanik plastischer und zäher Stoffe wieder aufzunehmen. Er nannte also ein Forschungsgebiet, das im Institut unter Prandtls Leitung üblich war. „Das Verhältnis zur Institutsleitung denke ich mir in ähnlicher Weise geregelt, wie es vor 1934 zwischen Herrn Professor Schuler einerseits und dem damaligen Institutsleiter Professor Prandtl andererseits bestanden hat; das bedeutet vollkommene Unabhängigkeit von der Institutsleitung mit dem Recht der Benutzung der Institutseinrichtungen und der Werkstatt bis zu etwa 1/3 ihrer etatmässigen Kapazität.“ Hohenemser forderte für sich Bezüge, „die mindestens einer planmässigen Assistentenstelle entsprechen, wie sie mir 1933 entzogen wurde, bzw. die Erteilung einer Diätendozentur.“ Er betonte, dass er nicht als Stellungssuchender anzusehen sei, sondern dass es sich um eine Mindestforderung der Wiedergutmachung handele, die ganz

\footnotetext{
2132 Grimme an Smend, 12. Januar 1946. GStAPK, I HA Rep. 92, Grimme 2359.

2133 Grimme an Freytag, 24. September 1945; Grimme an Schrader, 24. September 1945; Freytag an Grimme, 8. Dezember 1945. GStAPK, I HA Rep. 92, Grimme 1539.

2134 Zierold an Hohenemser, 26. April 1947.

2135 Hohenemser an Kurator, 18. November 1946, mit der schriftlichen Bitte um Besprechung, da er den Kurator telefonisch nicht erreichen konnte. UAG, Kur. PA Hohenemser.

2136 Hohenemser an Prager, April 1946. KHP. Hohenemser an Courant, 21. Mai 1946. Library of Congress, Veblen papers, Box 4.
} 
unabhängig davon bestehe, wie die Stellen besetzt waren. ${ }^{2137}$ Das Ministerium reagierte prompt und hob am 25. März 1946 die 1933 erfolgte Entziehung der Lehrbefugnis auf. ${ }^{2138}$ Hohenemser informierte die Universität, dass $\mathrm{ihm}$ in Hannover eine planmäßige Assistentenstelle bzw. eine Diätendozentur zugesagt worden sei. ${ }^{2139}$ Daraufhin konstruierten Schuler und der Kurator eine neue 'Argumentation' zur Abwehr Hohenemsers. ${ }^{2140}$ Das von Hohenemser angegebene Forschungsprogramm gehöre an eine TH, denn die Fakultät vertrat den Standpunkt, „dass das hiesige Institut für angewandte Mechanik in erster Linie mit der theoretischen Physik und der Mathematik zusammenarbeiten muss. Denn Göttingen ist ja der »Nabel« der Mathematik von ganz Deutschland.“2141 Diese Darstellung ist ein Baustein in der Konstruktion einer Nachkriegsidentität des Instituts. Die so vollkommen unterschiedlichen politischen Kontexte, die der nationalsozialistische Krieg und das besetzte Deutschland boten, brachten die Professoren dazu, innerhalb kurzer Zeit in derselben Sache vollkommen entgegengesetzt zu 'argumentieren'. 1938 begründete der Professor der Metallkunde, Georg Masing, die Schaffung eines Extraordinariats für angewandte Mechanik mit „der Göttinger Tradition, die neben der grundsätzlichen Pflege der Wissenschaft vor allen Dingen auch ihre lebensnahe Anwendung im Auge hat." Felix Kleins Förderung der angewandten Wissenschaften wird hier unmittelbar mit Schuler in Verbindung gebracht. 1938 stand die Festigkeitslehre noch argumentativ im Vordergrund: „Durch Schaffung eines lebensfähigen Instituts für angewandte Mechanik wird der erste Schritt zur Schaffung einer Art der grundsätzlichen Akademie der Stoffkunde in Verbindung mit der Physik, Chemie und Kristallographie getan." 2142 Zur selben Zeit betonte auch Schuler die Hinwendung zur praktischen Anwendung in seinem Institut: „Als ich 1934 das Institut übernahm, habe ich sofort den Arbeitsplan des Institutes, der früher auf reine Forschung eingestellt war, dahin umgestellt, daß den Studierenden vor allem die praktische Ausbildung auf dem Gebiete der Mechanik ermöglicht werden sollte.“2143 Und zur Verteidigung des Instituts an einer Universität formulierte er: „Sollte der Einwand gemacht werden, daß solche Forschungen in

${ }^{2137}$ Hohenemser an Oberpräsidenten der Provinz Hannover, Hauptabteilung Kultus, 20. März 1946. HStAH, Nds. 401, Acc. 92 / 85, Nr. 135. Siehe auch Hohenemser an Prandtl, 21. März 1946. KHP.

2138 Oberpräsident (Bearbeiter Zierold) an Hohenemser, 25. März 1946. HStAH, Nds. 401, Acc. 92 / 85, Nr. 135.

2139 Hohenemser an Rektor, 21. März 1946. KHP.

2140 Siehe die Entscheidung der Fakultät, Schuler und den Kurator mit der Ausarbeitung eines Vorschlags zu beauftragen. Protokoll der Fakultätssitzung, 30. März 1946. GPAMNFG, Protokollbuch III der mathematischnaturwissenschaftlichen Fakultät WS 1927/28 - SS 1946.

2141 Schuler an Kurator, 2. April 1946. UAG, Kur. PA Hohenemser.

2142 Siehe Masings „Begründung für die Errichtung eines planmässigen Extra-Ordinariats für angewandte Mechanik in Göttingen“, undatiert, wahrscheinlich Mitte 1938. UAG, Math.-nat. Fak 24 a. 
erster Linie in das Gebiet der technischen Hochschulen fallen, so ist darauf zu erwidern, daß die Sondergebiete, die oben aufgezählt sind [Kreisellehre, Schwingungslehre, Pendelmessungen und Festigkeitslehre], ein enges Zusammenarbeiten mit der höheren Mathematik, der Physik und Aerodynamik verlangen. Diese Verhältnisse liegen hier in Göttingen besonders günstig, da sich hier die großen Institute für Mathematik und Aerodynamik befinden.“2144 Ganz ähnlich argumentiert die Fakultät Ende 1939, als Schuler die Annahme eines Rufs nach Hamburg überlegte: „Sein drohender Ausfall würde damit eine große Lücke und eine große Störung in der traditionellen technischen Arbeit der Fakultät bedeuten. Diese Richtung hat andererseits durch den Neubau des Instituts, der vor seinem Ende steht, eine Anerkennung gefunden, was unbeachtet zu bleiben scheint.“2145

All diese Umdeutungen zeigen nur die Aussichtslosigkeit, aus den Kriegs- und Nachkriegsdarstellungen einen „wahren Kern“ herauszudestillieren. Die Selbstdarstellungen waren nicht auf das tatsächliche Forschungsprogramm am Institut zugeschnitten, sondern auf das, was der Empfänger vom Institut vermeintlich erwartete. Im konkreten Fall wurden die Darstellungen so konstruiert, dass Hohenemser im Institut keinen Platz hatte. Hohenemsers Vorschlag, die bis 1933 am Institut üblichen Arbeiten mit den noch vorhandenen Maschinen und Apparaten wieder aufzunehmen, standen eigentlich keine praktischen Hindernisse im Weg. Auch eine Genehmigung der Forschung, die keine Rüstungsforschung war, sondern grundsätzliche Fragen der Festigkeitslehre betraf, wäre vor allem unter dem Gesichtspunkt der Wiedergutmachung einfach von der Militärregierung zu erhalten gewesen. Ende März 1946 glaubte Hohenemser an das Gelingen seiner Rehabilitierung und freute sich darauf, Probleme der Plastizitätsmechanik wieder bearbeiten zu können. ${ }^{2146}$ Die Freude wurde getrübt durch Prandtls Mahnung, er müsse sich nun bei Schuler entschuldigen, da sonst eine reibungslose Eingliederung in den Lehrkörper unmöglich sei. ${ }^{2147}$ Für eine Entschuldigung sah Hohenemser gar keine Veranlassung. ${ }^{2148}$ Er informierte Schuler, dass er die

2143 Aus Schulers Darstellung über das Institut vom 14. Januar 1938, Hervorhebung original. UAG, Math.-nat. Fak. 24 a.

2144 Schuler: „Die Bedeutung des Instituts für angewandte Mechanik an der Universität Göttingen“, 19. Juli 1938. UAG, Math.-nat. Fak. 24 a.

2145 Dekan an REM, 22. Dezember 1939, Hervorhebung original. UAG, Kur. PA Schuler.

2146 Siehe Hohenemser an Prandtl, 21. März 1946. KHP.

2147 Prandtl an Hohenemser, 26. März 1946. Dieser Brief ist leider nicht erhalten. Sein Inhalt lässt sich aus den folgen Briefen Prandtls und Hohenemsers Antworten rekonstruieren.

2148 Hohenemser an Prandtl, 16. April 1946. MPG-Archiv, III, 61, 692. An Courant schrieb Hohenemser am 21. Mai 1946 diesbezüglich: „Von Herrn Prof. Prandtl bekam ich einen Brief, in welchen er mir schrieb, Herr Schuler sei sehr zornig auf mich, und ich solle mich vor Antritt meiner Göttinger Tätigkeit bei ihm entschuldigen. Ausserdem sei es eine Unmöglichkeit, dass ich mir durch behördlichen Druck auf Herrn Prof. Schuler einen Platz in seinem Institut verschaffe. Das war mir denn doch zu viel. Einem Mann gegenüber, der in 
Wiedereinstellung an der Universität Göttingen bald erwarte und Arbeiten auf dem Gebiet der Mechanik plastischer und zäher Stoffe am Institut fortzusetzen gedenke. „Ich nehme an, dass Sie gegen eine Inanspruchnahme der Institutseinrichtungen und eines Teiles der Werkstattkapazität innerhalb noch zu vereinbarender Grenzen nichts einzuwenden haben werden.“2149 Die Forderung nach unabhängig vom Institutsleiter durchzuführenden Forschungen wurde in Göttingen wieder als Angriff gegen Schuler gedeutet. Prandtl wiederholte seine Mahnung:

„Wenn Sie hier Ihre Lehrtätigkeit wieder aufnehmen, so hängt der Erfolg zu einem guten Teil von Ihrer reibungslosen Eingliederung in den Lehrkörper ab, und diese Eingliederung ist durch Ihre Methode gefährdet. [...] Danach stellen Sie den Anspruch, nicht nur Arbeitsräume im Institut für angewandte Mechanik sondern auch das Verfügungsrecht über ein Drittel des Sachetats zu erhalten und ebenso die Verfügung über ein Drittel der Arbeitsstunden des Werkstattpersonals. Etwas Derartiges kann nicht in Betracht kommen. Die Verantwortung für die Leitung eines Instituts und die Verfügungsberechtigung über das Personal und das Inventar muß in einer Hand bleiben. [...] Zur Begütigung der begreiflichen Mißstimmung von Herrn Schuler gegen Sie, zu der ich Ihnen erneut raten möchte, handelt es sich garnicht darum, daß Sie Ihre früheren Äußerungen zurücknehmen, sondern nur darum, daß Sie durchblicken lassen, daß Sie jetzt wünschen, die damaligen Äußerungen nicht gemacht zu haben, und daß Sie ihn bitten, die Sache als begraben anzusehen. Ich kann mir nicht vorstellen, wie sich ohne einen solchen Schritt von Ihrer Seite eine fruchtbare Zusammenarbeit zwischen Ihnen und Professor Schuler erzielen lassen soll.“"2150

Der Ratschlag Prandtls, Hohenemser solle doch Schuler signalisieren, dass „die Sache als begraben anzusehen“ sei, charakterisiert meines Erachtens deutlich, wie ein kollegiales Verhältnis zwischen Wissenschaftlern in dieser Zeit funktionierte. Prandtl und Schuler unterhielten weiterhin ein kollegiales Verhältnis, selbst nachdem 1934 der Leitungswechsel durchgesetzt und die Auseinandersetzung um die Assistentenstelle ausgefochten worden war. Das Begraben von vergangenen Streitpunkten scheint ein Element dieser Kollegialität gewesen zu sein. Wie diese Kollegialität 1946 wirkte, ersieht man an der Reaktion Schulers auf Hohenemsers angekündigtes Kommen. Er formulierte zwei Eingaben an den Dekan, wobei die längere wohl seinen eigenen ablehnenden Standpunkt darlegt, und die zweite

\footnotetext{
der Villa eines vertriebenen jüdischen Bürgers sitzt, der das Ordinariat eines vertriebenen jüdischen Kollegen inne hat, (Bernstein), der durch politischen Druck seiner Nazischüler ein Institut erworben hat, der mich bei meinem Besuch wie einen unerwünschten Hausierer abgefertigt hat, soll ich mich entschuldigen, weil ich gewagt habe, an seine nicht sehr einwandfreie Vergangenheit zu rühren und ihn höflichst um einen Platz an seinem Institut bitten! Ich lehnte dies eindeutig ab und zog mir dadurch weitere ernste Ermahnungen durch Herrn Prof. Prandtl zu, der mir schrieb, die Eingliederung in den Lehrkörper der Universität sei durch meine Methoden gefährdet." Library of Congress, Veblen papers, Box 4.

2149 Hohenemser an Schuler, 16. April 1946. GPAMNFG, Lehrkörper (ausgeschieden), Hohenemser.

2150 Prandtl an Hohenemser, 29. April 1946, Hervorhebung original. MPG-Archiv, III, 61, 692.
} 
kürzere vier Kompromisslösungen auflistet, die sehr wahrscheinlich von Prandtl in dieser Art vorgeschlagen wurden. In der ablehnenden Stellungnahme behauptete Schuler, es sei kein Platz für die Festigkeitslehre vorhanden, es müssten neue Räume errichtet und neue (Werkzeug-)Maschinen angeschafft werden. Für Hohenemsers Forschungen reiche der Sachetat nicht aus, es bedürfe eines eigenen Forschungsetats für ihn, außerdem einer eigenen Werkstatt mit eigenem Personal. Alles zusammen würde eine Ausgabe von RM 50000 notwendig machen „(nach Vorkriegspreisen gerechnet)“. Das war ein fantastisches Ausbauprogramm des Instituts für die Anstellung nur eines Assistenten, formuliert zu einer Zeit, als unkomplizierte Ad-hoc-Lösungen in der Personalpolitik üblich waren. Im zweiten Schreiben heißt es hingegen: „Nun habe ich noch folgende persönliche Anregungen in dieser Sache zu geben, bei denen ich mit Herrn Prof. Prandtl übereinstimme. Die Errichtung eines neuen Institutes für Herrn Hohenemser wird von heute auf morgen nicht möglich sein. [...] Dagegen besteht eine Lücke an der Universität Göttingen in dem Lehrplan der angewandten Mathematik und der Mechanik, die Herr Hohenemser während dieser Zeit auch ohne daß er ein Institut besitzt, gut ausfüllen könnte.“ Die vermutlich von Prandtl vorgeschlagenen vier Lehrgebiete waren: 1) Nummerisches Rechnen, 2) Mathematische Instrumente, 3) Theoretische Festigkeitslehre und 4) Graphische und analytische Statik. „Ich glaube, hiermit ein umfangreiches, gutes und fruchtbares Lehrgebiet für Herrn Hohenemser vorgeschlagen zu haben, wobei er als junger Dozent zeigen kann, welche Kenntnisse und Fähigkeiten er besitzt.“ 2151

Im Laufe des Instanzenwegs wurde Schulers erste Stellungnahme besonders vom Kurator noch weiter übertrieben. Von Eucken wurde aber vorher noch ein anderer heikler Punkt gegen Hohenemser ins Spiel gebracht. Ein Assistent habe sich dem Institutsdirektor unterzuordnen. Da dies von Hohenemser nicht erwartet werden könne, bliebe nur die Lösung, ihm eine Diäten-Dozentur zu übertragen. Das geschehe normalerweise erst nach einer Bewährung in Forschung und Lehre, die Hohenemser nicht vorzuweisen habe.

„Wenn auch zugegeben werden muss, dass diese Mängel keineswegs durch ein Verschulden Dr. Hohenemsers bedingt sind, so sieht sich die Fakultät doch veranlasst nachdrücklich darauf hinzuweisen, dass durch die Verleihung einer Diäten-Dozentur an Dr. H. ein sehr bedenklicher Präzedenzfall geschaffen werden würde, in dem hier, wieder ähnlich wie es im Dritten Reich öfter geschah, einem Anwärter eine akademische Stellung aus einem anderen Grunde verliehen würde, als dem einer Bewährung in Lehre und Forschung. Die Deutsche Universität wird in Zukunft unmöglich ihren ohnehin überaus schwierigen Aufgaben gerecht

2151 Zwei Schreiben von Schuler an den Dekan Eucken, 30. April 1946. GPAMNFG, Lehrkörper (ausgeschieden), Hohenemser. 
werden können, wenn der Grundsatz akademische Stellungen lediglich auf Grund einer Bewährung in Lehre und Forschung zu besetzen, nicht strikte gewahrt wird und wenn sie daher zu einer Art Versorgungsanstalt solcher würde, die politische Ansprüche an den heutigen Staat zu haben glauben." 2152

Dieser Standpunkt kam der Verweigerung einer Wiedergutmachung für junge Forscher wie Hohenemser gleich. Dieser Schritt erschien aber notwendig, wenn das Selbstbild erzeugt werden sollte, dass Stellen nur nach einer Bewährung in Lehre und Forschung vergeben werden. Dieses Bild diente der Legitimation der Hochschulen in der Nachkriegszeit, hatte aber mit den tatsächlichen Verhältnissen der Stellenvergabe wenig zu tun. Eucken hielt Hohenemsers Forderungen auch die hierarchische Organisation der Universität als alte akademische Tradition entgegen. Privatdozenten durften auch nach der gerade von Eucken formulierten neuen Habilitationsordnung zwar Hörsäle und Seminare unentgeltlich benutzen, die Benutzung von Instituten und Sammlungen bedürfe aber der Erlaubnis der zuständigen Direktoren. ${ }^{2153}$ Schuler hatte also ein Recht, Hohenemser die Benutzung des Instituts zu verweigern.

Wie oben schon angedeutet, verschärfte der Kurator Freytag selbständig die Argumentation gegen Hohenemser. Indem er implizit die Gültigkeit von Hohenemsers Habilitation von 1932 in Zweifel zog, stellte er in Frage, „ob er sich überhaupt zum Hochschullehrer eignet“. Die Forderungen Hohenemsers gab Freytag verfälscht wieder. Neben den Gehaltsforderungen wolle er laut Freytag „1/3 der Institutseinrichtungen, der Werkstatt und der Sachmittel des Instituts für angewandte Mechanik unter vollkommener Unabhängigkeit von der Institutsleitung“. Zum Vergleich der Originalwortlaut: ,[...] das bedeutet vollkommene Unabhängigkeit von der Institutsleitung mit dem Recht der Benutzung der Institutseinrichtungen und der Werkstatt bis zu etwa 1/3 ihrer etatmässigen Kapazität.“ Aus einer Verhandlungsbasis mit einer Obergrenze von einem Drittel der Kapazität machte Freytag eine nummerisch festgelegte Forderung. Durch diese Ungenauigkeit in der Formulierung wurde in Kauf genommen, dass die Forderungen vom Ministerium als Unverschämtheit oder mindestens anmaßend wahrgenommen wurden. Freytags Sprache ist sehr entschieden. Hohenemsers Forschungen ,gehören überhaupt nicht an eine Universität,

\footnotetext{
2152 Protokoll der Fakultätssitzung vom 3. Mai 1946. GPAMNFG, Protokollbuch III der mathematischnaturwissenschaftlichen Fakultät WS 1927/28 - SS 1946.

2153 Dekan Eucken an Kurator, 9. Mai 1946. HStAH, Nds. 401, Acc. .92 / 85, Nr. 135. Siehe $§ 9$ der Habilitationsordnung, deren selbst formulierten Entwurf Eucken am Tag zuvor im Senat gegen anfängliche Bedenken der juristischen Fakultät zur Annahme bringen konnte. Protokoll der Senatssitzung vom 8. Mai 1946. UAG, Senatsprotokolle 1945-1949. Rektor Rein schloss sich Euckens Stellungnahme an. Rektor Rein an Kurator, 13. Mai 1946. HStAH, Nds. 401, Acc. 92 / 85, Nr. 135.
} 
sondern an eine technische Hochschule. Die meisten Maschinen, die Dr. Hohenemser für seine Arbeiten braucht, sind im Institut nicht vorhanden, sondern müssten erst angeschafft werden. Ob sie überhaupt beschafft werden können, ist zweifelhaft.“ Aus Schulers angeblich benötigten RM 50000 machte Freytag mindestens 75 - 100000 RM. ${ }^{2154}$ Wie absurd diese Geldsummen sind zeigt der knapp ein Jahr später in Angriff genommene Umbau des Instituts für den neuen Ordinarius, der wirklich eine andere Forschungsrichtung vertrat. Für die komplette apparative Neuausstattung wurde ein Kostenaufwand von 50000 RM veranschlagt. ${ }^{2155}$

Hohenemsers Reaktion auf diese Art von Argumentation geht aus einem Brief an seinen Kollegen Flachsbart ${ }^{2156}$ von der TH Hannover hervor: „Ich musste laut lachen. Diese Art der Abhalfterung ist doch etwas gar zu primitiv."2157 Über die Missinterpretationen seines Antrags wurde Hohenemser von Prandtl informiert. Ohne ihn wäre er in einer deutlich schlechteren Verhandlungsposition gewesen, denn von offizieller Seite kamen nur spärlich und dann kurze Benachrichtigungen über den Stand der Angelegenheit. Er versuchte die Missdeutungen aufzuklären, schrieb an Prandtl und Schuler, dass seine Forderungen nur als Grundlage noch zu führender Verhandlungen gedacht waren, wie auch aus seinem früheren Schreiben an Schuler hervorging.

„Ich kann mir nicht vorstellen, auf welche Weise Schwierigkeiten oder Reibungen entstehen sollen, wenn ich mich als Gast in Herrn Prof. Schulers Institut einfüge, und wenn er meinen Anspruch auf Wiedergutmachung des Unrechts anerkennt, das mir angetan wurde, und mir gewisse Benutzungerechte an seinem Institut einräumt, die im einzelnen noch zwischen ihm und mir nach der Entscheidung des Herrn Oberpräsidenten über meinen Antrag zu vereinbaren wären. “2158

\subsubsection{Hohenemsers Bemühungen um eine Schulstelle}

Im Frühjahr 1946 trat ein Wandel in Hohenemsers Berufsplanung ein. Die Chancen auf einen positiven Ausgang der Rehabilitierung schätzte er nach den erneuten Missinterpretationen und Widerständen nicht mehr hoch ein. Er machte sich nun Gedanken um alternative

\footnotetext{
2154 Stellungnahme des mit Wahrung der Geschäfte beauftragten Kurators Freytag an den Oberpräsidenten in Hannover, 20. Mai 1946. HStAH, Nds. 401, Acc. 92 / 85, Nr. 135.

2155 Kurator Bojunga (nicht Freytag!) an Ministerium, 28. März 1947. UAG, Kur. PA Meyer.

2156 Otto Flachsbart zählte zu den im Nationalsozialismus entlassenen Hochschullehrern, die 1945 den Wiedereinstieg schafften. Im Oktober 1937 wurde er auf Grund der Rassegesetzte in den Ruhestand versetzt. Am 1. Oktober 1945 wurde er auf den Lehrstuhl für Mechanik der TH Braunschweig berufen, kurz darauf wurde er dort Dekan und von 1947-1950 Rektor. Schneider [1989] S. 333.

2157 Hohenemser an Flachsbart, 6. September 1946. KHP.

2158 Hohenemser an Prandtl, 20. Mai 1946. MPG-Archiv, III, 61, 692. Praktisch gleichlautend schrieb er am selben Tag auch an Schuler. HStAH, Nds. 401, Acc. .92 / 85, Nr. 135.
} 
Beschäftigungen. Schon am 25. März 1946 bewarb er sich beim Regierungspräsidenten in Darmstadt für den höheren Schuldienst. In seinem Bewerbungsschreiben bemerkte er aber, dass es sich vielleicht nur um eine vorrübergehende Tätigkeit handeln werde. Ohne sachliche Vorbereitung könne er Mathematik und Physik unterrichten, später unter Umständen auch Biologie. ${ }^{2159}$ Im Mai 1946 fand ein Vorstellungsgespräch statt und Ende Mai bekräftigte Hohenemser nochmals schriftlich sein Interesse am Schuldienst in Darmstadt. Die Schwierigkeiten in Göttingen verleideten ihm die Wiederaufnahme seiner dortigen Lehrtätigkeit, sodass er ,unter den gegebenen Verhältnissen sehr wahrscheinlich nach meiner vollen Rehabilitierung auf die Übernahme meines dortigen Amtes verzichten werde.“ Hohenemser hoffte, in den folgenden Wochen das endgültige Angebot des Ministeriums auf Wiedereinsetzung in seine alte Stelle in Händen zu haben. Wenn dann die Darmstädter Schule noch an ihm interessiert sei, würde er sich sehr auf diese Tätigkeit freuen, da er, „was die Leitung betrifft, die Gewähr hätte, nicht an dem »nationalen« Geist Anstoss nehmen zu müssen, der jetzt an so vielen Stellen wieder oben auf ist, der sich betont christlich gibt, und

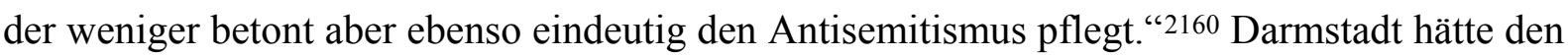
Vorteil gehabt, dass er dort mit seinem Freund und Professor an der TH, Gustav Mesmer, und dessen Familie zusammen gekommen wäre. Er hat die Lehrerstelle in Darmstadt aber nicht wahrgenommen. Während Hohenemsers Suche nach anderen Beschäftigungsmöglichkeiten trat in Göttingen eine gravierende Veränderung ein.

\subsubsection{Schulers frühzeitige Emeritierung. Diskussion um die Zukunft des Fachs}

Durch einen Aktenfund, in dem Schuler von Gengler in bedenklicher Weise gelobt wurde, forderte die Militärregierung Schuler auf, seine (frühzeitige) Emeritierung zu beantragen. ${ }^{2161}$ Dies kam wohl für alle Beteiligten überraschend, denn die Ende 1945 erfolgte Aufforderung an die Universität, fördernde Mitglieder der SS nachträglich zu melden, blieb für Schuler ohne Konsequenzen, sodass alle naheliegenden Gefahren einer Entnazifizierung als überstanden schienen. ${ }^{2162}$ Heinrich Düker schrieb euphorisch an Hohenemser:

\footnotetext{
2159 Hohenemser an den Herrn Regierungspräsidenten in Darmstadt, 25. März 1946. KHP.

2160 Hohenemser an den Direktor einer Darmstädter Schule, 22. Mai 1946. KHP.

2161 Wiedergegeben nach einem Brief von Prandtl an Hohenemser vom 28. Mai 1946, in dem es heißt: „Professor Schuler ist wegen eines aufgefundenen Aktenvermerks des Kreisleiters über ihn, in dem sein Verhalten in einer für heutige Verhältnisse bedenklichen Weise gelobt worden ist, von der britischen Aufsichtsstelle der Universität veranlaßt worden, seine Überführung in den Ruhestand zu beantragen. “ MPGArchiv, III, 61, 692.

2162 Die Aufforderung zur Meldung der fördernden Mitglieder der SS kam Anfang Dezember 1945. Siehe Protokoll der Senatssitzung vom 5. Dezember 1945. UAG, Senatsprotokolle 1945-1949.
} 
„Packen Sie Ihren Koffer und kommen Sie nach hier. Herr Schuler ist nämlich entlassen worden. Das Institut ist also ohne Chef. Ich nehme an, daß das Kuratorium Sie schon aufgefordert hat, nach hier zu kommen. Wie mir mitgeteilt worden ist, wurde Herr Schuler pensioniert. An eine Rückkehr ist also nicht mehr zu denken, so daß Sie hier nötig sein werden.“"2163

Düker zeigte wenig Gespür für die Verhältnisse in der Wiedergutmachungsangelegenheit Hohenemser. Da die Fakultät bis dahin Hohenemsers Anträge vornehmlich als Angriffe auffasste, ist es nicht verwunderlich, dass sie auch hinter der verordneten Emeritierung sein Treiben vermutete. ${ }^{2164}$ Die Situation wurde deshalb für Hohenemser nur noch verwickelter. Der Senat befürwortete ein sofortiges Pensionierungsgesuch von Schuler. ${ }^{2165}$ Am 17. Mai 1946 bat Schuler, von den Verpflichtungen als Institutsdirektor entbunden zu werden, reichte sein Gesuch um Emeritierung ein, und begründete dies mit seinem schlechten Gesundheitszustand. ${ }^{2166}$ Zwei ärztliche Atteste legte er dem Gesuch bei. Mit Ablauf des 31. Mai 1946 wurde er von den amtlichen Verpflichtungen entbunden. ${ }^{2167}$

\subsubsection{Die Diskussion um Schulers Nachfolge}

Die Fakultät beschloss für die Wiederbesetzung des Lehrstuhls folgende Viererliste: Walter Tollmien, Willy Prager, Egon Hiedemann und Werner Döring. ${ }^{2168}$ Für den Eingeweihten präsentiert sich die Liste als ein Ein-Personen-Vorschlag. Tollmien war in England für dortige Forschungen dienstverpflichtet und für Göttingen nicht zu haben. ${ }^{2169}$ Prager war Emigrant, von dem die Fakultät nicht einmal wusste, in welchem Land er sich aufhielt. ${ }^{2170}$ Er war der Pro-forma-Wiedergutmachungskandidat. ${ }^{2171}$ Bleibt allein Hiedemann übrig, denn Döring wurde nur auf die Liste gesetzt, um ihm bei anderen Berufungsverhandlungen Vorteile zu verschaffen. Die Fakultät beschloss nämlich für den Fall, „dass die Berufung Hiedemanns nicht zustandekommt, soll der Fakultät die Möglichkeit einer neuen Stellungnahme gegeben

\footnotetext{
2163 Düker an Hohenemser, 27. Mai 1946. KHP.

2164 Siehe Prandtl an Hohenemser, 28. Mai 1946. MPG-Archiv, III, 61, 692.

2165 Protokoll der Senatssitzung vom 15. Mai 1946. UAG, Senatsprotokolle 1945-1949.

2166 Schuler an Kurator (Freytag), 17. Mai 1946. Die Institutsdirektorvertretung übernahm Stellmacher. UAG, Kur. PA Schuler. Schuler an Kurator (Freytag), 17. Mai 1946. HStAH, Nds. 401, Acc. 112 / 83, Nr. 986.

2167 Oberpräsident von Hannover (Bearbeiter Zierold) an Kurator, 17. Juni 1946. HStAH, Nds. 401, Acc. 112 / 83, Nr. 986.

2168 Protokoll der außerordentlichen Fakultätssitzung vom 21. Mai 1946. GPAMNFG, Protokollbuch III der mathematisch-naturwissenschaftlichen Fakultät WS 1927/28 - SS 1946.

2169 Tollmien war durch einen Vertrag in England vom 1. Juni 1946 bis zum 31. August 1947 als German Scientist an das Royal Aircraft Establishment in Farnborough (Hants) gebunden.

2170 Dass Prager inzwischen Professor an der Brown University in den USA geworden war, bekam Prandtl schließlich von Hohenemser mitgeteilt. Hohenemser an Prandtl, 2. Juni 1946. MPG-Archiv, III, 61, 692.
} 
werden.“2172 Offiziell argumentierte die Fakultät gegenüber dem Ministerium, dass sie das Institut stärker auf zweckfreie Grundlagenwissenschaft ausrichten wolle. „Eine derartige Anpassung an die einem dauernden Wechsel unterworfenen Unterrichts- und Forschungsbedürfnissen entspricht durchaus dem Standpunkt Felix Kleins, dessen Weitblick die Fakultät durch die Schaffung einiger kleinerer physikalischer Lehrstühle und Institute eine ausserordentlich fruchtbare Entwicklung verdankt.“2173 Obwohl Felix Klein hier mit seinem Namen herhalten musste, war das Gegenteil vom ursprünglichen Klein'schen Programm geplant. Während sich Klein für den Ausbau der angewandten Physik in Göttingen erfolgreich eingesetzt hatte, ging die Fakultät 1946 daran, die Institute der angewandten Physik zu schließen (siehe Abschnitt 5.5).

Die Berufungsliste bestand nur aus Physikern mit früherem Bezug zu Göttingen und mit Ausnahme Pragers um welche, die ihre Hochschulstelle kriegsbedingt verloren hatten (in Dresden, Straßburg und Posen). Der erstgereihte Walter Tollmien war Schüler von Prandtl und seit 1938 Ordinarius an der TH Dresden. Nach der Bombardierung Dresdens im Februar 1945 kam er im März als Flüchtling in Göttingen an, wo er seine Forschungstätigkeit fortsetzen konnte. „Hierbei wurde ich durch die Professoren der Göttinger Universität Dr. L. Prandtl und Dr. Th. Kaluza bereitwillig und nachhaltig unterstützt, indem mir Arbeitsräume und andere Hilfsmittel zur Verfügung gestellt wurden.“2174 Egon Hiedemann war Schüler von James Franck. Ab 1942 war er Ordinarius am Institut für angewandte Physik in Straßburg. Sein Spezialgebiet war die Ultraschallforschung. ${ }^{2175} \mathrm{Zu}$ Werner Döring siehe Abschnitt 1.3.4.5.

Von Hohenemser war nicht die Rede. Dies zeigt, dass es sich eben nicht bloß um einen Streitfall zwischen Schuler und Hohenemser gehandelt hat. Nach dem Wegfall Schulers hätte die Fakultät mehrere Möglichkeiten gehabt, Hohenemser eine Wiedergutmachung zukommen zu lassen. Obwohl Hohenemser 1933 bereits als fähig gehalten wurden, das Institut für angewandte Mechanik zu leiten, wurde mit der Vertretung der Institutsleitung der planmäßige Assistent Karl Stellmacher beauftragt. Mit der Wahrnehmung der Geschäfte des

\footnotetext{
2171 Dass solche taktischen Nennungen von Emigranten auf Berufungslisten bei gleichzeitiger und tatsächlicher Bevorzugung von den aus dem Osten ,heimatvertriebenen“ Wissenschaftlern an den deutschen Universitäten der Besatzungszeit üblich waren, zeigen neuere Forschungen zur Remigration. Siehe Krohn [2002] S. 450. 2172 Protokoll der außerordentlichen Fakultätssitzung vom 21. Mai 1946. GPAMNFG, Protokollbuch III der mathematisch-naturwissenschaftlichen Fakultät WS 1927/28 - SS 1946.

2173 Dekan an Oberpräsident in Hannover, 22. Mai 1946. UAG, Rek. PA Schuler.

2174 Tollmien an Oberpräsident in Hannover, 10. Oktober 1945. HStAH, Nds. 401, Acc. 92 / 85, Nr. 80.

2175 Zu Hiedemann siehe Kant [1997] S. 10-12.
} 
Institutsdirektors wurde im August 1946 Professor Bartels beauftragt. ${ }^{2176}$ Hohenemser teilte seine Verbitterung seinem einzigen Göttinger Fürsprecher Prandtl mit: „Wenn also jetzt, wie Sie schreiben, Fakultätsmitglieder mutmassen, dass ich meine Interessen auf einem anderen als dem bekannten und korrekten Wege verteidigt haben könnte, so finde ich dies im höchsten Grade ungerechtfertigt. Ich habe nur den einen Wunsch, wieder in Ruhe meine Arbeit aufzunehmen, nachdem ich in den vergangenen Jahren ständig unter einem Druck gestanden habe, von dem sich niemand eine Vorstellung machen kann, der dies nicht direkt miterlebt hat.“2177 Das Ministerium wollte in der Causa Hohenemser nicht auf eigene Faust entscheiden und fragte bei der Universität im Juni 1946 nach, ob sich an ihrer Stellungnahme etwas geändert habe. Da nach vier Wochen keine Antwort eingetroffen war, bat das Ministerium erneut um Mitteilung. ${ }^{2178}$ Eucken gab am 29. Juli 1946 bekannt, dass die Fakultät an der alten Stellungnahme festhalte, außerdem erinnerte er daran, dass im Institut für angewandte Mechanik jede Forschungsarbeit untersagt sei. ${ }^{2179}$ Bei Hohenemser trafen aber keine aussagekräftigen offiziellen Schreiben ein. Der Rektor teilte ihm Mitte August mit, dass er eine Entscheidung aus Hannover erwarte. ${ }^{2180}$ Da sich die Universität besonders lange mit ihrer Stellungnahme Zeit ließ und vom Ministerium ermahnt werden musste, war eine solche Auskunft vom Rektor unverschämt. Hohenemser konnte dies nicht beurteilen. Er wandte sich Anfang September 1946 ans Ministerium und entkräftete sachlich das Argument, seine Anstellung sei nur durch kostspielige An- und Umbauten im Institut durchführbar. Zudem wies er darauf hin, dass er sich in seiner geplanten Forschungsarbeit mit dem Vorhandenen begnügen werde. Das Verbot von Forschungen der angewandten Mechanik durch das Kontrollratsgesetz Nummer 25 betrachtete er als eine nur vorübergehende Einschränkung, die seine Anstellung an sich nicht in Frage stellen könne. Wenn sein angegebenes Forschungsprogramm nicht durchführbar sei, „so müsste ein anderer Weg zur Befriedigung meines Wiedergutmachungsanspruchs gefunden werden z. B. über einen Lehrauftrag. So teilte mir Herr Prof. Prandtl noch vor dem Ausscheiden von Herrn Prof. Schuler mit, dass die Fächer Statik und Festigkeitslehre seit längerer Zeit in Göttingen gänzlich brach lägen, und er

\footnotetext{
2176 Die Fakultät bestimmte Bartels als Vertreter des Schuler'schen Lehrstuhls. Protokoll der Fakultätssitzung vom 17. August 1946. GPAMNFG, Protokollbuch III der mathematisch-naturwissenschaftlichen Fakultät WS 1927/28 - SS 1946.

2177 Hohenemser an Prandtl, 2. Juni 1946. MPG-Archiv, III, 61, 692.

2178 Oberpräsident in Hannover an Kurator, 21. Juni 1946 und 30. Juli 1946. HStAH, Nds. 401, Acc. 92 / 85, Nr. 135.

2179 Das Schreiben des Dekans Eucken ist in den Akten nicht überliefert. Es gibt nur eine teilweise Abschrift in dem Schreiben des Rektors Rein an den Kurator, 15. August 46. Rektor Rein und Kurator schlossen sich dieser Stellungnahme an. Der Kurator übersandte diese am 26. August 1946 ans Ministerium. HStAH, Nds. 401, Acc. 92 / 85, Nr. 135 .
} 
schlug mir vor, meine Dozententätigkeit mit diesen Fächern zu umgrenzen. Ich hoffe von Ihnen in der Angelegenheit bald Nachricht zu erhalten“. ${ }^{2181}$

Die Angelegenheit war für die nicht direkt beteiligten Fakultätsmitglieder schwer zu durchblicken. Rellich hatte es im September 1946 immer noch ,garnicht verstanden“, warum Hohenemser „,nicht längst schon“ Vorlesungen in Göttingen halte. Er gab Hohenemser die Auskunft: „Es ist selbstverständlich, daß gegen Ihre Wiedereinsetzung keine Widerstände gemacht werden und auch garnicht gemacht werden könnten." Er riet Hohenemser, er solle mit Eucken in aller Ruhe die Angelegenheit besprechen. ${ }^{2182}$ Diese Auskunft ist seltsam, da Rellich an den Fakultätssitzungen teilnahm, in denen die ablehnende Haltung der Fakultät gegen Hohenemsers Wiedereinstellung bestätigt wurde. Er hätte über den Inhalt der Eingaben ans Ministerium informiert gewesen sein müssen. Denkbar ist, dass die Diskussion und die Beschlüsse einen entgegenkommenderen Eindruck vermittelten als Euckens schließlich eingereichte Eingaben. Rellichs andere Wahrnehmung des Falls Hohenemser lässt den Schluss zu, dass die strikt ablehnende Haltung, die Eucken stets im Namen der Fakultät formulierte, in dieser Form nicht allgemein unter den Professoren vorhanden war. Auch der euphorische Brief Dükers vom Mai 1946 bestätigt diese Interpretation. Der Vorschlag, sich mit Eucken zu besprechen, war insofern angebracht, als Hohenemser und Eucken bis dahin überhaupt nicht in Kontakt waren, Eucken aber federführend in der Formulierung des Standpunkts der Fakultät war. Wenn auch ein Gespräch vermutlich wenig geholfen hätte, schlimmer hätte es die Angelegenheit nicht gemacht. Hohenemser sah jedoch nicht ein, warum er sich an Eucken wenden solle, da bis dahin alles über den Rektor lief. ${ }^{2183}$ Die Ansicht, dass eine kollegiale Zusammenarbeit mit Hohenemser unmöglich sei, blieb in Göttingen latent vorhanden und führte dazu, dass am Institut gegen ihn Stimmung gemacht wurde. Hohenemser erfuhr davon und zeigte Verständnis dafür, insbesondere „da unter den dortigen Doktoranden nur zwei nicht ehemalige Offiziere waren. Sie vermuten wohl mit Recht, dass ich für Offiziere der Hitlerarmee nicht allzu viel übrig haben werde, besonders, wenn sie den nationalsozialistischen Geist noch so wenig abgelegt haben, wie das meist der Fall ist." 2184

\footnotetext{
2180 Dieses Schreiben des Rektors konnte ich in den Akten nicht finden.

2181 Hohenemser an Ministerium, 2. September 1946. GPAMNFG, Lehrkörper (ausgeschieden), Hohenemser.

2182 Rellich an Hohenemser, 17. September 1946. KHP. Einen ähnlichen Ratschlag erteilte er ihm schon kurz zuvor, wie aus Hohenemser an Flachsbart, 6. September 1946 hervorgeht.

2183 Siehe Hohenemser an Flachsbart, 6. September 1946. KHP.

2184 Hohenemser an Odqvist, 2. August 1946. KHP.
} 
Das Ministerium war im September 1946 immer noch nicht bereit, eine Entscheidung zu treffen. Stattdessen bat sie die Universität erneut um Stellungnahme zu den von Hohenemser vorgeschlagenen Rehabilitierungsmöglichkeiten. ${ }^{2185}$ Die Fakultät wiederholte hierauf ihren alten Standpunkt in der Causa Hohenemser. Da Hohenemsers Arbeitspläne „rein technische Ziele" verfolgten, solle er an eine $\mathrm{TH}$ oder Bergakademie verwiesen werden, obwohl eingeräumt wurde, dass ein Lehrauftrag über theoretische Fächer auch in Göttingen denkbar sei. „Übrigens hält die Fakultät unbedingt an der Auffassung fest, dass eine Aufnahme eines Privatdozenten in einem Institut nur mit Zustimmung des Institutsdirektors erfolgen kann.“ In der Zwischenzeit hatte die Fakultät aber beschlossen, die angewandte Mechanik in Göttingen einzustellen und die Institute der angewandten Physik neu, und zwar rein wissenschaftlich, auszurichten (siehe Abschnitt 5.5). Deshalb sei für Hohenemser und seine Forschungen Göttingen nicht mehr der geeignete Ort. ${ }^{2186}$ Diese Eingabe Euckens wurde von ihm in der Fakultätssitzung vom 11. Oktober 1946 verlesen und ohne Einwand angenommen. ${ }^{2187}$

Der zweite Nachkriegsrektor Rein konnte sich der Fakultät „nur anschliessen“, und bat um nochmalige Prüfung, ob Hohenemser nicht einen Lehrauftrag an einer TH oder an der Bergakademie in Clausthal-Zellerfeld erhalten könne. ${ }^{2188}$ Im Ministerium war man immer noch nicht Willens, eine Entscheidung zu treffen. Hohenemser wurde zu einer mündlichen Erörterung nach Hannover gebeten, um „die Frage Ihrer Rehabilitierung weiter fördern zu können“. Die Reisekosten würden ihm erstattet. ${ }^{2189}$ Hohenemser dankte für das Angebot und sagte höflich ab, da er gerade den Rückfall eines alten Magenleidens zur Ausheilung zu bringen versuche. „Sobald ich meine Gesundheit wiedererlangt habe und reisefähig bin, werde ich Sie benachrichtigen.“"2190

\footnotetext{
2185 Oberpräsident in Hannover an Rektor, 20. September 1946. HStAH, Nds. 401, Acc..92 / 85, Nr. 135.

2186 Dekan Eucken an Minister, 17. Oktober 1946. HStAH, Nds. 401, Acc. 92 / 85, Nr. 135.

2187 Protokoll der Fakultätssitzung vom 11. Oktober 1946. An dieser Sitzung nahmen teil: Eucken, Rellich, Masing, ten Bruggencate, Tornau, Bederke, Schermer, Brockmann, Schäffer, Gärtner, Rippel, Meinardus, Allesch, Correns, Harder, Firbas, Henke, Bartels, Mollwo, Kaluza, Becker, Münzner, Steiner, Goubeau, Rein, Kopfermann und Wartenberg. GPAMNFG, Protokollbuch IV der mathematisch-naturwissenschaftlichen Fakultät WS 1946/47 - WS 1949/50.

2188 Rektor Rein an Ministerium, 23. Oktober 1946. HStAH, Nds. 401, Acc. 92 / 85, Nr. 135.

2189 Ministerium an Hohenemser, 29. November 1946. HStAH, Nds. 401, Acc. 92 / 85, Nr. 135.

2190 Hohenemser an Ministerium, 21. Dezember 1946. HStAH, Nds. 401, Acc. 92 / 85, Nr. 135. Tatsächlich lag Hohenemser damals mehrere Wochen mit Fieber im Bett. Der Hinweis auf seinen Gesundheitszustand diente ihm aber ab Herbst 1946 auch als Vorwand, die Verhandlungen hinauszuzögern, oder das Ministerium zu einer eigenständigen Entscheidung zu drängen.
} 


\subsubsection{Hohenemser erhielt Angebote anderer Hochschulen}

Hohenemser hätte auf Grund seiner fachlichen Ausrichtung durchaus an eine technische Hochschule gepasst. Er bemühte sich aber nicht selbständig um solche Stellen. Angebote erreichten ihn vielmehr ohne eigene Initiative, doch lehnte sie Hohenemser ab, solange er in Göttingen nicht rehabilitiert worden war. „Ich meine fast, ich müsste die Göttinger Sache wenigstens für eine gewisse Zeit durchbeissen, denn wenn ich jetzt verzichte, könnte mir das als schlechtes Gewissen gedeutet werden. Man muss mir doch zur Ablehnung meines Wiedereinsetzungsantrages schriftlich stichhaltige Gründe angeben“, ${ }^{2191}$ schrieb er im September 1946 an Flachsbart, der ihm an der TH Hannover eine Diätendozentur frei hielt. Hohenemser bedankte sich, legte aber seine Bedenken dar:

„Auf der einen Seite ist der Gedanke einer Zusammenarbeit mit Ihnen für mich ein höchst erfreulicher, und ich würde mich dabei gewiss sehr viel wohler fühlen als in den Göttinger »Brennesseln«. Auf der anderen Seite weiss ich nicht, ob es auf lange Sicht gesehen richtig ist, dass Sie es durch Ihr Angebot den Göttingern und der Behörde leicht machen, mich los zu werden. In Göttingen ist nach der geplanten Neubesetzung und nach Prandtls Emeritierung nur noch Betz als »Angewandter" vorhanden, und ein Arbeitsbereich wäre für mich dort ohne weiteres gegeben. Sachlich wäre also kein Grund vorhanden, mich abzulehnen, und vermutlich wird, wenn ich verzichte, ein anderer einen Lehrauftrag für angewandte Fächer erhalten. Der Verzicht auf Göttingen und die Annahme einer anderen gleichwertigen Hochschulstellung sieht doch allzu sehr nach Anerkennung der Beschuldigungen aus, die gänzlich ungerechtfertigterweise gegen mich erhoben wurden. Etwas anderes wäre die provisorische Übernahme eine[r] Schulstelle oder Industriestelle unter Aufrechterhaltung meines Göttinger Anspruchs. Sobald ich jedoch eine schriftliche und sachlich vernünftig begründete Ablehnung meines Göttinger Wiedereinsetzungsantrages und eine Klarstellung der Beleidigungsangelegenheit erhalten kann, würde ich Göttingen als einwandfrei liquidiert ansehen und dann Ihr freundliches Angebot mit Freuden annehmen." 2192

Hohenemser besaß auch 1946 noch ein relativ gut funktionierendes kollegiales Netz, das ihm zwar für die Göttinger Angelegenheit wenig nutzte, aber andere Angebote einbrachte. Flachsbart empfahl Hohenemser Ende 1946 für Clausthal. Mesmer wollte versuchen, ihn für Darmstadt als Nachfolger von Schlink und Blaess auf die Liste zu bekommen. In Berlin schlug Klotter Hohenemser als seinen Nachfolger an der TH vor. ${ }^{2193}$ All diese Angebote schätzte Hohenemser als nicht sehr aussichtsreich ein. So wie Hohenemser Ende 1946 bei einem möglichen Einlenken Göttingens doch lieber auf dieses „Brennesselnest“ verzichtet

\footnotetext{
2191 Hohenemser an Flachsbart, 6. September 1946. KHP.

2192 Hohenemser an Flachsbart, 6. September 1946. KHP.
}

2193 Hohenemser an Flachsbart, 27. Dezember 1946. KHP. 
hätte, so besaßen auch die anderen Alternativen an deutschen Hochschulen nur geringe Anziehungskraft und standen in Konkurrenz zu ganz anderen Plänen. Ab etwa Mai 1946 dachte Hohenemser ernsthaft über seine Auswanderung nach. Konkret wurden die Ausreiseplänen im Herbst 1946. Ein Grund für diese Entscheidung war der politische Zustand der deutschen Nachkriegsgesellschaft.

\subsubsection{Hohenemsers skeptischer Blick auf die deutsche Nachkriegsgesellschaft}

Hohenemser war ein zum Pessimismus neigender, sehr genauer Beobachter der gesellschaftlichen Veränderungen. Seine Beschreibung des geistigen Zustandes der Deutschen in den ersten beiden Nachkriegsjahren deckt sich mit publizierten kritischen Berichten deutscher wie ausländischer Beobachter. ${ }^{2194}$ Es geht im Folgenden aber nicht darum, Hohenemsers Sicht in den heutigen Forschungsstand einzuordnen, sie in einzelnen Punkten als typisch oder untypisch zu beschreiben. Vielmehr sollen seine Motive erkennbar werden, die ihn schließlich zur Auswanderung bewogen haben. Im Mai 1946, als er seine Göttinger Rehabilitation als gescheitert ansah, berichtet er seinem früheren Kollegen Courant:

„Als Gegenstück zu meinem Fall folgender: Hier wohnt seit Kriegsende ein Ministerialrat aus dem dritten Reich, natürlich ehemaliger Parteigenosse aber guter Katholik und braver Antisemit wie so viele hier (ich habe noch nie so viel auf die Juden schimpfen hören, die man für das deutsche Elend verantwortlich macht, wie unter diesen ,guten Katholiken“ hier). Noch neulich verkündete er bei Tisch die Nachricht, dass in Würzburg Kohlen verteilt wurden, aber natürlich bekämen die ehemaligen Parteigenossen wieder einmal keine; so etwas wäre unter den Nazis nicht möglich gewesen, das müsse man ihnen lassen, für gerechte Verteilung hätten sie gesorgt. Allgemeines Beifallsgemurmel, ja das müsse man ihnen lassen, für gerechte Verteilung hatten sie gesorgt. Dieser Mann wird jetzt wieder im höheren Verwaltungsdienst als Ministerialrat eingestellt und wird an einer Universität Vorlesungen halten. Er ist ja nur ein inaktiver Parteigenosse gewesen und ein so guter und frommer Katholik. [...] Aber so, wie die Dinge im westlichen Deutschland laufen - das östliche Deutschland ist eine Welt für sich und durch eine undurchdringliche Mauer von der hiesigen Welt geschieden kommt doch an allzu vielen Stellen wenn auch nicht der nationalsozialistische Geist direkt aber doch der deutsch-nationale und antisemitische Geist wieder obenauf. Sehr bezeichnend war, dass selbst in den letzten Kriegsjahren und unter den schärfsten Gegnern des Nationalsozialismus im bürgerlichen Lager keine Stimme für eine Sabotage des Nazikrieges zu finden war, sondern dass man allgemein eine deutsche Niederlage für das schlimmste aller Übel ansah und zur

\footnotetext{
2194 Siehe die sehr persönliche Alltagsgeschichte der ersten drei Nachkriegsjahre von Bernt Engelmann [1987] bes. auch die Abschnitte „Und immer noch: Die Juden sind unser Unglück...“ und „Briefe einer aus dem Exil Heimgekehrten: »Hier fühle ich mich so fremd und verloren«". Siehe auch Arendt [1950/93]; Balfour [1959]; Engelmann [1988]. Stärker wissenschaftlich 'abgehoben“ ist das Handbuch über Deutschland unter alliierter Besatzung von Wolfgang Benz (Hrsg.) [1999], in dessen reichhaltigem Stichwortverzeichnis leider Einträge wie „Antisemitismus“ oder „Juden“ fehlen. Trotz dieses Mangels geben beispielsweise die Aufsätze zu „Demokratisierung“, „Kultur und geistiges Leben“ und „Rückkehr aus dem Exil“ einen guten Überblick.
} 
Vermeidung dieses Übels selbst eine Duldung des Nationalsozialismus in Kauf zu nehmen bereit war. Es gilt auch jetzt in diesen wieder so sehr tonangebenden Kreisen für durchaus in Ordnung, dass man sich während des Krieges voll für einen deutschen Sieg eingesetzt hat, solange man nur genügend Distanz zur Partei wahrte und nicht an direkten Kriegsverbrechen beteiligt war." 2195

Noch prägnanter schrieb er zur selben Zeit an seine englische Tante Muriel: „Of course I shall continue to fight for my rehabilitation though you may imagine how comfortable I feel among a nation of which at least one half voted for a government which killed besides 10 or 20 million others, my family; which denies all responsibility for the deeds of this government and among which the anti-semitic and nationalistic tendencies have survived the desastre [sic] that was caused by this spirit." 2196 Die Nachwirkungen des Nationalsozialismus belasteten Hohenemsers berufliche wie private Beziehungen. Es scheint so, als habe das Ende der NSZeit im Privaten zu einer erneuten Belastung und Spannung geführt.

„Obwohl wir gerade genug unter dem vergangenen System gelitten haben [...], ist es mir passiert, daß ich von nahen Bekannten, die seinerzeit emigriert sind, und auf deren Briefe ich mich nach dieser langen Zeit der Eingeschlossenheit gefreut habe, entweder überhaupt keine Antwort oder kurze englische Antworten erhalten habe, die zeigen, wie peinlich es offenbar manchen Emigranten ist, Beziehungen zu Deutschen zu haben. Aber auch unter denen, die hiergeblieben [sind] und alles glücklich überstanden haben, sind teilweise Wände entstanden. Auf der einen Seite sind diejenigen, welche, wenn auch Nazigegner, den deutschen Sieg für wünschenswert gehalten haben und danach handelten. Es ist die übergrosse Mehrheit, und man wird einen Groll gegen solche Leute, auch wenn sie gute Bekannte waren, nicht los, da der Hass gegen das Hitlersystem allzu tief in uns verwurzelt war, um verstehen zu können, dass man zur Vermeidung von Deutschlands Untergang als Machtstaat einen Kompromiss mit diesem System wünschen könnte. Auf der anderen Seite stehen die Leute, welche aktiv in der Widerstandsbewegung gearbeitet haben. Allzuviele davon leben nicht mehr, und wir haben den Verlust einer Reihe von Freunden zu beklagen. Die Überlebenden, jahrelang in den verschiedenen Gestapohöhlen gequält, sind jetzt natürlich recht intolerant gegen Leute wie wir, die sich am aktiven Widerstand nicht beteiligten, und deren Groll richtet sich weniger gegen die Nazis als gegen diejenigen, welche ihre Überzeugung nicht in dem Kampf gegen das System eingesetzt haben. Sie vergessen, dass es schon einer ausserordentlichen Opferbereitschaft bedurfte, um diesen Kampf mit dem übergrossen Todesrisiko und seiner dadurch bewirkten Aussichtslosigkeit $\mathrm{zu}$ führen. [...] Wir fühlen uns jetzt in einer gewissen Isolierung nach 2 Seiten, die sich auch zum Beispiel darin äussert, dass es mir in der Nachkriegszeit noch nicht gelungen ist, zu einer Berufsarbeit zu kommen. Nicht einmal meine Rehabilitierung als Dozent für Mathematik und Mechanik an der Göttinger Universität, von der ich 1933 entlassen wurde, konnte ich erreichen. Nationalismus ist hier eben in gewissen Kreisen nach wie vor Trumpf, und leider

2195 Hohenemsers an Courant, 21. Mai 1946. Library of Congress, Veblen papers, Box 4.

2196 Hohenemser an seine Tante Muriel, 17. Mai 1946. KHP. 
ist die Weltpolitik nicht geeignet, dazu beizutragen, dieses Übel hier und anderswo auszurotten." 2197

Unter Hohenemsers guten Bekannten, die klare Regimegegner waren, herrschte Zwist. Albert Steen macht ihm den Vorwurf, mit der Produktion von Hubschraubern die Wissenschaft in den Dienst des Krieges gestellt zu haben und sah es als gerecht an, dass Hohenemser mit seiner Rehabilitierung scheitere. Auf der anderen Seite kritisierte Heinrich Düker gerade Albert Steen, da dieser während seiner Soldatenzeit als „kultureller Betreuer“ der Wehrmacht tätig war, Vorträge hielt, Bücher zum Ausleihen sammelte, kurz, dem Soldaten das Leben erleichterte und ihn zu einem besseren Kriegswerkzeug machte. „Ich schreibe Ihnen das, um Ihnen einen Eindruck zu geben von der Art, in welcher Weise gerade die Leute, die jetzt zusammenhalten sollten, da sie zu den wenigstens prinzipiellen Systemgegnern gehörten, sich gegenseitig Vorwürfe machen wegen der Kompromisse, die jeder von uns eingegangen ist. [...] Die Zustände hier und die Beziehungen zwischen den Menschen sind so über alle Maßen unerfreulich, daß auch ich oft meine, das beste sei, überhaupt nicht drüber nachzudenken, sondern sich zu distanzieren, so gut es geht; und nach Möglichkeit heraus zu kommen aus dieser stinkenden Jauchegrube!“‘2198

Anfang Juni 1946 erreichte Hohenemser ein Brief seines schwedischen Kollegen Folke Odqvist, der ihn besonders freute: „Man lebt hier seit vielen Jahren in einer solchen Atmosphäre von Übelwollen, Mißtrauen und Mißgunst, die sich seit Kriegsende sogar noch verschlechtert hat, daß uns Ihr Freundschaftsbeweis wie das plötzliche Einatmen von reiner frischer Luft vorkommt.“ Er berichtet vom Leid seiner jüdischen Verwandten. Verbittert war er über die Reaktion der meisten Deutschen auf die Judenverfolgung.

„Jeder fand es fast selbstverständlich, daß sie sich das Leben nahmen, man erwartete von ihnen nichts anderes. Man nahm ihre Lage hin, wie man das Schicksal hinnimmt; niemand machte sich klar, daß diese Lage die Schuld einer verbrecherischen Regierung ist, daß mindestens $50 \%$ der Deutschen, welche die Regierung gewählt haben, an dieser Schuld mitbeteiligt sind. Jetzt behauptet jeder Deutsche, er habe alle diese Dinge nicht gewußt und ist überzeugt, daß er die Regierung nicht unterstützt hätte, wenn ihm die Tatsache der millionenfachen planmäßigen Vernichtung von Menschenleben bekannt gewesen wäre. Dies ist einfach eine Lüge. Wenn auch die Einzelheiten und der Umfang der Regierungsmorde nicht bekannt waren, das was meine Eltern wußten und was sie dann bewog, freiwillig das Leben aufzugeben, konnte jeder Deutsche wissen und hat auch sicherlich fast jeder Deutsche gewußt."2199

\footnotetext{
2197 Hohenemser an Lothar Frank, 12. Januar 1947. KHP.

2198 Hohenemser an Prager, April 1946. KHP.

2199 Hohenemser an Odqvist, 4. Juni 1946. KHP.
} 
Die Mentalität der Deutschen nach dem verlorenen Krieg ließ ihn düster in die Zukunft blicken: „Schlimmer noch als das äußere Elend empfinden wir das geistige Chaos in Deutschland. In ganz großen Bevölkerungskreisen ist die nazistische Ideologie noch sehr lebendig, man hat manchmal den Eindruck, noch lebendiger als zur Zeit der politischen Naziherrschaft. Der Antisemitismus ist außerordentlich stark und man hört auf Schritt und Tritt feindselige Äußerungen gegen die Juden - wenigstens hier in Bayern, in ausgesprochenen Arbeitergegenden ist das natürlich nicht so“.2200 Die „Beschimpfungen der Juden, denen ein großer Teil der Deutschen die Schuld an ihrem jetzigen Elend gibt, [klingen] lieblich in den Ohren, wie Sie sich denken können, und es packt einen dann die hohle Wut über so viel Mangel an Einsicht in die wahren Ursachen unseres Elends. Die Zeitungen und Zeitschriften in Deutschland geben meiner Ansicht nach ein völlig falsches Bild über den Geisteszustand der Menschen hier. Ich fürchte fast, wenn heute oder morgen ein zweiter Hitler mit den gleichen nationalistischen und antisemitischen Parolen aufstehen könnte, würde dieser Mann ebensoviele Anhänger - vielleicht noch mehr - finden als Hitler 1932 u. 33.“

Nachdem ein Treffen von Hohenemser mit Odqvist auf Grund des langsamen Briefverkehrs nicht geklappt hatte, schrieb er resigniert: „Die Lebensverhältnisse heute sind hier mit einer derartigen Friktion belastet, dass das Leben fast zum Stillstand kommt.“2201 Zu der unerfreulichen Auseinandersetzung um seine Rehabilitierung an der Universität schrieb er verständnisvoll:

„Aber schließlich ist auch das menschlich zu verstehen, solange noch die gleichen Leute massgebend sind, welche während der Dauer des Hitlerstaates Kompromisse über Kompromisse eingegangen sind. Wenn man bedenkt, dass Prandtl der Präsident der Luftfahrtforschungsgesellschaft war und sozusagen direkt nach Hermann Göring kam, so kann man verstehen, dass er von »Denazifizierung« nicht viel wissen will, und für Leute wie mich kein Verständnis hat. Dabei ist Prandtl im Grunde ein rechtlich denkender Mensch, der damals 1933 sich sehr exponiert hat, um seinen jüdischen Kollegen zu helfen. Aber der Fluch der zahllosen mehr oder weniger grossen Kompromisse lastet heute auf jedem von uns, und trübt in weitem Masse den Sinn für Recht und Unrecht. [...Den Hartog] hat Göttingen aufgesucht und auch mit Prandtl gesprochen, den er Mesmer gegenüber als einen grossen Nazi bezeichnete. Ich fand das damals etwas unverständlich und übertrieben, da ich seine Haltung 1933 in Erinnerung hatte, aber meine seitherigen Erlebnisse in Göttingen bestätigten leider den Eindruck von Den Hartog. Prandtl gehört auch zu denen, der jetzt traurig erklärt, von all den Abscheulichkeiten des Hitlerstaates nichts gewusst zu haben. Dabei hatte ich ihm damals sogar die Todesanzeige meiner Eltern

2200 Hohenemser an Prager, April 1946. KHP.

2201 Hohenemser an Odqvist, 29. September 1946. KHP. 
geschickt, und er hat einen sehr teilnahmsvollen und erschütterten Brief geschrieben. Ein guter Psychologe könnte in diesem Lande die interessantesten Studien machen. Der Vorwurf bewusster Unwahrhaftigkeit oder Lüge wäre in einem solchen Fall viel zu einfach."2202

Seine Aussichten auf eine Zukunft an einer Hochschule schätzte er aus psychologischen Gründen gering ein: „Ich kämpfe nach wie vor ohne Erfolg um meine Wiedereinsetzung in Göttingen, und auch mein Anklopfen bei anderen Hochschulen war ergebnislos. Ich glaube auch, dass ich keine Chancen haben werde, ehe nicht alle ehemaligen Parteimitglieder »entnazifiziert» sind und ihre früheren Stellen wiederhaben. Man kann den Leuten schliesslich nicht verdenken, dass sie vorläufig zu sehr um ihre Stellen besorgt sind, als dass sie zulassen können, dass Leute wie ich hereinkommen und eventuell gefährlich werden können.“ Einen stärkeren Einfluss der Militärregierung auf Stellenbesetzungen hielt er aber nicht für eine Lösung des Problems, denn es sei ,alles andere als angenehm, durch die Besatzungsmacht den Kollegen aufgedrängt zu werden, und man hätte es dann gewiss nicht erfreulich. Diese Überlegungen haben mich dazu veranlasst, jetzt ernstlich meine Auswanderung zu betreiben, und zwar habe ich über ein Hilfskomite [sic] (das International Rescue and Relief Committee) meine Einwanderung in die United States beantragt.“2203

\subsubsection{Hohenemser wandert aus}

Es war im September oder Oktober 1946,2204 als Hohenemser die Einwanderung in die USA beantragte. Obwohl ihm zwei wesentliche Punkte für eine positive Entscheidung fehlten, nämlich erstens Häftling eines Konzentrationslagers gewesen zu sein, oder zweitens nahe Verwandte in den USA zu haben, beurteilte das Hilfskomitee, das für ihn die Bürgschaft übernehmen wollte, seinen Fall als nicht aussichtslos. „Wir haben zwar alle ein gewisses Unbehagen bei dem Gedanken der Emigration und auch ein etwas schlechtes Gewissen den Freunden gegenüber, die für ein besseres Deutschland ihr Leben auf Hitlers Schaffotten liessen, doch ist die Situation hier so verfahren, dass sich dieser Schritt vielleicht doch rechtfertigen lässt.“ 2205 Hohenemser rechnete mit einer Wartezeit von 4 bis 8 Monaten bis zur Annahme seines Antrages. Falls ihm in dieser Zeit von Göttingen eine Assistentenstelle oder eine Dozentur angeboten worden wäre, wollte er deren Annahme bis zur Entscheidung seines

\footnotetext{
2202 Hohenemser an Odqvist, 2. August 1946. KHP.

2203 Hohenemser an Odqvist, 14. November 1946. KHP.

2204 Siehe Hohenemser an Prager, 1. November 1946, und Hohenemser an Flachsbart, 8. November 1946. KHP. 2205 Hohenemser an Lothar Frank, 12. Januar 1947. KHP.
} 
Einwanderungsantrages hinausschieben. ${ }^{2206}$ Als das Ministerium Ende 1946 offenbar ernsthaft eine Lösung für seine Wiedergutmachung suchte, übernahm Hohenemser die Hinhaltetaktik, die die Universität ihm gegenüber die ganze Zeit ausübte. Auch als er die Ausreisebewilligung schon in der Hand hatte, beharrte er weiterhin auf einer klaren und begründeten Entscheidung des Ministeriums über seinen Antrag auf Wiedereinsetzung in die Assistentenstelle. Außerdem wünschte Hohenemser eine Berichtigung der Akten, in denen die nicht den Tatsachen entsprechende Behauptung steht, er habe Schuler beleidigt und später diese Beleidigung zurückgenommen.2207 Auf den letzten Punkt ging Ministerialrat Zierold nicht ein. Dafür bekam Hohenemser eine begründete Ablehnung seines Antrags. Da das Institut für angewandte Mechanik aufgehoben wurde, bestehe für die Übertragung einer Assistentenstelle an ihn keine Möglichkeit mehr. Stattdessen wurde ihm die Übertragung einer Diätendozentur angeboten.2208 Wäre ein solches Angebot mindestens ein Jahr früher offeriert worden, hätte es Hohenemser vermutlich gerne angenommen. ${ }^{2209}$

Hohenemser verließ Deutschland im Juli 1947. Für den Fall einer eventuellen Rückkehr beantragte er bei der Universität die Aufrechterhaltung seiner Lehrbefugnis. Selbst dieser Wunsch wurde von der Fakultät als kleine Drohung empfunden. Der neue Dekan Harder bat seinen Vorgänger: „Lieber Herr Eucken! Der Fall Hohenemser flackert noch einmal wieder auf. Darf ich Sie bitten, die letzten Schritte in der Angelegenheit freundlichst zu übernehmen?“"2210 Hohenemser wurde bis 1950 beurlaubt, dann schied er aus dem Lehrkörper der Universität Göttingen aus. ${ }^{2211}$ In den USA fand er als Hubschrauberspezialist sofort eine Anstellung als Chef-Aerodynamiker bei McDonnell Aircraft in St. Louis, Missouri. Auch wenn Hohenemser seine Arbeit nicht als Rüstungsforschung erkennen wollte, ${ }^{2212}$ leistete er sie doch in Deutschland wie in den USA im Auftrag des Militärs. Wie im Fall Magnus und Hoch führte auch bei Hohenemser das Scheitern der Nachkriegs-Hochschullaufbahn zu einer Fortsetzung der im Krieg betriebenen Rüstungsforschung, nur unter neuer staatlicher Einbindung.

\footnotetext{
2206 Siehe Hohenemser an Flachsbart, 8. November 1946. KHP.

2207 Hohenemser an Ministerialrat Zierold, 12. April 1947. HStAH, Nds. 401, Acc. 92 / 85, Nr. 135.

2208 Ministerialrat Zierold an Hohenemser, 26. April 1947. HStAH, Nds. 401, Acc. 92 / 85, Nr. 135.

2209 Hohenemser an Zierold, 17. Mai 1947. HStAH, Nds. 401, Acc. 92 / 85, Nr. 135.

2210 Dekan Harder an Eucken, 14. Juli 1947. GPAMNFG, Lehrkörper (ausgeschieden), Hohenemser.

2211 Zur Entscheidung der Beurlaubung siehe Raiser (i. V. des Rektors) an Hohenemser, 26. November 1947; Raiser an Minister über Kurator, 2. Dezember 1947; Kurator an Minister, 9. Dezember 1947; Minister an Hohenemser, 27. April 1948. HStAH, Nds. 401, Acc. 92 / 85, Nr. 135. Zur Diskussion über die letzte Beurlaubung siehe Protokoll der Fakultätssitzung vom 25. Februar 1949. GPAMNFG, Protokollbuch IV der mathematisch-naturwissenschaftlichen Fakultät WS 1946/47 - WS 1949/50.

2212 Rammer [2002] S. 92-94.
} 
1957 wurde Hohenemser an der Washington University in St. Louis visiting professor, sechs Jahre später full professor. In Deutschland erhielt er 1958, also 25 Jahre nach seiner Entlassung, Wiedergutmachung in Form eines Ruhegehalts eines ordentlichen Professors, wofür sich Max Born mit einem Gutachten eingesetzt hat. 2213

\subsection{Das III. Physikalische Institut - das Ende der angewandten Mechanik}

Die Entstehung des III. Physikalischen Instituts in Göttingen im April 1947 beruht einerseits auf einer fachlich argumentierten Neuausrichtung der angewandten Physik in Göttingen, die mit der von der Militärregierung verordneten Einschränkung bestimmter angewandter Forschung beeinflusst war, andererseits ist sie in Zusammenhang mit den Entnazifizierungsund Wiedergutmachungsauseinandersetzungen zu verstehen. Die äußeren Bedingungen für diese Umstrukturierung waren günstig. Drei Professoren der angewandten Fächer erreichten 1947 oder kurz zuvor ihre Altersgrenze, insbesondere die beiden Institutsdirektoren Zahn und Schuler, der Dritte war Prandtl. Bei der Berufung Zahns war die spätere Neuausrichtung der angewandten Elektrizität schon mit eingeplant gewesen (siehe Abschnitt 1.2.4). Schulers Emeritierung bot der Fakultät die Möglichkeit, die Zukunft beider Institute in Zusammenhang zu bringen. Im Oktober 1946 erklärte die Fakultät die eingereichten Vorschläge zur Wiederbesetzung von Schulers Lehrstuhl für ungültig und beschloss ein neues Vorgehen.

\subsubsection{Umstrukturierung der angewandten Physik}

Ende Oktober 1946 schlug die Fakultät vor, die beiden Institute der angewandten Physik zusammenzulegen und ein neues III. Physikalisches Institut zu gründen. Die beiden Extraordinariate sollten in ein Ordinariat und eine Oberassistentenstelle umgewandelt werden. ${ }^{2214}$ Die inhaltliche Ausrichtung der Forschung sollte rein wissenschaftlich sein: „Schwingungsforschung im allgemeinsten Sinne, sowohl im mechanischen wie im elektrischen Gebiet, müssten nach der Auffassung der Fakultät zur Zeit im Vordergrund stehen." Die Betonung des rein Wissenschaftlichen war einerseits eine Konzession an die

2213 Gutachten von Max Born, 2. August 1957. Kopie davon in KHP.

2214 Die beiden Varianten Ordinariat plus Oberassistentenstelle und zwei Extraordinariate schienen austauschbare Modelle für die personelle Ausstattung eines Instituts gewesen zu sein, die einen ähnlichen Etataufwand bedurften. Schon 1934 schlug die Fakultät in der Besetzung des II. Physikalischen Instituts den Austausch des einen Modells durch das andere vor, nur in umgekehrter Richtung wie 1946 in der angewandten Physik; siehe Abschnitt 1.2.1. 
Einschränkung der angewandten Forschung durch die Kontrollgesetzgebung, andererseits ein Abwehrargument gegen Hohenemser. In jedem Fall war sie Teil der Nachkriegsrhetorik. Für die Wahl des Direktors nannte die Fakultät folgende drei Herren: 1) Erwin Meyer, 2) Egon Hiedemann, 3) Hans Kneser. ${ }^{2215}$ Wie schon bei der Nachfolge Schulers dachte die Fakultät nur an einen Kandidaten, in diesem Fall Erwin Meyer, denn Hiedemann wurde 1946 auf ein Ordinariat an die TH Karlsruhe berufen und kam für Göttingen kaum in Frage.2216 Eigenartigerweise beurteilte ihn die Fakultät nun deutlich negativer als fünf Monate zuvor. ${ }^{2217}$ Seine Interessen haben sich „,im Laufe des letzten Jahrzehnts allzusehr auf das Gebiet des Ultraschalls und dessen technischen Anwendung verengt [...], ohne, dass ihm dort ein grosser Wurf gelungen ist.“ Dem drittgenannten Kneser sollte vermutlich die Nennung über seine politischen Schwierigkeiten hinweghelfen (dazu siehe Abschnitt 1.3.4.1). Die Fakultät räumte auch ein, dass er für das neue Institut weniger als die anderen in Frage komme, da er sich nur in der reinen Physik betätigt habe, „,während - wie bereits oben betont - für die Besetzung gerade der hier in fragekommenden Stelle ein Physiker mit einem gewissen technischen Einschlag erwünscht ist.“2218 Zur selben Zeit wurde Hohenemser mit dem Vorwand abgelehnt, seine angestrebten Forschungen seien technisch ausgerichtet und hätten deshalb keinen Platz im neuen Institut. Meyer war ein früherer Kollege von Kopfermann und Becker an der TH Berlin Charlottenburg. Im Krieg arbeitete er für die Marine unter anderem an der Schalldämpfung der U-Boote. ${ }^{2219}$ Er blieb auch nach dem Kriegsende in Neustadt in Holstein, wohin sein Berliner Institut verlegt worden war. Die Briten ließen ihn angeblich „,nicht mehr nach Berlin“, sodass er seine Berliner Professur offenbar aufgeben musste. ${ }^{2220}$ Er gehörte damit zu jenen wenigen Physikordinarien, die durch das Kriegsende ihre Stelle eingebüßt hatten und versorgt werden wollten. ${ }^{2221}$ Die alten kollegialen Verbindungen aus der Berliner Zeit bewiesen ihren Nutzen und brachten Meyer den Ruf nach Göttingen ein. Die Göttinger konnten durch die guten Beziehungen zum Research Officer Ronald Fraser auch die

2215 Dekan Eucken an Ministerium, 28. Oktober 1946. Am 21. März 1947 genehmigte der Niedersächsische Kultusminister diesen Antrag mit Wirkung vom 1. April 1947. UAG, Rek. 5250 / 7A.

2216 Dies teilte Dekan Eucken nachträglich dem Ministerium mit, 5. November 1946. UAG, Rek. 5250 / 7A.

2217 Selbst in der Kommissionssitzung vom 8. Oktober 1946 heißt es noch: „Direktor des neuen Institutes soll Prof. Hiedemann werden." GPAMNFG, Protokollbuch IV der mathematisch-naturwissenschaftlichen Fakultät WS 1946/47 - WS 1949/50.

2218 Siehe Vorschlagsliste der Fakultät, unterschrieben von Eucken; hieraus auch die Zitate der Beurteilung der Kandidaten. UAG, Rek. 5250 / 7A.

2219 Außerdem war Erwin Meyer im Krieg am Vierjahresplan-Institut für Schwingungsforschung in Berlin mit geheimen wissenschaftlichen Untersuchungen an Schalldämpfern für Infanteriewaffen tätig. Der im Juni 1944 erteilte Auftrag trug die Nummer O.H.-02/0019. BAB, R 26 III, Nr. 14.

2220 Cremer [1972] S. 183. Seine politischen Mitgliedschaften waren vermutlich nicht der Grund dafür: 193845 NSDDB, 1937-43 NSV, 1942-43 NS-Reichsbund für Leibesübungen. HStAH, Nds. 171 Hildesheim, 14232. ${ }^{2221}$ Siehe hierzu den Brief Pohl an Born vom August 1945, zitiert in Abschnitt 1.3.4. 
Zustimmung der Militärregierung erwirken.2222 Mit Meyers Berufung zum 1. April 1947 verlagerte das III. Physikalische Institut seine Arbeitsgebiete dann vorwiegend auf Akustik, Elektroakustik und Hochfrequenzforschung. Nur ein kleiner Teil der früher am Institut für angewandte Mechanik praktizierten mechanischen Schwingungsphysik blieb erhalten. Dafür erfuhr dieser durch Meyer in den Vorlesungen sowie in der Forschung eine aufschlussreiche Analogiebildung. Meyer koppelte gerne die mechanisch-akustischen Versuche mit den entsprechenden elektrischen. So kam es zu einer teilweisen inhaltlichen Symbiose der beiden alten Institute für Mechanik und Elektrizitätslehre. ${ }^{2223}$

Die Änderung der Forschungsrichtung stieß aber nicht auf ausschließliche Zustimmung in der Fakultät. Vor allem die angewandten Mechaniker sahen die kommende Entwicklung mit Sorge. Prandtl, der das Institut 40 Jahre zuvor aufgebaut hatte, äußerte seine Unzufriedenheit über den Plan der Fakultät im April 1947:

„Dieses Institut, das vor jetzt gerade 50 Jahren von Felix Klein gegründet worden ist, um den Ingenieurwissenschaften einen Platz an der Universität zu geben und das in dieser Zeit eine sehr fruchtbare Tätigkeit als Bindeglied zwischen den Universitätswissenschaften und den technischen Wissenschaften entfaltet hat, steht durch die neueste Entwicklung vor der Gefahr der Vernichtung. Es wäre unter normalen Umständen meine Aufgabe gewesen, Derartiges zu verhindern. Als auf der Tagesordnung einer Fakultätssitzung ein Punkt mit der Bezeichnung 'Drittes Physikalisches Institut' angekündigt war, lag ich mit einer Nachkrankheit meiner Operation nochmals in der Klinik. [...] In früheren Ausschußsitzungen, an denen ich noch teilgenommen hatte, war meiner Erinnerung nach nie davon die Rede gewesen, daß die Einrichtung des Mechanikpraktikums, die natürlich gleichzeitig auch Möglichkeiten für Mechanikforschung geboten hat, verschwinden sollte. Ich hörte von Letzterem erst durch Professor Betz bei der Rückkehr von meiner Erholungsreise in die Schweiz Mitte April. Ich stehe auf dem Standpunkt, daß die Einrichtung des Mechanikpraktikums in mancher Hinsicht eine Modernisierung vertragen würde, daß es aber nicht angängig erscheint, eine vom pädagogischen Standpunkt so lehrreiche Sache einfach verschwinden $\mathrm{zu}$ lassen, weil für eine in Göttingen neue Forschungsrichtung Räume gebraucht werden. Wenn Professor Meyer erst hier sein wird, bin ich bereit, mich mit ihm über eine Kompromißlösung $\mathrm{zu}$ unterhalten, die die Zerstörung von wertvollem Gerät vermeidet und andererseits einen Teil der Räume für die neuen Aufgaben freimacht.“2224

Zu einer von Prandtl gewünschten Kompromisslösung kam es nicht. Das Mechanikpraktikum wurde aufgegeben, wenngleich das von Meyer angebotene Praktikum anfangs noch

\footnotetext{
2222 Dekan Eucken teilte dem Ministerium am 5. November 1946 mit, dass die „Berufung auch wie durch mündliche Rücksprache mit Oberst Freser [sic] festgestellt wurde, den Wünschen der Mil. Reg. entsprechen würde." UAG, Rek. 5250 / 7A.

2223 Zu Meyer siehe Cremer [1972]; Grützmacher [1959], [1972]; Kuttruff [1969]; Schroeder [2000]. Seine Göttinger Antrittsvorlesung über den damaligen Stand der Theorie des Hörens ist publiziert in Meyer [1947].
} 
Mechanik- und Elektrophysikalisches Praktikum hieß. Meyer fügte eine Reihe neuer Aufgaben ins Praktikum ein, was dazu führte, ,daß der eine oder andere Versuch aus der Kreisellehre nur noch seltener herangezogen werden wird“.2225 In beharrlichen Verhandlungen mit der Universität erreichte Meyer nicht nur die Ausstattung mit UltraschallApparaten und modernen elektrischen Geräten sowie die Einrichtung spezieller schallgedämpfter und hallender Räume, sondern auch eine Etaterhöhung des III. Physikalischen Instituts auf etwa 8000 Mark jährlich, während die Vorgängerinstitute für angewandte Elektrizität und Mechanik zuletzt nur 1612 und 3153 Mark, zusammen also 4765 Mark Etat gehabt hatten (zum Vergleich hatte das I. Physikalische Institut damals 5850 RM und das II. 3170 RM). ${ }^{2226} 1953$ wurde auch der Sachfonds des III. Physikalischen Instituts um 5000 auf nunmehr 33000 Mark erhöht und damit denen der anderen beiden Institute angeglichen. ${ }^{2227}$

Eine wesentliche finanzielle Unterstützung des Instituts kam zusätzlich durch das Department of Scientific and Industrial Research (DSIR) zu Stande. ${ }^{2228}$ Als Ergebnis von Verhandlungen zwischen den Briten und Meyer führte das Göttinger Institut seit Ende 1947 Auftragsarbeiten fürs DSIR durch, wofür die Londoner Behörde weit über 50000 RM fließen ließ, darunter die Jahresgehälter von fünf promovierten Nachwuchswissenschaftlern, vier jüngeren Wissenschaftlern und vier Mechanikern. ${ }^{222}$ Bei den Forschungsthemen handelte es sich um Fragen der Schwingungsübertragung durch feste Bauteile und durch Trennwände mit körniger Füllung, daneben auch um Themen, die schon im Krieg der Rüstungsforschung dienten: Nun von den Briten finanziert wurden Messungen der Schalldämpfung in Flüssigkeiten (früher Schalldämpfung der U-Boote) und Arbeiten $\mathrm{zu}$ technischen Eichungsproblemen bei der Messung hoher Schalldrucke, wie sie unter anderem in Detonationswellen auftreten. ${ }^{2230}$ Die Briten umgingen also ihr selbst geschaffenes Gesetz zur Forschungskontrolle, da sie Nutznießer dieser militärisch relevanten Forschungen waren. Die Ergebnisse der Arbeiten durften auch nur nach deren vorheriger Billigung publiziert

\footnotetext{
2224 Prandtl an Kurator, 30. April 1947. MPG-Archiv, III, 61, 1735.

2225 Meyer an Prandtl, 3. Juni 1947. MPG-Archiv, III, 61, 1064.

2226 Kurator Bojunga an Kultusminister, 28. März 1947. UAG, Kur., PA Meyer. Dem I. und dem

II. Physikalischen Institut wurde aber (wie üblich, so auch) für das Rechnungsjahr 1947 eine Überschreitung des Etats genehmigt, sodass ihnen 10.500 und 8.500 RM zur Verfügung standen.

2227 Kurator an Kultusminister, 10. Juni 1953. UAG, Kur., PA Meyer.

$2228 \mathrm{Zu}$ der Forschungsförderungsinstitution DSIR, ihrer Geschichte und Funktion siehe Alter [1990];

Heinemann [2001] bes. S. 187-191.

2229 C. A. Spencer an Rektor, 24. Dezember 1947. UAG, Kur. XVI V.C. hh 6.

2230 C. A. Spencer an Rektor, 24. Dezember 1947, „Vorgeschlagenes Forschungsprogramm“. UAG, Kur. XVI V.C. hh 6.
} 
werden. $^{2231}$ Nach mehrfachen Verlängerungen dieser Forschungsverträge brach die Zusammenarbeit im September 1950 vorübergehend ab, da der Britischen Behörde nach der Währungsreform auf Grund des ungünstiger werdenden Umrechnungskurses die finanziellen Aufwendungen zu hoch wurden. 2232

\subsubsection{Die Besetzung der Oberassistentenstelle - König statt Hohenemser}

Bei der Schaffung des neuen Ordinariats und der Oberassistentenstelle fügte Eucken eine außergewöhnliche Klausel ein: „Dabei legt die Fakultät in diesem Sonderfall entscheidenden Wert darauf, dass diese Oberassistentenstelle nur mit Zustimmung der Fakultät besetzt werden dürf[e], damit die notwendige Vielseitigkeit der Institutsarbeit, wie bisher, sichergestellt wird.“2233 Die hier gegebene Begründung war nur ein Vorwand. Tatsächlich wurde aber Meyer die Bedingung gestellt, Hans König als Oberassistenten zu übernehmen (zu Königs Karriere siehe die Abschnitte 1.2.6.1.1 und 1.3.5.1). Die Fakultät, und allen voran Eucken, dürfte besorgt gewesen sein, dass im Ministerium in Hannover die Schaffung eines neuen Instituts mit dem Wiedergutmachungsanspruch von Hohenemser hätte gekoppelt werden können. Das hätte die Bemühungen der Fakultät, ihren (ehemaligen) nationalsozialistischen Physikern die Karriere zu retten, in Gefahr gebracht. Mit der von Pohl und Eucken durchgesetzten Lösung wurden zwei Fliegen mit einer Klappe erschlagen. Der stellungslose König wurde untergebracht und Hohenemser weiterhin fern gehalten. Hohenemser war diese für ihn sich nachteilig auswirkende Kopplung von verteidigten Entnazifizierungsfällen und abgewehrten Wiedergutmachungen nur zu klar. Er sah für sich solange keine Chancen, bis die ehemaligen Parteimitglieder ihre früheren Stellen wieder erlangt haben. Er zeigte Verständnis für diese Personalpolitik der Universität, die ihn als gefährlichen Unruhestifter begreifen konnte. ${ }^{2234}$ Ein Verständnis der Vorgänge darf in diesem Fall aber keine Rechtfertigung bedeuten. So ist es von Seiten der Göttinger Professoren durchaus verständlich, dass sie um eine kollegiale Zusammenarbeit besorgt waren. Wie hätte auch zwischen Hohenemser und König eine solche aussehen können? Die Rettung des

\footnotetext{
2231 C. A. Spencer an Rektor, 24. Dezember 1947, „Die Ergebnisse sind jedoch Eigentum des D.S.I.R. und können nicht ohne Zustimmung von D.S.I.R. veröffentlicht werden; D.S.I.R. behält sich das Recht vor, nach Beratung mit der Universität zu bestimmen, ob die Ergebnisse kommerziell ausgewertet werden sollen, durch Patente (sofern tunlich) oder in anderer Weise und gegebenenfalls unter welchen Bedingungen." UAG, Kur. XVI V.C. hh 6.

2232 Siehe dazu das Schreiben von D.I.S.R. an den Kurator der Univ. Göttingen, 22. 3. 1950, UAG, Kur XVI V.C. hh.2.

2233 Dekan Eucken an Ministerium, 28. Oktober 1946. UAG, Rek. 5250 / 7A.

2234 Hohenemser an Odqvist, 14. November 1946. Die entsprechende Stelle des Briefes wurde in Abschnitt 5.4.4.3 zitiert. KHP.
} 
Institutsfriedens bei Beibehaltung des vorhandenen Personals verhinderte nicht nur die Rehabilitierung Hohenemsers, sondern auch eine im Institut stattfindende politische Auseinandersetzung mit dem Vergangenen und der eigenen Beteiligung und Mitverantwortung.

Erwin Meyer verhielt sich in seiner neuen Wirkungsstätte kollegial zu 'seinem“ Oberassistenten. Es ist auch nicht klar, ob ihm damals die Situation missfiel. Vermutlich war er seinen Kollegen Becker und Kopfermann wegen der geglückten Berufung dankbar. Eine Kritikäußerung an der Göttinger Personalpolitik wäre in dieser Situation unangebracht gewesen - dies hätte ihm Undankbarkeit und unkollegiales Verhalten als Vorwurf eingebracht. Meyer wurde die Möglichkeit gegeben, mehrere seiner Assistenten aus Berlin mitzubringen. Nach der Wegberufung Königs setzte Meyer im Februar 1952 seinen Schüler Konrad Tamm auf die Oberassistentenstelle. Tamms politische Vergangenheit war zwar 1952 kein gesellschaftlich oder hochschulpolitisch bedeutendes Thema, doch zeigt sie Meyers Toleranz gegenüber früher (aus unterschiedlicher Motivation heraus) politisch engagierten Physikern. Tamm war Mitglied in: 1933-45 NSDAP, 1933-45 SA (Oberscharführer in Pioniersturm), 1933-36 NSDStB, 1938-39 NSDDB, 1939-45 DAF einschließlich NSBO, 1940-45 NSV. ${ }^{2235}$ Nach dem Ende von Königs Karriere und nachdem seine politische Vergangenheit 1967 bekannt geworden war, distanzierte sich Meyer deutlich von ihm. Er teilte dem Dekanat mit: „Herr König wurde auf Wunsch der Herren Professor Pohl und Professor Eucken, d. h. auf Anordnung unserer Fakultät bei meiner Berufung im Jahre 1947, Oberassistent im III. Physikalischen Institut.“2236 Zumindest im Nachhinein wollte Meyer nicht als Förderer von Königs Laufbahn angesehen werden.

\subsubsection{Schulers Stellung als Emeritus}

Schuler konnte sich als emeritierter Professor gegen die Demontage seines Instituts nicht zur Wehr setzen. Er verlor seine Arbeitsmöglichkeiten, konnte bald keine Mitarbeiter mehr anstellen, außerdem wurden seine Apparate und Instrumente aus dem Institut entfernt. Noch im Februar 1947 wurde seinem Mitarbeiter Christian Hoffrogge die Verwaltung der Dienstgeschäfte eines wissenschaftlichen Assistenten übertragen.2237 Hoffrogge war mit Messungen an der Schuler-Uhr beschäftigt. Doch die Uhr musste Meyers Apparaten Platz

2235 UAG, Kur., Neu. XVI. V. C. K. 1-3.

2236 Meyer an Dekanat, 17. März 1967. GPAMNFG, Lehrkörper (ausgeschieden), König.

2237 Kurator Bojunga an Hoffrogge, 6. Februar 1947. UAG, Rek. 5250 / 7A. 
machen und wurde an die PTB nach Braunschweig transferiert. ${ }^{2238}$ Hoffrogge folgte der Uhr und war ab 1947 Mitarbeiter der PTB. ${ }^{2239}$. Dort wurden im Jahr 1948 Versuche mit zwei von Schuler gebauten Pendeluhren im Vergleich mit einer Quarzuhr durchgeführt. ${ }^{2240}$ Hoffrogge sendete im Juni 1949 aus Braunschweig einen Aufsatz „Über Gangstörungen von SchulerUhren durch die Gezeitenkräfte, Erdbeben und durch Änderungen der Pendellänge“ an die Zeitschrift für Physik. ${ }^{2241}$

Vom Entnazifizierungs-Hauptausschuss erhielt Schuler im Oktober 1948 einen Einstellungsbescheid in dem festgestellt wurde, dass er vom Entnazifizierungsrecht nicht betroffen sei. ${ }^{2242} \mathrm{Da}$ die Militärregierung früher die Ausübung einer Lehrtätigkeit durch ihn nicht gewünscht habe, beantragte Schuler im Dezember 1948, künftig wieder Vorlesungen halten zu dürfen. ${ }^{2243}$ Der Antrag wurde von allen Stellen genehmigt, und Schuler bot wieder Lehrveranstaltungen über die klassische Theorie des Kreisels an. Der Umfang der wieder angebotenen Vorlesungen nahm aber eher bescheidene Ausmaße an, was vermutlich an dem geringen Interesse an seinen Spezialthemen nach der Neuausrichtung der angewandten Physik lag. ${ }^{2244}$ Aus Schulers Sicht glückte seine Rehabilitation noch aus einem anderen Grund nicht ganz, denn im April 1951 bescheinigte der Kurator, dass Schuler ein Arbeitszimmer nicht zur Verfügung gestellt werden könne. Wahrscheinlich insistierte Schuler telefonisch oder persönlich, sodass der Kurator im Dezember 1952 die negative Auskunft wiederholte.2245 Schuler widmete seine Arbeitskraft der Fertigstellung seiner Lehrbücher zur grundlegenden mechanischen Schwingungslehre, über Mechanik und über Regelungstechnik. ${ }^{2246}$

\subsection{Zusammenfassende Interpretation des Falles Hohenemser}

Die Wiedergutmachung Hohenemsers in Form einer Wiederanstellung an der Universität Göttingen scheiterte, da ein kollegiales Verhältnis zwischen ihm und den Nutznießern des Nationalsozialismus unter den Hochschullehrern undenkbar schien. Die in der Abwehr

\footnotetext{
2238 Siehe Schuler an Schimank, 10. November 1948. UH-HSGS, NL Schimank, Korr. Schuler.

2239 Siehe Moser (Hrsg.) [1962] S. 182.

2240 Siehe Moser (Hrsg.) [1962] S. 71f. Durch den Vergleich zweier Schuler-Uhren mit einer Quarzuhr konnte im Jahr 1948 die Kurve der von den Gezeitenkräften der Sonne und des Mondes verursachten Schwereschwankungen unmittelbar bestimmt werden.

2241 MPG-Archiv, III, 50, 139.

2242 Siehe Einstellungs-Bescheid vom 19. Oktober 1948. UAG, Kur. PA Schuler.

2243 Schuler an Kurator, 6. Dezember 1948. UAG, Kur. PA Schuler.

2244 Siehe Tabelle 23 am Ende des Kapitels 4.

2245 Konzept des Kurators, 30. April 1951, und mit identischem Wortlaut 5. Dezember 1952. UAG, Kur. PA Schuler.

2246 Schuler [1949], [1950]a, [1951]a, [1956], [1959].
} 
Hohenemsers vorgebrachten fachlichen Gründe waren bloße Vorwände, die ohne die strikt ablehnende Haltung der Universität nicht existiert hätten. Dann hätte die Fakultät auf den damals vorhandenen Unterrichtsbedarf in der angewandten Mathematik hingewiesen und Hohenemser einen entsprechenden Lehrauftrag erteilt. Die zahlreichen, unkomplizierten und unbürokratischen Hilfestellungen für stellenlose Kollegen, wie sie in Kapitel 1 beschrieben wurden, legen nahe, dass auch im Fall Hohenemser aus rein fachlicher Überlegung eine Wiedergutmachung leicht möglich gewesen wäre. Ihr stand aber entgegen, dass von Hohenemser ein kollegiales Verhalten gegenüber politisch Belasteten gefordert wurde, von dessen Einhaltung die Universität nicht überzeugt war. Auf ihrer Seite bestand die Befürchtung, dass Hohenemser die Ruhe der Selbstentnazifizierung gestört hätte. Sowohl die Universitätsleitung wie auch die Fakultät teilten diese Sorge um Ruhestörung, die von beiden jedoch auf leicht unterschiedliche 'Gefahren' bezogen wurde.

Die Universitätsführung befürchtete, durch Hohenemser in ihrer Konstruktion einer 'sauberen' Nachkriegsidentität gestört zu werden. Hohenemser signalisierte deutlich, die vergangenheitspolitische Übereinkunft nicht einzuhalten, das Vergangene als begraben anzusehen. Die Umdeutungen, welche die Universität bezüglich ihrer eigenen Vergangenheit anstrengte, wären durch seine Anwesenheit gefährdet gewesen. Statt die Arrangements der NS-Zeit umzudeuten, nannte Hohenemser die Professoren mit politisch begünstigter Karriere beim Namen. Die in den ersten Nachkriegsjahren auftauchenden kritischen Presseberichte über immer noch vorhandene nationalsozialistische Strömungen an der Universität Göttingen hätten durch ihn möglicherweise eine Unterstützung bekommen. Als 'Insider' hätte er dann Informationen über Stellenbesetzungen der Nachkriegszeit nach außen dringen lassen können, die das konstruierte Selbstbild der Universität ins Schwanken gebracht hätten.

In der Fakultät war zusätzlich die Sorge vorhanden, dass Hohenemser konkrete Nachkriegskarrieren angesehener Kollegen zum Scheitern hätte bringen können. Sie glaubte von ihm wahrscheinlich das, was wir aus seinen privaten Briefen bestätigt finden: Dass er zu einer Amnestie gegenüber Nationalsozialisten und engagierten Wehrmachtsoffizieren nicht bereit war. Die Fakultät befürchtete vermutlich zu Recht einen Konflikt zwischen Hohenemser und einigen Institutsangehörigen, wäre er im Institut wieder angestellt worden. Die Umstrukturierung der angewandten Physik ist in Zusammenhang mit seiner Abwehr zu interpretieren. Die Fakultät benutzte die neu eingerichteten Stellen, um 'bedürftige' Kollegen zu versorgen, welche die Nachkriegsidentität der Hochschule nicht in Frage stellten und von denen ein loyales Verhalten erwartet werden konnte. Hohenemser musste aber wegen der 
Politik dieser Stellenbesetzungen weiterhin fern gehalten werden, denn die Karriere von Hans König, dessen ,jugendliche Begeisterung“ für den Nationalsozialismus unter den Göttinger Physikern bekannt war, stand auf zu unsicherem Grund, als dass sie eine laut werdende Kritik verkraftet hätte.

Die Strategie der Göttinger war nicht, Hohenemsers Wiedereinstieg in die Hochschullaufbahn prinzipiell zu verhindern, sondern nur, ihn von der eigenen Universität fern zu halten. Dies gelang ihnen auch bis Anfang 1947. Im April dieses Jahres kam vom Ministerium ein ernst zu nehmendes Angebot auf eine Diätendozentur, das vermutlich zu einem positiven Ausgang der Wiedergutmachung geführt hätte. Hohenemser wäre dann in der angewandten Mathematik untergebracht worden und nicht in der fachlich neu ausgerichteten angewandten Physik. Doch zu diesem Zeitpunkt hatte sich Hohenemser schon zur Auswanderung in die USA entschieden. Letztlich konnte sich also die Fakultät durchsetzen und relativ ungestört ihre Personalpolitik umsetzen. 


\section{Zusammenfassung}

Welches Bild der Nazifizierung und Entnazifizierung der Göttinger Physik ergeben die fünf Kapitel mit ihren verschiedenen Zugängen zu dem Gegenstand in einer Zusammenschau?

Die einzelnen Kapitel haben gezeigt, dass die politische Beeinflussung der Wissenschaft sich in den verschiedenen Bereichen unterschiedlich stark auswirkte und einen jeweils anderen zeitlichen Verlauf nahm. Zusammen ergibt sich ein differenziertes Bild der Nazifizierung wie Entnazifizierung, die nicht mehr als homogene oder stetige Prozesse zu verstehen sind. Die Göttinger Physik durchlief beide dieser vielschichtigen Prozesse. In dieser Auseinandersetzung mit der politischen Beeinflussung wurde ihre Entwicklung geformt. Die Physiker nahmen aktiv an dieser Formung teil - die Prozesse vorantreibend wie abwehrend. Ihr Spielraum war allerdings durch Gesetze, ministerielle Erlasse und alliierte Verordnungen eingeschränkt.

Am deutlichsten wirkte die Nazifizierung in der konsequent umgesetzten „Arisierung“ des Lehrkörpers - verstanden als Vertreibung der Juden und „Nichtarier“. Etwa die Hälfte der Göttinger Physiker wurde 1933 entlassen. Dies schuf durch die folgenden Nachbesetzungen die Möglichkeit einer weiteren Nazifizierung. Inwieweit kamen politische Kriterien bei der personellen Erneuerung zum Tragen? Zur Beantwortung dieser Frage wurde der gesamte Lehrkörper prosopografisch untersucht. Durch dieses Vorgehen konnte die Nazifizierung des Personals in ihren Möglichkeiten und Grenzen sowie ihren unterschiedlichen Konsequenzen erfasst werden. Der Stereotyp einer Nazifizierung, den man in etwa so verstehen kann, dass 'Juden' vertrieben und durch Nationalsozialisten ersetzt wurden sowie bei Stellenbesetzungen engagierte Parteigänger gegenüber politisch Indifferenten bevorzugt wurden, stellt in Bezug auf die Göttinger Verhältnisse eine zu grobe Vereinfachung dar. Die Auswahl des Personals geschah nicht vorwiegend auf Grund politischer Gesichtspunkte. Sie waren in dem Anforderungskatalog an werdende Hochschullehrer nur ein Bestandteil neben anderen. Die politische Kontrolle und Beurteilung von Bewerbern um Universitätsstellen durch den NSDozentenbund wirkte vor allem im Mittelbau als selektierende Maßnahme; die etablierten Professoren waren davon weit weniger betroffen. Einzelne Physiker scheuten die politische Überprüfung und waren nicht bereit, bestimmte Anpassungen zu erbringen. Ein Beispiel hierfür ist Heinz Pick, der 1940 seine Hochschullaufbahn wegen des bevorstehenden NSDozentenlagers unterbrach und in die Industrie wechselte. Vor allem bei den Besetzungen von Assistentenstellen kam es vor, dass einem Bewerber die Stelle aus politischen Gründen 
verweigert wurde. Mit Ausnahme von Heinz Pick kehrte keiner von diesen in der Nachkriegszeit an die Universität Göttingen zurück. Gleichzeitig konnten aber junge Physiker auch mit nur minimaler politischer Anpassung Karriere machen, zum Beispiel mit einer kurzzeitigen NSKK-Mitgliedschaft. Außerdem führten die politischen Überprüfungen nicht automatisch dazu, dass die Nationalsozialisten unter den Physikern in ihrem beruflichen Aufstieg bevorzugt wurden. Dies zeigt der Fall des SS-Mitglieds Ruprecht, der sich zwar 1941 habilitieren konnte, dem die Fakultät aus fachlichen Gründen jedoch eine Dozentur verweigerte, obwohl in seinem Fach ein Bedarf an Dozenten herrschte. Am Beispiel von Heinz Schlechtweg ist noch klarer ersichtlich, dass die Nationalsozialisten nicht generell bevorzugt wurden. Ihm verweigerte Prandtl 1936 die Habilitation, obwohl seine fachlichen Leistungen diese gerechtfertigt hätten. Als Begründung wurde seine charakterliche Unreife angegeben.

Zusammengefasst stellt sich die politische Einflussnahme auf den Lehrkörper so dar, dass einerseits einigen qualifizierten Wissenschaftlern aus politischen Gründen die Möglichkeit zur Hochschullaufbahn genommen wurde, andererseits aber die Fakultät den politischen Eingriff begrenzte, indem sie Nationalsozialisten, die als Hochschullehrer ungeeignet erschienen, Stellen verweigerte. Während die Professoren in dem Bemühen, ministeriell verordnete Entlassungen rückgängig zu machen, nicht erfolgreich waren, konnten sie in Habilitationsverfahren und in Stellenbesetzungen ihre fachlichen wie charakterlichen Forderungen durchsetzen. Vom Kandidaten wurde ein bestimmtes Maß an wissenschaftlicher Produktivität gefordert sowie eine breite Kenntnis in den Grundlagen des Faches. Zu sehr auf ein Thema konzentrierte Spezialisten wurden abgelehnt. Eine Erklärung für die Durchsetzungskraft der Professoren in diesem Punkt liegt in dem intakt gebliebenen kollegialen Netz der Physiker. Die internen Grenzziehungen wurden von einem stabilen Netz der Professoren entschieden und getragen. Damit die Entscheidung eines Professors gegen die Förderung eines Nationalsozialisten von seinen Kollegen unterstützt wurde, waren verlässliche kollegiale Verbindungen eine Voraussetzung. Erst die Einigkeit der maßgebenden Physiker verlieh ihnen die Macht, diese Entscheidungen umzusetzen. Die Beibehaltung eines bestimmten fachlichen Standards ist aber nicht unbedingt als Abwehr einer Nazifizierung zu interpretieren. Ein hohes wissenschaftliches Niveau der Forschung stand in keinem Gegensatz zu den Zielen des NS-Staates. Es erhöhte die Qualität der in der Physik durchgeführten Rüstungsforschungen und diente somit dem Regime. 
Eine ganz andere Art von Nazifizierung erfolgte in der Studentenschaft. Die rassistischen Relegationen blieben in Göttingen auf Grund der schon 1933 sehr kleinen Zahl jüdischer Studenten in ihrem Ausmaß gering. Da zu Kriegsbeginn ein Mangel an Studenten herrschte und außerdem viele männliche Studenten zum Kriegsdienst eingezogen wurden, wurde von staatlicher Seite das Frauenstudium gezielt gefördert - auch in technischen und anderen kriegsrelevanten Fächern wie zum Beispiel der Physik. In diesem Sinn sind die exzeptionell hohen Physikstudentinnenzahlen der Kriegsjahre als Folge der Nazifizierung der Studentenschaft zu verstehen. Die Frauen dienten als Ersatz für die Männer; ihre Ausbildung und ihre Forschungen wurden für den Krieg benötigt.

Die so verstandene Nazifizierung der Studentenschaft machten die Professoren in der Nachkriegszeit mehr als rückgängig. Die Verdrängung der Frauen aus der Universität könnte konsequenterweise als Entnazifizierung der Studentenschaft bezeichnet werden und wurde von den Professoren teilweise auch tatsächlich als solche verstanden, nämlich als Rückgängigmachung einer vermeintlich falschen Föderungspolitik im Nationalsozialismus. Tatsächlich spielten aber andere Gesichtspunkte eine bedeutendere Rolle: eine konstante Mentalität der Professoren und daraus entspringende Vorstellungen über Charakter und Befähigung von Akademikern.

Betrachtet man die Entnazifizierung als Spiegel der Nazifizierung, so werden die tatsächlichen Prozesse durchaus verständlich. Die der Universität entzogenen männlichen Studenten, die jahrelang im Krieg gekämpft und zum Teil eine Offizierslaufbahn eingeschlagen hatten, kehrten zurück und wurden bevorzugt aufgenommen, gleichzeitig die Frauen hinaus gedrängt. Im Lehrkörper hatte sich die Fakultät der als ungeeignet eingestuften Physiker schon vor 1945 entledigt (Beispiel Schlechtweg und Ruprecht) und sah daher keine Notwendigkeit, fähige Physiker aus politischen Gründen zu entlassen. Einzelne der in der NSZeit aus politischen oder rassistischen Gründen aus der Universität verdrängten Physiker nahm die Fakultät nach Kriegsende in ihren Lehrkörper auf, so den schon erwähnten Heinz Pick sowie Fritz Houtermans, der 1933 in Berlin entlassen worden war. Die Fakultät empfand die überzeugten Nationalsozialisten in ihrem Lehrkörper nicht als ihr aufoktroyiert. Diese hatten vielmehr den geregelten Prozess einer akademischen Karriere durchlaufen, also alle von der Fakultät geforderten Qualitätsstandards erfüllt, und konnten deshalb ins kollegiale Netz integriert werden. Dieser Mechanismus funktionierte sogar bei tatsächlich aufgezwungenen Kollegen, wie am Beispiel von Georg Joos zu sehen ist. Joos war ein so 
fester Bestandteil des Netzes geworden, dass ihn die Fakultät in der Nachkriegszeit unbedingt zurückgewinnen und die erste frei gewordene Professur dafür verwenden wollte.

Betrachtet man die Entnazifizierung allerdings unter dem Gesichtspunkt der von den Alliierten geforderten politischen Überprüfung der Physiker, erkennt man sofort die ablehnende Haltung der deutschen Professoren. Diese wird aus dem inneren Zusammenhalt des kollegialen Netzes verständlich. Die Kollegialität beinhaltete eine politische Toleranz, die zu einem Arrangement der Zusammenarbeit zwischen Nationalsozialisten und anderen führte, das auf Grund des Tabus der Denunziation möglich war. Das Arrangement funktionierte in der NS-Zeit wie danach, nur die Einhaltung des Tabus wechselte die Seiten. Der hingegen als aufoktroyiert wahrgenommene Prozess der Entnazifizierung belastete das gesamte Netz, da anerkannte Mitglieder herausgerissen wurden, die von allen toleriert und von manchen hoch geschätzt wurden. Die Physiker setzten sich aus Kollegialität für die Rückkehr der Entlassenen ein; dies betraf die in Göttingen ansässigen Hellwege und Magnus sowie die andernorts entlassenen Meyer, Hiedemann, Joos, Sauter und andere, für die Göttingen vielfach zum Auffangbecken wurde. Die Personalentwicklung in der unmittelbaren Nachkriegszeit war entscheidend geprägt von der Unterstützung derjenigen Physiker, zu denen in der NS-Zeit eine kollegiale Verbindung existierte. Ihnen wurden großzügig und unbürokratisch Stellen vermittelt; fachliche wie politische Überlegungen spielten hierbei eine untergeordnete Rolle.

Im Gegensatz zu dieser Hilfestellung wehrte die Fakultät die Rückkehr eines im NS vertriebenen Physikers vehement ab. Sie tat dies auf Grund derselben Auffassung von Kollegialität, die sich in diesem Fall aber gegen den früheren Kollegen Kurt Hohenemser wandte, da seine Wiedereingliederung die Stabilität des Netzes gefährdete. Hohenemser wurde von der Fakultät als Ruhestörer empfunden, da er politisch unterstützte Karrieren auch jener Physiker kritisierte, die fest verankerte Kollegen waren. Seine Wiedereinstellung wurde deshalb auch von Rektor und Senat abgelehnt. Neben dem in Einzelfällen vermutlich zutreffenden Argument, dass eine kollegiale Zusammenarbeit mit ihm undenkbar schien, führte die Fakultät eine Reihe von Vorwänden gegen seine Anstellung an, die vor allem fachlich begründet wurden. Im Grundsatz ging es der Universität in der Abwehr Hohenemsers aber darum, die Grenzen der Entnazifizierung selbst möglichst eng zu halten und eine vorzeigbare Nachkriegsidentität der Hochschule zu konstruieren. Für dieses Vorhaben stellte Hohenemser eine Gefahr dar, da von ihm die Einhaltung des Tabus der Denunziation nicht erwartet wurde. Die Reaktion auf den Fall Hohenemser lässt vermuten, dass die Universität 
Göttingen eine Überprüfung ihres Lehrkörpers lieber nach ihren eigenen Kriterien der eingehaltenen oder verletzten Kollegialität durchführte als nach vorwiegend politischen Gesichtspunkten. Es ist kein bloßer Zufall, dass nach der erfolgreichen Abwehr Hohenemsers die von ihm beanspruchte Stelle Hans König übertragen wurde, der seit 1929 NSDAPMitglied war. Die Sicherstellung der Karrieren belasteter Kollegen hatte Vorrang vor einer Rehabilitierung von NS-Opfern.

Eine Konstante, die weder von der Nazifizierung noch der Entnazifizierung wesentlich beeinflusst werden konnte, war das Selbstverständnis der Göttinger Physiker in Bezug auf die Auswahlkriterien der Assistenten und Hochschullehrer. Die Bedingungen, welche die Professoren an die Aufnahme in die eigene Gemeinschaft stellten, waren nicht in erster Linie politisch bestimmt. Wichtiger waren fachliche und „charakterliche“ Qualifikationen. Dass es nicht nur auf die fachliche Befähigung ankam, zeigt die große Sorgfalt, mit der die Bewerber um Studienplätze auf ihren Charakter geprüft wurden. Auch in den Habilitationsgutachten vor wie nach 1945 finden sich kaum Stellungnahmen über die politische Haltung oder Aktivität der Kandidaten, dafür aber regelmäßig solche über ihre charakterliche Eignung für die Hochschullehrerlaufbahn.

Welche Auswirkungen hatte die Nazifizierung in der Forschung? Mit der Vorbereitung auf den Krieg wurde die physikalische Forschung auf militärische Verwertbarkeit ausgerichtet dies vor allem in der angewandten Physik. Während des Krieges wurde in allen Instituten Rüstungsforschung durchgeführt. Sie betraf beispielsweise die Radarentwicklung, die Entwicklung von Geräten zur Raketen- und Torpedosteuerung und Untersuchungen über die Ausbreitung elektromagnetischer Wellen unter Wasser, die für den U-Boot Einsatz relevant waren. Ein genaues Urteil über das Ausmaß der betriebenen Rüstungsforschung ist auf Grund der Quellenlage leider nicht möglich. Das Engagement in militärischer Forschung scheint nicht nur unter den einzelnen Instituten unterschiedlich stark gewesen zu sein, sondern auch innerhalb eines Instituts unter den verschiedenen Forschern. Während unter Hellweges Leitung das II. Physikalische Institut zum Spezialbetrieb der Rüstungsindustrie erklärt wurde, hielt sich der folgende Institutsleiter Kopfermann aus militärischen Forschungen weitgehend heraus. Ihm genehmigte 1943 der Reichsforschungsrat die Entwicklung eines Elektronenbeschleunigers, der auf medizinische Anwendung ausgelegt war. Gleichzeitig übernahm die theoretische Physik Aufträge zur Geschossentwicklung.

Um zu überprüfen, wie tief die Nazifizierung in die physikalische Forschung eindrang, wurde die Forschergruppe um Robert Pohl exemplarisch nach der wissenssoziologischen Methode 
Ludwik Flecks untersucht. Die Gruppe wurde als Denkkollektiv identifiziert und aus ihren Arbeiten ihr Denkstil analysiert. Als Ergebnis ist festzustellen, dass das Selbstverständnis der in der Physik geltenden Methoden und Theorien im Untersuchungszeitraum eine Konstante darstellt. Eine politische Beeinflussung des Denkstils ist nicht nachweisbar. Die von der PohlSchule auch während des Krieges durchgeführte Grundlagenforschung blieb im Kern frei von einer Nazifizierung. Die Inhalte und die Ausrichtung des Forschungsprogramms wurden vom inneren Kreis des Denkkollektivs bestimmt. Außenstehende Physiker hatten wenig Einfluss auf die Arbeit des Kollektivs. Diese Abschottung nach außen findet eine Parallele in der These vom kollegialen Netz. Die kollegiale Verbundenheit der Wissenschaftler wirkte in der Entwicklung der Physik und besonders in den Personalentscheidungen auch als Abgrenzung nach außen. Über die Netzzugehörigkeit definierte sich das „Innen“ des Faches; wer nicht eingebunden war, stand außen. In der Forschungstätigkeit in Pohls Institut erkennt man diese Trennung auch zwischen Kollektiv und Gastforschern. Auch wenn die Gäste ähnliche Themen bearbeiteten, benutzten sie andere Erklärungsmodelle und stellten ihre Ergebnisse in einen anderen Forschungskontext.

Obwohl das Pohl'sche Forschungsprogramm keiner politischen Lenkung unterworfen war, entsprangen aus ihm Anwendungen, die dem Kriegseinsatz unmittelbar dienten. Die Untersuchung des Germaniumkristalls auf seine elektrischen Eigenschaften stellte ein derart hybrides Projekt dar. Einerseits war es Teil des lang angelegten Forschungsprogramms der Pohl-Schule und brachte diesbezüglich auch neue Erkenntnisse, andererseits wurde es im Auftrag der Luftwaffe zur Entwicklung von Radargeräten durchgeführt und war in diesem Sinn Teil der Rüstungsforschung. Die in allen Göttinger Physikinstituten anzutreffenden Auftragsforschungen für das Militär wurden durch die Entnazifizierung beendet. Gleichwohl wurde der als Grundlagenforschung deklarierbare Anteil davon fortgesetzt, die Forschung und ihre Ergebnisse in einen neuen Kontext gestellt.

Zum neuen Kontext gehörte die Forschungskontrolle durch die Besatzungsmacht. Zur Fortsetzung der Arbeit war eine Genehmigung der Kontrollbehörde notwendig. Hierfür musste nachgewiesen werden, dass sie keiner militärischen Anwendung diene, sie friedliche Zwecke verfolge. Diese gesetzlichen Rahmenbedingungen wirkten innovationsfördernd. Die Umwidmung der Forschung zu friedlichen Zwecken erreichten die Physiker zum Teil durch eine neue Zusammenarbeit mit den Medizinern. Zum Beispiel wurde elektronenmikroskopische Forschung nun auf Bakterien angewandt und diente vorgeblich der Seuchenbekämpfung. In der Umgehung der Forschungsverbote kam auch die Kollegialität zu 
tragen, die sich zwischen Besatzungsoffizieren und Göttinger Physikern entwickelte. Auf diese Weise konnte beispielsweise die laut Gesetz verbotene angewandte Kernphysik weiter betrieben werden, während die angewandte Mechanik in Göttingen aufgegeben wurde. Sie musste einem neuen Institut weichen, in dem mit finanzieller Unterstützung der Briten und in ihrem Auftrag unter anderem Rüstungsforschungsprojekte der NS-Zeit fortgeführt wurden. In diesem Fall kam es während des Entnazifizierungsprozesses durch den 'Import' einer ehemals Berliner Wissenschaftlergruppe zu einer erneuten Militarisierung der Göttinger Forschung.

Ein Vergleich der politischen Beeinflussung der Forschung mit jener des Personals ergibt, dass diese Prozesse nicht synchron verliefen. Dies hängt mit der Entwicklung der Nazifizierung während der NS-Zeit zusammen. In der Formierungsphase stand die personelle Umgestaltung nach rassistischen und politischen Kriterien im Vordergrund, in der Konsolidierungsphase die Nutzbarmachung der wissenschaftlichen Ressourcen für den geplanten Krieg. Das stärkste Ausmaß hatte der politische Zugriff auf die Professorenschaft in den Jahren 1933 bis 1936. Die mit dem Vierjahresplan von 1936 vorangetriebene Aufrüstung in Deutschland wirkte sich allmählich auf die Forschung in den Göttinger Physikinstituten aus. Während die Professoren in der zweiten Hälfte der NS-Herrschaft wieder stärker Einfluss auf die Stellenbesetzungen ausüben konnten, wurde ihnen ein Stück der 'Forschungsfreiheit' genommen und von Heereswaffenamt, Marine und Luftwaffe kriegsbezogene Forschung vorgeschrieben. Teilweise wurde von den Göttingern die militärische Ausrichtung in eigener Initiative verfolgt. Das Kriegsende markiert dann einen schlagartigen Abbruch dieser Forschungen. Demgegenüber war die Entnazifizierung des Personals ein längerer Prozess, der sich verglichen mit der Nazifizierung schneller entwickelte und geringere Auswirkungen hatte. Entscheidend waren die ersten beiden Jahre. 1947 ging die Verantwortung in deutsche Hände über. Der einzig entlassene Physiker Hellwege kehrte daraufhin 1949 in seine frühere Stelle zurück. Das stabile kollegiale Netz konnte die durch die Entnazifizierung hervorgerufenen Eingriffe in die Personalstruktur vielfach abfangen. Dies war möglich, weil die Kontrolloffiziere in Göttingen keine gründliche Untersuchung aller Personen unternahmen, weil die Professoren von Anfang an erheblichen Einfluss in der politischen Überprüfung des Lehrkörpers besaßen, der mit Übergabe der Verantwortung an die Deutschen weiter stieg, und weil ein Ziel der Briten die Etablierung eines funktionierenden Forschungsbetriebs war, zu dessen Erreichung sie den deutschen Physikern auch in der Personalpolitik einen gewissen Spielraum gewährten. Dieser Spielraum wurde nicht nur genutzt, um die vorhandene Göttinger Physikerschaft in der Nachkriegszeit möglichst 
vollständig $\mathrm{zu}$ erhalten, sondern auch, um den vielen wandernden Physikern eine Übergangslösung anzubieten.

Im Entnazifizierungsprozess agierten die Physikordinarien Pohl, Kopfermann, Becker und Meyer in unterschiedlichen Wirkungsbereichen, in denen sie die Zukunft der Göttinger Physik in gewünschte Bahnen lenkten. Pohl war Mitglied des Entnazifizierungsausschusses und sorgte in der politischen Überprüfung des Lehrkörpers für personelle Kontinuität. Kopfermann handelte unterstützt durch die guten Beziehungen zu den Kontrolloffizieren die Fortsetzung der Forschungen aus. Becker war Vorsitzender des Immatrikulationsaussschusses. In dieser Funktion legte er die Kriterien für die Auswahl der Studenten fest, hierbei auch die Charakterprüfung. Meyer konnte durch einen Vertragsabschluss mit den Briten eine wichtige Zusatzfinanzierung des neuen Instituts und eine Fortführung der angewandten Physik in Göttingen erreichen.

Zuletzt sei noch die Entwicklung des Lehrangebots angesprochen, die sich durch eine große Kontinuität in den Inhalten der Grundausbildung auszeichnete. Mit den Nachbesetzungen der Lehrstühle am Anfang der NS-Zeit kam es insofern zu einer Veränderung, als den Professoren eine betont anschauliche Ausrichtung der Lehre gemeinsam war. Dies war keine bewusste Nazifizierung, sondern ein zufälliges Zusammentreffen gemeinsamer Physikanschauung. Während das Lehrangebot in der NS-Zeit eine geringe politisch bedingte Veränderung erfuhr, kam es in der Nachkriegszeit mit dem studium generale $\mathrm{zu}$ einem Aufleben alter Bildungsideale und einer breiteren Ausbildung auch in der Physik. Dem studium generale war in Göttingen nur eine relativ kurze Existenz beschieden. Auch das 1945 neu eingeführte Prüfungsfach Geschichte der Naturwissenschaft wurde bald wieder abgeschafft, da in ihm besonders jene Studenten gut abgeschnitten hätten, die angeblich bloß fleißig gelernt hätten, während die 'eigentlich` wissenschaftlich besser befähigten teilweise aus mangelndem Interesse schlechte Zensuren bekommen hätten und ihnen damit die Möglichkeit der Promotion genommen worden sei. Dieses Beispiel zeigt, dass die Auswahl des erwünschten Nachwuchses nicht über die alleinige Abprüfung von Wissen oder Bildung geregelt war, sondern es scheint vielmehr, als habe durch persönlichen Kontakt gelegentlich schon vor den Prüfungen festgestanden, wer für die wissenschaftliche Arbeit als geeignet anzusehen sei.

Dies führt zu den in dieser Arbeit einleitend zitierten Fragen von Thomas Kuhn, wie man Mitglied einer bestimmten Wissenschaftlergemeinschaft werde, wie die Sozialisation in der Gruppe verlaufe und welche Abweichungen die Gruppe toleriere. Eine umfassende Antwort ist auf Grundlage dieser Studie nicht möglich, doch sie erlaubt Hinweise auf bisher vielleicht 
zu wenig Beachtetes. Die von den Physikern selbst entworfenen und durchgeführten Aufnahmeprüfungen legten auf zweierlei Wert: auf logisches Denken und schnelle Aufnahmefähigkeit wie auf einen einwandfreien Charakter. Auch die Gutachten der Habilitationsverfahren weisen eine Zweiteilung auf in eine Würdigung der fachlichen Leistungen und Fähigkeiten sowie eine Beschreibung der menschlichen Qualitäten. Die Forderung nach fachlicher Meisterschaft wurde begleitet von einer Erwartung angemessener Verhaltensformen. Die Aufnahme in die engere Gemeinschaft war an das Durchlaufen einer wissenschaftlichen Schule gebunden. In diesem Prozess wurde das für die Gruppenstabilität wichtige kollegiale Verhalten erlernt. Die Ergebnisse dieser Arbeit legen nahe, dass für die Aufnahme und den Verbleib in der Physikergemeinschaft eine positive Mischung von fachlicher und charakterlicher Qualifikation in Verbindung mit einer loyalen Eingliederung in die vorhandene Struktur erforderlich war. Eine beachtenswerte Toleranz zeigte die Physikerschaft gegenüber der politischen Orientierung der einzelnen Kollegen. Ohne Berücksichtigung dieser Toleranz, die Kommunisten wie Nationalsozialisten gegenüber geübt wurde, bestünde die Gefahr einer Überinterpretation der Nazifizierungs- wie Entnazifizierungsprozesse in politischer Richtung. Diese Arbeit belegt jedoch, dass die internen Grenzen der Gemeinschaft während dieser Prozesse weniger nach politischen Kriterien gezogen wurden als nach Maßstäben der Kollegialität.

In welcher Beziehung stehen die Ergebnisse dieser Arbeit zu jenen anderer Untersuchungen zur Nazifizierung und Entnazifizierung der Wissenschaft? Als bester Vergleichsfall dient Steven Remys Studie zur Universität Heidelberg. Remy kommt zu einer Charakterisierung des Nazifizierungsprozesses, die mehr beinhaltet, als sich aus dem Beispiel der Göttinger Physik ablesen lässt. Dies liegt nicht nur daran, dass sich die Heidelberger Physik unter Philipp Lenard als einem der Propagandisten einer „Deutschen Physik“ in anderer Weise entwickelte. Gemeinsam ist den beiden Universitäten, dass der Nationalsozialismus nicht zu einer völligen, staatlichen Unterwerfung der Universitäten führte, auch nicht in dem Teilbereich der Personalpolitik. Die Professoren der Universität Heidelberg behielten wie die Göttinger Physiker weiterhin Einfluss auf Stellenbesetzungen. Politische Mitgliedschaften waren nicht allein ausschlaggebend für erfolgreiche Karrieren. Eine weitere Gemeinsamkeit ist die Ausrichtung der Forschung auf militärische Bedürfnisse. Unterschiede zeigen sich beim Eindringen rassistischer Kategorien in die Forschungsarbeit sowie in der Aufgabe der Objektivität als Grundlage wissenschaftlicher Arbeit. Für Remy waren dies Bestandteile eines „Deutschen Geistes“, der in der Wissenschaft übernommen worden war und der Teil der 
Nazifizierung war. Diese Charakterisierung des Nazifizierungsprozesses mag für Heidelberg gelten, auf die Göttinger Physik trifft sie nicht zu.

Eine Ungereimtheit ergibt sich in der ausgemachten Periodisierung der Nazifizierung. Remy erkennt die Jahre 1936 bis 1939 als „Wendepunkt“, ab dem sich der Prozess verschärft habe. Dies lässt sich für die Göttinger Physik generell nicht sagen. Es trifft zu, dass ab den letzten Friedensjahren Forschung und Lehre verstärkt auf kriegsrelevante Themen ausgerichtet wurden. Andererseits ist in der Personalpolitik ab 1936 ein Rückgewinn an Macht für die Fakultät festzustellen. Auch die Behauptung Remys, der Rassismus habe sich in der Wissenschaft ab dem „Wendepunkt“" verschärft, findet in meiner Studie keine Bestätigung. Stattdessen findet sich mit Fritz Houtermans ein Gegenbeispiel. Er konnte als „Nichtarier“ und Kommunist 1940 nach seiner Auslieferung aus der UdSSR nach Deutschland kriegswichtiger Forschung nachgehen. Dies gelang nur durch den mutigen Einsatz seiner früheren Kollegen. Die kollegiale Verbundenheit war im Vergleich zum Rassismus offensichtlich das stärker wirkende Kriterium. Allgemein scheint es, dass sich für den Nazifizierungsprozess nicht eine einzige Entwicklungslinie angeben lässt, sondern dass man die unterschiedlichen Bereiche Personal, Forschung und Lehre differenziert behandeln muss.

Die tiefgreifend wirkende Nazifizierung der Universität führt Remy auf bestimmte Einstellungen der Professoren zurück: Die beiden anzutreffenden Momente Opportunismus und politisches Engagement haben sich gegenseitig verstärkt. Hinzu komme ein ab 1933 üblicher werdender Antisemitismus. Möglicherweise hängt die schwächere Nazifizierung der Göttinger Physik mit einer geringeren Ausprägung der von Remy genannten Momente zusammen. Eine Überprüfung bedürfte aber Quellen, die verlässliche Schlüsse über beispielsweise die antisemitische Einstellung der Göttinger Physiker zulassen. Die benutzten Quellen geben in dieser Hinsicht leider nicht genügend Auskunft.

Im Zuge der Entnazifizierung schufen die Heidelberger Professoren laut Remy einen Mythos, der darin bestand, die vorangegangene Nazifizierung umzudeuten und den überwiegenden Teil der Professoren reinzuwaschen. Dieser Mythos war anfangs umstritten, da die Kontrolloffiziere Hartshorne und Penham versuchten, eine gründliche politische Überprüfung der Professoren durchzusetzen und damit den Mythos zu entlarven. Nach heftigen Auseinandersetzungen behielten schließlich die Professoren die Oberhand und wehrten einen Großteil der Entnazifizierung ab. In Göttingen musste die Konstruktion einer politisch reinen Identität der Universität nicht in diesem Maße erkämpft werden. Es gab keine mit Hartshorne 
oder Penham vergleichbaren Kontrolloffiziere. Die Abwehr der Entnazifizierung erfolgte besonders in der Physik ohne vergleichbare Tumulte.

Unklar bleibt bei Remy, wie die Professoren sowohl in der Nazifizierung wie in der Entnazifizierung eine Grenzziehung innerhalb ihrer akademischen Gemeinschaft durchsetzen konnten und nach welchen Kriterien die Grenze gezogen wurde. Remy beschreibt zwar für Heidelberg solche erfolgten oder versuchten Ausgrenzungen, doch er liefert kein geeignetes Konzept zur Erklärung dieser Vorgänge. Die vorliegende Arbeit schlägt dazu die These des kollegialen Netzes vor. 


\section{Danksagung}

Mein ganz besonderer Dank gilt meinen Eltern, die diese durch kein Stipendium getragene Arbeit großzügig finanziert haben. Weitere materielle Hilfe erhielt ich durch ein "grant-in-aid from the Friends of the Center for History of Physics, American Institute of Physics", das mir einen Forschungsaufenthalt in den USA ermöglicht hat. Für die besonders freundliche Aufnahme in der Niels Bohr Library danke ich Spencer Weart und den Bibliothekarinnen.

Angeregt wurde diese Arbeit von Klaus Hentschel, der mir bei der Durchführung jede erdenkliche Hilfe anbot. Seine kritischen Kommentare bei jedem Zwischenergebnis und die Ratschläge zur Fortführung der Arbeit waren eine äußerst wertvolle Unterstützung. Dafür und für seine Geduld mit meinem langsamen Arbeitsstil möchte ich ihm meinen allerherzlichsten Dank aussprechen!

Neben der 'professionellen' Betreuung waren auch die Diskussionen mit meinen Freunden und Studienkollegen eine große Hilfe. Mein besonderer Dank gilt Roman Balmasovich, Lorenz Bartosch, Wolfgang Böker, Carola Dietze, Barne und Mareike Flatow, Johanna Fulmek, Till Homann, Marita Hübner, Markus Koschinsky, Thomas Küntzel, Rotraut Mößner, Christian Rammer, Klaus Schlüpmann und (nur in alphabetischer Reihenfolge an letzter Stelle) Henning Trüper.

Aufrichtigen Dank schulde ich den Mitarbeitern der Archive und Bibliotheken, die mich bei meinen Recherchen ausnahmslos freundlich und hilfsbereit unterstützt haben. Wertvolle Kopien aus einer leider in der Zwischenzeit vernichteten Quelle, dem Dienstzimmernachlass von Robert Pohl, stellte mir freundlicherweise Mark Walker zur Verfügung, außerdem auch Tonbänder seiner Interviews mit Wilhelm Walcher und Wolfgang Paul; dafür danke ich ihm herzlichst. Meinen eigenen Interviewpartnern danke ich für ihre Auskunftsbereitschaft; für die Überlassung weiterer wichtiger Quellen sind unter ihnen besonders hervorzuheben: Gisela Bilitewski für Kopien ihres Studienbuches und ihrer Prüfungsscheine, Hanswalter Giesekus für eine Kopie seines Studienbuches und die Leihgabe etlicher Vorlesungsmitschriften, Friedrich Schlögl für Auszüge aus dem Tagebuch Max Schulers, Eva Opitz für die Leihgabe sämtlicher Soldatenbriefe ihres Vaters Richard Becker.

Des weiteren möchte ich danken Margot Fuchs vom historischen Archiv der TU München für eine schriftliche Auskunft über die Entlassung Fritz Sauters, Andreas Mahal vom Landesarchiv Berlin für Auskünfte zum Lebenslauf Erich Hahnkamms, Johannes Orphal für wertvolle Hinweise zu Richard Beckers Biografie, dem Schulleiter des Max-PlanckGymnasiums in Göttingen, Rainer Nickel, für Hinweise zu Ernst Lamla und für die freundliche Erlaubnis zur Einsicht in die Archivbestände der Schule. Mein Dank gilt außerdem Rüdiger Stutz und Oliver Lemuth für die im besten Sinn kollegiale Unterstützung bei meinen Recherchen zu Georg Joos in Jena, Agnes Korn für Kopien aus Frankfurter Zeitungen, dem Direktor des Instituts für Wissenschaftsgeschichte in Göttingen, Nicolaas Rupke, für den zur Verfügung gestellten Arbeitsplatz im Institut und Christian Frischkorn, der mir viele alte Physiklehrbücher geschenkt hat. Zuletzt möchte ich mich bei Anne, Lisa und Chris Hohenemser bedanken, die mir nicht nur Einblick in den Nachlass von Kurt Hohenemser gewährten, sondern mich in ihrem Haus herzlich aufgenommen und mir bei allen Fragen weitergeholfen haben. 


\section{Abkürzungsverzeichnis}

\begin{tabular}{|c|c|c|c|}
\hline \multirow{3}{*}{$\begin{array}{l}\text { AAC } \\
\text { AHQP }\end{array}$} & \multicolumn{2}{|l|}{ Academic Assistance Council } & Deutscher Technik \\
\hline & Archive for the History of Quantum & NSBO & Nationalsozialistische \\
\hline & Physics & & Betriebszellenorganisation \\
\hline A.R. & Artillerie-Regiment & NSDDB & Nationalsozialistischer Deutscher \\
\hline AVA & Aerodynamische Versuchsanstalt & & Dozentenbund \\
\hline $\mathrm{BAB}$ & Bundesarchiv Berlin & NSDStB & Nationalsozialistischer Deutscher \\
\hline BACZ & Betriebsarchiv Carl Zeiss & & Studentenbund \\
\hline BDC & Berlin Document Center & NSFB & Nationalsozialistischer \\
\hline BLO & Bodleian Library, Oxford & & Frontkämpferbund \\
\hline $\mathrm{BSC}$ & Bohr Scientific Correspondence & NSFK & Nationalsozialistischer Fliegerkorps \\
\hline DAF & Deutsche Arbeitsfront & NSKK & Nationalsozialistischer \\
\hline \multirow[t]{2}{*}{ DGLR } & Deutsche Gesellschaft für Luft- und & & Kraftfahrkorps \\
\hline & Raumfahrt & NSLB & Nationalsozialistischer Lehrerbund \\
\hline \multirow[t]{2}{*}{ DLR } & Deutsches Zentrum für Luft- und & NSV & Nationalsozialistische \\
\hline & Raumfahrt & & Volkswohlfahrt \\
\hline DMM & Deutsches Museum München & ObdL & Oberbefehlshaber der Luftwaffe \\
\hline DPG & Deutsche Physikalische Gesellschaft & $\mathrm{OKH}$ & Oberkommando des Heeres \\
\hline \multirow[t]{2}{*}{ DSIR } & Department of Scientific and & OKM & Oberkommando der Kriegsmarine \\
\hline & Industrial Research & PA & Personalakte \\
\hline \multirow[t]{2}{*}{ DVL } & Deutsche Versuchsanstalt für & PRO & Public Record Office \\
\hline & Luftfahrt & PTB & Physikalisch Technische \\
\hline FIAT & Field Intelligence Agency, Technical & & Bundesanstalt \\
\hline \multirow[t]{4}{*}{ GPAMNFG } & Gemeinsames Prüfungsamt der & PTR & Physikalisch Technische \\
\hline & Mathematisch- & & Reichsanstalt \\
\hline & Naturwissenschaftlichen Fakultäten & $\mathrm{RdL}$ & Reichsminister der Luftfahrt \\
\hline & Göttingen & Rek. & Rektorat \\
\hline GSTA PK & Geheimes Staatsarchiv Preußischer & REM & Reichserziehungsministerium \\
\hline & Kulturbesitz & & (Ministerium für Wissenschaft, \\
\hline GUZ & Göttinger Universitätszeitung & & Erziehung und Volksbildung) \\
\hline \multirow[t]{2}{*}{ HATUM } & Historisches Archiv der TU & RFR & Reichsforschungsrat \\
\hline & München & RLM & Reichsluftfahrtministerium \\
\hline HJ & Hitlerjugend & RSHA & Reichssicherheitshauptamt \\
\hline HStAH & Hauptstaatsarchiv Hannover & SBZ & Sowjetische Besatzungszone \\
\hline HUA & Harvard University Archives & Sek. & Sekretariat \\
\hline I.R. & Infanterie-Regiment & SHQP & Sources for the History of Quantum \\
\hline $\mathrm{KdF}$ & Kraft durch Freude & & Physics \\
\hline KHP & Kurt Hohenemser Papers & SPSL & Society of the Protection of Science \\
\hline Korr. & Korrespondenz & & and Learning \\
\hline Kur. & Kuratorium & StB-B & Staatsbibliothek Berlin \\
\hline kw & künftig wegfallend & SUBG & Staats- und Universitätsbibliothek \\
\hline KWG & Kaiser-Wilhelm-Gesellschaft & & Göttingen \\
\hline KWI & Kaiser-Wilhelm-Institut & $\mathrm{TH}$ & Technische Hochschule \\
\hline $\mathrm{KZ}$ & Konzentrationslager & UAG & Universitätsarchiv Göttingen \\
\hline LMU & Ludwig-Maximilians-Universität & UAHU & Universitätsarchiv der Humboldt \\
\hline \multirow[t]{2}{*}{ MIT } & Massachusetts Institute of & & Universität Berlin \\
\hline & Technology & $\mathrm{UCO}$ & University Control Officer \\
\hline MPG & Max-Planck-Gesellschaft & UH-HSGS & Universität Hamburg, Hans \\
\hline MPI & Max-Planck-Institut & & Schimank-Gedächtnis-Stiftung \\
\hline \multirow[t]{3}{*}{ NARA } & United States National Archives and & uk & unabkömmlich \\
\hline & Records Administration, College & UNESCO & United Nations Educational, \\
\hline & Park, Maryland & & Scientific and Cultural Organization \\
\hline NBL & Niels Bohr Library & & (Organisation für Erziehung, \\
\hline \multirow[t]{3}{*}{ NKWD } & Narodny Komissariat Wnutrennich & & Wissenschaft und Kultur) \\
\hline & Del (Volkskommissariat des Inneren & ZAMM & Zeitschrift für angewandte \\
\hline & der UdSSR) & & Mathematik und Mechanik \\
\hline NL & Nachlass & & \\
\hline NS & Nationalsozialismus & & \\
\hline NSB & Nationalsozialistischer Bund & & \\
\hline
\end{tabular}




\section{Verzeichnis der Lebensdaten der wichtigsten Personen}

Abel, Othelio (1875-1946)

Allesch, Johannes von (1882-1967)

Althoff, Karl-Heinz (geb. 1925)

Andrée, Karl (1880-1959)

Angenheister, Gustav Heinrich (1878-1945)

Anschütz-Kaempfe, Hermann (1872-1931)

Ardenne, Manfred (1907-1997)

Aristoteles (384 v.Chr.-322 v.Chr.)

Atkinson, Robert (1898-1982)

Autrum, Hansjochem (1907-2003)

Bachér, Franz (1894-?)

Baeumker, Adolf (1891-1976)

Bagge, Erich (1912-1996)

Bardeen, John (1908-1991)

Bartels, Julius (1899-1964)

Bassewitz, Kurt von (geb. 1924)

Becker, August (1879-1953)

Becker, Carl Heinrich (1876-1933)

Becker, Richard (1887-1955)

Bederke, Erich (1895-?)

Begemann, Friedrich (geb. 1927)

Bennewitz, Hans Gerhard (geb. 1924)

Bergmann, Ludwig (1898-?)

Bernal, John Desmond (1901-1971)

Bernstein, Felix (1878-1956)

Bethe, Hans (geb. 1906)

Betz, Albert (1885-1968)

Bewilogua, Ludwig (1906-1983)

Beyer, Kurt (1881-1952)

Biermann, Ludwig (1907-1986)

Birge, Raymond Thayer (1887-1980)

Birus, Karl August (1911-1942)

Bjerrum, Niels Janniksen (1879-1958)

Blackett, Patrick (1897-1974)

Blaess, Viktor (1876-1951)

Blau, Marietta (1894-1970)

Blount, Bertie K. (1907-1999)

Blume, Werner (1887-1965)

Bohr, Aage (geb. 1922)

Bohr, Harald (1887-1951)

Bohr, Niels (1885-1962)

Bojunga, Helmut (1898-1958)

Bok, Bart (1906-1983)

Bonhoeffer, Karl Friedrich (1899-1957)

Bormann, Martin (1900-1945)

Born, Max (1882-1970)

Borries, Bodo von (1905-1956)

Borsche, Walther (1877-1950)

Bothe, Walter (1891-1957)

Boyle, Robert (1627-1691)

Bragg, William Lawrence (1890-1971)

Brattain, Walter (1902-1987)

Brillouin, Léon (1889-1969)

Brix, Peter (geb. 1918)

Brockmann, Hans (1903-1988)

Brüche, Ernst (1900-1985)

Bruggencate, Paul ten (1901-1961)

Buchwald, Eberhard (1886-1975)
Bucka, Hans Günter (geb. 1925)

Buckel, Werner (1920-2003)

Busch, Hans (1884-1973)

Cario, Günther (1897-1984)

Casimir, Hendrik (1909-2000)

Chain, Ernst Boris (1906-1979)

Clay, Lucius D. (1897-1978)

Condon, Edward (1902-1974)

Correns, Carl (1893-1980)

Courant, Richard (1888-1972)

Creutzburg, Nikolaus (1893-1978)

Czerny, Marianus (1896-1985)

Dames, Wilhelm (1904-?)

Davisson, Clinton Joseph (1881-1958)

Debye, Peter (1884-1966)

Dehmelt, Hans-Georg (geb. 1922)

Delbrück, Max (1906-1981)

Descartes, René (1596-1650)

Diebner, Kurt (1905-1964)

Diltey, Wilhelm (1833-1911)

Döring, Werner (geb. 1911)

Drescher-Kaden, Karl Friedrich (1894-1988)

Drexler, Hans (1895-?)

Drude, Paul (1863-1903)

Düker, Heinrich (1898-1986)

Ehrenberg, Hans (geb. 1922)

Ehrenstein, Dieter (geb. 1931)

Einstein, Albert (1879-1955)

Emden, Robert (1862-1940)

Epp, Franz (1868-1946)

Esau, Abraham (1884-1955)

Eucken, Arnold (1884-1950)

Feher, Franz (1903-1991)

Fehrle, Eugen Joseph (1880-1957)

Finkelnburg, Wolfgang (1905-1967)

Firbas, Franz (1902-1964)

Flachsbart, Otto (1898-?)

Flammersfeld, Arnold (geb. 1913)

Fleck, Ludwik (1896-1961)

Fleischmann, Rudolf (1903-2002)

Flettner, Anton (1882-1961)

Flügge, Siegfried (1912-1997)

Flügge, Wilhelm (geb. 1904)

Foerster, Max (1867-1930)

Föppl, August (1854-1924)

Föppl, Ludwig (1887-1976)

Föppl, Otto (1885-1963)

Fowler, Ralph (1889-1944)

Franck, James (1882-1964)

Fredenhagen, Carl (1877-1949)

Frenkel, Jakow Iljitsch (1894-1952)

Freytag, Hans-Waldemar (c.1889-1954)

Frick, Wilhelm (1877-1946)

Fricke, Gerhard (geb. 1921)

Friedburg, Helmut (geb. 1913)

Friedrich, Walther (1883-1968)

Frisch, Otto Robert (1904-1979)

Fuchs, Rainer (geb. 1915) 
Fues, Erwin (1893-1970)

Galilei, Galileo (1564-1642)

Gamow, George (1904-1968)

Gans, Richard (1880-1954)

Geerk, Jens (1903-?)

Geiger, Hans (1882-1945)

Gengler, Thomas (1901-1974)

Gercke, Achim (1902-?)

Gerdien, Hans (1877-1951)

Gerlach, Walther (1889-1979)

Gerthsen, Christian (1894-1956)

Glaser, August (1895-1941)

Glum, Friedrich (1891-1974)

Gnade, Albert (1886-?)

Gockel, Heinrich (geb. 1912)

Gogarten, Friedrich (1887-1967)

Goldschmidt, Viktor Moritz (1888-1947)

Göring, Hermann (1893-1946)

Görtler, Henry (geb. 1909)

Goubau, Georg (geb. 1906)

Goubeau, Josef (1901-1990)

Goudsmit, Samuel (1902-1978)

Graeser, Ernst (geb. 1906)

Grimme, Adolf (1889-1963)

Gudden, Bernhard (1892-1945)

Guericke, Otto von (1602-1686)

Gund, Konrad (1907-1953)

Gyulai, Zoltán (1887-1968)

Haber, Fritz (1868-1934)

Häfele, Hans Georg (geb. 1928)

Haffner, Hans (geb. 1912)

Hahn, Otto (1879-1968)

Hahnkamm, Erich (1905-1944)

Handel, Paul von (1901-?)

Hanle, Wilhelm (1901-1993)

Harder, Richard (1888-1973)

Hartmann, Nicolai (1882-1950)

Hartog, Jacob Pieter den (1901-1989)

Hasse, Helmuth (1898-?)

Haxel, Otto (1909-1998)

Hecht, Karl (1903-?)

Heckmann, Otto (1901-1983)

Heimpel, Hermann (1901-1988)

Heisenberg, Werner (1901-1976)

Heitler, Walter (1904-1981)

Heller, August (1843-1902)

Hellwege, Karl Heinz (1910-1999)

Herglotz, Gustav (1881-1953)

Hertz, Gustav (1887-1975)

Hertz, Paul (1881-1940)

Hiedemann, Egon (1900-1969)

Hilbert, David (1862-1943)

Hilsch, Rudolf (1903-1972)

Himmler, Heinrich (1900-1945)

Hippel, Arthur von (1898-2003)

Hoch, Johann (1913-?)

Hoffrogge, Christian (geb. 1912)

Hohenemser, Alice (1879-1942)

Hohenemser, Kurt (1906-2001)

Hohenemser, Paula (1874-1944)

Hohenemser, Richard (1870-1942)
Hooke, Robert (1635-1703)

Hopmann, Josef (1890-1975)

Hoppe, Edmund (1854-1928)

Houtermans, Fritz Georg (1903-1966)

Humbach, Walter (geb. 1920)

Hund, Friedrich (1896-1997)

Huygens, Christiaan (1629-1695)

Jaspers, Karl (1883-1969)

Jensen, Hans Daniel (1907-1973)

Joffe, Abram Fjodorowitsch (1880-1960)

Joliot-Curie, Jean Frédéric (1900-1958)

Joliot-Curie, Irène (1897-1956)

Joos, Georg (1894-1959)

Jordan, Pascual (1902-1980)

Justi, Eduard (1904-1986)

Kaehler, Siegfried (1885-1963)

Kahrstedt, Ulrich (1888-1962)

Kalähne, Alfred (1874-1946)

Kaluza, Theodor (1885-1954)

Kamke, Detlef (1922-2004)

Kármán, Theodor (1881-1963)

Kastler, Alfred (1902-1984)

Kemble, Edwin C (1889-1984)

Kepler, Johannes (1571-1630)

Kepp, Richard (geb. 1912)

Kienle, Hans (1895-1975)

Kiepenheuer, Karl-Otto (1910-1975)

Klein, Felix (1849-1925)

Klotter, Karl (1901-?)

Kneser, Hans Otto (1901-1985)

Kneser, Hellmuth (1898-1973)

Knipping, Paul (1883-1935)

Knoll, Max (1897-1969)

Koehler, Otto (1889-1974)

Konen, Heinrich (1874-1948)

König, Hans (1910-2002)

Koops, Rudolf (geb. 1913)

Kopernikus, Nicolaus (1473-1543)

Kopfermann, Hans (1895-1963)

Koppe, Heinz (geb. 1918)

Kossel, Walther (1888-1956)

Kramers, Hendrik (1894-1952)

Kroebel, Werner (1904-2001)

Krüger, Hubert (1914-2002)

Kuhn, Heinrich (1904-1994)

Kuiper, Gerard Peter (1905-1973)

Kulenkampff, Helmuth (1895-1971)

Küstner, Hans (1887-1946)

Kyropoulos, Spiro (1887-?)

Ladenburg, Rudolf (1882-1952)

Lamla, Ernst (1888-1986)

Landau, Edmund (1877-1938)

Landé, Alfred (1888-1975)

Lange, Ludwig (1863-1936)

Laue, Max von (1879-1960)

Leibfried, Günther (1915-1977)

Leibniz, Gottfried Wilhelm (1646-1716)

Lenard, Philipp (1862-1947)

Lenkeit, Walter (1900-?)

Lewy, Hans (1904-1988)

Lietzmann, Walter (1880-1959) 
Linde, Carl von (1842-1934)

Listing, Johann Benedikt (1808-1882)

Lockemann, Georg (1871-1959)

Lorenz, Hans (1865-1940)

Lorenz, Konrad (1903-1989)

Lüders, Gerhart (1920-1995)

Ludwieg, Hubert (geb. 1912)

Ludwig, Günther (geb. 1918)

Lührs, Gerold (geb. 1927)

Lüneburg, Rudolf (1903-1949)

Lyra, Gerhard (1910-1975)

Madelung, Erwin (1881-1972)

Magnus, Kurt (1912-2003)

Maier-Leibnitz, Heinz (1911-2000)

Mannkopff, Reinhold (1894-1978)

Mariotte, Edme (c.1620-1684)

Martius, Heinrich (1885-1965)

Masing, Georg (1885-1956)

Mattauch, Josef (1895-1976)

Meinardus, Wilhelm (1867-1952)

Meinecke, Friedrich (1862-1954)

Meitner, Lise (1878-1968)

Mentzel, Rudolf (1900-1987)

Mertens, Otto (1907-?)

Mesmer, Gustav (1905-1981)

Meyer, Dietrich (geb. 1919)

Meyer, Erwin (1899-1972)

Meyer, Eugen (1868-1930)

Meyer, Peter (geb. 1920)

Meyer-Berkhout, Ulrich (geb. 1927)

Meyer-Schützmeister, Luise (1915-1981)

Mises, Richard von (1883-1953)

Möller, Hans Georg (1882-1967)

Møller, Christian (1904-1980)

Mollier, Richard (1863-1935)

Mollwo, Erich (1909-1993)

Mortensen, Hans (1894-1964)

Mott, Nevill (1905-1996)

Müller, Wilhelm (1880-1968)

Münzner, Hans (1906-1997)

Mußmann, Heinrich (geb. 1911)

Nádai, Árpád (1883-1963)

Nernst, Walther (1864-1941)

Neumann, Friedrich (1889-1979)

Newton, Isaac (1643-1727)

Nikuradse, Johann (1894-1979)

Nohl, Herman (1879-1960)

Nöldecke, Gerhard (geb. 1928)

Nordheim, Lothar (1899-1985)

Odqvist, Folke K. G. (1899-1984)

Oldenberg, Otto (1888-1983)

Ortega y Gasset, José (1883-1955)

Osberghaus, Otto (geb. 1919)

Osenberg, Werner (1900-1972)

Ossanna, Giovanni (1870-1952)

Ostwald, Wilhelm (1853-1932)

Oswatitsch, Klaus (1910-1993)

Otto, Wolfgang (1878-1957)

Papen, Franz von (1879-1969)

Pascal, Blaise (1623-1662)

Paul, Wolfgang (1913-1993)
Pauli, Wolfgang (1900-1958)

Pauling, Linus Carl (1901-1994)

Peierls, Rudolf (1907-1995)

Perrin, Jean (1870-1942)

Pick, Heinz (1912-1983)

Placzek, Georg (1905-1955)

Planck, Max (1858-1947)

Plischke, Hans (1890-?)

Poggendorff, Johann Christian (1796-1877)

Pohl, Robert Wichard (1884-1976)

Pohlhausen, Ernst (1890-1964)

Powell, Cecil Frank (1903-1969)

Prager, Willy (1903-1980)

Prandtl, Ludwig (1875-1953)

Proskauer, Walter (1890-c.1943)

Rabinowitch, Eugene (1901-1973)

Raiser, Ludwig (1904-1980)

Rausch von Traubenberg, Heinrich (1880-1944)

Reich, Herbert (geb. 1919)

Reich, Max (1874-1941)

Rein, Friedrich Hermann (1898-1953)

Rellich, Franz (1906-1955)

Riecke, Eduard (1845-1915)

Rompe, Robert (1905-1993)

Röntgen, Wilhelm Conrad (1845-1923)

Rosbaud, Paul (1896-1963)

Rothacker, Erich (1888-1965)

Rubbert, Friedrich Karl (geb. 1912)

Rudorf, Wilhelm (1891-1969)

Runge, Carl David Tolmé (1856-1927)

Ruprecht, Herbert (1904-?)

Bernhard Rust (1883-1945)

Saur, Eugen (geb. 1910)

Sauter, Fritz (1906-1983)

Schaefer, Clemens (1878-1968)

Schaefer, Helmut (geb. 1913)

Schardin, Hubert (1902-1965)

Schermer, Siegmund (1886-?)

Scherrer, Paul (1890-1969)

Scherzer, Otto (1909-1982)

Schilling, Friedrich (1868-1950)

Schimank, Hans (1888-1979)

Schlechtweg, Heinz (1905-1990)

Schlier, Christoph (geb. 1930)

Schlink, Wilhelm (1875-?)

Schmidt, Eberhard (1891-1977)

Schmidt, Jonas (1885-1958)

Schmucker, Theodor (1894-1970)

Schoch, Arnold (1911-1967)

Schoen, Rudolf (1892-?)

Schöffler, Herbert (1888-1946)

Schottky, Walter (1886-1976)

Schubert, Gerhard (1907-1964)

Schuler, Else (1886-1981)

Schuler, Max (1882-1972)

Schultz-Grunow, Fritz (1906-1987)

Schumacher, Elisabeth (1904-1942)

Schumann, Erich (1898-1985)

Schürmann, Artur (1903-?)

Schwarz, Hermann Amandus (1843-1921)

Schwenkhagen, Hans (1900-?) 
Schwertfeger, Bernhard (1868-1953)

Schwertfeger, Hertha (1902-1987)

Seedorf, Wilhelm (1881-?)

Segrè, Emilio (1905-1989)

Seitz, Frederick (geb. 1911)

Seiz, Walter (1885-?)

Severin, Hans (geb. 1920)

Seyfarth, Friedrich (1891-1960)

Shockley, William (1910-1989)

Siegel, Carl Ludwig (1896-1981)

Simon, Franz (1893-1956)

Simon, Hermann Theodor (1870-1918)

Smakula, Alexander (1900-1983)

Smekal, Adolph (1895-1959)

Smend, Rudolf (1882-1975)

Sommer, Otto (1902-?)

Sommerfeld, Arnold (1868-1951)

Spedding, Frank (1902-1984)

Sponer, Hertha (1895-1968)

Stark, Johannes (1874-1957)

Stasiw, Ostap (1903-1985)

Staudinger, Hermann (1881-1965)

Steen, Albert (1906-1976)

Steenbeck, Max (1904-1981)

Steinwedel, Helmut (geb. 1921)

Stellmacher, Karl (geb. 1909)

Stern, Otto (1888-1969)

Steudel, Andreas (geb. 1925)

Stierstadt, Otto (1905-?)

Stille, Ulrich (1910-1976)

Stobbe, Martin (1903-1944)

Stöckmann, Fritz (1918-1998)

Stoermer, Richard (1870-1940)

Stöve, Reta (1897-1961)

Tamm, Konrad (1913-1986)

Tammann, Gustav (1861-1938)

Taubert, Rolf (geb. 1924)

Teller, Edward (1908-2003)

Telschow, Ernst (1889-1988)
Teltow, Joachim (geb. 1913)

Tolle, Max (1864-1945)

Tollmien, Walter (1900-1968)

Torricelli, Evangelista (1608-1647)

Trefftz, Erich (1888-1937)

Trillhaas, Wolfgang (1903-1995)

Ulrich, Georg Karl Justus (1798-1879)

Unsöld, Albrecht (1905-1995)

Vahlen, Theodor (1869-1945)

Valentiner, Justus Theodor (1869-1952)

Vieweg, Richard (1896-1972)

Voigt, Woldemar (1850-1919)

Volmer, Max (1885-1965)

Walcher, Wilhelm (geb. 1910)

Warburg, Emil (1846-1931)

Wartenberg, Hans von (1880-1960)

Weber, Otto (1902-1966)

Weber, Wilhelm Eduard (1804-1891)

Wedekind, Edgar (1870-1938)

Weinreich, Max (1894-1969)

Weisskopf, Victor (1908-2002)

Weizsäcker, Carl Friedrich von (geb. 1912)

Welker, Heinrich (1912-1981)

Wertheimer, Max (1880-1943)

Westphal, Wilhelm (1882-1978)

Weyl, Hermann (1885-1955)

Wiechert, Emil (1861-1928)

Wieghardt, Karl (geb. 1913)

Wien, Max (1866-1938)

Wiesner, Werner (1902-?)

Wigner, Eugene (1902-1995)

Wilson, Alan (1906-1976)

Windaus, Adolf (1876-1959)

Wirtz, Karl (1910-1994)

Witt, Hans-Jürgen (geb. 1926)

Wolff, Otto (1859-1945)

Zahn, Hermann (1877-1952)

Zenneck, Jonathan (1871-1959)

Zierold, Kurt (1899-1989) 


\section{Quellenverzeichnis}

\section{Interviews}

Alexandr I. Achieser, befragt von Yurij Ranyuk, November/Dezember 1995. NBL.

Robert Atkinson, befragt von David DeVorkin, 22. April 1977. NBL.

Ludwig Biermann, befragt von Owen Gingerich, 23. Juni 1978. NBL.

James Franck und Hertha Sponer-Franck, befragt von Thomas Kuhn und Maria Goeppert-Mayer, 9. bis 14. Juli 1962. NBL.

Frederick Charles Frank, befragt von Mark Walker, 12. April 1985. NBL.

Wilhelm Hanle, befragt von Brenda Winnewisser, 23. Mai bis 2. Juni 1979. NBL.

Werner Heisenberg, befragt von Thomas Kuhn und John Heilbron, 30. November 1962. NBL.

Gustav Hertz, befragt von John Heilbron und Thomas Kuhn, 14. und 15. Mai 1963. NBL.

Pascual Jordan, befragt von Thomas Kuhn, 17. bis 20. Juni 1963. NBL.

Fritz Lüty, 3. und 4. Juni 1982. NBL.

Robert Maurer, 22. Dezember 1981. NBL.

Wolfgang Paul, befragt von Mark Walker, 14. November 1985. Privatbesitz.

Heinz Pick, befragt von Frau Torka und Jürgen Teichmann, 2. Oktober 1981. NBL.

Robert Pohl, 25. Juli 1974. NBL.

Fritz Reiche, befragt von Thomas Kuhn und George Eugène Uhlenbeck, 30. März bis 9. Mai 1962. NBL.

Léon Rosenfeld, befragt von Charles Weiner, 3. September 1968. NBL.

Frederick Seitz, befragt von Lillian Hoddeson und Paul Henriksen, 26. Januar 1981 und 16. März 1982. NBL.

Wilhelm Walcher, befragt von Mark Walker, 4. Juni 1985. Privatbesitz.

Adnan Waly, befragt von John Dropkin und Martin Pope, Februar bis April 1994. NBL.

Victor Weisskopf, befragt von Thomas Kuhn und John Heilbron, 10. Juli 1963. NBL.

Carl Friedrich Weizsäcker, befragt von Martin Harwit, 15. Februar 1984. NBL.

Carl Friedrich Weizsäcker, befragt von Mark Walker, 9. Mai 1985. NBL.

Carl Friedrich Weizsäcker, befragt von Kristie Macrakis, 28. Januar 1986. NBL.

\section{Selbst durchgeführte Interviews}

Gisela Bilitewski, 26. Februar 2001, 9. April 2001.

Ursula Dehnen, Dezember 2000.

Hanswalter Giesekus, 12. März 2001.

Kurt Hohenemser, 19. und 20. August 2000.

Hans König, 10. Februar 2001.

Heinke Marx, 19. Febraur 2001.

Friedrich Schlögl, 22. Juni 2001.

Eva Opitz, 21. November 2001.

Julius Rotta, 24. Januar 2001.

U. Schmidt-Rohr, 24. März 1999.

Jürgen Weisse, 22. Mai 2001.

Rudolf Wolgast, 31. Januar 2001.

\section{Schriftliche Auskunft}

Maria Ehrenberg, 4. März 2001.

Hanswalter Giesekus, 16. Februar 2001, 13. März 2001.

Friedrich Schlögl, 27. April 2004, 22. Mai 2004, 15. Juni 2004, 25. Juni 2004, 10. September 2004, 23. September 2004, 1. Oktober 2004, 22. November 2004.

\section{Archive}

\section{Deutschland}

\section{Bundesarchiv Berlin}

BDC, NSDAP-Mitgliederkartei; NSLB-Kartei; PK-Akten; REM; RFR; WI-Akten.

$\mathrm{R} 13$ / VI.

$\mathrm{R} 21$.

R 26 III. 
R 4901.

REM-Kartei.

RFR-Kartei.

ZA I.

ZB

Staatsbibliothek zu Berlin Preußischer Kulturbesitz

Autogr. I.

NL Born; Hückel; Jordan; Landé.

Geheimes Staatsarchiv Preußischer Kulturbesitz, Berlin

I. HA Rep. 76 Kultusministerium.

I. HA Rep. 92 Grimme.

Archiv zur Geschichte der Max-Planck-Gesellschaft, Berlin

Kaiser-Wilhelm-Institut für Strömungsforschung.

NL Betz; Bonhoeffer; Bothe; Hahn; Laue; Prandtl.

Archiv der Deutschen Physikalischen Gesellschaft, Berlin

10025; 20958; 40014; 40017; 40021-29; 40034-40.

Universitätsarchiv der Humboldt-Universität Berlin

Habilitationsakte Richard Becker, Rep. 1238.

Universitäts- und Landesbibliothek Bonn

NL Pfeiffer; Rothacker.

\section{Universitätsarchiv Göttingen}

Karteikarten Math.-Nat. Promotionen.

Kur. Personalakten.

Rek. Personalakten.

Kur. XVI. V., Institutsakten (inkl. Assistenten, Etat)

Rek. 5250, Institutsakten.

Kur. 4 V h / 35; Kur. IX. 83; Kur. IX. 97; IX 101; XXX. A. a..

Math.-Nat. Fak. 19a; 19b; 24a; 53; 56.

Matrikelverzeichnisse.

Rek. 1406; 1408; 2101a; 3206; 4106; 7101; 7112; 7201.

Rek. Fernbetreuung 1941-1944.

Rundschreiben der Georg-August-Universität.

Sek. 316.6; 335.58; 335.60; 340.c.

Senatsprotokolle.

Gemeinsames Prüfungsamt der Mathematisch-Naturwissenschaftlichen Fakultäten Göttingen

Personalakten.

Protokollbuch der Fakultätssitzungen.

Handschriftenabteilung der Staats- und Universitätsbibliothek Göttingen

Cod. Ms. H. Hasse ; G. Herglotz; Kahrstedt; H. Nohl; L. Prandtl; E. Weniger.

2 Cod. Ms. philos. 182.

4 Cod. Ms. philos. 221.

Historisches Archiv der DLR Göttingen

GOAR 208; 1364; 1365; 2728; 2736; 3664; 3668; 3670.

Universität Hamburg, Fachbereich Mathematik, Hans Schimank-Gedächtnis-Stiftung

NL Schimank. 


\title{
Hauptstaatsarchiv Hannover
}

Nds. 50: Staatskanzlei.

Nds. 171 Hildesheim: Entnazifizierungsakten Regierungsbezirk Hildesheim.

Nds. 401 Ministerium für Wissenschaft und Kunst.

\author{
Universitätsarchiv Jena \\ Bestand BA: 2163. \\ Bestand C: 494. \\ Bestand D: $\quad$ 1319, PA Joos \\ Bestand N: $\quad 46 / 1 ; 46 / 2 ; 187 / 1$
}

\section{Betriebsarchiv Carl Zeiss, Jena}

BACZ: $221 ; 1395 ; 8076 ; 8289 ; 12972 ; 13612 ; 14734 ; 15051 ; 15140 ; 15620 ; 19154 ; 22768 ; 30273 ; 30276$; PA 2105.

\section{Generallandesarchiv Karlsruhe}

Personalakte Willy Prager.

\section{England}

\section{Public Record Office, Kew, London}

FO 371, FO 935, FO 936, FO 942, FO 943, FO 944, FO 945, FO 1005, FO 1010, FO 1013, FO 1014, FO 1031, FO 1032, FO 1049, FO 1050, FO 1052, FO 1060, FO 1062.

\section{Bodleian Library, Oxford}

MS, SPSL, Max Born, Heinrich Düker, James Franck, Walter Heitler, Paul Hertz, Arthur Hippel, Kurt Hohenemser, Fritz Houtermans, Heinrich Kuhn, Spiro Kyropoulos, Rudolf Lüneburg, Richard Mises, Lothar Nordheim, Hans Reissner, Hertha Sponer, Martin Stobbe.

$U S A$

\section{Bancroft Library, Berkeley, California}

SHQP, W. Gerlach corr.; H. A. Kramers corr.

73/79c Birge, Raymond Thayer, corr. and papers.

\section{Harvard University Archives, Cambridge, Massachusetts}

Mises papers.

Hunt papers.

\section{Massachusetts Institute of Technology Archives, Cambridge, Massachusetts}

Norbert Wiener papers.

Library of Congress, Washington D.C.

\section{Manuscript Division}

von Neumann papers.

Oppenheimer papers.

Veblen papers.

\section{Niels Bohr Library, College Park, Maryland}

Misc. Physicists Coll.: Rudolf Ladenburg papers, Karl Meissner MPC.

MP 126, Laue.

MP 2002-523, Mataré.

AHQP, Bohr Scientific corr.; Kramers corr.; Schrödinger corr.; Sommerfeld corr..

Samuel Abraham Goudsmit papers.

Karl Ferdinand Herzfeld papers. 
National Archives and Record Administration, College Park, Maryland RG 77, Entry 22.

RG 319

\section{Gedruckte Quellen}

Chroniken der Universität Göttingen

Vorlesungsverzeichnisse der Universität Göttingen

Göttinger Universitätszeitung 


\section{Literaturverzeichnis}

Dieses Literaturverzeichnis ist zweigeteilt. Zuerst findet sich eine Zusammenstellung der Publikationen der in Göttingen anwesenden Physiker mit einem Schwerpunkt auf den Jahren 1940 bis 1950 . Ausgewählt wurden jene Physiker, die Mitglieder des Lehrkörpers oder Mitarbeiter an den Physikinstituten waren, oder um deren Gewinnung sich die Göttinger Fakultät bemühte. Um die inhaltliche Entwicklung der Physiker verfolgen zu können, sind nicht nur jene Arbeiten aufgeführt, die aus der eigentlichen Göttinger Schaffenszeit stammen. Die Bibliographie erhebt keinen Anspruch auf Vollständigkeit. Für den Zeitraum 1940 bis 1950 wurden folgende Zeitschriften systematisch auf Göttinger Publikationen hin ausgewertet: Annalen der Physik, Zeitschrift für Physik, Physikalische Zeitschrift, Die Naturwissenschaften, Zeitschrift für Naturforschung, Ergebnisse der exakten Naturwissenschaften, Zeitschrift für die gesamte Naturwissenschaft, Die Physik in regelmäßigen Berichten, Zeitschrift für angewandte Physik, Optik und Nachrichten der Akademie der Wissenschaften in Göttingen, Mathematisch-Physikalische Klasse. Zweck der Zusammenstellung ist es, einen Überblick über die Göttinger Beiträge zur physikalischen Forschung zu geben. Außerdem wurden auch Rezensionen von Büchern der Göttinger Physiker aufgenommen, sowie jene Rezensionen, die von Göttinger Physikern verfasst wurden. Nachrufe und Würdigungen sind, sofern sie nicht von Göttinger Physikern verfasst wurden, im zweiten Teil des Literaturverzeichnisses aufgeführt. Dieser zweite Teil listet die benutzte Literatur auf; er enthält auch spätere Publikationen von Göttinger Physikern.

\section{Primärquellen}

\section{Publikationen von (Göttinger) Physikern (Schwerpunkt 1940-1950)}

Abraham, Max [1930] Theorie der Elektrizität. Bd. 1, 8. Aufl. vollst. neubearb. von Richard Becker, Leipzig u.a.: Teubner.

Ackermann, Friedrich-Wilhelm [1940] 'Ultrarote Absorptionsspektren von AgCl-Kristallen mit Zusatz fremder Komplexionen“, Annalen der Physik (5) 37 (1940), S. 442-452.

Adolph, R. \& Hans Otto Kneser [1949] 'Anwendungen des Impulsmeßverfahrens auf physikalische Probleme“, Zeitschrift für angewandte Physik 1 (1949), S. 382-387.

Akpinar, Sait [1940] 'Über den Einbau chemisch definierter Zusätze in Alkalihalogenidkristallen', Annalen der Physik (5) 37 (1940), S. 429-441.

Artmann, Kurt [1951] Rezension von: Becker [1950]a, in: Die Naturwissenschaften 38 (1951), S. 18.

Auer, Heinz [1941] Rezension von Pohl [1927], 5. Aufl., 1940, in: Die Naturwissenschaften 29 (1941), S. 772773.

Auwers, Otto von [1940] Rezension von: Becker \& Döring [1939] in: Physikalische Zeitschrift 41 (1940), S. 341-344.

Bagge, Erich [1941] 'Kernzertrümmerungen und schwere Teilchen in der kosmischen Strahlung', Die Naturwissenschaften 29 (1941), S. 318.

Bagge, Erich [1943]a 'Kernzertrümmerung und schwere Teilchen in der kosmischen Strahlung', in: Heisenberg (Hrsg.) [1943] S. 119-131.

Bagge, Erich [1943]b 'Die Bedeutung der Ionendiffusion für den Aufbau der Ionosphäre', Physikalische Zeitschrift 44 (1943), S. 163-167.

Bagge, Erich [1944] 'Empirische Gesetzmäßigkeiten bei den Kerntermen und ihre theoretische Deutung', Die Naturwissenschaften 32 (1944), S. 291-292.

Bagge, Erich [1946] 'Der Massendefekt der Atomkerne und das relativistische Mehrkörperproblem', Zeitschrift für Naturforschung 1 (1946), S. 361-366.

Bagge, Erich [1947] 'Zur Theorie der Massen-Häufigkeitsverteilung der Bruchstücke bei der spontanen Kernspaltung', Zeitschrift für Naturforschung 2a (1947), S. 565-568.

Bagge, Erich [1948] 'Theoretische Arbeiten über Mesonen, Nukleonen und Kernzertrümmerungen in der kosmischen Strahlung‘, in: Flügge (Hrsg.) [1948] S. 21-41.

Bagge, Erich [1949] 'Ursprung und Eigenschaften der kosmischen Strahlung', Ergebnisse der exakten Naturwissenschaften 22 (1949), S. 202-262.

Bagge, Erich [1950] 'Eine Deutung der Expansion des Kosmos', Zeitschrift für Physik 128 (1950), S. 239-254.

Bagge, Erich \& Ludwig Biermann [1948] 'Die Erzeugung von Ultrastrahlung auf der Sonne', Die Naturwissenschaften 35 (1948), S. 120-121.

Bagge, Erich \& Karl Fincke [1949] 'Die Intensitätsverteilung der Höhenstrahlungsneutronen in der Atmosphäre', Annalen der Physik (6) 6 (1949), S. 321-337.

Bagge, Erich \& Paul Harteck [1946] 'Über einen Zusammenhang zwischen kritischer Temperatur und Ionisierungsspannung bei den Edelgasen', Zeitschrift für Naturforschung 1 (1946), S. 481-482.

Bayer, Horst [1951]a Quadrupolkopplung und Relaxationstheorie von Atomkernen in Molekülkristallen. Am Beispiel des Dichloräthylens $\mathrm{CIHC}=\mathrm{CHCl}$, Dissertation Göttingen, 10. März 1951.

Bayer, Horst [1951]b 'Zur Theorie der Spin-Gitterrelaxation in Molekülkristallen', Zeitschrift für Physik 130 (1951), S. 227-238. 
Beck, Friedrich [1951] 'Das elektrodynamische Potential in der erweiterten phänomenologischen Theorie der Supraleitung،, Zeitschrift für Physik 129 (1951), S. 246-274.

Becker, Gerhard [1951] 'Zum Verhältnis der Kernquadrupolmomente der Kupferisotope‘, Zeitschrift für Physik 130 (1951), S. 415-426.

Becker, Richard [1935] 'Magnetismus I‘ (unter Mitwirk. von R. Landshoff), Die Physik in regelmäßigen Berichten 3 (1935), S. 91-108.

Becker, Richard [1936] 'Messung der Permeabilität mit Hilfe des Hauteffektes', Annalen der Physik (5) 27 (1936), S. 123-128.

Becker, Richard [1938] 'Keimbildung bei der Ausscheidung in metallischen Mischkristallen', Annalen der Physik (5) 32 (1938), S. 128-140.

Becker, Richard [1939] 'Bremsung der Magnetisierung durch mikroskopische Wirbelströme', Annalen der Physik (5) 36 (1939), S. 340-348.

Becker, Richard [1940] 'Theorie der Reinschen Thermostrohmuhr', Nachrichten von der Gesellschaft der Wissenschaften zu Göttingen, N. F. 3 (1940), S. 183-200.

Becker, Richard [1941] Theorie der Elektrizität, neubearb. von Fritz Sauter, Stuttgart: Teubner.

Becker, Richard [1945] 'Die aus der Dirac-Gleichung des Elektrons folgende Zwei-Komponenten-Gleichung', Nachrichten der Akademie der Wissenschaften in Göttingen, Mathematisch-Physikalische Klasse (1945), S. 39-47.

Becker, Richard [1946] 'Paul Langevin, 1872-1946', Die Naturwissenschaften 33 (1946), S. 288.

Becker, Richard [1948] 'Ferromagnetismus', in: Joos (Hrsg.) [1948] S. 27-42.

Becker, Richard [1950]a Vorstufe zur Theoretischen Physik, Berlin u. a.: Springer.

Becker, Richard [1950]b 'Die Bose-Einstein-Kondensation als räumliches Phänomen I', Zeitschrift für Physik 128 (1950), S. 120-132.

Becker, Richard [1950]c Rezension von: Friedrich Hund: Einführung in die theoretische Physik, 2 Bde., 1947 u. 1948, Leipzig: Bibliographisches Institut, in: Die Naturwissenschaften 37 (1950), S. 118-119.

Becker, Richard [1952] 'Eine Bemerkung zur Massenträgheit der Blochwand', Zeitschrift für Physik 133 (1952), S. 134-139.

Becker, Richard [1955] Theorie der Wärme, Berlin u.a.: Springer.

Becker, Richard \& Werner Döring [1939] Ferromagnetismus, Berlin: Springer.

Becker, Richard \& Günther Leibfried [1946] 'On the Method of Second Quantization', Physical Review 69 (1946), S. 34.

Becker, Richard \& Günther Leibfried [1949] 'Zur Methode der Quantisierung von Wellengleichungen', Zeitschrift für Physik 125 (1949), S. 347-358.

Becker, Richard \& Hans Polley [1940] 'Der Einfluß innerer Spannungen auf das Einmündungsgesetz bei

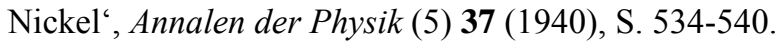

Begemann, Friedrich \& Fritz G. Houtermans [1952] 'Die Halbwertszeit des RaE', Zeitschrift für Naturforschung 7a (1952), S. 143-144; dazu Nachtrag, ebenda, S. 763.

Berger, H. \& Wolfgang Paul [1949] 'Verteilung der Ionisationsdichte in einem mit schnellen Elektronen bestrahlten KCl-Kristall', Zeitschrift für Physik 126 (1949), S. 422-430.

Bertalanffy, Ludwig von [1943] Rezension von: Jordan [1941], in: Die Naturwissenschaften 31 (1943), S. 2324.

Betz, Albert [1948]a Konforme Abbildung, Berlin u. a.: Springer.

Betz, Albert [1948]b 'Inkompressible Strömungen', in: Betz (Hrsg.) [1948] S. 1-20.

Betz, Albert [1948]c 'Kompressible Strömungen', in: Betz (Hrsg.) [1948] S. 79-96.

Betz, Albert [1950] 'Wie entsteht ein Wirbel in einer wenig zähen Flüssigkeit?', Die Naturwissenschaften 37 (1950), S. 194-196.

Betz, Albert [1953/62] [Nachruf auf Ludwig Prandtl], Jahrbuch der Akademie der Wissenschaften in Göttingen. Übergangsband für die Jahre 1944-1960 (1962), S. 158-164.

Betz, Albert [1954] 'Die Entwicklung der Fluggeschwindigkeit', Die Naturwissenschaften 41 (1954), S. 101107.

Betz, Albert (Hrsg.) [1948] Hydro- and Aoredynamics, Bd. 11 der Reihe: Fiat Review of German Science 19391946, Wiesbaden: Dieterichsche Verlagsbuchhandlung.

Biermann, Ludwig [1947] Rezension von: Jordan [1947]a, in: Zeitschrift für Naturforschung 2a (1947), S. 698699.

Bleek, H., Wolfgang Dittrich, Helmut Fass, Wolfgang Paul, Hans-Joachim Schmermund, Gerhard Schubert \& Arthur Stadtmüller [1950] 'Wirkungen schneller Elektronen eines $6 \mathrm{MeV}$-Betatrons auf das EhrlichKarzinom der weißen Maus', Strahlentherapie 81 (1950), S. 233-250.

Bleek, H., Wolfgang Paul, Hans-Joachim Schmermund \& Gerhard Schubert [1949] 'Über die Wirkung von Röntgenstrahlen und schnellen Elektronen auf Mitosevorgänge in Wurzelspitzelzellen von Hordeum', Die Naturwissenschaften 36 (1949), S. 28-29. 
Bode, Horst-Günther, Wolfgang Paul \& H. Theismann [1950] 'Vergleichende Untersuchungen über die Hautreaktionen nach Verabfolgung von schnellen Elektronen und Röntgenstrahlen', Strahlentherapie 81 (1950), S. 193-200.

Bode, Horst-Günther, Wolfgang Paul \& Gerhard Schubert [1950] 'Elektronentherapie menschlicher Hautkarzinome mit einem Betatron von 6 Millionen Elektronen-Volt‘, Strahlentherapie 81 (1950), S. 251-266.

Bopp, Fritz [1951] Rezension von: Becker [1941], Bd. 1, 14. Aufl., Bd. 2, 7. Aufl., 1949, in: 7 (1951), S. 236237.

Born, Max [1933] Moderne Physik. Sieben Vorträge über Materie und Strahlung, ausgearb. von Fritz Sauter, Berlin: Springer.

Borries, Bodo von \& Heinz Koppe [1947] 'Unelastische Streuung und diskrete Geschwindigkeitsverluste schneller Elektronen', Die Naturwissenschaften 34 (1947), S. 187.

Bothe, Walther \& Siegfried Flügge (Hrsg.) [1948] Nuclear Physics and Cosmic Rays, Part II, Bd. 14 der Reihe: Fiat Review of German Science 1939-1946, Wiesbaden: Dieterichsche Verlagsbuchhandlung.

Braunbek, Werner [1950] Rezension von: Hellwege (1949]a, in: Physikalische Blätter 6 (1950), S. 377-378.

Brenig, Wilhelm \& Manfred Schröder [1952] 'Zur Darstellung der spezifischen Wärme fester Körper durch Debye- und Einstein-Terme‘, Zeitschrift für Physik 132 (1952), S. 312-317.

Briegleb, Günther [1943] Rezension von: Eucken [1922], 5. Aufl, 1942, in: Die Naturwissenschaften 31 (1943), S. 351-352.

Brix, Peter [1949]a 'Die photographische Wirkung mittelschneller Protonen', Zeitschrift für Physik 126 (1949), S. 35-48.

Brix, Peter [1949]b 'Zur Isotopieverschiebung und zum Termschema des Samariumatoms (Sm I)', Zeitschrift für Physik 126 (1949), S. 431-439.

Brix, Peter [1949]c 'Eine Bemerkung zu den elektrischen Kernquadrupolmomenten der beiden Kupferisotope $\mathrm{Cu} 63$ und $\mathrm{Cu}$ 65', Zeitschrift für Physik 126 (1949), S. 725-727.

Brix, Peter [1952] 'Zum Isotopieverschiebungseffekt in den Atomspektren der Seltenen Erden (Die Isotopieverschiebungskonstanten von Eu, Gd und $\mathrm{Yb})^{`}$, Zeitschrift für Physik 132 (1952), S. 579-607.

Brix, Peter, Haro von Buttlar, Fritz G. Houtermans \& Hans Kopfermann [1951] 'Die Isotopieverschiebung zwischen Ra D und den stabilen Bleiisotopen', Nachrichten der Akademie der Wissenschaften in Göttingen, Mathematisch-Physikalische Klasse (1951), Nr. 7, S. 1-2.

Brix, Peter, Haro von Buttlar, Fritz G. Houtermans \& Hans Kopfermann [1952] 'Die Isotopieverschiebung zwischen Ra D und den stabilen Bleiisotopen', Zeitschrift für Physik 133 (1952), S. 192-200.

Brix, Peter \& Hans-Georg Dehmelt [1949] 'Die photographische Wirkung mittelschneller Protonen. II. Mitteilung. Messungen an Ilford-Q-Platten', Zeitschrift für Physik 126 (1949), S. 728-733.

Brix, Peter \& Hans Dietrich Engler [1951] 'Über die Isotopieverschiebung im Gd I-Spektrum‘, Die Naturwissenschaften 38 (1951), S. 214.

Brix, Peter \& Hans Dietrich Engler [1952] 'Die Isotopieverschiebung im Gd I-Spektrum', Zeitschrift für Physik 133 (1952), S. 362-369.

Brix, Peter \& Helmut Frank [1950] 'Zur Isotopieverschiebung im Spektrum des Cers', Zeitschrift für Physik 127 (1950), S. 289-296.

Brix, Peter \& Walter Humbach [1950] 'Zur Isotopieverschiebung in den CuI-Resonanzlinien', Zeitschrift für Physik 128 (1950), S. 506-510.

Brix, Peter \& Hans Kopfermann [1947] 'Über den Isotopieverschiebungseffekt der schweren Elemente', Nachrichten der Akademie der Wissenschaften in Göttingen, Mathematisch-Physikalische Klasse (1947), S. 31-32.

Brix, Peter \& Hans Kopfermann [1948] 'Zur Isotopieverschiebung in den Spektren von Samarium und Neodym‘, Die Naturwissenschaften 35 (1948), S. 189.

Brix, Peter \& Hans Kopfermann [1949] 'Zur Isotopieverschiebung im Spektrum des Samariums', Zeitschrift für Physik 126 (1949), S. 344-364.

Brix, Peter \& Hans Kopfermann [1951] 'Neuere Ergebnisse zum Isotopieverschiebungseffekt in den Atomspektren', in: Festschrift zur Feier des zweihundertjährigen Bestehens der Akademie der Wissenschaften in Göttingen, I Mathematisch-Physikalische Klasse, Berlin u.a.: Springer, 1951, S. 17-49.

Brix, Peter, Hans Kopfermann, Rudolf Martin \& Wilhelm Walcher [1951]a 'Über die Kernmomente der AgIsotope und die Isotopieverschiebung im Silberspektrum', Die Naturwissenschaften 38 (1951), S. 68-69.

Brix, Peter, Hans Kopfermann, Rudolf Martin \& Wilhelm Walcher [1951]b 'Die Isotopieverschiebung im Spektrum des Silbers und die magnetischen Kernmomente des Ag 107 und Ag 109', Zeitschrift für Physik 130 (1951), S. 88-99.

Brix, Peter, Hans Kopfermann \& Winrich von Siemens [1950] 'Über die Kernmomente der Iridium-Isotope‘, Die Naturwissenschaften 37 (1950), S. 397-398. 
Brix, Peter \& Andreas Steudel [1950] 'Die Isotropieverschiebung in der Cd I-Resonanzlinie $\lambda 3261 \AA^{\circ}$, Zeitschrift für Physik 128 (1950), S. 260-268.

Brix, Peter \& Andreas Steudel [1951] 'Über die Isotopieverschiebung im Pd I-Spektrum und die Kernmomente des Pd 105', Die Naturwissenschaften 38 (1951), S. 431-432.

Brüche, Ernst [1948] Rezension von: Joos (Hrsg.) [1947/48], Bd. 8, 1947, in: Physikalische Blätter 4 (1948), S. 79.

Bruggencate, Paul ten [1947] Rezension von: Jordan [1947]a, in: Die Naturwissenschaften 34 (1947), S. 28.

Bruggencate, Paul ten, Paul Harteck, Hans Kopfermann \& Rudolf Plank [1950] Arnold Eucken 3.7.188416.6.1950. Reden, gehalten bei der Gedächtnisfeier der mathematisch-naturwissenschaftlichen Fakultät der Georg-August-Universität in Göttingen am 2. Dezember 1950.

Bruns, K. H., Wolfgang Dittrich, Wolfgang Paul \& Gerhard Schubert [1950] 'Änderungen des Wurzellängenwachstums bei Gerstenkeimlingen durch schnelle Elektronen eines $6 \mathrm{MeV}$-Betatrons', Strahlentherapie 81 (1950), S. 173-176.

Buchwald, Eberhard \& Hans König [1935] 'Über Wasserglocken', Annalen der Physik (5) 23 (1935), S. 557569.

Buchwald, Eberhard \& Hans König [1936] 'Dynamische Oberflächenspannung aus Flüssigkeitsglocken', Annalen der Physik (5) 26 (1936), S. 659-672.

Buttlar, Haro von \& Fritz G. Houtermans [1950] 'Photographische Bestimmung der Aktivitätsverteilung in einer Manganknolle der Tiefsee', Die Naturwissenschaften 37 (1950), S. 400-401.

Chow, Yu-Kang [1948] 'Über das Absorptionsspektrum des Neodymfluorids $\mathrm{NdF}_{3}{ }^{\prime}$, Zeitschrift für Physik 124 (1948), S. 52-67.

Chow, Yu-Kang \& Karl-Heinz Hellwege [1949] 'Optische Untersuchungen zur Struktur elektrolytischer Lösungen', Zeitschrift für Physik 125 (1949), S. 18-26.

Clusisus, Klaus [1940] Rezension von: Eucken [1932], Bd. 1, 2. Aufl, 1938, in: Die Naturwissenschaften 28 (1940), S. 381.

Czech, H., R. Czech \& Hans-Joachim Schmermund [1950] 'Vergleichende Untersuchungen über die Wirkung von schnellen Elektronen und Röntgenstrahlen auf die Hornhaut von Salamanderlarven', Strahlentherapie 81 (1950), S. 187-192.

Czerny, Marianus [1950] Rezension von: Pohl [1940]a, 7. und 8. Aufl., 1948, in: Die Naturwissenschaften 37 (1950), S. 24.

Dehlinger, Ulrich [1947]a Rezension von: Schubert [1947]a, in: Physikalische Blätter 3 (1947), S. 366.

Dehlinger, Ulrich [1947]b Rezension von: Jordan [1947]a, in: Physikalische Blätter 3 (1947), S. 366-367.

Dehmelt, Hans-Georg [1950] 'Kernquadrupolfrequenzen in kristallinen Jodverbindungen', Die Naturwissenschaften 37 (1950), S. 398.

Dehmelt, Hans-Georg [1951]a 'Quadrupol-Resonanzfrequenzen von $\mathbf{J}^{127}$-Kernen in kristallinen kovalenten Jodverbindungen', Zeitschrift für Physik 130 (1951), S. 356-370.

Dehmelt, Hans-Georg [1951]b 'Quadrupolresonanzfrequenzen von des kristallinen Broms', Zeitschrift für Physik 130 (1951), S. 480-482.

Dehmelt, Hans-Georg [1952] ' Kernquadrupolspektren in zwei Bortrialkylen', Zeitschrift für Physik 133 (1952), S. 528-531.

Dehmelt, Hans-Georg \& Hubert Krüger [1950] 'Kernquadrupolfrequenzen in festem Dichloräthylen', Die Naturwissenschaften 37 (1950), S. 111-112.

Dehmelt, Hans-Georg \& Hubert Krüger [1951]a 'Quadrupol-Resonanzfrequenzen von Cl- und Br-Kernen in kristallinem Dichloräthylen und Methylbromid', Zeitschrift für Physik 129 (1951), S. 401-415.

Dehmelt, Hans-Georg \& Hubert Krüger [1951]b 'Über das Quadrupolresonanzspektrum in kristallinem Antimontrichlorid und das Verhältnis der Antimonkernquandrupolmomente', Zeitschrift für Physik 130 (1951), S. 385-391.

Deutschbein, Otto, Georg Joos \& Joachim Teltow [1942] 'Feinstruktur und Linienverschiebung in den Spektren der Chromphosphore', Die Naturwissenschaften 30 (1942), S. 228.

Dietze, Horst-Dietrich [1951/52]b 'Versetzungsstrukturen in kubisch-flächenzentrierten Kristallen II', Zeitschrift für Physik 131 (1951/52), S. 156-169.

Dietze, Horst-Dietrich [1952] 'Die Temperaturabhängigkeit der Versetzungsstruktur', Zeitschrift für Physik 132 (1952), S. 107-110.

Dittrich, Wolfgang, Helmut Fass, G. Höhne \& Gerhard Schubert [1950] 'Die Wirkung schneller Elektronen eines 6 MeV-Betatrons auf Eier von Drosophila melanogaster', Strahlentherapie 81 (1950), S. 223-232.

Dittrich, Wolfgang, G. Höhne, Wolfgang Paul \& Gerhard Schubert [1950] 'Über die Auslösung rezessivgeschlechtsgebundener Letalfaktoren bei Drosophila durch schnelle Elektronen eines $6 \mathrm{MeV}$-Betatrons', Die Naturwissenschaften 37 (1950), S. 545-546.

Dittrich, Wolfgang, Wolfgang Paul, M. Riedel \& Gerhard Schubert [1949] 'Über strahlenbiologische Wirkungen schneller Elektronen auf Gerstenkeimlinge‘, Strahlentherapie 80 (1949), S. 17-34. 
Domanic, Fahri [1943] 'Zum lichtelektrischen Primärstrom in Alkalihalogenidkristallen', Annalen der Physik (5) 43 (1943), S. 187-192.

Dorendorf, Heinz [1951] 'Ultraviolette Absorptionsbanden an photochemisch veränderten KCl- und KBrKristallen', Zeitschrift für Physik 129 (1951), S. 317-326.

Dorendorf, Heinz \& Heinz Pick [1950] 'Verfärbung von Alkalihalogenidkristallen durch energiereiche Strahlung', Zeitschrift für Physik 128 (1950), S. 166-171.

Döring, Werner [1943] 'Über den Detonationsvorgang in Gasen', Annalen der Physik (5) 43 (1943), S. 421-436.

Döring, Werner [1947] 'Richard Becker 60 Jahre', Physikalische Blätter 3 (1947), S. 393.

Döring, Werner [1948] 'Die Temperaturabhängigkeit der Anfangssuszeptibilität von Nickel unter Zug', Zeitschrift für Physik 124 (1948), S. 501-513.

Döring, Werner [1949]a 'Zur Definition des magnetischen Momentes', Annalen der Physik (6) 6 (1949), S. 6988.

Döring, Werner [1949]b 'Über das innere Magnetfeld in ferromagnetischen Materialien', Zeitschrift für Naturforschung 4a (1949), S. 605-610.

Döring, Werner [1950] 'Die Geschwindigkeit und Struktur von intensiven Stoßwellen in Gasen', Annalen der Physik (6) 5 (1950), S. 133-150.

Döring, Werner [1951] 'Über die Kraft und das Drehmoment auf magnetisierte Körper im Magnetfeld', Annalen der Physik (6) 9 (1951), S. 363-372.

Döring, Werner \& Hubert Schardin [1948] 'Detonationen‘, in: Betz (Hrsg.) [1948] S. 97-125.

Eser, Franz [1944] Rezension von Sauter [1942], in: Zeitschrift für die gesamte Naturwissenschaft 10 (1944), S. 76.

Eucken, Arnold [1922] Grundriß der physikalischen Chemie, Leipzig: Akademische Verlagsgesellschaft.

Eucken, Arnold [1932] Lehrbuch der chemischen Physik, (zugleich 3. Aufl. des Grundrisses der physikalischen Chemie), Leipzig: Akademische Verlagsgesellschaft.

Eucken, Arnold [1935] 'Physikalische Wärmelehre I', Die Physik in regelmäßigen Berichten 3 (1935), S. 63-90.

Eucken, Arnold [1939]a 'Physikalische Wärmelehre II', Die Physik in regelmäßigen Berichten 7 (1939), S. 1364.

Eucken, Arnold [1939]b Rezension von: Jordan [1936], 2. Aufl., 1938, in: Die Tatwelt 15 (1939), S. 140-141.

Eucken, Arnold [1940] 'Johannes Kelpers Weltharmonik', Die Tatwelt 16 (1940), S. 39-43.

Eucken, Arnold [1941] Rezension von: Bernhard Bavink: Ergebnisse und Probleme der Naturwissenschaften, eine Einführung in die heutige Naturphilosophie, 6. Aufl, Leipzig: Hirzel, 1940, in: Die Tatwelt 17 (1941), S. 49-51.

Eucken, Arnold [1943] 'Rückblicke auf die Entwicklung unserer Kenntnisse über die Molwärme der Gase', Die Naturwissenschaften 31 (1943), S. 314-322.

Eucken, Arnold [1944] 'Über den Zustand des Erdinnern', Die Naturwissenschaften 32 (1944), S. 112-121.

Eucken, Arnold [1946]a 'Zur Kenntnis der Konstitution des Wassers', Nachrichten der Akademie der Wissenschaften in Göttingen, Mathematisch-Physikalische Klasse (1946), S. 38-48.

Eucken, Arnold [1946]b '50. Wiederkehr des Eröffnungstages des Instituts für physikalische Chemie in Göttingen', Die Naturwissenschaften 33 (1946), S. 64

Eucken, Arnold [1946]c Rezension von: Jaspers [1946], in: Die Naturwissenschaften 33 (1946), S. 95-96.

Eucken, Arnold [1946]d 'Prof. G. N. Lewis †', Die Naturwissenschaften 33 (1946), S. 127.

Eucken, Arnold [1946]e Rezension von: Bernhard Bavink: Ergebnisse und Probleme der Naturwissenschaften, eine Einführung in die heutige Naturphilosophie, 8. Aufl, Leipzig: Hirzel, 1944, in: Die Naturwissenschaften 33 (1946), S. 222-223.

Eucken, Arnold [1946]f 'Bemerkung zu Kuhn [1946], in: Die Naturwissenschaften 33 (1946), S. 312.

Eucken, Arnold [1946]g Rezension von: G. M. Schwab (Hrsg.): Handbuch der Katalyse, Wien: Springer, in: Die Naturwissenschaften 33 (1946), S. 349-351.

Eucken, Arnold [1947] 'Der Einfluß gelöster Stoffe auf die Konstitution des Wassers', Nachrichten der Akademie der Wissenschaften in Göttingen, Mathematisch-Physikalische Klasse (1947), S. 33-36.

Eucken, Arnold [1948] Rezension von: Tenney L. Davis (Hrsg.): Chymnia. Annual Studies in the History of Chemistry, Vol. 1, Philadelphia: University of Pennsylvania Press, 1948, in: Die Naturwissenschaften 35 (1948), S. 223-224.

Eucken, Arnold [1949]a Rezension von: H. Kühnert: Der Briefwechsel zwischen Otto Schott und Ernst Abbe über das optische Glas 1879-1881, Jena: Fischer, 1946, in: Die Naturwissenschaften 36 (1949), S. 158159.

Eucken, Arnold [1949]b Rezension von: W. G. Frankenburg, V. I. Komarewsky \& E. K. Rideal: Advances in Catalysis and related Subjects, New York: Academic Press, 1948, in: Die Naturwissenschaften 36 (1949), S. 286-287. 
Eucken, Arnold [1950]a Rezension von: Tenney L. Davis: Chymnia. Annual Studies in the History of Chemistry, Bd. 2, Philadelphia: University of Pennsylvania Press, 1948, in: Die Naturwissenschaften 37 (1950), S. 263.

Eucken, Arnold [1950]b Rezension von: Paul Niggli: Probleme der Naturwissenschaften, erläutert am Begriff der Mineralart, Basel: Birkhäuser, 1949, in: Die Naturwissenschaften 37 (1950), S. 380.

Eucken, Arnold \& Ferdinand Springer [1946] 'Zur Einführung in den Jahrgang 1946', Die Naturwissenschaften 33 (1946), S. 1-2.

Eucken, Arnold \& Ewald Wicke [1944] 'Die Deutung heterogener Dehydratisierungskatalysen durch den Austausch von Wasserstoffatomen', Die Naturwissenschaften 32 (1944), S. 161-162.

Falk, Gottfried [1956] Rezension von: Becker [1955], in: Physikalische Blätter 12 (1956), S. 332-333.

Faß, Helmut, G. Höhne, Wolfgang Paul \& Gerhard Schubert [1949] 'Über die Letalschädigung von DrosophilaEiern durch Röntgenstrahlen und schnelle Elektronen eines $6 \mathrm{MeV}-B$ etatrons', Die Naturwissenschaften 36 (1949), S. 381-382.

Flügge, Charlotte \& Siegfried Flügge [1947] 'Der Einfluß des Coulomb-Feldes und der Elektronenhülle auf die Form des radioaktiven $\beta$-Spektrums“, Zeitschrift für Naturforschung 2a (1947), S. 6-8.

Flügge, Siegfried [1940] 'Über den Begriff »Austauschenergie« in der Quantenmechanik‘, Die Naturwissenschaften 28 (1940), S. 673-677.

Flügge, Siegfried [1941] 'Die Herstellung natürlich radioaktiver Elemente auf künstlichem Wege', Die Naturwissenschaften 29 (1941), S. 462-467.

Flügge, Siegfried [1943]a 'Mesontheorie des Deuterons‘, in: Heisenberg (Hrsg.) [1943] S. 110-115.

Flügge, Siegfried [1943]b 'Über die Erzeugung von Neutronen durch die Höhenstrahlung und ihre Verteilung in der Atmosphäre', in: Heisenberg (Hrsg.) [1943] S. 132-146.

Flügge, Siegfried [1943]c 'Zur spontanen Spaltung von Uran und seinen Nachbarelementen', Zeitschrift für Physik 121 (1943), S. 298-300.

Flügge, Siegfried [1946]a 'Zur Herleitung der Breit-Wigner-Formel', Zeitschrift für Naturforschung 1 (1946), S. 121-124.

Flügge, Siegfried [1946]b Rezension von: Küssner [1946], in: Die Naturwissenschaften 33 (1946), S. 223.

Flügge, Siegfried [1947] Rechenmethoden der Quantentheorie. Elementare Quantenmechanik dargestellt in Aufgaben und Lösungen, Berlin: Springer.

Flügge, Siegfried [1948]a Theoretische Optik. Die Entwicklung einer physikalischen Theorie, Wolfenbüttel u. a.: Wolfenbütteler Verlags-Anstalt.

Flügge, Siegfried [1948]b 'Zur Quantenmechanik regelmäßiger Strukturen endlicher Ausdehnung', Annalen der Physik (6) 3 (1948), S. 101-106.

Flügge, Siegfried [1948]c 'Theoretische Grundlagen des Kernbaus', in: Flügge (Hrsg.) [1948] S. 107-109.

Flügge, Siegfried [1948]d 'Zusammenstellung gemessener Wirkungsquerschnitte für thermische Neutronen', in: Flügge (Hrsg.) [1948] S. 139-141.

Flügge, Siegfried [1948]e 'Die spontane Spaltung des Urans und seiner Nachbarelemente', in: Flügge (Hrsg.) [1948] S. 218-220.

Flügge, Siegfried [1949]a 'Zur Entdeckung der Uranspaltung vor zehn Jahren', Zeitschrift für Naturforschung 4a (1949), S. 82-84.

Flügge, Siegfried [1949]b 'Transurane', Ergebnisse der exakten Naturwissenschaften 22 (1949), S. 1-12.

Flügge, Siegfried [1949]c 'Die Bedeutung der Entdeckung des Radiums für die Physik', Strahlentherapie 79 (1949), S. 327-329.

Flügge, Siegfried (Hrsg.) [1948] Nuclear Physics and Cosmic Rays, Part I, Bd. 13 der Reihe: Fiat Review of German Science 1939-1946, Wiesbaden: Dieterichsche Verlagsbuchhandlung.

Flügge, Siegfried \& A[dolf] Krebs [1944] 'Zur Entstehung des Elements 85 durch $\beta$-Zerfall von Ra A und Th A', Die Naturwissenschaften 32 (1944), S. 71-72.

Flügge, Siegfried \& Kurt Sauerwein [1948] 'Der Resonanzeinfang von Neutronen am Uran. Bruttobestimmung der Resonanzabsorption', in: Flügge (Hrsg.) [1948] S. 213-217.

Förster, Theodor [1948] 'Zwischenmolekulare Energiewanderung und Fluoreszenz', Annalen der Physik (6) 2 (1948), S. 55-75.

Förster, Theodor [1951] Fluoreszenz organischer Verbindungen, Göttingen: Vandenhoeck \& Ruprecht.

Friedburg, Helmut [1951] 'Optische Abbildung mit neutralen Atomen', Zeitschrift für Physik 130 (1951), S. 493-512.

Friedburg, Helmut \& Wolfgang Paul [1951] 'Optische Abbildungen mit neutralen Atomen', Die Naturwissenschaften 38 (1951), S. 159-160.

Friedburg, Helmut \& Robert Wichard Pohl [1950] 'Reflxion eines Atomstrahles am Rande eines Magnetfeldes`, Die Naturwissenschaften 37 (1950), S. 20.

Fritsch, Herbert [1940] 'Über die Temperaturabhängigkeit der Suszeptibilität von Neodymsalzen und die daraus folgenden Termaufspaltungen', Annalen der Physik (5) 38 (1940), S. 555-564. 
Fritsch, Herbert [1941] 'Über die Temperaturabhängigkeit der magnetischen Suszeptibilität von Europiumsulfat', Annalen der Physik (5) 39 (1941), S. 31-32.

Fritzsche, Hellmut [1952] 'Der Einfluß von gelöstem Sauerstoff auf die elektrische Leitfähigkeit von Zinkoxyd', Zeitschrift für Physik 133 (1952), S. 422-437.

Fues, Erwin [1947] Rezension von: Küssner [1946], in: Physikalische Blätter 3 (1947), S. 27-28.

Fues, Erwin [1947] Rezension von: Laue [1947]a, in: Physikalische Blätter 3 (1947), S. 365-366.

Fues, Erwin [1952] Rezension von: Laue [1919], Bd. 1, 5. Aufl., 1952, in: Physikalische Blätter 8 (1952), S. 380.

Fues, Erwin [1954] Rezension von: Laue [1919], Bd. 2, 3. Aufl., 1953, in: Physikalische Blätter 10 (1954), S. 476-477.

Geerk, Jens \& Peter Brix [1949] 'Eine massenspektrographische Methode zur Erzeugung von Schwärzungsstufen auf photographischen Platten mit mittelschnellen Protonen', Zeitschrift für Physik 125 (1949), S. 767-779.

Geiss, Johannes [1951]a 'Hochfrequenzwiderstand und Verzerrung eines schwachen Wechselstromes im Supraleiter bei Überlagerung eines starken Gleichstromes‘, Annalen der Physik (6) 9 (1951), S. 40-47.

Geiss, Johannes [1951]b 'Ergebnisse der erweiterten phänomenologischen Theorie der Supraleitung', Zeitschrift für Physik 129 (1951), S. 449-482.

Gengler, Thomas [1931] Das freie Pendel als Zeitnormale äußerster Präzision, Dissertation Jena, 1931.

Gengler, Thomas [1944] 'Nikolaus Kopernikus. Ein deutscher Forscher und sein Werk', Göttinger UniversitätsReden Nr. 14, Göttingen: Diederichsche Universitäts-Buchdruckerei, 1944.

Gericke, Otto von [1950] 'Zum zeitlichen Verlauf lichtelektrischer Ströme in Alkalihalogenid-Kristallen', Nachrichten der Akademie der Wissenschaften in Göttingen, Mathematisch-Physikalische Klasse (1950), Nr. 4, S. 1-8.

Gerstenkorn, H. \& Fritz Sauter [1951] 'Zur Änderung des elektrischen Widerstandes reiner Metalle am Schmelzpunkt", Die Naturwissenschaften 38 (1951), S. 158-159.

Gierer, Alfred [1950] 'Anomale $\mathrm{D}^{+}$- und $\mathrm{OD}^{-}$-Ionenbeweglichkeit in schwerem Wasser ', Zeitschrift für Naturforschung 5a (1950), S. 581-589.

Gierer, Alfred \& Karl Wirtz [1949] 'Anomale $\mathrm{H}^{+}$- und $\mathrm{OH}^{-}$-Ionenbeweglichkeit im Wasser', Annalen der Physik (6) 6 (1949), S. 257-304.

Gierer, Alfred \& Karl Wirtz [1950]a 'Zur Theorie der Ultraschallabsorption in Flüssigkeiten', Zeitschrift für Naturforschung 5a (1950), S. 270-275.

Gierer, Alfred \& Karl Wirtz [1950]b 'Zur Theorie der Wasserstruktur', Zeitschrift für Naturforschung 5a (1950), S. 577-580.

Gockel, Heinrich [1937] 'Über die Spannungskonstanz von Stabilovoltröhren bei Dauerbelastung', Physikalische Zeitschrift 28 (1937), S. 65-67.

Gockel, Heinrich [1938] 'Die Fehler bei der Aufnahme der drahtlosen Zeitsignale und Vorschläge zur Verbesserung', Schriftenreihe der Gesellschaft für Zeitmeßkunde und Uhrentechnik 9 (1938), S. 81-98.

Gockel, Heinrich [1939] 'Ein neuer Beitrag zur Frage der Gangsprünge bei Uhren in Greenwich und Göttingen', Zeitschrift für Physik 113 (1939), S. 188-191.

Gockel, Heinrich [1947] 'Gangstörungen zweier Pendeluhren durch Kopplung über einen mitschwingenden Pfeiler', Die Naturwissenschaften 34 (1947), S. 53.

Gollnow, Heinz [1941] Rezension von: Kopfermann [1940] in: Physikalische Zeitschrift 42 (1941), S. 147-148.

Görtler, Henry [1941] 'Neuere Beiträge zur Dynamik atmosphärischer und ozeanischer Strömungen', Die Naturwissenschaften 29 (1941), S. 473-479.

Görtler, Henry [1949] Rezension von: Betz [1948]a, in: Zeitschrift für Naturforschung 4a (1949), S. $395-396$.

Görtler, Henry \& Walter Tollmien (Hrsg.) [1955] 50 Jahre Grenzschichtforschung, Braunschweig: Vieweg.

Gott, Adelheid [1942] 'Thermische Gitterdehnung und makroskopische Ausdehnung von Alkalihalogenidschmelzflußkristallen‘, Annalen der Physik (5) 41 (1942), S. 520-536.

Gudden, Bernhard [1934] 'Elektrische Leitfähigkeit elektronischer Halbleiter', Ergebnisse der exakten Naturwissenschaften 13 (1934), S. 223-256.

Gund, Konrad [1946] 'Eine Elektronenschleuder für 6 MeV‘, Nachrichten der Akademie der Wissenschaften in Göttingen, Mathematisch-Physikalische Klasse (1946), S. 9-16.

Gund, Konrad [1947] 'Herausführung der Elektronen aus der Elektronenschleuder in einem engen Bündel', Die Naturwissenschaften 34 (1947), S. 343.

Gund, Konrad \& Herbert Reich [1949] 'Herausführung des Elektronenstrahls aus der Elektronenschleuder', Zeitschrift für Physik 126 (1949), S. 383-398.

Gund, Konrad \& Felix Wachsmann [1948] 'Versuche mit 1,5 bis 5 MeV-Elektronen einer Elektronenschleuder', Strahlentherapie 77 (1948), S. 573-584.

Haasen, Peter \& Günther Leibfried [1951/52] 'Zur Deutung der Orientierungsabhängigkeit der Verfestigungskurven von Aluminim-Einkristallen', Zeitschrift für Physik 131 (1951/52), S. 538-543. 
Haeman, D. \& Otto Haxel [1943] 'Energie und Reichweite langsamer $\alpha$-Stralen', Zeitschrift für Physik 120 (1943), S. 486-492.

Hahnkamm, Erich [1933]a 'Erzwungene Schwingungen reibungsgekoppelter Schwingungssysteme', Zeitschrift für angewandte Mathematik und Mechanik 13 (1933), S. 183-202.

Hahnkamm, Erich [1933]b 'Untersuchungen zur zahlenmäßigen Berechnung von Schlingertanks', Jahrbuch der Schiffbautechnischen Gesellschaft 34 (1933), S. 371-402.

Hanle, Wilhelm [1934] 'Anregung von Gasen I', Die Physik in regelmäßigen Berichten 2 (1934), S. 85-96.

Hanle, Wilhelm [1937] Künstliche Radioaktivität und ihre kernphysikalischen Grundlagen, Jena: Fischer.

Hanle, Wilhelm [1938] 'Anregung von Gasen II', Die Physik in regelmäßigen Berichten 6 (1938), S. 33-46.

Hanle, Wilhelm [1956] Rezension von: Weizsäcker [1948]a, 2. Aufl, 1954, in: Physikalische Blätter 12 (1956), S. 46.

Harten, Hans-Ulrich [1949]a 'Zur Streureflexion an matten Oberflächen', Zeitschrift für Physik 126 (1949), S. 27-34.

Harten, Hans-Ulrich [1949]b 'Zur Wirkung von Röntgenlicht auf KCl-Kristalle', Zeitschrift für Physik 126 (1949), S. 619-631.

Harten, Hans-Ulrich [1950] 'Durch Röntgenlicht ausgelöste Elektronenströme in KCl-Kristallen', Nachrichten der Akademie der Wissenschaften in Göttingen, Mathematisch-Physikalische Klasse (1950), Nr. 3, S. 1521.

Haxel, Otto [1948] 'Der Beitrag der schnellen Neutronen zur Neutronenvermehrung im Uran', in: Bothe \& Flügge (Hrsg.) [1948] S. 165-173.

Haxel, Otto [1953] Energiegewinnung aus Kernprozessen, Köln u. a.: Westdetuscher Verlag.

Haxel, Otto \& Fritz G. Houtermans [1948] 'Gleichzeitige Emission von zwei Elektronen beim radioaktiven Zerfall des Rubidium 87‘, Zeitschrift für Physik 124 (1948), S. 705-713.

Haxel, Otto, Fritz G. Houtermans \& Maria Kemmerich [1948] 'On the Half-Life of Rb ${ }^{87}$, Physical Review 74 (1948), S. 1886-1887.

Haxel, Otto, Fritz G. Houtermans \& Karlheinz Seeger [1951] 'Die Elektronenemission von Metalloberflächen als Nachwirkung einer mechanischen Bearbeitung oder Glimmentladung', Zeitschrift für Physik 130 (1951), S. 109-123.

Haxel, Otto, J. Hans D. Jensen \& Hans E. Suess [1948] 'Zur Interpretation der ausgezeichneten Nucleonenzahlen im Bau der Atomkerne', Die Naturwissenschaften 35 (1948), S. 376.

Haxel, Otto, J. Hans D. Jensen \& Hans E. Suess [1950] 'Modellmäßige Deutung der ausgezeichneten Nukleonenzahlen im Kernbau', Zeitschrift für Physik 128 (1950), S. 295-311.

Haxel, Otto \& Helmut Volz [1943] 'Über die Absorption von Neutronen in wässrigen Lösungen', Zeitschrift für Physik 120 (1943), S. 493-512.

Heiland, Gerhard [1950] 'Die Verfärbung von Kaliumchlorid auf elektrischem Wege', Zeitschrift für Physik 127 (1950), S. 144-165.

Heiland, Gerhard \& Heinke Kelting [1949] 'Zur Lichtabsorption von KCl-Kristallen mit K-Überschuß und CaCl-Zusatz', Zeitschrift für Physik 126 (1949), S. 689-696.

Heinrich, H. L., Wolfgang Paul \& Gerhard Schubert [1950] 'Über die Wirkung von schnellen Elektronen (4 $\mathrm{MeV})$ und Röntgenstrahlen $(180 \mathrm{kV})$ auf Mitosevorgänge in Wurzelspitzenzellen von Vicia faba', Die Naturwissenschaften 37 (1950), S. 544-545.

Heisenberg, Werner [1935] Wandlungen in den Grundlagen der Naturwissenschaft, Leipzig: Hirzel.

Heisenberg, Werner [1943]a Die Physik der Atomkerne, Braunschweig: Vieweg.

Heisenberg, Werner [1943]b 'Die »beobachtbaren Größen« in der Theorie der Elementarteilchen', Zeitschrift für Physik 120 (1943), S. 513-538.

Heisenberg, Werner [1943]c 'Die beobachtbaren Größen in der Theorie der Elementarteilchen II', Zeitschrift für Physik 120 (1943), S. 673-702.

Heisenberg, Werner [1943]d 'Zum Andenken an David Hilbert', Physikalische Zeitschrift 44 (1943), S. 277278.

Heisenberg, Werner [1943]e 'Übersicht über den jetzigen Stand von der kosmischen Strahlung', in: Heisenberg (Hrsg.) [1943] S. 1-10.

Heisenberg, Werner [1943]f 'Die Kaskadentheorie‘, in: Heisenberg (Hrsg.) [1943] S. 10-24.

Heisenberg, Werner [1943]g 'Der radioaktiver Zerfall der Mesonen', in: Heisenberg (Hrsg.) [1943] S. 78-84.

Heisenberg, Werner [1943]h 'Theorie der explosionsartigen Schauer', in: Heisenberg (Hrsg.) [1943] S. 115-118.

Heisenberg, Werner [1943]i Rezension von: Gregor Wentzel: Einführung in die Quantentheorie der Wellenfelder, Wien: Deuticke, 1943, in: Die Naturwissenschaften 31 (1943), S. 251-252.

Heisenberg, Werner [1943]j Rezension von: Arnold Sommerfeld: Vorlesung über theoretische Physik, Leipzig: Akademie-Verlagsgesellschaft Becker \& Erler, 1943, in: Die Naturwissenschaften 31 (1943), S. 350-351.

Heisenberg, Werner [1943]k 'Die Bewertung der »modernen theoretischen Physik «", Zeitschrift für die gesamte Naturwissenschaft 9 (1943), S. 201-211. 
Heisenberg, Werner [1944] 'Die beobachtbaren Größen in der Theorie der Elementarteilchen III', Zeitschrift für Physik 123 (1944), S. 93-112.

Heisenberg, Werner [1946]a 'Der mathematische Rahmen der Quantentheorie der Wellenfelder', Zeitschrift für Naturforschung 1 (1946), S. 608-622.

Heisenberg, Werner [1946]b 'Über die Arbeiten zur technischen Ausnutzung der Atomenergie in Deutschland', Die Naturwissenschaften 33 (1946), S. 325-329.

Heisenberg, Werner [1946]c 'Der unanschauliche Quantensprung', Neue Physikalische Blätter 2 (1946), Heft 1, S. 4-6.

Heisenberg, Werner [1946/47] 'Wissenschaft als Mittel zur Verständigung unter den Völkern', Rede, gehalten vor Göttinger Studenten am 13.7.1946, Deutsche Beiträge, Heft 2 (1947), S. 164-174, wiederabgedruckt in: Heisenberg [1989] Abteilung C, Bd. V, S. 384-394; sowie in: Rechenberg (Hrsg.) [1992] S. 174-186.

Heisenberg, Werner [1947]a 'Die Übertragung elektromagnetischer Kräfte im Supraleiter', Nachrichten der Akademie der Wissenschaften in Göttingen, Mathematisch-Physikalische Klasse (1947), S. 23-26.

Heisenberg, Werner [1947]b 'Zur Theorie der Supraleitung', Zeitschrift für Naturforschung 2a (1947), S. 185201.

Heisenberg, Werner [1948]a 'Zur statistischen Theorie der Turbulenz', Zeitschrift für Physik 124 (1948), S. 628657.

Heisenberg, Werner [1948]b 'Thermodynamische Betrachtungen zum Problem der Supraleitung', Annalen der Physik (6) 3 (1948), S. 289-296.

Heisenberg, Werner [1949]a 'Über die Entstehung von Mesonen in Vielfachprozessen', Zeitschrift für Physik 126 (1949), S. 569-582.

Heisenberg, Werner [1949]b 'Die Notwendigkeit wissenschaftlicher Forschung', Physikalische Blätter 5 (1949), S. $1-3$.

Heisenberg, Werner [1949]c 'Rede zur 100-Jahrfeier des Max-Gymnasiums in München am 13.7.1949', in: H. Scharold: 100 Jahre Maximilians-Gymnasium. Ein Beitrag zur Geschichte des Gymnasiums in Bayern, München: Maximilian-Gymnasium, 1949, S. 153-164, wiederabgedruckt in: Heisenberg [1989] Abteilung C, Bd. V, S. 395-408.

Heisenberg, Werner [1950]a 'Zur Quantentheorie der Elementarteilchen', Zeitschrift für Naturforschung 5a (1950), S. 251-259.

Heisenberg, Werner [1950]b 'Stationäre Zustände in der relativistischen Quantentheorie der Wellenfelder', Zeitschrift für Naturforschung 5a (1950), S. 367-373.

Heisenberg, Werner [1950]c 'Der Deutsche Forschungsrat. Interview mit Prof. Heisenberg', Physikalische Blätter 6 (1950), S. 170-172.

Heisenberg, Werner [1950]d 'Die Not der deutschen Wissenschaft', Die Tat, Zürich, 25.8.1950, wiederabgedruckt in: Heisenberg [1989] Abteilung C, Bd. V, S. 106-108.

Heisenberg, Werner [1950]e Rezension von: Wilhelm Kamlah: Der Mensch in der Profanität, Stuttgart: Kohlhammer, 1949, in: Die Naturwissenschaften 37 (1950), S. 311.

Heisenberg, Werner [1951]a Theorie des Atomkerns, Vorlesung SS 1950, ausgearbeitet von W. Macke, Göttingen: Max-Planck-Institut für Physik.

Heisenberg, Werner [1951]b 'Zur Frage der Kausalität in der Quantentheorie der Elementarteilchen', Zeitschrift für Naturforschung 6a (1951), S. 281-284.

Heisenberg, Werner [1951]c 'Paradoxien des Zeitbegriffs in der Theorie der Elementarteilchen', in: Festschrift zur Feier des zweihundertjährigen Bestehens der Akademie der Wissenschaften in Göttingen, I Mathematisch-Physikalische Klasse, Berlin u.a.: Springer, 1951, S. 50-64.

Heisenberg, Werner [1951]d 'Die Rolle der Wissenschaft im öffentlichen Leben', Deutsche UniversitätsZeitung, Heft VI/12 (1951), S. 15-16.

Heisenberg, Werner [1951] e 'Einheit von Forschung und Lehre', Göttinger Tageblatt, 10.11.1951, wiederabgedruckt in: Heisenberg [1989] Abteilung C, Bd. V, S. 409-411.

Heisenberg, Werner [1951]f 'Hat Deutschlands Forschung noch eine Chance? Interview mit dem Präsidenten der Göttinger Akadmie, Prof. Dr. Heisenberg', Göttinger Tageblatt, 10.11.1951, wiederabgedruckt in: Heisenberg [1989] Abteilung C, Bd. V, S. 112-114.

Heisenberg, Werner [1955] 'Der gegenwärtige Stand der Theorie der Elementarteilchen', Die Naturwissenschaften 42 (1955), S. 637-641.

Heisenberg, Werner (Hrsg.) [1943] Kosmische Strahlung, Berlin: Springer.

Heisenberg, Werner \& Max von Laue [1948] 'Das Barlowsche Rad aus supraleitendem Material', Zeitschrift für Physik 124 (1948), S. 514-518.

Heisenberg, Werner \& Carl Friedrich von Weizsäcker [1949] 'Die Gestalt der Spiralnebel', Zeitschrift für Physik 125 (1949), S. 290-292.

Heisenberg, Werner \& Karl Wirtz [1948] 'Großversuche zur Vorbereitung der Konstruktion eines Uranbrenners‘, in: Bothe \& Flügge (Hrsg.) [1948] S. 143-165. 
Hellwege, Anne-Marie [1940] 'Elektronensprung-Schwingungskombinationen in den Spektren der Praseodymsalze‘, Annalen der Physik (5) 37 (1940), S. 226-248.

Hellwege, Anne-Marie \& Karl-Heinz Hellwege [1950] 'Spektroskopisch verfolgte Strukturumwandlung von Kristallen', Zeitschrift für Physik 127 (1950), S. 334-343.

Hellwege, Anne-Marie \& Karl-Heinz Hellwege [1951] 'Die Aufspaltung der Pr $^{+++}$-Terme in trigonalen Einkristallen von Praesodymzink- und Praesodymmagnesium-Nitrat', Zeitschrift für Physik 130 (1951), S. 549-560.

Hellwege, Anne-Marie \& Karl-Heinz Hellwege [1952] 'Schwingungsstruktur von Elektronenübergängen in Einkristallen von Praseodym- Neodym-Salzen', Zeitschrift für Physik 133 (1952), S. 174-191.

Hellwege, Karl-Heinz [1941]a 'Über die Strahlungsfelder von $\operatorname{Pr}^{+++}$- und $\mathrm{Nd}^{+++}$-Ionen in hexagonalen Salzkristallen', Zeitschrift für Physik 117 (1941), S. 198-204.

Hellwege, Karl-Heinz [1941]b 'Über das Absorptionsspektrum des dampfförmigen Chromoxyfluorids', Zeitschrift für Physik 117 (1941), S. 596-601.

Hellwege, Karl-Heinz [1941]c 'Über die Fluoreszenz und die Kopplung zwischen Elektronentermen und Kristallgitter bei den wasserhaltigen Salzen der Seltenen Erden', Annalen der Physik (5) 40 (1941), S. 529-542.

Hellwege, Karl-Heinz [1942] 'Zur Ausmessung atomarer Strahlungsfelder in Kristallen', Zeitschrift für Physik 119 (1942), S. 325-333.

Hellwege, Karl-Heinz [1943] 'Zur Ausmessung atomarer Strahlungsquellen in Kristallen II. Berechnung der Absorptionsverteilung für Dipolstrahlung und Bestimmung von Übergangswahrscheinlichkeiten“, Zeitschrift für Physik 121 (1943), S. 588-603.

Hellwege, Karl-Heinz [1947]a 'Bestimmung von Übergangswahrscheinlichkeiten für strahlende und strahlungslose Prozessse in Kristallen', Die Naturwissenschaften 34 (1947), S. 212.

Hellwege, Karl-Heinz [1947]b ’Über die Spektren der kristallinen Salze Seltener Erden', Die Naturwissenschaften 34 (1947), S. 225-232.

Hellwege, Karl-Heinz [1947]c 'Elektronenterme und Strahlung von Atomen in Kristallen', Nachrichten der Akademie der Wissenschaften in Göttingen, Mathematisch-Physikalische Klasse (1947), S. 37-41.

Hellwege, Karl-Heinz [1947]d 'Analyse der Spektren von kristallinen Europiumsalzen', Nachrichten der Akademie der Wissenschaften in Göttingen, Mathematisch-Physikalische Klasse (1947), S. 58-66.

Hellwege, Karl-Heinz [1948] Rezension von: Ferdinand A. Kröger: Some Aspects of the Luminescence of Solids, New York u. a.: Elsevier, 1948, in: Die Naturwissenschaften 35 (1948), S. 160.

Hellwege, Karl-Heinz [1949]a Einführung in die Physik der Atome, Wolfenbüttel: Wolfenbütteler Verlagsanstalt.

Hellwege, Karl-Heinz [1949]b 'Elektronenterme und Strahlung von Atomen in Kristallen. I. Termaufspaltung und elektrische Dipolstrahlung', Annalen der Physik (6) 4 (1949), S. 95-126. Berichtigung dazu in: ebenda, S. 357-358.

Hellwege, Karl-Heinz [1949]c 'Elektronenterme und Strahlung von Atomen in Kristallen. II. Magnetische Dipolstrahlung‘, Annalen der Physik (6) 4 (1949), S. 127-135.

Hellwege, Karl-Heinz [1949]d 'Elektronenterme und Strahlung von Atomen in Kristallen. III. Elektrische Quadrupolstrahlung', Annalen der Physik (6) 4 (1949), S. 136-142.

Hellwege, Karl-Heinz [1949]e 'Elektronenterme und Strahlung von Atomen in Kristallen. IV. Symmetrieentartung und Kramersche Entartung', Annalen der Physik (6) 4 (1949), S. 145-149.

Hellwege, Karl-Heinz [1949]f 'Elektronenterme und Strahlung von Atomen in Kristallen. V. Kubische Kristalle', Annalen der Physik (6) 4 (1949), S. 150-160.

Hellwege, Karl-Heinz [1950]a 'Der lineare Zeeman-Effekt in Kristallen', Zeitschrift für Physik 127 (1950), S. 513-521. Berichtigung dazu in: Zeitschrift für Physik 128 (1950), S. 172.

Hellwege, Karl-Heinz [1950]b Rezension von: Christian Gerthsen: Physik. Ein Lehrbuch zum Gebrauch neben Vorlesungen, Berlin: Volk und Wissen, 1948, in: Die Naturwissenschaften 37 (1950), S. 311.

Hellwege, Karl-Heinz [1951]a 'Optische Anisotropie kubischer Kristalle bei Quadrupolstrahlung', Die Naturwissenschaften 38 (1951), S. 142.

Hellwege, Karl-Heinz [1951]b 'Optische Symmetrie nichtkubischer Kristalle bei Dipol- und Quadrupolstrahlung', Die Naturwissenschaften 38 (1951), S. 460.

Hellwege, Karl-Heinz [1951]c 'Optische Anisotropie kubischer Kristalle bei Quadrupolstrahlung', Zeitschrift für Physik 129 (1951), S. 626-641.

Hellwege, Karl-Heinz [1951/52] 'Dipol- und Quadrupolstrahlungsfelder in nichtkubischen Kristallen', Zeitschrift für Physik 131 (1951/52), S. 98-112.

Hellwege, Karl-Heinz \& H. G. Kahle [1951]a 'Spektrum und Struktur kristalliner Europiumsalze I. Europiumchlorid $\mathrm{EuCl}_{3} \cdot 6 \mathrm{H}_{2} \mathrm{O}^{\prime}$, Zeitschrift für Physik 129 (1951), S. 62-84.

Hellwege, Karl-Heinz \& H. G. Kahle [1951]b 'Spektrum und Struktur kristalliner Europiumsalze II. Europiumbrombat $\mathrm{Eu}\left(\mathrm{BrO}_{3}\right)_{3} \cdot 9 \mathrm{H}_{2} \mathrm{O}^{\prime}$, Zeitschrift für Physik 129 (1951), S. 85-103. 
Helwig, Gerhard [1952] 'Elektrische Leitfähigkeit und Struktur aufgestäubter Kadmiumoxydschichten', Zeitschrift für Physik 132 (1952), S. 621-642.

Helwig, Gerhard \& Hans König [1950] 'Die Kathodenzerstäubung, ein Hilfsmittel zur Untersuchung übermikroskopischer Objekte', Optik 7 (1950), S. 294-302.

Hilsch, Rudolf [1942] 'Anlage zur Verflüssigung von Wasserstoff', Annalen der Physik (5) 42 (1942), S. 165175.

Hilsch, Rudolf [1946] 'Die Expansion von Gasen im Zentrifugalfeld als Kälteprozeß', Zeitschrift für Naturforschung 1 (1946), S. 208-214.

Hilsch, Rudolf \&Robert Wichard Pohl [1938] 'Über photochemische Vorgänge in Kristallen', Annalen der Physik (5) 32 (1938), S. 155-160.

Hoch, Alois [1940] 'Die Absorptionsspektra einiger Zinksulfidphosphore im angeregten Zustand', Annalen der Physik (5) 38 (1940), S. 486-494.

Hoffrogge, Christian [1949]a 'Mit Schulerpendeln gemessene Schwereschwankungen durch Sonne und Mond', Die Naturwissenschaften 36 (1949), S. 312.

Hoffrogge, Christian [1949]b 'Gangstörungen von Schuler-Uhren durch Gezeitenkräfte, Erdbeben und Änderungen der Pendellänge', Zeitschrift für Physik 126 (1949), S. 671-688.

Hohenemser, Kurt [1929] Praktische Wege zur angenäherten Schwingungsberechnung elastischer Systeme, Berlin: Springer.

Hohenemser, Kurt [1930] 'Praktische Wege zur angenäherten Schwingungsberechnung elastischer Systeme', Ingenieur-Archiv 1 (1930), S. 271-292.

Hohenemser, Kurt [1931]a 'Zur Anwendbarkeit der Wahrscheinlichkeitsrechnung in der Naturwissenschaft', Die Naturwissenschaften 19 (1931), S. 833-838.

Hohenemser, Kurt [1931]b 'Elastisch-bildsame Verformungen statisch unbestimmter Stabwerke', IngenieurArchiv 2 (1931), S. 472-482.

Hohenemser, Kurt [1931/32] 'Beitrag zu den Grundproblemen in der Wahrscheinlichkeitsrechnung', Erkenntnis $2(1931 / 32)$, S. 354-364.

Hohenemser, Kurt [1932]a 'Bemerkungen über die Schwingungszahlen zusammengesetzter elastischer Systeme', Ingenieur-Archiv 3 (1932), S. 89-90.

Hohenemser, Kurt [1932]b 'Die Methoden zur angenäherten Lösung von Eigenwertproblemen in der Elastokinetik', Ergebnisse der Mathematik und ihrer Grenzgebiete, hrsg. von der Schriftleitung des Zentralblatt für Mathematik, erster Band, Springer: Berlin, 1932, S. 323-415.

Hohenemser, Kurt [1937]a 'Zur Festigkeit von umlaufenden und quer zur Drehebene belasteten Stäben, die gelenkig, und die biegesteif an die Drehachse angeschlossen sind', Ingenieur-Archiv 8 (1937), S. 203.

Hohenemser, Kurt [1937]b 'Zur Frage der Flugleistungen von Drehflüglern', Ingenieur-Archiv 8 (1937), S. 433.

Hohenemser, Kurt [1938] 'Über die dynamische Stabilität des Hubschraubers mit angelenkten Flügeln', Ingenieur-Archiv 9 (1938), S. 419.

Hohenemser, Kurt [1939] 'Flattern von Drehflügeln im Standlauf', Ingenieur-Archiv 10 (1939), S. 133.

Hohenemser, Kurt [1943] 'Zur Dynamik von umlaufenden, gelenkig an die Nabe angeschlossenene und in der Umlaufebene schwingenden Stäben', Ingenieur-Archiv 14 (1943).

Hohenemser, Kurt [1944]a 'Der Leistungsbedarf des idealen Hubschraubers', Technische Berichte 11 (1944), S. 159.

Hohenemser, Kurt [1944]b 'Neue Erkenntnisse zur Frage der Schwebeflugstabilität eines Hubschraubers mit zentraler Schraubenanordnung', Deutsche Luftfahrtforschung Forschungsbericht Nr. 1989/1 (1944).

Hohenemser, Kurt [1944]c 'Die Längsstabilität des Hubschraubers im Vorwärtsflug', Deutsche Luftfahrtforschung Forschungsbericht Nr. 1989/2 (1944).

Hohenemser, Kurt [1944]d 'Aufgaben aus der Theorie der Blattwinkelregelung des Hubschraubers', Deutsche Luftfahrtforschung Forschungsbericht Nr. 1989/3 (1944).

Hohenemser, Kurt [1944]e 'Zur Theorie der Schwingungen von Drehflügeln in der Umlaufebene', Deutsche Luftfahrtforschung Forschungsbericht Nr. 1989/4 (1944).

Hohenemser, Kurt [1944]f 'Zur Theorie der Hubschraubersteuerung im Schwebeflug', Deutsche Luftfahrtforschung Forschungsbericht Nr. 1989/5 (1944).

Hohenemser, Kurt [1944]g 'Die Seitenstabilität des Hubschraubers im Geradeausflug', Deutsche Luftfahrtforschung Forschungsbericht Nr. 1989/6 (1944).

Hohenemser, Kurt [1945]a 'Die Transportleistungen des Hubschraubers', Deutsche Luftfahrtforschung Forschungsbericht Nr. 1989/7 (1945).

Hohenemser, Kurt [1945]b 'Das Hochreissen des Hubschraubers', Deutsche Luftfahrtforschung Forschungsbericht Nr. 1989/8 (1945).

Hohenemser, Kurt [1945]c 'Das Leistungskennfeld der Hubschraube', Deutsche Luftfahrtforschung Forschungsbericht Nr. 1989/9 (1945). 
Hohenemser, Kurt \& Willy Prager [1932] 'Über das Gegenstück zum Rayleighschen Verfahren der Schwingungslehre', Ingenieur-Archiv 3 (1932), S. 306-310.

Hohenemser, Kurt \& Willy Prager [1933] Dynamik der Stabwerke, Berlin: Springer.

Hönl, Helmut [1942] Rezension von: Laue [1941]a, in: Die Naturwissenschaften 30 (1942), S. 186-188.

Hönl, Helmut [1952] Rezension von: Ludwig [1951], in: Zeitschrift für Naturforschung 7a (1952), S. 446.

Hoppe, Walter [1947] 'Ein elektrischer Rechner für Kreisfunktionen', Zeitschrift für Naturforschung 2a (1947), S. 585-586.

Houtermans, Fritz G. [1940] 'Halbwertszeit des Radiotantal', Die Naturwissenschaften 28 (1940), S. 578.

Houtermans, Fritz G. [1941] 'Über den Energieverbrauch bei der Isotopentrennung', Annalen der Physik (5) 40 (1941), S. 493-508.

Houtermans, Fritz G. [1941/42] 'Über Wirkungsquerschnitte einiger Elemente für thermische Neutronen (Mitteilung aus dem Laboratorium Manfred von Ardenne, Lichterfelde-Ost.)' Zeitschrift für Physik 118 (1941/42), S. 424-425.

Houtermans, Fritz G. [1942] 'Ein Neutronen-Integrator, eine Anordnung zur Messung der Ergiebigkeit von Neutronenquellen nach der Methode von Fermi und Amaldi‘, Physikalische Zeitschrift 43 (1942), S. 496503.

Houtermans, Fritz G. [1944]a ’Über eine halbempirische Beziehung zwischen der Ergiebigkeit einer Neutronenquelle und der maximal erreichbaren Dichte langsamer Neutronen in einem wasserstoffhaltigem Medium', Physikalische Zeitschrift 45 (1944), S. 258-264.

Houtermans, Fritz G. [1944]b ’Über eine halbempirische Beziehung zwischen der Ergiebigkeit einer Neutronenquelle und der maximal erreichbaren Dichte langsamer Neutronen in einem wasserstoffhaltigen Medium', Physikalische Zeitschrift 45 (1944), S. 258-264.

Houtermans, Fritz G. [1946]a 'Die Isotopenhäufigkeit im natürlichen Blei und das Alter des Urans', Die Naturwissenschaften 33 (1946), S. 185-186. Nachtrag dazu, ebenda, S. 219.

Houtermans, Fritz G. [1946]b 'Über den $(n, 2 n)$-Prozeß am Beryllium mit Neutronen einer $(P o \alpha+B e)$-Quelle“, Nachrichten der Akademie der Wissenschaften in Göttingen, Mathematisch-Physikalische Klasse (1946), S. 52-54.

Houtermans, Fritz G. [1947] 'Das Alter des Urans', Zeitschrift für Naturforschung 2a (1947), S. 322-328.

Houtermans, Fritz G. [1948] 'Meßverfahren für Neutronen', in: Bothe \& Flügge (Hrsg.) [1948] S. 13-24.

Houtermans, Fritz G. [1951] 'Die Kernemulsionsplatte als Hilfsmittel der Mineralogie und Geologie', Die Naturwissenschaften 38 (1951), S. 132-137.

Houtermans, Fritz G. \& Ilse Bartz [1942] 'Über die Entstehung von RaE aus Wismut durch den $(n, \gamma)$-Prozeß mit langsamen Neutronen', Die Naturwissenschaften 30 (1942), S. 758-759.

Houtermans, Fritz G. \& Ilse Bartz [1943] 'Über den Kernphotoeffekt im Beryllium‘, Physikalische Zeitschrift 44 (1943), S. 167-176.

Houtermans, Fritz G., Otto Haxel \& Joachim Heintze [1950] 'Die Halbwertszeit des K ${ }^{40 ،}$, Zeitschrift für Physik 128 (1950), S. 657-667.

Houtermans, Fritz G. \& J. Hans D. Jensen [1947] 'Über die thermische Dissoziation des Vakuums', Zeitschrift für Naturforschung 2a (1947), S. 146-148.

Houtermans, Fritz G. \& Pacual Jordan [1945] 'Die zeitliche Veränderlichkeit des $\beta$-Zerfalls und ihre experimentelle Prüfung', Nachrichten der Akademie der Wissenschaften in Göttingen, MathematischPhysikalische Klasse (1945), S. 80-82.

Houtermans, Fritz G. \& Pascual Jordan [1946] 'Über die Annahme der zeitlichen Veränderlichkeit des $\beta$ Zerfalls und die Möglichkeiten ihrer experimentellen Prüfung', Zeitschrift für Naturforschung 1 (1946), S. 125-130.

Houtermans, Fritz G. \& Martin Teucher [1948] 'Die Zahl der von einer (Ra $\alpha+$ Be)-Quelle emittierten »schnellen« Neutronen', Zeitschrift für Physik 124 (1948), S. 700-704.

Houtermans, Fritz G. \& Martin Teucher [1951] 'Das Primärspektrum der schnellen Neutronen einer (Ra $\alpha+$ Be)-Quelle und deren unelastische Stöße in Pb II', Zeitschrift für Physik 129 (1951), S. 365-368.

Intemann, K. \& Fritz Stöckmann [1951/52] 'Messungen des Hall-Effekts am Zinkoxyd', Zeitschrift für Physik $131(1951 / 52)$, S. 10-16.

Jahn, Helmut \& Hans Kopfermann [1949] 'Zur Theorie der Radialschwingungen der Elektronen in einer Elektronenschleuder', Annalen der Physik (6) 6 (1949), S. 305-320.

Jenckel, Ludolf \& Hans Kopfermann [1941] 'Über eine Methode zur Beobachtung sehr kleiner Stark-Effekte‘, Zeitschrift für Physik 117 (1941), S. 145-155.

Jensen, Hans [1948] Rezension von: Flügge [1947], in: Die Naturwissenschaften 35 (1948), S. 349.

Jensen, J. Hans D., Hans E. Suess \& Otto Haxel [1949] 'Modellmäßige Deutung der ausgezeichneten Nucleonenzahlen im Kernbau', Die Naturwissenschaften 36 (1949), S. 155-156.

Joos, Georg [1931] 'Wiederholungen des Michelson-Versuchs', Die Naturwissenschaften 19 (1931), S. $784-$ 789. 
Joos, Georg [1932] Lehrbuch der theoretischen Physik, Leipzig: Akademische Verlagsgesellschaft.

Joos, Georg [1933] 'Linienspektren der Atome I‘, Die Physik in regelmäßigen Berichten 1 (1933), S. 81-100.

Joos, Georg [1939] 'Die sichtbaren und ultravioletten Spektren fester Körper', Ergebnisse der exakten Naturwissenschaften 18 (1939), S. 78-98.

Joos, Georg [1942] 'Ergebnisse einer Untersuchung von $\mathrm{H}$. Meyer über die Ionisierung von $\mathrm{H}_{2}$ und $\mathrm{D}_{2}$ durch He- und durch Ne-Kanalstrahlen', Annalen der Physik (5) 41 (1942), S. 426-434.

Joos, Georg [1946] 'Die Änderung von Brechzahl, Dichte und Molrefraktion beim Tempern der Gläser', Optik 1 (1946), S. 320-323.

Joos, Georg [1948] 'Optische Eigenschaften der festen Körper', in: Joos (Hrsg.) [1948] S. 163-184.

Joos, Georg [1950] Rezension von: Becker [1950]a, in: Zeitschrift für angewandte Physik 2 (1950), S. 351.

Joos, Georg [1952] Rezension von: Hanle [1939], 2. Aufl., Stuttgart: Piscator, 1952, in: Zeitschrift für angewandte Physik 4 (1952), S. 400.

Joos, Georg [1954] 'Robert Pohl 70 Jahre', Zeitschrift für angewandte Physik 6 (1954), S. 339.

Joos, Georg (Hrsg.) [1947/48] Physics of Solids, Bd. 8 und Bd. 9 der Reihe: Fiat Review of German Science 1939-1946, Wiesbaden: Dieterichsche Verlagsbuchhandlung.

Joos, Georg \& Wolfgang Finkelnburg [1933] 'Kontinuierliche Spektren I', Die Physik in regelmäßigen Berichten 4 (1936), S. 35-46.

Joos, Georg \& Karl-Heinz Hellwege [1937] 'Linienspektren der Atome II‘, Die Physik in regelmäßigen Berichten 5 (1937), S. 33-41.

Joos, Georg \& Karl-Heinz Hellwege [1941] 'Über die wahre Linienbreite und Oszillatorenstärke der Linien des Europiumsulfats', Annalen der Physik (5) 39 (1941), S. 25-29. Berichtigung dazu in: ebenda, S. 128.

Joos, Georg \& Theodor Kaluza [1938] Höhere Mathematik für den Praktiker, (an Stelle einer 5. Aufl des Lehrbuchs der Differential- und Integralrechnung von H. A. Lorentz), Leipzig: Barth.

Joos, Georg \& August Köhler [1942] 'Über die Abbesche Mikroskoptheorie und die mit ihr zusammenhängenden Kohärenzfragen“, Die Naturwissenschaften 30 (1942), S. 553-563.

Joos, Georg \& Adelheid Saur-Gott [1942] 'Linienspektren der Atome III‘, Die Physik in regelmäßigen Berichten 10 (1942), S. 27-34.

Jordan, Pascual [1933] Statistische Mechanik auf quantentheoretischer Grundlage, Braunschweig: Vieweg.

Jordan, Pascual [1936/45] Die Physik des 20. Jahrhunderts. Einführung in den Gedankeninhalt der modernen Physik, Braunschweig: Vieweg, 6. Aufl. 1945.

Jordan, Pascual [1937]a 'Fortschritte der Theorie der Atomkerne', Ergebnisse der exakten Naturwissenschaften 16 (1937), S. 47-103.

Jordan, Pascual [1937]b Rezension von: Alois Wenzl: Wissenschaft und Weltanschauung. Natur und Geist als Probleme der Metaphysik, Leipzig: Meizner, 1936, in: Die Tatwelt 13 (1937), S. 55-57.

Jordan, Pascual [1937]c Rezension von: Gustav Mie: Die Denkweise der Physik und ihr Einfluß auf die geistige Einstellung des heutigen Menschen, Stuttgart, 1937, in: Die Tatwelt 13 (1937), S. 220-221.

Jordan, Pascual [1937]d Rezension von: Max Hartmann: Philosophie der Naturwissenschaften, Berlin, 1937, in: Die Tatwelt 13 (1937), S. 221-222.

Jordan, Pascual [1938]a 'Das Einheitsproblem der physikalischen und biologischen Wissenschaften', Die Tatwelt 14 (1938), S. 198-208.

Jordan, Pascual [1938]b Rezension von: Willy Hellpach: Schöpferische Unvernunft? Rolle und Grenze des Irrationalen in der Wissenschaft, Leipzig: Meizner, 1937, in: Die Tatwelt 14 (1938), S. 52-53.

Jordan, Pascual [1940]a Rezension von: Joos [1932], 3. Aufl, 1939, in: Die Naturwissenschaften 28 (1940), S. 462.

Jordan, Pascual [1940]b Rezension von: Richard Woltereck: Grundzüge einer allgemeinen Biologie, 2. Aufl., Stuttgart: Enke, 1940; und ders.: Ontologie des Lebendigen, Stuttgart: Enke, 1940, in: Die Tatwelt 16 (1940), S. 169-170.

Jordan, Pascual [1941] Die Physik und das Geheimnis des organischen Lebens, Braunschweig: Vieweg.

Jordan, Pascual [1941/42] 'Zur Deutung der sonnenbeschienenen Nordlichter' Zeitschrift für Physik 118 (1941/42), S. 441-442.

Jordan, Pascual [1942]a Rezension von: Carl Ramsauer (Hrsg.): Das freie Elektron in der Physik und Technik, Berlin: Springer, 1940, in: Die Naturwissenschaften 30 (1942), S. 440.

Jordan, Pascual [1942]b Rezension von: Enrico Persico: Introduzione alla Fisica Matematica, Bologna: Zanichelli, 1941, in: Die Naturwissenschaften 30 (1942), S. 477.

Jordan, Pascual [1944]a 'Über die Entstehung der Sterne. I. Grundlagen der Theorie', Physikalische Zeitschrift 45 (1944), S. 183-190.

Jordan, Pascual [1944]b 'Über die Entstehung der Sterne. II. Veränderliche Sterne', Physikalische Zeitschrift 45 (1944), S. 233-244.

Jordan, Pascual [1944]c 'Quantenphysik und Biologie', Die Naturwissenschaften 32 (1944), S. 309-316. 
Jordan, Pascual [1945]a 'Zur projektiven Relativitätstheorie', Nachrichten der Akademie der Wissenschaften in Göttingen, Mathematisch-Physikalische Klasse (1945), S. 74-76.

Jordan, Pascual [1945]b 'Zur Deutung der Höhenstrahlung', Nachrichten der Akademie der Wissenschaften in Göttingen, Mathematisch-Physikalische Klasse (1945), S. 77-79.

Jordan, Pascual [1946]a 'Zur Deutung der Höhenstrahlung‘, Zeitschrift für Naturforschung 1 (1946), S. 301304.

Jordan, Pascual [1946]b 'Relativistische Gravitationstheorie mit variabler Gravitationskonstante', Die Naturwissenschaften 33 (1946), S. 250-251.

Jordan, Pascual [1946]c 'Zur Lösung des Paradoxons von Chandrasekhar', Die Naturwissenschaften 33 (1946), S. 218-219.

Jordan, Pascual [1947]a Die Herkunft der Sterne, Stuttgart: Wissenschaftliche Verlagsgesellschaft.

Jordan, Pascual [1947]b Verdrängung und Komplementarität. Eine philosophische Untersuchung, HamburgBergedorf: Stromverlag.

Jordan, Pascual [1947]c Eiweiß-Moleküle. Ein Kapitel moderner Naturwissenschaft, Stuttgart:

Wissenschaftliche Verlagsgesellschaft.

Jordan, Pascual [1947]d Das Bild der modernen Physik, Hamburg-Bergedorf: Stromverlag.

Jordan, Pascual [1947] e 'Erweiterung der projektiven Relativitätstheorie', Annalen der Physik (6) 1 (1947), S. 219-228.

Jordan, Pascual [1947]f 'Zur Theorie der Sternentstehung', Physikalische Blätter 3 (1947), S. 97-106.

Jordan, Pascual [1947]g 'Zur Biophysik des Farbensehens', Optik 2 (1947), S. 169-189.

Jordan, Pascual [1947]h 'Max Planck †', Optik 2 (1947), S. 329-331.

Jordan, Pascual [1948]a Die Wandlung unseres Naturbildes, Lüneburg: Heiland-Verlag.

Jordan, Pascual [1948]b 'Über den Riemannschen Krümmungstensor I', Zeitschrift für Physik 124 (1948), S. 602-607.

Jordan, Pascual [1948]c 'Über den Riemannschen Krümmungstensor II', Zeitschrift für Physik 124 (1948), S. 608-613.

Jordan, Pascual [1948]d 'Der Zusammenhang der vier- und fünfdimensionalen Metrik', Annalen der Physik (6) 3 (1948), S. 153-155.

Jordan, Pascual [1948]e 'Probleme der Eiweiß-Molekül-Struktur', Physikalische Blätter 4 (1948), S. 229-238.

Jordan, Pascual [1948]f 'Farbensehen und Helligkeitsempfindung', in: Rajewsky \& Schön (Hrsg.) [1948] S. 156-160.

Jordan, Pascual [1948]g 'Die Entstehung der Sterne‘, Naturwissenschaftliche Rundschau 1 (1948), S. 193-200. Jordan, Pascual [1949]a Physik im Vordringen, Braunschweig: Vieweg.

Jordan, Pascual [1949]b 'Svedbergs $2^{\mathrm{n}} 3^{\mathrm{m}}$-Gesetz der Eiweiß-Moleküle', Naturwissenschaftiche Rundschau 2 (1949), S. 411-416.

Jordan, Pascual [1949]c 'Wann wird die Physik abgeschlossen sein', Physikalische Blätter 5 (1949), S. 101-107.

Jordan, Pascual [1952] a 'Über die Erhaltungssätze in der Physik', Zeitschrift für Naturforschung 7a (1952), S. 78-81.

Jordan, Pascual [1952]b 'Über die Erhaltungssätze in der Physik II‘, Zeitschrift für Naturforschung 7a (1952), S. 701-702.

Jordan, Pascual \& Claus Müller [1947] 'Über die Feldgleichungen der Gravitation bei variabler »Gravitationskonstante «', Zeitschrift für Naturforschung 2a (1947), S. 1-2.

Jusuf, M. [1942] 'Über die Ionisierung von Ortho- und Parawasserstoff durch Protonen- und Deuteronenkanalstrahlen', Annalen der Physik (5) 41 (1942), S. 435-442.

Kaempffer, Friedrich [1945] 'Der Göttinger Student', GUZ (1945/46), Nr. 7, S. 3.

Kaempffer, Friedrich [1949]a 'Zur Theorie des idealen Bose-Einstein-Gases', Zeitschrift für Physik 125 (1949), S. 359-369.

Kaempffer, Friedrich [1949]b 'Zur Thermodynamik der Materiewellen', Zeitschrift für Physik 125 (1949), S. 487-496.

Kamke, Detlef [1949] 'Zur Ausbeute-Steigerung bei der Kanalstrahl-Ionenquelle', Zeitschrift für Naturforschung 4a (1949), S. 391-393.

Kamke, Detlef [1950] 'Zum Mechanismus der Kanalstrahlentladung', Zeitschrift für Physik 128 (1950), S. 212238. Berichtigung dazu in: ebenda, S. 493.

Kamke, Detlef [1952] 'Eine Ionenquelle', Zeitschrift für Naturforschung 7a (1952), S. 341-344.

Karabascheff, N. [1941/42] 'Zur Einwanderung von Elektronen in Alkalihalogenidkristallen' Zeitschrift für Physik 118 (1941/42), S. 718-726.

Kauderer, Hans [1950] Rezension von: Schultz-Grunow [1949], in: Die Naturwissenschaften 37 (1950), S. 405. Kaufmann, Walther [1949] Rezension von: Betz [1948]a in: Zeitschrift für angewandte Physik 1 (1949), S. 484485. 
Kelting, Heinke \& Horst Witt [1949] 'Über KCl-Kristalle mit Zusätzen von Erdalkalichloriden', Zeitschrift für Physik 126 (1949), S. 697-710.

Kemmerich, Maria [1949] 'Die Halbwertezeit des Rubidiums ${ }^{87 ،, ~ Z e i t s c h r i f t ~ f u ̈ r ~ P h y s i k ~} 126$ (1949), S. 399-409.

Kepp, Richard Kurt [1950] 'Die Wirkung der Bestrahlung mit schnellen Elektronen auf die menschliche Haut', Strahlentherapie 81 (1950), S. 201-214.

Kerkhoff, Franz [1951] 'Überführungszahlen für KCl-Kristalle', Zeitschrift für Physik 130 (1951), S. 449-456.

Kersten, Martin [1947] 'Ein überraschender Vorlesungsversuch von R. Becker zum physikalischen Pendel', Physikalische Blätter 3 (1947), S. 390-391.

Kleinschrod, F. G. [1939] 'Photochemische Zersetzung von $K H$ und $K D$ in $K B r$-Kristallen', Nachrichten von der Gesellschaft der Wissenschaften zu Göttingen, Mathematisch-Physikalische Klasse, Neue Folge, Fachgruppe II (1939), S. 143-148.

Kneser, Hans Otto [1947]a 'Zur Deutung der Schallabsorption im Wasser', Die Naturwissenschaften 34 (1947), S. 53-54.

Kneser, Hans Otto [1947]b 'Relaxation der Schwingungswärme als Ursache der Schallabsorption in Flüssigkeiten', Die Naturwissenschaften 34 (1947), S. 54.

Kneser, Hans Otto [1948] 'Schallabsorption und Struktur der Flüssigkeiten', Die Naturwissenschaften 35 (1948), S. 88-91.

Kneser, Hans Otto [1949] 'Molekulare Schallabsorption und -dispersion', Ergebnisse der exakten Naturwissenschaften 22 (1949), S. 121-185.

Knoch, Mechthild \& Hans König [1951] 'Zur Struktur der Paramecien-Trichocysten', Die Naturwissenschaften 38 (1951), S. 531.

Kochendörfer, Albert [1949] Rezension von: Laue [1941]a, 2. Aufl., 1948, in: Physikalische Blätter 5 (1949), S. 483.

Kochendörfer, Albert [1951] Rezension von: Becker [1950]a, in: Physikalische Blätter 7 (1951), S. 136-137.

König, Hans [1942] 'Elektroneninterferenzen an Eis', Nachrichten der Akademie der Wissenschaften in Göttingen, Mathematisch-Physikalische Klasse (1942), S. 1-6.

König, Hans [1944]a 'Struktur und Aufbau dünner Germaniumschichten', Reichsberichte für Physik 1 (1944), S. 4-7.

König, Hans [1944]b 'Elektronenbeugung an Kupfer-Zinklegierungen‘, Reichsberichte für Physik 1 (1944), S. 7-10.

König, Hans [1946]a 'Die kleinsten ferromagnetischen Elementarbereiche des Eisens ', Die Naturwissenschaften 33 (1946), S. 71-75.

König, Hans [1946]b 'Gitterkonstantenbestimmung im Elektronenmikroskop', Die Naturwissenschaften 33 (1946), S. 343-344.

König, Hans [1946]c 'Zur Gitterkonstanten von Aluminiumaufdampfschichten', Die Naturwissenschaften 33 (1946), S. 367-368.

König, Hans [1946]d 'Veränderung organischer Präparate im Elektronenmikroskop', Nachrichten der Akademie der Wissenschaften in Göttingen, Mathematisch-Physikalische Klasse (1946), S. 24-25.

König, Hans [1946]e 'Ein elektronenmikroskopisches Abdruckverfahren für biologische Objekte', Nachrichten der Akademie der Wissenschaften in Göttingen, Mathematisch-Physikalische Klasse (1946), S. 68-70.

König, Hans [1947]a 'Über das Schmelzen des Kohlenstoffs‘, Die Naturwissenschaften 34 (1947), S. 108-111.

König, Hans [1947]b 'Die Gitterkonstante kleiner Kristalle‘, Die Naturwissenschaften 34 (1947), S. $375-376$.

König, Hans [1948]a 'Die Gitterkonstante von $\gamma-\mathrm{Al}_{2} \mathrm{O}_{3}{ }^{6}$, Die Naturwissenschaften 35 (1948), S. 92-93.

König, Hans [1948]b 'Die Rolle der Kohle bei elektronenmikroskopischen Abbildungen', Die Naturwissenschaften 35 (1948), S. 261-265.

König, Hans [1948]c 'Faradayeffekt und Aufbau dünner Eisenschichten', Optik 3 (1948), S. 101-119.

König, Hans [1948]d 'Experimente mit Gitterbausteinen des festen Körpers', Optik 3 (1948), S. 201-220.

König, Hans [1948]e 'Elektronenbeugungsversuche an Silizium und seinen Oxyden', Optik 3 (1948), S. 419429.

König, Hans [1948]f 'Plastische Elektronenbilder', Physikalische Blätter 4 (1948), S. 503-505.

König, Hans [1949]a 'Neue Ergebnisse der Elektronenmikroskopie', Optik 5 (1949), S. 460-462.

König, Hans [1949]b 'Diskussionstagung zum 65. Geburtstag von R. W. Pohl in Göttingen', Physikalische Blätter 5 (1949), S. 386.

König, Hans [1950]a Rezension von: Bodo von Borries: Die Übermikroskopie. Einführung, Untersuchung ihrer Grenzen und Abriß ihrer Ergebnisse, Berlin: Saenger, 1949, in: Die Naturwissenschaften 37 (1950), S. 380

König, Hans [1950]b 'Schlierenoptik im Elektronenmikroskop', Die Naturwissenschaften 37 (1950), S. 486490.

König, Hans [1950]c 'Zur Veränderung von Kristallen im Elektronenmikroskop', Optik 7 (1950), S. 261-262.

König, Hans [1951]a ’Über Kohlenstoffplatin', Die Naturwissenschaften 38 (1951), S. 154-155. 
König, Hans [1951]b 'Zur Veränderung von $\mathrm{MoO}_{3}$-Kristallen im Elektronenmikroskop', Zeitschrift für Physik 130 (1951), S. 483-492.

König, Hans [1951]c 'Verkohlung organischer Objekte durch Elektronen', Zeitschrift für Physik 129 (1951), S. 483-490.

König, Hans [1953] 'Präparative Methoden der Elektronenmikroskopie und ihre Ergebnisse', Ergebnisse der exakten Naturwissenschaften 27 (1953), S. 188-247.

König, Hans [1954] 'Zur Sichtbarmachung magnetischer Felder', Die Naturwissenschaften 41 (1954), S. 341346.

König, Hans \& Gerhard Helwig [1949] 'Zur elektronenmikroskopischen Abbildung von Inhomogenitäten in Glasoberflächen', Optik 5 (1949), S. 573-575.

König, Hans \& Gerhard Helwig [1950] 'Über die Struktur schräg aufgedampfter Schichten und ihr Einfluß auf die Entwicklung submikroskopischer Oberflächenrauhigkeiten', Optik 6 (1950), S. 111-124.

König, Hans \& Gerhard Helwig [1951] 'Über dünne aus Kohlenwasserstoffen durch Elektronen- oder Ionenbeschuß gebildete Schichten', Zeitschrift für Physik 129 (1951), S. 491-503.

König, Hans \& Annelise Winkler [1948] 'Über Einschlüsse in Bakterien und ihre Veränderung im Elektronenmikroskop“, Die Naturwissenschaften 35 (1948), S. 136-144.

Kopfermann, Hans [1940] Kernmomente, Leipzig: Akademische Verlagsanstalt.

Kopfermann, Hans [1941] 'Magnetische Dipolstrahlung und Kernmomente', Die Naturwissenschaften 29 (1941), S. 563-571 und 581-589.

Kopfermann, Hans [1948] 'Atomspektren', in: Kopfermann (Hrsg.) [1948] S. 1-17.

Kopfermann, Hans [1949] 'Die Elektronenschleuder', Ergebnisse der exakten Naturwissenschaften 22 (1949), S. 13-72.

Kopfermann, Hans [1951] 'Kernmomente und Kernmodelle', Die Naturwissenschaften 38 (1951), S. 29-34.

Kopfermann, Hans [1952]a 'Rudolf Ladenburg †', Die Naturwissenschaften 39 (1952), S. 289-290.

Kopfermann, Hans [1952]b 'James Franck 70 Jahre', Physikalische Blätter 8 (1952), S. 411.

Kopfermann, Hans [1953] 'Konrad Gund zum Gedächtnis‘, Physikalische Blätter 9 (1953), S. 416-417.

Kopfermann, Hans (Hrsg.) [1948] Physics of the Electron Shells, Bd. 12 der Reihe: Fiat Review of German Science 1939-1946, Wiesbaden: Dieterichsche Verlagsbuchhandlung.

Kopfermann, Hans, Hubert Krüger \& Hermann Öhlmann [1949] 'Zur anomalen Feinstruktur der He ${ }^{+}-L_{i n i e}$ $\lambda=4686 \AA^{\prime}$ ', Zeitschrift für Physik 126 (1949), S. 760-768.

Kopfermann, Hans \& Dietrich Meyer [1946] 'Zur Hyperfeinstruktur des W I-Spektrums', Nachrichten der Akademie der Wissenschaften in Göttingen, Mathematisch-Physikalische Klasse (1946), S. 106.

Kopfermann, Hans \& Dietrich Meyer [1948] 'Zur Hyperfeinstruktur des WI-Spektrums', Zeitschrift für Physik 124 (1948), S. 685-690.

Kopfermann, Hans \& Christian Otzen [1941] 'Über den Stark-Effekt der Strontium-I-Resonanzlinie $\lambda=$ 4607 Å', Zeitschrift für Physik 117 (1941), S. 156-167.

Kopfermann, Hans \& Wolfgang Paul [1943] 'Über den inversen Stark-Effekt der D-Linien des Natriums', Zeitschrift für Physik 120 (1943), S. 545-552.

Kopfermann, Hans \& Wolfgang Paul [1946] 'Experimentelle Untersuchungen an einer Elektronenschleuder für $6 \mathrm{MeV}^{\star}$, Nachrichten der Akademie der Wissenschaften in Göttingen, Mathematisch-Physikalische Klasse (1946), S. 17-18.

Kopfermann, Hans \& Wilhelm Walcher [1944] 'Trennung der Thalliumisotope. II. Optische Untersuchung verschiedener Thalliumgemische‘, Zeitschrift für Physik 122 (1944), S. 465-470.

Kopfermann, Hans \& Günter Wessel [1948] 'Zum Isotopieverschiebungseffekt im Ba I-Spektrum', Nachrichten der Akademie der Wissenschaften in Göttingen, Mathematisch-Physikalische Klasse (1948), S. 53-55.

Kopfermann, Hans \& Günter Wessel [1951]a 'Die absoluten $f$-Werte der Fe I-Resonanzlinien $\lambda=3720 \AA ̊ 丿$ und $\lambda$ $=3737 \AA^{\prime} '$, Zeitschrift für Physik 130 (1951), S. 100-108.

Kopfermann, Hans \& Günter Wessel [1951]b 'Zur Isotopieverschiebung im Ba-Spektrum', Nachrichten der Akademie der Wissenschaften in Göttingen, Mathematisch-Physikalische Klasse (1951), Nr. 3, S. 1-5.

Koppe, Heinz [1946] 'Über die Kornverteilung bei Zerkleinerungsprozessen', Nachrichten der Akademie der Wissenschaften in Göttingen, Mathematisch-Physikalische Klasse (1946), S. 119-122.

Koppe, Heinz [1947]a 'Der Einfluß der Austauschenergie auf die spezifische Wärme des Elektronengases', Zeitschrift für Naturforschung 2a (1947), S. 429-432.

Koppe, Heinz [1947]b 'Die spezifische Wärme der Supraleiter nach der Theorie von W. Heisenberg', Annalen der Physik (6) 1 (1947), S. 405-414.

Koppe, Heinz [1948]a 'Der Streuquerschnitt von Atomen für unelastische Streuung schneller Elektronen', Zeitschrift für Physik 124 (1948), S. 658-664.

Koppe, Heinz [1948]b 'Die Entartung des Elektronengases durch Paarerzeugung', Annalen der Physik (6) 2 (1948), S. 103-112.

Koppe, Heinz [1949]a Die Grundlagen der statistischen Mechanik, Leipzig: Hirzel. 
Koppe, Heinz [1949]b 'Die Energieverteilung thermischer Neutronen', Zeitschrift für Physik 125 (1949), S. 5997.

Koppe, Heinz [1949]c 'Zur Theorie der unvollständigen Supraleitung', Annalen der Physik (6) 6 (1949), S. 375 380.

Koppe, Heinz [1949]d 'Nichtlineare Erweiterung der Londonschen Theorie', Zeitschrift für Naturforschung 4a (1949), S. 74-75.

Koppe, Heinz [1949]e 'On the Production of Mesons', Physical Review 76 (1949), S. 688.

Koppe, Heinz [1950] 'Theorie der Supraleitung', Ergebnisse der exakten Naturwissenschaften 23 (1950), S. 283-358.

Koppe, Heinz [1950] 'Die Reflexion einer Welle an einer Potentialschwelle', Zeitschrift für Naturforschung 5 a (1950), S. 137-139.

Koppe, Heinz [1951]a 'Die Streuung eines Teilchens an einer Potentialschwelle', Zeitschrift für Naturforschung 6a (1951), S. 229-233.

Koppe, Heinz [1951]b 'Zur phänomenologischen Theorie der Supraleitung', Zeitschrift für Naturforschung 6a (1951), S. 284-287.

Koppe, Heinz [1951]c 'Fermi-Statistik für Systeme mit Wechselwirkung', Zeitschrift für Naturforschung 6a (1951), S. 517-519.

Koppe, Heinz [1952]a 'Zur Theorie der elektrischen Leitfähigkeit von Metallen I', Zeitschrift für Naturforschung 7a (1952), S. 17-22.

Koppe, Heinz [1952]b 'Zur Theorie der elektrischen Leitfähigkeit von Metallen II', Zeitschrift für Naturforschung 7a (1952), S. 156-161.

Koppe, Heinz [1952] 'Volumenänderung von Supraleitern', Zeitschrift für Naturforschung 7a (1952), S. 445.

Korsching, Horst [1946] 'Über einige Konstanten von Zinnetramethyl und Zinnetraäthyl', Zeitschrift für Naturforschung 1 (1946), S. 219-221.

Krenzien, O. [1949]a 'Zum Durchgang langsamer Elektronen durch Alkalihalogenidkristalle', Zeitschrift für Physik 126 (1949), S. 365-376.

Krenzien, O. [1949]b 'Über die Streuung langsamer Elektronen an festen Aluminiumoberflächen', Zeitschrift für Physik 126 (1949), S. 598-600.

Krenzien, O. [1949]c 'Herstellung eines lichtelektrischen Leiters aus PbTe', Zeitschrift für Physik 126 (1949), S. 666-670.

Krüger, Hubert [1951] 'Beiträge zur Untersuchung der reinen Kernquadrupolspektrum in Kristallen', Zeitschrift für Physik 130 (1951), S. 371-384.

Krüger, Hubert \& Ulrich Meyer-Berkhout [1952]a 'Kernquadrupol-Resonanzfrequenzen von Cu-Kernen in polykristallinen Kupferverbindungen', Zeitschrift für Physik 132 (1952), S. 171-178.

Krüger, Hubert \& Ulrich Meyer-Berkhout [1952]b 'Bestimmung des magnetischen Momentes des As ${ }^{75}$-Kerns aus dem Zeeman-Effekt eines Kernquadrupol-Resonanzübergangs ', Zeitschrift für Physik 132 (1952), S. 221-230.

Krüger, Hubert \& Ulrich Meyer-Berkhout [1952]c 'Bestimmung des magnetischen Momentes des As ${ }^{75}$-Kerns aus dem Zeeman-Effekt eines Kernquadrupolresonanzübergangs', Nachrichten der Akademie der Wissenschaften in Göttingen, Mathematisch-Physikalische Klasse (1952), Nr. 1, S. 1-3.

Kuhlmann, Doris [1948] 'Die Theorie der Nachwirkungserscheinungen', Zeitschrift für Physik 124 (1948), S. 468-481.

Kuhn, Werner [1946] 'Zur Diskussion über die Homogenität des Erdinnern', Die Naturwissenschaften 33 (1946), S. 311-312.

Kuhrt, Friedrich [1951/52]a 'Das Tröpfchenmodell realer Gase', Zeitschrift für Physik 131 (1951/52), S. 185204.

Kuhrt, Friedrich [1951/52]b 'Das Tröpfchenmodell übersättigter realer Gase', Zeitschrift für Physik 131 (1951/52), S. 205-214.

Kurtze, Günther [1952] 'Untersuchung der Schallabsorption in wäßrigen Elektrolytlösungen im Frequenzbereich 3 bis $100 \mathrm{MHz}^{6}$, Nachrichten der Akademie der Wissenschaften in Göttingen, Mathematisch-Physikalische Klasse (1952), Nr. 9, S. 57-79.

Küssner, Hans Georg [1946] Principia Physica, Göttingen: Vandenhoeck \& Ruprecht.

Küssner, Hans Georg [1947] 'Die Magnetfelder der Himmelskörper', Physikalische Blätter 3 (1947), S. 411413.

Küssner, Hans Georg \& Heinz Billing [1948] 'Instationäre Strömungen', in: Betz (Hrsg.) [1948] S. 127-180.

Lamla, Ernst [1925] Grundriß der Physik. Für Naturwissenschaftler, Mediziner und Pharmazeuten, Berlin: Springer.

Lamla, Ernst [1949] 'Max von Laue', Die Naturwissenschaften 36 (1949), S. 353-354. 
Laubert, Siegfried [1941] 'Die Massenschwächungs-, Photoabsorptions- und Streukoeffizienten monochromatischer Röntgenstrahlen von Ni (28), Cu (29), Ag (47), Cd (48), Sn (50), Ta (73), W (74), Ir (77), Pt (78), Au (79) und Pb (82)', Annalen der Physik (5) 40 (1941), S. 553-578.

Laue, Max von [1919] Die Relativitätstheorie, Braunschweig: Vieweg.

Laue, Max von [1940]a 'Das elektrostatische mittlere Potential in Kristallen', Die Naturwissenschaften 28 (1940), S. 515-516.

Laue, Max von [1940]b 'Interferenz-Doppelbrechung von Röntgenstrahlen in Kristallprismen', Die Naturwissenschaften 28 (1940), S. 645-646.

Laue, Max von [1940]c Rezension von: J. M. Bijvoet, N. H. Kolkmeijer \& C. H. Mac Gillavry: Röntgenanalyse von Krystallen, Berlin: Springer, 1940, in: Die Naturwissenschaften 28 (1940), S. 566.

Laue, Max von [1940]d Rezension von: Erich Wintergeist: Die technische Physik des Kraftwagens, Berlin: Springer, 1940, in: Die Naturwissenschaften 28 (1940), S. 184.

Laue, Max von [1941]a Röntgenstrahlinterferenzen, Leipzig: Akademische Verlagsgesellschaft Becker \& Erler.

Laue, Max von [1941]b 'Zum 40 jährigen Jubiläum des Wärmestrahlungsgesetzes', Die Naturwissenschaften 29 (1941), S. 137.

Laue, Max von [1941/42] 'Über die theoretische Bedeutung der Justi-Zicknerschen Versuche über Stromverzweigungen in Supraleitern' Zeitschrift für Physik 118 (1941/42), S. 455-460.

Laue, Max von [1942]a 'Eine Ausgestaltung der Londonschen Theorie der Supraleitung', Annalen der Physik (5) 42 (1942), S. 65-83.

Laue, Max von [1942]b 'Bemerkungen zur Supraleitung', Physikalische Zeitschrift 43 (1942), S. $274-284$.

Laue, Max von [1942]c 'Statistisches über Röntgenstrahlung vieler gleichartiger Schichten', Die Naturwissenschaften 30 (1942), S. 205-207.

Laue, Max von [1942]d Rezension von: Carl Stumpf: Erkenntnislehre, Leipzig: Barth, 1939/40, in: Die Naturwissenschaften 30 (1942), S. 123-124.

Laue, Max von [1943] 'Nochmals über Stromverteilung in Supraleitern', Zeitschrift für Physik 120 (1943), S. 578-587.

Laue, Max von [1944]a Materiewellen und ihre Interferenzen, Leipzig: Akademische Verlagsgesellschaft Becker \& Erler.

Laue, Max von [1944]b Rezension von: Weizsäcker [1943]a, in: Die Naturwissenschaften 32 (1944), S. 85-87.

Laue, Max von [1944]c 'Zum 50. Todestage von Hermann v. Helmholtz', Die Naturwissenschaften 32 (1944), S. 206-207.

Laue, Max von [1945] 'Royal Society. Deutsche Physiker auf britischen Tagungen`, GUZ (1945/46), Nr. 18, S. 12.

Laue, Max von [1946]a Geschichte der Physik, Bonn: Universitäts-Verlag.

Laue, Max von [1946]b 'Eindeutigkeitssätze in der Theorie der Supraleitung', Nachrichten der Akademie der Wissenschaften in Göttingen, Mathematisch-Physikalische Klasse (1946), S. 86-88.

Laue, Max von [1946]c 'ZumGedächtnis Wilhelm Conrad Röntgens', Die Naturwissenschaften 33 (1946), S. 37. Berichtigung dazu in: ebenda, S. 128.

Laue, Max von [1946]d Rezension von Weizsäcker [1943]a, 2. Aufl., 1944, in: Die Naturwissenschaften 33 (1946), S. 29.

Laue, Max von [1946]e 'Prof. E. Regener zum 65. Geburtstag', Die Naturwissenschaften 33 (1946), S. 128.

Laue, Max von [1946]f 'Mc. Lennans Hochfrequenz-Beobachtungen an Supraleitern', Die Naturwissenschaften 33 (1946), S. 92.

Laue, Max von [1946]g 'Arnold Berliner', Die Naturwissenschaften 33 (1946), S. 257-258.

Laue, Max von [1947]a Theorie der Supraleitung, Berlin: Springer.

Laue, Max von [1947]b 'Eine Erweiterung der Theorie der Supraleitung', Die Naturwissenschaften 34 (1947), S. 186.

Laue, Max von [1947]c Rezension von: Bernhard Bavink: Was ist Wahrheit in den Naturwissenschaften?, Weisbaden: Brockhaus, 1947, in: Die Naturwissenschaften 34 (1947), S. 283.

Laue, Max von [1947]d 'Zum Jahresbeginn 1947', Physikalische Blätter 3 (1947), S. 1.

Laue, Max von [1947]e 'Otto Hahn empfing den Nobelpreis', Physikalische Blätter 3 (1947), S. 18-19.

Laue, Max von [1947]f 'Max Planck †‘, Physikalische Blätter 3 (1947), S. 249-252.

Laue, Max von [1947]g 'Die Kriegstätigkeit der deutschen Physiker', Physikalische Blätter 3 (1947), S. 424425.

Laue, Max von [1948]a 'Supraleitung und Hertzsche Schwingungen', Zeitschrift für Physik 124 (1948), S. 135143.

Laue, Max von [1948]b 'Nochmals zur Thermodynamik der Supraleitung', Annalen der Physik (6) 2 (1948), S. $183-184$.

Laue, Max von [1948]c ' Londons Theorie für nicht-kubische Supraleiter', Annalen der Physik (6) 3 (1948), S. 31-39. 
Laue, Max von [1948]d 'Supraleitung und Kristallklasse', Annalen der Physik (6) 3 (1948), S. 40-42.

Laue, Max von [1948]e 'Max Planck', Die Naturwissenschaften 35 (1948), S. 1-7.

Laue, Max von [1948]f 'Dr. Ludwig Lange. 1863-1936. (Ein zu unrecht Vergessener)‘, Die Naturwissenschaften 35 (1948), S. 191-196.

Laue, Max von [1948]g 'Röntgen- und Elektroneninterferenzen', in: Kopfermann (Hrsg.) [1948] S. 91-93.

Laue, Max von [1948] 'Vorwort zum Kosselheft der »Optik «', Optik 3 (1948), S. 101-119.

Laue, Max von [1949] 'Supraleitung und elektrodynamisches Potential', Zeitschrift für Physik 125 (1949), S. $517-530$.

Laue, Max von [1950]a 'Zur Minkowskischen Elektrodynamik der bewegten Körper', Zeitschrift für Physik 128 (1950), S. 387-394.

Laue, Max von [1950]b 'Eine nicht-lineare, phänomenologische Theorie der Supraleitung', Annalen der Physik (6) 5 (1950), S. 197-207.

Laue, Max von [1950]c Rezension von: René Descartes: Briefe 1629-1650, hrsg. von Max Bense, Köln u. a.: Staufenverlag, 1949, in: Die Naturwissenschaften 37 (1950), S. 287.

Laue, Max von [1950]d Rezension von: Max Caspar: Johannes Kepler, Stuttgart: Kohlhammer, 1948, in: Die Naturwissenschaften 37 (1950), S. 47-48.

Laue, Max von [1950] 'Lichtschwebungen', Optik 7 (1950), S. 125-127.

Laue, Max von [1952] 'Mein physikalischer Werdegang. Eine Selbstdarstellung', in: Hartmann [1952] S. 178210.

Laue, Max von [1953] 'Zum Jahresbeginn', Physikalische Blätter 9 (1953), S. 1-2.

Laue, Max von \& Robert Wichard Pohl [1948] 'Hans Geiger †', Zeitschrift für Physik 124 (1948), S. 1.

Leibfried, Günther [1940]a 'Ramaneffektuntersuchungen an Alaunkristallen', Annalen der Physik (5) 37 (1940), S. 628-630.

Leibfried, Günther [1940]b 'Notiz über die Ramanlinien von Rohrzuckerkristallen', Annalen der Physik (5) 37 (1940), S. 631-632.

Leibfried, Günther [1947] 'Über die Anwendbarkeit der Sattelpunktsmethode bei tiefen Temperaturen am Beispiel des idealen Bose-Gases', Zeitschrift für Naturforschung 2a (1947), S. 305-310.

Leibfried, Günther [1949] 'Über die auf eine Versetzung wirkenden Kräfte', Zeitschrift für Physik 126 (1949), S. 781-789.

Leibfried, Günther [1950]a 'Über den Einfluß thermisch angeregter Schallwellen auf die plastische Deformation', Zeitschrift für Physik 127 (1950), S. 344-356.

Leibfried, Günther [1950]b 'Eine mechanische Anordnung zur Messung kleiner Längenänderungen', Zeitschrift für Physik 127 (1950), S. 580-587.

Leibfried, Günther [1950]c 'Die Kondensation des idealen Bose-Gases als räumliches Phänomen II', Zeitschrift für Physik 128 (1950), S. 133-143.

Leibfried, Günther [1950]d '50 Jahre Quantentheorie', Physikalische Blätter 6 (1950), S. 554-555.

Leibfried, Günther [1951]a 'Zur atomistischen Theorie der Elektrizität', Zeitschrift für Physik 129 (1951), S. 307-316.

Leibfried, Günther [1951]b 'Verteilung von Versetzungen im statischen Gleichgewicht', Zeitschrift für Physik 130 (1951), S. 214-226.

Leibfried, Günther [1951]c Rezension von: Sauter [1942], 2. Aufl., 1950, in: Physikalische Blätter 7 (1951), S. 133-134.

Leibfried, Günther [1955]a ’Richard Becker ††', Physikalische Blätter 11 (1955), S. 319-320.

Leibfried, Günther [1955]b 'Richard Becker †', Zeitschrift für Metallkunde 46 (1955), S. 400.

Leibfried, Günther [1958] Zur Theorie idealer Kristalle, Köln: Westdeutscher Verlag.

Leibfried, Günther \& Horst-Dietrich Dietze [1949] 'Zur Theorie der Schraubenversetzung', Zeitschrift für Physik 126 (1949), S. 790-808.

Leibfried, Günther \& Horst-Dietrich Dietze [1951/52] 'Versetzungsstrukturen in kubisch-flächenzentrierten Kristallen I‘, Zeitschrift für Physik 131 (1951/52), S. 113-129.

Leibfried, Günther \& Friedrich Kaempffer [1948] 'Über ein einfaches Verfahren zur Berechnung von Zustandssummen', Zeitschrift für Physik 124 (1948), S. 441-449.

Leibfried, Günther \& Kurt Lücke [1949] 'Über das Spannungsfeld einer Versetzung', Zeitschrift für Physik 126 (1949), S. 450-464.

Luck, Werner [1949] Rezension von: Joos (Hrsg.) [1947/48], in: Zeitschrift für Naturforschung 4a (1949), S. 241.

Ludwieg, Hubert [1954] Rezension von: Oswatitsch [1952], in: Die Naturwissenschaften 41 (1954), S. 409-410.

Ludwig, Günther [1947]a 'Der Zusammenhang zwischen den Variationsprinzipien der projektiven und der vierdimensionalen Relativitätstheorie', Zeitschrift für Naturforschung 2a (1947), S. 3-5.

Ludwig, Günther [1947]b 'Skalares Materiefeld in der projektiven Relativitätstheorie mit variabler Gravitationsinvarianten', Zeitschrift für Naturforschung 2a (1947), S. 482-489. 
Ludwig, Günther [1948]a 'Zur projektiven Relativitätstheorie mit variabler Gravitationsinvarianten', Zeitschrift für Physik 124 (1948), S. 450-457.

Ludwig, Günther [1948] Rezension von: Johann Jakob Burckhardt: Die Bewegungsgruppen der Kristallographie, Basel: Birkhäuser, 1947, in: Die Naturwissenschaften 35 (1948), S. 350.

Ludwig, Günther [1949] 'Zur projektiven Relativitätstheorie mit variabler Gravitationinvarianten II. Mitteilung. Variationsprinzipien und Feldgleichungen für Gravitation und Materie‘, Zeitschrift für Physik 125 (1949), S. 545-562.

Ludwig, Günther [1950] 'Ansatz einer divergenzfreien Quantenelektrodynamik', Zeitschrift für Naturforschung 5a (1950), S. 637-641.

Ludwig, Günther [1951]a Fortschritte der projektiven Relativitätstheorie, Braunschweig: Vieweg.

Ludwig, Günther [1951]b 'Die erzwungenen Schwingungen des harmonischen Oszillators nach der Quantentheorie', Zeitschrift für Physik 130 (1951), S. 468-476.

Ludwig, Günther [1952] 'Wie kann die unitäre Feldtheorie Strahlungsemission, Selbstenergie und Lambshift erklären', Zeitschrift für Naturforschung 7a (1952), S. 248-250.

Ludwig, Günther \& Claus Müller [1948] 'Ein Modell des Kosmos und der Sternenentstehung', Annalen der Physik (6) 2 (1948), S. 76-84.

Magnus, Kurt [1942] 'Über die Anwendungen der allgemeinen Bewegungsgleichungen starrer Körper in bewegten Bezugssystemen', Zeitschrift für angewandte Mathematik und Mechanik 22 (1942), S. 336356.

Magnus, Kurt [1945/65] Der Kreisel. Eine Einführung in die Lehre vom Kreisel. Mit Anleitung zur Durchführung von Versuchen, Göttingen: Industrie-Druck (1. Aufl. 1945).

Mannkopff, Reinhold [1943]a 'Die Berechnung der Lichtbogentemperatur und das Stabilitätsproblem der Lichtbogensäule', Zeitschrift für Physik 120 (1943), S. 228-251.

Mannkopff, Reinhold [1943]b 'Über den Energietransport durch Strahlung der Resonanzlinien in Gasen', Zeitschrift für Physik 120 (1943), S. 301-317.

Martienssen, Werner [1951/52]' Photochemische Vorgänge in Alkalihalogenidkristallen', Zeitschrift für Physik 131 (1951/52), S. 488-504.

Martienssen, Werner [1952] 'Photochemische Vorgänge in Alkalihalogenidkristallen bei tiefen Temperaturen', Nachrichten der Akademie der Wissenschaften in Göttingen, Mathematisch-Physikalische Klasse (1952), Nr. 11, S. 111-116.

Martienssen, Werner \& Heinz Pick [1952] 'Zur photochemischen Sensibilisierung von KBr-Kristallen durch KH-Zusatz', Nachrichten der Akademie der Wissenschaften in Göttingen, Mathematisch-Physikalische Klasse (1952), Nr. 12, S. 117-120.

Martienssen, Werner \& Robert Wichard Pohl [1952] 'Zur photochemischen Sensibilisierung', Zeitschrift für Physik 133 (1952), S. 153-157.

Masing, Georg [1940] Grundlagen der Metallkunde in anschaulicher Darstellung, Berlin: Springer.

Masing, Georg [1948] 'Zur Theorie der Verfestigung durch plastische Deformation', Zeitschrift für Physik 124 (1948), S. 586-601.

Masing, Georg [1950] Lehrbuch der allgemeinen Metallkunde, Berlin u. a.: Springer.

Matuschka, Herbert [1958] Rezension von: Schuler [1956], in: Physikalische Blätter 14 (1958), S. 94.

Meißner, O., H. Martin \& Thomas Gengler [1931] 'Beobachtungsverfahren und Apparaturen für sehr genaue relative Schwere- und Zeitmessungen“, Angewandte Geophysik 2 (1931) Heft 2/3, S. 1-177.

Meißner, Walther [1947] Rezension von: Laue [1947]a, in: Die Naturwissenschaften 34 (1947), S. 127-128.

Meißner, Walther [1949] Rezension von: Laue [1946]a, 2. Aufl., 1947, in: Zeitschrift für angewandte Physik 1 (1949), S. 195.

Meißner, Walther [1950] Rezension von: Laue [1946]a, 3. Aufl., 1950, in: Zeitschrift für angewandte Physik 2 (1950), S. 431-432.

Meixner, Josef [1949] Rezension von: Flügge [1948]a in: Zeitschrift für angewandte Physik 1 (1949), S. 341.

Meixner, Josef [1950] Rezension von: Koppe [1949]a, in: Zeitschrift für Naturforschung 5a (1950), S. 409.

Mesmer, Gustav [1939] Spannungsoptik, Berlin: Springer.

Meyer, Dietrich [1948] 'Zur Frage der Wechselwirkung zwischen Leuchtelektronen und Kristallgitter. Absorptionsmessung am kristallinen $\mathrm{Nd}_{2} \mathrm{Zn}_{3}\left(\mathrm{NO}_{3}\right)_{12} \cdot 24 \mathrm{H}_{2} \mathrm{O}^{\prime}$, Annalen der Physik (6) 2 (1948), S. 330344.

Meyer, Erwin [1934] 'Akustik I', Die Physik in regelmäßigen Berichten 2 (1934), S. 97-122.

Meyer, Erwin [1938] 'Akustik II‘, Die Physik in regelmäßigen Berichten 6 (1938), S. 127-162.

Meyer, Erwin [1939] Electro-acoustics, London: Bell and Sons.

Meyer, Erwin [1947] 'Über den derzeitigen Stand der Theorie des Hörens', Die Naturwissenschaften 34 (1947), S. 358-362. 
Meyer, Erwin [1948] Rezension von: Winfried Otto Schumann: Elektrische Wellen. Eine Einführung in die räumliche Ausbreitung elektro-magnetischer Vorgänge, München: Hanser, 1948, in: Die Naturwissenschaften 35 (1948), S. 349.

Meyer, Erwin [1950] 'Istituto Nazionale Di Ultracustica »O. M. Corbino« in Rom‘, Die Naturwissenschaften 37 (1950), S. 136-137.

Meyer, Erwin \& Georg R. Schodder [1952] 'Über den Einfluß von Schallrückwürfen auf Richtungslokalisation und Lautstärke bei Sprache', Nachrichten der Akademie der Wissenschaften in Göttingen, MathematischPhysikalische Klasse (1952), Nr. 6, S. 31-42.

Meyer, Erwin \& Hans Severin [1949] 'Über einige Demonstrationsversuche mit elektromagnetischen Zentimeter-Wellen', Zeitschrift für Physik 126 (1949), S. 711-720.

Meyer, Peter [1949] 'Eine Bestimmung der Bindungsenergie des Deuteriumkerns und der Neutronenmasse aus dem Kernphotoeffekt am Deuterium‘, Zeitschrift für Physik 126 (1949), S. 336-343.

Meyer, Peter [1950] 'Die Energietönung $Q_{\mathrm{n} p}$ des Prozesses $\mathrm{N}^{14}$ (n, p) C $\mathrm{C}^{14 ،}$, Zeitschrift für Physik 128 (1950), S. 451-454.

Meyer-Schützmeister, Luise [1951] 'Untersuchungen des äußeren Photoeffektes am Kupferoxydul und am Kupferoxyd‘, Zeitschrift für Physik 129 (1951), S. 148-160.

Mises, Richard von [1916/36] Fluglehre. Vorträge über Theorie und Berechnung der Flugzeuge in elemantarer Darstellung, 5. Aufl. neu bearbeitet von Kurt Hohenemser, Berlin: Springer, 1936.

Molière, Gert \& Fritz Sauter [1952] 'Zur Theorie der Vielfachstreuung geladener Teilchen“, Zeitschrift für Naturforschung 7a (1952), S. 280-282.

Mollwo, Erich [1939] 'Über lichtelektrische Ersatzleitung in Alkalihalogenid-Kristallen', Nachrichten von der Gesellschaft der Wissenschaften zu Göttingen, Mathematisch-Physikalische Klasse, Neue Folge, Fachgruppe II (1939), S. 149-155.

Mollwo, Erich [1941] 'Über die Ausscheidung von Gasen in Alkalihalogenidkristallen', Nachrichten der Akademie der Wissenschaften in Göttingen, Mathematisch-Physikalische Klasse (1941), S. 51-58.

Mollwo, Erich [1942] 'Ein einfacher Apparat zur Vorführung der Gruppengeschwindigkeit', Physikalische Zeitschrift 43 (1942), S. 256-258.

Mollwo, Erich [1943]a 'Zum Nachweis von Interferenzerscheinungen durch Streuteilchen im Interferenzfeld', Zeitschrift für Physik 120 (1943), S. 618-626.

Mollwo, Erich [1943]b 'Über Elektronen- und Ionenleitung in Alkalihalogenidkristallen', Nachrichten der Akademie der Wissenschaften in Göttingen, Mathematisch-Physikalische Klasse (1943), S. 91-103.

Mollwo, Erich [1944] 'Das ultraviolette Absorptionsspektrum der Sulfide und Oxyde von Zink und Kadmium', Reichsberichte für Physik 1 (1944), S. 1-4.

Mollwo, Erich [1948]a 'Die Lage der ultravioletten Absorptionskante in geschmolzenen Alkalihalogeniden', Zeitschrift für Physik 124 (1948), S. 118-120.

Mollwo, Erich [1948]b 'Quantitatives zur lichtelektrischen Leitung in Zinkoxyd', Annalen der Physik (6) 3 (1948), S. 230-239.

Mollwo, Erich [1948/49] 'Zur spektralen »Zerlegung« durch Dispersion', Optik 4 (1948/49), S. 450-453.

Mollwo, Erich [1954] 'Robert Wichard Pohl 70 Jahre', Physikalische Blätter 10 (1954), S. 375.

Mollwo, Erich [1959] 'R. W. Pohl zum 75. Geburtstag', Physikalische Blätter 15 (1959), S. 369.

Mollwo, Erich \& Robert Wichard Pohl [1941] 'Zur quantitativen Bestimmung kleiner Zusätze an Alkalihalogenidkristallen', Annalen der Physik (5) 39 (1941), S. 321-325.

Mollwo, Erich \& Fritz Stöckmann [1948]a 'Über die elektrische Leitfähigkeit von Zinkoxyd', Annalen der Physik (6) 3 (1948), S. 223-229.

Mollwo, Erich \& Fritz Stöckmann [1948]b 'Eine quantitative Deutung der elektrischen und lichtelektrischen Leitfähigkeit von Zinkoxyd auf Grund des Massenwirkungsgesetzes', Annalen der Physik (6) 3 (1948), S. 240-254.

Moritz, Ernst [1949] Rezension von: Weizsäcker [1948]a, in: Physikalische Blätter 5 (1949), S. 192.

Moritz, Ernst [1950] Rezension von: Laue [1946]a, 3. Aufl., 1950, in: Physikalische Blätter 6 (1950), S. 520521.

Müller, F. Horst [1940] Rezension von: Pohl [1940]a in: Physikalische Zeitschrift 41 (1940), S. 448-449.

Müller, R. [1952] Rezension von: Laue [1919], 5. Aufl., Bd. 1: Relativitätsprinzip der Lorentz-Transformation, Braunschweig: Vieweg, 1951, in: Zeitschrift für angewandte Physik 4 (1952), S. 240.

Mußmann, Heinrich \& Heinz Schlechtweg [1940] 'Drehmoment kubischer Rekristallisationstexturen im Magnetfeld', Annalen der Physik (5) 38 (1940), S. 215-231.

Naumann, Alexander [1956] Rezension von: Betz (Hrsg.) [1948], Aufl. von 1953, in: Physikalische Blätter 12 (1956), S. 189.

Oehme, Reinhard [1951] 'Erzeugung von Photonen beim Zusammenstoß von Nukleonen', Zeitschrift für Physik 129 (1951), S. 573-610. 
Oswatitsch, Klaus [1945] 'Der Luftwiderstand als Integral des Entropiestromes', Nachrichten der Akademie der Wissenschaften in Göttingen, Mathematisch-Physikalische Klasse (1945), S. 88-90.

Oswatitsch, Klaus [1952] Gasdynamik, Wien: Springer.

Paul, Wolfgang [1941] 'Eine Atomstrahlapparatur zur lichtstarken Anregung schwer verdampfbarer Elemente', Zeitschrift für Physik 117 (1941), S. 774-788.

Paul, Wolfgang [1943] 'Das Isotopenmischungsverhältnis von Silber', Die Naturwissenschaften 31 (1943), S. 419

Paul, Wolfgang [1948]a 'Eine Methode zur Bestimmung von Oszillatorenstärken (f-Werten) aus dem Starkeffekt', Zeitschrift für Physik 124 (1948), S. 121-128.

Paul, Wolfgang [1948]b 'Ein Massenspektrometer zur Bestimmung von Isotopen-Mischverhältnissen', Zeitschrift für Physik 124 (1948), S. 244-257.

Paul, Wolfgang [1948]c 'Experimentelle Arbeiten über das Betatron', in: Bothe \& Flügge (Hrsg.) [1948] S. 4960.

Paul, Wolfgang [1949] 'Spaltung des Deuterons durch Elektronenstoß', Die Naturwissenschaften 36 (1949), S. 31-32.

Paul, Wolfgang und M. Pahl [1944] 'Massenspektroskopische Atomgewichtsbestimmungen an natürlichem und angereichertem Kalium', Die Naturwissenschaften 32 (1944), S. 228-229.

Paul, Wolfgang \& Herbert Reich [1950] 'Energieverlust schneller Elektronen in Be, C, $\mathrm{H}_{2} \mathrm{O}, \mathrm{Fe}$ und $\mathrm{Pb}^{\text {', }}$ Zeitschrift für Physik 127 (1950), S. 429-442.

Paul, Wolfgang \& Herbert Reich [1951/52] 'Einzelstreuung von schnellen Elektronen um große Winkel', Zeitschrift für Physik 131 (1951/52), S. 326-330.

Paul, Wolfgang \& Gerhard Schubert [1950] 'Physikalische Vorgänge und biologische Wirkungen in mit schnellen Elektronen bestrahlten Objekten', Die Naturwissenschaften 37 (1950), S. 156-163.

Paul, Wolfgang \& Günter Wessel [1948] 'Messung von Dichte und mittlerer Molkulargeschwindigkeit in einem Atomstrahl', Zeitschrift für Physik 124 (1948), S. 691-699.

Petroff, St. [1950] 'Photochemische Beobachtungen an KCl-Kristallen', Zeitschrift für Physik 127 (1950), S. 443-454.

Philipp, Kurt [1950] Rezension von: Heisenberg [1943]a, 3. Aufl., 1949, in: Physikalische Blätter 6 (1950), S. 135-136.

Pick, Heinz [1938] 'Über den Einfluss der Temperatur auf die Erregung von Farbzentren', Annalen der Physik (5) 31 (1938), S. 365-376.

Pick, Heinz [1939] 'Über die Farbzentren in KCl-Kristallen mit kleinen Zusätzen von Erdalkalichloriden', Annalen der Physik (5) 35 (1939), S. 73-83.

Pick, Heinz [1940] 'Die Quantenausbeute des optischen Abbaues der F'-Bande in Alkalihalogenidkristallen', Annalen der Physik (5) 37 (1940), S. 421-428.

Pick, Heinz [1948] 'Über lichtelektrische Leitung am Bleisulfid', Annalen der Physik (6) 3 (1948), S. 255-269.

Pick, Heinz [1949] 'Herstellung spiegelnder Niederschläge durch chemische Reaktionen', Zeitschrift für Physik 126 (1949), S. 12-19.

Pick, Heinz [1951] 'Der photographische Elementarprozeß', Die Naturwissenschaften 38 (1951), S. 323-330.

Pick, Heinz [1954] 'Festkörperphysik', Die Naturwissenschaften 41 (1954), S. 346-354.

Pick, Heinz \& Robert Wichard Pohl [1951] 'Zur Stabilisierung der photochemischen Reaktionsprodukte in Ionenkristallen', Zeitschrift für Naturforschung 6a (1951), S. 360-363.

Pick, Heinz \& Heinrich Weber [1950] 'Dichteänderung von KCl-Kristallen durch Einbau zweiwärtiger Ionen', Zeitschrift für Physik 128 (1950), S. 409-413.

Planck, Max [1946] 'Persönliche Erinnerungen aus alten Zeiten', Die Naturwissenschaften 33 (1946), S. 230235.

Pohl, Robert [1912] Die Physik der Röntgenstrahlen, Braunschweig: Vieweg.

Pohl, Robert \& Peter Pringsheim [1914] Die lichtelektrischen Erscheinungen, Braunschweig: Vieweg.

Pohl, Robert Wichard [1927] Einführung in die Elektrizitätslehre, Berlin: Springer.

Pohl, Robert Wichard [1930] Einführung in die Physik. Bd. 1: Einführung in die Mechanik und Akustik, Berlin u. a.: Springer.

Pohl, Robert Wichard [1931] 'Über den Bumerang', Die Naturwissenschaften 19 (1931), S. 789-790.

Pohl, Robert Wichard [1938] 'Zusammenfassender Bericht über Elektronenleitung und photochemische Vorgänge in Alkalihalogenidkristallen', Physikalische Zeitschrift 39 (1938), S. 36-54.

Pohl, Robert Wichard [1940]a Einführung in die Physik. Bd. 3: Einführung in die Optik, Berlin u. a.: Springer.

Pohl, Robert Wichard [1940]b 'Ein neuer Versuch zur Interferenz divergierender Lichtbündel', Physikalische Zeitschrift 41 (1940), S. 498-499.

Pohl, Robert Wichard [1940]c 'Ein einfacher Interferenzversuch mit divergierenden Lichtbündeln', Die Naturwissenschaften 28 (1940), S. 585-586. 
Pohl, Robert Wichard [1940]d Rezension von: Eduard Rüchard: Sichtbares und unsichtbares Licht, Berlin: Springer, 1938, in: Die Naturwissenschaften 28 (1940), S. 286.

Pohl, Robert Wichard [1942]a 'Zur Definition der Loschmidtschen Zahl', Physikalische Zeitschrift 43 (1942), S. 125-128.

Pohl, Robert Wichard [1942]b 'Über die mit dem Wort Mol gebildeten Begriffe', Physikalische Zeitschrift 43 (1942), S. 531-533.

Pohl, Robert Wichard [1943] 'Nebenbegriffe und Gasgesetz', Zeitschrift für Physik 121 (1943), S. 543-545.

Pohl, Robert Wichard [1948] 'Die elektrischen Einheiten', Physikalische Blätter 4 (1948), S. 190-193.

Pohl, Robert Wichard [1949] 'Zur Winkelmessung', Physikalische Blätter 5 (1949), S. 115-116.

Pohl, Robert Wichard [1950] Zur Darstellung der Elektrizitätslehre. Eine Erwiderung, Göttingen: Musterschmidt.

Pohl, Robert Wichard [1951]a 'Dosierung von Röntgenlicht', Die Naturwissenschaften 38 (1951), S. 147-150.

Pohl, Robert Wichard [1951]b 'Grundgrößen und abgeleitete Größen', Die Naturwissenschaften 38 (1951), S. 247-248.

Pohl, Robert Wichard [1951]c 'Nachweis stehender Wellen im freien Schallfeld und ein einfacher Empfänger für kurze Schallwellen', Die Naturwissenschaften 38 (1951), S. 486-490.

Pohl, Robert Wichard [1951]d 'Electron Traps and Electron Conduction in Irradiated Alkali Halide Crystals', in: Henisch (Hrsg.) [1951] S. 106-113.

Pohl, Robert Wichard [1952]a 'Die Bedeutung von Kristallfehlern für die Physik fester Körper', Die Naturwissenschaften 39 (1952), S. 9-13.

Pohl, Robert Wichard [1952]b 'Physik und Schule', Die Naturwissenschaften 39 (1952), S. 535-537.

Pohl, Robert Wichard \& Fritz Stöckmann [1944]a 'Zur Behandlung der Stoffmenge als Grundgröße', Zeitschrift für Physik 122 (1944), S. 534-538.

Pohl, Robert Wichard \& Fritz Stöckmann [1944]b 'Zur Anwendung des Gleichheitszeichens', Zeitschrift für Physik 122 (1944), S. 680-685.

Pohl, Robert Wichard \& Fritz Stöckmann [1947] 'Die Rolle sekundärer Elektronen bei der lichtelektrischen Leitung', Annalen der Physik (6) 1 (1947), S. 275-284.

Pohl, Robert Wichard \& Fritz Stöckmann [1948] 'Zur Empfindlichkeitsgrenze der Strahlungsempfänger', Annalen der Physik (6) 3 (1948), S. 199-200.

Pohl, Robert Wichard \& Fritz Stöckmann [1949] 'Zur Verstärkung von Elektronenströmen in bestrahlten Kristallen', Annalen der Physik (6) 6 (1949), S. 89-92.

Planck, Max [1946] 'Scheinprobleme der Wissenschaft', Neue Physikalische Blätter 2 (1946), S. 161-168.

Prager, Willy \& Kurt Hohenemser [1933] Dynamik der Stabwerke. Eine Schwingungslehre für Bauingenieure, Berlin: Springer.

Prandtl, Ludwig [1931] Abriß der Strömungslehre, Braunschweig: Vieweg.

Prandtl, Ludwig [1942] Führer durch die Strömungslehre, Braunschweig: Vieweg.

Prandtl, Ludwig [1945] 'Über ein neues Formelsystem für die ausgebildete Turbulenz', Nachrichten der Akademie der Wissenschaften in Göttingen, Mathematisch-Physikalische Klasse (1945), S. 6-19.

Prandtl, Ludwig [1946] 'Zur Berechnung des Wetterablaufs', Nachrichten der Akademie der Wissenschaften in Göttingen, Mathematisch-Physikalische Klasse (1946), S. 102-105.

Prandtl, Ludwig [1947] 'Zum Wesen der Oberflächenspannung', Annalen der Physik (6) 1 (1947), S. 59-64.

Prandtl, Ludwig [1948]a 'Turbulenz', in: Betz (Hrsg.) [1948] S. 1-20.

Prandtl, Ludwig [1948]b 'Mein Weg zu Hydrodynamischen Theorien', Physikalische Blätter 4 (1948), S. 89-92.

Prandtl, Ludwig [1949] 'Betrachtungen zur Rheologie', Physikalische Blätter 5 (1949), S. 161-172.

Rajewsky, Boris \& Michael Schön (Hrsg.) [1948] Biophysics, Part II, Bd. 22 der Reihe: Fiat Review of German Science 1939-1946, Wiesbaden: Dieterichsche Verlagsbuchhandlung.

Reich, Herbert [1951] 'Die Messung der Einzelstreuung schneller Elektronen', Zeitschrift für Physik 130 (1951), S. 144-158.

Rellich, Franz [1945] 'Der Eindeutigkeitssatz für die Lösungen der quantenmechanischen Vertauschungsrelationen (Inhaltsangabe)', Nachrichten der Akademie der Wissenschaften in Göttingen, Mathematisch-Physikalische Klasse (1945), S. 73.

Rellich, Franz [1946] 'Der Eindeutigkeitssatz für die Lösungen der quantenmechanischen Vertauschungsrelationen', Nachrichten der Akademie der Wissenschaften in Göttingen, MathematischPhysikalische Klasse (1946), S. 107-115.

Rellich, Franz [1950] Rezension von: Betz [1948]a, in: Die Naturwissenschaften 37 (1950), S. 94-95.

Riegels, Friedrich-Wilhelm [1949] Rezension von: Prandtl [1942], 3. Aufl., 1949, in: Physikalische Blätter 5 (1949), S. 294.

Riezler, Wolfgang [1949] Rezension von: Schubert [1947] in: Zeitschrift für angewandte Physik 1 (1949), S. 342 . 
Rögener, Heinz [1940] 'Einfluß von Feldstärke und Wellenlänge auf den lichtelektrischen Primärstrom in NaClund KCl-Kristallen', Nachrichten von der Gesellschaft der Wissenschaften zu Göttingen, MathematischPhysikalische Klasse, Neue Folge, Fachgruppe II (1940), S. 219-225.

Rohn, Karl [1949] 'Herstellung dünner Metall- und Salzschichten durch Aufdampfen im Vakuum', Zeitschrift für Physik 126 (1949), S. 20-26.

Rosa, Anne-Marie [1943] 'Über die Absorptionsspektren einiger wasserhaltiger Salze des Dysprosiums', Annalen der Physik (5) 43 (1943), S. 161-181.

Rubbert, Friedrich Karl [1950]a 'Erzwungene Pendelschwingungen endlicher Amplitude', Zeitschrift für Physik 127 (1950), S. 72-84.

Rubbert, Friedrich Karl [1950]b 'Zur Theorie des sphärischen Pendels', Zeitschrift für Physik 128 (1950), S. 5671.

Rubbert, Friedrich Karl [1950]c 'Zur Theorie des momentfreien Kreisels‘, Annalen der Physik (6) 5 (1950), S. $237-250$.

Rüchardt, Eduard [1949] Rezension von: Pohl [1927], 13. und 14. Aufl., 1949, in: Zeitschrift für angewandte Physik 1 (1949), S. 533-534.

Ryde, Nils [1952] Rezension von: Hellwege [1949]a, in: Zeitschrift für Naturforschung 7a (1952), S. 500.

Saur, Eugen [1942]a 'Experimentelle Untersuchungen über die Feinstruktur der Röntgenabsorptionskanten. I. Die Feinstruktur der TiK-Absorptionskante von Titan und einfachen Titanverbindungen', Annalen der Physik (5) 42 (1942), S. 223-240.

Saur, Eugen [1942]b 'Experimentelle Untersuchungen über die Feinstruktur der Röntgenabsorptionskanten. II. Die Feinstruktur der VK-Absorptionskante von Vanadin und einfachen Vanadinverbindungen', Annalen der Physik (5) 42 (1942), S. 348-356.

Saur, Eugen \& Ostap Stasiw [1938] 'Einfluss geringer Fremdionenzusätze auf die Gitterkonstante von Alkalihalogenidkristallen', Nachrichten von der Gesellschaft der Wissenschaften zu Göttingen, Mathematisch-Physikalische Klasse, Neue Folge, Fachgruppe II (1938), S. 77-83.

Sauter, Anneliese \& Fritz Sauter [1944] 'Die Erzeugung von möglichst homogenen Magnetfeldern durch Stromsysteme', Zeitschrift für Physik 122 (1944), S. 120-136.

Sauter, Fritz [1942] Differentialgleichungen der Physik, Berlin: De Gruyter.

Sauter, Fritz [1942] 'Zur Theorie der metallischen Elektrizitätsleitung', Annalen der Physik (5) 42 (1942), S. 110-141.

Sauter, Fritz [1943]a 'Über die verschiedenen Darstellungsmöglichkeiten eines homogenen elektrischen Feldes in der Wellenmechanik', Annalen der Physik (5) 43 (1943), S. 404-416.

Sauter, Fritz [1943]b 'Gibt es Dichtemaxima der freien Elektronen im Metallgitter?', Die Naturwissenschaften 31 (1943), S. 302-303.

Sauter, Fritz [1948] Rezension von: Otto Hahn: Künstliche neue Elemente, Weinheim: Verlag Chemie, 1948, in: Die Naturwissenschaften 35 (1948), S. 223.

Sauter, Fritz [1949]a 'Über die elektronentheoretische Begründung der Maxwell-Gleichungen in der Materie', Zeitschrift für Physik 126 (1949), S. 207-223.

Sauter, Fritz [1949]b 'Über die Zustandsgleichung verdünnter realer Gase', Annalen der Physik (6) 6 (1949), S. 59-66.

Sauter, Fritz [1949]c 'Zur Statistik bei Elektronenvervielfachern', Zeitschrift für Naturforschung 4a (1949), S. 682-691.

Sauter, Fritz [1949]d Rezension von: Gustav Mie: Lehrbuch der Elektrizität und des Magnetismus, Stuttgart: Enke, 1948, in: Die Naturwissenschaften 36 (1949), S. 128.

Sauter, Fritz [1949]e Rezension von: Erich Lange: Chemische Thermodynamik, Stuttgart: Hirzel, 1949, in: Die Naturwissenschaften 36 (1949), S. 349-350.

Sauter, Fritz [1949]f Rezension von: Wolfgang Finkelnburg: Einführung in die Atomphysik, Berlin u. a.: Springer, 1948, in: Die Naturwissenschaften 36 (1949), S. 382-383.

Sauter, Fritz [1950]a 'Über die Reflexion elastischer Wellen an der Grenzfläche eines festen Mediums', Zeitschrift für angewandte Mathematik und Mechanik 30 (1950), S. 94-95.

Sauter, Fritz [1950]b 'Der flüssige Halbraum bei einer mechanischen Beeinflussung seiner Oberfläche. (Zweidimensionales Problem)', Zeitschrift für angewandte Mathematik und Mechanik 30 (1950), S. 149153.

Sauter, Fritz [1950]c 'Der elastische Halbraum bei einer mechanischen Beeinflussung seiner Oberfläche.

(Zweidimensionales Problem)', Zeitschrift für angewandte Mathematik und Mechanik 30 (1950), S. 203215.

Sauter, Fritz [1950]d Rezension von: Paul Gombás: Die statistische Theorie des Atoms und ihre Anwendungen, Wien: Springer, 1949, in: Die Naturwissenschaften 37 (1950), S. 213. 
Sauter, Fritz [1950]e Rezension von: Fritz Oberhettinger und Wilhelm Magnus: Anwendung der elliptischen Funktionen in Physik und Technik, Berlin u. a.: Springer, 1949, in: Die Naturwissenschaften 37 (1950), S. 237.

Sauter, Fritz [1950]f Rezension von: Laue [1944]a, 2. Aufl., 1948, in: Die Naturwissenschaften 37 (1950), S. 237.

Sauter, Fritz [1950]g Rezension von: Laue [1947]a, 2. Aufl, 1949, in: Die Naturwissenschaften 37 (1950), S. 263.

Sauter, Fritz [1950]h Rezension von: Becker [1941], Bd. 1, 14. Aufl., Bd. 2, 7. Aufl., 1949, in: Die Naturwissenschaften 37 (1950), S. 479.

Sauter, Fritz [1950]i Rezension von: Fritz Emde: Quirlende elektrische Felder, Braunschweig: Vieweg, 1949, in: Die Naturwissenschaften 37 (1950), S. 528.

Sauter, Fritz [1950]j Rezension von: Joos (Hrsg.) [1948], in: Die Naturwissenschaften 37 (1950), S. 547.

Sauter, Fritz [1950]k Rezension von: Hans Falkenhagen: Die Grundlagen der theoretischen Physik, Band: Optik, Stuttgart: Hirzel, 1949, in: Die Naturwissenschaften 37 (1950), S. 548.

Sauter, Fritz [1951]a Rezension von: Erwin Madelung: Die mathematischen Hilfsmittel des Physikers, 4. Aufl., Berlin u. a.: Springer, 1950, in: Die Naturwissenschaften 38 (1951), S. 103.

Sauter, Fritz \& H. Wanke [1952] 'Zur Theorie der Vielvachstreuung geladener Teilchen', Zeitschrift für Naturforschung 7a (1952), S. 33-39.

Schaefer, Clemens [1944] Rezension von: Heisenberg [1935], 3. Aufl., 1942, in: Die Naturwissenschaften 32 (1944), S. 87.

Schaefer, H. \& Wilhelm Walcher [1943] 'Negative Ionen in Braunschen Röhren und ihr Zusammenhang mit dem Oxydkathoden-Mechanismus', Zeitschrift für Physik 121 (1943), S. 679-701.

Scherrer, Paul [1942] Rezension von: Laue [1941]a in: Physikalische Zeitschrift 43 (1942), S. 72.

Schimank, Hans [1947] Rezension von: Laue [1946]a, in: Die Naturwissenschaften 34 (1947), S. 60-61.

Schimank, Hans [1948] Rezension von: Laue [1946]a, in: Physikalische Blätter 4 (1948), S. 77-78.

Schlichting, Hermann [1951] Grenzschicht-Theorie, Karlsruhe: Braun.

Schlögl, Friedrich [1949] 'Der (e, n)-Prozeß am Deuteron', Zeitschrift für Naturforschung 4a (1949), S. 664671.

Schmermund, Hans-Joachim, H. Bleek \& H. L. Heinrich [1950] 'Chromosomenveränderungen bei Gerstenkeimlingen durch schnelle Elektronen eines $6 \mathrm{MeV}$-Betatrons', Strahlentherapie 81 (1950), S. 177-186.

Schmillen, Albert [1941] 'Über den quadratischen Zeemaneffekt der Linien des Europiumsulfats', Annalen der Physik (5) 39 (1941), S. 502-511.

Schoch, Arnold [1949] Rezension von: Lothar Cremer: Die wissenschaftliche Grundlagen der Raumakustik, Bd. 1: Geometrische Raumakustik, Stuttgart: Hirzel, 1948, in: Die Naturwissenschaften 36 (1949), S. 221.

Schoch, Arnold [1950] 'Schallreflexion, Schallbrechung und Schallbeugung', Ergebnisse der exakten Naturwissenschaften 23 (1950), S. 127-234.

Schoch, Arnold [1952] 'Zur Frage nach dem Impuls einer Schallwelle', Zeitschrift für Naturforschung 7a (1952), S. 273-279.

Schoch, Arnold \& Helmut Steinwedel [1952] 'Zum Energie-Impuls-Tensor linearer klassischer Feldtheorien', Zeitschrift für Naturforschung 7a (1952), S. 66-70.

Schubert, Gerhard [1947]a Kernphysik und Medizin, Göttingen: Muster-Schmidt.

Schubert, Gerhard [1947]b Rezension von: Laue [1947]a, in: Zeitschrift für Naturforschung 2a (1947), S. 475476.

Schubert, Gerhard [1947]c 'Erfahrungen und Ergebnisse von Untersuchungen mit künstlich radioaktiven Indikatoren', Strahlentherapie 76 (1947), S. 389-406.

Schubert, Gerhard [1949] 'Die Strahlenanalyse biologischer Elementarstrukturen', Strahlentherapie 80 (1949), S. 1-16.

Schubert, Gerhard U. [1950]a Rezension von: Laue [1947]a, 2. Aufl., 1949, in: Zeitschrift für angewandte Physik 2 (1950), S. 192.

Schubert, Gerhard U. [1950]b Rezension von: Koppe [1949]a, in: Zeitschrift für angewandte Physik 2 (1950), S. 472.

Schubert, Gerhard U. [1952] Rezension von: Flügge [1947], I. Teil: Elementare Quantenmechanik, in: Zeitschrift für angewandte Physik 4 (1952), S. 37.

Schubert, Gerhard \& Wolfgang Riezler [1946] 'Lokale Hautschädigungen durch Einwirkung von Deuteronen`, Die Naturwissenschaften 33 (1946), S. 285-286.

Schubert, Gerhard \& Wolfgang Riezler [1947] 'Zur biologischen Wirkung injizierter künstlich radioaktiver Substanzen', Strahlentherapie 76 (1947), S. 407-416. 
Schubert, Gerhard, Wolfgang Riezler \& Viktor Dubrauszky [1947] 'Zur Frage der Strahlenbeeinflussung der Haut durch Deuteroneneinwirkung', Strahlentherapie 76 (1947), S. 417-424.

Schubert, Hedwig [1941] 'Die relative Energieverteilung im Kontinuum von Unterflüssigkeitsfunken zwischen 9000 und $5000 \AA `$ ', Annalen der Physik (5) 39 (1941), S. 295-307.

Schüler, Hermann [1941] Rezension von: Kopfermann [1940], in: Die Naturwissenschaften 29 (1941), S. 340.

Schuler, Max [1909] 'Mathematischer Anhang zu dem Vortrag von Anschütz-Kaempfe über »Der Kreisel als Richtungsweiser "', Jahrbuch der Schiffbautechnischen Gesellschaft 10 (1909), S. 561-576.

Schuler, Max [1922]a 'Einwirkung periodischer Momente auf den Kreiselkompaß' (Dissertation TH München), Zeitschrift für angewandte Mathematik und Mechanik 2 (1922), Heft 4, S. 5-33.

Schuler, Max [1922]b 'Der Kreiselkompaß unter Einfluß der Schiffsschwingungen', Zeitschrift für angewandte Mathematik und Mechanik 2 (1922), S. 233-250.

Schuler, Max [1923] 'Die Störung von Pendel- und Kreiselapparaten durch die Beschleunigung des Fahrzeuges', Physikalische Zeitschrift 24 (1923), S. 344-350.

Schuler, Max [1924] 'Der Kreisel als Richtungsweiser', Zeitschrift für Geophysik 1 (1924), S. 59-65.

Schuler, Max [1927]a 'Ein neues Pendel mit unveränderlicher Schwingungszeit', Zeitschrift für Physik 42 (1927), S. 547-554.

Schuler, Max [1927]b 'Schwankungen in der Länge des Tages', Zeitschrift für Geophysik (1927).

Schuler, Max [1927]c 'Resonanzerscheinungen beim Schlingertank', in: Verhandlungen des 2. Internationalen Kongresses für technische Mechanik, Zürich 1926, Orell Füssli, Zürich 1927, S. 219-224.

Schuler, Max [1928] 'Schlingertank und Schiffskreisel, die Mittel zur Verringerung der Schlingerbewegung', Werft-Reederei-Hafen 9 (1928), S. 277-282.

Schuler, Max [1929]a 'Kreisellehre', in: Erich Waetzmann (Hrsg.): Müller-Pouillet. Lehrbuch der Physik, Bd. 1, Mechanik punktförmiger Massen und starrer Körper, Braunschweig: Vieweg 11. Aufl., 1929, S. 731-848.

Schuler, Max [1929]b 'Ein neues Pendel mit unveränderlicher Schwingungszeit', Zeitschrift für technische Physik 10 (1929), S. 392-395.

Schuler, Max [1929]c 'Eine Berichtigung der Gleichungen des Schlingertanks', Zeitschrift für technische Physik 10 (1929), S. 369-373.

Schuler, Max [1929]d 'Die Fehler unserer Zeitmessung und ein Vorschlag zur Verbesserung der astronomischen Uhren', Physikalische Zeitschrift 30 (1929), S. 884-887.

Schuler, Max [1930] 'Betrachtungen über die Stabilität bewegter Systeme', Physikalische Zeitschrift 31 (1930), S. 849-856.

Schuler, Max [1931]a 'Die Stabilität bewegter Systeme', Die Naturwissenschaften 19 (1931), S. 419-421.

Schuler, Max [1931]b 'Die Notwendigkeit eines Normalmaßes der Zeit und meine bisherigen Erfolge beim Schaffen einer Zeitnormale', Zeitschrift für technische Physik 12 (1931), S. 678-684.

Schuler, Max [1931]c 'Störungen von Pendeluhren durch Erdbeben', Astronomische Nachrichten 243 (1931), S. 301-304.

Schuler, Max [1931]d 'Die Wichtigkeit eines Normalmaßes der Zeit', Feinmechanik und Präzision 39 (1931), S. 205-208.

Schuler, Max [1932]a 'Die Berechnung der Gleichgewichtslage von gemessenen Schwingungen auf Grund der Fehlertheorie', Zeitschrift für angewandte Mathematik und Mechanik 12 (1932), S. 152-156.

Schuler, Max [1932]b 'Das freie unveränderliche Pendel an der Sternwarte zu Göttingen', Schriftenreihe der Gesellschaft für Zeitmeßkunde und Uhrentechnik 4 (1932), S. 199-219.

Schuler, Max [1933] 'Der Umschlag von Oberflächenwellen', Zeitschrift für angewandte Mathematik und Mechanik 13 (1933), S. 443-446.

Schuler, Max [1935]a 'Die Föpplsche Methode zur Lösung von Kreiselproblemen', Zeitschrift für angewandte Mathematik und Mechanik 15 (1935), S. 88-91.

Schuler, Max [1935]b 'Die bisherigen Gangergebnisse der Uhr mit Ausgleichspendel an der UniversitätsSternwarte in Göttingen', Schriftenreihe der Gesellschaft für Zeitmeßkunde und Uhrentechnik 6 (1935), S. 95-106.

Schuler, Max [1935]c 'Bisherige Gangergebnisse der Uhr mit Ausgleichspendel an der Sternwarte zu Göttingen', Deutsche Uhrmacher-Zeitung 59 (1935), S. 57-58, 91-93.

Schuler, Max [1936] 'Erzeugung von Oberflächenwellen durch schwingende Körper', Zeitschrift für angewandte Mathematik und Mechanik 16 (1936), S. 65-72.

Schuler, Max [1938]a 'Pendule partiellement équilibré de l'Université de Göttingen', Annales françaises de Chronométrie 8 (1938), S. 23-42.

Schuler, Max [1938]b 'Nouvelles contributions à l'étude du Pendule partiellement équilibré de l'Université de Göttingen', Annales françaises de Chronométrie 8 (1938), S. 287-296.

Schuler, Max [1938]c 'Sur les définitions des Chronomètres des Montres de précision et des Horoges de précision', Annales françaises de Chronométrie 8 (1938), S. 297-299. 
Schuler, Max [1939]a 'Gangergebnisse der Schuleruhren zu Göttingen im Jahre 1937‘, Schriftenreihe der Gesellschaft für Zeitmeßkunde und Uhrentechnik 10 (1939), S. 85-100.

Schuler, Max [1939]b 'Gangergebnisse der Schuleruhren zu Göttingen im Jahre 1937', Deutsche UhrmacherZeitung 63 (1939), S. 335-336, 347-349.

Schuler, Max [1947/48] 'Conservation de l'heure et son importance', Annales Guébhard-Séverine 23/24 (1947/48), S. 45-51.

Schuler, Max [1949] Mechanische Schwingungslehre. Teil 1: Einfache Schwinger, Wolfenbüttel u. a.: Wolfenbütteler Verlags-Anstalt.

Schuler, Max [1950]a Einführung in die Mechanik. Teil 1: Mechanik des Massenpunktes, Wolfenbüttel: Kracke.

Schuler, Max [1950]b 'Sprungweise Längenänderungen des Invars', Schweizer Zeitschrift für Vermessungswesen 48 (1950), S. 140-150.

Schuler, Max [1951] a Einführung in die Mechanik. Teil 2: Mechanik der Punktsysteme, Wolfenbüttel: Kracke.

Schuler, Max [1951]b 'Sprungweise Längenänderungen des Invars', Mitteilungen des Markscheidewesen 58 (1951), S. 138-148.

Schuler, Max [1956] Einführung in die Theorie der selbsttätigen Regler, Leipzig: Akademische Verlagsgesellschaft Geest \& Portig.

Schuler, Max [1959] Mechanische Schwingungslehre. Teil 2: Mehrfache Schwinger, Leipzig: Akademische Verlagsgesellschaft Geest \& Portig.

Schuler, Max [1962]a 'Die geschichtliche Entwicklung des Kreiselkompasses in Deutschland. Teil 1: Schiffskreiselkompasse', VDI Zeitschrift 104 (1962), Nr. 11, S. 469-476.

Schuler, Max [1962]b 'Die geschichtliche Entwicklung des Kreiselkompasses in Deutschland. Teil 2: Flugzeugund Vermessungskreisel, selbsttätige Schiffssteuerung, Hilfsgeräte', VDI Zeitschrift 104 (1962), Nr. 13, S. 593-599.

Schuler, Max \& August Dimpker [1935] 'Über die Druckfestigkeit von Kristallen`, Zeitschrift für Instrumentenkunde 55 (1935), S. 63-70.

Schuler, Max \& Hans Gebelein [1955]a Acht- und neunstellige Tabellen zu den elliptischen Funktionen. Dargestellt mittels des Jacobischen Parameters q. Mit einem englischen Text von Lauritz S. Larsen, Berlin u. a.: Springer.

Schuler, Max \& Hans Gebelein [1955]b Fünfstellige Tabellen zu den elliptischen Funktionen Dargestellt mittels des Jacobischen Parameters q. Mit einem englischen Text von Lauritz S. Larsen, Berlin u. a.: Springer.

Schuler, Max \& Heinrich Gockel [1938] 'Über eine neue Schuler-Uhr mit Selbstantrieb und die Gangleistungen zweier Schuler-Pendel von Mai bis September 1937‘, Zeitschrift für Physik 109 (1938), S. 433-458.

Schuler, Max \& Heinrich Gockel [1939] 'Bemerkungen zu der Arbeiten von R. d'E. Atkinson: Über Gangsprünge der Uhren in Greenwich und Göttingen', Zeitschrift für Physik 111 (1939), S. 680-682.

Schuler, Max \& Kurt Magnus [1939] 'Dämpfungsarten für die Schwingungen des Kreiselhorizontes und ihre Wirkungen im Kurvenflug', Luftfahrt-Forschung 16 (1939), S. 318-325.

Schuler, Max \& Herbert Wolf [1954] 'Zur Bestimmung der wahrscheinlichsten Gleichgewichtslage bei ungedämpften und gedämpften Schwingungen', Mitteilungen des Markscheidewesen 61 (1954), S. 97108.

Schultz, Walter [1951] 'Energieverlust schneller Elektronen beim Durchgang durch Folien (Vielfachstreuung)', Zeitschrift für Physik 129 (1951), S. 530-546.

Schultz-Grunow, Fritz [1949] Einführung in die Festigkeitslehre, Düsseldorf-Lohausen: Werner.

Schultz-Grunow, Fritz [1950] Rezension von: Prandtl [1942] 3. Aufl., 1949, in: Die Naturwissenschaften 37 (1950), S. 24.

Schumann, Günther [1955] Rezension von: Kopfermann (Hrsg.) [1948], Aufl. von 1953, in: Physikalische Blätter 11 (1955), S. 40-41.

Schütz, Wilhelm [1954] Rezension von: Pohl [1941], 12. Aufl., 1953, in: Physikalische Blätter 10 (1954), S. 138-139.

Seeliger, Rudolf [1942] Rezension von: Joos [1932] 3. Aufl., 1939, in: Physikalische Zeitschrift 43 (1942), S. 30 .

Severin, Hans [1946] 'Beugung elektromagntischer Zentimeterwellen an metallischen Blenden', Zeitschrift für Naturforschung 1 (1946), S. 487-495.

Severin, Hans [1947] 'Absorptionsspektren einiger wasserhaltiger Salze des Erbiums', Annalen der Physik (6) 1 (1947), S. 41-58.

Severin, Hans [1949] 'Absorptionsspektrum und Strahlungsfelder des Ho ${ }^{+++}$-Ions in festen Salzen', Zeitschrift für Physik 125 (1949), S. 455-474.

Severin, Hans [1950]a 'Der Schlitzstrahler, ein magnetischer Dipol für Zentimeterwellen', Zeitschrift für Physik 128 (1950), S. 108-119.

Severin, Hans [1950]b 'Beugung elektromagnetischer Zentimeterwellen an metallischen Kreisscheiben', Zeitschrift für angewandte Physik 2 (1950), S. 499-505. 
Severin, Hans [1951] 'Zur Theorie der Beugung elektromagnetischer Wellen', Zeitschrift für Physik 129 (1951), S. 426-439.

Severin, Hans \& Walter von Baeckmann [1951] 'Beugung elektromagnetischer Zentimeterwellen an metallischen und dielektrischen Scheiben', Zeitschrift für angewandte Physik 3 (1951), S. 22-28.

Sissingh, Gerhard [1941] 'Die Berechnug der Rotoren von Drehflügelflugzeugen bei höheren Fortschrittsgraden mit bsonderer Berücksichtigung der Probleme des Schnellfluges', Jahrbuch der deutschen Luftfahrtforschung 18 (1941), S. I 351- I 366.

Sissingh, Gerhard [1945] Beiträge zur Dynamischen Stabilität der Drehflügelflugzeuge mit gelenkig angeschlossenen Blättern, AVA-Bericht.

Sissingh, Gerhard [1946] Überblick über die deutsche Entwicklung und Forschung auf dem Gebiete derDrehflügelflugzeuge, Göttingen: AVA-Monografien N1-N4.

Sommerfeld, Arnold [1940] Rezension von: Pohl [1940]a, in: Die Naturwissenschaften 28 (1940), S. 726.

Sommerfeld, Arnold [1946] Rezension von: Jordan [1933], 2. Aufl., 1944, in: Die Naturwissenschaften 33 (1946), S. 96.

Steinwedel, Helmut [1952]a 'Zur Massenstabilität des Elektrons in linearen Verallgemeinerungen der klassischen Elektrodynamik', Zeitschrift für Naturforschung 7a (1952), S. 205-206.

Steinwedel, Helmut [1952]b '»Runaway-Solutions« und Quantenelektrodynamik', Zeitschrift für Naturforschung 7a (1952), S. 292-293.

Stellmacher, Karl [1937] 'Zum Anfangswertproblem der Gravitationsgleichungen', Mathematische Annalen 115 (1937), S. 136-152.

Stellmacher, Karl [1938]a 'Ausbreitungsgesetze für charakteristische Singularitäten der Gravitationsgleichungen', Mathematische Annalen 115 (1938), S. 740-783.

Stellmacher, Karl [1938]b 'Fehlerbestimmung eines Kreiselhorizontes auf Schiffen mit Hilfe des Scheinlotes', Werft-Reederei-Hafen 19 (1938), S. 42-44.

Stellmacher, Karl [1938]c 'Kreiselrechnung im Komplexen', Bericht der Schwingungstagung des VDI in Göttingen, Oktober 1938, S. 4.

Stellmacher, Karl [1939]a 'Zum Schulerschen Prinzip von der beschleunigungsfreien Abstimmung', Zeitschrift für angewandte Mathematik und Mechanik 19 (1939), S. 154-165.

Stellmacher, Karl [1939]b 'Zum Schulerschen Prinzip von der beschleunigungsfreien Abstimmung. Zuschrift zu der Veröffentlichung von E. Schmid »Bemerkungen zum Pendel von 84 Minuten Schwingungsdauer« Jahrbuch 1938 der Deutschen Luftfahrtforschung S. III 8‘, Luftfahrt-Forschung 16 (1939), S. 247-250.

Steudel, Andreas [1952]a 'Die Hyperfeinstruktur im Pb I-Spektrum und die Kernmomente des Pd ${ }^{105}$, Zeitschrift für Physik 132 (1952), S. 429-445.

Steudel, Andreas [1952]b 'Die Hyperfeinstruktur der Pb I-Linie $\lambda 4058$ Á', Zeitschrift für Physik 133 (1952), S. 438-442.

Stille, Ulrich [1951] Rezension von: Pohl [1950], in: Physikalische Blätter 7 (1951), S. 93-94.

Stöckmann, Fritz [1946] 'Zum selektiven Grenzschicht-Photoeffekt der Alkalimetalle', Nachrichten der Akademie der Wissenschaften in Göttingen, Mathematisch-Physikalische Klasse (1946), S. 6-8.

Stöckmann, Fritz [1949] 'Die physikalischen Grundlagen der Kristallzähler', Die Naturwissenschaften 36 (1949), S. 82-86.

Stöckmann, Fritz [1950]a 'Über die elektrische Leitfähigkeit von Zinkoxyd', Zeitschrift für Physik 127 (1950), S. 563-579.

Stöckmann, Fritz [1950]b 'Theorie der elektrischen Leitung in Mischleitern', Zeitschrift für Physik 128 (1950), S. 185-211.

Stöckmann, Fritz [1950]c 'Über die Elektrizitätsleitung in Halbleitern', Die Naturwissenschaften 37 (1950), S. 85-89 und 105-111, Nachtrag, ebenda, S. 523.

Stöckmann, Fritz [1951] 'Über Valenzhalbleiter', Die Naturwissenschaften 38 (1951), S. 151-154.

Stöckmann, Fritz [1951]b 'Strahlungslose Elektronenübergänge in Kristallen', Zeitschrift für Physik 130 (1951), S. $477-479$

Stöckmann, Fritz [1952] 'Zur Physik der Kristallphosphore', Die Naturwissenschaften 39 (1952), S. 226-233 und 246-254.

Stuke, Joseph [1947] Zur Eigenleitung elektronischer Halbleiter, Dissertation Göttingen, 1947.

Suess, Hans E., Otto Haxel \& J. Hans D. Jensen [1949] 'Zur Interpretation der ausgezeichneten Nucleonenzahlen im Bau der Atomkerne', Die Naturwissenschaften 36 (1949), S. 153-155.

Tamm, Konrad [1952] 'Schallabsorptionsmessungen in Wasser und in wässerigen Elektrolytlösungen im Frequenzbereich $5 \mathrm{kHz}$ bis $1 \mathrm{MHz}^{`}$, Nachrichten der Akademie der Wissenschaften in Göttingen, Mathematisch-Physikalische Klasse (1952), Nr. 10, S. 81-110.

Teucher, Martin [1949] 'Über das Primärspektrum der schnellen Neutronen einer (Ra $\alpha+\mathrm{Be})$-Quelle und deren unelastische Stöße in Be, Bi und Pb', Zeitschrift für Physik 126 (1949), S. 410-421. 
Timoféeff-Ressovsky, Nikolaj Wladimirowic [1942] Rezension von: Jordan [1942]a in: Physikalische Zeitschrift 43 (1942), S. 332.

Thiessen, Georg [1940] 'Elementarprozesse der Magnetisierung im Gebiet der Anfangssuszeptibilität', Annalen der Physik (5) 38 (1940), S. 153-176. Berichtigung dazu in: Annalen der Physik (5) 39 (1941), S. 30.

Thomas, Hans [1940] 'Zur Photochemie des KH-KBr-Mischkristalles', Annalen der Physik (5) 38 (1940), S. 601-608.

Tollmien, Walter [1948] 'Laminare Grenzschichten‘, in: Betz (Hrsg.) [1948] S. 21-54.

Tollmien, Walter [1949] Rezension von: Richard von Mises \& Theodor von Kármán: Advances in Applied Mechanics, New York: Academic Press, 1948, in: Die Naturwissenschaften 36 (1949), S. 255-256.

Tollmien, Walter [1950]a Rezension von: Walther Kaufmann: Einführung in die technische Mechanik, Bd. 1: Statik starrer Körper, Berlin u. a.: Springer, 1949, in: Die Naturwissenschaften 37 (1950), S. 479.

Tollmien, Walter [1950]b Rezension von: Theodor Pöschl: Lehrbuch der technischen Mechanik für Ingenieure und Physiker, Bd. 1: Statik und Dynamik, Berlin u. a.: Springer, 1949, in: Die Naturwissenschaften 37 (1950), S. 478-479.

Tollmien, Walter [1955]a '50 Jahre Grenzschichtforschung, ihre Entwicklung und Problematik', in: Görtler \& Tollmien (Hrsg.) [1955] S. 1-12.

Tollmien, Walter [1955]b Rezension von: Schlichting [1951], in: Die Naturwissenschaften 42 (1955), S. 81-82.

Trurnit, Hans Jochen \& Walter Hoppe [1946] 'Über Linsen für Röntgenstrahlen', Nachrichten der Akademie der Wissenschaften in Göttingen, Mathematisch-Physikalische Klasse (1946), S. 29-32.

Trurnit, Hans Jochen \& Walter Hoppe [1947] 'Geometrie und Kristallphysik einer Röntgenlinse für monochromatische Strahlung', Zeitschrift für Naturforschung 2a (1947), S. 608-615.

Vogt, Eckhart [1949] Rezension von: Pohl [1927], 13. und 14. Aufl., 1949, und Pohl [1940]a, 7. und 8. Aufl., 1948, in: Zeitschrift für Naturforschung 4a (1949), S. 723.

Voth, Gerhard [1942] 'Die Intensitätsverhältnisse der K-Serienlinien bei den Schwerelementen $\mathrm{Re}(75) \mathrm{bis} \mathrm{Pb}$ (82)', Annalen der Physik (5) 41 (1942), S. 375-408.

Walcher, Wilhelm [1938] 'Über einen Massenspektrographen hoher Intensität und die Trennung der Rubidiumisotope', Zeitschrift für Physik 108 (1938), S. 376-390.

Walcher, Wilhelm [1939] 'Isotopentrennung', Ergebnisse der exakten Naturwissenschaften 18 (1939), S. 155228.

Walcher, Wilhelm [1943]a 'Über die Verwendungsmöglichkeiten der Kunsman-Anode zur massenspektroskopischen Isotopentrennung', Zeitschrift für Physik 121 (1943), S. 604-613.

Walcher, Wilhelm [1943]b 'Der Einfluß der Raumladung auf die Abbildungseigenschaften magnetischer Sektorfelder', Zeitschrift für Physik 121 (1943), S. 719-728.

Walcher, Wilhelm [1944]a 'Über eine Ionenquelle für massenspektroskopische Isotopentrennung', Zeitschrift für Physik 122 (1944), S. 62-85.

Walcher, Wilhelm [1944]b 'Trennung der Thalliumisotope. I. Massenspektroskopische Trennung', Zeitschrift für Physik 122 (1944), S. 401-406.

Walcher, Wilhelm [1948] 'Isotopentrennung in kleinen Mengen', in: Bothe \& Flügge (Hrsg.) [1948] S. 94-107.

Walcher, Wilhelm [1949] Rezension von: Heisenberg (Hrsg.) [1943], in: Zeitschrift für Naturforschung 4a (1949), S. 643.

Walcher, Wilhelm [1950] Rezension von: Ludwig Bergmann \& Clemens Schaefer: Lehrbuch der Experimentalphysik, Bd. 1: Mechanik, Akustik, Wärmelehre, 2. und 3. Aufl., Berlin: Walter de Gruyter, 1945, in: Die Naturwissenschaften 37 (1950), S. 568.

Walkenhorst, Wilhelm [1947] 'Ein einfaches Verfahren zur Herstellung strukturloser Trägerschichten aus Aluminiumoxyd‘, Die Naturwissenschaften 34 (1947), S. 373.

Weber, Heinrich [1951]a 'Die Verfärbung von MgO-Kristallen durch gittereigene Bausteine', Zeitschrift für Physik 130 (1951), S. 392-402.

Wein, Hermann [1950] Rezension von: Weizsäcker [1948]a, in: Die Naturwissenschaften 37 (1950), S. 22-24.

Weizsäcker, Carl Friedrich von [1937] 'Ist in der Gegenwart eine systematische Einheit der Wissenschaft möglich?‘, Die Tatwelt 13 (1937), S. 68-79.

Weizsäcker, Carl Friedrich von [1939] 'Methode der Physik', Die Tatwelt 15 (1939), S. 97-105.

Weizsäcker, Carl Friedrich von [1941]a 'Die Physik der Gegenwart und das physikalische Weltbild', Die Naturwissenschaften 29 (1941), S. 185-194.

Weizsäcker, Carl Friedrich von [1941]b 'Das Verhältnis der Quantenmechanik zur Philosophie Kants', Die Tatwelt 17 (1941), S. 66-98.

Weizsäcker, Carl Friedrich von [1941/42] 'Zur Deutung der Quantenmechanik', Zeitschrift für Physik 118 (1941/42), S. 489-509.

Weizsäcker, Carl Friedrich von [1943]a Zum Weltbild der Physik, Leipzig: Hirzel.

Weizsäcker, Carl Friedrich von [1943]b 'Stoßerzeugung durch Mesonen', in: Heisenberg (Hrsg.) [1943] S. 6878. 
Weizsäcker, Carl Friedrich von [1943]c 'Theorie der Mesonen“, in: Heisenberg (Hrsg.) [1943] S. 90-110.

Weizsäcker, Carl Friedrich von [1943]d 'Deutung einer Auswahlregel für Neutronen- und Protronenemission aus Kernen ungerader Ladung', Die Naturwissenschaften 31 (1943), S. 207-208.

Weizsäcker, Carl Friedrich von [1945/83]a 'Versuch einer Geschichtskonstruktion`, in: Weizsäcker [1983] S. 221-237.

Weizsäcker, Carl Friedrich von [1945/83]b 'Zur Beurteilung des deutschen Geistes', in: Weizsäcker [1983] S. 238-273.

Weizsäcker, Carl Friedrich von [1946] 'Die Entstehung des Planetensystems ‘, Die Naturwissenschaften 33 (1946), S. 8-14.

Weizsäcker, Carl Friedrich von [1947]a 'Das Experiment', Studium Generale 1 (1947/48), S. 3-9.

Weizsäcker, Carl Friedrich von [1947]b Rezension von: Hans Adolf Bauer: Grundlagen der Atomphysik. Eine Einführung in das Studium der Wellenmechanik, 3. Aufl., Wien: Springer, in: Die Naturwissenschaften 34 (1947), S. 91-92.

Weizsäcker, Carl Friedrich von [1948]a 'Das Spektrum der Turbulenz bei großen Reynoldschen Zahlen', Zeitschrift für Physik 124 (1948), S. 614-627.

Weizsäcker, Carl Friedrich von [1948]b 'Die obere Grenze der Größe der Spiralnebel', Die Naturwissenschaften 35 (1948), S. 188-189.

Weizsäcker, Carl Friedrich von [1948/56] Die Geschichte der Natur, 3. Aufl., Göttingen: Vandenhoeck \& Ruprecht, 1956 (1. Aufl. 1948, Zürich: Hirzel).

Weizsäcker, Carl Friedrich von [1949] 'Eine Bemerkung über die Grundlagen der Mechanik', Annalen der Physik (6) 6 (1949), S. 67-68.

Weizsäcker, Carl Friedrich von [1951]a 'Kontinuität und Möglichkeit. Eine Studie über die Beziehung zwischen den Gegenständen der Mathematik und der Physik', Die Naturwissenschaften 38 (1951), S. 533-543.

Weizsäcker, Carl Friedrich von [1951]b 'Anwendungen der Hydrodynamik auf Probleme der Kosmogonie', in: Festschrift zur Feier des zweihundertjährigen Bestehens der Akademie der Wissenschaften in Göttingen, I Mathematisch-Physikalische Klasse, Berlin u.a.: Springer, 1951, S. 86-122.

Weizsäcker, Carl Friedrich von [1952]a Physik der Gegenwart, Bonn: Athenäum-Verlag.

Weizsäcker, Carl Friedrich von [1952]b 'Eine Frage über die Rolle der quadratischen Metrik in der Physik', Zeitschrift für Naturforschung 7a (1952), S. 141.

Weizsäcker, Carl Friedrich von [1952]c 'Werner Heisenberg zum 50. Geburtstag', Zeitschrift für Naturforschung 7a (1952), S. 1.

Weizsäcker, Carl Friedrich von [1952/83] 'Ein Brief über den Nationalsozialismus‘, in: Weizsäcker [1983] S. 274-309.

Weizsäcker, Carl Friedrich von [1955] 'Komplementarität und Logik', Die Naturwissenschaften 42 (1955), S. 521-529 und 545-555.

Weizsäcker, Carl Friedrich von [1957] Die Verantwortung der Wissenschaft im Atomzeitalter, Göttingen: Vandenhoeck \& Ruprecht.

Wessel, Günter [1949] 'Messung der Oszillatorenstärke der Bariumresonanzlinie', Zeitschrift für Physik 126 (1949), S. 440-449.

Wessel, Günter [1951] 'Messung von Dampfdrucken und Kondensationskeoffizienten an Eisen, Cadmium und Silber', Zeitschrift für Physik 130 (1951), S. 539-548.

Westphal, Wilhelm [1950] Rezension von: Laue [1946]a, 3. Aufl., 1950, in: Zeitschrift für Naturforschung 5a (1950), S. 472.

Wieghardt, Karl [1943] 'Über Kapilarwellen mit Oberflächenzähigkeit', Physikalische Zeitschrift 44 (1943), S. 101-108.

Winkler, Annelise, Mechthild Knoch \& Hans König [1951] 'Vergleichende licht- und elektronenmikroskopische Untersuchungen von Bakterien“, Die Naturwissenschaften 38 (1951), S. 241247.

Wintergerst, Erich [1950] Rezension von: Schuler [1949] in: Zeitschrift für angewandte Physik 2 (1950), S. 192.

Wirtz, Karl [1941/42] 'Über die van’t Hoffsche Theorie des Soret-Effektes', Zeitschrift für Physik 118 (1941/42), S. 510-514.

Wirtz, Karl [1942] 'Spezifisches Gewicht von $\mathrm{D}_{2} \mathrm{O}$ bei verschiedenen Temperaturen', Die Naturwissenschaften 30 (1942), S. 330-332.

Wirtz, Karl [1943]a 'Die Entstehung der Mesonen', in: Heisenberg (Hrsg.) [1943] S. 38-54.

Wirtz, Karl [1943]b 'Isotopentrennung durch Thermodiffusion in Flüssigkeiten nach der kinitischen Theorie‘, Die Naturwissenschaften 31 (1943), S. 349.

Wirtz, Karl [1946]a 'Die neuen Elemente Neptunium, Plutonium, Americium und Curium', Zeitschrift für Naturforschung 1 (1946), S. 543-544.

Wirtz, Karl [1946]b 'Bremslänge der Neutronen in Kohle und schwerem Wasser', Die Naturwissenschaften 33 (1946), S. 366. 
Wirtz, Karl [1947]a 'Resonanz und Wasserstoffbindung der Carboxyl- und der Amidgruppe', Zeitschrift für Naturforschung 2a (1947), S. 264-271.

Wirtz, Karl [1947]b 'Wasserstoffbindung, Struktur und Energietransport in Proteinen', Zeitschrift für Naturforschung 2a (1947), S. 304.

Wirtz, Karl [1947]c 'Zustandsgleichung fester Körper', in: Georg Joos (Hrsg.): Physics of Solids, Bd. 8 der Reihe: Fiat Review of German Science 1939-1946, Wiesbaden: Dieterichsche Verlagsbuchhandlung, 1948, S. 189-192.

Wirtz, Karl [1947]d 'Historisches zu den Uranarbeiten in Deutschland in den Jahren 1940-1945', Physikalische Blätter 3 (1947), S. 371-379.

Wirtz, Karl [1948] 'Thermodiffussion und Überführungswärme in kondensierten Phasen', Zeitschrift für Physik 124 (1948), S. 482-500.

Wirtz, Karl [1949] Rezension von: Hermann Dänzer: Einführung in die theoretische Kernphysik, Karlsruhe: Braun, 1948, in: Die Naturwissenschaften 36 (1949), S. 189.

Wirtz, Karl [1954]a 'Kernreaktoren‘, Die Naturwissenschaften 41 (1954), S. 269-277.

Wirtz, Karl [1954]b 'Stand und Aussichten der Gewinnung mechanischer Energie aus Kernreaktionen', Physikalische Blätter 10 (1954), S. 359-369.

Witt, Horst [1950] 'Elektronenstromstöße in NaCl-Kristallen, ausgelöst durch $\alpha$-Teilchen', Zeitschrift für Physik 128 (1950), S. 442-450.

Witt, Horst [1952] 'Über die Verminderung der Kristalldichte durch Farbzentren', Nachrichten der Akademie der Wissenschaften in Göttingen, Mathematisch-Physikalische Klasse (1952), Nr. 4, S. 17-20.

Wolf, Franz [1942] 'Elektrostatische Aufladung als Problem der Metallelektronik', Annalen der Physik (5) 41 (1942), S. 103-116.

\section{Allgemeine Literatur}

Achilles, Manfred [1977] 'R. W. Pohl', Praxis der Naturwissenschaften, Physik 26 (1977), S. 155-159.

Ahlheim, Klaus [2000] Geschöntes Leben. Eine deutsche Wissenschaftlerkarriere, Hannover: Offizin.

Albert, W. \& Ch. Oehler [1969] Materialien zur Entwicklung der Hochschulen 1950 bis 1967, Hochschulforschung, Band 1.

Albrecht, Helmuth (Hrsg.) [1993] Naturwissenschaft und Technik in der Geschichte, Stuttgart: Verlag für Geschichte der Naturwissenschaft und der Technik.

Albrecht, Helmuth \& Armin Hermann [1990] 'Die Kaiser-Wilhelm-Gesellschaft im Dritten Reich', in: Vierhaus \& Brocke (Hrsg.) [1990] S. 356-406.

Albrecht, Ulrich [1994] 'Military Technology and National Socialist Ideology“, in: Renneberg \& Walker (Hrsg.) [1994] S. 88-125.

Albrecht, Ulrich, Andreas Heinemann-Grüder \& Arend Wellmann [1992] Die Spezialisten. Deutsche Naturwisenschaftler und Techniker in der Sowjetunion nach 1945, Berlin: Dietz.

Albring, Werner [1991] Gorodomlia. Deutsche Raketenforscher in Rußland, Zürich: Literaturverlag.

Alter, Peter [1990] 'Die Kaiser-Wilhelm-Gesellschaft in den deutsch-britischen Wissenschaftsbeziehungen', in: Vierhaus \& Brocke (Hrsg.) [1990] S. 727-746.

Amaldi, Edoardo [1998] 'The adventurous life of Friedrich Georg Houtermans, physicist (1903-1966)', in: Battimelli \& Paolini (Hrsg.) [1998] S. 592-695.

Anger, Hans [1960] Probleme der deutschen Universität. Bericht über eine Erhebung unter Professoren und Dozenten, Tübingen: Mohr.

Antirassismus-Referat der Studentischen Versammlung an der Friedrich-Alexander-Universität ErlangenNürnberg (Hrsg.) [1998] Ungeahntes Erbe. Der Fall Schneider/Schwerte: Persilschein für eine Lebenslüge, Aschaffenburg: Alibri.

Ardenne, Manfred von [1972/82] Ein glückliches Leben für Technik und Forschung, Berlin: Verlag der Nation, 6. Aufl. 1982.

Arendt, Hannah [1950/93] Besuch in Deutschland, Berlin: Rotbuch-Verlag.

Arndt, Karl, Gerhard Gottschalk \& Rudolf Smend (Hrsg.) [2001] Göttinger Gelehrte. Die Akademie der Wissenschaften zu Göttingen in Bildnissen und Würdigungen 1751-2001, Göttingen: Wallstein.

Ash, Mitchell G. [1995]a 'Wissenschaftswandel in Zeiten politischer Umwälzungen: Entwicklungen, Verwicklungen, Abwicklungen', Internationale Zeitschrift für Geschichte und Ethik der Naturwissenschaften, Technik und Medizin 3 (1995), S. 1-21.

Ash, Mitchell G. [1995]b 'Verordnete Umbrüche - Konstruierte Kontinuitäten: Zur Entnazifizierung von Wissenschaftlern und Wissenschaften nach 1945', Zeitschrift für Geschichtswissenschaft 43 (1995), S. 903-923.

Ash, Mitchell G. [1996] 'Denazifying scientists - and science', in: Judt \& Ciesla (Hrsg.) [1996] S. 61-80.

Ash, Mitchell G. [1999]a 'Scientific Changes in Germany 1933, 1945, 1990: Towards a Comparison', Minerva 37 (1999), S. 329-354. 
Ash, Mitchell G. [1999]b 'Mythos Humboldt gestern und heute - Zur Einführung‘, in: Ash (Hrsg.) [1999] S. 725.

Ash, Mitchell G. [2000]a 'Emigration und Wissenschaftswandel als Folgen der nationalsozialistischen Wissenschaftspolitik', in: Kaufmann (Hrsg.) [2000] S. 610-631.

Ash, Mitchell G. [2000]b 'Krise der Moderne oder Modernität als Krise? Stimmen aus der Akademie‘, in: Fischer (Hrsg.) [2000] S. 121-142.

Ash, Mitchell G. (Hrsg.) [1999] Mythos Humboldt. Vergangenheit und Zukunft der deutschen Universitäten, Wien: Böhlau.

Ash, Mitchell G. \& Alfons Söllner [1996] 'Introduction: Forced Migration and Scientific Change after 1933', in: Ash \& Söllner (Hrsg.) [1996] S. 1-19.

Ash, Mitchell G. \& Alfons Söllner (Hrsg.) [1996] Forced Migration and Scientific Change. Emigre GermanSpeaking Scientists and Scholars after 1933, Cambridge u. a.: Cambridge University Press.

AutorInnenkollektiv für Nestbeschmutzung [1996] Schweigepflicht. Eine Reportage. Der Fall Schneider und andere Versuche, nationalsozialistische Kontinuitäten in der Wissenschaftsgeschichte aufzudecken, Münster: Unrast, 2. Aufl., 1996.

Bähr, Johannes, Paul Erker \& Geoffrey Giles [1996] 'The Politics of Ambiguity: Reparations, Buisness Relations, Denazification and the Allied Transfer of Technology‘, in: Judt \& Ciesla (Hrsg.) [1996] S. 131-144.

Bahrdt, Hans Paul [1988] 'Studium in Göttingen in der Zeit nach 1945', in: Göttingen ohne Gänseliesel: Texte und Bilder zur Stadtgeschichte, hrsg. von Kornelia Duwe im Auftrag der Geschichtswerkstatt Göttingen e.V., Gudensberg-Gleichen: Wartberg, 1988, S. 203-211.

Balfour, Michael [1959] Vier-Mächte-Kontrolle in Deutschland 1945-1946, Düsseldorf: Droste.

Bartholomé, Ernst [1950] 'Arnold Eucken †', Die Naturwissenschaften 37 (1950), S. 481-483.

Battimelli, Giovanni \& Giovanni Paolini (Hrsg.) [1998] $20^{\text {th }}$ Century Physics: Essays and Recollections. A Selection of Historical Writings by Edoardo Amaldi, Singapore u. a.: World Scientific.

Bäumer-Schleinkofer, Änne [1994] 'Wissenschaftsgeschichte als Mittel der politischen Indioktrination: Physikund Chemiegeschichte im Schulunterricht im Dritten Reich‘, in: Meinel \& Voswinckel (Hrsg.) [1994] S. 282-294.

Baumgarten, Marita [1993] 'Zur Sozialgeschichte der Hochschullehrer im 19. Jahrhundert am Beispiel der Gießener Universität: Berufungswandel, Universitätssystem und das Verhältnis zu den Technischen Hochschulen', in: Kertz (Hrsg.) [1993], S. 43-56.

Beck, Friedrich [1959] 'Max von Laue zum 80. Geburtstag', Physikalische Blätter 15 (1959), S. 446-452.

Beck, F. \& W. Godin [1951] Russian Purge and the Extraction of Confession, London u. a.: Hurst \& Blackett.

Becke-Goehring, Margot \& Margaret Eucken [1995] Arnold Eucken: Chemiker-Physiker-Hochschullehrer. Glanzvolle Wissenschaft in zerbrechender Zeit, Berlin: Springer.

Becker, Heinrich [1987/98] 'Von der Nahrungssicherung zu Kolonialträumen: Die landwirtschaftlichen Institute im Dritten Reich‘, in: Becker, Dahms \& Wegeler (Hrsg.) [1987/98] S. 630-656.

Becker, Heinrich, Hans-Joachim Dahms \& Cornelia Wegeler (Hrsg.) [1987/98] Die Universität Göttingen unter dem Nationalsozialismus, München: Saur, 2. Aufl., 1998.

Becker, Josef [1949] Von der Bauakademie zur Technischen Universität. 150 Jahre technisches Unterrichtswesen in Berlin, Berlin.

Becker, Josef, Theo Stammen \& Peter Waldmann (Hrsg.) [1979] Vorgeschichte der Bundesrepublik Deutschland. Zwischen Kapitulation und Grundgesetz, München: Wilhelm Fink.

Beckhough, Harry [1990] 'The Role of the British University Control Officer in Post-War Germany', in: Heinemann (Hrsg.) [1990]a S. 85-99.

Behrens, Helmut [1998] Wissenschaft in turbulenter Zeit. Erinnerungen eines Chemikers an die Technische Hochschule München 1933-1953, München: Institut für Geschichte der Naturwissenschaften.

Bell, Frank Coffman [1969] 'Schuler's Principle and Inertial Navigation', Annals of the New York Academy of Science 147 (1969), S. 493-513.

Benecke, Theodor \& A. W. Quick (Hrsg.) [1957] History of German Guided Missiles Development, Braunschweig: E. Appelhans \& Co.

Bennewitz, Hans Gerhard (Hrsg.) [1973] Professor Dr. Ing. Wolfgang Paul zum sechzigsten Geburtstag, Physikalisches Institut der Universität Bonn.

Benz, Wolfgang (Hrsg.) [1998] Jüdisches Leben in der Weimarer Republik/Jews in the Weimar Republic, Tübingen: Mohr Siebeck.

Benz, Wolfgang, Hermann Graml \& Hermann Weiß (Hrsg.) [1997/98] Enzyklopädie des Nationalsozialismus, München: dtv, 1998 (1. Aufl. 1997).

Berghahn, Volker R. [1995] 'Technologieexport und amerikanische Industriekultur im Nachkriegsdeutschland', in: Frieß \& Steiner (Hrsg.) [1995] S. 49-56.

Bergmann, Gerhard [1951] 'Das Korporationsstudententum‘, Deutscher Hochschulführer 1951, hrsg. vom Verband Deutscher Studentenschaften, S. 197-200. 
'Bericht über die Entwicklung des Universitätsbundes in den Jahren 1945 bis 1947`, in: Universitätsbund Göttingen e. V., Jg. 25, Mitteilungen 1947, S. 33-34.

'Bericht über die Tätigkeit des Universitätsbundes in den Jahren 1948 und 1949‘, in: Universitätsbund Göttingen e. V., Jg. 26, Mitteilungen 1949, S. 17-18.

Bernal, John Desmond [1939/86] Die soziale Funktion der Wissenschaft, hrsg. von Helmut Steiner, Köln: PahlRugenstein, 1986.

Bernal, John Desmond [1947] 'The British Association of Scientific Workers', Physikalische Blätter 3 (1947), S. 303-305.

Bernhardi, Horst [1957] 'Die Göttinger Burschenschaft 1933 bis 1945. Ein Beitrag zur studentischen Geschichte in der nationalsozialistischen Zeit‘, in: Wentzck (Hrsg.) [1957] S. 205-247.

Bernhardi, Horst [1963] 'Neue studentische Gemeinschaften an der Universität Göttingen in den Jahren 1945 bis 1950‘, Der Convent 14 (1963), S. 202-213.

Bernhardt, Hannelore [1993] 'Skizzen zu Leben und Werk von Richard Mises‘, in: Kerber (Hrsg.) [1993] S. 5162.

Bernhardt, Markus [1990] Giessener Professoren zwischen Drittem Reich und Bundesrepublik. Ein Beitrag zur hessischen Hochschulgeschichte 1945-1957, Gießen: Ferbersche Universitäts-Buchhandlung.

Bernhardt, Markus [1994] 'Professoren in der NSDAP - ein sozialgeschichtiliches Modell zur sogenannten „Selbst“-Gleichschaltung der Hochschulen am Beispiel der Universität Gießen“, in: Kertz (Hrsg.) [1994] S. 37-52.

Betz, Albert [1957] 'Aus der Geschichte der Aerodynamischen Versuchsanstalt Göttingen. Erinnerungen zu ihrem 50-jährigen Bestehen“, Jahrbuch der Max-Planck-Gesellschaft zur Förderung der Wissenschaften e. V. 1957, S. 40-59.

Betz, Albert [1961] 'Aerodynamische Versuchsanstalt Göttingen e. V. in der Max-Planck-Gesellschaft z. F. d. W. in Göttingen‘, Jahrbuch der Max-Planck-Gesellschaft zur Förderung der Wissenschaften e. V. 1961, Teil II, S. 3-15.

Beuermann, Gustav \& Gunther von Minnigerode [2001] 'Die Sammlung historischer physikalischer Apparate im I. Physikalischen Institut', in: Hoffmann \& Maack-Rheinländer (Hrsg.) [2001] S. 182-187.

Beyerchen, Alan D. [1980/82] Wissenschaftler unter Hitler. Physiker im Dritten Reich, Frankfurt a. M. u. a.: Ullstein, 1982 (1. deutsche Auflage Köln: Kiepenheuer \& Witsch, 1980).

Beyerchen, Alan D. [1996] 'Emigration from Country and Discipline: The Journey of a German Physicist into American Photosynthesis Research', in: Ash \& Söllner (Hrsg.) [1996] S. 71-85.

Beyler, Richard H. [1994] From Positivism to Organicism: Pascual Jordan's Interpretation of Modern Physics in Cultural Context, Dissertation Cambridge, Massachusetts, Harvard University.

Beyler, Richard H. [1996]a 'The concept of specialisation in debates on the role of science in post-war Germany: A preliminary analysis‘, in: Hoffmann, Bevilacqua \& Stuewer (Hrsg.) [1996] S. 389-401.

Beyler, Richard H. [1996]b 'Targeting the Organism. The Scientific and Cultural Context of Pascual Jordan's Quantum Biology, 1932-1947‘, Isis 87 (1996), S. 248-273.

Beyler, Richard H. [1999] 'Evolution als Problem für Quantenphysiker', in: Rainer Brömer, Uwe Hoßfeld \& Nicolaas A. Rupke (Hrsg.): Evolutionsbiologie von Darwin bis heute, Berlin: Verlag für Wissenschaft und Bildung, 1999, S. 137-160.

Beyler, Richard H. \& Morris F. Low [2003] 'Science Policy in Post-1945 West Germany and Japan', in: Walker (Hrsg.) [2003] S. 97-123.

Biagioli, Mario [1992] 'Science, Modernity, and the »Final Solution«", in: Friedlander (Hrsg.) [1992] S. 185205.

Biagioli, Mario (Hrsg.) [1998] The Science Studies Reader, New York u. a.: Routledge.

Bickenbach, Werner [1947] 'Heinrich Martius zum 60. Geburtstag', Strahlentherapie 76 (1947), S. 339-341.

Billstein, Reinhold [1984] Neubeginn ohne Neuordnung. Dokumente und Materialien zur politischen Weichenstellung in den Westzonen nah 1945, Köln: Pahl-Rugenstein.

Bird, Geoffrey [1978] 'The Universities', in: Hearnden (Hrsg.) [1978] S. 146-157.

Bird, Geoffrey [1981] 'Wiedereröffnung der Universität Göttingen‘, in: Heinemann (Hrsg.) [1981] S. 167-171.

Bird, Geoffrey [1983] 'Educational Reconstruction of the Universities in the British Zone', in: Phillips (Hrsg.) [1983] S. 93-95.

Birke, Adolf M. [1984] 'Geschichtsauffassung und Deutschlandbild im Foreign Office Research Department', in: Wendt (Hrsg.) [1984] S. 171-197.

Bludau, Dietrich \& Peter Kaltenbach [1955] Anschütz \& Co GmbH 1905-1955, Kiel: Anschütz \& Co.

Bock, Klaus Dieter [1972] Strukturgeschichte der Assistentur, Düsseldorf: Bertelsmann.

Bock, Ulla, Anne Braszeit \& Christiane Schmerl (Hrsg.) [1983] Frauen an den Universitäten. Zu Situation von Studentinnen und Hochschullehrerinnen in der männlichen Wissenschaftshirarchie, Frankfurt a. M., New York: Campus. 
Boedeker, Elisabeth \& Maria Meyer-Plath [1974] 50 Jahre Habilitation von Frauen in Deutschland. Eine Dokumentation über den Zeitraum von 1920-1970, Göttingen: Otto Schwartz.

Boehling, Rebecca [1994] 'Geschlechterpolitik in der US-Besatzungszone unter besonderer Berücksichtigung der Kommunalpolitik', in: Clemens (Hrsg.) [1994] S. 69-82.

Böhme, Ernst [1998] 'Operation »big dog« in Göttingen. Die Währungsreform von 1948 und die Deutschlandpolitik nach 1945', Göttinger Jahrbuch 1998, S. 139-147.

Böhnigk, Volker [2002] Kulturanthropologie als Rassenlehre. Nationalsozialistische Kulturphilosophie aus der Sicht des Philosophen Erich Rothacker, Würzburg: Königshausen \& Neumann.

Bolck, Franz (Hrsg.) [1982] Sektion Physik. Zur Physikentwicklung nach1945 an der Friedrich-SchillerUniversität Jena, Jenaer Reden und Schriften der Friedrich-Schiller-Universität Jena 1982.

Bollmann, Erika [1956] 'Ende und neuer Beginn', in: Erinnerungen und Tatsachen. Die Kaiser-WilhelmGesellschaft zur Förderung der Wissenschaften, Göttingen-Berlin, 1945/1946, Stuttgart: Thieme, 1956, S. 9-46.

Bollnow, Hermann [1950] 'Bericht der Universität Göttingen', Studium Generale 3 (1950), Heft 2/3, S. 155162.

Bookmann, Hartmut [1994] 'Die Verfassung der Georg-August-Universität von den Anfängen bis 1968', in: Schlotter (Hrsg.) [1994] S. 11-24.

Born, Max [1962] 'James Franck', Physikalische Blätter 20 (1964), S. 324-327.

Born, Max [1965] Von der Verantwortung des Naturwissenschaftlers, München: Nymphenburger.

Born, Max [1975] Mein Leben. Die Erinnerungen des Nobelpreisträgers, München: Nymphenburger Verlagshandlung.

Bourdieu, Pierre [1987/93] Sozialer Sinn. Kritik der theoretischen Vernunft, Frankfurt a. M.:Suhrkamp, 1. Aufl. 1993.

Bourdieu, Pierre [1988/98] Homo academicus, Frankfurt a. M.:Suhrkamp, 2. Aufl. 1998.

Brämer, Rainer [1983] 'Heimliche Komplizen. Zur politischen Situation der Naturwissenschaftler im NS-Staat', in: Brämer (Hrsg.) [1983] S. 7-29.

Brämer, Rainer \& Georg Nolte [1983] Die heile Welt der Wissenschaft. Zur Empirie des »typischen Naturwissenschaftlers", Marburg: Redaktionsgemeinschaft Soznat.

Brämer, Rainer (Hrsg.) [1983] Naturwissenschaft im NS-Staat, Marburg: Redaktionsgemeinschaft Soznat.

Brandt, Leo [1950/62] 'Rückblick auf die deutsche Funkmeßtechnik', in: ders.: Forschen und Gestalten, Köln u. a.: Westdeutscher Verlag, 1962, S. 53-79.

Brandt, Peter [1979] 'Wiederaufbau und Reform. Die Technische Universität Berlin 1945-1950‘, in: Rürup (Hrsg.) [1979] S. 495-522.

Breger, Herbert [1985/86] 'Steifzug durch die Geschichte der Mathematik und Physik an der Universität Heidelberg', in: Buselmeier, Harth \& Jansen (Hrsg.) [1985/86] S. 27-50.

Brentano, Margherita von [1963] 'Die Situation der Frauen und das Bild »der Frau« an der Universität', in: Universitätstage 1963. Veröffentlichung der Freien Universität Berlin. Universität und Universalität, Berlin: de Gruyter, 1963, S. 73-93.

Brinkmann, Jens-Uwe [1985]a '»Noch mehr zusammenrücken...«-Die letzten Kriegsmonate in Göttingen', in: Schmeling (Hrsg.) [1985] S. 9-23.

Brinkmann, Jens-Uwe [1985]b '»Das Vorlesungsverzeichnis ist noch unvollständig...« - Der Wiederbeginn an der Georgia Augusta،, in: Schmeling (Hrsg..) [1985] S. 301-314.

Brix, Peter [1981] '50 Jahre Kernvolumeneffekt in den Atomspektren', Physikalische Blätter 37 (1981), S. 181183.

Brix, Peter [1989] 'Laudatio auf Hans-Georg Dehmelt', Physikalische Blätter 45 (1989), S. 427-428.

Brix, Peter [1994]a 'Wolfgang Paul zum Gedenken', Physikalische Blätter 50 (1994), S. 1153-1157.

Brix, Peter [1994]b 'Erinnerungen an die Physik von 1945 bis 1970 - Göttingen, Ottawa, Heidelberg, Darmstadt', in: Marx \& Moses (Hrsg.) [1994] S. 9-30.

Brix, Peter \& Gisbert zu Putlitz [1986] 'Rückblicke auf die Heidelberger Physik im Jubiläumsjahr der Universität‘, Physikalische Blätter 42 (1986), S. 65-68.

Brix, Peter \& Achim Richter [1981] 'Luise Meyer-Schützmeister (1915-1981)‘, Physikalische Blätter 37 (1981), S. 300-301.

Broder, Henryk M. \& Michel R. Lang (Hrsg.) [1979] Fremd im eigenen Land. Juden in der Bundesrepublik, Frankfurt a. M.: Fischer.

Broelmann, Jobst [2002] Intution und Wissenschaft in der Kreiseltechnik 1750 bis 1930, München: Deutsches Museum.

Brown, Laurie M., Max Dresden \& Lillian Hoddeson (Hrsg.) [1989] Pions to quarks. Particle physics in the 1950 s, Cambridge u. a.: Cambridge University Press.

Brown, Louis [2000] A Radar History of World War II: Technical and Military Imperatives, Bristol u. a.: Institute of Physics Publishing. 
Bruch, Rüdiger vom [1993] 'Professoren im Deutschen Kaiserreich', in: Kertz (Hrsg.) [1993] S. 7-22.

Bruch, Rüdiger vom [1999] 'Langsamer Abschied von Humboldt? Etappen deutscher Universitätsgeschichte 1810-1945', in: Ash (Hrsg.) [1999] S. 29-57.

Bruch, Rüdiger vom [2002] 'Nachkriegszeit: Einführung', in: Bruch \& Kaderas (Hrsg.) [2002] S. 369-372.

Bruch, Rüdiger vom \& Brigitte Kaderas (Hrsg.) [2002] Wissenschaften und Wissenschaftspolitik. Bestandsaufnahmen zu Formationen, Brüchen und Kontinuitäten im Deutschland des 20. Jahrhunderts, Stuttgart: Franz Steiner.

Brüche, Ernst [1944] 'Grundlagenforschung im Kriege', Physikalische Blätter 1 (1944), S. 112-115.

Brüche, Ernst [1949] 'Champion of Freedom', Physikalische Blätter 5 (1949), S. 448-449.

Brüche, Ernst [1955] 'Richard Becker $\dagger^{\prime}$, Physikalische Blätter 11 (1955), S. 176.

Brüche, Ernst (Hrsg.) [1952] Physiker Anekdoten. Gesammelt und mitgeteilt von Kollegen, Mosbach: Physik Verlag.

Brumlik, Micha, Doron Kiesel, Cilly Kugelmann \& Julius H. Schoeps (Hrsg.) [1986] Jüdisches Leben in Deutschland seit 1945, Frankfurt a. M.: Jüdischer Verlag bei Athenäum.

Brüning, Jochen, Dirk Ferus \& Reinhard Siegmund-Schultze [1999] Terror and Exile. Persecution and Expulsion of Mathematicians from Berlin between 1933 and 1945, Berlin: Deutsche MathematikerVereinigung.

Bruns-Wüstefeld, Alex [1997] Lohnende Geschäfte. Die »Entjudung« der Wirtschaft am Beispiel Göttingens, Hannover.

Brynjølfsson, Einar [1996] Die Entnazifizierung der Universität Göttingen am Beispiel der Philosophischen Fakultät, Magisterarbeit Göttingen.

Buchholz, Werner (Hrsg.) [2004] Die Universität Greifswald und die deutsche Hochschullandschaft im 19. und 20. Jahrhundert, Stuttgart: Steiner.

Buchwald, Eberhard [1951] 'Die Göttinger-Jenaer Kolloquien', Physikalische Blätter 7 (1951), S. $225-227$.

Buckel, Werner [1972] 'Rudolf Hilsch‘, Physikalische Blätter 28 (1972), S. 274.

Buckel, Werner, Claus Klingshirn, Wolfgang Ruppel \& Wolfgang Stößel [1998] 'Fritz Stöckmann zum Gedenken', Physikalische Blätter 54 (1998), S. 539.

Budrass, Lutz [1998] Flugzeugindustrie und Luftrüstung in Deutschland 1918-1945, Düsseldorf: Droste.

Budrass, Lutz [2002] 'Zwischen Unternehmen und Luftwaffe. Die Luftfahrtforschung im »Dritten Reich«", in: Maier (Hrsg.) [2002] S. 142-182.

Bürgel, Tanja [1999] '»Geschlechterfragen waren für uns überhaupt kein Thema«. Zu einem Interviewprojekt mit Frauen an der Jenaer Universität nach dem Zweiten Weltkrieg‘, in: Horn (Hrsg.) [1999] S. 175-201.

Burke, John G. [1966] Origins of the science of crystals, Berkeley u. a.: University of California Press.

Burmann, Hans-Wilhelm, Stefan Krämer \& Samuel J. Patterson [2001] 'Die Sammlung Mathematischer Modelle und Instrumente des Mathematischen Instituts‘, in: Hoffmann \& Maack-Rheinländer (Hrsg.) [2001] S. 175-181.

Busch, Alexander von [1959] Die Geschichte des Privatdozenten, Stuttgart: Enke.

Buselmeier, Karin, Dietrich Harth \& Christian Jansen (Hrsg.) [1985/86] Auch eine Geschichte der Universität Heidelberg, Mannheim: Edition Quadrat, 2. Aufl., 1986.

Busemann, A. [1959] 'Ludwig Prandtl 1875-1953،, Biographical Memoirs of Fellows of the Royal Society 5 (1959), S. 193-205.

Busemann, Hertha Luise [1991] 'Deutsche und Juden in Göttingen im ersten Jahr nach dem Holocaust', Göttinger Jahrbuch 1991, S. 205-225.

Busemann, Hertha Luise \& Werner Fölling [1990] 'Göttingen im Jahre 1945: Zwei Briefe über ein College für das britische Militär in den Räumen der Universität und die überlebenden Juden`, Göttinger Jahrbuch 1990, S. 237-240.

Bußmann, Hadumod (Hrsg.) [1994] Stieftöchter der Alma Mater? 90 Jahre Frauenstudium in Bayern - am Beispiel der Universität München, München: Kunstmann.

Buttlar, Haro von (Hrsg.) [1982] Leonium und andere Anekdoten um den Physikprofessor Dr. F. G. Houtermans 1903-1966, Bochum.

Büttner, Ursula [1986] Not nach der Befreiung. Die Situation der deutschen Juden in der britischen Besatzungszone 1945 bis 1948, Hamburg: Landeszentrale für politische Bildung.

Cahn, Robert W. [1987] 'Solid State Physics and Metallurgy', in: Weaire \& Windsor (Hrsg.) [1987] S. 79-107.

Campenhausen, Axel von [1987] 'Rudolf Smend (1882-1975). Integration in zerissener Zeit', in: Fritz Loos (Hrsg.): Rechtswissenschaft in Göttingen. Göttinger Juristen aus 250 Jahren, Göttingen: Vandenhoeck \& Ruprecht, 1987, S. 510-527.

Carson, Cathryn [1999] 'New models for science in politics: Heisenberg in West Germany', Historical Studies in the Physical and Biological Sciences 30 (1999), S. 115-171.

Carson, Cathryn [2000] 'Old Programms, New Politics? Nuclear Reactor Studies after 1945 in the Max-PlanckInstitut für Physik', in: Kaufmann (Hrsg.) [2000] S. 726-749. 
Carson, Cathryn [2003] 'Bildung als Konsumgut. Physik in der westdeutschen Nachkriegskultur', in: Dieter Hoffmann (Hrsg.) [2003] S. 73-85.

Carson, Cathryn \& Michael Gubser [2002] 'Science Advising and Science Policy in Post-War West Germany: The Example of the Deutscher Forschungsrat', Minerva 40 (2002), S. 147-179.

Casimir, Hendrik [1983] Haphazard Reality. Half a Century of Science, New York: Harper \& Row.

Cassidy, David C. [1979] 'Gustav Hertz, Hans Geiger und das Physikalische Institut der Technischen Hochschule Berlin in den Jahren 1933 bis 1945', in: Rürup (Hrsg.) [1979] S. 373-387.

Cassidy, David C. [1993] 'Werner Heisenberg - Die deutsche Wissenschaft und das Dritte Reich', in: Albrecht (Hrsg.) [1993] S. 65-80.

Cassidy, David C. [1994] 'Controlling German science, I: U. S. and Allied forces in Germany, 1945-1947', Historical Studies in the Physical and Biological Sciences 24 (1994), S. 197-235.

Cassidy, David C. [1995] Werner Heisenberg. Leben und Werk, Heidelberg u. a.: Spektrum.

Cassidy, David C. [1996] 'Controlling German science, II: Bizonal occupation and the struggle over West German science policy, 1946-1949', Historical Studies in the Physical and Biological Sciences 26 (1996), S. 197-239.

Chroust, Peter [1993] 'Deutsche Universitäten und Nationalsozialismus, Forschungsstand und eine Fallstudie: Karrieremuster und politische Orientierung der Gießener Professorenschaft (1918-1945)', in: Schriewer, Keiner \& Charle (Hrsg.) [1993] S. 61-112.

Chroust, Peter [1999] 'Demokratie auf Befehl? Grundzüge der Entnazifizierungspolitik an den deutschen Hochschulen', in: Knigge-Tesche (Hrsg.) [1999] S. 133-149.

Chubin, D. E. [1985] 'Beyond Invisible Colleges: Inspirations and Aspirations of post-1972 Social Studies of Science', Scientometrics 7 (1985), S. 221-254.

Ciesla, Burghard [1996] 'German High Velocity Aerodynamics and their Significance for the US Air Force 1945-52‘, in: Judt \& Ciesla (Hrsg.) [1996] S. 93-106.

Ciesla, Burghard [2000] 'Abschied von der »reinen« Wissenschaft. »Wehrtechnik« und Anwendungsforschung in der Preußischen Akademie nach 1933', in: Fischer (Hrsg.) [2000] S. 483-513.

Ciesla, Burghard [2002] 'Ein »Meister deutscher Waffentechnik«. General-Professor Karl Becker zwischen Militär und Wissenschaft (1918-1940)‘, in: Bruch \& Kaderas (Hrsg.) [2002] S. 263-281.

Citron, A. [1967] 'Arnold Schoch †', Physikalische Blätter 23 (1967), S. 475.

Clemens, Gabriele (Hrsg.) [1994] Kulturpolitik im besetzten Deutschland 1945-1949, Stuttgart: Steiner.

Clephas-Möcker, Petra \& Kristina Krallmann [1988] Akademische Bildung - eine Chance zur Selbstverwirklichung für Frauen?. Lebensgeschichtlich orientierte Interviews mit Gymnasiallehrerinnen und Ärztinnen der Geburtsjahrgänge 1909 bis 1923, Weinheim: Deutscher Studien Verlag.

Clephas-Möcker, Petra \& Kristina Krallmann [1992] 'Studentinnenalltag in der Weimarer Republik und im Nationalsozialismus im Spiegel biographischer Interviews‘, in: Schlüter (Hrsg.) [1992] S. 169-189.

Coates, Steve [2002] Helicopters of the Third Reich, Hersham: Classis Publications.

Cobey, William E. [o.D.] Evaluation and Tests of the Flettner-282 German Helicopter, Technical Report No. FTR-1193-ND.

Connelly, John \& Michael Grüttner (Hrsg.) [2003] Zwischen Autonomie und Anpassung. Universitäten in den Diktaturen des 20. Jahrhunderts, Paderborn u. a.: Schöningh.

Conze, Werner [1950] 'Die Georg-August-Universität in Göttingen in den Nachkriegsjahren', Universitätsbund Göttingen e. V., Jg. 26, Mitteilungen 1950, Heft 2, S. 1-12.

Coppi, Hans \& Geertje Andresen (Hrsg.) [1999] Dieser Tod paßt zu mir. Harro Schulze-Boysen - Grenzgänger im Widerstand. Briefe 1915 bis 1942, Berlin: Aufbau-Verlag.

Coppi, Hans, Jürgen Danyel \& Johannes Tuchel (Hrsg.) [1994] Die Rote Kapelle im Widerstand gegen den Nationalsozialismus, Berlin: Edition Hentrich.

Costas, Ilse [1997] 'Zu den Anfängen des Frauenstudiums an der Universität', Göttinger Jahrbuch 1997, S. 145156.

Cramer, Konrad [2000] 'Auslöschung einer Universität. Die »Sonderaktion Krakau« der SS am 6. November 1939', Spektrum 4 (2000), S. 20-22.

Crane, Diana [1969] 'Social Structure in a Group of Scientists: A Test of the »Invisible College« Hypothesis', American Sociological Review 34 (1969), S. 335-352.

Crane, Diana [1972] Invisible Colleges. Diffusion of Knowledge in Scientific Communities, Chicago, London: The University of Chicago Press.

Cremer, Lothar [1972] 'Erwin Meyer. 21. Juli 1899 - 6. März 1972‘, Jahrbuch der Akademie der Wissenschaften in Göttingen 1972, S. 179-185.

Cunningham, Caroline [1990] 'Kiel: Randbemerkungen', in: Heinemann (Hrsg.) [1990]a S. 153-155.

Dageförde, Astrid [1991] 'Frauen an der Hamburger Universität 1933 bis 1945: Emanzipation oder Repression? ', in: Krause, Huber \& Fischer (Hrsg.) [1991] S. 255-270. 
Dahms, Hans-Joachim [1986] 'Verluste durch Emigration. Die Auswirkungen der nationalsozialistischen 'Säuberungen' an der Universität Göttingen. Eine Fallstudie', Exilforschung. Ein internationales Jahrbuch. Band 4, Das jüdische Exil und andere Themen, 1986, S. 160-185.

Dahms, Hans-Joachim [1987/98] 'Einleitung', in: Becker, Dahms \& Wegeler (Hrsg.) [1987/98] S. 29-74.

Dahms, Hans-Joachim [1999] 'Die Universität Göttingen 1918 bis 1989: Vom »Goldenen Zeitalter« der Zwanziger Jahre bis zur »Verwaltung des Mangels« in der Gegenwart', in: Thadden \& Trittel (Hrsg.) [1999] S. 395-456.

Dahms, Hans-Joachim [2002] 'Appointment Politics and the Rise of Modern Theoretical Physics at Göttingen', in: Rupke (Hrsg.) [2002] S. 143-157.

'Das Gesetz Nr. 22 des Rates der Alliierten Hohen Kommission', Physikalische Blätter 6 (1950), S. $218-221$.

Decker-Hauff, Hansmartin \& Wilfried Setzler (Hrsg.) [1977] Die Universität Tübingen von 1477 bis 1977 in Bildern und Dokumenten, Tübingen: Attempto.

Defrance, Corine [2000] 'Deutsche Universitäten in der Besatzungszeit zwischen Brüchen und Traditionen 1945-1949‘, in: Pappenfuß \& Schreder (Hrsg.) [2000] S. 409-428.

Deichmann, Ute [1992] Biologen unter Hitler. Vertreibung, Karrieren, Forschung, Frankfurt a. M. u. a.: Campus.

Deichmann, Ute [1995] Biologen unter Hitler. Portrait einer Wissenschaft im NS-Staat, Frankfurt a. M.: Fischer.

Deichmann, Ute [2000] 'Kriegsbezogene biologische, biochemische und chemische Forschung an den Kaiser Wilhelm-Instituten für Züchtungsforschung, für physikalische Chemie und Elektrochemie und für medizinische Forschung', in: Kaufmann (Hrsg.) [2000] S. 231-257.

Deichmann, Ute [2001] 'The Expulsion of German-Jewish Chemists and Biochemists and their Correspondence with Colleagues in Germany after 1945: The Impossibility of Normalization? ', in: Szöllösi-Janze (Hrsg.) [2001] S. 243-280.

Deichmann, Ute [2002] 'Chemiker und Biochemiker in der NS-Zeit', Angewandte Chemie 114 (2002), S. 13641383.

Deist, Wilhelm [2000] 'Rüstungsforschung und Wehrmacht. Ein Kommentar', in: Kaufmann (Hrsg.) [2000] S. 363-370.

De Maria, Michalangelo, Mario Grilli \& Fabio Sebastiani (Hrsg.) [1989] Proceedings of the International Conference on the Reconstructuring of Physical Sciences in Europe and the United States 1945-1960, Singapore u. a.: Worls Scientific.

Dickmann, Elisabeth \& Eva Schöck-Quinteros (Hrsg.) [2000] Barrieren und Karrieren. Die Anfänge des Frauenstudiums in Deutschland, Berlin: Trafo.

Diederich, Werner (Hrsg.) [1974] Theorien der Wissenschaftsgeschichte. Beiträge zur diachronen Wissenschaftstheorie, Frankfurt a. M.: Suhrkamp.

Dietze, Carola [2002] 'Kein Gestus des Neubeginns. Helmuth Plessner als remigrierter Soziologe in der Wissenschaftskultur der Nachkriegszeit', in: Weisbrod (Hrsg.) [2002] S. 75-96.

Dinghaus, Angela [1993] 'Wissenschaft und Politik - Frauen in Männerdomänen', in: Angela Dinghaus (Hrsg.): Frauenwelten. Biographisch-historische Skizzen aus Niedersachsen, Hildesheim u. a.: Olms, 1993, S. 229-251.

Doering-Manteuffel, Anselm [1993] 'Deutsche Zeitgeschichte nach 1945. Entwickung und Problemlagen der historischen Forschung zur Nachkriegszeit‘, Vierteljahrshefte für Zeitgeschichte 41 (1993), S. 1-29.

Dotterweich, Volker [1979] 'Die »Entnazifizierung«“, in: Becker, Stammen \& Waldmann (Hrsg.) [1979] S. 123161.

Dreisigacker, Ernst [1995] 'Gedenkkolloquium für Hans Kopfermann“, Physikalische Blätter 51 (1995), S. 527.

Dreisigacker, Ernst \& Helmut Rechenberg [1995] 'Karl Scheel, Ernst Brüche und die Publikationsorgane', Physikalische Blätter 51 (1995), S. F-135-F-142.

Duelli-Klein, Renate, Maresi Nerad \& Sigrid metz-Göckel (Hrsg.) [1982] Feministische Wissenschaft und Frauenstudium, Hamburg: Arbeitsgemeinschaft für Hochschuldidaktik.

Dundas-Grant, Valerie [1983] 'As Assistant University officer in Göttingen and Bonn: An Erfahrungsbericht', in: Phillips (Hrsg.) [1983] S. 96-106.

Duwe, Kornelia \& Uta Schäfer [1988] 'Damals herrschte nicht Temperatur Null, sondern minus 30 Grad', in: Göttingen ohne Gänseliesel: Texte und Bilder zur Stadtgeschichte, hrsg. von Kornelia Duwe im Auftrag der Geschichtswerkstatt Göttingen e.V., Gudensberg-Gleichen: Wartberg, 1988, S. 238-243.

Düwell, Kurt [1998] 'Zwischen Entnazifizierungs- und Berufungsproblemen. Die RWTH im Kontext der deutschen Universitätsgeschichte nach 1945`, in: Loth \& Rusinek (Hrsg.) [1998] S. 313-331.

Ebel, Wilhelm [1962] Catalogus Professorum Gottingensium 1734-1962, Göttingen: Vandenhoeck \& Ruprecht.

Eberle, Henrik [2002] Die Martin-Luther-Universität in der Zeit des Nationalsozialismus 1933-1945, Halle: Mitteldeutscher Verlag.

Ebert, Hans [1964] 'Reinhold Mannkopff 70 Jahre', Physikalische Blätter 20 (1964), S. 226. 
Ebert, Hans [1947] 'Zeitschriften und literarische Unternehmungen. Aus der Vergangenheit für die Zukunft', Physikalische Blätter 3 (1947), S. 148-151.

Ebert, Hans \& Hermann-Josef Rupieper [1979] 'Technische Wissenschaft und nationalsozialistische Rüstungspolitik: Die Wehrtechnische Fakultät der Technischen Hochschule Berlin 1933-1945', in: Rürup (Hrsg.) [1979] S. 469-491.

Eckert, Michael [1985] 'Die »Deutsche Physik« und das Deutsche Museum. Eine Fallstudie über das Verhältnis von NS-Ideologie, Wissenschaft und Institution', Physikalische Blätter 41 (1985), S. 87-92.

Eckert, Michael [1989] 'Heisenberg and the Beginnings of Nuclear Energy in the FRG', in: De Maria, Grilli \& Sebastiani (Hrsg.) [1989] S. 247-256.

Eckert, Michael [1990] 'Primacy doomed to failure: Heisenberg's role as scientific advisor for nuclear policy in the Federal Republic of Germany“, Historical Studies in the Physical Sciences 21 (1990), S. 29-58.

Eckert, Michael [1993] Die Atomphysiker. Eine Geschichte der theoretischen Physik am Beispiel der Sommerfeldschule, Braunschweig u. a.: Vieweg.

Eckert, Michael [2000] 'Theoretische Physiker in Kriegsprojekten. Zur Problematik einer internationalen vergleichenden Analyse', in: Kaufmann (Hrsg.) [2000] S. 296-308.

Eckert, Michael \& Maria Osietzki [1989] Wissenschaft für Macht und Markt. Kernforschung und Mikroelektronik in der Bundesrepublik Deutschland, München: Beck.

Eckert, Michael \& Helmut Schubert [1986] Kristalle, Elektronen, Transistoren. Von der Gelehrtenstube zur Industrieforschung, Reinbek: Rowohlt.

Edingshaus, Anne-Lydia [1986] Heinz Maier-Leibnitz. Ein halbes Jahrhundert experimentelle Physik, München: Piper.

Ehlers, Anita [1994] Liebes Hertz! Physiker und Mathematiker in Anekdoten, Basel u. a.: Birkhäuser.

Ehlers, Carl Theo [1995] 'Studium generale für angehende Mediziner', Göttinger Tageblatt, 13. Oktober 1995, S. 22.

Ehlers, Jürgen \& Engelbert Schücking [2002] '»Aber Jordan war der Erste«. Zur Erinnerung an Pascual Jordan (1902-1980)', Physik Journal 1 (2002), Nr. 11, S. 71-74.

Eickemeyer, Hellmuth [1949] 'Gründung des Deutschen Forschungsrates', Physikalische Blätter 5 (1949), S. 197-201.

Einstein, Albert [1952] 'Über die moralische Verpflichtung des Wissenschaftlers', Physikalische Blätter 8 (1952), S. 193-195.

Eisenmenger, Wolfgang [1985] 'Hans Kneser zum Gedenken', Physikalische Blätter 41 (1985), S. 320.

'Einweihung des Instituts für Metallphysik', in: Universitätsbund Göttingen e. V., Jg. 31, Mitteilungen 1960, S. 28-30.

Elsner, Rudolf [1995] 'Wandlungen in der Lehre', in: Kertz (Hrsg.) [1995]b S. 721-731.

Engelmann, Bernt [1987] Wir haben den Kopf noch fest auf dem Hals. Die Deutschen zwischen »Stunde Null« und Wirtschaftswunder, Köln: Kiepenheuer \& Witsch.

Engelmann, Bernt [1988] Deutschland ohne Juden. Eine Bilanz, Köln: Pahl-Rugenstein.

Engfer, Roland \& Helmut Frank [1988] 'Peter Brix zum 70. Geburtstag', Physikalische Blätter 44 (1988), S. 463

Epple, Moritz [2002] 'Rechnen, Messen, Führen. Kriegsforschung am Kaiser-Wilhelm-Institut für Strömungsforschung 1937-1945', in: Maier (Hrsg.)[2002] S. 305-356.

Epple, Moritz \& Volker Remmert [2000] '»Eine ungeahnte Synthese zwischen reiner und angewandter Mathematik«. Kriegsrelevante mathematische Forschung in Deutschland während des II. Weltkrieges', in: Kaufmann (Hrsg.) [2000] S. 258-295.

Erichsen, Regine [1991] 'Die Emigration deutschsprachiger Naturwissenschaftler von 1933 bis 1945 in die Türkei in ihrem sozial- und wissenschaftshistorischem Wirkungszusammenhang', in: Strauss, Fischer, Hoffmann \& Söllner (Hrsg.) [1991] S. 73-104.

Ermenc, Joseph J. (Hrsg.) [1989] Atomic Bomb Scientists. Memoirs, 1939-1945, Westport u. a.: Meckler.

Etzemüller, Thomas [2001] Sozialgeschichte als politische Geschichte. Werner Conze und die Neuorientierung der westdeutschen Geschichtswissenschaft nach 1945, München: Oldenbourg.

Evans, R. C. [1947] 'Naturforschung in Deutschland', Physikalische Blätter 3 (1947), S. 12-15.

Ewald, Peter Paul [1960] 'Max von Laue‘, Biographical Memoirs of Fellows of the Royal Society 6 (1960), S. 135-156.

Exner, Birgit, Jörg Ehtreiber \& Adolf Hohenester [1996] Physiker-Anekdoten. 246 Annekdoten von 91 bekannten Physiker, Wien: Hölder-Pichler-Tempsky.

Exodus Professorum. Akademische Feier zur Enthüllung einer Ehrentafel für die zwischen 1933 und 1945 entlassenen und vertriebenen Professoren und Dozenten der Georgia Augusta am 18. April 1989, Göttingen: Vandenhoeck \& Ruprecht.

Faßnacht, Wolfgang [2000] Universitäten am Wendepunkt? Die Hochschulpolitik in der französischen Besatzungszone (1945-1949), München: Alber. 
Federspiel, Ruth [2002] 'Mobilisierung der Rüstungsforschung? Werner Osenberg und das Planungsamt im Reichsforschungsrat 1943-1945‘, in: Maier (Hrsg.) [2002] S. 72-105.

Felt, Ulrike, Helga Nowotny \& Klaus Taschwer [1995] Wissenschaftsforschung. Eine Einführung, Frankfurt a. M. u. a.: Campus.

Ferber, Christian von [1956] Die Entwicklunge des Lehrkörpers der deutschen Universitäten und Hochschulen 1864-1954, Göttingen: Vandenhoeck \& Ruprecht.

Fesefeldt, Wiebke [1962] Der Wiederbeginn des kommunalen Lebens in Göttingen. Die Stadt in den Jahren 1945 bis 1948, Göttingen: Vandenhoeck \& Ruprecht.

Feyl, Renate [1981] Der lautlose Aufbruch. Frauen in der Wissenschaft, Berlin: Verlag Neues Leben.

Fieseler, Gerhard [1979] Meine Bahn am Himmel. Der Erbauer des Fieseler Storch und der V 1 erzählt sein Leben, München: Bertelsmann.

Finkelnburg, Wolfgang [1948/51] Einführung in die Atomphysik, Berlin u. a.: Springer, 2. Aufl. 1951.

Fischer, Klaus [1988]a 'Die Emigration deutschsprachiger Kernphysiker nach 1933', Exilforschung. Ein internationales Jahrbuch. Band 6, Vertreibung der Wissenschaften und andere Themen, 1988, S. 44-72.

Fischer, Klaus [1988]b 'Der quantitative Beitrag der nach 1933 emigrierten Naturwissenschaftler zur deutschsprachigen physikalischen Forschung', Berichte zur Wissenschaftsgeschichte 11 (1988), S. 83104.

Fischer, Klaus [1991]a 'Die Emigration deutschsprachiger Physiker nach 1933: Strukturen und Wirkungen“, in: Strauss, Fischer, Hoffmann \& Söllner (Hrsg.) [1991] S. 25-72.

Fischer, Klaus [1991]b 'Die Emigration von Wissenschaftlern nach 1933: Möglichkeiten und Grenzen einer Bilanzierung‘, Vierteljahreshefte für Zeitgeschichte 39 (1991), S. 535-549.

Fischer, Klaus [1995] 'Emigration und Wissenschaftswandel zwischen 1933 und 1945', in: Frieß \& Steiner (Hrsg.) [1995] S. 36-48.

Fischer, Klaus [1996] 'Identification of Emigration-Induced Scientific Change', in: Ash \& Söllner (Hrsg.) [1996] S. 23-47.

Fischer, Klaus [1998] 'Jüdische Wissenschaftler in Weimar. Marginalität, Identität und Innovation', in: Benz (Hrsg.) [1998] S. 89-116.

Fischer, Manfred M. \& Christian Rammer [1992] Kommunikationsnetze von Wissenschaftlern. Ergebnisse einer Fallstudie an Wiener Universitäten, WSG-Discussion Paper 25, August 1992.

Fischer, Wolfram (Hrsg.) [2000] Die Preußische Akademie der Wissenschaften zu Berlin 1914-1945, Berlin: Akademie Verlag.

Flammersfeld, Arnold [1972] 'Rudolf Hilsch. 16. Dezember 1903 - 29. Mai 1972‘, Jahrbuch der Akademie der Wissenschaften in Göttingen 1972, S. 186-188.

Flammersfeld, Arnold (Hrsg.) [1978] R. W. Pohl. Gedächtnis-Kolloquium am 29. November 1976, Göttingen u. a.: Musterschmidt.

Fleck, Ludwik [1935/99] Entstehung und Entwicklung einer wissenschaftlichen Tatsache. Einführung in die Lehre vom Denkstil und Denkkollektiv. Mit einer Einleitung herausgegeben von Lothar Schäfer und Thomas Schelle, Frankfurt a. M.: Suhrkamp, 4. Aufl., 1999.

Fleischmann, Rudolf [1973] 'Rudolf Hilsch', Bayerische Akademie der Wissenschaften, Jahrbuch 1973, S. 223226.

Fleischmann, Rudolf [1994] 'Vom Atomkern zur Uranspaltung - Erfahrungen aus meinem Berufsleben', in: Marx \& Moses (Hrsg.) [1994] S. 35-57.

Flitner, Andreas (Hrsg.) [1965] Deutsches Geistesleben und Nationalsozialismus, Tübingen: Wunderlich.

Flügge, Siegfried [1974] Wege und Ziele der Physik, Berlin u. a.: Springer.

Forkl, Martha \& Elisabeth Koffmahn (Hrsg.) [1968] Frauenstudium und akademische Frauenarbeit in Österreich, Wien u. a.: Braumüller.

Forman, Paul [1989] 'Social Niche and Self-Image of the American Physicist', in: De Maria, Grilli \& Sebastiani (Hrsg.) [1989] S. 96-104.

Forschung heißt Arbeit und Brot, hrsg. vom Stifterverband für die deutsche Wissenschaft, Stuttgart: Steingrüben, 1950.

Forstmann, Walther [1956] 'Es geschah in Berlin', in: Erinnerungen und Tatsachen. Die Kaiser-WilhelmGesellschaft zur Förderung der Wissenschaften, Göttingen-Berlin, 1945/1946, Stuttgart: Thieme, 1956, S. 56-64.

Foschepoth, Josef \& Rolf Steininger (Hrsg.) [1985] Die britische Deutschland- und Besatzungspolitik 19451949, Paderborn: Schöningh.

Fraenkel, A. Peter [1990] 'Some Reflections on Education in Post-War Germany', in: Heinemann (Hrsg.) [1990]b S. 53-64.

Franke, Martin [1993] 'Die Leipziger Schüler und Gäste‘, in: Geyer, Herwig \& Rechenberg (Hrsg.) [1993] S. 66-73.

Fraser, Ronald G. J. [1931] Molecular Rays, Cambridge: The University Press.

Fraser, Ronald G. J. [1937] Molecular Beams, London: Methuen. 
Frei, Norbert [1996/99] Vergangenheitspolitik. Die Anfänge der Bundesrepublik und die NS-Vergangenheit, München: dtv, 1999 (Erstaufl. Beck, 1996).

Frei, Norbert [1998] 'Vergangenheitspolitik in den fünfziger Jahren', in: Loth \& Rusinek (Hrsg.) [1998] S. 7992.

Frei, Norbert (Hrsg.) [2001] Karrieren im Zwielicht. Hitlers Eliten nach 1945, Frankfurt a. M. u. a.: Campus.

Freise, Gerda [1983] 'Das Selbstverständnis von Naturwissenschaftlern im Nationalsozialismus', in: Brämer (Hrsg.) [1983] S. 31-58.

Friedlander, Saul (Hrsg.) [1992] Probing the limits of representation: Nazism and the "Final Solution", Cambridge, Mass. u.a.: Harvard Univ. Press.

Frieß, Peter \& Peter M. Steiner (Hrsg.) [1995] Forschung und Technik in Deutschland nach 1945, München: Deutscher Kunstverlag.

Frowein, Friedrich [1950]a 'Forschungskontrolle in Westdeutschland', Physikalische Blätter 6 (1950), S. $222-$ 228.

Frowein, Friedrich [1950]b 'Nochmals Gesetz 22. Einige Bemerkungen zum Gesetz 22‘, Physikalische Blätter 6 (1950), S. 316-321.

Fues, Erwin [1962] 'Zum 80. Geburtstag von Max Born‘, Physikalische Blätter 18 (1962), S. 545-551.

Führ, Christoph [1993] 'The German university: basically healthy or rotten? Reflections on a overdue reorientation of German higher education policy‘, in: Phillips (Hrsg.) [1995] S. 80-91.

Fülgraff, Georges \& Annegret Falter (Hrsg.) [1990] Wissenschaft in der Verantwortung. Möglichkeiten der institutionellen Steuerung, Frankfurt a. M., New York: Campus.

Galison, Peter [1998] 'Trading Zone: Coordinating Action and Belief', in: Biagioli (Hrsg.) [1998] S. 137-160.

Gebelein, Hans [1952] 'Zu Prof. Schulers 70. Geburtstag', Zeitschrift für angewandte Mathematik und Mechanik 32 (1952), S. 228.

Geimer, Hildegard \& Reinhold Geimer [1995] 'Das deutsche Bildungs- und Forschungssystem - Grundstruktur und Entwicklung seit 1945`, in: Frieß \& Steiner (Hrsg.) [1995] S. 145-158.

Geiss, Johannes \& Edward D. Goldberg (Hrsg.) [1963] Earth Science and Meteoritics, Amsterdam: NorthHolland Publishing Company.

Gerlach, Walther [1953] 'Humanismus und Naturwissenschaft', Deutsche Universitätszeitung 8 (1953), Nr. 14, S. 3-6.

Gersdorf, Kyrill von \& Kurt Knobling [1999] Hubschrauber und Tragschrauber. Entwicklungsgeschichte der deutschen Drehflügler von den Anfängen bis zu den internationalen Gemeinschaftsentwicklungen, Bonn: Bernard \& Graefe, 3. Aufl 1999.

Gerlach, Walther [1965] 'Hans Kopfermann‘, Bayerische Akademie der Wissenschaften, Jahrbuch 1965, S. 198-203.

Gerlach, Walther [1978] 'Robert Wichard Pohl', Bayerische Akademie der Wissenschaften, Jahrbuch 1978, S. 214-219.

Gerstein, Hannelore [1965] Studierende Mädchen. Zum Problem des vorzeitigen Abgangs von der Universität, München: Piper.

'Gesetz Nr. 25 des Kontrollrats. Überwachung der Wissenschaftlichen Forschung', Neue Physikalische Blätter 2 (1946), S. 49-52.

Geyer, Bodo, Helge Herwig \& Helmut Rechenberg (Hrsg.) [1993] Werner Heisenberg. Physiker und Philosoph, Heidelberg/Berlin/Oxford: Spektrum Akademischer Verlag.

Gievers, Johannes G. [1971] 'Erinnerungen an Kreiselgeräte. Herrn Professor Dr.-Ing., Dr.-Ing. E. h. Max Schuler zum 90. Geburtstag am 5. Februar 1972 gewidmet', Jahrbuch 1971 der DGLR, S. 263-291.

Giles, Geoffrey J. [1985] Students and National Socialism in Germany, Princeton: Princeton University Press.

Giles, Geoffrey J. [1991] 'Professor und Partei: Der Hamburger Lehrkörper und der Nationalsozialismus', in: Krause, Huber \& Fischer (Hrsg.) [1991] S. 113-124.

Gimbel, John [1946/90] 'Deutsche Wissenschaftler in britischem Gewahrsam', Vierteljahrshefte für Zeitgeschichte 38 (1990), S. 459-483.

Gimbel, John [1990] Science, Technology, and Reparations. Exploitation and Plunder in Postwar Germany, Stanford: Stanford University Press.

Gizewski, Christian [1979] 'Zur Geschichte der Studentenschaft der Technischen Universität Berlin seit 1879`, in: Rürup (Hrsg.) [1979] S. 115-154.

Gizler, Gerhard [1985] 'Studium nach der Stunde Null. Gerhard Gizler über das erste Nachkriegssemester an der Georgia Augusta’, DUZ Universitätszeitung 41 (1985), Nr. 22, S. 16-19.

Glemser, Otto [1994] 'Die Entwicklung der Chemie in Göttinen seit Gründung der Universität 1734‘, in: Schlotter (Hrsg.) [1994] S. 173-184.

Golczewski, Frank [1988] Kölner Universitätslehrer und der Nationalsozialismus. Personengeschichtliche Ansätze, Köln u. a.: Böhlau. 
Goldschmidt, Dietrich [1949] '1 Student auf 545 Einwohner. Entwicklungstendenzen der deutschen Studentenzahlen', GUZ 4 (1949), Nr. 16, S. 5-7.

Gordin, Michael, Walter Grunden, Mark Walker \& Zuoyue Wang [2003] '»Ideologically Correct Science«', in: Walker (Hrsg.) [2003] S. 35-65.

Görtler, Henry [1950] 'Ludwig Prandtl 75 Jahre', Physikalische Blätter 6 (1950), S. 30-32.

Görtler, Henry [1953]a Rezension von: Oswatitsch [1952], in: Physikalische Blätter 9 (1953), S. 284-285.

Görtler, Henry [1953]b 'Ludwig Prandtl †', Physikalische Blätter 9 (1953), S. 466-468.

Gottwaldt, Alfred \& Silke Klewin (Hrsg.) [1995] Ich diente nur der Technik. Sieben Karrieren zwischen 1940 und 1950, Berlin: Nicolaische Verlagsbuchhandlung.

Goudsmit, Samuel A. [1946] 'Wissenschaft oder Geheimhaltung', Neue Physikalische Blätter 2 (1946), S. 203207.

Goudsmit, Samuel A. [1947/83] Alsos, New York: Schumann (Reprint Los Angeles: Tomash, 1983).

Gramsch, Robert [1998] 'Der Jenaer Studentenausschuß und die Wiedereröffnung der Friedrich-SchillerUniversität 1945،, in: John, Wahl \& Arnold (Hrsg.) [1998] S. 103-114.

Greising, G. [1948] Die Entnazifizierung in Niedersachsen. Text der amtlichen Verordnungen und Erlasse des Niedersächsischen Ministera für die Entnazifizierung, [ohne Ort und Verlag].

Griebel, Regina, Marlies Coburger \& Heinrich Scheel [1992] Erfasst? Das Gestapo-Album zur Roten Kapelle, Halle: audioscop.

Grosser, Hartmut \& Hans-Heinrich Voigt [2001] 'Die Universitäts-Sternwarte', in: Hoffmann \& MaackRheinländer (Hrsg.) [2001] S. 188-193.

Grothe, Ewald [1999] 'Eine lautlose Angelegenheit? Zur Rückkehr des Verfassungshistorikers Ernst Rudolf Huber in die universitäre Wissenschaft nach 1945', Zeitschrift für Geschichtswissenschaft 47 (1999), S. 980-1001.

Grothusen, Klaus-Detlev (Hrsg.) [1987] Der Scuorla-Bericht: Migration deutscher Professoren in die Türkei im Dritten Reich, Frankfurt a. M.: Dağyeli.

Grun, Hans-Hellmut [1995]a 'Wärmestube bei Cron \& Lanz, zwei Briketts für Theaterbesuch und 20 Mark Zimmermiete', Göttinger Tageblatt, 23. September 1995, S. 38.

Grun, Hans-Hellmut [1995]b 'Selbstgebrannter Schnaps für Speisung der Studenten', Göttinger Tageblatt, 30. September 1995, S. 29.

Grun, Hans-Hellmut [1995]c 'Doktorprüfung in Lederhose bei Tee und Gebäck', Göttinger Tageblatt, 6. Oktober 1995, S. 29.

Grüttner, Michael [1994] 'Studenten im Dritten Reich', in: Kertz (Hrsg.) [1994] S. 69-77.

Grüttner, Michael [1995] Studenten im Dritten Reich, Paderborn u. a.: Schöningh.

Grüttner, Michael [2000] 'Wissenschaftspolitik im Nationalsozialismus', in: Kaufmann (Hrsg.) [2000] S. $557-$ 585.

Grüttner, Michael [2003]a 'Die deutschen Universitäten unter dem Hakenkreuz', in: Connelly \& Grüttner (Hrsg.) [2003] S. 67-100.

Grüttner, Michael [2003]b 'Schlussüberlegungen: Universität und Diktatur', in: Connelly \& Grüttner (Hrsg.) [2003] S. 265-276.

Grützmacher, Martin [1959] 'Erwin Meyer 60 Jahre', Physikalische Blätter 15 (1959), S. 321-322.

Grützmacher, Martin [1972] 'Erwin Meyer $\dagger^{\prime}$, Acustica 26 (1972), S. 240a-b.

Gudden, Bernhard [1944] 'R. W. Pohl zum 60. Geburtstag', Die Naturwissenschaften 32 (1944), S. 166-169.

Gundelach, Ernst [1955] Die Verfassung der Göttinger Universität in drei Jahrhunderten, Göttingen: Schwartz.

Gundler, Bettina [1993] 'Zur Sozialgeschichte der Braunschweiger Hochschullehrer 1862-1945: Soziale Herkunft, Werdegang und Karrieremuster', in: Kertz (Hrsg.) [1993] S. 57-78.

Hafner, R. [1956] 'Die Hubschrauberentwicklung in England', in: Deutsche Studiengemeinschaft Hubschrauber e. V., Bericht 27, 1956, S. 27-54.

Hahn, Otto [1952] 'Atomenergie für den Frieden', Jahrbuch der Max-Planck-Gesellschaft 1952, S. 80-101.

Hahn, Otto \& Hermann Rein [1947] 'Einladung nach USA‘, Physikalische Blätter 3 (1947), S. 33-35.

Halls, W. D. [1983] 'The »German Question« and Post-War University Reform in Germany: A Comparative Note', in: Phillips (Hrsg.) [1983] S. 28-37.

Hammerstein, Notker [1999] Die Deutsche Forschungsgemeinschaft in der Weimarer Republik und im Dritten Reich. Wissenschaftspolitik in Republik und Diktatur 1920-1945, München: Beck.

Hammerstein, Notker [2000] 'Die Geschichte der Deutschen Forschungsgemeinschaft im Nationalsozialismus', in: Kaufmann (Hrsg.) [2000] S. 600-609.

Handel, Kai [2000] 'Halbleiterforschung und Radar im Zweiten Weltkrieg', in: Meinel (Hrsg.) [2000] S. 158167.

Handel, Kai [2003] 'Physik und Industrieforschung oder die Suche nach dem »richtigen« Halbleitermaterial', in: Dieter Hoffmann (Hrsg.) [2003] S. 167-177. 
Handel, Paul von [1947] Gedanken zu Physik und Metaphysik. Erkenntnistheoretische Wandlungen im Weltbild der Naturwissenschaften, Bergen: Müller \& Kiepenheuer.

Hanle, Wilhelm [1954] 'Georg Joos zum 60. Geburtstag', Optik 11 (1954), S. 489-490.

Hanle, Wilhelm [1989] Memoiren, Gießen: Erstes Physikalisches Institut der Universität Gießen.

Häntzschel, Hiltrud [1999] 'Der Exodus der Wissenschaftlerinnen aus Deutschland nach 1933', in: Horn (Hrsg.) [1999] S. 137-155.

Hartmann, Hans [1952] Schöpfer des neuen Weltbildes. Große Physiker unserer Zeit, Bonn: Athenäum.

Harwood, Jonathan [1993] '»Mandarine« oder »Außenseiter«? Selbstverständnis deutscher Naturwissenschaftler (1900-1933)‘, in: Schriewer, Keiner \& Charle (Hrsg.) [1993] S. 183-212.

Harwood, Jonathan [2000]a 'The Rise of the Party-Political Professor? Changing Self-understandings amoung German Academics, 1890-1933', in: Kaufmann (Hrsg.) [2000] S. 21-45.

Harwood, Jonathan [2000]b 'Das Selbstverständnis des Naturwissenschaftlers im Wandel. Die Lage innerhalb und außerhalb der Akadmie zu Beginn des 20. Jahrhunderts', in: Fischer (Hrsg.) [2000] S. 143-168.

Harwood, Jonathan [2002] 'Forschertypen im Wandel 1880-1930‘, in: Bruch \& Kaderas (Hrsg.) [2002] S. 162168.

Haude, Rüdiger [1993] Dynamiken des Beharrens. Die Geschichte der Selbstverwaltung der RWTH Aachen seit 1945. Ein Beitrag zur Theorie der Reformprozesse, Aachen: Alano.

Haude, Rüdiger [1998] 'Die Nachkriegssituation an deutschen Hochschulen - Wer machte Karriere?', in: Ungeahntes Erbe. Der Fall Schneider/Schwerte: Persilschein für eine Lebenslüge, hrsg. vom Antirassismus-Referat der Studentischen Versammlung an der Friedrich-Alexander-Universität ErlangenNürnberg, Aschaffenburg: Alibri, 1998, S. 48-60.

Haxel, Otto [1982] 'Erinnerungen an Hans Geiger, den Vater der Zählmethode', Physikalische Blätter 38 (1982), S. 296-297.

Haxel, Otto [1994] 'Wie ich die Entstehung der Physik der Atomkerne erlebte', in: Marx \& Moses (Hrsg.) [1994] S. 63-95.

Hearnden, Arthur (Hrsg.) [1978] The British in Germany. Educational Reconstruction after 1945, London: Hamish Hamilton.

Heber, Johann [1999] 'Nachruf auf Karl-Heinz Hellwege', Physikalische Blätter 55 (1999), S. 70.

Heckmann, Otto [1976] Sterne, Kosmos, Weltmodelle, München u. a.: Piper.

Heiber, Helmut [1991-94] Universität unterm Hakenkreuz, München u. a.: Saur.

Heiland, Gerhard [1984] 'Erich Mollwo zum 75. Geburtstag', Physikalische Blätter 40 (1984), S. 231-232.

Heim, Susanne [2000] '»Vordenker der Vernichtung«. Wissenschaftliche Experten als Berater der nationalsozialistischen Politik', in: Kaufmann (Hrsg.) [2000] S. 7-91.

Heimpel, Hermann [1986] 'Neubeginn 1945', in: Heimpel, Kamp \& Kertz [1986] S. 11-22.

Heimpel, Hermann, Norbert Kamp \& Walter Kertz [1986] Der Neubeginn der Georgia Augusta zum Wintersemester 1945-46: akademische Feier zur Erinnerung an die Wiedereröffnung der Georgia Augusta vor 40 Jahren am 29. November 1985 im Zentralen Hörsaalgebäude der Georg-AugustUniversität Göttingen, Göttingen: Vandenhoeck \& Ruprecht.

Hein, Katharina [1995] Adolf Baeumker (1891-1976). Einblicke in die Organisation von Luft- und Raumfahrtforschung von 1920 bis 1970, Göttingen: DLR.

Heinemann, Manfred [1983] 'Hochschulgeschichte der Nachkriegszeit', Bildung und Erziehung 36 (1983), S. 14.

Heinemann, Manfred [1990]a '1945: Universitäten aus britischer Sicht', in: Heinemann (Hrsg.) [1990]a S. 4160.

Heinemann, Manfred [1990]b 'Der Wiederaufbau der Kaiser-Wilhelm-Gesellschaft und die Neugründung der Max-Planck-Gesellschaft (1945-1949)‘, in: Vierhaus \& Brocke (Hrsg.) [1990] S. 407-470.

Heinemann, Manfred [2001] 'Überwachung und »Inventur« der deutschen Forschung. Das Kontrollratsgesetz Nr. 25 und die alliierte Forschungskontrolle im Bereich der Kaiser-Wilhelm-/Max-Planck-Gesellschaft (KWG/MPG) 1945-1955', in: Mertens (Hrsg.) [2001] S. 167-199.

Heinemann, Manfred (Hrsg.) [1981] Umerziehung und Wiederaufbau. Die Bildungspolitik der Besatzungsmächte in Deutschland und Österreich, Stuttgart: Klett-Cotta.

Heinemann, Manfred (Hrsg.) [1990]a Hochschuloffiziere und Wiederaufbau des Hochschulwesens in Westdeutschland 1945-1952. Teil 1: Die Britische Zone, Hildesheim: Lax.

Heinemann, Manfred (Hrsg.) [1990]b Hochschuloffiziere und Wiederaufbau des Hochschulwesens in Westdeutschland 1945-1952. Teil 2: Die US-Zone, Hildesheim: Lax.

Heinemann, Manfred (Hrsg.) [1990]c Nordwestdeutsche Hochschulkonferenzen 1945-1948. Teil 1, Hildesheim: Lax.

Heinemann, Manfred (Hrsg.) [1990]d Nordwestdeutsche Hochschulkonferenzen 1945-1948. Teil 2, Hildesheim: Lax. 
Heinemann, Manfred (Hrsg.) [1991] Hochschuloffiziere und Wiederaufbau des Hochschulwesens in Westdeutschland 1945-1952. Teil 3: Die Französische Zone, Hildesheim: Lax.

Heinemann, Manfred (Hrsg.) [1996] Vom Studium generale zur Hochschulreform, Berlin: Akademie Verlag. Heinemann, Manfred (Hrsg.) [1997] Süddeutsche Hochschulkonferenzen 1945-1949, Berlin : Akademie Verlag. Heinemann, Manfred (Hrsg.) [1999] Zwischen Restauration und Innovation. Bildungreformen in Ost und West nach 1945, Köln u. a.: Böhlau.

Heinemann, Manfred \& Ullrich Schneider [1983] 'Akten zur Geschichte des Hochschulwesens in Westdeutschland nach 1945. Eine quellenkundliche Übersicht‘, Bildung und Erziehung 36 (1983), S. 77 89.

Heinemann-Grüder, Andreas [1994] 'Keinerlei Untergang: German Armaments Engineers during the Second World War and in the Service of the Victorious Powers', in: Renneberg \& Walker (Hrsg.) [1994] S. 3050 .

Heintze, Joachim [1984] 'Otto Haxel zum 75. Geburtstag', Physikalische Blätter 40 (1984), S. 105.

Heintze, Joachim [1998] 'Otto Haxel zum Gedenken', Physikalische Blätter 54 (1998), S. 356.

Heinz, Erhard [1972] 'Richard Courant. 8. Januar 1888 - 27. Januar 1972‘, Jahrbuch der Akademie der Wissenschaften in Göttingen 1972, S. 173-178.

Heisenberg, Elisabeth [1983] Das politische Leben eines Unpolitischen. Erinnerungen an Werner Heisenberg, München u. a.: Piper.

Heisenberg, Werner [1969] Der Teil und das Ganze, München: Piper.

Heisenberg, Werner [1970] 'Max Born zum Gedächtnis', Physikalische Blätter 26 (1970), S. 49-54.

Heisenberg, Werner [1971] 'Das Kaiser-Wilhelm-Institut für Physik, Geschichte eines Instituts', Jahrbuch der Max-Planck-Gesellschaft zur Förderung der Wissenschaften 1971, S. 46-89.

Heisenberg, Werner [1989] Gesammelte Werke, hrsg. von Walter Blum, Hans-Peter Dürr \& Helmut Rechenberg, Berlin u. a.: Springer, München u. a.: Piper.

Heisenberg, Wolfgang [1993] 'Erinnerungen an meinen Vater', in: Geyer, Herwig \& Rechenberg (Hrsg.) [1993] S. 31-41.

Heiß, Gernot, Siegfried Mattl, Sebastian Meissl, Edith Saurer \& Karl Stuhlpfarrer (Hrsg.) [1989] Willfährige Wissenschaft. Die Universität Wien 1938-1945, Wien: Verlag für Gesellschaftskritik.

Heller, August [1882-1884] Geschichte der Physik von Aristoteles bis auf die neueste Zeit, 2 Bde., Stuttgart: Enke.

Hellmich, Waldemar [1948] 'Der geistige Aufbruch der deutschen Ingenieure', Zeitschrift des Vereines Deutscher Ingenieure 90 (1948), S. 2-7.

Helwig, Gisela \& Hildegard Maria Nickel (Hrsg.) [1993] Frauen in Deutschland 1945-1992, Berlin: Akademie Verlag.

Henisch, Heinz Karl (Hrsg.) [1951] Semi-Conducting Materials, London: Butterworth Scientific Publications.

Henke, Klaus-Dietmar [1986] 'Die Grenzen der politischen Säuberung in Deutschland nach 1945', in: Herbst (Hrsg.) [1986] S. 127-133.

Hentschel, Klaus [1990] Interpretationen und Fehlinterpretationen der speziellen und der allgemeinen Relativitätstheorie durch Zeitgenossen Albert Einsteins, Basel: Birkhäuser.

Hentschel, Klaus [2002] 'Spectroscopy or Spektroscopies?', Nuncius 17 (2002), S. 589-614.

Hentschel, Klaus \& Gerhard Rammer [2000] 'Kein Neuanfang: Physiker an der Universität Göttingen 19451955', Zeitschrift für Geschichtswissenschaft 48 (2000), S. 718-741.

Hentschel, Klaus \& Gerhard Rammer [2001] 'Physicists at the University of Göttingen, 1945-1955 ', Physics in Perspective 3 (2001), S. 189-209.

Hentschel, Klaus \& Gerhard Rammer [2003] 'Nachkriegsphysik an der Leine: eine Göttinger Vogelperspektive', in: Dieter Hoffmann (Hrsg.) [2003] S. 27-56.

Hentschel, Klaus \& Monika Renneberg [1994] '»Ausschaltung« oder »Verteidigung« der allgemeinen Relativitätstheorie - Interpretationen einer Kosmologen-Karriere im Nationalsozialismus', in: Meinel \& Voswinckel (Hrsg.) [1994] S. 201-207.

Hentschel, Klaus \& Monika Renneberg [1995] 'Eine akademische Karriere. Der Astronom Otto Heckmann im »Dritten Reich«", Vierteljahrshefte für Zeitgeschichte 43 (1995), S. 581-610.

Hentschel, Klaus \& Renate Tobies [1996] 'Friedrich Hund zum 100. Geburtstag', Internationale Zeitschrift für Geschichte und Ethik der Naturwissenschaften, Technik und Medizin 4 (1996), S. 1-18.

Hentschel, Klaus \& Ann M. Hentschel (Hrsg.) [1996] Physics and National Socialism. An Anthology of Primary Sources, Basel: Birkhäuser.

Herbert, Ulrich [1998] 'NS-Eliten in der Bundesrepublik', in: Loth \& Rusinek (Hrsg.) [1998] S. 93-115.

Herbert, Ulrich (Hrsg.) [2002] Wandlungsprozesse in Westdeutschland. Belastung, Integration, Liberalisierung 1945-1980, Göttingen: Wallstein.

Herbst, Ludolf (Hrsg.) [1986] Westdeutschland 1945-1955. Unterwerfung, Kontrolle, Integration, München: Oldenbourg. 
Herf, Jeffrey [2000] '»Reactionary Modernism« and After: Modernity and Nazi Germany Reconsidered', in: Kaufmann (Hrsg.) [2000] S. 65-76.

Hering, Rainer [1991] 'Der »unpolitische« Professor? Parteimitgliedschaften Hamburger Hochschullehrer in der Weimarer Republik und im »Dritten Reich«‘, in: Krause, Huber \& Fischer (Hrsg.) [1991] S. 85-111.

Hering, Rainer [1994] 'Deutsch, völkisch, national: Parteipolitisches Engagement Hamburger Hochschullehrer in der Weimarer Republik und im »Dritten Reich «", in: Kertz (Hrsg.) [1994] S. 7-22.

Hermann, Armin [1973] Max Planck in Selbstzeugnissen und Bilddokumenten, Reinbek: Rowohlt.

Hermann, Armin [1979] Die neue Physik. Der Weg ins Atomzeitalter, München: Moos.

Hermann, Armin [1993] 'Werner Heisenberg im Urteil seiner Kollegen', in: Geyer, Herwig \& Rechenberg (Hrsg.) [1993] S. 47-55.

Hermann, Armin [1995] 'Die Deutsche Physikalische Gesellschaft 1899-1945', Physikalische Blätter 51 (1995), S. F-61-F-105.

Hermann, Grete [1945] Politik und Ethik, London: Welbecson Press.

Heß, Jürgen C., Hartmut Lehmann \& Volker Sellin (Hrsg.) [1996] Heidelberg 1945, Stuttgart: Steiner.

Hessenauer, Heike [2000] 'Studentinnen vor 1939 - Eine Fallstudie zur Entwicklung des Frauenstudiums', in: Dickmann \& Schöck-Quinteros (Hrsg.) [2000] S 315-327.

Hettner, Gerhard [1954] 'Georg Joos 60 Jahre', Physikalische Blätter 10 (1954), S. 230-231.

Heymann, Dagmar (Hrsg.) [1995] Elfenbisse. Feministische Naturwissenschaft, Mössingen-Talheim: Talheimer.

Hilberg, Raul [1961/97] Die Vernichtung der europäischen Juden, Frankfurt a. M.: Fischer, 29.-30. tausend. Aufl., 1997.

Hille, Barbara [1993] 'Geschlechtstypische Präferenzen und Benachteiligungen - Weibliche Jugendliche in Bildung, Ausbildung und Studium‘, in: Helwig \& Nickel (Hrsg.) [1993] S. 215-231.

Hinterberger, Monika [1996] »Man räume ihnen Kanzeln und Lehrstüle ein« - Zur Geschichte der Physikerinnen an der Universität Bonn, Bonn: Universität Bonn (Zoom, Schriftenreihe der Frauenbeauftragten der Rheinischen Friedrich-Wilhelms-Universität-Bonn, Band 2).

Hodge, Philip G. [1980] 'William Prager 1903-1980', Journal of Applied Mechanics 47 (1980), S. 225-226.

Hoer, Renate (Hrsg.) [1999] Chemie erlebt. 50 Jahre GDCh, Frankfurt a. M.: Gesellschaft Deutscher Chemiker.

Hoffmann, Dieter [1989] 'Die Physikdenkschriften von 1934/1936 und zur Situation der Physik im faschistischen Deutschland', in: Wissenschaft und Staat. Denkschriften und Stellungnahmen von Wissenschaftlern als Mittel wissenschaftspolitischer Artikulation, hrsg. vom Institut für Theorie, Geschichte und Organisation der Wissenschaft der Akademie der Wissenschaften der DDR, Berlin 1989, S. 185-211.

Hoffmann, Dieter [1995] 'Die Physikalische Gesellschaft (in) der DDR', Physikalische Blätter 51 (1995), S. F157-F-182.

Hoffmann, Dieter [2000] 'Das Verhältnis der Akademie zu Republik und Diktatur. Max Planck als Sekretar', in: Fischer (Hrsg.) [2000] S. 53-85.

Hoffmann, Dieter [2002] 'Carl Ramsauer, die Deutsche Physikalische Gesellschaft und die Selbstmobilisierung der Physikerschaft im »Dritten Reich«", in: Maier (Hrsg.) [2002] S. 273-304.

Hoffmann, Dieter [2003] Pascual Jordan im Dritten Reich - Schlaglichter, Max-Planck-Institut für Wissenschaftsgeschichte, Preprint 248.

Hoffmann, Dieter (Hrsg.) [1993] Operation Epsilon. Die Farm-Hall-Protokolle oder Die Angst der Alliierten vor der deutschen Atombombe, Berlin: Rowohlt.

Hoffmann, Dieter (Hrsg.) [2003] Physik im Nachkriegsdeutschland, Frankfurt a. M.: Deutsch.

Hoffmann, Dieter \& Mark Walker [1997] 'Der Physiker Friedrich Möglich (1902-1957) - Ein Antifaschist?‘, in: Hoffmann \& Macrakis (Hrsg.) [1997] S. 361-382.

Hoffmann, Dieter \& Rüdiger Stutz [2003] 'Grenzgänger der Wissenschaft. Abraham Esau als Industriephysiker, Universitätsrektor und Forschungsmanger', in: Hoßfeld, John, Lemuth \& Stutz (Hrsg.) [2003] S. 136179.

Hoffmann, Dieter, Fabio Bevilacqua \& Roger H. Stuewer (Hrsg.) [1996] The Emergence of modern physics, Pavia: Università degli Studi di Pavia.

Hoffmann, Dieter \& Kristie Macrakis (Hrsg.) [1997] Naturwissenschaft und Technik in der DDR, Berlin: Akademie Verlag.

Hoffmann, Dietrich \& Kathrin Maack-Rheinländer (Hrsg.) [2001] »Ganz für das Studium angelegt«: Die Museen, Sammlungen und Gärten der Universität Göttingen, Göttingen: Wallstein.

Hohlfeld, Rainer [2000] 'Die Differenzierung der Naturwissenschaften und ihre Repräsentation in der Akademie 1914-1945', in: Fischer (Hrsg.) [2000] S. 459-481.

Hopkins, H. G. [1980] 'Obituary Professor William Prager', International Journal of Mechanical Sciences 22 (1980), S. 393-394.

Hoppe, Edmund [1926] Geschichte der Physik, Braunschweig: Vieweg. 
Hörisch, Jochen [1998] '»Verhaften Sie die üblichen Verdächtigen«. Unheimliche Dimensionen in den Fällen Schwerte/Schneider, de Man, Jauß‘, in: Loth \& Rusinek (Hrsg.) [1998] S. 181-195.

Horn, Gisela (Hrsg.) [1999] Die Töchter der Alma mater Jenensis. Neunzig Jahre Frauenstudium an der Universität von Jena, Rudolstadt u. a.: Hain.

Hoßfeld, Uwe [1999] 'Die Jenaer Jahre des »Rasse-Günther« von 1930 bis 1935‘, Medizinhistorisches Journal 34 (1999), S. 47-103.

Hoßfeld, Uwe, Jürgen John \& Rüdiger Stutz [2003] 'Weaving Networks. The University of Jena in the Weimar Republic, The Third Reich, and the postwar East German state', in: Walker (Hrsg.) [2003] S. 186-226.

Hoßfeld, Uwe, Jürgen John, Oliver Lemuth \& Rüdiger Stutz (Hrsg.) [2003] »Kämpferische Wissenschaft«. Studien zur Universität Jena im Nationalsozialismus, Köln u. a.: Böhlau.

Hoyer, Ulrich [1993] 'Walther Gerlach (1889-1979)', in: Albrecht (Hrsg.) [1993] S. 133-142.

Huber, C. \& W. J. Bogers [1983] The Schuler Principle: A discussion of some facts and misconceptions, Eindhoven: University of Technology.

Huber, E. R. [1976] 'Rudolf Smend. 15. Januar 1882 -5. Juli 1975', Jahrbuch der Akademie der Wissenschaften in Göttingen 1976, S. 105-121.

Hückel, Erich [1975] Ein Gelehrtenleben. Ernst und Satire, Weinheim: Verlag Chemie.

Huerkamp, Claudia [1994] 'Weibliche Konkurrenz auf dem akademischen Arbeitsmärkten', in: Tenfelde \& Wehler (Hrsg.) [1994] S. 273-288.

Huerkamp, Claudia [1996]a Bildungsbürgerinnen: Frauen im Studium und in akademischen Berufen 19001945, Göttingen: Vandenhoeck \& Ruprecht.

Huerkamp, Claudia [1996]b 'Geschlechterspezifischer numerus clausus - Verordnung und Realität', in: Elke Kleinau \& Claudia Opitz (Hrsg.): Geschichte der Mädchen- und Frauenbildung. Band 2: Vom Vormärz bis zur Gegenwart, Frankfurt a. M.: Campus, 1996, S. 325-341.

Hund, Friedrich [1969] 'Höhepunkte der Göttinger Physik', Physikalische Blätter 25 (1969), S. 145-153, 210 215.

Hund, Friedrich [1976] 'Werner Heisenberg. 5. Dezember 1901 - 1. Februar 1976', Jahrbuch der Akademie der Wissenschaften in Göttingen 1976, S. 121-128.

Hund, Friedrich [1982] 'Max Born, Göttingen und die Quantenmechanik', Physikalische Blätter 38 (1982), S. 349-351.

Hund, Friedrich [1987] Die Geschichte der Göttinger Physik, Göttingen: Vandenhoeck \& Ruprecht.

Hund, Friedrich [1994] 'Die Geschichte der Physik an der Universität Göttingen‘, in: Schlotter (Hrsg.) [1994] S. 160-172.

Jäger, Ludwig [1998] Seitenwechsel. Der Fall Schneider/Schwerte und die Diskretion der Germanistik, München: Fink.

Jaeckel, Barbara \& Wolgang Paul [1970] 'Die Entwicklung der Physik in Bonn 1918-1968', in: Bonner Gelehrte. Beiträge zur Geschichte der Wissenschaften in Bonn, Bonn: Bouvier und Röhrscheid, 1970, S. 91-100.

Jansen, Dorothea [1999] Einführung in die Netzwerkanalyse. Grundlagen, Methoden, Anwendungen, Opladen: Leske und Budrich.

Jarausch, Konrad H. [1984] Deutsche Studenten 1800-1970, Frankfurt a. M.: Suhrkamp.

Jarausch, Konrad H. [1999] 'Das Humboldt-Syndrom: Die westdeutschen Universitäten 1945-1989 - Ein akademischer Sonderweg?', in: Ash (Hrsg.) [1999] S. 58-79.

Jaspers, Karl [1946] Die Idee der Universität, Berlin: Springer.

Jens, Walter [1977] Eine deutsche Universität. 500 Jahre Tübinger Gelehrtenrepublik, München: Kindler.

John, Eckhard, Bernd Martin, Marc Mück \& Hugo Ott (Hrsg.) [1991] Die Freiburger Universität in der Zeit des Nationalsozialismus, Freiburg i. Br. u. a.: Ploetz.

John, Jürgen [1998] 'Die Jenaer Universität im Jahre 1945‘, in: John, Wahl \& Arnold (Hrsg.) [1998] S. 12-74.

John, Jürgen, Volker Wahl \& Leni Arnold (Hrsg.) [1998] Die Wiedererüffnung der Friedrich-SchillerUniversität Jena 1945. Dokumente und Festschrift, Rudolstadt u. a.: Hain.

Johnson, Jeffrey A. \& Roy M. MacLeod [2002] 'War Work and Scientific Self-Image. Pursuing Comparative Perspectives on German and Allied Scientists in the Great War', in: Bruch \& Kaderas (Hrsg.) [2002] S. 169-179.

Jonas, Hans [1991] 'Erinnerungen an Göttingen, Sommer 1945`, Göttinger Jahrbuch 1991, S. 199-203.

Jordan, Carlo [2001] Kaderschmiede Humboldt-Universität zu Berlin. Aufbegehren, Säuberung und Militarisierung 1945-1989, Berlin: Christoph Links.

Jordan, Pascual [1975] 'Die Anfangsjahre der Quantenmechanik - Erinnerungen“, Physikalische Blätter 31 (1975), S. 97-103.

Judt, Matthias \& Burghard Ciesla (Hrsg.) [1996] Technology transfer out of Germany after 1945, Amsterdam u. a.: Harwood. 
Jungk, Robert [1956/90] Heller als tausend Sonnen. Das Schicksal der Atomforscher, München: Heyne, 1990 (1. Aufl. 1956).

Jürgensen, Kurt [1981] 'Zum Problem der »Political Re-education«‘, in: Heinemann (Hrsg.) [1981] S. 114-139.

Jürgensen, Kurt [1990] 'Was there a British Policy towards Higher Education? Some retrospective thoughts on the Oxford Symposium‘, in: Heinemann (Hrsg.) [1990]a S. 79-84.

Kaiser, Walter [1995] 'Zur historischen Problematik des Übergangs von Grundlagenwissen in die technische Anwendung', in: Frieß \& Steiner (Hrsg.) [1995] S. 76-90.

Kaiser, Walter [1997] 'Wissenschaft und Technik nach 1945', in: König, Kuhlmann \& Schwabe (Hrsg.) [1997] S. 241-256.

Kalkmann, Ulrich [1997] 'Die TH Aachen unter dem Nationalsozialismus', in: König, Kuhlmann \& Schwabe (Hrsg.) [1997] S. 146-161.

Kamke, Detlef [1980] 'Prof. Dr. Ing., Dr. rer. nat. h. c. Wilhelm Walcher 70 Jahre', Physikalische Blätter 36 (1980), S. 234-235.

Kamp, Michael [2002] Die Geschichte der Physik an der Ludwig-Maximilians-Universität München, München: Buchendorfer Verlag.

Kamp, Norbert [1986] 'Die Georgia Augusta als Exemplum', in: Heimpel, Kamp \& Kertz [1986] S. 5-10.

Kant, Horst [1988] 'Die Entstehung und Entwicklung der Festkörperphysik', in: Schreier (Hrsg.) [1988] S. 363 373.

Kant, Horst [1992] 'Institutsgründung in schwieriger Zeit: 75 Jahre Kaiser-Wilhelm/Max-Planck Institut für Physik', Physikalische Blätter 48 (1992), S. 1031-1033.

Kant, Horst [1993] 'Peter Debye und das Kaiser-Wilhelm-Institut für Physik in Berlin', in: Albrecht (Hrsg.) [1993] S. 161-177.

Kant, Horst [1997] Zur Geschichte der Physik an der Reichsuniversität Straßburg in der Zeit des Zweiten Weltkrieges, Berlin: Max-Planck-Institut für Wissenschaftsgeschichte, Reprint 73.

Karner, Stefan [1979] 'Die Steuerung der V-2. Zum Anteil der Firma Siemens an der Entwicklung der ersten selbstgesteuerten Großrakete', Technikgeschichte 46 (1979), S. 45-66.

Kath, Gerhard [1952] Das soziale Bild der Studentenschaft in Westdeutschland und Berlin, Frankfurt a. M.

Kath, Gerhard [1954] Das soziale Bild der Studentenschaft in Westdeutschland und Berlin, Berlin: Colloquium Verlag.

Kath, Gerhard [1957] Das soziale Bild der Studentenschaft in Westdeutschland und Berlin, Berlin: Colloquium Verlag.

Kath, Gerhard [1960] Das soziale Bild der Studentenschaft in Westdeutschland und Berlin, Berlin: Colloquium Verlag.

Kaufmann, Doris (Hrsg.) [2000] Geschichte der Kaiser-Wilhelm-Gesellschaft im Nationalsozialismus. Bestandsaufnahme und Perspektiven der Forschung, 2 Bde., Göttingen: Wallstein.

Kellmann, Klaus [1989] 'Literaturbericht. Deutsche Geschichte nach 1945', Geschichte in Wissenschaft und Unterricht 6 (1989), S. 353-381.

Kendall, James T. [1947] 'Science and Technical Education in Germany. International Congress for Technical Education', Nature 160 (1947), S. 721-722.

Kepp, Richard Kurt [1949] 'Naturwissenschaftliche Fragen auf dem 27. Deutschen Gynäkologenkongreß in Karlsruhe vom 20. bis 23. April 1949“, Die Naturwissenschaften 36 (1949), S. 340-342.

Kerber, Wolfgang (Hrsg.) [1993] Österreichische Mathematik und Physik. Wolfgang Gröbner-Richard von Mises - Wolfgang Pauli, Wien: Zentralbibliothek für Physik in Wien.

Kern, Ulrich [1994] Forschung und Präzisionsmessung. Die Physikalisch-Technische Reichsanstalt zwischen 1918 und 1948, Weinheim u. a.: VCH.

Kernbauer, Alois [1996] 'Statistik des Frauenstudiums an der Universität Graz im Zeitraum 1910-1963', in: Kernbauer \& Schmidlechner-Lienhart (Hrsg.) [1996] S. 167-192.

Kernbauer, Alois \& Karin Schmidlechner-Lienhart (Hrsg.) [1996] Frauenstudium und Frauenkarrieren an der Universität Graz, Graz: Akademische Druck- und Verlagsanstalt.

Kersten, Martin [1976] 'Eberhard Buchwald *16.7.1886 †14.8.1975‘, Physikalische Blätter 32 (1976), S. 353360.

Kersten, Martin [1978] 'Richard Becker 1887-1955. Laudatio zur feierlichen Enthüllung einer Gedenktafel am Hause Herzberger Landstraße 58 in Göttingen am 3. Dezember 1977`, Physikalische Blätter 34 (1978), S. 379-382.

Kertz, Walter [1986] 'Student im Wintersemester 1945/46', in: Heimpel, Kamp \& Kertz [1986] S. 23-35.

Kertz, Walter (Hrsg.) [1993] Hochschullehrer an Technischen Hochschulen und Universitäten: Sozialgeschichte, soziodemographische Strukturen und Karrieren im Vergleich, Braunschweig: Universitätsbibliothek der Technischen Universität.

Kertz, Walter (Hrsg.) [1994] Hochschule und Nationalsozialismus, Braunschweig: Universitätsbibliothek der TH Braunschweig. 
Kertz, Walter (Hrsg.) [1995]a Technische Hochschulen und Studentenschaft in der Nachkriegszeit, Braunschweig: Universitätsbibliothek der TH Braunschweig.

Kertz, Walter (Hrsg.) [1995]b Technische Universität Braunschweig. Vom Collegium Carolinum zur Technischen Universität 1745-1995, Hildesheim u.a.: Olms.

Kesaris, Paul L. (Hrsg.) [1979] The Rote Kapelle. The CIA's History of Soviet Intelligence and Espionage Networks in Western Europe, 1936-1945, Washington: Univ. Pupl. of America.

Keßler, G. [1994] 'Zum Gedenken an Karl Wirtz', Physikalische Blätter 50 (1994), S. 867.

Kettenacker, Lothar [1984] 'Preußen-Deutschland als britisches Feindbild im zweiten Weltkrieg', in: Wendt (Hrsg.) [1984] S. 145-168.

Khriplovich, Iosif B. [1992] 'The eventful life of Fritz Houtermans', Physics Today 45 (1992), July, S. 29-37.

Killy, Walther [1952] Studium Generale und studentisches Gemeinschaftsleben, Berlin: Duncker \& Humblot.

Kistiakowsky, Vera [1980] 'Women in physics: unnecessary, injurious and out of place?', Physics Today 33 (1980) February, S. 32-40.

Kistner, Adolf [1906] Geschichte der Physik, 2 Bände, Leipzig: Göschen.

Kleinert, Andreas [1978] 'Vom Trieb zur theoretischen Physik', Physikalische Blätter 34 (1978) S. 31-32.

Kleinert, Andreas [1983] 'Das Spruchkammerverfahren gegen Johannes Stark', Sudhoffs Archiv 67 (1983), S. 13-24.

Kleinert, Andreas \& Christoph J. Scriba [1997] 'Der Nachlaß von Hans Schimank (1888-1979). Bericht über ein Seminar', Acta historica Leopoldina 27 (1997), S. 287-314.

Kleint, Christian \& Gerald Wiemers (Hrsg.) [1993] Werner Heisenberg in Leipzig 1927-1942, Berlin: Akademie-Verlag.

Klemperer, Victor [1957/99] LTI, Leipzig: Reclam, 18. Aufl. 1999.

Klofat, Rainer [1994] 'Das letzte Interview [mit Wolfgang Paul]', Alexander von Humboldt Stiftung, Mitteilungen 63, Juli 1994, S. 4-6.

Klumb, H. [1944] 'Ziele und Wege der physikalischen Forschung', Physikalische Blätter 1 (1944), S. 41-43.

Kneser, Hellmuth [1949] 'Felix Klein als Mathematiker', in: Universitätsbund Göttingen e. V., Jg. 26, Mitteilungen 1949, S. 1-6.

Knigge-Tesche, Renate (Hrsg.) [1999] Berater der braunen Macht. Wissenschaft und Wissenschaftler im NSStaat, Frankfurt a. M.: Anabas-Verlag.

Knop, Gerhard [1973] 'Betatron und Elektronenstreuung،, in: Bennewitz (Hrsg.) [1973] S. 19-22.

Knop, Gerhard [1988] 'Wolfgang Paul zum 75. Geburtstag', Physikalische Blätter 44 (1988), S. 464.

Kohl, Ulrike [2002] Die Präsidenten der Kaiser-Wilhelm-Gesellschaft im Nationalsozialismus. Max Planck, Carl Bosch und Albert Vögler zwischen Wissenschaft und Macht, Stuttgart: Franz Steiner.

Kohler, Max [1978] 'Nachruf auf Reinhold Mannkopff', Physikalische Blätter 34 (1978), S. 436-437.

Kohler, Max [1982] 'Max von Laue. Nobelpreisträger für Physik', Göttinger Jahrbuch 1982, S. 210-213.

Kollath, R. [1947] 'Die Betatron-Entwicklung in Deutschland', Physikalische Blätter 3 (1947), S. 180-184.

König, Helmut, Wolfgang Kuhlmann \& Klaus Schwabe (Hrsg.) [1997] Vertuschte Vergangenheit. Der Fall Schwerte und die NS-Vergangenheit der deutschen Hochschulen, München: Beck.

König, Helmut (Hrsg.) [1998] Der Fall Schwerte im Kontext, Opladen: Westdeutscher Verlag.

Konvent der Philipps-Universität (Hrsg.)[1996] Die Philipps-Universität im Nationalsozialismus, Marburg: Philipps-Universität.

Kossel, Walther [1942] 'Zu P. Lenards achtzigstem Geburtstag', Die Naturwissenschaften 30 (1942), S. $317-$ 318.

Kossel, Walther [1950] 'Zu Max von Laue's 70. Geburtstag', Zeitschrift für Naturforschung 5a (1950), S. 64.

Kossel, Walther [1954] 'Max von Laue 75 Jahre', Physikalische Blätter 10 (1954), S. 513-514.

Kraemer, K. \& E. A. Müller [1968] 'Walter Tollmien. 13. Oktober 1900 - 25. November 1968‘, Jahrbuch der Akademie der Wissenschaften in Göttingen 1968, S. 86-90.

Kraemer, K. [1975] 'Geschichte der Gründung des Max-Planck-Instituts für Strömungsforschung in Göttingen', in: Max-Planck-Institut für Strömungsforschung Göttingen 1925-1975. Festschrift zum 50jährigen Bestehen des Instituts, S. 16-34.

Kragh, Helge [1999] Quantum Generations. A History of Physics in the Twentieth Century, Princeton: Princeton University Press.

Kramer, Dieter \& Christina Vanja (Hrsg.) [1977] Universität und demokratische Bewegung. Ein Lesebuch zur 450-Jahrfeier der Philipps-Universität Marburg, Marburg: Verlag Arbeiterbewegung und Gesellschaftswissenschaft.

Krämer, Jörg D. [2001] Das Verhältnis der politischen Parteien zur Entnazifizierung in Nordrhein-Westfalen, Frankfurt a. M. u. a.: Lang.

Kramish, Arnold [1986] Der Greif. Paul Rosbaud - der Mann, der Hitlers Atompläne scheitern ließ, München: Kindler. 
Krammer, Hilde \& Elisabeth Bartsch [1992/99] Lexikon Nationalsozialismus. Begriffe, Organisationen und Institutionen, Reinbek: Rowohlt, 1999 (1. Aufl. 1992).

Kraus, Elisabeth [2001] Von der Uranspaltung zur Göttinger Erklärung. Otto Hahn, Werner Heisenberg, Carl Friedrich von Weizsäcker und die Verantwortung des Wissenschaftlers, Würzburg: Königshausen \& Neumann.

Krause, Christiane [1994] Studenten im Aufbruch. Ein Beitrag nicht nur zur Rostocker Universitätsgeschichte, Rostock: Norddeutscher Hochschulschriften Verlag.

Krause, Eckart, Ludwig Huber \& Holger Fischer (Hrsg.) [1991] Hochschulalltag im »Dritten Reich«. Die Hamburger Universität 1933-1945, Berlin u. a.: Reimer.

Kreutzer, Karl \& Heinrich Müller [1944] Physik in der Kriegsmarine. Ein Beitrag zur Wehrphysik, Berlin: Heymanns.

Krieger, Wolfgang [1995] 'Forschung und Staat', in: Frieß \& Steiner (Hrsg.) [1995] S. 91-111.

Kroebel, Werner [1958] 'Ernst Lamla 70 Jahre', Physikalische Blätter 14 (1958), S. 513-514.

Kroebel, Werner [1982] 'Zum 100. Geburtstag von James Franck', Physikalische Blätter 38 (1982), S. 269-270.

Krohn, Claus-Dieter [2002] 'Deutsche Wissenschaftsemigration seit 1933 und ihre Remigrationsbarrieren nach 1945‘, in: Bruch \& Kaderas (Hrsg.) [2002] S. 437-452.

Krohn, Wolfgang \& Günter Küppers [1989] Die Selbstorganisation der Wissenschaft, Frankfurt a. M.: Suhrkamp.

Krönig, Waldemar [1995] 'Studentische Existenz in Ost und West 1945-1961', in: Kertz (Hrsg.) [1995]a S. 5160.

Krönig, Waldemar \& Klaus-Dieter Müller [1990] Nachkriegs-Semester. Studium in Kriegs- und Nachkriegszeit, Stuttgart: Steiner.

Krukowska, Uta [1993] Die Studierenden an der Universität Hamburg in den Jahren 1945-1950, Dissertation Hamburg.

Kucklich, Clarissa (Hrsg.) [1994] Unternehmen Zukunft. Frauen erobern die Naturwissenschaft und die Technik, Frankfurt a. M. u. a.: Lang.

Kuhn, Annette [1994] 'Die stille Kulturrevolution der Frau. Versuch einer Deutung der Frauenöffentlichkeit (1945-1947)', in: Clemens (Hrsg.) [1994] S. 83-101.

Kuhn, Annette, Valentine Rothe \& Brigitte Mühlenbruch (Hrsg.) [1996] 100 Jahre Frauenstudium. Frauen der Rheinischen Friedrich-Wilhelms-Universität Bonn, Dortmund: Ebersbach.

Kuhn, Thomas S. [1962/97] Die Struktur wissenschaftlicher Revolutionen, Frankfurt a. M.: Suhrkamp, 14. Aufl., 1997.

Kuhn, Thomas S. [1969/97] 'Postscriptum - 1969‘, in: Kuhn [1962/97] S. 186-221.

Küpfmüller, K. [1944] 'Zur Geschichte des Elektronenmikroskops', Physikalische Zeitschrift 45 (1944), S. 4751.

Kurz, Lothar \& Klaus Witte [1980] 'Die Entnazifizierung an der Universität Münster', in: Kurz (Hrsg.) [1980] S. 117-126.

Kurz, Lothar (Hrsg.) [1980] 200 Jahre zwischen Dom und Schloß. Ein Lesebuch zu Vergangenheit und Gegenwart der Westfälischen Wilhelms-Universität Münster, Münster: Selbstverl. d. Verf.

Kuttruff, Heinrich [1969] 'Erwin Meyer zum 70. Geburtstag', Physikalische Blätter 25 (1969), S. 324.

Laak, Dirk van [1998] 'Trotz und Nachurteil. Rechtsintellektuelle im Anschluß an das »Dritte Reich»', in: Loth \& Rusinek (Hrsg.) [1998] S. 55-54.

Laitko, Hubert [2002] 'Wissenschaftler im Berlin der frühen Nachkriegszeit. Bausteine und Fragestellungen zu einem Soziogramm', in: Bruch \& Kaderas (Hrsg.) [2002] S. 373-392.

Landrock, Konrad [2003] 'Friedrich Georg Houtermans (1903-1966) - Ein bedeutender Physiker des 20. Jahrhunderts', Naturwissenschaftliche Rundschau, 56 (2003), S. 187-199.

Laukien, Günther [1981] 'Hans Otto Kneser 80 Jahre', Physikalische Blätter 37 (1981), S. 274-275.

Lauterborn, Werner [2000] 'Walter Tollmien (1900-1968). Professor für Angewandte Mechanik und Strömungsphysik an der Universität Göttingen‘, Göttinger Jahrbuch 2000, S. 197-198.

Lauterer-Pirner, Heidi \& Margret Schepers-S.-W. [1985/86] 'Studentin in Heidelberg', in: Buselmeier, Harth \& Jansen (Hrsg.) [1985/86] S. 101-122.

Lawson, Robert F. [1981] 'Die Politik der Umstände. Eine Kritik der Analysen des Bildungswandels im Nachkriegsdeutschland‘, in: Heinemann (Hrsg.) [1981] S. 23-39.

Leggewie, Claus [1998] Von Schneider zu Schwerte. Das ungewöhnliche Leben eines Mannes, der aus der Geschichte lernen wollte, München u. a.: Hanser.

Lemmerich, Jost [1982] Max Born, James Franck. Physiker in ihrer Zeit. Der Luxus des Gewissens, Wiesbaden: Reichert.

Lemmerich, Jost [1987]a Zur Geschichte der Physik an der Technischen Hochschule Berlin-Charlottenburg, Berlin: David-Verlag-Gesellschaft. 
Lemmerich, Jost [1987]b Maß und Messen - Ausstellung aus Anlaß der Gründung der PhysikalischTechnischen Reichsanstalt vor 100 Jahren, Berlin: Physikalisch-Technische Bundesanstalt Braunschweig und Berlin.

Lemuth, Oliver \& Rüdiger Stutz [2003] '»Patriotic Scientists«: Jenaer Physiker und Chemiker zwischen berufsständischen Eigeninteressen und »vaterländischer Pflichterfüllung «", in: Hoßfeld, John, Lemuth \& Stutz (Hrsg.) [2003] S. 596-678.

Lenard, Philipp [1929/43] Große Naturforscher. Eine Geschichte der Naturforschung in Lebensbeschreibungen, München: Lehmann, 6. Aufl., 1943.

Lichtenberger-Fenz, Brigitte [1989] 'Österreichs Universitäten und Hochschulen - Opfer oder Wegbereiter der nationalsozialistischen Gewaltherrschaft? (Am Beispiel der Universität Wien)`, in: Heiß, Mattl, Meissl, Saurer \& Stuhlpfarrer (Hrsg.) [1989] S. 3-15.

Lietzmann, Walter [1949] 'Felix Klein und der mathematische Unterricht', in: Universitätsbund Göttingen e. V., Jg. 26, Mitteilungen 1949, S. 11-16.

Lilienthal, Dorothee [1949] 'Die Frau als Physikerin', Physikalische Blätter 5 (1949), S. 95-97.

Linnemann, Kai Arne [2002] 'Die Wiederkehr des akademischen Bürgers. Herman Nohl und die Pädagogik der Sittlichkeit‘, in: Weisbrod (Hrsg.) [2002] S. 167-189.

Litten, Freddy [1995] 'Forschungsbericht: »Das Schicksal der Naturissenschaftler an der Universität München 1945-1949«", Berichte zur Wissenschaftsgeschichte 18 (1995), S. 34-36.

Litten, Freddy [2000] Mechanik und Antisemitismus. Wilhelm Müller (1880-1968), München: Institut für Geschichte der Naturwissenschaften.

Lockenour, Jay [2002] Soldiers as Citizens: Former Wehrmacht Officers in the Federal Republic of Germany, 1945-1955, Lincoln: University of Nebraska Press.

Lohmann, Adolf W. [1994]a 'In memoriam Erich Mollwo', Physikalische Blätter 50 (1994), S. 1158.

Lohmann, Adolf W. [1994]b 'Erich Mollwo', Bayerische Akademie der Wissenschaften, Jahrbuch 1994, S. 232234.

Lohmeier, Dieter \& Bernhardt Schell (Hrsg.) [1992] Einstein, Anschütz, und der Kieler Kreiselkompaß, Heide: Westholsteinische Verlagsanstalt Boyens.

Lohse, Gerhart [1993] Die Bibliothek der Rheinisch-Westfälischen Technischen Hochschule Aachen in der Zeit des Nationalsozialismus und in den ersten Jahren des Wiederaufbaus (1933-1950), Aachen: Hochschulbibliothek der RWTH Aachen.

Lorenz, Charlotte [1943]a Zehnjahres-Statistik des Hochschulbesuchs und der Abschlußprüfungen. I. Band: Hochschulbesuch, hrsg. vom Reichsminister für Wissenschaft, Erziehung und Volksbildung, Berlin: Schmidt.

Lorenz, Charlotte [1943]b Zehnjahres-Statistik des Hochschulbesuchs und der Abschlußprüfungen. II. Band: Abschlußprüfungen, hrsg. vom Reichsminister für Wissenschaft, Erziehung und Volksbildung, Berlin: Schmidt.

Lorenz, Charlotte [1944] Die Entwicklung des Fachstudiums während des Krieges. Beilage zur ZehnjahresStatistik des Hochschulbesuchs und der Abschlussprüfungen, Berlin: Schmidt.

Lorenz, Charlotte [1953] Entwicklung und Lage der weiblichen Lehrkräfte an den wissenschaftlichen Hochschulen Deutschlands, Berlin: Duncker \& Humblot.

Loth, Wilfried \& Bernd-A. Rusinek (Hrsg.) [1998] Verwandlungspolitik. NS-Eliten in der westdeutschen Nachkriegsgesellschaft, Frankfurt a.M. u. a.: Campus.

Lübbe, Hermann [1983] 'Der Nationalsozialismus im deutschen Nachkriegsbewusstsein', Historische Zeitschrift 236 (1983), S. 579-599.

Ludwig, Karl-Heinz [1974/79] Technik und Ingenieure im Dritten Reich, Königstein/Ts.: Athenäum-Verlag, unveränd. Nachdr. 1979.

Lüscher, Edgar [1966] 'Physics in West Germany', Physics Today 19 (1966), Aug., S. 46-54.

Maaß, Rainer [1995]a 'Auf dem Weg zur Demokratie: Die Braunschweiger Studentenschaft der ersten Nachkriegssemester', in: Kertz (Hrsg.) [1995]a S. 79-93.

Maaß, Rainer [1995]b 'Zur Geschichte der Studentenschaft nach 1945`, in: Kertz (Hrsg.) [1995]b S. 645-667.

Maßß, Rainer [1998] Die Studentenschaft derTechnischen Hochschulen Braunschweig in der Nachkriegszeit, Husum: Matthiesen.

Mach, Ernst [1872] Die Geschichte und die Wurzel des Satzes von der Erhaltung der Arbeit, Prag: Calve.

MacKenzie, Donald [1993] Inventing Accuracy. A Historical Sociology of Nuclear Missile Guidance, Cambridge u. a.: MIT Press.

MacKenzie, Donald \& Graham Spinardi [1989] 'Politics and Technology in the Arm Race: A Case-Study in the History of Nuclear Weapons Systems', in: Visser, Bos, Palm \& Snelders (Hrsg.) [1989] S. 121-143.

Macrakis, Kristie [1986] 'Wissenschaftsförderung durch die Rockefellerstiftung im Dritten Reich', Geschichte und Gesellschaft 12 (1986), S. 348-379. 
Macrakis, Kristie [1993] Surviving the Swastika: The Kaiser-Wilhelm-Society 1933-1945, New York: Oxford University Press.

Macrakis, Kristie [2000] '»Surviving the Swastika« Revisited: The Kaiser-Wilhelm-Gesellschaft and Science Policy in Nazi Germany‘, in: Kaufmann (Hrsg.) [2000] S. 586-599.

Madelung, Otfried [2003] 'Schottky - Spenke - Welker. Erinnerungen an die »Gründerjahre« der Halbleiterphysik in Deutschland nach dem Zweiten Weltkrieg', in: Dieter Hoffmann (Hrsg.) [2003] S. 179-188.

Maerker, Dietrich von [1979] 'Die Zahlen der Studierenden an der Georg-August-Universität in Göttingen von 1734/37 bis 1978', Göttinger Jahrbuch 1979, S. 141-158.

Magnus, Kurt [1962] 'Max Schuler 80 Jahre‘, Zeitschrift für Flugwissenschaft 10 (1962), Heft 2, S. 66.

Magnus, Kurt [1968] 'Klassische Mechanik im Zeitalter der Raumfahrt?', Physikalische Blätter 24 (1968), S. 412.

Magnus, Kurt [1972]a 'Max Schuler 90 Jahre‘, Physikalische Blätter 28 (1972), S. 80-81.

Magnus, Kurt [1972]b ’Max Schuler †', Jahrbuch 1972 der DGLR, S. 456-461.

Magnus, Kurt [1993] Raketensklaven. Deutsche Forscher hinter rotem Stacheldraht, Stuttgart: Deutsche Verlags-Anstalt.

Magnus, Kurt (Hrsg.) [1993] 125 Jahre Technische Universität München, München: TU München.

Maier, Helmut [2002]a »Wehrhaftmachung « und »Kriegswichtigkeit«. Zur rüstungstechnologischen Relevanz des Kaiser-Wilhelm-Instituts für Metallforschung in Stuttgart vor und nach 1945, Ergebnisse 5, Vorabdruck aus dem Forschungsprogramm „Geschichte der Kaise-Wilhelm-Gesellschaft im Nationalsozialismus“, Berlin.

Maier, Helmut [2002]b 'Ideologie, Rüstung und Ressourcen. Das Kaiser-Wilhelm-Institut für Metallforschung und die »Deutschen Metalle« 1933-1945', in: Maier (Hrsg.) [2002] S. 357-388.

Maier, Helmut [2002]c '»Unidologische Normalwissenschaft« oder Rüstungsforschung? Wandlungen naturwissenschaftlich-technischer Forschung im »Dritten Reich «", in: Bruch \& Kaderas (Hrsg.) [2002] S. 253-262.

Maier, Helmut (Hrsg.) [2002] Rüstungsforschung im Nationalsozialismus. Organisation, Mobilisierung und Entgrenzung der Technikwissenschaften, Göttingen: Wallstein.

Maier-Leibnitz, Heinz [1974] 'Die große Zeit in Göttingen. Robert W. Pohl, ein Patriarch der Physik, wird neunzig', Frankfurter Allgemeine Zeitung, 10. August 1974.

Maier-Leibnitz, Heinz [1991]a 'Walther Bothe (1891-1957)', Physikalische Blätter 47 (1991), S. 62-64.

Maier-Leibnitz, Heinz [1991]b 'Wandlungen des Verhältnisses Wissenschaft - Politik - Öffentlichkeit in meiner Zeit‘, in: Oesterreicher-Mollwo (Hrsg.) [1991] S. 49-55.

Majer, Ulrich [1998] 'Vom Weltruhm der zanziger Jahre zur Normalität der Nachkriegszeit: Die Geschichte der Chemie in Göttingen von 1930 bis 1950‘, in: Becker, Dahms \& Wegeler (Hrsg.) [1987/98] S. 589-629.

Manegold, Karl Heinz [1968] 'Felix Klein als Wissenschaftsorganisator. Ein Beitrag zum Verhältnis von Naturwissenschaft und Technik im 19. Jahrhundert', Technikgeschichte 35 (1968), S. 177-204.

Mann, Are [1958] Denkschrift zur Lage der Physik, Wiesbaden: Steiner.

Mark, James [1990] 'The Art of the Possible. The British and German Universities, 1945-1948‘, in: Heinemann (Hrsg.) [1990]a S. 71-78.

Markus, Benno [1973] 'Anwendung des Betatrons in Biologie und Strahlentherapie‘, in: Bennewitz (Hrsg.) [1973] S. 23-28.

Marshall, Barbara [1989] 'British Democratisation Policy in Germany', in: Turner (Hrsg.) [1989] S. 189-214.

Martienssen, Werner [1974] 'Robert Wichard Pohl zum 90. Geburtstag', Physikalische Blätter 30 (1974), S. 313-314.

Martin, Bernd [1995] 'Die Entlassung der jüdischen Lehrkräfte an der Freiburger Universität und die Bemühung um ihre Wiedereingliederung nach 1945', Freiburger Universitätsblätter 34 (1995), Heft 129, S. 7-46.

Martius, Ursula Maria [1947] 'Videant consules ...', Deutsche Rundschau 70 (1947), Heft 11, S. 99-102.

Martius, Ursula Maria [1948] Die Anregung von Leuchtstoffen mit Gammastrahlen und Röntgenstrahlen verschiedener Wellenlänge, Dissertation Technische Universität Berlin-Charlottenburg.

Marx, Otto M. \& Annett Moses (Hrsg.) [1994] Emeriti erinnern sich. Rückblicke auf die Lehre und Forschung in Heidelberg, Bd. II, Die Naturwissenschaftlichen Fakultäten, Weinheim u. a.: VCH.

Mathematik, Physik, Chemie und Grenzgebiete. Literatur aus den Jahren 1945-1952, Berlin u. a.: Springer, 1952.

Mattes, Peter [1992] 'Die Charakterologen. Westdeutsche Psychologie nach 1945 ', in: Pehle \& Sillem (Hrsg.) [1992] S. 125-135.

'Das Max-Planck-Instituts für Strömungsforschung in Göttingen. Eine Übersicht zu seiner Entwicklung', in: Max-Planck-Institut für Strömungsforschung Göttingen 1925-1975. Festschrift zum 50jährigen Bestehen des Instituts, 1975, S. 11-15. 
Maurer, Margarete [1986] 'Die Verdrängung der Frauen aus Naturwissenschaft und Technik', in: Schlüter \& Kuhn (Hrsg.) [1986] S. 234-256.

Maurer, Margarete [1993] Frauenforschung in Naturwissenschaften, Technik und Medizin. Dokumentation und Bibliographie. Literatur, Zeitschriften, Adressen, Wien: Wiener Frauenverlag.

Mehrtens, Herbert [1979] 'Die Naturwissenschaften im Nationalsozialismus', in: Rürup (Hrsg.) [1979] S. 427443.

Mehrtens, Herbert [1980] 'Das Dritte Reich in der Naturwissenschaftsgeschichte: Literaturbericht und Problemskizze', in: Mehrtens \& Richter (Hrsg.) [1980] S. 15-87.

Mehrtens, Herbert [1990] 'Verantwortungslose Reinheit. Thesen zur politischen und moralischen Struktur mathematischer Wissenschaften am Beispiel des NS-Staates', in: Fülgraff \& Falter (Hrsg.) [1990] S. $37-$ 54.

Mehrtens, Herbert [1993] 'Abstrakte Außenseiter? Mathematiker an deutschen Technischen Hochschulen 18901950‘, in: Kertz (Hrsg.) [1993] S. 137-154.

Mehrtens, Herbert [1994]a 'Kollaborationsverhältnisse: Natur- und Technikwissenschaften im NS-Staat und ihre Historie', in: Meinel \& Voswinckel (Hrsg.) [1994] S. 13-32.

Mehrtens, Herbert [1994]b 'Irresponsible Purity: The Political and Moral Structure of Mathematical Sciences in the National Socialist State', in: Renneberg \& Walker (Hrsg.) [1994] S. 324-338.

Mehrtens, Herbert [1994]c 'The Social System of Mathematics and National Socialism: A Survey', in: Renneberg \& Walker (Hrsg.) [1994] S. 291-311.

Mehrtens, Herbert [1994]d 'Hochschule und Nationalsozialismus. Schlussbetrachtungen zum Hochschultag 1993‘, in: Kertz (Hrsg.) [1994] S. 173-187.

Mehrtens, Herbert [1995] '»Missbrauch«. Die rhetorische Konstruktion der Technik in Deutschland nach 1945', in: Kertz (Hrsg.) [1995]a S. 33-50.

Mehrtens, Herbert \& Steffen Richter (Hrsg.) [1980] Naturwissenschaft, Technik und NS-Ideologie. Beiträge zur Wissenschaftsgeschichte des Dritten Reiches, Frankfurt a. M.: Suhrkamp.

Meinecke, Friedrich [1946] Die deutsche Katastrophe. Betrachtungen und Erinnerungen, Wiesbaden: Brockhaus.

Meinel, Christoph (Hrsg.) [2000] Instrument-Experiment. Historische Studien, Berlin u. a.: GNT-Verlag.

Meinel, Christoph \& Peter Voswinckel (Hrsg.) [1994] Medizin, Naturwissenschaft, Technik und Nationalsozialismus. Kontinuitäten und Diskontinuitäten, Stuttgart: GNT-Verlag.

Meinel, Christoph \& Monika Renneberg (Hrsg.) [1996] Geschlechterverhältnise in Medizin, Naturwissenschaft und Technik, Bassum u. a.: GNT-Verlag.

Meißner, Walther [1954] 'Zum 60. Geburtstag von Georg Joos', Zeitschrift für angewandte Physik 6 (1954), S. 193-194.

Meißner, Walther [1959]a 'Georg Joos †‘, Physikalische Blätter 15 (1959), S. 320-321.

Meißner, Walther [1959]b 'Georg Joos', Bayerische Akademie der Wissenschaften, Jahrbuch 1959, S. 177-180.

Mertens, Lothar [1989] 'Die Entwicklung des Frauenstudiums in Deutschland bis 1945', Aus Politik und Zeitgeschichte 28 (1989), S. 3-12.

Mertens, Lothar [1991] Vernachlässigte Töchter der Alma Mater. Ein sozialhistorischer und bildungssoziologischer Beitrag zur strukturellen Entwicklung des Frauenstudiums in Deutschland seit der Jahrhundertwende, Berlin: Dunker \& Humblot.

Mertens, Lothar [1996] 'Forschungsförderung im Dritten Reich', Zeitschrift für Geschichtswissenschaft 44 (1996), S. 119-126.

Mertens, Lothar (Hrsg.) [2001] Politischer Systemumbruch als irreversibler Faktor von Modernisierung in der Wissenschaft?, Berlin: Duncker \& Humblot.

Metz-Göckel, Sigrid (Hrsg.) [1979] Frauenstudium. Zur alternativen Wissenschaftsaneignung von Frauen, Hamburg: Arbeitsgemeinschaft für Hochschuldidaktik.

Metz-Göckel, Sigrid, Christine Roloff \& Anne Schlüter [1989] 'Frauenstudium nach 1945 - Ein Rückblick', Aus Politik und Zeitgeschichte 28 (1989), S. 13-21.

Metzler, Gabriele [1995] 'Kernphysik und Politik. Werner Heisenberg in der Wissenschafts- und Zeitgeschichte. Ein Forschungsbericht', Historisches Jahrbuch 115 (1995), S. 207-222.

Metzler, Gabriele [2000] Internationale Wissenschaft und nationale Kultur. Deutsche Physiker in der internationalen Community 1900-1960, Göttingen: Vandenhoeck \& Ruprecht.

Meyenn, Karl von \& Armin Hermann [1976] 'Wolfgang Paulis Beitrag zur Göttinger Quantenmechanik', Physikalische Blätter 32 (1976), S. 145-150.

Meyer, Peter [1983] 'Wolfgang Paul zum 70. Geburtstag', Physikalische Blätter 39 (1983), S. 409-410.

Meyers, Reinhard [1984] 'Das Dritte Reich in britischer Sicht. Grundzüge und Determinanten britischer Deutschlandbilder in den dreißiger Jahren', in: Wendt (Hrsg.) [1984] S. 127-144.

Michel, Kurt [1937] Vom Flohglas zum Elektronenmikroskop, Berlin: VDI-Verlag. 
Mick, Christoph [2000] Forschen für Stalin: deutsche Fachleute in der sowjetischen Rüstungsindustrie 19451958, München u. a.: Oldenburg.

Mikoletzky, Juliane [1997]a 'Die ersten Generationen von Technikstudentinnen an der Technischen Hochschule in Wien (1919-1945)', in: Mikoletzky, Georgeacopol-Winischhofer \& Pohl (Hrsg.) [1997] S. 109-183.

Mikoletzky, Juliane [1997]b 'Das Frauenstudium an den österreichischen technischen Hochschulen (Universitäten) nach 1945`, in: Mikoletzky, Georgeacopol-Winischhofer \& Pohl (Hrsg.) [1997] S. 185300 .

Mikoletzky, Juliane, Ute Georgeacopol-Winischhofer \& Margit Pohl (Hrsg.) [1997] Dem Zuge der Zeit entsprechend... Zur Geschichte des Frauenstudiums in Österreich am Beispiel der Technischen Universität Wien, Wien: WUV.

Miller, P. H. Jr. [1951] 'Electrical and Oprical Properties of Zinc Oxide‘, in: Henisch (Hrsg.) [1951] S. 172-179.

Minnigerode, Gunther von [1976] 'Robert Pohl. 10. August 1884 - 5. Juni 1976‘, Jahrbuch der Akademie der Wissenschaften in Göttingen 1976, S. 137-143.

Minnigerode, Gunther von [1978] 'Nachruf auf Robert Wichard Pohl', in: Flammersfeld (Hrsg.) [1978] S. 5358.

Minnigerode, Gunther von [1995] 'Robert Wichard Pohl', Göttinger Jahrbuch 1995, S. 151-152.

Miquel, Marc von [2001] 'Juristen: Richter in eigener Sache', in: Frei (Hrsg.) [2001] S. 181-237.

Mises, Richard von [1918] Fluglehre, Berlin: Springer.

Mises, Richard von [1919]a 'Fundamentalsätze der Wahrscheinlichkeitsrechnung', Mathematische Zeitschrift 4 (1919), S. 1-97.

Mises, Richard von [1919]b 'Grundlagen der Wahrscheinlichkeitsrechnung', Mathematische Zeitschrift 5 (1919), S. 52-99.

Mises, Richard von [1928] Wahrscheinlichkeit, Statistik und Wahrheit, Wien: Springer.

Mises, Richard von [1931] Wahrscheinlichkeitsrechnung und ihre Anwendung in der Statistik und theoretischen Physik, Leipzig u. a.: Deuticke.

Mises, Richard von [1945] Theory of Flight, with the collaboration of William Prager and Gustav Kuerti, New York u. a.: McGraw-Hill.

Mitscherlich, Alexander [1947] 'Die Not der Studenten', in: Marburger Hochschulgespräche 12. bis 15. Juni 1946. Referate und Diskussion, Frankfurt a. M.: Klostermann, 1947, S. 157-159, anschließende Diskussion S. 159-167.

Mladjenovic, Milorad [1989] 'Nuclear energy centres as pioneers of science in less developed countries', in: De Maria, Grilli \& Sebastiani (Hrsg.) [1989] S. 312-318.

Mohr, Wilma [1987] Frauen in der Wissenschaft. Ein Bericht zur sozialen Lage von Studentinnen und Wissenschaftlerinnen im Hochschulbereich, Freiburg i. Br.: Dreisam.

Mollwo, Erich [1959] 'R. W. Pohl zum 75. Geburtstag', Physikalische Blätter 15 (1959), S. 369.

Mollwo, Erich [1963] 'Rudolf Hilsch 60 Jahre‘, Physikalische Blätter 19 (1963), S. 569-570.

Mollwo, Erich [1976] 'R. W. Pohl 1884-1976‘, Physikalische Blätter 32 (1976), S. 509-510.

Mollwo, Erich [1978] 'Gedenkrede auf Robert Wichard Pohl', in: Flammersfeld (Hrsg.) [1978] S. 13-19.

Mollwo, Erich [1991] '»Das wichtigstge Forschungsinstrument sollte die technisch und logisch geschulte, physikalisch gemäßigte Phantasie sein «", in: Oesterreicher-Mollwo (Hrsg.) [1991] S. 39-47.

Mommsen, Hans [1986] 'Die Kontinuität der Institution des Berufsbeamtentums und die Rekonstruktion der Demokratie in Westdeutschland', in: Schwegmann (Hrsg.) [1986] S. 65-79.

Mönch, Günther Christian [1951] Das Institut für Angewandte Mechanik (II. Physikalisches Institut) der Universität Halle (Aufbau und Ausbau) 1945-1950, Halle: Martin Luther-Universität.

M[oritz, Ernst] [1953] 'Zum Entwicklungsstand der Teilchenbschleuniger', Physikalische Blätter 9 (1953), S. 268-270.

Morris, Charles Lester [1945] Pioneering the Helicopter, New York u. a.: McGraw-Hill.

Morrison, Philip [1947] 'Die amerikanische Physik im Jahre 1946', Physikalische Blätter 3 (1947), S. 177-179.

Moser, Helmut [1962] Forschung und Prüfung. 75 Jahre Physikalisch-Technische Bundesanstalt / Reichsanstalt, Braunschweig: Vieweg \& Sohn.

Mott, Nevill F. \& R. W. Gurney [1940/48] Electronic Processes in Ionic Cristals, Oxford: Clarendon Press, 2. Aufl. 1948.

Mueller, Fritz K. [1985] 'A History of Inertial Guidance', Journal of the British Interplanetary Society 38 (1985), S. 180-192.

Mühlschlegl, B. [1983] 'Nachruf auf Fritz Sauter', Physikalische Blätter 39 (1983), S. 350.

Müller, Marianne [1988] 'Frauen an der Universität Zürich von 1864 bis 1988: Zahlenmässige Entwicklung', in:[Verein Feministische Wissenschaft Schweiz (Hrsg.)] »Ebenso neu als kühn«: 120 Jahre

Frauenstudium an der Universität Zürich, Zürich: eFeF-Verlag, 1988, S. 197-211.

Müller, Otto [1957] 'The Control System of the V-2‘, in: Benecke \& Quick (Hrsg.) [1957] S. 80-101.

Müller, Siegfried [1990] 'Einleitung‘, in: Heinemann (Hrsg.) [1990]c S. 1-30. 
Murray, George [1978] 'The British Contribution', in: Hearden (Hrsg.) [1978] S. 64-94.

Nagel, Anne Christine (Hrsg.) [2000] Die Philipps-Universität Marburg im Nationalsozialismus. Dokumente zu ihrer Geschichte, Stuttgart: Steiner.

Nagler-Springmann, Sibylle [1995] 'Aschenputtel an Reißbrett und Reagenzglas. Naturwissenschaftlerinnen als »Reservearmee« der deutschen Wirtschaft und Wissenschaft (1933-1945)', in: Renate Michel (Hrsg.):

21. Kongreß von Frauen in Naturwissenschaft und Technik, Darmstadt: Frauen in der Technik - FiT e. V., 1995, S. 207-218.

Nagler-Springmann, Sibylle [1997] 'Naturwidrige Amazonen. Frauen und Naturwissenschaft', in: Häntzschel \& Bußmann (Hrsg.) [1997] S 164-177.

Nath, Axel [1988] Die Studienratskarriere im Dritten Reich, Frankfurt a. M.: dipa.

Nauck, Ernst Theodor [1953] Das Frauenstudium an der Universität Freiburg i. Br., Freiburg i. Br.: Verlag Eberhard Albert Universitätsbuchhandlung.

Nelkowski, Horst [1995] 'Die Physikalische Gesellschaft zu Berlin in den Jahren nach dem Zweiten Weltkrieg', Physikalische Blätter 51 (1995), S. F-143-F-156.

Neuenschwander, Erwin \& Hans-Wilhelm Burmann [1994] 'Die Entwicklung der Mathematik an der Universität Göttingen', in: Schlotter (Hrsg.) [1994] S. 141-159.

Neufeld, Michael J. [1994] 'The Guided Missile and the Third Reich: Peenemünde and the Forging of a Technological Revolution', in: Renneberg \& Walker (Hrsg.) [1994] S. 51-71.

Neufeld, Michael J. [1997] Die Rakete und das Reich. Wernher von Braun, Peenemünd und der Beginn des Raketenzeitalters, Berlin: Brandenburgisches Verlagshaus.

Neuhaus, Rolf [1961] Dokumente zur Hochschulreform 1945-1959, Wiesbaden: Steiner.

Niemeier, G. [1944] 'Grundlagenforschung und Zweckforschung', Physikalische Blätter 1 (1944), S. 106-109.

Niethammer, Lutz [1972] Entnazifizierung in Bayern. Säuberung und Rehabilitierung unter amerikanischer Besatzung, Frankfurt a.M.: Fischer.

Niethammer, Lutz [1986] 'Zum Wandel der Kontinuitätsdiskussion', in: Herbst (Hrsg.) [1986] S. 65-83.

Oberst, Hermann [1961] 'Hans Otto Kneser 60 Jahre', Physikalische Blätter 17 (1961), S. 328-329.

Oehler, Christoph \& Christiane Bradatsch [1998] 'Die Hochschulentwicklung nach 1945', in: Christoph Führ \& Carl-Ludwig Furck (Hrsg.): Handbuch der deutschen Bildungsgeschichte, Bd. VI: 1945 bis zur Gegenwart, Erster Teilband: Bundesrepublik Deutschland, München: Beck, 1998, S. 412-446.

Oesterreicher-Mollwo, Marianne (Hrsg.) [1991] Was uns bewegt. Naturwissenschaftler sprechen über sich und ihre Welt, Weinheim u. a.: Beltz.

Oexle, Otto G. [1994] 'Wie in Göttingen die Max-Planck-Gesellschaft entstand', Max-Planck-Gesellschaft, Jahrbuch 1994, S. 43-60.

Oexle, Otto G. [2003] 'Hahn, Heisenberg und die anderen. Anmerkungen zu »Kopenhagen«, »Farm Hall« und »Göttingen «", Ergebnisse 9. Vorabdruck aus dem Forschungsprogramm »Geschichte der KaiserWilhelm-Gesellschaft im Nationalsozialismus.

Oittner-Torkar, Gisela \& Jürgen Teichmann [1997] 'Max von Laue (1879-1960), William Hanry Bragg (18621942), William Lawrence Bragg (1890-1971) und Robert Wichard Pohl (1884-1976)', in: Karl von Meyenn (Hrsg.): Die großen Physiker, 2. Bd., München: Beck, 1997, S. 160-177.

Ortega y Gasset, José [1931] Der Aufstand der Massen, Stuttgart u. a.: Deutsche Verlags-Anstalt.

Osietzki, Maria [1984] Wissenschaftsorganisation und Restauration. Der Aufbau außeruniversitärer Forschungseinrichtungen und die Gründung des westdeutschen Staates 1945-1952, Köln u. a.: Böhlau.

Osietzki, Maria [1988] 'Kernphysikalische Großgeräte zwischen naturwissenschaftlicher Forschung, Industrie und Politik. Zur Entwicklung der ersten deutschen Teilchenbeschleuniger bei Siemens 1935-45‘, Technikgeschichte 55 (1988), S. 25-46.

Osietzki, Maria [1994] 'The ideology of early particle accelerators: an association between knowledge and power', in: Renneberg \& Walker (Hrsg.) [1994] S. 255-270.

Ostwald, Wilhelm von [1909] Grosse Männer, Leipzig: Akademische Verlagsgesellschaft.

Ott, Hugo [1991] 'Schuldig - mitschuldig - unschuldig? Politische Säuberungen und Neubeginn 1945', in: John, Martin, Mück \& Ott (Hrsg.) [1991] S. 243-258.

Overesch, Manfred [1983/91] Das III. Reich 1939-1945. Eine Tageschronik der Politik, Wirtschaft, Kultur, Augsburg: Weltbild Verlag, 1991 (1. Aufl. 1983).

Overesch, Manfred [1986/92]a Das besetzte Deutschland 1945-1947. Eine Tageschronik der Politik, Wirtschaft, Kultur, Augsburg: Weltbild Verlag, 1992 (1. Aufl. 1986).

Overesch, Manfred [1986/92]b Das besetzte Deutschland 1948-1949. Eine Tageschronik der Politik, Wirtschaft, Kultur, Augsburg: Weltbild Verlag, 1992 (1. Aufl. 1986).

Overesch, Manfred \& Friedrich Wilhelm Saal [1982/91] Das III. Reich 1933-1939. Eine Tageschronik der Politik, Wirtschaft, Kultur, Augsburg: Weltbild Verlag, 1991 (1. Aufl. 1982).

Pakschies, Günter [1979] Umerziehung in der Britischen Zone 1945-1949. Untersuchungen zur britischen Reeducation-Politik, Weinheim u. a.: Beltz. 
Pakschies, Günter [1981] 'Re-education und die Vorbereitung der britischen Bildungspolitik in Deutschland während des Zweiten Weltkrieges‘, in: Heinemann (Hrsg.) [1981] S. 103-113.

Paletschek, Sylvia [2001] 'The Invention of Humboldt and the Impact of National Socialism: The German University Idea in the First Half of the Twentieth Century‘, in: Szöllösi-Janze (Hrsg.) [2001] S. 37-58.

Paletschek, Sylvia [2002] 'Entnazifizierung und Universitätsentwicklung in der Nachkriegszeit am Beispiel der Universität Tübingen', in: Bruch \& Kaderas (Hrsg.) [2002] S. 393-408.

Paneth, Friedrich-Adolf [1948] 'Scientific Research in the British Zone of Germany', Nature 161 (1948), S. 191-192.

Panofsky, Wolfgang K. H. [1989] 'Big and small science - how different?', in: De Maria, Grilli \& Sebastiani (Hrsg.) [1989] S. 319-338.

Pappenfuß, Dietrich \& Wolfgang Schreder (Hrsg.) [2000] Deutsche Umbrüche im 20. Jahrhundert, Köln u. a.: Böhlau.

Paquin, Grete [1985] Göttinger Tagebuch 1938-1947, Göttingen: edition herodot.

Päsler, M. [1960] 'Leben und wissenschaftliches Werk Max von Laues', Physikalische Blätter 16 (1960), S. 552-567.

Patat, Franz [1944] 'Arnold Eucken zum 60. Geburtstag', Die Naturwissenschaften 32 (1944), S. 101-102.

Patat, Franz [1950] 'Arnold Eucken zum Gedenken', Zeitschrift für Naturforschung 5a (1950), S. 689.

Paul, Rainer [1987/98] 'Psychologie unter den Bedingungen der »Kulturwende«. Das Psychologische Institut 1933-1945',in: Becker, Dahms \& Wegeler (Hrsg.) [1987/98] S. 499-522.

Paul, Wolfgang [1992] 'Erfolg mit menschlichem Gesicht. Familienausflug in die Quantenphysik', in: Géza Csomós \& Hans Thomas (Hrsg.): Unternehmenskultur. Leitbild der Darstellung oder Abbild der Einstellung, Herford: Busse Seeald, 1992, S. 39-61.

Pauls, Margarete [1979] 'Zur Situation der Studentinnen in der Natur- und Ingenieurwissenschaft', in: MetzGöckel (Hrsg.) [1979] S. 99-114.

Pauwels, Jacques R. [1984] Women, Nazis, and Universities. Female University Students in the Third Reich, 1933-1945, London: Grennwood Press.

Pehle, Walter H. \& Peter Sillem (Hrsg.) [1992] Wissenschaft im geteilten Deutschland. Restauration oder Neubeginn nach 1945?, Frankfurt a. M.: Fischer.

Peltzer, Lilli [1995] Die Demontage deutscher naturwissenschaftlicher Intelligenz nach dem 2. Weltkrieg. Die Physikalisch-Technische Reichsanstalt 1945-1948, Berlin: ERS-Verlag.

Peterlin, Anton [1959] 'Herbert Stuart 60 Jahre', Physikalische Blätter 15 (1959), S. 224.

Pfeiffer, Heinrich [1994] 'In memoriam Wolfgang Paul', Alexander von Humboldt Stiftung, Mitteilungen 63, Juli 1994, S. 3-4.

Pfetsch, Frank R. [1985/86] 'Neugründung der Universität nach 1945?`, in: Buselmeier, Harth \& Jansen (Hrsg.) [1985/86] S. 365-380.

Philipp, Michael [1994] 'Distanz und Anpassung. Sozialgeschichtliche Aspekte der Inneren Emigration', Exilforschung. Ein internationales Jahrbuch. Band 12, Aspekte der künstlerischen Inneren Emigration 1933-1945, 1994, S. 11-30.

Phillips, David [1981] 'Britische Initiative zur Hochschulreform in Deutschland. Zur Vorgeschichte und Entstehung des »Gutachtens zur Hochschulreform« von 1948`, in: Heinemann (Hrsg.) [1981] S. 172-189.

Phillips, David [1983]a 'Die Wiedereröffnung der Universitäten in der britischen Zone. Nationalistische Gesinnung, Entnazifizierung und das Problem der Zulassung zum Studium', Bildung und Erziehung 36 (1983), S. 35-53.

Phillips, David [1983]b Zur Universitätsreform in der britischen Besatzungszone 1945-1948, Köln/Wien: Böhlau.

Phillips, David [1983]c 'The Re-opening of Universities in the British Zone: The Problem of Nationalism and the Student Admissions', in: Phillips (Hrsg.) [1983] S. 4-19.

Phillips, David [1983]d 'The University Officers of the British Zone‘, in: Phillips (Hrsg.) [1983] S. 51-75.

Phillips, David [1990] 'Introduction: The Work of the British University Officers in Germany', in: Heinemann (Hrsg.) [1990]a S. 11-40.

Phillips, David [1994] 'The rekindling of cultural and intellectual life in the universities of occupied Germany with particular reference to the British Zone', in: Clemens (Hrsg.) [1994] S. 102-116.

Phillips, David [1995] Pragmatismus und Idealismus. Das 'Blaue Gutachten' und die britische Hochschulpolitik in Deutschland 1948, Köln u. a.: Böhlau.

Phillips, David (Hrsg.) [1983] German Universities after the Surrender - British Occupation Policy and the Control of Higher Education, Oxford: University of Oxford Department of Educational Studies.

Phillips, David (Hrsg.) [1995] Education in Germany. Tradition and reform in historical context, London u. a.: Routledge. 
Physics in a new era: an overview, Physics Survey Overview Committee, Board on Physics and Astronomy, Division on Engineering and Physical Sciences, National Research Council, Washington, D.C.: National Academy Press, 2001.

Physik einschließlich technischer Physik 1945-1967, Koehler \& Volckmar-Fachbibliographien, Köln u. a.: Koehler \& Volckmar, 1968.

Pick, Heinz [1978] '50 Jahre Farbzentrenphysik‘, in: Flammersfeld (Hrsg.) [1978] S. 20-28.

Pingel, Falk [1983] 'Attemps at University Reform in the British Zone', in: Phillips (Hrsg.) [1983] S. 20-27.

Pingel, Falk [1984] 'Verborgener Nazismus unter demokratischem Gewand? - Ein Beitrag zum Deutschlandbild im Wandel (Britische Besatzungszone 1945/46)', in: Wendt (Hrsg.) [1984] S. 198-218.

Pingel, Falk [1985] 'Wissenschaft, Bildung und Demokratie - der gescheiterte Versuch einer Universitätsreform‘, in: Foschepoth \& Steininger (Hrsg.) [1985] S. 183-209.

Pinl, Maximilian [1969] 'Kollegen in einer dunklen Zeit', Jahresbericht der deutschen MathematikerVereinigung 71 (1969), S. 167-228.

Pinl, Maximilian [1971] 'Kollegen in einer dunklen Zeit. II Teil', Jahresbericht der deutschen MathematikerVereinigung 72 (1971), S. 165-189.

Pinl, Maximilian [1976] 'Kollegen in einer dunklen Zeit. (Nachtrag und Berichtigung)', Jahresbericht der deutschen Mathematiker-Vereinigung 77 (1976), S. 161-164.

Planck, Max [1919] 'Das Wesen des Lichts', in: ders. [1933/45] S. 85-97.

Planck, Max [1933/45] Wege zur physikalischen Erkenntnis. Reden und Vorträge von Max Planck, Leipzig: Hirzel, 4. Aufl. 1945.

Plank, Rudolf [1944] 'Arnold Eucken und die Verfahrenstechnik', Die Naturwissenschaften 32 (1944), S. 103104.

Plato, Alexander von [1998] 'Helden des Fortschritts? Zum Selbstbild von Technikern und Ingenieuren im Nationalsozialismus und in der Nachkriegszeit', in: Wilhelm Füß1 \& Stefan Ittner (Hrsg.): Biographie und Technikgeschichte, Sonderheft von BIOS 11 (1998), S. 127-165.

Plessner, Helmuth [1954] 'Die ideologische Anfälligkeit der Wissenschaftler', in: Wissenschaft und Freiheit: internationale Tagung, Hamburg, 23.-26. Juli 1953, Congress for Cultural Freedom, Berlin: GrunewaldVerlag, 1954, S. 159-161.

Plessner, Helmuth (Hrsg.) [1956] Nachwuchsfragen im Spiegel einer Erhebung 1953-1955, Göttingen: Vandenhoeck \& Ruprecht.

Poggendorff, Johann Christian [1879] Geschichte der Physik, Leipzig: Barth.

Pohl, Robert Wichard [1972] 'Von den Studien- und Assistentenjahren James Francks', Physikalische Blätter 28 (1972), S. 542-544.

Pollmann, Klaus Erich [1995] 'Hochschulpolitik und Hochschulentwicklung nach 1945', in: Kertz (Hrsg.) [1995]b S. 601-643.

Polm, Rita [1990] »... neben dem Mann die andere Hälfte eines Ganzen zu sein?! « Frauen in der Nachkriegszeit - Zur Situation und Rolle der jüngeren Frauen in den Städten der Bundesrepublik (1945-1949), Münster: Unrast.

Powers, Thomas [1993] Heisenbergs Krieg. Die Geheimgeschichte der deutschen Atombombe, Hamburg: Hoffmann und Campe.

Pr., U. [1963] 'Hans Kopfermann †‘, Physikalische Blätter 19 (1963), S. 77-78.

Prandtl, Ludwig [1949] 'Felix Klein und die Anwendungen der Mathematik', in: Universitätsbund Göttingen e. V., Jg. 26, Mitteilungen 1949, S. 7-11.

Pula, Ralf [1998] 'Über die strukturelle Bedeutung der Hochschule in der institutionalisierten Großraketenforschung und -entwicklung des Dritten Reiches', Dresdner Beiträge zur Geschichte der Technikwissenschaften 25 (1998), S. 89-104.

Pump-Uhlmann, Holger [1995] 'Wiederaufbau und Ausbau der Hochschule nach 1945', in: Kertz (Hrsg.) [1995]b S. 733-779.

Putlitz, Gisbert zu \& Konrad Mauersberger [1998] 'Zum 80. Geburtstag von Peter Brix‘, Physikalische Blätter 54 (1998), S. 1136.

Quetsch, Cäcilie [1960] Die zahlenmäßige Entwicklung des Hochschulbesuches in den letzten fünfzig Jahren, Berlin u. A.: Springer.

Rabkin, Yakov M. \& Elena Z. Mirskaya [2003] 'Science and Totalitarianism. Lessons for the twenty-first century', in: Walker (Hrsg.) [2003] S. 17-34.

Radkau, Joachim [1995] 'Kontinuität und Wandel nach 1945 in Ost- und Westdeutschland', in: Frieß \& Steiner (Hrsg.) [1995] S. 57-75.

Raiser, Ludwig [1946/47] 'Entnazifizierung. Politische Säuberung oder Bestrafung?`, Göttinger UniversitätsZeitung 2 (1946/47), Nr. 3, S. 6-8.

Raiser, Ludwig [1950] 'Ein Wort an die Studenten', Universitätsbund Göttingen e. V., Jg. 26, Mitteilungen 1950, Heft 2, S. 15-16. 
Raiser, Ludwig [1966] 'Wiedereröffnung der Hochschulen - Ansätze zum Neubeginn', in: Universitätstage 1966. Veröffentlichung der Freien Universität Berlin. Nationalsozialismus und die deutsche Universität, Berlin: de Gruyter, 1966, S. 174-188.

Rammer, Gerhard [2001] 'Die Geschichte einer doppelten Vertreibung', Spektrum, Georg-August-Universität Göttingen 3/2001, S. 22-24.

Rammer, Gerhard [2002] 'Der Aerodynamiker Kurt Hohenemser. Befragt von Gerhard Rammer', Internationale Zeitschrift für Geschichte und Ethik der Naturwissenschaften, Technik und Medizin 10 (2002), S. 78-101.

Rammer, Gerhard [2003] 'Göttinger Physiker nach 1945. Über die Wirkung kollegialer Netze', Göttinger Jahrbuch 2003, S. 83-104.

Ramsauer, Carl [1938/44] 'Stellung der Physik innerhalb der Naturwissenschaft und der Technik', Physikalische Blätter 1 (1944), S. 38-39.

Rauh-Kühne, Cornelia [1995] 'Die Entnazifizierung und die deutsche Gesellschaft', Archiv für Sozialgeschichte 35 (1995), S. 35-70.

Rechenberg, Helmut [1981] 'Werner Heisenberg und das Kaiser-Wilhelm-(Max-Planck-)Institut für Physik', Physikalische Blätter 37 (1981), S. 357-364.

Rechenberg, Helmut [1992]a 'Einleitung: Aspekte der Physik im Dritten Reich', in: Rechenberg (Hrsg.) [1992] S. 7-20.

Rechenberg, Helmut [1992]b 'E. Bagge, S. Flügge und C. F. v. Weizsäcker zum achtzigsten Geburtstag', Physikalische Blätter 48 (1992), S. 946-947.

Rechenberg, Helmut [1993] 'Nachruf auf Wilhelm Hanle', Physikalische Blätter 49 (1993), S. 678.

Rechenberg, Helmut [1996] 'Zum Tod von Erich Bagge', Physikalische Blätter 52 (1996), S. 891.

Rechenberg, Helmut (Hrsg.) [1992] Werner Heisenberg. Deutsche und Jüdische Physik, München u. a.: Piper.

Reichling, Michael [1983] 'Biographie eines Unpolitischen. Werner Heisenberg im Dritten Reich', in: Brämer (Hrsg.) [1983] S. 59-74.

Reimann, Bruno W. [1999] 'Hochschule zwischen Kaiserreich und Diktatur', in: Knigge-Tesche (Hrsg.) [1999] S. 11-25.

Rein, Hermann [1945] '»Entnazifizierung« und Wissenschaft‘, Göttinger Universitätszeitung (1945), Nr. 1, S. 6-9.

Rein, Hermann [1946] Die gegenwärtige Situation der Universität. Rede des Rektors Prof. der Physiologie Dr. F. H. Rein bei der feierlichen Verpflichtung der Studenten an der Georg August Universität in Göttingen am 18. Juni 1946, Sonderdruck aus Göttinger Universitätszeitung, Göttingen 1955.

Rein, Hermann [1948] 'Die Georgia-Augusta nach dem Kriege‘, Universitas 3 (1948), S. 229-230.

Rein, Hermann [1949] 'Politische Verantwortung der Wissenschaft. Entgegnung auf »Social action «", Göttinger Universitätszeitung (1949), Nr. 18, S. 9-11.

Reinold, Marianne [1956] 'Wir sind noch einmal davongekommen', in: Erinnerungen und Tatsachen. Die Kaiser-Wilhelm-Gesellschaft zur Förderung der Wissenschaften, Göttingen-Berlin, 1945/1946, Stuttgart: Thieme, 1956, S. 65-71.

Reiter, Raimond [1998] 'Denunziationen im »Dritten Reich« im Kreis Göttingen“, Göttinger Jahrbuch 1998, S. 127-137.

Remmert, Volker [2001] 'In the Service of the Reich: Aspects of Copernicus and Galileo in Nazi Germany's Historiographical and Political Discourse', Science in Context 14 (2001), S. 333-359.

Remy, Steven P. [2002] The Heidelberg Myth. The Nazification and Denazification of a German University, Cambridge u. a.: Harvard Univ. Press.

Renneberg, Monika [1991]a 'Zur Mathematisch-Naturwissenschaftlichen Fakultät der Hamburger Universität im »Dritten Reich«“, in: Krause, Huber \& Fischer (Hrsg.) [1991] S. 1051-1074.

Renneberg, Monika [1991]b 'Die Physik und die physikalischen Institute an der Hamburger Universität im »Dritten Reich«", in: Krause, Huber \& Fischer (Hrsg.) [1991] S. 1097-1118.

Renneberg, Monika \& Mark Walker [1994] 'Scientists, Engineers and National Socialism', in: Renneberg \& Walker (Hrsg.) [1994] S. 1-29.

Renneberg, Monika \& Mark Walker [1995] 'Naturwissenschaftler, Techniker und der Nationalsozialismus', in: Gottwaldt \& Klewin (Hrsg.) [1995] S. 15-24.

Renneberg, Monika \& Mark Walker (Hrsg.) [1994] Science, technology and national socialism, Cambridge u. a.: Cambridge Univ. Press.

Respondek, Peter [1992] Der Wiederaufbau der Universität Münster in den Jahren 1945-1952 auf dem Hintergrund der britischen Besatzungspolitik, Dissertation Münster.

Reusch, Ulrich [1985] 'Versuche zur Neuordnung des Berufsbeamtentums', in: Foschepoth \& Steininger (Hrsg.) [1985] S. 171-181.

Reuter, Frank [1971] Funkmeß. Die Entwicklung und der Einsatz des RADAR-Verfahrens in Deutschland bis zum Ende des Zweiten Weltkrieges, Opladen: Westdeutscher Verlag. 
Richarz, Monika [1986] 'Juden in der Bundesrepublik Deutschland und in der Deutschen Demokratischen Republik seit 1945`, in: Brumlik, Kiesel, Kugelmann \& Schoeps (Hrsg.) [1986] S. 13-30.

Richter, Steffen [1977] 'Physik und Gesellschaft. Einige äußere Einflüsse auf die Enticklung der Physik in Deutschland 1850-1945', Physikalische Blätter 33 (1977), S. 49-57.

Richter, Steffen [1980] 'Die »Deutsche Physik«', in: Mehrtens \& Richter (Hrsg.) [1980] S. 116-141.

Riecke, E. [1905] 'Das neue physikalische Institut der Universität Göttingen', Physikalische Zeitschrift 6 (1906), S. 881-892.

Riecke, E. u. a. [1906] Die physikalischen Institute der Universität Göttingen. Festschrift im Anschluß an die Einweihung der Neubauten am 9. Dez. 1905, Leipzig u. Berlin: Teubner.

Riegels, Friedrich-Wilhelm [1951] 'Albert Betz 65 Jahre', Physikalische Blätter 7 (1951), S. 32-33.

Riegels, Friedrich-Wilhelm \& Hermann Schlichting [1968] 'Albert Betz. 25. Dezember 1885 - 16. April 1968', Jahrbuch der Akademie der Wissenschaften in Göttingen 1968, S. 70-73.

Ringer, Fritz K. [1969] The delcine of the German mandarins. The German academic community 1890-1933, Cambridge, Mass.: Harvard University Press.

Rollnik, Horst [1973] 'Theoretische Physik um Wolfgang Paul', in: Bennewitz (Hrsg.) [1973] S. 105-109.

Rollnik, Horst [1985] 'Wilhelm Walcher zum Fünfundsiebzigsten', Physikalische Blätter 41 (1985), S. 156.

Rollnik, Horst [1994] 'Zum Tode von Wolfgang Paul', Physikalische Blätter 50 (1994), S. 62.

Roloff, Christine [1992] 'Chemikerinnen. Zur Bildungs- und Berufsfrage in der Chemie', in: Schlüter (Hrsg.) [1992] S. 201-215.

Rose, Paul Lawrence [1998] Heisenberg and the Nazi Atomic Bomb Project. A Study in German Culture, Berkeley: University of California Press.

Rosenberger, Ferdinand [1882-1890] Die Geschichte der Physik, 3 Bde., Braunschweig: Vieweg.

Rosenow, Ulf [1987/98] 'Göttinger Physik unter dem Nationalsozialismus', in: Becker, Dahms \& Wegeler (Hrsg.) [1987/98] S. 552-588.

Rosner, Robert \& Brigitte Strohmaier (Hrsg.) [2003] Marietta Blau - Sterne der Zertrümmerung. Biographie einer Wegbereiterin der modernen Teilchenphysik, Wien u. a.: Böhlau.

Rössler, Eberhard [1984] Die Torpedos der deutschen U-Boote. Entwicklung, Herstellung und Eigenschaften der deutschen Marine-Torpedos, Herford: Koehler.

The Rote Kapelle. The CIA's History of Soviet Intelligence and Espionage Networks in Western Europe, 19361945, Washington: University Publications of America, 1979.

Roth, Karl Heinz [2000] 'Strukturen, Paradigmen und Mentalitäten in der luftfahrtmedizinischen Forschung des »Dritten Reichs« 1933 bis 1941: Der Weg ins Konzentrationslager Dachau‘, 199915 (2000), S. 49-77.

Rothacker, Erich [1943] Wissenschaftsgeschichte und Universitätsgeschichte, Bonn: Scheur.

Rotta, Julius C. [1980] 'Kurzbiographien aus der Luft- und Raumfahrt: Ludwig Prandtl', Luft- und Raumfahrt 4 (1980).

Rotta, Julius C. [1990] Die Aerodynamische Versuchsanstalt in Göttingen, ein Werk Ludwig Prandtls. Ihre Geschichte von den Anfängen bis 1925, Göttingen: Vandenhoeck \& Ruprecht.

Rübsamen, Rosemarie [1995] 'Die Physik - Elemente zu einer feministischen Wissenschaft', in: Heymann (Hrsg.) [1995] S. 94-130.

Ruck, Michael [1998] 'Kontinuität und Wandel - Westdeutsche Verwaltungseliten unter dem NS-Regime und in der alten Bundesrepublik', in: Loth \& Rusinek (Hrsg.) [1998] S. 117-142.

Rühle, Stefanie [2000] Frauenstudium in den 50er Jahren: Lebensentwürfe und Alltagserfahrungen von Studentinnen der Rechtswissenschaft - am Beispiel Göttingens, Magisterarbeit, Göttingen, Dezember 2000.

Runge, Carl \& Ludwig Prandtl [1906] 'Das Institut für angewandte Mathematik und Mechanik', in: Die physikalischen Institute der Universität Göttingen, Festschrift im Anschlusse an die Einweihung der Neubauten am 9. Dezember 1905, hrsg. von der Göttinger Vereinigung zur Förderung der angewandten Physik und Mathematik, Leipzig u. a.: Teubner, 1906, S. 95-111.

Rupke, Nicolaas (Hrsg.) [2002] Göttingen and the Development of the Natural Sciences, Göttingen: Wallstein.

Rürup, Reinhard (Hrsg.) [1979] Wissenschaft und Gesellschaft. Beiträge zur Geschichte der Technischen Universität Berlin 1879-1979, Berlin u. a.: Springer.

Rürup, Reinhard [1979] 'Die Technische Universität Berlin 1879-1979: Grundzüge und Probleme ihrer Geschichte', in: Rürup (Hrsg.) [1979] S. 3-47.

Rusinek, Bernd-A. [1998] 'Von Schneider zu Schwerte. Anatomie einer Wandlung', in: Loth \& Rusinek (Hrsg.) [1998] S. 143-179.

Sachse, Carola [2002] '»Persilscheinkultur«. Zum Umgang mit der NS-Vergangenheit in der Kaiser-Wilhelm / Max-Planck-Gesellschaft‘, in: Weisbrod (Hrsg.) [2002] S. 217-246.

Schaaf, Michael [1997] '»Nach Göttingen ging einer, der sich etwas zutraute«. Ein Gespräch mit Professor Friedrich Hund vom 12. März 1994', Physikalische Blätter 53 (1997), S. 542-545.

Schaefer, Clemens [1953] 'Erwin Fues 60 Jahre', Physikalische Blätter 9 (1953), S. 37-39. 
Schael, Oliver [2002] 'Die Grenzen der akademischen Vergangenheitspolitik: Der Verband der nichtamtierenden (amtsverdrängten) Hochschullehrer und die Göttinger Universität‘, in: Weisbrod (Hrsg.) [2002] S. 53-72.

Schäfer, Klaus [1984] 'Arnold Eucken. Physikochemiker', Göttinger Jahrbuch 1984, S. 263-266.

Schäfer-Richter, Uta \& Jörg Klein [1992] Die jüdischen Bürger im Kreis Göttingen 1933-1945. Göttingen, Hann. Münden, Duderstadt. Ein Gedenkbuch, Göttingen: Wallstein.

Schappacher, Norbert [1987/98] 'Das mathematische Institut der Universität Göttingen 1929-1950`, in: Becker, Dahms \& Wegeler (Hrsg.) [1987/98] S. 523-551.

Scheibe, Günter [1950] 'Arnold Thomas Eucken', Bayerische Akademie der Wissenschaften, Jahrbuch 1950, S. 200-203.

Scheich, Elvira [1997] 'Science, Politics, and Morality. The Relationship of Lise Meitner and Elisabeth Schiemann', in: Sally Gregory Kohlstedt \& Helen Longino (Hrsg.): Women, Gender, and Science: New Directions, Osiris, Second Series, Vol. 12, 1997, S. 143-168.

Scherzer, Otto [1965] 'Physik im totalitären Staat', in: Flitner (Hrsg.) [1965] S. 47-58.

Schildt, Axel [1997] 'Im Kern gesund? Die deutschen Hochschulen 1945‘, in: König, Kuhlmann \& Schwabe (Hrsg.) [1997] S. 223-240.

Schildt, Axel [1998] 'Der Umgang mit der NS-Vergangenheit in der Öffentlichkeit der Nachkriegszeit', in: Loth \& Rusinek (Hrsg.) [1998] S. 19-54.

Schiller, Kay [2004] 'Review Article. The Presence of the Nazi Past in the Early Decades of the Bonn Republic', Journal of Contemporary History 39 (2004), S. 286-294.

Schimank, Hans [1944]a 'Der Einfluß der Physik auf das Wehrwesen im Wandel der Zeiten', Physikalische Blätter 1 (1944), S. 119-124.

Schimank, Hans [1944]b 'Deutsch-französische Beziehungen in der Naturwissenschaft', Physikalische Blätter 1 (1944), S. 141-143.

Schimank, Hans [1951] 'Wissenschaftsgeschichte als Bildungsmittel', Physikalische Blätter 7 (1951), S. 337341.

Schlicker, Wolfgang [1983] 'Physiker im faschistischen Deutschland. Zum Geschehen um eine naturwissenschaftlich-technische Grundlagendisziplin seit 1933‘, Jahrbuch für Geschichte 1983, S. 109142.

Schlögl, Friedrich [1982] 'Siegfried Flügge 70 Jahre alt', Physikalische Blätter 38 (1982), S. 298.

Schlögl, Friedrich [1998] 'Siegfried Flügge', Physics Today 51 (1998), August, S. 77.

Schlögl, Friedrich \& Heinrich Klar [1998] 'Siegfried Flügge zum Gedenken', Physikalische Blätter 54 (1998), S. 448.

Schlotfeldt-Schäfer, Irmgard [1981] Das Frauenstudium in Kiel unter besonderer Berücksichtigung der Medizin, Dissertation Kiel.

Schlotter, Hans-Günther (Hrsg.) [1994] Die Geschichte der Verfassung und der Fachbereiche derGeorgAugust-Universität zu Göttingen, Göttingen: Vandenhoeck \& Ruprecht.

Schlüpmann, Klaus [http] Vergangenheit im Blickfeld eines Physikers. Hans Kopfermann 1895-1963, http://www.aleph99.org/etusci/ks/.

Schlüter, Anne [1986] '»Wenn zwei das Gleiche tun, ist das noch lange nicht dasselbe« - Diskriminierungen von Frauen in der Wissenschaft', in: Schlüter \& Kuhn (Hrsg.) [1986] S 10-33.

Schlüter, Anne (Hrsg.) [1992] Pionierinnen - Feministinnen - Karrierefreuen?: Zur Geschichte des Frauenstudiums in Deutschland, Pfaffenweiler: Centaurus.

Schlüter, Anne \& Annette Kuhn (Hrsg.) [1986] Lila Schwarzbuch. Zur Diskriminierung von Frauen in der Wissenschaft, Düsseldorf: Schwann.

Schmeiser, Martin [1994] Akademischer Hasard. Das Berufsschicksal des Professors und das Schicksal der deutschen Universität 1870-1920. Eine verstehend soziologische Untersuchung, Stuttgart: Klett-Cotta.

Schmeling, Hans-Georg (Hrsg.) [1985] Göttingen 1945. Kriegsende und Neubeginn, Göttingen: Städtisches Museum.

Schmeling, Hans-Georg [1985] 'Göttinger Nachkriegsalltag 1945', in: Schmeling (Hrsg.) [1985] S. 149-197.

Schmid, Manfred \& Volker Schäfer [1985] Wiedergeburt des Geistes. Die Universität Tübingen im Jahre 1945, Tübingen: Universitätsarchiv.

Schmid, Roswitha \& Anthony R. Michaelis [1983] Wissenschaft in Deutschland. Niedergang und neuer Aufstieg, Stuttgart: Wissenschaftliche Verlagsgesellschaft.

Schmidt-Rohr [1996] Erinnerungen an die Vorgeschichte und die Gründerjahre des Max-Planck-Instituts für Kernphysik, Heidelberg: Max-Planck-Institut für Kernphysik.

Schmidt-Rohr [1998] Die Aufbaujahre des Max-Planck-Instituts für Kernphysik, Heidelberg: Max-PlanckInstitut für Kernphysik.

Schnabel, Thomas [1991] 'Die Universität Freiburg im Krieg', in: John, Martin, Mück \& Ott (Hrsg.) [1991] S. 221-241. 
Schneider, Christian [1998] 'Identität und Identitätswandel der Deutschen nach 1945', in: Loth \& Rusinek (Hrsg.) [1998] S. 247-258.

Schneider, Ullrich [1980] Der Kampf um Demokratisierung in Wirtschaft und Gesellschaft - Niedersachsen unter britischer Besatzung 1945-47, Hamburg: Focke \& Jaffe.

Schneider, Ullrich [1983] 'Hochschulreform, Studium generale und das Collegium Academicum Heidelberg 1945-1952', Bildung und Erziehung 36 (1983), S. 55-67.

Schneider, Ullrich [1984] 'Die Hochschulen in Westdeutschland nach 1945. Wandel und Kontinuität aus britischer Sicht', in: Wendt (Hrsg.) [1984] S. 219-240.

Schneider, Ullrich [1989] 'Zur Entnazifizierung der Hochschullehrer in Niedersachsen', Niedersächsisches Jahrbuch für Landesgeschichte 1989, S. 325-346.

Schneider, Ullrich [1990] 'The Reconstruction of the Universities in American Occupied Germany', in: Heinemann (Hrsg.) [1990]b S. 1-8.

Schneider, Ullrich \& Wolfgang Dumke [1985] 'Die Universität Göttingen zwischen Besetzung und Wiedereröffnung 1945', in: Schmeling (Hrsg.) [1985] S. 291-300.

Schnelle, Gertraude [1971] Zur Geschichte des Frauenstudiums in Deutschland bis 1945, Berlin: Inst. für Hochschulbildung und -ökonomie.

Schnoor, Herbert [1986] 'Gedanken zum Neuaufbau der Verwaltung nach 1945', in: Schwegmann (Hrsg.) [1986] S. 17-24.

Schodel, Wolf [1953] 'Hermann Rein †‘, Die Naturwissenschaften 40 (1953), S. 565-566.

Scholl, Lars U. [1998] '»Zum Besten der besonders in Göttingen gepflegten Anglistik«. Das Seminar für englische Philologie‘, in: Becker, Dahms \& Wegeler (Hrsg.) [1987/98] S. 391-426.

Schöne, Albrecht [1983] Göttinger Bücherverbrennung 1933. Rede am 10. Mai 1983 zur Erinnerung an die »Aktion wider den undeutschen Geist", Göttingen: Vandenhoeck \& Ruprecht.

Schörken, Rolf [1990] Jugend 1945, Opladen: Leske \& Budrich.

Schopper, Herwig [1978] 'Rudolf Fleischmann zum 75. Geburtstag', Physikalische Blätter 34 (1978), S. 335 337.

Schotte, Ursula [1981] 'Ich kann mich nicht beklagen über Diskriminierung - aber ich halte sie durchaus für möglich‘, Bild der Wissenschaft 11 (1981), S. 159-160.

Schrader, Hans-Jürgen [1976] 'Ulrich Stille †', Physikalische Blätter 32 (1976), S. 330-331.

Schreiber, Hermann [2001] 'Historische Instrumente im Institut für Geophysik', in: Hoffmann \& MaackRheinländer (Hrsg.) [2001] S. 194-200.

Schreier, Wolfgang (Hrsg.) [1988] Geschichte der Physik. Ein Abriß, Berlin: VEB Deutscher Verlag der Wissenschaften.

Schriewer, Jürgen, Edwin Keiner \& Christophe Charle (Hrsg.) [1993] Sozialer Raum und akademische Kulturen. Studien zur europäischen Hochschul- und Wissenschaftsgeschichte im 19. und 20. Jahrhundert, Frankfurt a. M. u. a.: Lang.

Schroeder, Manfred [2000] 'Erwin Meyer. Professor für Physik an der Universität Göttingen', Göttinger Jahrbuch 2000, S. 181-183.

Schröder, Reinald [1993] 'Die »schöne deutsche Physik« von Gustav Hertz und der »weiße Jude« Heisenberg Johannes Starks ideologischer Antisemitismus', in: Albrecht (Hrsg.) [1993] S. 327-341.

Schröder-Werle, Renate [1979] 'Studentenstatistik (1879-1979)', in: Rürup (Hrsg.) [1979] S. 567-591.

Schulle, Diana [2001] Das Reichssippenamt. Eine Institution nationalsozialistischer Rassenpolitik, Berlin: Logos Verlag.

Schultz, Johannes \& Willy Müller (Hrsg.) [1952] Abschluß der Entnazifizierung und Durchführung des Gesetzes zu Art. 131 GG in Niedersachsen. I. Gesetz zum Abschluß der Entnazifizierung im Lande Niedersachsen, Göttingen: Otto Schwartz \& Co.

Schumacher, Michaela [1986] 'Lehrende, forschende und studierende Frauen an der Universität Münster - eine empirische Untersuchung', in: Schlüter \& Kuhn (Hrsg.) [1986] S 58-90.

Schüring, Michael [2002] 'Ein Dilemma der Kontinuität. Das Selbstverständnis der Max-Planck-Gesellschaft und der Umgang mit Emigranten in den 50er Jahren', in: Bruch \& Kaderas (Hrsg.) [2002] S. 453-463.

Schwabe, Klaus (Hrsg.) [1988] Deutsche Hochschullehrer als Elite 1915-1945, Boppard am Rhein: Boldt.

Schwegmann, Friedrich Gerhard (Hrsg.) [1986] Die Wiederherstellung des Berufsbeamtentums nach 1945. Geburtsfehler oder Stützpfeiler der Demokratisierung in Westdeutschland?, Düsseldorf: Schwann.

Seidlmayer, Michael [1949] Der Student und das öffentliche Leben, Würzburg: Schöningh.

Seier, Hellmut [1988] 'Die Hochschullehrerschaft im Dritten Reich', in: Schwabe (Hrsg.) [1988] S. $247-295$.

Seiler, Karl [1948] 'Detektoren', in: Georg Goubau \& Jonathan Zenneck: Elektronenemission,

Elektronenbewegung und Hochfrequenztechnik, Teil I, Bd. 15 der Reihe: Fiat Review of German Science 1939-1946, Wiesbaden: Dieterichsche Verlagsbuchhandlung, 1948, S. 272-292.

Seitz, Frederick [1994] On the Frontier. My Life in Science, New York: American Institute of Physics. 
Sellin, Volker [1996] 'Die Universität Heidelberg im Jahre 1945‘, in: Heß, Lehmann \& Sellin (Hrsg.) [1996] S. 91-106.

Shinn, Terry [1982] 'Scientific Disciplines and Organizational Specificity: The Social and Cognitive Configuration of Laboratory Activities', in: Norbert Elias, Herminio Martins \& Richard Whitley (Hrsg.): Scientific Establishments and Hierarchies, Dordrecht u. a.: Reidel, 1982, S. 239-264.

Sieg, Ulrich [2001] 'Strukturwandel der Wissenschaft im Nationalsozialismus', Berichte zur Wissenschaftsgeschichte 24 (2001), S. 255-270.

Siegmund-Schultze, Reinhard [1994] 'The Problem of anti-Fascist Resistance of »Apolitical« German Scholars`, in: Renneberg \& Walker (Hrsg.) [1994] S. 312-323.

Siegmund-Schultze, Reinhard [1998] Mathematiker auf der Flucht vor Hitler. Quellen und Studien zur Emigration einer Wissenschaft, Braunschweig u. a.: Vieweg.

Siegrist, Hannes [1994] 'Der Wandel als Krise und Chance. Die westdeutschen Akademiker 1945-1965', in: Tenfelde \& Wehler (Hrsg.) [1994] S. 289-314.

Sietmann, Richard [1981] 'Die seltenen Frauen in der Physik', Bild der Wissenschaft 11 (1981), S. 150-156.

Simon, Gerhard \& Volkmar Zehler [1981] 'Werner Döring 70 Jahre‘, Physikalische Blätter 37 (1981), S. 300.

Simonsohn, Gerhard [1992] 'Physiker in Deutschland 1933-1945' Physikalische Blätter 48 (1992), S. 23-28.

Simonsohn, Gerhard [1997] Physik an der Freien Universität Berlin. Der Anfang und die ersten beiden Jahrzehnte (1949-1968), Berlin: Freie Universität Berlin, Fachbereich Physik.

Smend, Rudolf [1951] 'Die Göttinger Gesellschaft der Wissenschaften', in: Festschrift zur Feier des zweihundertjährigen Bestehens der Akademie der Wissenschaften in Göttingen, I Mathematischphysikalische Klasse, Berlin u. a.: Springer, 1951, S. V-XIX.

Smith, Cyril S. [1987] 'Notes on the Prehistory of Solid State Physics‘, in: Weaire \& Windsor (Hrsg.) [1987] S. 11-42.

Soden, Kristine von [1979] 'Zur Geschichte des Frauenstudiums', in: Soden \& Zipfel (Hrsg.) [1979] S. 9-42.

Soden, Kristine von \& Gaby Zipfel (Hrsg.) [1979] 70 Jahre Frauenstudium. Frauen in der Wissenschaft, Köln: Pahl-Rugenstein.

Solla Price, Derek. J. de [1963/74] Little Science, Big Science, New York: Columbia University Press, deutsche Ausgabe Frankfurt a. M.: Suhrkamp Taschenbuch, 1974.

Sommerfeld, Arnold [1948] 'Gedächtnisfeier der Physikalischen Gesellschaft in Württemberg-Baden zu Heidenheim am 15. November 1947', Annalen der Physik (6) 3 (1948), S. 3-6.

Sommerfeld, Arnold [1949] 'Max von Laue zum 70. Geburtstag', Physikalische Blätter 5 (1949), S. 443.

Spangenberg, Arno [2000] 'Felix Klein und Göttingen“, Göttinger Jahrbuch 2000, S. 171-178.

Speck, Dieter [1995] 'Aus den Trümmern eine neue Zukunft bauen. Zerstörung und Neubeginn der AlbertLudwigs-Universität', Freiburger Universitätsblätter 34 (1995), Heft 127, S. 41-53.

Stamm, Thomas [1981] Zwischen Staat und Selbstverwaltung. Die deutsche Forschung im Wiederaufbau 1945 1965, Köln: Verlag Wissenschaft und Politik.

Stamm, Thomas [1989] 'New Opportunities - Old Traditions: The Struggle for Autonomy of Post-War German Science', in: De Maria, Grilli \& Sebastiani (Hrsg.) [1989] S. 228-246.

Stammen, Theo [1979] 'Das alliierte Besatzungsregime in Deutschland', in: Becker, Stammen \& Waldmann (Hrsg.) [1979] S. 61-91.

Stange, Thomas [1998] 'Die kernphysikalischen Ambitionen des Reichspostministers Ohnesorg', Berichte zur Wissenschaftsgeschichte 21 (1998), S. 159-174.

Stanner, Walter [1960] Radar. 7 Jahrzehnte geschichte und Technik, Garmich-Partenkirchen: Deutsche RADAR-Verlagsgesellschaft, 4. Aufl., 1960.

Stark, Johannes [1936] 'Philipp Lenard als deutscher Naturforscher', Nationalsozialistische Monatshefte 7 (1936), S. 106-112.

Steiner, Peter M. [1995] 'Wolfgang Paul im Gespräch', in: Frieß \& Steiner (Hrsg.) [1995] S. 197-214.

Stichweh, Rudolf [1993] 'Wissenschaftliche Disziplinen: Bedingungen ihrer Stabilität im 19. und 20. Jahrhundert', in: Schriewer, Keiner \& Charle (Hrsg.) [1993] S. 235-250.

Stickler, Matthias [2001] 'Neuerscheinungen zur Studentengeschichte seit 1994. Ein Forschungsbericht über ein bisweilen unterschätztes Arbeitsfeld der Universitätsgeschichte', Jahrbuch für Universitätsgeschichte 2001, S. 262-270.

Stierstadt, Klaus [1980] 'Walther Gerlach †‘, Physikalische Blätter 36 (1980), S. 18-19.

Stille, Ulrich [1957] 'Günther Cario 60 Jahre', Physikalische Blätter 13 (1957), S. 374-376.

Stöckmann, Fritz [1964] 'Robert Wichard Pohl', Physikalische Blätter 20 (1964), S. 366.

Stöckmann, Fritz [1978] 'Photoeffekte', in: Flammersfeld (Hrsg.) [1978] S. 29-37.

Strauss, Herbert A., Klaus Fischer, Christhard Hoffmann \& Alfons Söllner (Hrsg.) [1991] Die Emigration der Wissenschaften nach 1933, München u. a.: Saur.

Strohmeier, Renate [1998] Lexikon der Naturwissenschaftlerinnen und naturkundigen Frauen Europas. Von der Antike bis zum 20. Jahrhundert, Frankfurt a. M.: Deutsch. 
[Studentenzahlen] Der Präsident der Georg-August-Universität Göttingen (Hrsg.) [1987] 250 Jahre GeorgAugust-Universität Göttingen. Studentenzahlen 1734/37-1987, Göttingen: Universität Göttingen.

Stutz, Rüdiger [1998] 'Hochschulerneuerung unter Besatzungsherrschaft. Der Landespräsident von Thüringen als »politischer Rektor« der Universität Jena (Sommer 1945 bis Frühjahr 1946)`, in: John, Wahl \& Arnold (Hrsg.) [1998] S. 75-102.

Stutz, Rüdiger \& Uwe Hoßfeld [2004] 'Jenaer Profilwandel: von der philosophischen zur rassisch und naturwissenschaftlich »ausgerichteten« Universität in der NS-Zeit‘, in: Buchholz (Hrsg.) [2004] S. 217 269.

Sutor, Bernhard [1999] 'Restauration oder Neubeginn? Politische Bildung 1945-1960', Aus Politik und Zeitgeschichte B 7-8 (1999), S. 3-12.

Sutton, L. H. [1946/83] 'Shuffling Feet: A Discourse on the University of Göttingen“, in: Phillips (Hrsg.) [1983] S. 109-117.

Swinne, Edgar [1992] Richard Gans. Hochschullehrer in Deutschland und Argentinien, Berlin: ERS-Verlag. Sywottek, Arnold [1991] 'Kontinuität im Neubeginn: Über die Anfänge der »Universität Hamburg “', in: Krause, Huber \& Fischer (Hrsg.) [1991] S. 1387-1416.

Szabó, Anikó [1996] 'Verordnete Rückberufungen. Die Hochschulkonferenzen und die Diskussion um die emigrierten Hochschullehrer', in: Marlis Buchholz, Claus Füllberg-Stollberg \& Hans-Dieter Schmid (Hrsg.): Nationalsozialismus und Region. Festschrift für Herbert Obenaus zum 65. Geburtstag, Bielefeld: Verlag für Regionalgeschichte, 1996, S. 339-352.

Szabó, Anikó [2000] Vertreibung, Rückkehr, Wiedergutmachung. Göttinger Hochschullehrer im Schatten des Nationalsozialismus, Göttingen: Wallstein.

Szöllösi-Janze, Margit [2001] 'National Socialism and the Sciences: Reflections, Conclusions and Historical Perspectives', in: Szöllösi-Janze (Hrsg.) [2001] S. 1-35.

Szöllösi-Janze, Margit (Hrsg.) [2001] Science in the Thrid Reich, Oxford u. a.: Berg.

Teltow, Joachim [1985] 'In memoriam Ostap Stasiw', Physikalische Blätter 41 (1985), S. 207.

Temme, Heinrich [1957] 'Development and Testing of the V-1 Auto-Pilot', in: Benecke \& Quick (Hrsg.) [1957] S. 70-79.

Tenfelde, Klaus \& Hans-Ulrich Wehler (Hrsg.) [1994] Wege zur Geschichte des Bürgertums, Göttingen: Vandenhoeck \& Ruprecht.

Tent, James F. [1982] Mission on the Rhine. Reeducation and Denazification in American-Occupied Germany, Chicago u. a.: The University of Chicago Press.

Tent, James F. [1983] 'Amerikanische Bildungspolitik im besetzten Deutschland 1945-1949“, Bildung und Erziehung 36 (1983), S. 5-17.

Tent, James F. [1990] 'Denazification of Higher Education in U. S. Occupied Germany, 1945-1949‘, in: Heinemann (Hrsg.) [1990]b S. 9-15.

Tepe, Peter [1998] 'Überwindung - Wandlung - Anpassung - Tarnung? Arbeit am Fall Schneider/Schwerte', in: Loth \& Rusinek (Hrsg.) [1998] S. 197-245.

Teusch, Chr. [1950] 'Probleme des Frauenstudiums', in : Verband deutscher Studentenschaften (Hrsg.) Deutscher Hochschulführer 1950, Bonn: Stollfuss, 1950, S. 7-8.

Thadden, Rudolf von \& Günter J. Trittel (Hrsg.) [1999] Göttingen. Geschichte einer Universitätsstadt, Bd. 3, Göttingen: Vandenhoeck \& Ruprecht,

Thadden, Wiebke von [1985] 'Göttingen und seine Militärregierung', in: Schmeling (Hrsg.) [1985] S. 69-92.

Titze, Hartmut [1984] 'Die zyklische Überproduktion von Akademikern im 19. und 20. Jahrhundert', Geschichte und Gesellschaft 10 (1984), S. 92-121.

Titze, Hartmut [1987] Das Hochschulstudium in Preußen und Deutschland 1820-1944, Göttingen: Vandenhoeck \& Ruprecht.

Titze, Hartmut [1990] Der Akademikerzyklus: historische Untersuchung über die Wiederkehr von Überfüllung und Mangel in akadelischen Karrieren, Göttingen: Vandenhoeck \& Ruprecht.

Titze, Hartmut [1995] Wachstum und Differenzierung der deutschen Universitäten 1830-1945, Göttingen: Vandenhoeck \& Ruprecht.

Tobies, Renate [1981] Felix Klein, Leipzig: Teubner.

Tobies, Renate [1987] 'Zur Berufungspolitik Felix Kleins', NTM-Schriftenreihe Geschichte der Naturwissenschaften, Technik, Medizin 24 (1987), S. 43-52.

Tobies, Renate [1996] 'Einflußfaktoren auf eine Wissenschaftlerinnenkarriere am Beispiel der Physikerin Hertha Sponer (1.9.1895-17.2.1968)', in: Zur Geschichte des Frauenstudiums und weiblicher Berufskarrieren an der Berliner Universität. Dokumentation eines Workshops, veranstaltet am 25. November 1995 vom Zentrum für interdisziplinäre Frauenforschung (ZiF) und der Frauenbeauftragten der Humboldt-Universität zu Berlin, hrsg. vom ZiF und der Frauenbeauftragten der Humboldt-Universität zu Berlin, Berlin, 1996, S. 58-78. 
Tobies, Renate [1997] 'Einführung: Einflußfaktoren auf die Karriere von Frauen in Mathematik und Naturwissenschaften', in: Tobies (Hrsg.) [1997] S. 17-67.

Tobies, Renate (Hrsg.) [1997] Aller Männerkultur zum Trotz. Frauen in Mathematik und Naturwissenschaften, Frankfurt a. M. u. a.: Campus.

Tolansky, S. [1947] 'German Physical Society in the British Zone', Nature 160 (1947), S. 723-724.

Tollmien, Cordula [1987/98] 'Das Kaiser-Wilhelm-Institut für Strömungsforschung verbunden mit der Aerodynamischen Versuchsanstalt', in: Becker, Dahms \& Wegeler (Hrsg.) [1987/98] S. 684-708.

Tollmien, Cordula [1998] Nationalsozialismus in Göttingen (1933-1945), Dissertation Göttingen.

Tollmien, Walter, Hermann Schlichting \& Henry Görtler (Hrsg.) [1961] Ludwig Prandtl. Gesammelte Abhandlungen zur angewandten Mechanik, Hydro- und Aerodynamik, Berlin u. a.: Springer.

Tomaschek, Rudolf [1934/43] Grimsehls Lehrbuch der Physik, Bd. 3, Leipzig u. a.: Teubner, 11. Aufl. 1943.

Töpfer, Erich [1968] 'Ernst Lamla 80 Jahre', Physikalische Blätter 24 (1968), S. 509.

Trenkle, Fritz [1979] Die deutschen Funkmeßverfahren bis 1945, Stuttgart: Motorbuch Verlag.

Trischler, Helmuth [1992] Luft- und Raumfahrtforschung in Deutschland 1900-1970. Politische Geschichte einer Wissenschaft, Frankfurt a. M.: Campus.

Trischler, Helmuth [1994] 'Self-mobilization or Resistance? Aeronautical Research and National Socialism', in: Renneberg \& Walker (Hrsg.) [1994] S. 72-87.

Trischler, Helmuth [1995] 'Großforschung und Großforschungseinrichtungen', in: Frieß \& Steiner (Hrsg.) [1995] S. 112-123.

Trischler, Helmuth [2000] '»Big Science« or »Small Science«? Die Luftfahrtforschung im Nationalsozialismus`, in: Kaufmann (Hrsg.) [2000] S. 328-362.

Trischler, Helmuth [2001] 'Aeronautical Research under National Socialism: Big Science or Small Science? ', in: Szöllösi-Janze (Hrsg.) [2001] S. 79-110.

Tröger, Jörg (Hrsg.) [1984] Hochschule und Wissenschaft im Dritten Reich, Frankfurt a. M. u. a.: Campus.

Truckenbrodt, Erich [1982] 'Laudatio für Professor Dr. rer. nat. Kurt Magnus anläßlich der Vollendung des 70. Lebensjahres', in: Truckenbrodt (Hrsg.) [1982] S. 9-21.

Truckenbrodt, Erich (Hrsg.) [1982] Festschrift zum 70. Geburtstag von Herrn Prof. Dr. rer. nat. K. Magnus gewidmet von seinen Schülern, München: Lehrstuhl B für Mechanik, Techn. Univ. München.

Turner, Ian D. [1989]a 'Introduction: The British Occupation and its Impact on Germany', in: Turner (Hrsg.) [1989] S. 3-14.

Turner, Ian D. [1989]b 'Denazification in the British Zone‘, in: Turner (Hrsg.) [1989] S. 239-267.

Turner, Ian D. [1989]c 'Research on the British Occupation of Germany', in: Turner (Hrsg.) [1989] S. 327-358.

Turner, Ian D. (Hrsg,) [1989] Reconstruction in Post-War Germany. British Occupation Policy and the Western Zones, 1945-55, Oxford u. a.: Berg.

Turner, James [1989] 'German University History in Comparative Perspective: The Case of Göttingen', Archiv für Sozialgeschichte 29 (1989) S. 482-487.

Uhl, Matthias [2001] Stalins V-2. Der Technologietransfer der deutschen Fernlenkwaffentechnik in die UdSSR und der Aufbau der sowjetischen Raketenindustrie 1945 bis 1959, Oberhaching: Bernhard \& Graefe.

Verein Feministische Wissenschaft Schweiz (Hrsg.) [1988] "Ebenso neu als kühn": 120 Jahre Frauenstudium an der Universität Zürich, Zürich: eFeF-Verlag.

Vierhaus, Rudolf \& Bernhard vom Brocke (Hrsg.) [1990] Forschung im Spannungsfeld von Politik und Gesellschaft: Geschichte und Struktur der Kaiser-Wilhelm/Max Planck-Gesellschaft, Stuttgart: Deutsche Verlags-Anstalt.

Visser, R. P. W., H. J. M. Bos, L. C. Palm \& H. A. M. Snelders (Hrsg.) [1989] New Trends in the History of Science. Proceedings of a conference held at the University of Utrecht, Amsterdam: Rodopi.

Vocelka, Karl [2002] Geschichte Österreichs. Kultur - Gesellschaft - Politik, München: Heyne.

Vogel, Barbara [1991] 'Anpassung und Widerstand. Das Verhältnis Hamburger Hochschullehrer zum Staat 1919 bis $1945^{\prime}$, in: Krause, Huber \& Fischer (Hrsg.) [1991] S. 3-83.

Vogel-Prandtl, Johanna [1993] Ludwig Prandtl. Ein Lebensbild, Göttingen: Max-Planck-Institut für Strömungsforschung.

Vogt, Annette [1996]a Lise Meitner und ihre Kolleginnen - Naturwissenschaftlerinnen in den Instituten der Kaiser-Wilhelm-Gesellschaft zwischen 1912 und 1945, Max-Planck-Institut für Wissenschaftsgeschichte, Preprint 46.

Vogt, Annette [1996]b Die Fräulein Doktor werden immer mehr. Zur Entwicklung des Frauenstudiums und der Berufstätigkeit von Frauen am Beispiel der Promotionen von Frauen zu naturwissenschaftlichen Themen an der philosophischen bzw. ab 1936 der Mathematisch-Naturwissenschaftlichen Fakultät der Berliner Universität zwischen 1898 und 1945, Max-Planck-Institut für Wissenschaftsgeschichte, Preprint 45.

Vogt, Annette [1997]a Vom Hintereingang zum Hauptportal - Wissenschaftlerinnen in der Kaiser-WilhelmGesellschaft, Max-Planck-Institut für Wissenschaftsgeschichte, Preprint 67. 
Vogt, Annette [1997]b '»In Ausnahmefällen ja« - Max Planck als Förderer seiner Kolleginnen', MPG-Spiegel 4 (1997), S. 48-53.

Vogt, Annette [1997]c Findbuch [Index-Book]. Die Promotionen von Frauen an der Philosophischen Fakultät von 1898 bis 1936 und an der Mathematisch-Naturwissenschaftlichen Fakultät von 1936 bis 1945 der Friedrich-Wilhelms-Universität zu Berlin sowie die Habilitationen von Frauen an beiden Fakultäten von 1919 bis 1945, Max-Planck-Institut für Wissenschaftsgeschichte, Preprint 57.

Vogt, Annette [2000] 'Die ersten Karriereschritte - Physikerinnen im Berliner Raum zwischen 1900 und 1945', in: Dickmann \& Schöck-Quinteros (Hrsg.) [2000] S 195-230.

Vogt, Hannah [1985] 'Aus meinem Tagebuch 1945', in: Schmeling (Hrsg.) [1985] S. 57-68.

Vollnhals, Clemens (Hrsg.) [1991] Entnazifizierung. Politische Säuberung und Rehabilitierung in den vier Besatzungszonen 1945-1949, München: dtv.

Wachsmann, Felix [1947] 'Ausblick auf die Anwendungsmöglichkeiten der Elektronenschleuder in der Medizin', Strahlentherapie 76 (1947), S. 371-388.

Wächter, Christine, Felicitas Konecny \& Gudrun Kapl (Hrsg.) [1993] Frauen in Naturwissenschaft und Technik, München, Wien: Profil.

Wagner, H. Gg. (Hrsg.) [ca. 1984] Beiträge zur Wiederkehr des 100. Geburtstages von Arnold Eucken, Göttingen.

Walcher, Wilhelm [1960] 'Hans Kopfermann 65 Jahre', Physikalische Blätter 16 (1960), S. 288-289.

Walcher, Wilhelm [1973] 'Arbeiten zur optischen Spektroskopie‘, in: Bennewitz (Hrsg.) [1973] S. 1-13.

Walcher, Wilhelm [1990] 'Wilhelm Hanle zum Neunzigsten', Physikalische Blätter 46 (1990), S. 495-496.

Walcher, Wilhelm [1995] 'Physikalische Gesellschaften im Umbruch', Physikalische Blätter 51 (1995), S. F107-F-133.

Waldl, Elfriede [1968] 'Österreichische Physikerinnen im In- und Ausland', in: Forkl \& Koffmahn (Hrsg.) [1968] S. 98-102.

Walk, Joseph (Hrsg.) [1996] Das Sonderrecht für die Juden im NS-Staat, Heidelberg: Müller.

Walker, Mark [1989] German National Socialism and the quest for nuclear power 1939-1949, Cambridge u. a.: Cambridge University Press.

Walker, Mark [1990] 'Legenden um die deutsche Atombombe', Vierteljahrshefte für Zeitgeschichte 38 (1990), S. 45-74.

Walker, Mark [1990/92] Die Uranmaschine. Mythos und Wirklichkeit der deutschen Atombombe, Goldmann, 1992 (zuerst erschienen bei Siedler, Berlin, 1990).

Walker, Mark [1993] 'Selbstreflexionen deutscher Atomphysiker', Vierteljahrshefte für Zeitgeschichte 41 (1993), S. 519-542.

Walker, Mark [1994]a 'The Nazification and Denazification of Physics', in: Kertz (Hrsg.) [1994] S. 79-89.

Walker, Mark [1994]b 'Vergangenheitsbewältigung im Licht der 'Farm Hall-Aufnahmen', in: Meinel \& Voswinckel (Hrsg.) [1994] S. 246-251.

Walker, Mark [1995] Nazi science: myth, truth, and the German atomic bomb, New York u. a.: Plenum Press.

Walker, Mark [1996] 'The Nazification and Denazification of Physics', in: Judt \& Ciesla (Hrsg.) [1996] S. 4959.

Walker, Mark [2000] 'A Comparative History of Nuclear Weapon', in: Kaufmann (Hrsg.) [2000] S. 309-327.

Walker, Mark [2002] 'Von Kopenhagen bis Göttingen und zurück. Verdeckte Vergangenheitspolitik in den Naturwissenschaften', in: Weisbrod (Hrsg.) [2002] S. 247-259.

Walker, Mark [2003]a 'Introduction: Science and Ideology', in: Walker (Hrsg.) [2003] S. 1-16.

Walker, Mark [2003]b 'Otto Hahn. Verantwortung und Verdrängung', Ergebnisse 10. Vorabdruck aus dem Forschungsprogramm »Geschichte der Kaiser-Wilhelm-Gesellschaft im Nationalsozialismus.

Walker, Mark [2003]c '»Nazi Science«? Natural Science in National Socialism', in: Hoßfeld, John, Lemuth \& Stutz (Hrsg.) [2003] S. 993-1012.

Walker, Mark (Hrsg.) [2003] Science and Ideology. A Comparative History, London u. a.: Routledge.

Walther, Peter Th. [2000] '»Arisierung«, Nazifizierung und Militarisierung. Die Akademie im »Dritten Reich «', in: Fischer (Hrsg.) [2000] S. 87-118.

Weaire, Denis L. [1987] 'Semiconductors', in: Weaire \& Windsor (Hrsg.) [1987] S. 143-151.

Weaire, Denis L. \& Colin G. Windsor (Hrsg.) [1987] Solid State Science. Past, Resent and Predicted, Bristol: Hilger.

Weber, Max [1919] Wissenschaft als Beruf, München u. a.: Duncker \& Humblot.

Wegeler, Cornelia [1996] »... wir sagen ab der internationalen Gelehrtenrepublik«. Altertumswissenschaft und Nationalsozialismus. Das Göttinger Institut für Altertumskunde 1921-1962, Wien u. a.: Böhlau.

Weick, Clemens [1993] 'Zur soziodemographischen Struktur des wissenschaftlichen Personals an badenwürttembergischen Universitäten', in: Kertz (Hrsg.) [1993] S. 93-122. 
Weiher, Sigfrid von (Hrsg.) [1983] Männer der Funktechnik. Eine Sammlung von 70 Lebenswerken deutscher Pioniere der Funktechnik (drahtlose Telegrafie, Radar, Rundfunk und Fernsehen), Berlin u. a.: VDEVerlag.

Wein, Martin [1994/96] 'Carl Friedrich und Richard von Weizsäcker', in: Deutsche Brüder: zwölf Doppelporträts, Reinbek: Rowohlt, 1996, S. 366-393.

Weingart, Peter [1976] Wissensproduktion und soziale Struktur, Frankfurt a. M.: Suhrkamp.

Weingart, Peter \& Matthias Winterhager [1984] Die Vermessung der Forschung. Theorie und Praxis der Wissenschaftsindikatoren, Frankfurt a. M. u. a.: Campus.

Weinreich, Max [1946/99] Hitler's Professors. The Psrt of Scholarship in Germany's Crimes Against the Jewish People, New Haven u. a.: Yale University Press.

Weisbrod, Bernd [2002] 'Dem wandelbaren Geist. Akademisches Ideal und wissenschaftliche Transformation in der Nachkriegszeit', in: Weisbrod (Hrsg.) [2002] S. 11-35.

Weisbrod, Bernd [2003] 'The Moratorium of the Mandarins and the Self-Denazification of German Academe: a View from Göttingen', Contemporary European History 12 (2003), S. 47-69.

Weisbrod, Bernd (Hrsg.) [2002] Akademische Vergangenheitspolitik. Beiträge zur Wissenschaftskultur der Nachkriegszeit, Göttingen: Wallstein.

Weissberg-Cybulski, Alexander [1951] Hexensabbat. Rußland im Schmelztigel der Säuberungen, Frankfurt a. M.: Verlag der Frankfurter Hefte.

Weiss, Burghard [1994]a 'Das Beschleunigerlaboratorium am KWI/MPI für Chemie: Kontinuiät deutscher Großforschung‘, in: Meinel \& Voswinckel (Hrsg.) [1994] S. 111-119.

Weiss, Burghard [1994]b 'The »Minerva« Project. The Accelerator Laboratory at the Kaiser Wilhelm Institute/Max Planck Institute of Chemistry: Continuity in Fundamental Research`, in: Renneberg \& Walker (Hrsg.) [1994] S. 271-290.

Weiss, Burghard [2000] 'Groß, teuer und gefährlich? Kernphysikalische Forschungstechnologien an Instituten der Kaiser-Wilhelm-Gesellschaft vor, während und nach Ende des »Dritten Reiches«", in: Kaufmann (Hrsg.) [2000] S. 699-725.

Weisskopf, Victor [1964] 'Hans Kopfermann (1895-1963)', Nuclear Physics 52 (1964), S. 177-188.

Weizel, Walter [1948] 'Die Zulassung zum Studium', Physikalische Blätter 4 (1948), S. 340-341.

Weizsäcker, Carl Friedrich von [1977] Der Garten des Menschlichen. Beoträge zur geschichtlichen Anthropologie, München: Hanser.

Weizsäcker, Carl Friedrich von [1983] Wahrnehmung der Neuzeit, München u. a.: Hanser.

Weizsäcker, Carl Friedrich von [1993] 'Werner Heisenberg als Physiker und Philosoph', in: Geyer, Herwig \& Rechenberg (Hrsg.) [1993] S. 13-24.

Welch, David [1989] 'Priming the Pump of German Democracy. British »Re-education« Policy in Germany after the Second World War', in: Turner (Hrsg.) [1989] S. 215-238.

Wendt, Bernd Jürgen (Hrsg.) [1984] Das britische Deutschlandbild im Wandel des 19. und 20. Jahrhundert, Bochum: Brockmeyer.

Wengenroth, Ulrich [1993]a 'Zwischen Aufruhr und Diktatur. Die Technische Hochschule 1918-1945', in: Wengenroth (Hrsg.) [1993] S. 215-260.

Wengenroth, Ulrich [1993]b 'Die Technische Hochschule nach dem Zweiten Weltkrieg. Auf dem Weg zu HighTech und Massenbetrieb', in: Wengenroth (Hrsg.) [1993] S. 261-298.

Wengenroth, Ulrich [1995] 'Die Technische Hochschule München. Skizze ihrer Entwicklung nach dem Zweiten Weltkrieg', in: Kertz (Hrsg.) [1995]a S. 7-17.

Wengenroth, Ulrich (Hrsg.) [1993] Technische Universität München. Annäherungen an ihre Geschichte, München: Technische Universität München.

Wentzck, Paul (Hrsg.) [1957] Darstellungen und Quellen zur Geschichte der deutschen Einheitsbewegung im neunzehnten und zwanzigsten Jahrhundert, Heidelberg: Winter.

Westphal, Wilhelm H. [1928/47] Physik. Ein Lehrbuch, Berlin u. a.: Springer, 12. Aufl. 1947.

Westphal, Wilhelm H. [1960] 'Der Mensch Max von Laue', Physikalische Blätter 16 (1960), S. 549-551.

Weyrather, Irmgard [1981] 'Numerus Clausus für Frauen - Studentinnen im Nationalsozialismus', in: Frauengruppe Faschismusforschung: Mutterkreuz und Arbeitsbuch. Zur Geschichte der Frauen in der Weimarer Republik und im Nationalsozialismus, Frankfurt a. M.: Fischer, 1981, S. 131-162.

Wicke, Ewald [1984] 'Arnold Eucken zum 100. Geburtstag: Was bleibt?‘, in: Wagner (Hrsg.) ]1984] S. 23-46 (Wiederabdruck aus Die Naturwissenschaften 71 (1984) S. 439-445).

Widmann, Horst [1973] Exil und Bildungshilfe. Die deutschsprachige akademische Emigration in die Türkei nach 1933, Bern u. a.: Lang.

Wien, Max [1938/44]a 'Der Nachwuchs der Physiker', Physikalische Blätter 1 (1944), S. 55-57.

Wien, Max [1938/44]b 'Einer der Gründe für den geringen Physikernachwuch', Physikalische Blätter 1 (1944), S. 88-89. 
Wise, M. Norton [1994] 'Pascual Jordan: Quantum Mechanics, Psychology, National Socialism', in: Renneberg \& Walker (Hrsg.) [1994] S. 224-254.

'Wissenschaftliche Tagung der nordwestdeutschen Physiker in Göttingen', Die Naturwissenschaften 33 (1946), S. 160 .

Witte, H. [1954] 'Reinhold Mannkopff 60 Jahre', Physikalische Blätter 10 (1954), S. 229-230.

Wohofsky, Otto [1993] 'Georg Joos', in: Kurt Magnus (Hrsg.): TUM. 125 Jahre Technische Universität München 1868-1993, München: Technische Universität, 1993, S. 105.

Wolf, Hans Christoph [1984] 'In memoriam Heinz Pick', Physikalische Blätter 40 (1984), S. 106.

Wolff, Stefan L. [1993] 'Vertreibung und Emigration in der Physik', Physik in unserer Zeit 24 (1993), S. $267-$ 273.

Wolff, Stefan L. [2000] 'Frederick Lindemanns Rolle bei der Emigration der aus Deutschland vertriebenen Physiker', The Yearbook of the Research Centre for German an Austrian Exile Studies 2 (2000), S. 2558.

Wolgast, Eike [1996] 'Karl Heinrich Bauer - der erste Heidelberger Nachkriegsrektor. Weltbild und Handeln 1945-1946‘, in: Heß, Lehmann \& Sellin (Hrsg.) [1996] S. 108-129.

Wrigley, Walter [1950] 'Schuler Tuning Characteristics in Navigational Instruments', Navigation 2 (1950), S. 282-290.

Zachmann, E. [1949] 'Der humanistische Bildungswert des Physikunterrichts', Physikalische Blätter 5 (1949), S. 97-99.

Zauner, Stefan [1998] 'Die Johannes Gutenberg-Universität als »Université Rhénane«. Zur Wiedergründung der Mainzer Hochschule 1946 im Kontext der französischen Besatzungspolitik', Berichte zur Wissenschaftsgeschichte 21 (1998), S. 123-142.

Zauner, Stefan [1999] 'Universität Tübingen und Leibniz-Kolleg in der französischen Besatzungszeit 19451949. Aspekte des akademischen Neubeginns im Nachkriegsdeutschland`, Historisches Jahrbuch 119 (1999), S. 209-231.

Zenneck, Jonathan [1944] 'Die Bedeutung der Forschung', Physikalische Blätter 1 (1944), S. 6-12.

Zentrum für interdisziplinäre Frauenforschung und Frauenbeauftragte der Humboldt-Universität zu Berlin (Hrsg.) [1996] Zur Geschichte des Frauenstudiums und weiblicher Berufskarrieren an der Berliner Universität, Berlin: Zentrum für interdisziplinäre Frauenforschung und Frauenbeauftragte der HumboldtUniversität zu Berlin.

Zierold, Kurt [1984] Forschung, Lehre und Erziehung. Aufsätze aus der Zeit des Wiederaufbaus und der Neugründung deutscher Hochschulen, Weinheim: Acta Humanioria.

Zuckmayer, Carl [2002] Geheimreport, hrsg. von Gunther Nickel und Johanna Schrön, Göttingen: Wallstein. 